\title{
International Union of Basic and Clinical Pharmacology. CX. Classification of Receptors for 5-hydroxytryptamine; Pharmacology and Function
}

\begin{abstract}
Nicholas M. Barnes, Gerard P. Ahern, Carine Becamel, Joël Bockaert, Michael Camilleri, Severine Chaumont-Dubel, Sylvie Claeysen, Kathryn A. Cunningham, Kevin C. Fone, Michael Gershon, Giuseppe Di Giovanni, Nathalie M. Goodfellow, Adam L. Halberstadt, Rachel M. Hartley, Ghérici Hassaine, Katharine Herrick-Davis, Ruud Hovius, Enza Lacivita, Evelyn K. Lambe, Marcello Leopoldo, Finn Olav Levy, Sarah C. R. Lummis, Philippe Marin, Luc Maroteaux, Andrew C. McCreary, ${ }^{1}$ David L. Nelson, John F. Neumaier, Adrian Newman-Tancredi, Hugues Nury, Alexander Roberts, Bryan L. Roth, Anne Roumier, Gareth J. Sanger, Milt Teitler, Trevor Sharp, Carlos M. Villalón, Horst Vogel, Stephanie W. Watts, and Daniel Hoyer
\end{abstract}

Neuropharmacology Research Group, College of Medical and Dental Sciences, University of Birmingham, Birmingham, United Kingdom (N.M.B., A.R.); Department of Pharmacology and Therapeutics, School of Biomedical Sciences, Faculty of Medicine, Dentistry and Health Sciences, The University of Melbourne, Parkville, Victoria, Australia (N.M.B., D.H.); Department of Pharmacology, Georgetown University Medical Center, Washington, DC (G.P.A.); Institut de Génomique Functionnelle, Université Montpellier, Centre National de la Recherche Scientifique, Institut National de la Santé et de la Recherche Médicale, Montpellier, France (C.B., J.B., S.C.-D., S.C., P.M.); Université de Montpellier, Montpellier, France (C.B., J.B.,

S.C.-D., S.C., P.M.); C.E.N.T.E.R. Division of Gastroenterology and Hepatology Mayo Clinic, Rochester, Minnesota (M.C.); Center for Addiction Research and Department of Pharmacology and Toxicology, University of Texas Medical Branch, Galveston, Texas (K.A.C., R.M.H.); School of Life Sciences, Medical School, Queen's Medical Centre, The University of Nottingham, Nottingham, United Kingdom (K.C.F.); Department of Pathology and Cell Biology, Columbia University College of Physicians and Surgeons, New York, New York (M.G.); Laboratory of Neurophysiology, Department of Physiology and Biochemistry, Faculty of Medicine and Surgery, University of Malta, Msida, Malta (G.D.G.); Department of Physiology, Department of Obstetrics and Gynaecology, Department of Psychiatry, University of Toronto, Toronto, Ontario, Canada (N.M.G., E.K.L.); Department of Psychiatry, University of California San Diego, La Jolla, California (A.L.H.); Theranyx, Marseille, France (G.H.); Department of Neuroscience and Experimental Therapeutics, Albany Medical College, Albany, New York (K.H.-D.); Ecole Polytechnique Fédérale de Lausanne, Institute of Chemical Sciences and Engineering, Lausanne, Switzerland (R.H., H.V.); Department of Pharmacy-Drug Science, University of Bari Aldo Moro, Bari, Italy (E.L., M.L.);

Department of Pharmacology, Faculty of Medicine, University of Oslo and Oslo University Hospital, Oslo, Norway (F.O.L.); Department of Biochemistry, University of Cambridge, Cambridge, United Kingdom (S.C.R.L.); INSERM UMR-S 1270, Paris, France (L.M., A.R.); Sorbonne Université, Paris, France (L.M., A.R.); Institut du Fer à Moulin, Paris, France (L.M., A.R.); Drug Development, Grunenthal GmbH, Aachen, Germany

(A.C.M.); Tucson, Arizona (D.L.N.); Departments of Psychiatry and Behavioral Sciences and Pharmacology, University of Washington, Seattle, Washington (J.F.N.); Neurolixis Inc., Dana Point, California (A.N.-T.); Université Grenoble Alpes, Institut de Biologie Structurale, Grenoble, France (H.N.); CNRS, Institut de Biologie Structurale, Grenoble, France (H.N.); Commissariat à l'Energie Atomique et aux Energies Alternatives, DSV, Institut de Biologie Structurale, Grenoble, France (H.N.); Department of Pharmacology, University of North Carolina, Chapel Hill, North Carolina (B.L.R.); Blizard Institute, Barts and the London School of Medicine and Dentistry, Queen Mary University of London, London, United Kingdom (G.J.S.); Center for Neuropharmacology and Neuroscience, Albany Medical College, Albany, New York (M.T.); Department of Pharmacology, University of Oxford, Oxford, United Kingdom (T.S.); Cinvestav-Coapa, Pharmacobiology, Mexico City, Tlalpan, Mexico (C.M.V.); Department of Pharmacology and Toxicology, Michigan State University, East Lansing, Michigan (S.W.W.); The Florey Institute of Neuroscience and Mental Health, The University of Melbourne, Parkville, Victoria, Australia (D.H.); and Department of Molecular Medicine,

The Scripps Research Institute, La Jolla, California (D.H.)

Address correspondence to: Professor Nicholas M. Barnes, PhD, FBPhS,Neuropharmacology Research Group, College of Medical and Dental Sciences, University of Birmingham, Birmingham B15 2TT, UK. E-mail: n.m.barnes@bham.ac.uk; or Professor Daniel Hoyer, PhD, DSc, HonFBPhS, Department of Pharmacology and Therapeutics, School of Biomedical Sciences, Faculty of Medicine, Dentistry and Health Sciences, The University of Melbourne, Parkville, Victoria 3010, Australia. E-mail: d.hoyer@unimelb.edu.au

${ }^{1}$ Current affiliation: GW Research Ltd, Chivers Way, Histon, Cambridge, United Kingdom.

This work was supported by Ministry of Defence [JFC7a/00018], the University of Birmingham and Celentyx Ltd. Centre national de la recherche scientifique (France), the Institut national de la santé et de la recherche médicale (France), University of Montpellier, Fondation pour la Recherche Médicale [Grant DPA20140629800] and l'Agence nationale de la recherche (France) [Grants ANR-11-BSV4-008-01 "SERO6COGNET," ANR-12-BSV4-0008-01 “ADAMGUARD" and ANR-17-CE16-0013-01 "StopSero6TOR," ANR-17-CE16-0010 "Sero6Dev"], France Alzheimer, Languedoc Roussillon region, Fondation Plan Alzheimer and Fondation Vaincre Alzheimer [Grant 12721 and LECMA FR-15072], National Institutes of Health National Institute on Drug Abuse [Grants T32 DA007287, P50 DA033935, and K05 DA020087], Banting and Best Canada Graduate Scholarship from the Canadian Institutes of Health Research, South-Eastern Norway Regional Health Authority, The Norwegian Council on Cardiovascular Diseases, The Research Council of Norway, The Kristian Gerhard Jebsen Foundation, Anders Jahre's Foundation for the Promotion of Science, The Family Blix foundation, The Simon Fougner Hartmann Family Foundation and the University of Oslo, the European Research Council [Grant ERC-2014-StG PentaBrain], Consejo Nacional de Ciencia y Tecnología [Grant CONACyT, No. 219707], University of Melbourne, Hallmark initiative, National Health and Medical Research Council (Australia) [Grants APP1105284 and APP1105332], Alzheimer's Association, and Royal Australian College of General Practitioners Ltd foundation (Australia). https://doi.org/10.1124/pr.118.015552. 


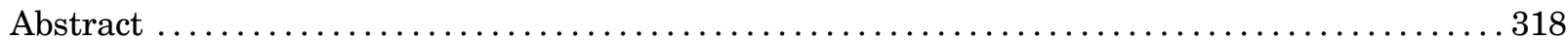

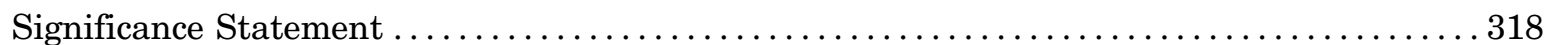

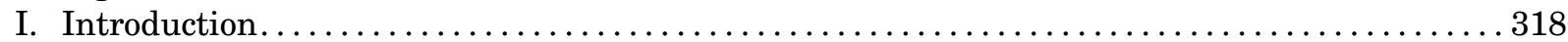

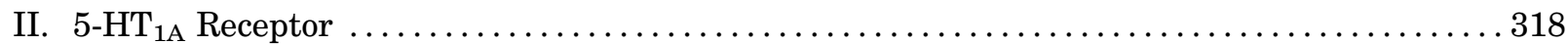

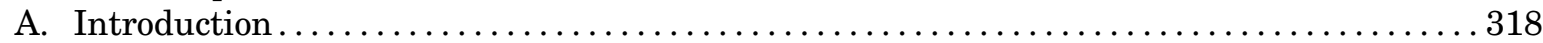

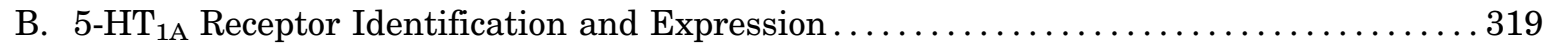

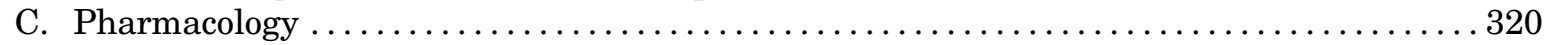

D. Biased Agonism: Differential Activation of 5-HT $\mathrm{HA}_{1 \mathrm{~A}}$ Receptor Subpopulations ......... 321

E. $5-\mathrm{HT}_{1 \mathrm{~A}}$ Receptor Intracellular Signal Transduction ......................... 323

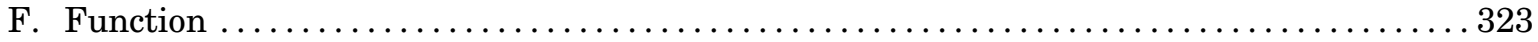

1. Differential Function of $5-\mathrm{HT}_{1 \mathrm{~A}}$ Receptors at Cellular, Tissue, and In Vivo

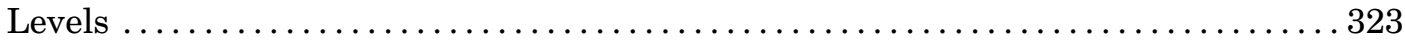

a. $5-\mathrm{HT}_{1 \mathrm{~A}}$ receptors in depression and anxiety $\ldots \ldots \ldots \ldots \ldots \ldots \ldots \ldots \ldots \ldots \ldots \ldots \ldots \ldots \ldots \ldots$

\begin{abstract}
ABBREVIATIONS: AA, arachidonic acid; AC, adenylyl cyclase; AChE, Acetylcholinesterase; AD, Alzheimer disease; ADAR, RNA-specific adenosine deaminase; ADHD, attention deficiency hyperactivity disorder; AIM, abnormal involuntary movement; AIWG, antipsychoticinduced weight gain; AngII, Angiotensin II; AP-1, activator protein 1; AP-2, activator protein 2; AP-MS, affinity purification-mass spectrometry; APP, amyloid precursor protein; ARF1, ADP-ribosylation factor 1; ASD, autism spectrum disorder; AT1, angiotensin II receptor type 1; $\mathrm{A} \beta$, amyloid- $\beta$; $\mathrm{BAC}$, bacterial artificial chromosome; $\mathrm{BDNF}$, brain-derived neutrophic factor; BNP, brain natriuretic peptide; $\mathrm{BPAD}$, bipolar affective disorder; BSS, behavioral satiety sequence; CCI, chronic constriction injury; CD, cluster of differentiation; CDK5, cyclindependent kinase 5; cGMP, cyclic guanosine monophosphate; CGRP, calcitonin gene-related peptide; CHO, Chinese Hamster Ovary; CIPP, channel-interacting PDZ protein; cNOS, constitutive nitric-oxide synthase; CNS, central nervous system; CpG, methyl-cytosine-phosphateguanine; CRMP, collapsing response mediator protein; 5-CT, 5-carboxamidotryptamine; CXCL, chemokine ligand; CYP, cyanopindolol; DA, dopamine; DAG, diacylglycerol; DARPP 32 , dopamine and cAMP regulated phosphoprotein; DHE, dihydroergotamine; DOB, 2,5-Dimethoxy-4bromoamphetamine; DOCA, deoxycorticosterone; DOI, 2,5-Dimethoxy-4-iodoamphetamine; DRG, dorsal root ganglion; DRN, dorsal raphe nucleus; EB, embryoid body; EC, enterochromaffin cells; ECD, extracellular domain; ECL2, extracellular loop 2; EEG, electroencephalography; ENS, enteric nervous system; EPS, extrapyramidal side effects; ER, endoplasmic reticulum; ERK, extracellular signal-regulated kinase; E3, ubiquitine E3 ligase; FDA, Food and Drug Administration; Fmr1, fragile X mental retardation 1; FST, forced swim test; FXS, fragile X syndrome; GASPs, GPCR-associated sorting proteins; GEF, guanine nucleotide exchange factor; GH, growth hormone; GI, gastrointestinal; GIP, glucose-dependent insulinotropic peptide; GIP, GPCR interacting protein; GIRK, G protein-coupled inwardly rectifying potassium channel; GLIC, gloeobacter ligand-gated ion channel; gp5-ht 1e $_{\text {e }}$, guinea pig 5-ht te $_{\mathrm{e}}$ receptor; GPCR, G protein-coupled receptor; GR, glucocorticoid receptor; GRK, G protein-coupled receptor kinase; GSK3, glycogen synthase kinase-3; HB-EGF, heparin-binding EGF-like growth factor; HCC, hepatocellular carcinoma; HDAC, histone deacetylase; 5-HIAA, 5-hydroxyindole acetic acid; HSC, hepatic stellate cells; 5HT, 5-hydroxytryptamine; 5-HTBP, 5-HT binding protein; IBS, irritable bowel syndrome; IBS-C, IBS with constipation; IBS-D, IBS with diarrhea; ICC, interstitial cells of Cajal; ICD, intracellular domain; IDO, indoleamine 2,3-dioxygenase; IL, interleukin; IP ${ }_{3}$, inositol-1,4,5triphosphate; ISHH, in situ hybridization histochemistry; IUPHAR, International Union of Basic and Clinical Pharmacology; Jab, Jun activation domain-binding protein; JAK, Janus kinase; JCV, John Cunningham virus/polyomavirus; KO, knockout; L-DOPA, levodopa; LID, L-DOPA-induced dyskinesia; LNX, ligand of numb protein X; LPS, lipopolysaccharide; LSD, lysergic acid diethylamide; LTD, long-term depression; M1, proinflammatory macrophgase; M2, anti-inflammatory macrophage; MAGI2, membrane-associated guanylate kinase with inverted domain structure 2; Man, mannoses; MAP, microtubule-associated protein; MAP1B-LC1, light chain 1 subunit of MAP1B protein; MAPK, mitogen-activated protein kinase; mCPP, M-chlorophenylpiperazine; MDA, 3,4-methylene dioxyamphetamine; MDMA, 3,4methylenedioxy methamphetamine; MeCP2, methyl-CpG-binding protein 2; miRNA, microRNA; MK, megakaryocyte; MMP, matrix metalloproteinase; mPFC, medial prefrontal cortex; MPP, MAGUK p55 subfamily member; MPP3, MAGUK p55 subfamily member 3; mTOR, mechanistic target of rapamycin; mTORC1, mTOR complex 1; MUPP1, multi-PDZ domain protein 1; NAc, nucleus accumbens; ND2, adaptor protein NADH dehydrogenase subunit 2 ; NF- $\kappa$ B, nuclear factor- $\kappa \mathrm{B}$; NHE-1, type 1 sodium-proton exchanger; NHERF, $\mathrm{Na}^{+} / \mathrm{H}^{+}$exchanger regulatory factor; NK, neurokinin; NMDA, N-methyl-D-aspartic acid; NO, nitric oxide; NOS, nitric oxide synthase; nNOS, neuronal NOS; NOX, NADPH oxidase; NR1, NMDA receptor subunit 1; NREM, non-rapid eye movement sleep; OCD, obsessive-compulsive disorder; 8-OH DPAT, ( \pm )-8-Hydroxy-2-dipropylaminotetralin; P2, purinergic 2 receptors; PAH, pulmonary arterial hypertension; PAM, positive allosteric modulator; PCP, phencyclidine; PCR, polymerase chain reaction; PD, Parkinson disease; PDE, phosphodiesterase; PDGFR, platelet-derived growth factor receptor; PDZ 10, MUPP1 PDZ domain 10; PDZ, PSD-95/Disc large/Zonula occludens; $\mathrm{pEC}_{50}$, negative log of $50 \%$ effective concentration; PET, positron emission tomography; PFC, prefrontal cortex; PI3K, phosphatidylinositol-3 kinase; PKA, protein kinase A; PKC, protein kinase C; $\mathrm{PLA}_{2}$, phospholipase $\mathrm{A}_{2}$; PLAC-24, protein that localizes at cell-cell contacts; PLC, phospholipase C; PLD, phospholipase D; POMC, pro-opiomelanocortin; POV, postoperative vomiting; PPAR, peroxisome proliferator-activated receptors; PPI, PR, progressive ratio; PSD, postsynaptic marker; PSD-95, postsynaptic density-95; PTEN, phosphatase and tensin homolog deleted on chromosome 10; PX, phox homology; qPCR, quantitative polymerase chain reaction; REM, rapid eye movement sleep; Rheb, Ras homolog enriched in brain; RGS, regulator of G protein signaling; ROS, reactive oxygen species; RSK2, P90 ribosomal S6 kinase 2; RT-PCR, reverse transcriptase polymerase chain reaction; RTT, Rett syndrome; SAP97, synapse-associated protein 97; sAPP, soluble amyloid precursor protein; SAR, structure activity relationship; SCFAs, short-chain fatty acids; SERT, serotonin transporter; Sf9, spodoptera frugiperda 9 cells; siRNA, small-interfering RNA; SN, substantia nigra; snoRNA, small nucleolar RNA; SNP, single-nucleotide polymorphism; SNX, sorting nexin family member; SRE, serum response element; SRI, serotonin reuptake inhibitor; SSRI, selective serotonin reuptake inhibitor; STAT, signal transducer and activator of transcription; SW, slow wave; TASK-1, acid-sensitive potassium channel protein-1; TG, tissue transglutaminase; TGF- $\beta 1$, transforming growth factor beta 1; Th, T-helper cells; THC, $\Delta^{9}$-tetrahydrocannabinol; TLR, Toll-like receptors; TMD, transmembrane domain; TNAP, tissue nonspecific alkaline phosphatase; TNF, tumor necrosis factor; TPH, tryptophan hydroxylase; TSC, tuberous sclerosis; TST, tail suspension test; VTA, ventral tegmental area; WAVE-1, Wiskott-Aldrich syndrome protein family verprolin homologous protein 1; WT, wild type; Yif1B, Yip1 interacting factor homolog $\mathrm{B} ; 2 \mathrm{Cfl}$, full length $5-\mathrm{HT}_{2 \mathrm{C}}$ receptor.
\end{abstract}


b. $5-\mathrm{HT}_{1 \mathrm{~A}}$ receptor activation for improved antipsychotic action $\ldots \ldots \ldots \ldots \ldots \ldots 26$

G. $5-\mathrm{HT}_{1 \mathrm{~A}}$ Receptors and Some Emerging Treatment Areas $\ldots \ldots \ldots \ldots \ldots \ldots \ldots \ldots \ldots \ldots \ldots$

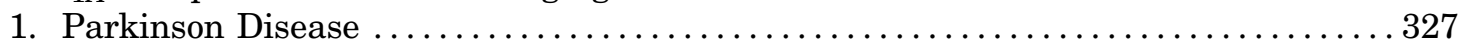

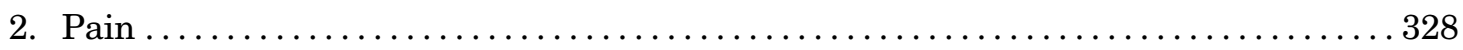

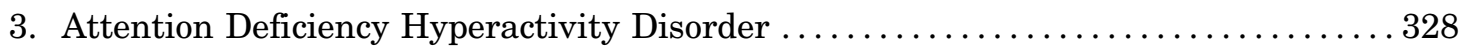

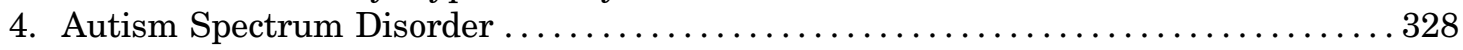

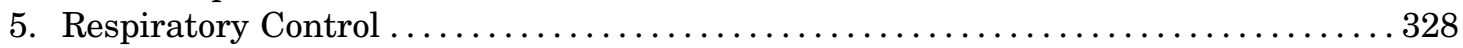

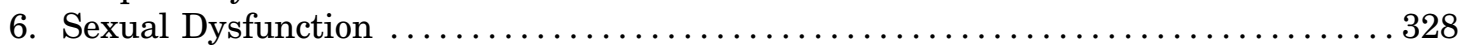

7. Food Intake and Eating Disorders ................................. 329

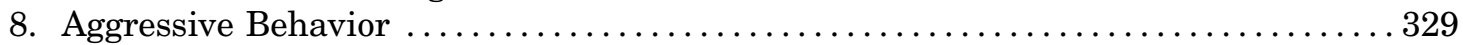

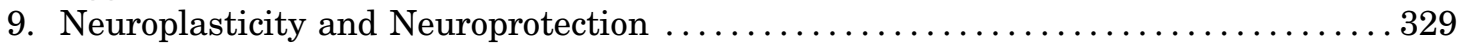

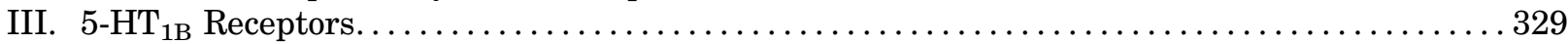

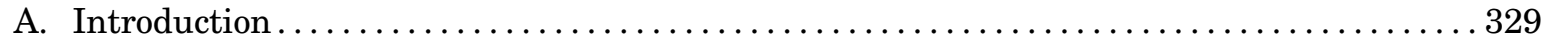

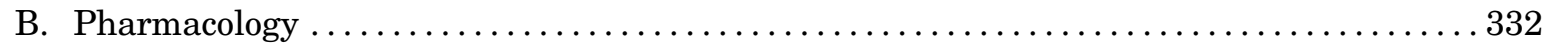

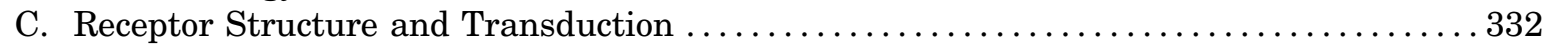

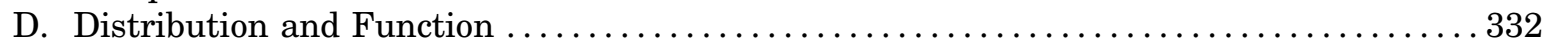

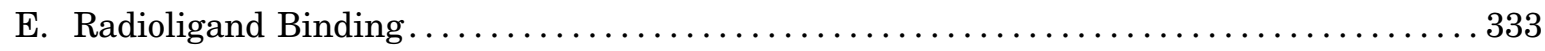

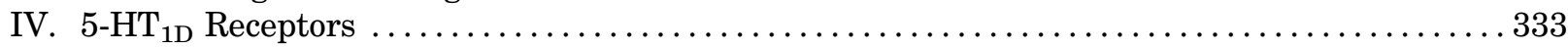

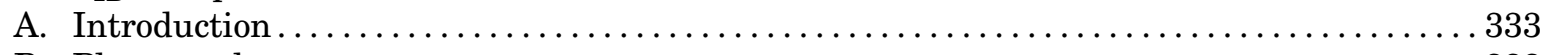

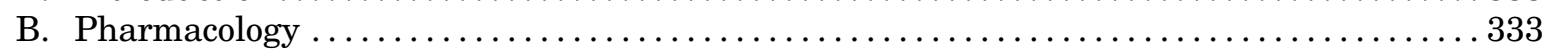

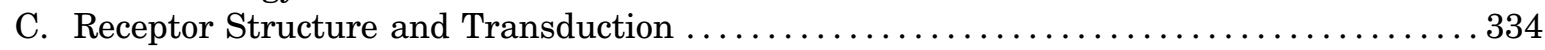

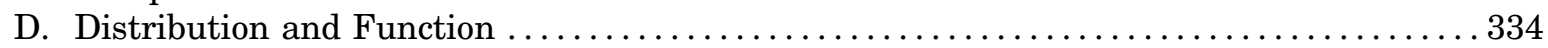

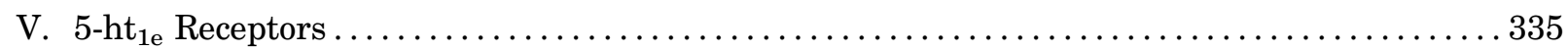

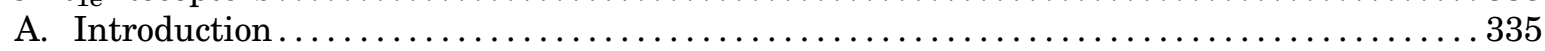

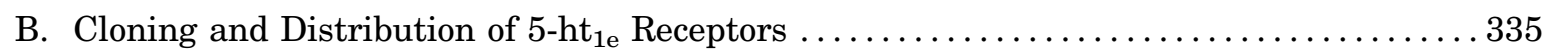

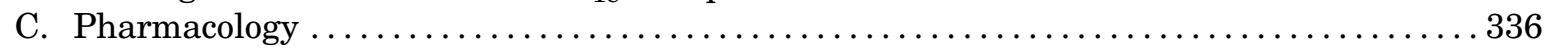

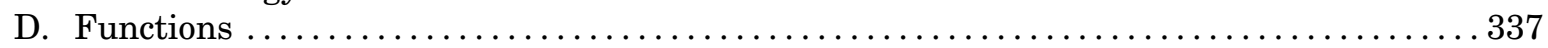

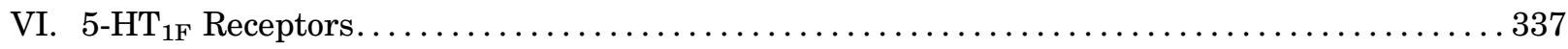

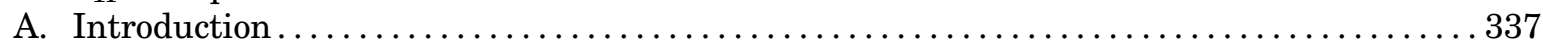

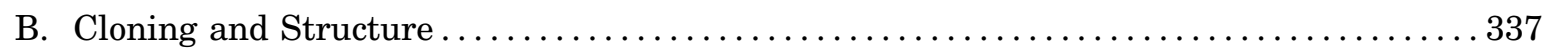

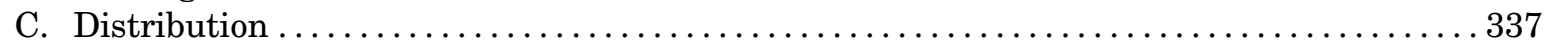

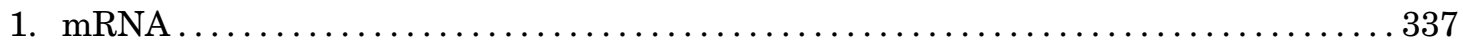

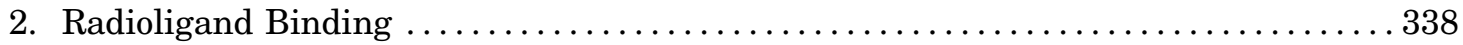

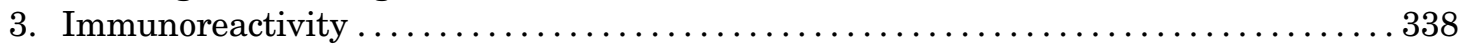

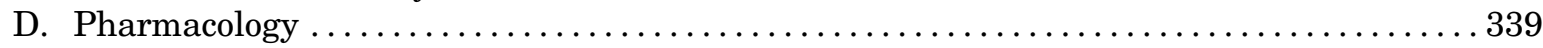

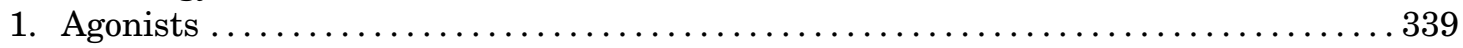

2. Partial Agonists and Antagonists.................................. 340

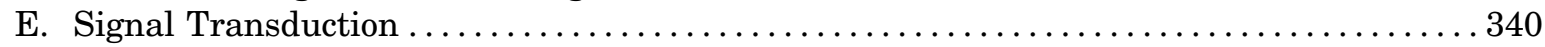

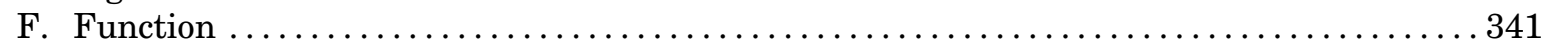

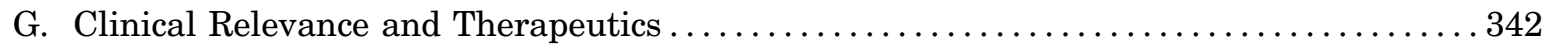

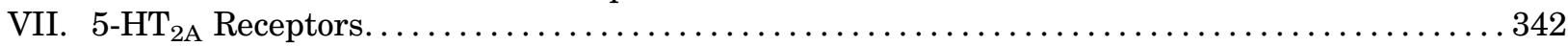

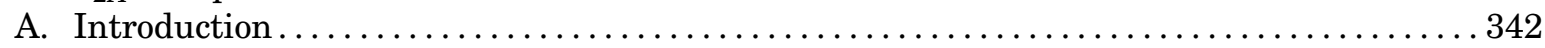

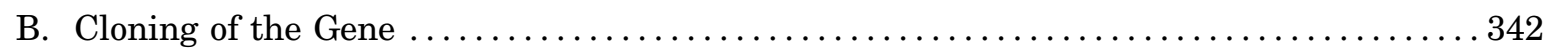

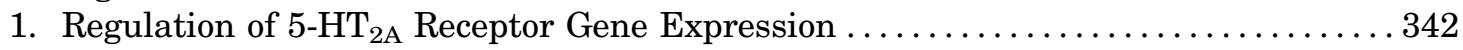

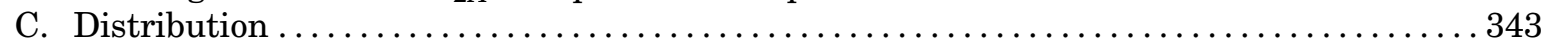

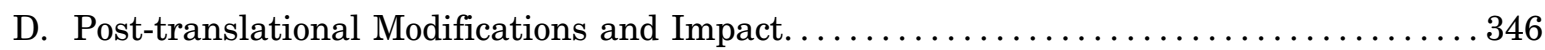

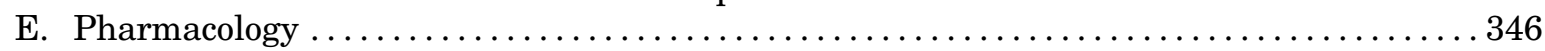

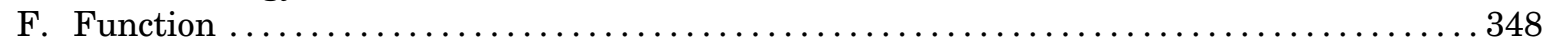

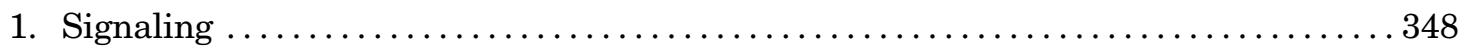

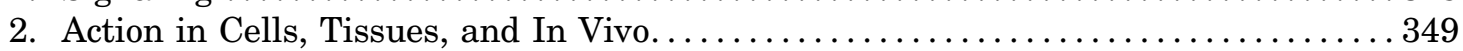

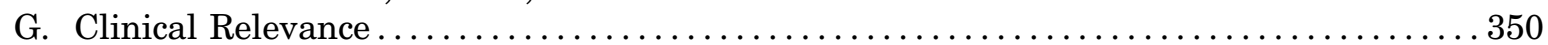

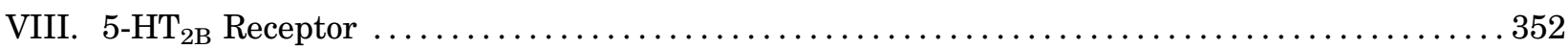

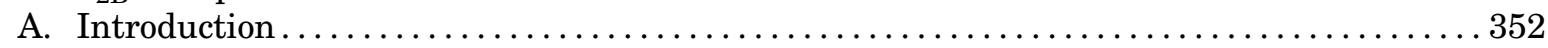

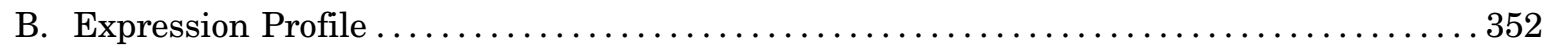

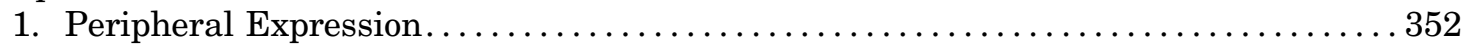

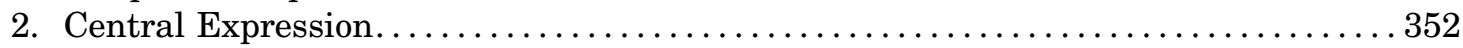

C. Post-translational Modifications and Impact............................. 352 


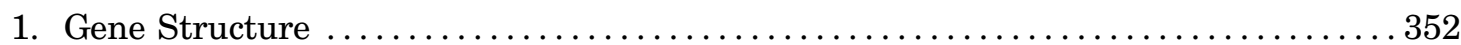

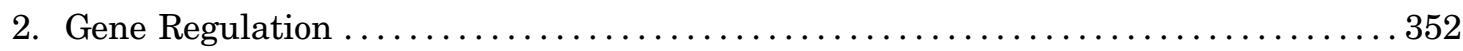

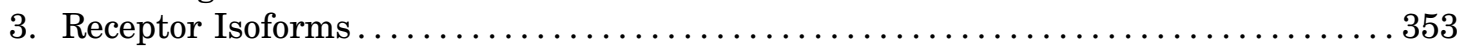

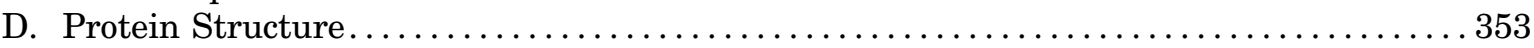

E. Heteromeric Receptor Associations . . . . . . . . . . . . . . . . . . . . . . . . . . . 353

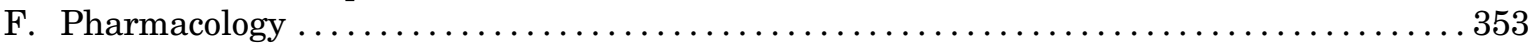

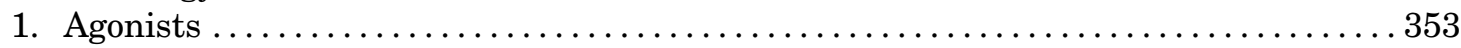

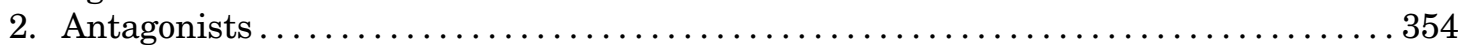

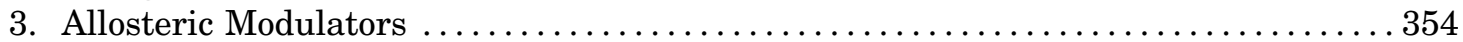

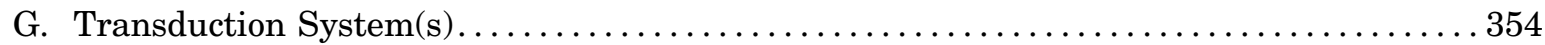

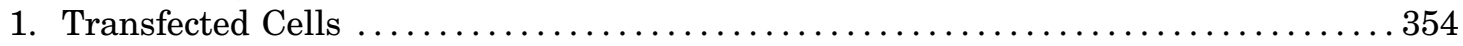

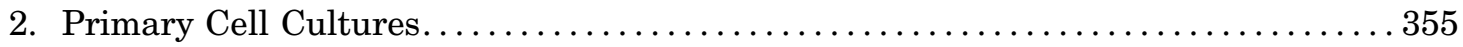

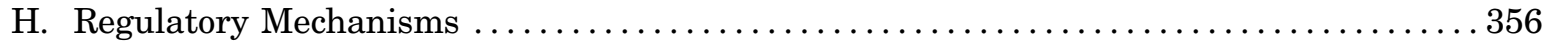

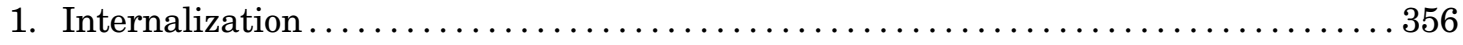

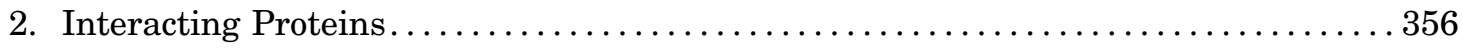

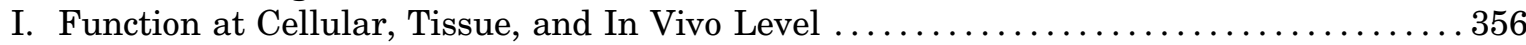

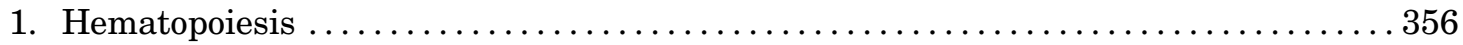

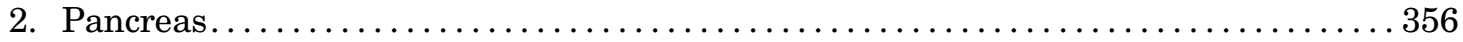

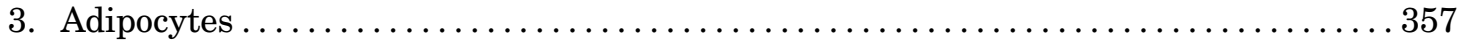

4. Cardiovascular and Pulmonary Systems ............................. 357

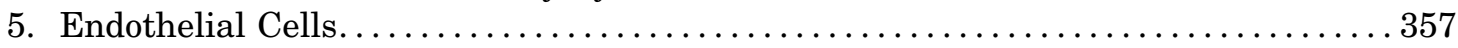

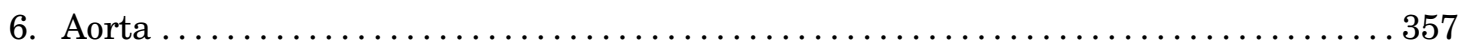

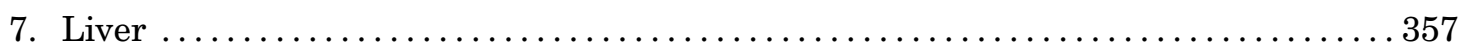

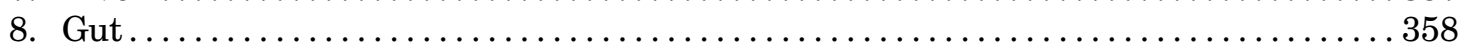

9. Central Autonomic Nervous System ............................... 358

10. Peripheral Autonomic Nervous System ............................ 358

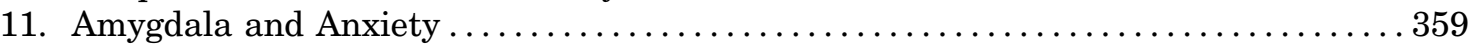

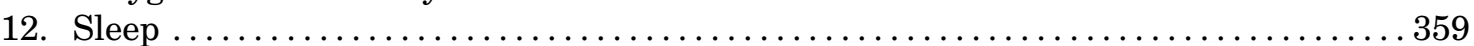

J. Clinical Relevance ................................................. 359

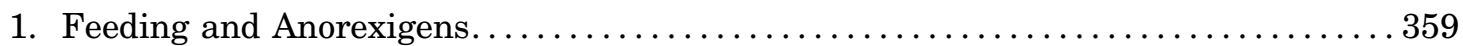

2. Raphe and Antidepressant Activity ................................. 360

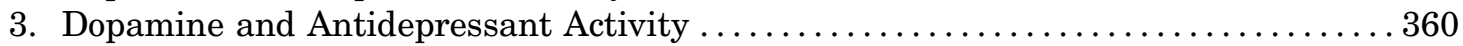

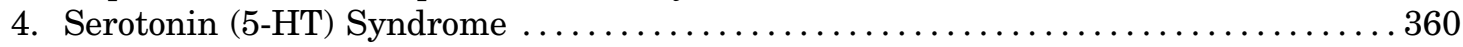

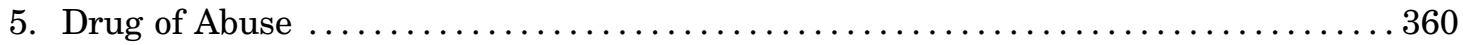

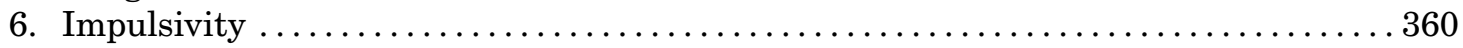

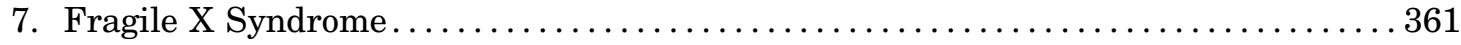

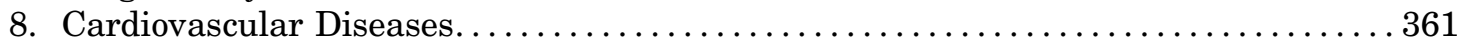

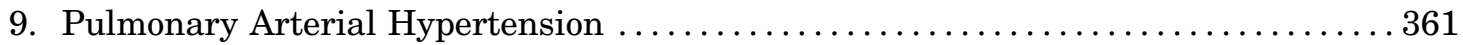

10. Vascular Hypertension . . . . . . . . . . . . . . . . . . . . . . . . . . . . 361

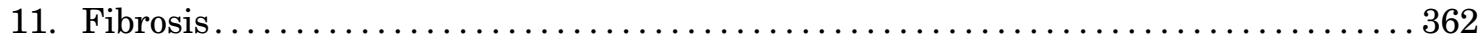

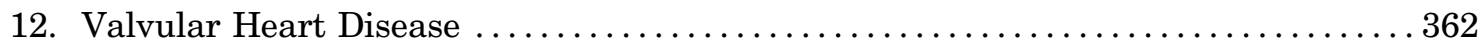

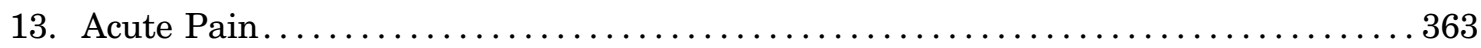

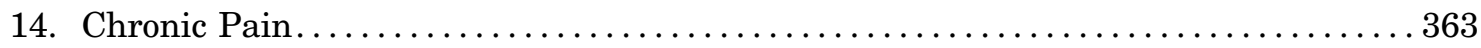

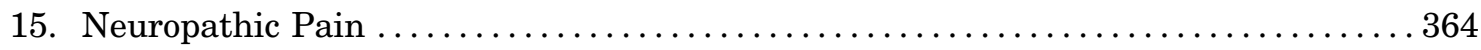

16. Spasticity in Amyotrophic Lateral Sclerosis ........................... 364

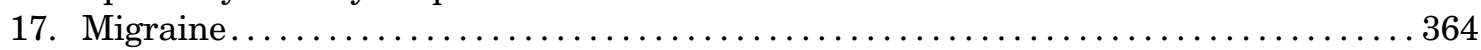

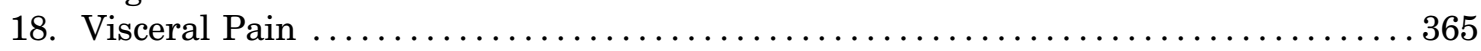

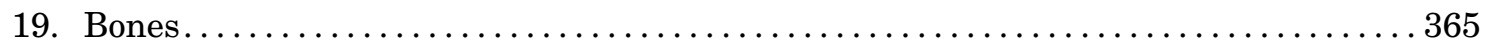

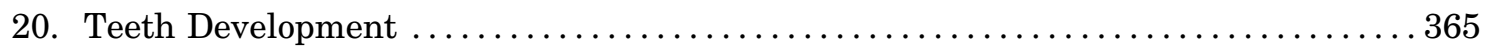

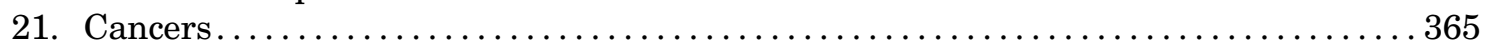

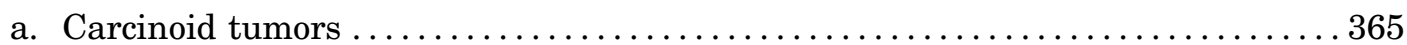

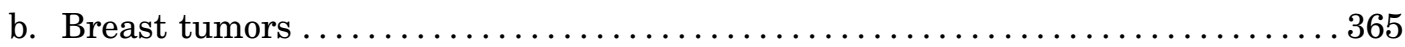

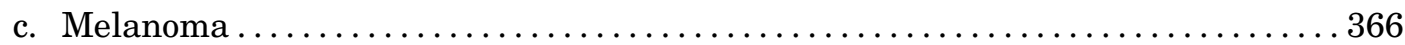

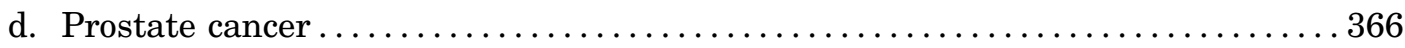

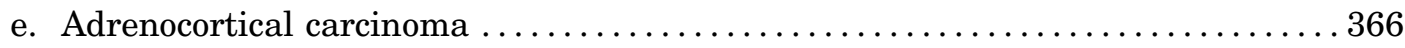

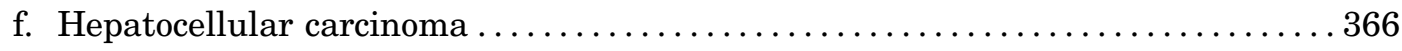

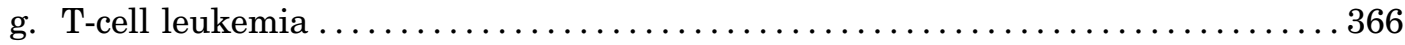




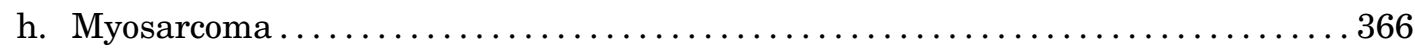

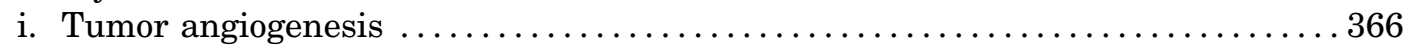

22. Clinically Relevant Knowledge Gained from the Gene................... 367

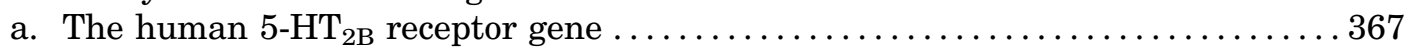

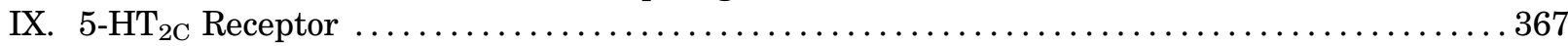

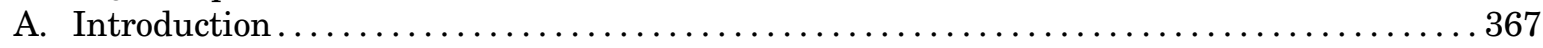

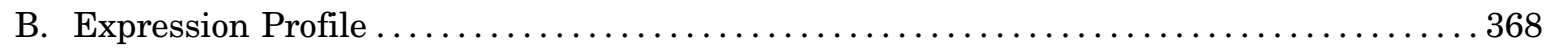

C. Post-transcriptional and Post-translational Modifications $\ldots \ldots \ldots \ldots \ldots \ldots \ldots \ldots \ldots \ldots \ldots \ldots$

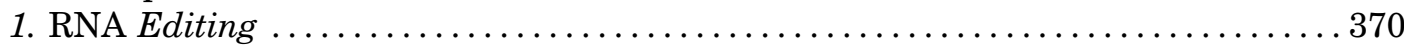

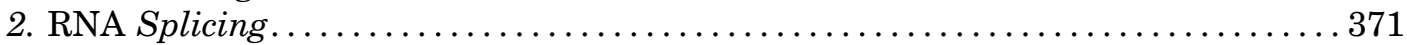

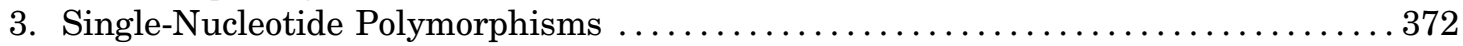

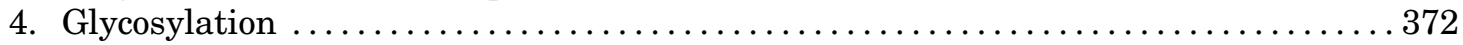

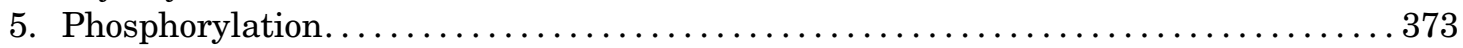

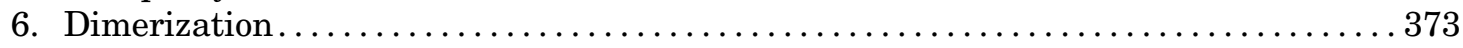

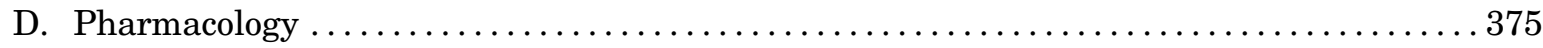

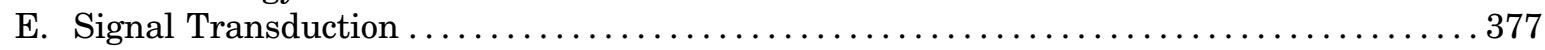

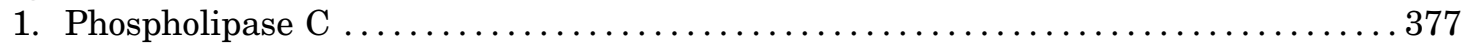

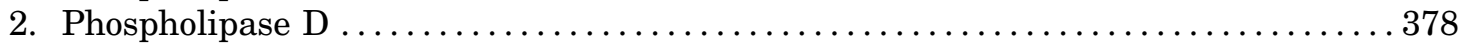

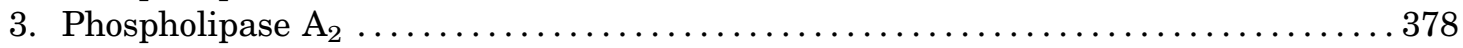

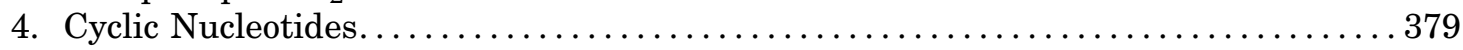

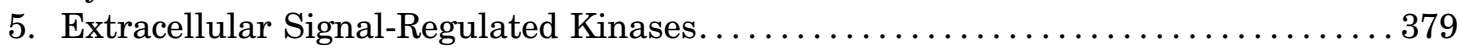

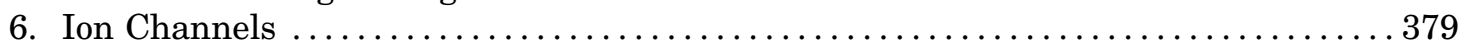

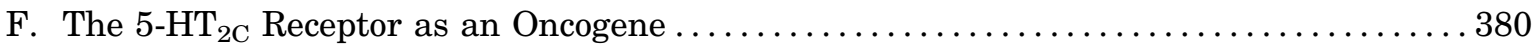

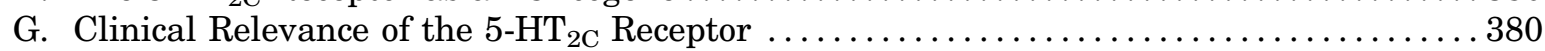

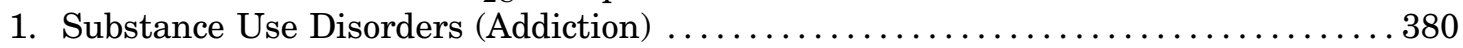

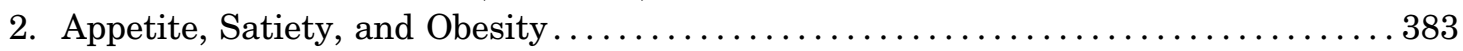

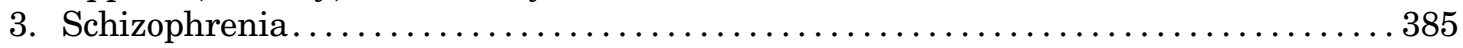

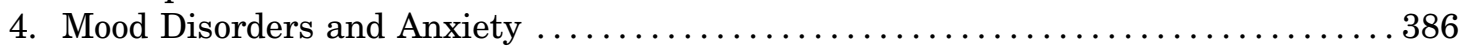

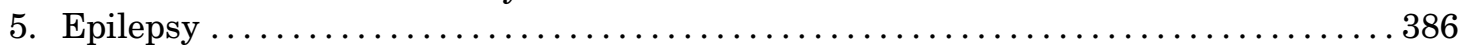

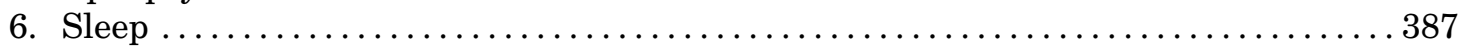

7. Clinical Impact of RNA Editing of the $5-\mathrm{HT}_{2 \mathrm{C}}$ Receptor $\ldots \ldots \ldots \ldots \ldots \ldots \ldots \ldots \ldots$

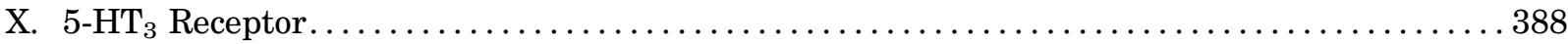

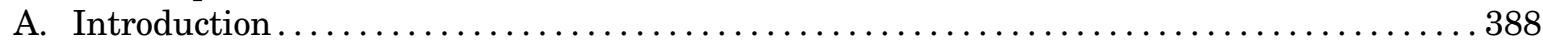

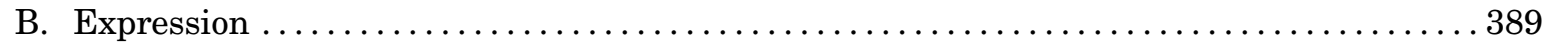

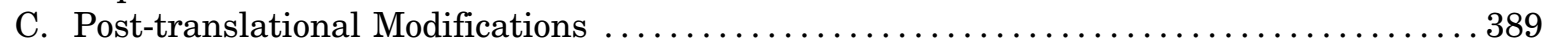

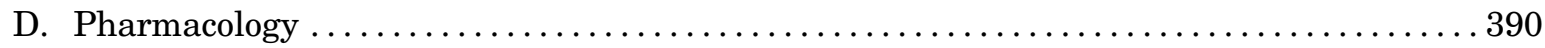

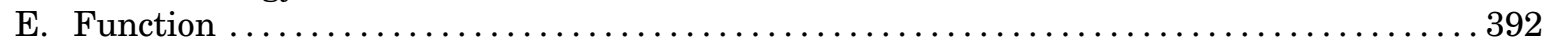

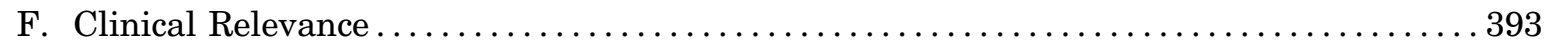

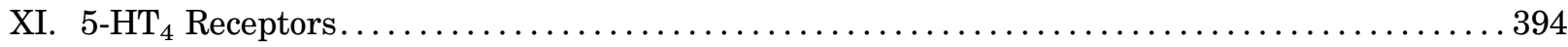

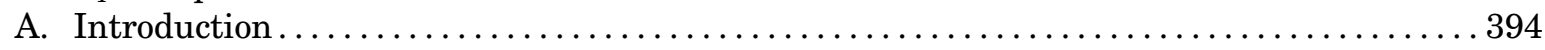

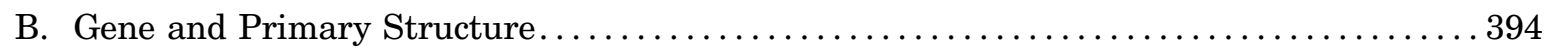

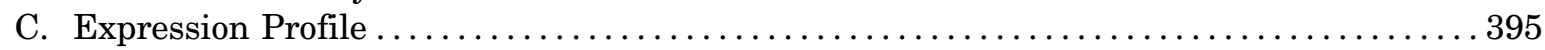

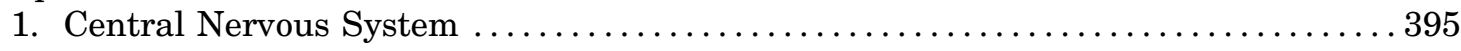

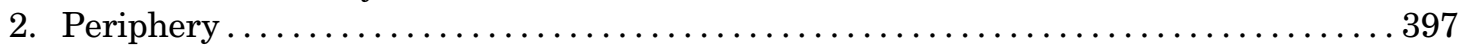

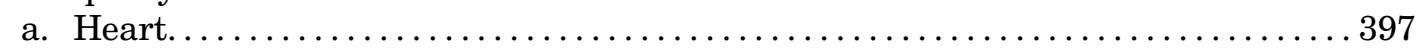

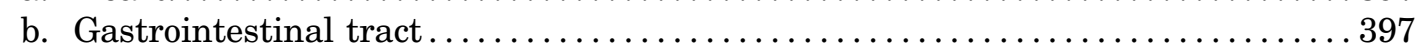

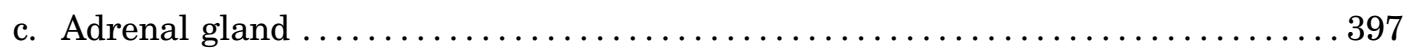

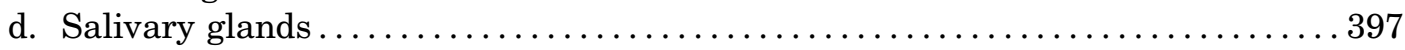

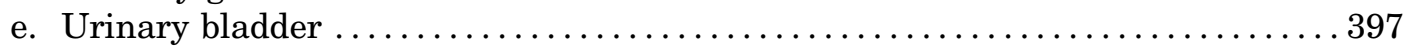

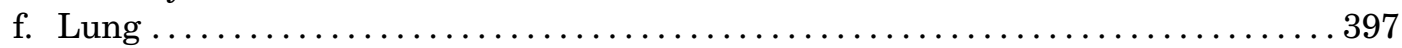

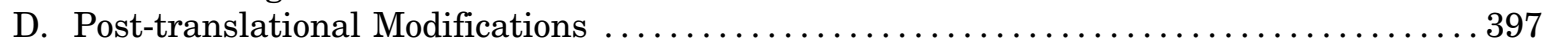

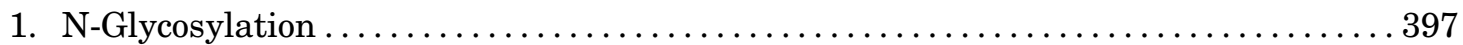

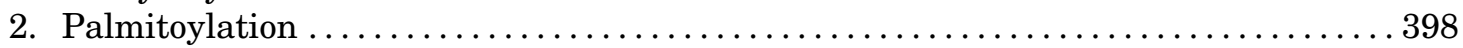

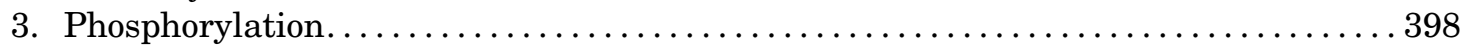

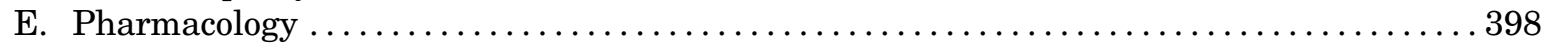

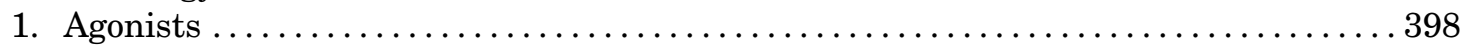

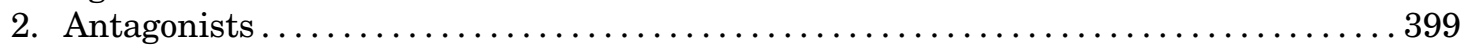


3. Inverse Agonists . ............................................ 399

4. Multifunctional Ligand.......................................... 400

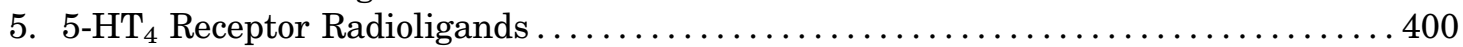

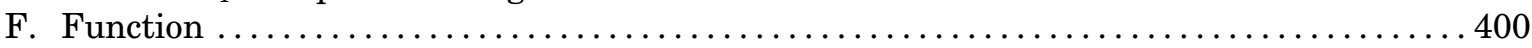

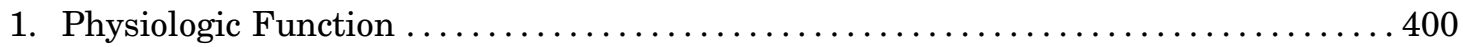

2. Cellular Function ............................................ 401

a. G protein coupling of $5-\mathrm{HT}_{4}$ receptors and primary signaling events $\ldots \ldots \ldots \ldots 401$

b. G protein-independent coupling of $5-\mathrm{HT}_{4}$ receptors $\ldots \ldots \ldots \ldots \ldots \ldots \ldots \ldots \ldots 1$

3. Gastrointestinal Tract........................................ 401

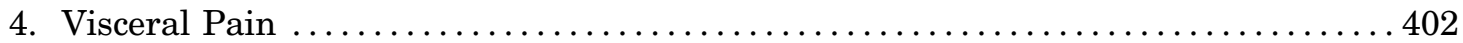

5. Enteric Nervous System Development and Enteric Nervous System Adult

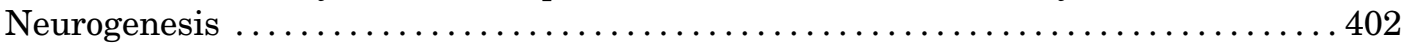

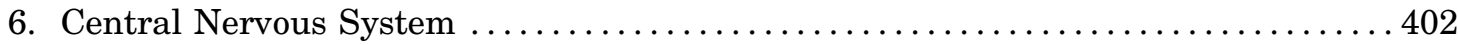

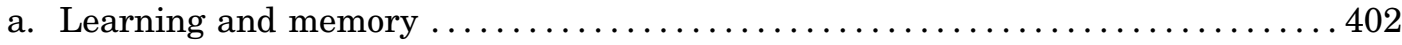

b. Control of mood and role of $5-\mathrm{HT}_{4}$ receptor agonists $\ldots \ldots \ldots \ldots \ldots \ldots \ldots \ldots 2$

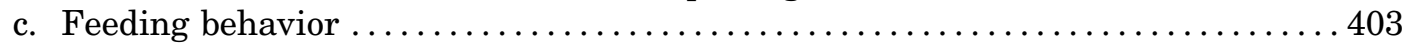

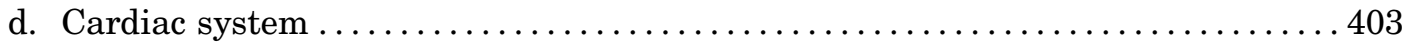

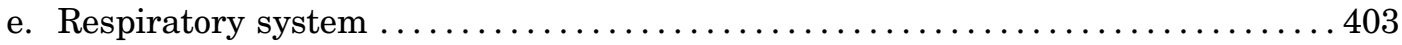

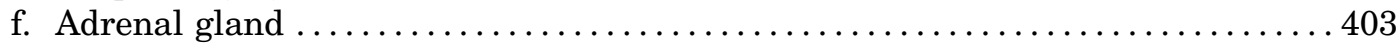

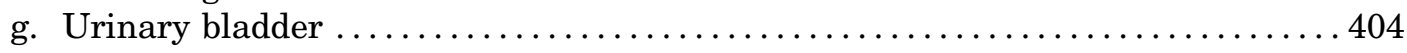

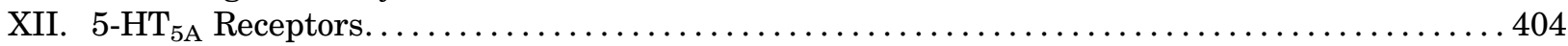

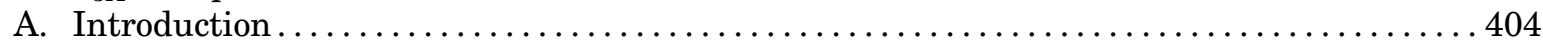

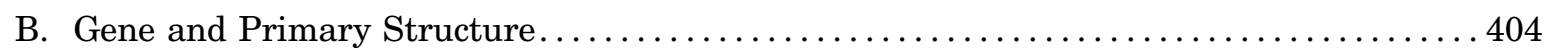

C. Expression Profile .......................................... 404

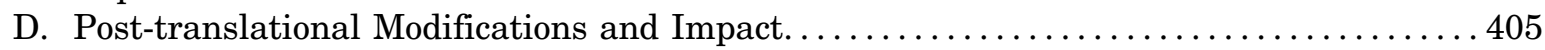

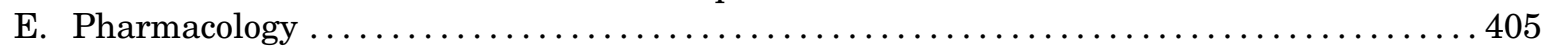

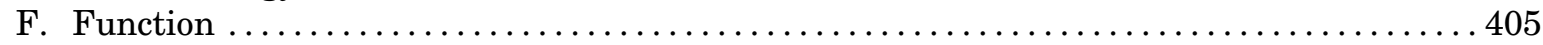

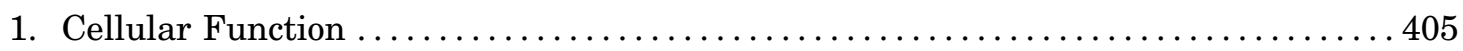

2. G Protein Coupling of the $5-\mathrm{HT}_{5 \mathrm{~A}}$ Receptor In Vitro...................... 405

3. G Protein Coupling of the $5-\mathrm{HT}_{5 \mathrm{~A}}$ Receptor Ex Vivo..................... 407

4. $5-\mathrm{HT}_{5 \mathrm{~A}}$ Receptor Function in the Spinal Cord ........................ 407

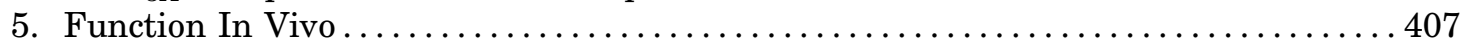

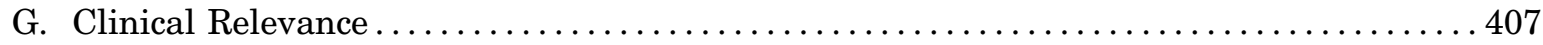

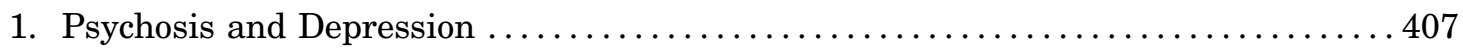

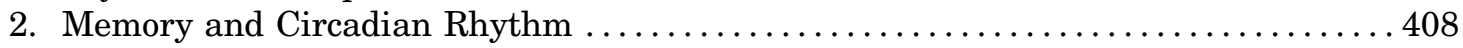

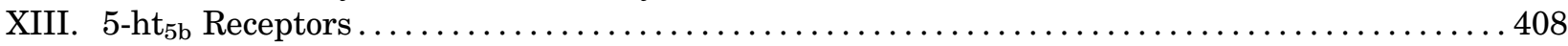

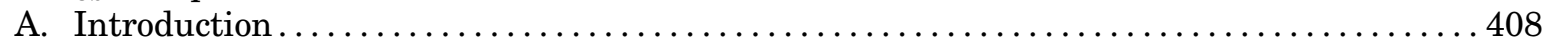

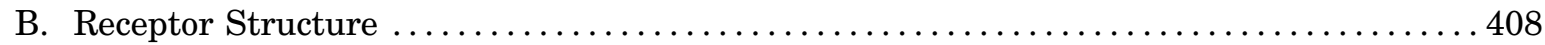

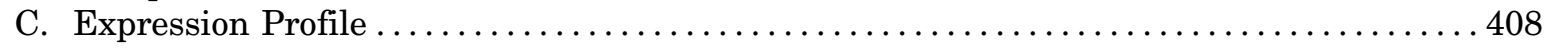

D. Regulatory Mechanisms and Post-translational Modifications................... 408

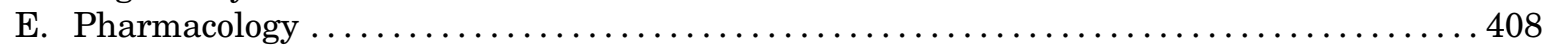

F. Function at Cellular, Tissue, and In Vivo Levels $\ldots \ldots \ldots \ldots \ldots \ldots \ldots \ldots \ldots \ldots \ldots . \ldots \ldots$

G. Clinical Relevance.............................................. 409

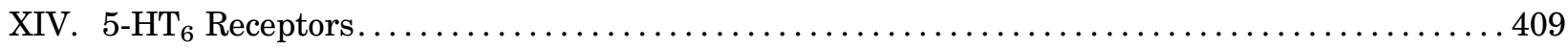

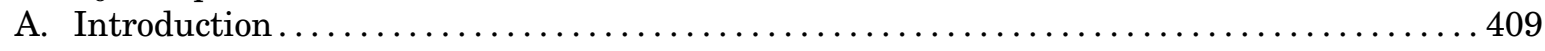

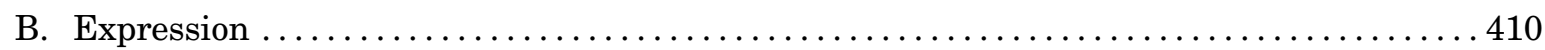

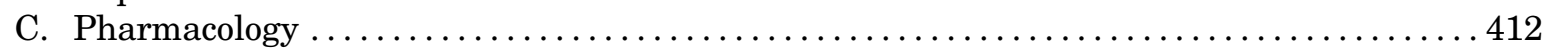

D. Post-translational Modifications and Protein Interactions $\ldots \ldots \ldots \ldots \ldots \ldots \ldots \ldots \ldots 413$

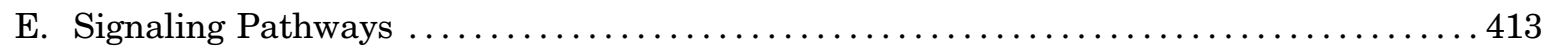

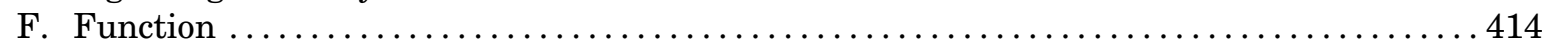

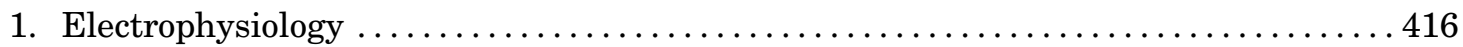

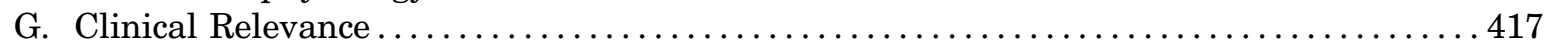

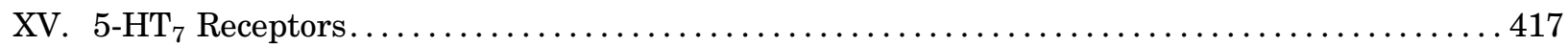

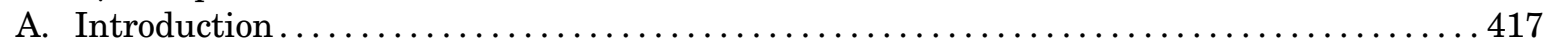

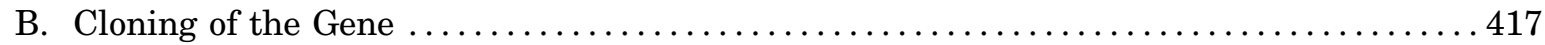

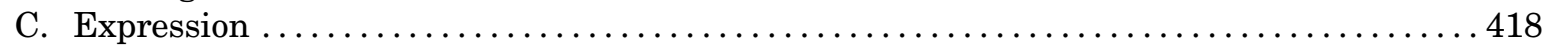

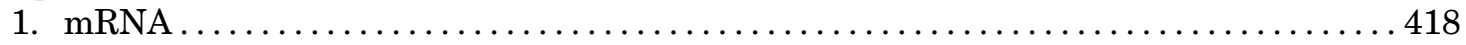




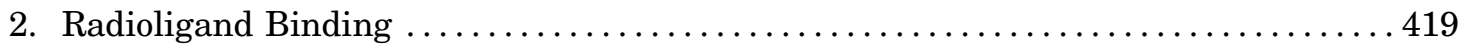

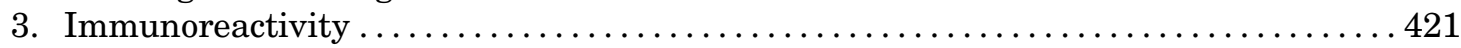

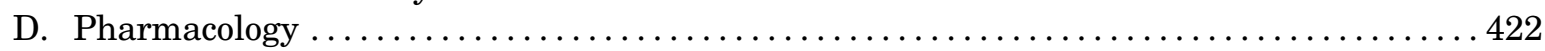

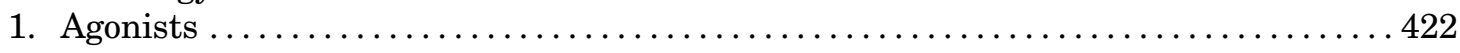

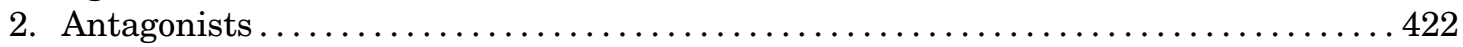

3. Allosteric Modulators ........................................ 423

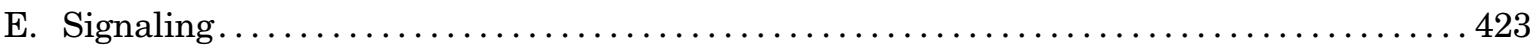

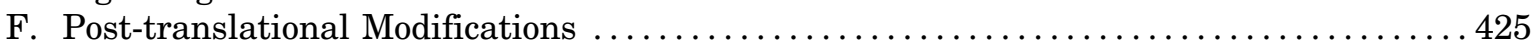

1. Regulatory Mechanisms ...................................... 425

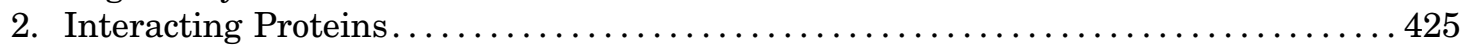

3. Homo- and Heteromeric Receptor Associations .......................... 425

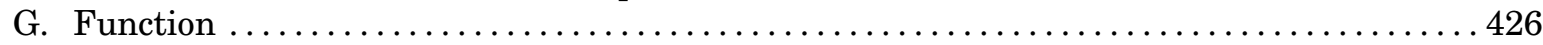

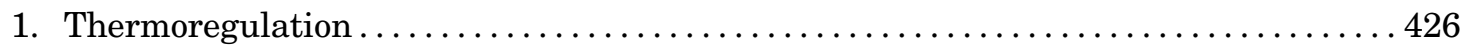

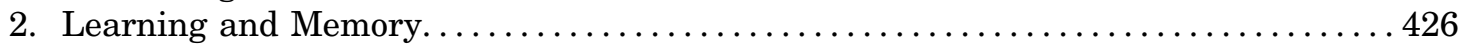

3. Antipsychotic Potential......................................... 426

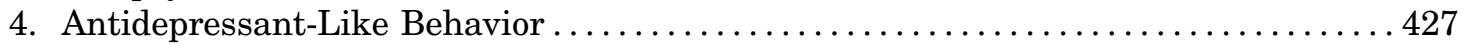

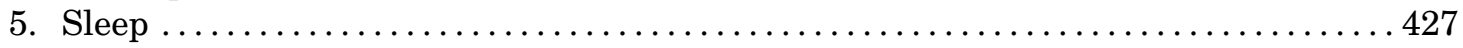

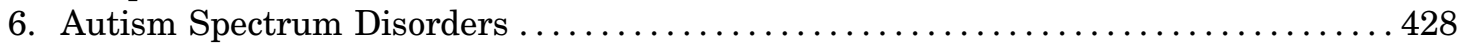

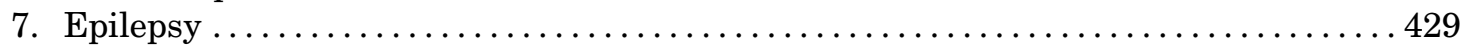

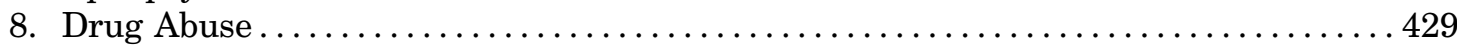

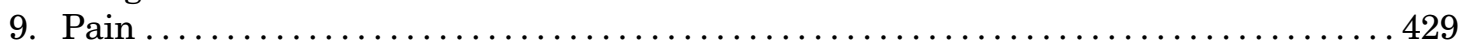

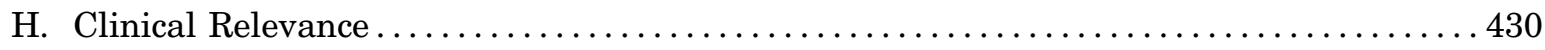

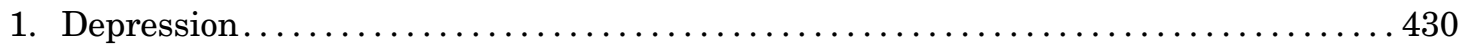

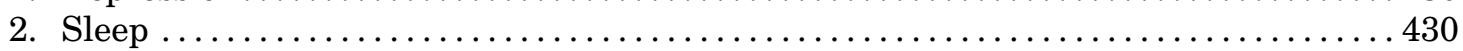

XVI. High-Resolution Structure of 5 -HT Receptors $\ldots \ldots \ldots \ldots \ldots \ldots \ldots \ldots \ldots \ldots \ldots \ldots \ldots \ldots \ldots 430$

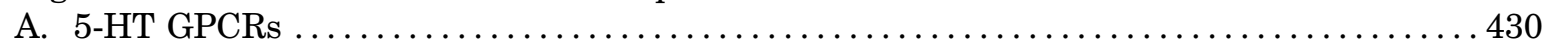

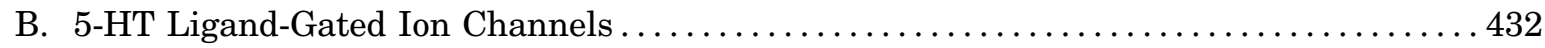

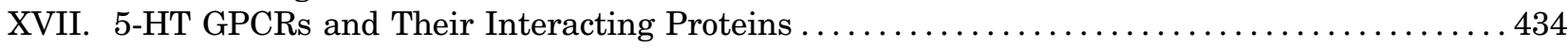

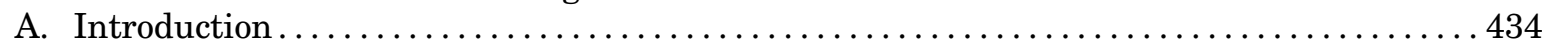

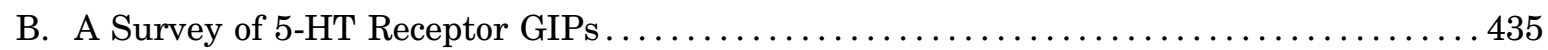

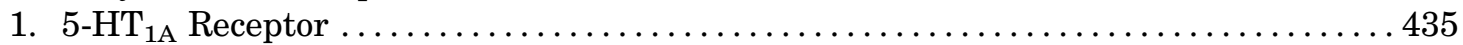

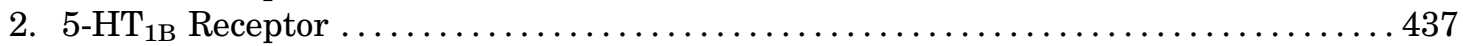

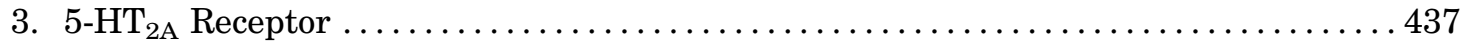

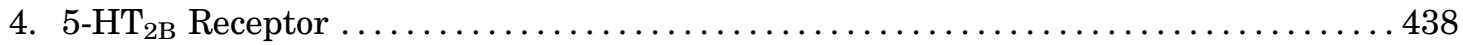

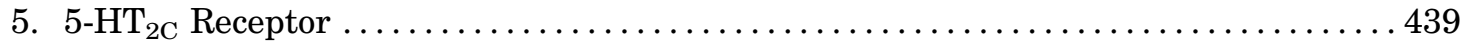

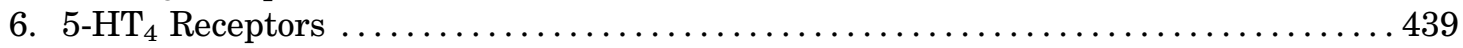

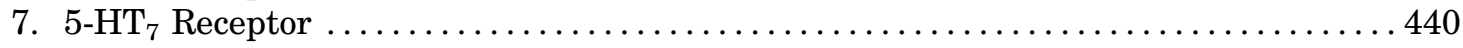

C. 5-HT $\mathrm{H}_{6}$ Receptor Receptosome: Toward New Signaling Mechanisms Underlying Its Control of Cognition and Neurodevelopmental Processes ...................... 440

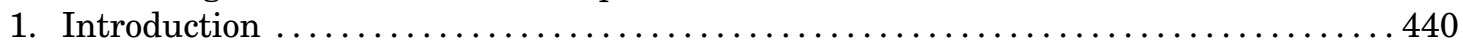

2. Fine-Tuning of 5-HT $\mathrm{HT}_{6}$ Receptor Trafficking and Signal Transduction by GIPs . . . . 441

3. Recruitment of mTOR Complex 1 by $5-\mathrm{HT}_{6}$ Receptor: Potential Role in Cognitive Deficits Associated with Schizophrenia ........................ 442

4. Recruitment of Cyclin-Dependent Kinase 5 by $5-\mathrm{HT}_{6}$ Receptor: An Essential Step in Its Control of Neuronal Migration and Differentiation............... 443

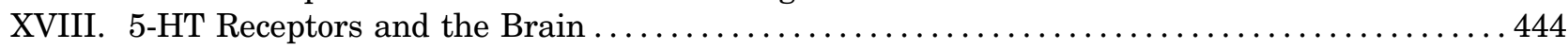

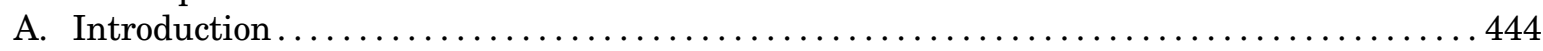

B. 5-HT Receptor Signaling in Neurons ................................ 444

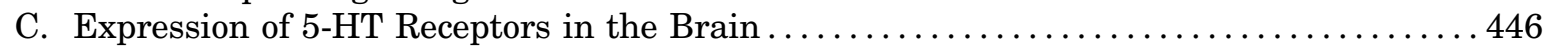

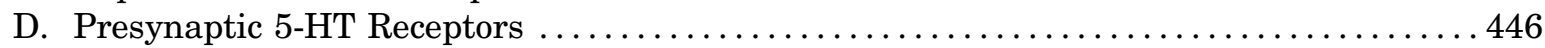

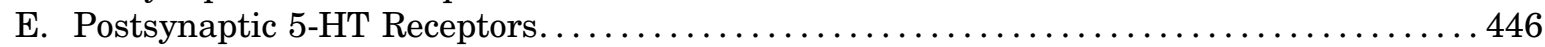

F. Cellular Localization of Central Nervous System 5-HT Receptors . . . . . . . . . 447

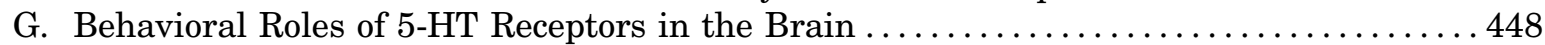

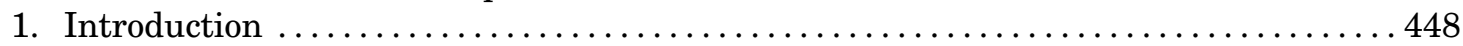

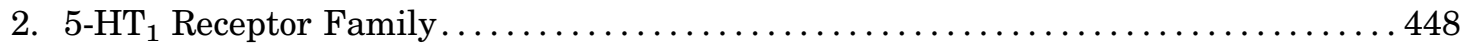

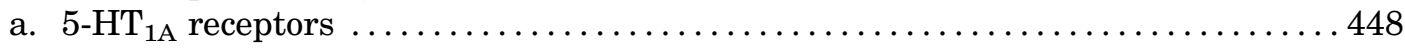

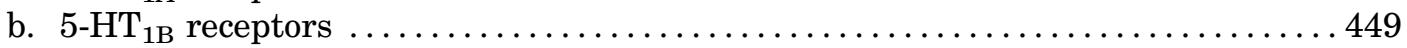




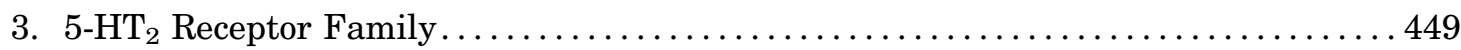

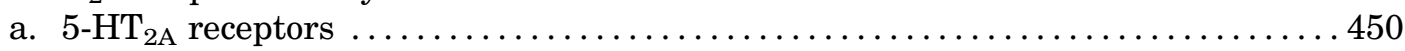

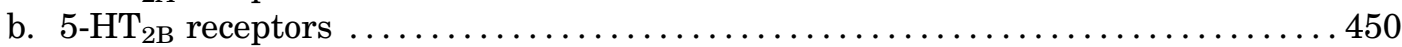

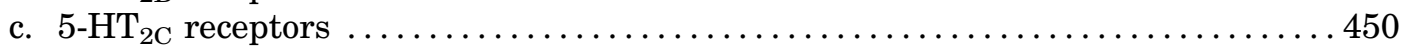

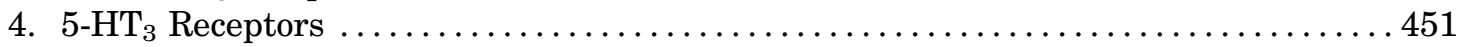

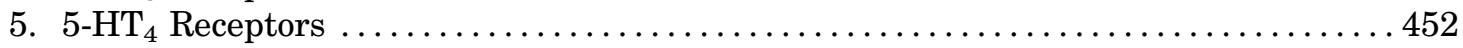

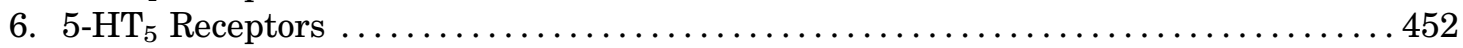

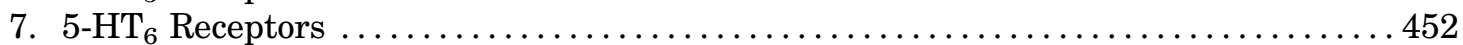

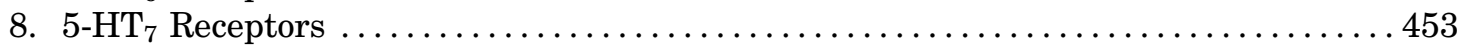

XIX. 5-HT Receptors and the Cardiovascular System ........................... 453

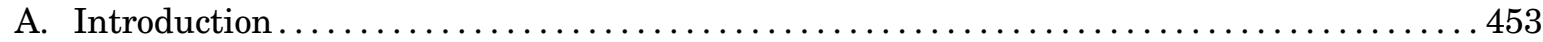

B. 5 -HT in Cardiovascular Tissues.................................. 454

C. Cardiovascular Effects Mediated by 5 -HT Receptors $\ldots \ldots \ldots \ldots \ldots \ldots \ldots \ldots \ldots \ldots \ldots 4$

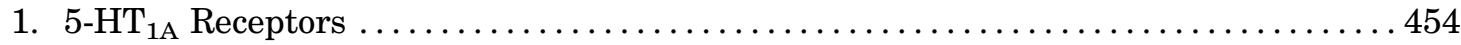

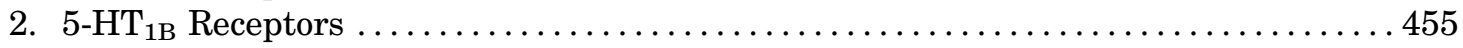

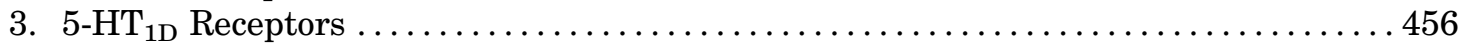

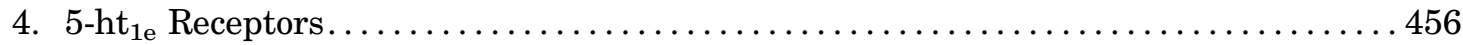

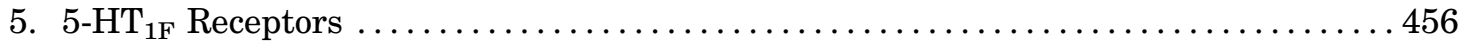

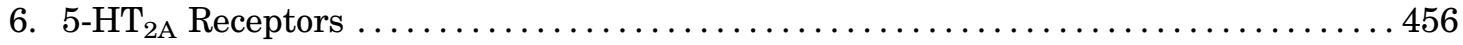

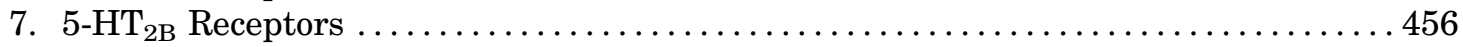

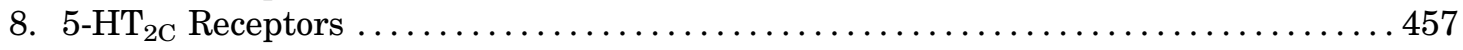

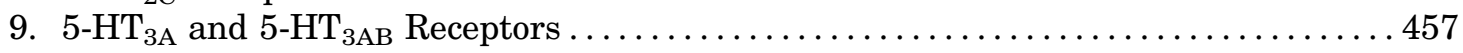

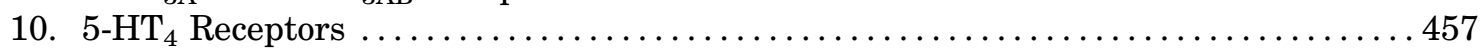

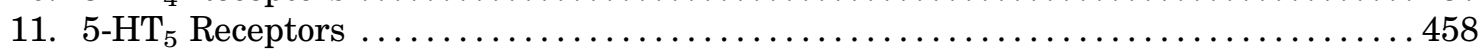

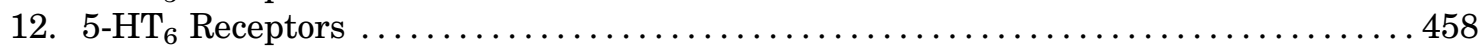

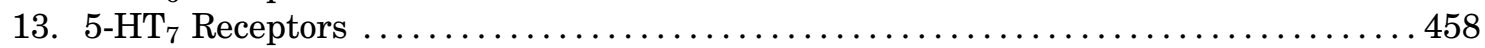

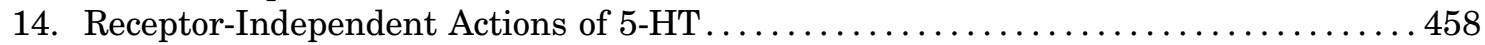

XX. 5-HT Receptors and the Gastrointestinal Tract........................... 458

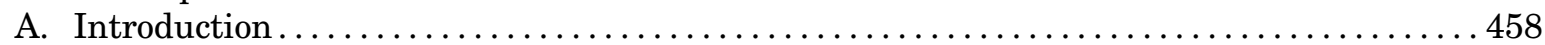

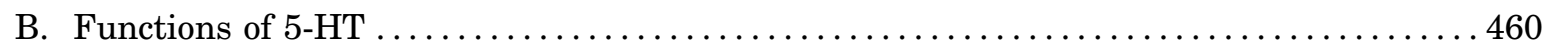

1. Movements of the Hungry Stomach............................. 460

2. Movements and Sensations of the Stomach and Duodenum after Meals ........ 461

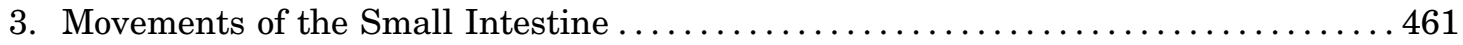

4. Movements of the Colon......................................... 461

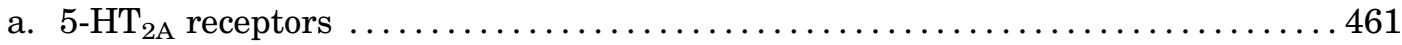

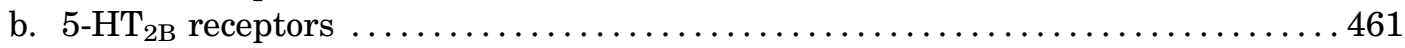

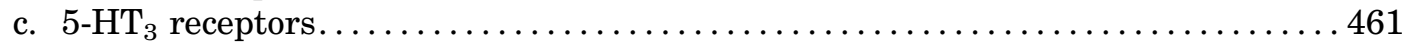

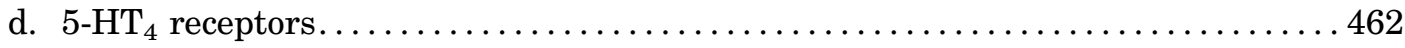

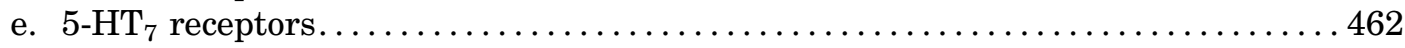

C. 5 -HT in Gastrointestinal Pathology .................................... 462

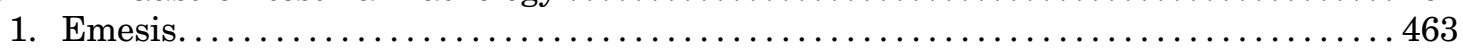

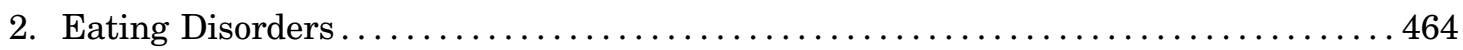

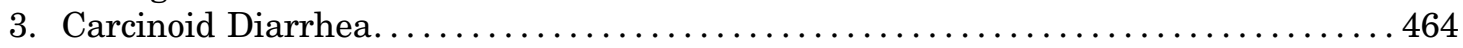

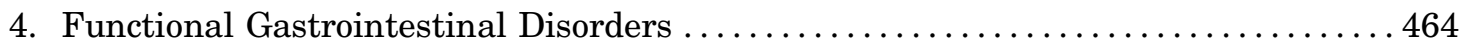

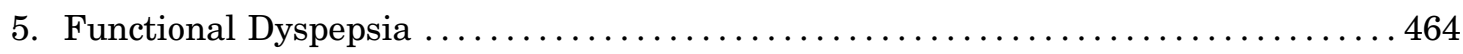

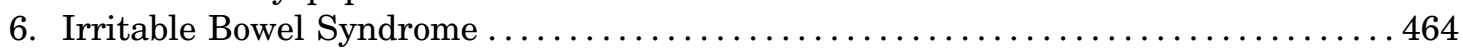

7. Other Gastrointestinal Disorders ................................ 465

D. Therapeutic Benefits of 5-HT Receptor Agonists and Antagonists . . . . . . . . . . 465

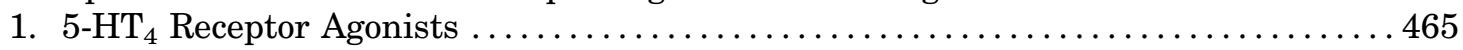

2. Other 5-HT Receptor Agonists................................. 466

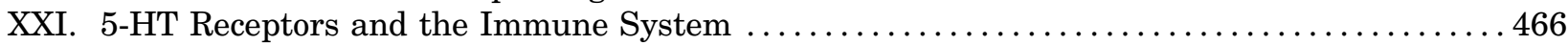

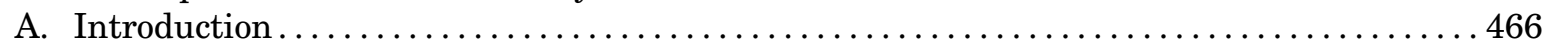

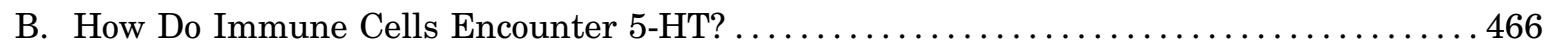

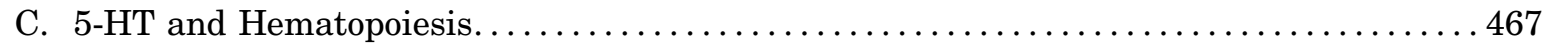

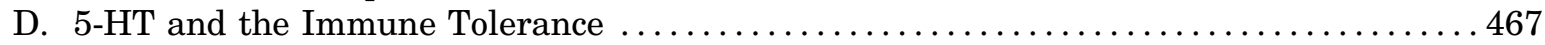

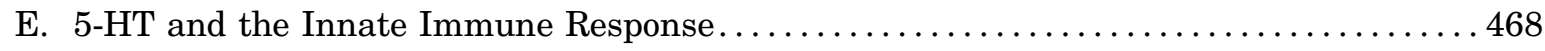

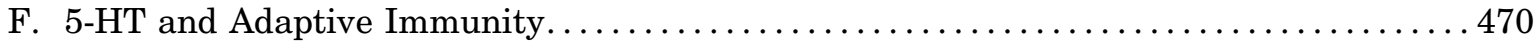




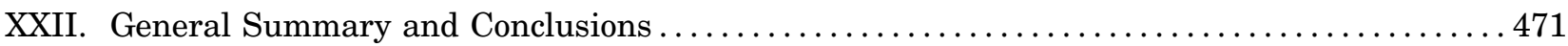

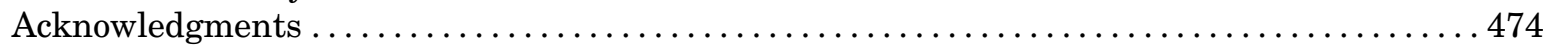

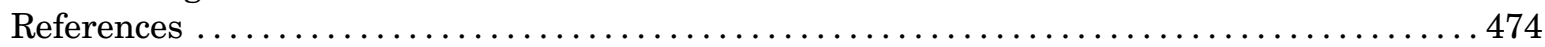

Abstract_-5-HT receptors expressed throughout the human body are targets for established therapeutics and various drugs in development. Their diversity of structure and function reflects the important role 5-HT receptors play in physiologic and pathophysiological processes. The present review offers a framework for the official receptor nomenclature and a detailed understanding of each of the 14 5-HT receptor subtypes, their roles in the systems of the body, and, where appropriate, the (potential) utility of therapeutics targeting these receptors.

Significance Statement_— This review provides a comprehensive account of the classification and function of 5-hydroxytryptamine receptors, including how they are targeted for therapeutic benefit.

\section{Introduction}

Classification of 5-HT receptors extends back to the middle of the last century when Gaddum and Picarelli (1957) suggested that the 5-HT-induced contraction of guinea pig ileum was mediated by two different receptors: a neurotropic "M" receptor located on parasympathetic ganglia (effect blocked by morphine and atropine; now known to be the $5-\mathrm{HT}_{3}$ receptor) and a musculotropic " $D$ " receptor located on smooth muscles (effect blocked by dibenzyline, lysergide, 2-bromolysergide, and dihydroergotamine; now known to be the $5-\mathrm{HT}_{2 \mathrm{~A}}$ receptor). This original classification served well for around two decades, although, from time to time, it was reported that some 5-HT-induced effects (e.g., vasoconstriction in the canine carotid arterial bed) were not mediated by "M" or "D" but instead by "special" receptors (Saxena, 1974). Then, Bennett and Aghajanian (1974) reported the first successful radioligand binding study of 5-HT receptors using $\left[{ }^{3} \mathrm{H}\right]$ lysergide, and subsequent studies using $\left[{ }^{3} \mathrm{H}\right] 5-\mathrm{HT},\left[{ }^{3} \mathrm{H}\right]$ spiperone, and $\left[{ }^{3} \mathrm{H}\right]$ lysergide enabled Peroutka and Snyder (1979) to identify two 5-HT "receptors" named 5-HT 1 (nanomolar affinity for 5-HT) and 5- $\mathrm{HT}_{2}$ (micromolar affinity for 5-HT). Subsequently, 5- $\mathrm{HT}_{1}$ "receptors" were subdivided pharmacologically into $5-\mathrm{HT}_{1 \mathrm{~A}}$ and 5 - $\mathrm{HT}_{1 \mathrm{~B}}$ receptors (Pedigo et al., 1981), and 8-OH-DPAT was designated as a selective $5-\mathrm{HT}_{1 \mathrm{~A}}$ ligand (Gozlan et al., 1983; Middlemiss and Fozard, 1983). However, at these times, 5 -HT receptors were being classified by various names (e.g., "D," "M," $5-\mathrm{HT}_{1}, 5-\mathrm{HT}_{2}, \mathrm{~S}_{1}, \mathrm{~S}_{2}$ ), hence the clear need for uniform terminology. This effort culminated in the Bradley et al. (1986) publication, classifying 5 -HT receptors into " 5 - $\mathrm{HT}_{1}$-like" (equivalent to some "D" or $5-\mathrm{HT}_{1}$ ), $5-\mathrm{HT}_{2}$ (equivalent to most "D" or $5-\mathrm{HT}_{2}$ ), and $5-\mathrm{HT}_{3}$ (equivalent to "M") receptors. The authors emphasized that this classification was a "general framework," which would be regularly updated with new findings. Indeed, with the explosion in new findings around the time, it was clear a new classification was required that gave rise to the 5-HT receptor IUPHAR subcommittee-sanctioned classification of 5-HT receptors into 5-HT ( $^{-5} 5 \mathrm{HT}_{1}$-like," 5- $\mathrm{HT}_{1 \mathrm{~A}}, 5-\mathrm{HT}_{1 \mathrm{~B}}, 5-\mathrm{HT}_{1 \mathrm{D}}$, $5-\mathrm{ht}_{1 \mathrm{e}}$, and $\left.5-\mathrm{ht}_{1 \mathrm{f}}\right), 5-\mathrm{HT}_{2}\left(5-\mathrm{HT}_{2 \mathrm{~A}}, 5-\mathrm{HT}_{2 \mathrm{~B}}\right.$, and $\left.5-\mathrm{HT}_{2 \mathrm{C}}\right)$,
$5-\mathrm{HT}_{3}, 5-\mathrm{HT}_{4}$, recombinant $\left(5-\mathrm{ht}_{5 \mathrm{a} / 5 \mathrm{~b}}, 5-\mathrm{ht}_{6}, 5-\mathrm{ht}_{7}\right)$, and "orphan" receptors (Hoyer et al., 1994). This new classification scheme was based on the conjunction of structural (molecular structure), transductional (intracellular transduction mechanisms), and operational (selective agonists and antagonists and ligand binding affinities) criteria. This first IUPHAR review on 5-HT receptors (Hoyer et al., 1994) was a landmark for the then rather complex 5-HT receptor field and the associated diversity of nomenclature used by operators in the field. In the 1994 review, we noted that the authors had a cumulated 100 years of active 5-HT research to share. A number of our colleagues have, in the meantime, retired from active research or have moved to other professional priorities. The present review provides a comprehensive overview of each of the recognized 5-HT receptors (Table 1) as well as reviewing the roles of 5-HT receptors in the major organs. There is a lot of new "blood" on board to reflect the growing diversity of the research, which is currently performed in many different academic and industrial centers; the combined years in 5-HT research of the present authors has increased considerably, partly because of the expansion of authors to ensure a comprehensive review of 5-HT receptors guided by the IUPHAR subcommittee on 5-HT receptors, which is chaired by Nicholas Barnes and Danny Hoyer.

In the present review, we address each receptor separately, as was performed previously, and then have sections that deal with specific aspects in more detail, such as the structures of 5-HT receptors, their functions in the major systems, and translational/clinical outcomes arising from 5-HT research. Readers are also directed to a website (http://www.guidetopharmacology.org/GRAC/FamilyDisplayForward?familyId=1) and the Concise Guide to Pharmacology (Alexander et al., 2019).

\section{5-HT IA $_{\text {Receptor }}$}

\section{A. Introduction}

$5-\mathrm{HT}_{1 \mathrm{~A}}$ receptors have attracted particular interest because of their negative feedback on 5-HT neurons, 
TABLE 1

Nomenclature for 5-HT receptors

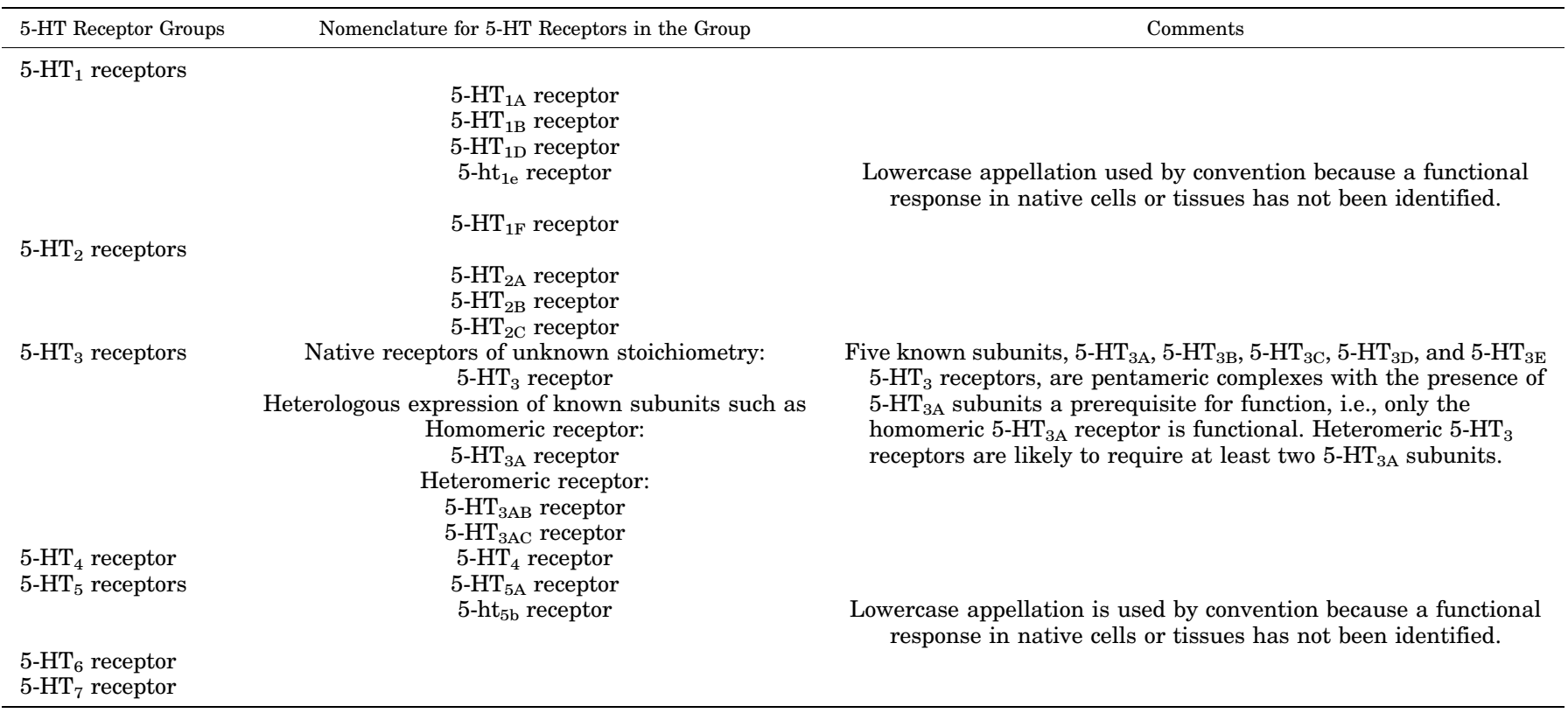

thus inhibiting 5-HT release and having broad influence on 5-HT tone. Additionally, $5-\mathrm{HT}_{1 \mathrm{~A}}$ receptors are widely distributed in terminal areas of the brain, where they are expressed as postsynaptic heteroceptors in a variety of different brain regions, influencing a range of neuropsychopharmacological sequalae (Albert and Fiori, 2014). After outlining the molecular structure, tissue expression, and the tools that can aid in the delineation of 5- $\mathrm{HT}_{1 \mathrm{~A}}$ receptor function, the focus will be on the diverse therapeutic fields in which $5-\mathrm{HT}_{1 \mathrm{~A}}$ receptors have become a target. Accordingly, substantial efforts have focused on targeting $5-\mathrm{HT}_{1 \mathrm{~A}}$ receptors for pharmacotherapy of a variety of neurologic and psychiatric disorders, including major depressive disorder, anxiety, and schizophrenia. In addition, activation or blockade of $5-\mathrm{HT}_{1 \mathrm{~A}}$ receptors has been implicated in control of diverse other effects, including cognition, pain, fear, substance use disorder, and Parkinson disease (PD), and, more recently, in emerging clinical opportunities such as female sexual dysfunction and the treatment of respiratory deficits. The complexity of the effects of $5-\mathrm{HT}_{1 \mathrm{~A}}$ receptors presents both a challenge and a considerable opportunity for investigation of 5-HT function and for the potential identification of novel and improved therapeutic drugs.

\section{B. 5-HT $T_{1 \mathrm{~A}}$ Receptor Identification and Expression}

The introduction of tritiated $\left[{ }^{3} \mathrm{H}\right]$ receptor-binding techniques revealed the existence of $5-\mathrm{HT}_{1}$ (and 5- $\mathrm{HT}_{2}$ ) receptor families in the prefrontal cortex $(\mathrm{PFC})$ of the brain (Peroutka and Snyder, 1979), and extended studies indicated the existence of different $5-\mathrm{HT}_{1}$ receptor populations, designated, for the first time, 5- $\mathrm{HT}_{1 \mathrm{~A}}$ and 5- $\mathrm{HT}_{1 \mathrm{~B}}$ receptors (Pedigo et al., 1981; Middlemiss and Fozard, 1983), leading to a much greater understanding of the pharmacological and functional role of the $5-\mathrm{HT}_{1 \mathrm{~A}}$ receptor in health and disease.

The cloning of the $5-\mathrm{HT}_{1 \mathrm{~A}}$ receptor from various species confirmed the existence of $5-\mathrm{HT}_{1 \mathrm{~A}}$ receptors as distinct gene products that correlated with pharmacologically defined receptor responses (Table 2).

The $5-\mathrm{HT}_{1 \mathrm{~A}}$ receptor has been located in a wide variety of peripheral and central targets. In the periphery, immunohistochemical studies have demonstrated that the receptor is located in human and rat kidney, including medulla and cortical ascending limbs, the convoluted tubules, connecting tubule cells, and the principal cells of the initial collecting tubule (Raymond et al., 1993), and murine peritoneal macrophages (FreireGarabal et al., 2003). However, other techniques have revealed a wider distribution: Western blotting found the receptor in human benign and malignant prostate tissue (Dizeyi et al., 2004), whereas reverse transcriptase polymerase chain reaction (RT-PCR) demonstrated the presence of $5-\mathrm{HT}_{1 \mathrm{~A}}$ receptors in rat taste buds (Kaya et al., 2004). However, the receptor is relatively poorly expressed in human coronary arteries, heart atrium, heart ventricles, and epicardium (Nilsson et al., 1999a,b). The brain and spinal cord have particularly dense populations of $5-\mathrm{HT}_{1 \mathrm{~A}}$ receptors, consistent with the role of this receptor in neuropsychiatric disease. The use of $5-\mathrm{HT}_{1 \mathrm{~A}}$ receptor agonists has been linked with the management of pain; accordingly, radioligand-binding and in situ hybridization studies have indicated the 
TABLE 2

Overview of the amino acid structure, gene loci, and symbols and gene name of the human, mouse, rat, dog, and rhesus macaque monkey for $5-\mathrm{HT}_{1 \mathrm{~A}}$ receptors

High receptor homology, but homology in binding receptor domains is higher. Homologs described for other nonhuman primates, mosquito, Gallus gallus domesticus, Danio rerio, Caenorhabditis elegans, Drosophila melanogaster, Bos taurus, Xenopus laevis, Cavia porcellus, Equus caballus, etc. A total of 160 species have orthologs of the human receptor (https://www.ncbi.nlm.nih.gov/gene/?Term=ortholog_gene_3350[group]; http://www.ncbi.nlm.nih.gov/probe/?term=479890[unistsid]).

\begin{tabular}{|c|c|c|c|c|c|}
\hline Species & Bp & AA & AA Homology with Human (\%) & Chromosome Location & Gene Symbol \\
\hline Human $^{a, b}$ & 1269 & 422 & $100 \%$ & $5 q 11.2-q 13$ & HTR1A \\
\hline Mouse $^{c}$ & 1266 & 421 & $88 \%$ & $13 \mathrm{D} 2.1$ & Htr1a \\
\hline $\operatorname{Rat}^{d, e}$ & 1269 & 422 & $90 \%$ & $2 q 16$ & Htr1a \\
\hline Monkey ${ }^{g}$ & 1266 & 421 & $98 \%$ & $6.122 .4 \mathrm{cr}$ & HTR1A \\
\hline
\end{tabular}

AA, number of amino acids; Bp, coding base pairs.

${ }^{a}$ Fargin et al., 1988.

${ }^{b}$ Stam et al., 1992.

${ }^{c}$ Charest et al., 1993.

${ }^{d}$ Albert et al., 1990.

${ }^{e}$ Fujiwara et al., 1990

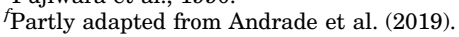

${ }^{g}$ Macaca mulatta.

presence in the human and rat dorsal and ventral horns (Pompeiano et al., 1992; Laporte et al., 1996) and rat superior cervical ganglia (Pierce et al., 1996). In the brain, a wide distribution of the receptor has been described in both terminal regions as postsynaptic sites and in the raphe nuclei, where it has a somatodendritic autoreceptor function (Jacobs and Azmitia, 1992; Fornal et al., 1994). Generally, there is much conservation in regional expression across species, although rat-human cortical and hippocampal differences in laminar organization were reported (Burnet et al., 1995; Barnes and Sharp, 1999). Within the brain, different techniques, including receptor binding, RT-PCR, in situ hybridization (Fig. 1), Western and Northern blotting, and immunohistochemistry, have localized the receptor to the septum, thalamus, hippocampus, entorhinal cortex, interpeduncular nucleus, olfactory bulb, amygdala, hypothalamic subnuclei, and subareas of the cortex and raphe nuclei (Gozlan et al., 1983; Hall et al., 1985; Pazos and Palacios, 1985; Weissmann-Nanopoulos et al., 1985; Dourish et al., 1986; Hoyer et al., 1986a; Vergé et al., 1986; Daval et al., 1987; Hamon et al., 1988; Albert et al., 1990; Hirose et al., 1990; Chalmers and Watson, 1991; Radja et al., 1991; Francis et al., 1992; Miquel et al., 1992; Pompeiano et al., 1992; Khawaja, 1995; Kung et al., 1995; Pike et al., 1995; Lemoine et al., 2010, 2012). More particularly, $5-\mathrm{HT}_{1 \mathrm{~A}}$ receptors are located on septal cholinergic neurons, cortical and hippocampal glutamatergic pyramidal neurons and granule cells (Francis et al., 1992; Pompeiano et al., 1992; Burnet et al., 1995), and calbindin- and parvalbumin-positive neurons (Aznar et al., 2003).

\section{Pharmacology}

In view of the involvement of $5-\mathrm{HT}_{1 \mathrm{~A}}$ receptors in a wide variety of physiologic responses, the pharmacological profile of these receptors has been investigated extensively using an impressive variety of ligands, with varying degrees of selectivity. These range from drugs preferentially targeting $5-\mathrm{HT}_{1 \mathrm{~A}}$ receptors to nonselective compounds that have broad pharmacological activities.
Examples of the latter are atypical antipsychotic drugs such as clozapine, ziprasidone, or aripiprazole, which interact with many receptor subtypes. Notably, there are currently no selective $5-\mathrm{HT}_{1 \mathrm{~A}}$ receptor drugs approved for therapeutic use. This is somewhat surprising in view of the broad therapeutic interest of $5-\mathrm{HT}_{1 \mathrm{~A}}$ receptors but likely reflects the difficulty of identifying chemical scaffolds that selectively engage this target. For example, the anxiolytic agent, buspirone, and its chemical analogs such as ipsapirone and gepirone lack selectivity over some other receptors (for example, buspirone displays submicromolar affinity for dopamine $\mathrm{D}_{2}, \mathrm{D}_{3}$, and $\mathrm{D}_{4}$ receptors; $5-\mathrm{HT}_{2 \mathrm{~A}}, 5-\mathrm{HT}_{2 \mathrm{~B}}, 5-\mathrm{HT}_{2 \mathrm{C}}, 5-\mathrm{HT}_{6}$, and $5-\mathrm{HT}_{7}$ receptors; and $\alpha 1$ adrenoceptors). Similarly, several antagonist ligands have been proposed, but few have proved to be selective "silent antagonists." Nevertheless, some recent "full agonists" (notably befiradol) have been identified that exhibit good selectivity for $5-\mathrm{HT}_{1 \mathrm{~A}}$ receptors and, as such, may constitute first-in-class therapeutic agents.

Tables 3 and 4 summarize the receptor-binding properties of many $5-\mathrm{HT}_{1 \mathrm{~A}}$ receptor ligands that have been described over the last decades. It is also worth noting that even though certain compounds do display measurable receptor-binding affinity, this may be too low to induce functional responses at the $5-\mathrm{HT}_{1 \mathrm{~A}}$
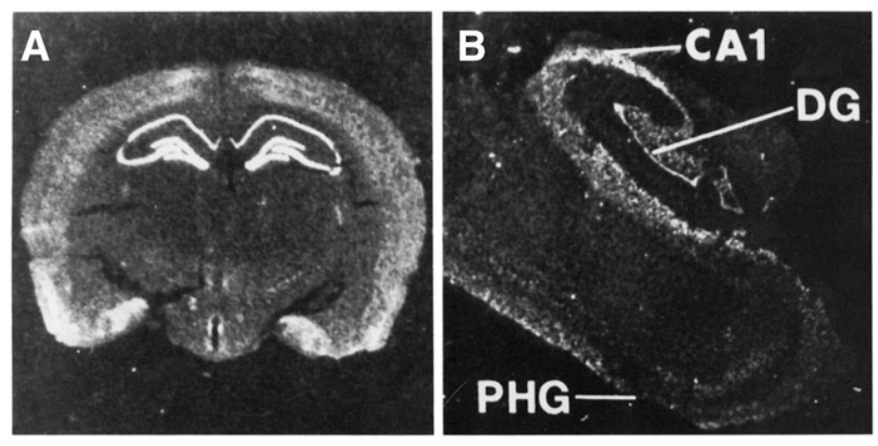

Fig. 1. In situ hybridization detection of $5-\mathrm{HT}_{1 \mathrm{~A}}$ receptor mRNA expression in rat (A) and human brain (B) at the level of the hippocampus. CA1, dentate gyrus (DG) of the hippocampus, and parahippocampal gyrus (PHG) are shown. Adapted from Burnet et al. (1995) (with permission). 
receptor. Such an example is olanzapine, fails to elicit electrophysiological actions at the level of somatodendritic autoreceptors in contrast to ziprasidone and clozapine (Sprouse et al., 1999). Many of the ligands have been decisive in the operational definition of biochemical and pharmacological function at a basic science level and in key disease models. In addition to the receptor agonists and antagonists, there is some evidence for the existence of allosteric modulators, such as zinc, Galphimine-B, and RS-30199 (Spedding et al., 1998; Barrondo and Sallés, 2009; Jimenez-Ferrer et al., 2011).

The use of $\left[{ }^{35} \mathrm{~S}\right] \mathrm{GTP} \gamma \mathrm{S}$ binding, a nonhydrolysable analog of GTP that binds to agonist-activated G proteins, has proved useful for investigating $5-\mathrm{HT}_{1 \mathrm{~A}}$ receptor signaling and pharmacology (Newman-Tancredi et al., 1996b, 1997b, 1998; Barr and Manning, 1997; Pauwels et al., 1997; Sim et al., 1997; Stanton and Beer, 1997; Dupuis et al., 1999a,b; Cosi and Koek, 2000; GonzalezMaeso et al., 2000; McLoughlin and Strange, 2000; Shen et al., 2002; Odagaki and Toyoshima, 2005a,b, 2007). Notably, the use of $\left[{ }^{35} \mathrm{~S}\right] \mathrm{GTP} \gamma \mathrm{S}$ binding enabled the investigation of both positive and negative efficacy ligands at $5-\mathrm{HT}_{1 \mathrm{~A}}$ receptors. Thus, whereas a range of ligands efficaciously stimulated $\mathrm{G}$ proteins, other drugs, such as spiperone and methiothepin, markedly inhibited the $\left[{ }^{35} \mathrm{~S}\right] \mathrm{GTP} \gamma \mathrm{S}$ basal binding in both membranes prepared from $5-\mathrm{HT}_{1 \mathrm{~A}}$ receptor-transfected Chinese Hamster Ovary (CHO) cells and native tissue, confirming the capacity of 5- $\mathrm{HT}_{1 \mathrm{~A}}$ receptors to elicit constitutive activation of $\mathrm{G}$ proteins in vitro (Newman-Tancredi et al., 1997a; Stanton and Beer, 1997; McLoughlin and Strange, 2000; Corradetti et al., 2005; Martel et al., 2007). In contrast to spiperone, WAY1000635 exhibited neither positive nor negative efficacy yet blocked the actions of both agonists and inverse agonists, consistent with "neutral antagonist" properties (Fletcher et al., 1996; Martel et al., 2007) also evident in vivo using electrophysiological procedures (e.g., Fornal et al., 1996). This was important because other compounds claimed as antagonists at $5-\mathrm{HT}_{1 \mathrm{~A}}$ receptors, such as NAN190, BMY7378, SDZ216,525, and even WAY100135, were found to display partial agonist properties when tested in systems that exhibit high degrees of receptor reserve (Greuel and Glaser, 1992; Routledge, 1996); changes in receptor expression level can markedly affect functional responses, and this is important when considering the nature of ligand engagement and the notion that different brain areas exert distinct physiologic influence (Newman-Tancredi et al., 1997c). A threefold increase in receptor:G protein ratio almost doubled relative efficacy of the partial agonist eltoprazine (53\%-93\%), without a change in potency, whereas 5-HT exhibited a twofold increase in potency (decrease in $\mathrm{EC}_{50}$ value) (Newman-Tancredi et al., 1997c). In addition to these changes, the increase in $5-\mathrm{HT}_{1 \mathrm{~A}}$ receptor:G protein ratio roughly doubled the negative efficacy of spiperone. These data therefore lead to the supposition that the targeting of agonist efficacy in vivo at different receptor populations is possible, which may offer therapeutic benefits.

\section{Biased Agonism: Differential Activation of 5-HT Receptor Subpopulations}

The term "biased agonism" ("functional selectivity" or "agonist-directed signaling") (Berg and Clarke, 2006; Evans et al., 2010; Kenakin, 2010; Tzingounis et al., 2010) was coined to denote a pattern of agonist signaling that was distinct from the concept of "intrinsic activity." Whereas the latter posits that receptor activation is an outcome of the "intrinsic" properties of the agonist, the concept of "biased agonism" is based on the capacity of agonists to preferentially mediate receptor signaling via specific pathways while not affecting, or even blocking, other secondary messenger pathways coupled to the same receptor. If the different signaling cascades mediate distinct functionality (e.g., therapeutic vs. side effects), then biased agonism will offer a strategy to potentially target different mechanisms with the opportunity to potentially develop more effective, better-tolerated drugs.

An early study of $5-\mathrm{HT}_{1 \mathrm{~A}}$ receptors suggested that different agonists displayed differential G $\alpha \mathrm{i} 2$ and $\mathrm{G} \alpha \mathrm{i} 3$ activation, determined using a photoreactive GTP analog (4-azidoanilido- $\left[\alpha{ }^{32} \mathrm{P}\right] \mathrm{GTP}$ ) (Gettys et al., 1994). Rauwolscine displayed similar $\mathrm{EC}_{50}$ values for activation of the two G protein subtypes; ipsapirone showed a nearly fourfold lower $\mathrm{EC}_{50}$ for $\mathrm{G} \alpha \mathrm{i} 3$ activation. 5-HT and 8-OH-DPAT had intermediate $\mathrm{EC}_{50}$ values (Gettys et al., 1994). In another study, the presence of anti-G $\alpha \mathrm{i} 3$ antibodies almost completely suppressed $\mathrm{G}$ protein activation by pindolol, a $5-\mathrm{HT}_{1 \mathrm{~A}}$ receptor partial agonist that preferentially elicits activation of G $\alpha \mathrm{i} 3$, a property that may underlie its preferential occupancy of midbrain $5-\mathrm{HT}_{1 \mathrm{~A}}$ autoreceptors (Hirani et al., 2000; Martinez et al., 2001; Newman-Tancredi et al., 2002). Drug differences were also seen in transduction experiments on native rat raphe; buspirone elicited G $\alpha \mathrm{i} 2-, \mathrm{G} \alpha \mathrm{i} 3-$, and $\mathrm{G} \alpha \mathrm{0}$-mediated responses as well as inhibition of adenylyl cyclase (AC), whereas 8-OH-DPAT only elicited coupling to $\mathrm{G} \alpha \mathrm{i} 3$ and did not elicit the other responses (Valdizán et al., 2010).

Together, these data support that different 5 - $\mathrm{HT}_{1 \mathrm{~A}}$ receptor agonists possess different $G$ protein activation "fingerprints," backing the biased agonist concept and hence suggesting that $5-\mathrm{HT}_{1 \mathrm{~A}}$ receptor subpopulation targeting is possible (Fig. 2). Compounds such as the biased $5-\mathrm{HT}_{1 \mathrm{~A}}$ receptor agonists, $\mathrm{F} 15599$ and $\mathrm{F} 13714$, reversed immobility in the rat forced swim test via actions at presumed postsynaptic receptors. Similarly, anxiolytic-like actions were seen in the rat ultrasonic vocalization test (De Vry et al., 1993; Assié et al., 2010). However, in animal tests related to side effects, F15599 exhibited a better profile compared with F13714 (Gaggi et al., 1997; Prinssen et al., 2000; Assié et al., 2010), further supporting the potential for improved therapeutics utilizing biased agonists to target the appropriate 
TABLE 3

Receptor-binding characteristics of $5-\mathrm{HT}_{1 \mathrm{~A}}$ receptor agonists

Data are extracted and adapted from Colpaert et al. (2002), Glennon et al. (2006), McCreary et al. (2007), Andrade et al. (2019), and McCreary and Newman-Tancredi (2019).

\begin{tabular}{|c|c|c|c|c|}
\hline Agonist & Agonist Action & Affinity & Units & Clinical Utility \\
\hline 1-naphthylpiperazine & Full & 8 & $\mathrm{p} K_{\mathrm{i}}$ & \\
\hline $5-\mathrm{CT} \quad-\mathrm{T}-2-5$ & Full & $9.4-10.3$ & $\mathrm{p} K_{\mathrm{i}}$ & \\
\hline 5-hydroxytryptamine & Full & $9.1-9.7$ & $\mathrm{p} K_{\mathrm{i}}$ & \\
\hline 7-methoxy-1-naphthylpiperazine & Full & 8.6 & $\mathrm{p} K_{\mathrm{i}}$ & \\
\hline 8-OH-DPAT & Full & $8.4-9.4$ & $\mathrm{p} K_{\mathrm{i}}$ & \\
\hline (R)-UH 301 & Partial & 8.6 & $\mathrm{p} K_{\mathrm{i}}$ & \\
\hline Adoprazine (SLV313) & Full/Partial & $8.64-9.1$ & $\mathrm{p} K_{\mathrm{i}}$ & Schizophrenia \\
\hline Apomorphine & Partial & 6.9 & $\mathrm{p} K_{\mathrm{i}}$ & $\mathrm{PD}$, erectile dysfunction \\
\hline Aripiprazole & Full & 8.2 & $\mathrm{p} K_{\mathrm{i}}$ & Schizophrenia \\
\hline Asenapine & Full & $8.0-8.3$ & $\mathrm{p} K_{\mathrm{i}}$ & Schizophrenia \\
\hline BMY-7378 & Partial & $6.8-8.0$ & $\mathrm{pIC}_{50}$ & \\
\hline BMY-1480 & Full & 7.2 & $\mathrm{p} K_{\mathrm{i}}$ & \\
\hline Befiradol & Full & 9.1 & $\mathrm{pKi}$ & PD dyskinesia \\
\hline Bifeprunox & Partial & $7.19-8.95$ & $\mathrm{p} K_{\mathrm{i}}$ & Schizophrenia \\
\hline Brexpiprazole & Partial & 9.92 & $\mathrm{p} K_{\mathrm{i}}$ & Schizophrenia \\
\hline BRL-15572 & Partial & 7.7 & $\mathrm{p} K_{\mathrm{i}}$ & \\
\hline Bromocriptine & Partial & 7.9 & $\mathrm{p} K_{\mathrm{i}}$ & PD \\
\hline Buspirone & Partial & $7.7-8.0$ & $\mathrm{p} K_{\mathrm{i}}$ & Anxiety \\
\hline Cabergoline & Full & 7.7 & $\mathrm{p} K_{\mathrm{i}}$ & PD \\
\hline Capeserod & Partial & 6 & $\mathrm{p} K_{\mathrm{i}}$ & \\
\hline Cariprazine & Partial & 8.59 & $\mathrm{p} K_{\mathrm{i}}$ & Schizophrenia \\
\hline Clozapine & Full & $6.8-6.9$ & $\mathrm{p} K_{\mathrm{i}}$ & Schizophrenia \\
\hline CP 93129 & Full & 6.1 & $\mathrm{p} K_{\mathrm{i}}$ & \\
\hline Donitriptan & Full & 7.6 & $\mathrm{p} K_{\mathrm{i}}$ & Migraine \\
\hline Eletriptan & Full & 7.4 & $\mathrm{p} K_{\mathrm{i}}$ & \\
\hline Eltoprazine & Partial & 8.03 & $\mathrm{p} K_{\mathrm{i}}$ & \\
\hline EMDT & Full & 6.8 & $\mathrm{p} K_{\mathrm{i}}$ & \\
\hline F13714 & Full & 10.1 & $\mathrm{pKi}$ & \\
\hline F15063 & Partial & 8.24 & $\mathrm{p} K_{\mathrm{i}}$ & \\
\hline F15599 & Full & 8.6 & pKi & Rett syndrome \\
\hline FG-5893 & Full & 8.7 & $\mathrm{p} K_{\mathrm{i}}$ & \\
\hline Flesinoxan & Full & 9.3 & $\mathrm{p} K_{\mathrm{i}}$ & Major depression \\
\hline Flibanserin & Agonist & 9 & $\mathrm{p} K_{\mathrm{i}}$ & Female hypoactive sexual desire \\
\hline Fluparoxan & Partial & 6.8 & $\mathrm{p} K_{\mathrm{i}}$ & \\
\hline Frovatriptan & Agonist & 7.2 & $\mathrm{p} K_{\mathrm{i}}$ & \\
\hline GR127935 & Partial & $7.1-7.2$ & $\mathrm{p} K_{\mathrm{i}}$ & \\
\hline Ipsapirone & Partial & $8.6-8.8$ & $\mathrm{p} K_{\mathrm{i}}$ & \\
\hline L-694,247 & Full & 9.3 & $\mathrm{p} K_{\mathrm{i}}$ & \\
\hline L-772,405 & Full & 7.2 & $\mathrm{pIC}_{50}$ & \\
\hline Lisuride & Full & $9.7-9.8$ & $\mathrm{p} K_{\mathrm{i}}$ & Migraine \\
\hline LP-12 & Agonist & 7.2 & $\mathrm{p} K_{\mathrm{i}}$ & \\
\hline LP-44 & Agonist & 7.3 & $\mathrm{p} K_{\mathrm{i}}$ & \\
\hline LP-211 & Agonist & 6.7 & $\mathrm{p} K_{\mathrm{i}}$ & \\
\hline LSD & Full & 9 & $\mathrm{p} K_{\mathrm{i}}$ & \\
\hline Lurasidone & Full & 8.17 & $\mathrm{p} K_{\mathrm{i}}$ & Schizophrenia \\
\hline LY293284 & Full & 10.1 & $\mathrm{p} K_{\mathrm{i}}$ & \\
\hline LY334370 & Full & 7.8 & $\mathrm{p} K_{\mathrm{i}}$ & \\
\hline LY344864 & Full & 6.3 & $\mathrm{p} K_{\mathrm{i}}$ & \\
\hline LY 165,163 & Full & 8.9 & $\mathrm{p} K_{\mathrm{i}}$ & \\
\hline Nafadotride & Full & 7.3 & $\mathrm{p} K_{\mathrm{i}}$ & \\
\hline Naratriptan & Full & $7.1-7.6$ & $\mathrm{p} K_{\mathrm{i}}$ & Migraine \\
\hline Nemonapride & Partial & 8.35 & $\mathrm{p} K_{\mathrm{i}}$ & Schizophrenia \\
\hline Ocaperidone & Full & 8 & $\mathrm{p} K_{\mathrm{i}}$ & \\
\hline Olanzapine & Full & $5.6-5.8$ & $\mathrm{p} K_{\mathrm{i}}$ & Schizophrenia \\
\hline Pardoprunox (SLV308) & Full & 8.5 & $\mathrm{p} K_{\mathrm{i}}$ & PD \\
\hline Pergolide & Partial & 8.7 & $\mathrm{p} K_{\mathrm{i}}$ & PD \\
\hline Piribedil & Partial & 6.4 & $\mathrm{p} K_{\mathrm{i}}$ & $\mathrm{PD}$ \\
\hline Quetiapine & Full & $6.5-6.6$ & $\mathrm{p} K_{\mathrm{i}}$ & Schizophrenia \\
\hline Quinpirole & Full & 5.8 & $\mathrm{p} K_{\mathrm{i}}$ & \\
\hline Repinotan & Full & 9.4 & $\mathrm{p} K_{\mathrm{i}}$ & \\
\hline Rizatriptan & Full & 6.4 & $\mathrm{p} K_{\mathrm{i}}$ & Migraine \\
\hline Roxindole & Partial & $9.4-9.9$ & $\mathrm{p} K_{\mathrm{i}}$ & \\
\hline RU 24969 & Full & 9 & $\mathrm{p} K_{\mathrm{i}}$ & \\
\hline S 16924 & Partial & 8.4 & $\mathrm{p} K_{\mathrm{i}}$ & \\
\hline S-14506 & Full & $9.6-9.7$ & $\mathrm{p} K_{\mathrm{i}}$ & \\
\hline S-14671 & Full & $10.2-10.5$ & $\mathrm{p} K_{\mathrm{i}}$ & \\
\hline S-15535 & Partial & 9.2 & $\mathrm{p} K_{\mathrm{i}}$ & \\
\hline Sarizotan & Partial & 8.65 & $\mathrm{pKi}$ & PD dyskinesia \\
\hline SB 216641 & Partial & 6.3 & $\mathrm{p} K_{\mathrm{i}}$ & \\
\hline Spiroxatrine & Full & 8.8 & $\mathrm{p} K_{\mathrm{i}}$ & \\
\hline SSR181507 & Partial & 8.53 & $\mathrm{pKi}$ & \\
\hline Sumatriptan & Full & 6 & $\mathrm{p} K_{\mathrm{i}}$ & Migraine \\
\hline Tandospirone & Partial & 8.2 & $\mathrm{p} K_{\mathrm{i}}$ & Anxiety \\
\hline
\end{tabular}


TABLE 3-Continued

\begin{tabular}{|c|c|c|c|c|}
\hline Agonist & Agonist Action & Affinity & Units & Clinical Utility \\
\hline Terguride & Partial & 8.5 & $\mathrm{p} K_{\mathrm{i}}$ & $\mathrm{PD}$ \\
\hline U92016A & Full & 9.7 & $\mathrm{p} K_{\mathrm{i}}$ & \\
\hline Vilazodone & Partial & 9.7 & $\mathrm{p} K_{\mathrm{i}}$ & Depression \\
\hline Vilazodone & Partial & 9.5 & $\mathrm{pIC}_{50}$ & Depression \\
\hline Vortioxetine & Partial & 7.8 & $\mathrm{p} K_{\mathrm{i}}$ & Depression \\
\hline WAY-100135 & Partial & 8 & $\mathrm{pKi}$ & \\
\hline Xanomeline & Full & 7.2 & $\mathrm{p} K_{\mathrm{i}}$ & \\
\hline Zalospirone & Full & 8.1 & $\mathrm{p} K_{\mathrm{i}}$ & \\
\hline Ziprasidone & Partial & $7.9-8.9$ & $\mathrm{p} K_{\mathrm{i}}$ & Schizophrenia \\
\hline Zolmitriptan & Full & 6.6 & $\mathrm{p} K_{\mathrm{i}}$ & Migraine \\
\hline
\end{tabular}

EMDT, 2-Ethyl-5-methoxy-N,N-dimethyltryptamine.

$5-\mathrm{HT}_{1 \mathrm{~A}}$ receptor subpopulation (Table 5), which includes potential to improve the cognitive state of patients with schizophrenia (Depoortère et al., 2010; Horiguchi and Meltzer, 2012).

\section{E. 5-HT ${ }_{1 A}$ Receptor Intracellular Signal Transduction}

The transfection (Fargin et al., 1988) and heterologous expression of $5-\mathrm{HT}_{1 \mathrm{~A}}$ receptors in various different cellular environments (including COS7, HeLa, CHO, NIH3T3, Sf9, and Escherichia coli cells) enabled the study of their G protein coupling to secondary messenger systems (Raymond et al., 1999). A well characterized intracellular functional response is the inhibition of $\mathrm{AC}$ activity and has been extensively used to differentiate ligands for this receptor, their agonist and partial agonist actions, or their degree of antagonism (De Vivo and Maayani, 1986; Markstein et al., 1986; Bockaert et al., 1987; Shenker et al., 1987; Dumuis et al., 1988b; Fargin et al., 1989; Varrault and Bockaert, 1992; Raymond et al., 2006). $5-\mathrm{HT}_{1 \mathrm{~A}}$ receptors can also activate $\mathrm{G}$ protein inward rectifying potassium channels (GIRK), highconductance anion channels to inhibit calcium conductance modulating intracellular calcium mobilization, and stimulate nitric oxide synthase (NOS) and an NADP oxidase-like enzyme (Adayev et al., 2003; Hsiung et al., 2005; Polter and Li, 2010). The receptor can affect metabolism and arachidonic acid (AA) production (Raymond et al., 1999); activate protein kinase C production, Src kinase, and mitogen-activated protein kinases (MAPKs); and activate or inhibit phosphoinositol hydrolysis and stimulate reactive oxygen species (ROS) production (superoxide and peroxide) (Raymond et al., 1999). Together, the elucidation of this diverse pattern has led to important developments in establishing test systems to probe receptor and drug function.

\section{F. Function}

1. Differential Function of 5-HT $1 \mathrm{~A}$ Receptors at Cellular, Tissue, and In Vivo Levels. The functional properties of $5-\mathrm{HT}_{1 \mathrm{~A}}$ receptors have been extensively investigated. The overall conclusion from these studies is that subpopulations of $5-\mathrm{HT}_{1 \mathrm{~A}}$ receptors expressed in different brain regions exhibit specific patterns of receptor signaling, with differing impact on central function. These diverse properties indicate that separate subpopulations of $5-\mathrm{HT}_{1 \mathrm{~A}}$ receptors mediate particular responses and may constitute therapeutic targets in their own right (see also Fig. 2). For example, agonist activation of somatodendritic $5-\mathrm{HT}_{1 \mathrm{~A}}$ autoreceptors expressed on serotonergic neurons in the raphe elicits inhibition of 5-HT release in terminal regions such

TABLE 4

Receptor-binding characteristics of $5-\mathrm{HT}_{1 \mathrm{~A}}$ receptor antagonists Table adapted from Andrade et al. (2019).

\begin{tabular}{|c|c|c|}
\hline Antagonist & Affinity & Units \\
\hline$(+)$-butaclamol & 6.4 & $\mathrm{p} K_{\mathrm{i}}$ \\
\hline (-)-propranolol & 7.5 & $\mathrm{p} K_{\mathrm{i}}$ \\
\hline (-)-tertatolol & 8.2 & $\mathrm{p} K_{\mathrm{i}}$ \\
\hline (R)-flurocarazolol & 6.5 & $\mathrm{p} K_{\mathrm{i}}$ \\
\hline (S)-flurocarazolol & 7.5 & $\mathrm{p} K_{\mathrm{i}}$ \\
\hline (S)-UH 301 & 7.9 & $\mathrm{p} K_{\mathrm{i}}$ \\
\hline$\left[{ }^{3} \mathrm{H}\right] \mathrm{p}-\mathrm{MPPF}$ & 8.4 & $\mathrm{p} K_{\mathrm{d}}$ \\
\hline$\left[{ }^{3} \mathrm{H}\right]$ robalzotan & 9.8 & $\mathrm{p} K_{\mathrm{d}}$ \\
\hline$\left[{ }^{3} \mathrm{H}\right]$ WAY 100635 & 9.5 & $\mathrm{p} K_{\mathrm{d}}$ \\
\hline$\left[{ }^{11} \mathrm{C}\right]$ WAY100635 & - & - \\
\hline Chlorpromazine & 6.2 & $\mathrm{p} K_{\mathrm{i}}$ \\
\hline Cyamemazine & 6.3 & $\mathrm{p} K_{\mathrm{i}}$ \\
\hline Fluspirilene & 7.2 & $\mathrm{p} K_{\mathrm{i}}$ \\
\hline GR 125,743 & 7.3 & $\mathrm{p} K_{\mathrm{i}}$ \\
\hline GR 218,231 & 6.8 & $\mathrm{p} K_{\mathrm{i}}$ \\
\hline Haloperidol & $5.7-5.8$ & $\mathrm{p} K_{\mathrm{i}}$ \\
\hline Iloperidone & $6.8-7$ & $\mathrm{p} K_{\mathrm{i}}$ \\
\hline Ketanserin & 5 & $\mathrm{p} K_{\mathrm{i}}$ \\
\hline Mesoridazine & 7 & $\mathrm{p} K_{\mathrm{i}}$ \\
\hline Methiothepin & $7.8-8.1$ & $\mathrm{p} K_{\mathrm{i}}$ \\
\hline MPDT & 5.8 & $\mathrm{p} K_{\mathrm{i}}$ \\
\hline NAN 190 & 9.4 & $\mathrm{p} K_{\mathrm{i}}$ \\
\hline $\mathrm{p}-\left[{ }^{18} \mathrm{~F}\right] \mathrm{MPPF}$ & - & - \\
\hline p-MPPI & 8.4 & $\mathrm{p} K_{\mathrm{i}}$ \\
\hline Pimozide & 6.8 & $\mathrm{p} K_{\mathrm{i}}$ \\
\hline Pindolol & 8.1 & $\mathrm{p} K_{\mathrm{i}}$ \\
\hline Pipamperone & 5.6 & $\mathrm{p} K_{\mathrm{i}}$ \\
\hline Pizotifen & 7.4 & $\mathrm{p} K_{\mathrm{i}}$ \\
\hline Raclopride & 5.2 & $\mathrm{p} K_{\mathrm{i}}$ \\
\hline $\operatorname{Rec} 15 / 3079$ & 9.7 & $\mathrm{p} K_{\mathrm{i}}$ \\
\hline Risperidone & $6.2-6.5$ & $\mathrm{p} K_{\mathrm{i}}$ \\
\hline 9-OH-risperidone & 6.2 & $\mathrm{p} K_{\mathrm{i}}$ \\
\hline ritanserin & $5.2-5.5$ & $\mathrm{pIC}_{50}$ \\
\hline robalzotan & 9.2 & $\mathrm{p} K_{\mathrm{i}}$ \\
\hline SB 272183 & 8 & $\mathrm{p} K_{\mathrm{i}}$ \\
\hline SB 649915 & 8.6 & $\mathrm{p} K_{\mathrm{i}}$ \\
\hline SB $71478 \overline{6}$ & 6.5 & $\mathrm{p} K_{\mathrm{i}}$ \\
\hline SDZ-216525 & $7.8-8.2$ & $\mathrm{pIC}_{50}$ \\
\hline Sertindole & $6.4-6.6$ & $\mathrm{p} K_{\mathrm{i}}$ \\
\hline Spiperone & $6.7-8.8$ & $\mathrm{p} K_{\mathrm{i}}$ \\
\hline Thioridazine & 7.1 & $\mathrm{p} K_{\mathrm{i}}$ \\
\hline Tiospirone & 8.3 & $\mathrm{p} K_{\mathrm{i}}$ \\
\hline WAY-100635 & $7.9-9.2$ & $\mathrm{p} K_{\mathrm{i}}$ \\
\hline Yohimbine & 7.3 & $\mathrm{p} K_{\mathrm{i}}$ \\
\hline Zotepine & 6.5 & $\mathrm{p} K_{\mathrm{i}}$ \\
\hline
\end{tabular}

MPPF, 2'-methoxyphenyl-p-fluoro-benzamidoethyipiperazine. 
Serotonin 5- $\mathrm{HT}_{1 \mathrm{~A}}$ Receptor Subpopulations: Molecular, Neurochemical and Physiological Correlates

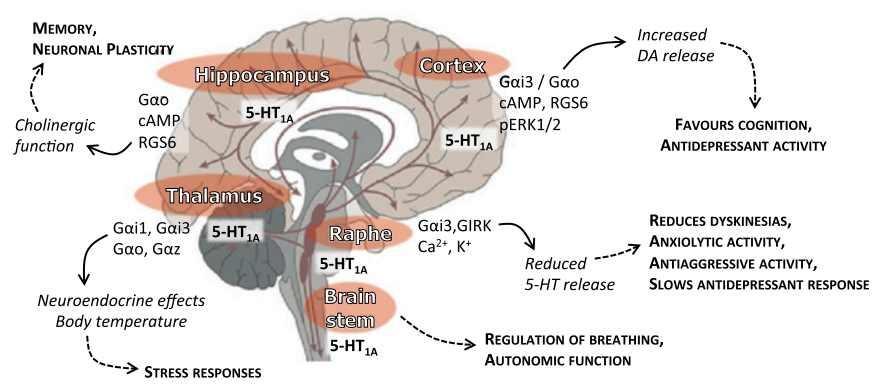

Fig. 2. Biased agonism at the $5-\mathrm{HT}_{1 \mathrm{~A}}$ receptor offers the potential to target subpopulations of $5-\mathrm{HT}_{1 \mathrm{~A}}$ receptors.

as the hippocampus and cortex. In contrast, activation of postsynaptic cortical $5-\mathrm{HT}_{1 \mathrm{~A}}$ heteroreceptors expressed on glutamatergic pyramidal cells and/or GABAergic interneurons elicits different neurochemical responses, including stimulation of dopamine release in the frontal cortex (Santana et al., 2004; Bortolozzi et al., 2010).

Activation of $5-\mathrm{HT}_{1 \mathrm{~A}}$ autoreceptors induces anxiolytic activity in rodent behavioral tests (De Vry et al., 2004; Akimova et al., 2009), whereas antidepressant-like responses are seen upon activation of $5-\mathrm{HT}_{1 \mathrm{~A}}$ heteroceptors (De Vry et al., 2004). These data obtained in rat behavioral experiments are consistent with observations in transgenic mice overexpressing raphe $5-\mathrm{HT}_{1 \mathrm{~A}}$ autoreceptors; accentuated depressive-like behavior was observed and diminished response to antidepressant treatment (Richardson-Jones et al., 2010). These data support the interpretation that desensitization of presynaptic $5-\mathrm{HT}_{1 \mathrm{~A}}$ receptors is necessary before antidepressant efficacy may be achieved (Artigas et al., 2006; Millan, 2006), consistent with the relatively long latency (typically 3 to 4 weeks) to clinical responsivity in patients with depression treated with 5 -HT reuptake inhibitors.

Diverse responses to $5-\mathrm{HT}_{1 \mathrm{~A}}$ receptor agonists are also observed in tests of cognition/memory function relevant to numerous neuropsychiatric diseases, including major depressive disorder, schizophrenia, Parkinson disease, and Alzheimer disease. Interestingly, the prototypical 5- $\mathrm{HT}_{1 \mathrm{~A}}$ receptor agonist, 8-OH-DPAT, facilitated rat passive avoidance at low doses, whereas higher doses impaired performance (Lüttgen et al., 2005; Madjid et al., 2006). This suggests that opposite responses are mediated by $5-\mathrm{HT}_{1 \mathrm{~A}}$ receptor subpopulations (i.e., improved performance is elicited by $5-\mathrm{HT}_{1 \mathrm{~A}}$ autoreceptors, whereas impairment is due to activation of hippocampal $5-\mathrm{HT}_{1 \mathrm{~A}}$ heteroreceptors) (Ogren et al., 2008). This interpretation is supported by local administration experiments in which the $5-\mathrm{HT}_{1 \mathrm{~A}}$ receptor weak partial agonist/antagonist S15535 was microinjected into the hippocampus. The compound reversed the memory deficit elicited by systemic injection of 8-OH-DPAT in a spatial discrimination task (Millan et al., 2004), indicating that activation of postsynaptic receptors in this brain region was detrimental to mnesic performance.

Given that only a single 5 - $\mathrm{HT}_{1 \mathrm{~A}}$ receptor gene has been identified in human and rat, and that it is intronless and hence without splice variants (Fargin

TABLE 5

Comparison of properties of 5-HT 1 A receptor "biased agonists" F15599, F13714, and befiradol, and the reference agonists 8-OH-DPAT and 5-HT

Based on the publications indicated below. Target brain regions are those identified in microPET imaging and neurochemical experiments. In vivo readouts are nonexhaustive and focus on the primary activities of the biased agonists.

\begin{tabular}{|c|c|c|c|c|c|}
\hline Agonist & $\begin{array}{l}\text { In Vitro } \\
\text { Affinity/Selectivity }^{a}\end{array}$ & $\begin{array}{c}\text { Cellular Transduction } \\
\text { Pathways }^{b}\end{array}$ & Target Brain Regions $^{c}$ & Readout In Vivo ${ }^{d}$ & $\begin{array}{l}\text { Relevant Therapeutic } \\
\text { Indications }\end{array}$ \\
\hline F13714 & $\begin{array}{l}\text { Subnanomolar/highly } \\
\text { selective }\end{array}$ & $\begin{array}{l}\text { Multiple (pERK, receptor } \\
\text { internalization, } \mathrm{G} \text { protein, } \\
\text { cAMP, } \mathrm{Ca}^{2+} \text { release) }\end{array}$ & $\begin{array}{l}\text { Mid-brain, thalamus, } \\
\text { hippocampus, }\end{array}$ & $\begin{array}{l}\text { Potently eliminates } \\
\text { L-DOPA-induced AIMs, } \\
\text { active in antidepressant } \\
\text { and anxiolytic tests }\end{array}$ & $\begin{array}{l}\text { Not clinically tested } \\
\quad \text { (research tool) }\end{array}$ \\
\hline Befiradol & $\begin{array}{l}\text { Nanomolar/highly } \\
\text { selective }\end{array}$ & $\begin{array}{l}\text { Multiple (pERK, receptor } \\
\text { internalization, } \mathrm{G} \text { protein, } \\
\text { cAMP, } \mathrm{Ca}^{2+} \text { release) }\end{array}$ & $\begin{array}{l}\text { Mid-brain, cortex, } \\
\text { thalamus, hippocampus }\end{array}$ & $\begin{array}{l}\text { Potently eliminates } \\
\text { L-DOPA-induced AIMs, } \\
\text { active in antidepressant } \\
\text { and anxiolytic tests }\end{array}$ & $\begin{array}{c}\text { Dyskinesias in Parkinson } \\
\text { disease, mood deficits, } \\
\text { chronic pain }\end{array}$ \\
\hline $\begin{array}{l}\text { 8-OH- } \\
\text { DPAT }\end{array}$ & $\begin{array}{c}\text { Nanomolar/binds } \\
5-\mathrm{HT}_{7}\end{array}$ & $\begin{array}{l}\text { Preferential pERK } \\
\text { activation }\end{array}$ & $\begin{array}{l}\text { Hippocampus, mid-brain, } \\
\text { cortex, thalamus, brain } \\
\text { stem }\end{array}$ & $\begin{array}{l}\text { Disparate effects on } \\
\text { cognition tests, active in } \\
\text { antidepressant and } \\
\text { anxiolytic tests, reduces } \\
\text { L-DOPA-induced AIMs }\end{array}$ & $\begin{array}{l}\text { Not clinically tested } \\
\quad \text { (research tool) }\end{array}$ \\
\hline
\end{tabular}

N/A, not applicable.

${ }^{a}$ Colpaert et al., 2002; Newman-Tancredi et al., 2009a.

${ }^{b}$ Colpaert et al., 2002; Pauwels and Colpaert, 2003; Buritova et al., 2009; Newman-Tancredi et al., 2009b.

${ }^{c}$ Lemoine et al., 2010, 2012; Lladó-Pelfort et al., 2010, 2012; Vidal et al., 2014.

${ }^{d}$ Assié et al., 2010; Depoortere et al., 2010; Levitt et al., 2013; Iderberg et al., 2015; van Goethem et al., 2015 
et al., 1988; Albert et al., 1990; Kobilka et al., 1987), the variety of responses described above are likely attributable to regional "receptor interactome" differences, including coupling to distinct $\mathrm{G}$ protein subtypes (see below) (Mannoury la Cour et al., 2006), regulators of G protein signaling (RGS) (Talbot et al., 2010), or transcriptional regulation.

At a molecular level, 5- $\mathrm{HT}_{1 \mathrm{~A}}$ receptor inactivation studies using N-ethoxycarbonyl-2-ethoxy-1,2-dihydroquinoline demonstrated the existence of receptor reserve in the raphe for inhibition of 5-HT synthesis (Meller et al., 1990). In contrast, receptor reserve was not evident in the hippocampus for the inhibition of adenylyl cyclase or for control of hypothermia (Meller et al., 1992; Yocca et al., 1992).

The agonist radioligand, $\left[{ }^{3} \mathrm{H}\right] 8-\mathrm{OH}-\mathrm{DPAT}$, which preferentially recognizes $5-\mathrm{HT}_{1 \mathrm{~A}}$ receptors when coupled to G proteins, displayed fivefold higher affinity for hippocampal compared with raphe binding sites (Johnson et al., 1997b), supporting differing receptor-G protein coupling state between the two brain regions. Furthermore, whereas $5-\mathrm{HT}_{1 \mathrm{~A}}$ receptors are coupled to inhibition of adenylyl cyclase in hippocampus, such coupling was not detected in raphe homogenates (Clarke et al., 1996). Further support that $5-\mathrm{HT}_{1 \mathrm{~A}}$ receptors couple to different $\mathrm{G}$ protein subtypes depending on brain region arises from immunoprecipitation studies in which raphe $5-\mathrm{HT}_{1 \mathrm{~A}}$ receptors couple preferentially to $\mathrm{G} \alpha \mathrm{i} 3$ subtypes, whereas they couple preferentially to G $\alpha$ o in hippocampus and to a combination of $\mathrm{G}$ proteins in cortex and hypothalamus (Mannoury la Cour et al., 2006).

Functional $\left(\left[{ }^{35} \mathrm{~S}\right] \mathrm{GTP} \gamma \mathrm{S}\right)$ autoradiography experiments also support the contention that regional variations exist in native brain activation of $\mathrm{G}$ proteins by $5-\mathrm{HT}_{1 \mathrm{~A}}$ receptors. Indeed, whereas $5-\mathrm{HT}_{1 \mathrm{~A}}$ receptor density is similar in the raphe and hippocampus, agonist-induced $\left[{ }^{35} \mathrm{~S}\right] \mathrm{GTP} \gamma \mathrm{S}$ labeling was markedly lower in the former [Hensler, 2003; see also Newman-Tancredi et al. (2003) for relevant evidence].

An additional level of complexity of $5-\mathrm{HT}_{1 \mathrm{~A}}$ receptor signaling has been reported (i.e., the existence of receptor homo-, hetero-, and potential trimers with a variety of targets). First, $5-\mathrm{HT}_{1 \mathrm{~A}}$ homodimers may be formed constitutively (Łukasiewicz et al., 2007; Renner et al., 2012) and are affected by the presence of selective ligands such as 8-OH-DPAT, which enhanced dimerization, whereas methysergide reduced dimer formation potentially via a mechanism modulated by $\mathrm{G} \alpha \mathrm{s}$ subunits. The $5-\mathrm{HT}_{7}$ receptor, like the $5-\mathrm{HT}_{1 \mathrm{~A}}$ receptor, has been reported to play a role in depression and form homodimers; but it has also heterodimerized with the $5-\mathrm{HT}_{1 \mathrm{~A}}$ receptor and may have functional consequences insofar as $5-\mathrm{HT}_{1 \mathrm{~A}}-5-\mathrm{HT}_{7}$ heterodimerization reduces GIRK currents in a heterologous cell system, potentially affecting $5-\mathrm{HT}_{1 \mathrm{~A}}$ receptor internalization in the hippocampus (Renner et al., 2012; Naumenko et al., 2014). Heterodimerization with a novel negative response element of $5-\mathrm{HT}_{1 \mathrm{~A}}$ receptors has been suggested with glucocorticoid and mineralocorticoid receptors, which may also be key players in depression (Ou et al., 2001). Galanin receptors form heteromers with a variety of targets, including galanin receptor-5- $\mathrm{HT}_{1 \mathrm{~A}}$ heteromers and trimers (Fuxe et al., 2012). With potential relevance to the influence of 5- $\mathrm{HT}_{1 \mathrm{~A}}$ receptors in ascending and central pain perception, heterodimerization has also been demonstrated with $5-\mathrm{HT}_{1 \mathrm{~A}}$ receptors and $\mu$-opioid receptors in vitro, and further data suggested that both receptors could exert effects on extracellular signal-regulated kinase (ERK)1/2 phosphorylation (Cussac et al., 2012). a. 5-HT $T_{1 A}$ receptors in depression and anxiety. The key role of $5-\mathrm{HT}_{1 \mathrm{~A}}$ receptors in major depression and anxiety has been recognized for nearly four decades [see Barnes and Sharp (1999); Albert et al. (2014)]. Accordingly, animal behavioral models of fear, anxiety, depression, and cognition have been used to identify potential antidepressant and clinically active anxiolytics, such as the partial agonists buspirone, gepirone, ipsapirone, and tandospirone (Peroutka, 1985; Taylor et al., 1985; Gilbert and Dourish, 1987). Buspirone and tandospirone were both clinically developed and received marketing approval for treating anxiety. However, their azapirone chemical structures are associated with only limited selectivity (e.g., vs. $\alpha_{1}$ adrenoceptors and $\mathrm{D}_{2}$ dopamine receptors), and they also exhibit relatively poor metabolic stability and generate pharmacologically active metabolites, such as 1-(2-pyrimidinyl)-piperazine, which is an $\alpha_{2}$ adrenoceptor antagonist (Garattini et al., 1982; Cao and Rodgers, 1997; Zuideveld et al., 2002; Sugimoto et al., 2005; Wong et al., 2007). Consequently, the therapeutic usefulness of selective $5-\mathrm{HT}_{1 \mathrm{~A}}$ receptor agonists still remains to be determined.

Indeed, data suggest that the phenotypic expression of normal behavior, anxiety, or depression may be influenced by the differential $5-\mathrm{HT}_{1 \mathrm{~A}}$ receptor-sensitive circuitry at the level of the PFC; the balance between $5-\mathrm{HT}_{1 \mathrm{~A}}$ receptor stimulation of glutamatergic pyramidal cells and GABAergic interneurons may impact the expression of anxiety (Goodfellow et al., 2009; Albert et al., 2014), although juvenile development processes play a key role in determining vulnerability to mood disorders (Leonardo and Hen, 2008; Donaldson et al., 2014; Garcia-Garcia et al., 2014). In depression, the neurobiology appears different. Therefore, activation of pyramidal neurons by stimulation of $5-\mathrm{HT}_{1 \mathrm{~A}}$ receptors expressed on GABAergic interneurons disinhibits the "antidepressive" pyramidal neurons (Albert et al., 2014). It is interesting to note that the rapid antidepressant activity of ketamine appears to be partly mediated via $5-\mathrm{HT}_{1 \mathrm{~A}}$ receptor activation. Indeed, ketamine inhibits 5-HT reuptake in vivo (Martin et al., 1982; Martin and Smith, 1982) and elicits its prolonged antidepressant-like effects in rodents via a 5-HTdependent mechanism (Gigliucci et al., 2013). This is likely to involve indirect activation of $5-\mathrm{HT}_{1 \mathrm{~A}}$ receptors, 
as exemplified by the fact that the effects of ketamine in the novelty-suppressed feeding test are blocked by a 5- $\mathrm{HT}_{1 \mathrm{~A}}$ receptor antagonist (Fukumoto et al., 2014).

Additional evidence that $5-\mathrm{HT}_{1 \mathrm{~A}}$ receptors are involved in affective disorders comes from genetic studies. The expression of 5 - $\mathrm{HT}_{1 \mathrm{~A}}$ receptors is differentially regulated by a single-nucleotide polymorphism (SNP) in the promoter region of the $5-\mathrm{HT}_{1 \mathrm{~A}}$ receptor gene $(\mathrm{C}-1019 \mathrm{G}$ substitution) (Lesch and Gutknecht, 2004; Albert and Francois, 2010). This SNP impairs repression of the $5-\mathrm{HT}_{1 \mathrm{~A}}$ promoter by the nuclear DEAF-1-related/drosophila deformed epidermal autoregulatory factor-1 transcription factors in raphe cells, consistent with overexpression of presynaptic $5-\mathrm{HT}_{1 \mathrm{~A}}$ receptors (Lemonde et al., 2004; Parsey et al., 2006). Thus, C-1019G polymorphism is associated with higher levels of symptom remission failure and suicidal behavior in patients with depression (Lemonde et al., 2003), consistent with impaired antidepressant efficacy caused by excessive feedback inhibition by presynaptic $5-\mathrm{HT}_{1 \mathrm{~A}}$ receptors.

Taken together, the above considerations indicate that $5-\mathrm{HT}_{1 \mathrm{~A}}$ receptors remain promising targets for the pharmacotherapy of affective disorders, both as a somatodendritic and postsynaptic receptor target in the brain. Accordingly, various efforts have been made to incorporate $5-\mathrm{HT}_{1 \mathrm{~A}}$ receptor activity in antidepressant/anxiolytic drug candidates For example, SB-649915-B is a 5-HT reuptake inhibitor (SSRI) that also acts as a $5-\mathrm{HT}_{1 \mathrm{~A}}$ receptor antagonist (Hughes et al., 2007; Starr et al., 2007) based on the rationale that accelerated antidepressant response may be achieved by avoiding feedback inhibition of terminal 5-HT release by blocking the activation of 5- $\mathrm{HT}_{1 \mathrm{~A}}$ autoreceptors (Gartside et al., 1999; Artigas et al., 2006; Portella et al., 2011). However, though antidepressant efficacy may be enhanced by $5-\mathrm{HT}_{1 \mathrm{~A}}$ autoreceptor antagonism, the blockade of postsynaptic $5-\mathrm{HT}_{1 \mathrm{~A}}$ receptors likely opposes antidepressant activity (De Vry et al., 2004; Berrocoso and Mico, 2009). Accordingly, a clinical trial in which a selective $5-\mathrm{HT}_{1 \mathrm{~A}}$ receptor antagonist was administered as adjunct to fluoxetine did not show any acceleration of antidepressant onset of efficacy (Scorza et al., 2012), likely because of its concurrent blockade of both pre- and postsynaptic $5-\mathrm{HT}_{1 \mathrm{~A}}$ receptors. In contrast, adjunct treatment with pindolol, which preferentially occupies $5-\mathrm{HT}_{1 \mathrm{~A}}$ autoreceptors (Martinez et al., 2001), appears to reliably elicit acceleration of antidepressant efficacy (Artigas et al., 1996, 2006; Portella et al., 2011). Compounds such vilazodone, vortioxetine, and VN2222 are SRIs possessing partial agonist actions at 5- $\mathrm{HT}_{1 \mathrm{~A}}$ receptors (Romero et al., 2003; Dawson and Watson, 2009; Mork et al., 2009; Alvarez et al., 2012) that might assist in engaging diverse frontal circuitry, leading to better treatment of the disease.

b. $5-H T_{1 A}$ receptor activation for improved antipsychotic action. A noteworthy development in the study of $5-\mathrm{HT}_{1 \mathrm{~A}}$ receptors has been the increasing therapeutic interest for this target in psychotic disorders. This has stemmed from extensive clinical and preclinical observations [see McCreary and Newman-Tancredi (2015) for review].

Schizophrenia, which shares some symptoms with other neuropsychiatric diseases, includes positive symptoms (auditory and visual hallucinations, delusions, conceptual disorganization, thought disorders, and some motor disturbances); negative symptoms (affective blunting, social withdrawal, anhedonia, avolition, and poverty of thought and speech); and cognitive impairments, such as working-memory abnormalities, deficits of cognitive processing, and attention and affective disorders (depression and anxiety) (Meltzer, 1999). 5-HT $1 \mathrm{~A}$ receptors appear involved both in the pathophysiology and in functionality of potential novel treatments. Thus, the newer generation antipsychotics clozapine, ziprasidone, quetiapine, aripiprazole, lurasidone, and cariprazine possess (partial) agonist effects at $5-\mathrm{HT}_{1 \mathrm{~A}}$ receptors; however, interestingly, risperidone and olanzapine do not (McCreary and Newman-Tancredi, 2015; NewmanTancredi et al., 1996a, 2005). In patients, changes in $5-\mathrm{HT}_{1 \mathrm{~A}}$ receptor binding or functional activity have been identified (Burnet et al., 1996; Kasper et al., 2002; Yasuno et al., 2003; Bantick et al., 2004; Frankle et al., 2006; Lerond et al., 2013; Billard et al., 2014) along with SNPs at loci ss212928868 and rs6294, which are associated with the clinical outcome in women with paranoid schizophrenia (Zhou et al., 2013). Polymorphisms were also associated with much of the depression and negative treatment outcomes (Reynolds et al., 2006; Newman-Tancredi and Albert, 2012). Preliminary studies assessing cytosine methylation at a site close to this rs6295 polymorphism suggested that this was associated with a lower incidence of negative symptoms (Reynolds et al., 2006; Tang et al., 2014b), reinforcing the importance of this site in the negative symptoms of schizophrenia. Taken together, these accumulated data support the assertion that there is involvement of $5-\mathrm{HT}_{1 \mathrm{~A}}$ receptors in the pathophysiology and treatment-related facets of the disease, particularly negative symptomatology.

A net hypofunctionality of the PFC, a brain area key in working memory, decision, and attentional processing, has been proposed in schizophrenia (Weinberger and Lipska, 1995; McCreary et al., 2007). It is therefore interesting that many atypical antipsychotic drugs may impact this deficit (McCreary and Newman-Tancredi, 2015). It may therefore be relevant that the $5-\mathrm{HT}_{1 \mathrm{~A}}$ receptor agonist agents possessing antipsychotic properties (SSR181507, adoprazine, and lurasidone) augment extracellular microdialysate dopamine and acetylcholine levels in the PFC to "normalize" hypofrontal tone (Claustre et al., 2003; McCreary et al., 2007; Huang et al., 2014b) and promote potential therapeutic outcomes. This is supported by preclinical evidence (Depoortère et al., 2007) and clinical evidence with the partial agonist, tandospirone, which improved cognitive symptoms in patients with schizophrenia treated with 
neuroleptics (Sumiyoshi et al., 2001a,b, 2007; Meltzer and Sumiyoshi, 2008). Additionally, blonanserin, tandospirone, lurasidone, and buspirone reduced MK-801induced novel object recognition deficits (Horiguchi and Meltzer, 2012; Horiguchi and Meltzer, 2013), and PCPinduced reversal learning was attenuated by $5-\mathrm{HT}_{1 \mathrm{~A}}$ receptor activation (McLean et al., 2009b). In the social interaction test, a model for negative symptoms, aripiprazole, SSR181507, and F-15063 induced a 5-HT $1 \mathrm{~A}$ receptor-dependent performance improvement (Boulay et al., 2004; Bruins Slot et al., 2005; Depoortère et al., 2007; Snigdha and Neill, 2008). In addition, administration of $5-\mathrm{HT}_{1 \mathrm{~A}}$ receptor (partial) agonists reversed PCP-induced decreases of tickling-induced $50-\mathrm{kHz}$ ultrasound vocalization in juvenile rats, a model for negative symptoms, and improved attentional processing in a five-choice serial reaction time task (Winstanley et al., 2003; Boulay et al., 2013). In conclusion, data from preclinical and clinical findings support that $5-\mathrm{HT}_{1 \mathrm{~A}}$ receptor activation will benefit the treatment of cognitive, attentional, and negative symptom domains.

An additional complication of antipsychotic treatment is so-called extrapyramidal side effects induced by the typical antipsychotics, such as haloperidol, which can reduce striatal output and lead to a parkinsonian phenotype. Such symptoms in preclinical models can be reduced by $5-\mathrm{HT}_{1 \mathrm{~A}}$ receptor agonists (McCreary et al., 2007).Compounds such as adoprazine, bifeprunox, and F-15063 elicit less catalepsy than neuroleptics such as haloperidol. However, treatment, with WAY100635 unmasked this blockade of catalepsy, indicating a key role of $5-\mathrm{HT}_{1 \mathrm{~A}}$ receptors (Kleven et al., 2005; Bardin et al., 2006). Consistently, mesolimbic selectivity, and therefore the ability to treat the positive symptoms, was supported with electrophysiological studies demonstrating that depolarization block of VTA, but not substantia nigra pars compacta, dopaminergic neurons was mediated by $5-\mathrm{HT}_{1 \mathrm{~A}}$ receptor agonists (Nakamura et al., 2006; McCreary et al., 2007) and that PFC 5-HT $1 \mathrm{~A}$ receptors influenced VTA cell firing by indirectly affecting pyramidal cell afferents to the VTA, thereby increasing dopamine cell firing (Lladó-Pelfort et al., 2012; Santana et al., 2013). Such mechanisms may indirectly influence mesoaccumbal dopaminergic output and impact positive symptoms. Some clinical meta-analytical studies support this assertion and suggest a trend for improved cognitive symptoms following the addition of $5-\mathrm{HT}_{1 \mathrm{~A}}$ receptor partial agonists, together with a trend for improved positive symptoms (Kishi et al., 2013), but more extensive clinical studies are warranted. It is interesting to speculate that fully efficacious agents might offer added benefit. Moreover, benefit in other symptom domains might be expected, particularly mood. Accordingly, bifeprunox, SSR181507, and adoprazine (SLV313) all demonstrated anxiolytic-like and antidepressive-like properties (Depoortere et al., 2003), and $5-\mathrm{HT}_{1 \mathrm{~A}}$ receptors appear to mediate the antidepressant effects of ketamine and metabotropic glutamate (2/3) receptor antagonists (Fukumoto et al., 2014). Moreover, $5-\mathrm{HT}_{1 \mathrm{~A}}$ gene loci polymorphism linkage studies support this in schizophrenic patients with depression (Albert, 2012).

Taken together, these data support a role for the $5-\mathrm{HT}_{1 \mathrm{~A}}$ receptor in schizophrenia. This is particularly interesting in light of the clinical development and marketing approval of lurasidone and cariprazine, which possess dopamine $\mathrm{D}_{2}$ and $5-\mathrm{HT}_{1 \mathrm{~A}}$ receptor agonist action (Ishibashi et al., 2010; Kiss et al., 2010). Indeed, pharmacodynamic studies support the described $5-\mathrm{HT}_{1 \mathrm{~A}}$ receptor-mediated mechanisms in the actions of lurasidone on augmented PFC dopamine and acetylcholine levels and cognitive actions (Horiguchi and Meltzer, 2012; Huang et al., 2012, 2014). Consistently, clinical benefit in a variety of symptom domains was evident (Veselinović et al., 2013; Citrome et al., 2014; Durgam et al., 2014; Loebel et al., 2014a,b).

\section{G. 5-HT $T_{1 A}$ Receptors and Some Emerging Treatment Areas}

1. Parkinson Disease. Parkinson disease is characterized by a loss of nigrostriatal dopaminergic neurons, resulting in the cardinal motor symptoms (Schapira et al., 2006). Symptomatic treatment ultimately relies on the gold-standard medication and dopamine precursor levodopa (L-DOPA) (Jenner et al., 2011). However, over time, the effects of L-DOPA are prone to wearing off (i.e., there is a tolerance to the actions of L-DOPA), and patients develop dose-limiting dyskinesia (Jenner et al., 2011). The treatment of L-DOPAinduced dyskinesia (LID) has been hampered by a lack of approved medications. Recently, the 5-HT system has emerged as a key player in the induction of LID. 5 -HT neurons possess the enzymes necessary to convert exogenous L-DOPA to dopamine (DA) and mediate its vesicular storage and "false neurotransmitter" release. However, 5-HT neurons lack appropriate control mechanisms to regulate synaptic DA levels (e.g., via presynaptic $\mathrm{D}_{2}$ receptors or dopamine transporters), resulting in excessive DA release and pulsatile (over) stimulation of postsynaptic dopamine receptors that generate dyskinesia. Theoretically, it might be possible to mitigate dopamine release from serotonergic neurons by suppressing serotonergic tone by the application of $5-\mathrm{HT}_{1 \mathrm{~A}}$ (or $5-\mathrm{HT}_{1 \mathrm{~B}}$ ) receptor agonists, which suppress neurotransmission by influencing the negative feedback somatodendritic (or terminal autoreceptors). Indeed $5-\mathrm{HT}_{1 \mathrm{~A}}$ receptor agonist treatment does reduce LID in both rat and nonhuman primate models (Bibbiani et al., 2001; Eskow et al., 2007, 2009; Munoz et al., 2009; Huot, 2015; Iderberg et al., 2015) and appears to translate in clinical studies using the partial agonists buspirone and the mixed $5-\mathrm{HT}_{1 \mathrm{~A}} / 5-\mathrm{HT}_{1 \mathrm{~B}}$ agonist eltoprazine (Svenningsson et al., 2015). However, other clinical attempts to target the $5-\mathrm{HT}_{1 \mathrm{~A}}$ receptor have been disappointing, 
with compounds such as sarizotan and tandospirone also impairing the antiparkinsonian activity (Bonifati et al., 1994; Kannari et al., 2002; Olanow et al., 2004; Goetz et al., 2007), whereas eltoprazine showed only modest effects (Svenningsson et al., 2015). Together, this suggests that although $5-\mathrm{HT}_{1 \mathrm{~A}}$ receptors can reduce dyskinesia, compounds tested to date may be less than optimal (Hamik et al., 1990; Newman-Tancredi et al., 1997c, 1998, 2003). Interestingly, only full agonists succeed in completely reversing haloperidol-induced catalepsy, whereas partial agonists failed to do so (Prinssen et al., 2002), suggesting that maximal efficacy may be required. The selective $5-\mathrm{HT}_{1 \mathrm{~A}}$ receptor "biased agonist" $\mathrm{F} 13714$, which preferentially targets raphe $5-\mathrm{HT}_{1 \mathrm{~A}}$ autoreceptors (Assié et al., 2006), completely abolished abnormal involuntary movements (AIMs) along with inhibiting 5-HT release (Iderberg et al., 2015). Comparable findings were evident with Befiradol (McCreary and NewmanTancredi, 2015).

In addition, "full agonist" activity at $5-\mathrm{HT}_{1 \mathrm{~A}}$ receptors may also provide beneficial influence on nonmotor symptoms of PD, such as the mood deficits likely elicited by deficient 5 -HT neurotransmission (Eskow Jaunarajs et al., 2010; Politis, 2010). Indeed, whereas treatment of depressive symptoms in PD using 5-HT reuptake inhibitors is poorly effective, direct activation of postsynaptic (cortical) $5-\mathrm{HT}_{1 \mathrm{~A}}$ receptors is associated with potent antidepressant actions (Celada et al., 2004). In restless legs syndrome, another movement disorder typically managed with low doses of dopamine receptor agonists or L-DOPA, $5-\mathrm{HT}_{1 \mathrm{~A}}$ receptor agonists may also display clinical benefit (Shioda et al., 2006).

2. Pain. There is good evidence for the involvement of the 5-HT system in chronic pain (Millan, 2002), which is not surprising given their expression by descending pathways of the dorsal horn and other relevant structures. The receptors of the dorsal horn appear pivotally involved in the pronociceptive effects (Fasmer et al., 1986; Millan, 1994, 2002; Millan et al., 1996; You et al., 2005; Colpaert, 2006; Avila-Rojas et al., 2015; Sagalajev et al., 2015) and may also influence antinociception (Millan et al., 1996). Recent evidence suggests that the newer generation antipsychotic agent (e.g., aripiprazole), which possesses 5 - $\mathrm{HT}_{1 \mathrm{~A}}$ receptor partial agonist actions, displays antinociceptive effects (Fei et al., 2012; Almeida-Santos et al., 2015). Moreover, the ability of $5-\mathrm{HT}_{1 \mathrm{~A}}$ receptors to form heterodimers with $\mu$-opioid receptors (Cussac et al., 2012) suggests 5 - $\mathrm{HT}_{1 \mathrm{~A}}$ receptor targeting as an adjunct to opioid strategies may be useful.

3. Attention Deficiency Hyperactivity Disorder. In animal models of impulse control, $5-\mathrm{HT}_{1 \mathrm{~A}}$ receptor stimulation reduced the impulsivity, suggesting potential benefit in diseases such as attention deficiency hyperactivity disorder (ADHD; Winstanley et al., 2003). Furthermore, in an isolation rearing model, which models some components of $\mathrm{ADHD}, 5-\mathrm{HT}_{1 \mathrm{~A}}$ receptor binding sites were altered in a region-specific manner (Preece et al., 2004). Pharmacological study using the agonists SSR181507 (Terranova et al., 2005) and sarizotan (Danysz et al., 2015) suggest efficacy in animal models of ADHD. It is also relevant that a HTR1A rs10042486 polymorphism is associated with ADHD (Park et al., 2013). Indeed, buspirone may benefit ADHD management (Levin, 2015), though to a lesser extent than methylphenidate (Mohammadi et al., 2012).

4. Autism Spectrum Disorder. Preclinical studies reveal altered central $5-\mathrm{HT}_{1 \mathrm{~A}}$ receptor activity, in a rat valproate model of autism (Wang et al., 2013b) and BTBR mice(BTBR $\mathrm{T}^{+}$Itpr $3^{\mathrm{tf}} / \mathrm{J}$ mouse), which have a phenotype paralleling that of autism spectrum disorder, elevated $\left.{ }^{35} \mathrm{~S}\right] \mathrm{GTP} \gamma \mathrm{S}$ binding is evident, corresponding to enhanced $5-\mathrm{HT}_{1 \mathrm{~A}}$ receptor functional activity that potentially contributes to poor social behavior (Gould et al., 2011). Clinical data are limited, but anti-5- $\mathrm{HT}_{1 \mathrm{~A}}$ receptor antibodies have been identified in the blood of an autistic boy (Todd and Ciaranello, 1985). Furthermore, a HTR1A C-1019G polymorphism in autism may influence clinical outcomes (Egawa et al., 2012).

5. Respiratory Control. 5- $\mathrm{HT}_{1 \mathrm{~A}}$ receptor agonists increased respiration in rats and cats (Edwards et al., 1990; Rose et al., 1995), and morphine-induced ventilatory depression was reduced by the $5-\mathrm{HT}_{1 \mathrm{~A}}$ receptor agonist repinotan (Guenther et al., 2010). Electrophysiological studies support a modulatory role of the $5-\mathrm{HT}_{1 \mathrm{~A}}$ receptor in the bursting activity of respiratory neurons (Onimaru et al., 1998), and 5- $\mathrm{HT}_{1 \mathrm{~A}}$ receptors activate bronchioconstrictor vagal preganglionic neurons and phrenic nerve neurons (Bootle et al., 1998; Valic et al., 2008). These and other data have led to the suggestion that $5-\mathrm{HT}_{1 \mathrm{~A}}$ receptor agonists display potential to treat sleep apnea (Futuro-Neto et al., 1993; Khater-Boidin et al., 1996, 1999; Dando et al., 1998; Sahibzada et al., 2000) that may translate to the clinic given an evident reduction in apnea evoked by buspirone (Wilken et al., 1997). In addition, activation of $5-\mathrm{HT}_{1 \mathrm{~A}}$ receptors may be beneficial to reverse compromised respiration; for instance, in a transgenic mouse model of Rett syndrome that also models disordered breathing, (+)8-OH-DPAT and sarizotan reduced the apneic frequency to restore the respiratory pattern (Abdala et al., 2010, 2014a,b; Levitt et al., 2013). Furthermore, the $5-\mathrm{HT}_{1 \mathrm{~A}}$ receptorbiased agonist, F15599, impacts apnea and respiration frequency in MECP2-null male and heterozygous female mice (Levitt et al., 2013). Clinical experiences investigating the $5-\mathrm{HT}_{1 \mathrm{~A}}$ receptor role in Rett syndrome are limited, but buspirone administered with fluoxetine reduced the frequency of hyperventilation and apneic attacks (Gokben et al., 2012).

6. Sexual Dysfunction. $5-\mathrm{HT}_{1 \mathrm{~A}}$ receptors may be a promising target in the treatment of sexual dysfunction. The $5-\mathrm{HT}_{1 \mathrm{~A}}$ receptor agonist flibanserin (which also possesses $5-\mathrm{HT}_{2 \mathrm{~A}}$ receptor antagonist and dopamine $\mathrm{D}_{4}$ receptor partial agonist properties; Mendelson 
and Gorzalka, 1986; Borsini et al., 2002; Heusler et al., 2009; Stahl, 2015) is a treatment of female hypoactive sexual desire disorder (Clayton et al., 2010; Jayne et al., 2012; Thorp et al., 2012; Katz et al., 2013) and is the culmination of research indicating a role for $5-\mathrm{HT}_{1 \mathrm{~A}}$ receptors in sexual function (e.g., Mendelson and Gorzalka, 1986; Olivier et al., 2011; Aubert et al., 2012; Gelez et al., 2013; Snoeren et al., 2014a,b), although its clinical effects are likely not exclusively related to actions at $5-\mathrm{HT}_{1 \mathrm{~A}}$ receptors (Allers et al., 2010; Stahl et al., 2011; Stahl, 2015). However, inclusion of 5-HT $\mathrm{HT}_{1 \mathrm{~A}}$ agonist actions in the profile of activity of psychotropic drugs has been reasoned to potentially alleviate the sexual dysfunction seen in some patients treated with antidepressant or antipsychotic agents.

7. Food Intake and Eating Disorders. The role of 5 -HT in modulating food intake and satiety has been investigated extensively (Blundell et al., 1995; Halford et al., 2007). Early studies demonstrated $5-\mathrm{HT}_{1 \mathrm{~A}}$ receptor activation induces hyperphagia, suggesting agonists may help treat patients with eating disorders such as bulimia and/or anorexia nervosa (Dourish et al., 1987). In vivo imaging studies suggest $5-\mathrm{HT}_{1 \mathrm{~A}}$ receptor binding increases in cortical and limbic structures of the brain of patients with anorexia and/or bulimia, consistent with a potential role in anxiety, behavioral inhibition, and body ideation (Kaye et al., 2005; Bailer et al., 2007, 2011; Galusca et al., 2008; Bailer and Kaye, 2011). Although clinical pharmacology studies are limited, and restricted to case studies, the partial agonist tandospirone improved the weight gain of patients with anorexia nervosa (restricting and binge-eating/purging subtypes) and also improved scores on the Eating Disorder Examination Questionnaire following treatment of up to 6 months (Okita et al., 2013). The mechanistic basis for this may involve control of mood: the anxiolytic effects of $5-\mathrm{HT}_{1 \mathrm{~A}}$ receptor agonists are likely to be beneficial (Crow and Mitchell, 1994) and potentially contribute to treatment outcome.

8. Aggressive Behavior. $5-\mathrm{HT}_{1 \mathrm{~A}}$ receptor activation appears to reduce aggressive behavior in preclinical and clinical (buspirone) settings (Olivier and Mos, 1992; Bell and Hobson, 1994; Takahashi et al., 2012) with animal models, indicating impact at the level of the dorsal raphe, and hence a reduction in 5-HT neurotransmission, may underlie the response (Mos et al., 1993). This is supported by results generated with $\mathrm{S} 15535$, a preferential autoreceptor agonist and, possibly, via blockade of hypersensitive postsynaptic 5- $\mathrm{HT}_{1 \mathrm{~A}}$ heteroreceptors (Millan et al., 1997; de Boer et al., 2000). Indeed, elevated postsynaptic $5-\mathrm{HT}_{1 \mathrm{~A}}$ heteroceptors in the forebrain are associated with aggressive behavior (Korte et al., 1996), although direct administration of $\mathrm{F} 15599$ into ventral orbital $\mathrm{PFC}$ reduces aggression in male mice (Stein et al., 2013).

9. Neuroplasticity and Neuroprotection. $5-\mathrm{HT}_{1 \mathrm{~A}}$ receptor agonists evoke neurogenesis and synaptogenesis in the adult hippocampus, thereby improving cognitive performance in this structure that is important for mnemonic function (Mogha et al., 2012; Vines et al., 2012; Schreiber and Newman-Tancredi, 2014). Moreover, $5-\mathrm{HT}_{1 \mathrm{~A}}$ receptor stimulation can lead to long-term potentiation or depression (Meunier et al., 2013) with consequent elevated BDNF expression to influence neurogenesis (Luoni et al., 2013; Quesseveur et al., 2013).

In addition to the effects of $5-\mathrm{HT}_{1 \mathrm{~A}}$ receptor agonists on neuroplasticity, targeting this receptor may also have a beneficial role in neuroprotection. Indeed, there is considerable data supporting this assertion: repinotan reduced staurosporine-induced apoptosis (Suchanek et al., 1998), and 8-OH-DPAT reduced the impact of excitotoxic doses of NMDA in vivo (Oosterink et al., 1998) and, further, may protect neurons via protective effects of astrocytes; conversely, $5-\mathrm{HT}_{1 \mathrm{~A}}$ receptor antagonism by WAY100635 increased damage (Ramos et al., 2004). Similarly, the selective $5-\mathrm{HT}_{1 \mathrm{~A}}$ receptor agonist F13714 and the antipsychotic drugs clozapine, ziprasidone, and aripiprazole attenuated kainic acid-induced lesion volume in the striatum-effects that were reversed by WAY100635 (Cosi et al., 2005).

In models of Parkinson disease, $5-\mathrm{HT}_{1 \mathrm{~A}}$ receptor agonists may slow neuronal damage (Bezard et al., 2006) and limit astrogliosis (Miyazaki et al., 2013). In the experimental autoimmune encephalopathy model of multiple sclerosis and in vitro cell-based models, the efficacy of a novel arylpiperazine $\mathrm{D}_{2} / 5-\mathrm{HT}_{1 \mathrm{~A}}$ receptor ligand suggested this was due to combined action of the compound to limit inflammation and neuroprotective actions (Popovic et al., 2015), and buspirone appears to exert some efficacy against apneusis in multiple sclerosis (O'Sullivan et al., 2008). Interestingly, repinotan was developed for activity in ischemic stroke and traumatic brain injury (Lutsep, 2002; Berends et al., 2005; Mauler and Horváth, 2005; Guenther et al., 2010), therapeutic areas that are historically very difficult for drug development. However, repinotan failed to show efficacy in acute ischemic stroke, and its development was discontinued (Teal et al., 2009).

\section{5-HT 1 Beceptors}

\section{A. Introduction}

The $5-\mathrm{HT}_{1 \mathrm{~B}}$ receptor and its counterpart the $5-\mathrm{HT}_{1 \mathrm{D}}$ receptor have experienced a complex and debated history (Fig. 3) that is explained here. The two receptors are clearly closely related and result probably from gene duplication, which explains that in most species, their pharmacological profiles are almost indistinguishable (however, this is less evident in some species such as rat, mouse, hamster, or opossum; see below). In addition, 1) expression levels of the $5-\mathrm{HT}_{1 \mathrm{D}}$ receptor are very low compared with those of the $5-\mathrm{HT}_{1 \mathrm{~B}}$ receptor, 2) the two receptors tend to be expressed together in many brain regions (although not in the periphery; Fig. 4), and 3) $5-\mathrm{HT}_{1 \mathrm{~B}}$ and $5-\mathrm{HT}_{1 \mathrm{D}}$ receptors are coexpressed and 
may form heterodimers in certain brain cells. In essence, the $5-\mathrm{HT}_{1 \mathrm{~B}}$ receptor is predominant, and, in the absence of selective compounds, it is very challenging to identify a separate population of $5-\mathrm{HT}_{1 \mathrm{D}}$ receptors in the brain. Except in rodents, hamster, and opossum, in which both receptors display somewhat different pharmacological profiles, the $5-\mathrm{HT}_{1 \mathrm{~B}}$ receptor is still largely predominant in terms of expression and function.

The 5-HT $\mathrm{T}_{1 \mathrm{~B}}$ receptor was originally defined according to operational and transductional criteria, and it was initially thought to be a rodent-specific receptor [for references, see Hoyer et al. (1994)]. In the 1970s, Peroutka and Snyder (1979) and others postulated that whereas $\left[{ }^{3} \mathrm{H}\right] 5$-HT labeled $5-\mathrm{HT}_{1}$ binding sites, $\left[{ }^{3} \mathrm{H}\right]$ spiperone (and later $\left[{ }^{3} \mathrm{H}\right]$ ketanserin) labeled $5-\mathrm{HT}_{2}$ binding sites, and $\left[{ }^{3} \mathrm{H}\right] \mathrm{LSD}$ labeled both $5-\mathrm{HT}_{1}$ and $5-\mathrm{HT}_{2}$ binding sites. In 1981, Nelson and colleagues (Pedigo et al., 1981) proposed that $5-\mathrm{HT}_{1}$ binding sites were a heterogeneous population, as $\left[{ }^{3} \mathrm{H}\right] 5$-HT was displaced biphasically by spiperone; accordingly, the high affinity site for spiperone was called $5-\mathrm{HT}_{1 \mathrm{~A}}$, and the low affinity was $5-\mathrm{HT}_{1 \mathrm{~B}}$. Middlemiss et al. (1977) had reported earlier that certain indole $\beta$-blockers displayed high affinity for some 5-HT receptors. In 1982/1983, a breakthrough was reached when Hjorth et al. (1982) and Middlemiss and Fozard (1983) described 8-OH-DPAT as a selective $5-\mathrm{HT}_{1 \mathrm{~A}}$ ligand. Furthermore, Gozlan et al. (1983) reported the selective labeling of $5-\mathrm{HT}_{1 \mathrm{~A}}$ sites using $\left[{ }^{3} \mathrm{H}\right] 8-\mathrm{OH}-\mathrm{DPAT}$. This allowed a clear definition of the $5-\mathrm{HT}_{1 \mathrm{~A}}$ pharmacological profile and, by extension, of the features of non-5-HT 1 A sites [see Pazos et al. (1984a,b); Hoyer et al. (1985a,b)]. Thus, Palacios and Hoyer and colleagues (Hoyer et al, 1985b) at Sandoz in Basel characterized $\left[{ }^{3} \mathrm{H}\right]$ mesulergine binding in the choroid plexus (Pazos et al., 1984a), which 5-HT competed for with high affinity, but the relatively low affinity of ketanserin and spiperone suggested a $5-\mathrm{HT}_{1}$ receptor pharmacology. The features of $\left[{ }^{3} \mathrm{H}\right]$ mesulergine-labeled sites were different from classic $5-\mathrm{HT}_{2}$ binding sites labeled with, for example, $\left[{ }^{3} \mathrm{H}\right]$ ketanserin. The novel $\left[{ }^{3} \mathrm{H}\right]$ mesulergine-labeled binding site was named $5-\mathrm{HT}_{1 \mathrm{C}}$ (now $5-\mathrm{HT}_{2 \mathrm{C}}$ ). Indeed, $\left[{ }^{3} \mathrm{H}\right]$ mesulergine binding was also markedly different from $5-\mathrm{HT}_{1 \mathrm{~B}}$ binding as evidenced in radioligand binding and autoradiographic studies (Hoyer et al., 1985a,b, 1986a,b; Pazos and Palacios, 1985; Pazos et al., 1985, 1987a,b). More specifically in rodents, $5-\mathrm{HT}_{1 \mathrm{~B}}$ binding sites were characterized extensively with the iodinated version of cyanopindolol, $\left[{ }^{125}\right]$ ICYP (Engel et al., 1981), a potent $\beta$-blocker with high affinity for $5-\mathrm{HT}_{1 \mathrm{~B}}$ binding sites. These sites displayed high affinity for 5-HT, 5 -carboxamidotryptamine (5-CT), some $\beta$-blockers, some ergolines, lysergic acid diethylamide (LSD), and RU24969 (Hoyer et al., 1985a, 1986a; Engel et al., 1986). Species differences in receptor pharmacology soon became evident with $\left[{ }^{3} \mathrm{H}\right]$ mesulergine, which had different binding profiles in rodents, pigs, and humans;

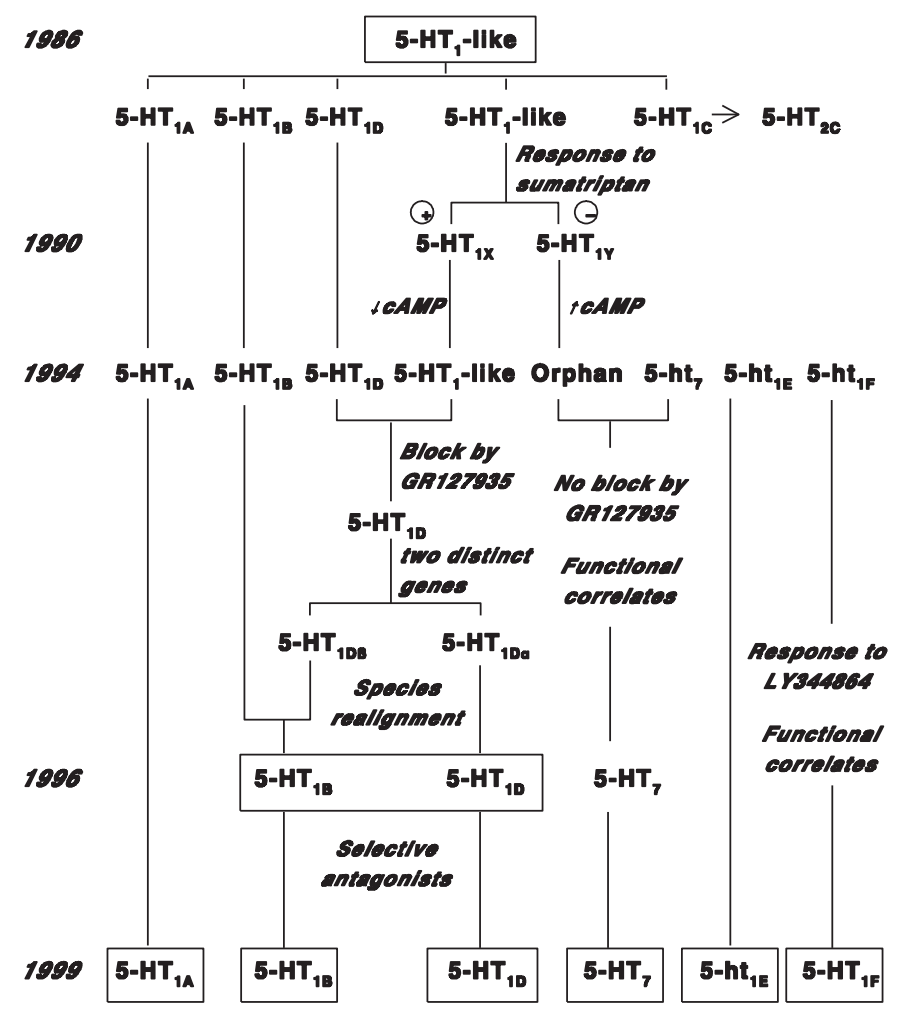

Fig. 3. The evolution of " $5-\mathrm{HT}_{1}-\mathrm{like}$ " receptors into the different sumatriptan-sensitive $5-\mathrm{HT}_{1}$ receptor subtypes and the sumatriptaninsensitive $5-\mathrm{HT}_{7}$ receptor. Modified from Saxena et al. (1998). For references, see Hartig et al. (1996), Hoyer and Martin (1997), Villalón et al. (1997a), and Villalón and Centurión (2007).

this pattern would repeat itself with a number of 5-HT receptors, most prominently with the $5-\mathrm{HT}_{1 \mathrm{~B}}$ receptor (Hoyer et al., 1988; Waeber et al., 1988a,b). The Sandoz group used rat, mouse, hamster, rabbit, guinea pig, cat, dog, bovine, human, and more atypical for research species such as pigeons, opossum, and trout (e.g., Waeber et al., 1988a,b, 1989a,b) to investigate the pharmacology of $5-\mathrm{HT}_{1 \mathrm{~A}}, 1 \mathrm{~B}, 1 \mathrm{C}$, and $5-\mathrm{HT}_{2}$ receptor-binding sites. In addition, the pharmacology, transduction, and distribution of non-5- $\mathrm{HT}_{1 \mathrm{~A} / 1 \mathrm{~B} / 1 \mathrm{C}}$ receptor binding sites, identified initially in calf and human brain and then most other species investigated, was termed $5-\mathrm{HT}_{1 \mathrm{D}}$ receptor binding sites (Hoyer and Schoeffter, 1988; Schoeffter et al., 1988; Waeber et al., 1988a,b; Hoyer et al., 1988). Although the pharmacology of 5-HT 1 в and $5-\mathrm{HT}_{1 \mathrm{D}}$ binding sites/receptors displayed some distinct differences, their distribution pattern in brain was similar (if not overlapping), and they shared transductional and functional responses (Hoyer and Schoeffter, 1988; Schoeffter and Hoyer, 1989a, 1990). Therefore, rodent " $5-\mathrm{HT}_{1 \mathrm{~B}}$ " and nonrodent " $5-\mathrm{HT}_{1 \mathrm{D}}$ " receptors were proposed initially to represent species homologs (Hoyer and Middlemiss, 1989), a view that was unequivocally confirmed when genetic and structural information became available with the cloning of these receptors (Voigt et al., 1991; Adham et al., 1992; Hamblin et al., 1992a,b; Hartig et al., 1992; Levy et al., 1992b; Maroteaux et al., 1992; Mochizuki et al., 1992). 

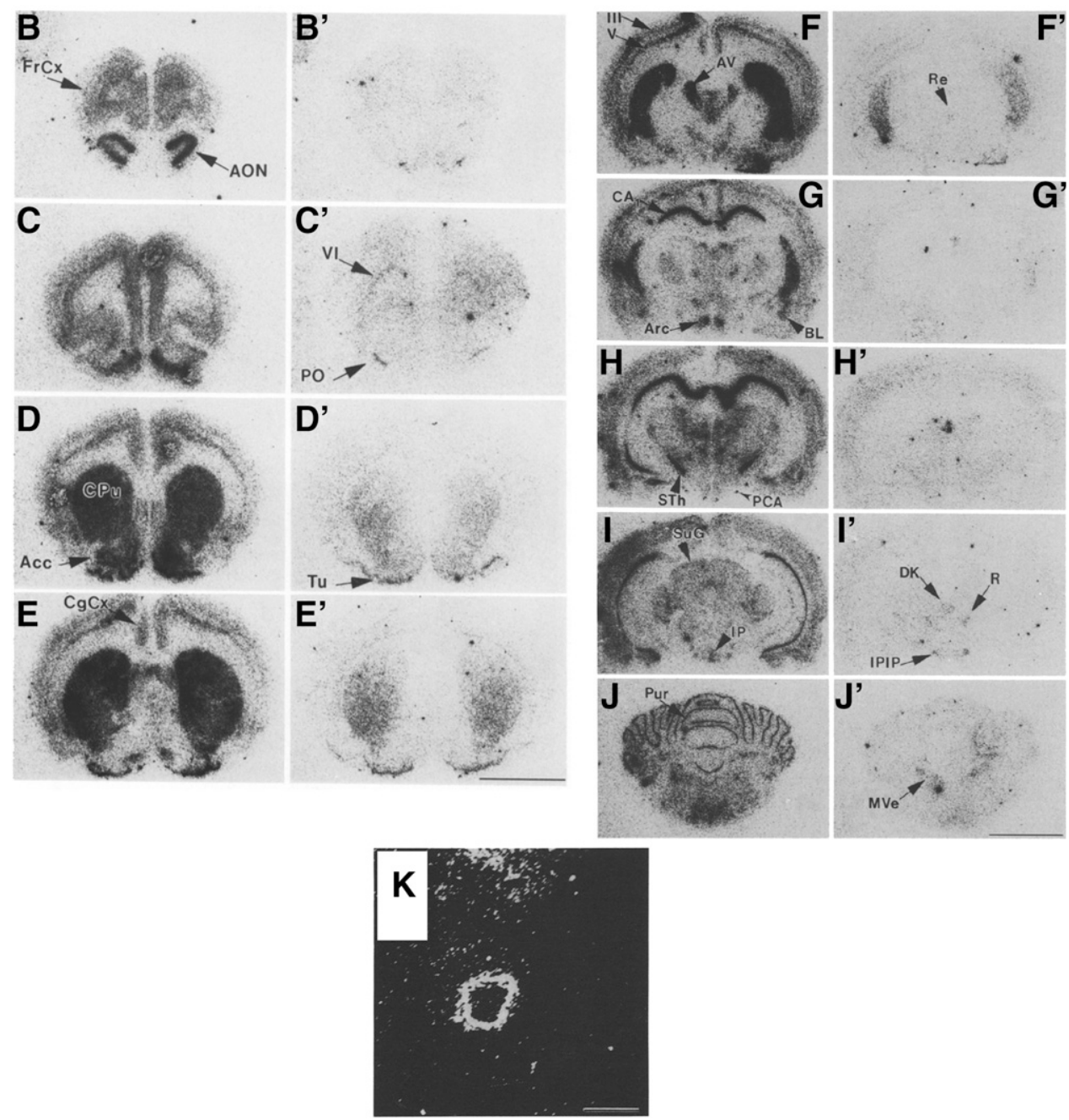

Fig. 4. In situ hybridization detection of $5-\mathrm{HT}_{1 \mathrm{~B}}$ and $5-\mathrm{HT}_{1 \mathrm{D}}$ receptor mRNA in rat brain (and 5- $\mathrm{HT}_{1 \mathrm{~B}}$ receptor mRNA in the posterior communicating artery [reverse autoradiogram; $\mathrm{K}]$ ). 5- $\mathrm{HT}_{1 \mathrm{~B}}(\mathrm{~B}-\mathrm{K})$ and $5-\mathrm{HT}_{1 \mathrm{D}}\left(\mathrm{B}^{\prime}-\mathrm{J}^{\prime}\right)$ receptor mRNA. Ace, nucleus accumbens; AON, anterior olfactory nucleus; Arc, arcuate hypothalamic nucleus; AV, anteroventral thalamic nucleus; BL, basolateral amygdaloid nucleus; CA1, CA1 region of the hippocampus; CgCx, cingulate cortex; $\mathrm{CPu}$, caudate putamen; DK, nucleus of Darkschewitsch; FrCx [layer VI], frontal cortex; IP, interpeduncular nucleus; IPIP, inner posterior subnucleus of the interpeduncular nucleus; layers III and V, parietal motor cortex; MVe, medial vestibular nucleus; PCA, posterior communicating artery; PO, primary olfactory cortex; Pur, Purkinje cells of the cerebellum; R, red nucleus; Re, reuniens nucleus; STh, subthalamic nucleus; SuG, superficial gray layer of the superior colliculus; Tu, olfactory tubercle. Scale bar, $5 \mathrm{~mm}$ (except $\mathrm{K}$, where it is $0.5 \mathrm{~mm}$ ). Adapted from Bruinvels et al. (1994a) (with permission).

However, matters were further complicated when Weinshank et al. (1992) identified two structurally distinct genes encoding human $5-\mathrm{HT}_{1}$ receptors with, at the time, almost overlapping pharmacological profiles, both resembling the $5-\mathrm{HT}_{1 \mathrm{D}}$ receptor. Earlier on, a canine "orphan" clone called RDC4 (later named $\left.5-\mathrm{HT}_{1 \mathrm{D} \alpha}\right)$ had been reported to display a $5-\mathrm{HT}_{1 \mathrm{D}}$-like pharmacological profile (Libert et al., 1990; Hamblin and Metcalf, 1991; Maenhaut et al., 1991; Zgombick et al., 1991). A human receptor, initially called S12, was cloned independently and differed in sequence from the canine $\mathrm{RDC} 4$, yet it displayed $5-\mathrm{HT}_{1 \mathrm{D}}$-like pharmacology (Levy et al., 1992b). Since the operational profiles of these two new receptors were mostly indistinguishable, they were called $5-\mathrm{HT}_{1 \mathrm{D} \alpha}$ (canine RDC4 and species homologs) and $5-\mathrm{HT}_{1 \mathrm{D} \beta}$ receptors (human $\mathrm{S} 12$ and species homologs). It soon became evident, however, that in spite of some fundamental differences in their pharmacological profiles (see below), the $5-\mathrm{HT}_{1 \mathrm{D} \beta}$ receptor was a human homolog of the rodent $5-\mathrm{HT}_{1 \mathrm{~B}}$ receptor (displaying 96\% overall sequence homology; Adham et al., 1992). The subsequent identification of the $5-\mathrm{HT}_{1 \mathrm{D} \alpha}$ gene in rats confirmed that $5-\mathrm{HT}_{1 \mathrm{~B}}$ and $5-\mathrm{HT}_{1 \mathrm{D}}$ receptors represent just two different receptor classes (Hartig et al., 1992), which prompted a realignment of 5-HT receptor nomenclature to recognize primacy (preeminence) of the human genome (Hartig et al., 1996). As a result, the $5-\mathrm{HT}_{1 \mathrm{D} \beta}$ receptor was renamed $5-\mathrm{HT}_{1 \mathrm{~B}}$ (subsuming the rodent $5-\mathrm{HT}_{1 \mathrm{~B}}$ receptor), whereas the $5-\mathrm{HT}_{1 \mathrm{D} \alpha}$ nomenclature was abandoned for $5-\mathrm{HT}_{1 \mathrm{D}}$ in recognition of the fact that this gene product encodes the 5-HT ${ }_{1 \mathrm{D}}$ receptor (see Fig. 3; Hartig et al., 1996). This nomenclature for $5-\mathrm{HT}_{1 \mathrm{~B}}$ and $5-\mathrm{HT}_{1 \mathrm{D}}$ receptors has been used since 1996 and remains to date. 


\section{B. Pharmacology}

The 5 - $\mathrm{HT}_{1}$-like receptor mediating smooth muscle contraction and inhibition of noradrenaline release showed close similarities to the $5-\mathrm{HT}_{1 \mathrm{~B}}$ and/or $5-\mathrm{HT}_{1 \mathrm{D}}$ receptors; however, the lack of selective ligands at these receptors made it difficult to distinguish these receptors with confidence, hampering research for quite some time (Hoyer, 1988a; Hoyer et al., 1994). Clitherow et al. (1994) reported the properties of several compounds, including a piperazinylbenzanilide derivative, GR127935, which shows a high affinity for and selective antagonist activity at $5-\mathrm{HT}_{1 \mathrm{~B} / 1 \mathrm{D}}$ receptors. But more importantly, the subsequent identification of potent and relatively selective antagonists at either the 5- $\mathrm{HT}_{1 \mathrm{~B}}$ (SB224289; Hagan et al., 1997; Gaster et al., 1998) or 5-HT $1 \mathrm{D}$ (BRL15572; Price et al., 1997) receptors allowed responses to be attributed to either $5-\mathrm{HT}_{1 \mathrm{~B}}$ or $5-\mathrm{HT}_{1 \mathrm{D}}$ receptors; for example, the sumatriptan-induced contraction of vascular smooth muscle was mediated via the $5-\mathrm{HT}_{1 \mathrm{~B}}$ receptor (e.g., De Vries et al., 1998, 1999; Verheggen et al., 1998, 2004).

Despite the $96 \%$ amino acid sequence homology in the transmembrane regions (Adham et al., 1992), the rodent $5-\mathrm{HT}_{1 \mathrm{~B}}$ receptor displays a distinct pharmacology compared with the 5 - $\mathrm{HT}_{1 \mathrm{~B}}$ receptor in other species (Hartig et al., 1996). The differences in the pharmacology of these species homologs are largely attributed to the mutation of a single amino acid in the transmembrane spanning region $\mathrm{Asp}^{123}$ to $\mathrm{Arg}^{123}$ (Adham et al., 1994a). Thus, CP93129 is a selective agonist at the rodent $5-\mathrm{HT}_{1 \mathrm{~B}}$ receptor, whereas some $\beta$-adrenoceptor antagonists, such as cyanopindolol, (-)pindolol, and (-)propranolol, are selective antagonists at the rodent $5-\mathrm{HT}_{1 \mathrm{~B}}$ receptor but not in other species. Unfortunately, no selective agonist is thus far available for the nonrodent $5-\mathrm{HT}_{1 \mathrm{~B}}$ receptor.

\section{Receptor Structure and Transduction}

The $5-\mathrm{HT}_{1 \mathrm{~B}}$ receptor gene is intronless, encoding for a 386-amino-acid protein in rat and mouse and 390 -amino-acid protein in humans that displays the typical structure of a seven-transmembrane-spanning GPCR. The human, mouse, and rat $5-\mathrm{HT}_{1 \mathrm{~B}}$ receptor genes are located on chromosomes $6 \mathrm{q} 13,9 \mathrm{E} 1$, and $8 \mathrm{q} 31$, respectively. The rat receptor has $96 \%$ homology in the TMR with the human receptor, but the rat and mouse receptor (Voigt et al., 1991; Adham et al., 1992; Maroteaux et al., 1992) exhibit the typical 5- $\mathrm{HT}_{1 \mathrm{~B}}$ receptor operational profile in contrast to the human receptor, which is close to the $5-\mathrm{HT}_{1 \mathrm{D}}$ receptor operational profile (Levy et al., 1992b; Weinshank et al., 1992).

The $5-\mathrm{HT}_{1 \mathrm{~B}}$ receptor couples negatively to adenylyl cyclase (Bouhelal et al., 1988; Hoyer and Schoeffter, 1988, 1991; Adham et al., 1992; Levy et al., 1992b; Maroteaux et al., 1992). Native $5-\mathrm{HT}_{1 \mathrm{~B}}$ receptors expressed in opossum kidney cells also mediate elevation of intracellular calcium (Zgombick and Branchek, 1998).

It is noteworthy that $5-\mathrm{HT}_{1 \mathrm{~B}}$ (and $5-\mathrm{HT}_{2 \mathrm{~B}}$ ) receptors have been crystallized (Wang et al., 2013; Wacker et al.,
2013; McCorvy and Roth, 2015; see section XVI. A. 5-HT GPCRs), which greatly increases knowledge of the structure pharmacology of the receptor. Indeed, the conformation of a number of agonists is different when bound to $5-\mathrm{HT}_{1 \mathrm{~B}}$ or $5-\mathrm{HT}_{2 \mathrm{~B}}$ receptors, in spite of very similar orthosteric binding sites (Wacker et al., 2013; Wang et al., 2013; McCorvy and Roth, 2015). Sumatriptan and a range of other triptans fit well into the orthosteric pocket of the human $5-\mathrm{HT}_{1 \mathrm{~B}}$ receptor (in contrast to the $5-\mathrm{HT}_{2 \mathrm{~B}}$ receptor), thus confirming the high affinity and potency reported for the triptans at $5-\mathrm{HT}_{1 \mathrm{~B}}$ (and $5-\mathrm{HT}_{1 \mathrm{D}}$ ) receptors. Some ergolines [LSD, metergoline, dihydroergotamine (DHE), ergotamine] bind to an accessory, possibly allosteric, site, which is located outside of the orthosteric pocket. It has been proposed that a short peptide, 5-HT-moduline, is a negative allosteric modulator of both $5-\mathrm{HT}_{1 \mathrm{~B}}$ and $5-\mathrm{HT}_{1 \mathrm{D}}$ receptors (Rousselle et al., 1998). Research concerning this peptide appears to have waned in recent years; the interested reader is directed to previous reviews on the subject (Fillion, 2000; Moret et al., 2003).

\section{Distribution and Function}

Autoradiographic studies performed in various species showed that both $5-\mathrm{HT}_{1 \mathrm{~A}}$ and $5-\mathrm{HT}_{1 \mathrm{C}}$ (now named $5-\mathrm{HT}_{2 \mathrm{C}}$ ) receptor binding was evident, in addition to $5-\mathrm{HT}_{2}$ receptor binding. However, what was then called $5-\mathrm{HT}_{1 \mathrm{~B}}$ binding site was apparently absent in pig, calf, and human brain in contrast to rodent brain. This observation was extended to the guinea pig and then to an increasing number of other species (Hoyer at al., 1988; Waeber et al., 1988a,b; Hoyer and Middlemiss, 1989). Eventually, it was found that only rat, mouse, hamster, and opossum had a $5-\mathrm{HT}_{1}$ receptor with a classic $5-\mathrm{HT}_{1 \mathrm{~B}}$ profile [see Hoyer et al. (1985a,b)]. By contrast, other species expressed what was called $5-\mathrm{HT}_{1 \mathrm{D}}$ receptors in the brain (e.g., guinea pig, bovine, dog, rabbit, monkey, and humans) (see Waeber et al., 1988a, 1989a,b; Hoyer and Schoeffter, 1991; Hoyer et al., 1992). It was subsequently shown that $\left[{ }^{3} \mathrm{H}\right]$ sumatriptan and a number of other triptans label both $5-\mathrm{HT}_{1 \mathrm{~B}}$ and $5-\mathrm{HT}_{1 \mathrm{D}}$ sites. However, they may also label $5-\mathrm{HT}_{1 \mathrm{~F}}$ sites (Waeber and Moskowitz, 1995b). It also became evident when using selective antagonists that both $5-\mathrm{HT}_{1 \mathrm{~B}}$ and $5-\mathrm{HT}_{1 \mathrm{D}}$ receptors could be detected in a single species (Bruinvels et al., 1993a,b, 1994a; Doménech et al., 1997; Bonaventure et al., 1997; Napier et al., 1999; Varnäs et al., 2001), but $5-\mathrm{HT}_{1 \mathrm{D}}$ receptor levels were minor when compared with the $5-\mathrm{HT}_{1 \mathrm{~B}}$ receptor.

An elegant study demonstrated the rat brain autoreceptors mediating inhibition of 5-HT release displayed the pharmacology of the $5-\mathrm{HT}_{1 \mathrm{~B}}$ receptor (Engel et al., 1986). In various other species, including humans, inhibitory autoreceptors displayed $5-\mathrm{HT}_{1 \mathrm{D}}$ receptor pharmacology (Schlicker et al., 1989). 5- $\mathrm{HT}_{1 \mathrm{~B}}$ receptors were also reported to mediate inhibition of GABA, cholinergic, and glutamatergic neurotransmission (Maura and Raiteri, 1986; Johnson et al., 1992; Singer et al., 1996; 
Chadha et al., 2000; Morikawa et al., 2000). The 5-HT $1 \mathrm{~B}$ receptor is highly concentrated in the substantia nigra (SN) and was shown to be negatively coupled to adenylyl cyclase activity (Bouhelal et al., 1988; Hoyer and Schoeffter, 1988, 1991).

Both 5- $\mathrm{HT}_{1 \mathrm{~B}}$ and 5-HT $\mathrm{HD}_{1 \mathrm{D}}$ receptors have a neuronal localization (Waeber et al., 1990a,b; Bruinvels et al., 1991, 1992a,b, 1993a,b, 1994a,b; Sari et al., 1999), including in the trigeminal ganglia (Bruinvels et al., 1992a, 1994a,b; Hou et al., 2001; Ma, 2001; Potrebic et al., 2003). There is also evidence that both receptors colocalize and may form heterodimers (Xie et al., 1999; Ma, 2001).

Evidence from radioligand binding experiments using 5 -HT neuronal lesions is equivocal regarding the location of the rat $5-\mathrm{HT}_{1 \mathrm{~B}}$ receptor, with some studies finding that the lesion causes an upregulation of $5-\mathrm{HT}_{1 \mathrm{~B}}$ binding sites and others finding a downregulation in the same areas. However, it is now clear that, like the $5-\mathrm{HT}_{1 \mathrm{~A}}$ receptor, the $5-\mathrm{HT}_{1 \mathrm{~B}}$ receptor functions as a presynaptic autoreceptor (see also section XVIII. 5-HT Receptors and the Brain). In situ hybridization studies have located mRNA encoding the $5-\mathrm{HT}_{1 \mathrm{~B}}$ receptor in the dorsal and median raphe nuclei (Bruinvels et al., 1994a). Furthermore, $5-\mathrm{HT}_{1 \mathrm{~B}}$ receptor mRNA in the raphe nuclei is markedly reduced by a 5-HT neuronal lesion. Together, these data suggest that $5-\mathrm{HT}_{1 \mathrm{~B}}$ receptors are located both presynaptically (inhibitory autoreceptor) and postsynaptically (heteroreceptor) relative to 5-HT neurons [see Waeber et al. (1990b)]; as an example of the latter, $5-\mathrm{HT}_{1 \mathrm{~B}}$ heteroreceptors inhibit CGRP release from sensory perivascular nerves in the rat systemic vasculature (González-Hernández et al., 2010).

$5-\mathrm{HT}_{1 \mathrm{~B}}$ receptors are also located on cerebral arteries and other vascular tissues mediating direct vasoconstriction [see Villalón et al. (2003) and Villalón and Centurión (2007)]. Furthermore, it seems that the receptor may be "silent" in a number of vascular preparations, becoming responsive in conditions such as atherosclerosis or when costimulated with "priming" factors (Sahin Erdemli et al., 1991; Kaumann et al., 1993, 1994). Other peripheral effects have also been described, such as 1) inhibition of noradrenaline release from sympathetic nerves in vena cava (Göthert et al., 1986) and systemic vasculature (Villalón et al., 1998) and 2) inhibition of plasma extravasation produced by trigeminal ganglion stimulation (Buzzi and Moskowitz., 1991). $5-\mathrm{HT}_{1 \mathrm{~B}}$ receptors also mediate vasoconstriction in the rat caudal arteries (Craig and Martin, 1993) and the canine external carotid circulation (De Vries et al., 1998) or guinea pig iliac artery (Sahin Erdemli et al., 1991), although endothelium-mediated relaxation has also been reported (Schoeffter and Hoyer, 1989, 1990). Interestingly 5 - $\mathrm{HT}_{1 \mathrm{~B}}$ receptor mRNA is more abundant within vascular smooth muscle cells compared with $5-\mathrm{HT}_{1 \mathrm{D}}$ receptor mRNA (Bouchelet et al., 1996; Sgard et al., 1996). The latter was reinforced by evident $5-\mathrm{HT}_{1 \mathrm{~B}}$ but not $5-\mathrm{HT}_{1 \mathrm{D}}$ receptor immunoreactivity in cranial blood vessels (Longmore et al., 1997). Consistent with these findings, the subsequent advent of the potent and relatively selective antagonists at either the $5-\mathrm{HT}_{1 \mathrm{~B}}$ (SB224289; Hagan et al., 1997; Gaster et al., 1998) or 5-HT 1 (BRL15572; Price et al., 1997) receptors made it possible to demonstrate that the $5-\mathrm{HT}_{1 \mathrm{~B}}$, but not the $5-\mathrm{HT}_{1 \mathrm{D}}$, receptor mediates the sumatriptan-induced contraction of vascular smooth muscle (e.g., De Vries et al., 1998, 1999; Verheggen et al., 1998), 2004.

\section{E. Radioligand Binding}

Autoradiographic studies using $\left[{ }^{3} \mathrm{H}\right]-5$-HT (in the presence of 8-OH-DPAT), $\left.{ }^{[25 \mathrm{I}}\right] \mathrm{ICYP}$ (in the presence of isoprenaline), or [ $\left.{ }^{125} \mathrm{I}\right]$-carboxymethylglycyl iodotyrosinamide demonstrated a high density of $5-\mathrm{HT}_{1 \mathrm{~B}}$ sites in the rat basal ganglia (particularly the substantia nigra, globus pallidus, ventral pallidum, and entopeduncular nucleus) but also in many other regions (Hoyer, 1988; Palacios et al, 1992; Hoyer et al., 1994; Mengod et al., 2010). The discrimination of $5-\mathrm{HT}_{1 \mathrm{~B}}$ and $5-\mathrm{HT}_{1 \mathrm{D}}$ receptors in both rodent and nonrodent species has become more straightforward with the availability of a new 5-HT $1 \mathrm{~B} / 1 \mathrm{D}$ radioligand, namely, $\left[{ }^{3} \mathrm{H}\right]-\mathrm{GR}-125743$ (Doménech et al., 1997; Varnäs et al., 2001), or various triptans (Leysen et al., 1996; Bonaventure et al., 1997; Napier et al., 1999) as well as cold ligands, which discriminate $5-\mathrm{HT}_{1 \mathrm{~B}}$ and $5-\mathrm{HT}_{1 \mathrm{D}}$ receptors (Price et al., 1997; Middlemiss et al., 1999).

\section{5-HT 1 Receptors}

\section{A. Introduction}

To recap, following the cloning of $5-\mathrm{HT}_{1 \mathrm{D} \alpha}$ and $5-\mathrm{HT}_{1 \mathrm{D} \beta}$ receptor genes in various species, $5-\mathrm{HT}_{1 \mathrm{D} \alpha}$ was renamed the $5-\mathrm{HT}_{1 \mathrm{D}}$, and $5-\mathrm{HT}_{1 \mathrm{D} \beta}$ became the $5-\mathrm{HT}_{1 \mathrm{~B}}$ receptor, keeping in mind that $5-\mathrm{HT}_{1 \mathrm{D}}$ expression levels are generally low compared with the $5-\mathrm{HT}_{1 \mathrm{~B}}$ receptor (see section III. 5-HT $1 B$ Receptors for more detail).

\section{B. Pharmacology}

As noted in III. 5-HT $1 B$ Receptors, the pharmacological distinction of $5-\mathrm{HT}_{1 \mathrm{~B}}$ from $5-\mathrm{HT}_{1 \mathrm{D}}$ receptors was a challenge until the advent of selective and silent antagonists (devoid of intrinsic activity) for $5-\mathrm{HT}_{1 \mathrm{~B}}$ and $5-\mathrm{HT}_{1 \mathrm{D}}$ receptors (Hagan et al., 1997).

A series of isochroman-6-carboxamide derivatives, including PNU109291 (Ennis et al., 1998), PNU142633 (McCall, 1997; McCall et al., 2002), and L775606 (MacLeod et al., 1997), have been reported to be selective $5-\mathrm{HT}_{1 \mathrm{D}}$ receptor agonists, although they display low intrinsic efficacy at primate $5-\mathrm{HT}_{1 \mathrm{D}}$ receptors in $\mathrm{GTP} \gamma^{35} \mathrm{~S}$ binding assays (Pregenzer et al., 1999).

The $5-\mathrm{HT}_{1 \mathrm{D}}$ receptor is potently antagonized by the $5-\mathrm{HT}_{1 \mathrm{~B} / 1 \mathrm{D}}$ receptor antagonist GR127935 (Clitherow et al., 1994; Skingle et al., 1996) and by the selective $5-\mathrm{HT}_{1 \mathrm{D}}$ receptor antagonist BRL15572 (Price et al., 1997). Additionally, some $5-\mathrm{HT}_{2}$ receptor antagonists (e.g., 
ketanserin and ritanserin) can discriminate the 5 - $\mathrm{HT}_{1 \mathrm{D}}$ receptor from $5-\mathrm{HT}_{1 \mathrm{~B}}$ and 5 - $\mathrm{HT}_{1 \mathrm{~F}}$ receptors (Hoyer et al., 1994), although this is highly species-dependent (see Branchek et al., 1995; Zgombick et al., 1995, 1997). Sumatriptan and the second-generation triptans are potent agonists at the $5-\mathrm{HT}_{1 \mathrm{D}}$ receptor (but also interact with 5- $\mathrm{HT}_{1 \mathrm{~B}}$ and 5- $\mathrm{HT}_{1 \mathrm{~F}}$ receptors; Villalón et al., 2003; Table 6). It has been demonstrated that the $5-\mathrm{HT}_{1 \mathrm{D}}$ receptor is located preferentially on neuronal, rather than vascular, tissues (Ullmer et al., 1995; Sgard et al., 1996; Longmore et al., 1997).

Given the cardiovascular liabilities of triptans potentially via $5-\mathrm{HT}_{1 \mathrm{~B}}$ receptors expressed by vasculature (Nilsson et al., 1999a,b), which is not the case for 5-HT $\mathrm{H}_{1 \mathrm{D}}$ receptors (Nilsson et al., 1999b), it was hypothesized that selective $5-\mathrm{HT}_{1 \mathrm{D}}$ receptor agonists may treat migraine, with reduced cardiovascular side effects. Unfortunately, this has not translated to the clinic; the $5-\mathrm{HT}_{1 \mathrm{D}}$ receptor agonist $\mathrm{PNU}-142633$ was ineffective in the acute treatment of migraine (Gómez- Mancilla et al., 2001), although the intrinsic activity of this compound may complicate interpretation.

\section{Receptor Structure and Transduction}

The $5-\mathrm{HT}_{1 \mathrm{D}}$ receptor gene, like the $5-\mathrm{HT}_{1 \mathrm{~B}}$ receptor gene, is intronless. The human $5-\mathrm{HT}_{1 \mathrm{D}}$ receptor gene is located on chromosome 1p34.3-p36.3, codes for a 377-amino-acid protein, and possesses $63 \%$ overall structural homology with the $5-\mathrm{HT}_{1 \mathrm{~B}}$ receptor; the mouse and rat receptor genes are located on chromosomes 4D3 and 5q36 and code for 374-aminoacid proteins. These receptors are made of a single polypeptide chain that spans the membrane seven times, with the amino terminus being extracellular and the carboxyl terminus intracellular in the manner typical of GPCRs (Hamblin and Metcalf, 1991; Hamblin et al., 1992; Weinshank et al., 1992; Weydert et al., 1992). The receptor is negatively coupled to adenylyl cyclase activity (Weinshank et al., 1992).

\section{Distribution and Function}

The distribution of $5-\mathrm{HT}_{1 \mathrm{D}}$ receptors is known but understood with less confidence because protein levels are low along with the relative difficulty of radioligands to discriminate this receptor from the $5-\mathrm{HT}_{1 \mathrm{~B}}$ receptor. Receptor autoradiographic studies in rat (CP93129-insensitive [ $\left.{ }^{125} \mathrm{I}\right]$-carboxymethylglycyl iodotyrosinamide binding) or human (ketanserin-insensitive $\left[{ }^{3} \mathrm{H}\right]$-sumatriptan binding) brain clearly indicate $5-\mathrm{HT}_{1 \mathrm{D}}$ receptor site is expressed in the basal ganglia (globus pallidus, substantia nigra, and caudate putamen) and also the hippocampus and cortex (Pineyro et al., 1995; Hou et al., 2001; Potrebic et al., 2003; Mengod et al., 2010).

TABLE 6

$\mathrm{p} K_{\mathrm{i}}$ values of sumatriptan and second-generation triptans at human (except when stated otherwise) 5-HT receptors

\begin{tabular}{|c|c|c|c|c|c|c|c|c|}
\hline Receptor & Sumatriptan & Zolmitriptan & Naratriptan & Rizatriptan & Eletriptan & Almotriptan & Frovatriptan & F11356 \\
\hline \multirow[t]{3}{*}{$5-\mathrm{HT}_{1 \mathrm{~A}}$} & $6.4^{a}$ & $6.6^{b}$ & $7.6^{c}$ & $6.4^{b}$ & $7.4^{b}$ & $6.3^{d}$ & $7.3^{e}$ & $7.6^{f}$ \\
\hline & $6.9^{c}$ & $6.5^{g}$ & $7.1^{b}$ & & & & & \\
\hline & $6.0^{b}$ & & $7.1{\text { (rat })^{h}}^{h}$ & & & & & \\
\hline \multirow{3}{*}{$5-\mathrm{HT}_{1 \mathrm{~B}}$} & $7.8^{a}$ & $7.7^{b}$ & $8.1^{b}$ & $6.9^{b}$ & $8.0^{b}$ & $8.0^{d}$ & $8.6^{e}$ & $9.4^{f}$ \\
\hline & $7.4^{b}$ & $8.3^{g}$ & $8.7^{h}$ & $7.7^{i}$ & & & & \\
\hline & $8.3^{j}$ & & & $8.1^{k}$ & & & & \\
\hline \multirow{2}{*}{$5-\mathrm{HT}_{1 \mathrm{D}}$} & $8.5^{a}$ & $8.9^{b}$ & $8.4^{b}$ & $7.9^{b}$ & $8.9^{b}$ & $8.0^{d}$ & $8.4^{e}$ & $9.3^{f}$ \\
\hline & $8.0^{b}$ & $9.2^{g}$ & $8.3^{h}$ & $8.6^{k}$ & & & & \\
\hline \multirow[t]{2}{*}{$5-\mathrm{ht}_{1 \mathrm{e}}$} & $5.8^{a}$ & $7.7^{b}$ & $7.7^{b}$ & $6.8^{b}$ & $7.3^{b}$ & & $<6.0^{e}$ & $5.9^{f}$ \\
\hline & $\begin{array}{l}5.8^{b} \\
5.6^{l}\end{array}$ & $8.0^{k}$ & & & & & & \\
\hline \multirow{3}{*}{$5-\mathrm{HT}_{1 \mathrm{~F}}$} & $7.9^{a}$ & $7.5^{b}$ & $8.2^{b}$ & $6.8^{b}$ & $8.0^{b}$ & & $7.0^{e}$ & $5.5^{f}$ \\
\hline & $7.9^{b}$ & $7.2^{g}$ & & & & & & \\
\hline & $7.6^{l}$ & & & & & & & \\
\hline $5-\mathrm{HT}_{2 \mathrm{~A}}$ & $<5.5^{b}$ & $<5.5^{b}$ & $<5.5^{b}$ & $<5.5^{b}$ & $<5.5^{b}$ & & $<5.3^{e}$ & $6.7^{f}$ \\
\hline $5-\mathrm{HT}_{2 \mathrm{~B}}$ & $6.9^{m}$ & $7.2^{m}$ & & $6.6^{m}$ & & & & \\
\hline $5-\mathrm{HT}_{2 \mathrm{C}}$ & $<5.5^{b}$ & $<5.5^{b}$ & $<5.5^{b}$ & $<5.5^{b}$ & $<5.5^{b}$ & & $<5.3^{e}$ & \\
\hline $\mathrm{m} 5-\mathrm{HT}_{3}$ & $<5.5^{b}$ & $<5.5^{b}$ & $<5.5^{b}$ & $<5.5^{b}$ & $<5.5^{b}$ & & $<6.0^{e}$ & $<5.0^{f}$ \\
\hline${\mathrm{gp} 5-\mathrm{HT}_{4}}$ & $<5.5^{b}$ & $<5.5^{b}$ & $<5.5^{b}$ & $<5.5^{b}$ & $<5.5^{b}$ & & & $5.7^{f}$ \\
\hline $5-\mathrm{HT}_{5 \mathrm{~A}}$ & $<5.5(\mathrm{rat})^{b}$ & $6.4(\mathrm{rat})^{b}$ & $5.5(\mathrm{rat})^{b}$ & $5.3(\mathrm{rat})^{b}$ & $5.8(\mathrm{rat})^{b}$ & & & $6.1^{f}$ \\
\hline $5-\mathrm{HT}_{6}$ & $<5.5^{b}$ & $<5.5^{b}$ & $<5.5^{b}$ & $<5.5^{b}$ & $6.3^{b}$ & & & $5.6^{f}$ \\
\hline $5-\mathrm{HT}_{7}$ & $5.9^{b}$ & $7.0^{b}$ & $<5.5^{b}$ & $5.7^{b}$ & $6.7^{b}$ & $<6.5^{d}$ & $6.7^{e}$ & $6.4^{f}$ \\
\hline
\end{tabular}

gp, guinea pig; m, Mouse.

${ }^{a}$ Data taken from Leysen et al. (1996).

${ }^{b}$ Data taken from Napier et al. (1999).

${ }^{c}$ Data taken from Newman-Tancredi et al. (1997b).

${ }^{d}$ Data taken from Bou et al. (1997).

${ }^{e}$ Data taken from Brown et al. (1998c).

${ }^{f}$ Data taken from John et al. (1999).

${ }^{g}$ Data taken from Martin (1997).

${ }^{h}$ Data taken from Connor et al. (1997).

${ }^{i}$ Data taken from Wurch et al. (1997).

${ }^{j}$ Data taken from Beer et al. (1998).

${ }^{k}$ Data taken from P. J. Pauwels, personal communication.

${ }^{l}$ Data taken from Adham et al. (1993).

${ }^{m}$ Data taken from P. Gupta, personal communication. 
In situ hybridization experiments allow a greater confidence of gene expression, albeit not at the level of protein. Thus, $5-\mathrm{HT}_{1 \mathrm{D}} \mathrm{mRNA}$ is present in rat brain, including the caudate putamen, nucleus accumbens (NAc), olfactory cortex, dorsal raphe nucleus, and locus coeruleus (e.g., Bruinvels et al., 1994a; Mengod et al., 2010; Fig. 4). The mRNA shows low abundance in all regions and was undetectable in the globus pallidus, ventral pallidum, and substantia nigra where, as noted above, $5-\mathrm{HT}_{1 \mathrm{D}}$ receptor sites appear to be present, which is perhaps indicative of the $5-\mathrm{HT}_{1 \mathrm{D}}$ receptor being located predominantly on axon terminals of both 5-HT and non-5-HT neurons.

In the periphery, the presence of $5-\mathrm{HT}_{1 \mathrm{D}}$ receptors is rather limited with evidence of presence in autonomic and trigeminal nerve terminals/ganglia (Molderings et al., 1996; Villalón et al., 1998).

The function of the $5-\mathrm{HT}_{1 \mathrm{D}}$ receptor still remains, to some extent, enigmatic. There is little evidence supporting the role of the $5-\mathrm{HT}_{1 \mathrm{D}}$ receptor in any pathology. The availability of suitable tools for investigation in vivo has limited the investigations into the importance of $5-\mathrm{HT}_{1 \mathrm{D}}$ receptors; they have been identified as autoreceptors in the dorsal raphe (Pineyro et al., 1995) or terminal brain regions. Thus, given their autoreceptor activity, $5-\mathrm{HT}_{1 \mathrm{D}}$ receptor antagonists may have antidepressant potential, and to maximize 5 -HT release in terminal brain regions, $5-\mathrm{HT}_{1 \mathrm{D}}, 5-\mathrm{HT}_{1 \mathrm{~B}}$, and $5-\mathrm{HT}_{1 \mathrm{~A}}$ receptors must be blocked simultaneously.

Operationally, $5-\mathrm{HT}_{1 \mathrm{D}}$ receptors mediate inhibition of noradrenaline release in human atrium. Additionally, the $5-\mathrm{HT}_{1 \mathrm{D}}$ receptor seems to be involved in the inhibition of guinea pig dural plasma protein extravasation (Ennis et al., 1998) and the central trigeminal inhibitory effects by some antimigraine compounds (Mills and Martin, 1995; Cumberbatch et al., 1998; De Vries et al., 1999a,b; Villalón et al., 2003).

It has been proposed that the $5-\mathrm{HT}_{1 \mathrm{D}}$ receptor modulates growth hormone release (Mota et al., 1995; Whale et al., 1999), although this requires clearer pharmacological verification.

\section{5-ht 1 e Receptors}

\section{A. Introduction}

There has been relatively limited research on the 5 -ht $_{1 \mathrm{e}}$ receptor, with an apparent lack of expression in rodents complicating preclinical studies. The lack of functional data concerning natively expressed $5-\mathrm{ht}_{1 \mathrm{e}}$ receptors means by convention lower case appellation is still used for nomenclature.

With hindsight, the 5 -ht $_{1 \mathrm{e}}$ receptor was likely discovered by virtue of an atypical pharmacology of a $\left[{ }^{3} \mathrm{H}\right] 5-\mathrm{HT}$ binding site in human frontal cortex (Leonhardt et al., 1989), which was sensitive to guanyl nucleotides, suggesting association with the GPCR family. The high affinity $\left[{ }^{3} \mathrm{H}\right] 5-\mathrm{HT}$ displayed for the binding sites and the low affinity of drugs displaying affinity for the $5-\mathrm{HT}_{2}$ receptor (e.g., mesulergine) supported membership of the $5-\mathrm{HT}_{1}$ receptor family. However, the low affinity of 5 -CT, the prototypical $5-\mathrm{HT}_{1}$ receptor agonist, and detailed pharmacological characterization of the new $\left[{ }^{3} \mathrm{H}\right] 5$-HT binding site in human and bovine cortical homogenates highlighted that this site likely represented a further member of the $5-\mathrm{HT}_{1}$ family, and hence it was given that next available name: $5-\mathrm{HT}_{1 \mathrm{E}}$ (Leonhardt et al., 1989; now reclassified as 5-ht ${ }_{1 \mathrm{e}}$ until a functional response in native tissue/cell preparation can be attributed).

\section{B. Cloning and Distribution of $5-h t_{1 e}$ Receptors}

Soon after the 5 -ht $\mathrm{t}_{1 \mathrm{e}}$ receptor binding site was pharmacologically characterized by radioligand binding in human and bovine brain tissue, a human GPCR gene, termed S31, was cloned (Levy et al., 1992a; see h5-ht 1e $_{\mathrm{e}}$ in Fig. 5 for sequence) and assigned to human chromosome 6q14-q15 (Levy et al., 1994). When S31 was expressed in cell lines, the gene product was found to have pharmacological properties similar to the tissue-expressed $5-\mathrm{ht}_{1 \mathrm{e}}$ receptor binding site, and the conclusion was that this gene encodes the protein for the receptor binding site discovered by Leonhardt et al. (1989) (McAllister et al., 1992; Zgombick et al., 1992; Gudermann et al., 1993). However, the $5-\mathrm{HT}_{1 \mathrm{~F}}$ receptor, discovered subsequent to these early reports on the $5-\mathrm{ht}_{1 \mathrm{e}}$ receptor, shares a high degree of sequence homology with the $5-\mathrm{ht}_{1 \mathrm{e}}$ receptor compared with other 5-HT receptors (see Fig. 5 for $\mathrm{h} 5-\mathrm{ht}_{1 \mathrm{e}}$ and $\mathrm{h} 5-\mathrm{HT}_{1 \mathrm{~F}}$ amino acid sequence alignment) and bears a pharmacological profile very similar to the 5-ht $\mathrm{H}_{1 \mathrm{e}}$ receptor (Adham et al., 1993a,b; Lovenberg et al., 1993b). A careful examination of the binding data presented in the original report on the $5-\mathrm{ht}_{1 \mathrm{e}}$ receptor (Leonhardt et al., 1989) suggests the binding site identified in this report is likely a composite of both $5-\mathrm{ht}_{1 \mathrm{e}}$ and $5-\mathrm{HT}_{1 \mathrm{~F}}$ receptor binding sites. Drugs that can discriminate between these receptor subtypes were not identified until after a number of studies were published that attempted to identify the distribution of $5-\mathrm{ht}_{1 \mathrm{e}}$ receptors via radioligand binding and autoradiography methodologies (Miller and Teitler, 1992; Beer et al., 1993; Barone et al., 1994; Stanton et al., 1996; Fugelli et al., 1997). This resulted in reports that incorrectly attributed $\left[{ }^{3} \mathrm{H}\right] 5-\mathrm{HT}$ radioligand binding to the $5-\mathrm{ht}_{1 \mathrm{e}}$ receptor in both rat and mouse brain tissue, species that were later identified to lack the 5 -ht $_{1 \mathrm{e}}$ receptor gene (Bai et al., 2004). Even those reports that used tissue from species that do express a 5 -ht $t_{1 \mathrm{e}}$ receptor gene (e.g., humans, monkeys, guinea pigs, and bovine) were, in hindsight, confounded by the labeling of $5-\mathrm{HT}_{1 \mathrm{~F}}$ receptors and thus need to be viewed as data that reflects a mixture of $5-\mathrm{ht}_{1 \mathrm{e}}$ and $5-\mathrm{HT}_{1 \mathrm{~F}}$ receptor populations. Subsequent pharmacological isolation of 5 -ht $\mathrm{h}_{1 \mathrm{e}}$ receptors (Klein and Teitler, 2012) has shown the following pattern of expression of the 
5 -ht $_{1 \mathrm{e}}$ receptor binding sites: olfactory bulb $=$ hippocampus $>$ frontal cortex $>$ hypothalamus $=$ cerebellum $>$ brainstem-thalamus $=$ striatum (Fig. 6). Issues impacting the ability to define with confidence the distribution of the 5 -ht $t_{1 \mathrm{e}}$ receptor were to some extent overcome with the development of an antibody recognizing the 5 -ht $t_{1 \mathrm{e}}$ receptor protein (Klein and Teitler, 2012), allowing protein expression to be revealed in native tissue. Such immunohistochemical studies revealed that the 5 -ht $_{1 \mathrm{e}}$ receptor immunoreactivity was expressed in the olfactory bulb (glomerula cells), whereas in the hippocampus, expression is limited to the dentate gyrus (Klein and Teitler, 2012). Interestingly, 5 -ht $_{1 \mathrm{e}}$ receptor immunoreactivity was also expressed in cerebral arteries (guinea pig; Klein and Teitler, 2012).

\section{Pharmacology}

Bai et al. (2004) demonstrated that the rhesus monkey, pig, rabbit, and guinea pig express a homolog of the human $5-\mathrm{ht}_{1 \mathrm{e}}$ receptor gene. Because of the relative utility in preclinical models, the guinea pig 5 -ht $_{1 \mathrm{e}}$ receptor (gp5-ht $t_{1 \mathrm{e}}$ ) sequence was cloned for further study. The guinea pig homolog shares $88 \%$ nucleic acid and $95 \%$ amino acid sequence homology with the human 5 -ht $\mathrm{h}_{\mathrm{e}}$ receptor. The pharmacological properties of the guinea pig recombinant $5-\mathrm{ht}_{1 \mathrm{e}}$ receptor correlate well with the human counterpart in terms of affinity $\left(R^{2}=0.99\right)$ and potency $\left(R^{2}=0.96\right)$, indicating a high degree of evolutionary conservation for the receptor.

Quantitative RT-PCR of guinea pig brain regions revealed high levels of gp5-ht ${ }_{1 \mathrm{e}}$ receptor mRNA in the cortex, hippocampus, and olfactory bulb and moderate expression in some other regions, similar to the expression pattern in the human brain (Bai et al., 2004). Thus, the structural and pharmacological similarities of the human and guinea pig receptors, along with comparable patterns of expression in gross brain regions, lend a great deal of support to the guinea pig as a valid model to study the functionality of the $\mathrm{h} 5-\mathrm{ht}_{1 \mathrm{e}}$ receptor.

Some attempts have been made to develop selective pharmacological tools for the $\mathrm{h} 5$-ht $_{1 \mathrm{e}}$ receptor (Dukat et al., 2004) but failed to identify 5 -ht $\mathrm{H}_{1 \mathrm{e}}$ receptor ligands with affinities substantially higher than 5-HT. A relatively selective high-affinity $5-\mathrm{ht}_{1 \mathrm{e}}$ receptor ligand has been identified, BRL54443 (Brown et al., 1998); this drug displays similar affinities for the $h 5-h t_{1 \mathrm{e}}$ and $\mathrm{h} 5-\mathrm{HT}_{1 \mathrm{~F}}$ receptors but, more usefully, at least 60 -fold lower affinities for other 5-HT, dopamine, and adrenergic receptors. Few published reports exist regarding the pharmacology of this compound, and the reports of BRL54443 action in vivo have used species that do not express the 5 -ht $_{1 \mathrm{e}}$ receptor (mice and rats; Adham et al., 1994; Brown et al., 1998; McKune and Watts, 2001; Watts et al., 2001; Hisadome et al., 2009; Granados-Soto et al., 2010).

A high throughput screening study conducted at the Scripps Research Institute's Molecular Screening Center in collaboration with Milt Teitler's laboratory, with the aim of identifying highly potent, selective agonists or antagonists for the 5 -ht $\mathrm{h}_{1 \mathrm{e}}$ receptor, has been performed [PubChem BioAssay Database, AID (accession \#): 567; 574; 613; 718; 726; 730]. Nearly 65,000 compounds from a broad range of structural classes were screened for agonist and antagonist properties at the $\mathrm{h} 5-\mathrm{ht}_{1 \mathrm{e}}$ receptor and counter-screened at the $5-\mathrm{HT}_{1 \mathrm{~A}}$ receptor as an assessment of selectivity. Though none of the compounds were highly selective for the $\mathrm{h} 5-\mathrm{ht}_{1 \mathrm{e}}$ receptor, a number of high-potency agonists $\left(\mathrm{EC}_{50}\right.$ low nanomolars) were identified that displayed some structural similarity to BRL54443. In a more recent study comparing 51 tryptamine-based compounds for affinities at the human 5 -ht $\mathrm{t}_{1 \mathrm{e}}$ and $5-\mathrm{HT}_{1 \mathrm{~F}}$ receptors, no drugs were identified that showed a significant preference for the 5 - $_{1 \mathrm{e}}$ receptor over the

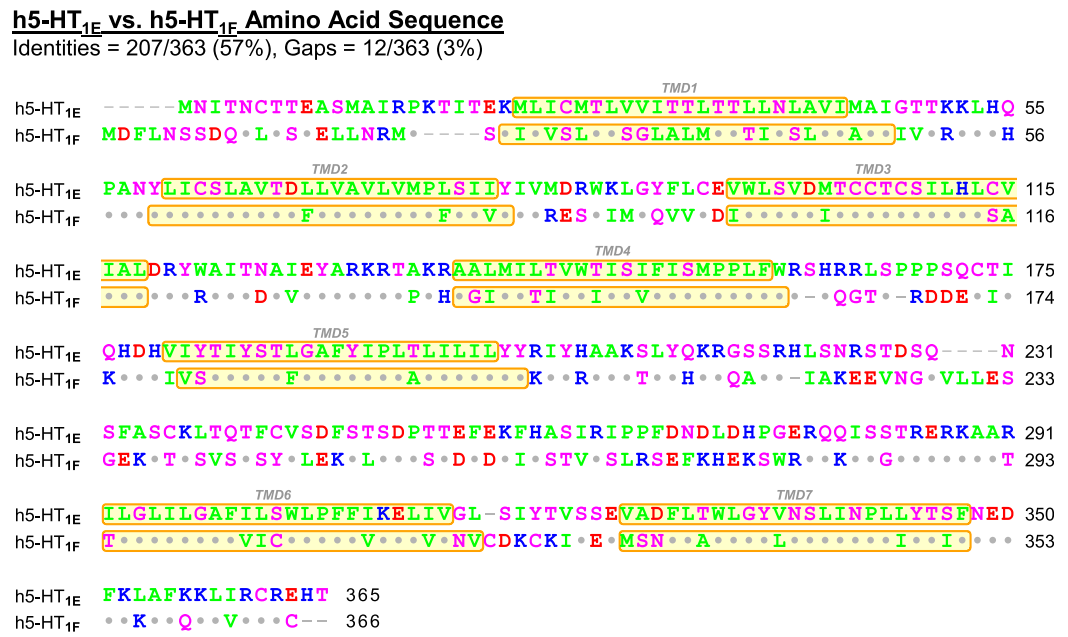

Fig. 5. Alignment of human $5-\mathrm{ht}_{1 \mathrm{e}}$ and $5-\mathrm{HT}_{1 \mathrm{~F}}$ receptor amino acid sequences. Sequence homology is assessed by Basic Local Alignment Search Tool (BLAST, copyright National Library of Medicine) for protein sequences. Transmembrane domains (TMD 1-7) were determined previously (Bai et al., 2004) and highlighted by yellow rectangles. Nonpolar, uncharged polar, acidic polar, and basic polar amino acids are labeled by corresponding color. 

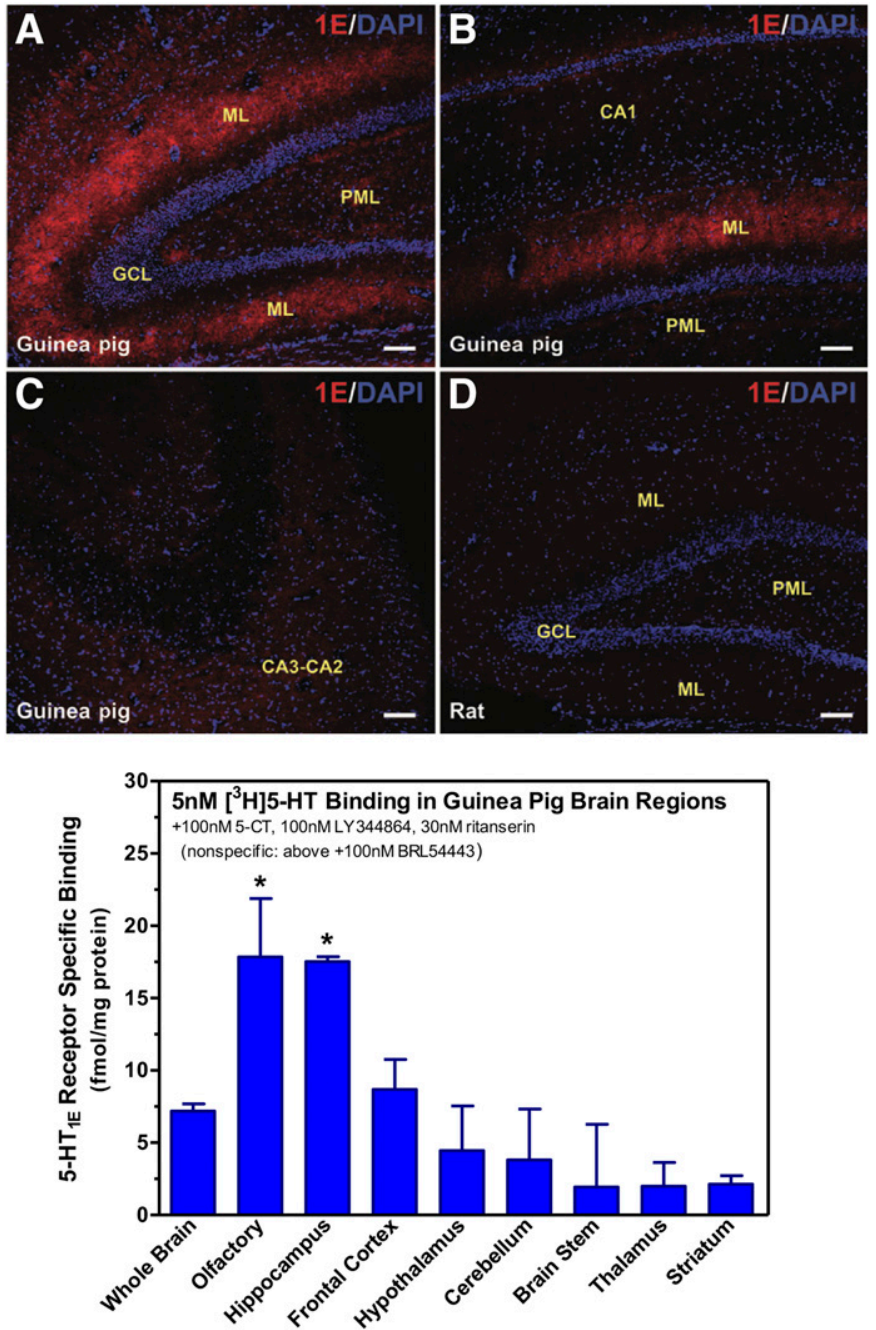

Fig. 6. $5-\mathrm{ht}_{1 \mathrm{e}}$ receptor expression in guinea pig and rat brain. The top image shows immunohistochemical staining of the 5 -ht $\mathrm{h}_{1 \mathrm{e}}$ receptor in the hippocampus. (A) Coronal section of guinea pig hippocampus at the septal pole of the DG. (B) Coronal section of guinea pig hippocampus near the temporal pole of the DG. (C) Coronal section of rostral guinea pig hippocampus shows a lack of $5-\mathrm{ht}_{1 \mathrm{e}}$ receptor staining in the CA3-CA2 region. (D) Rat hippocampus (coronal section of DG septal pole) does not stain for 5 -ht $_{1}$ receptors. GCL, granular cell layer; ML, molecular layer; PML, polymorphic layer. Scale bars, $100 \mu \mathrm{m}$. The bottom image shows histogram of radioligand 5 -ht $_{1 \mathrm{e}}$ receptor binding sites in homogenates of guinea pig brain. High levels of 5 -ht $\mathrm{He}_{\mathrm{e}}$ receptor binding sites are detected in the hippocampus and olfactory bulb. $* P<0.05$ compared with "whole-brain," one-way ANOVA with Dunnett's post-test. Data are the means \pm S.E.M. of three independent experiments performed in triplicate. Adapted from Klein and Teitler (2012) (with permission).

$5-\mathrm{HT}_{1 \mathrm{~F}}$ receptor, again demonstrating the difficulties in attempting to identify $5-\mathrm{ht}_{1 \mathrm{e}}$ receptor-selective drugs (Klein et al., 2011).

\section{Functions}

Recombinant expression of the $5-\mathrm{ht}_{1 \mathrm{e}}$ receptor in cell lines demonstrates the coupling to $\mathrm{G}_{\mathrm{i} / \mathrm{o}}$ signaling pathways (Levy et al., 1992a; Gudermann et al., 1993; Adham et al., 1994) although no signaling pathways have been identified in native tissues, and in the absence of a recognized functional response, the lower case appellation nomenclature is retained.

\section{5-HT 1F $_{\text {Receptors }}$}

\section{A. Introduction}

Although the first published reports for the $5-\mathrm{HT}_{1 \mathrm{~F}}$ receptor occurred in 1992 and 1993 (Amlaiky et al., 1992; Adham et al., 1993b; Lovenberg et al., 1993), there is still only limited information about this receptor. Much of the current literature centers on possible roles for the $5-\mathrm{HT}_{1 \mathrm{~F}}$ receptor in the treatment of migraine despite the $5-\mathrm{HT}_{1 \mathrm{~F}}$ receptor displaying a broad distribution within the central nervous system (CNS), and it also appears to be expressed in the periphery.

\section{B. Cloning and Structure}

The $5-\mathrm{HT}_{1 \mathrm{~F}}$ receptor was discovered as the result of homology cloning strategies. The first report of the cloning of the human $5-\mathrm{HT}_{1 \mathrm{~F}}$ receptor was in a patent application by Synaptic Pharmaceuticals, Inc., (Weinshank et al. 1994, U.S. patent number 5,360,735, filed in 1992, issued in 1994). Amlaiky et al. (1992) reported the cloning of the mouse receptor (initially called $5-\mathrm{HT}_{1 \mathrm{E} \beta}$ ) that same year, followed by a peer-reviewed report on the human receptor (Adham et al., 1993b) and the cloning of both the rat and human versions (initially called $5-\mathrm{HT}_{1 \mathrm{E} \text {-like }}$ ) of the receptor in 1993 (Lovenberg et al., 1993) (Table 7).

The $5-\mathrm{HT}_{1 \mathrm{~F}}$ receptor gene is intronless, coding for a GPCR of 366 amino acids that conform to the classic GPCR structure, and has been sequenced in a number of species (mouse, rat, guinea pig, pig, human; Amlaiky et al., 1992; Adham et al., 1993b, 1997; Lovenberg et al., 1993; Bhalla et al., 2002b). In mouse and rat, it appears that the $5-\mathrm{HT}_{1 \mathrm{~F}}$ receptor is encoded by three different mRNA transcripts (Guptan et al., 1997), which differ in their $3^{\prime}$ untranslated regions.

\section{Distribution}

1. $m R N A$. The initial studies of $5-\mathrm{HT}_{1 \mathrm{~F}}$ receptor distribution located $5-\mathrm{HT}_{1 \mathrm{~F}}$ receptor mRNA, either by RT-PCR or in situ hybridization (Fig. 7; Table 8). 5-HT $1 \mathrm{~F}$ receptor mRNA has a rather broad distribution within the brain; the cerebral cortex shows a relatively dense band of expression within the internal layers (approximately layers IV-VI), and hippocampal areas CA1-CA3 display relatively high expression, as do the thalamus and striatum.

Documentation of the presence of $5-\mathrm{HT}_{1 \mathrm{~F}}$ receptor mRNA in peripheral tissues is limited to a few single reports in different species, including human, bovine, pig, rat, and rabbit (Table 8). Overall, there is still a need for a systematic mapping of the peripheral distribution of $5-\mathrm{HT}_{1 \mathrm{~F}}$ receptors. Peripheral blood vessels such as the coronary artery have been reported to express $5-\mathrm{HT}_{1 \mathrm{~F}}$ message, although the findings in human coronary appear variable, with Ishida et al. (1999) finding none, Nilsson et al. (1999b) reporting a strong signal, and Bouchelet et al. (2000) reporting a weak signal in about $40 \%$ of patients. Bhalla et al. 
(2002b) found a $5-\mathrm{HT}_{1 \mathrm{~F}}$ receptor mRNA signal in porcine coronary artery. Regardless, the 5 - $\mathrm{HT}_{1 \mathrm{~F}}$ receptor agonist LY334370 did not elicit contractions in human coronary artery (Nilsson et al., 1999b). 5- $\mathrm{HT}_{1 \mathrm{~F}}$ receptor transcripts are also present in vascular preparations from the CNS (Table 8). However, when the brain microvessel preparations were treated to yield cultures of either smooth muscle or endothelial cells, no $5-\mathrm{HT}_{1 \mathrm{~F}}$ receptor mRNA was detected (Cohen et al., 1999).

In contrast to peripheral tissues, evidence for the presence of $5-\mathrm{HT}_{1 \mathrm{~F}}$ receptor mRNA in the peripheral nervous system is clear; thus, multiple studies in trigeminal ganglia and dorsal root ganglia (fresh or cultured) have identified $5-\mathrm{HT}_{1 \mathrm{~F}}$ receptor mRNA (Table 8 ).

2. Radioligand Binding. The first localization studies of $5-\mathrm{HT}_{1 \mathrm{~F}}$ receptor binding sites used $\left[{ }^{3} \mathrm{H}\right]$ sumatriptan, which displays high affinity for $5-\mathrm{HT}_{1 \mathrm{~F}}$ receptors as well as $5-\mathrm{HT}_{1 \mathrm{~B} / 1 \mathrm{D}}$ receptors. This radioligand has been used to map the $5-\mathrm{HT}_{1 \mathrm{~F}}$ receptor in a variety of species (including "cold" competing ligands such as 5-CT or methiothepin prevents radiolabeling of $5-\mathrm{HT}_{1 \mathrm{~B}}$ and $5-\mathrm{HT}_{1 \mathrm{D}}$ receptors; Waeber and Moskowitz, 1995b; Mengod et al., 1996; Scarr et al., 2004; Dean et al., 2006). Although $\left[{ }^{3} \mathrm{H}\right] 5$-HT can be used to label heterologous expression of $5-\mathrm{HT}_{1 \mathrm{~F}}$ receptors in cultured cells (Adham et al., 1993b), lack of selectivity makes 5 - $\mathrm{HT}_{1 \mathrm{~F}}$ receptor localization studies with $\left[{ }^{3} \mathrm{H}\right] 5$ - $\mathrm{HT}$ challenging (Fugelli et al., 1997). A second useful radioligand to label the $5-\mathrm{HT}_{1 \mathrm{~F}}$ receptor is $\left[{ }^{3} \mathrm{H}\right] \mathrm{LY} 334370$, albeit in the presence of $5-\mathrm{HT}_{1 \mathrm{~A}}$ receptor ligands such as 8-OH-DPAT to prevent labeling of the latter receptor (Wainscott et al., 2005). It is probably noteworthy that with all $5-\mathrm{HT}_{1 \mathrm{~F}}$ receptor-labeling studies, the lack of a selective radioligand necessitating the use of "cold" blocking drugs to better isolate radioligand binding to the $5-\mathrm{HT}_{1 \mathrm{~F}}$ receptor may underestimate the reported levels of $5-\mathrm{HT}_{1 \mathrm{~F}}$ receptors, or conversely, the specific radioligand binding signal consists of a heterogenous population of sites that includes the $5-\mathrm{HT}_{1 \mathrm{~F}}$ receptor; either way, interpretation should be made with caution.

3. Immunoreactivity. Relatively few studies have used antibodies to localize $5-\mathrm{HT}_{1 \mathrm{~F}}$ receptors (Table 9 ). The antibody studies of Ma (2001) and Classey et al. (2010) are consistent with investigations showing $5-\mathrm{HT}_{1 \mathrm{~F}}$ receptor mRNA in trigeminal ganglia and dorsal root ganglia (Table 8). Classey et al. (2010) describe 5- $\mathrm{HT}_{1 \mathrm{~F}}$ receptor-like immunoreactivity in dorsal root ganglia

TABLE 7

Chromosomal location of the $5-\mathrm{HT}_{1 \mathrm{~F}}$ receptor gene

The chromosomal location of $5-\mathrm{HT}_{1 \mathrm{~F}}$ receptor genes can be found in the following databases: http://www.ncbi.nlm.nih.gov/gene/?term=HTR1F\%5Bsym\%5D and http:// www.guidetopharmacology.org/GRAC/ObjectDisplayForward?objectId $=5$.

\begin{tabular}{lcc}
\hline Species & Locus & Name \\
\hline Human $^{a}$ & $3 \mathrm{p} 12$ & HTR1F \\
Rat & $11 \mathrm{p} 12$ & Htr1f \\
Mouse & $16 \mathrm{C} 1.3$ & Htr1f \\
\hline
\end{tabular}

${ }^{a}$ Maassen Vandenbrink et al. (1998).
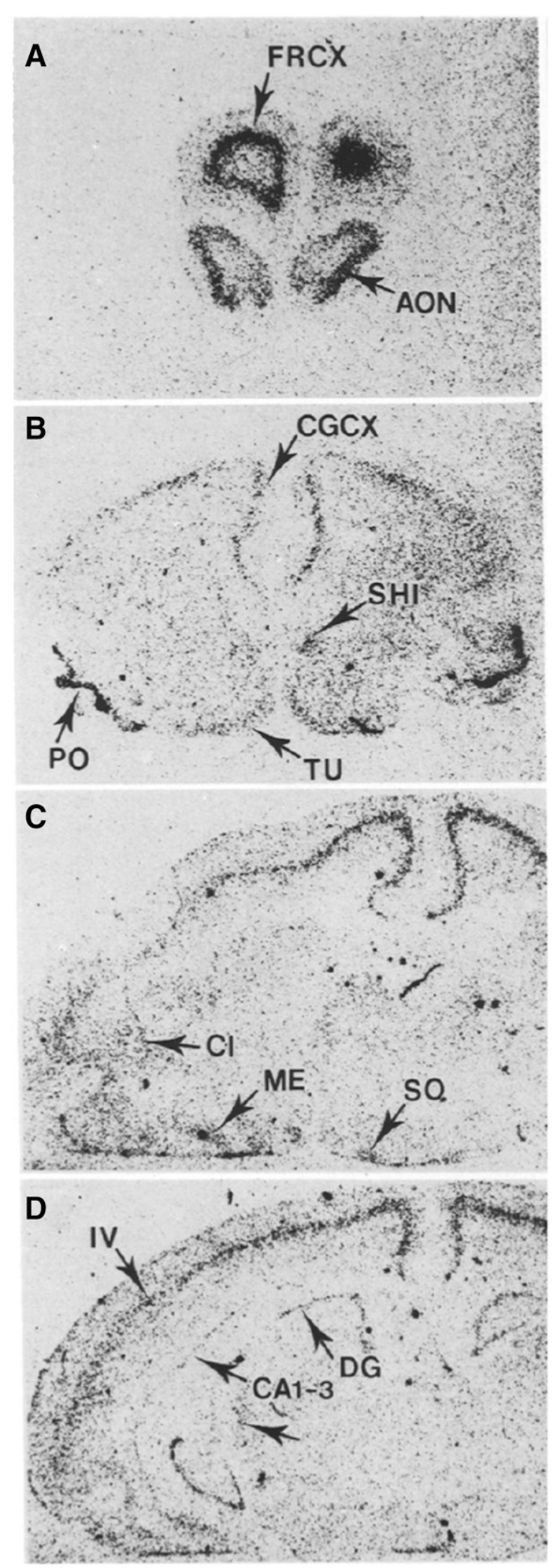

Fig. 7. In situ hybridization detection of $5-\mathrm{HT}_{1 \mathrm{~F}}$ receptor mRNA expression in guinea pig brain. (A) Frontal cortex (FRCX), anterior olfactory nucleus (AON). (B) Cingulate cortex (CGCX), septo-hippocampal nucleus (SHI), olfactory tubercle (TU), primary olfactory cortex (PO). (C) Claustrum (CL), medial amygdaloid nucleus (ME), supraoptic hypothalamic nucleus (SO). (D) Layer IV of the parietal motor cortex (IV), dentate gyrus (DG), and CA1-3 field (CA1-3) of the hippocampus are shown. Adapted from Bruinvels et al. (1994) (with permission). 
TABLE 8

Localization of $5-\mathrm{HT}_{1 \mathrm{~F}}$ receptor mRNA

The most intensely labeled regions or areas of unique interest from the different references are listed in this table. See the original references for a more complete expression profile.

\begin{tabular}{|c|c|c|c|}
\hline Tissue or Cells & Species & Method & Reference \\
\hline Forebrain, hindbrain, spinal cord, cerebellum & Mouse & RT-PCR & Amlaiky et al., 1992 \\
\hline CA1, CA2, CA3 of the hippocampus & Mouse & ISHH & Amlaiky et al., 1992 \\
\hline Brain, uterus, mesentery & Human & RT-PCR & Adham et al., $1993 \mathrm{a}$ \\
\hline $\begin{array}{l}\text { Layer V of cerebral cortex (pyramidal cells), layer VI nonpyramidal cells, CA1-CA3 of the } \\
\text { hippocampus (pyramidal cells), Dorsal raphe (large neurons), Dentate gyrus (granule cells) }\end{array}$ & $\begin{array}{l}\text { Guinea } \\
\text { pig }\end{array}$ & ISHH & Adham et al., 1993a \\
\hline Cerebral cortex, striatum, hippocampus, thalamus, pons, hypothalamus, cerebellum & Rat & RT-PCR & Lovenberg et al., 1993 \\
\hline $\begin{array}{l}\text { Olfactory, cingulate, frontal, and entorhinal cortex (especially layer V), hippocampus } \\
\text { (CA1, CA2, CA3 and dentate gyrus) }\end{array}$ & $\begin{array}{l}\text { Guinea } \\
\text { Pig }\end{array}$ & ISHH & Bruinvels et al., 1994 \\
\hline Claustrum, cerebral cortex, thalamus, striatum & $\begin{array}{l}\text { Guinea } \\
\text { Pig }\end{array}$ & ISHH & Mengod et al., 1996 \\
\hline Trigeminal ganglion & Human & RT-PCR & Bouchelet et al., 1996 \\
\hline Cerebral blood vessels & Human & RT-PCR & Bouchelet et al., 1996 \\
\hline Trigeminal ganglion & $\begin{array}{l}\text { Guinea } \\
\text { pig }\end{array}$ & ISHH & Johnson et al., 1997 \\
\hline Dorsal root ganglia, trigeminal ganglion & $\begin{array}{l}\text { Guinea } \\
\text { pig }\end{array}$ & ISHH & Adham et al., 1997 \\
\hline Dorsal root ganglia & Human & RT-PCR & Pierce et al., 1997 \\
\hline Cerebral cortex, hippocampus, cerebellum, brain stem & Mouse & $\begin{array}{l}\text { Northern } \\
\text { blot }\end{array}$ & Guptan et al., 1997 \\
\hline Hippocampus, cerebral cortex & Rat & $\begin{array}{l}\text { Northern } \\
\text { blot }\end{array}$ & Guptan et al., 1997 \\
\hline Dorsal root ganglia (cultured) & Rat & RT-PCR & Chen et al., 1998 \\
\hline Neonatal and cultured astrocytes & Rat & RT-PCR & Hirst et al., 1998 \\
\hline Coronary arteries, atrium, ventricle, and epicardium & Human & RT-PCR & Nilsson et al., $1999 \mathrm{~b}$ \\
\hline Brain cortical microvessels and capillaries & Human & RT-PCR & Cohen et al., 1999 \\
\hline Astrocytes (cultured) & Human & RT-PCR & Cohen et al., 1999 \\
\hline Immune tissue: spleen, thymus, mitogen-activated spleen cells, and peripheral blood lymphocytes & Rat & RT-PCR & Stefulj et al., 2000 \\
\hline Lumbar dorsal root ganglia & Rat & RT-PCR & Wu et al., 2001 \\
\hline Cerebral cortex, trigeminal ganglion & Pig & RT-PCR & Bhalla et al., 2002 \\
\hline Coronary artery, pulmonary artery, saphenous vein & Pig & RT-PCR & Bhalla et al., 2002 \\
\hline Lumbar dorsal root ganglia & Rat & RT-PCR & Liu et al., 2005 \\
\hline Intestine (four separate regions) & Bovine & RT-PCR & Engel et al., 2006 \\
\hline $\begin{array}{l}\text { Various forebrain areas of embryonic brain, including cerebral cortex, amygdala, globus pallidus, } \\
\text { caudate putamen, hippocampus, dentate gyrus }\end{array}$ & Mouse & ISHH & Bonnin et al., 2006 \\
\hline Midbrain periaqueductal gray & Rat & RT-PCR & Jeong et al., 2008 \\
\hline Neonatal rat: cerebellum, cortex, cortical astrocytes; adult rat: cerebellum, cortex & Rat & RT-PCR & $\begin{array}{l}\text { Osredkar and Kržan, } \\
\qquad 2009\end{array}$ \\
\hline Trigeminal ganglion, trigeminal nucleus caudalis & Rat & RT-PCR & Amrutkar et al., 2012 \\
\hline Renal proximal tubule cells & Rabbit & RT-PCR & Garrett et al., 2014 \\
\hline Heart, liver & Mouse & RT-PCR & Garrett et al., 2014 \\
\hline
\end{tabular}

from all regions examined, including cervical, thoracic, and lumbar. $\mathrm{Ma}(2001)$ reported colocalization of $5-\mathrm{HT}_{1 \mathrm{~F}}$ receptor with glutamate-containing neurons of the trigeminal ganglion, and Ahn et al. (2009) showed colocalization of $5-\mathrm{HT}_{1 \mathrm{~F}}$ receptors with CGRP in neurons of rat vestibular nuclei. Garrett et al. (2014) provide a unique perspective on the $5-\mathrm{HT}_{1 \mathrm{~F}}$ receptor, showing the presence of both mRNA (Table 8) and protein (Table 9) in the rabbit renal proximal tubule.

\section{Pharmacology}

1. Agonists. The $5-\mathrm{HT}_{1 \mathrm{~F}}$ receptor, like the other members of the $5-\mathrm{HT}_{1}$ family, has high affinity for 5-HT itself. This characteristic has driven much of the structural work devoted to developing high-affinity, selective $5-\mathrm{HT}_{1 \mathrm{~F}}$ receptor agonists.

Compared with $5-\mathrm{HT}_{1 \mathrm{~A}}, 5-\mathrm{HT}_{1 \mathrm{~B}}$, and $5-\mathrm{HT}_{1 \mathrm{D}}$ receptors, the pharmacology described for $5-\mathrm{HT}_{1 \mathrm{~F}}$ receptors is rather sparse. Because of a potential link between $5-\mathrm{HT}_{1 \mathrm{~F}}$ receptor activation and the treatment of migraine (see below), most of the effort to develop selective compounds has focused on the development of orthosteric agonists. No selective orthosteric $5-\mathrm{HT}_{1 \mathrm{~F}}$ receptor antagonists have been reported. Likewise, there are no literature descriptions of allosteric $5-\mathrm{HT}_{1 \mathrm{~F}}$ receptor ligands.

Almost all of the structure activity relationship (SAR) work has come from the laboratories of Eli Lilly and Company, which had exclusive rights to the $5-\mathrm{HT}_{1 \mathrm{~F}}$ receptor through a collaborative agreement with the patent holder, Synaptic Pharmaceutical Corporation. Table 10 summarizes published named compounds showing selectivity for the $5-\mathrm{HT}_{1 \mathrm{~F}}$ receptor. Lasmidi$\tan$ (COL-144, LY573144) and LY344864 display very good selectivity for the $5-\mathrm{HT}_{1 \mathrm{~F}}$ receptor relative to all other 5-HT receptors, as does LY334370, except that it is only about eight- to ninefold selective over the $5-\mathrm{HT}_{1 \mathrm{~A}}$ receptor. LY302148 was an early molecule that showed selectivity for the $5-\mathrm{HT}_{1 \mathrm{~F}}$ receptor relative to other $5-\mathrm{HT}_{1}$ subtypes. However, it also has high affinity for $5-\mathrm{HT}_{2 \mathrm{~A}}$ and $5-\mathrm{HT}_{2 \mathrm{~B}}$ receptors (Table 10 ) and is illustrative of the difficulty in identifying 5-HT receptor subtype selectivity in simple indole-based compounds.

Lasmiditan (COL-144, LY573144) is a departure from the other structures in that it contains no indole nucleus. The progression from a bicyclic aromatic nucleus (indole) 
TABLE 9

Localization of $5-\mathrm{HT}_{1 \mathrm{~F}}$ receptor protein using antibodies

\begin{tabular}{|c|c|c|c|}
\hline Tissue or Cells & Species & Method & Reference \\
\hline Trigeminal ganglion neurons & Rat & Immunohistochemistry & $\mathrm{Ma}, 2001$ \\
\hline Superior, lateral, spinal, and medial vestibular nuclei & Rat & Immunohistochemistry & Ahn et al., 2009 \\
\hline $\begin{array}{l}\text { Neurons of trigeminal ganglia and dorsal root ganglia } \\
\text { (C2, C5, T5, and L5 levels) }\end{array}$ & Rat & Immunohistochemistry & Classey et al., 2010 \\
\hline Renal proximal tubule cells & Rabbit & Immunoblot & Garrett et al., 2014 \\
\hline
\end{tabular}

to the monocyclic nucleus of lasmiditan apparently involved some serendipity, as Zhang et al. (2015) describe how, in the process of producing a homolog of LY334370, a monocyclic intermediate was formed that had moderately good affinity for the $5-\mathrm{HT}_{1 \mathrm{~F}}$ receptor. Expanding an SAR around this finding, they discovered several compounds that had high affinity and good selectivity for the $5-\mathrm{HT}_{1 \mathrm{~F}}$ receptor (Zhang et al., 2015). Replacing the indole to eventually generate lasmiditan resulted in a highly selective $5-\mathrm{HT}_{1 \mathrm{~F}}$ receptor agonist.

Several additional studies have generated significant SAR for $5-\mathrm{HT}_{1 \mathrm{~F}}$ receptor agonists (Xu et al., 2001; Filla et al., 2003; Mathes et al., 2004; Zhang et al., 2004). The most potent and selective compounds are included in Table 11. These molecules represent riffs on the indoleethylamine core of 5-HT. For example, compound A (Table 11) employs N,N-dimethyltryptamine as its core, resulting in a molecule that has slightly lower affinity for the $5-\mathrm{HT}_{1 \mathrm{~F}}$ receptor compared with LY334370 but overall greater selectivity. Compounds B, C, D, and E illustrate that the indole nucleus can be replaced with other bicycles (e.g., azaindole, indazole, and indoline), resulting in compounds with very good $5-\mathrm{HT}_{1 \mathrm{~F}}$ receptor affinity and selectivity.

2. Partial Agonists and Antagonists. There are no published SAR studies for $5-\mathrm{HT}_{1 \mathrm{~F}}$ receptor antagonists. Methiothepin has been used in in vitro functional studies, but it is nonselective and of only moderate affinity for the 5- $\mathrm{HT}_{1 \mathrm{~F}}$ receptor (Adham et al., 1993b). 1-naphthylpiperazine and metergoline were described as partial agonists to inhibit adenylyl cyclase activity (Adham et al., 1993a). Other compounds have been reported as partial agonists at $5-\mathrm{HT}_{1 \mathrm{~F}}$ receptorstimulated $\left[{ }^{35} \mathrm{~S}\right] \mathrm{GTP} \gamma \mathrm{S}$ binding, such as dihydroergotamine (68\% of 5-HT; Wainscott et al., 1998), LY302148 (17\% of 5-HT; Wainscott et al., 1998), frovatriptan (46\% of 5-HT; Nelson et al., 2010), 2-thienyl-LYX (61\% of 5-HT; Filla et al., 2003), and 2-pyridyl-LYX (63\% of 5-HT; Filla et al., 2003).

The prototypical triptan, sumatriptan, has relatively high affinity for the $5-\mathrm{HT}_{1 \mathrm{~F}}$ receptor, and for comparison with the selective $5-\mathrm{HT}_{1 \mathrm{~F}}$ compounds, Table 6 lists the affinities of a number of triptans across the 5-HT receptor subtypes. In efficacy studies using a $\left[{ }^{35} \mathrm{~S}\right] \mathrm{GTP} \gamma \mathrm{S}$ binding system to measure functional activity at the $5-\mathrm{HT}_{1}$ family of receptors, naratriptan, rizatriptan, sumatriptan, and zolmitriptan were found to act as full agonists at all the $5-\mathrm{HT}_{1}$ receptors that they stimulated. Frovatriptan, the only carbazole (i.e., a three-ring system containing indole), was a full agonist at $5-\mathrm{HT}_{1 \mathrm{~B}}$ and $5-\mathrm{HT}_{1 \mathrm{D}}$ receptors but only a partial agonist at $5-\mathrm{HT}_{1 \mathrm{~A}}$ and 5-HT $\mathrm{HF}_{1 \mathrm{~F}}$ receptors (Nelson et al., 2010). Hence, several triptans have high affinity for the $5-\mathrm{HT}_{1 \mathrm{~F}}$ receptor and may activate $5-\mathrm{HT}_{1 \mathrm{~F}}$ receptors in vivo at doses sufficient to also activate $5-\mathrm{HT}_{1 \mathrm{~B} / 1 \mathrm{D}}$ receptors (as well as other receptors; Table 6).

\section{E. Signal Transduction}

The $5-\mathrm{HT}_{1 \mathrm{~F}}$ receptor inhibits forskolin-stimulated adenylyl cyclase activity in recombinant cell systems

TABLE 10

Affinities of selective 5 - $\mathrm{HT}_{1 \mathrm{~F}}$ receptor agonists at cloned human 5 -HT receptors

Binding values are expressed as $\mathrm{K}_{\mathrm{i}}$ in nanomolar ( \pm S.E.M. where available) from studies using cloned human receptors. Values in parentheses are the number of individual determinations from the cited references.

\begin{tabular}{|c|c|c|c|c|c|c|}
\hline & LY302148 & LY306258 & LY334370 ${ }^{a}$ & LY344864 ${ }^{b}$ & LY397584 & Lasmiditan $^{a}$ (COL-144, LY573144) \\
\hline Receptor & $K_{\mathrm{i}}, \mathrm{nM}$ & $K_{\mathrm{i}}, \mathrm{nM}$ & $K_{\mathrm{i}} \pm$ S.E.M., nM & $K_{\mathrm{i}}, \mathrm{nM}$ & $K_{\mathrm{i}}, \mathrm{nM}$ & $K_{\mathrm{i}} \pm$ S.E.M., nM \\
\hline $5-\mathrm{HT}_{1 \mathrm{~A}}$ & $12.0^{c}$ & $5370^{c}$ & $16.4 \pm 2.7(9)$ & 530 & $1046^{d}$ & $1053 \pm 134(8)$ \\
\hline $5-\mathrm{HT}_{1 \mathrm{~B}}$ & $53.7^{e}$ & $1698^{e}$ & $189 \pm 25(10)$ & 549 & $723^{d}$ & $1043 \pm 124$ \\
\hline $5-\mathrm{HT}_{1 \mathrm{D}}$ & $21.9^{e}$ & $794.3^{e}$ & $281 \pm 58(10)$ & 575 & $724^{d}$ & $1357 \pm 156$ \\
\hline $5-\mathrm{ht}_{1 \mathrm{e}}$ & $50.1^{c}$ & $73.6^{f}$ & $176 \pm 34(8)$ & 1415 & $776^{c}$ & $594 \pm 59.1(6)$ \\
\hline $5-H_{1 F}$ & $2.5^{e}$ & $10.2^{e}$ & $1.87 \pm 0.34$ & 6 & $\mathbf{5 . 5 ^ { d }}$ & $2.21 \pm 0.22(8)$ \\
\hline $5-\mathrm{HT}_{2 \mathrm{~A}}$ & $5.89^{c}$ & $1072^{c}$ & $1530 \pm 200$ & 3935 & $3890^{c}$ & $>5 \mu \mathrm{M}(6)$ \\
\hline $5-\mathrm{HT}_{2 \mathrm{~B}}$ & $6.17^{c}$ & $1072^{c}$ & $1280 \pm 90(3)$ & 1695 & $6166^{c}$ & $>2 \mu \mathrm{M}(6)$ \\
\hline $5-\mathrm{HT}_{2 \mathrm{C}}$ & $13.5^{c}$ & $813^{c}$ & $3250 \pm 930(3)$ & 3499 & $309^{c}$ & $>3 \mu \mathrm{M}(6)$ \\
\hline $5-\mathrm{HT}_{6}$ & & & $>3 \mu \mathrm{M}(2)$ & & & $>4 \mu \mathrm{M}(6)$ \\
\hline $5-\mathrm{HT}_{7}$ & & & $1550 \pm 260$ & 4851 & & $>3 \mu \mathrm{M}(6)$ \\
\hline
\end{tabular}

${ }^{a}$ Taken from Nelson et al. (2010).

${ }^{b}$ Taken from Phebus et al. (1997).

${ }^{c}$ Taken from Johnson (2005).

${ }^{d}$ Taken from Ramadan et al. (2003) (structure not reported).

${ }^{e}$ Taken from Johnson et al. (1997).

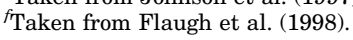


TABLE 11

Affinities of selective $5-\mathrm{HT}_{1 \mathrm{~F}}$ receptor agonists from $\mathrm{SAR}$ studies at cloned human 5-HT receptors

Binding values are expressed as $K_{\mathrm{i}}$ in nanomolar from studies using cloned human receptors.

\begin{tabular}{|c|c|c|c|c|c|}
\hline & Compound $\mathrm{A}^{a}$ & Compound $\mathrm{B}^{b}$ & Compound $\mathrm{C}^{c}$ & Compound $\mathrm{D}^{d}$ & Compound $\mathrm{E}^{e}$ \\
\hline Receptor & $K_{\mathrm{i}} \pm$ S.E.M., nM & $K_{\mathrm{i}} \pm$ S.E.M., nM & $K_{\mathrm{i}} \pm$ S.E.M., nM & $K_{\mathrm{i}}, \mathrm{nM}$ & $K_{\mathrm{i}}, \mathrm{nM}$ \\
\hline $5-\mathrm{HT}_{1 \mathrm{~A}}$ & $265 \pm 99$ & $620 \pm 37$ & $1000 \pm 270$ & 870 & 240 \\
\hline $5-\mathrm{HT}_{1 \mathrm{~B}}$ & $1060 \pm 204$ & $270 \pm 47$ & $720 \pm 220$ & 2300 & $>10 \mu \mathrm{M}$ \\
\hline $5-\mathrm{ht}_{1 \mathrm{e}}$ & $>4830$ & $660 \pm 110$ & $770 \pm 80$ & & \\
\hline $5-\mathbf{H} \mathbf{T}_{1 F}$ & $8.2 \pm 1.2$ & $5.0 \pm 0.5$ & $5.5 \pm 0.6$ & 3.9 & 9 \\
\hline $5-\mathrm{HT}_{2 \mathrm{~A}}$ & $1000 \pm 85$ & $4800 \pm 2000$ & $3400 \pm 1600$ & & \\
\hline $5-\mathrm{HT}_{2 \mathrm{~B}}$ & $676 \pm 118$ & $>10,000$ & $>10,000$ & & \\
\hline $5-\mathrm{HT}_{6}$ & $380 \pm 40$ & $>10,000$ & $1120 \pm 203$ & & \\
\hline $5-\mathrm{HT}_{7}$ & $1770 \pm 130$ & $>5000$ & Not determined & & \\
\hline
\end{tabular}

${ }^{a} \mathrm{~N}$-[3-(2-(dimethylamino)-ethyl)-2-methyl-1H-indol-5-yl]-4-fluorobenzamide, from Xu et al. (2001).

${ }^{b} \mathrm{~N}$-(3-(1-methyl-4-piperidinyl)-1H-pyrrolo(3,2-b)pyridin-5-yl)acetamide, from Filla et al. (2003).

${ }^{c} \mathrm{~N}$-[3-(1-Methyl-4-piperidinyl)-1H-pyrrolo[3,2-b]pyridin-5-yl]propanamide, from Filla et al. (2003),

$d_{4}$-Fluoro-N-[3-(1-methyl-4-piperidinyl)-1H-indazol-5-yl]benzamide, from Zhang et al. (2004).

${ }^{e}$ 4-Fluoro-N-[3-(1-methyl-4-piperidinyl)-2,3-dihydro-1H-indol-5-yl]benzamide, from Zhang et al. (2004).

(Amlaiky et al., 1992; Adham et al., 1993b), with later studies suggesting coupling through Gi/Go proteins based on pertussis toxin sensitivity (Adham et al., 1993a). The human $5-\mathrm{HT}_{1 \mathrm{~F}}$ receptor can also mediate inositol phosphate production and calcium flux through a pertussis toxin-sensitive mechanism in a recombinant system (Adham et al., 1993a). There are no reports on the transduction mechanisms affected by the $5-\mathrm{HT}_{1 \mathrm{~F}}$ receptor in native tissues.

\section{F. Function}

As noted above, signal transduction studies with heterologously expressed $5-\mathrm{HT}_{1 \mathrm{~F}}$ receptor readily identify responses, such as inhibition of forskolin-stimulated adenylyl cyclase activity (Amlaiky et al., 1992; Adham et al., 1993b), stimulation of inositol phosphate production and cellular calcium flux (Adham et al., 1993a), and stimulation of $\left[{ }^{35} \mathrm{~S}\right] \mathrm{GTP} \gamma \mathrm{S}$ binding (Wainscott et al., 1998).

Neurogenic dural inflammation has been used as a model for the development of antimigraine drugs, in which the triptans display efficacy. Early dogma considered the mechanism of action of the triptans to be exclusively through the activation of $5-\mathrm{HT}_{1 \mathrm{~B} / 1 \mathrm{D}}$ receptors (Buzzi and Moskowitz., 1991; Humphrey, 2007). Yet other studies (Johnson et al., 1997; Wainscott et al., 1998) demonstrate that the pharmacologic profile for the inhibition of neurogenic dural inflammation in the guinea pig correlated better with the pharmacology of the $5-\mathrm{HT}_{1 \mathrm{~F}}$ receptor. Several additional studies support that $5-\mathrm{HT}_{1 \mathrm{~F}}$ receptor-selective agonists inhibit neurogenic dural inflammation; LY344864 and lasmiditan inhibit neurogenic dural inflammation in the rat (Phebus et al., 1997; Nelson et al., 2010), and "Compound A, B, and C" likewise in the guinea pig (Xu et al., 2001; Filla et al., 2003).

Several studies have examined the effects of $5-\mathrm{HT}_{1 \mathrm{~F}}$ receptor agonists on $c$-fos levels in the trigeminal system. Intracisternal administration of capsaicin in rats stimulates $c$-fos production in the trigeminal nucleus caudalis, an effect that is inhibited by pretreatment with either sumatriptan or LY344864 (Mitsikostas et al., 1999). The effect of sumatriptan, but importantly not that of LY344864, was blocked by a rat $5-\mathrm{HT}_{1 \mathrm{~B}}$ receptor antagonist. The inhibition of capsaicin-induced c-fos production by LY344864 and sumatriptan was also reproduced in the mouse (Mitsikostas et al., 2002). Electrical stimulation of the trigeminal ganglion in the rat induces $c$-fos production in the nucleus caudalis, which was blocked by lasmiditan in a dose-dependent fashion (Nelson et al., 2010). LY334370 was also active in this model.

Other models of neuronal stimulation have shown that $5-\mathrm{HT}_{1 \mathrm{~F}}$ receptor agonists produce inhibitory effects. For example, LY344864 inhibited a CGRP-mediated vasodepressor response produced by electrical stimulation of primary sensory nerves in the rat (González-Hernández et al., 2011). It did not affect vasodepressor responses induced by exogenously administered CGRP, consistent with the concept that prejunctional $5-\mathrm{HT}_{1 \mathrm{~F}}$ receptors inhibit CGRP release. LY344864 inhibited potassiumstimulated release of CGRP in the dura mater of the rat but not in the trigeminal ganglion or trigeminal nucleus caudalis (Amrutkar et al., 2012). Additionally, LY344864 inhibited activation of second-order neurons in the trigeminal nucleus caudalis elicited by electrical stimulation of the dura mater in rats (Shepheard et al., 1999).

Little work has been devoted to potential peripheral actions of 5-HT $1 \mathrm{~F}$ receptors. Granados-Soto et al. (2010) have suggested that $5-\mathrm{HT}_{1 \mathrm{~F}}$ receptors are involved in peripheral pain mechanisms, as LY344864 blocked nociception induced by formalin injection into the rat paw. In a more direct examination of peripheral tissues LY334370 and LY344864 stimulated the production of markers of mitochondrial biogenesis in isolated rabbit renal proximal tubules, which was diminished when the tubule preparation was subject to $5-\mathrm{HT}_{1 \mathrm{~F}}$ receptor knockdown by siRNA transfection (Garrett et al., 2014). Administration of LY344864 in vivo to mice also led to an increase in a panel of markers for mitochondrial biogenesis in renal cortex, heart, and liver (Garrett et al., 2014). 
Extensive study has failed to demonstrate that 5 -HT $1 \mathrm{~F}$ receptors contract blood vessels (e.g., Johnson et al., 1997; Cohen and Schenck, 1999, 2000; Razzaque et al., 1999; Shepheard et al., 1999; Bouchelet et al., 2000; Nelson et al., 2010). As detailed in III. 5-HT Receptors, this contrasts functions associated with the $5-\mathrm{HT}_{1 \mathrm{~B}}$ receptor, through which triptans act to contract certain vascular tissues, including coronary artery, that can present serious adverse effects for patients, hence the optimism for 5 - $\mathrm{HT}_{1 \mathrm{~F}}$ receptor agonists as treatments for migraine with a reduced side-effect profile (see below).

\section{G. Clinical Relevance and Therapeutics}

As discussed above, because $5-\mathrm{HT}_{1 \mathrm{~F}}$ receptor agonism correlates with the pharmacology of the inhibition of a model of neurogenic dural inflammation-combined with the apparent absence of the $5-\mathrm{HT}_{1 \mathrm{~F}}$ receptor to contract vasculature-much of the translatable work concerning the $5-\mathrm{HT}_{1 \mathrm{~F}}$ receptor has centered on the treatment of migraine. This led, ultimately, to the development of LY334370, the first selective $5-\mathrm{HT}_{1 \mathrm{~F}}$ receptor agonist examined clinically for which efficacy to treat the pain of acute migraine attacks was noted (Goldstein et al., 2001). However, development of LY334370 was terminated because of safety concerns identified in animal toxicology studies (Ramadan et al., 2003; Ramadan and Buchanan, 2006). Further efforts to search for a more selective $5-\mathrm{HT}_{1 \mathrm{~F}}$ receptor agonist with preclincal toxicology issues identified LY573144. This molecule was subsequently out-licensed to CoLucid Pharmaceuticals (becoming COL-144; lasmiditan; Table 10), although the acquisition of CoLucid in 2017 by Eli Lilly returned the molecule to the parent company.

Lasmitidan is efficacious in alleviating symptoms of acute migraine in clinical trials. The first peer-reviewed published trial was a proof-of-concept investigation that demonstrated the efficacy of lasmiditan given intravenously (Ferrari et al., 2010). The primary efficacy measure was headache relief 2 hours after administration; a significant dose-response effect on efficacy separated lasmitidan from placebo. A trial using oral lasmiditan used the same primary efficacy measure, and all doses significantly improved headache response at 2 hours compared with placebo (Färkkilä et al., 2012). The most common side effects were dizziness, fatigue, vertigo, and paresthesia. Positive results from two pivotal phase III trials of lasmitidan (Kuca et al., 2018; Loo et al., 2019) led to subsequent marketing approval in 2019.

\section{5-HT 2A $_{\text {Receptors }}$}

\section{A. Introduction}

The 5 - $\mathrm{HT}_{2 \mathrm{~A}}$ receptor (formerly $5-\mathrm{HT}_{2}$ ) was first identified as a binding site in rat brain with high (nanomolar) affinity for $\left[{ }^{3} \mathrm{H}\right]$ spiperone and $\left[{ }^{3} \mathrm{H}\right]$ ketanserin and low (micromolar) affinity for 5-HT (Peroutka and Snyder,
1979; Leysen et al., 1981). Soon after its discovery, the $5-\mathrm{HT}_{2 \mathrm{~A}}$ receptor was found to mediate several effects of 5-HT in the periphery, including platelet aggregation (De Clerck et al., 1982) and smooth muscle contraction (Cohen et al., 1981; Maayani et al., 1984; Engel et al., 1985). The peripheral $5-\mathrm{HT}_{2 \mathrm{~A}}$ receptors were originally classified as "D-type" 5-HT receptors based on pharmacological evidence (Bradley et al., 1986). The $5-\mathrm{HT}_{2 \mathrm{~A}}$ receptor was also the first 5-HT receptor found to couple to stimulate phosphatidyl inositol hydrolysis (Conn and SandersBush, 1984).

\section{B. Cloning of the Gene}

The first $5-\mathrm{HT}_{2 \mathrm{~A}}$ receptor clone was isolated from rat brain cDNA libraries by homology screening based on the sequence of structurally related $5-\mathrm{HT}_{2 \mathrm{C}}$ receptor (Pritchett et al., 1988; Julius et al., 1990). Functional expression of the cloned receptor confirmed coupling to phosphoinositide hydrolysis and $\mathrm{Ca}^{2+}$ mobilization. The human $5-\mathrm{HT}_{2 \mathrm{~A}}$ receptor was subsequently cloned by Saltzman et al. (1991) and displayed 87\% homology with the rat receptor. The receptor contains 471 amino acids, with five potential glycosylation sites in the $\mathrm{N}$-terminal extracellular domain and 11 potential phosphorylation sites in the C-terminal intracellular domain. The HTR2A gene encoding the human $5-\mathrm{HT}_{2 \mathrm{~A}}$ receptor has been mapped to chromosome 13q14-q21 (Sparkes et al., 1991). Analysis of the genomic structure of the human $5-\mathrm{HT}_{2 \mathrm{~A}}$ receptor revealed that it contains three exons separated by two introns, spanning more than $20 \mathrm{~kb}$ (Chen et al., 1992; Stam et al., 1992). Other species from which the $5-\mathrm{HT}_{2 \mathrm{~A}}$ receptor has been cloned include hamster (Van Obberghen-Schilling et al., 1991), mouse (Yang et al., 1992), and pig and rhesus monkey (Johnson et al., 1995) (Table 12). Sequence alignments for the $5-\mathrm{HT}_{2 \mathrm{~A}}$ receptor from eight species are shown in Fig. 8.

1. Regulation of 5-HT $T_{2 A}$ Receptor Gene Expression. The structure of the $5-\mathrm{HT}_{2 \mathrm{~A}}$ promoter region has been characterized in humans, rats, and mice; the promoters lack canonical TATA or CAAT boxes. Fragments of a $1.6-\mathrm{kb}$ segment from the $5^{\prime}$ flanking region of the human gene showed promoter activity when transfected into receptor-expressing human cell lines (Zhu et al., 1995). The human promoter sequence contains multiple transcription initiation sites, along with several binding sites for transcription factors, including simian virus 40 promoter factor 1 , polyomavirus enhancer activator 3, cAMP response element, and E-box binding proteins. There was also evidence that the $5^{\prime}$ flanking sequence contains an alternative promoter as well as a silencing element upstream from the translation start codon. Falkenberg et al. (2011) subsequently demonstrated that the human promoter contains a glucocorticoid receptor (GR) binding site at position -1420 . Furthermore, the A-allele of the -1438G/A (rs6311) polymorphism is believed to create a binding site for the 
TABLE 12

$5-\mathrm{HT}_{2 \mathrm{~A}}$ receptor genes, transcripts, and proteins

\begin{tabular}{|c|c|c|c|c|c|c|}
\hline \multicolumn{3}{|c|}{ Gene } & \multicolumn{2}{|c|}{ mRNA Transcript } & \multicolumn{2}{|c|}{ Receptor Protein } \\
\hline Organism & Location & Ensembl Gene ID & NCBI RefSeq ID & $\begin{array}{l}\text { Base } \\
\text { Pairs }\end{array}$ & NCBI RefSeq ID & $\begin{array}{l}\text { Amino Acids } \\
\text { (aa) }\end{array}$ \\
\hline Bos taurus (cow) & Ch 12: $16.82-16.88 \mathrm{Mb}$ & ENSBTAG00000013498 & NM_001001157 & $3562 \mathrm{bp}$ & NP_001001157 & 470 aа \\
\hline Equus caballus (horse) & Ch 17: 23.89-23.95 Mb & ENSECAG00000024282 & NM_001081784 & $1413 \mathrm{bp}$ & NP_001075253 & 470 aа \\
\hline Homo sapiens (human) & $\begin{array}{c}\mathrm{Ch} 13: 46.83-46.89 \mathrm{Mb} \\
(13 q 14-q 21)\end{array}$ & ENSG00000102468 & NM_000621 & 5429 bp & NP_000612 & 471 aa \\
\hline $\begin{array}{l}\text { Macaca mulatta (rhesus } \\
\text { macaque) }\end{array}$ & Ch 17: 25.98-26.05 Mb & ENSMMUG00000004210 & NM_001032966 & $1438 \mathrm{bp}$ & NP_001028138 & 471 aа \\
\hline Mus musculus (mouse) & Ch 14: 74.64-74.70 Mb & ENSMUSG00000034997 & NM_172812 & $2971 \mathrm{bp}$ & NP_766400 & 471 aа \\
\hline Rattus norvegicus (rat) & $\begin{array}{c}\text { Ch 15: } 56.66-56.73 \mathrm{Mb} \\
(15 q 11)\end{array}$ & ENSRNOG00000010063 & NM_017254 & $1566 \mathrm{bp}$ & NP_058950 & 471 aa \\
\hline Sus scrofa (pig) & Ch 11: 20.89-20.95 Mb & ENSSSCG00000009406 & NM_214217 & $1432 \mathrm{bp}$ & NP_999382 & 470 aa \\
\hline
\end{tabular}

transcription factor Th1/E47, which reportedly increases promoter activity (Smith et al., 2008).

Multiple cis elements in the mouse $5-\mathrm{HT}_{2 \mathrm{~A}}$ promoter act in a dynamic manner to regulate transcription. The 5 ' flanking region of the mouse $5-\mathrm{HT}_{2 \mathrm{~A}}$ receptor gene contains a basal promoter (located -0.6 to $-2.3 \mathrm{~kb}$ from the translational start site), which includes 11 transcription initiation sites, and binding sites for AP-2 (activating protein 2), polyomavirus enhancer activator 3 , and simian virus 40 promoter factor 1 transcription factors (Ding et al., 1993; Toth et al., 1994). The activity of the basal promoter is attenuated in nonneuronal cells by two upstream repressor elements (extending from -2.3 to $-4.2 \mathrm{~kb}$ ), domains that presumably contain binding sites for transcription-inhibiting factors present in nonneuronal but not in neuronal cell types. Repressed genes can be reactivated in particular cell types via cell-specific activators, which may be responsible for $5-\mathrm{HT}_{2 \mathrm{~A}}$ receptor expression in certain nonneuronal cells. For example, Ding et al. (1993) identified a domain located upstream $(-4.2$ to $-5.6 \mathrm{~kb})$ from the repressor elements that reactivates transcription of the $5-\mathrm{HT}_{2 \mathrm{~A}}$ gene in $\mathrm{C} 6$ glioma cells.

The organization of the rat $5-\mathrm{HT}_{2 \mathrm{~A}}$ promoter is similar to that of mice, containing multiple negative and positive regulatory elements. Garlow et al. (1994) identified a primary transcription initiation site -1173 from the translational start site and a minimal promoter sequence in the $0.2-\mathrm{kb}$ sequence immediately upstream from the primary initiation site. The activity of the minimal promoter is enhanced by proximal positive transitional elements $0.2-1.1 \mathrm{~kb}$ from the initiation site and attenuated by two distal negative domains located further upstream (1.1-2.2 and 2.3$2.5 \mathrm{~kb}$ from the initiation site, respectively). Analysis of the promoter and enhancer sequences revealed the presence of binding sites for the transcription factors nuclear factor 1, AP-1, AP-2, and Egr 1 as well as a GR element (Garlow et al., 1994; Garlow and Ciaranello, 1995). Experiments with transfected promoter-reporter plasmids showed that dexamethasone and AP-1 affected transcription of the promoter (Garlow and Ciaranello, 1995). The GR element appears to regulate $5-\mathrm{HT}_{2 \mathrm{~A}}$ receptor transcription in rat brain, as evidenced by the significant increase in $5-\mathrm{HT}_{2 \mathrm{~A}}$ mRNA expression induced by GR knockdown (Islam et al., 2004). AP-1 may play a role in agonist-induced upregulation of the $5-\mathrm{HT}_{2 \mathrm{~A}}$ receptor in rat cerebellar granule cells (Chalecka-Franaszek et al., 1999). In contrast, Du et al. $(1994,1995)$ reported that the primary $5-\mathrm{HT}_{2 \mathrm{~A}}$ transcriptional start site in rat myometrial smooth muscle cells is located at position -1120 from the translational start site. They also identified a basal promoter and two upstream repressor domains, but no enhancer region was detected. These discrepant findings may reflect cell type-specific differences in the function of the rat $5-\mathrm{HT}_{2 \mathrm{~A}}$ promoter.

\section{Distribution}

Many cell types in peripheral tissues express $5-\mathrm{HT}_{2 \mathrm{~A}}$ receptors, including platelets, fibroblasts, lymphocytes, and myocytes. In the CNS, neurons are the main site of localization, although the presence of $5-\mathrm{HT}_{2 \mathrm{~A}}$ receptors on nonneuronal cells types (glia, astrocytes) has also been reported (see below). The localization of $5-\mathrm{HT}_{2 \mathrm{~A}}$ receptors in the brain has been mapped by a combination of receptor autoradiography, in situ hybridization, immunocytochemistry, and, more recently, PET neuroimaging. Receptor autoradiography studies using $\left[{ }^{3} \mathrm{H}\right]$ spiperone, $\left[{ }^{3} \mathrm{H}\right]$ ketanserin, $\left[{ }^{125} \mathrm{I}\right] \mathrm{DOI}$, and $\left[{ }^{3} \mathrm{H}\right] \mathrm{MDL}$ 100907 as radioligands have revealed high levels of $5-\mathrm{HT}_{2 \mathrm{~A}}$ receptor binding sites in many forebrain regions, including cortical and hippocampal areas, the basal ganglia, and olfactory tubercle, and the pattern is similar across species (e.g., Pazos et al., 1987b and López-Giménez et al., 1997). The distribution of 5- $\mathrm{HT}_{2 \mathrm{~A}}$ receptor binding sites agrees well with that of $5-\mathrm{HT}_{2 \mathrm{~A}}$ mRNA (Mengod et al., 1990b; Morilak et al., 1994; Burnet et al., 1995), suggesting that $5-\mathrm{HT}_{2 \mathrm{~A}}$ receptors are largely expressed in the region of the somatodendritic and not trafficked along axons; however, there are some conflicting immunohistochemical data (for review, see Weber and Andrade, 2010; Nocjar et al., 2015). Moreover, much 5- $\mathrm{HT}_{2 \mathrm{~A}}$ receptor immunoreactivity in rat neocortex has been detected in the cytoplasmic rather than membrane-bound compartments (CorneaHébert et al., 1999, 2002), which might reflect a high 


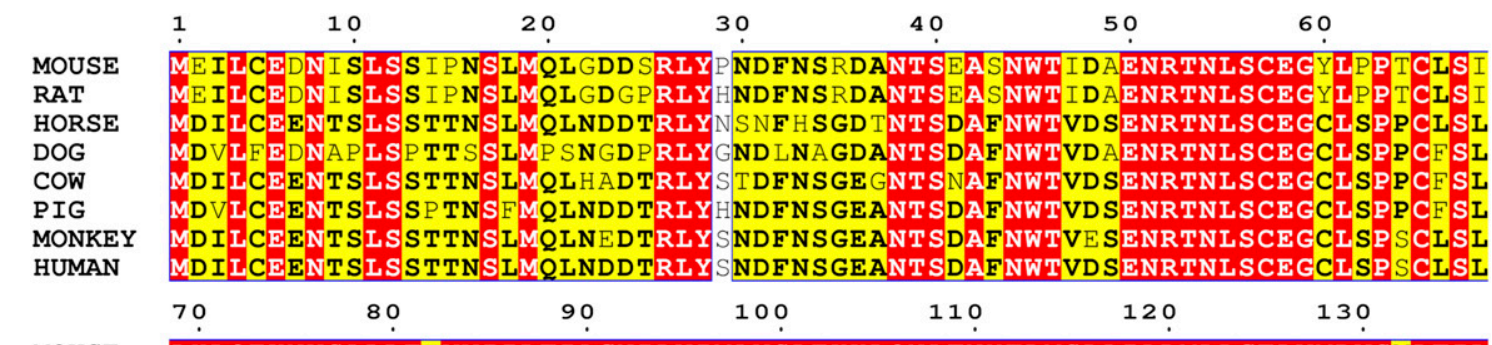

$\begin{array}{ll}\text { MOUSE } & \text { LHLQEKNWSALLTTVVIILTIAGNI LVIMAVSLEKKLQNATNYF LMS LA I ADMLLGF LVMPVSMLT I I } \\ \text { RAT } & \text { LHLOEKNWSALLTTVVI I TT I GNI LVIMAVSLEKKLONATNYF LMSLA I ADMLLGF LVMPVSMLT I I }\end{array}$ HORSE LHLQEKNWSALLTTVVIILTIAGNI LVIMAVSLEKKLQNATNYF LMSLA IADMLLGE LVMPVSMITII

DOG LHLQEKNWSALLTAVVIILTIAGNI LVIMAVSLEKKLQNATNYF LMSLA I ADMLLGE LVMPVSMLT I I COW LHLQEKNWSALLTAVVI I LTIAGNI LV IMAVS LEKKLQNATNYF LMS LA I ADMLLGE LVMPVST IT I I PIG LHLQEKNWSALLTAVVIILTIAGNILVIMAVS LEKKLQNA TNYF LMS LA I ADMLLGE LVMPVSMLT I I MONKEY LHLQEKNWSALLTAVVIILTIAGNILVIMAVSLEKKLQNATNYF LMS LA I ADMLLGF LVMPVSMLT I I HUMAN LHLQEKNWSALLTAVVI I LTIAGN I IVIMAVSLEKKLONA TNYF LMS LA I ADMLLGE LVMPVSMLT IL

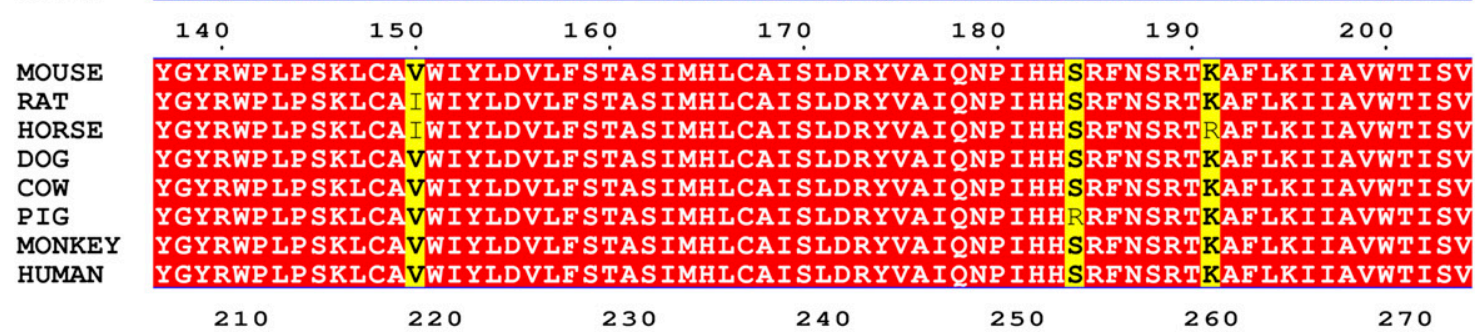

MOUSE GISMPIPVFGLQDDSKVFKEGSCLLADDNFVLIGSFVAFF IPLTIMVI TYFLTIKSLQKEATLCVSDI RAT GISMPIPVEGLODD KVEKEGSCLLADDNFVLI GSFVAFF IPLTIMVITYFLTIKSLOKEATLCVSDI HORSE GISMPVPVEGLQDDSKVFKEGSCLLADDNFVLIGSFVAFFIPLTIMVITYFLTIKSLQKEATLCVNDI DOG GISMPIPVEGLQDDSKVFKEGSCLLADDNFVLIGSFVSFFIPLTIMVITYFLTIKSLQKEATLCVSDP COW GISMPIPVFGLQDDSKVFKEGSCLLADENFVLI GSFVAFF IPLTIMVITYFLTIKSLQKEATLCVSDP PIG GISMPIPVEGLQDDSKVEKEGSCLLADDNFVLIGSFVSEF I P L T IMVI TYFLT I KSLQKEATLCVSDI MONKEY GISMPIPVEGLQDDSKVEKEGSCLLADDNFVLIGSFVSFFIPLTIMVITYELTIKSLQKEATLCVSDL HUMAN GI SMPIPVEGLQDDSKVFKEGSCLLADDNFVLIGSFVSFF IPLTIMVITYFLTIKSLQKEATLCVSDL

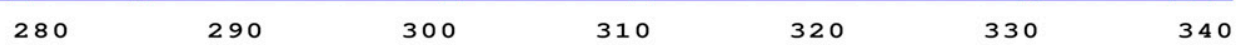

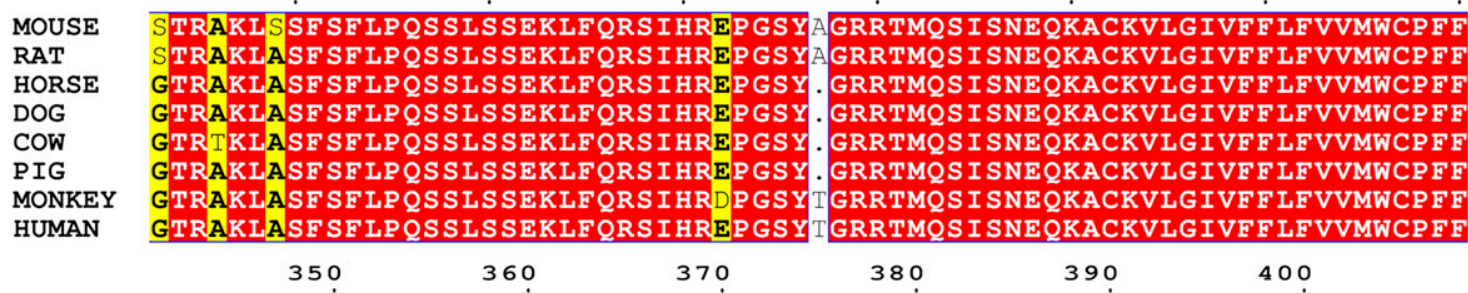

MOUSE ITNIMAVICKESCNENVIGALLLNVFVWIGYLSSAVNP LVYTLFNKTYRSAFSRY I QCQYKENRKPLQI RAT ITNIMAVICKESCNENVIGALLNVFVWI GYLSSAVNP LVYTLFNKTYRSAF SRY I QCQYKENRKP LQI HORSE ITNIMAVMCKESCNEEVIGALLNVFVWI GYLSSAVNP LVYTLFNKTYRSAFSRY IQCQYKENKKP LQI DOG ITNIMAVICKESCNEDIIGALLNVEVWIGYLSSAVNP LVYTLFNKTYRSAFSRYIQCQYKENKKPLQI COW ITNIMAVICKESCNRDVIEALLNVFVWI GYLSSAVNP LVYTLFNKTYRSAF SRY I QCQYKENKKP LQI PIG ITNIMAVICKESCNEDVIGALLNVFVWIGYLSSAVNP LVYTLFNKTYRSAF SRY IQCQYKENKKP LQI MONKEY ITNIMAVICKESCNEDVI GALLNVFVWIGYLSSAVNP LVYTLFNKTYRSAFSRYIQCQYKENKKPLQI HUMAN ITNIMAVICKESCNEDVIGALLNVEVWIGYLSSAVNP LVYT LFNKTYRSAF SRY I QCOYKENKKP LQL
410
420
430
440
450
460
470

MOUSE ILVNTIPTLAYKSSQLQVGQKKNSQEDAET ANDCSMVT LENQHSEEMCTDNIETVNEKVSCV

RAT ILVNTIPALAYKSSQLQVGQKKNSQEDAEQTVDDCSMVTLGKQQSEENCTDNIETVNEKVSCV

HORSE ILVNTIPTLAYKSSQLQMGQNKNSKKDAKMTDNDC TMVALGKQC S DAPTDK INTVNEKVSCV

DOG ILVNTIPALAYKSSQLQMEQKKNSKKDAK T DND Y SMVALGKQHSEDAPTDN INTVNEKVSCV

COW ILVNTIPALAYKSSQLQMEPKKNSKKDDKTTDNDCTMVALGKEHP DAPADS SNTVNEKVSCV

PIG ILVNTIPALAYKSSQLQTGQKENSKQDDKATENDC TMVALGKQHSEDAPADNSNTVNEKVSCV

$\begin{array}{ll}\text { MONKEY } & \text { I LVNT I PALAYKS SQLQMEQKKNSKQDAKT TDNDCSMVALGKQHSEDASKDNSD GVNEKVSCV } \\ \text { HUMAN } & \text { ILVNTIPALAYKSSOLOMEOKKNSKODAKTTDNDCSMVALGKOHSFEASKDNSDGVNEKVSCV }\end{array}$

Fig. 8. Primary structure of $5-\mathrm{HT}_{2 \mathrm{~A}}$ receptors from various species.

intracellular reserve of the $5-\mathrm{HT}_{2 \mathrm{~A}}$ receptors and could be useful for the dynamic insertion of these receptors into the membrane.

A combination of immunocytochemical and in situ hybridization studies have investigated the cell types expressing the $5-\mathrm{HT}_{2 \mathrm{~A}}$ receptor in cerebral cortex (Fig.
9). Early data demonstrated the presence of $5-\mathrm{HT}_{2 \mathrm{~A}}$ receptors in cortical glutamatergic pyramidal (projection) neurons (Burnet et al., 1995), which have subsequently been mapped to specific cortical pathways (Vázquez-Borsetti et al., 2009; Mocci et al., 2014). Most such studies indicate that these cortical $5-\mathrm{HT}_{2 \mathrm{~A}}$ 
receptors are predominantly postsynaptic and localized to either the apical dendrites or soma of pyramidal neurons. However, $5-\mathrm{HT}_{2 \mathrm{~A}}$ receptors have also been detected in GABAergic interneurons in the cortex (Morilak et al., 1994; Burnet et al., 1995; Mengod et al., 2015) and amygdala. There has also been an immunohistochemical analysis of $5-\mathrm{HT}_{2 \mathrm{~A}}$ receptor localization in the ventral tegmental area, and the majority of immunolabeling was colocalized with tyrosine hydroxlyase, suggesting that the receptors are expressed on dopaminergic neurons; however, there is also evidence for localization on VTA GABA neurons (Doherty and Pickel, 2000; Nocjar et al., 2002).

More recently, $5-\mathrm{HT}_{2 \mathrm{~A}}$ receptor localization has been mapped using bacterial artificial chromosome (BAC) transgenic mice engineered to express a fluorescent reporter (enhanced green fluorescent protein) under the control of the $5-\mathrm{HT}_{2 \mathrm{~A}}$ receptor promoter, thus revealing $5-\mathrm{HT}_{2 \mathrm{~A}}$ expression (Weber and Andrade, 2010). These data show a striking pattern of $5-\mathrm{HT}_{2 \mathrm{~A}}$ receptor distribution at the regional and cellular levels. Mapping within the cortical microcircuitry revealed $5-\mathrm{HT}_{2 \mathrm{~A}}$ receptor expression in specific lamina and in both pyramidal and interneurons. Interestingly, and in agreement with previous observations (Puig et al., 2010), expression was marked in cortical parvalbumin-positive interneurons, which underpin the formation of certain network oscillations (gamma frequency) thought critical for sensory information processing. The BAC transgenic mouse study and previous immunocytochemical studies (Stein et al., 2000; Weber and Andrade, 2010) also found $5-\mathrm{HT}_{2 \mathrm{~A}}$ receptors are located on parvalbumincontaining interneurons in the basolateral nucleus of the amygdala. This finding is consistent with data from electrophysiological studies showing that in the amygdala, 5-HT acts on $5-\mathrm{HT}_{2 \mathrm{~A}}$ receptors to potentiate GABAergic inhibition, including the GABA input to pyramidal neurons in this region (Jiang et al., 2009; Bocchio et al., 2015).

The study of BAC transgenic mice with enhanced green fluorescent protein under the control of the $5-\mathrm{HT}_{2 \mathrm{~A}}$ receptor promoter (Weber and Andrade, 2010) did not report the presence of $5-\mathrm{HT}_{2 \mathrm{~A}}$ receptors in nonneuronal cells, as suggested in earlier immunocytochemical studies (Xu and Pandey, 2000); however, further confirmation is awaited. Colocalization of $5-\mathrm{HT}_{2 \mathrm{~A}}$ receptors with other 5 -HT receptor subtypes has been reported $\left(5-\mathrm{HT}_{1 \mathrm{~A}}\right.$, 5-HT $\mathrm{HC}_{2 \mathrm{C}}$; e.g., Puig et al., 2010; Stephens et al., 2014; Mengod et al., 2015; Nocjar et al., 2015; Tian et al., 2016), providing further evidence of potential crosstalk in 5-HT signaling at the receptor level.

The development of a number of $5-\mathrm{HT}_{2 \mathrm{~A}}$ receptorselective radioligands has been useful for research tools, such as the imaging of $5-\mathrm{HT}_{2 \mathrm{~A}}$ receptors in humans, with the most successful including the single-photon emission computerized tomography radioligand $\left[{ }^{123} \mathrm{I}\right]$ $\mathrm{R} 91150$ and the PET radioligands $\left[{ }^{18} \mathrm{~F}\right]$ setoperone, $\left[{ }^{18} \mathrm{~F}\right]$ altanserin, and $\left[{ }^{11} \mathrm{C}\right] \mathrm{MDL} 100907$ (Paterson et al., 2013; Herth and Knudsen, 2015). The first $5-\mathrm{HT}_{2 \mathrm{~A}}$ receptor agonist PET ligand, $\left[{ }^{11} \mathrm{C}\right] N$-(2-methoxybenzyl)-2,5-dimethoxy-4-bromophenethylamine $\left(\left[{ }^{11} \mathrm{C}\right] \mathrm{Cimbi}-36\right)$, has recently been reported (Ettrup et al., 2014) and raised
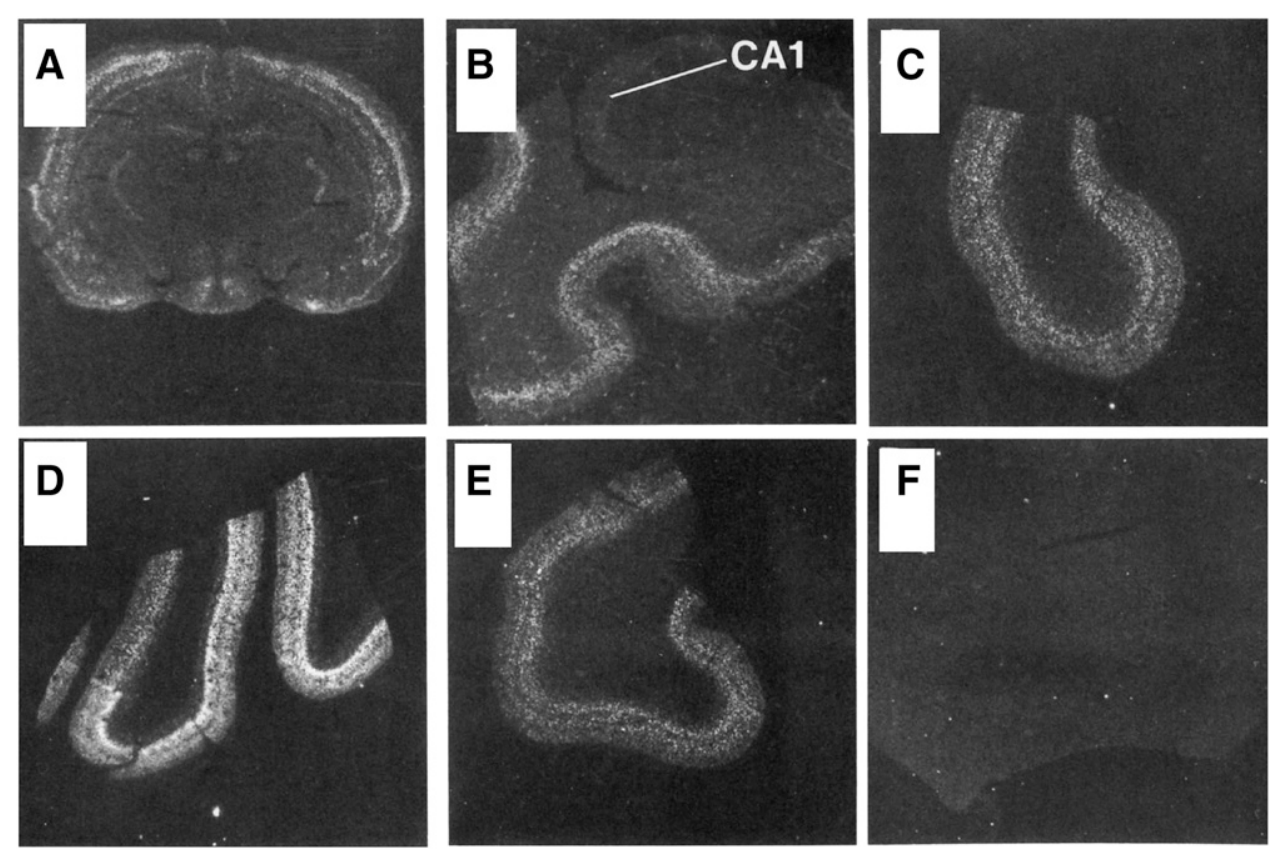

Fig. 9. In situ hybridization detection of 5- $\mathrm{HT}_{2 \mathrm{~A}}$ receptor mRNA expression in rat and human brain. Reverse autoradiograms of the rat (A) and human brain (B-F). Human section: hippocampus and surrounding cortex (B), orbitofrontal cortex (Brodmann area 11) (C), striate cortex (Brodmann area 17) (D), superior temporal gyrus (Brodmann area 22) (E), and brainstem at the level of the raphe nucleus (F); no lack of 5-HT $2 \mathrm{~A}$ receptor mRNA was evident. Adapted from Burnet et al. (1995) (with permission). 
the interesting possibility that this may be displaceable by endogenous 5 -HT and therefore provide an index of 5-HT release. $\left[{ }^{18} \mathrm{~F}\right]$ Altanserin PET has also been used to quantify 5-HT release (Quednow et al., 2012). A potential confound for the development of $5-\mathrm{HT}_{2 \mathrm{~A}}$ receptor $\mathrm{PET}$ ligands is the reported high levels of $5-\mathrm{HT}_{2 \mathrm{~A}}$ receptors in the intracellular compartment (see above). If the significant levels of PET binding are intracellular, then it is less likely to be in a position to be displaced by endogenous 5-HT. However, collectively, these imaging studies confirm the cross-species localization of $5-\mathrm{HT}_{2 \mathrm{~A}}$ receptor and, more importantly, have opened the way for investigations of $5-\mathrm{HT}_{2 \mathrm{~A}}$ receptors in disease states.

\section{Post-translational Modifications and Impact}

$\mathrm{N}$-Glycosylation is known to regulate the intracellular sorting, surface expression, ligand binding, and signal transduction of GPCRs (Couvineau et al., 1996; Michineau et al., 2004). The extracellular $N$-terminus of the $5-\mathrm{HT}_{2 \mathrm{~A}}$ receptor contains five potential $N$-glycosylation sites; glycosylation is apparently required for the $5-\mathrm{HT}_{2 \mathrm{~A}}$ receptor to be targeted to the cell surface (Maginnis et al., 2010). Multiple proteins have been shown to interact with the $5-\mathrm{HT}_{2 \mathrm{~A}}$ receptor (Table 13; see also XVII. 5-HT GPCRs and their Interacting Proteins).

\section{E. Pharmacology}

The three members of the $5-\mathrm{HT}_{2}$ receptor family share significant sequence homology (Fig. 10). Depending on the species examined, the seven transmembrane domains of $5-\mathrm{HT}_{2 \mathrm{~A}}$ and $5-\mathrm{HT}_{2 \mathrm{C}}$ receptors display $79 \%-80 \%$ amino acid sequence conservation. Because of the high degree of structural homology, not surprisingly, $5-\mathrm{HT}_{2 \mathrm{~A}}$ and $5-\mathrm{HT}_{2 \mathrm{C}}$ receptor binding affinities are highly correlated (Glennon et al., 1992a,b, 1994; Nelson et al., 1999). It is now recognized that most of the antagonists that have traditionally been used to block $5-\mathrm{HT}_{2 \mathrm{~A}}$ receptors, including $N$-alkylpiperidines (e.g., ketanserin, ritanserin, pirenperone, and altanserin), ergolines (e.g., methysergide, metergoline, and LY53857), and tricyclic benzocycloheptenes (e.g., cyproheptadine and pizotifen), are also active at $5-\mathrm{HT}_{2 \mathrm{C}}$ receptor (Newton et al., 1996; Hoyer, 1988a,b). For example, altanserin is only 20 -fold selective for 5 - $\mathrm{HT}_{2 \mathrm{~A}}$ versus $5-\mathrm{HT}_{2 \mathrm{C}}$ receptor sites (Table 14). Ketanserin has been used extensively for reported pharmacological definition of $5-\mathrm{HT}_{2 \mathrm{~A}}$ receptor responses and does show some selectivity for $5-\mathrm{HT}_{2 \mathrm{~A}}$ receptor $\left(\mathrm{p} K_{\mathrm{i}}=8.7\right)$ compared with $5-\mathrm{HT}_{2 \mathrm{~B}}\left(\mathrm{p} K_{\mathrm{i}}=6.4\right)$ and $5-\mathrm{HT}_{2 \mathrm{C}}\left(\mathrm{p} K_{\mathrm{i}}=6.8\right)$ receptors (Wainscott et al., 1996). However, ketanserin also has moderate affinity for adrenergic $\left(\alpha_{1}\right)$ and histaminergic $\left(\mathrm{H}_{1}\right)$ receptors as well as $5-\mathrm{HT}_{1 \mathrm{D}}$ receptors and the vesicular monoamine transporter (Erickson et al., 1996; Leysen et al., 1996; Bucholtz et al., 1999; Yoshio et al., 2001), which can complicate interpretation of arising data. Ritanserin is even less selective for $5-\mathrm{HT}_{2 \mathrm{~A}}$ versus $5-\mathrm{HT}_{2 \mathrm{C}}$ receptors and also interacts with $5-\mathrm{HT}_{1 \mathrm{D}}$, $5-\mathrm{HT}_{6}, 5-\mathrm{HT}_{7}, \mathrm{D}_{2}, \mathrm{D}_{3}, \mathrm{D}_{4}, \mathrm{H}_{1}$, and $\alpha_{1}$ sites (Bard et al., 1993; Monsma et al., 1993; Shen et al., 1993; Leysen et al., 1996; Seeman and Tallerico, 1998; Yoshio et al., 2001). The butyrophenone neuroleptic spiperone displays 500- to 2000 -fold selectivity for $5-\mathrm{HT}_{2 \mathrm{~A}}$ versus $5-\mathrm{HT}_{2 \mathrm{C}}$ and has often been used to discriminate those receptors, but it binds to numerous other receptors, including dopaminergic $\mathrm{D}_{2}, \mathrm{D}_{3}$, and $\mathrm{D}_{4}$; adrenergic $\alpha_{1}$ and $\alpha_{2}$; and 5 - $\mathrm{HT}_{1 \mathrm{~A}}$ and $5-\mathrm{HT}_{7}$ receptors (Ruat et al., 1993b; Tang et al., 1994; Metwally et al., 1998; Corradetti et al., 2005). The spiperone derivative AMI-193 (8-[3-(4-fluorophenoxy)propyl]-1-phenyl-1,3,8-triazaspiro[4,5]decan-4-one) is twice as selective as spiperone for $5-\mathrm{HT}_{2 \mathrm{~A}}$ versus $5-\mathrm{HT}_{2 \mathrm{C}}$ but retains nanomolar affinity for $\mathrm{D}_{2}$ and $5-\mathrm{HT}_{1 \mathrm{~A}}$ (Ismaiel et al., 1993). Atypical antipsychotics such as risperidone, olanzapine, and clozapine block $5-\mathrm{HT}_{2 \mathrm{~A}}$ receptors with high affinity but generally have limited selectivity versus $5-\mathrm{HT}_{2 \mathrm{C}}$ and dopamine receptors. By contrast, haloperidol and other typical antipsychotics have higher affinity for dopamine $\mathrm{D}_{2}$ receptors than for $5-\mathrm{HT}_{2 \mathrm{~A}}$ receptors.

The 4-carbinolpiperidines volinaserin (MDL 100907, M100907) and glemaserin (MDL 11939) were the first truly selective $5-\mathrm{HT}_{2 \mathrm{~A}}$ receptor antagonists. Volinaserin

TABLE 13

Proteins reported to interact with the $5-\mathrm{HT}_{2 \mathrm{~A}}$ receptor

\begin{tabular}{|c|c|c|}
\hline Interacting Protein & Region of the $5-\mathrm{HT}_{2 \mathrm{~A}}$ Receptor & Reference \\
\hline ADP-ribosylation factor 1 (Arf1) & C-terminus (NPxxY motif) & Robertson et al., 2003; Johnson et al., 2006 \\
\hline$\beta$-arrestin & ICL3, C-terminus (ASK motif ${ }^{a}$ ) & Gelber et al., 1999; Bhattacharya et al., 2010 \\
\hline Calmodulin (CaM) & ICL2, C-terminus & Turner and Raymond, 2005 \\
\hline Caveolin-1 (Cav-1) & ND & Bhatnagar et al., 2004 \\
\hline Glutamine synthetase & ICL3 & Sheffler et al., 2006 \\
\hline Jak2 kinase & ND & Guillet-Deniau et al., 1997 \\
\hline Microtubule-associated protein 1A (MAP1A) & ICL3 & Sheffler et al., 2006 \\
\hline Multi-PDZ domain protein 1 (MUPP1) & C-terminus (PDZ domain) & Jones et al., 2009 \\
\hline $\mathrm{Na}^{+} / \mathrm{H}^{+}$exchange regulatory factor 3 (NHERF3) & ND & Walther et al., 2015 \\
\hline Nucleoside-diphosphate kinase 3 (NME3) & ICL3 & Sheffler et al., 2006 \\
\hline Paraoxonase 2 (PON2) & ICL3 & Sheffler et al., 2006 \\
\hline Postsynaptic density protein $95 \mathrm{kDa}$ (PSD-95) & C-terminus (PDZ domain) & Xia et al., 2003 \\
\hline Protein phosphatase 5 (PP-5) & ICL3 & Sheffler et al., 2006 \\
\hline Ribosomal S6 kinase 2 (RSK2) & ICL3 & Sheffler et al., 2006 \\
\hline Synapse-associated protein 97 (SAP97) & C-terminus (PDZ domain) & Dunn et al., 2014 \\
\hline
\end{tabular}

C-terminus, carboxyl-terminus; ICL2, second intracellular loop; ICL3, third intracellular loop; ND, not determined.

${ }^{a}$ Specific to the human and monkey $5-\mathrm{HT}_{2 \mathrm{~A}}$ receptor. 
has subnanomolar affinity for $5-\mathrm{HT}_{2 \mathrm{~A}}$ and 50- to 100 -fold lower affinity for $5-\mathrm{HT}_{2 \mathrm{C}}$ and $\alpha_{1}$ receptors, with negligible affinity for other investigated sites (Palfreyman et al., 1993; Kehne et al., 1996). In contrast to most $5-\mathrm{HT}_{2 \mathrm{~A}}$ receptor antagonists, the selectivity of M100907 for $5-\mathrm{HT}_{2 \mathrm{~A}}$ versus $5-\mathrm{HT}_{2 \mathrm{C}}$ receptors has been verified in mice (Canal et al., 2013). Compared with volinaserin, glemaserin displays even greater selectivity for $5-\mathrm{HT}_{2 \mathrm{~A}}$ receptor $\left(K_{\mathrm{i}}=2.893 \mathrm{nM}\right)$ versus $5-\mathrm{HT}_{2 \mathrm{~B}}\left(K_{\mathrm{i}}=1419 \mathrm{nM}\right)$, $5-\mathrm{HT}_{2 \mathrm{C}}\left(K_{\mathrm{i}}=853.6 \mathrm{nM}\right)$, and $\alpha_{1}\left(K_{\mathrm{i}}=588 \mathrm{nM}\right)$ receptor sites (Dudley et al., 1988; Pehek et al., 2006). Like most drugs that block $5-\mathrm{HT}_{2 \mathrm{~A}}$ receptor responses, volinaserin and glemaserin were initially thought to be neutral antagonists but are now known to act as inverse agonists (Weiner et al., 2001; Aloyo et al., 2009). Although it was previously difficult to conclusively discriminate responses mediated by individual $5-\mathrm{HT}_{2}$ receptor subtypes in vitro and in vivo, volinaserin or glemaserin at appropriate concentrations in combination with selective $5-\mathrm{HT}_{2 \mathrm{~B}}$ and $5-\mathrm{HT}_{2 \mathrm{C}}$ receptor antagonists, such as RS-127445 and SB-242084, respectively, allow such pharmacological investigations.
In contrast to initial reports, it is now recognized that the $5-\mathrm{HT}_{2 \mathrm{~A}}$ receptor has high affinity for $5-\mathrm{HT}$. For example, 5-HT competes for the agonist radioligand $\left[{ }^{3} \mathrm{H}\right] \mathrm{DOB}$ with a $K_{\mathrm{i}}$ of $6.13 \mathrm{nM}$ (Titeler et al., 1985), and $\left[{ }^{3} \mathrm{H}\right] 5-\mathrm{HT}$ reportedly radiolabels the $5-\mathrm{HT}_{2 \mathrm{~A}}$ receptor with $K_{\mathrm{d}}=1.3 \mathrm{nM}$ (Sleight et al., 1996). In contrast, competition binding experiments with antagonist radioligands tend to underestimate the affinity of $5-\mathrm{HT}_{2 \mathrm{~A}}$ receptor agonists; $5-\mathrm{HT}_{2 \mathrm{~A}}$ receptors exist in low-affinity and high-affinity agonist binding conformations depending on whether they are coupled to $\mathrm{G}$ proteins, and only a small fraction of $5-\mathrm{HT}_{2 \mathrm{~A}}$ receptors are in the $\mathrm{G}$ protein-coupled, agonist highaffinity conformation at any given time. $5-\mathrm{HT}_{2 \mathrm{~A}}$ receptor antagonists bind to both conformations with equal affinity (Lyon et al., 1987; Glennon et al., 1988). Therefore, the apparent affinity of $5-\mathrm{HT}_{2 \mathrm{~A}}$ receptor agonists varies depending on the intrinsic activity of the radioligand used to label the receptor, with agonists displaying 10- to 100-fold higher affinity for agonistlabeled receptors versus antagonist-labeled receptors
$5-\mathrm{HT} 2 \mathrm{~B}$
$5-\mathrm{HT} 2 \mathrm{~A}$

5-HT2C

$5-\mathrm{HT} 2 \mathrm{~B}$

5-HT2A

$5-\mathrm{HT} 2 \mathrm{C}$

5-HT2B

5-HT2A

5-HT2C

5-НT2B

5-HT2A

5-HT2C

5-HT2B

5-HT2A

5-HT2C

5-НT2B

5-HT2A

5-HT2C

5-НT2B

5-HT2A

5-HT2C

5-HT2B

5-HT2A

5-HT2C

5-НT2B

5-HT2A

5-HT2C

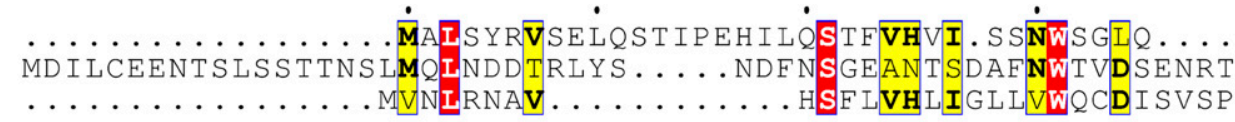

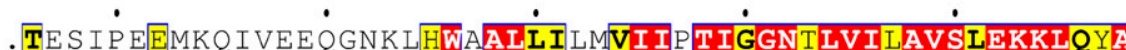
NLS.CEGCL . . SP SCL S L L H LEKNWSALITAVVI I T IAGNI LVIMAVSLEKKLQNA VAA IVTD I F NTSD GGRF KF P D GVNWPALS IVIII IMI I GGNIIVIMAVSMEKKLHNA

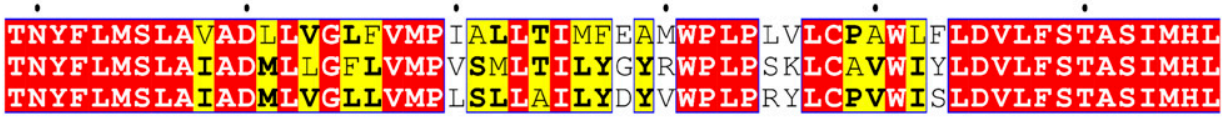
TNYF LMS LA IADMLVGLLVMP LSLLA I L YD YVWP LP R Y LCPVWI S LDVLF STAS IMHL

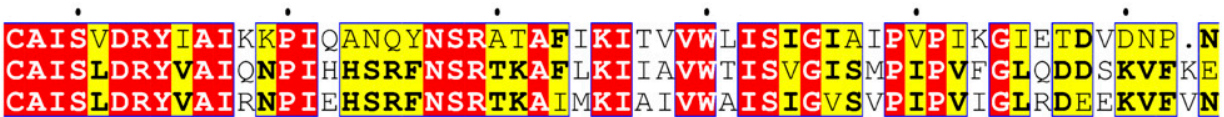
CA I SLDRYVA I RNP I E HSRFNSRTKA IMKI A IVWA I I IVS VP IPVI GLRDE KVFVN

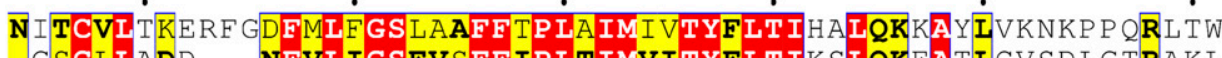
. GSCLIADD . . . NEVLIGSFVSFE IP LT IMVITYFLTIKSLQKEATICVSD L GTRAKL NTTCVLNDP . . . NFVLIGSFVAFEIPLTIMVITYCLT IYVLRRQA LML L HGH TEEP P G

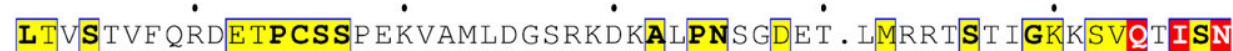

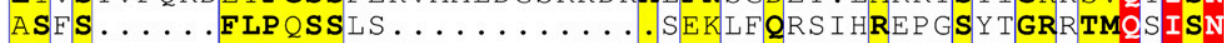
259 LSLD . . . . FLKCCKRNTAE . . . EENSANPNQDQNARRRKKKERRPRGTMOAINN 
TABLE 14

Affinities of $5-\mathrm{HT}_{2 \mathrm{~A}}$ receptor antagonists

\begin{tabular}{|c|c|c|c|c|c|c|c|}
\hline Ligand & $\underset{(\mathrm{nM})}{\mathrm{h} 5-\mathrm{HT}_{2 \mathrm{~A}}} K_{\mathrm{i}}$ & $\underset{(\mathrm{nM})}{\mathrm{r} 5-\mathrm{HT}_{2 \mathrm{~A}}} K_{\mathrm{i}}$ & $\underset{(\mathrm{nM})}{\mathrm{h} 5-\mathrm{HT}_{2 \mathrm{C}}} K_{\mathrm{i}}$ & $\underset{(\mathrm{nM})}{\mathrm{r} 5-\mathrm{HT}_{2 \mathrm{C}}} K_{\mathrm{i}}$ & $\underset{(\mathrm{nM})}{\mathrm{h} \alpha_{1 \mathrm{~A}} K_{\mathrm{i}}}$ & $\underset{(\mathrm{nM})}{\mathrm{h} \alpha_{1 \mathrm{~B}} K_{\mathrm{i}}}$ & References \\
\hline Spiperone & 1.4 & 0.43 & 661 & 871 & 5.0 & 0.6 & Bonhaus et al., 1997; Yoshio et al., 2001 \\
\hline Ketanserin & 3.2 & 1.3 & 200 & 63 & 6.3 & 6.3 & Yoshio et al., 2001; Bonhaus et al., 1995 \\
\hline Ritanserin & 0.25 & 0.30 & 0.25 & 2.7 & 4.0 & 10 & Bonhaus et al., 1997; Yoshio et al., 2001 \\
\hline Pirenpirone & 1.08 & & 77 & & & & Wainscott et al., 1996 \\
\hline Risperidone & 1.1 & 0.16 & 12 & 32 & 4.0 & 10 & $\begin{array}{c}\text { Yoshio et al., 2001; Roth et al., 1992; Kongsamut } \\
\text { et al., 1996; Schotte et al., } 1996\end{array}$ \\
\hline Altanserin & 0.51 & 0.3 & & 6.0 & & & Smith et al., 1998; Tan et al., 1999 \\
\hline $\begin{array}{l}\text { MDL } \\
11,939\end{array}$ & 6.06 & 2.893 & 1020 & 853.6 & 1876 & 1579 & Wainscott et al., 1996; Pehek et al., 2006 \\
\hline M100,907 & 1.50 & 1.92 & & 88 & 128 & 424.7 & Pehek et al., 2006; Kehne et al., 1996 \\
\hline
\end{tabular}

h, human; r, rat.

(Titeler et al., 1987; Glennon et al., 1994; Sleight et al., 1996).

Numerous $5-\mathrm{HT}_{2 \mathrm{~A}}$ receptor agonists are available (Table 15). Tryptamines such as $\alpha$-methyl-5-HT and 5 -methoxy- $N, N$-dimethyltryptamine are widely used as $5-\mathrm{HT}_{2 \mathrm{~A}}$ receptor agonists, but they tend to activate $5-\mathrm{HT}$ receptors nonselectively and can inhibit the 5-HT transporter at micromolar concentrations (Ismaiel et al., 1990; Nagai et al., 2007; Blough et al., 2014). 2,5-Dimethoxy-4iodoamphetamine (DOI) and its structural analogs 2,5-dimethoxy-4-methylphenyl)-2-aminopropane, DOB, and (4-Bromo-3,6-dimethoxybenzocyclobuten-1-yl)methylamine have high affinity and selectivity for $5-\mathrm{HT}_{2}$ receptors but do not discriminate between the three $5-\mathrm{HT}_{2}$ receptor subtypes. In contrast to most phenylalkylamines, which are nonselective for $5-\mathrm{HT}_{2 \mathrm{~A}}$ versus $5-\mathrm{HT}_{2 \mathrm{C}}$ receptors, 25CN-NBOH (N-(2-hydroxybenzyl)-2,5-dimethoxy4-cyanophenethylamine) is reportedly 100 -fold selective for $5-\mathrm{HT}_{2 \mathrm{~A}}\left(K_{\mathrm{i}}=1.3 \mathrm{nM}\right)$ versus $5-\mathrm{HT}_{2 \mathrm{C}}$ receptors $\left(K_{\mathrm{i}}=\right.$ $132 \mathrm{nM}$ ) (Hansen et al., 2014). The conformationally restricted phenethylamine $(+)-(2 S, 6 S)$-trans-2- $(2,5$ dimethoxy-4-bromobenzyl)-6-(2-methoxyphenyl)piperidine displays even greater selectivity for $5-\mathrm{HT}_{2 \mathrm{~A}}$ receptors, binding to $5-\mathrm{HT}_{2 \mathrm{C}}$ receptors with 124-fold lower affinity (Juncosa et al., 2013). Racemic trans-DMBMPP is less selective but still shows 98-fold higher affinity for $5-\mathrm{HT}_{2 \mathrm{~A}}$ over $5-\mathrm{HT}_{2 \mathrm{C}}$ receptors.

\section{F. Function}

1. Signaling. The $\mathrm{G} \alpha_{\mathrm{q}}-\mathrm{PLC} \beta$ cascade is the canonical signaling pathway coupled to $5-\mathrm{HT}_{2 \mathrm{~A}}$ receptor activation (Conn and Sanders-Bush, 1984; Kendall and Nahorski, 1985), resulting in the hydrolysis of membrane phospholipids to inositol-1,4,5-triphosphate $\left(\mathrm{IP}_{3}\right)$ and diacylglycerol (DAG). In turn, $\mathrm{IP}_{3}$ elevates the concentration of
$\mathrm{Ca}^{2+}$ in the cytosol by releasing it from the endoplasmic reticulum (ER), whereas DAG activates protein kinase $\mathrm{C}$ (PKC) and facilitates its translocation from the cytosol to the membrane. Both PKC and $\mathrm{Ca}^{2+}$ are known to have widespread and far-reaching influences on intracellular signaling; PKC phosphorylates various target proteins, whereas $\mathrm{Ca}^{2+}$ is known to modulate the activity of enzymes (e.g., $\mathrm{Ca}^{2+} /$ calmodulin-dependent kinases) and ion channels.

In addition to the classic signaling mediated by the PLC-IP ${ }_{3}$ cascade, the $5-\mathrm{HT}_{2 \mathrm{~A}}$ receptor can activate a variety of other effector mechanisms. For example, the $5-\mathrm{HT}_{2 \mathrm{~A}}$ receptor has been shown to stimulate phospholipase $\mathrm{A}_{2}\left(\mathrm{PLA}_{2}\right)$, resulting in increased production of the second messenger AA (Felder et al., 1990; Berg et al., 1996). The $5-\mathrm{HT}_{2 \mathrm{~A}}$ receptor also increases release of the endocannabinoid 2-arachidolylglycerol (Parrish and Nichols, 2006). The 5- $\mathrm{HT}_{2 \mathrm{~A}}$ receptor can also couple to an MAPK such as ERK1/2 (Hershenson et al., 1995; Watts, 1996; Greene et al., 2000). Other signaling molecules that have been linked to $5-\mathrm{HT}_{2 \mathrm{~A}}$ activation in native tissues and in cell lines expressing the receptor, including Akt (Johnson-Farley et al., 2005), phospholipase D1 (PLD) (Barclay et al., 2011), JAK/STAT (Guillet-Deniau et al., 1997; Banes et al., 2005), NOS (Miller et al., 1997), cAMP response element binding (CREB) (Chalecka-Franaszek et al., 1999), calmodulin (Turner and Raymond, 2005), and glycogen synthase kinase- $3 \beta$ ( $\mathrm{Li}$ et al., 2004).

Some of the aforementioned signaling pathways are coupled to the $5-\mathrm{HT}_{2 \mathrm{~A}}$ receptor in a $\mathrm{G} \alpha_{\mathrm{q}}$-independent manner. The ability of the $5-\mathrm{HT}_{2 \mathrm{~A}}$ receptor to stimulate $\mathrm{PLD}$ is mediated by the monomeric G protein ADPribosylation factor-1 (ARF1), which interacts directly with the receptor (Barclay et al., 2011). The coupling of the $5-\mathrm{HT}_{2 \mathrm{~A}}$ receptor to $\mathrm{PLA}_{2}$ in NIH3T3 cells appears to

TABLE 15

Affinities of 5- $\mathrm{HT}_{2 \mathrm{~A}}$ receptor agonists

\begin{tabular}{|c|c|c|c|}
\hline Ligand $^{a}$ & h5- $\mathrm{HT}_{2 \mathrm{~A}} K_{\mathrm{i}}(\mathrm{nM})\left[{ }^{3} \mathrm{H}\right]$ ketanserin & h5- $\mathrm{HT}_{2 \mathrm{~A}} K_{\mathrm{i}}(\mathrm{nM})\left[{ }^{3} \mathrm{H}\right]$ mesulergine & Reference \\
\hline$( \pm)-\mathrm{DOI}$ & 3.2 & 19.1 & Canal et al., 2013 \\
\hline Cimbi-5 (25I-NBOMe) & 0.52 & 0.69 & Nichols et al., 2015 \\
\hline Cimbi-36 (25B-NBOMe) & 0.19 & 4.0 & Juncosa et al., 2013 \\
\hline (+)-(2S,6S)-DMBMPP & 2.5 & 310 & Juncosa et al., 2013 \\
\hline $25 \mathrm{CN}-\mathrm{NBOH}(\mathrm{NBOH}-2 \mathrm{C}-\mathrm{CN})$ & 2.2 & 49.8 & Halberstadt et al., 2016 \\
\hline
\end{tabular}

${ }^{a}$ Alternative names are shown in parentheses. 
be mediated by two independent signaling cascades. In the first case, activation of $S r c$ by $\mathrm{G} \alpha_{\mathrm{i} / \mathrm{o}}$-associated $\mathrm{G} \beta \gamma$ subunits results the formation of a ternary complex between SHC/GRB/SOS, which in turn activates the Ras-Raf-MEK1/2-ERK1/2 cascade. In the second, activation of RhoA by $\mathrm{G} \alpha_{12 / 13}$ stimulates p38 MAPK (Kurrasch-Orbaugh et al., 2003a). Reports also indicate PLC and PKC are not involved in the ERK activation produced by $5-\mathrm{HT}_{2 \mathrm{~A}}$ receptor agonists in $\mathrm{PC} 12$ and vascular smooth muscle cells (Florian and Watts, 1998; Banes et al., 1999; Quinn et al., 2002). Nevertheless, in certain cell types, the coupling of ERK1/2 to $5-\mathrm{HT}_{2 \mathrm{~A}}$ receptors is dependent on $\mathrm{G} \alpha \alpha_{\mathrm{q}}$. Activation of the RasRaf-MEK-ERK1/2 cascade by $5-\mathrm{HT}_{2 \mathrm{~A}}$ receptors in tracheal smooth muscle cells and mesangial cells is downstream from $\mathrm{G} \alpha_{\mathrm{q}}$ and dependent on PKC (Hershenson et al., 1995; Watts, 1996; Greene et al., 2000). The coupling of the $5-\mathrm{HT}_{2 \mathrm{~A}}$ receptor to MAPK may actually be ligand-specific. In mouse embryonic fibroblasts transfected with the $5-\mathrm{HT}_{2 \mathrm{~A}}$ receptor, the stimulation of ERK1/2 by DOI is dependent on PLC, whereas the stimulation by 5 -HT is PLC-independent and requires $\beta$-arrestin2 (Schmid et al., 2008).

The $5-\mathrm{HT}_{2 \mathrm{~A}}$ receptor was one of the first receptors shown to display functional selectivity. According to Berg et al. (1998a,b), $5-\mathrm{HT}_{2 \mathrm{~A}}$ receptors activate $\mathrm{PLC}$ and $\mathrm{PLA}_{2}$ independently in $\mathrm{CHO}$ cells, and the relative efficacies of agonists differ depending on which response is measured. Subsequent studies confirmed the PLC-IP ${ }_{3}$ and $\mathrm{PLA}_{2}-\mathrm{AA}$ pathways coupled to $5-\mathrm{HT}_{2 \mathrm{~A}}$ receptor in NIH3T3 cells have different receptor reserves, indicating they are activated independently (Kurrasch-Orbaugh et al., 2003b). It has been proposed that $5-\mathrm{HT}_{2 \mathrm{~A}}$ receptor functional selectivity (biased signaling) may explain why certain $5-\mathrm{HT}_{2 \mathrm{~A}}$ receptor agonists produce hallucinogenic effects, whereas other agonists such as lisuride are nonhallucinogenic (González-Maeso et al., 2007). Specifically, although both hallucinogenic and nonhallucinogenic $5-\mathrm{HT}_{2 \mathrm{~A}}$ receptor agonists increase the expression of the immediate-early gene $c$-fos by activating $\mathrm{G} \alpha$, only agonists with hallucinogenic effects increase the cortical expression of the immediate-early gene (e.g., $r$-2) by activating $\mathrm{G} \alpha_{\mathrm{i} / \mathrm{o}}$ and $S r c$. Another group has reported that the activation of the $5-\mathrm{HT}_{2 \mathrm{~A}}$ receptor by $5-\mathrm{HT}$ and hallucinogens results in vastly different downstream signaling responses (Schmid and Bohn, 2010). The behavioral response to 5-HT in mice requires Akt phosphorylation and formation of a complex between Akt, Src, and $\beta$-arrestin2, whereas the response to hallucinogens is independent of Akt and $\beta$-arrestin2.

It is now apparent that many $5-\mathrm{HT}_{2 \mathrm{~A}}$ receptor antagonists act in a functionally selective manner. Like most GPCRs, the $5-\mathrm{HT}_{2 \mathrm{~A}}$ receptor is downregulated by exposure to agonists. Somewhat paradoxically, however, prolonged exposure to certain $5-\mathrm{HT}_{2 \mathrm{~A}}$ receptor antagonists also induces $5-\mathrm{HT}_{2 \mathrm{~A}}$ receptor downregulation (Leysen et al., 1986; Eison et al., 1989; Pranzatelli,
1991; Moreno et al., 2013). The anomalous downregulation of $5-\mathrm{HT}_{2 \mathrm{~A}}$ receptors induced by antagonists is not a consequence of altered gene transcription (Roth and Ciaranello, 1991) but is likely caused by redistribution of the receptor from the cell surface to intracellular compartments (Willins et al., 1998, 1999; Bhatnagar et al., 2001). Interestingly, although the $5-\mathrm{HT}_{2 \mathrm{~A}}$ receptor antagonists ketanserin, clozapine, and olanzapine reduce 5- $\mathrm{HT}_{2 \mathrm{~A}}$ immunoreactivity and $\left[{ }^{3} \mathrm{H}\right]$ ketanserin binding in mouse frontal cortex, M100907, MDL 11939, and altanserin do not alter receptor expression (Yadav et al., 2011). These findings indicate that certain $5-\mathrm{HT}_{2 \mathrm{~A}}$ receptor antagonists have agonist-like effects on the signaling pathways responsible for promoting receptor internalization. For example, although ketanserin and risperidone act as inverse agonists on the $5-\mathrm{HT}_{2 \mathrm{~A}^{-}}$ PLC and $5-\mathrm{HT}_{2 \mathrm{~A}}-\mathrm{ERK}$ pathways, they also act as $5-\mathrm{HT}_{2 \mathrm{~A}}$ receptor agonists by stimulating $\beta$-arrestin translocation (Clarke et al., 2013). Nevertheless, it appears that $5-\mathrm{HT}_{2 \mathrm{~A}}$ receptor antagonists can promote $5-\mathrm{HT}_{2 \mathrm{~A}}$ receptor internalization through multiple mechanisms because clozapine does not recruit $\beta$-arrestin (Schmid et al., 2014). Clozapine does act in a functionally selective manner-it has been shown to induce Akt phosphorylation in cortical neuronal cultures via the $5-\mathrm{HT}_{2 \mathrm{~A}}$ receptor (Schmid et al., 2014); but the mechanism by which clozapine promotes receptor downregulation remains to be determined.

Adding to the complexity of $5-\mathrm{HT}_{2 \mathrm{~A}}$ receptor signaling is the discovery that it can oligomerize with other GPCRs, potentially allowing the 5- $\mathrm{HT}_{2 \mathrm{~A}}$ receptor to couple to an even wider range of effector mechanisms. Gonzalez-Maseo et al. (2008) have reported that $5-\mathrm{HT}_{2 \mathrm{~A}}$ and $\mathrm{mGlu}_{2}$ receptors form heterocomplexes, providing a mechanism whereby $5-\mathrm{HT}_{2 \mathrm{~A}}$ receptors can modulate $\mathrm{G} \alpha_{\mathrm{i} / \mathrm{o}}$ signaling. Heteromers between $5-\mathrm{HT}_{2 \mathrm{~A}}$ and $\mathrm{D}_{2}$ receptors (BorrotoEscuela et al., 2010; Lukasiewicz et al., 2010) and 5- $\mathrm{HT}_{2 \mathrm{~A}}$ and $\mathrm{CB}_{1}$ receptors (Viñals et al., 2015) have also been detected in transfected cells, but the functional significance of these interactions and the extent to which they occur in native tissues is unclear.

2. Action in Cells, Tissues, and In Vivo. 5- $\mathrm{HT}_{2 \mathrm{~A}}$ receptor activation produces a variety of physiologic effects in peripheral tissues and in the CNS. There is evidence for $5-\mathrm{HT}_{2 \mathrm{~A}}$ receptor involvement in the proliferation, differentiation, and contraction of vascular and extravascular smooth muscle (Maayani et al., 1984; Watts and Cohen, 1992; Fanburg and Lee, 1997; Shum et al., 2002; Itoh and Kajikuri, 2011) as well as increased contractility of cardiac muscle, where it is expressed in neonatal and reexpressed in failing and hypertrophic heart (Qvigstad et al., 2005c; Birkeland et al., 2007b; Brattelid et al., 2007a,b, 2012; Levy et al., 2008). Similarly, the $5-\mathrm{HT}_{2 \mathrm{~A}}$ receptor increases the proliferation and synthesis of extracellular matrix proteins by glomerular mesangial cells (Kasho et al., 1998; Göoz et al., 2006). 5- $\mathrm{HT}_{2 \mathrm{~A}}$ receptor antagonists inhibit the platelet 
aggregation and shape change induced by $5-\mathrm{HT}$, DOB, and DOI (de Clerck et al., 1982, 1984; Seggel et al., 1987). The neuroendocrine effects of DOI in rats, including increases in the release of adrenocorticotropic hormone, corticosterone, oxytocin, renin, and prolactin, appear to be mediated by $5-\mathrm{HT}_{2 \mathrm{~A}}$ (Calogero et al., 1990; van de Kar et al., 2001; Zhang et al., 2002). 5- $\mathrm{HT}_{2 \mathrm{~A}}$ receptor activation produces sympathoexcitatory effects and increases arterial pressure through a combination of central and peripheral effects (Tadepalli et al., 1975; McCall et al., 1987; Alper, 1990; Dedeoğlu and Fisher, 1991; Chaouche-Teyara et al., 1994).

$5-\mathrm{HT}_{2 \mathrm{~A}}$ receptor activation produces long-lasting increases in the excitability and firing rate of glutamatergic and GABAergic neurons, resulting in increased excitatory and inhibitory network activity (McCormick and Wang, 1991; Sheldon and Aghajanian, 1991; Cumming-Hood et al., 1993; Pessia et al., 1994; Marek and Aghajanian, 1996; Aghajanian and Marek, 1997; Shen and Andrade, 1998; Zhou and Hablitz, 1999; Lambe and Aghajanian, 2006, 2007; Béïque et al., 2007; Benekareddy et al., 2010; Avesar and Gulledge, 2012; but see also Carr et al., 2002; Tian et al., 2016). These electrophysiological effects are absent in Htr2A-knockout mice and are restored upon conditional cortical rescue of $5-\mathrm{HT}_{2 \mathrm{~A}}$ receptors (Weisstaub et al., 2006). Reductions in resting $\mathrm{K}^{+}$-conductances are thought to contribute to many of the excitatory effects of $5-\mathrm{HT}_{2 \mathrm{~A}}$ receptor activation. For example, 5- $\mathrm{HT}_{2 \mathrm{~A}}$ receptor activation induces membrane depolarization, reduces afterhyperpolarization, and evokes a slow afterdepolarization in layer $\mathrm{V}$ pyramidal neurons in the PFC, effects thought to be mediated by inhibition of the $\mathrm{Ca}^{2+}$-activated $\mathrm{K}^{+}$-current $I_{\mathrm{K}(\mathrm{Ca})}$ and activation of the $\mathrm{Ca}^{2+}$-dependent nonselective cation current $I_{\mathrm{CAN}}$ (Araneda and Andrade, 1991; Tanaka and North, 1993; Villalobos et al., 2005, 2011; Zhang and Arsenault, 2005). The ability of $5-\mathrm{HT}_{2 \mathrm{~A}}$ receptor activation to enhance motoneuron excitability is mediated by inhibition of a leak $\mathrm{K}^{+}$-current $\left[I_{\mathrm{K}(\mathrm{leak})}\right]$ and enhancement of the hyperpolarizing-activated nonselective cation current (Garratt et al., 1993; Hsiao et al., 1997; Larkman and Kelly, 1998; Xu et al., 2009). TASK-1 and TASK-3 two-pore domain $\mathrm{K}^{+}$-channels are believed to be responsible for $I_{\mathrm{K}(\text { leak })}$ in motoneurons (Talley et al., 2000; Larkman and Perkins, 2005). Likewise, the $5-\mathrm{HT}_{2 \mathrm{~A}}$ receptor-mediated depolarization produced by 5 -HT in entorhinal cortex interneurons occurs as a consequence of TASK-3 channel inhibition (Deng and Lei, 2008). 5- $\mathrm{HT}_{2 \mathrm{~A}}$ has been shown to depolarize nucleus accumbens medium spiny neurons by inhibiting an inwardly rectifying $\mathrm{K}^{+}$-current (North and Uchimura, 1989). There is also evidence that $5-\mathrm{HT}_{2 \mathrm{~A}}$ receptor-induced arterial constriction is mediated by inhibition of $\mathrm{Kv}$ channels (Cogolludo et al., 2006; Sung et al., 2013). Other ion channels known to couple to the $5-\mathrm{HT}_{2 \mathrm{~A}}$ receptor include rapidly inactivating and persistent voltage-dependent $\mathrm{Na}^{+}$channels (Carr et al., 2002),
CaV 1.2 L-type $\mathrm{Ca}^{2+}$ channels (Day et al., 2002), Kv1.2 $\mathrm{K}^{+}$channels (Lambe and Aghajanian, 2001), and voltageindependent $\mathrm{Ca}^{2+}$ channels (Hagberg et al., 1998).

\section{G. Clinical Relevance}

$5-\mathrm{HT}_{2 \mathrm{~A}}$ receptors are clinically relevant to numerous CNS disorders, ranging from mood disorder and schizophrenia to drug dependence. The links between the $5-\mathrm{HT}_{2 \mathrm{~A}}$ receptor and the causes of such CNS disorders are not well understood. Early life stress has been shown trigger strong upregulation of the functional effects of $5-\mathrm{HT}_{2 \mathrm{~A}}$ receptors on electrophysiology, signaling, and gene expression in prefrontal cortex (Benekareddy et al., 2010). Emerging findings regarding $5-\mathrm{HT}_{2 \mathrm{~A}}$ gene polymorphisms and epigenetic regulation of $5-\mathrm{HT}_{2 \mathrm{~A}}$ receptor expression are also of great interest. The association between the $5-\mathrm{HT}_{2 \mathrm{~A}}$ receptor and successful treatment of certain CNS disorders is strong, and there is an ongoing active research interest in the therapeutic potential of $5-\mathrm{HT}_{2 \mathrm{~A}}$ receptor ligands. The majority of these studies have had a particular focus on schizophrenia and depression and the actions of antipsychotic and antidepressant drugs.

In schizophrenia, there are reports of reduced $5-\mathrm{HT}_{2 \mathrm{~A}}$ receptor binding in frontal cortex of postmortem brains, and there is supporting evidence from PET imaging studies for similar changes, as recently reviewed (Selvaraj et al., 2014). However, given that not all the PET studies used $5-\mathrm{HT}_{2 \mathrm{~A}}$ receptor-selective radiotracers and that there are inconsistencies in the postmortem studies, the extent to which impaired cortical $5-\mathrm{HT}_{2 \mathrm{~A}}$ receptor function contributes to the symptoms of schizophrenia is unclear.

The psychotomimetic effects of hallucinogens such as LSD and psilocybin are undoubtedly linked to activation of 5- $\mathrm{HT}_{2 \mathrm{~A}}$ receptors (Halberstadt, 2015). Furthermore, commonly used second-generation antipsychotics such as clozapine, risperidone, and sertindole are potent $5-\mathrm{HT}_{2 \mathrm{~A}}$ receptor antagonists in addition to having affinity at other 5-HT receptor subtypes and receptors for other neurotransmitters (Meltzer, 2012). $5-\mathrm{HT}_{2 \mathrm{~A}}$ receptor blockade has been linked to the antipsychotic efficacy of secondgeneration antipsychotics as well as a reduced side effect profile (Meltzer and Massey, 2011). This provided support for the idea that selective $5-\mathrm{HT}_{2 \mathrm{~A}}$ receptor antagonists might be useful as a monotherapy for some psychoses and as antipsychotic augmenting agents, although schizophrenia trials with the selective $5-\mathrm{HT}_{2 \mathrm{~A}}$ receptor antagonist MDL 100907 were disappointing. Nevertheless, the subsequent discovery that $5-\mathrm{HT}_{2 \mathrm{~A}}$ receptor inverse agonists have antipsychotic actions in preclinical models (Weiner et al., 2001) suggests an alternative way to treat psychosis. This thinking advanced to the clinical development of pimavanserin (Vanover et al., 2006) for the treatment of psychosis in patients with Parkinson disease (Meltzer and Roth, 2013). In 2016, pimavanserin was approved by the U.S. FDA as a treatment for hallucinations and delusions associated with Parkinson disease. Although the degree 
of inverse agonism required for an antipsychotic effect is uncertain, $5-\mathrm{HT}_{2 \mathrm{~A}}$ receptor inverse agonists are currently considered as a potential new generation of antipsychotic agents.

In postmortem studies of suicide victims, there is evidence of an upregulation in $5-\mathrm{HT}_{2 \mathrm{~A}}$ receptors in cortex [for review, see Meyer (2013)]. This finding parallels results from PET imaging studies that report increased $5-\mathrm{HT}_{2 \mathrm{~A}}$ receptor binding in patients with depression, particularly in association with severe pessimism (Meyer et al., 2003; Bhagwagar et al., 2006). The latter observations fit with findings in healthy subjects, in that individuals with high scores for pessimistic personality had higher cortical $5-\mathrm{HT}_{2 \mathrm{~A}}$ receptor binding (Frokjaer et al., 2008). It has been hypothesized that the increase in cortical $5-\mathrm{HT}_{2 \mathrm{~A}}$ receptor binding in depression is associated with severe pessimism and arises as an adaptive response to chronic 5-HT deficiency (Meyer, 2013).

The above findings in patients with depression link to evidence that certain antidepressants, and particularly tricyclics, have high affinity for $5-\mathrm{HT}_{2 \mathrm{~A}}$ receptors (e.g., Millan, 2006). Though tricyclic antidepressants have high affinity for multiple receptors, it can be argued that evidence of the superior therapeutic efficacy of tricyclic antidepressant drugs over other antidepressant drug classes, particularly in the treatment of severe melancholic depression, is linked in part to their ability to block $5-\mathrm{HT}_{2 \mathrm{~A}}$ receptors. Thus, $5-\mathrm{HT}_{2 \mathrm{~A}}$ receptor antagonists augment the effect of 5-HT uptake inhibitors in preclinical models (Marek et al., 2005; Boothman et al., 2006), and drugs with $5-\mathrm{HT}_{2 \mathrm{~A}}$ receptor antagonist properties are advocated as an add-on to antidepressant therapy in treatment-resistant cases (Marek et al., 2003); all are a possible link to evidence of an inhibitory $5-\mathrm{HT}_{2 \mathrm{~A}}$ receptor-mediated feedback on 5-HT neurons (Sharp et al., 2007).

Aside from schizophrenia and depression, 5- $\mathrm{HT}_{2 \mathrm{~A}}$ receptors are relevant to the pathophysiology of many other CNS disorders. Currently, there is large and ongoing research effort to understand the importance of polymorphic variation in the $5-\mathrm{HT}_{2 \mathrm{~A}}$ receptor gene to a large variety of psychiatric disorders (e.g., Smith et al., 2013; Paquette and Marsit, 2014). Despite the many reports of associations between $5-\mathrm{HT}_{2 \mathrm{~A}}$ gene polymorphisms and neuropsychiatric disorders, some of which are subject to careful meta-analysis, effect sizes are at best modest, and the role of genetic $5-\mathrm{HT}_{2 \mathrm{~A}}$ variability in mental health continues to be uncertain. This work is expanding to incorporate recent findings of epigenetic variation of the $5-\mathrm{HT}_{2 \mathrm{~A}}$ receptor gene and specifically methylation sites near the gene promoter region [for review, see Paquette and Marsit (2014)].

Ligands for $5-\mathrm{HT}_{2 \mathrm{~A}}$ receptors have a current untapped potential for the management of cognitive dysfunction. There are well established links between the receptor and the formation of different memory types, including recognition (Morici et al., 2015) and fear memories
(Bombardi and Di Giovanni, 2013; Zhang and Stackman, 2015). The latter connects with the considerations of ecstasy and other similar psychotomimetics for the management of post-traumatic stress disorder (Smith et al., 2014; Sessa and Nutt, 2015). There are also very interesting links between the $5-\mathrm{HT}_{2 \mathrm{~A}}$ receptor and impulse control; in animal models, $5-\mathrm{HT}_{2 \mathrm{~A}}$ receptor antagonists consistently reduce measures of impulsivity (Higgins et al., 2003; Winstanley et al., 2004; Fletcher et al., 2007; Winstanley, 2011) and attenuate abuse-related effects of cocaine (Howell and Cunningham, 2015). This raises the possibility that $5-\mathrm{HT}_{2 \mathrm{~A}}$ antagonists/inverse agonists may have utility in the control of addictions and disorders of impulse control more generally.

$5-\mathrm{HT}_{2 \mathrm{~A}}$ receptors are required for entry of $\mathrm{JC}$ polyomavirus (JCV) into cells (Elphick et al., 2004). JCV causes progressive multifocal leukoencephalopathy, a fatal demyelinating disease. JCV attaches to the sialic acid receptor motif $\alpha 2,6$-linked lactoseries tetrasaccharide $c$ on the cell surface and then undergoes endocytosis with the $5-\mathrm{HT}_{2 \mathrm{~A}}$ receptor (Assetta et al., 2013). 5- $\mathrm{HT}_{2 \mathrm{~A}}$ antagonists have been found to inhibit infection of cell by JCV (O'Hara and Atwood, 2008). Furthermore, treatment with mirtazepine, an antidepressant that acts as a $5-\mathrm{HT}_{2 \mathrm{~A}}$ receptor antagonist, has proven beneficial in patients infected with JCV (Verma et al., 2007; O'Hara and Atwood, 2008; Cettomai and McArthur, 2009; Park et al., 2011a).

$5-\mathrm{HT}_{2 \mathrm{~A}}$ receptor agonists have ocular hypotensive effects. $\quad R$-(-)-DOI, 5-methoxy- $N, N$-dimethyltryptamine, and $\alpha$-methyl-5-HT have been shown to lower intraocular pressure in a cynomolgus monkey model of ocular hypertension (May et al., 2003). $5-\mathrm{HT}_{2 \mathrm{~A}}$ receptors have been identified in tissues involved in the regulation of aqueous humor dynamics, including ciliary muscle (Sharif et al., 2006a), ciliary epithelium (InoueMatsuhisa et al., 2003), and trabecular meshwork (Sharif and Senchyna, 2006; Sharif et al., 2006b). Studies have not completely elucidated the mechanism for the reduction of intraocular pressure by $5-\mathrm{HT}_{2 \mathrm{~A}}$ receptor agonists, but increased uveoscleral outflow may play a role (Gabelt et al., 2005). This effect led to the evaluation of $5-\mathrm{HT}_{2 \mathrm{~A}}$ receptor agonists as potential treatments for glaucoma. To reduce the potential for psychotropic side effects, much of the work to develop $5-\mathrm{HT}_{2 \mathrm{~A}}$ receptor agonists as ocular hypotensive agents has focused on compounds with limited blood-brain barrier permeability. Several $5-\mathrm{HT}_{2 \mathrm{~A}}$ receptor agonists with limited blood-brain barrier permeability have been shown to lower intraocular pressure following topical ocular administration to monkeys, including AL-34662 (1-[(2S)-2-aminopropyl]-1H-indazol-6-ol) (Sharif et al., 2007), (8R)-1-[(2S)-2-aminopropyl]8,9-dihydro-7 $H$-pyrano[2,3-g]indazol-8-ol (May et al., 2015), phenylisopropylamines incorporating $\alpha$-hydroxy or $\alpha$-methoxy substituents (Glennon et al., 2004), and benzodifuran derivatives (Feng et al., 2007). 
Ketanserin can reportedly lower interocular pressure in patients with glaucoma (Costagliola et al., 1993; Mastropasqua et al., 1997). However, the ocular hypotensive effect of ketanserin is attenuated in unilaterally sympathectomized rabbits and therefore is thought to be mediated by a blockade of $\alpha_{1}$-adrenoceptors (Chang et al., 1985).

\section{5-HT 2B $_{\text {Receptor }}$}

\section{A. Introduction}

5-HT-induced contractions of rat stomach fundus strips were used as a sensitive bioassay for 5-HT long before more specific analytical assays became available (Vane, 1957); however, the 5-HT receptor was only defined more than three decades later as the $5-\mathrm{HT}_{2 \mathrm{~B}}$ receptor. Early pharmacological studies suggested a strong similarity to the $5-\mathrm{HT}_{2 \mathrm{C}}$ receptor, in line with the high potency of $5-\mathrm{HT}$ and blockade by $5-\mathrm{HT}_{2}$ receptor antagonists. However, $5-\mathrm{HT}_{2 \mathrm{C}}$ receptor mRNA was absent, and molecular cloning identified the new receptor, first in rat and mouse (Foguet et al., 1992a,b; Kursar et al., 1992; Loric et al., 1992; Wainscott et al., 1993) and then in humans (Choi et al., 1994; Kursar et al., 1994; Schmuck et al., 1994; Wainscott et al., 1996). Initially, given the tissue associated primarily with the functional receptor, the receptor was named the $5-\mathrm{HT}_{2 \mathrm{~F}}$ receptor, but it was reclassified subsequently to the $5-\mathrm{HT}_{2 \mathrm{~B}}$ receptor to better fit 5-HT receptor nomenclature. The pharmacological characterization of this receptor in various species confirmed its close relationship to both $5-\mathrm{HT}_{2 \mathrm{C}}$ and $5-\mathrm{HT}_{2 \mathrm{~A}}$ receptors, as expected from their closely related structural and transductional features. The physiological and pathophysiological functions of the $5-\mathrm{HT}_{2 \mathrm{~B}}$ receptor both in the peripheral and central nervous systems are rather unique.

\section{B. Expression Profile}

1. Peripheral Expression. 5- $\mathrm{HT}_{2 \mathrm{~B}}$ receptor mRNA and/or protein are detected in the stomach fundus, intestine, liver, kidney, pancreas, spleen, lung, and heart in rats, mice, and humans (Kursar et al., 1992; Choi et al., 1994; Kursar et al., 1994; Choi and Maroteaux, 1996). Functionally active $5-\mathrm{HT}_{2 \mathrm{~B}}$ receptors are present in human uterine smooth muscle (Kelly and Sharif, 2006). The $5-\mathrm{HT}_{2 \mathrm{~B}}$ receptor is also expressed in the vasculature, in various smooth muscle cells (Ullmer et al., 1995), endothelial cells of pig pulmonary arteries (Glusa and Pertz, 2000), human meningeal blood vessels (Schmuck et al., 1996), and rat jugular vein (Ellis et al., 1995). The $5-\mathrm{HT}_{2 \mathrm{~B}}$ receptor is expressed in rat spleen, thymus, and peripheral blood lymphocytes (Stefulj et al., 2000) and rat osteocytes, osteoblasts, and periosteal fibroblasts containing osteoblast precursor cells (Bliziotes et al., 2001; Westbroek et al., 2001). The 5- $\mathrm{HT}_{2 \mathrm{~B}}$ receptor gene is expressed in human and rodent anagen, but not telogen skin, in various melanomas and $\mathrm{Mel} \mathrm{A}$ melanocytes (Slominski et al., 2003, 2004). Finally, the $5-\mathrm{HT}_{2 \mathrm{~B}}$ receptor is expressed in c-kit+ bone marrow cells (Launay et al., 2012). Together, the very heterogeneous expression of the $5-\mathrm{HT}_{2 \mathrm{~B}}$ receptor suggests very diverse physiological and pathophysiological roles.

2. Central Expression. The $5-\mathrm{HT}_{2 \mathrm{~B}}$ receptor is expressed in human cerebral cortex, cerebellar nuclei and their projection areas, lateral septum, dorsal hypothalamus, and medial amygdala (Kursar et al., 1992; Choi et al., 1994; Kursar et al., 1994; Choi and Maroteaux, 1996). The presence of $5-\mathrm{HT}_{2 \mathrm{~B}}$ receptor mRNA was reported in several mammalian brain nuclei, including the dorsal raphe (Bonaventure et al., 2002a). 5-HT $2 \mathrm{~B}$ receptor expression (determined by qPCR) was confirmed in the human frontal, temporal, parietal, and occipital lobes and the olfactory region, cerebellum, diencephalon, hippocampus, thalamus, pituitary gland, pons, medulla oblongata, and nucleus accumbens (Bevilacqua et al., 2010). $5-\mathrm{HT}_{2 \mathrm{~B}}$ receptor $\mathrm{mRNA}$ was reported in rat cultured astrocytes (Sanden et al., 2000; Osredkar and Kržan, 2009). Microglial expression of $5-\mathrm{HT}_{2 \mathrm{~B}}$ receptors was documented in primary cultured and acutely isolated adult microglia, using two-photon microscopy on brain slices (Kolodziejczak et al., 2015) and patch-clamp studies in cultured microglia (Krabbe et al., 2012), suggesting $5-\mathrm{HT}_{2 \mathrm{~B}}$ receptor_may mediate modulation of microglial functions such as phagocytosis and migration, synaptogenesis, and neuronal death.

The $5-\mathrm{HT}_{2 \mathrm{~B}}$ receptor modulates the release of rat growth hormone $(\mathrm{GH})$ in the pituitary (Papageorgiou and Denef, 2007). The 5- $\mathrm{HT}_{2 \mathrm{~B}}$ receptor is expressed in the spinal cord (Helton et al., 1994; Holohean and Hackman, 2004), the rat organ of Corti lateral wall, and spiral ganglion subfractions (Oh et al., 1999) and is upregulated in ageing mice cochlea (Tadros et al., 2007). $5-\mathrm{HT}_{2 \mathrm{~B}}$ receptor mRNA is expressed predominantly in the human retina, ciliary body, ciliary epithelium, choroid, conjunctiva, and iris. $5-\mathrm{HT}_{2 \mathrm{~B}}$ receptor mRNA was also documented in optic nerve tissue of human donor trabecular meshwork cells (Sharif and Senchyna, 2006).

\section{Post-translational Modifications and Impact}

1. Gene Structure. The $5-\mathrm{HT}_{2 \mathrm{~B}}$ receptor gene is composed of four Exons, including one 5 ' noncoding exon and three coding exons in all vertebrates that have been sequenced.

2. Gene Regulation. The transcriptional regulation of the $5-\mathrm{HT}_{2 \mathrm{~B}}$ receptor gene is not well understood. In breast tumors, the c-Myc transformation induces an increased 5- $\mathrm{HT}_{2 \mathrm{~B}}$ receptor expression (Pai et al., 2009). In human umbilical endothelial cells, Wnt2 downstream targets the $5-\mathrm{HT}_{2 \mathrm{~B}}$ receptor gene (Klein et al., 2009). The $5-\mathrm{HT}_{2 \mathrm{~B}}$ receptor expression is downregulated via nuclear factor $-\kappa \mathrm{B}(\mathrm{NF}-\kappa \mathrm{B})(\mathrm{RelAp} 65-\mathrm{p} 52)$ in C-reactive protein-stimulated pulmonary arterial endothelial cells (Wynants et al., 2013). In pulmonary 
artery smooth muscle cells, 5-HT induces $5-\mathrm{HT}_{2 \mathrm{~B}}$ receptor mRNA expression, which is inhibited by peroxisome proliferator-activated receptor (PPAR) $\gamma$ activation and suggests the suppression of AP-1 activity (Liu et al., 2012b; Maroteaux, 2013). The presence of retinoic acid response elements in the $5-\mathrm{HT}_{2 \mathrm{~B}}$ receptor promoter suggests a negative regulatory relationship between retinoic acid and 5-HT signaling at sites of epitheliomesenchymal interaction (Bhasin et al., 2004).

3. Receptor Isoforms. Only a few studies have investigated putative splice variants in the $5-\mathrm{HT}_{2 \mathrm{~B}}$ receptor. In puffer fish, $5-\mathrm{HT}_{2 \mathrm{~B}}$ receptor splicing variants have been identified (De Lucchini et al., 2001). Splice variant 1 contains a 136-bp deletion that eliminates a portion of exon 2 by alternative splice sites located within transmembrane regions I and II, which results in a premature stop codon to produce a very short truncated 31-amino-acid protein. Splice variant 2 contains a 201-bp deletion because of an exon-skipping mechanism that eliminates exon 3 (which is also found in human and mice). The resulting RNA retains the same open reading frame. Splice variant 3 contains a 19-bp deletion, probably by an alternative $5^{\prime}$ splice site upstream of the canonical $5^{\prime}$ splice site of intron $\mathrm{C}$; this leads to a frame shift and a premature termination codon, which was also found in human and mice. This short variant results in a putative 177 -amino-acid protein, with 28 specific residues at the carboxyl terminus. The functions of these splice variants remain to be defined. Finally, an exon-skipping mechanism that eliminates exon 3 was found in fish, humans, and rodents; this leads to a truncated receptor containing only the first transmembrane domain.

\section{Protein Structure}

The $5-\mathrm{HT}_{2 \mathrm{~B}}$ receptor displays the characteristic structure of a GPCR receptor, with a relatively long $\mathrm{N}$-terminus of about 55 amino acids. The human $5-\mathrm{HT}_{2 \mathrm{~B}}$ receptor has 481 amino acids (479 amino acids in rat or mouse), with $79 \%$ and $82 \%$ homology for human versus rat and mouse, respectively. The $5-\mathrm{HT}_{2 \mathrm{~B}}$ receptor $\mathrm{N}$-terminus may act as a negative modulator, affecting both constitutive and agonist-stimulated activity (Belmer et al., 2014).

The ergotamine-bound $5-\mathrm{HT}_{2 \mathrm{~B}}$ receptor crystal structure exhibits some conformational features of both the active and inactive states: an active-like state in the helix VII conformation but only partial changes in helix VI, which mirror the strong $\beta$-arrestin bias of ergotamine seen in functional assays (Wacker et al., 2013; Wang et al., 2013). A structural explanation for the distinct conformational features and the biased pharmacology of ergotamine can be seen in the extracellular loop 2 (ECL2) junction with helix V, E212-R213-F214 forming an additional helical turn stabilized by a structured water molecule at the extracellular tip of helix $\mathrm{V}$. The segment of ECL2 connecting helices III and V via the conserved disulfide bond is, therefore, shortened and creates a conformational constraint on the extracellular tip of helix V (Martí-Solano et al., 2014). However, this structured water molecule involved in ECL2 junction with helix V has been challenged, as differential interactions of ergotamine with the top of helices V and VI could determine the rotational freedom of helix VI (Liu et al., 2013a). For more discussion of the crystal structure, see XVI. A. 5-HT GPCRs.

\section{E. Heteromeric Receptor Associations}

In cardiac fibroblasts, angiotensin AT1 receptors and $5-\mathrm{HT}_{2 \mathrm{~B}}$ receptors, which share common signaling pathways, could exist in heterodimeric complexes as shown by coimmunolocalization and a pull-down assay (Jaffre et al., 2009), but experimental confirmation is lacking.

\section{F. Pharmacology}

1. Agonists. Biased agonism is evident with a range of drugs that impact the $5-\mathrm{HT}_{2 \mathrm{~B}}$ receptor, and the influence of this phenomenon on the pharmacological profile of agonists can be profound (see, for example, Huang et al., 2009). Hence, when defining the action of agonists at the $5-\mathrm{HT}_{2 \mathrm{~B}}$ receptor-at least in terms of their potency and efficacy - the particular readout (e.g., $\left[\mathrm{Ca}^{2+}\right]_{i}$, arrestin, $\mathrm{ERK}, \mathrm{IP}_{3}$ ) and the nature of the receptor preparation needs to be taken into account. Against this background, the pharmacology of agonists will be described.

BW723C86, 1-methyl-2-[5-(2-thienylmethoxy)-1H-indole-3-yl] ethylamine hydrochloride, has 10- and 100-fold selectivity for the human $5-\mathrm{HT}_{2 \mathrm{~B}}$ receptor over the human $5-\mathrm{HT}_{2 \mathrm{C}}$ and $5-\mathrm{HT}_{2 \mathrm{~A}}$ receptors, respectively. (recommended use: $\leq 100 \mathrm{nM}$ concentration or $\leq 3 \mathrm{mg} / \mathrm{kg}$ i.p. in rodents; Porter et al., 1999; Jerman et al., 2001; Knight et al., 2004; Cussac et al., 2008). $\alpha$-Methyl-5-HT is a full agonist with high potency for the $5-\mathrm{HT}_{2 \mathrm{~B}}$ receptor $\left(\mathrm{pEC}_{50}=8.4\right)$ and lower potency for both $5-\mathrm{HT}_{2 \mathrm{C}}$ and $5-\mathrm{HT}_{2 \mathrm{~A}}$ receptors. 5-Methoxytryptamine is also 25 - and 400 -fold selective over the $5-\mathrm{HT}_{2 \mathrm{~A}}$ and $5-\mathrm{HT}_{2 \mathrm{C}}$ receptors, respectively. Nordexfenfluramine (metabolite of dexfenfluramine), methylergonovine (metabolite of methysergide), and Ro 60-0175 (2(S)-1-(6-chloro-5-fluoro-1H-indol-1-yl)2-propanamine fumarate) are all somewhat preferential $5-\mathrm{HT}_{2 \mathrm{~B}}$ receptor agonists with about 10 -fold selectivity over $5-\mathrm{HT}_{2 \mathrm{C}}$ receptor.

The $5-\mathrm{HT}_{2 \mathrm{~B}}$ receptor displays high affinity to 5 -HT $(\mathrm{Kd} \sim 10 \mathrm{nM})$ and many nonselective $5-\mathrm{HT}_{2}$ receptor active compounds, including some metabolites of therapeutics and drugs of abuse. Such agonists include MDA (3,4-methylene dioxyamphetamine-MDA, a metabolite of 3,4-methylenedioxy methamphetamineMDMA) (Setola et al., 2003), MDMA ("ecstasy") itself, tryptamine, and LSD. DOI is a nearly full agonist at $5-\mathrm{HT}_{2 \mathrm{~B}}$ receptors but with similar affinity to $5-\mathrm{HT}_{2 \mathrm{~A}}$ and $5-\mathrm{HT}_{2 \mathrm{~B}}$ receptors (Porter et al., 1999; Jerman et al., 2001; Knight et al., 2004; Cussac et al., 2008). 
Many substances known as "legal highs" display notable affinity for $5-\mathrm{HT}_{2 \mathrm{~B}}$ receptors, including 5-APB, commonly "marketed" as "benzofury" $\left(K_{\mathrm{i}}=14 \mathrm{nM}\right)$ and 6-APB $\left(K_{\mathrm{i}}=3.7 \mathrm{nM}\right)$, and 5-iodo-aminoindane $\left(K_{\mathrm{i}}=\right.$ $70 \mathrm{nM}$ ). 5-APB and 6-APB act as potent (i.e., nanomolar $\mathrm{EC}_{50}$ values) full agonists at $5-\mathrm{HT}_{2 \mathrm{~B}}$ receptors (Iversen et al., 2013; Rickli et al., 2015). 5-APB contracts the rat stomach fundus and is antagonized by the $5-\mathrm{HT}_{2 \mathrm{~B}}$ receptor antagonist, RS127445 (Dawson et al., 2014). Other such drugs show submicromolar affinities for the $5-\mathrm{HT}_{2 \mathrm{~B}}$ receptor (mephedrone, naphyrone, 1-naphyrone, and methylenedioxy-aminotetralin). Indeed, there is a correlation in a series of phenyliso-propylamines between hallucinogenic activity and affinity for the $5-\mathrm{HT}_{2 \mathrm{~B}}$ receptor (Nelson et al., 1999), although $5-\mathrm{HT}_{2 \mathrm{~A}}$ receptor agonism is still also considered to play a major role in "psychedelics," such as LSD or psyloscibine. Activation of the $5-\mathrm{HT}_{2 \mathrm{~B}}$ receptor appears to play a key role in the behavioral stimulant and 5-HT releasing effects of MDMA (Doly et al., 2008) and in the reinforcing effects of MDMA in mice (Doly et al., 2009).

2. Antagonists. The first highly $5-\mathrm{HT}_{2 \mathrm{~B}}$ selective antagonist is LY266097, 1-(2-chloro-3,4- dimethoxybenzyl)-6-methyl-1,2,3,4-tetrahydro-9Hpyrido [3,4-b]indole hydrochloride, with a $\mathrm{p} K_{\mathrm{i}}$ of 9.7 for the human cloned $5-\mathrm{HT}_{2 \mathrm{~B}}$ receptor and a 100 -fold greater selectivity over human $5-\mathrm{HT}_{2 \mathrm{C}}$ and $5-\mathrm{HT}_{2 \mathrm{~A}}$ receptor binding sites (recommended use: $20 \mathrm{nM}$ concentration in vitro or $0.5 \mathrm{mg} / \mathrm{kg}$ i.p. in rodents; Audia et al., 1996). SB204741, N-(1methyl-5-indolyl)-N'-(3-methyl-5-isothiazolyl)urea, is another selective $5-\mathrm{HT}_{2 \mathrm{~B}}$ receptor antagonist with approximately 100 -fold selectivity over the $5-\mathrm{HT}_{2 \mathrm{C}}$ and $5-\mathrm{HT}_{2 \mathrm{~A}}$ sites but with rather low potency $\left(K_{\mathrm{i}}\right.$ around $100 \mathrm{nM}$ ) (recommended use: $500 \mathrm{nM}$ concentration in vitro or $10 \mathrm{mg} / \mathrm{kg}$ i.p. in rodents; Bonhaus et al., 1995). The tetrahydro- $\beta$-carboline, LY272015 (6-chloro-5-methyl-N-(5-quinolinyl)-2,3-dihydro-1H-indole1-carboxamide) is also a fairly selective and highly potent antagonist (recommended use: $50 \mathrm{nM}$ concentration in vitro or $1.0 \mathrm{mg} / \mathrm{kg}$ i.p. in rodents; Cohen et al., 1996). RS127445, 2-amino-4-(4-fluoronaphth-1-yl)-6-isopropylpyrimidine, has subnanomolar affinity for the $5-\mathrm{HT}_{2 \mathrm{~B}}$ receptor $\left(\mathrm{p} K_{\mathrm{i}}=9.5\right)$ and 1000 -fold selectivity compared with numerous other receptors and ion channels, and it appears as the most selective, high-affinity $5-\mathrm{HT}_{2 \mathrm{~B}}$ receptor antagonist suitable now (Bonhaus et al., 1999; recommended use: $20 \mathrm{nM}$ concentration or $0.25 \mathrm{mg} / \mathrm{kg}$ i.p. in rodents). The methoxythioxanthene BF-1 is a highly selective and potent 5 - $\mathrm{HT}_{2 \mathrm{~B}}$ receptor antagonist lacking high affinities for $5-\mathrm{HT}_{1 \mathrm{~A}}, 5-\mathrm{HT}_{2 \mathrm{~A}}, 5-\mathrm{HT}_{2 \mathrm{C}}$, histamine $\mathrm{H}_{1}$, dopamine $\mathrm{D}_{1}$, and $\mathrm{D}_{2}$ as well as muscarinic $\mathrm{M}_{1}$ and $\mathrm{M}_{2}$ receptors (Schmitz et al., 2015). S33526, 6-chloro-2,3,4,9-tetrahydro-1H-b-carbolin-1-yl)phenyl-acetic acid ethyl ester, is a high-affinity and relatively selective antagonist at $5-\mathrm{HT}_{2 \mathrm{~B}}$ receptors (Cussac et al., 2002). SB215505, 6-chloro-5-methyl-N-(5-quinolinyl)-2,3-dihydro-1H-indole-1-carboxamide, behaves as a high-affinity and preferential inverse agonist at $5-\mathrm{HT}_{2 \mathrm{~B}}$ receptors. SB206553, 5-methyl-N-(3-pyridyl)1,2,3,5-tetrahydrobenzo[1,2-b:4,5-b']dipyrrole-1-carboxamide, is a mixed $5-\mathrm{HT}_{2 \mathrm{C}} / 5-\mathrm{HT}_{2 \mathrm{~B}}$ receptor inverse agonist with 50- to 100 -fold lower affinity for the $5-\mathrm{HT}_{2 \mathrm{~A}}$ and other sites.

Nonselective $5-\mathrm{HT}_{2}$ receptor antagonists such as ritanserin and metergoline antagonize $5-\mathrm{HT}_{2 \mathrm{~B}}$ receptormediated effects. Furthermore, the $\alpha_{2}$ adrenergic receptor antagonists yohimbine and rauwolscine are potent $5-\mathrm{HT}_{2 \mathrm{~B}}$ antagonists, with low affinity for the $5-\mathrm{HT}_{2 \mathrm{C}}$ and $5-\mathrm{HT}_{2 \mathrm{~A}}$ receptors. Atypical antipsychotics have also fairly high affinity for $5-\mathrm{HT}_{2 \mathrm{~B}}$ receptors, including clozapine, asenapine, or cariprazine (Wainscott et al., 1996; Millan et al., 2003; Shahid et al., 2009; Kiss et al., 2010). Aripiprazole (OPC-14597) is a novel atypical antipsychotic, with high antagonist affinity $\left(\mathrm{IC}_{50}=\right.$ $11 \mathrm{nM}$ ) for the human $5-\mathrm{HT}_{2 \mathrm{~B}}$ receptor (Shapiro et al., 2003).

3. Allosteric Modulators. No selective $5-\mathrm{HT}_{2 \mathrm{~B}}$ allosteric modulator has been definitely identified. In the crystal, ergotamine binds to two distinct sites at the $5-\mathrm{HT}_{2 \mathrm{~B}}$ receptor, the orthosteric site, where the indole nucleus of ergotamine resides, and the "extended" binding site, to which the tripeptide portion of the ergoline binds. This potential allosteric site is also present in the muscarinic M2 receptor at the same extracellular region. The similarities in both the M2 and $5-\mathrm{HT}_{2 \mathrm{~B}}$ receptors suggest that the location of the extracellular allosteric site for class A GPCRs is rather similar and conserved; these common features suggest that ergotamine and other ergolines may function as "bitopic" ligands, acting at both the orthosteric and the putative extracellular allosteric site in the $5-\mathrm{HT}_{2 \mathrm{~B}}$ receptor. It is thought that a sodium ion allosterically modulates the binding pocket to reduce $G$ protein signaling, thus favoring $\beta$-arrestin recruitment (McCorvy and Roth, 2015).

\section{G. Transduction System(s)}

1. Transfected Cells. 5- $\mathrm{HT}_{2 \mathrm{~B}}$ receptors expressed in mouse fibroblast L-cells stimulate GTPase activity and inositol 1,4,5-triphosphate production upon agonist stimulation. This GTPase activation is mediated by $\mathrm{G} \alpha_{\mathrm{q} / 11}$ but not by $\mathrm{G} \alpha \mathrm{s}$ or $\mathrm{G} \alpha \mathrm{i}$. The GTPase activation was also blocked by anti- $\beta 1-4$ or anti- $\gamma 2$ subunit antibodies. The $5-\mathrm{HT}_{2 \mathrm{~B}}$ receptor couples to phospholipase A2 (PLA2)-mediated release of arachidonic acid (Tournois et al., 1998). In addition, stimulation of the $5-\mathrm{HT}_{2 \mathrm{~B}}$ receptor triggers intracellular cyclic guanosine monophosphate (cGMP) production through dual activation of constitutive nitric-oxide synthase (cNOS) and inducible NOS. The group I PDZ motif at the carboxy terminus of the $5-\mathrm{HT}_{2 \mathrm{~B}}$ receptor is required for cNOS transduction pathways, whereas inducible NOS stimulation is $\mathrm{G} \alpha 13$-dependent (Manivet et al., 2000). The 5- $\mathrm{HT}_{2 \mathrm{~B}}$ receptor shares the C-terminal 
E-X-V/I-S-X-V sequence with the $5-\mathrm{HT}_{2 \mathrm{C}}$ receptors and binds MUPP1-PDZ domains in vitro (Becamel et al., 2001). Agonist-induced stimulation of the $5-\mathrm{HT}_{2 \mathrm{~B}}$ receptor promotes rapid and transient activation of the proto-oncogene product $\mathrm{p} 21^{\mathrm{ras}}$, as measured by an increase in GTP-bound Ras (Launay et al., 1996). 5- $\mathrm{HT}_{2 \mathrm{~B}}$ receptor stimulation activates the MAPKs $\mathrm{p} 42^{\mathrm{mapk}} / \mathrm{p} 44^{\mathrm{mapk}}$ as well as ERK2/ERK1. It results in the formation of foci and to the formation of tumors from these foci in nude mice (Launay et al., 1996). The 5- $\mathrm{HT}_{2 \mathrm{~B}}$ receptor-dependent cell-cycle progression happens through retinoblastoma protein hyperphosphorylation and the activation of both cyclin D1/cdk4 and cyclin E/cdk2 kinases. The induction of cyclin D1, but not that of cyclin E expression, is under MAPK control, indicating an independent regulation of these two cyclins in 5- $\mathrm{HT}_{2 \mathrm{~B}}$ receptor-induced mitogenesis. Similarly, platelet-derived growth factor receptor (PDGFR) kinase activity is essential for $5-\mathrm{HT}_{2 \mathrm{~B}}$-triggered $\mathrm{MAPK} /$ cyclin D1, but not cyclin E, signaling pathways. $5-\mathrm{HT}_{2 \mathrm{~B}}$ receptor activation also increases activity of the Src family kinases c-Src, Fyn, and c-Yes. Strikingly, c-Src, but not Fyn or c-Yes, is the crucial link between the Gq protein-coupled $5-\mathrm{HT}_{2 \mathrm{~B}}$ receptor and the cell-cycle regulators (Nebigil et al., 2000b). Inhibition of c-Src activity is sufficient to abolish 5-HT-induced PDGFR tyrosine kinase phosphorylation and MAPK activation, cyclin D1 and cyclin E expression levels, and thymidine incorporation. Thus, c-Src activation by the $5-\mathrm{HT}_{2 \mathrm{~B}}$ receptor controls cyclin $\mathrm{E}$ induction and, in concert with PDGFR, also induces cyclin D1 expression via the MAPK/ERK pathway (Nebigil et al., 2000b). The 5- $\mathrm{HT}_{2 \mathrm{~B}}$ signal transduction pathways are thus quite diverse and are similar to those of $5-\mathrm{HT}_{2 \mathrm{~A} / 2 \mathrm{C}}$ receptors. On the other hand, the NOS pathway seems to be $5-\mathrm{HT}_{2 \mathrm{~B}}$ receptorspecific.

2. Primary Cell Cultures. In cultivated cardiac fibroblasts, angiotensin II (AngII)- or 5-HT-dependent cytokine release is critical for the expression of HB-EGF and Src activity via endogenous $\mathrm{AT} 1$ and $5-\mathrm{HT}_{2 \mathrm{~B}}$ receptors (Jaffre et al., 2009). Matrix metalloproteinases (MMPs) are responsible for HB-EGF shedding and subsequent EGF-receptor transactivation induced by AngII or 5-HT. Tumor necrosis factor- $\alpha$ (TNF- $\alpha$ )-converting enzyme controls HB-EGF shedding in fibroblasts and is directly regulated by $5-\mathrm{HT}_{2 \mathrm{~B}}$ receptors (Pietri et al., 2005). Blockade of one of the two receptors prevents cytokine release induced by the other receptor (Jaffre et al., 2009). These findings also indicate that AT1 and $5-\mathrm{HT}_{2 \mathrm{~B}}$ receptors share common EGF receptordependent signaling pathways in adult cardiac fibroblasts, and the two receptors were shown to interact in a common cell compartment. Together, the data support $\mathrm{AT} 1$ and $5-\mathrm{HT}_{2 \mathrm{~B}}$ receptors exist as heterodimers that may play a key role in receptor maturation and trafficking to the plasma membrane and/or signaling (Bulenger et al., 2005) to drive common signaling regulating hypertrophic factors in the heart (Jaffre et al., 2009).
$5-\mathrm{HT}_{2 \mathrm{~B}}$ receptor stimulation in hepatic stellate cells (HSC) activates the expression of TGF $\beta 1$ (a powerful suppressor of hepatocyte proliferation) via ERK/JunD signaling. $5-\mathrm{HT}_{2 \mathrm{~B}}$ receptor antagonists decrease the mRNA levels of TGF $\beta 1$, connective growth factor, plasminogen activator inhibitor-1, Smad-3, and JunD in lung and skin fibroblasts (Dees et al., 2011). 5- $\mathrm{HT}_{2 \mathrm{~B}}$ receptor activation leads to sustained phosphorylation of two downstream targets of mTOR, p70S6K and 4E-BP1, thereby facilitating survival and inhibiting autophagy of hepatocellular carcinomas (Soll et al., 2010). The 5- $\mathrm{HT}_{2 \mathrm{~B}}$ receptor protects newborn postmitotic cardiomyocytes against serum deprivation-induced apoptosis as manifested by DNA fragmentation, nuclear chromatin condensation, and terminal deoxynucleotidyl transferase dUTP nick end labeling. 5-HT prevents cytochrome c release and caspase- 9 and -3 activation after serum deprivation via crosstalk between phosphatidylinositol3 kinase (PI3K)/Akt and ERK1/2 signaling pathways. $5-\mathrm{HT}_{2 \mathrm{~B}}$ receptor-activated ERK kinases inhibit Bax expression induced by serum deprivation. 5-HT activates $\mathrm{NF}-\kappa \mathrm{B}$ via PI3K/Akt required for the regulation of the mitochondrial adenine nucleotide translocator and mitochondrial permeability. Thus, $5-\mathrm{HT}$ via the $5-\mathrm{HT}_{2 \mathrm{~B}}$ receptor is a novel survival factor targeting mitochondria (Nebigil et al., 2003). Interestingly, NF- $\kappa \mathrm{B}$ regulation by $5-\mathrm{HT}_{2 \mathrm{~B}}$ receptors is confirmed in a large screen for genes regulating NF- $\kappa \mathrm{B}$ and the MAPK pathways (Matsuda et al., 2003).

Primary osteoblasts from mutant $5-\mathrm{HT}_{2 \mathrm{~B}}$ receptor $\mathrm{KO}$ mice show reduced proliferation and delayed differentiation; calcium incorporation is markedly reduced in osteoblasts after $5-\mathrm{HT}_{2 \mathrm{~B}}$ receptor inactivation (by genetic invalidation or by pharmacological inhibition; Collet et al., 2008). A functional link between the $5-\mathrm{HT}_{2 \mathrm{~B}}$ receptor and the activity of the tissue-nonspecific alkaline phosphatase (TNAP) was established in an osteoprogenitor C1 cell line (Baudry et al., 2010a). During osteogenic differentiation, both $5-\mathrm{HT}_{2 \mathrm{~B}}$ receptor and TNAP mRNA translations are delayed with respect to extracellular matrix deposition. Once the receptor is expressed, it constitutively controls TNAP activity at a post-translational level along the entire period of mineral deposition. The lack of $5-\mathrm{HT}_{2 \mathrm{~B}}$ receptors is associated with a 10-fold overproduction of prostacyclin in osteoblast primary cultures. A specific prostacyclin synthase (CYP8A1) inhibitor (U51605) totally rescued osteoblast aggregation and matrix mineralization in $5-\mathrm{HT}_{2 \mathrm{~B}}$ receptor $\mathrm{KO}$ osteoblasts without any effect on WT osteoblasts. Prostacyclin is the endogenous ligand of the nuclear receptor PPAR- $\beta / \delta$, and its inhibition in $5-\mathrm{HT}_{2 \mathrm{~B}} \mathrm{KO}$ cells totally rescued the alkaline phosphatase TNAP and osteopontin SPP1 mRNA levels, cell-cell adhesion, and matrix mineralization. The absence of $5-\mathrm{HT}_{2 \mathrm{~B}}$ receptors leads to the overproduction of prostacyclin, inhibiting osteoblast differentiation because of PPAR- $\beta / \delta$-dependent target regulation and defective 
cell-cell adhesion and matrix mineralization (ChabbiAchengli et al., 2013), supporting a physiologic negative control of prostacyclin synthase by $5-\mathrm{HT}_{2 \mathrm{~B}}$ receptors. Thus, endogenously expressed 5 - $\mathrm{HT}_{2 \mathrm{~B}}$ receptors can modulate various transduction pathways, including Src, MMPs, and PLA2 activities in a cell type-dependent manner.

\section{H. Regulatory Mechanisms}

1. Internalization. In transfected cells, prior exposure to 5-HT results in a rapid and considerable (up to 80\%) $5-\mathrm{HT}_{2 \mathrm{~B}}$ receptor desensitization (Porter et al., 2001). Internalization of $5-\mathrm{HT}_{2 \mathrm{~B}}$ receptors is caveolin1-independent and clathrin- and $\beta$-arrestin2-dependent (Janoshazi et al., 2007).

Some ergot derivatives are "slow" 5 - $\mathrm{HT}_{2 \mathrm{~B}}$ receptor binders, with very slow association and dissociation rates. The compounds have apparent lower potency to increase intracellular concentrations of calcium ions relative to inositol phosphate accumulation assays. Similarly, the potency of ergolines to activate ERK1/2 is highly time-dependent. In addition, a number of ergot derivatives produce "wash-resistant" $5-\mathrm{HT}_{2 \mathrm{~B}}$ receptor signaling that persists for hours without appreciable loss of potency, which is not explained simply by slow receptor-dissociation kinetics. Thus, this persistent signaling has been proposed to originate from internalized or sequestered receptors (Unett et al., 2013). The $5-\mathrm{HT}_{2 \mathrm{~B}}$ receptor crystal structure (Huang et al., 2009) reveals an intermediate state of activation stabilized by the extracellular-facing tripeptide portion of ergotamine, which likely drives $\beta$-arrestin bias and is not seen in unbiased ligands such as 5-HT itself. Thus, the long duration of action of some ergolines may be explained by a combination of very slow kinetics at the receptor, coupled with persistent intracellular signaling.

2. Interacting Proteins. Proteins known to interact with the $5-\mathrm{HT}_{2 \mathrm{~B}}$ receptor include constitutive and inducible NOS; $\mathrm{G} \alpha \mathrm{q}, \mathrm{G} \alpha 11$, and $\mathrm{G} \alpha 13$, involved in signaling of the receptor; and MUPP1, a multivalent PDZ scaffolding protein. (Becamel et al., 2001).

For more details on proteins that interact with the 5- $\mathrm{HT}_{2 \mathrm{~B}}$ receptor, see XVII. B. 4. 5-HT $\mathrm{T}_{2 B}$ Receptor.

\section{Function at Cellular, Tissue, and In Vivo Level}

1. Hematopoiesis. 5-HT promotes megakaryocyte (MK) proliferation and reduces cell apoptosis via activation of the $5-\mathrm{HT}_{2 \mathrm{~B}}$ receptor and Akt pathway (Liu and Yang, 2006). 5-HT increases proplatelet-bearing MKs and polymerizes actin via ERK1/2 (Ye et al., 2014). $T p h 1^{-1-}$ mice are deficient in peripheral 5-HT and display features of ineffective erythropoiesis. The central event starts in the bone marrow where the absence of 5-HT inhibits the terminal differentiation of erythroid precursors expressing $5-\mathrm{HT}_{2 \mathrm{~A}}$ and $5-\mathrm{HT}_{2 \mathrm{~B}}$ receptors. In addition, red blood cells from 5-HT-deficient mice are more sensitive to macrophage phagocytosis and have a shortened in vivo half-life (Amireault et al., 2011). In addition, the $5-\mathrm{HT}_{2 \mathrm{~B}}$ receptor is expressed in c-kit+ bone marrow cells (Launay et al., 2012). The $5-\mathrm{HT}_{2 \mathrm{~B}}$ receptor antagonist RS127445 decreases colonyforming capacity, with inhibition of both early stem/progenitors and erythroid burst-forming unit formation attributed to a reduction of cell proliferation and/or an apoptotic effect. By contrast, 5-HT significantly enhances the expansion of CD34+ cells to early stem/progenitors and committed progenitors (erythroid burst-forming units) (Yang et al., 2007).

In human macrophages, 5-HT inhibits the LPS-induced release of proinflammatory cytokines to upregulate the expression of M2 polarization-associated genes and to reduce the expression of M1-associated genes. $5-\mathrm{HT}_{2 \mathrm{~B}}$ receptors mediate the pro-M2 skewing effect of 5-HT. Blockade of this receptor during in vitro monocyte-to-macrophage differentiation preferentially modulates the acquisition of M2 polarization markers. $5-\mathrm{HT}_{2 \mathrm{~B}}$ receptor mRNA is preferentially expressed by anti-inflammatory M2 (macrophage colony-stimulating factor) macrophages and is detected in vivo in liver Kupffer cells and in tumor-associated macrophages (de Las Casas-Engel et al., 2013). 5- $\mathrm{HT}_{2 \mathrm{~B}}$ receptor expression is found in postnatal microglia, suggesting that 5-HT participates in microglial functions (Kolodziejczak et al., 2015). $5-\mathrm{HT}_{2 \mathrm{~B}}$ receptor mRNA expression is evident in spleen, thymus, and peripheral blood lymphocytes (Stefulj et al., 2000). Immature dendritic cells express $5-\mathrm{HT}_{2 \mathrm{~B}}$ receptor mRNA, and $5-\mathrm{HT}_{2 \mathrm{~B}}$ receptor stimulation induces intracellular $\mathrm{Ca}^{2+}$ mobilization in immature, but not mature, dendritic cells. Thus, 5-HT stimulates, in a maturation-dependent manner, different signaling pathways in dendritic cells (Idzko et al., 2004).

A proper balance between different T-helper (Th) cell subsets is necessary for normal functioning of the adaptive immune system. Th cells (from human umbilical cord blood) differentiated in vitro into Th1 or Th2 cells reveal the latter express $5-\mathrm{HT}_{2 \mathrm{~B}}$ receptor mRNA (Aijö et al., 2012). In gene expression profiles during human CD41 T-cell differentiation, 5- $\mathrm{HT}_{2 \mathrm{~B}}$ receptor mRNA was found to be SP4-specific ( $\sim 10$-fold) among the 16 transcripts expressed in SP4 thymocytes at levels threefold or higher than in any other isolated T-cell subpopulation (Lee et al., 2004b).

Treatment with aggregated (1-40 or 1-42) and oligomeric (1-42) amyloid $\beta(\mathrm{A} \beta$, found in Alzheimer disease) promoted differentiation of bone marrow-derived mesenchymal stem cells without toxic effects. The effect of $\mathrm{A} \beta$ was shown to be mediated by the neuropeptide $\mathrm{Y} 1$ receptor and the $5-\mathrm{HT}_{2 \mathrm{~B}}$ receptor via $\mathrm{PI} 3 \mathrm{~K}$-dependent activation of the MAPK/ERK1/2 pathway (Jin et al., 2009). Thus, the $5-\mathrm{HT}_{2 \mathrm{~B}}$ receptor, among others, mediates the balance among various hematopoietic lineages.

2. Pancreas. A strong lactogen-dependent upregulation of 5-HT biosynthesis takes place in a subpopulation of 
mouse islet $\beta$-cells during pregnancy (Schraenen et al., 2010). Pancreatic islet cells express the genes encoding all of the products necessary for synthesizing, packaging, and secreting 5-HT, including both isoforms of the 5-HT synthetic enzyme tryptophan hydroxylase (TPH) and the archetypal 5-HT transcription factor Pet1. In $\beta$-cells, Pet1 can bind to the 5-HT-relevant genes but also to a conserved insulin gene regulatory element. Mice lacking Pet1 display reduced insulin production and secretion and impaired glucose tolerance (Ohta et al., 2011). Inhibition of 5 -HT synthesis blocks $\beta$-cell expansion and induced glucose intolerance in pregnant mice without affecting insulin sensitivity. Expression of the $5-\mathrm{HT}_{2 \mathrm{~B}}$ receptor in maternal islets has been reported to increase during pregnancy and to normalize just before parturition. Blocking $5-\mathrm{HT}_{2 \mathrm{~B}}$ receptor signaling in pregnant mice may also block $\beta$-cell expansion and cause glucose intolerance (Kim et al., 2010).

3. Adipocytes. By inhibiting $5-\mathrm{HT}_{2 \mathrm{~B}}$ receptor signaling during adipogenesis using RS127445, an increased fat accumulation was observed similar to the knockdown phenotype (Söhle et al., 2012). In adipocytes, $5-\mathrm{HT}_{2 \mathrm{~B}}$ receptors favor lipolysis by increasing phosphorylation and activity of hormone-sensitive lipase (Sumara et al., 2012).

4. Cardiovascular and Pulmonary Systems. $5-\mathrm{HT}_{2 \mathrm{~B}}$ receptor inactivation in mice leads to partial embryonic lethality caused by major defects in heart development (Monassier et al., 2010). Neonates exhibit a second wave of partial lethality because of cardiac dilation resulting from contractility deficits and structural deficits at the intercellular junctions between cardiomyocytes. Echocardiography and electrocardiography studies in animals that live past the first week and survive until adulthood confirm the presence of left-ventricular dilation and decreased systolic function. 5 - $\mathrm{HT}$, via the $5-\mathrm{HT}_{2 \mathrm{~B}}$ receptor, regulates heart differentiation and proliferation during development as well as cardiac structure and function in adults (Nebigil et al., 2000a). The $5-\mathrm{HT}_{2 \mathrm{~B}}$ receptor is functionally coupled to ROS synthesis through NADPH oxidase (NOX) stimulation in 1C11 cells (Schneider et al., 2006) and in angiotensin II and isoproterenol-induced cardiac hypertrophy (Monassier et al., 2008). In human atrial myocytes, 5-HT reduces the amplitude of L-type calcium currents and affects the strength of gap junctional intercellular communication, which is markedly reduced by blocking receptors, showing that activation of $5-\mathrm{HT}_{2 \mathrm{~B}}$ receptors inhibit gap junctional intercellular communication (Derangeon et al., 2010). Upon pulmonary artery banding, the $5-\mathrm{HT}_{2 \mathrm{~B}}$ receptor antagonist $\mathrm{SB} 204741$ reduces right-ventricular fibrosis and improves heart function in mice (Janssen et al., 2015).

A model in which 5- $\mathrm{HT}_{2 \mathrm{~B}}$ receptor signaling promotes cardiac hypertrophy by stimulating calcineurin/nuclear factor of activated $\mathrm{T}$ cells signaling suggests the recruitment of histone acetyl transferases to regulatory regions of nuclear factor of activated T-cells target genes. 5- $\mathrm{HT}_{2 \mathrm{~B}}$ receptor agonist-induced hypertrophy of cardiac muscle cells results from a signaling pathway involving calcineurin and a kinase-dependent mechanism that inactivates class II histone deacetylases (HDAC), which act as repressors of cardiac growth (Bush et al., 2004). Because it also stimulates nuclear export of class II HDACs, myocyte enhancer factor-2 protein may play a role in the mechanism by which $5-\mathrm{HT}_{2 \mathrm{~B}}$ receptor signaling triggers cardiac remodeling (McKinsey and Olson, 2005). A cDNA encoding the $5-\mathrm{HT}_{2 \mathrm{~B}}$ receptor was found in a screen for genes encoding HDAC5 modulators, and the ability of $5-\mathrm{HT}_{2 \mathrm{~B}}$ receptors to promote HDAC5 phosphorylation and cardiomyocyte hypertrophy was confirmed (McKinsey and Olson, 2005). The 5- $\mathrm{HT}_{2 \mathrm{~B}}$ receptor-triggered intracellular calcium ion release and PKC activation accounts, at least in part, for the overexpressed receptor-induced HDAC5 phosphorylation (Chang et al., 2005).

5. Endothelial Cells. In human pulmonary artery endothelial cells, $5-\mathrm{HT}_{2 \mathrm{~B}}$ receptors stimulate calcium ion release from intracellular stores (Ullmer et al., 1996a). $5-\mathrm{HT}_{2 \mathrm{~B}}$ receptors mediate the endotheliumdependent relaxation of rat jugular vein (Ellis et al., 1995) and pig pulmonary artery (Glusa and Pertz, 2000). Activation of $5-\mathrm{HT}_{2 \mathrm{~B}} / 5-\mathrm{HT}_{1 \mathrm{~B}}$ receptors stimulates NO production in human coronary artery endothelial cells (Ishida et al., 1998). Compared with nonstimulated pulmonary artery endothelial cells, C-reactive protein-stimulated cells show downregulation of $5-\mathrm{HT}_{2 \mathrm{~B}}$ receptor by $25 \%$, of inhibitor of NF- $\kappa \mathrm{B}$ kinase subunit epsilon by $30 \%$, and of toll-like receptor4 and -6 by $18 \%$ and $39 \%$, respectively (Wynants et al., 2013). A cardioprotective function of the $5-\mathrm{HT}_{2 \mathrm{~B}}$ receptor in an integrated model of heart failure with preserved ejection fraction can be explained by a contribution of the endothelial $5-\mathrm{HT}_{2 \mathrm{~B}}$ receptors to coronary vasodilatation (Ayme-Dietrich et al., 2015).

6. Aorta. In normotensive rats, 5-HT-induced contraction of the aorta is primarily $5-\mathrm{HT}_{2 \mathrm{~A}}$ receptordependent; however, in hypertensive rats, it is mediated by both $5-\mathrm{HT}_{2 \mathrm{~A}}$ and $5-\mathrm{HT}_{2 \mathrm{~B}}$ receptors. The endothelium-denuded isolated superior mesenteric artery of hypertensive (DOCA-salt) rat displays a marked increase in maximum arterial contraction to $5-\mathrm{HT}_{2 \mathrm{~B}}$ receptor agonists when compared with control rats, confirming that the $5-\mathrm{HT}_{2 \mathrm{~B}}$ receptor plays a greater role in 5-HT-induced contraction in arteries from hypertensive rats (Watts and Fink, 1999; Banes and Watts, 2003).

7. Liver. 5-HT is a potent growth factor for liver development and regeneration. The expression of both $5-\mathrm{HT}_{2 \mathrm{~A}}$ and $5-\mathrm{HT}_{2 \mathrm{~B}}$ receptors in the liver increases following hepatectomy. $5-\mathrm{HT}_{2}$ receptor inhibition by ketanserin blocks liver regeneration when administrated close to the G1/S transition point, suggesting 5-HT as a cofactor for DNA synthesis (Papadimas et al., 2006). In $T p h 1^{-1-}$ mice, the failure of liver regeneration 
is rescued by reloading 5 -HT-free platelets with a 5 - $\mathrm{HT}$ precursor molecule (Lesurtel et al., 2006). Elderly mice have decreased ability of the liver to restore normal volume after partial hepatectomy. The $5-\mathrm{HT}_{2}$ receptor agonist DOI reverses the age-related pseudocapillarization of old liver and improves hepatosinusoidal blood flow (Furrer et al., 2011); it also enhances hepatocyte proliferation after liver transplantation in mice. $5-\mathrm{HT}_{2 \mathrm{~B}}$ receptor activation significantly improves survival in recipients of a small, otherwise nonviable graft by enhancing liver regeneration and hepatic microcirculation, thereby reducing ischemia/reperfusion injury (Tian et al., 2011). 5-HT protects the liver in an IL-6-independent manner. The protective effects of DOI is lost in animals treated with $\mathrm{SB} 206553$, a $5-\mathrm{HT}_{2 \mathrm{~B}} / 2 \mathrm{C}$ receptor antagonist. DOI may thus preserve microcirculation and accelerate liver regeneration via $5-\mathrm{HT}_{2 \mathrm{~B}}$ receptors, thus preventing the liver parenchyma from further injury (Tian et al., 2011). However, in a pathophysiological setting, the regenerative influence of $5-\mathrm{HT}$ acting through $5-\mathrm{HT}_{2 \mathrm{~A}}$ receptors on hepatocytes may be subjected to opposite antiregenerative effects arising from 5-HT acting through $5-\mathrm{HT}_{2 \mathrm{~B}}$ receptors in hepatic stellate cells (Ebrahimkhani et al., 2011). In hepatocytes, signaling through $5-\mathrm{HT}_{2 \mathrm{~B}}$ receptors also promotes gluconeogenesis (Sumara et al., 2012).

8. Gut. The $5-\mathrm{HT}_{2 \mathrm{~B}}$ receptor was initially characterized as the receptor contracting the rat stomach fundus (Vane, 1957). The 5- $\mathrm{HT}_{2 \mathrm{~B}}$ receptor is expressed by smooth muscles in the small intestine, the stomach, and by enteric neurons. 5-HT, stimulating $5-\mathrm{HT}_{2 \mathrm{~B}}$ receptors, affects the fate of the large subset of enteric neurons that arises after the development of endogenous sources of 5-HT (Fiorica-Howells et al., 2000). High levels of both 5- $\mathrm{HT}_{2 \mathrm{~B}}$ receptor mRNA and protein are found predominantly in the muscle layers and in the myenteric nerve plexus throughout the colon, where they cause neuronally mediated contractions of longitudinal muscle (Borman et al., 2002) and tonically regulate colonic motility (Bassil et al., 2009).

Ghrelin, an orexigenic peptide present in the stomach, has gastroprokinetic properties. In vivo, the ghrelin receptor antagonist D-Lys(3)-GHRP-6 reduces food intake and delays gastric emptying in rodents. D-Lys(3)GHRP-6 contracts stomach strips, an effects blocked by methysergide and yohimbine, suggesting an interaction with $5-\mathrm{HT}_{2 \mathrm{~B}}$ receptors (Depoortere et al., 2006).

Normal gastrointestinal (GI) motility requires functional interstitial cells of Cajal (ICC) that proliferate in adult mice. $5-\mathrm{HT}_{2 \mathrm{~B}}$ receptor activation increases the proliferation of ICC in vivo. On the other hand, lack of $5-\mathrm{HT}_{2 \mathrm{~B}}$ receptor signaling reduces the density of ICC networks in mature mice. Targeting $5-\mathrm{HT}_{2 \mathrm{~B}}$ receptors may protect ICC networks from injury and/or help repair them after injury (Tharayil et al., 2010).

9. Central Autonomic Nervous System. 5- $\mathrm{HT}_{2 \mathrm{~B}}$ and $5-\mathrm{HT}_{2 \mathrm{~A}}$ receptors are expressed in pontomedullary respiratory motor centers. They are colocalized in the Kolliker-Fuse and parabrachial regions of the pons and in the Bötzinger and pre-Bötzinger complex of the ventral medulla with a stronger expression of $5-\mathrm{HT}_{2 \mathrm{~A}}$ receptors in all regions. BW723C86 applied in the preBötzinger complex increases respiratory frequency and is blocked by the $5-\mathrm{HT}_{2 \mathrm{~B}}$ receptor-selective antagonist, LY272015. Hence, endogenous 5-HT appears to support tonic action on respiratory rhythm generation via $5-\mathrm{HT}_{2 \mathrm{~B}}$ receptors. However, respiratory activity is unaffected in 5- $\mathrm{HT}_{2 \mathrm{~B}}$ receptor-deficient mice; BW723C86 and LY272015 had no effects, whereas ketanserin blocked rhythmic activity. Thus, endogenous $5-\mathrm{HT}_{2 \mathrm{~B}}$ receptor activation has a stimulatory role at the pre-Bötzinger complex and hypoglossal motoneurons that can be substituted by $5-\mathrm{HT}_{2 \mathrm{~A}}$ receptors in the absence of $5-\mathrm{HT}_{2 \mathrm{~B}}$ receptors. The presence of functional $5-\mathrm{HT}_{2 \mathrm{~B}}$ receptors in the neonatal medullary breathing center suggests a potential convergent regulatory role of $5-\mathrm{HT}_{2 \mathrm{~B}}$ and $5-\mathrm{HT}_{2 \mathrm{~A}}$ receptors on the central respiratory network (Günther et al., 2006). When $5-\mathrm{HT}_{2 \mathrm{~A}}$ and $5-\mathrm{HT}_{2 \mathrm{~B}}$ receptor agonists are applied concurrently, there is a frequency increase that exceeds the effects of either agonist alone. This is an expected outcome if frequency-controlling neurons are preferred targets for $5-\mathrm{HT}_{2 \mathrm{~B}}$ receptor modulation in the pontomedullary respiratory compartment (Niebert et al., 2011).

Phrenic motor neurons express $5-\mathrm{HT}_{2 \mathrm{~B}}$ receptors, and acute intermittent hypoxia induces phrenic long-term facilitation via spinal $5-\mathrm{HT}_{2}$ receptor activation and NOX activity. Pretreatment with NOX inhibitors blocks $5-\mathrm{HT}_{2 \mathrm{~B}}$ receptor-induced phrenic motor facilitation (Macfarlane et al., 2011). Episodic spinal 5-HT receptor activation alone, without changes in oxygenation, is sufficient to elicit NOX-dependent phrenic motor facilitation. Intrathecal BW723C86 elicits progressive and sustained phrenic motor facilitation, blocked by the $5-\mathrm{HT}_{2 \mathrm{~B}}$ receptor antagonist SB206553. Spinal neuronal NOS (nNOS) activity is necessary for acute intermittent hypoxia-induced phrenic long-term facilitation (Macfarlane et al., 2014). Thus, episodic spinal NO elicits phrenic longterm facilitation via $5-\mathrm{HT}_{2 \mathrm{~B}}$ receptor activation and NOXderived ROS formation.

10. Peripheral Autonomic Nervous System. Heart rate control originates in parasympathetic preganglionic cardiac vagal neurons in the nucleus ambiguus. $5-\mathrm{HT}_{2}$ receptors modulate spontaneous and respiratoryevoked GABAergic neurotransmission to cardioinhibitory vagal neurons within the nucleus ambiguus as well as rhythmic fictive inspiratory-related activity. Neurons in the rat nucleus tractus solitarius are affected differently by $5-\mathrm{HT}_{2}$ receptor ligands regarding their vagal postsynaptic location, the type of cardiopulmonary afferent they receive, and the nature of the $5-\mathrm{HT}_{2}$ receptor. $5-\mathrm{HT}_{2 \mathrm{~B}}$ receptors are excitatory, whereas $5-\mathrm{HT}_{2 \mathrm{C}}$ receptors are inhibitory (Jordan, 2005). In neurons of the nucleus tractus solitarius receiving vagal afferent input, 
the selective $5-\mathrm{HT}_{2 \mathrm{~B}}$ receptor antagonist LY202715 significantly reduced the excitatory actions of BW723C86 on "intermediate" and "polysynaptic" cells (Sévoz-Couche et al., 2000).

Multiple, as opposed to single, applications of $\alpha$-methyl5 -HT cause a long-lasting inhibition of both spontaneous and fictive inspiratory-related GABAergic neurotransmission to cardioinhibitory vagal neurons, which are prevented by the $5-\mathrm{HT}_{2 \mathrm{~B}}$ receptor antagonist SB204741 (Dergacheva et al., 2008). BW723C86 reversibly increases both the frequency and amplitude of miniature excitatory postsynaptic currents in cardiac vagal neurons. The facilitation evoked by $\alpha$-methyl-5-HT is blocked by the $5-\mathrm{HT}_{2 \mathrm{~B} / 2 \mathrm{C}}$ receptor antagonist SB206553. Interestingly, the blockade of both NMDA and non-NMDA glutamatergic receptors did not prevent $\alpha$-methyl-5-HT-evoked facilitation of miniature excitatory postsynaptic currents; however, the responses were blocked by $\mathrm{P} 2$ receptor antagonists (Dergacheva et al., 2008). These results indicate that activation of $5-\mathrm{HT}_{2}$ receptors facilitates excitatory purinergic, but not glutamatergic, neurotransmission to cardiac vagal neurons.

11. Amygdala and Anxiety. Animals administered the $5-\mathrm{HT}_{2 \mathrm{~B}}$ receptor agonist $\mathrm{BW} 723 \mathrm{C} 86$ exhibit anxiolytic-like behavior in both the rat social interaction test and two conflict models of anxiety, the rat Geller-Seifter and marmoset conflict test (Kennett et al., 1995). Adult rat neurons in the medial amygdolid nucleus express $5-\mathrm{HT}_{2 \mathrm{~B}}$ receptors protein (Fig. 11), where local application of a $5-\mathrm{HT}_{2 \mathrm{~B}}$ receptor agonist displays anxiolytic activity in the social-interaction model but has little effect on behavior in a punished conflict model of anxiety (Kennett et al., 1996a,b). This $5-\mathrm{HT}_{2 \mathrm{~B}}$ receptor agonist also increased the time spent in feeding behavior of freely fed rats in observation cages over 15 minutes. The effect was also likely to be $5-\mathrm{HT}_{2 \mathrm{~B}}$ receptor-mediated, as no response to $\mathrm{BW} 723 \mathrm{C} 86$ was evident in freely fed rats pretreated with the $5-\mathrm{HT}_{2 \mathrm{C}}_{2 \textrm{B}}$ receptor antagonist SB206553. BW723C86 also reduced the frequency of grooming bouts of rats in observation cages (Kennett et al., 1997a). Finally, BW723C86 increased the number of punishments accepted in a rat Vogel drinking conflict paradigm over 3 minutes, as do anxiolytic benzodiazepine drugs. The antipunishment effect of BW723C86 was blocked by the $5-\mathrm{HT}_{2 \mathrm{~B}} / 2 \mathrm{C}$ receptor antagonists SB206553 or SB215505 but not by the selective $5-\mathrm{HT}_{2 \mathrm{C}}$ receptor antagonist SB242084. Thus, the antipunishment action of BW723C86 is likely to be $5-\mathrm{HT}_{2 \mathrm{~B}}$ receptor-mediated (Kennett et al., 1998).

12. Sleep. $5-\mathrm{HT}_{2 \mathrm{~A}}$ and $5-\mathrm{HT}_{2 \mathrm{C}}$ receptors modulate deep [slow wave (SW)] sleep and low-frequency EEG power in humans and rodents. Antagonists of $5-\mathrm{HT}_{2 \mathrm{~A}}$ and/or $5-\mathrm{HT}_{2 \mathrm{C}}$ receptors have a well known slow-wave sleep-enhancing effect. In contrast, blockade of 5- $\mathrm{HT}_{2 \mathrm{~B}}$ receptors increases motor activity and wakefulness along with decreased theta activity during wakefulness and REM sleep. The 5-HT $2 \mathrm{~B}$ receptor antagonist
SB215505 dose-dependently increases wakefulness at the expense of the intermediate stage of sleep, REM sleep, and slow-wave sleep and reduces low-frequency $(<8 \mathrm{~Hz})$ EEG power. In REM sleep, the $5-\mathrm{HT}_{2 \mathrm{~B}}$ receptor antagonist SB215505 dose-dependently decreases EEG power solely in the theta $(6-9 \mathrm{~Hz})$ band, primarily affecting the peak power value $(7 \mathrm{~Hz}$ ) (Kantor et al., 2004). 5-HT exerts a 5-HT $2 \mathrm{~B}$ receptor-mediated facilitation of NREM sleep and an influence that is, respectively, inhibitory on NREM sleep and facilitatory on sleep apnea generation via $5-\mathrm{HT}_{2 \mathrm{~A}}$ receptors (Popa et al., 2005). $\mathrm{Htr}_{2 B}^{-1-}$ mice exhibited significantly increased wakefulness, with less NREM sleep, whereas REM sleep is not affected. Chronic oral intake of haloperidol restored the balance between wakefulness and NREM sleep in $\mathrm{Htr}_{2 B}^{-1-}$ mice (Pitychoutis et al., 2015). Activation of $5-\mathrm{HT}_{2 \mathrm{~B}}$ receptors may thus contribute to initiation of sleep and to theta generation during wakefulness and REM sleep under physiologic conditions. However, it should be kept in mind that, clinically, there have been no successes in insomnia/sleep disorders with $5-\mathrm{HT}_{2}$ receptor antagonists in spite of multiple attempts, at least with $5-\mathrm{HT}_{2 \mathrm{~A}}$ receptor antagonists.

\section{J. Clinical Relevance}

1. Feeding and Anorexigens. The hypophagic response to the anorexigen and 5-HT releaser, dexfenfluramine, observed in wild-type mice is absent in $\mathrm{Htr}_{2 B}^{-1-}$ mice or in wild-type mice treated with RS127445. The dexfenfluramine-induced hypothalamic peak of 5-HT release is strongly reduced in $\mathrm{Htr}_{2 B}^{-1-}$ awake mice

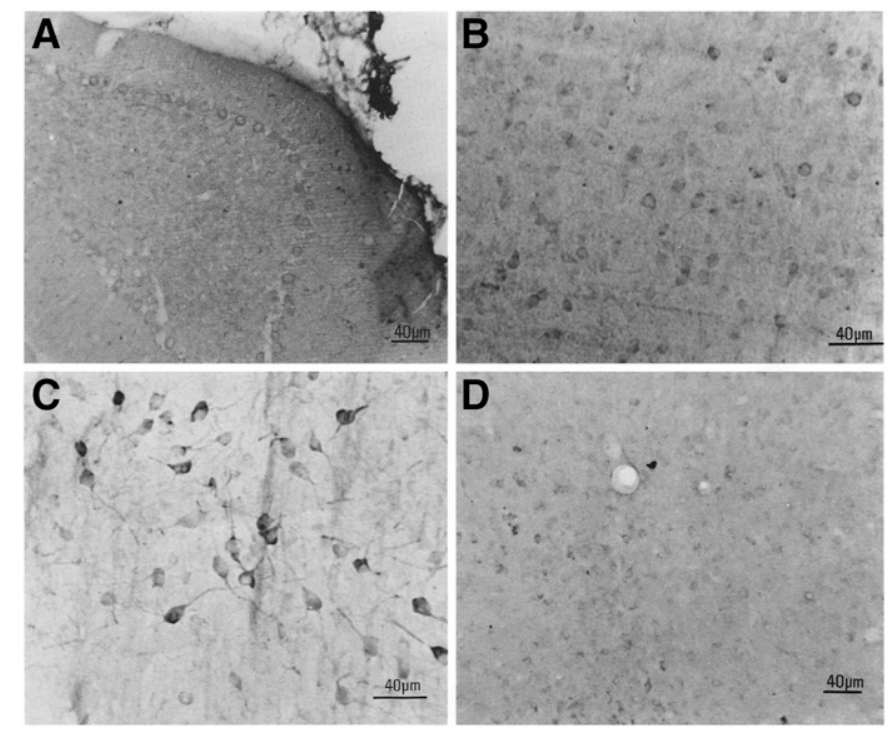

Fig. 11. $5-\mathrm{HT}_{2 \mathrm{~B}}$ receptor immunoreactivity in rat brain. Immunohistochemical detection of $5-\mathrm{HT}_{2 \mathrm{~B}}$ receptor immunoreactivity within Purkinje cells in the cerebellum (A), multipolar neurons in the lateral septum (B), multipolar and bipolar neurons in the medial amygdala $(C)$, and cells in the dorsal hypothalamic nucleus (D). In each case, the staining was abolished in adjacent sections by coincubation with synthetic $5-\mathrm{HT}_{2 \mathrm{~B}}$ receptor peptide (data not shown). Adapted from Duxon et al. (1997) (with permission). 
compared with control mice. Dexfenfluramine-induced 5 -HT release is observed in synaptosomal preparation from wild-type mice but absent in $\mathrm{Htr}_{2 B}^{-1-}$ mice (Banas et al., 2011). 5- $\mathrm{HT}_{2 \mathrm{~B}}$ receptor-induced $\mathrm{NO}$ production phosphorylates SERT and maximizes 5-HT uptake in raphe neuron primary culture. $5-\mathrm{HT}_{2 \mathrm{~B}}$ receptor-PKC coupling promotes additional phosphorylation of both SERT and $\mathrm{Na}^{+}, \mathrm{K}^{+}$-ATPase $\alpha$-subunit, impairing the electrochemical gradient necessary for 5-HT uptake. Such 5-HT $2 \mathrm{~B}$ receptor-mediated control of SERT activity operated in primary neurons from the raphe nuclei (Launay et al., 2006). Thus, activation of $5-\mathrm{HT}_{2 \mathrm{~B}}$ receptors is a limiting step in the SERT-dependentreleasing effect of dexfenfluramine, whereas other 5-HT receptors may act downstream with respect to feeding behavior.

2. Raphe and Antidepressant Activity. 5-HT neurotransmission is tightly regulated by autoreceptors that fine-tune 5-HT neurotransmission through negative feedback inhibition at the cell bodies (predominantly $5-\mathrm{HT}_{1 \mathrm{~A}}$ ) or at the axon terminals (predominantly $5-\mathrm{HT}_{1 \mathrm{~B}}$ ), although $5-\mathrm{HT}_{2 \mathrm{~B}}$ receptors may play different roles (McDevitt and Neumaier, 2011). The therapeutic effects induced by 5-HT-selective reuptake inhibitor (SSRI) antidepressants are initially triggered by blocking the SERT and rely on long-term adaptations of preand postsynaptic receptors. Long-term behavioral and neurogenic SSRI effects were abolished after either genetic or pharmacologic inactivation of $5-\mathrm{HT}_{2 \mathrm{~B}}$ receptors (Diaz et al., 2012). Conversely, direct agonist stimulation of $5-\mathrm{HT}_{2 \mathrm{~B}}$ receptors induced an SSRI-like response in behavioral and neurogenic assays. The $5-\mathrm{HT}_{2 \mathrm{~B}}$ receptor is expressed in raphe serotonergic neurons. The SSRI-induced increase in hippocampal extracellular 5-HT concentration is strongly reduced in the absence of functional $5-\mathrm{HT}_{2 \mathrm{~B}}$ receptors; hence, selective $5-\mathrm{HT}_{2 \mathrm{~B}}$ activation mimics SSRI effects (Diaz et al., 2012). Thus, the 5- $\mathrm{HT}_{2 \mathrm{~B}}$ receptor modulates $5-\mathrm{HT}$ neuron activity and may be required for the therapeutic actions of SSRIs.

3. Dopamine and Antidepressant Activity. Agomelatine, a potent melatonin MT1/MT2 receptor agonist, is an effective antidepressant and a potent $5-\mathrm{HT}_{2 \mathrm{~B} / 2 \mathrm{C}}$ receptor antagonist (Millan et al., 2003). Twice daily melatonin increases the number of spontaneously active dopamine neurons without affecting noradrenaline neurons. Long-term administration of either melatonin or the $5-\mathrm{HT}_{2 \mathrm{C}}$ receptor antagonist SB242084 has no effect on the firing rate and burst parameters of 5-HT and dopamine neurons, whereas their combination enhances the number of spontaneously active dopamine neurons while leaving the firing of 5 -HT neurons unchanged. The addition of the $5-\mathrm{HT}_{2 \mathrm{~B}}$ receptor antagonist LY266097 to the previous regimen, which by itself is devoid of effect, increases the activity of dopamine neurons (Chenu et al., 2014). Hence, the combination of melatonin receptor activation, $5-\mathrm{HT}_{2 \mathrm{C}}$, and $5-\mathrm{HT}_{2 \mathrm{~B}}$ receptor blockade results in a disinhibition of dopamine neurons, reproducing the antidepressant effect of agomelatine.

4. Serotonin (5-HT) Syndrome. The 5-HT syndrome occurs in humans after a combination of drugs inducing a massive increase in extracellular 5-HT or direct targeting of several 5-HT receptor subtypes [see Scotton et al. (2019)]. Htr ${ }_{2 B}^{--}$mice are more prone to develop the 5-HT syndrome symptoms after administration of high dose of SSRI or the 5-HT precursor, 5-hydroxytryptophan, although increases in 5-HT plasma levels are similar in both genotypes (Diaz and Maroteaux, 2011).

5. Drug of Abuse. The "club drug" MDMA ("ecstasy") inhibits SERT activity, releasing 5-HT stores from nerve terminals. The subsequent activation of postsynaptic 5-HT receptors by released 5-HT is critical for the unique psychostimulatory effects of MDMA. Acute pharmacological inhibition or genetic ablation of the $5-\mathrm{HT}_{2 \mathrm{~B}}$ receptor in mice completely abolishes MDMAinduced hyperlocomotion and 5-HT release in nucleus accumbens and ventral tegmental area. The MDMAstimulated release of endogenous 5-HT from superfused midbrain synaptosomes is $5-\mathrm{HT}_{2 \mathrm{~B}}$ receptor-dependent (Doly et al., 2008). Htr ${ }_{2 B}^{-1-}$ mice show no behavioral sensitization or conditioned place preference following MDMA. In addition, MDMA-induced reinstatement of conditioned place preference and locomotor sensitization are both abolished by RS127445 in mice, whereas MDMA-induced dopamine D1 receptor-dependent phosphorylation of extracellular regulated kinase in nucleus accumbens is abolished in mice lacking functional $5-\mathrm{HT}_{2 \mathrm{~B}}$ receptors. These results underpin the importance of $5-\mathrm{HT}_{2 \mathrm{~B}}$ receptors in the reinforcing properties of MDMA (Doly et al., 2009).

The selective 5-HT $2 \mathrm{~B}$ receptor antagonist LY266097 reduces dopamine outflow in the ventral striatum/nucleus accumbens but not in the dorsal striatum (Auclair et al., 2010). The locomotor response of $\mathrm{Htr}_{2 B}^{-1-}$ mice to both dizocilpine and amphetamine is significantly enhanced compared with control mice (Pitychoutis et al., 2015). $5-\mathrm{HT}_{2 \mathrm{~B}}$ receptor antagonists reduce cocaine-induced hyperlocomotion independently of changes of subcortical dopamine outflow, supporting a regulatory control exerted by this receptor on ascending dopamine pathways (Devroye et al., 2015). Thus, $5-\mathrm{HT}_{2 \mathrm{~B}}$ receptors may also exert, in addition to 5-HT neurons, a facilitatory control on mesoaccumbens dopamine pathway activity.

6. Impulsivity. A functional stop codon in the human $5-\mathrm{HT}_{2 \mathrm{~B}}$ receptor gene enhances impulsive behavior (Bevilacqua et al., 2010). Especially under conditions in which control is impaired, the carriers of the stop codon are more vulnerable to alcohol and more impulsive upon drinking. Similarly, $\mathrm{Htr}_{2 B}^{-1-}$ mice display more impulsive choice in delayed discounting tasks, sought novelty, and are more active after receiving a $D_{1}$ dopamine receptor agonist (Bevilacqua et al., 2010). Interestingly, early onset schizophrenia is more prevalent in human 
$5-\mathrm{HT}_{2 \mathrm{~B}}$ receptor gene $\mathrm{Q} * 20$ carriers. Domains related to the positive, negative, and cognitive symptom clusters of schizophrenia are affected in $\mathrm{Htr}_{2 B}^{-1-}$ mice, with deficits in sensorimotor gating, selective attention, social interactions, learning, and memory processes. $\mathrm{Htr}_{2 B}^{-1-}$ mice show enhanced locomotor response to dizocilpine and amphetamine and alterations in sleep architecture. $5-\mathrm{HT}_{2 \mathrm{~B}}$ receptor ablation induces a region-selective decrease of dopamine and glutamate concentrations in the dorsal striatum. Importantly, selected schizophrenic-like phenotypes and endophenotypes are rescued by chronic haloperidol treatment (Pitychoutis et al., 2015). The phenotypes of $\mathrm{Htr}_{2 B}^{-1-}$ mice result from a combination of both the direct absence of $5-\mathrm{HT}_{2 \mathrm{~B}}$ receptor signaling and the resultant neural adaptations.

7. Fragile X Syndrome. Fragile X syndrome, caused by the loss of Fmr1 gene function, is the most common form of inherited mental retardation, with no current effective treatment. $5-\mathrm{HT}_{2 \mathrm{~B}}$ receptor activation moderately enhances Ras-PI3K/PKB signaling input, GluA1dependent synaptic plasticity, and learning in Fmr1 knockout mice without causing anxiety-related side effects (Lim et al., 2014).

8. Cardiovascular Diseases. $5-\mathrm{HT}_{2 \mathrm{~B}}$ receptors are overexpressed in heart tissue from patients with congestive heart failure, in parallel to increased cytokine and norepinephrine plasma levels (Jaffre et al., 2009). 5-HT plasma levels are also increased in patients with heart failure and in rodents with cardiac hypertrophy induced by aortic constriction. Thus, 5-HT-induced cardiac hypertrophy and/or heart failure may be $5-\mathrm{HT}_{2 \mathrm{~B}}$ receptor-dependent or at least have responses likely exacerbated via the lack of $5-\mathrm{HT}_{2 \mathrm{~B}}$ receptor. In support of which, $5-\mathrm{HT}_{2 \mathrm{~B}}$ receptor $\mathrm{KO}$ mice do not develop isoproterenol-induced left-ventricular hypertrophy (Jaffré et al., 2004). Mice expressing the $5-\mathrm{HT}_{2 \mathrm{~B}}$ receptor exclusively in cardiomyocytes, similarly to global 5- $\mathrm{HT}_{2 \mathrm{~B}}$ receptor-null mice, are resistant to isoproterenol-induced cardiac hypertrophy and dysfunction as well as to isoproterenol-induced increases in plasma cytokine levels (Jaffre et al., 2009). In primary culture of cardiac fibroblasts, angiotensin II- and isoproterenol-stimulated NOX activity is prevented by the selective $5-\mathrm{HT}_{2 \mathrm{~B}}$ receptor antagonist (SB215505). SB215505 prevents the increase in cardiac superoxide generation and hypertrophy in two models of cardiac hypertrophy (i.e., angiotensin II and isoproterenol infusions in mice) (Monassier et al., 2008). A functional interaction between $\mathrm{AT}_{1}$ and $5-\mathrm{HT}_{2 \mathrm{~B}}$ receptors via a transinhibition mechanism may involve heterodimeric receptor complexes and trigger cytokine release in cardiac fibroblasts (Jaffre et al., 2009).

The 5- $\mathrm{HT}_{2 \mathrm{~B}}$ receptor is involved in cardiac hypertrophy by acting directly on cardiac myocytes. After 2 weeks of aortic banding surgery, 5 - $\mathrm{HT}_{2 \mathrm{~B}}$ receptor $\mathrm{mRNA}$ and protein expression are increased. SB215505 significantly reduces the arising increase in heart weight, heart wall thickness, left-ventricular mass, and expression of the brain natriuretic peptide (BNP) but does not attenuate the upregulation of $5-\mathrm{HT}_{2 \mathrm{~B}}$ receptor protein expression in rats after aortic banding. Following in vitro mechanical stretch of cardiomyocytes and incubation with $5-\mathrm{HT}$, the level of $5-\mathrm{HT}_{2 \mathrm{~B}}$ receptors and $\mathrm{BNP}$ protein increases time-dependently. $5-\mathrm{HT}_{2 \mathrm{~B}}$ receptor siRNA applied to cardiomyocytes reversed both the increase of $\mathrm{NF}-\kappa \mathrm{B}$ translocation and BNP protein induced by 5 -HT incubation plus mechanical stretch (Liang et al., 2006). 5- $\mathrm{HT}_{2 \mathrm{~B}}$ receptors are involved in the generation of apoptotic events associated with cardiac remodeling during increased adrenergic stimulation (Bai et al., 2010). Thus, there is a dual role for $5-\mathrm{HT}_{2 \mathrm{~B}}$ receptors on both cardiomyocytes and cardiac fibroblasts in regulating cardiac hypertrophy in vivo.

9. Pulmonary Arterial Hypertension. Pulmonary arterial hypertension (PAH) is a progressive and often fatal disorder that results from increased pulmonary blood pressure associated with abnormal vascular proliferation. 5-HT is associated with the pathogenesis of PAH (Chan and Loscalzo, 2008). Therapeutics with PAH as a side effect (e.g., dexfenfluramine) are potent 5 -HT releasers acting at SERT and/or $5-\mathrm{HT}_{2 \mathrm{~B}}$ receptor agonists (Weir et al., 2008). The blockade of 5- $\mathrm{HT}_{2 \mathrm{~B}}$ receptors, either by genetic $\left(\mathrm{Htr}_{2 B}^{-1}\right)$ or pharmacologic inactivation $\left(5-\mathrm{HT}_{2 \mathrm{~B}}\right.$ receptor antagonist $\left.\mathrm{RS} 127445\right)$, completely prevents the development of hypoxia-induced pulmonary hypertension in mice and lung remodeling including the increase in vascular proliferation, elastase activity, and TGF $\beta 1$ levels (Launay et al., 2002). In the monocrotaline-induced pulmonary hypertension model, a number of $5-\mathrm{HT}_{2 \mathrm{~B}}$ receptor antagonists (terguride, PRX-08066, or C-122) reduce pulmonary pressure, arterial wall thickening, and lumen occlusion but maintained cardiac function (Porvasnik et al., 2010; Dumitrascu et al., 2011; Zopf et al., 2011). Pulmonary hypertension is associated with a substantial increase in $5-\mathrm{HT}_{2 \mathrm{~B}}$ receptor expression in the pulmonary arteries of both rodents and humans (Launay et al., 2002; Dumitrascu et al., 2011). Activation of $5-\mathrm{HT}_{2 \mathrm{~B}}$ receptors appears to be, therefore, a limiting step in the development of pulmonary hypertension. However, the restricted expression of $5-\mathrm{HT}_{2 \mathrm{~B}}$ receptors to bone marrow cells is necessary and sufficient for pulmonary hypertension to develop via an action at hematopoietic stem cell differentiation (Launay et al., 2012). There appears to be a limiting role of $5-\mathrm{HT}_{2 \mathrm{~B}}$ receptors in $\mathrm{PAH}$ development; thus, the contribution of 5-HT to PAH may be an extrapulmonary, and specifically hematopoietic, event.

10. Vascular Hypertension. Mesenteric arteries from DOCA-salt hypertensive rodents predominantly contract via $5-\mathrm{HT}_{2 \mathrm{~B}}$ receptors; they display an increase in $5-\mathrm{HT}_{2 \mathrm{~B}}$ receptor mRNA and receptors (Watts et al., 1996). The isolated endothelium-denuded superior mesenteric artery of DOCA-salt rats displays a marked 
increase in the maximal contraction to the $5-\mathrm{HT}_{2 \mathrm{~B}}$ receptor agonist $\mathrm{BW} 723 \mathrm{C} 86$. In chronically instrumented rats, the $5-\mathrm{HT}_{2 \mathrm{~B}}$ receptor antagonist LY272015 significantly reduces mean blood pressure (Watts and Fink, 1999). LY272015 also inhibited 5-HT-induced contractions in aorta from rats made hypertensive by exposure to the nitric-oxide synthase inhibitor N(omega)-nitro-Larginine, whereas ketanserin was inactive (Russell et al., 2002). Thus, the $5-\mathrm{HT}_{2 \mathrm{~B}}$ receptor appears to play an important role in 5-HT-induced contraction in hypertensive rodent arteries.

11. Fibrosis. 5-HT increases proliferation and collagen synthesis of lung fibroblasts. 5-HT concentrations in lung homogenates increase significantly following bleomycin-induced fibrosis, paralleled with an increased expression of $5-\mathrm{HT}_{2 \mathrm{~A}}$ and $5-\mathrm{HT}_{2 \mathrm{~B}}$ receptors (Königshoff et al., 2010). Blockade of $5-\mathrm{HT}_{2 \mathrm{~B}}$ receptors by SB215505 reduces bleomycin-induced lung fibrosis, with reduced lung collagen levels and procollagen 1 and 3 mRNA expression. $5-\mathrm{HT}_{2 \mathrm{~B}}$ receptor antagonists decrease levels of lung TGF $\beta 1$ mRNA, connective tissue growth factor and plasminogen activator inhibitor-1, and JunD mRNA, consistent with their antifibrotic activity. Interestingly, the $5-\mathrm{HT}_{2 \mathrm{~B}}$ receptor is strongly overexpressed in fibroblastic foci in human idiopathic pulmonary fibrosis (Fabre et al., 2008). Thus, it is likely that 5 -HT-induced lung fibrosis is controlled by $5-\mathrm{HT}_{2 \mathrm{~B}}$ receptors regulating TGF $\beta 1$ levels.

In the liver, fibrogenic HSC, which are negative regulators of hepatocyte regeneration, are known to express both $5-\mathrm{HT}_{2 \mathrm{~A}}$ and $5-\mathrm{HT}_{2 \mathrm{~B}}$ receptors, which may regulate TGF $\beta 1$ and Smad signaling (Li et al., 2006). HSCs play a key role in hepatic wound healing and fibrosis. After $\mathrm{HSC}$ activation, expression of $5-\mathrm{HT}_{2 \mathrm{~A}}$ and $5-\mathrm{HT}_{2 \mathrm{~B}}$ receptors is around 100 - and 50 -fold that of quiescent cells, respectively. The $5-\mathrm{HT}_{2 \mathrm{~B}}$ receptor expression is strongly associated with fibrotic tissue in diseased liver. $5-\mathrm{HT}_{2}$ receptor antagonist-treated $\mathrm{HSCs}$ display suppressed proliferation and increased apoptosis. 5-HT synergizes with platelet-derived growth factor to stimulate HSC proliferation (Ruddell et al., 2006). In contrast to quiescent cells, activated HSCs exhibit $\left[\mathrm{Ca}^{2+}\right] \mathrm{i}$ transients following treatment with 5-HT, which is inhibited by ritanserin. Expression of type 1 inositol-5' -triphosphate receptor and type 2 sarcoplasmic/endoplasmic reticulum $\mathrm{Ca}^{2+}$ ATPase is also increased during activation of HSCs and serves as the major isotype for $\mathrm{ER} \mathrm{Ca}^{2+}$ storage and release in activated HSCs. ER $\mathrm{Ca}^{2+}$-binding chaperone proteins, including calreticulin, calnexin, and calsequestrin, are upregulated following activation of HSCs (Park et al., 2011). 5- $\mathrm{HT}_{2 \mathrm{~B}}$ receptor stimulation of HSCs increases the expression of TGF $\beta 1$ (a powerful suppressor of hepatocyte proliferation) via ERK/JunD signaling. Similar effects are evident in mice lacking $5-\mathrm{HT}_{2 \mathrm{~B}}$ receptor or JunD or when HSCs have been selectively depleted. $5-\mathrm{HT}_{2 \mathrm{~B}}$ receptor blockade attenuates fibrogenesis and improves liver function in disease models in which fibrosis is pre-established and progressive (Ebrahimkhani et al., 2011). Therefore, the hepatic $5-\mathrm{HT}_{2 \mathrm{~B}}$ receptor appears to have a dual role, promoting regeneration in physiologic conditions and fibrosis in pathologic conditions.

Dermal fibrosis is reduced in $\mathrm{Htr}_{2 B}^{-1-}$ mice using both inducible and genetic models of fibrosis. Pharmacologic inactivation of the $5-\mathrm{HT}_{2 \mathrm{~B}}$ receptor effectively prevents the onset of experimental fibrosis and ameliorates established fibrosis by decreasing mRNA levels of TGF $\beta 1$, connective growth factor, plasminogen activator inhibitor1, and Smad-3 (Dees et al., 2011). Moreover, inhibition of platelet activation prevents fibrosis in models of skin fibrosis. In TPH1-deficient mice, the rate-limiting enzyme for 5-HT production outside the central nervous system shows reduced experimental skin fibrosis (Dees et al., 2011). Skin fibrosis is thus controlled by $5-\mathrm{HT}_{2 \mathrm{~B}}$ receptors via regulation of TGF $\beta 1$ levels.

Treatment of neonatal rat cardiac fibroblasts with 5 -HT increases the expression of smooth muscle $\alpha$-actin, a marker of fibroblast differentiation into myofibroblasts and stimulated cardiac fibroblast migration. 5-HT enhances secretion of TGF $\beta 1$ and expression of MMPs in cardiac fibroblasts (Yabanoglu et al., 2009). 5-HT- or AngII-stimulated cytokine release and secretion of TGF $\beta 1$ in adult cardiac fibroblasts is sensitive to $5-\mathrm{HT}_{2 \mathrm{~B}}$ receptor blockade. Treatments with epidermal growth factor receptor (ErbB1/4)-selective inhibitors or with selective inhibitors of MMPs also abolished AngIIand 5-HT-induced cytokine release. Finally, the use of $H B-E G F^{-1-}$ cardiac fibroblasts confirmed that epidermal growth factor receptor stimulation is absolutely required for AngII- and 5-HT-dependent cytokine release (Jaffre et al., 2009). Collectively, these results highlight that a convergent action of norepinephrine, AngII, and 5-HT via interactions between $\mathrm{AT}_{1}$ and $5-\mathrm{HT}_{2 \mathrm{~B}}$ receptors coexpressed by noncardiomyocytes is limiting key events in cardiac hypertrophy.

12. Valvular Heart Disease. Valvular heart disease occurs in over $65 \%$ of patients with carcinoid syndrome and is characterized by fibrous thickening of cardiac valves, leading to heart failure [for review, see Roth (2007)]. High plasma 5-HT levels correlate with valvular abnormalities detected by cardiac catheterization and echocardiography (Robiolio et al., 1995). The similarity of lesions in carcinoid heart disease and in methysergide-associated valvular disease suggested a direct stimulation of myofibroblast growth by an unknown 5-HT receptor agonism (Hendrikx et al., 1996). The increase in fenfluramine-associated valvular heart disease raised concerns that other 5-HT-relevant medications might also increase the risk of valvular heart disease (Connolly et al., 1997). Dexfenfluramine had been approved in the United States for long-term use as an appetite suppressant until it was associated with valvular heart disease. The valvular changes 
(myofibroblast proliferation) are histopathologically indistinguishable from those observed in carcinoid disease or following long-term exposure to $5-\mathrm{HT}_{2}$ receptorpreferring ergot drugs (ergotamine, methysergide). The amphetamine derivative, MDMA ("ecstasy"), and its $\mathrm{N}$-demethylated metabolite, 3,4-methylenedioxyamphetamine (MDA), both preferentially bind to and activate human recombinant $5-\mathrm{HT}_{2 \mathrm{~B}}$ receptors. Like fenfluramine and norfenfluramine, they elicit mitogenic responses in human valvular interstitial cells via likely activation of $5-\mathrm{HT}_{2 \mathrm{~B}}$ receptors (Setola et al., 2003). Based on these strikingly similar echocardiographic and histopathologic features, it is now considered that ergot-derived dopamine agonists (e.g., pergolide and cabergoline) cause a valvular heart disease nearly identical to that seen in patients with carcinoid syndrome (Horvath et al., 2004). Population studies of patients with Parkinson disease compared with nonparkinsonian controls show that pergolide and cabergoline have a similar risk of inducing fibrotic changes in cardiac valve leaflets. Pergolide and cabergoline have high affinity for the $5-\mathrm{HT}_{2 \mathrm{~B}}$ receptors. The frequency of moderate-to-severe regurgitation in at least one heart valve was higher in patients receiving cabergoline or pergolide compared with patients taking nonergot agonists or controls, and the incidence of new-onset valvulopathy was relatively high in patients taking the ergot-derived drugs (Antonini and Poewe, 2007; Roth, 2007). A simultaneous mitral bioprosthesis hypertrophic scaring and native aortic valve fibrosis was recently reported following benfluorex therapy. The bioprosthesis and aortic valves exhibit similar histopathological lesions. Thickening and plaque deposits made by smooth muscle $\alpha$-actin- and vimentin-positive cells in a glycosaminoglycan matrix were observed, supporting that activation of the $5-\mathrm{HT}_{2 \mathrm{~B}}$ receptor by norfenfluramine may trigger the development of drug-induced heart disease (AymeDietrich et al., 2012).

$5-\mathrm{HT}_{2 \mathrm{~B}}$ and $5-\mathrm{HT}_{2 \mathrm{~A}}$ receptor transcripts are reported to be present in heart valves, whereas no $5-\mathrm{HT}_{2 \mathrm{C}}$ receptor transcript is detectable. Preferential stimulation of valvular $5-\mathrm{HT}_{2 \mathrm{~B}}$ receptors (with or without accompanying $5-\mathrm{HT}_{2 \mathrm{~A}}$ receptor activation) may contribute to valvular fibroplasia in humans (Fitzgerald et al., 2000). Mitral valve regurgitation has been associated with increased mRNA expression of valvular $5-\mathrm{HT}_{2 \mathrm{~B}}$ receptors and SERT in pigs (Cremer et al., 2015b). Canine myxomatous mitral valve disease was associated with higher expression of $5-\mathrm{HT}_{2 \mathrm{~B}}$ receptors in mitral valve (Cremer et al., 2015a).

These findings suggest that $5-\mathrm{HT}_{2 \mathrm{~B}}$ receptor signaling links vascular damage and platelet activation to tissue remodeling and identify the $5-\mathrm{HT}_{2 \mathrm{~B}}$ receptor as a novel potential therapeutic target to treat valvular heart diseases. As a result of these investigations, the development of $5-\mathrm{HT}_{2 \mathrm{~B}}$ receptor agonists have been banned by the FDA.
13. Acute Pain. 5-HT released from mast cells or platelets in peripheral tissues is an important inflammatory mediator of pain. The involvement of 5-HT in pain is complex since it can inhibit or facilitate nociceptive transmission because of the presence of multiple functionally opposing 5-HT receptors on peripheral and central nociceptors. An acute injection of 5-HT or the 5 - $\mathrm{HT}_{2}$ receptor, agonist $\alpha$-methyl-5-HT, into hindpaws of mice induces significant hyperalgesia to mechanical stimuli, which can be inhibited by the $5-\mathrm{HT}_{2 \mathrm{~B}} / 2 \mathrm{C}$ receptor antagonist SB206553, which also blocks 5-HTinduced transient $\left[\mathrm{Ca}^{2+}\right]$ signaling in DRG neurons. $5-\mathrm{HT}_{2 \mathrm{~B}}$ receptors are involved in mechanical hyperalgesia in mice (Lin et al., 2011). 5-HT released from descending pain modulation pathways to the dorsal horn is crucial in spinal nociception processing. Local peripheral ipsilateral, but not contralateral, administration of RS127445 significantly prevents formalin-induced flinching behavior. Moreover, local peripheral ipsilateral, but not contralateral, administration of the $5-\mathrm{HT}_{2}$ receptor agonist DOI augmented formalin-induced nociception. The local pronociceptive effect of DOI is prevented by local RS127445. Moreover, intrathecal RS127445 also prevented formalin-induced nociception. By contrast, spinal DOI increases flinching behavior induced by formalin. The spinal pronociceptive effect of DOI is prevented by intrathecal RS127445 (CervantesDurán et al., 2012). It is therefore evident that $5-\mathrm{HT}_{2 \mathrm{~B}}$ receptors play a pronociceptive role in peripheral as well as spinal sites in the rat formalin test.

14. Chronic Pain. In rats subjected to spinal nerve ligation, the $5-\mathrm{HT}_{2 \mathrm{~B}}$ receptor agonist $\mathrm{BW} 723 \mathrm{C} 86$ enhances evoked potentials, whereas the $5-\mathrm{HT}_{2 \mathrm{~B}}$ receptor antagonist SB204741 depresses them. Spinal hyperexcitation promoted by $5-\mathrm{HT}_{2 \mathrm{~B}}$ receptors has been proposed as a pathogenic pathway contributing to pain (Aira et al., 2010). Plasticity of spinal serotonergic neurotransmission selectively reduces spinal $\mu$-opioid receptor mechanisms via increased expression of $5-\mathrm{HT}_{2 \mathrm{~B}}$ receptors in dorsal horn neurons also expressing the $\mu$-opioid receptor (Aira et al., 2012). The involvement of glutamate receptors in dorsal neuron hyperexcitation can also be promoted by $5-\mathrm{HT}_{2 \mathrm{~B}}$ receptor after spinal nerve ligation. Augmentation of C-fiber-evoked potentials by spinal superfusion with the $5-\mathrm{HT}_{2 \mathrm{~B}}$ receptor agonist BW723C86 in nerve-ligated rats is impeded by coadministration of NMDA receptor antagonist. Evoked potentials are increased by NMDA receptor agonist in nerve-injured rats, irrespective of simultaneous $5-\mathrm{HT}_{2 \mathrm{~B}}$ receptor blockade by SB204741. In uninjured rats, NMDA receptor agonist enhances evoked potentials in the presence of BW723C86 but not if administered alone. Blockade of $5-\mathrm{HT}_{2 \mathrm{~B}}$ receptors with the selective antagonist SB204741 after spinal nerve ligation bilaterally decreases phosphorylation of the NMDA receptor subunit NR1 (pNR1), in the synaptic fraction, and colocalization of both $\mathrm{PKC} \gamma$ and $\mathrm{pNR} 1$ with 
postsynaptic marker PSD-95. Delivery of SB204741 bilaterally attenuates thermal and mechanical allodynia occurring after spinal nerve ligation, at early time periods, day 2 postinjury. The transient activation of the PKC $\gamma /$ NMDA receptor pathway is critically involved in $5-\mathrm{HT}_{2 \mathrm{~B}}$ receptor-mediated facilitation in the spinal nerve ligation model (Aira et al., 2013). The adaptor protein NADH dehydrogenase subunit 2 (ND2) is involved in NR1 phosphorylation and spinal hyperexcitability secondary to peripheral nerve injury. Spinal nerve ligation is followed by increased colocalization of ND2 with pNR1. C-fiber-evoked dorsal horn field potentials are increased after spinal nerve ligation by superfusion with an NMDA receptor agonist. This increased postsynaptic upregulation of ND2/pNR1 can be prevented by prior administration of selective $5-\mathrm{HT}_{2 \mathrm{~B}}$ antagonist SB204741 (Aira et al., 2014). Thus, NMDA receptor phosphorylation is instrumental in coupling $5-\mathrm{HT}_{2 \mathrm{~B}}$ receptor-mediated input to NMDA receptor expressing synapses in spinal hyperexcitation involved in pain.

15. Neuropathic Pain. 5-HT was also implicated in a rat model of neuropathic pain evoked by chronic constriction injury (CCI) of the sciatic nerve. $5-\mathrm{HT}_{2 \mathrm{~B}}$ receptor activation has been reported to both prevent and reduce CCI-induced allodynia at 3 weeks postinjury. Intrathecal administration of the $5-\mathrm{HT}_{2 \mathrm{~B}}$ receptor agonist BW723C86 attenuated established mechanical and cold allodynia, an effect prevented by coinjection of RS127445. A single application of BW723C86 on the sciatic nerve concomitantly to CCI dose-dependently prevented mechanical allodynia and reduced cold allodynia 17 days after CCI. This behavioral effect is accompanied with a marked decrease in macrophage infiltration into the sciatic nerve and, in the DRG, with an attenuated abnormal expression of several markers associated with local neuroinflammation and neuropathic pain. CCI results in a marked upregulation of $5-\mathrm{HT}_{2 \mathrm{~B}}$ receptor expression in sciatic nerve and DRG. In the latter structure, it is biphasic, consisting of a transient early increase 2 days after surgery (around 23-fold) before neuropathic pain emergence, followed by a steady (around fivefold) increase that remains relatively constant until the pain disappeared. In DRG and sciatic nerve, $5-\mathrm{HT}_{2 \mathrm{~B}}$ receptors are immunolocalized on sensory neurons and infiltrating macrophages (Urtikova et al., 2012).

It thus appears that $5-\mathrm{HT}_{2 \mathrm{~B}}$ receptor involvement in pain takes place at various sites and time periods; early events are more pronociceptive, whereas at later stages, this receptor contribution may be more antinociceptive, although this varies according to the animal models.

16. Spasticity in Amyotrophic Lateral Sclerosis. Spinal cord injury leads to an initial phase of hyporeflexia followed by hyperreflexia, often referred to as spasticity. Spasticity is a common and disabling symptom also observed in patients with amyotrophic lateral sclerosis, a disease that can affect both upper and lower motor neurons. A rat tail spasticity model with a caudal spinal transection demonstrates $5-\mathrm{HT}_{2 \mathrm{~B}}$ receptor downregulation at 21 days postinjury (Wienecke et al., 2010). Motoneurons, which recover from denervation, function autonomously, exhibiting large persistent calcium currents that help with functional recovery and contribute to uncontrolled muscle spasms. Application of agonists relatively selective to $5-\mathrm{HT}_{2 \mathrm{~B}}$ receptors (including BW723C86) increase persistent calcium currents. $5-\mathrm{HT}_{2 \mathrm{~B}}$ receptors on motoneurons ultimately contribute to recovery of motoneuron function and emergence of spasms (Murray et al., 2011). In amyotrophic lateral sclerosis, spasticity is traditionally thought to be the result of degeneration of the upper motor neurons in the cerebral cortex, although degeneration of other neuronal types, particularly 5-HT neurons, might also underlie the spasticity. In superoxide dismutase 1 (G86R) mice, a transgenic model of amyotrophic lateral sclerosis, 5-HT levels are decreased in brainstem and spinal cord before onset of motor symptoms. Furthermore, there is noticeable atrophy of 5-HT neuronal cell bodies along with neuritic degeneration at disease onset. In superoxide dismutase 1 (G86R) mice, tail muscle spastic-like contractions occur at end-stage. Importantly, they are abolished by the $5-\mathrm{HT}_{2 \mathrm{~B} / 2 \mathrm{C}}$ receptors inverse agonist, SB206553. In keeping with this, $5-\mathrm{HT}_{2 \mathrm{~B}}$ receptor expression is strongly increased at disease onset (Dentel et al., 2013). In summary, 5 - $\mathrm{HT}_{2 \mathrm{~B}}$ receptors on motoneurons can become constitutively active after injury and ultimately contribute to some recovery of motoneuron function and emergence of spasms.

17. Migraine. A role for 5-HT in migraine is supported by changes in circulating levels of 5-HT and its metabolites during the phases of a migraine attack. A migraine headache is thought to be transmitted by the trigeminal nerve from the meninges and their associated blood vessels. Correlation of the receptor affinities with the potencies of drugs used in migraine prophylaxis demonstrates correlations with the $5-\mathrm{HT}_{2 \mathrm{~B}}$ receptor, and various human meningeal tissues express $5-\mathrm{HT}_{2 \mathrm{~B}}$ mRNAs (Schmuck et al., 1996). The $5-\mathrm{HT}_{2 \mathrm{~B}}$ receptor can activate the release of the smooth muscle relaxant NO and induce relaxation of the cerebral arteries and the jugular vein. $5-\mathrm{HT}_{2 \mathrm{~B}}$ receptors expressed by endothelial cells of meningeal blood vessels may trigger migraine headache through the formation of NO, which results in the dilation of cerebral blood vessels and the concomitant activation of sensory trigeminovascular afferents, thus initiating the manifestation of head pain (Johnson et al., 2003). In addition, a genetic study identified $5-\mathrm{HT}_{2 \mathrm{~B}}$ receptors as a susceptibility gene to migraine (Corominas et al., 2010). Endothelial 5- $\mathrm{HT}_{2 \mathrm{~B}}$ receptors may thus trigger dilation of meningeal blood vessels, which by activating sensory trigeminovascular afferents, induces head pain. 
18. Visceral Pain. 5- $\mathrm{HT}_{2 \mathrm{~B}}$ receptors are involved in signaling from the colon in rats, in which there is visceral hypersensitivity. Oral administration of RS127445 inhibits visceral hypersensitivity provoked by restraint stress without significant effect on the visceral nociceptive threshold of naive rats (Ohashi-Doi et al., 2010). Moreover, when administered intracerebroventricularly, RS127445 also decreases the number of pain behaviors during noxious colorectal distension. A selective $5-\mathrm{HT}_{2 \mathrm{~B}}$ receptor antagonist has thus been proposed to have therapeutic potential for the treatment of gut disorders characterized by visceral hypersensitivity (O'Mahony et al., 2010). The $5-\mathrm{HT}_{2 \mathrm{~B}}$ receptor appears thus to be involved in regulating sensory pathways but only under hyperalgesic conditions, suggesting the possible utility of $5-\mathrm{HT}_{2 \mathrm{~B}}$ receptor antagonism in reducing visceral hypersensitivity in patients with irritable bowel syndrome and other hypersensitivity conditions.

19. Bones. 5- $\mathrm{HT}_{2 \mathrm{~B}}$ receptor mRNA, which is undetectable in anaplastic osteoblasts, appears in differentiated and matured osteoblasts (Bliziotes et al., 2001; Westbroek et al., 2001). The differentiation and maturation of osteoblasts might thus be regulated by $5-\mathrm{HT}_{2 \mathrm{~B}}$ receptor activation (Hirai et al., 2009). Of interest, $\mathrm{Htr}_{2 B}^{-1-}$ female mice display reduced bone density from the age of 4 months that intensifies by 12 and 18 months. This histomorphometrically confirms that osteopenia is due to reduced bone formation (Collet et al., 2008). Using the osteoprogenitor cell line $\mathrm{C} 1$, blockade of $5-\mathrm{HT}_{2 \mathrm{~B}}$ receptor intrinsic activity affects the efficiency of mineralization by decreasing calcium incorporation. Optimal bone matrix mineralization involves both NO and PLA2 signaling pathways, and the $5-\mathrm{HT}_{2 \mathrm{~B}}$ receptor promotes prostaglandin E2 production through cyclooxygenase activation. When $\mathrm{C} 1$ osteoblasts undergo conversion into osteocyte-like cells, cyclooxygenase activity is quenched. The $5-\mathrm{HT}_{2 \mathrm{~B}}$ receptor contributes in an autocrine manner to osteogenic differentiation (Locker et al., 2006). There is a functional link between the $5-\mathrm{HT}_{2 \mathrm{~B}}$ receptor and the activity of the tissue nonspecific alkaline phosphatase (TNAP). Agonist stimulation of the receptor increases TNAP activity during the initial mineralization phase, whereas inhibition of $5-\mathrm{HT}_{2 \mathrm{~B}}$ receptor intrinsic activity prevents TNAP activation. In contrast, agonist stimulation of the receptor further increased TNAP activity during the initial mineralization phase. The $5-\mathrm{HT}_{2 \mathrm{~B}}$ receptor couples to PLA2 pathway and prostaglandin production at the beginning of mineral deposition. The $5-\mathrm{HT}_{2 \mathrm{~B}}$ receptor also controls leukotriene synthesis via PLA2 at the terminal stages of differentiation. These two 5-HT $2 \mathrm{~B}$ receptor-dependent eicosanoid productions delineate distinct time windows of TNAP regulation during the osteogenic program. Finally, prostaglandins or leukotrienes relay the post-translational activation of TNAP via stimulation of the phosphatidylinositol-specific phospholipase C. In agreement with this, primary calvarial osteoblasts from $\mathrm{Htr}_{2 B}^{-1-}$ mice exhibit defects in TNAP activity (Baudry et al., 2010). Brain 5-HT may indirectly favor bone mass accrual following activation of $5-\mathrm{HT}_{2 \mathrm{C}}$ receptors on ventromedial hypothalamic neurons and $5-\mathrm{HT}_{2 \mathrm{~B}}$ receptors on arcuate neurons (Yadav et al., 2009). Compared with control osteoblasts, the lack of $5-\mathrm{HT}_{2 \mathrm{~B}}$ receptors is associated with a 10 -fold overproduction of prostacyclin, and the specific prostacyclin synthase inhibitor (U51605) totally rescues osteoblast aggregation and matrix mineralization in $\mathrm{Htr}_{2 B}^{-{ }^{-}}$osteoblasts without effect on WT osteoblasts. Prostacyclin is the endogenous ligand of PPAR- $\beta / \delta$, and its inhibition in $\mathrm{Htr}_{2 B}^{-1-}$ cells totally rescues the alkaline phosphatase and osteopontin mRNA levels, cell-cell adhesion, and matrix mineralization. The absence of $5-\mathrm{HT}_{2 \mathrm{~B}}$ receptors leads to the overproduction of prostacyclin, inducing reduced osteoblast differentiation because of PPAR- $\beta / \delta$-dependent target regulation and defective cell-cell adhesion and matrix mineralization (Chabbi-Achengli et al., 2013). Of relevance, the 5- $\mathrm{HT}_{2 \mathrm{~A}}$ receptor is expressed only in osteoblasts, whereas $5-\mathrm{HT}_{2 \mathrm{~B}}$ receptor expression increases from precursor to mature osteoclasts (Hodge et al., 2013b). The $5-\mathrm{HT}_{2 \mathrm{~B}}$ receptor therefore appears to contribute in an autocrine manner to osteogenic differentiation.

20. Teeth Development. Periodontal diseases occur in patients treated with antidepressants such as SSRIs (e.g., fluoxetine). In the molar teeth of $\mathrm{Htr}_{2 B}^{-1-}$ mice, rod curvatures and twisting are altered compared with WT mice, suggesting involvement of the $5-\mathrm{HT}_{2 \mathrm{~B}}$ receptor at early stages of enamel formation. The volume of the enamel layer in $\mathrm{Htr}_{2 B}^{-1-}$ mice is also reduced, with smaller crystallite thickness. The outer aprismatic enamel border is 1.5- to twofold larger in $\mathrm{Htr}_{2 B}^{-1-}$ compared with WT mice. Finally, although no noticeable difference is observed in dentin, the micro-CT three-dimensional pulp reconstruction reveals a decrease in both length and width of dentin formation in the root canals of the $\mathrm{Htr}_{2 B}^{-1-}$ mice (Dimitrova-Nakov et al., 2014). Therefore, 5- $\mathrm{HT}_{2 \mathrm{~B}}$ receptors may mediate some harmful effects of longterm use of SSRIs on bone and teeth regeneration.

\section{Cancers.}

a. Carcinoid tumors. $5-\mathrm{HT}_{2 \mathrm{~B}}$ receptor expression is observed in spontaneous human carcinoid tumors, along with coupling to $\mathrm{p} 21^{\mathrm{ras}}$ activation (Launay et al., 1996). The tumor proliferative activity of small intestinal neuroendocrine tumors (including cell growth and the development of desmoplasia) is associated with the particular microenvironment in the peritoneum, and tumor cells support this necessary milieu through the secretion of profibrotic/angiogenetic factors (Svejda et al., 2010).

b. Breast tumors. Increased 5-HT biosynthetic capacity accompanied by multiple changes in 5-HT receptor expression and signaling favor malignant progression of 
human breast cancer cells. Among them, expression of $5-\mathrm{HT}_{2 \mathrm{~B}}$ receptors is increased (Pai et al., 2009). 5- $\mathrm{HT}_{2 \mathrm{~B}}$ receptor mRNA expression is lower in basal estrogen receptor-negative tumors compared with luminal tumors, which are most commonly estrogen receptor-positive. $5-\mathrm{HT}_{2 \mathrm{~B}}$ receptor mRNA is elevated in carcinomas, increased with tumor stage, and higher in lymph nodepositive tumors compared with node-negative tumors. c-Myc transformation induces an increase in 5 - $\mathrm{HT}_{2 \mathrm{~B}}$ receptor expression (Pai et al., 2009). In human breast cancer, there is a significant correlation of $5-\mathrm{HT}_{2 \mathrm{~B}}$ receptor expression with estrogen receptor- $\alpha$ expression (Kopparapu et al., 2013).

c. Melanoma. Uveal (ocular) melanoma is an aggressive cancer that often forms undetectable micrometastases before diagnosis of the primary tumor. High increases in $5-\mathrm{HT}_{2 \mathrm{~B}}$ receptor $\mathrm{mRNA}$ are evident in all uveal melanomas with monosomy 3 compared with low expression in all tumors with disomy 3. As monosomy 3 is associated with metastatic disease, $5-\mathrm{HT}_{2 \mathrm{~B}}$ receptor expression has been proposed as a marker to identify patients with poor prognosis (Tschentscher et al., 2003). The $5-\mathrm{HT}_{2 \mathrm{~B}}$ receptor gene is among the genes showing the highest overexpression in class 2 uveal melanoma (van Gils et al., 2008). A PCR-based 15-gene assay comprising 12 discriminating genes, including the $5-\mathrm{HT}_{2 \mathrm{~B}}$ receptor gene, is now part of a prognostic assay, which provides an important addition to help manage patients with uveal melanoma (Onken et al., 2010) by distinguishing whether uveal melanomas contain liver metastases and thus aid in the diagnosis and prevention of uveal melanoma liver metastases based on their different features (Zhang et al., 2014a).

d. Prostate cancer. Prostate cancer is the most commonly diagnosed noncutaneous cancer in men. Despite this fact, many of the genetic changes that coincide with prostate cancer progression remain enigmatic. The $5-\mathrm{HT}_{2 \mathrm{~B}}$ receptor has been shown to be upregulated in tumors (Magee et al., 2001). Overexpression of receptors to neuroendocrine cell products may contribute to development of hormone-refractory prostate cancer. Immunostaining for the $5-\mathrm{HT}_{2 \mathrm{~B}}$ receptor is evident in low-grade and high-grade tumors, prostatic intraepithelial neoplastic and benign prostatic hyperplasia cells, and vascular endothelial cells. Antagonists for the $5-\mathrm{HT}_{2 \mathrm{~B}}$ receptor inhibit proliferation of prostate cancer cells in a dose-dependent manner (Dizeyi et al., 2005).

e. Adrenocortical carcinoma. Gene expression profiles of adrenocortical tumors demonstrate underexpression of $5-\mathrm{HT}_{2 \mathrm{~B}}$ receptor mRNA as a marker of malignant adrenocortical carcinoma (Fernandez-Ranvier et al., 2008). Analysis of biomarkers of malignancy of adrenocortical cancers in a meta-analysis suggests the combination of overexpressed anillin and underexpressed $5-\mathrm{HT}_{2 \mathrm{~B}}$ receptor mRNA to be the best predictor of malignancy (Zsippai et al., 2011). However, in adrenocorticotropin-dependent adrenal hyperplasia, the mechanisms responsible for the ectopic adrenal expression of glucose-dependent insulinotropic peptide (GDIP) receptor in GDIP-dependent Cushing's syndrome are unknown. Chronic adrenal stimulation by GDIP in GDIP-dependent adrenocorticotropic hormoneindependent macronodular adrenal hyperplasia leads to the significant induction of genes for the GPR54, $5-\mathrm{HT}_{2 \mathrm{~B}}$, GPR4, and endothelial differentiation sphingolipid EDG8 receptor (Lampron et al., 2006).

f. Hepatocellular carcinoma. Among 64 genes for which mRNA expression differed between non-hepatitis $\mathrm{B}$ and non-hepatitis $\mathrm{C}$ compared with hepatitis C-type hepatocellular carcinoma (HCC), the most affected is the gene for the 5- $\mathrm{HT}_{2 \mathrm{~B}}$ receptor (Iizuka et al., 2004). The function of 5-HT as a survival factor of $\mathrm{HCC}$ cells has been demonstrated; activation of the $5-\mathrm{HT}_{2 \mathrm{~B}}$ receptor leads to sustained phosphorylation of two downstream targets of mTOR, p70S6K and 4E-BP1, thereby facilitating survival and inhibiting autophagy. Inhibiting the $5-\mathrm{HT}_{2 \mathrm{~B}}$ receptor reduces cancer cell growth in vitro and in vivo. The presence of $5-\mathrm{HT}_{2 \mathrm{~B}}$ receptors in $\mathrm{HCC}$ and the activation of autophagy-related mechanisms provide novel insights of 5-HT in cancer biology and propose 5-HT-mediated signaling as a therapeutic target (Soll et al., 2010). $5-\mathrm{HT}_{1 \mathrm{~B}}$ and $5-\mathrm{HT}_{2 \mathrm{~B}}$ receptors are expressed, respectively, in around $32 \%$ and $35 \%$ of the patients with hepatocellular cancer. Both receptors are associated with an increased proliferation index (Soll et al., 2012). The $5-\mathrm{HT}_{2 \mathrm{~B}}$ receptor mediates 5-HT-induced proliferation in the serum-deprived $\mathrm{HCC} \mathrm{Huh} 7$ cells. Additionally, selective $5-\mathrm{HT}_{2 \mathrm{~B}}$ receptor antagonism using SB204741 in Huh7 cells decreases the expression of FOXO3a (Liang et al., 2013).

g. T-cell leukemia. A proteasome inhibitor, bortezomib, is a potential therapeutic agent to treat adult T-cell leukemia. A network including the $5-\mathrm{HT}_{2 \mathrm{~B}}$ receptor was identified that converges upon the secreted protein acidic and rich in cysteine gene, a tumor-invasiveness-related gene, which may act as a modulator of bortezomib-induced cell death in adult T-cell leukemia cells (Ohyashiki et al., 2008).

$h$. Myosarcoma. In the pathogenesis of uterine leiomyosarcoma, there is a fourfold overexpression of the $5-\mathrm{HT}_{2 \mathrm{~B}}$ receptor gene, and it is one of the most overexpressed genes (Arslan et al., 2005; Matsumura et al., 2006).

$i$. Tumor angiogenesis. 5-HT does not enhance colon cancer tumor cell proliferation but may act as a regulator of angiogenesis by reducing the expression of MMP-12 and lower levels of angiostatin-an endogenous inhibitor of angiogenesis (Nocito et al., 2008). 5-HT stimulates the phosphorylation of ERK1/2 in bovine endothelial cells, and the $5-\mathrm{HT}_{2 \mathrm{~B}}$ receptor plays a role in the activation of eNOS in human endothelial cells. In SB204741-treated mice, the selective blockade of the $5-\mathrm{HT}_{2 \mathrm{~B}}$ receptor results in the reduction of tumor angiogenesis and growth through the inhibition effect of ERK1/2 and eNOS (Asada et al., 2009). Therefore, the $5-\mathrm{HT}_{2 \mathrm{~B}}$ receptor may participate in tumor angiogenesis. 


\section{Clinically Relevant Knowledge Gained from the} Gene.

a. The human 5-HT $T_{2 B}$ receptor gene. The human $5-\mathrm{HT}_{2 \mathrm{~B}}$ receptor gene (MIM 601122) is located on chromosome 2q37.1 (Le Coniat et al., 1996). The human $5-\mathrm{HT}_{2 \mathrm{~B}}$ receptor gene rate of evolution displays high conservation in primates (Andrés et al., 2007). Within the 23 sites that are highly conserved among primates and that have changed on the modern human lineage after separation from Denisovan ancestors, one (D216N) is found in ECL2 of the $5-\mathrm{HT}_{2 \mathrm{~B}}$ receptor, suggesting that crucial aspects of synaptic transmission involving the receptor may have changed in modern humans (Meyer et al., 2012). There is evidence of the contribution of $5-\mathrm{HT}_{2 \mathrm{~B}}$ receptor gene variants to intelligence quotation, intellectual disability, and language onset delay in patients with autism spectrum disorders (ASD) (Hervas et al., 2014).

The $5-\mathrm{HT}_{2 \mathrm{~B}}$ receptor gene was identified as a susceptibility gene for impulsivity disorders; one single-nucleotide polymorphism (SNP) introducing a stop codon after amino acid 21 was found more frequently in severely impulsive individuals presenting suicidal behavior (Bevilacqua et al., 2010). In the same cohort, early-onset schizophrenia was more prevalent in $5-\mathrm{HT}_{2 \mathrm{~B}}$ receptor gene $\mathrm{Q} * 20$ carriers. Other work testing SNPs within the $5-\mathrm{HT}_{2 \mathrm{~B}}$ receptor gene for potential associations with the behavioral inhibition system and the three components of the behavioral approach system (fun-seeking, drive, and reward responsiveness) in a Han Chinese sample found four $5-\mathrm{HT}_{2 \mathrm{~B}}$ receptor gene SNPs significantly associated with behavioral approach system fun-seeking (Zhu et al., 2012a).

Several SNPs confer a double-mutant R6G/E42G of the receptor protein associated with drug abuse, suggesting that $5-\mathrm{HT}_{2 \mathrm{~B}}$ receptor contributes to pathways that are involved in drug dependence (Lin et al., 2004). Peripheral blood DNA methylation levels of CpGs in the promoter regions were examined in African Americans and European Americans. In European Americans, six CpGs in the 5- $\mathrm{HT}_{2 \mathrm{~B}}$ receptor gene promoter are significantly hypermethylated in alcohol-dependent cases (Zhang et al., 2013a).

An association study on susceptibility to migraine in a Spanish population supports the involvement of the $5-\mathrm{HT}_{2 \mathrm{~B}}$ receptor gene and the monoamine oxidase $\mathrm{A}$ gene in the genetic predisposition to migraine without aura (Corominas et al., 2010). Finally, by investigating the $5-\mathrm{HT}_{2 \mathrm{~B}}$ receptor gene in patients who developed pulmonary hypertension after use of fenfluramine, a heterozygous mutation was identified in one female patient who, 5 years earlier, had followed a 9-month anorexigen treatment (Blanpain et al., 2003). This heterozygous mutation $\mathrm{R} 393 \mathrm{X}$ in the $5-\mathrm{HT}_{2 \mathrm{~B}}$ receptor generates a carboxy terminus-truncated receptor characterized by a switch of coupling from $\mathrm{G} \alpha \mathrm{q} / 11$ to $\mathrm{G} \alpha 13$, reduced NOS activation, and an increase in cell proliferation, modifications relevant to pathophysiological vasoconstriction (Deraet et al., 2005).

\section{5-HT 2 Receptor}

\section{A. Introduction}

The $5-\mathrm{HT}_{2 \mathrm{C}}$ receptor is a $\mathrm{G}$ protein-coupled receptor (GPCR) with the characteristic seven-transmembrane domain structure with an extracellular $\mathrm{N}$ terminus and intracellular $\mathrm{C}$ terminus. Binding of 5-HT to the $5-\mathrm{HT}_{2 \mathrm{C}}$ receptor results in a conformational change that catalyzes the diffusion of multiple second messenger effectors. The canonical $G$ protein-dependent signaling through the $5-\mathrm{HT}_{2 \mathrm{C}}$ receptor is engendered by 5 -HTstimulated coupling predominantly to $\mathrm{G} \alpha_{\mathrm{q} / 11}$ to activate the enzyme phospholipase C (PLC), which generates phosphoinositide hydrolysis and intracellular calcium $\left(\mathrm{Ca}_{i}^{2+}\right)$ mobilization (Conn and Sanders-Bush, 1986a; Hoyer et al., 1989c; Chang et al., 2000).The 5- $\mathrm{HT}_{2 \mathrm{C}}$ receptor also signals through other second messengers, which can include phospholipase D (PLD) and phospholipase $\mathrm{A}_{2}\left(\mathrm{PLA}_{2}\right)$, cyclic nucleotides, and extracellular signal-regulated kinases (Berg et al., 1994, 1998b; Kaufman et al., 1995; Werry et al., 2005). Landmarks in the progress of $5-\mathrm{HT}_{2 \mathrm{C}}$ receptor research are illustrated in Fig. 12 [see also Palacios et al. (2017)].

The gene for the human $5-\mathrm{HT}_{2 \mathrm{C}}$ receptor $($ HTR2C) was cloned and localized to the X chromosome (Xq24) in the early 1990s (Yu et al., 1991; Milatovich et al., 1992; Stam et al., 1994; Xie et al., 1996). The genomic DNA for the $5-\mathrm{HT}_{2 \mathrm{C}}$ receptor is divided into six exons with five introns (Xie et al., 1996), whereas the coding region contains four exons with three introns (Stam et al., 1994). The gene encodes a 458-amino-acid protein in humans and 460-amino-acid protein in rats, which share $90 \%$ amino acid homology (Saltzman et al., 1991). The 5-HT $2 \mathrm{C}$ receptor is the only GPCR known to undergo RNA editing, resulting in the functional expression of multiple isoforms of the receptor that differ in their distribution, pharmacology, and signaling capabilities.

The $5-\mathrm{HT}_{2 \mathrm{C}}$ receptor was first identified in choroid plexus tissue by receptor autoradiography as a highly expressed binding site with high affinity for radioligands that bind to the $5-\mathrm{HT}_{1}$ receptor family (Pazos et al., 1984; Yagaloff and Hartig, 1985). This binding site displayed a different pharmacological profile from the known $5-\mathrm{HT}_{1 \mathrm{~A}}$ receptor and $5-\mathrm{HT}_{1 \mathrm{~B}}$ receptor and thus was originally named $5-\mathrm{HT}_{1 \mathrm{C}}$ receptor. It was cloned by functional expression of choroid plexus RNA injected into Xenopus oocytes (Lübbert et al., 1987; Julius et al., 1988). The genomic organization of the $5-\mathrm{HT}_{1 \mathrm{C}}$ receptor (with the presence of introns), a $50 \%$ overall homology to the $5-\mathrm{HT}_{2 \mathrm{~A}}$ receptor and similar signal transduction mechanisms as $5-\mathrm{HT}_{2 \mathrm{~A}}$ receptor and $5-\mathrm{HT}_{2 \mathrm{~B}}$ receptor, indicated that the $5-\mathrm{HT}_{1 \mathrm{C}}$ receptor was more similar to members of the $5-\mathrm{HT}_{2}$ receptor family than the intronless, adenylyl cyclase-coupled members of 


\section{Landmarks in 5- $\mathrm{HT}_{2 \mathrm{C}}$ Receptor Research and Development}

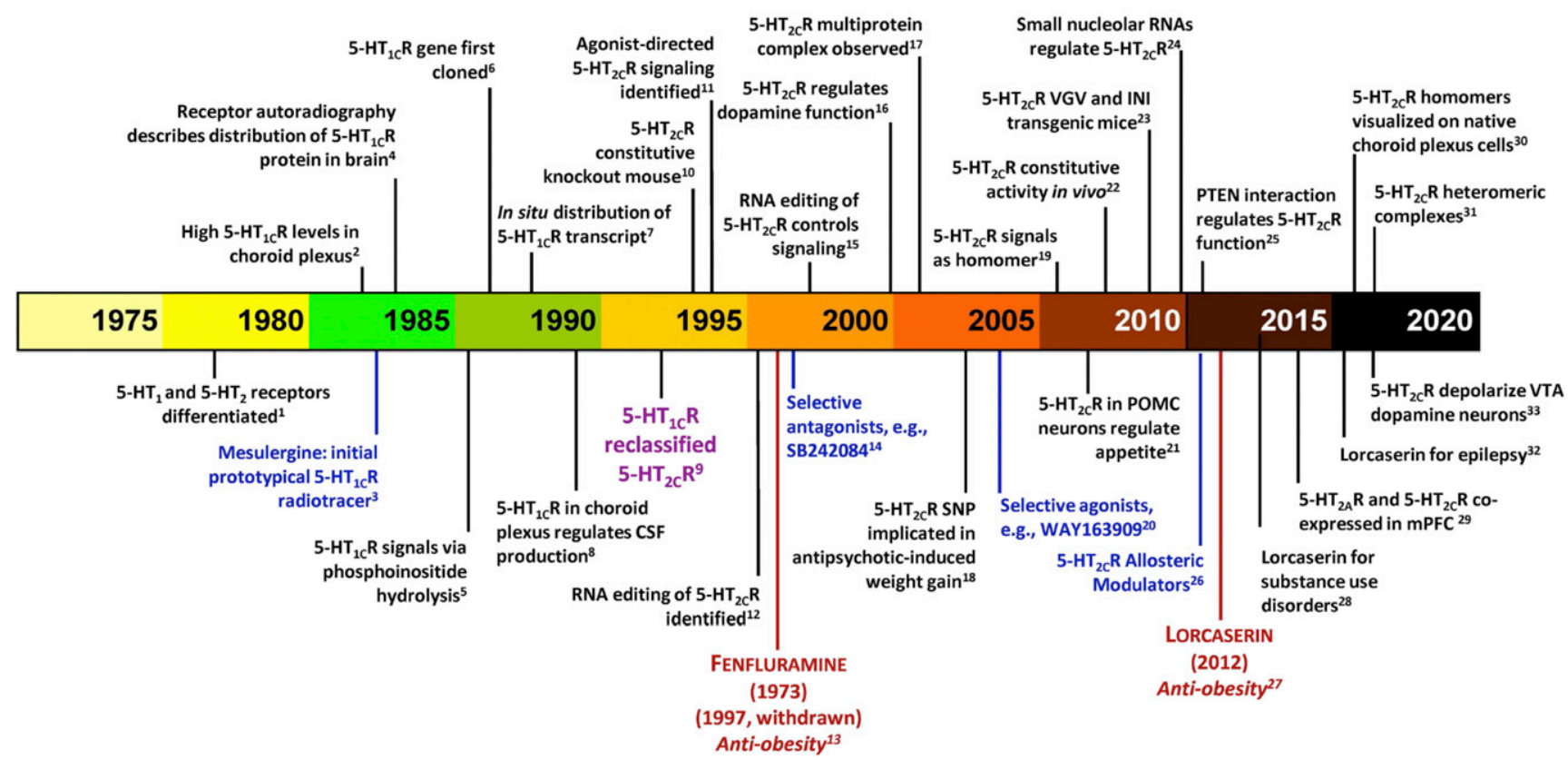

Fig. 12. Landmarks in 5- $\mathrm{HT}_{2 \mathrm{C}}$ receptor research and development. Identification and characterization of the 5-HT $2 \mathrm{C}$ receptor and the development of 5 - $\mathrm{HT}_{2 \mathrm{C}}$ receptor-directed ligands has evolved over the last 40 years (black text). The $5-\mathrm{HT}_{1 \mathrm{C}}$ receptor was reclassified as the 5 - $\mathrm{HT}_{2 \mathrm{C}}$ receptor in the mid-1990s (purple text). Examples of novel pharmacological tools (blue text) as well as the first-in-class selective 5-HT $\mathrm{H}_{2 \mathrm{C}}$ receptor agonist approved for obesity (red text) are illustrated in the timeline. Refer to the text for details; superscripted numbers indicate literature citations: 1) Peroutka and Snyder, 1979; 2) Pazos et al., 1984b; Yagaloff and Hartig, 1985; 3) Closse, 1983; 4) Pazos et al., 1984a; Pazos and Palacios, 1985; Pazos et al., 1985; Hoyer et al., 1986; 5) Conn et al., 1986; Conn and Sanders-Bush, 1986a; Hoyer et al., 1989; Chang et al., 2000; 6) (rat) Lübbert et al., 1987; Julius et al., 1988; (human) Saltzman et al., 1991; Milatovich et al., 1992; Stam et al., 1994; Xie et al., 1996; (mouse) Yu et al., 1991; Foguet et al., 1992a,b; 7) Hoffman and Mezey, 1989; Molineaux et al., 1989; Mengod et al., 1990; 8) Millar et al., 2007; 9) Hoyer, 1988a,b; Humphrey et al., 1993; Hoyer et al., 1994; 10) Tecott et al., 1995; 11) Berg et al., 1994, 1998a; 12) Burns et al., 1997; 13) http://www.fda.gov/Drugs/DrugSafety/PostmarketDrugSafetyInformationforPatientsandProviders/ucm180078.htm; 14) Bromidge et al., 1997; Kennett et al., 1997; 15) Herrick-Davis et al., 1999; 16) Di Giovanni et al., 1999; Di Matteo et al., 1999; Gobert et al., 2000; 17) Bécamel et al., 2002, 2004; 18) Basile et al., 2002; Tsai et al., 2002; Theisen et al., 2004; Templeman et al., 2005; 19) Herrick-Davis et al., 2006; Herrick-Davis et al., 2007; 20) Rosenzweig-Lipson et al., 2007a; Tong et al., 2010; Dunlop et al., 2011; Dunlop et al., 2005; 21) Xu et al., 2008 22) Leggio et al., 2009b; 23) Kawahara et al., 2008; Morabito et al., 2010a; 24) Kishore and Stamm, 2006; Doe et al., 2009; Kishore et al., 2010; 25) Ji et al., 2006; Anastasio et al., 2013; 26) Im et al., 2003; Ding et al., 2012; Wild et al., 2019; 27) http:// www.fda.gov/NewsEvents/Newsroom/PressAnnouncements/ucm309993.htm; Thomsen et al., 2008; Smith et al., 2009; Smith et al., 2010; 28) http:// www.eisai.com/news/news201465.html; Cunningham and Anastasio, 2014; Rezvani et al., 2014; Higgs et al., 2015; Howell and Cunningham, 2015; Harvey-Lewis et al., 2016; 29) Nocjar et al., 2015; Anastasio et al., 2015; 30) Herrick-Davis et al., 2015; 31) Schellekens et al., 2015; Kamal et al., 2015; 32) Di Giovanni and De Deurwaerdere, 2016; Venzi et al., 2016; 33) Xu et al., 2017.

the $5-\mathrm{HT}_{1}$ receptor family. Therefore, the $5-\mathrm{HT}_{1 \mathrm{C}}$ receptor was reclassified as a member of the $5-\mathrm{HT}_{2}$ receptor family and renamed 5-HT $2 \mathrm{C}$ receptor (Hoyer et al., 1994).

Early autoradiography studies reported a predominant localization of this receptor in choroid plexus tissue, whereas subsequent in situ hybridization studies revealed a widespread distribution throughout the basal ganglia, limbic system, and prefrontal cortex (Hoyer et al., 1986; Hoffman and Mezey, 1989; Molineaux et al., 1989; Mengod et al., 1990; Fig. 13). In fact, 5-HT $2 \mathrm{C}$ receptor mRNA has been reported to be more abundant and widespread throughout the CNS than mRNA of the closely related $5-\mathrm{HT}_{2 \mathrm{~A}}$ receptor (Pompeiano et al., 1994; Wright et al., 1995). Thus, the $5-\mathrm{HT}_{2 \mathrm{C}}$ receptor, largely thought of as "the choroid plexus receptor," is actually well positioned throughout the CNS to mediate many of the central actions of 5-HT, including regulation of appetite, cognition, mood, movement, and sleep [for reviews, see Berg et al. (2008a) and Di Giovanni et al., 2010)]. The $5-\mathrm{HT}_{2 \mathrm{C}}$ receptor has been implicated in addiction, anxiety, depression, epilepsy, schizophrenia, and obesity. Therefore, the $5-\mathrm{HT}_{2 \mathrm{C}}$ receptor is a therapeutic target of great interest [for reviews, see Bubar and Cunningham (2006); Howell and Cunningham (2015); Sullivan et al. (2015); Di Giovanni and De Deurwaerdere (2016)].

\section{B. Expression Profile}

The $5-\mathrm{HT}_{2 \mathrm{C}}$ receptor mRNA is differentially overexpressed in neurons relative to astrocytes and oligodendrocytes in the postnatal mouse forebrain (Cahoy et al., 2008). Regional analyses indicate that the $5-\mathrm{HT}_{2 \mathrm{C}}$ receptor mRNA is present in high levels in the choroid plexus, hippocampus, and the subthalamic and lateral habenular nuclei (Hoffman and Mezey, 1989; Molineaux et al., 1989; Mengod et al., 1990). Brain regions with moderate to high levels of $5-\mathrm{HT}_{2 \mathrm{C}}$ receptor mRNA include the amygdala, nuclei of the basal ganglia (NAc, striatum, VTA, SN, and internal globus pallidus), cortex, hypothalamus, dorsal raphe, brain stem, and spinal cord (Hoffman and 
Mezey, 1989; Molineaux et al., 1989; Mengod et al., 1990). The $5-\mathrm{HT}_{2 \mathrm{C}}$ receptor $\mathrm{mRNA}$ is found in regions containing the major dopaminergic cell bodies, including the SN and the VTA (Mengod et al., 1990; Pompeiano et al., 1994; Eberle-Wang et al., 1997; Bubar and Cunningham, 2007; Bubar et al., 2011); cholinergic cell bodies (Lopez-Gimenez et al., 2001); encephalin-, substance $\mathrm{P}-$, and dynorphin-containing neuropeptidergic neurons in the dorsal and ventral striatum (Ward and Dorsa, 1996); and neuropeptide Y-containing neurons in the lateral and basolateral amygdala (Bonn et al., 2013). The $5-\mathrm{HT}_{2 \mathrm{C}}$ receptor mRNA is not present in neurons expressing 5-HT transporter (SERT) mRNA in the raphe nuclei but is localized to GABA interneurons in this region (Serrats et al., 2005).

There is good agreement between mRNA and protein distribution in the majority of brain regions, suggesting that the $5-\mathrm{HT}_{2 \mathrm{C}}$ receptor is predominantly localized in somatodendritic compartments (Mengod et al., 1990; Abramowski et al., 1995; Abramowski and Staufenbiel, 1995; Eberle-Wang et al., 1997; Clemett et al., 2000; Anastasio et al., 2010). The exceptions are the subthalamic nucleus, in which 5- $\mathrm{HT}_{2 \mathrm{C}}$ receptor mRNA expression is high while its protein levels are low, and the external globus pallidus where the $5-\mathrm{HT}_{2 \mathrm{C}}$ receptor is present but $5-\mathrm{HT}_{2 \mathrm{C}}$ receptor mRNA is absent.

Early radioligand binding studies suggested that the $5-\mathrm{HT}_{2 \mathrm{C}}$ receptor is located on the apical surface of epithelial cells in the choroid plexus (Hartig et al., 1990). More recently, confocal microscopy and fluorescence correlation spectroscopy were used to directly visualize native $5-\mathrm{HT}_{2 \mathrm{C}}$ receptors and reveal their expression as homodimers on the apical surface of choroid epithelial cells (Herrick-Davis et al., 2015).

The $5-\mathrm{HT}_{2 \mathrm{C}}$ receptor is widely distributed throughout the basal ganglia and limbic-corticostriatal circuit. The $5-\mathrm{HT}_{2 \mathrm{C}}$ receptor is located postsynaptic to serotonergic neurons on GABAergic, glutamatergic, dopaminergic, neuropeptidergic, and cholinergic neurons. For example, the $5-\mathrm{HT}_{2 \mathrm{C}}$ receptor is expressed on GABAergic interneurons in the raphe nuclei (Serrats et al., 2005) and on GABAergic projection neurons in the NAc and striatum (Alex and Pehek, 2007). They are also found on GABAergic neurons in the substantia nigra (EberleWang et al., 1997; Invernizzi et al., 2007) and VTA (Di Giovanni et al., 2001; Bubar and Cunningham, 2007; Bubar et al., 2011). Because the 5- $\mathrm{HT}_{2 \mathrm{C}}$ receptor stimulates IP turnover (Conn and Sanders-Bush, 1986a; Hoyer et al., 1989; Chang et al., 2000) and increases $\mathrm{Ca}_{i}^{2+}$ levels resulting in membrane depolarization and neuronal firing (Stanford et al., 2005), activation of the $5-\mathrm{HT}_{2 \mathrm{C}}$ receptor on GABAergic neurons would be expected to increase the firing of these neurons, which have an inhibitory influence in that region. For example, stimulation of the $5-\mathrm{HT}_{2 \mathrm{C}}$ receptor in the VTA increases the firing rate of GABAergic interneurons, resulting in a decreased firing rate of dopaminergic neurons (Prisco

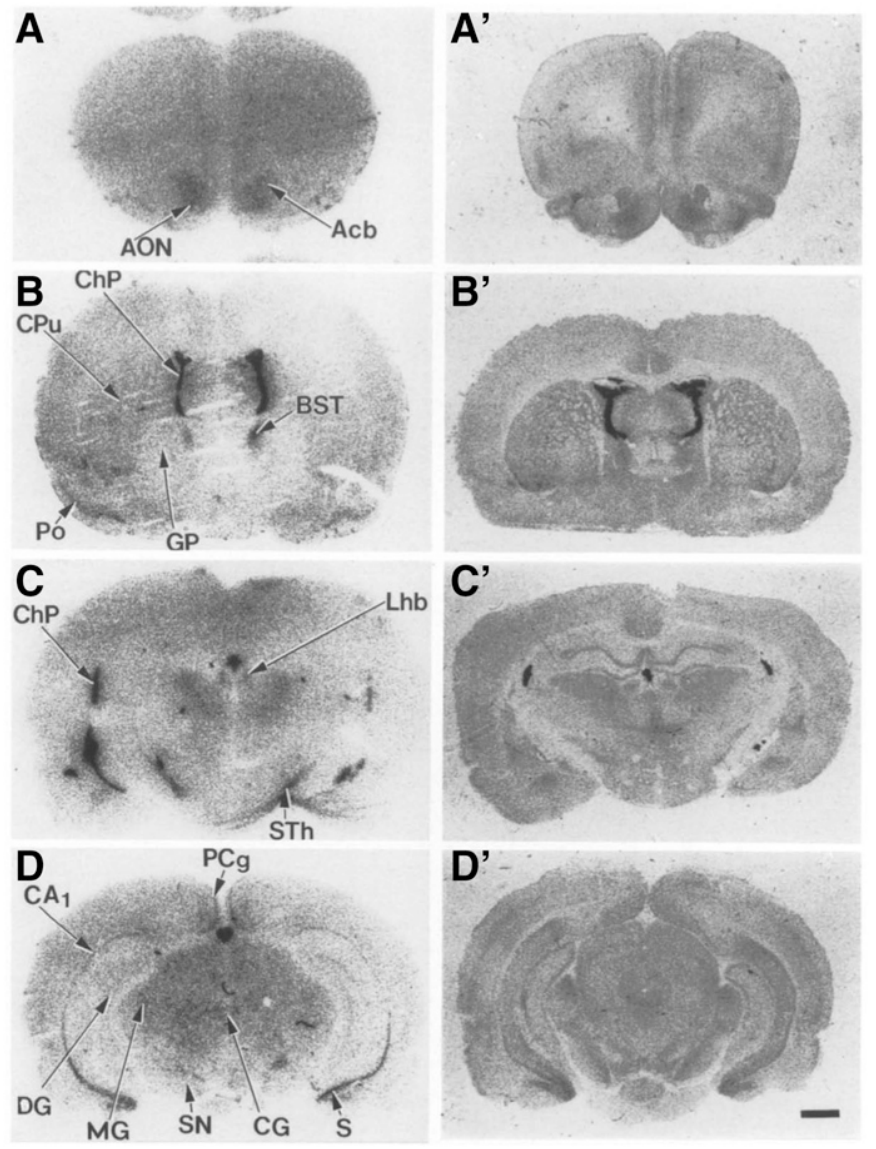

Fig. 13. $5-\mathrm{HT}_{2 \mathrm{C}}$ receptor expression in rat brain. In situ hybridization detection of $5-\mathrm{HT}_{2 \mathrm{C}}$ receptor mRNA (A-D) and $5-\mathrm{HT}_{2 \mathrm{C}}$ receptor autoradiography (A'-D') from adjacent sections. Acb, nucleus accumbens; AON, anterior olfactory nucleus; BST, bed nucleus stria terminalis; CA1, hippocampus CA1 field; CG, central gray; ChP, choroid plexus; $\mathrm{CPu}$, caudate-putamen; DG, dentate gyrus; GP, globus pallidus; Lhb, lateral habenular nucleus; $\mathrm{MG}$, medial geniculate nucleus; $\mathrm{PCg}$, posterior cingulate cortex; PO, primary olfactory cortex; S, subiculum; SN, substantia nigra; STh, subthalamic nucleus. Scale bar, $1 \mathrm{~mm}$. Adapted from Mengod et al. (1990) (with permission).

et al., 1994; Di Giovanni et al., 2001). Conversely, 5-HT $2 \mathrm{C}$ receptor antagonism has been reported to increase dopaminergic neurotransmission and dopamine levels in the NAc and prefrontal cortex (Di Giovanni et al., 1999; Di Matteo et al., 1999; Gobert et al., 2000). However, the story is likely to be more complicated, as the $5-\mathrm{HT}_{2 \mathrm{C}}$ receptor has also been shown to be expressed on a subset of dopaminergic neurons in the VTA, with higher expression in the middle relative to the rostral and caudal regions (Bubar and Cunningham, 2007; Bubar et al., 2011). These findings suggest the possibility that activation of the $5-\mathrm{HT}_{2 \mathrm{C}}$ receptor may directly enhance dopamine neurotransmission within specific subnuclei of the VTA in a region-specific manner.

5 -HT neurons from the raphe terminate in layers $\mathrm{V}$ and VI of the medial prefrontal cortex, adjacent to GABAergic interneurons that express the $5-\mathrm{HT}_{2 \mathrm{C}}$ receptor (Liu et al., 2007; Nocjar et al., 2015). In turn, the GABAergic interneurons terminate on pyramidal efferents (likely glutamatergic), which may also express the 
5-HT ${ }_{2 \mathrm{C}}$ receptor (Vysokanov et al., 1998; Carr et al., 2002; Liu et al., 2007; Nocjar et al., 2015). In the prefrontal cortex, the $5-\mathrm{HT}_{2 \mathrm{C}}$ receptor associates with PSD-95 in postsynaptic densities (Anastasio et al., 2010) and colocalizes with the $5-\mathrm{HT}_{2 \mathrm{~A}}$ receptor on GABAergic interneurons (Nocjar et al., 2015). In the hypothalamus, the $5-\mathrm{HT}_{2 \mathrm{C}}$ receptor is expressed on pro-opiomelanocortin (POMC) neurons in the arcuate nucleus, where they stimulate the release of the anorectic peptide $\alpha$-melanocyte-stimulating hormone (Heisler et al., 2002).

Previous studies provide little evidence that the $5-\mathrm{HT}_{2 \mathrm{C}}$ receptor is expressed outside the CNS. However, portions of the HTR2C gene are expressed outside the CNS. Exons I and II of the HTR2C gene are located in the $5^{\prime}$ untranslated region, and the translational start site for the $5-\mathrm{HT}_{2 \mathrm{C}}$ receptor protein is located in the middle of exon III (Xie et al., 1996). Exons I-III of the HTR2C gene have been reported to be expressed in non-neuronal cells, along with four different microRNAs (miRNA) generated from intron II (Zhang et al., 2013c). Expression of these miRNAs is regulated by the small nucleolar RNAs (snoRNA) SNORD 115/MBII-52 and SNORD 116/MBII-85. Patients with Prader-Willi syndrome lack MBII-52 and MBII-85 and express different levels of the 5- $\mathrm{HT}_{2 \mathrm{C}}$ receptor miRNAs than control subjects (Zhang et al., 2013c). Although the function of these miRNAs is not fully understood, it is possible that their dysregulation may contribute to the Prader-Willi syndrome phenotype as explored in $5-\mathrm{HT}_{2 \mathrm{C}}$ receptor transgenic mouse models.

Because the $5-\mathrm{HT}_{2 \mathrm{C}}$ receptor mRNA in human brain includes exons I-VI, and the mRNA found outside the CNS contains exons I-III, it was hypothesized that a transcriptional termination signal prior to exon IV may be employed in non-neuronal cells outside the CNS (Zhang et al., 2013c). In contrast, a 185-base-pair fragment of $5-\mathrm{HT}_{2 \mathrm{C}}$ receptor mRNA was identified by quantitative RT-PCR from rat adipocyte visceral tissue (Stunes et al., 2011). The expression level of the $5-\mathrm{HT}_{2 \mathrm{C}}$ receptor mRNA was only $5 \%$ of the expression level of the $\beta$-actin housekeeping gene control, and Western blots revealed that $5-\mathrm{HT}_{2 \mathrm{C}}$ receptor expression in undifferentiated adipocytes was negligible compared with expression in rat brain (Stunes et al., 2011). However, expression of $5-\mathrm{HT}_{2 \mathrm{C}}$ receptor mRNA and protein expression could be induced in cultured adipocytes. In addition, low levels of $5-\mathrm{HT}_{2 \mathrm{C}}$ receptor mRNA and protein have been reported in rat pancreatic islet cells (Zhang et al., 2013b). Further research is required to elucidate the physiologic role of the 5- $\mathrm{HT}_{2 \mathrm{C}}$ receptor in the function of adipocytes (Stunes et al., 2011) and potentially pancreatic $\beta$-cells (Zhang et al., 2013b).

\section{Post-transcriptional and Post- translational Modifications}

1. RNA Editing. The 5- $\mathrm{HT}_{2 \mathrm{C}}$ receptor is the only GPCR reported to undergo RNA editing. The $5-\mathrm{HT}_{2 \mathrm{C}}$ receptor pre-mRNA is unique in containing a region of exonic and intronic sequence complementarity between the distal half of exon $\mathrm{V}$ and the beginning of intron $\mathrm{V}$ (Burns et al., 1997). This results in base pairing between the exonic and intronic sequences, giving the pre-mRNA a double-stranded, stem-loop structure. The secondary structure of the $5-\mathrm{HT}_{2 \mathrm{C}}$ receptor pre-mRNA influences the pattern of editing (Fukuda et al., 2015) as well as splicing (Shen et al., 2013). The double-stranded RNA is a substrate for adenosine deaminases that act on RNA and RNA-specific adenosine deaminase (ADAR) 1 and ADAR2 (Burns et al., 1997; Liu et al., 1999). These enzymes catalyze the deamination of adenosine to inosine, which is read as guanosine when the RNA is translated into protein. Adenosine to inosine RNA editing can occur at up to five different locations (termed A-E) within exon V (Burns et al., 1997; Fitzgerald et al., 1999; Niswender et al., 1999; Wang et al., 2000a) and one site located in intron V (Flomen et al., 2004). The editing sites in exon $\mathrm{V}$ are located in the second intracellular loop of the receptor in close proximity to the highly conserved "DRY" motif at the base of transmembrane domain III. The resulting adenosine to guanosine conversions change the coding potential of amino acids I156, N158, and I160 from INI (isoleucine, asparagine, isoleucine) in the unedited isoform to VSV (valine, serine, valine) or VGV (valine, glycine, valine) in the fully edited isoforms.

The RNA editing of the HTR2C gene can produce up to 32 different $5-\mathrm{HT}_{2 \mathrm{C}}$ receptor pre-mRNAs encoding 24 different proteins. There are seven predominant $5-\mathrm{HT}_{2 \mathrm{C}}$ receptor isoforms that are expressed in a region-specific manner in human and rodent brain (Burns et al., 1997; Fitzgerald et al., 1999; Niswender et al., 1999; Wang et al., 2000; Dracheva et al., 2009; Abbas et al., 2010; Morabito et al., 2010b). The more highly edited isoforms are the predominant isoforms expressed in whole brain, with VSV and VNV being the most prominent. Regions such as the hypothalamus, hippocampus, striatum, and cortex predominantly express the edited VNV, VSV, and VSI isoforms, whereas the choroid plexus and cerebellum express significantly higher levels of the unedited INI and partially edited INV and ISV isoforms.

Because RNA editing occurs in the second intracellular loop of the receptor, a region known to play an important role in $\mathrm{G}$ protein activation, it has profound effects on the pharmacology and signaling capabilities of the $5-\mathrm{HT}_{2 \mathrm{C}}$ receptor. RNA editing decreases agonist binding affinity and $\mathrm{G}$ protein coupling efficiency (Burns et al., 1997; Fitzgerald et al., 1999; Herrick-Davis et al., 1999; Niswender et al., 1999; Wang et al., 2000; Berg et al., 2001). In these studies, the fully edited VSV and VGV isoforms displayed a 5 - to 40 -fold decrease in 5 -HT binding affinity and potency for stimulating phosphoinositide production compared with the unedited INI isoform, and they displayed decreased affinity and potency for a variety 
of different agonists. When expressed in COS-7 cells at levels similar to native $5-\mathrm{HT}_{2 \mathrm{C}}$ receptor in choroid epithelial cells, the unedited INI isoform displayed high constitutive activity that was successively diminished by RNA editing to very low levels of constitutive activity in the fully edited VSV and VGV isoforms (HerrickDavis et al., 1999; Niswender et al., 1999). In addition to regulating the level of basal activity, RNA editing alters the specificity of $\mathrm{G}$ protein coupling and second messenger activation. For example, the unedited INI isoform can signal through $\mathrm{G}_{\mathrm{q}}, \mathrm{G}_{13}$, and $\mathrm{G}_{15}$, but the fully edited VSV and VGV isoforms predominantly couple to and signal through $\mathrm{G}_{\mathrm{q}}$ (Price et al., 2001; McGrew et al., 2002, 2004). The $5-\mathrm{HT}_{2 \mathrm{C}}$ receptor has been shown to signal in an agonist-specific manner to differentially regulate phosphoinositide and arachadonic acid production (Berg et al., 1998b) and the phosphorylation of $\mathrm{ERK}_{1 / 2}$ (Werry et al., 2005), effects which are diminished following RNA editing (Berg et al., 2001, 2008b; Werry et al., 2008). In addition to impacting signaling, RNA editing also influences receptor desensitization and trafficking (Marion et al., 2004).

The $5-\mathrm{HT}_{2 \mathrm{C}}$ receptor pre-mRNA editing is regulated by ADAR1 and ADAR2 (Burns et al., 1997). Both in vitro and in vivo studies have reported that RNA editing at amino acid 156 of the $5-\mathrm{HT}_{2 \mathrm{C}}$ receptor is predominantly accomplished by ADAR1, editing at amino acid 160 requires ADAR2, and both enzymes participate in editing at amino acid 158 (Liu et al., 1999; Wang et al., 2000, 2004; Hartner et al., 2004). ADAR1 and ADAR2 may act in a concerted manner whereby ADAR 1 editing at amino acid 156 enhances ADAR2 pre-mRNA binding and subsequent editing at amino acids 160 and 158 (Carmel et al., 2012). In addition, factors that regulate the alternative splicing of the ADAR1 and ADAR2 premRNAs have been reported to influence $5-\mathrm{HT}_{2 \mathrm{C}}$ receptor RNA editing (Liu et al., 1999; Schmauss et al., 2010). Alterations in ADAR activity or pattern of expression can result in altered $5-\mathrm{HT}_{2 \mathrm{C}}$ receptor isoform expression. Studies using neuronal cell cultures showed that factors that increase ADAR1 expression, such as treatment with interferon, increase $5-\mathrm{HT}_{2 \mathrm{C}}$ receptor editing at amino acid 156 (Yang et al., 2004) and that reduced ADAR1 expression abolished editing at amino acid 156 (Sukma et al., 2005). In vivo evidence supporting this hypothesis is provided by a recent study reporting a downregulation in ADAR2 expression following spinal cord injury in rats, which resulted in decreased $5-\mathrm{HT}_{2 \mathrm{C}}$ receptor $\mathrm{RNA}$ editing at amino acid 160 (Di Narzo et al., 2015). Conversely, RNA editing has been reported to be increased in transgenic mice overexpressing ADAR2, which resulted in an increase in the expression of the more fully edited, and a decrease in expression of the unedited, $5-\mathrm{HT}_{2 \mathrm{C}}$ receptor isoforms (Singh et al., 2011). The results of these studies indicate that alterations in ADAR activity and expression patterns alter the degree and pattern of $5-\mathrm{HT}_{2 \mathrm{C}}$ receptor editing, resulting in changes in $5-\mathrm{HT}_{2 \mathrm{C}}$ receptor isoform expression and signal transduction.

2. RNA Splicing. Three different variants of the $5-\mathrm{HT}_{2 \mathrm{C}}$ receptor are produced by RNA splicing, only one of which is expressed on the plasma membrane and is fully functional. The full-length functional $5-\mathrm{HT}_{2 \mathrm{C}}$ receptor $(2 \mathrm{Cfl})$ is generated following splicing at the traditional exon/intron boundaries to remove introns III-V (Xie et al., 1996). There are two alternative donor splice sites flanking the traditional donor splice site located at the exon V/intron V boundary: one located in the middle of exon V (Canton et al., 1996; Xie et al., 1996) and an infrequently used site located within intron V (Wang et al., 2000; Flomen et al., 2004). The splice sites are conserved across rat, mouse, and human species. Splicing at either one of the alternative splice sites produces an RNA that encodes a prematurely truncated protein. Use of the donor splice site located in the middle of exon $\mathrm{V}$ results in the deletion of the last 95 nucleotides of exon $\mathrm{V}$, including the RNA editing sites, and causes a frame shift mutation with stop codon. The result is a truncated protein (2Ctr) containing the $\mathrm{N}$ terminus and first three transmembrane domains followed by 96 unique amino acids (Canton et al., 1996; Xie et al., 1996; Wang et al., 2000). In human brain tissue, 2Ctr mRNA is found in all brain regions containing $2 \mathrm{Cfl}$ mRNA. Though Western blots of membrane extracts from 2Ctr-transfected NIH3T3 cells revealed immunoreactive bands the predicted size of $2 \mathrm{Ctr}$ protein, radioligand binding and phosphoinositide production were not observed in the transfected cells (Canton et al., 1996; Wang et al., 2000). The $2 \mathrm{Ctr}$ protein is not expressed on the plasma membrane but is retained within the endoplasmic reticulum where the 2Ctr can form heterodimers with 2Cfl (Herrick-Davis and Farrington, 2011; Martin et al., 2013). Thus, one possible function of $2 \mathrm{Ctr}$ is to regulate $5-\mathrm{HT}_{2 \mathrm{C}}$ receptor signaling by forming heterodimers with $2 \mathrm{Cfl}$ and trapping 2Cfl in the endoplasmic reticulum (Herrick-Davis and Farrington, 2011; Martin et al., 2013).

Factors that influence splice site selection will impact $5-\mathrm{HT}_{2 \mathrm{C}}$ receptor function and signaling by altering the relative balance between $2 \mathrm{Cfl}$ and $2 \mathrm{Ctr}$ within a given brain region. RNA editing and factors that influence RNA editing, such as ADAR1 and ADAR2 activity, have been shown to influence splice site selection (Rueter et al., 1999; Maas et al., 2001; Flomen et al., 2004; Tohda et al., 2004; Dracheva et al., 2008a). Increased editing of the $5-\mathrm{HT}_{2 \mathrm{C}}$ receptor pre-mRNA, generating the more fully edited and less active isoforms, promotes the use of the traditional donor splice site at the exon V/intron $\mathrm{V}$ boundary and favors the generation of $2 \mathrm{Cfl}$ over 2Ctr (Flomen et al., 2004). On the other hand, the unedited and highly active INI isoform is associated with increased use of the alternative donor splice site in the middle of exon $\mathrm{V}$, increasing the production of $2 \mathrm{Ctr}$. The preferred splicing of the INI isoform into $2 \mathrm{Ctr}$ (Flomen et al., 2004) may explain the higher plasma 
membrane expression levels of $2 \mathrm{Cfl}$ observed in transgenic mice expressing the VGV isoform compared with mice expressing the INI isoform of the $5-\mathrm{HT}_{2} \mathrm{R}$ (Kawahara et al., 2008). These results are consistent with the original studies in which $2 \mathrm{Ctr}$ was first identified and was reported to be most abundant in the choroid plexus (Canton et al., 1996; Xie et al., 1996), the same brain region that was subsequently reported to express the highest levels of unedited and partially edited isoforms of the 5- $\mathrm{HT}_{2 \mathrm{C}}$ receptor (Burns et al., 1997; Niswender et al., 1999; Wang et al., 2000).

Several studies have provided evidence for a link between $5-\mathrm{HT}_{2 \mathrm{C}}$ receptor RNA editing and splicing in vivo. In postmortem brain samples from patients who committed suicide, RNA editing was increased along with the ratio of $2 \mathrm{Cfl}$ to $2 \mathrm{Ctr}$, with increased expression of the less-active 5 - $\mathrm{HT}_{2 \mathrm{C}}$ receptor isoforms (Dracheva et al., 2008a). In malignant gliomas from human brain, decreased ADAR2 activity (predicted to reduce RNA editing) was positively correlated with increased alternative splicing and the production of $2 \mathrm{Ctr}$ (Maas et al., 2001). In several of the gliomas examined and in glioma-derived cells lines, 2Ctr was predominant and $2 \mathrm{Cfl}$ was mostly absent (Maas et al., 2001; Tohda et al., 2004). In light of these findings, it is interesting to note that patients with glioblastoma have an increased incidence of seizures, as do $5-\mathrm{HT}_{2 \mathrm{C}}$ receptor knockout mice.

noRNAs also regulate $5-\mathrm{HT}_{2 \mathrm{C}}$ receptor RNA splicing. The snoRNA MBII-52 binds to exon V of the HTR2C gene in the region containing the alternative splice site and the RNA editing sites (Kishore and Stamm, 2006; Kishore et al., 2010). MBII-52 reduces RNA editing and the use of the alternative splice site, thereby favoring the production of the full-length, unedited, and more active $5-\mathrm{HT}_{2 \mathrm{C}}$ receptor isoforms. In mice lacking MBII-52, RNA editing is increased, leading to increased expression of the edited and less-active $5-\mathrm{HT}_{2 \mathrm{C}}$ receptor isoforms (Doe et al., 2009). These mice display phenotypic and behavioral changes similar to those observed in Prader-Willi syndrome (Doe et al., 2009). Consistent with these findings, transgenic mice expressing only the fully edited VGV isoform display characteristics of Prader-Willi syndrome (Morabito et al., 2010a). The human homolog HBII-52 has been shown to be absent in patients with Prader-Willi syndrome, and $5-\mathrm{HT}_{2 \mathrm{C}}$ receptor RNA editing is increased in patients with Prader-Willi syndrome (Kishore and Stamm, 2006). These studies highlight the important roles that RNA editing and splicing play in the regulation of $5-\mathrm{HT}_{2 \mathrm{C}}$ receptor activity and demonstrate how deregulation of this system can have profound phenotypic and behavioral consequences.

3. Single-Nucleotide Polymorphisms. The $5-\mathrm{HT}_{2 \mathrm{C}}$ receptor not only achieves diversity through RNA editing and splicing but also through the incorporation of SNPs, substitutions of a novel nucleotide for a wild- type nucleotide, a common type of genetic variation (Wang et al., 1998). These SNPs can produce an unstable conformation that alters the protein structure of a GPCR and affects its ultimate functional properties (Wenkert et al., 1996). A number of HTR2C SNPs have been reported in the literature: three polymorphisms as well as a GT nucleotide repeat variation have been identified in the promoter (Xie et al., 1996); three polymorphisms have been reported within intronic regions (Gibson et al., 2004); one polymorphism has been reported in the coding region, resulting in the replacement of cysteine with serine at amino acid 23 (C23S) in the amino-terminus of the receptor (Lappalainen et al., 1995); and there is one polymorphism in the $3^{\prime}$ untranslated region (Song et al., 1999). Few studies are reported that have ascertained the impact of these HTR2C SNPs on function at either the cellular or whole organism level. The impact of the S23 variant, when expressed in insect cells, was reported to have slightly higher affinity for 5 -HT than the C23 variant and to alter $5-\mathrm{HT}_{2 \mathrm{C}}$ receptor desensitization/ resensitization mechanisms (Okada et al., 2004; Walstab et al., 2011). However, this finding remains controversial, as other studies have reported no difference between the C23 and S23 variants with respect to agonist-binding affinity or potency, G protein coupling, constitutive activity, and homodimerization (Lappalainen et al., 1995; Fentress et al., 2005). Given suggestions that the C23 variant may have clinical implications (Lappalainen et al., 1995; Okada et al., 2004; Piva et al., 2011; Walstab et al., 2011), further studies of this and other HTR2C SNPs are required.

4. Glycosylation. The rat $5-\mathrm{HT}_{2 \mathrm{C}}$ receptor is reported to be glycosylated, and bands with different molecular weights were observed on Western blot of brain and cells expressing the receptor (Abramowski and Staufenbiel, 1995). Antibodies raised against the third and fourth cytoplasmic domain of the $5-\mathrm{HT}_{2 \mathrm{C}}$ receptor identified an $N$-glycosylated polypeptide with a $60-\mathrm{kDa}$ apparent molecular mass. Polypeptides were detected in immunoprecipitates from extracts of pig choroid plexus upon Western blot and binding assays with $\left[{ }^{3} \mathrm{H}\right]$-mesulergine. A signal sequence was cleaved during membrane insertion, resulting in a $38-\mathrm{kDa}$ polypeptide. During further maturation, the receptor was $N$-glycosylated at two sites via a $48-\mathrm{kDa}$ intermediate, which was more abundant in choroid plexus than in hippocampus. However, there may be more glycosylated species, as following transfection of $5-\mathrm{HT}_{2 \mathrm{C}}$ receptor cDNAs into cultured cells, polypeptides were observed that differed from the ones found in the brain. Similarly, the $N$-glycosylated $5-\mathrm{HT}_{2 \mathrm{C}}$ receptor was identified in solubilized extracts from cell lines and rat brain (Backstrom et al., 1995). Extracts from NIH3T3 fibroblasts stably expressing rat $5-\mathrm{HT}_{2 \mathrm{C}}$ receptor contained immunoreactive proteins of 51 to $52 \mathrm{kDa}$ and 58 to $68 \mathrm{kDa}$. In the brain, immunoreactive proteins were identified from choroid plexus extracts with masses of $51 \mathrm{kDa}$ and 
$58-62 \mathrm{kDa}$. On the other hand, the major 58- to $62-\mathrm{kDa}$ and minor $51-\mathrm{kDa}$ proteins were not detected in extracts prepared from the hippocampus, striatum, or frontal cortex prepared under the same conditions. The association of asparagine-linked (N-linked) oligosaccharides with the receptors was also examined. Cells grown in the presence of tunicamycin to inhibit $\mathrm{N}$-linked glycosylation resulted in proteins with masses of 40 and $41 \mathrm{kDa}$. Extracts prepared from NIH3T3 cells and choroid plexus incubated with $\mathrm{N}$-glycosidase $\mathrm{F}$ showed proteins of 41 and $42 \mathrm{kDa}$ from NIH3T3 cells and $41 \mathrm{kDa}$ from choroid plexus. Neuraminidase treatment, to cleave sialic acid, reduced the mass of the $51-\mathrm{kDa}$ and 58 - to $62-\mathrm{kDa}$ proteins from the choroid plexus to $50 \mathrm{kDa}$ and $54-58 \mathrm{kDa}$, whereas the proteins from NIH3T3 cells were not affected by neuraminidase. Altogether, the $5-\mathrm{HT}_{2 \mathrm{C}}$ receptor contains N-linked sugars, and it is suggested that sialic acid residues associate with the receptor from the choroid plexus but not from other brain regions. These oligosaccharide moieties contribute up to approximately $30 \%$ of the relative mass of the receptor and may affect the functional properties of the $5-\mathrm{HT}_{2 \mathrm{C}}$ receptor.

5. Phosphorylation. The constitutively active $5-\mathrm{HT}_{2 \mathrm{C}}$ receptor is phosphorylated under basal conditions, and phosphorylation is increased by agonist treatment (Westphal et al., 1995). Pretreatment of cells with 5-HT resulted in $5-\mathrm{HT}_{2 \mathrm{C}}$ receptor desensitization, which was blocked by calcineurin (presumably by its phosphatase activity) (Boddeke et al., 1993). It was subsequently shown that S458 and S459 are phosphorylated (Backstrom et al., 2000). Phosphorylation of a mutant $5-\mathrm{HT}_{2 \mathrm{C}}$ receptor that lacks the carboxyl-terminal PDZ recognition motif [Ser(458)-Ser-Val-COOH; $\delta \mathrm{PDZ}]$ was not detectable, although these cells produced similar amounts of phosphoinositide and $\mathrm{Ca}_{i}^{2+}$ with similar kinetics as wild-type cells. Alanine mutations S458A or S459A decreased phosphorylation to $50 \%$ of wild-type receptor levels. Subsequent $\mathrm{Ca}_{i}^{2+}$ responses of S459A receptors were diminished relative to $\mathrm{S} 458 \mathrm{~A}$ and wild-type receptors. Thus, desensitization may occur in the absence of $5-\mathrm{HT}_{2 \mathrm{C}}$ receptor phosphorylation, suggesting that receptor phosphorylation at S459 enhances resensitization of $5-\mathrm{HT}_{2 \mathrm{C}}$ receptor responses. Agonist-induced phosphorylation of the $5-\mathrm{HT}_{2 \mathrm{C}}$ receptor was later established to regulate the receptor interaction with multiple PDZ protein 1 (Parker et al., 2003), also known as MUPP1 (Ullmer et al., 1998). MUPP1 is a putative scaffolding protein containing 13 PSD-95, Dlg, ZO-1 (PDZ) domains, identified by a yeast two-hybrid screen as one of a series of $5-\mathrm{HT}_{2 \mathrm{C}}$ receptor-interacting proteins. The MUPP1 PDZ domain 10 (PDZ 10) associates with Ser458-Ser-Val of the 5- $\mathrm{HT}_{2 \mathrm{C}}$ receptor. An Asp mutation at Ser458 significantly decreased receptor interaction with PDZ 10. Also, 5-HT treatment of $5-\mathrm{HT}_{2 \mathrm{C}}$ receptor-NIH3T3 cells reduced receptor interaction with PDZ 10, an effect that was blocked by a $5-\mathrm{HT}_{2 \mathrm{C}}$ receptor antagonist.
Phosphatase and tensin homolog deleted on chromosome 10 (PTEN) interacts within several amino acids of the third intracellular loop (termed $3 \mathrm{~L} 4 \mathrm{~F}$ ) of the $5-\mathrm{HT}_{2 \mathrm{C}}$ receptor (Ji et al., 2006). The tumor suppressor PTEN is widely distributed in the brain (Lachyankar et al., 2000). The PTEN and 5- $\mathrm{HT}_{2 \mathrm{C}}$ receptor proteins coimmunoprecipitate in fractions of the VTA (Ji et al., 2006; Anastasio et al., 2013). Employing a proximity ligation assay, the assembly of the 5- $\mathrm{HT}_{2 \mathrm{C}}$ receptor:PTEN complex, and the ability of $3 \mathrm{~L} 4 \mathrm{~F}$ to disrupt the complex, was validated under native conditions within intact live cells (Anastasio et al., 2013). A peptide fragment of the $5-\mathrm{HT}_{2 \mathrm{C}}$ receptor third intracellular loop $(3 \mathrm{~L} 4 \mathrm{~F})$, labeled with the cell-penetrating peptide TAT, disrupts the $5-\mathrm{HT}_{2 \mathrm{C}}$ receptor:PTEN complex and PTEN-mediated dephosphorylation of the $5-\mathrm{HT}_{2 \mathrm{C}}$ receptor in PC12 cells (Ji et al., 2006) as well as enhances 5 -HT-mediated ${\mathrm{i} \mathrm{Ca}_{i}^{2+}}^{2+}$ release in CHO cells stably transfected with the human $5-\mathrm{HT}_{2 \mathrm{C}-\mathrm{INI}}$ receptor (but not the 5- $\mathrm{HT}_{2 \mathrm{~A}}$ receptor) (Anastasio et al., 2013). Interestingly, the cell-adhesion molecule close homology of L1 protein also binds to the third intracellular loop of the 5- $\mathrm{HT}_{2 \mathrm{C}}$ receptor (amino acids 292-304) and may regulate the $5-\mathrm{HT}_{2 \mathrm{C}}$ receptor association with PTEN and $\beta$-arrestin 2 to control its phosphorylation (Kleene et al., 2015).

Systemic administration of the TAT-3L4F peptide suppresses the $\Delta^{9}$-tetrahydrocannabinol (THC)-induced increase in firing rate of VTA dopaminergic neurons in the rat (Ji et al., 2006) and suppresses the place association conditioned to $\Delta^{9}$-THC and nicotine in rats (Ji et al., 2006). In more recent studies, whereas TAT-3L4F had no effect alone, the combination of ineffective doses of TAT-3L4F plus WAY163909 synergize to suppress motor impulsivity, a primary symptomatic element of multiple neuropsychiatric disorders (American Psychiatric Association, 2013) that is consistently suppressed by pretreatment with a selective $5-\mathrm{HT}_{2 \mathrm{C}}$ receptor agonist (Winstanley et al., 2004; Fletcher et al., 2007; Fletcher et al., 2011; Anastasio et al., 2013; Cunningham et al., 2013). In addition, TAT-3L4F augments $5-\mathrm{HT}_{2 \mathrm{C}}$ receptor agonist-mediated suppression of spontaneous locomotor activity, effects that are consistent with positive allosteric modulation of $5-\mathrm{HT}_{2 \mathrm{C}}$ receptor function (Anastasio et al., 2013; Wild et al., 2014, 2019). Together, coupled with the findings that Tat-3L4F did not affect spatial learning and memory (Maillet et al., 2008) or generate the total behavioral profile of $5-\mathrm{HT}_{2 \mathrm{C}}$ receptor agonists (Ji et al., 2006; Anastasio et al., 2013), inhibition of the PTEN:5-HT $\mathrm{HC}_{2 \mathrm{C}}$ receptor interface and, thus, $5-\mathrm{HT}_{2 \mathrm{C}}$ receptor dephosphorylation is a novel pharmacological approach with therapeutic potential in substance use disorders (Ji et al., 2006; Muller and Carey, 2006; Maillet et al., 2008; Anastasio et al., 2013; Cunningham and Anastasio, 2014).

6. Dimerization. Homodimerization for many GPCRs is thought to be a post-translational event that occurs within the endoplasmic reticulum as a prerequisite for the transport and expression of functional receptors on the 
plasma membrane [for review, see Milligan (2010)]. Many members of the 5-HT receptor family, including the $5-\mathrm{HT}_{2 \mathrm{C}}$ receptor, have been reported to form homodimers [for review, see Herrick-Davis (2013)]. Using a confocal microscopy-based resonance energy-transfer technique, $5-\mathrm{HT}_{2 \mathrm{C}}$ receptor homodimer formation was visualized within the endoplasmic reticulum during receptor biosynthesis (Herrick-Davis et al., 2006). The $5-\mathrm{HT}_{2 \mathrm{C}}$ receptor is transported through the Golgi complex to the plasma membrane as a homodimer.

The $5-\mathrm{HT}_{2 \mathrm{C}}$ receptor forms detergent-sensitive homodimers (Herrick-Davis et al., 2004) that do not dissociate or associate to form higher-order complexes following agonist or inverse agonist treatment (Herrick-Davis et al., 2007). Coexpression of wild-type receptors with inactive, mutant receptors provided evidence that the $5-\mathrm{HT}_{2 \mathrm{C}}$ receptor homodimer interacts with a single $\mathrm{G}$ protein, that both protomers participate in signaling, and that both protomers must be functional in order for signaling to occur (Herrick-Davis et al., 2005). Timelapse fluorescence confocal microscopy provided direct visualization of $\beta$-arrestin ${ }_{2}$ recruitment to the plasma membrane following 5-HT binding to the homodimer (Herrick-Davis et al., 2007; Herrick-Davis et al., 2012). Homodimerization was observed for both the unedited INI and the fully edited (VSV and VGV) isoforms (Herrick-Davis et al., 2007; Herrick-Davis et al., 2012).

Advanced imaging techniques with near-single-molecule sensitivity have been employed more recently in an attempt to distinguish between dimers and higherorder oligomers. Fluorescence correlation spectroscopy studies report that the $5-\mathrm{HT}_{2 \mathrm{C}}$ receptor expressed in HEK293 cells exists as homodimers, with no evidence for monomers, tetramers, or higher-order oligomers (Herrick-Davis et al., 2012). Spatial intensity distribution analysis was used to monitor the oligomer status of the $5-\mathrm{HT}_{2 \mathrm{C}}$ receptor over a wide range of receptorexpression levels (Ward et al., 2015). In this study, the $5-\mathrm{HT}_{2 \mathrm{C}}$ receptor was expressed as a mixture of monomers, dimers, and tetramers; treatment with a $5-\mathrm{HT}_{2 \mathrm{C}}$ receptor antagonist for 90 minutes converted the majority of dimers and tetramers to monomers. However, it should be noted that tetramers were prominent only when $5-\mathrm{HT}_{2 \mathrm{C}}$ receptor expression exceeded 100 receptors $/ \mu \mathrm{m}^{2}$ (Ward et al., 2015), greatly in excess of physiologic expression levels for native GPCRs (Hegener et al., 2004; Herrick-Davis et al., 2015). Similarly, the homodimer was the predominant species observed for biogenic amine receptors when expressed within their normal physiologic range in HEK293 cells (HerrickDavis et al., 2013).

Only one study to date has examined the $5-\mathrm{HT}_{2 \mathrm{C}}$ receptor endogenously expressed in its native cellular environment. The native $5-\mathrm{HT}_{2 \mathrm{C}}$ receptor, endogenous to the choroid plexus, is expressed as homodimers on the apical surface of the epithelial cells at a density of 32 receptors $/ \mu \mathrm{m}^{2}$ (Herrick-Davis et al., 2015). Though this is similar to a reported density of 20 receptors $/ \mu \mathrm{m}^{2}$ for native $\beta_{2}$-adrenergic receptors in alveolar epithelial cells, expression levels in neurons were much lower at 4.5 receptors $/ \mu \mathrm{m}^{2}$ (Hegener et al., 2004). The study by Herrick-Davis et al. (2015) found no evidence for monomers or tetramers of the native $5-\mathrm{HT}_{2 \mathrm{C}}$ receptor in choroid epithelial cells or when the $5-\mathrm{HT}_{2 \mathrm{C}}$ receptor was expressed at normal physiologic levels in HEK293 cells. In this study, the signaling properties of the $5-\mathrm{HT}_{2 \mathrm{C}}$ receptor homodimer were investigated using agonists that bind in a wash-resistant manner to one or both protomers of the 5- $\mathrm{HT}_{2 \mathrm{C}}$ receptor homodimer. Agonist binding to one protomer stimulated a half-maximal phosphoinositide response, whereas binding to both protomers was required to produce a maximal response (Herrick-Davis et al., 2015). These experiments provide pharmacological evidence supporting the hypothesis that the $5-\mathrm{HT}_{2 \mathrm{C}}$ receptor functions as a homodimer.

Heterodimers can form between the different isoforms of the $5-\mathrm{HT}_{2 \mathrm{C}}$ receptor generated by RNA editing (Herrick-Davis and Farrington, 2011). In HEK293 cells, positive resonance energy transfer was observed between the INI/VSV, INI/VGV, and VSV/VGV isoform pairs. However, the influence of heteromer pairs of edited $5-\mathrm{HT}_{2 \mathrm{C}}$ receptor isoforms on receptor signaling and neural function in vivo are yet to be demonstrated. In terms of heterodimers between the $5-\mathrm{HT}_{2 \mathrm{C}}$ receptor and other members of the 5-HT receptor family, the $5-\mathrm{HT}_{2 \mathrm{~A}}$ receptor would be the most likely candidate given the similarity in structure (for review, see Hannon and Hoyer, 2008a,b). Immunohistochemical analyses indicate that the $5-\mathrm{HT}_{2 \mathrm{~A}}$ receptor and $5-\mathrm{HT}_{2 \mathrm{C}}$ receptor protein colocalize in the same GABAergic neurons as well as in a population of pyramidal projection neurons in the rat medial prefrontal cortex (mPFC) (Nocjar et al., 2015). Coimmunoprecipitation studies suggest that the $5-\mathrm{HT}_{2 \mathrm{~A}}$ receptor and $5-\mathrm{HT}_{2 \mathrm{C}}$ receptor are found in the same protein complex in the rat $\mathrm{mPFC}$ (Anastasio et al., 2015). Further analyses of the structural and biologic significance of a possible heteromeric protein complex incorporating both the $5-\mathrm{HT}_{2 \mathrm{~A}}$ receptor and $5-\mathrm{HT}_{2 \mathrm{C}}$ receptor are required to understand its potential role in behavior and neuropsychiatric disorders.

Selective $5-\mathrm{HT}_{2 \mathrm{~A}}$ receptor antagonists and selective $5-\mathrm{HT}_{2 \mathrm{C}}$ receptor agonists have been noted to suppress a wide range of behaviors that are particularly well studied in preclinical models of addictive disorders (Bubar and Cunningham, 2008; Cunningham and Anastasio, 2014; Howell and Cunningham, 2015). The combination of low doses of the selective $5-\mathrm{HT}_{2 \mathrm{~A}}$ receptor antagonist M100907 plus the preferential 5- $\mathrm{HT}_{2 \mathrm{C}}$ receptor agonist MK212 evoked modest effects but resulted in an approximately additive suppression of cocaine-evoked hyperlocomotion and Fos expression in the caudate putamen (Pockros et al., 2012). In a second study, the combination of subthreshold doses of M100907 plus the selective $5-\mathrm{HT}_{2 \mathrm{C}}$ receptor agonist WAY163909 
synergistically suppressed inherent and cocaine-evoked motor impulsivity as well as cocaine-induced hyperactivity and cocaine-seeking behavior (Cunningham et al., 2013). These data raise the possibility that the $5-\mathrm{HT}_{2 \mathrm{~A}}$ receptor and $5-\mathrm{HT}_{2 \mathrm{C}}$ receptor may act in concert to regulate the neural bases for behavior. Further analyses of the structural and functional interactions between the $5-\mathrm{HT}_{2 \mathrm{~A}}$ receptor and $5-\mathrm{HT}_{2 \mathrm{C}}$ receptor are necessary to disentangle the manner in which these GPCRs interact at neuronal and circuit levels.

Microinfusion of the preferential $5-\mathrm{HT}_{2 \mathrm{~A}}$ receptor agonist DOI into the mPFC enhances (Wischhof et al., 2011), whereas intra-mPFC infusion of M100907 (Winstanley et al., 2003) suppresses, motor impulsivity. The density of $5-\mathrm{HT}_{2 \mathrm{~A}}$ receptor (Fink et al., 2015) as well as $5-\mathrm{HT}_{2 \mathrm{C}}$ receptor protein expression in the mPFC (Anastasio et al., 2014b) predicts the level of motor impulsivity in outbred rats. Highly impulsive rats exhibit a greater $5-\mathrm{HT}_{2 \mathrm{~A}}$ receptor-mediated head twitch response and are more sensitive to the suppressive effects of the selective $5-\mathrm{HT}_{2 \mathrm{~A}}$ receptor antagonist M100907 on motor impulsivity (Fink et al., 2015). The levels of $5-\mathrm{HT}_{2 \mathrm{~A}}$ receptor and $5-\mathrm{HT}_{2 \mathrm{C}}$ receptor protein predicted the intensity of motor impulsivity, and the ratio of the $5-\mathrm{HT}_{2 \mathrm{~A}}$ receptor to $5-\mathrm{HT}_{2 \mathrm{C}}$ receptor protein in $\mathrm{mPFC}$ positively correlated with levels of motor impulsivity in individual outbred rats (Anastasio et al., 2015). High phenotypic motor impulsivity was associated with a diminished $\mathrm{mPFC}$ synaptosomal $5-\mathrm{HT}_{2 \mathrm{~A}} \mathrm{R}$ : $5-\mathrm{HT}_{2 \mathrm{C}}$ receptor protein:protein interaction assessed by coimmunoprecipitation (Anastasio et al., 2015). Knockdown of $5-\mathrm{HT}_{2 \mathrm{C}}$ receptor in the $\mathrm{mPFC}$ resulted in increased motor impulsivity and triggered a compensatory upregulation of $5-\mathrm{HT}_{2 \mathrm{~A}}$ receptor protein expression in $\mathrm{mPFC}$ and a leftward shift in the potency of M100907 to suppress impulsive behavior (Anastasio et al., 2015). These data further support the concept that an interactive relationship between the $\mathrm{mPFC}$ $5-\mathrm{HT}_{2 \mathrm{~A}}$ receptor and $5-\mathrm{HT}_{2 \mathrm{C}}$ receptor is behaviorally relevant. The manner in which a potential $5-\mathrm{HT}_{2 \mathrm{~A}}$ receptor and $5-\mathrm{HT}_{2 \mathrm{C}}$ receptor heteromeric protein complex in the mPFC contributes to high levels of inherent motor impulsivity remains to be uncovered.

The 5- $\mathrm{HT}_{2 \mathrm{C}}$ receptor has also been reported to form heterodimers with ghrelin GHS-R1a receptor when overexpressed in HEK293 cells and to colocalize with the GHS-R1a in cultured primary hypothalamic and hippocampal neurons from the rat (Schellekens et al., 2015). In this study, activation and blockade of $5-\mathrm{HT}_{2 \mathrm{C}}$ receptor in vivo attenuated and potentiated, respectively, the orexigenic effects of ghrelin. Heterodimers between $5-\mathrm{HT}_{2 \mathrm{C}}$ receptor and melatonin $\mathrm{MT}_{2}$ receptors have also been reported in transfected cells as well as human cortex and hippocampus (Kamal et al., 2015). Interestingly, the novel antidepressant agomelatine demonstrates biased signaling and displays $5-\mathrm{HT}_{2 \mathrm{C}}$ receptor and $\mathrm{MT}_{2}$ receptor agonist properties, suggesting the heterodimer as a potential target for the development of a novel class of therapeutics for the treatment of psychiatric disorders as well as eating disorders and obesity.

Immunohistochemical studies demonstrated that the NMDA receptor GluN2A colocalizes with the $5-\mathrm{HT}_{2 \mathrm{C}}$ receptor in rat spinal cord neurons, whereas coimmunoprecipitation analysis of synaptosomal fractions suggests formation of a $5-\mathrm{HT}_{2} \mathrm{C}$ receptor and GluN2A protein complex (Bigford et al., 2012). Stimulation of the $5-\mathrm{HT}_{2 \mathrm{C}}$ receptor enhanced NMDA-evoked motoneuron depolarization through involvement of Src tyrosine kinase (Bigford et al., 2012). These results support the assembly of a functionally relevant $5-\mathrm{HT}_{2 \mathrm{C}}$ receptor and NMDA receptor complex in the spinal cord, although the presence of this complex in the brain and its involvement in higher-order neural function is unexplored.

\section{Pharmacology}

For the $5-\mathrm{HT}_{2 \mathrm{C}}$ receptor, the identification of selective orthosteric ligands relative to the close family members $5-\mathrm{HT}_{2 \mathrm{~A}}$ receptor and $5-\mathrm{HT}_{2 \mathrm{~B}}$ receptor is challenged by their $\sim 50 \%$ overall homology, which rises to $\sim 80 \%$ in the transmembrane domains, comprising the orthosteric receptor-binding pocket (Hoyer et al., 2002). Because of this challenge, the earliest preclinical and clinical research employed "preferential" $5-\mathrm{HT}_{2 \mathrm{C}}$ receptor ligands, which frequently displayed affinity (agonists, antagonists) and/or efficacy (agonists) at the $5-\mathrm{HT}_{2 \mathrm{~A}}$ receptor and $5-\mathrm{HT}_{2 \mathrm{~B}}$ receptor. Because of the lack of selectivity of available agonists [e.g., MK212 and $m$-chlorophenylpiperazine (mCPP)] and antagonists (e.g., ketanserin), experimental outcomes with such compounds initially led to ambiguous conclusions concerning the biologic roles for the $5-\mathrm{HT}_{2 \mathrm{C}}$ receptor, particularly in vivo. Furthermore, with the understanding that $5-\mathrm{HT}_{2 \mathrm{~A}}$ receptor or $5-\mathrm{HT}_{2 \mathrm{~B}}$ receptor agonists may evoke hallucinations (Nichols, 2004) or cardiac valvulopathy (Fitzgerald et al., 2000; Roth, 2007), respectively, the need for $5-\mathrm{HT}_{2 \mathrm{C}}$ receptor orthosteric agonists that lack demonstrable efficacy at $5-\mathrm{HT}_{2 \mathrm{~A}}$ receptor or $5-\mathrm{HT}_{2 \mathrm{~B}}$ receptor is recognized. In 1997, the chemists at SmithKline Beecham synthesized and characterized SB242084 as the first selective $5-\mathrm{HT}_{2 \mathrm{C}}$ receptor antagonist (Bromidge et al., 1997; Kennett et al., 1997). Because the $5-\mathrm{HT}_{2 \mathrm{C}}$ receptor exhibits constitutive activity dependent on the edited isoform and the in vitro and in vivo conditions employed for analyses, SB242084 and other compounds in this series (e.g., SB206553 and SB243213) (Bromidge et al., 1997; Kennett et al., 1997) have been noted to act as inverse agonists to attenuate constitutive 5 - $\mathrm{HT}_{2 \mathrm{C}}$ receptor activity (for reviews, see Aloyo et al., 2009; Sullivan et al., 2015). Atypical antipsychotic drugs are also reported to act as inverse agonists with the ability to inhibit $5-\mathrm{HT}_{2 \mathrm{C}}$ receptor constitutive activity (Herrick-Davis et al., 2000; Rauser et al., 2001) and Spampinato and colleagues have identified the role 
of $5-\mathrm{HT}_{2 \mathrm{C}}$ receptor constitutive activity in the control of dopamine corticoaccumbens function (Aloyo et al., 2009; Leggio et al., 2009b).

A body of knowledge has been developed around several useful $5-\mathrm{HT}_{2 \mathrm{C}}$ receptor agonists that have been available to scientists for the last 10 years. The compound RO60-0175 (Knight et al., 2004) has generated a great deal of information concerning the biologic role of the $5-\mathrm{HT}_{2 \mathrm{C}}$ receptor (Millan et al., 1998; Di Matteo et al., 2000; Grottick et al., 2000; Filip and Cunningham, 2002; Tomkins et al., 2002; Leggio et al., 2009a; Fletcher et al., 2012). RO60-0175 exhibits affinity and efficacy for all three $5-\mathrm{HT}_{2}$ receptor subtypes, although many of its effects in vivo are blocked by SB242084 (Martin et al., 1998; Porter et al., 1999; Knight et al., 2004). Lorcaserin is a selective, highefficacy $5-\mathrm{HT}_{2 \mathrm{C}}$ receptor agonist that was marketed as Belviq for weight reduction in patients with a body mass index $>30$ or with a body mass index $>27$ comorbid with type 2 diabetes, hypertension, or dyslipidemia (www. us.eisai.com/). The availability of lorcaserin for clinical research has prompted a growing number of studies, particularly focused on addictive disorders (Rezvani et al., 2014; Higgs et al., 2016; Harvey-Lewis et al., 2016; for review, see Higgins et al., 2020). The preliminary results of a clinical trial (http://www.eisai.com/ news/news201465.html) demonstrated the efficacy of lorcaserin to increase abstinence from nicotine, a highly abused psychostimulant, whereas preclinical studies continue to promote the prospects of lorcaserin as a tool to reduce substance use disorders (Levin et al., 2011; Cunningham and Anastasio, 2014; Rezvani et al., 2014; Howell and Cunningham, 2015; Harvey-Lewis et al., 2016; Higgins et al., 2012; for review, see Higgins et al., 2020). Strikingly, Di Giovanni's group has also recently shown that lorcaserin is very effective as an anticonvulsant in both animal models of generalized nonconvulsive absence epilepsy and temporal lobe epilepsy (Orban et al., 2014; Venzi et al., 2016).

A compound series developed at Wyeth Research includes vabicaserin (SCA-136), which acts as a selective $5-\mathrm{HT}_{2 \mathrm{C}}$ receptor full agonist $\left(K_{\mathrm{i}}=3 \mathrm{nM}\right.$; efficacy $100 \%$ relative to $5-\mathrm{HT}$ ), a $5-\mathrm{HT}_{2 \mathrm{~B}}$ receptor antagonist $\left(\mathrm{IC}_{50}=\right.$ $29 \mathrm{nM})$, and a weak $5-\mathrm{HT}_{2 \mathrm{~A}}$ receptor antagonist $\left(\mathrm{IC}_{50}=\right.$ $1650 \mathrm{nM}$ ) (Rosenzweig-Lipson et al., 2007a; Tong et al., 2010; Dunlop et al., 2011). A randomized, double-blind, placebo-controlled study suggested the efficacy, safety, and tolerability of vabicaserin in the treatment of acute schizophrenia (Shen et al., 2014), although few preclinical analyses of this compound are published. WAY163909 is chemically similar to vabicaserin with high affinity $\left(K_{\mathrm{i}}=10.5 \mathrm{nM}\right)$ and full efficacy $(90 \%$ relative to 5 -HT) at the $5-\mathrm{HT}_{2 \mathrm{C}}$ receptor. WAY163909 exhibits a lower affinity $\left(K_{\mathrm{i}}=212 \mathrm{nM}\right)$ and no efficacy at the $5-\mathrm{HT}_{2 \mathrm{~A}}$ receptor and is a weak partial agonist at the $5-\mathrm{HT}_{2 \mathrm{~B}}$ receptor (Dunlop et al., 2005). WAY163909 has been employed as a tool compound to test hypotheses related to the involvement of the $5-\mathrm{HT}_{2 \mathrm{C}}$ receptor in animal models of addiction, depression, impulsivity, and schizophrenia (Dunlop et al., 2006; Marquis et al., 2007; Rosenzweig-Lipson et al., 2007b; Navarra et al., 2008; Cunningham et al., 2011, 2013; Anastasio et al., 2013; Navailles et al., 2013b; Anastasio et al., 2014a). More recently, rational medicinal chemistry approaches have been employed to craft novel, highly selective 5- $\mathrm{HT}_{2 \mathrm{C}}$ receptor agonists (Storer et al., 2014; Rouquet et al., 2015; Cheng et al., 2016). Some of these newer $5-\mathrm{HT}_{2 \mathrm{C}}$ receptor agonists have been made commercially available (e.g., PF-3246799 and PF-4479745 from Pfizer) (Storer et al., 2014), which will allow their increasing employment in in vitro and in vivo studies and provide greater breakthroughs in our understanding of $5-\mathrm{HT}_{2 \mathrm{C}}$ receptor biology.

The orthosteric site of a GPCR at which the endogenous agonist binds has been the traditional target for ligand discovery, but the chemical space for GPCR neuroprobes and therapeutics has greatly expanded with the discovery of allosteric ligands for many GPCR subfamilies. An allosteric modulator is a ligand that binds to a spatially distinct allosteric site and alters the receptor conformation to modulate its interaction with other ligands and/or signal transduction molecules [for reviews, see Conn et al. (2009) and Christopoulos et al. (2014)]. Allosteric sites are expected to exhibit higher sequence divergence across receptor subtypes relative to the highly conserved orthosteric domain (Kenakin, 2009; Kenakin and Miller, 2010). For example, a positive allosteric modulator (PAM) can increase the affinity and/or efficacy of the orthosteric ligand (Conn et al., 2009) and, thus, has the potential to improve its therapeutic index and diminish negative side effects. Such allosteric modulation is saturable (comes to a finite magnitude when the allosteric site is fully occupied) and probe-dependent (varies dependent on the orthosteric ligand) with the prospects for separate control of affinity and efficacy, making allosteric ligands intriguing therapeutic chemical targets (Kenakin, 2010). At present, allosteric modulators are defined operationally as positive (PAM), negative allosteric modulators, or neutral allosteric ligands, with the possibility of the additional property of allosteric agonism (agonist effects consequent to binding to allosteric sites; Christopoulos et al., 2014).

Adron Harris and colleagues were the first to identify the effects of the fatty acid amide oleamide to positively modulate $5-\mathrm{HT}_{2 \mathrm{C}}$ receptor-mediated activity in Xenopus oocytes (Huidobro-Toro et al., 1996a), and further analyses have identified oleamide as a member of a family of amphipathic lipid metabolites that allosterically promote 5 -HT receptor signaling through other receptors (e.g., $5-\mathrm{HT}_{2 \mathrm{~A}}$ receptor and $5-\mathrm{HT}_{7}$ receptor; Thomas et al., 1997; Thomas et al., 1998; Alberts et al., 2001) but also exhibit a myriad of additional effects on receptor signaling (Leggett et al., 2004). In 2003, 
chemical library screening at Pharmacia (now Pfizer) resulted in the discovery and characterization of PNU-69176E as a PAM highly selective for the $5-\mathrm{HT}_{2 \mathrm{C}}$ receptor over the $5-\mathrm{HT}_{2 \mathrm{~A}}$ receptor, $5-\mathrm{HT}_{2 \mathrm{~B}}$ receptor, $5-\mathrm{HT}_{7}$ receptor, and dopamine receptors (Im et al., 2003). In 2012, Zhou and colleagues optimized the synthetic route to generate PNU-69176E and its diastereomer (Ding et al., 2012). A series of new molecules based on the 4-alkylpiperidine-2-carboxamide scaffold were designed, synthesized, and pharmacologically evaluated as $5-\mathrm{HT}_{2 \mathrm{C}}$ receptor PAMs (Wild et al., 2019). Several analogs, potentiated 5 -HT-evoked $\mathrm{Ca}_{i}^{2+}$ in $5-\mathrm{HT}_{2 \mathrm{C}}$ receptor $\mathrm{CHO}$ cells but not in $5-\mathrm{HT}_{2 \mathrm{~A}}$ receptor $\mathrm{CHO}$ cells; one compound was further evaluated in vivo and exhibited a favorable overall pharmacokinetic and behavioral profile in rats (Wild et al., 2018). In addition, two predicted allosteric sites were identified by molecular docking to a $5-\mathrm{HT}_{2 \mathrm{C}}$ receptor homology model (Wild et al., 2018). Taken together, these data provide proof of concept that allosteric modulation of $5-\mathrm{HT}_{2 \mathrm{C}}$ receptor may be a viable strategy toward the discovery of novel neurotherapeutics. Recent preclinical indications of the efficacy of allosteric modulators in disease models, coupled with the launch of cinacalcet and maraviroc as the first marketed GPCR allosteric modulators, provide strong validation of the potential clinical utility of allosteric modulators (Conn et al., 2009). Ultimately, further analyses of novel allosteric modulators will improve understanding of $5-\mathrm{HT}_{2 \mathrm{C}}$ receptor function and how allosteric modulators may provide gain (or loss) of function in this system.

\section{E. Signal Transduction}

Intracellular signaling cascades stimulated by the $5-\mathrm{HT}_{2 \mathrm{C}}$ receptor have been assessed predominantly in recombinant cellular models and to a lesser extent within natural cellular environments (e.g., choroid plexus epithelial cells). Multiple G proteins (e.g., $\mathrm{G} \alpha_{\mathrm{q} / 11}, \mathrm{G} \alpha_{12 / 13}$, and $\mathrm{G} \alpha_{\mathrm{i} / \mathrm{o}}$ ) and activation of second messengers such as phospholipases, cyclic nucleotides, and $\mathrm{ERK}_{1 / 2}$ are essential mediators of $5-\mathrm{HT}_{2 \mathrm{C}}$ receptor actions in cells. By the late 1990s, structurally diverse $5-\mathrm{HT}_{2 \mathrm{C}}$ receptor agonists (Berg et al., 1994, 1998a; Moya et al., 2007) were noted to differentially activate intracellular signaling pathways, variably referred to as "agonist-directed trafficking of receptor stimulus," biased agonism (signaling), stimulus trafficking, collateral efficacy, and functional selectivity (Berg and Clarke, 2009; Whalen et al., 2011; Kenakin and Christopoulos, 2013). Recent modeling studies suggest that $5-\mathrm{HT}_{2 \mathrm{C}}$ receptor ligands with fewer docking poses may stabilize a structural conformation contributory to a specific signaling pathway (Canal et al., 2011). Thus, distinct conformational states may differentially modulate the receptor interaction with immediate effectors (e.g., G proteins vs. $\beta$-arrestins), resulting in biased intracellular signal transduction patterns depending on the recruited effector (Gesty-Palmer et al., 2006; Whalen et al., 2011; Kenakin and Christopoulos, 2013). For example, G protein-dependent signaling pathways result in activation of specific downstream signaling effectors (e.g., $\mathrm{pERK}_{1 / 2}$ ), whereas $\beta$-arrestin ${ }_{2}-$ dependent signaling can result in a different subset of downstream effectors as well as subcellular distribution of shared effectors (e.g., cytoplasmic vs. nuclear $\left.\mathrm{pERK}_{1 / 2}\right)$. These signaling profiles can then lead to distinct overall effects of GPCR activation (GestyPalmer et al., 2006). Targeting G protein- versus $\beta$-arrestin 2 -dependent mechanisms can allow for selectively inducing certain outcomes of receptor activation and perhaps not only reducing undesired side effects but also providing new therapeutic possibilities (Luttrell et al., 2015), a hypothesis that is supported for the $5-\mathrm{HT}_{2 \mathrm{C}}$ receptor system (Berg and Clarke, 2009) as well as for other GPCR signaling systems (GestyPalmer et al., 2006; Masri et al., 2008; Allen et al., 2011; Lovell et al., 2015; Marti-Solano et al., 2015).

1. Phospholipase $C$. The $5-\mathrm{HT}_{2 \mathrm{C}}$ receptor is characterized to stimulate phospholipase C (PLC) signaling through pharmacological analyses in heterologous expression systems (Westphal and Sanders-Bush, 1996; Briddon et al., 1998; Herrick-Davis et al., 1999; Rosendorff et al., 2000; Devlin et al., 2004), choroid plexus cells (Conn and Sanders-Bush, 1986b; Conn et al., 1986; Sanders-Bush and Conn, 1986), and corticostriatal regions of the brain (Wolf and Schutz, 1997). In this regard, the $5-\mathrm{HT}_{2 \mathrm{C}}$ receptor is largely thought to act through pertussis toxin-insensitive $\mathrm{G} \alpha_{\mathrm{q} / 11}$ proteins (Conn et al., 1986; Berg et al., 1994; Chang et al., 2000), although there is evidence that pertussis toxin-sensitive $\mathrm{G} \alpha_{\mathrm{i} / \mathrm{o}} \mathrm{G}$ proteins may couple the $5-\mathrm{HT}_{2 \mathrm{C}}$ receptor to $\mathrm{PLC}$ in Xenopus laevis oocytes (Chen et al., 1994) and HEK293 cells (Alberts et al., 1999). Thus, the canonical G proteindependent signaling through the $5-\mathrm{HT}_{2 \mathrm{C}}$ receptor is engendered by 5 -HT-stimulated coupling to $\mathrm{G} \alpha_{\mathrm{q} / 11}$ to activate the enzyme phospholipase $\mathrm{C}_{\beta}\left(\mathrm{PLC}_{\beta}\right)$, which generates the intracellular second messenger inositol-1,4,5-trisphosphate $\left(\mathrm{IP}_{3}\right)$, accumulation of the downstream $\mathrm{IP}_{3}$ metabolite inositol monophosphate $\left(\mathrm{IP}_{1}\right)$, and DAG. $\mathrm{IP}_{3}$ interacts with the $\mathrm{IP}_{3}$ receptor, leading to increased i $\mathrm{Ca}_{i}^{2+}$ into the cytoplasm; $\mathrm{Ca}_{i}^{2+}$ mobilization, measured with calcium-binding fluorescent dyes, and $\mathrm{IP}_{1}$ levels, assessed with $\left[{ }^{3} \mathrm{H}\right]$-inositol, are well characterized to be elevated following activation of the $5-\mathrm{HT}_{2 \mathrm{C}}$ receptor [for reviews, see Raymond et al. (2001) and Millan et al. (2008)]. Utilizing cellpermeable small peptide disruptors mimicking the $\mathrm{C}$ terminal of $\mathrm{G} \alpha_{\mathrm{q}}$, Sanders-Bush and colleagues demonstrated that a $\mathrm{G} \alpha_{\mathrm{q}}$, but not a $\mathrm{G}_{\mathrm{s}}$, disruptor was able to block $5-\mathrm{HT}_{2 \mathrm{C}}$ receptor-mediated phosphoinositide hydrolysis in choroid plexus endothelial cells (Chang et al., 2000). Furthermore, a $\mathrm{PLC}_{\beta 1}$, but not a $\mathrm{PLC}_{\beta 2}$, peptide blocked $5-\mathrm{HT}_{2 \mathrm{C}}$ receptor activation, suggesting that $5-\mathrm{HT}_{2 \mathrm{C}}$ receptor-evoked phosphoinositide hydrolysis 
is mediated through a $\mathrm{G} \alpha_{\mathrm{q}^{-}}$and $\mathrm{PLC}_{\beta 1^{-}}$-dependent mechanism (Chang et al., 2000).

Hydrolysis of phosphoinositides generates the signaling lipid DAG, leading to activation of PKC and downstream stimulation of the MAPK cascade, resulting in phosphorylation of $\mathrm{ERK}_{1 / 2}$ (Werry et al., 2005). In fact, $5-\mathrm{HT}_{2 \mathrm{C}}$ receptor-transfected $\mathrm{CHO}$ cells were shown to couple $\mathrm{ERK}_{1 / 2}$ via a PLD- and PKC-dependent pathway likely through $\mathrm{G} \alpha_{12 / 13}$ proteins (Werry et al., 2005). The PLD and PKC involvement in $\mathrm{ERK}_{1 / 2}$ phosphorylation evoked by $5-\mathrm{HT}_{2 \mathrm{C}}$ receptor stimulation was recently validated in a hypothalamic cell line (mHypoA-2/10) derived from the periventricular nucleus of an adult male mouse (Lauffer et al., 2016). These further analyses indicated that the native $5-\mathrm{HT}_{2 \mathrm{C}}$ receptor activates the cellular transcription factor CREB via $\mathrm{PKC}$-induced $\mathrm{ERK}_{1 / 2}$ activation in this cellular model (Lauffer et al., 2016).

Desensitization and resensitization processes regulate the functional activity of $5-\mathrm{HT}_{2 \mathrm{C}}$ receptor. Agonistdependent desensitization is associated with $5-\mathrm{HT}_{2 \mathrm{C}}$ receptor phosphorylation involving $\mathrm{G}$ protein-coupled receptor kinase (GRK) 2 (Berg et al., 2001), binding of $\beta$-arrestins, and uncoupling of the receptor from the $\mathrm{G}$ protein to result in receptor internalization into endosomes; resensitization and recycling to the plasma membrane occurs with dephosphorylation (Marion et al., 2004; Schlag et al., 2004). The interaction of the $5-\mathrm{HT}_{2 \mathrm{C}}$ receptor with the C-terminal domain of PSD95/Disc large/Zonula occludens (PDZ) domain-containing proteins (Bécamel et al., 2002, 2004; Anastasio et al., 2010; Anastasio et al., 2014b) is known to play an important role in $5-\mathrm{HT}_{2 \mathrm{C}}$ receptor desensitization/ resensitization processes and trafficking (Gavarini et al., 2006). Intracellular $\mathrm{Ca}_{i}^{2+}$ release in mouse cortical neurons in primary culture is regulated by the PDZ proteins postsynaptic density 95 (PSD-95) and MAGUK p55 subfamily member 3 (MPP3) (Gavarini et al., 2006; Møller et al., 2013). Although PSD-95 and MPP3 do not modify the efficacy of $5-\mathrm{HT}_{2 \mathrm{C}}$ receptor signaling triggered by a single 5 -HT exposure, PSD-95 increases signal desensitization and trafficking upon repeated agonist exposure, an effect that is blocked by a peptidyl mimetic of the $5-\mathrm{HT}_{2 \mathrm{C}}$ receptor C-terminus, which disrupts the interaction between the $5-\mathrm{HT}_{2 \mathrm{C}}$ receptor and PSD-95 (Gavarini et al., 2006). On the other hand, MPP3 stabilizes the $5-\mathrm{HT}_{2 \mathrm{C}}$ receptor at the plasma membrane and prevents desensitization of the $5-\mathrm{HT}_{2 \mathrm{C}}$ receptor-mediated $\mathrm{Ca}_{i}^{2+}$ release (Gavarini et al., 2006). This regulation correlates with surface expression of the receptor and indicates that $5-\mathrm{HT}_{2 \mathrm{C}}$ receptor signaling is highly regulated by $\mathrm{PDZ}$ proteins.

2. Phospholipase D. The $5-\mathrm{HT}_{2 \mathrm{C}}$ receptor also activates PLD, an enzyme that catalyzes the conversion of phosphatidylcholine to choline and phosphatidic acid; phosphatidic acid transduces most of PLD-evoked activity, whereas soluble choline diffuses into the cytosol, but has little second messenger activity [for reviews, see Frohman (2015) and Nelson and Frohman (2015)]. The activation of PLD can occur through the canonical receptor/G protein/effector signal transduction cascade via $\mathrm{G} \alpha_{12 / 13}$. In rat choroid plexus epithelial cells, 5-HT-evoked PLD activation occurs at levels similar to PLC activation; however, PLD activation is not downstream to G protein-linked PLC activation (McGrew et al., 2002). The 5- $\mathrm{HT}_{2 \mathrm{C}}$ receptor antagonist SB206553 and a peptide targeting the $\mathrm{G} \alpha_{13}$, but not the $\mathrm{G} \alpha_{\mathrm{q}}$, subunit blocked 5-HT-evoked PLD activation (McGrew et al., 2002). Inactivation of RhoA GTPase in NIH3T3 cells stably expressing the $5-\mathrm{HT}_{2 \mathrm{C}}$ receptor by the C3 exoenzyme from Clostridia botulinum blocks $5-\mathrm{HT}_{2 \mathrm{C}}$ receptor-evoked $\mathrm{PLD}$, but not PLC, signaling (McGrew et al., 2002). Also, in a NIH3T3 cell line derived from $\mathrm{G} \alpha_{\mathrm{q} / 11}$-deficient mice, 5 - $\mathrm{HT}_{2 \mathrm{C}}$ receptor-dependent stress fiber formation is dependent on $\mathrm{G} \alpha_{13}$ and Rho signaling (Gohla et al., 1999). The PLD signaling was not seen in cells transfected with the $5-\mathrm{HT}_{2 \mathrm{C}-\mathrm{VGV}}$ receptor; this highly edited isoform has a diminished ability to couple to $\mathrm{G} \alpha_{13}$ and is unable to promote Rho GTPase activity (McGrew et al., 2004). Together, these studies suggest that $5-\mathrm{HT}_{2 \mathrm{C}}$ receptor-mediated $\mathrm{PLD}$ signaling is dependent on $\mathrm{G} \alpha_{13}$ activation of Rho, a property of this receptor that is affected by pre-RNA editing.

3. Phospholipase $A_{2}$. Stimulation of the $5-\mathrm{HT}_{2 \mathrm{C}}$ receptor is thought to activate cytosolic $\mathrm{PLA}_{2}$, which hydrolyzes arachidonic acid-containing phospholipids to produce free arachidonic acid and a host of its metabolites (for reviews, see Burke and Dennis, 2009a,b). In an early study, 5-HT was demonstrated to stimulate the release of arachidonic acid through activation of $\mathrm{PLA}_{2}$, but not phosphoinositide turnover, in hippocampal neurons cocultured with glial cells, but not in glial cultures alone; the studies supported the involvement of the $5-\mathrm{HT}_{2}$ receptor subtype in the $\mathrm{PLA}_{2}$ activation (Felder et al., 1990). In $5-\mathrm{HT}_{2 \mathrm{C}}$ receptor-transfected $\mathrm{CHO}$ cells, 5-HT increases the release of arachidonic acid, an effect that is blocked by the $\mathrm{PLA}_{2}$ inhibitor mepacrine, which had no effect on $5-\mathrm{HT}_{2 \mathrm{C}}$ receptor-mediated phosphoinositide hydrolysis (Berg et al., 1996). The $G$ protein effector is sensitive to pertussis toxin inactivation, but the exact $\mathrm{G}$ proteins involved are as of yet unknown (Felder et al., 1990). This research was extended to demonstrate that the relative efficacy of agonists is distinct for the $\mathrm{PLA}_{2}$-arachidonic acid versus PLC-phosphoinositide pathways. For example, DOI acts as a full agonist to stimulate arachidonic acid release (equivalent to 5 -HT), whereas 3 -trifluoromethylphenylpiperazine and $d$-LSD preferentially activate the PLC-phosphoinositide and $\mathrm{PLA}_{2}-$ arachidonic acid pathways, respectively (Berg et al., 1998b). In addition, arachidonic acid release, though sensitive to pretreatment with 5-HT, is not as sensitive 
as phosphoinositide hydrolysis, suggesting that arachidonic acid release may be more difficult to demonstrate in vivo as a $5-\mathrm{HT}_{2 \mathrm{C}}$ receptor-mediated output when compared with phosphoinositide hydrolysis (Berg et al., 1998b). The involvement of arachidonic acid stimulation in $5-\mathrm{HT}_{2}$ receptor signaling in vivo is supported by the observation that systemic administration of DOI resulted in increased incorporation of labeled arachidonic acid into brain membranes (Qu et al., 2005). The increases were seen in brain regions with the highest densities of $5-\mathrm{HT}_{2 \mathrm{~A}}$ receptor (e.g., cerebral cortex) but not in the choroid plexus, which expresses the highest $5-\mathrm{HT}_{2 \mathrm{C}}$ receptor density (choroid plexus). Future studies are necessary to clarify the relative roles of the $5-\mathrm{HT}_{2 \mathrm{~A}}$ receptor and $5-\mathrm{HT}_{2 \mathrm{C}}$ receptor in the control of arachidonic acid incorporation in vivo (Basselin et al., 2012).

4. Cyclic Nucleotides. Signaling through cyclic nucleotides, such as cAMP and cGMP, are also reported to be engaged by the $5-\mathrm{HT}_{2 \mathrm{C}}$ receptor. Activation of the $5-\mathrm{HT}_{2 \mathrm{C}}$ receptor inhibits forskolin-stimulated cAMP production in AV12 fibroblast cells that stably express the receptor at high density ( $\sim 12 \mathrm{pmol} / \mathrm{mg}$ membrane protein); at low $5-\mathrm{HT}_{2 \mathrm{C}}$ receptor density $(\sim 150 \mathrm{fmol} / \mathrm{mg}$ of membrane protein), 5-HT couples to the PLC-IP pathway but evokes a stimulation rather than an inhibition of cAMP production (Lucaites et al., 1996). Upon pertussis toxin treatment, a modest 5 - $\mathrm{HT}_{2 \mathrm{C}}$ receptor stimulatory effect on cAMP accumulation as well as its potential dependence on the $\mathrm{G}_{\mathrm{i} / \mathrm{o}}$ family of $\mathrm{G}$ proteins was observed (Lucaites et al., 1996). In Xenopus oocytes transfected with the $5-\mathrm{HT}_{2 \mathrm{C}}$ receptor and $\mathrm{G}$ proteins, the $5-\mathrm{HT}_{2 \mathrm{C}}$ receptor was shown to couple to $\mathrm{G}_{\mathrm{o}}$ in addition to $\mathrm{G}_{\mathrm{q}}$ (Quick et al., 1994). Because there is limited evidence that the $5-\mathrm{HT}_{2 \mathrm{C}}$ receptor links to cAMP in cells natively expressing the receptor (porcine choroid plexus) (Palacios et al., 1986), further analyses as to its biologic significance in vitro and in vivo are required.

The antimigraine medication dihydroergotamine, which inhibits $\left[{ }^{3} \mathrm{H}\right]$-mesulergine binding to the $5-\mathrm{HT}_{2 \mathrm{C}}$ receptor and is a full $5-\mathrm{HT}_{2 \mathrm{C}}$ receptor agonist in porcine choroid plexus (Brown et al., 1991), elevates cGMP levels in LMTK $^{-}$fibroblasts stably expressing the $5-\mathrm{HT}_{2 \mathrm{C}}$ receptor (Schaerlinger et al., 2003). 5-HT rapidly elevates cGMP production in the $5-\mathrm{HT}_{2 \mathrm{C}}$ receptorenriched porcine choroid plexus tissue slices (Kaufman et al., 1995) with an efficacy similar to phosphatidyl inositol turnover (Conn et al., 1986); the potencies of antagonists that suppress 5-HT-mediated cGMP formation align with their affinity for the $5-\mathrm{HT}_{2 \mathrm{C}}$ receptor (Kaufman et al., 1995). The pertussis toxin-insensitive $5-\mathrm{HT}_{2 \mathrm{C}}$ receptor-mediated cGMP formation is dependent on calcium and $\mathrm{PLA}_{2}$-arachidonate release as well as lipoxygenase (Kaufman et al., 1995). Thus, the $5-\mathrm{HT}_{2 \mathrm{C}}$ receptor appears to exhibit efficacy to evoke cGMP formation in a native tissue in a $\mathrm{PLA}_{2}$-dependent manner (Kaufman et al., 1995) as well as regulate NMDA- mediated production of nitric oxide and elevation of cGMP (Marcoli et al., 1997).

5. Extracellular Signal-Regulated Kinases. The activation of the 5 - $\mathrm{HT}_{2 \mathrm{C}}$ receptor can diverge to influence several G protein-dependent downstream cascades and may also converge on others, such as members of the MAPK class, P42 and 44 (p44/p42-MAPK), also known as $\mathrm{ERK}_{1 / 2}$. In fact, there is evidence to suggest that phosphorylation of $\mathrm{ERK}_{1 / 2}$ is an important integrator of the multiple upstream signaling events for the $5-\mathrm{HT}_{2 \mathrm{C}}$ receptor. In CHO cells stably expressing the $5-\mathrm{HT}_{2 \mathrm{C}}$ receptor, 5-HT stimulated phosphorylation of $\mathrm{ERK}_{1 / 2}$, which is inhibited by the $5-\mathrm{HT}_{2 \mathrm{C}}$ receptor antagonist mianserin (Werry et al., 2005). Though PKC and PLD inhibitors suppress 5-HT-mediated phosphorylation of $\mathrm{ERK}_{1 / 2}, \mathrm{PLC}$ and $\mathrm{PLA}_{2}$ inhibitors are ineffective, suggesting the $5-\mathrm{HT}_{2 \mathrm{C}}$ receptor-mediated $\mathrm{pERK}_{1 / 2}$ is dependent on PKC and PLD signaling (Werry et al., 2005). Activation of $\mathrm{ERK}_{1 / 2}$ by $5-\mathrm{HT}_{2 \mathrm{C}}$ receptor ligands is not solely mediated by coupling of the $5-\mathrm{HT}_{2 \mathrm{C}}$ receptor to $\mathrm{G}$ proteins and can, in fact, be mediated by coupling to other protein transducers. The $\mathrm{C}$ terminus of the $5-\mathrm{HT}_{2 \mathrm{C}}$ receptor contains a calmodulin domain that is critical for $\beta$-arrestin recruitment and $\mathrm{ERK}_{1 / 2}$ signaling (Labasque et al., 2008). A calmodulin mutant prevented phosphorylation of $\mathrm{ERK}_{1 / 2}$ in cortical neurons and choroid plexus epithelial cells, suggesting that the calmodulin interaction is critical for $\mathrm{G}$ protein-independent signaling (Labasque et al., 2008). In HEK293 cells transiently expressing the $5-\mathrm{HT}_{2 \mathrm{C}}$ receptor, $\mathrm{pERK}_{1 / 2}$ levels were increased over nontransfected cells, suggesting the expression of constitutive activity of the $5-\mathrm{HT}_{2 \mathrm{C}}$ receptor (Labasque et al., 2008). This elevated basal $\mathrm{pERK}_{1 / 2}$ was inhibited by a $5-\mathrm{HT}_{2 \mathrm{C}}$ receptor inverse agonist toward PLC (Labasque et al., 2008), again suggesting that pERK $_{1 / 2}$ activity is PLC-mediated. Interestingly, this activity was unaffected by depletion of $\mathrm{G} \alpha_{12}$ or $\mathrm{G} \alpha_{13}$ proteins, whereas in cells lacking $\beta$-arrestin or calmodulin, basal $\mathrm{pERK}_{1 / 2}$ levels were decreased, providing the first evidence of constitutive activity of a $G$ protein-coupled receptor toward a $G$ proteinindependent, $\beta$-arrestin-dependent signaling mechanism (Labasque et al., 2008).

6. Ion Channels. The impact of $5-\mathrm{HT}_{2 \mathrm{C}}$ receptor on the function of ion channels has been addressed extensively in the choroid plexus, which controls the composition and secretion of cerebrospinal fluid, a function in which chloride $\left(\mathrm{Cl}^{-}\right)$and potassium $\left(\mathrm{K}^{+}\right)$channels play a key role (Millar et al., 2007). 5-HT acting through the $5-\mathrm{HT}_{2 \mathrm{C}}$ receptor has been noted to activate $\mathrm{Cl}^{-}$and inhibit $\mathrm{K}^{+}$channels in mouse and rat choroid plexus epithelium (Hung et al., 1993; Speake et al., 2004), and the $5-\mathrm{HT}_{2 \mathrm{C}}$ receptor has been shown to inhibit $\mathrm{K}^{+}$ channels through a PKC-dependent pathway in rat choroid plexus epithelial cells (Speake et al., 2004). Activation of the $5-\mathrm{HT}_{2 \mathrm{C}}$ receptor leads to $\mathrm{G}$ proteindependent PLC activation, $\mathrm{IP}_{3}$ and DAG production, and 
the release of $\mathrm{Ca}_{i}^{2+}$ from the endoplasmic reticulum, which triggers the opening of calcium-activated $\mathrm{Cl}^{-}$ channels in Xenopus oocytes (Julius et al., 1988; Panicker et al., 1991; Woodward et al., 1992; DiMagno et al., 1996). The $G_{\alpha}$ and $G_{q}$ subunits may be involved in the generation of this calcium-activated $\mathrm{Cl}^{-}$current, which also involves PLC $\beta$ production (Quick et al., 1994; DiMagno et al., 1996). Upon coexpression of the $5-\mathrm{HT}_{2 \mathrm{C}}$ receptor and a brain-derived $\mathrm{K}^{+}$channel in Xenopus oocytes, 5-HT suppresses $\mathrm{K}^{+}$conductance through a calcium/calmodulin-activated phosphatase thought to dephosphorylate the $\mathrm{K}^{+}$channel in a kinase-dependent manner, evoking its closure (Hoger et al., 1991).

The $5-\mathrm{HT}_{2 \mathrm{C}}$ receptor also modulates the Kv1.5 channel through a PLC-dependent pathway in Xenopus oocytes (Panicker et al., 1991), which contrasts the observation that the $5-\mathrm{HT}_{2 \mathrm{C}}$ receptor inhibits $\mathrm{K}^{+}$channels through a PKC-dependent pathway in rat choroid plexus epithelial cells (Speake et al., 2004). The 5- $\mathrm{HT}_{2 \mathrm{C}}$ receptor also inhibits the $\mathrm{GABA}_{\mathrm{A}}$ receptor in Xenopus oocytes through a calcium-dependent, phosphorylation-independent mechanism (Huidobro-Toro et al., 1996b) and by suppressing an inwardly rectifying $\mathrm{K}^{+}$current in striatal cholinergic interneurons and rat brain slices (Blomeley and Bracci, 2005; Blomeley and Bracci, 2009). The $5-\mathrm{HT}_{2 \mathrm{C}}$ receptor was $\mathrm{G} \alpha_{\mathrm{q}}$-coupled to PLC activation and phosphoinositide hydrolysis to directly inhibit GIRK channels in POMC neurons of the arcuate (Qiu et al., 2007) as well as in lateral (but not basolateral) amygdala neurons (Yamamoto et al., 2014), which are known to stabilize resting membrane potential and therefore polarization of these neurons (Delmas and Brown, 2005). Hence, though stimulation of $5-\mathrm{HT}_{2 \mathrm{C}}$ receptor significantly modulates ion channel function, the involvement of specific signal transduction molecules in the processes is variable and underexplored at present.

\section{$F$. The 5-HT $T_{2 C}$ Receptor as an Oncogene}

5 -HT is known to act as a mitogen to regulate the proliferation and differentiation of a variety of cells through its binding to several 5-HT receptors and control of downstream signaling (for review, see Fanburg and Lee, 1997). The NIH3T3 mouse fibroblast cells are often used to identify oncogenes (genes that can transform a cell to a tumor cell) because they display several well characterized phenotypes that are indicative of cellular transformation, including the formation of foci (regions of dense cell growth within an otherwise confluent monolayer) (Land et al., 1983). Stimulation of NIH3T3 cells transfected with the $5-\mathrm{HT}_{2 \mathrm{C}}$ receptor leads to the generation of transformed foci, maintenance of which requires the activation of the $5-\mathrm{HT}_{2 \mathrm{C}}$ receptor as a $5-\mathrm{HT}_{2 \mathrm{C}}$ receptor antagonist blocks foci formation (Julius et al., 1988; Julius et al., 1989). Upon injection of these cells into nude mice, tumors form, a finding that led to the initial conclusion that the $5-\mathrm{HT}_{2 \mathrm{C}}$ receptor is a proto-oncogene (Julius et al., 1989).
The constitutive activity of the 5 - $\mathrm{HT}_{2 \mathrm{C}}$ receptor also stimulated cell division in the transfected NIH3T3 cells, and these data further suggested that multiple G proteins and signaling pathways were engaged in the cell division generated by agonist-evoked and constitutively active receptor signaling (Westphal and SandersBush, 1996).

\section{G. Clinical Relevance of the 5-HT 2 Receptor}

The $5-\mathrm{HT}_{2 \mathrm{C}}$ receptor is widely distributed throughout the basal ganglia, limbic system, and prefrontal cortex (Hoyer et al., 1986; Hoffman and Mezey, 1989; Molineaux et al., 1989; Mengod et al., 1990) and is well poised to mediate 5-HT-dependent appetite, cognition, mood, movement, and sleep, whereas dysfunctional $5-\mathrm{HT}_{2 \mathrm{C}}$ receptor signaling has been implicated in neuropsychiatric (e.g., addiction, anxiety, and depression) and neuropathological conditions (e.g., schizophrenia) as well as obesity and metabolic disorders (Berg et al., 2008a; Di Giovanni et al., 2010; Fig. 14). Therefore, the $5-\mathrm{HT}_{2 \mathrm{C}}$ receptor is a therapeutic target of great interest (for other reviews, see Cunningham and Anastasio, 2014; Howell and Cunningham, 2015; Sullivan et al., 2015; Di Giovanni and De Deurwaerdere, 2016; Fig. 12). The behavioral pharmacology of $5-\mathrm{HT}_{2 \mathrm{C}}$ receptor ligands as well as the clinical relevance of a dysfunctional $5-\mathrm{HT}_{2 \mathrm{C}}$ receptor system has recently been reviewed in detail (Cunningham and Anastasio, 2014; Howell and Cunningham, 2015; Sullivan et al., 2015; Di Giovanni and De Deurwaerdere, 2016), and an overview of clinical implications of the $5-\mathrm{HT}_{2 \mathrm{C}}$ receptor system is provided here.

1. Substance Use Disorders (Addiction). The pharmacological and molecular mechanisms underlying the effects of abused drugs have been the subject of extensive study. As early work unfolded, a central concept emerged that the dopamine pathway projection from the VTA to the nucleus accumbens plays a mechanistic role in the rewarding and incentive-salience value of abused drugs (for reviews, see Koob and Volkow, 2010; Volkow et al., 2010). As the research progressed, the field began to recognize that the transition to problematic drug abuse and substance use disorder (addiction and dependence) involves an "expanding cycle of dysfunction" (Koob and Volkow, 2010), engaging multiple neurotransmitter substrates within limbic-corticostriatal circuitry, including 5-HT (for reviews, see Kalivas and Volkow, 2005; Koob and Volkow, 2010; Volkow et al., 2010; Cunningham and Anastasio, 2014; Muller and Homberg, 2015; Di Giovanni and De Deurwaerdere, 2016; Wolf, 2016). Much of the research has focused on abused drugs as rewarding substances and the evoked, long-lasting dysregulation of the dopamine mesoaccumbens pathway (for reviews, see Koob and Volkow, 2010; Volkow et al., 2010). However, a second focus has evolved toward identifying genotypic and phenotypic drivers of individual differences in 
Serotonin $5-\mathrm{HT}_{2 \mathrm{C}}$ Receptor Subpopulations: Molecular, Neurochemical and Physiological Correlates

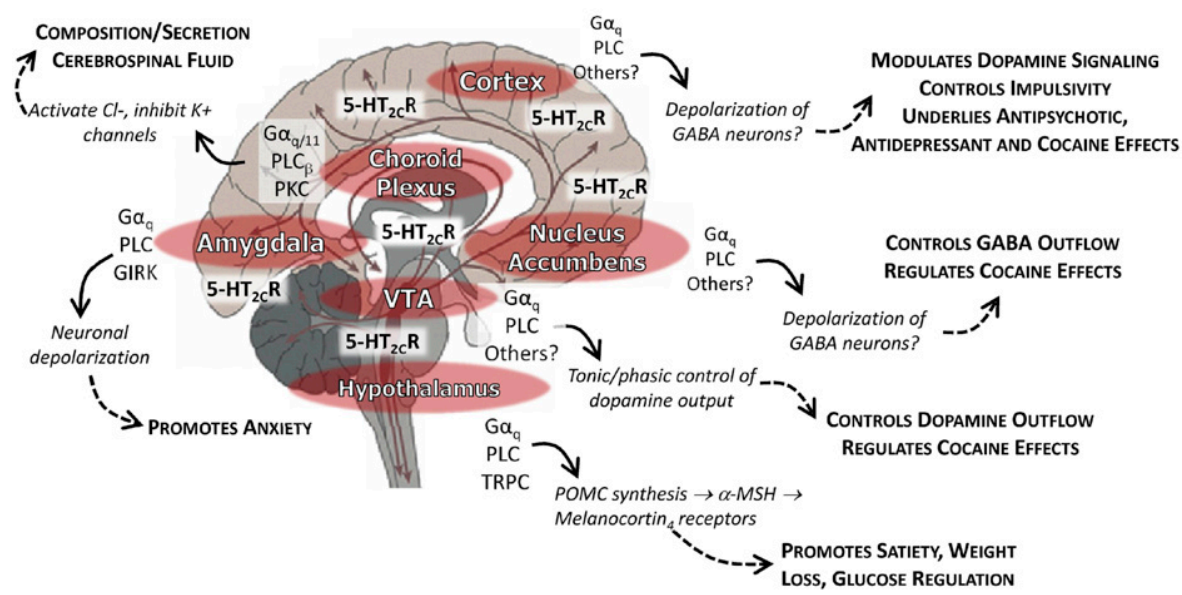

Fig. 14. Regional CNS localization 5 - $\mathrm{HT}_{2 \mathrm{C}}$ receptors and functional correlates. The full-length 5 - $\mathrm{HT}_{2 \mathrm{C}}$ receptor is localized exclusively in the central nervous system with good agreement between mRNA and protein distribution in the majority of brain regions. The postulated signaling components (shown in normal text), neurochemical and/or neurophysiological correlates (shown in italic text), and in vivo effects (shown in CAPITAL text) are illustrated.

vulnerability to substance use disorders and relapse, as drug abuse culminates in addiction in only a subset of users (SAMHSA, 2015). Impulsivity, a predisposition toward rapid unplanned reactions to stimuli without regard to the negative consequences, is one such phenotype that contributes to initial drug use and is perpetrated by continued use of the abused drug (for reviews, see Moeller et al., 2001a,b; Cunningham and Anastasio, 2014). The impact of impulsivity in psychostimulant addiction is best described with roles for 5-HT and dopamine prominently identified (for reviews, see Moeller et al., 2001a; Dalley and Roiser, 2012; Bari and Robbins, 2013; Cunningham and Anastasio, 2014; Logue and Gould, 2014). Cue reactivity, the sensitivity to cues previously linked with the drugtaking experience, is a second such phenotype that plays a prominent role in craving and relapse in humans (Carter and Tiffany, 1999; O'Brien et al., 1998; Drummond, 2001). The extended limbic-corticostriatal circuitry underlies both impulsivity and cue reactivity with multiple neurotransmitters involved (Childress et al., 1999; Bechara, 2005; Goldstein et al., 2007; Liu et al., 2012). Thus, addiction involves the generation of drug use within a background of vulnerability (e.g., propensity for impulsive behavior) and progresses with repeated drug exposure, neuronal plasticity, and the entrainment of addictive behaviors. In particular, the role of the $5-\mathrm{HT}_{2 \mathrm{C}}$ receptor in various aspects of these addictive processes has been well studied for the class of psychostimulants; several studies have reported the efficacy of $5-\mathrm{HT}_{2 \mathrm{C}}$ receptor agonists to suppress nicotine intake and nicotine seeking (Grottick et al., 2001; Levin et al., 2011; Higgins et al., 2012). Relevant to this are the extensive studies of the role of the $5-\mathrm{HT}_{2 \mathrm{C}}$ receptor in the rewarding and incentive-salience value of cocaine as well as factors involved in vulnerability to addiction and relapse, especially impulsivity and cue reactivity.

Cocaine is a psychomotor stimulant that inhibits 5-HT reuptake (Koe, 1976). Employing the self-administration assay, the preclinical model with the best validity for human drug taking, studies demonstrated that voluntary cocaine administration elevates 5 -HT efflux in the nucleus accumbens (Parsons and Justice, 1993; Parsons et al., 1996; Howes et al., 2000). Depletion of forebrain 5 -HT induces compulsive cocaine seeking, which is reversed by a $5-\mathrm{HT}_{2 \mathrm{C}}$ receptor antagonist (Pelloux et al., 2012). Constitutive knockout of the $5-\mathrm{HT}_{2 \mathrm{C}}$ receptor increases the motivation to take cocaine and enhances cocaine-induced elevation in dopamine in the nucleus accumbens (but not the dorsal striatum) of mice (Rocha et al., 2002). Pretreatment with a $5-\mathrm{HT}_{2 \mathrm{C}}$ receptor agonist, systemically or into the VTA, enhances, whereas systemic administration of a $5-\mathrm{HT}_{2 \mathrm{C}}$ receptor antagonist inhibits, the elevated dopamine efflux in the NAc evoked by nonresponse contingent cocaine administration (Navailles et al., 2004, 2008; Cathala et al., 2015). The 5- $\mathrm{HT}_{2 \mathrm{C}}$ receptor control over dopamine function is thought to mediate, in large part, the efficacy of a selective $5-\mathrm{HT}_{2 \mathrm{C}}$ receptor agonist (e.g., RO60-0175 or WAY163909) to suppress the voluntary intake of cocaine (Grottick et al., 2000; Fletcher et al., 2002a; Fletcher et al., 2004; Neisewander and Acosta, 2007; Cunningham et al., 2011).

Stimulation of the $5-\mathrm{HT}_{2 \mathrm{C}}$ receptor also dosedependently suppresses reinstatement induced by cocaine and cocaine-associated cues as measures of cue reactivity (Grottick et al., 2000; Neisewander and Acosta, 2007; Burbassi and Cervo, 2008; Fletcher et al., 2008; Cunningham et al., 2011; Swinford-Jackson et al., 2016). Conversely, systemic administration of $5-\mathrm{HT}_{2 \mathrm{C}}$ 
receptor antagonists have been shown to exert effects opposite to those following agonist administration, thus enhancing cocaine self-administration (Fletcher et al., 2002a) and cue reactivity (Fletcher et al., 2002a; Pelloux et al., 2012). In nonhuman primates, a $5-\mathrm{HT}_{2 \mathrm{C}}$ receptor agonist attenuated the stimulant, reinforcing, and reinstatement effects of cocaine, effects reversed by the selective $5-\mathrm{HT}_{2 \mathrm{C}}$ receptor antagonist SB242084 (Manvich et al., 2012a,b; Ruedi-Bettschen et al., 2015). Interestingly, SB242084 induced modest stimulant effects and exhibited reinforcing effects in primates (Manvich et al., 2012a,b) but had contrasting results (Ruedi-Bettschen et al., 2015).

The efficacy of $5-\mathrm{HT}_{2 \mathrm{C}}$ receptor agonists to suppress cue reactivity upon systemic administration is mirrored following intracranial microinjection of a $5-\mathrm{HT}_{2 \mathrm{C}}$ receptor agonist into the $\mathrm{mPFC}$, which attenuates both cocaine- and cue-induced reinstatement (Pentkowski et al., 2010). These data highlight the importance of the $5-\mathrm{HT}_{2 \mathrm{C}}$ receptor in regulation of cortical substrates underlying cocaine-associated cue reactivity specifically, as $5-\mathrm{HT}_{2 \mathrm{C}}$ receptor agonist microinfusions did not alter cocaine intake (Pentkowski et al., 2010). Thus, the $5-\mathrm{HT}_{2 \mathrm{C}}$ receptor provides inhibitory tone over cocaine reward and cue reactivity as well as the neurochemical effects of cocaine (for reviews, see Cunningham and Anastasio, 2014; Howell and Cunningham, 2015; Di Giovanni and De Deurwaerdere, 2016), and mPFClocalized $5-\mathrm{HT}_{2 \mathrm{C}}$ receptors underlie, in part, the generation of cue reactivity.

Cocaine administered nonresponse contingently has been reported to result in $5-\mathrm{HT}_{2 \mathrm{C}}$ receptor neuroadaptations (Zayara et al., 2011; Craige et al., 2015) as well as regulation of the brain-specific snoRNA MBII-52, which is involved in the regulation of the $5-\mathrm{HT}_{2 \mathrm{C}}$ receptor pre-mRNA (Chen et al., 2014). Abstinent cocaine users exhibit lower sensitivity to the effects of a $5-\mathrm{HT}_{2 \mathrm{C}}$ receptor agonist (Lee and Meltzer, 1994; Buydens-Branchey et al., 1997; Patkar et al., 2006), whereas the highest cue reactivity was observed in those cocaine-dependent subjects carrying the C23S $\mathrm{SNP}$ in the $5-\mathrm{HT}_{2 \mathrm{C}}$ receptor gene (Anastasio et al., 2014a), which may be associated with diminished $5-\mathrm{HT}_{2 \mathrm{C}}$ receptor signal transduction (Lappalainen et al., 1995; Okada et al., 2004; Piva et al., 2011; Walstab et al., 2011). Further evidence that the functional status of the $5-\mathrm{HT}_{2 \mathrm{C}}$ receptor in the $\mathrm{mPFC}$ (Lopez-Gimenez et al., 2001; Liu et al., 2007; Nocjar et al., 2015) influences the incentive-motivational effects of cocaine and cocaine-associated cues has accumulated in rats (Anastasio et al., 2014a,b; SwinfordJackson et al., 2016). Cunningham and colleagues found that the highest levels of cocaine cue reactivity correlated with the lowest levels of $\mathrm{mPFC} 5-\mathrm{HT}_{2 \mathrm{C}}$ receptor protein and a blunted sensitivity to the suppressive effects of the selective 5- $\mathrm{HT}_{2 \mathrm{C}}$ receptor agonist WAY163909 (Anastasio et al., 2014a; Swinford-Jackson et al., 2016). The efficacy of WAY163909 to suppress high levels of cue reactivity associated with extended forced abstinence ("incubation") was also reduced at a time point (30 days) at which lower synaptosomal expression of $5-\mathrm{HT}_{2 \mathrm{C}}$ receptor protein was observed in the mPFC (Swinford-Jackson et al., 2016), a key site involved in incubation phenomena (Koya et al., 2009; Whitfield et al., 2011; $\mathrm{Ma}$ et al., 2014). Furthermore, a greater proportion of the expressed $5-\mathrm{HT}_{2 \mathrm{C}}$ receptor protein was sequestered in the cytoplasmic (vs. membrane) compartment of the mPFC at prolonged versus early forced abstinence, and there was an inverse correlation of the membrane to cytoplasmic $5-\mathrm{HT}_{2 \mathrm{C}}$ receptor ratio in the $\mathrm{mPFC}$ with levels of cocaine cue reactivity. Collectively, these outcomes indicate that the functional status of the $5-\mathrm{HT}_{2 \mathrm{C}}$ receptor system in the $\mathrm{mPFC}$ is a key contributor to cocaine cue reactivity and its incubation.

Cocaine-dependent subjects who express high cocaine cue reactivity express high impulsivity (Liu et al., 2011b), and a similar relationship has been observed in cigarette smokers (Doran et al., 2007, 2008). In outbred rats, lower $\mathrm{mPFC} 5-\mathrm{HT}_{2 \mathrm{C}}$ receptor membrane protein levels and an increase in edited $5-\mathrm{HT}_{2 \mathrm{C}}$ receptor mRNA variants with reduced $5-\mathrm{HT}_{2 \mathrm{C}}$ receptor signaling capacity distinguish high impulsive rats from low impulsive rats (Anastasio et al., 2014b) as well high and low responders to novelty, another model of addiction vulnerability (Dracheva et al., 2009). The virally mediated knockdown of the $5-\mathrm{HT}_{2 \mathrm{C}}$ receptor localized to the mPFC also results in elevated impulsivity and cue reactivity relative to controls (Anastasio et al., 2014b), suggesting that reduced $5-\mathrm{HT}_{2 \mathrm{C}}$ receptor tone in the mPFC confers vulnerability to these interlocked behaviors (Anastasio et al., 2014b). The status of $5-\mathrm{HT}_{2 \mathrm{C}}$ receptor function in the orbitofrontal cortex may also be a contributor to the vulnerability of impulsive rats to cocaine reward and cue reactivity (Besson et al., 2013). Together, these data suggest that the functional status of the cortical $5-\mathrm{HT}_{2 \mathrm{C}}$ receptor system may be a mechanistic driver in the generation of cocaine use disorder and relapse phenomena.

The body of knowledge in support of a role of the $5-\mathrm{HT}_{2 \mathrm{C}}$ receptor in regulating the rewarding properties and voluntary intake of other abused substances is less well developed than that of cocaine and nicotine. However, stimulation of the $5-\mathrm{HT}_{2 \mathrm{C}}$ receptor has been noted to suppress ethanol self-administration (Maurel et al., 1999; Tomkins et al., 2002; Kasper et al., 2013; Rezvani et al., 2014) and reinstatement in rodents (Kasper et al., 2013). Exposure to ethanol vapor for several days is associated with increased expression of the $5-\mathrm{HT}_{2 \mathrm{C}}$ receptor transcript in several corticostriatal and hypothalamic nodes (Yoshimoto et al., 2012), higher levels of the $5-\mathrm{HT}_{2 \mathrm{C}}$ receptor protein in the NAc (Yoshimoto et al., 2012), and enhanced pre-mRNA editing of the $5-\mathrm{HT}_{2 \mathrm{C}}$ receptor (Watanabe et al., 2014), suggesting that neuroadaptations in the $5-\mathrm{HT}_{2 \mathrm{C}}$ 
receptor function are mechanistically involved in ethanol preference behavior.

Pretreatment with $5-\mathrm{HT}_{2 \mathrm{C}}$ receptor ligands have been shown to impact various behavioral sequela associated with $d$-amphetamine (O'Neill et al., 1999; Rippberger et al., 2015; Wöhr et al., 2015), MDMA (Bankson and Cunningham, 2002; Fletcher et al., 2002b), methamphetamine (Steed et al., 2011; Graves and Napier, 2012), and the marijuana alkaloid $\Delta^{9}$-THC (Ji et al., 2006), suggesting that rich prospects to explore the potential therapeutic value of selective $5-\mathrm{HT}_{2 \mathrm{C}}$ receptor agonists in addictive processes engaged by these abused drugs remain.

5-HT is involved in the pharmacology of opioid abused drugs (including heroin and prescription opioids) (Tao and Auerbach, 1994; Tao et al., 1998; Singh et al., 2003), and systemic administration of a 5-HT releaser (e.g., dexfenfluramine) was shown to suppress heroin selfadministration in rats (Wang et al., 1995). Pretreatment with a selective $5-\mathrm{HT}_{2 \mathrm{C}}$ receptor agonist also reduced opioid-induced behavioral sensitization (Wu et al., 2015a; Zhang et al., 2016). Recent studies have further demonstrated that lorcaserin significantly decreases the reinforcing effects of oxycodone and shifts the oxycodone dose-effect curve downward at doses that do not alter motor activity (Neelakantan et al., 2017). Thus, $5-\mathrm{HT}_{2 \mathrm{C}}$ receptor agonists may prove therapeutically useful to promote recovery and extend abstinence from several classes of abused drugs.

2. Appetite, Satiety, and Obesity. Hunger is the physiologic need for food. Appetite (the desire for food), satiation (the end of the desire for food during a meal), and satiety (the feeling of "fullness" that prevents further eating before the return of hunger) include both internal (e.g., glucose homeostasis) and conditioned factors (e.g., hedonics) (Blundell, 1999). 5-HT in the CNS has long been implicated in the control of the processes involved in satiation and satiety (Lucki, 1998; Halford and Blundell, 2000; Saper et al., 2002; Voigt and Fink, 2015). The 5-HT releaser $d$-fenfluramine, employed clinically for weight loss (until withdrawn in 1997), its metabolite $d$-norfenfluramine, and preferential 5- $\mathrm{HT}_{2 \mathrm{C}}$ receptor agonists (e.g., $\mathrm{mCPP}$ ) evoke hypophagia in rodents, which is associated with increased satiety, an effect blocked by $5-\mathrm{HT}_{2 \mathrm{C}}$ receptor antagonists or constitutive knockdown of the $5-\mathrm{HT}_{2 \mathrm{C}}$ receptor (Kennett and Curzon, 1988; Tecott et al., 1995; Halford et al., 1997; Vickers et al., 1999; Dalton et al., 2006; Nonogaki et al., 2008). Selective 5- $\mathrm{HT}_{2 \mathrm{C}}$ receptor agonists (e.g., lorcaserin, RO60-0175) have been consistently demonstrated to suppress food intake (Clifton et al., 2000; Somerville et al., 2007; Thomsen et al., 2008; Grottick et al., 2015; Higgs et al., 2015; for review, see Higgins et al., 2020). In fact, the selective $5-\mathrm{HT}_{2 \mathrm{C}}$ receptor agonist WAY163909 dose-dependently decreases food intake in normal Sprague-Dawley rats, obese Zuker rats, and mice with diet-induced obesity (Dunlop et al.,
2005 ) without the anxiogenic profile of mCPP (Dunlop et al., 2006). Tecott et al. (1995) reported that the constitutive $5-\mathrm{HT}_{2 \mathrm{C}}$ receptor knockout mouse exhibited hypophagia and increased body mass in the context of both insulin resistance and late-onset obesity (Nonogaki et al., 2008), whereas weight gain as well as a greater relative risk of metabolic dysfunction and diabetes develops with the chronic treatment of atypical antipsychotics with $5-\mathrm{HT}_{2 \mathrm{C}}$ receptor antagonist properties (e.g., olanzapine) in humans and animals (Wirshing et al., 1999; Kirk et al., 2009). Interestingly, a selective $5-\mathrm{HT}_{2 \mathrm{C}}$ receptor antagonist has been reported to variably increase (Bonhaus et al., 1997) or decrease food intake depending on the preclinical model employed (Kennett et al., 1997; Murotani et al., 2011).

The behavioral satiety sequence (BSS) describes the orderly process through which eating transitions to other behaviors (e.g., grooming and resting) and is a well validated model for analyzing satiation (meal termination) and satiety (postingestive inhibition of food intake) in rodents and humans (for review, see Rodgers et al., 2010). Consistent with the proposed role of 5-HT to promote satiety, $d$-fenfluramine, its metabolite analogs, and preferential and selective $5-\mathrm{HT}_{2 \mathrm{C}}$ receptor agonists (Halford et al., 1998; Clifton et al., 2000; Hewitt et al., 2002; Dalton et al., 2006; Somerville et al., 2007) accelerate the BSS without disruption of its integrity (for review, see Rodgers et al., 2010). For example, $d$-fenfluramine and RO60-0175 reduced the rate of feeding and meal size as well as increased the latency to feed consistent with enhanced satiety (Clifton et al., 2000). The effects of $d$-fenfluramine on the BSS was markedly reduced in mice constitutively lacking the $5-\mathrm{HT}_{2 \mathrm{C}}$ receptor (Vickers et al., 1999). In contrast, appetite-enhancing drugs (e.g., cyproheptadine) (Chinuck et al., 2007) disrupt the satiety sequence (Bergen, 1964; Ishii et al., 2003). A recent microstructural analysis of ingestive behavior found that lorcaserin reduced the number of bouts of licking behavior (Higgs et al., 2016) indicative of the promotion of satiety (Davis et al., 2001). Thus, the $5-\mathrm{HT}_{2 \mathrm{C}}$ receptor is an important mediator of food intake through the control of satiety mechanisms (for reviews, see Lucki, 1998; Halford and Blundell, 2000; Voigt and Fink, 2015).

Investigations of 5-HT involvement in the mechanisms underlying satiety have focused predominantly on neural loci in the hypothalamus and midbrain/ hindbrain circuits, which synchronize energy balance and glucose homeostasis in concert with peripheral systems (for reviews, see Saper et al., 2002; Gautron et al., 2015; Voigt and Fink, 2015). The 5-HT neurons in the dorsal and median raphe innervate multiple hypothalamic subnuclei (van de Kar and Lorens, 1979; Peyron et al., 1998), which richly express $5-\mathrm{HT}_{2 \mathrm{C}}$ receptor mRNA and protein (Hoffman and Mezey, 1989; Molineaux et al., 1989; Mengod et al., 1990). A subpopulation of arcuate POMC neurons 
express the $5-\mathrm{HT}_{2 \mathrm{C}}$ receptor and are activated by $d$-fenfluramine and mCPP (Heisler et al., 2002; Lam et al., 2008). Elmquist and colleagues elegantly demonstrated that the activation of the $5-\mathrm{HT}_{2 \mathrm{C}}$ receptor localized to POMC neurons stimulates POMC synthesis and its cleavage into $\alpha$-melanocyte-stimulating hormone, which acts on melanocortin 4 receptors in the paraventricular nucleus of the hypothalamus to promote satiety, weight loss, and glucose regulation (Heisler et al., 2007a; Zhou et al., 2007; Xu et al., 2008; Berglund et al., 2013). Stimulation of the $5-\mathrm{HT}_{2 \mathrm{C}}$ receptor following application of $\mathrm{mCPP}$ depolarized a subpopulation of POMC neurons potentially via PLC-dependent activation of transient receptor potential channels, independent of GIRK channel activity (Sohn et al., 2011). In mice that selectively lack the $5-\mathrm{HT}_{2 \mathrm{C}}$ receptor in POMC neurons, body weight was normal; however, these mice were insensitive to $d$-fenfluramine- or mCPP-evoked hypophagia and developed metabolic dysfunction, including hyperinsulinemia, hyperglucagonemia, hyperglycemia, and insulin resistance (Berglund et al., 2013). Rescue of $5-\mathrm{HT}_{2 \mathrm{C}}$ receptor in POMC neurons of $5-\mathrm{HT}_{2 \mathrm{C}}$ receptor-null mice normalized food intake, adiposity, and body weight as well as the anorexigenic effects of $d$-fenfluramine and mCPP (Xu et al., 2008). Interestingly, $\mathrm{POMC}$ expression within $5-\mathrm{HT}_{2 \mathrm{C}}$ receptorexpressing neurons in the arcuate regulates whole body energy balance, body weight, and adiposity in male, but not female, mice; these authors proposed that this molecular mechanism may explain, in part, sex differences in the prevalence of obesity (Burke et al., 2016). This provocative idea requires further investigation; however, the observations corroborate the conclusion that the $5-\mathrm{HT}_{2 \mathrm{C}}$ receptor in POMC neurons is a required component of the neural mechanisms that control energy and glucose homeostasis.

The adipocyte-derived $o b$ gene product leptin (Halaas et al., 1995) acts via the leptin receptor (Tartaglia et al., 1995) to regulate long-term energy stores and homeostasis (Friedman, 2014). This landmark discovery marshalled in an era of advanced understanding of the CNS circuits involved in obesity [for review, see Friedman (2014)]. It was not long before genetic deletion of the leptin receptor in neurons was shown to result in hyperphagia and obesity (Cohen et al., 2001), whereas the rescue of central leptin receptor signaling corrects the obesity and diabetes phenotype of $d b / d b$ mice, which possess mutations in the leptin receptor (de Luca et al., 2005). Mice deficient for both leptin and the $5-\mathrm{HT}_{2 \mathrm{C}}$ receptor exhibited a synergistic disruption of glucose homeostasis and a profound diabetes phenotype (Wade et al., 2008). On the other hand, transgenic mice that overexpress leptin but lack the $5-\mathrm{HT}_{2 \mathrm{C}}$ receptor exhibited a lean phenotype on a chow diet; however, on a high-fat diet, these mice developed diet-induced obesity (Wang and Chehab, 2006). In POMC neurons, pharmacological stimulation of the $5-\mathrm{HT}_{2 \mathrm{C}}$ receptor was shown to activate the same POMC neurons activated by leptin (Qiu et al., 2010). Lastly, coadministration of the preferential $5-\mathrm{HT}_{2 \mathrm{C}}$ receptor agonist $\mathrm{mCPP}$ plus leptin was recently shown to have an additive effect on reducing body weight in diet-induced obese mice (Yan et al., 2015). The growing knowledge of the interface between leptin and 5-HT regulatory systems prompted Halford and Blundell to propose that these systems function independently, but coordinate within the hypothalamus, to control satiety and energy reserves (Halford and Blundell, 2000).

The drive to eat palatable foods, composed essentially of high fat and/or sugars, involves hedonic mechanisms, which are also important for maintaining the homeostatic nutritional requirements for energy balance [for reviews, see Saper et al. (2002) and Volkow et al. (2012)]. These foods activate limbic-corticostriatal systems, which mediate reward and motivation [for reviews, see Gautron et al. (2015) and Voigt and Fink (2015)], and hedonic eating has been identified is a contributor to the obesity epidemic (Saper et al., 2002; Volkow et al., 2012). Preclinical analysis of the rewarding (reinforcing) and motivational effects of food self-administration can be evaluated on a fixed ratio and a progressive ratio (PR) schedule, respectively, in either freely fed or food-restricted animals. Performance under PR schedules is thought to reflect the motivational "efficacy" of the food given that deprivation level as well as reinforcer magnitude can increase breakpoints on the PR schedule (Hodos and Kalman, 1963). The preferential (mCPP, MK212) and selective $5-\mathrm{HT}_{2 \mathrm{C}}$ receptor agonists (R0 60-0175) decrease the breakpoint for a grain reinforcer on a PR schedule in food-restricted pigeons (Wolff and Leander, 2000). WAY163909 dose-dependently reduces self-administration of sucrose on a fixed ratio schedule in freely fed rats, an effect blocked by pretreatment with SB242084 (Cunningham et al., 2011), whereas mCPP decreases the breakpoint for Ensure in freely fed mice (Ward et al., 2008). Lorcaserin efficaciously suppresses the rewarding effects of food in food-restricted rats based on its $5-\mathrm{HT}_{2 \mathrm{C}}$ receptor agonist actions [Higgins et al., 2012; for review, see Higgins et al. (2020)]. Interestingly, though $5-\mathrm{HT}_{2 \mathrm{C}}$ receptor agonists effectively suppress cocaine seeking [for reviews, see Cunningham and Anastasio (2014) and Howell and Cunningham (2015)], WAY163909 failed to affect sucrose seeking (Cunningham et al., 2011), suggesting that the $5-\mathrm{HT}_{2 \mathrm{C}}$ receptor differentially regulates the incentive-salience value of cocaine- versus sucrose-associated cues. Thus, there is evidence that the $5-\mathrm{HT}_{2 \mathrm{C}}$ receptor system controls the hedonic, rewarding aspects of palatable food; the brain locus of action for the $5-\mathrm{HT}_{2 \mathrm{C}}$ receptor to control these behaviors requires further evaluation (Pratt et al., 2009; Pratt et al., 2012; Clissold et al., 2013).

Multiple lines of investigation suggest a relationship between $5-\mathrm{HT}_{2 \mathrm{C}}$ receptor SNPs and obesity, 
antipsychotic-induced weight gain, and transcriptional activity of the HTR2C gene. Eight HTR2C gene polymorphisms have been reported in the literature: three polymorphisms, as well as a GT nucleotide repeat variation, have been identified in the promoter (Xie et al., 1996); three polymorphisms have been reported within intronic regions (Gibson et al., 2004); one polymorphism has been reported in the coding region, resulting in the replacement of cysteine with serine at amino acid 23 (C23S) in the amino-terminus of the receptor (Lappalainen et al., 1995); and there is one polymorphism in the 3 ' untranslated region (Song et al., 1999).

The C23S SNP occurs with a frequency of approximately 10\%-15\% in the human population (Lappalainen et al., 1995). However, there is no evidence for an association of this SNP with obesity (Lentes et al., 1997; Gibson et al., 2004). The promoter haplotype 995A/-759T/-697C has been reported to be associated with obesity in a Japanese population (Yuan et al., 2000) and the $-759 \mathrm{C}$ allele to be more common in obese than nonobese Caucasian women (Pooley et al., 2004). Several studies suggest that the $-759 \mathrm{~T}$ allele may be associated with less weight gain following antipsychotic drug treatment (Reynolds et al., 2003; Miller, 2005; Templeman et al., 2005). Although additional research has reported no association between antipsychotic-induced weight gain (AIWG) and HTR2C promoter polymorphisms (Basile et al., 2002; Tsai et al., 2002; Theisen et al., 2004; Templeman et al., 2005), others have reported an association of the $-759 \mathrm{C}$ allele with AIWG (Wallace et al., 2011). It is interesting to note that greater promoter activity, resulting in increased HTR2C transcription, has been reported to be associated with the $-759 \mathrm{~T}$ allele (Yuan et al., 2000). Also, in a luciferase-based reporter assay, HTR2C promoter haplotypes containing the $759 \mathrm{C}$ allele showed lower transcriptional activity than those containing the -759T haplotype (Buckland et al., 2005). Although these studies suggest that the $-759 \mathrm{C} / \mathrm{T}$ polymorphism may regulate gene transcription in vitro, a subsequent study reported that $5-\mathrm{HT}_{2 \mathrm{C}}$ receptor mRNA levels in the frontal cortex of 43 subjects are unaffected by $-759 \mathrm{C} / \mathrm{T}$ status (Pooley et al., 2004).

3. Schizophrenia. Both selective $5-\mathrm{HT}_{2 \mathrm{C}}$ receptor agonists and $5-\mathrm{HT}_{2 \mathrm{C}}$ receptor antagonists have been suggested for the treatment of schizophrenia. Antipsychotic medications with a profile as a $5-\mathrm{HT}_{2 \mathrm{C}}$ receptor antagonist seem to be effective to suppress positive symptoms, whereas $5-\mathrm{HT}_{2 \mathrm{C}}$ receptor agonists appear useful for inhibition of the negative symptoms and cognitive impairments in schizophrenia (Wood et al., 2001; Rosenzweig-Lipson et al., 2007a, 2012) with fewer motor side effects (Di Giovanni et al., 2006; Di Giovanni and De Deurwaerdere, 2016). The therapeutic potential of a specific antipsychotic would depend indirectly on the opposite modulation that these receptors exert on dopaminergic systems and the preferential $5-\mathrm{HT}_{2 \mathrm{C}}$ receptor modulation of the mesocortical and limbic system versus the nigrostriatal system (Di Giovanni et al., 2006; Di Giovanni and De Deurwaerdere, 2016). Moreover, the analysis of the pharmacological profile of some atypical antipsychotics led to $5-\mathrm{HT}_{2 \mathrm{C}}$ receptor blockade as a valuable strategy to improve the efficacy of dopamine antagonists in long-term treatments (Meltzer, 1999). Vabicaserin is a novel antipsychotic and anorectic agent with high agonist efficacy at the $5-\mathrm{HT}_{2 \mathrm{C}}$ receptor (Dunlop et al., 2011) and has been shown to be effective in treating schizophrenia, improving positive symptoms (Shen et al., 2014). Unfortunately, the clinical development of vabicaserin by Pfizer was terminated because the drug failed to meet the primary efficacy end point in clinical trials (https:// clinicaltrials.gov/ct2/show/results/NCT00563706?term = vabicaserin\&rank $=2$ ).

Sertindole, a newer antipsychotic (Juruena et al., 2011), alternatively exerts a potent inverse agonist activity at the $5-\mathrm{HT}_{2 \mathrm{C}}$ receptor (Herrick-Davis et al., 2000), along with dopamine $\mathrm{D}_{2}, \alpha_{1}$-adrenergic receptor and 5 - $\mathrm{HT}_{2 \mathrm{~A}}$ receptor blockade (Hietala et al., 2001). Sertindole is effective in reducing anxiety and improving cognition/ memory and brain plasticity, most probably by reducing $5-\mathrm{HT}_{2 \mathrm{C}}$ receptor tonic activation (Hietala et al., 2001).

Several lines of evidence have identified the $5-\mathrm{HT}_{2 \mathrm{C}}$ receptor in the origin of some side effects, both motor and metabolic, associated with the chronic use of antipsychotic drugs. For instance, $5-\mathrm{HT}_{2 \mathrm{C}}$ receptor blockade seems to contribute to AIWG, one of the most common and debilitating side effects induced by chronic treatment with these medications (Reynolds et al., 2005; Shams and Muller, 2014). Therefore, $5-\mathrm{HT}_{2 \mathrm{C}}$ receptor agonists may have an antipsychotic activity without inducing AIWG and alterations of glucose homeostasis caused by atypical antipsychotics. However, agomelatine as a $5-\mathrm{HT}_{2 \mathrm{C}}$ receptor antagonist has a more favorable profile and does not influence body weight in depressed patients (Pompili et al., 2013).

Other important side effects induced by the chronic use of antipsychotics that may be related to the activation of the $5-\mathrm{HT}_{2 \mathrm{C}}$ receptor are the movement disorders, such as dystonia, acute Parkinsonism, and tardive dyskinesia, referred to globally as antipsychoticinduced extrapyramidal side effects (EPS) (Tarsy and Baldessarini, 1984; Tarsy et al., 2002; Janno et al., 2004). The inverse agonism at the $5-\mathrm{HT}_{2 \mathrm{C}}$ receptor evoked by some atypical antipsychotics might indeed explain their fewer EPS effects (Herrick-Davis et al., 2000). Consistently, ritanserin, a nonselective $5-\mathrm{HT}_{2}$ antagonist, limits the occurrence of EPS in patients treated with typical neuroleptic drugs (Bersani et al., 1990). Moreover, the affinity of typical antipsychotics toward the $5-\mathrm{HT}_{2 \mathrm{C}}$ receptor inversely correlates to the EPS severity (Richtand et al., 2007; Richtand et al., 2008). Nevertheless, experimental evidence suggests that concurrent $5-\mathrm{HT}_{2 \mathrm{C}}$ receptor agonism might 
increase the efficacy of typical and atypical antipsychotics, allowing dose-sparing with a reduction of side effects (Grauer et al., 2009).

4. Mood Disorders and Anxiety. Depression and anxiety are complex illnesses that have in common an altered central 5-HT tone. Compelling evidence accumulating over more than four decades has indicated the $5-\mathrm{HT}_{2 \mathrm{C}}$ receptor is critically involved in the serotonergic regulation of these pathologic states. Indeed, mCPP and MK-212 induce anxiogenic-like behaviors in animals (Kennett et al., 1989; Benjamin et al., 1990; Shepherd et al., 1994; Bilkei-Gorzo et al., 1998; Millan, 2005; Martin et al., 2013) and induce anxiety and panic when administered in humans (Lowy and Meltzer, 1988; Kahn and Wetzler, 1991; Sevy et al., 1994; Southwick et al., 1997; Gatch, 2003). These anxiogenic effects are likely due to the activation of the $5-\mathrm{HT}_{2 \mathrm{C}}$ receptor. In agreement, Tecott and colleagues showed that $5-\mathrm{HT}_{2 \mathrm{C}}$ receptor knockout mice exhibit an anxiolytic-like phenotype not attributable to locomotor alterations (Heisler et al., 2007b). Moreover, desensitization of the $5-\mathrm{HT}_{2 \mathrm{C}}$ receptor in SERT knockout mice has been shown to contribute to the moderation of the anxiety phenotype (Martin et al., 2014b5) and to the antidepressant effects (Prisco and Esposito, 1995; Di Giovanni et al., 2006). On the other hand, mCPP induced anxiolytic effects in mice (Nic Dhonnchadha et al., 2003) but showed antidepressant-like properties in the anhedonia model in rats (Moreau et al., 1996) and was recently observed to be anorexigenic without inducing anxiety/depression in humans (Thomas et al., 2014). Moreover, RO60-0175 presented an antidepressant profile or an anxiolytic/ anticompulsive profile in some tests (Cryan and Lucki, 2000; Nic Dhonnchadha et al., 2003). Interestingly, anxiogenic responses induced by RO60-0175 (Martin et al., 2013, 2014a) are sometimes related to its sedative properties (Kennett et al., 2000). CP809101 is ineffective in some models (Siuciak et al., 2007) and anxiogenic in others (Strong et al., 2009, 2011; Christianson et al., 2010).

Consistent with proposed anxiogenic effects of $5-\mathrm{HT}_{2 \mathrm{C}}$ receptor activation, $5-\mathrm{HT}_{2 \mathrm{C}}$ receptor antagonists display anxiolytic/antidepressant properties in numerous tests (Kennett et al., 1994, 1996, 1997; Wood et al., 2001; Millan, 2005; Harada et al., 2006). Interestingly, there are models in which both $5-\mathrm{HT}_{2 \mathrm{C}}$ receptor agonists and antagonists display anxiolytic/antidepressant properties, including the chronic mild stress-induced anhedonia model and the activity consequent to olfactory bulbectomy. The tendency is that selective $5-\mathrm{HT}_{2 \mathrm{C}}$ receptor agonists would be more appropriate in the treatment of depression, obsessive-compulsive disorder (OCD), or panic attacks, whereas the antagonists would be better suited for generalized anxiety and obsessivecompulsive disorder (Jenck et al., 1998; Millan, 2003, 2005). On the contrary, the atypical antidepressants mirtazapine and mianserin (Hayasaka et al., 2015) and a recently developed new antidepressant agomelatine
(Millan et al., 2003, 2011; Millan, 2005) have clear antagonistic $5-\mathrm{HT}_{2 \mathrm{C}}$ receptor profiles. The lack of selectivity of the pharmacological $5-\mathrm{HT}_{2 \mathrm{C}}$ receptor tools employed to date as well as the limited appreciation of $5-\mathrm{HT}_{2 \mathrm{C}}$ receptor function and its unique molecular mechanisms (e.g., edited and spliced $5-\mathrm{HT}_{2 \mathrm{C}}$ receptor isoforms, constitutive activity, and biased signaling) complicate final conclusions at present.

The paradoxical efficacy of both $5-\mathrm{HT}_{2 \mathrm{C}}$ receptor agonists and antagonists is likely due to the complex neurobiological basis of depression/anxiety and the fact that different behavioral responses involve different areas expressing the $5-\mathrm{HT}_{2 \mathrm{C}}$ receptor, of which activation produces opposite effects (Millan et al., 2005). Indeed, local activation of the $5-\mathrm{HT}_{2 \mathrm{C}}$ receptor in the basolateral part of the amygdala induces anxiety (Campbell and Merchant, 2003), whereas the activation of those in the dorsal periaqueducal gray triggers anxiolytic responses (Yamashita et al., 2011). Thus, the long-term antidepressant effect of compounds such as SSRIs may be related to a region-dependent desensitization of the $5-\mathrm{HT}_{2 \mathrm{C}}$ receptor in determined regions (Prisco and Esposito, 1995; Di Giovanni et al., 2006; Martin et al., 2014a).

In summary, selective $5-\mathrm{HT}_{2 \mathrm{C}}$ receptor antagonists may present promising molecules for developing new antidepressant/anxiolytic drugs. These could be considered as monotherapy or for augmentation strategies to improve other antidepressant responses (Cremers et al., 2004, 2007) with the ability to reverse several SSRI-induced side effects.

5. Epilepsy. Early evidence implicated a 5-HT involvement in the pathophysiology of epilepsy (Bonnycastle et al., 1957). Since then, evidence has accumulated clearly showing that there is a direct link between 5 -HT levels and epilepsy. Increasing 5 -HT levels in the CNS is generally antiepileptic, whereas a decrease favors epileptogenesis and seizure generation [for reviews, see Bagdy et al. (2007) and Guiard and Di Giovanni (2015)]. Moreover, a common 5-HT dysfunction might underlie both epilepsy and comorbid depression seen in patients with epilepsy (Kanner et al., 2012; Guiard and Di Giovanni, 2015).

The $5-\mathrm{HT}_{2 \mathrm{C}}$ receptor is thought to be involved in seizure generation and cell excitability (Jakus et al., 2003; Isaac, 2005). Tecott and colleagues showed that $5-\mathrm{HT}_{2 \mathrm{C}}$ receptor knockout mice display spontaneous convulsive generalized seizures, which cause their high mortality rate (Tecott et al., 1995) and a reduced threshold for various convulsing stimuli (Applegate and Tecott, 1998; Heisler et al., 1998b). Conversely, 5- $\mathrm{HT}_{2 \mathrm{C}}$ receptor activation increased the threshold of general convulsion induced by pentylenetetrazole and electroshock in mice (Upton et al., 1998). The $5-\mathrm{HT}_{2 \mathrm{C}}$ receptor also negatively controls nonconvulsive generalized seizures. Di Giovanni and colleagues showed that, in the polygenic animal model of absence epilepsy, the Genetic Absence Epilepsy 
Rat from Strasbourg (Danober et al., 1998), RO60-0175 (unpublished data), lorcaserin, and CP809101 were capable of blocking spike and wave discharges (Venzi et al., 2016). Interestingly, as expected, SB242084 blocked the effect of lorcaserin and CP809101 but also showed some antiabsence effects. One possible mechanism by which 5 - $\mathrm{HT}_{2 \mathrm{C}}$ receptor activation exerts antiepileptic effects is via the normalization of the aberrant $\mathrm{GABA}_{\mathrm{A}}$ receptor tonic inhibition in the ventrobasal thalamus seen in different animal models of absence epilepsy (Cope et al., 2009; Crunelli and Di Giovanni, 2014, 2015). Findings with the Genetic Absence Epilepsy Rat from Strasbourg animal model of absence epilepsy are in agreement with those obtained in another model of absence epilepsy, the Wistar Albino Glaxo/Rij-rat, in which mCPP decreases the cumulative duration of spike and wave discharges via the activation of the 5- $\mathrm{HT}_{2 \mathrm{C}}$ receptor (Jakus et al., 2003; Jakus and Bagdy, 2011).

The $5-\mathrm{HT}_{2 \mathrm{C}}$ receptor system seems devoid of any modulatory role in partial seizures or, paradoxically, has a proepileptic role in this type of epilepsy. Indeed, observations from Di Giovanni's group show that mCPP and lorcaserin, but not RO60-0175, were able to halt hippocampal after discharges in a rat model of temporal lobe epilepsy, an effect potentiated and insensitive to SB242084 pretreatment (Orban et al., 2014). These data indicate that other 5-HT receptors are involved in the antiepileptic effect of $\mathrm{mCPP}$ and lorcaserin, probably the $5-\mathrm{HT}_{1 \mathrm{~A} / 7}$ receptor (Orban et al., 2013) or unknown targets, confirming previous findings (Damjanoska et al., 2003; Navailles et al., 2013a; Orban et al., 2014).

In summary, $5-\mathrm{HT}_{2 \mathrm{C}}$ receptor agonists may have new therapeutic utility in epilepsy. In particular, the FDAapproved lorcaserin may be useful for the treatment of human generalized convulsive and nonconvulsive epilepsy, which is very important in consideration of the fact that the epileptic drug pipeline is limited. Moreover, activation of the $5-\mathrm{HT}_{2 \mathrm{C}}$ receptor may also be useful for treating comorbid neuropsychiatric comorbidity commonly seen in patients with epilepsy (Di Giovanni and De Deurwaerdere, 2016; Venzi et al., 2016).

6. Sleep. A role for 5-HT in the sleep-wake cycle is well documented, as 5-HT has been shown to promote wakefulness and reduce REM sleep [for review, see Monti (2011)]. In general, nonselective $5-\mathrm{HT}_{2 \mathrm{~A} / 2 \mathrm{C}}$ receptor agonists and selective $5-\mathrm{HT}_{2 \mathrm{C}}$ receptor agonists increase wakefulness and decrease SW and/or REM sleep following systemic administration in rats, whereas nonselective $5-\mathrm{HT}_{2 \mathrm{~A} / 2 \mathrm{C}}$ receptor antagonists and selective $5-\mathrm{HT}_{2 \mathrm{C}}$ receptor antagonists tend to decrease wakefulness and promote SW with reduced REM sleep [for review, see Monti (2011)]. In contrast to what may be anticipated, $5-\mathrm{HT}_{2 \mathrm{C}}$ receptor knockout mice display increased wakefulness with reduced SW and non-REM sleep (Frank et al., 2002). The increased wakefulness and reduced SW sleep have been attributed to compensatory mechanisms, possibly including the enhanced dopaminergic and adrenergic neurotransmission that occurs as a result of the constitutive knockout of the $5-\mathrm{HT}_{2 \mathrm{C}}$ receptor (Frank et al., 2002).

The nonselective $5-\mathrm{HT}_{2 \mathrm{C} / 2 \mathrm{~A}}$ receptor antagonists ritanserin and ketanserin enhanced SW sleep in a dosedependent manner in human subjects with normal sleep patterns (Sharpley et al., 1990; Idzikowski et al., 1991). Similar results were observed following treatment with seganserin, ICI169369, and SR46349B (Dijk et al., 1989; Landolt et al., 1999). In addition, ritanserin has been reported to improve SW sleep in subjects with insomnia (Adam and Oswald, 1989), major depression (Staner et al., 1992), and generalized anxiety disorder (da Roza Davis et al., 1992). In patients with schizophrenia, typical and atypical antipsychotic drugs with nonselective $5-\mathrm{HT}_{2 \mathrm{C} / 2 \mathrm{~A}}$ receptor antagonist properties tend to increase total sleep time and efficiency but reduce the latency and duration of REM sleep (Taylor et al., 1991; Nofzinger et al., 1993; Wetter et al., 1996; Sharpley et al., 2000; Muller et al., 2004). Taken together, these results indicate an involvement of the $5-\mathrm{HT}_{2 \mathrm{C}}$ receptor in the maintenance of normal sleep architecture and suggest possible avenues for future research and medication development for the treatment of insomnia.

7. Clinical Impact of RNA Editing of the 5-HT $2 \mathrm{C}$ Receptor. Many studies have attempted to analyze $5-\mathrm{HT}_{2 \mathrm{C}}$ receptor RNA editing profiles in postmortem samples from patients with psychiatric disorders. The majority of these reported that $5-\mathrm{HT}_{2 \mathrm{C}}$ receptor $\mathrm{RNA}$ editing in postmortem prefrontal cortex samples from patients with schizophrenia or bipolar disorder is not altered (Niswender et al., 2001; Dracheva et al., 2003, 2008b; Iwamoto and Kato, 2003; Zhu et al., 2012). In contrast, mixed results were obtained from postmortem prefrontal cortex samples from patients with major depression, with some studies reporting no change (Niswender et al., 2001; Zhu et al., 2012; Lyddon et al., 2013) and other studies reporting a decrease (Gurevich et al., 2002b) or increase in $5-\mathrm{HT}_{2 \mathrm{C}}$ receptor RNA editing (Iwamoto and Kato, 2003). Several studies have reported that psychiatric patients who committed suicide had increased $5-\mathrm{HT}_{2 \mathrm{C}}$ receptor RNA editing with increased levels of the less-active $5-\mathrm{HT}_{2 \mathrm{C}}$ receptor isoforms (Niswender et al., 2001; Gurevich et al., 2002b; Iwamoto and Kato, 2003; Dracheva et al., 2008b; Lyddon et al., 2013; Di Narzo et al., 2014) as well as increased expression of ADAR1 (Simmons et al., 2010). However, there were notable differences in the patterns of $5-\mathrm{HT}_{2 \mathrm{C}}$ receptor RNA editing that were reported in these studies. In a similar fashion, there is great variation in the reported effects of antipsychotic and antidepressant medications on RNA editing (Sodhi et al., 2005; Abbas et al., 2010; Iwamoto et al., 2011; Martin et al., 2014a) and the effect of altered synaptic 5 -HT levels on $5-\mathrm{HT}_{2 \mathrm{C}}$ receptor RNA editing (Gurevich 
et al., 2002a; Abbas et al., 2010; Lyddon et al., 2010; Moya et al., 2011). These variations in results highlight the requirement of a large sample size and the need to analyze hundreds of sequences per sample to obtain an accurate profile of all possible RNA editing events. In some of the more recent studies, the statistical power of the results has been increased by employing highthroughput sequencing methods that allow larger numbers of samples to be processed, in a more timely and less expensive manner, along with the ability to analyze hundreds or even thousands of sequences from a single sample (Lanfranco et al., 2009; Abbas et al., 2010; Morabito et al., 2010b; O'Neil and Emeson, 2012; Zhu et al., 2012; Lyddon et al., 2013; Anastasio et al., 2014b; Di Narzo et al., 2014). Although these studies have reported changes in $5-\mathrm{HT}_{2 \mathrm{C}}$ receptor RNA editing patterns following chronic drug treatment in rodent models or changes in editing in patients with psychiatric disorders who committed suicide, the magnitude of the observed change is small, typically less than $10 \%$. This raises several important questions. Could such a small change in $5-\mathrm{HT}_{2 \mathrm{C}}$ receptor editing be physiologically relevant? Could there be larger changes in $5-\mathrm{HT}_{2 \mathrm{C}}$ receptor RNA editing occurring within discrete neuronal populations, and could these changes be underestimated or masked when sampling an entire brain region?

A few of the studies described in the preceding paragraph examined RNA editing in both cortical and subcortical regions, whereas many studies examined RNA editing only in the prefrontal cortex of patients with psychiatric illnesses. Because the $5-\mathrm{HT}_{2 \mathrm{C}}$ receptor is located within mesolimbic and mesostriatal regions that have been shown to regulate the activity of ascending dopamine, it still remains possible that changes in RNA editing occurring within discrete populations of neurons in cortical and/or subcortical regions could play a role in the etiology of psychiatric disorders. Future studies capable of examining RNA editing profiles of individual neuronal populations within localized subregions will provide a more accurate picture of the relationship between $5-\mathrm{HT}_{2 \mathrm{C}}$ receptor RNA editing, $5-\mathrm{HT}_{2 \mathrm{C}}$ receptor isoform expression, and the functional regulation of 5-HT and dopamine neurotransmission in psychiatric disorders.

\section{5-HT 3 Receptor}

\section{A. Introduction}

The $5-\mathrm{HT}_{3}$ receptor is a Cys-loop ligand-gated ion channel, which is structurally and functionally distinct from the other six classes of 5-HT receptors whose metabotropic actions are mediated via $\mathrm{G}$ proteins. $5-\mathrm{HT}_{3}$ receptors are pentameric assemblies of five identical or nonidentical subunits that pseudosymmetrically surround the ion pore (Boess et al., 1992; Green et al., 1995). Each subunit has a large extracellular domain
(ECD), four transmembrane domains (TMD I-IV), and an intracellular domain (ICD) between M3 and M4.

The ECD contains the agonist binding site, which is located at the interface of two adjacent subunits and is formed by three loops (A-C) from one (the principal) subunit and three $\beta$-strands (referred to as loops D-F) from the adjacent or complementary subunit; key residues that contribute to the binding pocket in these loops have been identified from structural data (Hassaine et al., 2014), and these are supported by a range of functional studies [for reviews, see Barnes et al. (2009) and Thompson et al. (2010)]. The binding site contains the aromatic box, which is found in all Cysloop receptors, and in the homomeric $5-\mathrm{HT}_{3} \mathrm{~A}$ receptor, is constituted of W183 (loop B), W90 (loop D), Y153 (loop E), F226 (loop C), and Y234 (loop C).

The transmembrane domain of each $5-\mathrm{HT}_{3}$ receptor subunit is composed of four (M1-M4) transmembrane $\alpha$-helices, with short loops between M1 and M2 (intracellular) and M2 and M3 (extracellular). The M2 $\alpha$-helices line the ion pore, and pore-facing residues contribute to ion flux and selectivity. M1, M3, and M4 all protect M2 from the surrounding membrane lipids and play a role in receptor function. The conserved proline in M1, for example, is essential for activation, and the receptor is expressed but cannot function when this proline is replaced by alanine, glycine, or leucine (Dang et al., 2000). However, substitution with noncanonical amino acids that lack hydrogen bond donor activity yields active channels similar to wild-type receptors. These suggest flexibility in secondary structure in this region of $\mathrm{M} 1$ is a key element in channel gating.

The ICD is formed primarily by the large M3-M4 intracellular loop; this region is responsible for receptor modulation and also plays a role in trafficking. Deletion studies reveal the ICD is not essential, as the mouse 5-HT3A receptor subunit ICD can be replaced by the heptapeptide M3-M4 linker of GLIC without loss of function (Jansen et al., 2008). Further evidence that the ICD can function as a separate domain comes from studies in which it was added to the GLIC linker peptide, resulting in modification of function by the intracellular protein RIC-3 (Goyal et al., 2011).

ICD structural details are sparse, but each subunit is known to possess an $\alpha$-helix, which contributes to openings, known as portals, just below the level of the membrane. The residues that line these portals are important for ion conductance; when the 5-HT3A subunit residues are replaced with those found in the 5-HT3B subunit, the single channel conductance, which is very low in the homomeric $5-\mathrm{HT}_{3} \mathrm{~A}$ receptor, is increased to that of the heteromeric $5-\mathrm{HT}_{3} \mathrm{AB}$ receptor (Kelley et al., 2003b).

Only 5-HT3A subunits can form functional homomeric $5-\mathrm{HT}_{3}$ receptors. These subunits have been cloned from a range of species, including human hippocampus, 
amygdala, and colon (Belelli et al., 1995; Miyake et al., 1995); guinea pig small intestine (Lankiewicz et al., 1998); ferret colon (Mochizuki et al., 2000); and dog brain (Jensen et al., 2006); however, homologs are absent from invertebrates (although there is a related 5-HT-gated anion selective receptor). Multiple isoform of 5-HT3A subunits are known. Alternative splicing of the transcript encoding guinea pig, mouse, and rat, (but not dog, ferret, or human) 5-HT3A subunits results in "long" [5-HT3A(a)] and short [5-HT3A(b)] isoforms, where the 5-HT3A(b) isoform lacks five or six amino acid residues within the M3-M4 intracellular loop, which results in some subtle differences in receptor properties (Hope et al., 1993; Lankiewicz et al., 1998). In the human 5-HT3A subunit, three different splice variants have been described. Two of these (5-HT3AL and HT3Rext) would result in larger proteins, whereas the other (5-HT3AT) codes for a truncated subunit containing only a single transmembrane domain. 5-HT3Rext has not yet been functionally evaluated, but 5-HT3AT and 5-HT3AL, while not functional when expressed alone, form receptors with modified functional properties when coexpressed with canonical 5-HT3A subunits (Brüss et al., 2000).

A range of other $5-\mathrm{HT}_{3}$ receptor subunits have been identified (B-E), of which only the 5-HT3B subunit has been extensively investigated (Davies et al., 1999; Dubin et al., 1999; Niesler et al., 2003). Coexpression of this subunit with the 5-HT3A subunit to yield hetermeric $5-\mathrm{HT}_{3} \mathrm{AB}$ receptors resulted in functional receptors with properties that more closely represented those found in some native neuronal receptors, including relatively high single-channel conductance and relatively low $\mathrm{Ca}^{2+}$ permeability compared with homomeric $5-\mathrm{HT}_{3} \mathrm{~A}$ receptors.

The stoichiometry of heteromeric receptors is still not clear, although the presence of at least one $5-\mathrm{HT}_{3} \mathrm{~A}$ subunit appears to be obligatory in heteromeric receptors (Niesler et al., 2008; Holbrook et al., 2009). $5-\mathrm{HT}_{3} \mathrm{AB}$ receptors were originally suggested to possess a $3 \mathrm{~B}: 2 \mathrm{~A}$ subunit ratio, and using atomic force microscopy with tagged subunits indicated a BABBA arrangement (Barrera et al., 2005). The physiologic relevance of this, however, has been questioned in more recent studies, in which the presence of an AA interface was clearly demonstrated (Lochner and Lummis, 2010; Thompson et al., 2011b), and fluorescently tagged subunits indicate a $3 \mathrm{~A}: 2 \mathrm{~B}$ arrangement at the plasma membrane (Miles et al., 2013). This is also consistent with the near identical orthosteric binding site pharmacology when comparing h5- $\mathrm{HT}_{3} \mathrm{~A}$ and $\mathrm{h} 5-\mathrm{HT}_{3} \mathrm{AB}$ receptors (Brady et al., 2001). The arrangement and number of 5-HT3C, 5-HT3D, and 5-HT3E subunits in functional receptors has not yet been determined, although there are many potential $5-\mathrm{HT}_{3}$ receptor isoforms arising from the utilization of multiple subunits in different combinations.
For more information of the structure of the $5-\mathrm{HT}_{3}$ receptor, see XVI. B. 5-HT Ligand-Gated Ion Channels.

\section{B. Expression}

$5-\mathrm{HT}_{3}$ receptors are located in many brain areas, including the hippocampus (Fig. 15), entorhinal cortex, frontal cortex, cingulated cortex, dorsal horn ganglia, amygdala, nucleus accumbens, substantia nigra, and ventral tegmental area (Parker et al., 1996a; Barnes et al., 2009). The dorsal vagal complex in the brainstem, which is key to the vomiting reflex and contains the area postrema and nucleus tractus solitarius, has the highest levels, consistent with the potent antiemetic properties of 5- $\mathrm{HT}_{3}$ receptor antagonists (Pratt et al., 1990; Parker et al., 1996; Fig. 16).

The functional studies are supported by expression studies, with $5-\mathrm{HT}_{3} \mathrm{~A}$ receptor mRNA and protein being observed in regions of the CNS known to have $5-\mathrm{HT}_{3}$ receptors. Such studies also indicate $5-\mathrm{HT}_{3}$ receptor expression in a wide range of other tissues, including peripheral and sensory ganglia and the gastrointestinal tract (e.g., Michel et al., 2005; Barnes et al., 2009; Fig. 17). In addition, expression of the 5-HT3A subunit has been reported in immune cells such as monocytes, chondrocytes, $\mathrm{T}$ cells, synovial tissue, and platelets (Fiebich et al., 2004; Stratz et al., 2008).

There was initial controversy as to the presence of 5-HT3B subunits in brain, but later studies show it is expressed here (e.g., Brady et al., 2007), with a preference for distinct "brain-type" isoforms. The longer canonical 5-HT3B subunit is broadly expressed in many tissues, including kidney, liver, and the gastrointestinal tract, with relatively high levels in spleen, colon, small intestine, and kidney (Tzvetkov et al., 2007; Holbrook et al., 2009).

5-HT3C, 5-HT3D, and 5-HT3E receptor subunits were first identified in humans, and genes for these proteins have now been shown to exist in a range of species, although not in rodents (Niesler et al., 2008; Holbrook et al., 2009). Initial studies suggested that the 5-HT3D and 5-HT3E subunits had a very restricted expression in the GI tract, but more recent data suggests all these subunits have a relatively widespread distribution. Studies examining protein levels have lagged behind the genetic work, but expression of 5-HT3C, 5-HT3D, and 5-HT3E subunits at the protein level in the GI tract has recently been confirmed (Kapeller et al., 2011).

\section{Post-translational Modifications}

The human 5-HT3A subunit has four consensus sequence $N$-glycosylation sites in the $\mathrm{N}$-terminal ECD domain and all can be $N$-glycosylated (Monk et al., 2004). $N$-glycosylation is essential for export from the ER, cell surface expression, and radioligand binding, although it is not necessary to preserve a ligand binding site once the receptor has matured (Green 


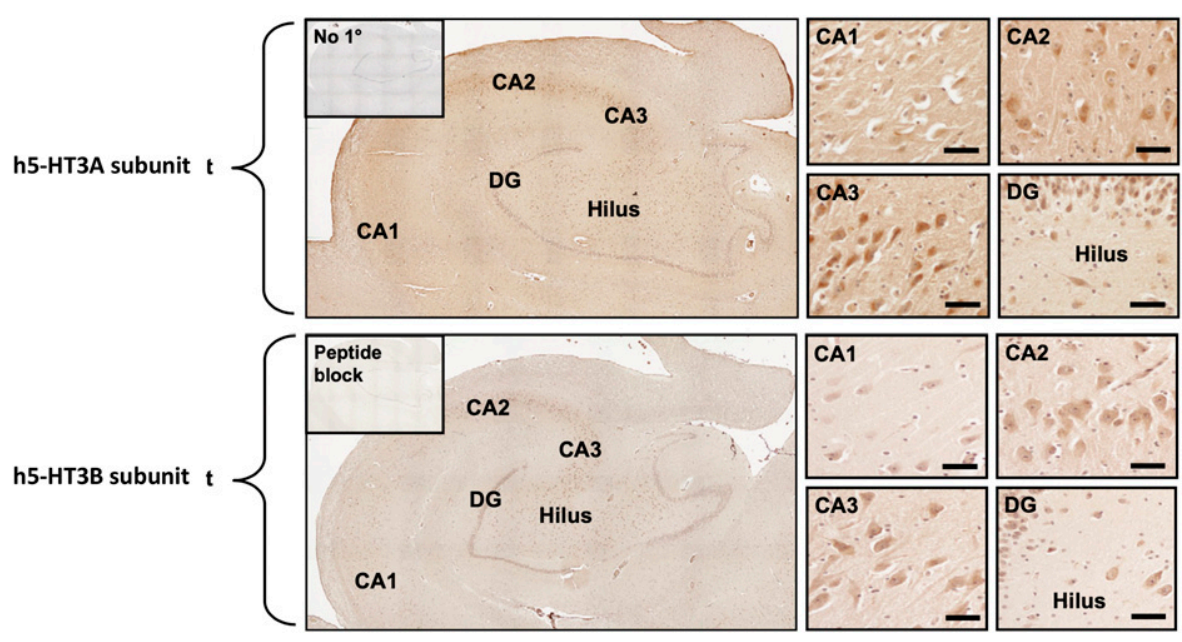

Fig. 15. Immunohistochemical detection of 5-HT3A and 5-HT3B receptor subunit expression in human hippocampus. 5-HT3A and 5-HT3B subunit immunoreactivity brown immunoreaction product in whole hippocampal section (large plates) is shown with fields of the hippocampus CA1-CA3, hilus (CA4), and dentate gyrus (DG), which are also shown at higher magnification (small plates; Scale bar, $50 \mu$ m). Immunoreactivity was not detected when either primary antibody was replaced by preimmune serum (No $1^{\circ}$ ) or following preabsorption with the immunizing peptide (peptide block). Subsequent to the detection of immunoreactivity, sections were histologically stained with hematoxylin to aid identification of hippocampal fields. Adapted from Brady et al. (2007) (with permission).

et al., 1995; Boyd et al., 2003; Quirk et al., 2004). Three of the four $N$-glycosylation sites are conserved between a range of species (N104, N170, and N186) and appear to be critical, whereas the $N$-glycosylation site at residue 28 is less important and indeed absent in rodents (Monk et al., 2004).

The other subunits have been less well studied, but it has been shown that 5-HT3B receptor subunits, when expressed alone, fail to exit the ER, providing a possible explanation as to why these subunits cannot form functional homomeric receptors. ER retention is due, at least in part, to a CRAR retention motif, which forms part of the M1-M2 intracellular loop (Boyd et al., 2003). Coexpression with the 5-HT3A subunit may shield this ER retention motif, allowing heteromeric $5-\mathrm{HT}_{3} \mathrm{AB}$ receptors to reach the cell surface. There is some evidence that the 5-HT3B subunit forces a preference for expression of the heteromeric $5-\mathrm{HT}_{3}$ receptor, as coexpression of the 5-HT3A and 5-HT3B subunits in tsA-201 cells did not indicate the presence of homomeric 5-HT3A receptors (Barrera et al., 2005), although the physiologic relevance of this finding is not yet clear.

BiP, calnexin, and RIC-3 have been identified as ER chaperone proteins that associate with the $5-\mathrm{HT}_{3}$ receptor and are likely to promote correct folding, oligomerisation, post-translational modification, and/ or export from the ER (Boyd et al., 2003). RIC-3 has been the most widely studied but has different effects depending on the subunits, the species they originated from, and the expression system (Castillo et al., 2005; Cheng et al., 2005, 2007). Expression of human homomeric $5-\mathrm{HT}_{3} \mathrm{~A}$ receptors in transfected mammalian cells, for example, is enhanced by RIC-3, but it causes inhibition of heteromeric $\left(5-\mathrm{HT}_{3} \mathrm{AB}\right)$ receptor expression, and mouse $5-\mathrm{HT}_{3} \mathrm{~A}$ receptor expression in oocytes is completely abolished (Cheng et al., 2005). This apparent discrepancy may be due to other proteins that could influence $5-\mathrm{HT}_{3}$ receptor expression. Cyclophillin A, for example, promotes $5-\mathrm{HT}_{3} \mathrm{~A}$ receptor expression in the cell membrane via an integral peptidyl prolyl isomerase activity (Helekar and Patrick, 1997), and there may be a range of other proteins yet to be identified that can modify $5-\mathrm{HT}_{3}$ receptor expression.

Similar to the human 5-HT3A subunit, the human 5-HT3B subunit has a number of consensus sequences for $N$-glycosylation sites in the $\mathrm{N}$-terminal ECD domain (five; Massoura et al., 2011), and all can be $N$-glycosylated (Massoura et al., 2011). $N$-glycosylation of the human 5-HT3B subunit at each of the five consensus sites facilitates export from the ER and efficient cell surface expression when the 5-HT3B subunit is coexpressed with the human 5-HT3A subunit to generate hetermeric $5-\mathrm{HT}_{3} \mathrm{AB}$ receptors (Massoura et al., 2011).

\section{Pharmacology}

There are many selective and potent compounds that act at $5-\mathrm{HT}_{3}$ receptors. Many $5-\mathrm{HT}_{3}$ receptor agonists have in common a basic amine, an aromatic ring, a hydrophobic group, and two hydrogen bond acceptors; potent agonists include 2-methyl-5-HT, phenylbiguanide, and $\mathrm{m}$-chlorophenylbiguanide (Kilpatrick et al., 1990; Cockcroft et al., 1995). Data from AChBP suggest that agonists tend to be relatively small compounds, as they need to allow the $\mathrm{C}$ loop to close over the binding site, initiating the gating process; the structure of 5 -HT binding protein (5-HTBP), 

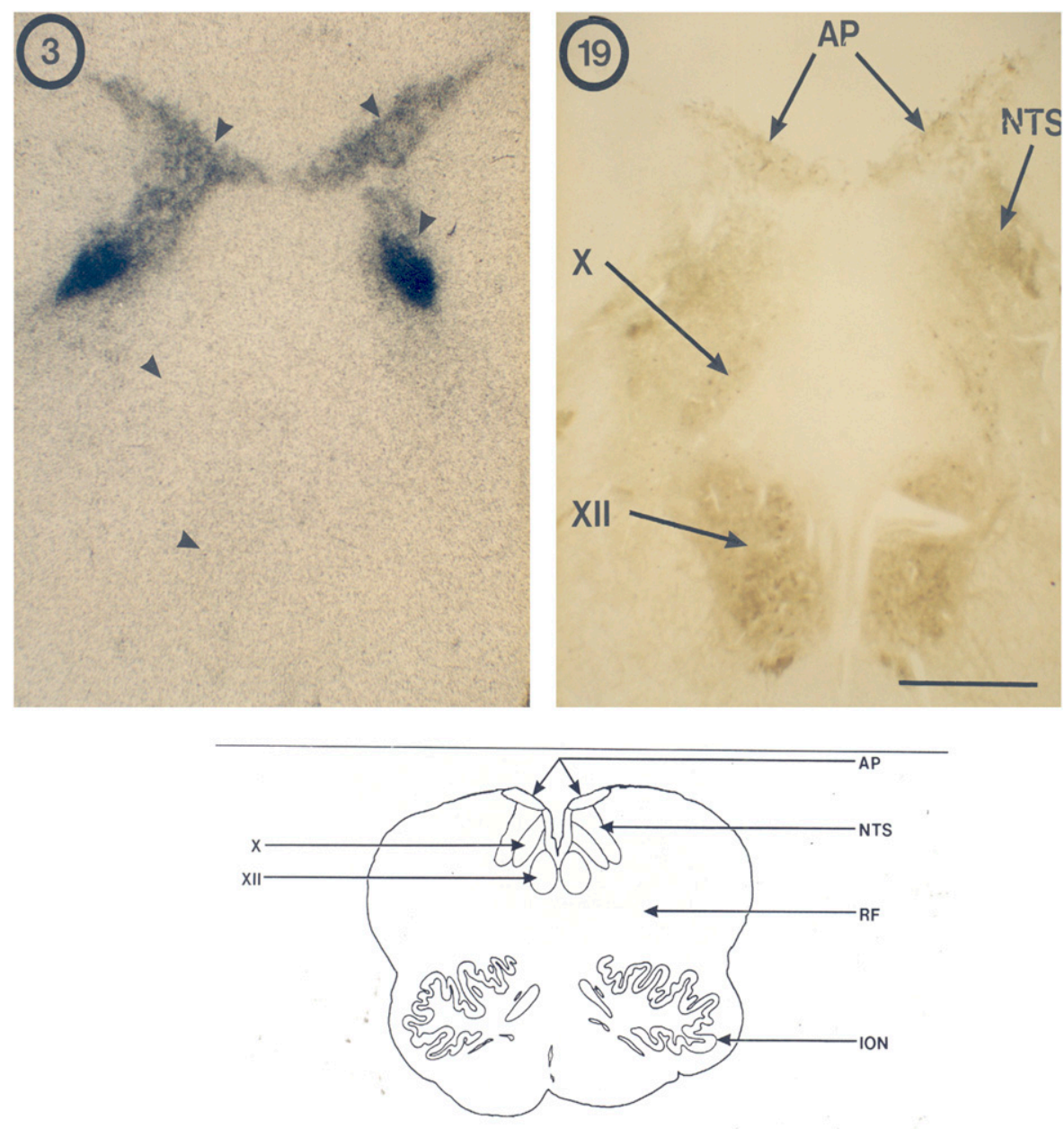

Fig. 16. $5-\mathrm{HT}_{3}$ receptor autoradiography in the human brainstem. Left: $\left[{ }^{3} \mathrm{H}\right]$-(S)-zacopride binding to the 5 -HT $\mathrm{H}_{3}$ receptor in coronal section of human brainstem at the level of the chemoreceptor trigger zone (AP, area postrema; NTS, nucleus tractus solitarius; X, dorsal motor nucleus of the vagus nerve). Right: Adjacent section stained for acetylcholinesterase (hypoglossal nerve nucleus). $\left[{ }^{3} \mathrm{H}\right]$-(S)-zacopride binding in the presence of ondansetron $(1.0 \mu \mathrm{M})$ was absent (data not shown).

a modified version of AChBP, which binds 5-HT and granisetron, supports a similar mechanism of action for the $5-\mathrm{HT}_{3}$ receptor (Tsetlin and Hucho, 2009; Kesters et al., 2013).

A range of highly selective $5-\mathrm{HT}_{3}$ receptor partial agonists with a range of intrinsic activities are available (e.g., Manning et al., 2011, 2014; Roberts et al., 2020) that have been proposed as therapeutics to treat the symptoms of, for example, irritable bowel syndrome (IBS) with diarrhea (IBS-D) and carcinoid syndrome (Roberts et al., 2020).

$5-\mathrm{HT}_{3}$ receptor competitive antagonists, which bind at the orthosteric (agonist) binding site, are usually larger than agonists; they require an aromatic part, a basic moiety, and an intervening hydrogen bond acceptor. For most antagonists, these are a rigid aromatic or heteroaromatic ring system, a basic amine, and a carbonyl group (or isosteric equivalent) that is coplanar to the aromatic system (Evans et al., 1991), and there are slightly longer distances between the aromatic and amine group when compared with the agonist pharmacophore. Only small substituents, such as a methyl group, can be accommodated on the charged amine (Schmidt and Peroutka, 1989). Many potent antagonists of $5-\mathrm{HT}_{3}$ receptors have 6.5 heterocyclic rings, and the most potent compounds contain an aromatic six-membered ring. Morphine and cocaine (Gaddum and Picarelli, 1957) were the first antagonists used to characterize the $5-\mathrm{HT}_{3}$ receptor, with more selective $5-\mathrm{HT}_{3}$ receptor antagonists being developed in the 1980s, including MDL72222 or bemestron (Fozard, 1984) and ICS 205-930 or tropisetron (Donatsch et al., 1985). Other compounds that were developed include ondansetron, granisetron, and zacopride, which act at nanomolar concentrations, and there is now a wide range of similarly potent compounds, with many containing bicyclic heteroaromatic structures, that is, quinoxalines, quinazolines, or quinolines (Verheij et al., 2012). Data indicate that these compounds, and therefore possibly all ligands that bind to the orthosteric site, are stabilized in the binding pocket by interaction with water molecules. 

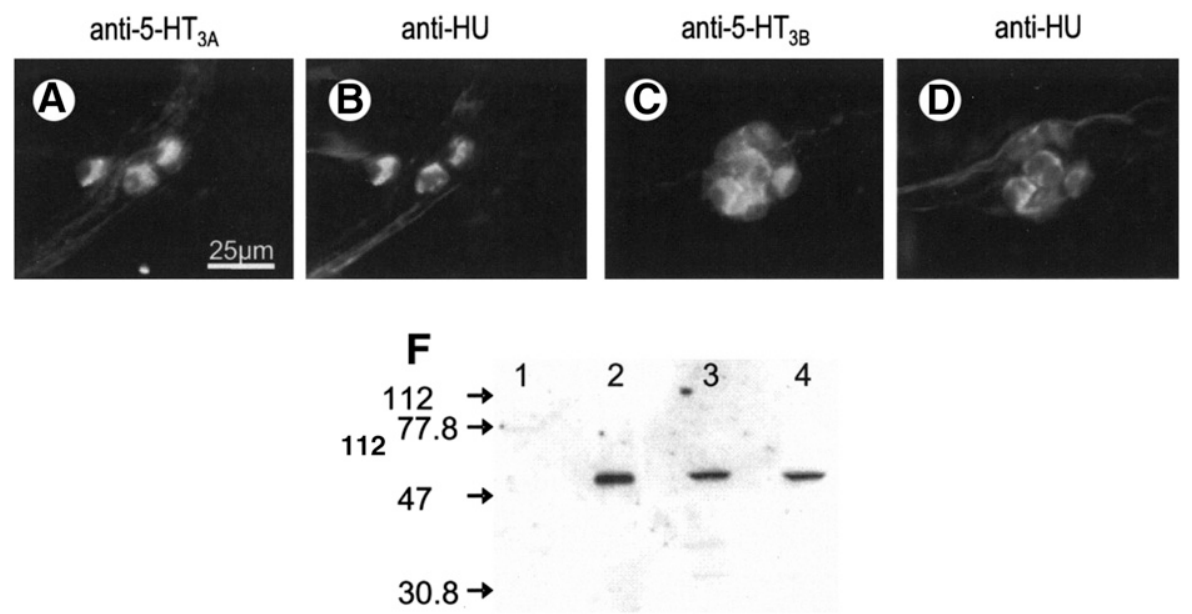

Fig. 17. 5- $\mathrm{HT}_{3}$ receptor protein expression (5-HT3A and 5-HT3B subunits) in human gut. (A) Immunolabeling of a ganglion in the human submucous plexus with an antibody against the 5-HT3A subunit. (B) The same ganglion as in (A) stained with an antibody against the human neuronal protein $\mathrm{HuC} / \mathrm{HuD}$, which labels all neurons. All anti-HuC/HuD-positive neurons are immunoreactive for the 5-HT3A antibody. (C) Immunolabeling of another human submucous ganglion with an antibody against the 5-HT3B subunit. (D) The same ganglion as in (C) stained with anti-HuC/HuD. All anti-HuC/HuD-positive neurons were immunoreactive for the 5-HT3B antibody. Scale bar, 25 $\mu \mathrm{m}$ (A-D). (F) Detection of h5-HT3B immunoreactivity by SDS polyacrylamide gel electrophoresis/Western blot. Lane 1, HEK293 cells stably expressing with h5-HT3A subunit; lane 2, HEK293 cells stably expressing both the h5-HT3A and h5-HT3B subunits; lane 3, human large intestine; lane 4, human small intestine. Numbers are the positions of the molecular weight markers (kilodalton). Adapted from Michel et al. (2005) (with permission).

Some $5-\mathrm{HT}_{3}$ receptor inhibitors act by blocking the channel; picrotoxin, which was originally considered to be relatively selective for the $\mathrm{GABA}_{\mathrm{A}}$ receptor, also blocks the $5-\mathrm{HT}_{3}$ receptor channel; the binding of picrotoxinin (the active component of picrotoxin) has been localized to the 6' position of M2 (Das and Dillon, 2003; Thompson et al., 2011a). Compounds structurally similar to picrotoxin, such as the gingkolides and bilobalide, act similarly (Thompson et al., 2011a). Diltiazem, which blocks voltage-gated calcium channels, is also known to block the $5-\mathrm{HT}_{3}$ receptor pore and acts close to the 7' and/or 12' residues in homomeric receptors (Gunthorpe and Lummis, 1999; Thompson et al., 2011a). Morphine and its analog methadone as well as the antimalarial compounds quinine and mefloquine may also exert their inhibitory effects via binding to the pore, highlighting the common mechanisms that many of these drugs share and also the promiscuity that many of these compounds display (Brady et al., 2001; Deeb et al., 2009; BaptistaHon et al., 2012)

There are a number of allosteric modulators that effect $5-\mathrm{HT}_{3}$ receptor function, including n-alcohols, anesthetics, antidepressants, cannabinoids, opioids, steroids, and natural compounds; these can inhibit or enhance receptor activity, and many also modulate other Cys-loop receptors, although not always in the same direction [see reviews by Parker et al. (1996), Walstab et al. (2010), Davies (2011), and Machu (2011)]. Specific binding sites for these compounds have mostly not yet been confirmed, although some may bind in an intersubunit binding cavity at the top of the TMD (Trattnig et al., 2012). The effects of these compounds have mostly been studied on $5-\mathrm{HT}_{3} \mathrm{~A}$ receptors [see
Downie et al. (1995) and Parker et al. (1996), but see Bentley and Barnes (1998) for impact on native 5- $\mathrm{HT}_{3}$ receptors], although alcohols and inhaled anesthetics have been shown to have reduced sensitivity at $5-\mathrm{HT}_{3} \mathrm{AB}$ receptors, whereas the effects of etomidate, propofol, and pentobarbital are similar at $5-\mathrm{HT}_{3} \mathrm{~A}$ and $5-\mathrm{HT}_{3} \mathrm{AB}$ receptors (Solt et al., 2005; Stevens et al., 2005; Rusch et al., 2007).

A further pharmacological phenomenon termed cryptic orthosteric modulation was identified using the human $5-\mathrm{HT}_{3} \mathrm{~A}$ receptor as a model (Powell et al., 2016); this pharmacological mechanism may convey therapeutic benefits when targeting ligand-gated ion channels (Powell et al., 2016).

\section{E. Function}

The $5-\mathrm{HT}_{3}$ receptor pore is a relatively nonselective cation channel, constructed of five pseudosymmetrically arranged M2 $\alpha$-helices (one from each of the five subunits). The residues that line the ion-accessible face of M2 are predominantly nonpolar and are the major controlling influence on ion flux (Reeves et al., 2001; Panicker et al., 2002; McKinnon et al., 2011). Currents are primarily carried by $\mathrm{Na}^{+}$and $\mathrm{K}^{+}$ions, although divalent and small organic cations are also permeable (Derkach et al., 1989; Yang, 1990; Maricq et al., 1991).

Ionic selectively is predominantly mediated via residues in M2. A triple mutant receptor with a proline insertion at -1 ' and the substitutions E-1'A and V13'T resulted in an anion-permeable mouse $5-\mathrm{HT}_{3} \mathrm{~A}$ receptor (Gunthorpe and Lummis, 2001), although subsequent studies showed that the replacement of only two residues (E-1' and S19'R) was needed to invert ion selectivity (Thompson and Lummis, 2003). 
Changing -1 'E alone resulted in nonselective channels, indicating that the rings of charge at either end of M2 charge make the most critical contribution (Thompson and Lummis, 2003). Equivalent residues participate in the selectivity filters of other Cys-loops (Thompson et al., 2010).

$5-\mathrm{HT}_{3} \mathrm{~A}$ receptors are almost equally permeable to monovalent and divalent cations $\left(\mathrm{P}_{\mathrm{Ca}} / \mathrm{P}_{\mathrm{Cs}}=1.0-1.4\right)$ (Brown et al., 1998; Davies et al., 1999; Livesey et al., 2011). However, human $5-\mathrm{HT}_{3} \mathrm{AB}$ receptors have lower $\mathrm{Ca}^{2+}$ permeability $\left[\mathrm{P}_{\mathrm{Ca}} / \mathrm{P}_{\mathrm{Cs}}=0.6\right.$ (Davies et al., 1999)], possibly the consequence of the 20 ' residue being neutral (Asn and not Asp) in human 5-HT3B subunits. Consistent with this, a D20'A substitution in 5-HT3A subunits reduces $\mathrm{Ca}^{2+}$-relative permeability $\left[\mathrm{P}_{\mathrm{Ca}} / \mathrm{P}_{\mathrm{Cs}}=0.4\right.$ (Livesey et al., 2008)]. Recent studies suggest that the ICD may also play a role in $\mathrm{Ca}^{2+}$ permeability, as substitutions of charged residues in this region can have a major effect on $\mathrm{Ca}^{2+}$ permeability (Livesey et al., 2011).

The single-channel conductance of the homomeric receptor is low; values of $0.4-0.76 \mathrm{pS}$ have been reported (Davies et al., 1999; Gunthorpe et al., 2000; Kelley et al., 2003). The presence of Lys in the M2 regions was originally considered a possible explanation, but substitutions here revealed this was not the case (Gunthorpe et al., 2000). Subsequent work revealed that the low conductance was due to Arg residues located in the amphipathic helix of the M3-M4 loop, which forms holes, known as portals, through which ions can cross between the intracellular vestibule of the receptor and the cell interior (Kelley et al., 2003).

Heteromeric $5-\mathrm{HT}_{3} \mathrm{AB}$ receptors show a range of distinct biophysical characteristics when compared with 5-HT3A receptors: their desensitization is more rapid, concentration-response curves reveal lower $\mathrm{EC}_{50}$ values and Hill slopes, their voltage dependence is linear, and their divalent cation permeability is much reduced; most noticeable, however, is the large singlechannel conductance (13-16 pS) (Peters et al., 2005). This has been shown to be due to the substitution of Arg residues in the M3-M4 helical region of the 5-HT3A subunit by neutral or negative-charged residues in the 5-HT3B subunit (Kelley et al., 2003).

Other heteromeric receptors have not yet been extensively investigated, but studies to date indicate that they are more similar to homomeric $5-\mathrm{HT}_{3} \mathrm{~A}$ receptors.

The gate of the $5-\mathrm{HT}_{3} \mathrm{~A}$ receptor channel is located centrally within M2 (Panicker et al., 2002), consistent with the "hydrophobic girdle" model of channel gating. The hydrophobic girdle is a region in the center of M2 that is less than $3.5 \AA$ diameter over a distance of $\sim 8 \AA$; the residues that face the pore here are hydrophobic (13'Val and 9'Leu), making it effectively impermeable to ions in the closed conformation (Miyazawa et al., 2003). Data consistent with this hypothesis are substitution of Val13' residues in the $5-\mathrm{HT}_{3} \mathrm{~A}$ receptor by threonine or serine, which caused an increase in agonist potency (Dang et al., 2000) or spontaneous channel openings (Bhattacharya et al., 2004a), and substitutions of Leu9' by a range of amino acids, which affected agonist potency and desensitization rates (Yakel et al., 1993).

\section{F. Clinical Relevance}

Studies implicate the malfunction of $5-\mathrm{HT}_{3}$ receptors in a range of neurologic and gastrointestinal disorders (Walstab et al., 2010; Niesler, 2011). Selective 5-HT receptor antagonists (e.g., first-generation selective antagonists such as ondansetron and granisetron and second-generation antagonists such as palonosetron) have revolutionized the control of emesis, particularly in patients receiving high aggressive cytotoxic anticancer chemotherapy (e.g., cisplatin) and radiotherapy. Thus, the release of substantial amounts of 5-HT from enterochromaffin cell stores in the gastrointestinal tract as a consequence of antimitotic anticancer therapy may activate local (vagal) and central (chemoreceptor trigger zone) $5-\mathrm{HT}_{3}$ receptors to evoke nausea and vomiting. Simple antagonism of these $5-\mathrm{HT}_{3}$ receptors offers substantial relief to patients. See XX. 5-HT Receptors and the Gastrointestinal Tract for further discussion of the $5-\mathrm{HT}_{3}$ receptor and emesis.

The identification of $5-\mathrm{HT}_{3}$ receptors in immune cells also suggests a possible role of $5-\mathrm{HT}_{3}$ receptors in immunologic processes and inflammation and suggests that they may plausibly be involved in diseases such as atherosclerosis, tendomyopathies, and fibromyalgia (Fiebich et al., 2004; Stratz et al., 2008).

Some SNPs have been identified in patients with bipolar affective disorder (BPAD) or schizophrenia, disorders that segregate with cytogenetic abnormalities involving a region on chromosome 11 that harbors the HTR3A gene (Weiss et al., 1995). Further studies are needed with two SNPs found in schizophrenic patients (R344H and P391R) to determine if they contribute to disease in these patients, but a significant association was found in BPAD with a P16S mutation in the 5-HT3A subunit, with reporter constructs indicating this mutant could modulate expression levels. (Niesler et al., 2001; Thompson et al., 2006; Krzywkowski et al., 2007). Additional SNPs in the HTR3A gene result in the 5-HT3A(A33T) and 5-HT3A(M257I) subunit variants, both of which are associated with reduced levels of cell surface expression, and the 5 -HT3A(S253N) variant, which does not appear to compromise plasma membrane expression (Krzywkowski et al., 2007). The significance of these is yet to be determined.

In the 5-HT3B subunit, there has been an extensive investigation into a very common SNP, Y129S, which is linked both to BPAD and major depression in women (Krzywkowski, 2006; Hammer et al., 2012). Unusually, the Y129S variant is a gain of function mutation, as $5-\mathrm{HT}_{3} \mathrm{AB}(\mathrm{Y} 129 \mathrm{~S})$ receptors have an increased maximal response to 5-HT, decreased desensitization and 
deactivation kinetics, and a sevenfold increase in mean channel open time in comparison with heteromeric receptors containing the wild-type 5-HT3B subunit (Krzywkowski et al., 2008). An intermediate effect is apparent for receptors assembled from a mixture of wildtype $5-\mathrm{HT}_{3} \mathrm{~A}$, wild-type $5-\mathrm{HT}_{3} \mathrm{~B}$, and $5-\mathrm{HT}_{3} \mathrm{~B}(\mathrm{Y} 129 \mathrm{~S})$ subunits, suggesting that signaling via the $5-\mathrm{HT}_{3} \mathrm{AB}$ receptor in heterozygous as well as homozygous individuals is altered by this SNP (Krzywkowski et al., 2008).

Studies in the more recently discovered HTR3C, HTR3D, and HTR3E genes also indicate possible involvement in disease. An SNP in the 5-HT3C gene (N163K) has been correlated with IBS, and expression studies suggest it causes an increase in receptor density (Kapeller et al., 2011). Increased expression has also been associated with an SNP in the 3' untranslated region of the HTR3E gene, also associated with IBS, which inhibits the binding of a microRNA, as described above (Kapeller et al., 2008).

IBS-D is another disorder in which $5-\mathrm{HT}_{3}$ receptor antagonists can be effective therapeutic agents, although side effects that may be associated with a high level of $5-\mathrm{HT}_{3}$ receptor inhibition supports the development of $5-\mathrm{HT}_{3}$ receptor partial agonists (e.g., Roberts et al., 2020). See XX. 5-HT Receptors and the Gastrointestinal Tract for discussion of the role of the $5-\mathrm{HT}_{3}$ receptor and IBS.

Additional studies suggest that a wide range of other diseases have the potential to be treated with $5-\mathrm{HT}_{3}$ receptor-selective drugs, including addiction, pruritis, migraine, chronic heart pain, bulimia, and neurologic phenomena such as anxiety, psychosis, nociception, and cognitive function (Thompson and Lummis, 2007; Walstab et al., 2010).

See XVIII. 5-HT Receptors and the Brain, XIX. 5-HT Receptors and the Cardiovascular System, XX. 5-HT Receptors and the Gastrointestinal Tract, and XXI. 5-HT Receptors and the Immune System for further discussion of the clinical relevance of the $5-\mathrm{HT}_{3}$ receptor.

\section{5-HT 4 Receptors}

\section{A. Introduction}

An atypical 5-HT receptor was initially identified to be positively coupled to adenylyl cyclase in colliculi neurons (Dumuis et al., 1988), guinea pig hippocampus (Bockaert et al., 1990), and human and porcine cardiac atria (Kaumann, 1990; Kaumann et al., 1990; Villalon et al., 1990). This receptor was insensitive to $5-\mathrm{HT}_{1}$ receptor and $5-\mathrm{HT}_{2}$ receptor antagonists and was antagonized (but with a relatively low affinity) by tropisetron (at the time thought to be a relatively selective $5-\mathrm{HT}_{3}$ receptor antagonist) but not by another $5-\mathrm{HT}_{3}$ receptor antagonist, MDL 72222. This new 5-HT receptor was named the " $5-\mathrm{HT}_{4}$ " receptor.

\section{B. Gene and Primary Structure}

The cloning of the rat cDNA by Gerald et al. (1995) revealed the first primary sequence of $5-\mathrm{HT}_{4}$ receptor. It is a classic GPCR with seven transmembrane domains (TMD). Two splice variant sequences were found initially $\left[5-\mathrm{HT}_{4 \mathrm{~S}}\right.$ and $5-\mathrm{HT}_{4 \mathrm{~L}}$, later renamed $5-\mathrm{HT}_{4(\mathrm{a})}$ and $\left.5-\mathrm{HT}_{4(\mathrm{~b})}\right]$ coding for proteins of 387 and 388 amino acids, respectively. The splicing occurs within the C-terminal domain following the splicing site coding for the leucine $358\left(\mathrm{~L}^{358}\right)$. This splicing site at position $\mathrm{L}^{358}$ was subsequently found in the majority of the numerous splice variant transcripts sequenced in rodents, pig, and human (Blondel et al., 1997, 1998; Claeysen et al., 1999; Bach et al., 2001; Brattelid et al., 2004a; Bockaert et al., 2006; Coupar et al., 2007). Subsequently in human, additional splice variants differing in their C-terminal sequences following $\mathrm{L}^{358}$ have been identified [a, b, c (a shorter nonrelevant form of the $\mathrm{c}$ variant has been reported that is due to a sequencing error), d, e, f, g, i, and n; Bockaert et al., 2006; Coupar et al., 2007; Fig. 18]. For a complete analysis of intron/exon junctions of the human gene, see Bockaert et al. (2004a). Another splice variant (h) occurs in the second extracellular loop (Bender et al., 2000). In pig, at least nine other different splice variants, not described in humans, have been reported, including a functional homofusion variant (De Maeyer et al., 2008a). The coding sequence of the $5-\mathrm{HT}_{4}$ receptor gene (HTR4) extends over more than $200 \mathrm{~kb}$ (Genes, Ensembl release 82) and is localized on chromosome 5 (5q31-q-33) (Claeysen et al., 1997). It contains at least 14 exons. Each of the C-terminal variant sequences contains one of the exons 8-13 (Bockaert et al., 2006). The variant $h$ is the only form that results from expression of exon 6 . The presence or not of exon 1 in the $5-\mathrm{HT}_{4(\mathrm{a})}$ transcript is debated (Hodge et al., 2013), as the ATG starting site is localized in exon 2. Recently, a novel transcript has been found in the human brain in which exon 1 and 2 are substituted for a novel exon $(\mathrm{N})$ containing an expected ATG starting site, the C-terminal sequence being identical to the $5-\mathrm{HT}_{4(\mathrm{~b})}$ receptor splice variant (Hodge et al., 2013). The predicted protein sequence for this $5-\mathrm{HT}_{4}$ receptor variant should have a different $\mathrm{N}$ terminus sequence, as it is longer and the $N$-linked glycosylation site is at N2 instead of N7 (Hodge et al., 2013). Similar additional N-terminal exons have been identified in mouse brain and heart (Azim et al., 2012). However, further studies to clone the complete cDNA sequences and express and functionally characterize them are required before concluding on the physiologic importance of this splice variant. As some exons (such as h or i) do not present any in-frame stop codons, many additional combinations probably remain to be discovered (Brattelid et al., 2004a). SNPs within the noncoding region of HTR 4 gene have been associated with chronic obstructive pulmonary disease and asthma/airways obstruction (Repapi et al., 2010; Hodge et al., 2013). The locus presents features consistent with a regulatory region and involves SNPs that significantly alter the binding motifs of a transcription factor regulating lung development (Foxp1) 
(Hodge et al., 2013). Consistent with this finding, mice devoid of the $5-\mathrm{HT}_{4}$ receptor have an altered baseline lung function (House et al., 2015).

\section{Expression Profile}

1. Central Nervous System. Brain distribution of 5 - $\mathrm{HT}_{4}$ receptors has been studied using radiolabeled antagonists $\left[{ }^{3} \mathrm{H}\right] \mathrm{GR}$ 113808, $\left[{ }^{125} \mathrm{I}\right] \mathrm{SB} 207710$, and $\left[{ }^{3} \mathrm{H}\right]$ R116712 in many species, including mouse, rat, guinea pig, monkey, and human (Eglen et al., 1995b; Bockaert et al., 1997; Bonaventure et al., 2000; Fig. 19). Generally, a heterogeneous and comparable distribution is found in the adult brain of these various species with some interspecies differences in the globus pallidus, the substantia nigra, and the interpeduncular nucleus. The highest receptor densities are found in several regions of the limbic system (islands of Calleja, olfactory bulbs, striatum, ventral pallidum, septum, hippocampus, and amygdala) or in areas belonging to several pathways such as hippocampo-habenulo-interpeduncular and striato-nigro-tectal pathways (Waeber et al., 1993, 1994, 1996; Jakeman et al., 1994). Abundant localization of $5-\mathrm{HT}_{4}$ receptor mRNA in the rat brain was reported in the olfactory system, striatum, medial habenula, and the hippocampus (Ullmer et al., 1996). In the rat striatum, lesion studies showed the presence of $5-\mathrm{HT}_{4}$ receptor on the cell bodies of neurons that project to the substantia nigra and/or globus pallidus (Compan et al., 1996), whereas in situ hybridization experiments performed in guinea pig reported a localization of $5-\mathrm{HT}_{4}$ receptors on the terminals of the striatopallidal and striatonigral projections (Mengod et al., 1996). In the rat brain, comparison of mRNA distribution with $\left[{ }^{125} \mathrm{I}\right] \mathrm{SB} 207710$ binding sites confirmed that 5 - $\mathrm{HT}_{4}$ receptors are localized both somatodendritically (caudate putamen) and on axon terminals (substantia nigra and globus pallidus) (Vilaró et al., 1996). Bonaventure et al. (2000) performed a mapping

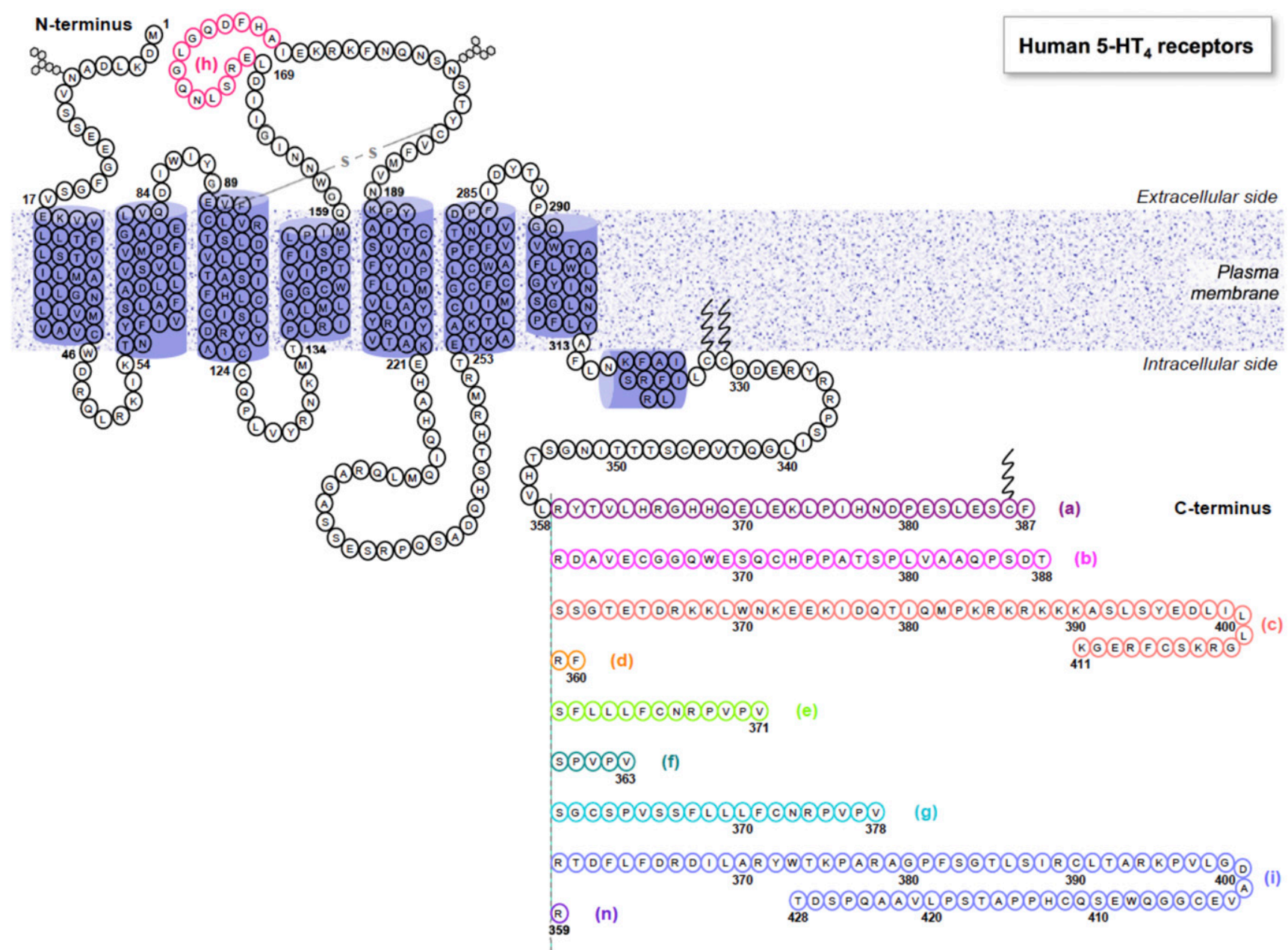

Fig. 18. Primary structure of human 5 - $\mathrm{HT}_{4}$ receptors. The amino acid sequences of the identified splice variants are depicted. 5 - $\mathrm{HT}_{4}$ receptors have identical sequences up to $\mathrm{L}^{358}$ and differ by the length and composition of their C-terminal domain. The 5-HT $\mathrm{T}_{4(\mathrm{~h})}$ variant, which presents an insertion of 14 residues in the second extracellular loop, has been isolated in combination with the $\mathrm{b}$ isoform, and it is called 5-HT (hb). $^{2}$ $\mathrm{N}$-glycosylation sites on $\mathrm{N}^{7}$ and $\mathrm{N}^{180}$ are indicated. Palmytoylation sites on $\mathrm{C}^{328}, \mathrm{C}^{329}$ (common to all splice variants), and $\mathrm{C}^{386}$ (in the a isoform) are schematized. This figure has been established in accordance with the last human genome assembly (Genes, Ensembl release 82) and modified from Padayatti et al. (2013). 
analysis of both $5-\mathrm{HT}_{4}$ receptor mRNA and binding sites in postmortem human brains and reported combined receptor detection in caudate nucleus, putamen, nucleus accumbens, and hippocampus with moderate to low densities in the cortex. Mismatches between absence of $5-\mathrm{HT}_{4}$ receptor mRNA with high densities of receptor-binding sites in the globus pallidus and the substantia nigra suggested that the receptors may be localized on axonal projections originating from the striatum (Bonaventure et al., 2000).

In the cortex, hippocampus, and amygdala, $5-\mathrm{HT}_{4}$ receptors were described on cholinergic neurons, where they stimulate the release of acetylcholine, as well as on the glutamatergic neurons (King et al., 2008). In the striatum and nucleus accumbens, the receptors have been found on the intrinsic GABA neurons (spiny neurons) but also on glutamatergic neurons (King et al., 2008). Work using dual-label in situ hybridization found precise localization of $5-\mathrm{HT}_{4}$ receptors in relation with the cholinergic system. In the basal forebrain, $5-\mathrm{HT}_{4}$ receptor mRNA was not detected in the cholinergic cell population but in parvalbumin synthesizing and glutamatergic cells (Penas-Cazorla and Vilaro, 2015). Thus, noncholinergic cell populations within the basal forebrain, hippocampal and cortical areas that express $5-\mathrm{HT}_{4}$ receptors (likely glutamatergic cells) would mediate the $5-\mathrm{HT}_{4}$ receptor-mediated enhancement of acetylcholine (Penas-Cazorla and Vilaro, 2015) and other neurotransmitters, such as the increase in 5-HT release in the hippocampus $(\mathrm{Ge}$ and Barnes, 1996).
[3H] R116712
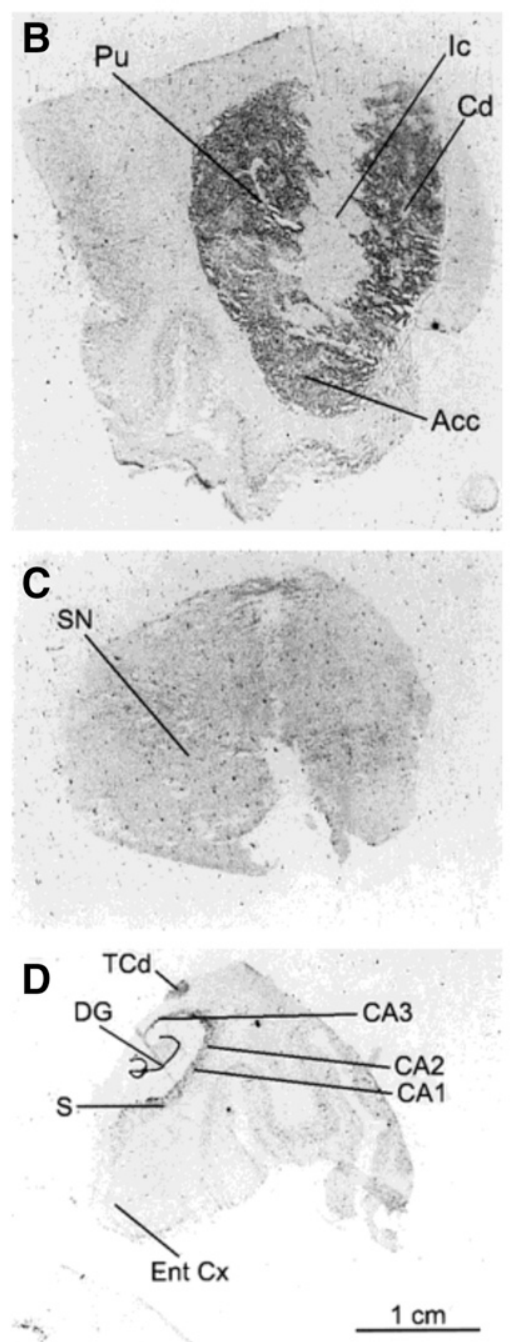

G

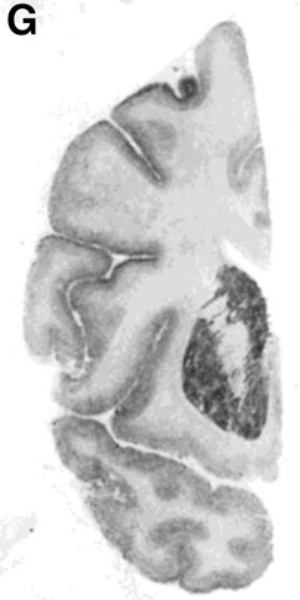

$72.2 \mathrm{~mm}$

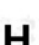

H

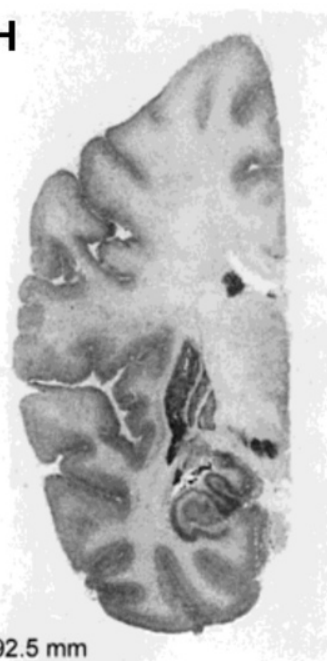

[3H] R116712

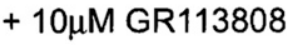

J

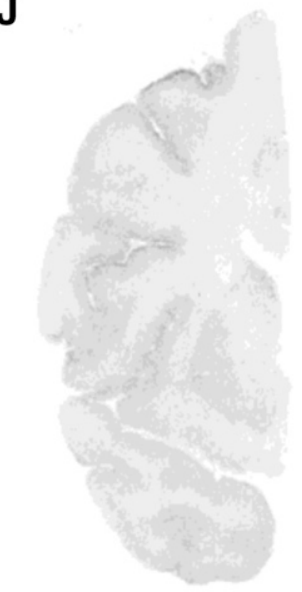

$72.3 \mathrm{~mm}$

K

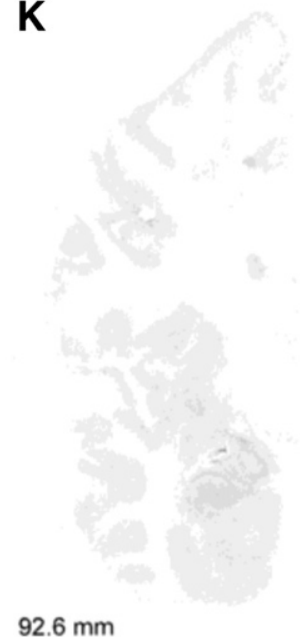

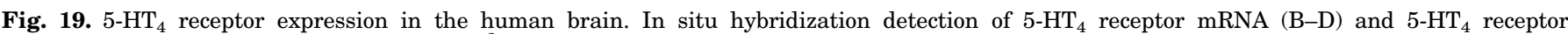

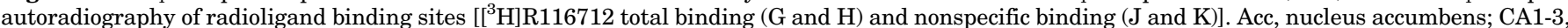

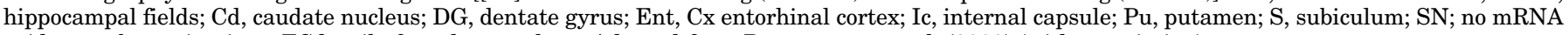
evident, substantia nigra; TCd, tail of caudate nucleus. Adapted from Bonaventure et al. (2000) (with permission). 
Localization of $5-\mathrm{HT}_{4}$ receptor splice variants in rodents appears to be similar within brain areas and concordant to the binding studies, with a low level of $5-\mathrm{HT}_{4}$ receptor mRNA in the cerebellum, where no receptor-binding site is detected (Claeysen et al., 1999; Vilaro et al., 1996). A complex pattern of human 5-HT receptor isoforms, which depends not only on the region studied but also on each individual brain, requires analysis of a larger cohort to be conclusive (Bender et al., 2000). However, the variations in C-terminal domain of the $5-\mathrm{HT}_{4}$ receptor influence its constitutive activity (Claeysen et al., 1999), internalization properties (Mnie-Filali et al., 2010), and subcellular localization via interacting partners (Joubert et al., 2004) (see 2.). The distribution of $5-\mathrm{HT}_{4(\mathrm{a})}$ receptors in the juvenile rat brain and spinal cord recently achieved using a polyclonal antibody have produced global data in accordance with the literature. However, striking staining of cerebellum cells raises a doubt on the specificity of the antibody used, which has not been tested on animals devoid of $5-\mathrm{HT}_{4}$ receptor (KO) (Suwa et al., 2014).

$5-\mathrm{HT}_{4}$ receptors are also located on the respiratory Pre-Boetzinger complex in the ventrolateral medulla of the brainstem, where they modulate spontaneous respiratory activity (Manzke et al., 2003; Richter et al., 2003).

\section{Periphery.}

a. Heart. In porcine and human heart, 5- $\mathrm{HT}_{4}$ receptors are mainly expressed in the atrial myocytes, and their expression was long believed to be atriaselective (Kaumann et al., 1991; Ouadid et al., 1992; Kaumann and Levy, 2006). However, expression was later also found in human and porcine ventricle (Bach et al., 2001; Brattelid et al., 2004a,b), and during heart failure and cardiac hypertrophy, their mRNA level and expression increased in the porcine, rat, and human ventricles (Brattelid et al., 2004b; Qvigstad et al., 2005a,b,c), possibly reflecting reactivation of a fetal gene expression pattern (Brattelid et al., 2012).

b. Gastrointestinal tract. In rodents, $5-\mathrm{HT}_{4}$ receptors are expressed in the smooth muscle of the esophagus. In many species, they are present on the intrinsic afferent neurons, motor neurons, and enterocytes of the gastrointestinal tract (Hegde and Eglen, 1996). The expression of $5-\mathrm{HT}_{4}$ receptors on excitatory motor neurons in the gut facilitates acetylcholine release, which stimulates gastrointestinal motility (Liu et al., 2005a; Gershon and Tack, 2007; Ren et al., 2008). In the human colon, $5-\mathrm{HT}_{4}$ receptors are also expressed on circular smooth muscle cells, where they induce relaxation (McLean et al., 1995). The 5-HT $\mathrm{H}_{4(\mathrm{~h})}$ receptor variants appear to be predominantly expressed in porcine GI mucosa, suggesting their contribution to the $5-\mathrm{HT}_{4}$ receptor-mediated mucosal effects of 5-HT (Priem et al., 2013). In human colon, RT-PCR analysis shows that $5-\mathrm{HT}_{4(\mathrm{~d})}$ and $5-\mathrm{HT}_{4(\mathrm{~g})}$ receptor splice variants are significantly less likely to be detected in mucosa and longitudinal muscle compared with the 5-HT $4(\mathrm{a}), 4(\mathrm{~b}), 4(\mathrm{c}), 4(\mathrm{n})$ splice variants (Yaakob et al., 2015). c. Adrenal gland. $5-\mathrm{HT}_{4}$ receptors are present in glomerulosa and zona fasciculata of the adrenal cortex (Lefebvre et al., 1992, 1998a). An RT-PCR study demonstrated that $5-\mathrm{HT}_{4}$ receptors are overexpressed in adrenocortical aldosterone-producing adenoma tissues in comparison with normal adrenal cortex (Cartier et al., 2005). Moreover, a different splicing mechanism seems to occur in these tumors, where the $5-\mathrm{HT}_{4(\mathrm{a})}$ and $5-\mathrm{HT}_{4(\mathrm{~b})}$ receptor splice variants, usually present in normal adrenal cortex, are absent, and the $5-\mathrm{HT}_{4(\mathrm{~d})}$, a rare isoform, is over-represented (Cartier et al., 2005).

d. Salivary glands. In the rat submandibular gland, expression of $5-\mathrm{HT}_{4(\mathrm{~b})}$ but not $5-\mathrm{HT}_{4(\mathrm{a})}$ receptors was demonstrated and linked to cyclic AMP formation and regulation of volume and protein content of saliva, together with $5-\mathrm{HT}_{7}$ receptors (Turner et al., 1996; Bourdon et al., 2000).

e. Urinary bladder. In the bladder, $5-\mathrm{HT}_{4}$ receptors are present on cholinergic/purinergic neurons that innervate the smooth muscle (detrusor) (Candura et al., 1996). Their stimulation with cisapride enhances human bladder contraction without affecting urethral contractions or relaxations (Kullmann et al., 2013).

f. Lung. $5-\mathrm{HT}_{4}$ receptor mRNA has been detected at low density in human alveolar epithelial cells type II, airway epithelial cell lines, and human airway smooth muscle (Bayer et al., 2007; Einstein et al., 2008; Hodge et al., 2013).

\section{Post-translational Modifications}

Post-translational modifications of $5-\mathrm{HT}_{4}$ receptors and their related functional consequences have been studied on receptors expressed in heterologous cells rather than native tissues.

1. $N$-Glycosylation. There are two putative $N$-linked glycosylation sites in the extracellular side of $5-\mathrm{HT}_{4}$ receptors that conform to the consensus sequence N-X-S/T, where X can be any amino acid except a Pro residue (N-terminal $\mathrm{N} 7$ and second extracellular loop N180; Fig. 18). The pattern of glycosylation is dependent on the nature of the cell in which $5-\mathrm{HT}_{4}$ receptors are expressed. Salom et al. (2012) report that the glycosylation pattern of $5-\mathrm{HT}_{4}$ receptors ectopically expressed in mouse rod cells in vivo is more homogeneous than the glycosylation pattern of $5-\mathrm{HT}_{4}$ receptors expressed artificially in HEK293 cells. The $\mathrm{h} 5-\mathrm{HT}_{4(\mathrm{~b})}$ receptors expressed in mouse rod cell display high-mannose-type and complextype sugars at both $\mathrm{N} 7$ and N180 sites. Most of the oligosaccharides had the core structure of three mannoses (Man) and two $N$-acetylglucosamine 
residues (23 species for $\mathrm{N} 7$ and eight species for N180). This $N$-glycosylation pattern is much more complex than for other GPCRs expressed in mouse rod cells.

2. Palmitoylation. The first crystal structure of rhodopsin reveals that after the TM7, there is a fourth intracellular loop (I-4) with $\alpha$-helical structure. Thus, this I-4 loop is also called helix 8 and terminates with two palmitoyled cysteines that are well conserved in many GPCRs as in the 5 - $\mathrm{HT}_{4}$ receptors $\left(\mathrm{C}^{328}\right.$ and $\left.\mathrm{C}^{329}\right)$. The palmitoylation/depalmitoylation of those cysteines are associated with the wide spectrum of GPCRs biologic activities, from coupling to $G$ proteins and regulated endocytosis to receptor phosphorylation and desensitization. Ponimaskin et al. (2002a) were the first to show that, in insect Sf9 cells, palmitoylation of the $5-\mathrm{HT}_{4(\mathrm{a})}$ is a reversible process and that agonist increases the turnover rate for receptor-bound palmitate. They identified $\mathrm{C}^{328} / \mathrm{C}^{329}$ as potential acylation sites in the $5-\mathrm{HT}_{4(\mathrm{a})}$ receptor, but, in contrast to most other palmitoyled GPCRs, an additional cysteine residue $\mathrm{C}^{386}$, located in the very distal portion of the C-terminal domain, was also identified as a palmitoylation site. Therefore, "complete" palmitoylation of the $5-\mathrm{HT}_{4(\mathrm{a})}$ may result in the formation of a putative additional intracellular loop (I-5). Mutation of the proximal palmitoylation sites $\left(\mathrm{C}^{328} \mathrm{~S}\right.$ and $\left.\mathrm{C}^{329} \mathrm{~S}\right)$ increased the capacity of the receptor to convert from the inactive $(\mathrm{R})$ to the active $\left(\mathrm{R}^{*}\right)$ form in the absence of agonists, whereas the mutation of $\mathrm{C}^{386} \mathrm{~S}$ had no effect on this parameter. $5-\mathrm{HT}_{4}$ receptors expressed in rod cells in vivo are palmitoylated either on $\mathrm{C}^{328}$ or $\mathrm{C}^{329}$ (Salom et al., 2012).

3. Phosphorylation. The $5-\mathrm{HT}_{4}$ receptor C-terminal sequence, common to all splice variants (upstream of $\mathrm{L}^{358}$ ), contains a remarkable cluster of serine and threonine residues $\left(\mathrm{S}^{347}\right.$ TTTINGSTHVL ${ }^{358}$ ), which are potential phosphorylated sites for GRK. This cluster is absolutely required for $\beta$-arrestin/dynamin-dependent receptor endocytosis but not for receptor uncoupling (Barthet et al., 2005). This cluster is also required for $\beta$-arrestin binding to the receptor (Barthet et al., 2005). Like many GPCRs, $5-\mathrm{HT}_{4}$ receptors stimulate ERK. However, this stimulation is $\mathrm{G}_{\mathrm{s}} / \mathrm{G}_{\mathrm{q}} / \mathrm{G}_{\mathrm{i}} / \mathrm{G}_{\mathrm{o}} / \mathrm{cAMP} / \mathrm{PKA}$ independent as well as $\beta$-arrestin-independent. In contrast, this stimulation requires activation of Src tyrosine kinase (Barthet et al., 2007). This $\mathrm{G}_{\mathrm{s}}$-independent Src-mediated ERK activation is inhibited by GRK5, which is physically associated with the proximal region of the $\mathrm{C}$ terminus (upstream of the S/T cluster) (Barthet et al., 2009). Tandem mass spectra of the stimulated $5-\mathrm{HT}_{4}$ receptors in HEK293 cells expressing GRK5 revealed a peptide $\left(\mathrm{R}^{336}-\mathrm{R}^{359}\right)$ found under a nonphosphorylated and three phosphorylated forms with one, two, and three phosphates attached, respectively (Barthet et al., 2009). Loss of phosphate on fragmentation indicated phosphorylation of S354 in the monophosphorylated peptide and the presence of an additional phosphorylated residue within the $\mathrm{S}^{347} \mathrm{TTT}^{350}$ motif. The triphosphorylated peptide incorporated an additional phosphate within the $\mathrm{S}^{347} \mathrm{TTT}^{350}$ motif. This indicates that GRK5 sequentially phosphorylates the peptide, first on $\mathrm{S}^{354}$ and then in the $\mathrm{S}^{347} \mathrm{TTT}^{350}$ motif. The same $5-\mathrm{HT}_{4}$ receptor peptide was found to be phosphorylated in receptors expressed in mouse rods (0-5 phosphorylated residues) (Salom et al., 2012). In the same model, another peptide was found to be phosphorylated within the I-3 loop $\left(\mathrm{A}^{232}\right.$ to $\left.\mathrm{R}^{250}\right) . \mathrm{S}^{235}, \mathrm{~S}^{236}$, $\mathrm{S}^{238}$, and $\mathrm{S}^{242}$ residues were the targets for phosphorylation as well as $\mathrm{S}^{247}$ or $\mathrm{T}^{248}$ (Salom et al., 2012).

\section{E. Pharmacology}

1. Agonists. Very early, benzamides substituted by 2-methoxy-4-amino-5-chloro such as metoclopramide, renzapride, cisapride, or zacopride were identified as potent agonists of the $5-\mathrm{HT}_{4}$ receptors [for reviews, see Bockaert et al. (1997, 2004a, 2008) and Langlois and Fischmeister (2003)]. This was an important step in the pharmacological characterization of $5-\mathrm{HT}_{4}$ receptors (Clarke et al., 1989) and prompted a number of pharmaceutical companies to develop selective ligands for this receptor.

The first class of $5-\mathrm{HT}_{4}$ receptor to be discussed includes indole derivatives such as tryptamines (including 5-HT) and indole carbazimidamines derivatives. Tegaserod, prescribed to treat IBS in women suffering from constipation, belongs to this class. This compound was withdrawn from the market in 2007 because of cardiovascular side effects but has made a recent return to the market, albeit with limitations on use.

The second class includes benzamide derivatives such as metoclopramide, which was commercialized as an antiemetic (action via dopamine $\mathrm{D}_{2}$ receptors and $5-\mathrm{HT}_{3}$ receptors at higher doses) and stimulating gastrointestinal transit (action via $5-\mathrm{HT}_{4}$ receptors). Mosapride, which also acts as a $5-\mathrm{HT}_{4}$ receptor agonist, is used to treat gastrointestinal disorders, as it accelerates gastric emptying (Curran and Robinson, 2008; Tack et al., 2012), but a main metabolite is pharmacologically active and antagonizes the $5-\mathrm{HT}_{3}$ receptor.

The benzofurane carboxamide prucalopride is selective for the $5-\mathrm{HT}_{4}$ receptor (Briejer et al., 1999) and has been approved for the treatment of chronic constipation, in case of laxative resistance, in Europe (2009) and in Canada (2011) (Tack et al., 2013).

Lead of the benzoates class is ML10302, which presents a high affinity for $5-\mathrm{HT}_{4}$ receptor and weak affinity for $5-\mathrm{HT}_{3}$ receptors (Yang et al., 1997). ML10302 was described as the first potent and selective $5-\mathrm{HT}_{4}$ receptor agonist, but further investigation in vivo was limited by its susceptibility to hydrolysis. 
Benzodioxane class is represented by only one product, the SL65.0155, particularly proactive as a mnemonic in several species. This compound has reached Phase IIlb for the treatment of Alzheimer disease (Moser et al., 2002). It was abandoned for undisclosed reasons that may be related to its low efficacy and very partial agonist profile on $5-\mathrm{HT}_{4}$ receptors.

The sixth class includes aryl ketones, which were developed to overcome the metabolic lability related to the related $5-\mathrm{HT}_{4}$ receptor ester ligands. These compounds have a high bioavailability and easily pass the blood-brain barrier. RS 67333 (Eglen et al., 1995a), containing a large alkyl group, was widely used in vivo in rodent and particularly for behavioral studies demonstrating the procognitive effects of $5-\mathrm{HT}_{4}$ receptor agonists (Fontana et al., 1997; Marchetti et al., 2000; Lamirault and Simon, 2001; Lelong et al., 2001; Kulla and Manahan-Vaughan, 2002).

The seventh class is represented by a carboxamide pyridine, PRX-03140 (also known in the literature as VRX-03011), another partial 5- $\mathrm{HT}_{4}$ receptor agonist and promnemonic substance that reached Phase IIb for the treatment of Alzheimer disease (Mohler et al., 2007) in 2008, although development of the drug was then stopped.

Benzimidazolone derivatives constitute the eighth class with BIMU1 and BIMU8 as examples, which are potent and efficacious $5-\mathrm{HT}_{4}$ receptor agonists with good brain-penetrating properties (Dumuis et al., 1991; Rizzi et al., 1992). However, their affinity for $5-\mathrm{HT}_{3}$ and $\sigma_{2}$ receptors limits their utility (Bonhaus et al., 1993).

The last two classes include naphthalimide derivatives (Eglen et al., 1994) (RS 56532 and RS 66332) and the quinoline derivative velusetrag (Beattie et al., 2008). Velusetrag displays promising efficacy in patients with constipation (e.g., Nelson et al., 2017) and may also be useful in Alzheimer disease.

Other $5-\mathrm{HT}_{4}$ receptor agonists are listed in Table 16, indicating key pharmacological parameters.

2. Antagonists. GR 113808, belonging to the indole class, was the first selective $5-\mathrm{HT}_{4}$ receptor antagonist presenting low affinity for $5-\mathrm{HT}_{3}$ receptors (Gale et al., 1994) and the first tritiated radioligand commercially available. This molecule enabled the accurate definition of pharmacological characteristics and localization of $5-\mathrm{HT}_{4}$ receptors, especially in the brain (Grossman et al., 1993). Other antagonists are benzoate derivatives (such as SDZ 205557) or benzoate dioxane derivatives such as SB 204070, which by substitution of the chlorine by a radioactive iodine, lead to $\left[{ }^{125} \mathrm{I}\right] \mathrm{SB} 207710$, another excellent radioligand (Kaumann et al., 1995). Other antagonist classes include benzimidazolones, imidazolpyridines, and aryl ketones.

$5-\mathrm{HT}_{4}$ receptor antagonists have been mainly developed for the purpose of binding studies and in situ labeling using radioligands. Recent work includes the development of imaging probes for positron emission tomography (PET) (Dubost et al., 2012; Buiter et al., 2013; Tavares et al., 2014). However, because of the presence of $5-\mathrm{HT}_{4}$ in the failing heart, some antagonists have been designed for cardioprotective purposes, trying to avoid CNS penetration and improving oral administration route (Brudeli et al., 2010, 2013a,b, 2014).

Some 5- $\mathrm{HT}_{4}$ receptor antagonists are listed in Table 16 , indicating key pharmacological parameters.

3. Inverse Agonists. Inverse agonists of the $5-\mathrm{HT}_{4}$ receptor (Claeysen et al., 2000; Joubert et al., 2002) have

TABLE 16

Affinities and efficacies of several $5-\mathrm{HT}_{4}$ receptor ligands in radioligand binding $\left(\mathrm{p} K_{\mathrm{i}}\right)$ and functional $\left(\mathrm{pEC}_{50}\right)$ studies

\begin{tabular}{|c|c|c|c|c|}
\hline \multirow[t]{2}{*}{ Compounds } & \multirow{2}{*}{$\begin{array}{c}\text { Affinity } \\
\mathrm{p} K_{\mathrm{i}}\end{array}$} & \multicolumn{2}{|l|}{ Efficacy } & \multirow[t]{2}{*}{ References } \\
\hline & & $\mathrm{pEC}_{50}$ or $\mathrm{pIC}_{50}$ & $\mathrm{E}_{\max }$ or $\mathrm{I}_{\max }$ & \\
\hline Agonists & & & & \\
\hline PF-00885706 & 8.4 & $8.2-8.4$ & $78 \%-84 \%$ & Komada et al., 2009 \\
\hline PF-01354082 & 8.7 & $8.1-8.5$ & $74 \%-66 \%$ & Mikami et al., 2009 \\
\hline Compound 26 & 7.9 & 9.4 & $63 \%$ & McKinnell et al., 2009 \\
\hline ATI-75025 (Naronapride) & 8.9 & & & $\begin{array}{l}\text { Camilleri et al., 2007; } \\
\text { Bowersox et al., } 2011\end{array}$ \\
\hline Compound 2d & $9.3-9.8$ & $9.2-9.6$ & $7 \%-33 \%$ & Brodney et al., 2012 \\
\hline Compound 3 & $8.1-8.6$ & $8.7-9.1$ & $21 \%-63 \%$ & Brodney et al., 2012 \\
\hline TD-2749 & 8.0 & 8.6 & $85 \%$ & Long et al., 2012 \\
\hline PF-4995274 (TBPT) & 9.5 & 9.0 & $19 \%$ & Sawant-Basak et al., 2013 \\
\hline SSP-002392 & $9.1-9.2$ & $10.4-10.8$ & $\sim 100 \%$ & Tesseur et al., 2013 \\
\hline TD-8954 & 9.4 & 8.6 & $55 \%$ & McKinnell et al., 2013 \\
\hline Dual ligands & & & & \\
\hline 5- $\mathrm{HT}_{4}$ agonist/5- $\mathrm{HT}_{3}$ antagonist $\mathrm{Cpd} 17$ & $6.7\left(5-\mathrm{HT}_{4} \mathrm{R}\right) 7.4\left(\mathrm{H}_{3} \mathrm{R}\right)$ & $7.3\left(\mathrm{H}_{3} \mathrm{R}\right)$ & & Lepailleur et al., 2014 \\
\hline Donecopride $5-\mathrm{HT}_{4}$ agonist/AChE inhibitor & $8.1\left(5-\mathrm{HT}_{4}\right)$ & $9.0\left(5-\mathrm{HT}_{4}\right) 7.8\left(\mathrm{pIC}_{50} \mathrm{AChE}\right)$ & $48 \%\left(5-\mathrm{HT}_{4}\right)$ & $\begin{array}{l}\text { Lecoutey et al., } 2014 \\
\text { Rochais et al., } 2015\end{array}$ \\
\hline Antagonists & & & & \\
\hline Compound 34d & 8.8 & 9.2 & $80 \%-100 \%$ & Lemaître et al., 2009 \\
\hline Compound 30 & 8.8 & $7.9(\mathrm{pKb})$ & & Brudeli et al., 2010 \\
\hline Compound $12 \mathrm{~g}$ & 8.7 & 8.6 & $100 \%$ & Furlotti et al., 2012 \\
\hline Compound 20 & 11.9 & $10.6(\mathrm{pKb})$ & & Brudeli et al., 2013a \\
\hline Compound 9 & 9.9 & $8.6(\mathrm{pKb})$ & & Brudeli et al., 2013b \\
\hline Compound 25 & 10.1 & $9.1(\mathrm{pKb})$ & & Brudeli et al., 2014 \\
\hline
\end{tabular}


been generated by Roche in collaboration with Bockaert's group (RO 116-0086, RO 116-1148, and RO 1162617; Fig. 20). SB 207266, which is a carboxylate indole derivative, is also an inverse agonist at the $5-\mathrm{HT}_{4}$ receptor (Fig. 20).

4. Multifunctional Ligand. Dallemagne and colleagues reported the synthesis and characterization of donecopride, a multitarget directed molecule combining $5-\mathrm{HT}_{4}$ receptor agonist properties with acetylcholinesterase (AChE) inhibition (Lecoutey et al., 2014); the drug may display disease-modifying actions by increasing soluble amyloid precursor protein $(\operatorname{sAPP} \alpha)$ release as well as procognitive effects (Lecoutey et al., 2014; Rochais et al., 2015).

5. 5-HT 4 Receptor Radioligands. The first tritiated or iodinated $5-\mathrm{HT}_{4}$ receptor compounds, mainly antagonists, were particularly useful to determine brain regional distribution of the receptor (Grossman et al., 1993; Waeber et al., 1993, 1994, 1996), $\left[{ }^{3} \mathrm{H}\right] \mathrm{GR}$ 113808 and $\left[{ }^{125} \mathrm{I}\right] \mathrm{SB} 207710$ being the lead compounds (Kaumann et al., 1995). Then, several $\left[{ }^{11} \mathrm{C}\right]-$ labeled compounds have been developed for use in PET (Gee et al., 2008; Xu et al., 2010; Buiter et al., 2013), enabling live imaging studies in animals (Kornum et al., 2009) and in humans (Marner et al., 2009; Madsen et al., 2011). New [ $\left.{ }^{125} \mathrm{I}\right]$-labeled antagonists have also been developed for use as PET tracers (Dubost et al., 2012). More recently, promising fluoride radioligands have been described: $\left[{ }^{18} \mathrm{~F}\right] \mathrm{MNI}-698$ and $\left[{ }^{18} \mathrm{~F}\right] \mathrm{MNI}-699$ (Caille et al., 2013; Tavares et al., 2014).

\section{F. Function}

1. Physiologic Function. The $5-\mathrm{HT}_{4}$ receptors have many physiologic functions. They are implicated in learning and memory and in the stimulation of the nonamyloidogenic cleavage of APP (Bockaert et al., 2008, 2011; Claeysen et al., 2015). Thus, they are potential targets to treat Alzheimer disease.

A role of $5-\mathrm{HT}_{4}$ receptors in feeding behavior is now clear. Agonists and antagonists have hypo- and hyperphagic properties, respectively (Jean et al., 2007; Bockaert et al., 2011).

$5-\mathrm{HT}_{4}$ receptor stimulation has rapid antidepressant action and may contribute to the actions of SSRI (Lucas, 2009; Samuels et al., 2016).

In the periphery, the role of $5-\mathrm{HT}_{4}$ receptors in gastrointestinal tract is well established. $5-\mathrm{HT}_{4}$ receptors evoke gastric emptying, peristaltic reflex, intestinal motility, inhibition of hypersensibility, short free fatty acid-stimulated $\mathrm{HCO}_{3}^{-}$secretion, and, importantly, enteric nervous system development and adult neurogenesis of enteric plexus (Matsuyoshi et al., 2010; Gershon, 2011, 2013; Hoffman et al., 2012; Akiba et al., 2015). For further discussion, see XX. 5-HT Receptors and the Gastrointestinal Tract.

Although it was initially believed that $5-\mathrm{HT}_{4}$ receptors were confined to the atria of porcine and human heart (Kaumann and Levy, 2006), functional $5-\mathrm{HT}_{4}$ receptors mediating increased cardiac contractility (inotropic effect), as well as hastened relaxation (lusitropic effect), were later found in porcine and human ventricle (Brattelid et al., 2004b). In human, and also rat ventricle, $5-\mathrm{HT}_{4}$ receptor mRNA expression and function is increased or even induced in pathologies such as heart failure and hypertrophy, and following cardiac infarction (Brattelid et al., 2004b; Qvigstad et al., 2005a,c), maybe reflecting reactivation of foetal gene expression (Brattelid et al., 2012). 5- $\mathrm{HT}_{4}$ receptor antagonists may be useful in those cardiac pathologies (Birkeland et al., 2007a; Kjekshus et al., 2009).
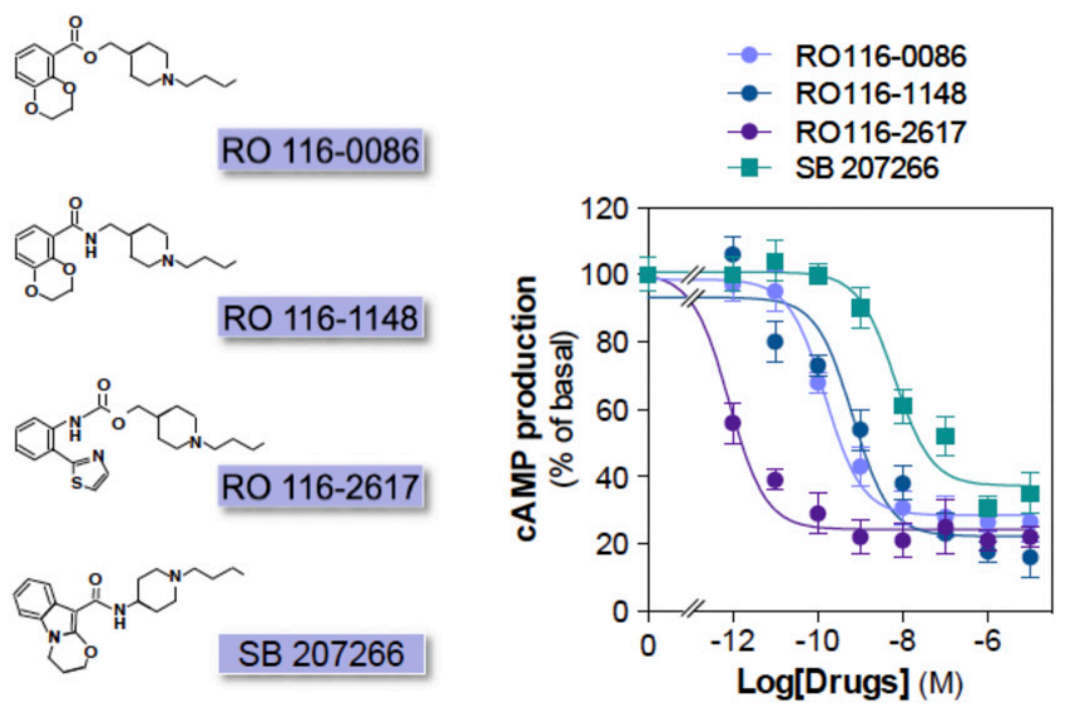

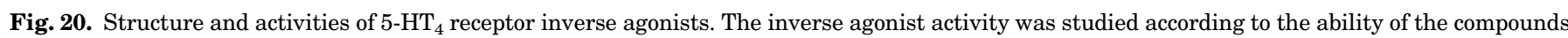

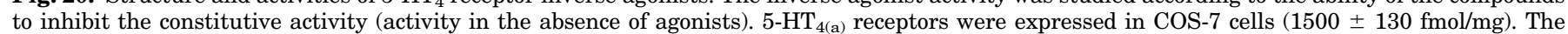

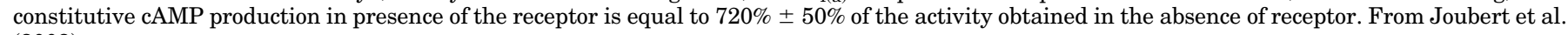
(2002). 
Although 5- $\mathrm{HT}_{4}$ receptors are weakly expressed in whole lung, airways epithelial cells, and airways smooth muscle cells, meta-analyses of genome-wide association studies indicate that intronic SNPs in HTR4 gene are associated with some pulmonary diseases (Hancock et al., 2010; Repapi et al., 2010; Soler Artigas et al., 2011; Hodge et al., 2013).

$5-\mathrm{HT}_{4}$ receptors are present in corticoadrenal gland where they stimulate aldosterone production, in salivary glands where they modify the volume and protein content of saliva (Turner et al., 1996; Bourdon et al., 2000), and in urinary bladder (Hegde and Eglen, 1996; Lefebvre et al., 2015).

\section{Cellular Function.}

a. G protein coupling of $5-\mathrm{HT}_{4}$ receptors and primary signaling events. $5-\mathrm{HT}_{4}$ receptors stimulate adenylyl cyclase in colliculi neurons as well as in hippocampus (Dumuis et al., 1988). This coupling has also been found in nucleus accumbens (Jean et al., 2007) and in heart atrium (Kaumann et al., 1990; Ouadid et al., 1992) and ventricle (Afzal et al., 2008). Thus, in native tissues, the $5-\mathrm{HT}_{4}$ receptor-mediated $\mathrm{G}_{\mathrm{s}} / \mathrm{cAMP} / \mathrm{PKA}$ signaling pathway is well established. In primary cortical neurons and HEK293 cells, cAMP produced by $5-\mathrm{HT}_{4}$ receptors also activates the exchange factor Epac. Epac, via an Epac/Rap1/Ras pathway, activates an $\alpha$-secretase and the release of $\operatorname{sAPP} \alpha$ (Lezoualc'h and Robert, 2003; Cochet et al., 2013).

In transfected cell lines, several signaling pathways have been found, including coupling to $\mathrm{G}_{\mathrm{i}} / \mathrm{o}_{\mathrm{o}}, \mathrm{G}_{\mathrm{q}}$, and $\mathrm{G}_{13}$ (Ponimaskin et al., 2002b; Bockaert et al., 2006; Woehler and Ponimaskin, 2009). Expression of different 5 - $\mathrm{HT}_{4}$ receptor splices variants in heterologous cells (COS and HEK293 cells, rodent cardiac myocytes) have identified putative differences in their signaling coupling. One clear difference is their constitutive activities measured on $\mathrm{G}_{\mathrm{s}}$ coupling. Generally, the shorter the $\mathrm{C}$ terminus, the higher the constitutive activity (Claeysen et al., 1999). In addition, it has been reported that, in HEK293 cells and adult cardiac myocytes, $5-\mathrm{HT}_{4(\mathrm{~b})}$ but not $5-\mathrm{HT}_{4(\mathrm{a})}$ or $5-\mathrm{HT}_{4(\mathrm{~d})}$ are coupled to both $\mathrm{G}_{\mathrm{s}}$ and $\mathrm{G}_{\mathrm{i}} /$ o (Pindon et al., 2002). In similar heterologous systems, activation of transiently expressed $5-\mathrm{HT}_{4(\mathrm{a})}$ receptors by $5-\mathrm{HT}$ and other agonists induce both cAMP and inositol phosphate accumulation (Chang et al., 2007; Gaven et al., 2013).

Following PKA activation, a series of ionic currents are modulated in colliculi and CA1 hippocampal neurons (Andrade and Chaput, 1991; Ansanay et al., 1995). These include a long-lasting inhibition of $\mathrm{K}^{+}$currents, including $\mathrm{Ca}^{2+}$-activated $\mathrm{K}^{+}$channels (mediated by a PKA-dependent inhibition of phosphatases), which generates neuronal excitability and a decrease in spike accommodation (Ansanay et al., 1995) as well as activation of the hyperpolarization-activated current known to adjust repetitive discharge behavior in CA1 neurons (Andrade and Chaput, 1991). In prefrontal cortex pyramidal neurons, $\mathrm{GABA}_{\mathrm{A}}$ current and
GABAergic transmission are either stimulated or inhibited by $5-\mathrm{HT}_{4}$ receptors. A role of PKA and A kinase anchoring proteins has been reported (Cai et al., 2002). 5 - $\mathrm{HT}_{4}$ receptors also activate L-type $\mathrm{Ca}^{2+}$ channels in human and porcine atrial myocytes via a cAMP/PKA pathway (Ouadid et al., 1992; Kaumann and Levy, 2006).

The receptor- $\mathrm{G}_{\mathrm{s}}$ uncoupling phase of $5-\mathrm{HT}_{4}$ receptor desensitization is very rapid and efficient in colliculi neurons (Ansanay et al., 1992) and rat esophagus (Ronde et al., 1995) and is specifically dependent on the presence of a high expression of GRK2 but not of its catalytic activity (Barthet et al., 2005). In contrast, the $\beta$-arrestin/dynamin-dependent endocytosis of $5-\mathrm{HT}_{4}$ receptors in HEK293 cells does not require a high expression of GRK2 and is dependent of the $\mathrm{S} / \mathrm{T}$ cluster upstream of $\mathrm{L}^{258}$ (Barthet et al., 2005).

b. G protein-independent coupling of $5-\mathrm{HT}_{4}$ receptors. $5-\mathrm{HT}_{4}$ receptors activate $\mathrm{ERK}$ in a $\mathrm{G}$ protein- and $\beta$-arrestin-independent manner, both in colliculi neurons and HEK293 cells (Barthet et al., 2007). The first step in $5-\mathrm{HT}_{4}$ receptor-ERK activation is the phosphorylationactivation of the tyrosine kinase Src bound to the receptor (Barthet et al., 2007). This G protein-independent activation of Src by $5-\mathrm{HT}_{4}$ receptors has also been described in epithelial cell lines (Gill et al., 2005). Indeed, in the enterocyte cell line, Caco 2, 5- $\mathrm{HT}_{4}$ receptor-induced Src activation was required to activate the $\operatorname{PLC} \gamma 1$ pathway and to inhibit $\mathrm{Na}^{+} / \mathrm{H}^{+}$exchanger (Gill et al., 2005).

$5-\mathrm{HT}_{4}$ receptor-operated Src/ERK pathway, but not the $\mathrm{G}_{\mathrm{s}}$ pathway, was negatively regulated by GRK5 physically preassociated with the proximal C-terminal region of the receptor in both human HEK293 cells and mouse colliculi neurons (Barthet et al., 2009). This desensitization requires two sequences of events: the association of $\beta$-arrestin 1 to the phosphorylated $\mathrm{S} / \mathrm{T}$ cluster already described and the phosphorylation, by GRK5, of $\beta$-arrestin1 (at $\mathrm{S}^{412}$ ) bound to the receptor. Phosphorylated $\beta$-arrestin1, in turn, prevented the activation of Src constitutively bound to $5-\mathrm{HT}_{4}$ receptors (Barthet et al., 2009).

3. Gastrointestinal Tract. $5-\mathrm{HT}_{4}$ receptor localization and functions in GI tract have been extensively studied in many species, including guinea pig, pig, dog, mice, rat, and human (Craig and Clarke, 1990; McLean et al., 1995; Hegde and Eglen, 1996; Poole et al., 2006; Gershon and Tack, 2007; Sanger, 2008; Priem et al., 2013).

Activation of $5-\mathrm{HT}_{4}$ receptors is prokinetic on GI and stimulate guinea pig ileum contractions is concomitant to discovery of $5-\mathrm{HT}_{4}$ receptors (Craig and Clarke, 1990). Subsequently, $5-\mathrm{HT}_{4}$ receptor facilitation of the peristaltic reflex has been identified (Hegde and Eglen, 1996; Grider et al., 1998). The mechanism by which $5-\mathrm{HT}_{4}$ receptors stimulate peristaltic reflex is debated. Two proposals have been provided. 1) Within circular muscles of colon (human), $5-\mathrm{HT}_{4}$ receptors stimulate the release the inhibitory (descending relaxation) and excitatory (ascending contractions) neurotransmitters 
(nitric oxide and acetylcholine respectively) (Tonini et al., 1989; Liu et al., 2005; Cellek et al., 2006; Ren et al., 2008). 2) $5-\mathrm{HT}_{4}$ receptors localized on the luminal surface of epithelial cells, including enterochromaffin cells and goblet cells, stimulate the peristaltic effect via secreted mucus, 5-HT, and fluid secretion (Hegde and Eglen, 1996). Luminal $\mathrm{HCO}_{3}^{-}$secretion is an important component of normal colonic fluid and electrolyte movement and is a major fraction of the fluid secreted in several diarrheal diseases. It has been recently found that short-chain fatty acids (SCFAs) stimulate $\mathrm{HCO}_{3}^{-}$ secretion. This effect involves several steps, including the following ones. SCFA via the stimulation of a GPCR receptor localized on enterochromaffin cells (free fatty acid 2) increases 5-HT release, and $5-\mathrm{HT}_{4}$ receptors localized on epithelial cells and afferent neurons stimulate $\mathrm{HCO}_{3}^{-}$secretion (Akiba et al., 2015).

4. Visceral Pain. Tegaserod, a 5- $\mathrm{HT}_{4}$ receptor agonist, administered orally in human reduces abdominal pain and discomfort (De Maeyer et al., 2008b; Sanger, 2008). Because tegaserod is also a $5-\mathrm{HT}_{2 \mathrm{~B}}$ receptor antagonist, its exact mechanism of action is not clear. Hoffman et al. (2012) found that on a colorectal distension model of visceral pain, a more selective $5-\mathrm{HT}_{4}$ receptor agonist (naronapride) is also active and that both tegaserod and naronapride effects were blocked by a $5-\mathrm{HT}_{4}$ receptor antagonist. The mechanism of this antivisceral pain action of 5- $\mathrm{HT}_{4}$ receptor agonists is unknown.

5. Enteric Nervous System Development and Enteric Nervous System Adult Neurogenesis. $5-\mathrm{HT}_{4}$ receptors are important in the early development of enteric neurons, whose number increases through 4 months of age (Gershon, 2013). In mice lacking $5-\mathrm{HT}_{4}$ receptors (KO), the early increase fails, and the later decline is more severe. $5-\mathrm{HT}_{4}$ receptors specifically protect cultured enteric neurons from apoptosis and also activate CREB (Liu et al., 2009). In adults, 5- $\mathrm{HT}_{4}$ receptors are also able to stimulate neurogenesis in mice (Gershon, 2011). Adult neurogenesis appears to only start when ENS is injured, either following rectal transection and end-to-end anastomosis or chemical ablation with, for example, benzalkonium chloride (Matsuyoshi et al., 2010; Laranjeira et al., 2011). In the former model, mosapride, a $5-\mathrm{HT}_{4}$ receptor agonist, promoted the regeneration of the neural circuit in the impaired myenteric plexus and the recovery of the defecation reflex in the distal gut (Matsuyoshi et al., 2010; Kawahara et al., 2012).

6. Central Nervous System.

a. Learning and memory. One of the first roles of $5-\mathrm{HT}_{4}$ receptors in vivo was their promnesic effect in rat, mouse, monkey, and human (Eglen et al., 1995b; Bockaert et al., 2008, 2011; Haahr et al., 2013; Meneses, 2015). Procognitive effects of $5-\mathrm{HT}_{4}$ receptor agonists have been described, both on short-term memory (such as social olfactory memory) and on long-term olfactory memory (such as olfactory associative memory). Acute treatments with $5-\mathrm{HT}_{4}$ receptor agonists induced an increase in memory acquisition in autoshaping task, object and social recognition, Morris water-maze, task with long intertrial intervals ( 2 hours), delayed matching performance, and impeded spontaneous alteration scores (King et al., 2008; Bockaert et al., 2011). Chronic treatments also improve memory performance (Quiedeville et al., 2015) and increase working memory. Old rats have poor memory relative to adult rats that can be upgraded with $5-\mathrm{HT}_{4}$ receptor agonists, which are also reported to antagonize atropine- or scopolamine-induced learning and memory deficits in a variety of tasks, such as spatial navigation in Morris water maze, spontaneous alternation, and olfaction (Lamirault and Simon, 2001; Lelong et al., 2003; King et al., 2008; Marchetti et al., 2011). In $5-\mathrm{HT}_{4}$ receptor $\mathrm{KO}$ mice, the loss of learning and memory appears to be circumvented by adaptative changes in cholinergic systems (Buhot et al., 2003).

Hippocampal $5-\mathrm{HT}_{4}$ receptor expression correlates inversely with human memory (Haahr et al., 2013). The cellular basis of such learning and memory effects may be an increase in acetylcholine release found in frontal cortex and hippocampus, a complex modulation of synaptic plasticity (long-term potentiation and LTD) and a potentiation of learning-induced spine growth in the hippocampus [see Kemp and Manahan-Vaughan (2004), King et al. (2008), and Bockaert et al. (2011)]. Interestingly, the 5- $\mathrm{HT}_{4}$ receptor agonist SL65.0155 enhances simultaneous olfactory discrimination performance and potentiates learning-induced dendritic spine growth in the mouse hippocampus (Restivo et al., 2008). Finally, an association between $5-\mathrm{HT}_{4}$ receptor mRNA and protein expression in cortical areas, hippocampus, olfactory tubercles on one hand, and memory consolidation on the other hand has been reported (Manuel-Apolinar et al., 2005).

b. Control of mood and role of $5-H_{4} T_{4}$ receptor agonists. SSRIs are common drugs to treat depression that eventually increase tonic 5-HT release in relevant limbic structures such as the hippocampus. It has been established that stimulation of $5-\mathrm{HT}_{4}$ receptors localized on pyramidal mPFC stimulate the activity of a fraction of DRN 5-HT neurons (responder neurons with high-frequency discharges), an effect expected to result in a positive effect on mood behavior (Lucas and Debonnel, 2002; Lucas, 2009). Thus, 5- $\mathrm{HT}_{4}$ receptor agonists may have relatively fast antidepressant actions or may be used in combination to reduce the delay of action of SSRIs when given alone (Samuels et al., 2016).

$5-\mathrm{HT}_{4}$ receptors interact with $\mathrm{p} 11$, a protein that is downregulated in brain of depressed patients. This interaction is particularly clear in brain regions important for anxiety/depression and cognition such as the hippocampus (Warner-Schmidt et al., 2009; Egeland et al., 2011). The antidepressant-like activity of RS 67333, a $5-\mathrm{HT}_{4}$ receptor agonist, was abolished in $\mathrm{p} 11-\mathrm{KO}$ mice, which are known to have a depressive-like phenotype (Warner-Schmidt et al., 2009). 
Adult hippocampal neurogenesis in the subgranular zone has gained considerable attention in relation to mood and depression. The hypothesis is that a decrease in newborn dentate granule cell production leads to depression, whereas enhanced neurogenesis (proliferation, survival, and maturation) is required for treatment of depression (Duman and Monteggia, 2006; Samuels et al., 2016). Chronic antidepressant treatments, including SSRIs, stimulate adult hippocampal neurogenesis (proliferation of newborn cells as well as the survival and maturation of the young neurons). $5-\mathrm{HT}_{4}$ receptor agonists can also induce a rapid neurogenesis in the hippocampus in adult rodents (Duman and Monteggia, 2006; Pascual-Brazo et al., 2012; Ishizuka et al., 2014) and the synthesis of BDNF, a key growth factor implicated in antidepressant actions and neurogenesis. Interestingly, the $5-\mathrm{HT}_{4}$ receptor antagonist GR 125487 partially blocks the neurogenic effects of chronic fluoxetine treatment and its antidepressant and anxiolytic effects (Mendez-David et al., 2014), which may relate to a reduced hippocampal 5 -HT release evident with $5-\mathrm{HT}_{4}$ receptor antagonists (Ge and Barnes, 1996). In addition to neurogenesis, SSRIs can reverse neuronal maturation in the adult hippocampal granular cell neurons via $5-\mathrm{HT}_{4}$ receptormediated signaling (Kobayashi et al., 2010).

c. Feeding behavior. In $5-\mathrm{HT}_{4}$ receptor $\mathrm{KO}$ mice, the stress-induced hypophagia and novelty-induced exploratory activity were reduced (Compan et al., 2004). This suggests that $5-\mathrm{HT}_{4}$ receptors may be involved in stressinduced anorexia. Anorexia and bulimia are motivation disorders, which may implicate a reward structure such as nucleus accumbens that displays relatively high expression of $5-\mathrm{HT}_{4}$ receptors. Direct stimulation of $5-\mathrm{HT}_{4}$ receptors in the nucleus accumbens reduced the physiologic drive to eat and increased the mRNA of the anorectic peptide cocaine- and amphetamineregulated transcript in WT but not $\mathrm{KO}$ mice (Jean et al., 2007, 2012). 5- $\mathrm{HT}_{4}$ receptors control cocaine- and amphetamine-regulated transcript mRNA expression via a cAMP/PKA signaling pathway. Finally, intra-accumbal injection of 5- $\mathrm{HT}_{4}$ receptor antagonists or siRNA-mediated 5- $\mathrm{HT}_{4}$ receptor $\mathrm{KO}$ decrease satiety (Jean et al., 2007).

d. Cardiac system. 5 -HT via $5-\mathrm{HT}_{4}$ receptors induces cardioexcitation in atrial but not in ventricles of healthy humans and pig (Kaumann, 1990; Kaumann et al., 1991; Jahnel et al., 1992). However, an inotropic effect can also be found in human and porcine cardiac ventricle under phosphodiesterase inhibition (Brattelid et al., 2004b). In the atrium, 5- $\mathrm{HT}_{4}$ receptors activate and phosphorylate L-type $\mathrm{Ca}^{2+}$ channels via a cAMP/PKA signaling pathway (Ouadid et al., 1992; Kaumann and Levy, 2006). It has been proposed that atrial fibrillation, mediated by $5-\mathrm{HT}_{4}$ receptors, may occur in case of altered circulation during, for example, ageing (Kaumann and Levy, 2006). 5- $\mathrm{HT}_{4}$ receptors expressed in sinoatrial node in piglets, and possibly in humans, may be responsible for some 5-HT-mediated arrhythmias (Sanders and Kaumann, 1992). In addition, in failing human heart (Brattelid et al., 2004b), there is an upregulation of $5-\mathrm{HT}_{4}$ receptor mRNA level in ventricles accompanied by a $5-\mathrm{HT}_{4}$ receptor-mediated positive inotropic response to 5-HT. Similar observations have been reported in infarcted, failing, and hypertrophic rat hearts (Qvigstad et al., 2005a,c; Brattelid et al., 2007a). Note that $5-\mathrm{HT}_{4}$ receptors are not expressed in healthy rat ventricles. Because in those pathologies there is an increase in plasma 5-HT concentration, likely released from platelets, this may result in cardiotoxic effects mediated via $5-\mathrm{HT}_{4}$ receptors.

Cardiac remodeling in heart failure is characterized by activation of a fetal gene program. Indeed, Brattelid et al. (2012) found, in rat, that $5-\mathrm{HT}_{4}$ receptor mRNA expression and $5-\mathrm{HT}_{4}$ receptor-mediated inotropic response are augmented not only in heart failure but also in ventricles during late fetal development. In rodent cardiomyocytes, prucalopride responses, characterized by a high propensity to trigger diastolic $\mathrm{Ca}^{2+}$ events, absent in controls, can be achieved following BDNF and imipramine treatments (Meschin et al., 2015). Because both treatments increase expression of $\mathrm{p} 11$, the authors are logically proposing that it is $\mathrm{p} 11$ that upregulates $5-\mathrm{HT}_{4}$ receptor responses as seen in the brain. This is likely but not formally demonstrated in the report. The difference in p11 expression in human and rodent cardiomyocytes could explain their different responsiveness to $5-\mathrm{HT}_{4}$ receptor agonists. This remains to be demonstrated.

For further discussion, see XIX. 5-HT Receptors and the Cardiovascular System.

e. Respiratory system. At the level of the brainstem central respiratory center, the Pre-Boetzinger complex, $5-\mathrm{HT}_{4(\mathrm{a})}$ receptors via a cAMP signaling pathway, control respiration (Manzke et al., 2003). They stimulate phrenic nerve activity and respiratory minute volume. Thus, $5-\mathrm{HT}_{4}$ receptors are able to avert opioid-induced breathing depression, likely by having an opposing effect on the cAMP decrease induced by those drugs in the respiratory center (Manzke et al., 2003). Although noncoding variant SNPs in HTR4 are associated with pulmonary diseases in human genome?wide association studies (Hancock et al., 2010; Repapi et al., 2010; Soler Artigas et al., 2011; Hodge et al., 2013), the relatively low expression of $5-\mathrm{HT}_{4}$ receptors in lungs cast some doubt on the functional impact of $5-\mathrm{HT}_{4}$ receptors in pulmonary functions (Hodge et al., 2013). However, 5- $\mathrm{HT}_{4}$ receptor $\mathrm{KO}$ mice display an altered baseline lung function (lung resistance, tissue resistance, and tissue elastance) and an increase in methacholine and 5-HT-induced airway hyper-responsiveness (House et al., 2015).

f. Adrenal gland. In the human adrenal gland, $5-\mathrm{HT}_{4}$ receptors are mainly localized on zona glomerulosa (Lefebvre et al., 2015), which is consistent with 5 -HT stimulating preferentially aldosterone secretion 
rather than cortisol in vitro. Similarly, $5-\mathrm{HT}_{4}$ receptor agonists administered to healthy individuals increases plasma aldosterone levels without any change in plasma cortisol concentrations (Lefebvre et al., 2015).

g. Urinary bladder. Neuromuscular cholinergic transmission in human isolated detrusor muscle is facilitated by neural $5-\mathrm{HT}_{4}$ receptors (Tonini et al., 1994). In contrast, in urinary bladder strips from rhesus and Cynomolgus monkeys, experiments using direct electrical stimulation of bladder smooth muscle indicate that the $5-\mathrm{HT}_{4}$ receptors are located postjunctionally (Waikar et al., 1994).

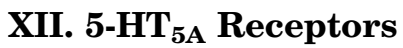

\section{A. Introduction}

In the early 1990s, the genes encoding the human and rodent $5-\mathrm{HT}_{5 \mathrm{~A}}$ receptor genes were cloned and localized. Subsequent work in the mid-1990s revealed the primary protein structure, expression pattern, and cellular function of the receptor using in vitro preparations (Plassat et al., 1992; Erlander et al., 1993; Matthes et al., 1993; Rees et al., 1994). Yet, the function of the receptor in vivo remained elusive until the early 2000s. By generating the Htr5A receptor knockout mouse, Grailhe et al. (1999, 2001) were the first to provide evidence of $5-\mathrm{HT}_{5 \mathrm{~A}}$ receptor function in vivo. Subsequently, an ex vivo approach was used to characterize the electrophysiological effects of 5 - $\mathrm{HT}_{5 \mathrm{~A}}$ receptors in native mouse and rat cortical brain tissue and the consequences of its deletion (Goodfellow et al., 2012), which led to the Receptor Nomenclature Committee promoting to receptor status (i.e., $5-\mathrm{ht}_{5 \mathrm{a}}$ to $5-\mathrm{HT}_{5 \mathrm{~A}}$ receptor). Though further investigations have been pursued in vivo (Curtin et al., 2013; Muñoz-Islas et al., 2014; Yamazaki et al., 2014, 2015), clinical examination has been severely limited by the lack of selective ligands.

\section{B. Gene and Primary Structure}

The human HTR5A is located on chromosome 7 at position 7q36 (Matthes et al., 1993). Partial sequencing revealed an intron-exon boundary located in the middle of the third cytoplasmic loop at exactly the same position as in the mouse and rat $5-\mathrm{HT}_{5 \mathrm{~A}}$ genes (Rees et al., 1994; Grailhe et al., 2001). The homologous mouse Htr5A is located on chromosome 5 at position 5B (Matthes et al., 1993). Partial sequence analysis revealed that the $5-\mathrm{HT}_{5 \mathrm{~A}}$ receptor gene contains an intron in the third cytoplasmic loop (Matthes et al., 1993), approximately $8 \mathrm{~kb}$ in length (Matthes et al., 1993). The human $5-\mathrm{HT}_{5 \mathrm{~A}}$ receptor, composed of a 1071-bp open reading frame, displays approximately $82 \%$ nucleotide homology with the mouse $5-\mathrm{HT}_{5 \mathrm{~A}}$ gene (Rees et al., 1994; Grailhe et al., 2001).

Polymorphisms in the $5-\mathrm{HT}_{5 \mathrm{~A}}$ receptor have been reported, including two nucleotide substitutions in the $5^{\prime}$ untranslated region and two synonymous substitutions in the coding region as well as a Pro15Ser amino acid substitution near the $\mathrm{N}$ terminus (Shimron-Abarbanell et al., 1997; Iwata et al., 1998; Birkett et al., 2000; Iwata et al., 2001; Arias et al., 2001; Dubertret et al., 2004). The latter polymorphism is proximal to a phosphorylation site and is located in a region likely involved in agonist-induced downregulation (Iwata et al., 1998; Thomas, 2006). Additional polymorphisms in the promoter region of the $5-\mathrm{HT}_{5 \mathrm{~A}}$ receptor have been identified (Zhang et al., 2010).

Hydropathy analysis revealed that the $5-\mathrm{HT}_{5 \mathrm{~A}}$ receptor contains seven hydrophobic domains (numbered I-VII), a classic feature of GPCRs (Plassat et al., 1992; Erlander et al., 1993; Matthes et al., 1993; Rees et al., 1994; Grailhe et al., 2001; Thomas et al., 2004). Sequencing analysis of the $5-\mathrm{HT}_{5 \mathrm{~A}}$ receptor protein uncovered a single long open reading frame and a poly A tail (Plassat et al., 1992; Matthes et al., 1993; Hurley et al., 1998; Grailhe et al., 2001; Thomas et al., 2004). The length of the $5-\mathrm{HT}_{5 \mathrm{~A}}$ receptor protein is 357 amino acids for the human, mouse, and rat proteins (Plassat et al., 1992; Erlander et al., 1993; Matthes et al., 1993; Rees et al., 1994; Hurley et al., 1998; Grailhe et al., 2001) but 356 amino acids in length for the guinea pig receptor (Thomas et al., 2004). In all species, the 5- $\mathrm{HT}_{5 \mathrm{~A}}$ receptors display $N$-linked glycosylation sites on the amino terminals as well as consensus phosphorylation sites for protein kinase $\mathrm{C}$ and protein kinase $\mathrm{A}$ on the presumed cytoplasmic domains (Plassat et al., 1992; Erlander et al., 1993; Grailhe et al., 2001).

\section{Expression Profile}

The $5-\mathrm{HT}_{5 \mathrm{~A}}$ receptor is expressed widely in the central nervous system (Plassat et al., 1992; Rees et al., 1994; Pasqualetti et al., 1998a; Grailhe et al., 2001; Kinsey et al., 2001; Tanaka et al., 2012; Fig. 21) but seemingly not in peripheral organs (Plassat et al., 1992; Rees et al., 1994; Grailhe et al., 2001). There is some controversy over its expression in the peripheral nervous system (Pierce et al., 1996; Chen et al., 1998a; Wang et al., 2000; Nicholson et al., 2003; Avila-Rojas et al., 2015).

In the human brain, the $5-\mathrm{HT}_{5 \mathrm{~A}}$ receptor mRNA expression has been reported in many regions of the cerebral cortex, including prefrontal, parietal, temporal, occipital, and entorhinal cortices (Pasqualetti et al., 1998b; Grailhe et al., 2001; Lambe et al., 2011; Fig. 22). The 5- $\mathrm{HT}_{5 \mathrm{~A}}$ mRNA was also detected in the hippocampus, the amygdala, the cerebellum, the striatum, the caudate nucleus, and the substantia nigra (Rees et al., 1994; Pasqualetti et al., 1998a; Grailhe et al., 2001; Fig. 22). Similar expression patterns have been reported in the mouse (Plassat et al., 1992; Tanaka et al., 2012) and the rat (Erlander et al., 1993; Kinsey et al., 2001; GarcíaAlcocer et al., 2010; Lopez-Esparza et al., 2015). Expression was also noted in the suprachiasmatic nucleus of the hypothalamus, raphe nuclei, the ventral tegmental area, 

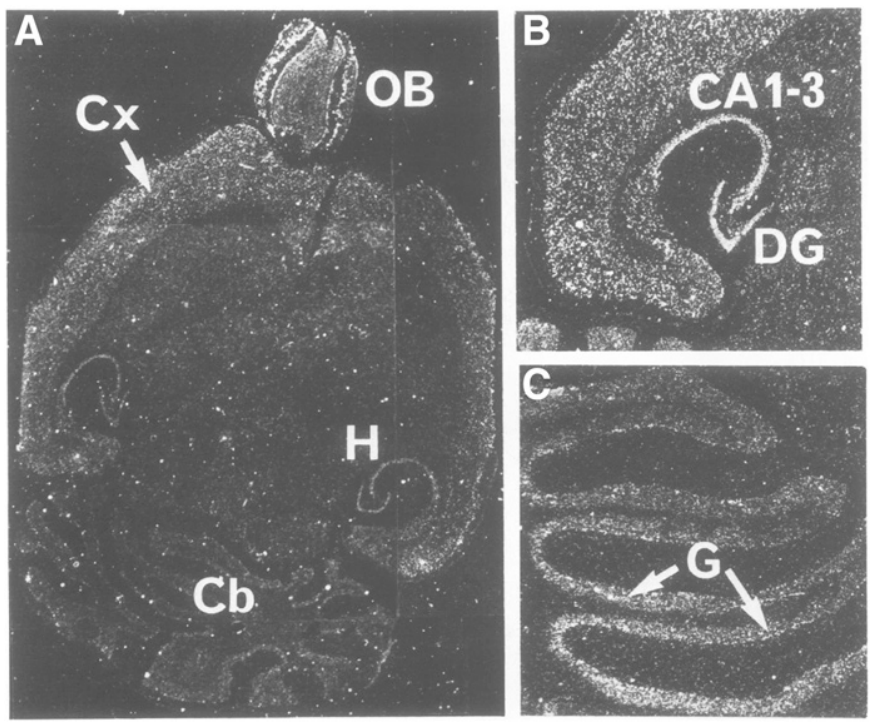

Fig. 21. In situ hybridization detection of $5-\mathrm{HT}_{5 \mathrm{~A}}$ receptor mRNA expression in mouse brain. (A) Dark field of the emulsion autoradiograph of a horizontal section through an adult mouse brain, with images at higher magnification showing (B) hippocampus and (C) cerebellum. CA13, CA fields of the hippocampus $\mathrm{CA}$; $\mathrm{Cb}$, cerebellum; $\mathrm{Cx}$, cerebral cortex; DG, dentate gyrus; G, granule cell layer of the cerebellum; $H$, hippocampus; OB, olfactory bulb. Adapted from Plassat et al. (1992) (with permission).

and the locus coeruleus (Duncan et al., 2000; Oliver et al., 2000). Because the 5- $\mathrm{HT}_{5 \mathrm{~A}}$ receptor mRNA has not been detected in astrocytes (Hirst et al., 1998), expression of this receptor in the central nervous system is likely restricted to neuronal cells, consistent with the morphology of cells expressing $5-\mathrm{HT}_{5 \mathrm{~A}}$ receptor immunoreactivity (Oliver et al., 2000).

\section{Post-translational Modifications and Impact}

Treatment with the $N$-glycosylation inhibitor tunicamycin fails to alter $\left[{ }^{3} \mathrm{H}\right] 5-\mathrm{HT}$ binding to the $5-\mathrm{HT}_{5 \mathrm{~A}}$ receptor yet results in redistribution of the $5-\mathrm{HT}_{5 \mathrm{~A}}$ receptor from the cell membrane to the intracellular compartment, suggesting that the $N$-glycosylation sites may play a role in targeting the $5-\mathrm{HT}_{5 \mathrm{~A}}$ receptor to the cell membrane (Dutton et al., 2008). Although both the N6 and N21 residues appear $N$-glycosylated within the mature human receptor protein, amino acid mutagenesis demonstrates that $N$-glycosylation of only the $\mathrm{N} 6$ residue results in protein insertion into the cell membrane (Dutton et al., 2008), a presumed prerequisite for receptor function.

\section{E. Pharmacology}

The psychedelic hallucinogen LSD binds to and stimulates the $5-\mathrm{HT}_{5 \mathrm{~A}}$ receptor with high affinity, as does another nonselective 5-HT receptor agonist, 5-CT. However, the quest to characterize the functions of the $5-\mathrm{HT}_{5 \mathrm{~A}}$ receptor in native tissue has been limited by a lack of selective agonists. Such characterization has relied on nonselective agonists in the presence of antagonists for other 5-HT receptors (Goodfellow et al., 2012).
Among selective antagonists for $5-\mathrm{HT}_{5 \mathrm{~A}}$ receptors, SB699551 (Corbett et al., 2005) has been most widely used in the literature (Table 17). It is important to note, however, that although SB-699551 possesses high affinity for the human and guinea pig $5-\mathrm{HT}_{5 \mathrm{~A}}$ receptor $\left(\sim \mathrm{p} K_{\mathrm{i}}\right.$ 8.3), it displays a 100 -fold lower affinity for the rat and mouse $5-\mathrm{HT}_{5 \mathrm{~A}}$ receptor $\left(\mathrm{p} K_{\mathrm{i}} 6.3\right.$; Thomas et al., 2006), limiting its utility in preclinical studies.

Other $5-\mathrm{HT}_{5 \mathrm{~A}}$ receptor antagonists have been proposed, including A-842377 (Garcia-Ladona et al., 2006) and 2-aminodihydroquinazolines (Peters et al., 2008). However, only SB699551 and a series of compounds, ASP5736 (Yamazaki et al., 2014, 2015), AS2030680, and AS2674723 (Yamazaki et al., 2015) have extensive published pharmacological validation. Nonselective antagonists for the 5- $\mathrm{HT}_{5 \mathrm{~A}}$ receptor include methiothepin and ritanserin (Thomas et al., 2004).

Based on rank order of affinity alone, the following in vitro pharmacological profile can be suggested for the human and mouse $5-\mathrm{HT}_{5 \mathrm{~A}}$ receptors: LSD (human $\mathrm{p} K_{\mathrm{i}}$ 8.40-8.70; mouse $\left.\mathrm{p} K_{\mathrm{i}} 9.10\right)>5$-CT (human $\mathrm{p} K_{\mathrm{i}} 7.6-8.28$; mouse $\left.\mathrm{p} K_{\mathrm{i}} 7.8\right)>5$-HT (human $\mathrm{p} K_{\mathrm{i}} 6.7-7.40 ;$ mouse $\mathrm{p} K_{\mathrm{i}}$ 6.6-7.12) > 8-OH-DPAT (human $\mathrm{p} K_{\mathrm{i}}$ 5.6-6.07; mouse $\mathrm{p} K_{\mathrm{i}}$ 6.13-5.9) (Plassat et al., 1992; Rees et al., 1994; Francken et al., 1998; Grailhe et al., 2001; Thomas et al., 2004). By contrast, the human and mouse $5-\mathrm{HT}_{5 \mathrm{~A}}$ receptors display low affinity for ketanserin, norepinephrine, dopamine, or spiperone $\left(\mathrm{p} K_{\mathrm{i}}<5\right)$ (Plassat et al., 1992; Rees et al., 1994; Francken et al., 1998).

\section{F. Function}

1. Cellular Function. Functional effects of $5-\mathrm{HT}_{5 \mathrm{~A}}$ receptors have been examined in cell systems, in native tissue, and in vivo. Broadly, these data suggest that the $5-\mathrm{HT}_{5 \mathrm{~A}}$ receptor can activate pertussis toxin-sensitive G proteins (Francken et al., 1998; Hurley et al., 1998; Thomas et al., 2004) and suppress adenylyl cyclase and production of cAMP (Francken et al., 1998; Hurley et al., 1998; Thomas et al., 2000; Noda et al., 2003). Electrophysiological examination in native rodent cerebral cortex is consistent with coupling to $\mathrm{G} \alpha_{\mathrm{i} / \mathrm{o}}$ proteins that activate Kir3 channels (Goodfellow et al., 2012). Studies in vivo indicate $5-\mathrm{HT}_{5 \mathrm{~A}}$ receptors may influence cognitive function and memory (Gonzalez et al., 2013; Yamazaki et al., 2014, 2015; Nikiforuk et al., 2016) and participate in acoustic startle circuitry (Curtin et al., 2013) and potentially antinociception (MuñozIslas et al., 2014).

2. $G$ Protein Coupling of the 5-HT $T_{5 A}$ Receptor In Vitro. To elaborate on the functional work in cell systems, treatment of cell lines transfected with the $5-\mathrm{HT}_{5 \mathrm{~A}}$ receptor with either 5-HT or 5-CT increases labeled GTP $\gamma \mathrm{S}$ binding (Francken et al., 1998; Hurley et al., 1998; Thomas et al., 2004), an effect that could be abolished by pretreatment with pertussis toxin (Francken et al., 1998; Thomas et al., 2004). Conversely, pretreatment of the nonhydrolysable GTP analog, Gpp(NH)p, 

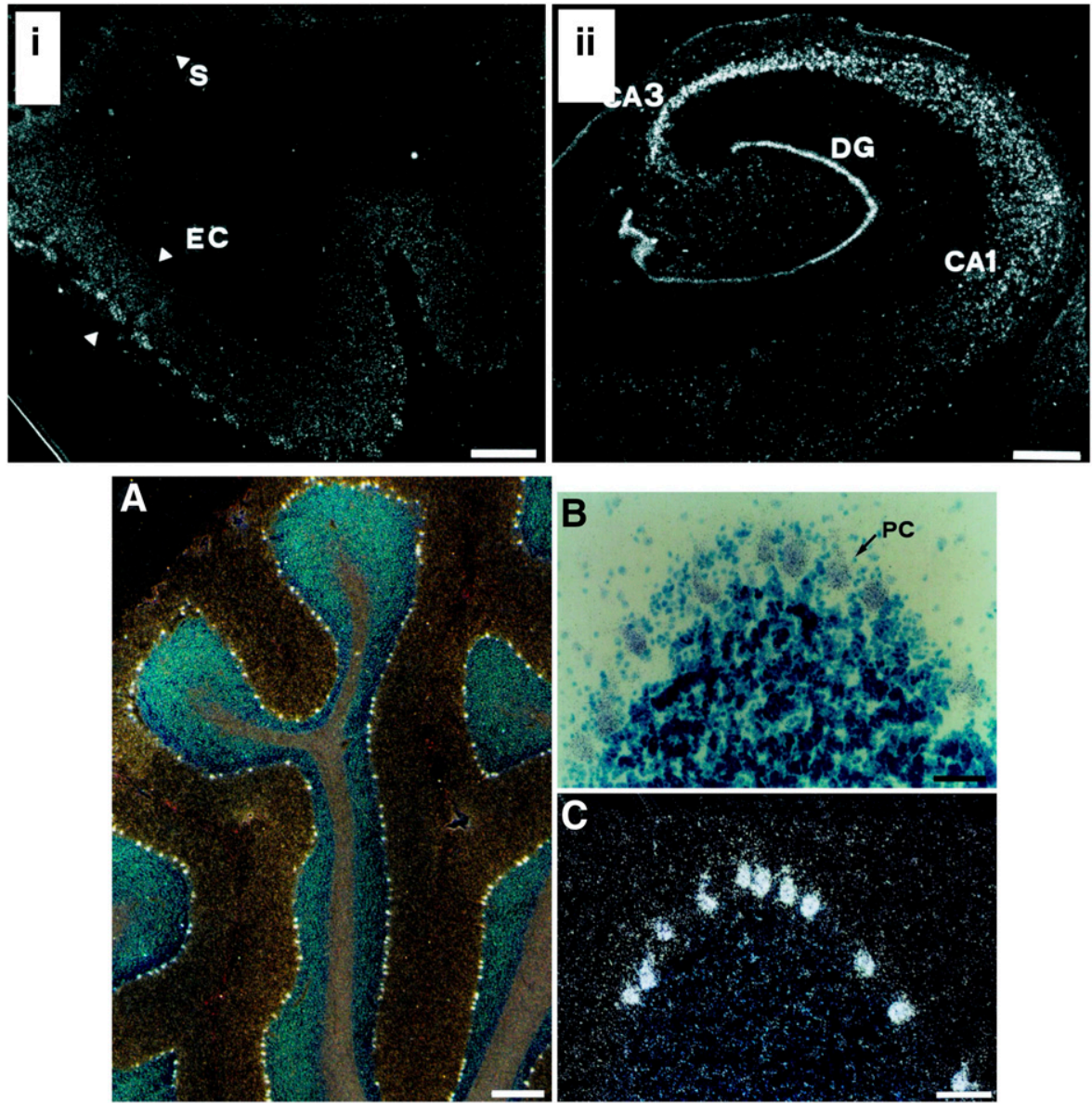

Fig. 22. In situ hybridization detection of 5- $\mathrm{HT}_{5 \mathrm{~A}}$ receptor mRNA expression in human brain. (i and ii) Dark-field autoradiographs of coronal sections of human hippocampus and surrounding regions. CA1, CA3 fields and the dentate gyrus (DG) of hippocampus, entorhinal cortex (EC), and subiculum (S). Scale bars, $0.2 \mathrm{~cm}$. (A) Dark-field autoradiograph of a coronal section of the cerebellar cortex: the Purkinje cells are heavily labeled [high magnification of Purkinje cells in bright-field (B) and dark-field (C)]. Scale bars, $600 \mu \mathrm{m}$ (A), $500 \mu \mathrm{m}$ (B), and $900 \mu \mathrm{m}$ (C). Adapted from Pasqualetti et al. (1998b) (with permission).

reduced the high affinity binding of $\left[{ }^{3} \mathrm{H}\right] 5-\mathrm{CT}$ in transfected HEK293 cells (Francken et al., 1998). Moreover, stimulation of the $5-\mathrm{HT}_{5 \mathrm{~A}}$ receptor with 5 - $\mathrm{HT}$ can reduce the basal activity of adenylyl cyclase (Noda et al., 2003) and inhibit forskolin-induced formation of cAMP in both C6 glioma and HEK293 cell lines (Francken et al., 1998;

TABLE 17

Affinities of selective antagonists at 5- $\mathrm{HT}_{5 \mathrm{~A}}$ and other 5 -HT receptors

Adapted from data reported in Corbett et al. (2005) (for SB699551; compound 11a), Thomas (2006) (for SB699551), and Yamazaki et al. (2015) (for ASP5736, AS2030680,

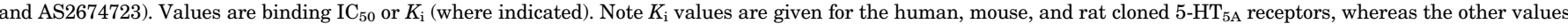
have been reported mainly for the human receptor (also see Thomas et al., 2004 for guinea pig values).

\begin{tabular}{|c|c|c|c|c|c|}
\hline Receptor & Species & SB699551 & ASP5736 & AS2030680 & AS2674723 \\
\hline $5-\mathrm{HT}_{1 \mathrm{~A}}$ & Human & $K_{\mathrm{i}}=501 \mathrm{nM}$ & $>1000 \mathrm{nM}$ & $K_{\mathrm{i}}=21 \mathrm{nM}^{a}$ & $K_{\mathrm{i}}=84 \mathrm{nM}$ \\
\hline $5-\mathrm{HT}_{1 \mathrm{~B}}$ & Human & $K_{\mathrm{i}}=316 \mathrm{nM}$ & NR & NR & NR \\
\hline $5-\mathrm{HT}_{1 \mathrm{D}}$ & Human & $K_{\mathrm{i}}=398 \mathrm{nM}$ & NR & NR & NR \\
\hline $5-\mathrm{ht}_{1 \mathrm{e}}$ & Human & $K_{\mathrm{i}}>1000 \mathrm{nM}$ & $\mathrm{NR}$ & $\mathrm{NR}$ & NR \\
\hline $5-\mathrm{HT}_{1 \mathrm{~F}}$ & Human & $K_{\mathrm{i}}>1000 \mathrm{nM}$ & NR & NR & NR \\
\hline $5-\mathrm{HT}_{2 \mathrm{~A}}$ & Human & $K_{\mathrm{i}}=794 \mathrm{nM}$ & $>1000 \mathrm{nM}$ & $>300 \mathrm{nM}$ & $>300 \mathrm{nM}$ \\
\hline $5-\mathrm{HT}_{2 \mathrm{~B}}$ & Human & $K_{\mathrm{i}}=1000 \mathrm{nM}$ & $>1000 \mathrm{nM}$ & $K_{\mathrm{i}}=22 \mathrm{nM}^{a}$ & $>300 \mathrm{nM}$ \\
\hline $5-\mathrm{HT}_{2 \mathrm{C}}$ & Human & $K_{\mathrm{i}}=398 \mathrm{nM}$ & $K_{\mathrm{i}}=287 \mathrm{nM}$ & $>300 \mathrm{nM}$ & $>300 \mathrm{nM}$ \\
\hline $5-\mathrm{HT}_{3}$ & Human & NR & $>1000 \mathrm{nM}$ & $>100 \mathrm{nM}$ & $>300 \mathrm{nM}$ \\
\hline $5-\mathrm{HT}_{4}$ & Guinea pig & $\mathrm{NR}$ & $>1000 \mathrm{nM}$ & $>100 \mathrm{nM}$ & $>300 \mathrm{nM}$ \\
\hline $5-\mathrm{HT}_{5 \mathrm{~A}}$ & Human & $K_{\mathrm{i}}=3-6 \mathrm{nM}^{a}$ & $K_{\mathrm{i}}=4 \mathrm{nM}^{a}$ & $K_{\mathrm{i}}=1 \mathrm{nM}^{a}$ & $K_{\mathrm{i}}=1 \mathrm{nM}^{a}$ \\
\hline $5-\mathrm{HT}_{5 \mathrm{~A}}$ & Rat & $K_{\mathrm{i}}=501 \mathrm{nM}$ & $K_{\mathrm{i}}=2 \mathrm{nM}^{a}$ & $K_{\mathrm{i}}=1 \mathrm{nM}^{a}$ & $K_{\mathrm{i}}=1 \mathrm{nM}^{a}$ \\
\hline $5-\mathrm{HT}_{5 \mathrm{~A}}$ & Mouse & $K_{\mathrm{i}}=501 \mathrm{nM}$ & $K_{\mathrm{i}}=4 \mathrm{nM}^{a}$ & $K_{\mathrm{i}}=3 \mathrm{nM}^{a}$ & $K_{\mathrm{i}}=2 \mathrm{nM}^{a}$ \\
\hline $5-\mathrm{HT}_{6}$ & Human & $K_{\mathrm{i}}>1000 \mathrm{nM}$ & $>1000 \mathrm{nM}$ & $K_{\mathrm{i}}=39 \mathrm{nM}$ & $>300 \mathrm{nM}$ \\
\hline $5-\mathrm{HT}_{7}$ & Human & $K_{\mathrm{i}}>1000 \mathrm{nM}$ & $K_{\mathrm{i}}=123 \mathrm{nM}$ & $K_{\mathrm{i}}=10 \mathrm{nM}^{a}$ & $K_{\mathrm{i}}=7 \mathrm{nM}^{a}$ \\
\hline
\end{tabular}

NR, not reported.

${ }^{a}$ High affinity binding at $5-\mathrm{HT}_{5 \mathrm{~A}}$ receptors or medium- to high-affinity nonselective binding. 
Hurley et al., 1998; Thomas et al., 2000; Noda et al., 2003). Moreover, pretreatment with pertussis toxin prevented this 5-HT-elicited inhibition of basal adenylyl cyclase activity (Noda et al., 2003). These findings are also consistent with the $5-\mathrm{HT}_{5 \mathrm{~A}}$ receptor coupling to a $\mathrm{G} \alpha \mathrm{i} / \mathrm{o}$ protein pathway. However, this inhibitory effect of the $5-\mathrm{HT}_{5 \mathrm{~A}}$ receptor on cAMP could not be replicated in transfected HeLa or COS-M6 cells (Erlander et al., 1993). Similarly, in both HEK and NIH-3T3 cell lines, stimulation of the transfected $5-\mathrm{HT}_{5 \mathrm{~A}}$ receptors had no detectable effect in basal cAMP levels, forskolin-induced cAMP levels, or accumulation of inositol phosphates (Grailhe et al., 2001). In C6 glioma cells, 5- $\mathrm{HT}_{5 \mathrm{~A}}$ receptor has been shown to inhibit ADP-ribosyl cylase activity in response to 5-HT, an effect that was abolished following pretreatment with pertussis toxin (Noda et al., 2003).

3. G Protein Coupling of the 5-HT $T_{5 A}$ Receptor Ex Vivo. Research in native tissue has shown that cerebral cortical 5- $\mathrm{HT}_{5 \mathrm{~A}}$ receptors couple to $\mathrm{G}$ proteins and has assessed the electrophysiological consequences of such coupling. In the presence of clozapine and spiperone, cortical slices from wild-type mice display a rightward shift of the $\left[{ }^{3} \mathrm{H}\right] 5$-CT binding following pretreatment with $\mathrm{Gpp}(\mathrm{NH}) \mathrm{p}$, suggesting that in the native system, the $5-\mathrm{HT}_{5 \mathrm{~A}}$ receptor is coupled to $\mathrm{G}$ proteins (Waeber et al., 1998). The 5- $\mathrm{HT}_{5 \mathrm{~A}}$ receptor-activated ion current has been characterized in native prefrontal cortical tissue of both rats and mice (Goodfellow et al., 2012). The native $5-\mathrm{HT}_{5 \mathrm{~A}}$ receptor produces a small outward current that has a potent inhibitory effect on excitability of layer $\mathrm{V}$ pyramidal neurons of the prefrontal cortex. 5 -HT has submicromolar potency at the native $5-\mathrm{HT}_{5 \mathrm{~A}}$ receptor and activates inwardly rectifying potassium channels (Goodfellow et al., 2012).

4. 5-HT $T_{5 A}$ Receptor Function in the Spinal Cord. Spinal $5-\mathrm{HT}_{5 \mathrm{~A}}$ receptors are upregulated by painful stimuli (Muñoz-Islas et al., 2014) and have been suggested to participate in antinociception and pain (Doly et a., 2004; Muñoz-Islas et al., 2014; Avila-Rojas et al., 2015). Their spinal localization suggests possible motor, somatosensory, and autonomic functions (Doly et al., 2004).

5. Function In Vivo. Grailhe et al. (1999) generated $5-\mathrm{HT}_{5 \mathrm{~A}}$ receptor knockout mice. In terms of its biologic phenotype, the central nervous system of the $5-\mathrm{HT}_{5 \mathrm{~A}}$ receptor knockout mice appeared normal. There were no major differences in the cytoarchitectonic divisions, neuronal morphology, or distribution of glia (Grailhe et al., 1999). Moreover, $5-\mathrm{HT}_{5 \mathrm{~A}}$ receptor knockout mice display no differences in the distribution of neuronal markers for the monoaminergic system, calcium binding protein, neuropeptides, nitric oxide synathase, or amino acid receptor subunits (Grailhe et al., 1999).

There appears to be the potential for significant cross talk between $5-\mathrm{HT}_{5 \mathrm{~A}}$ receptors and $5-\mathrm{HT}_{1 \mathrm{~A}}$ receptors in cerebral cortex given their electrophysiological function (Goodfellow et al., 2012, 2014). In mice constitutively deleted for Htr5A, however, there were striking, supracompensatory changes in the magnitude of the prefrontal $5-\mathrm{HT}_{1 \mathrm{~A}}$ receptor currents, with $5-\mathrm{HT}_{5 \mathrm{~A}}$ receptor knockout mice displaying nearly a doubling of the $5-\mathrm{HT}_{1 \mathrm{~A}}$ receptor outward current in layer $\mathrm{V}$ neurons from the prefrontal cortex (Goodfellow et al., 2012). The mechanism underlying this homeostatic plasticity is unknown. Further electrophysiological examination of $5-\mathrm{HT}_{5 \mathrm{~A}}$ receptor knockout mice revealed no difference in $\mathrm{GABA}_{\mathrm{B}}$ receptor-mediated outward current, $5-\mathrm{HT}_{1 \mathrm{~A}}$ receptor protein levels, or cell intrinsic properties in the adult prefrontal cortical neurons (Goodfellow et al., 2012).

Mice deleted for Htr5A display an increase of explorative-like behaviors, rather than anxiety-like behaviors, on the open field, the elevated plus maze, and the marble burying task (Grailhe et al., 1999). Moreover, $5-\mathrm{HT}_{5 \mathrm{~A}}$ receptor knockout mice display greater increase in the number of entries into the central region after the introduction of the novel object into the center of the open field, suggesting an increase in "inspective" explorative-like behaviors (Grailhe et al., 1999). In addition, 5- $\mathrm{HT}_{5 \mathrm{~A}}$ receptor knockout mice displayed a reduction on LSD-elicited increase in locomotion in the open field (Grailhe et al., 1999). These changes occurred in the absence of any difference in motor activity (Grailhe et al., 1999). Given the evident considerable homeostatic plasticity detected in the cerebral cortex of the $5-\mathrm{HT}_{5 \mathrm{~A}}$ receptor knockout mice (strong upregulation of $5-\mathrm{HT}_{1 \mathrm{~A}}$ receptor-mediated effects; Goodfellow et al., 2012), the behavioral characterization of the $5-\mathrm{HT}_{5 \mathrm{~A}}$ receptor knockout may underestimate its behavioral effects.

\section{G. Clinical Relevance}

The $5-\mathrm{HT}_{5 \mathrm{~A}}$ receptors are positioned neuroanatomically to play a role in emotional regulation, cognition, antinociception, and control of circadian rhythms and metabolism (Plassat et al., 1992; Pasqualetti et al., 1998a,b; Oliver et al., 2000; Duncan et al., 2000; Grailhe et al., 2001; Doly et al., 2004; Lambe et al., 2011; Tanaka et al., 2012). Unfortunately, clinical examination of $5-\mathrm{HT}_{5 \mathrm{~A}}$ receptors has been restricted by the lack of selective ligands.

1. Psychosis and Depression. A nonsynonomous SNP (Pro15Ser) in the HTR5A gene has been linked to schizophrenia (Iwata et al., 2001; Dubertret et al., 2004) and depression (Birkett et al., 2000), and polymorphisms in the promoter region of the $5-\mathrm{HT}_{5 \mathrm{~A}}$ receptor link to elevated triglyceride levels (Zhang et al., 2010). The high affinity of the psychedelic hallucinogen LSD for the $5-\mathrm{HT}_{5 \mathrm{~A}}$ receptor also underscores a potential link to psychosis (Thomas, 2006), keeping in mind that LSD, like many other ergolines, has affinity for multiple 5-HT receptors, of which only the $5-\mathrm{HT}_{2 \mathrm{~A}}$ receptor has been shown to play a significant role in hallucinations or psychosis. Yet in additional relevance to schizophrenia, 
$5-\mathrm{HT}_{5 \mathrm{~A}}$ receptors have been suggested to participate in prepulse inhibition of the acoustic startle response (Curtin et al., 2013). This effect was demonstrated in goldfish with SB-699551 and with A-843277. The latter compound has been reported to have antipsychotic and antidepressant properties in rodent models, in line with the distribution of the receptor in higher cortical and limbic regions (Garcia-Ladona et al., 2006; Jongen-Relo et al., 2006; but see Kassai et al., 2012). Recent work suggests that blocking $5-\mathrm{HT}_{5 \mathrm{~A}}$ receptors may ameliorate positive symptoms in a rodent model of schizophrenia and will potentially enhance cognition and social behavior in such models (Yamazaki et al., 2014; Nikiforuk et al., 2016). It may be relevant that the atypical antipsychotic drug asenapine has high affinity for h5$\mathrm{HT}_{5 \mathrm{~A}}$ receptors (along with a number of other receptors; Shahid et al., 2009).

2. Memory and Circadian Rhythm. Yamazaki et al. $(2014,2015)$ demonstrated the $5-\mathrm{HT}_{5 \mathrm{~A}}$ receptor antagonists (ASP5736, AS2030680, and AS2674723; Table 17) benefit memory, supporting a role for $5-\mathrm{HT}_{5 \mathrm{~A}}$ receptors in memory consolidation (Gonzalez et al., 2013). Additional preclinical work focuses on the localization of $5-\mathrm{HT}_{5 \mathrm{~A}}$ receptors in the hypothalamus, where it is densely expressed in the suprachiasmatic nucleus (Oliver et al., 2000; Duncan et al., 2000), suggesting potential roles in circadian rhythm and metabolism.

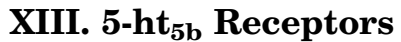

\section{A. Introduction}

The genes encoding the human and rodent $5-\mathrm{ht}_{5 \mathrm{~b}}$ receptor were identified in 1993 . The human 5 -ht $t_{5 b}$ receptor gene $H T R 5 B$ is located on chromosome 2 at position 1q11-13 (Matthes et al., 1993). However, this gene contains stop codons in exon I, resulting in a transcriptional product likely yielding a presumed nonfunctional truncated protein (Grailhe et al., 2001). The mouse 5 -ht $_{5 \mathrm{~b}}$ receptor gene Htr5B is located on chromosome 1 at position $1 \mathrm{~F}$ (Matthes et al., 1993) and forms a functional protein upon heterologous expression. Partial sequence analysis revealed that the $5-\mathrm{ht}_{5 \mathrm{~b}}$ receptor gene contained an intron in the third cytoplasmic loop (Matthes et al., 1993; Grailhe et al., 2001).

\section{B. Receptor Structure}

Using hydropathy analysis, the predicted $5-\mathrm{ht}_{5 \mathrm{~b}}$ receptor protein has been shown to contain seven hydrophobic domains (numbered I-VII), a classic feature of GPCRs (Plassat et al., 1992, 1992; Erlander et al., 1993; Matthes et al., 1993; Wisden et al., 1993; Rees et al., 1994; Grailhe et al., 2001). Sequencing analysis of the 5 -ht $_{5 \mathrm{~b}}$ receptor protein revealed a single long open reading frame and a poly A tail (Erlander et al., 1993; Matthes et al., 1993; Wisden et al., 1993). The length of the $5-\mathrm{ht}_{5 \mathrm{~b}}$ receptor is 370 amino acids in both the rat and mouse protein (Erlander et al., 1993; Matthes et al., 1993; Wisden et al., 1993).

\section{Expression Profile}

The $5-\mathrm{ht}_{5 \mathrm{~b}}$ receptor has a restricted expression profile within the central nervous system. In the rodent, expression of the $5-\mathrm{ht}_{5 \mathrm{~b}}$ receptor is exclusively found in the CA1 field of the hippocampus, the habenula, the inferior olivary nucleus, and the raphe nuclei (Erlander et al., 1993; Matthes et al., 1993; Wisden et al., 1993; Kinsey et al., 2001; Serrats et al., 2004, 2004; Tanaka et al., 2012; Fig. 23). Interestingly, the 5 -ht $_{5 \mathrm{~b}}$ receptor mRNA was strongly expressed in the medial portion of the raphe nuclei and was found to have high coexpression with 5-HT transporter, suggesting that this receptor may be localized on 5-HT-producing neurons (Erlander et al., 1993; Matthes et al., 1993; Wisden et al., 1993; Serrats et al., 2004; Fig. 24). Expression of the 5-ht ${ }_{5 \mathrm{~b}}$ receptor has not been detected in any peripheral organs, including the heart, kidney, lung, liver, or intestine (Erlander et al., 1993; Matthes et al., 1993; Wisden et al., 1993). Evidence for the 5 -ht $_{5 \mathrm{~b}}$ receptor being expressed primarily in endosomes rather than the cell membrane raises potentially novel mechanisms of the functional relevance of this protein (Niebert et al., 2017) by impacting cell membrane expression of the $5-\mathrm{HT}_{1 \mathrm{~A}}$ receptor via intracellular direct protein-protein interaction.

\section{Regulatory Mechanisms and Post- translational Modifications}

The 5 -ht $_{5 \mathrm{~b}}$ gene expression is regulated by the transcription factor ATF-7, which can directly bind to the 5 -ht $t_{5 \mathrm{~b}}$ promoter region, resulting in histone methylation and, ultimately, silencing of the receptor gene transcription (Maekawa et al., 2010). The 5-ht ${ }_{5 b}$ receptor displays $N$-linked glycosylation sites on the amino-terminal end as well as consensus phosphorylation sites for protein kinase $\mathrm{C}$ and protein kinase $\mathrm{A}$ on the presumed cytoplasmic domains (Erlander et al., 1993; Matthes et al., 1993; Wisden et al., 1993).

\section{E. Pharmacology}

To date, selective ligands for the 5 -ht 5 b receptor have not been reported. Nonselective agonists include LSD and 5-CT, and a nonselective antagonist is methiothepin. Based on affinity alone, the following in vitro pharmacological profile can be suggested for rodent 5 -ht $_{5 \mathrm{~b}}$ receptors: LSD (rat pKi 7.49), 5-CT (mouse pKi 7.4; rat pKi 6.26-8.88), and methiothepin (mouse pKi 7.8; rat pKi 7.35-8.87) but low affinity for ketanserin, dopamine, and norepinephrine (Matthes et al., 1993).

\section{F. Function at Cellular, Tissue, and In Vivo Levels}

The transduction pathway of the 5 -ht $_{5 \mathrm{~b}}$ receptor has not been well examined. Pretreatment with $\mathrm{Gpp}(\mathrm{NH}) \mathrm{p}$ reduced $\left[{ }^{3} \mathrm{H}\right] 5-\mathrm{CT}$ binding in 5 -ht $\mathrm{t}_{5 \mathrm{~b}}$-transfected COS1 cells, suggesting that the $5-\mathrm{ht}_{5 \mathrm{~b}}$ receptor readily couples 

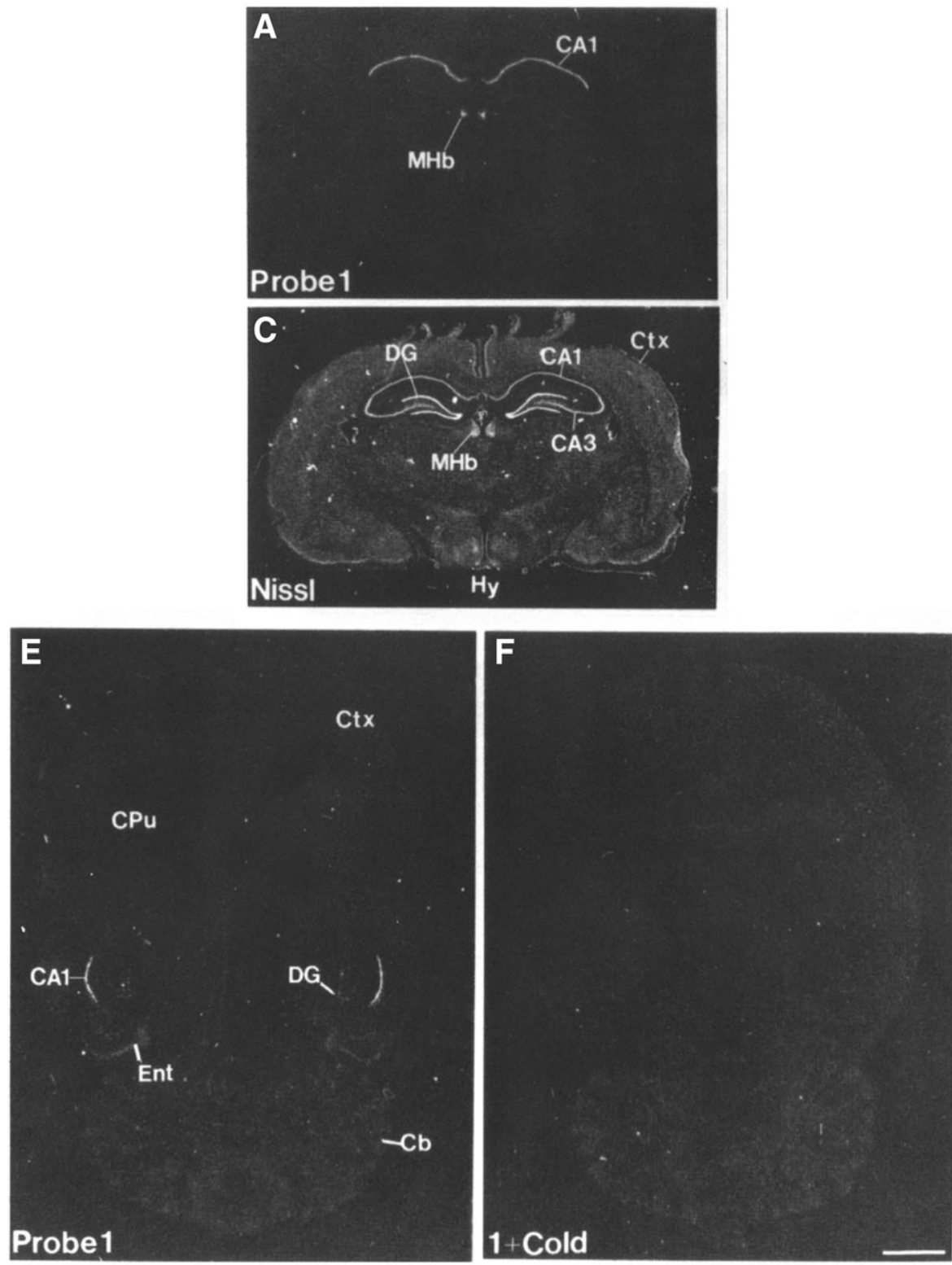

Fig. 23. In situ hybridization detection of 5 -ht $t_{5 b}$ receptor mRNA expression in rat brain. Coronal (A) and horizontal (E) rat brain sections. (C) Nissl stain of the section used to generate the autoradiogram in (A). (F) Radioactive oligonucleotide probe in the presence of excess unlabeled probe. CA1 and $\mathrm{CA} 3$, CA fields of the hippocampus; $\mathrm{Cb}$, cerebellum; $\mathrm{CPu}$, caudate-putamen; Ctx, cortex; DG, dentate granule cells; Ent, entorhinal cortex; Hy, hypothalamus; MHb, medial habenula. Adapted from Wisden et al. (1993) (with permission).

to $\mathrm{G}$ protein (Wisden et al., 1993). However, this receptor had no effect on basal cAMP levels in either HeLa or COSM6 cell lines (Erlander et al., 1993), although high levels of 5 -ht $_{5 \mathrm{~b}}$ expression in mouse brain are associated with low cAMP levels (Vogelgesang et al., 2017).

It is speculated that the $5-\mathrm{ht}_{5 \mathrm{~b}}$ receptor acts as an inhibitory autoreceptor on 5-HT neurons in the raphe in rodents. However, neither an electrophysiological nor pharmacological profile has been described for the 5 - $_{5 \mathrm{~b}}$ receptor in native tissue.

In a mouse model of Rett syndrome, there is a relatively high level of $5-\mathrm{ht}_{5 \mathrm{~b}}$ receptor expression in the brainstem because of a failure to downregulate receptor expression (Vogelgesang et al., 2017), with further studies suggesting a role for the $5-\mathrm{ht}_{5 \mathrm{~b}}$ receptor in the modulation of the complex breathing phenotype of the mouse model of Rett syndrome (Vogelgesang et al., 2018) as well a potential link to the native receptor inhibiting generation of cAMP.

\section{G. Clinical Relevance}

Functional 5 -ht 5 b receptors are likely not expressed in humans (Grailhe et al., 2001), which limits interest in this receptor particularly from the pharmaceutical industry.

\section{5-HT 6 Receptors}

\section{A. Introduction}

The 5- $\mathrm{HT}_{6}$ receptor has moderately high affinity for 5 -HT, with an apparent binding affinity of approximately $30 \mathrm{nM}$. The gene for the $5-\mathrm{HT}_{6}$ receptor was 

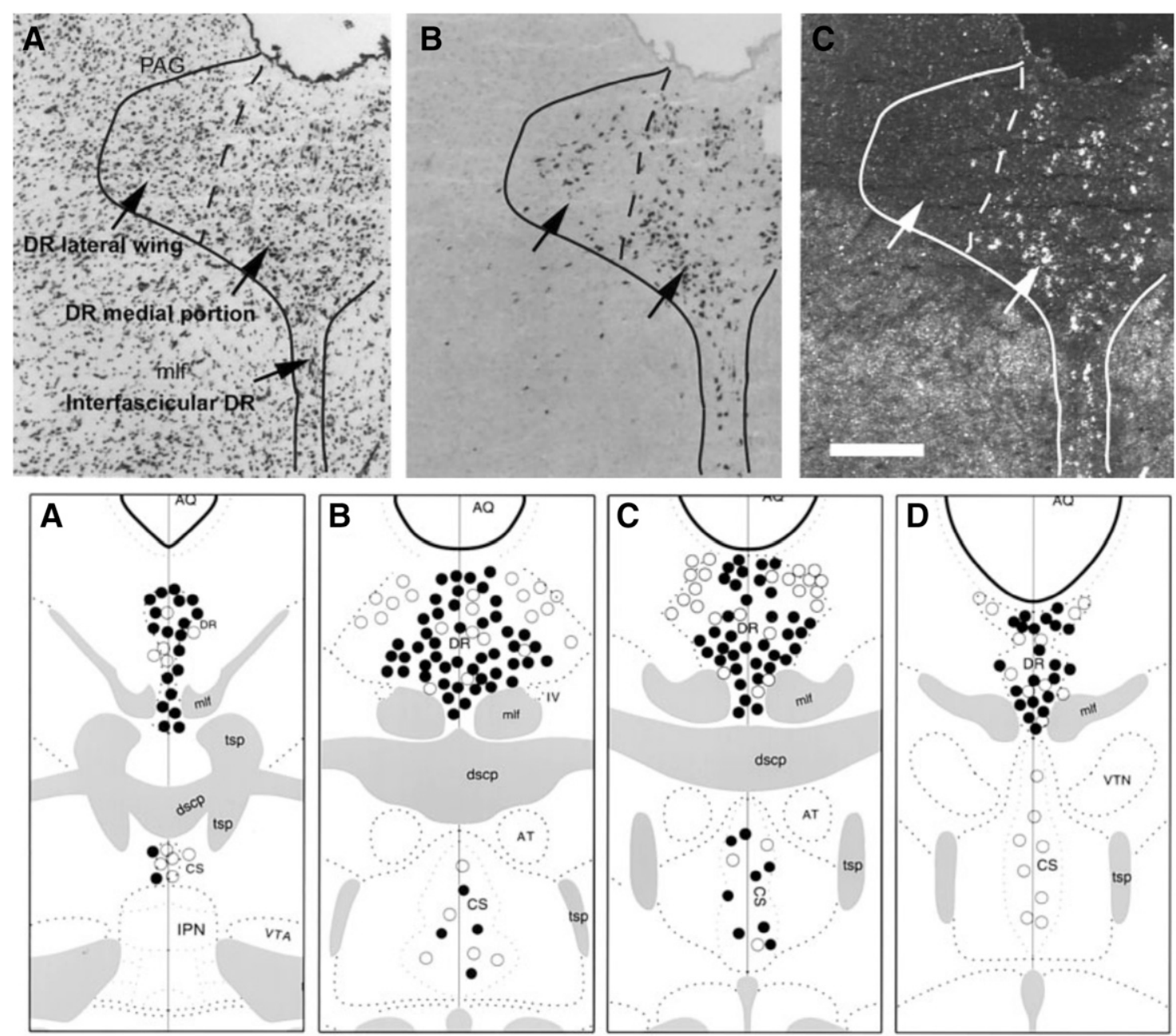

Fig. 24. Evidence for 5-HT raphe neurons expressing the 5-ht $t_{5 b}$ receptor. Top row: Visualization of 5-HTT and 5-ht $t_{5 b}$ receptor mRNAs in the dorsal raphe. (A) A consecutive section to (B and C), stained with cresyl violet for anatomic reference. The approximate limits of the dorsal raphe (DR) and its subdivisions-lateral wings and medial portion-are depicted. (B) a bright-field photomicrograph where numerous cell profiles express 5-HTT mRNA are visualized using digoxigenin-labeled oligonucleotide probes. (C) A dark-field photomicrograph from an emulsion-dipped tissue section displaying 5 -ht ${ }_{5 \mathrm{~b}}$ receptor mRNA signal in the DR. mlf, medial longitudinal fasciculus; PAG, periaqueductal gray. Scale bar, $0.5 \mathrm{~mm}$. Bottom row: Schematic representations of the rat lower midbrain and upper pons showing the subregional location of cells coexpressing 5-ht ${ }_{5 \mathrm{~b}}$ receptor mRNA and 5-HTT mRNA (filled circles) and cells expressing only 5-HTT mRNA (empty circles) in the DR and central superior nucleus (CS or median raphe). AQ, cerebral aqueduct; AT, anterior tegmental nucleus; dscp, decussation of the superior cerebellar peduncle; IPN, interpeduncular nucleus; tsp, tectospinal pathway; VTA, ventral tegmental area; VTN, ventral tegmental nucleus. Adapted from Serrats et al. (2004) (with permission).

originally cloned from rat in the early 1990s (Monsma et al., 1993; Ruat et al., 1993a) and later from human (Kohen et al., 1996) and mouse (Kohen et al., 2001) cDNA libraries; the human gene was located on chromosome 1 (Kohen et al., 1996). For each known species, the complete gene contains three exons and has a total length of around $14 \mathrm{~kb}$ with a coding sequence of approximately $1.4 \mathrm{~kb}$. The receptor protein is composed of 440 amino acids in humans and mice and 436 amino acids in rats; a sequencing error in the originally published rat sequence was later corrected (Kohen et al., 1996). In humans, there is one described polymorphism (a C267T variant; Masellis et al., 2001) as well as a truncated, nonfunctional splice variant (Olsen et al., 1999). No replicated polymorphisms in the human gene have been associated with human diseases, including schizophrenia, methamphetamine-associated psychosis, tardive dyskinesia, Alzheimer disease, obesity, or antidepressant drug responsiveness.

The protein structure of the $5-\mathrm{HT}_{6}$ receptor conforms to the typical motif of GPCRs with the typical seven transmembrane domain configuration. There have been no detailed investigations of whether this receptor exists in dimers or higher-order oligomers.

\section{B. Expression}

5 - $\mathrm{HT}_{6}$ receptor mRNA is expressed primarily in the brain (Fig. 25), being detectable in rat brain by day 12 of embryogenesis (Grimaldi et al., 1998). Originally, Northern blot analyses detected RNA transcripts in brain tissue with the following regional density profile: hypothalamus $>$ hippocampus $=$ mesencephalon $>$ cerebral cortex $=$ olfactory bulb $>$ olfactory tubercle (Monsma et al., 1993). Ruat et al. (1993a) also reported 
a very similar distribution, noting highest expression in dorsal and ventral striatum, olfactory tubercle, and hippocampus, with lower expression in stomach and very low to no expression detected in a variety of other peripheral tissues. Radioligand binding and immunohistochemical localization supported a similar distribution in rat and human brain (Gerard et al., 1997; Marazziti et al., 2013b). Using RT-PCR, Hirst et al. (2003) detected a similar distribution of $5-\mathrm{HT}_{6}$ receptor mRNA in various regions of rat and human brain, whereas mouse brain had much lower apparent levels of $5-\mathrm{HT}_{6}$ receptor mRNA and, unlike in other species, no enrichment in the basal ganglia. Specific binding of $\left[{ }^{125} \mathrm{I}\right]-\mathrm{SB} 258585$, a highly selective $5-\mathrm{HT}_{6}$ receptor radioligand, displayed the same patterns of regional localization, with substantially higher levels of $5-\mathrm{HT}_{6}$ receptors in striatum than in other regions in rats and humans but fairly homogenous levels of expression in all of the mouse brain regions that expressed $5-\mathrm{HT}_{6}$ receptors. Differences in $5-\mathrm{HT}_{6}$ receptor pharmacology between these species were evident but did not explain the disparate distributions of receptor expression, highlighting important species differences in $5-\mathrm{HT}_{6}$ receptor distribution (and pharmacology).

The cellular profile of expression has been examined in some detail in several brain regions. In the hippocampus and cortex, $5-\mathrm{HT}_{6}$ receptor mRNA is present in glutamatergic neurons containing vGluT1 mRNA as well as a subset of GABAergic interneurons that coexpress the $5-\mathrm{HT}_{3} \mathrm{~A}$ receptor; $5-\mathrm{HT}_{6}$ receptor mRNA is also detected in other classes of interneurons at a lower frequency (Helboe et al., 2015). 5- $\mathrm{HT}_{6}$ receptor immunoreactive glial cells have also been reported in human cortex (Lorke et al., 2006; Marazziti et al., 2013b). In striatum, 5- $\mathrm{HT}_{6}$ receptor mRNA is expressed in both direct and indirect pathway medium spiny neurons (Ward and Dorsa, 1996; Helboe et al., 2015) and occasionally in cholinergic interneurons (Bonsi et al., 2007; Helboe et al., 2015).

$5-\mathrm{HT}_{6}$ receptors are not presynaptic autoreceptors on 5-HT neurons, as $5-\mathrm{HT}_{6}$ receptor mRNA in rat is not altered by ablation of the DRN with 5,7dihydroxtryptamine (Gérard et al., 1996) and is not colocalized with SERT mRNA (Helboe et al., 2015). Nonetheless, their abundant expression on forebrain cortical neurons thought to project to DRN 5-HT neurons may explain how $5-\mathrm{HT}_{6}$ receptor ligands can modify 5-HT neuronal firing (see Electrophysiology below).

The localization of $5-\mathrm{HT}_{6}$ receptors within neurons is still somewhat controversial, perhaps because of differences in antibody specificity. Initial studies described
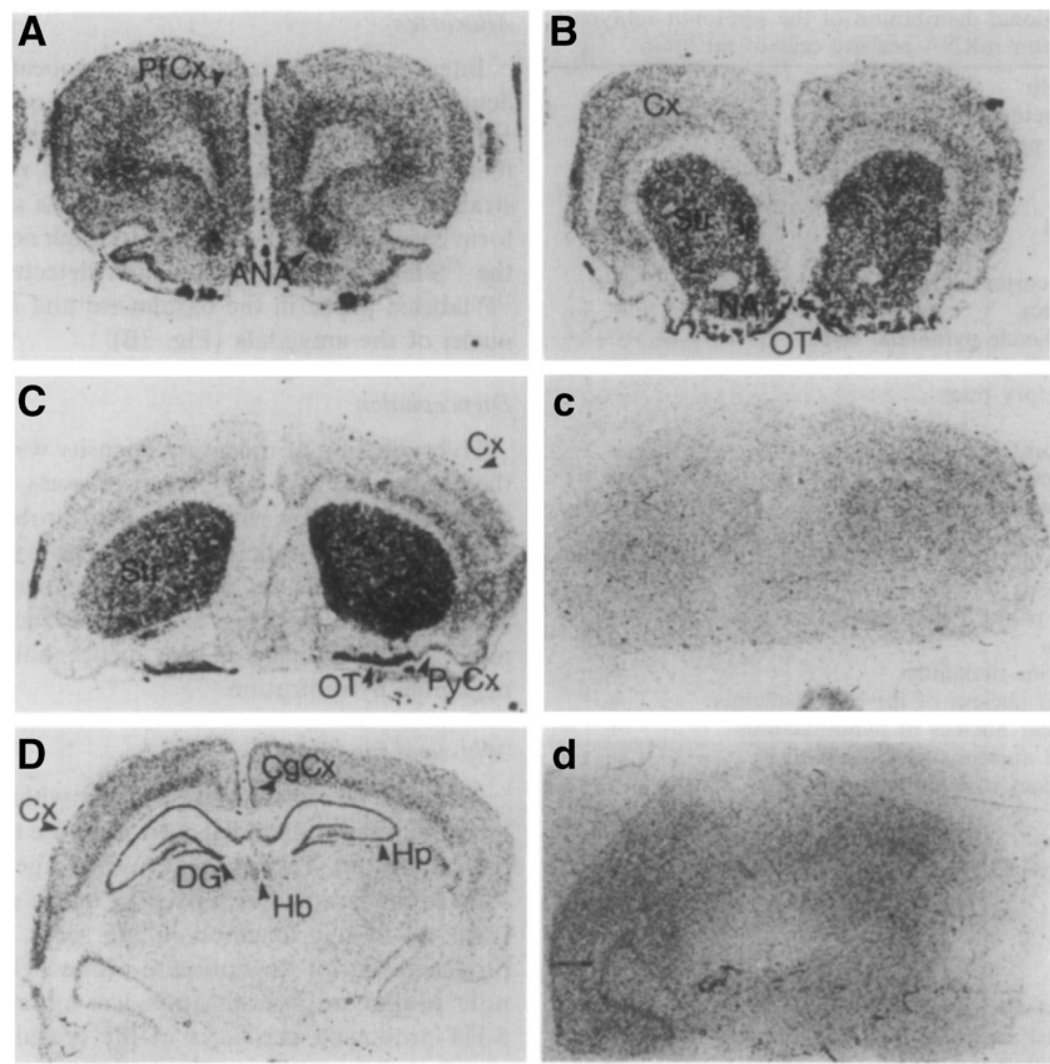

Fig. 25. In situ hybridization detection of 5- $\mathrm{HT}_{6}$ receptor mRNA expression in rat brain. Autoradiographic visualization of 5-HT $\mathrm{H}_{6}$ receptor mRNA in rat brain (A-D) and relative absence of signal when adjacent sections probed with the sense control (c and d). ANA, anterior nucleus accumbens; $\mathrm{CgCx}$, cingulate cortex; Cx, cortex; DG, dentate gyrus; Hb, habenula; Hp, hippocampus; OT, olfactory tubercle; PfCx, prefrontal cortex; PyCx, pyriform cortex. Adapted from Ward et al. (1995) (with permission). 
$5-\mathrm{HT}_{6}$ receptors in the neuropil and electron microscopy suggested that immunolabeling was predominantly associated with dendrites (Gerard et al., 1997). A subsequent electron microscopy study revealed that $5-\mathrm{HT}_{6}$ receptor immunolabeling is not only associated with dendrites but also with primary neuronal cilia (Hamon et al., 1999; Brailov et al., 2000). This is a surprising result because there are few GPCRs that localize to primary neuronal cilia (e.g., somatostatin sst3 receptor), and the $5-\mathrm{HT}_{6}$ receptor is the only 5 - $\mathrm{HT}$ receptor that may do so (Berbari et al., 2008). The ciliary localization may require the presence of key amino acids in the third intracellular loop of the receptor, which is the case for $5-\mathrm{HT}_{6}$ receptors in mice, rats, and humans (Berbari et al., 2008). This subcellular distribution may have implications for interactions with other signaling proteins, such as adenylyl cyclase 3, which is localized exclusively in primary cilia (Baker et al., 1998), and resultant functional consequences of $5-\mathrm{HT}_{6}$ receptor signaling. However, the distribution and function of $5-\mathrm{HT}_{6}$ receptors that are heterologously expressed may be strongly dependent on a number of factors, including the differentiation state of the neuron and the amount of receptor expressed. As an example, exogenous overexpression of transfected $5-\mathrm{HT}_{6}$ plasmid DNA has a strong effect on cilia localization, with heavy expression leading to increased rates of nonciliary localization.

\section{Pharmacology}

There are important species differences between mammalian $5-\mathrm{HT}_{6}$ receptors. The mouse $5-\mathrm{HT}_{6}$ receptor has similar sequence homology to the homologous receptor of human, pig, or rat, but the pharmacological profile is much closer between human and rat than mouse (Setola and Roth, 2003). Hirst et al. (2003) detected marked differences in the affinity of a number of ligands for the $5-\mathrm{HT}_{6}$ receptor in these three species. For example, the antagonist compound Ro 04-6790 binds to recombinant rat or human $5-\mathrm{HT}_{6}$ receptors with similar affinity $\left(\mathrm{p} K_{\mathrm{i}} \sim 7.4\right)$ but has relatively very low affinity for mouse $5-\mathrm{HT}_{6}$ receptor $\left(\mathrm{p} K_{\mathrm{i}}<4\right)$; several other antagonists (including SB-258585 and mianserin) have lower affinities (5- and 12-fold, respectively) at mouse compared with rat or human receptors (Hirst et al., 2003); these differences are explained to some degree by variances in the binding pocket as demonstrated by site-directed mutagenesis. On the other hand, several highly selective agonists have similar affinities for mouse, human, and rat $5-\mathrm{HT}_{6}$ receptors.

There are relatively far lower levels of $5-\mathrm{HT}_{6}$ receptor radioligand binding sites in mouse brain, with lesser density variation across regions, than is evident in rat and human brain. Importantly, this reduced level of receptor binding and rather homogenous density across the mouse brain is method-independent, as it is equally observed using a variety of techniques to localize the receptors. Differences in residues 188 in TM5 and 290 in TM6 contribute to these species differences.

A null mutation (knockout) for the mouse $5-\mathrm{HT}_{6}$ receptor results in only subtle changes to the physiologic and behavioral phenotype (Bonasera et al., 2006), consistent with a limited contribution of the $5-\mathrm{HT}_{6}$ receptor to baseline mouse behavior. Thus, rats may be a more useful model for studying the pharmacological and (patho)physiogical roles of $5-\mathrm{HT}_{6}$ receptors in relation to humans, whereas the availability of a knockout strain makes mice very useful for studying other aspects of the biology of this receptor.

Several strategies for radiolabeling $5-\mathrm{HT}_{6}$ receptor have been described. $\left[{ }^{125} \mathrm{I}\right]-\mathrm{SB} 258585$ (Hirst et al., 2006) is the most selective, commercially available option; other radioligands require masking of non-5- $\mathrm{HT}_{6}$ receptor sites and include $\left[{ }^{3} \mathrm{H}\right]-\mathrm{LSD}$ (Sleight et al., 1998), $\left[{ }^{3} \mathrm{H}\right]$-clozapine (Glatt et al., 1995), and $\left[{ }^{11} \mathrm{C}\right]$-GSK215083 (Parker et al., 2012, 2015).

Several selective 5 - $\mathrm{HT}_{6}$ receptor agonists are available. 2-Ethyl-5-methoxy-N,N-dimethyltryptamine was the first moderately selective agonist developed (Glennon et al., 2000); it is brain penetrant and has $>10$-fold selectivity for 5 - $\mathrm{HT}_{6}$ compared with other 5 -HT receptors. More selective agonists include WAY181187, WAY208466 (Schechter et al., 2008), and ST1936 (Borsini et al., 2015). Some of these ligands display partial agonism under certain circumstances, such as EMD386088 (Jastrzebska-Wiesek et al., 2013) and E6801 (Romero et al., 2006); many nonselective 5-HT receptor agonists are either full or partial agonists at $5-\mathrm{HT}_{6}$ receptors, which can be useful tools in specific cases, but care must be given to rule out actions at other 5-HT receptors. For instance, EMD386088 has moderate affinity $\left(\mathrm{IC}_{50}=\right.$ $34 \mathrm{nM}$ ) for the $5-\mathrm{HT}_{3}$ receptor (Mattson et al., 2005), and ST1936 has moderate affinity for $5-\mathrm{HT}_{7}, 5-\mathrm{HT}_{2 \mathrm{~B}}$, and $\alpha 2$-adrenoceptors $\left(K_{\mathrm{i}}=168,245\right.$, and $300 \mathrm{nM}$, respectively; Riccioni et al., 2011). However, the contribution of partial agonism to the behavioral or physiologic effects of $5-\mathrm{HT}_{6}$ receptor ligands has not been thoroughly characterized.

A number of clinically effective drugs have affinity for $5-\mathrm{HT}_{6}$ receptors but also for other receptor targets. Several antidepressants and antipsychotics have high affinity for 5-HT $\mathrm{HT}_{6}$ receptors (Monsma et al., 1993; Ruat et al., 1993a), but none of these are selective for the receptors. After the discovery of the $5-\mathrm{HT}_{6}$ receptor, a number of modestly selective antagonists were reported based on high-throughput screening of chemical libraries, although these often shared affinity for other 5-HT or dopamine receptors (Upton et al., 2008). The first CNS penetrant selective $5-\mathrm{HT}_{6}$ receptor antagonists were produced by Roche (e.g., Ro 04-6790; Sleight et al., 1998) and GlaxoSmithKline (e.g., SB-271046; Bromidge et al., 1999). Subsequently, more highly selective $5-\mathrm{HT}_{6}$ receptor antagonists were developed, which are useful for both in vitro and in vivo 
experimentation. Among these are SB258585, SB399885 (Hirst et al., 2003), and Ro4368554 (Lieben et al., 2005).

In heterologous systems expressing wild-type or constitutively active $5-\mathrm{HT}_{6}$ receptors, a number of the selective agonists may show partial agonist activity, whereas numerous antagonists display inverse agonist properties (Purohit et al., 2003; Romero et al., 2006).

The first $5-\mathrm{HT}_{6}$ receptor somewhat selective PET ligand, $\left[{ }^{11} \mathrm{C}\right]$-GSK215083 (with approximately fivefoldlower affinity for the $5 \mathrm{HT}_{2 \mathrm{~A}}$ receptor), demonstrates $5-\mathrm{HT}_{6}$ receptor occupancy in the human striatum (Parker et al., 2012, 2015) and will no doubt help to investigate the role of this receptor in human pathology and in therapeutic response/target engagement of existing or new therapeutics or drugs.

\section{Post-translational Modifications and Protein Interactions}

There is a predicted glycosylation site in the amino terminal of the $5-\mathrm{HT}_{6}$ receptor and a number of predicted phosphorylation sites (Monsma et al., 1993; Ruat et al., 1993a; Kohen et al., 1996, 2001), although none of these have been examined systematically. However, phosphorylation of serine 350 appears to be mediated by cyclin-dependent kinase 5 (Cdk5); treatment of NG108 cells with a $5-\mathrm{HT}_{6}$ receptor-selective agonist leads to coimmunoprecipitation of $5-\mathrm{HT}_{6}$ receptor and Cdk5, whereas the $5-\mathrm{HT}_{6}$ receptor-selective antagonist SB258585 reduces the receptor phosphorylation and coimmunoprecipitation with Cdk5 (Duhr et al., 2014). Furthermore, bioluminescence energy transfer experiments confirm the direct interaction of this receptor and Cdk5 in transfected NG108 cells, which is also inhibited by the $5-\mathrm{HT}_{6}$ receptor antagonist SB258585. Duhr et al. (2014) demonstrated that Cdk5dependent phosphorylation of the $5-\mathrm{HT}_{6}$ receptor leads to activation of Cdc42 (a Rho GTPase), which can in turn activate further downstream mechanisms. The role of serine 350 phosphorylation was confirmed by sitedirected mutagenesis, which may result in constitutive activity of the receptor in the absence of agonist and inhibition of phosphorylation and downstream events by the $5-\mathrm{HT}_{6}$ receptor-selective antagonist SB258585. These signaling events may enhance NG108 cell differentiation and neurite outgrowth both in this cell line and in striatal and cultured hippocampal and striatal neurons.

Using HEK293 cells transfected with epitope-tagged $5-\mathrm{HT}_{6}$ receptors, Marin's group also detected direct interactions of this receptor with $\mathrm{mTOR}$ and several related proteins in the mTOR complex 1 (Meffre et al., 2012). 5- $\mathrm{HT}_{6}$ receptor-selective agonists induce mTOR activation, social cognition impairments in mice, and object recognition impairment in rats that could be blocked with the mTOR antagonist rapamycin. In summary, these data suggest that direct protein-protein interactions involving the $5-\mathrm{HT}_{6}$ receptor may lead to activation of multiple signaling cascades in addition to the canonical $\mathrm{G}_{\mathrm{s}}$-mediated activation of adenylyl cyclase (see XVII. C. 5-HT Receptor Receptosome: Toward New Signaling Mechanisms Underlying Its Control of Cognition and Neurodevelopmental Processes for further discussion of protein-protein interactions with the $5-\mathrm{HT}_{6}$ receptor).

Though not examined in detail, dimerization of $5-\mathrm{HT}_{6}$ receptors can be inferred from the immunoprecipitation and Western blot analysis (Meffre et al., 2012; Duhr et al., 2014).

\section{E. Signaling Pathways}

There is growing appreciation for the complexity of the pharmacological and signaling properties of the $5-\mathrm{HT}_{6}$ receptor. The ability of the $5-\mathrm{HT}_{6}$ receptor to activate adenylyl cyclase in $\mathrm{a}_{\mathrm{s}}$-dependent manner was first described when the receptor was originally cloned and expressed heterologously as well as in native tissues (Monsma et al., 1993; Ruat et al., 1993a; Sebben et al., 1994; Unsworth and Molinoff, 1994; Choi et al., 2007; Kim et al., 2014b). 5- $\mathrm{HT}_{6}$ receptors can activate several adenylyl cyclase isoforms, including AC3, AC5, and AC8, but not AC1 or AC8 (Baker et al., 1998). Because $5-\mathrm{HT}_{6}$ receptors activate adenylyl cyclase, thereby increasing cAMP and therefore protein kinase A activity, a number of additional downstream signaling consequences can be presumed, although these have not been systematically examined. Svenningsson et al. (2002) examined the potential synergistic interactions between $5-\mathrm{HT}_{6}$ and $\mathrm{D}_{1}$ dopamine receptors; 5 - $\mathrm{HT}_{6}$ receptor activation in striatum regulates $\mathrm{DARPP}_{32}$, an enzyme previously associated mainly with dopaminergic neurotransmission. Selective $5-\mathrm{HT}_{6}$ receptor agonists modulate the $\mathrm{DARPP}_{32}$ phosphorylation state in a manner consistent with increasing this enzyme's activity; phosphorylation of $\mathrm{DARPP}_{32}$ is blocked by selective $5-\mathrm{HT}_{6}$ receptor antagonists; 5-HT-mediated c-Fos activation and motor activity is blunted in $\mathrm{DARPP}_{32}$ knockout mice (Svenningsson et al., 2002). However, 5-HT regulation of $\mathrm{DARPP}_{32}$ is unlikely to involve exclusively $5-\mathrm{HT}_{6}$ receptors, as $5-\mathrm{HT}_{4}$ and $5-\mathrm{HT}_{7}$ receptors can also activate $\mathrm{DARPP}_{32}$. This pathway is an interesting regulatory node that potentially integrates 5-HT and dopamine signaling in neurons that coexpress $5-\mathrm{HT}_{6}$ and $\mathrm{D}_{1}$ receptors, such as striatonigral (direct pathway) medium spiny neurons.

The $5-\mathrm{HT}_{6}$ receptor induces fyn kinase activation. (Yun et al., 2007; Riccioni et al., 2011). Fyn is an src tyrosine kinase family member, present in both cilia and neuronal soma. Fyn is expressed in the same brain regions as $5-\mathrm{HT}_{6}$ receptor. Phosphorylated-Fyn is thought to activate Erk1/Erk2 kinases via the Ras-Raf-MEK pathway. Direct protein interactions with Cdk5 also predict that $5-\mathrm{HT}_{6}$ receptors signal through this kinase pathway, which was shown to regulate neurite outgrowth in NG108 cells and primary neurons (Duhr et al., 2014). 
This pathway regulates neuronal migration in both slice cultures and in vivo (Jacobshagen et al., 2014). 5-HT 6 receptor activation phosphorylates doublecortin and focal adhesion kinase, two mediators of neuronal migration, and is Cdk5-dependent, although additional or alternative mediators may be at play. Similarly, mTOR interactions were predicted based on studies of protein interactions, and $5-\mathrm{HT}_{6}$ receptor agonists induce phosphorylation of mTOR into the active form, which is blocked by selective $5-\mathrm{HT}_{6}$ receptor antagonists both in vitro and in vivo (Meffre et al., 2012).

The constitutive activity of $5-\mathrm{HT}_{6}$ receptors represents an intriguing issue. Constitutive activity implies that the receptor couples to and activates downstream effectors in the absence of the agonist; the clearest evidence for this with $5-\mathrm{HT}_{6}$ receptors comes from heterologous expression systems and with activation of Cdk5, Fyn, and mTOR signaling events (Meffre et al., 2012; Duhr et al., 2014; Jacobshagen et al., 2014; see XVII. C. 5-HT 6 Receptor Receptosome: Toward New Signaling Mechanisms Underlying Its Control of Cognition and Neurodevelopmental Processes). However, it has been more difficult to confirm this in systems that are dependent on activation of $5-\mathrm{HT}_{6}$ receptors expressed in native cells or tissues. For example, Sebben et al. (1994) described 5- $\mathrm{HT}_{6}$ receptor-mediated cAMP accumulation in primary cultured mouse striatal neurons, and several full agonists, such as 5-HT and LSD, caused cAMP production, but no constitutive activity was apparent. Because the cell type, signal transduction pathways, and level of receptor expression may all affect the extent of constitutive activity, its contribution to $5-\mathrm{HT}_{6}$ function likely varies a great deal depending on the cellular context; hence, it still remains to be demonstrated with natural expression levels in vivo. However, the $5-\mathrm{HT}_{6}$ receptor clearly has a propensity to display constitutive activity, and many of the available antagonists are in fact inverse agonists, meaning they will reduce $5-\mathrm{HT}_{6}$ signaling if constitutive activity is present (Purohit et al., 2003).

\section{F. Function}

Prior to the availability of selective $5-\mathrm{HT}_{6}$ receptor antagonists, antisense oligonucleotides were used to reduce expression/function of the $5-\mathrm{HT}_{6}$ receptor; yawning and stretching behavior (Bourson et al., 1995), weight loss, and reduced retention of spatial learning in the Morris water maze were reported following receptor knockdown (Woolley et al., 2001), later replicated by the use of selective antagonists. Interestingly, the extent of $5-\mathrm{HT}_{6}$ receptor knockdown was limited (20\%-30\% using [ $\left.{ }^{3} \mathrm{H}\right] \mathrm{LSD}$ binding), and it is only more recently that knockout mice have been available. Tecott and Brennan (2000) produced the first $5-\mathrm{HT}_{6}$ receptor knockout mouse and reported weight loss in a patent, which triggered the exploration of $5-\mathrm{HT}_{6}$ receptor antagonists as appetite suppressants (Heal et al.,
2008; Higgs et al., 2016). More recently, germ-line knockout of $5-\mathrm{HT}_{6}$ receptors produced no changes in viability, health, weight, or longevity of the null mutant mice (Bonasera et al., 2006) and no deficits in fertility or maternal behavior. Furthermore, no overt changes in circadian activity, emotional behavior, sensorimotor gating, or cognition were detected. The only behavioral change evident was a reduced sensitivity to the sedative and ataxic effects of acute ethanol administration. However, mouse $5-\mathrm{HT}_{6}$ receptor $\mathrm{KO}$ may underestimate the potential roles of $5-\mathrm{HT}_{6}$ receptors in any of these effects, as mice have much lower $5-\mathrm{HT}_{6}$ receptor expression than many other mammalian species (Hirst et al., 2003), as discussed above.

Though $5-\mathrm{HT}_{6}$ null mutant mice seem to develop normally, there are very interesting effects of acute modulation of $5-\mathrm{HT}_{6}$ receptors during cortical development. Using both in vivo and explant culture models, Dayer and colleagues have shown that modulating $5-\mathrm{HT}_{6}$ receptor signaling produces deficits in neuronal migration (Jacobshagen et al., 2014). The $5-\mathrm{HT}_{6}$ receptor partial agonist EMD386088 delays the rate of pyramidal neuron and interneuron migration (Riccio et al., 2009, 2001), which can be blocked by the antagonist SB 258585 , although the concentrations of drugs used are rather high, questioning receptor classification.

The effect of activation versus inhibition of $5-\mathrm{HT}_{6}$ receptor activity is complex, though, as short hairpin RNA knockdown of endogenous $5-\mathrm{HT}_{6}$ receptors produces deficits in neuronal speed and extent of neuronal migration (Jacobshagen et al., 2014). This deficit is partially rescued by coexpressing $5-\mathrm{HT}_{6}$ receptors or overexpressing Cdk5 but not by coexpressing $5-\mathrm{HT}_{6}$ receptor mutants that disrupt Gs-coupling and thus adenylyl cyclase activation. Furthermore, $5-\mathrm{HT}_{6}$ receptor-mediated Cdk5 signaling facilitates dendritic outgrowth. There may be additional mechanisms of $5-\mathrm{HT}_{6}$ receptor-mediated developmental effects, as the selective agonist WAY181187 activates mTOR in mouse cortex, and this is blocked by SB258585 (Meffre et al., 2012). The psychomimetic drug phencyclidine, which models aspects of the development and symptoms of schizophrenia, induces mTOR activation in neonatal rat cortex and impairs social cognition in the adult mice, both of which are blocked by the mTOR inhibitor rapamycin or the $5-\mathrm{HT}_{6}$ receptor-selective antagonist SB258585. Interestingly, both drugs also reverse visual recognition impairments associated with isolation rearing in rats (Marsden et al., 2011; Meffre et al., 2012). Though adenylyl cyclase, mTOR, Cdk5, and fyn kinase signaling are complex and impacted by many parallel pathways, the potential that multiple signaling pathways emanating from $5-\mathrm{HT}_{6}$ receptors play a crucial role in establishing normal cortical circuitry has far-reaching implications given that drugs that modulate 5-HT dynamics (such as SSRIs and other antidepressants) or that directly interact with $5-\mathrm{HT}_{6}$ receptors (whether exclusively so or not) may 
produce alterations in cortical development. These issues need to be examined more fully to understand the consequences of 5-HT drug treatments during gestation or in adolescence.

It is reasonable to conclude that $5-\mathrm{HT}_{6}$ receptors may increase the excitability of neurons, as this is the expected result following activation of adenylyl cyclase. The $5-\mathrm{HT}_{6}$ receptor agonist WAY181187 increases foslike immunoreactivity in cortex (Burnham et al., 2010), and the $5-\mathrm{HT}_{6}$ receptor antagonist Ro4368554 reduces scopolamine-induced increase of fos-like immunoreactivity in lateral amygdala (Mitchell et al., 2009b); however, both of these manipulations produce complex behavioral and pharmacological changes that make it difficult to conclude that the effects are directly related to $5-\mathrm{HT}_{6}$ receptors or are more indirect consequences of circuitry level events.

$5-\mathrm{HT}_{6}$ receptors modulate many different neurotransmitter systems (Mitchell and Neumaier, 2005; Dawson, 2011). The impacts on extracellular levels of acetylcholine, glutamate, GABA, dopamine, and norepinephrine have been reported using microdialysis. Selective $5-\mathrm{HT}_{6}$ receptor ligands alter neuronal firing in a variety of brain regions, but it is difficult to conclude whether these effects are direct or indirect. In any event, it appears that $5-\mathrm{HT}_{6}$ receptor ligands modulate numerous brain regions and neurotransmitter systems.

There is a rich literature addressing the potential cognitive effects of $5-\mathrm{HT}_{6}$ receptor modulation (Woolley et al., 2004; Mitchell and Neumaier, 2005; King et al., 2008; Codony et al., 2011; Marsden et al., 2011; Meneses, 2015). In most cases, $5-\mathrm{HT}_{6}$ receptor antagonists display procognitive effects in a variety of rodent memory tasks, such as spatial learning, novel object recognition, social discrimination, and autoshaping (Mitchell and Neumaier, 2005). Generally, these experiments used parenteral drug administration either just before or just after a memory "training" session that was then assessed after a short interval. The procognitive effects of $5-\mathrm{HT}_{6}$ receptor antagonists have often been shown to be associated with changes in other neurotransmitter systems, especially acetylcholine, glutamate, or GABA release. However, it is difficult to reach mechanistic conclusions based on the correlative nature of these observations. At this time, it is not possible to attribute the memory-enhancing effects of $5-\mathrm{HT}_{6}$ receptor antagonists to a single brain region or neurotransmitter system, and it seems likely that multiple mechanisms are responsible.

Although there are numerous reports that inhibiting $5-\mathrm{HT}_{6}$ receptors promotes (or restores) memory, there is some apparent inconsistency in the cognitive role of $5-\mathrm{HT}_{6}$ receptor agonists. For example, WAY117187 (an agonist) impaired social recognition in an antagonistsensitive manner whether given systemically or locally into frontal cortex (Loiseau et al., 2008); EMD386088 or WAY466 impaired memory in the autoshaping or social recognition tasks, respectively (Meneses et al., 2008;
Schechter et al., 2008). However, other reports have observed procognitive effects of $5-\mathrm{HT}_{6}$ receptor agonists (Kendall et al., 2011; Woods et al., 2012; Pereira et al., 2015). There are several potential explanations for these discrepancies. One explanation is that $5-\mathrm{HT}_{6}$ receptor activation in some brain regions is procognitive, whereas inhibition of $5-\mathrm{HT}_{6}$ receptors in other brain regions is also procognitive. Another possible explanation is that the effect of increased or decreased $5-\mathrm{HT}_{6}$ receptor activity is entirely dependent on the specific cognitive domain being tested. A third possibility is that either high or low levels of $5-\mathrm{HT}_{6}$ receptor activity enhance cognition in specific regions, albeit by different neurochemical mechanisms (e.g., facilitating glutamatergic function in states with a relative deficit or facilitating GABAergic function in states of excessive glutamatergic activity). Even when the same cognitive task has been used, each laboratory likely performs these tests in at least slightly different ways -with or without amnestic maneuvers (such as using scopolamine to disrupt memory function), in young or old animals, or with short- versus long-interval testing; thus, it seems unlikely that agonists or antagonists will "win" this battle, but instead there may be a role for both $5-\mathrm{HT}_{6}$ receptor agonists and antagonists for different cognitive problems in different pathologic states.

The effects of striatal $5-\mathrm{HT}_{6}$ receptors on autoshaping and related instrumental learning tasks have been investigated based on the early observations that $5-\mathrm{HT}_{6}$ receptor antagonists facilitate cholinergic function (Mitchell and Neumaier, 2005); it was thought that these drugs facilitate consolidation of memory by cortical or hippocampal mechanisms. However, because $5-\mathrm{HT}_{6}$ receptors are most heavily expressed in medium spiny neurons in striatum, these neurons might also be an important site of 5- $\mathrm{HT}_{6}$ receptor action in cognition. Because the autoshaping task used extensively by Meneses' group was clearly sensitive to $5-\mathrm{HT}_{6}$ receptor antagonism, this task was studied in mice with striatumspecific increased $5-\mathrm{HT}_{6}$ receptor expression (Meneses 2015; Mitchell et al., 2007). High 5- $\mathrm{HT}_{6}$ receptor density in dorsomedial striatum impaired the acquisition but not the expression of previously learned instrumental learning. This effect is unlikely to involve memory consolidation, as the deficit is only reversed by giving a $5-\mathrm{HT}_{6}$ receptor antagonist before but not after the training session. The operant conditioning parameters were altered to allow single-session acquisition; increased $5-\mathrm{HT}_{6}$ receptor expression interfered with learning under these conditions (Eskenazi and Neumaier, 2011b). Furthermore, the type of learning affected by increasing the local expression of $5-\mathrm{HT}_{6}$ receptors depended entirely on the subregion of striatum targeted (Mitchell et al., 2007; Ferguson et al., 2008; Eskenazi and Neumaier, 2011a,b). These studies do not exclude a role of $5-\mathrm{HT}_{6}$ receptors in cholinergic interneurons in striatum, 
as the focus was on the direct and indirect striatal output pathways, which have generally opposing effects on behavior (Yager et al., 2015). Increased $5-\mathrm{HT}_{6}$ receptor expression in indirect pathway medium spiny neurons is sufficient to disrupt instrumental learning in dorsomedial striatum or to facilitate learning of new behavior in overtrained animals when the dorsolateral striatum was targeted (Eskenazi et al., 2015). Indeed, 5- $\mathrm{HT}_{6}$ receptors tend to oppose the effects of dopamine on striatal-based behaviors including learning, as they are expressed in both output pathways, whereas $\mathrm{D}_{1}$ and $\mathrm{D}_{2}$ dopamine receptors are differentially expressed in these pathways (Gerfen and Surmeier, 2011). These subtleties illustrate how $5-\mathrm{HT}_{6}$ receptors can have diverse effects on behavior depending on the cells that express these receptors. Thus, a full understanding of how $5-\mathrm{HT}_{6}$ receptors modulate learning and memory in a specific cognitive disorder may depend, at least in part, on how that disorder changes 5 -HT receptor signaling.

In addition to effects on cognition, $5-\mathrm{HT}_{6}$ receptors have been proposed to promote satiety and reduce feeding and body weight (Woolley et al., 2001; Fisas et al., 2006; Voigt and Fink, 2015; Higgs et al., 2016); however, not all studies report effects of chronic $5-\mathrm{HT}_{6}$ receptor antagonism on body weight in rats or humans (Mitchell et al., 2009; Wilkinson et al., 2014; Quiedeville et al., 2015). Most of these studies used animals with normal body weight, whereas the $5-\mathrm{HT}_{6}$ receptor antagonist idalopirdine reduced feeding, peritoneal fat, and body weight when rats were fed a high-fat diet (Dudek et al., 2015). This metabolic profile might be advantageous clinically, as reducing feeding only in obese individuals would mitigate the risks of the drug when used for treating individuals with dementia. Furthermore, as several atypical antipsychotics that have high affinity for $5-\mathrm{HT}_{6}$ receptors (along with many other sites) are associated with increased appetite, weight gain, and the development of the metabolic syndrome, the preclinical and limited clinical data available suggest that $5-\mathrm{HT}_{6}$ receptor antagonism is unlikely to be responsible for these adverse effects, which are more likely due, at least in part, to $5-\mathrm{HT}_{2 \mathrm{C}}$ receptor antagonism.

The $5-\mathrm{HT}_{6}$ receptor has also been examined in relation to drug dependence given their dense expression in the striatum, a key mediator of reward seeking and habit formation. However, some reports have found no effect of systemic $5-\mathrm{HT}_{6}$ receptor ligands on cocaine selfadministration (Frantz et al., 2002; Fijał et al., 2010; Valentini et al., 2013), whereas others suggest that cocaine reinforcement or reinstatement is regulated by $5-\mathrm{HT}_{6}$ receptor activity (van Gaalen et al., 2010; Valentini et al., 2013). Increased striatal 5- $\mathrm{HT}_{6}$ receptors modulate learning of drug-associated behaviors as well as the stability of habitual responding (Ferguson et al., 2008; Eskenazi and Neumaier, 2011a; Eskenazi et al., 2015), but selectively increasing $5-\mathrm{HT}_{6}$ receptors in the indirect pathway medium spiny neurons in ventral striatum increases the sensitivity to the reinforcing properties of self-administered cocaine (Brodsky et al., 2016).

5 - $\mathrm{HT}_{6}$ receptors may also play a role in the development and treatment of epilepsy (Hirst et al., 2006). Increased 5- $\mathrm{HT}_{6}$ receptor levels were detected in brain tissue surgically removed from humans with epilepsy and in the pilocarpine model of epilepsy in rats (Wang et al., 2015). The selective antagonist SB399885 reduces mTOR activation and epileptic activity in this animal model. Furthermore, the colocalization of $5-\mathrm{HT}_{3} \mathrm{~A}$ and $5-\mathrm{HT}_{6}$ receptors in a subset of cortical interneurons (Helboe et al., 2015) is intriguing given the potential role of these interneurons in cortical excitability for both normal cognition as well as pathologic states.

1. Electrophysiology. Much of the electrophysiological data concerning $5-\mathrm{HT}_{6}$ receptors primarily concerns in vivo recording; the cellular mechanisms are difficult to infer. The selective 5- $\mathrm{HT}_{6}$ receptor agonist WAY181187 increases excitability and spiking by rat medium spiny neurons in acutely prepared striatal slices in a SB258585reversible manner; but this has not been sufficiently explored to identify whether this is a direct or indirect phenomenon. In whole-cell patch clamp mode, the $5-\mathrm{HT}_{6}$ receptor agonist ST1936 reduces spontaneous excitatory postsynaptic currents in striatal medium spiny neurons and cortical pyramidal neurons, which is prevented by SB258585 (Tassone et al., 2011). Thus, the agonistinduced reduction in glutamatergic neuronal activity (consistent with microdialysis reports of enhanced glutamate overflow following microinfusion of $5-\mathrm{HT}_{6}$ receptor antagonists; Upton et al., 2008; Dawson, 2011) might be indirect by modulation of GABAergic interneurons in these brain areas. Although systemic administration of $5-\mathrm{HT}_{6}$ receptor agonists to anesthetized rats produced both excitation and inhibition of ventral tegmental area (VTA) dopamine neurons, only excitation is observed following microiontophoretic application (Borsini et al., 2015), suggesting a direct excitatory activation, which may be relevant for cognitive and addictive properties of $5-\mathrm{HT}_{6}$ receptor ligands.

Moderate levels of 5- $\mathrm{HT}_{6}$ receptors are also expressed in the DRN, and local injection of the agonist WAY208466 decreases REM sleep and increases wakefulness (Monti et al., 2013). Single-unit recording in the anesthetized rat shows that systemic application of the full agonist WAY-181187 increases and the antagonist SB-399885 decreases firing of putative DRN 5-HT neurons; further studies are needed to establish if this involves cortical feedback loops, interneurons, and/or a direct effect on 5-HT neurons as proposed by the authors (Brouard et al., 2015). Consistent with this idea of indirect modulation of 5-HT release in the raphe, the $5-\mathrm{HT}_{6}$ receptor antagonist SB399885 inhibits spontaneous firing of GABAergic interneurons (expressing $5-\mathrm{HT}_{6}$ receptor mRNA) in the $\mathrm{DRN}$ in mouse brain slices (Asaoka et al., 2015). This mechanism may be 
relevant to the action of antipsychotic drugs, as the effect is mirrored by olanzapine.

\section{G. Clinical Relevance}

Treatment of cognitive impairment is a leading potential application of $5-\mathrm{HT}_{6}$ receptor ligands in humans. There is ample evidence that manipulation of $5-\mathrm{HT}_{6}$ receptors can improve cognitive function based on preclinical animal models. Though schizophrenia is associated with positive and negative symptoms that can respond to available antipsychotic drugs, cognitive impairment is an often disabling and persistent problem that typically does not respond well to antipsychotic medications. Although there are some preliminary clinical trials in schizophrenia, these trials had technical limitations because the $5-\mathrm{HT}_{6}$ receptor ligands investigated were as add-ons to treatments already underway, and in some cases, the ongoing treatments were atypical antipsychotic drugs that possess potent antagonist properties at $5-\mathrm{HT}_{6}$ receptors, making it unlikely that additional benefits from $5-\mathrm{HT}_{6}$ receptor blockade could be readily detected. Early clinical studies with $5-\mathrm{HT}_{6}$ receptor ligands are reviewed elsewhere (Heal et al., 2008; Codony et al., 2011). A double-blind, placebocontrolled phase II trial for treatment of dementia associated with Alzheimer Disease (Wilkinson et al., 2014) investigated whether the addition of Lundbeck's idalopirdine, a selective $5-\mathrm{HT}_{6}$ receptor antagonist, to an established treatment (donepezil, a cholinesterase inhibitor) delays the progression of dementia. This study was successful in two important ways: the addition of idalopirdine was well tolerated and led to improved cognitive function as compared with addition of placebo. However, disappointingly, idalopirdine suffered a latestage failure in a pivotal phase III trial. Along the same lines, intepirdine, previously known as RVT-101, a 5-HT 6 receptor antagonist originally developed by GSK, displayed positive effects in patients with $\mathrm{AD}$ in a phase II clinical trial. A subsequent phase III trial of the drug after it was acquired by Axovant failed to achieve any of its main efficacy targets in mild to moderate $\mathrm{AD}$ patients. Intepirdine did not improve symptoms compared with placebo on two widely used $\mathrm{AD}$ symptom measures-the ADAS-Cog (the Alzheimer's Disease Assessment ScaleCognitive Subscale) and ADCSADL (Alzheimer's Disease Cooperative Study Activities of Daily Living Scale) scales. Subsequently, intepirdine was evaluated in a clinical trial of patients with dementia with Lewy bodies also without success, leading to a halt in the development of this drug. Hence, although the availability of new effective treatments for dementia is a crucial health imperative, it would appear that 5 - $\mathrm{HT}_{6}$ receptor antagonism may not transform the preclinical promises into clinical practice; understanding the mechanisms that underlie this apparent failure is important and may allow opportunity for patient stratification to better identify patients that may respond favorably to $5-\mathrm{HT}_{6}$ receptor ligands.
Several other pathologies might also be amenable to treatment with $5-\mathrm{HT}_{6}$ receptor ligands, as preclinical data suggests that other progressive dementing disorders, depression, obesity, and epilepsy have potential to become indications for $5-\mathrm{HT}_{6}$ receptor ligands. As now appreciated, the multiple signal transduction pathways engaged by $5-\mathrm{HT}_{6}$ receptors and various $5-\mathrm{HT}_{6}$ receptor ligands with differing degrees of intrinsic efficacy; the role of agonism partial agonism, antagonism, and inverse agonism; and biased signaling need to be considered in future development of 5- $\mathrm{HT}_{6}$ receptor therapeutic agents. Such pharmacological complexity may also account for the apparent opposing actions of $5-\mathrm{HT}_{6}$ receptor ligands in preclinical behavioral models as discussed above.

\section{5-HT 7 Receptors}

\section{A. Introduction}

The $5-\mathrm{HT}_{7}$ receptor was the last 5 -HT receptor to be discovered. In 1993, several research groups, almost at the same time, identified the $5-\mathrm{HT}_{7}$ receptor from the screening of cDNA libraries from various species, including humans. 5- $\mathrm{HT}_{7}$ receptor mRNA is localized in discrete areas of the mammalian brain, including thalamus, hippocampus, and cortex, and matched with the expression of $5-\mathrm{HT}_{7}$ receptor protein. Based on its distribution in the $\mathrm{CNS}$, the $5-\mathrm{HT}_{7}$ receptor is proposed to be involved in thermoregulation, circadian rhythm, learning and memory, hippocampal signaling, and sleep. Various drugs (clozapine, cyproheptadine, and amitryptiline) and pharmacological tools (5-CT and 8-OH-DPAT) binding to $5-\mathrm{HT}_{7}$ receptor poses the question of whether some of the effects of these compounds are mediated, at least in part, by $5-\mathrm{HT}_{7}$ receptor. Initially, the lack of selective $5-\mathrm{HT}_{7}$ receptor agonists and antagonists slowed down the elucidation of the (patho)physiologic role of the receptor, especially because of the high sequence homology in the transmembrane domains of 5- $\mathrm{HT}_{7}$ and $5-\mathrm{HT}_{1 \mathrm{~A}}$ receptors. Moreover, the two receptors are distributed in the same areas of the CNS and, at the cellular level, they may have opposite effects: the $5-\mathrm{HT}_{7}$ receptor is positively coupled to adenylyl cyclase whereas the $5-\mathrm{HT}_{1 \mathrm{~A}}$ receptor is negatively coupled. After 2000 , various selective antagonists (SB-258719 and SB-269970) and agonists (AS19, LP-211, and E-55888) became available, providing the scientific community with powerful pharmacological tools to get deeper insights on the role of $5-\mathrm{HT}_{7}$ receptors in health and disease.

\section{B. Cloning of the Gene}

The $5-\mathrm{HT}_{7}$ receptor is a class A GPCR, cloned by screening of cDNA libraries from mouse (Plassat et al., 1993), rat (Lovenberg et al., 1993a, Meyerhof et al., 1993, Ruat et al., 1993b; Shen et al., 1993), human (Bard et al., 1993), guinea pig (Tsou et al., 1994), Xenopus laevis (Nelson et al., 1995), pig (Bhalla et al., 2002a), 
Caenorhabditis elegans (Hobson et al., 2003), and honeybee (Schlenstedt et al., 2006).

The open reading frame of the human cDNA codes for a protein of 445 amino acids with $57 \%$ sequence identity within the transmembrane regions in comparison with the Drosophila melanogaster $5-\mathrm{HT}_{\mathrm{dro} 1}$ receptor and $39 \%-53 \%$ homology with human $5-\mathrm{HT}_{1}, 5-\mathrm{HT}_{2}, 5-\mathrm{HT}_{5}$, and $5-\mathrm{HT}_{6}$ receptors (Bard et al., 1993). The gene encoding the human $5-\mathrm{HT}_{7}$ receptor is located on chromosome 10 (q21-q24) (Gelernter et al., 1995) and contains several introns in the coding region (Ruat et al., 1993b, Erdmann et al., 1996; Heidmann et al., 1997). The guinea pig $5 \mathrm{HT}_{7}$ receptor has 466 amino acids, with an amino acid homology within the transmembrane regions with other 5-HT receptors of 34\% and $48 \%$ (Tsou et al., 1994). The mouse brain $5-\mathrm{HT}_{7}$ receptor cDNA has one long open reading frame for 448 amino acids. The homology with other 5-HT receptors is low, with the best score with the $5-\mathrm{HT}_{\mathrm{dro}}$ receptor $(42 \%)$ and the next closest homology being with $5-\mathrm{HT}_{1 \mathrm{~B}}, 5-\mathrm{HT}_{1 \mathrm{D}}$, and $5-\mathrm{ht}_{1 \mathrm{e}}$ receptors (Plassat et al., 1993). The $5-\mathrm{HT}_{7}$ receptor was cloned from rat by four groups, which reported different amino acid lengths ranging from 404 to 448 . Shen et al. (1993) reported the sequencing of a full-length clone isolated from a rat hippocampal cDNA library, revealing a 404-amino-acid protein with seven hydrophobic regions. Within these regions, rat $5-\mathrm{HT}_{7}$ receptor is $44 \%-50 \%$ identical with members of the $5-\mathrm{HT}_{1}, 5-\mathrm{HT}_{5}$, and $5-\mathrm{HT}_{6}$ subfamilies, with lower homology to the $5-\mathrm{HT}_{2}$ receptor subtypes (37\%-40\%). Lovenberg et al. (1993a) isolated and determined the nucleotide sequence of a clone showing an open reading frame that encoded a 435-amino-acid protein. Within the conserved transmembrane domains of known 5-HT receptors, the rat $5-\mathrm{HT}_{7}$ receptor exhibited the greatest identity with the $5-\mathrm{HT}_{\text {dro1 }}$ receptor $(54 \%)$. Instead, the entire coding sequence showed low identity (33\%-39\%) with 5- $\mathrm{HT}_{\mathrm{dro1}}, 5-\mathrm{HT}_{1 \mathrm{~A}}, 5-\mathrm{HT}_{1 \mathrm{D}}, 5-\mathrm{ht}_{1 \mathrm{e}}, 5-\mathrm{HT}_{5}$ receptor subtypes. Ruat et al. (1993b) reported the characterization of a nucleotide sequence containing an open reading frame encoding a 448-amino-acid protein. This rat $5-\mathrm{HT}_{7}$ receptor showed the highest sequence homology in the hydrophobic regions with the $5 \mathrm{HT}_{\text {dro1 }}$ receptor $(60 \%)$. In the transmembrane domains, the homologies with other 5 -HT receptors were as follows: $5-\mathrm{HT}_{1 \mathrm{~A}}, 51 \% ; 5-\mathrm{HT}_{1 \mathrm{~B}}, 55 \% ; 5-\mathrm{HT}_{1 \mathrm{D}}, 52 \% ; 5-\mathrm{ht}_{1 \mathrm{e}}, 53 \%$; $5-\mathrm{HT}_{1 \mathrm{~F}}, 52 \% ; 5-\mathrm{HT}_{2 \mathrm{~A}}, 43 \% ; 5-\mathrm{HT}_{2 \mathrm{~B}}, 40 \% ; 5-\mathrm{HT}_{2 \mathrm{C}}, 42 \%$; $5-\mathrm{HT}_{5}, 48 \%$; and $5-\mathrm{HT}_{6}, 45 \%$. The rat $5-\mathrm{HT}_{7}$ receptor reported by Meyerhof et al. (1993) has an open reading frame encoding a 448-amino-acid protein, showing the highest sequence homology with $5-\mathrm{HT}_{\mathrm{dro}}$ receptor $(36 \%$ identity). The $5-\mathrm{HT}_{7}$ receptor from pig (Bhalla et al., 2002a) encoded an open reading frame of a 447-aminoacid protein that showed high homology $(92 \%-96 \%)$ with the $5-\mathrm{HT}_{7}$ receptor protein cloned from the other species.

The presence of introns in the $5-\mathrm{HT}_{7}$ receptor gene results in a number of functional splice variants.
Although no alternative splicing has been reported for the first intron, located in the sequence encoding the second intracellular loop of the receptor, alternative splicing at the second intron, which is located in the sequence encoding the C-terminal end, generates a number of splice variants, namely $5-\mathrm{HT}_{7(\mathrm{a}),(\mathrm{b}),(\mathrm{c}) \text {, (e) }}$ receptors in rat and $5-\mathrm{HT}_{7(\mathrm{a}) \text {, (b), (d) receptors in man }}$ (Heidmann et al., 1998; Krobert et al., 2001; Liu et al., 2001). Splice variants in dog, marmoset, and zebrafish are to be found in the www.ensembl.org database, but no related reports are available in the literature. In the mouse, two additional splice variants have been described, named $5-\mathrm{HT}_{7(\mathrm{~b})}$ and $5-\mathrm{HT}_{7(\mathrm{c})}$ in analogy with the rat (Gellynck et al., 2008). In guinea pig and pig, the $5-\mathrm{HT}_{7}$ receptor is homologous to the human $5-\mathrm{HT}_{7(\mathrm{a})}$ variant. Although the splice variants differ in the lengths of their carboxy terminal ends, they do not show major differences in their membrane localization nor significant differences in their respective pharmacology and signal transduction properties or functional coupling to $\mathrm{G}_{\mathrm{s}}$ protein (see below).

A transcribed human $5-\mathrm{HT}_{7}$ receptor pseudogene has been identified by a degenerate PCR approach. The original clone (S771) has homology greater than $90 \%$ to the $5-\mathrm{HT}_{7}$ receptor sequence; expression of the pseudogene transcript is detected throughout the brain and peripheral tissues, in general agreement with $5-\mathrm{HT}_{7}$ receptor mRNA localization. However, the transcript was also detected in tissues not known to express the $5-\mathrm{HT}_{7}$ receptor (i.e., liver and kidney) (Olsen et al., 1999).

There is as yet no crystal structure of the $5-\mathrm{HT}_{7}$ receptor, but molecular modeling and site-directed mutagenesis has identified essential residues for ligand binding and activation of the human receptor (Impellizzeri et al., 2015).

\section{Expression}

1. $m R N A$. The distribution of mRNA encoding the $5-\mathrm{HT}_{7}$ receptor protein has been studied in several species using various techniques, as summarized in Tables 18 and 19. In all species, high levels of $5-\mathrm{HT}_{7}$ receptor mRNA are expressed in the CNS (hypothalamus, thalamus, and hippocampus; Fig. 26). In peripheral tissues, $5-\mathrm{HT}_{7}$ receptor mRNA is present in the ileum, spleen, endocrine glands, and arteries. In blood vessels and the gastrointestinal tract, $5-\mathrm{HT}_{7}$ receptor mRNA expression is generally present in smooth muscle cells.

The relative abundance of the three human $5-\mathrm{HT}_{7}$ isoforms $5-\mathrm{HT}_{7(\mathrm{a})}$, (b), and (d) within brain (fetal brain, caudate, hippocampus) and peripheral tissues (uterus, trachea, small intestine, stomach, saphenous vein) has been examined (Krobert et al., 2001; Guthrie et al., 2005). These tissues expressed all three isoforms. Although the 5 - $\mathrm{HT}_{7(\mathrm{~b})}$ isoform is most prevalent, the relative amounts of $5-\mathrm{HT}_{7(\mathrm{a})}$ and $5-\mathrm{HT}_{7(\mathrm{~d})}$ differed by 
TABLE 18

Localization and relative abundance of $5-\mathrm{HT}_{7}$ receptor mRNA in the rat

\begin{tabular}{|c|c|}
\hline Technique & Localization (Relative Abundance) \\
\hline In situ hybridization ${ }^{a}$ & Hippocampus $(+++)$, thalamus $(+)$, hypothalamus $(+)$ \\
\hline In situ hybridization ${ }^{b}$ & Hippocampus, thalamus, enthorinal and piriform cortices, tenia tecta \\
\hline In situ hybridizatioc ${ }^{c}$ & $\begin{array}{c}\text { Thalamus }(+++) \text {, hippocampus }(++) \text {, retrosplenial cortex }(++) \text {, neocortex }(++) \text {, hypothalamus }(+)(\text { not detected in } \\
\text { suprachiasmatic nucleus) }\end{array}$ \\
\hline In situ hybridization ${ }^{d}$ & Outer layer of the cortex, thalamus, hippocampus \\
\hline In situ hybridization ${ }^{e}$ & $\begin{array}{c}\text { Thalamus }(+++) \text {, hippocampus }(+++) \text {, retrosplenial cortex }(+++) \text {, mammillary region }(+++) \text {, posterior thalamic } \\
\text { nucleus }(+) \text {, suprachiasmatic nucleus }(+)\end{array}$ \\
\hline In situ hybridization ${ }^{f}$ & $\begin{array}{r}\text { Forebrain }(+++) \text {, olfactory complex }(+++) \text {, thalamus }(+++) \text {, hippocampal formation }(+++) \text {, hypothalamus }(+++) \text {, } \\
\text { suprachiasmatic nucleus }(+++) \text {, septal region }(++) \text {, amygdala }(++) \text {, parvicellular }(++)\end{array}$ \\
\hline In situ hybridization ${ }^{g}$ & $\begin{array}{r}\text { Retrosplenial cortex }(+++) \text {, hippocampus }(+++) \text {, tenia tecta }(+++) \text {, indusium griseus }(+++) \text {, posterior } \\
\text { hypothalamus }(+++) \text {, medial amygdala nucleus }(+++) \text {, thalamus }(+++) \text {, cerebellum-Purkinije cell layer- }(+++) \text {, } \\
\text { pontine nuclei }(+++) \text {, superior colliculus }(+) \text {, raphe nucleus }(+)\end{array}$ \\
\hline Northern Blot ${ }^{h}$ & $\begin{array}{l}\text { Hypothalamus }(+++) \text {, hippocampus }(++) \text {, mesencephalon }(++) \text {, cortex }(++) \text {, olfactory bulb }(+) \text {, olfactory tubercle }(+) \text {, } \\
\text { spleen }(+) \text { (not detected in retina, pituitary, testis, stomach, prostate, ovary, skeletal muscle, lung, liver, kidney, gut) }\end{array}$ \\
\hline Northern Blot ${ }^{g}$ & Hypothalamus $(+++)$, brainstem $(+++)$, hippocampus $(+++)$, stomach $(+)$, ileum $(+)$ \\
\hline Northern Blot ${ }^{a}$ & $\begin{array}{c}\text { Hypothalamus }(+++) \text {, thalamus }(+++) \text {, hippocampus }(+) \text {, cortex }(+) \text { (not detected in urinary bladder, testis, liver, } \\
\text { spleen, adrenal gland, kidney, lung, heart, pituitary) }\end{array}$ \\
\hline Northern Blot ${ }^{c}$ & $\begin{array}{c}\text { Hypothalamus }(+++) \text {, thalamus }(+++) \text {, hippocampus }(++) \text {, cortex }(++) \text {, medulla }(++) \text { (not detected in cerebellum, } \\
\text { striatum, heart, liver, kidney, adrenal glands, testis, ovaries, spleen) }\end{array}$ \\
\hline RT-PCR ${ }^{i}$ & Lumbar dorsal root ganglia, superior cervical ganglia, lumbar synpathetic ganglia \\
\hline RT-PCR ${ }^{j}$ & Vena cava $(+++)$, femoral vein $(++)$, aorta $(+)$, renal artery $(+)$, portal vein $(+)$ (not detected in jugular vein) \\
\hline RT-PCR ${ }^{k}$ & Frontocortical astrocytes, hypothalamus \\
\hline RT-PCR ${ }^{l}$ & Adrenal gland \\
\hline RT-PCR ${ }^{m}$ & Submandibular gland \\
\hline RT-PCR ${ }^{n}$ & Thymus, peripheral blood lymphocytes, spleen, mitogen activate spleen cells \\
\hline RT-PCR & Adrenal cortex \\
\hline RT-PCR ${ }^{p}$ & Jejunum, ileum, stomach fundus, esophagus, colon \\
\hline
\end{tabular}

${ }^{a}$ Meyerhof et al. (1993).

${ }^{b}$ Kinsey et al. (2001).

${ }^{c}$ Lovenberg et al. (1993).

${ }^{d}$ Mengod et al. (1996).

${ }^{e}$ Venero et al. (1997).

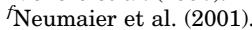

${ }^{g}$ Ruat et al. (1993b).

${ }^{h}$ Shen et al. (1993).

${ }^{i}$ Pierce et al. (1997)

${ }^{j}$ Ullmer et al. (1995).

${ }^{k}$ Shimizu et al. (1996)

${ }^{l}$ Contesse et al. (1999).

${ }^{m}$ Bourdon et al. (2000).

${ }^{n}$ Stefulj et al. (2000).

${ }^{o}$ Lenglet et al. (2000).

${ }^{p}$ Liu et al. (2001).

tissue type, with the $5-\mathrm{HT}_{7(\mathrm{~d})}$ isoform being most abundant in smooth muscle and least common in brain tissues (Krobert et al., 2001; Guthrie et al., 2005). In the rat, the $5-\mathrm{HT}_{7(\mathrm{a})}$ receptor isoform is most prevalent in both the CNS (cerebellum, cortex, hippocampus, hindbrain, thalamus) and the periphery (heart, kidney, spleen) (Heidmann et al., 1997, 1998).

2. Radioligand Binding. Radioligand binding assays have been used to study the distribution of $5-\mathrm{HT}_{7}$ receptor protein in native tissues. A first study to define $5-\mathrm{HT}_{7}$ receptor binding sites in rat hypothalamic membranes was performed using $\left[{ }^{3} \mathrm{H}\right] 5$ - $\mathrm{HT}$ in the presence of $100 \mathrm{nM}$ pindolol that blocks the binding of the radioligand to $5-\mathrm{HT}_{1 \mathrm{~A}}$ and $5-\mathrm{HT}_{1 \mathrm{~B}}$ receptors. The pharmacology of the identified binding sites correlated well with that of rat recombinant $5-\mathrm{HT}_{7}$ receptors (Sleight et al., 1995). A subsequent study showed that $100 \mathrm{nM}$ of pindolol does not completely mask 5 - $\mathrm{HT}_{1 \mathrm{~A}}$ and $5-\mathrm{HT}_{1 \mathrm{~B}}$ receptors and that the population of pindololinsensitive receptors labeled by $\left[{ }^{3} \mathrm{H}\right] 5-\mathrm{HT}$ in rat hypothalamus appeared to be heterogeneous (Gobbi et al., 1996). Also, $\left[{ }^{3} \mathrm{H}\right] 5$-CT failed to define a homogeneous population of $5-\mathrm{HT}_{7}$ binding sites in rat hypothalamus homogenates even in the presence of various masking agents (pindolol, sumatriptan, DOI) (Stowe and Barnes, 1998). $\left[{ }^{3} \mathrm{H}\right] 5-\mathrm{CT}$ has been used to label $5-\mathrm{HT}_{7}$ receptors in guinea pig brain cortex membranes in the presence of sumatriptan and cyanopindolol (To et al., 1995). The pharmacology of these binding sites was well correlated to that of the guinea pig cloned $5-\mathrm{HT}_{7}$ receptor. Because affinity values of reference compounds were consistently lower in the binding assay performed in native tissue, the authors hypothesized that sumatriptan and cyanopindolol were likely to occupy, at least in part, the $5-\mathrm{HT}_{7}$ receptors. $\left[{ }^{3} \mathrm{H}\right]$ Mesulergine labels $5-\mathrm{HT}_{7}$ receptors in guinea pig ileal longitudinal muscle in the presence of several masking agents (cinanserin, prazosin, raclopride, RS 102221, and yohimbine). However, under these same conditions, no binding was detected in the ratjejunum (Hemedah et al., 1999).

$\left[{ }^{3} \mathrm{H}\right] \mathrm{SB}-269970$ is the first selective radioligand to label with high affinity $5-\mathrm{HT}_{7}$ receptors in rat, mouse, guinea pig, pig, marmoset, and human brain homogenates. Guinea pig brain homogenate displays markedly higher $5-\mathrm{HT}_{7}$ receptor expression in comparison with 
TABLE 19

Localization and abundance of $5-\mathrm{HT}_{7}$ receptor mRNA in guinea pig, human, mouse, and pig

\begin{tabular}{|c|c|c|}
\hline Species & Technique & Localization (Relative Abundance) \\
\hline Guinea pig ${ }^{a}$ & In situ hybridization & $\begin{array}{c}\text { Hippocampus }(+++), \text { periventricular thalamus }(+++), \text { superficial cortex }(+++) \\
\text { cerebellar granule cells }(+++)\end{array}$ \\
\hline Guinea pig ${ }^{b}$ & In situ hybridization & $\begin{array}{c}\text { Medial thalamic nucleus }(+++) \text {, hippocampal formation }(+++) \text {, superficial layer cortex } \\
(++) \text {, medial geniculate nucleus }(++) \text {, amygdala }(++) \text {, hypothalamus }(++) \text {, midbrain }(+) \text {, } \\
\text { hindbrain }(+)\end{array}$ \\
\hline Guinea pig ${ }^{c}$ & In situ hybridization & Outer layer of the cortex, thalamus, hippocampus \\
\hline Guinea pig ${ }^{a}$ & Northern Blot & 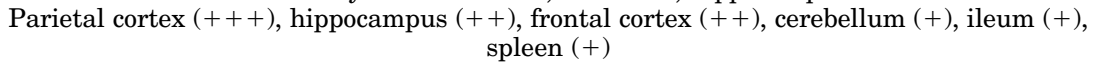 \\
\hline Guinea pig ${ }^{d}$ & Northern Blot ${ }^{b}$ & $\begin{array}{l}\text { Thalamus }(+++) \text {, brainstem }(+++) \text {, hypothalamus }(+++) \text {, substantia nigra }(+++) \text {, } \\
\text { olfactory bulb }(+++) \text {, olfactory tubercle }(+++) \text { (not detected in peripheral organs) }\end{array}$ \\
\hline Hamster ${ }^{e}$ & In situ hybridization & $\begin{array}{l}\text { Thalamus }(+++) \text {, cortex }(++) \text {, hypothalamus }(++) \text {, amygdala }(++) \text {, midbrain }(+) \text {, basal } \\
\text { forebrain }(+)\end{array}$ \\
\hline $\operatorname{Human}^{f}$ & RT-PCR & $\begin{array}{c}\text { Artery smooth cells }(+++) \text {, pulmonay artery smooth cells }(++) \text { (not detected in coronary } \\
\text { artery, pulmonary artery, aortic endothelial) }\end{array}$ \\
\hline Human ${ }^{g}$ & RT-PCR & Dorsal root ganglia \\
\hline Human ${ }^{h}$ & RT-PCR & Granulosa-lutein cells \\
\hline $\operatorname{Human}^{i}$ & RT-PCR & $\begin{array}{c}\text { Brain }(+++) \text {, kidney }(+) \text {, liver }(+) \text {, pancreas }(+) \text {, spleen }(+) \text {, coronary artery }(++) \text {, } \\
\text { stomach }(++) \text {, descending colon }(++) \text {, ileum }(++)\end{array}$ \\
\hline Human $^{j}$ & RT-PCR & Trigeminal ganglia \\
\hline Human $^{k}$ & qPCR & Colonic circular muscle \\
\hline Mouse ${ }^{l}$ & Northern Blot & Not detected in brain, heart, kidney, lung, liver \\
\hline Mouse $^{l}$ & RT-PCR & $\begin{array}{l}\text { Forebrain }(+++) \text {, brain stem }(+++) \text {, cerebellum }(++) \text {, colliculi }(++) \text {, intestine }(+) \text {, heart } \\
(+) \text {, not detected in spleen, kidney, lung, liver }\end{array}$ \\
\hline Mouse $^{m}$ & RT-PCR & Substantia gelatinosa of the trigeminal subnucleus caudalis \\
\hline $\mathrm{Pig}^{f}$ & RT-PCR & Pulmonary artery $(++)$, coronary artery $(++)$, cerebral artery $(++)$, cerebral vein $(++)$ \\
\hline Pig $^{n}$ & RT-PCR & Myometrium \\
\hline $\mathrm{Pig}^{\circ}$ & RT-PCR & $\begin{array}{l}\text { Brain cortex, trigeminal ganglion, cerebellum, pulmonary artery, coronary artery, superior } \\
\text { vena cava, saphenous vein, not detected in heart }\end{array}$ \\
\hline
\end{tabular}

${ }^{a}$ Tsou et al. (1994).

${ }^{b}$ To et al. (1995).

${ }^{c}$ Mengod et al. (1996).

${ }^{d}$ Ruat et al. (1993).

${ }^{e}$ Duncan and Franklin (2007).

fUllmer et al. (1995).

${ }^{g}$ Pierce et al. (1997).

${ }^{h}$ Graveleau et al. (2000).

${ }^{i}$ Bard et al. (1993).

${ }^{j}$ Terrón et al. (2001).

${ }^{k}$ Irwing et al. (2007).

${ }^{l}$ Plassat et al. (1993)

${ }^{m}$ Yang et al. (2014).

${ }^{n}$ Kitazawa et al. (2001)

${ }^{o}$ Bhalla et al. (2002).

rat, mouse, and pig brain homogenates (Thomas et al., 2002).

Autoradiographic studies on the localization of $5-\mathrm{HT}_{7}$ receptors have been performed by using various radioligands. $\left[{ }^{3} \mathrm{H}\right] 5-\mathrm{CT}$ has been used in the presence of various masking agents (To et al., 1995; Waeber and Moskowitz, 1995a; Gustafson et al., 1996; Mengod et al., 1996). In guinea pig and rat brain, the distribution of the $5-\mathrm{HT}_{7}$ receptor binding sites was largely consistent with that reported for $5-\mathrm{HT}_{7}$ receptor mRNA. The highest densities were in the medial thalamic nuclei and related limbic and cortical regions. However, as the detected densities were very low, it was hypothesized that the masking compounds might have sufficient affinity for $5-\mathrm{HT}_{7}$ receptor sufficient to compete with $\left[{ }^{3} \mathrm{H}\right] 5$-CT to some degree for the $5-\mathrm{HT}_{7}$ receptor. In a subsequent study, the localization of $5-\mathrm{HT}_{7}$ receptor was studied in $5-\mathrm{HT}_{1 \mathrm{~A}}$ receptor knockout and $5-\mathrm{HT}_{1 \mathrm{~A} / \mathrm{B}}$ receptor double-knockout mice by using $\left[{ }^{3} \mathrm{H}\right] 5-\mathrm{CT}$ $\left(5-\mathrm{HT}_{1 \mathrm{~A}}, 5-\mathrm{HT}_{1 \mathrm{~B}}\right.$, and $5-\mathrm{HT}_{7}$ agonist) and $\left[{ }^{3} \mathrm{H}\right] 8-\mathrm{OH}-$ DPAT (5- $\mathrm{HT}_{1 \mathrm{~A}}$ and $5-\mathrm{HT}_{7}$ agonist) (Bonaventure et al., 2002b). $\left[{ }^{3} \mathrm{H}\right] 8-\mathrm{OH}-\mathrm{DPAT}$ was better than $\left[{ }^{3} \mathrm{H}\right] 5-\mathrm{CT}$ for measuring $5-\mathrm{HT}_{7}$ receptor binding sites, even if it displays lower $5-\mathrm{HT}_{7}$ receptor affinity than $\left[{ }^{3} \mathrm{H}\right] 5-\mathrm{CT}$ in tissue homogenates. The anatomic distribution of the $\left[{ }^{3} \mathrm{H}\right] 8-\mathrm{OH}-\mathrm{DPAT}-\mathrm{labeled}$ sites observed in these knockout mice was in agreement with the distribution of $5-\mathrm{HT}_{7}$ receptor mRNA and immunoreactivity reported previously. Within the hippocampal formation, strong labeling was found in the CA3 region, whereas low binding was found in CA1 region. $5-\mathrm{HT}_{7}$ receptors were also found within the dorsal raphe and the hypothalamus, including the suprachiasmatic nucleus.

The selective high-affinity radioligand $\left[{ }^{3} \mathrm{H}\right] \mathrm{SB}-269970$ was used to localize the $5-\mathrm{HT}_{7}$ receptors in human brain (Varnäs et al., 2004; Fig. 27). The distribution of the $5-\mathrm{HT}_{7}$ receptors was largely similar to that shown by the autoradiographic studies in rat (Gustafson et al., 1996), guinea pig (To et al., 1995), and mouse (Martín-Cora and Pazos, 2004). High receptor density was detected in thalamus, hypothalamus, and hippocampus. However, unlike in rodents, human brain $5-\mathrm{HT}_{7}$ receptors were also found in high levels in caudate nucleus, putamen, and substantia nigra (Varnäs et al., 2004). Eventually, using $\left[{ }^{3} \mathrm{H}\right] \mathrm{SB}-269970$, Horisawa et al. (2013) reported that $5-\mathrm{HT}_{7}$ receptor distribution in rat brain was similar 
ISHH
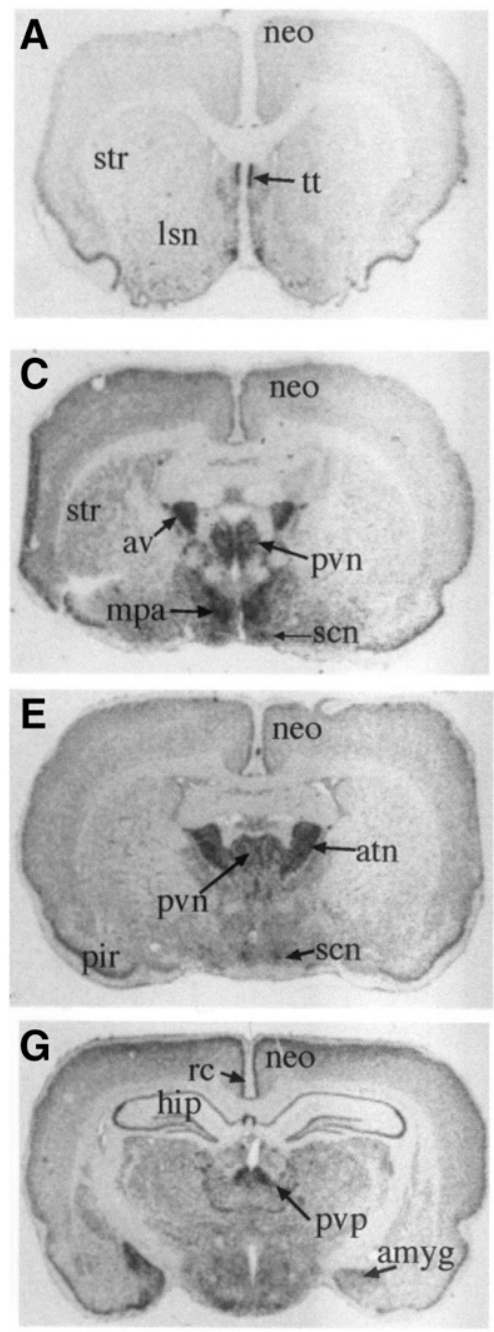
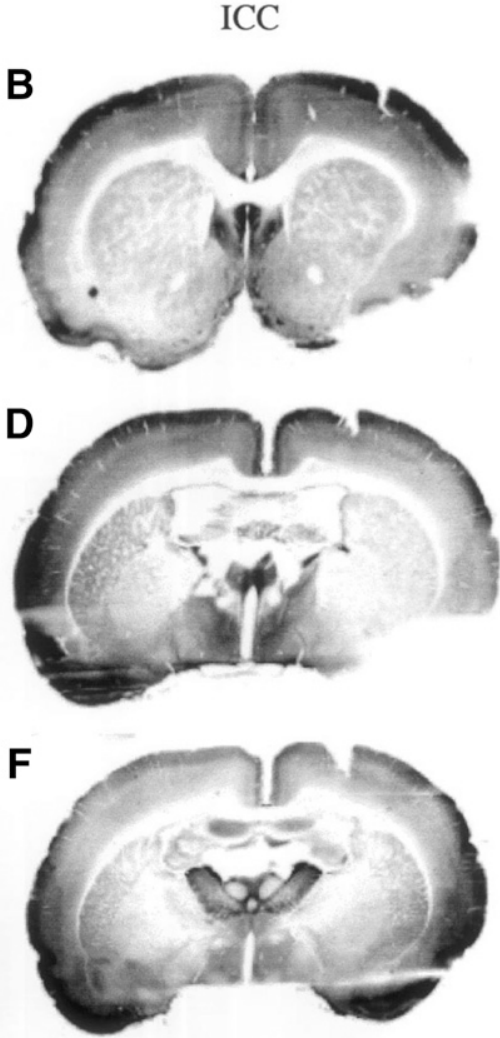

H

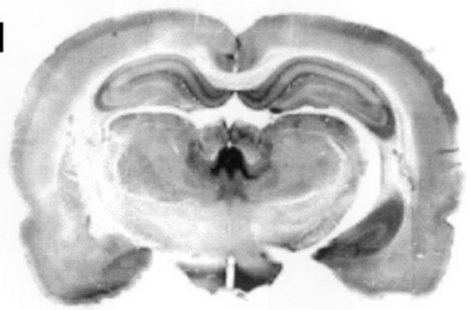

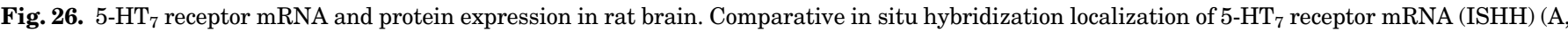

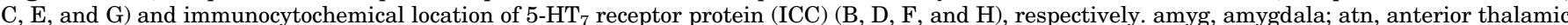

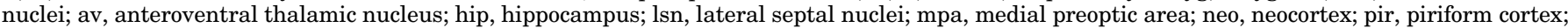

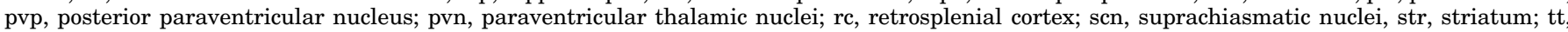
tenia tecta. Adapted from Neumaier et al. (2001) (with permission).

to that in human (Varnäs et al., 2004), with small differences in regions with an intermediate to low density of $5-\mathrm{HT}_{7}$ receptors.

3. Immunoreactivity. Rabbit polyclonal antibodies raised against amino acid sequence $8-23$ of the rat $5-\mathrm{HT}_{7}$ receptor are commercially available. Immunocytochemistry has been used to localize the distribution of $5-\mathrm{HT}_{7}$ receptors in rat forebrain (Neumaier et al., 2001), which were detected in the cortex, hippocampal formation, tenia tecta, thalamus, and hypothalamus, in agreement with the localization reported for the $5-\mathrm{HT}_{7}$ receptor mRNA. In particular, in the suprachiasmatic nucleus, both cell bodies and proximal fibers were strongly stained, suggesting a somatodentric subcellular distribution of the receptor. The presence of $5-\mathrm{HT}_{7}$ receptors was also reported in both pre- and postsynaptic GABA, vasoactive intestinal polypeptide, and vasopressin processes in the suprachiasmatic nucleus in mouse (Belenky and Pickard, 2001). 5- $\mathrm{HT}_{7}$ receptors are detected in Purkinje cells of rat cerebellum but not in the cerebellar cortex or in deep nuclei (Geurts et al., 2002).

$5-\mathrm{HT}_{7}$ receptor immunolabeling was detected mainly in the two superficial laminae of the dorsal horn and in small- and medium-sized dorsal root ganglion cells in the rat spinal cord (Doly et al., 2005), consistent with a predominant role of $5-\mathrm{HT}_{7}$ receptor in nociception. In addition, moderate labeling was found in the lumbar dorsolateral nucleus (Onuf's nucleus), suggesting an involvement of the receptor in the control of pelvic floor muscles (Doly et al., 2005). Electron microscopic examination of the dorsal horn shows three main localizations of the receptor: 1) a postsynaptic localization on peptidergic cell bodies in laminae I-III and in numerous dendrites, 2) a presynaptic localization on unmyelinated and thin myelinated peptidergic fibers, 


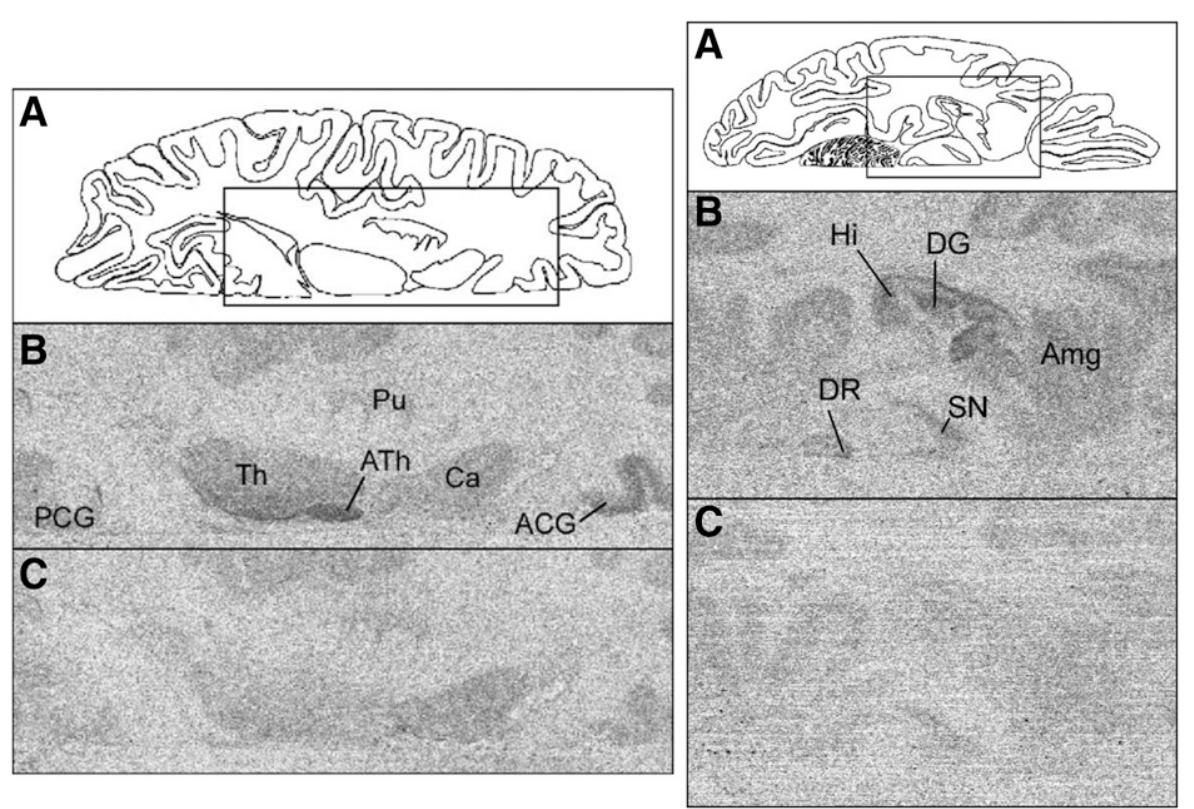

Fig. 27. $5-\mathrm{HT}_{7}$ receptor binding sites in human brain. Autoradiographic detection of $\left[{ }^{3} \mathrm{H}\right] \mathrm{SB}-269970$ binding to 5 - $\mathrm{HT}_{7}$ receptors in the human brain Autoradiograms showing the distribution of 5- $\mathrm{HT}_{7}$ receptors at the level of the thalamus (left column) and dorsal striatum (right column). (A) Plates; line drawings of brain hemisphere contours with square showing location of sections for the autoradiograms below. (B) Plates; total binding. (C) Plates; nonspecific binding (inclusion of 5-HT, $10 \mu \mathrm{M}$ ). ACG, anterior cingulate gyrus; Amg, amygdala; Ath, anterior thalamus; Ca, caudate nucleus; DG, dentate gyrus; DR, dorsal raphe; Hi, hippocampus; PCG, posterior cingulate gyrus; Pu, putamen; SN, substantia nigra; Th, thalamus. Adapted from Varnäs et al. (2004) (with permission).

and 3) in lamina I and II in astrocytes (Doly et al., 2005). $5-\mathrm{HT}_{7}$ receptors have been localized to numerous myenteric neurons, some submucosal neurons, and a few smooth muscle cells of guinea pig ileum (Tonini et al., 2005) and in human corneal epithelium and endothelium (Grueb et al., 2006). An upregulated expression of $5-\mathrm{HT}_{7}$ receptors was detected during maturation of bone marrow-derived dendritic cells, suggesting a critical role of $5-\mathrm{HT}_{7}$ receptors in the regulation of immune cell polarization and, thus, in the peripheral inflammatory processes (Holst et al., 2015).

\section{Pharmacology}

1. Agonists. Various selective $5-\mathrm{HT}_{7}$ receptor agonists have been identified (Table 20). The aminotetraline derivative AS-19 has a $K_{\mathrm{d}}$ of $0.6 \mathrm{nM}$ at human cloned $5-\mathrm{HT}_{7}$ receptors, with high selectivity over all the other 5-HT receptor subtypes (>100-fold) except $5-\mathrm{HT}_{1 \mathrm{D}}$ receptors (11-fold). However, AS-19 behaves as a potent partial $5-\mathrm{HT}_{7}$ receptor agonist $\left(\mathrm{EC}_{50}=9 \mathrm{nM}\right)$ with a maximal effect reaching $77 \%$ of that of $5-\mathrm{HT}$ in a functional assay measuring cAMP stimulation in HEK293F cells overexpressing human $5-\mathrm{HT}_{7}$ receptors (Brenchat et al., 2009), which can complicate interpretation of arising data using tissue and in vivo preparations.

E-55888 is another potent and selective $5-\mathrm{HT}_{7}$ receptor agonist with high efficacy, displaying high affinity for $5-\mathrm{HT}_{7}$ receptors $(K \mathrm{~d}=2.5 \mathrm{nM})$, low affinity for 5 - $\mathrm{HT}_{1 \mathrm{~A}}$ $(K \mathrm{~d}=700 \mathrm{nM})$, and no significant affinity for the other 5-HT receptors. E-55888 behaves as a full agonist $\left(\mathrm{EC}_{50}=16 \mathrm{nM}\right)$ and increases cAMP levels in HEK293F-expressing human $5-\mathrm{HT}_{7}$ receptors (Brenchat et al., 2009). Another selective $5-\mathrm{HT}_{7}$ receptor agonist is LP-211, with high but different affinities for rat and human recombinant $5-\mathrm{HT}_{7}$ receptors $(K \mathrm{~d}=0.58$ and $15.0 \mathrm{nM}$, respectively) and moderate to low affinity for other 5-HT receptors, including $5-\mathrm{HT}_{1 \mathrm{~A}}$ (Leopoldo et al., 2008; Hedlund et al., 2010). LP-211 induces 5-HT mediated relaxation of substance P-stimulated guinea pig ileum contracture ( $82 \%$ of the maximal effect elicited by 5-CT). However, in HEK293 cells stably expressing human 5- $\mathrm{HT}_{7}$ receptor (Atanes et al., 2013), LP-211 displayed insurmountable antagonism of 5-CT-stimulated cAMP signaling. These results were unexpected, as LP-211 have been extensively characterized as a $5-\mathrm{HT}_{7}$ receptor agonist in several ex vivo and in vivo studies [for review, see Di Pilato et al. (2014)]. The authors suggested that the inhibitory effects of LP-211 are due to an irreversible stabilization of an inactive conformational state of the receptor that is tightly associated with $\mathrm{G}_{\mathrm{s}}$ protein, independent of agonist binding (Bruheim et al., 2003; Andressen et al., 2006).

2. Antagonists. Various selective $5-\mathrm{HT}_{7}$ receptor antagonists have been identified (Table 20). The first was SB-258719, which displays useful $5-\mathrm{HT}_{7}$ receptor affinity $\left(K_{\mathrm{i}}=31.6 \mathrm{nM}\right)$ with 100 -fold selectivity against all the other 5-HT receptors (Forbes et al., 1998). In HEK293 cells stably expressing the human $5-\mathrm{HT}_{7}$ receptor, SB-258719 did not stimulate basal adenylyl cyclase activity, suggesting a lack of agonist activity, but produced a surmountable antagonism of the 5-CT response with a $\mathrm{p} K_{\mathrm{B}}$ of 7.0. Further chemical optimization of SB-258719 led to SB-269970, which is the 
TABLE 20

Binding profile of the selective $5-\mathrm{HT}_{7}$ receptor agonists and antagonists

$K_{\mathrm{i}}>1 \mu \mathrm{M}$ or percent inhibition at $1.0 \mu \mathrm{M}$ lower than $50 \%$.

\begin{tabular}{|c|c|c|c|c|c|c|}
\hline \multirow{3}{*}{ Receptor } & \multicolumn{6}{|c|}{ Affinity $\left(K_{\mathrm{i}}[\mathrm{nM}]\right)$} \\
\hline & \multicolumn{3}{|c|}{ Agonists/Partial Agonists } & \multicolumn{3}{|c|}{ Antagonists } \\
\hline & $\mathrm{E}-55888^{a}$ & $\mathrm{AS}-19^{a}$ & $\mathrm{LP}-211^{b}$ & SB-258719 ${ }^{c}$ & SB-269970 ${ }^{d}$ & SB-656104 ${ }^{e}$ \\
\hline h5-HT 7 & 0.6 & 2.5 & 15 & 31.6 & 1.3 & 2.0 \\
\hline $\mathrm{h} 5-\mathrm{HT}_{1 \mathrm{~A}}$ & 89.7 & 700 & 379 & $>7900$ & $>10,000$ & 562 \\
\hline $\mathrm{h} 5-\mathrm{HT}_{1 \mathrm{~B}}$ & ND & ND & 215 & $>5000$ & $>1000$ & 630 \\
\hline $\mathrm{r} 5-\mathrm{HT}_{1 \mathrm{~B}}$ & 490 & n.s. & ND & ND & ND & ND \\
\hline h5-HT $1 \mathrm{D}$ & 6.6 & n.s. & 394 & 3162 & 1584 & 25 \\
\hline $\mathrm{b} 5-\mathrm{HT}_{1 \mathrm{D}}$ & n.s. & n.s. & ND & ND & ND & ND \\
\hline h5-ht $1 \mathrm{e}$ & ND & ND & $>10,000$ & $>10,000$ & $>6000$ & $>5000$ \\
\hline h5-HT ${ }_{2 \mathrm{~A}}$ & n.s. & n.s. & 626 & $>10,000$ & $>10,000$ & 63 \\
\hline h5-HT $2 \mathrm{~B}$ & n.s. & n.s. & 67 & $>5000$ & 10,000 & 91 \\
\hline h5 $5-\mathrm{HT}_{2 \mathrm{C}}$ & n.s. & n.s. & ND & $>10,000$ & 10,000 & 269 \\
\hline $\mathrm{r} 5-\mathrm{HT}_{2 \mathrm{C}}$ & ND & ND & 91 & ND & ND & ND \\
\hline $\mathrm{h} 5-\mathrm{HT}_{3}$ & n.s. & n.s. & $>10,000$ & ND & ND & ND \\
\hline h5-HT & ND & n.s. & ND & $>10,000$ & 1259 & 1900 \\
\hline h5-HT & 98.5 & n.s. & 178 & ND & 63 & 182 \\
\hline h5-HT 6 & n.s. & n.s. & 1571 & $>10,000$ & 6300 & 851 \\
\hline h5-HT transporter & n.s. & n.s. & 812 & ND & ND & ND \\
\hline
\end{tabular}

ND, not determined; n.s., not significant.

${ }^{a}$ Data taken from Brenchat et al. (2009).

${ }^{b}$ Data taken from Hedlund et al. (2010).

${ }^{c}$ Data taken from Forbes et al. (1998).

${ }^{d}$ Data taken from Lovell et al. (2000).

${ }^{e}$ Data taken from Thomas et al. (2003).

prototype $5-\mathrm{HT}_{7}$ receptor antagonist (Hagan et al., 2000). SB-269970 displays high affinity at both human cloned $5-\mathrm{HT}_{7}$ receptors $\left(\mathrm{p} K_{\mathrm{i}}=8.9\right)$ and in guinea pig cortex $\left(\mathrm{p} K_{\mathrm{i}}=8.3\right)$. The compound is at least 100 -fold selective against a wide range of receptors, except for the human $5-\mathrm{HT}_{5 \mathrm{~A}}$ receptor (about 50-fold). SB-269970 displays potent antagonism in both HEK293 cells stably expressing the $5-\mathrm{HT}_{7}$ receptor $\left(\mathrm{pA}_{2}=8.5\right)$ and in the guinea pig hippocampal membranes $\left(\mathrm{p} K_{\mathrm{B}}=8.3\right)$. SB-269970 also produces a small inhibition of basal adenylyl cyclase activity in the absence of added 5-CT, consistent with inverse agonism (Hagan et al., 2000). Subsequent studies led to the identification of the antagonist SB-656104, which is as potent as SB-269970 $\left(K_{\mathrm{i}}=2 \mathrm{nM}\right.$; $\left.\mathrm{pA}_{2}=8.4\right)$ but displays only 10 -fold selectivity over the $5-\mathrm{HT}_{1 \mathrm{D}}$ receptor. Both SB-269970 and SB-656104 are brainpenetrant, and the latter is more stable metabolically (Thomas et al., 2003).

3. Allosteric Modulators. Oleamide, an amidated fatty acid, is an allosteric modulator of the $5-\mathrm{HT}_{7}$ receptor (Thomas et al., 1997a, 1999,b; Hedlund et al., 1999; Alberts et al., 2001). In cells expressing the $5-\mathrm{HT}_{7}$ receptor, oleamide increases cAMP accumulation in a concentration-dependent manner but with a lower efficacy than 5-HT. In the presence of 5-HT, oleamide displayed the opposite effect on cAMP, causing insurmountable antagonism of 5-HT, suggesting that oleamide acts at an allosteric site on the $5-\mathrm{HT}_{7}$ receptor. In receptor-binding studies, oleamide modulated the binding properties of $5-\mathrm{HT}_{7}$ receptors expressed in vitro (Hedlund et al., 1999). In addition, the binding of both agonists and antagonists at human recombinant $5-\mathrm{HT}_{7}$ receptors stably expressed in HEK293 cells was allosterically inhibited by zinc (Satała et al., 2018).

\section{E. Signaling}

The $5-\mathrm{HT}_{7}$ receptor is positively coupled to adenylyl cyclase through activation of $\mathrm{G}_{\mathrm{s}}$, resulting in intracellular increase in cAMP (Bard et al., 1993; Lovenberg et al., 1993a; Ruat et al., 1993b). The human, rat, and mouse splice variants all activate adenylyl cyclase (Heidmann et al., 1998; Krobert et al., 2001; Krobert and Levy, 2002; Gellynck et al., 2008) and do not show evident differences in their respective pharmacology and signal transduction properties or functional coupling to $\mathrm{G}_{\mathrm{s}}$ protein (Heidmann et al., 1998; Krobert et al., 2001). The only reported functional difference is that the human $5-\mathrm{HT}_{7(\mathrm{~d})}$ receptor displays a differential pattern of receptor internalization (Guthrie et al., 2005). Furthermore, variation in the length of the C-terminal tails and in the number of consensus sites for phosphorylation by PKA and PKC raises the possibility that the splice variants can display different desensitization or trafficking properties (Heidmann et al., 1997). Moreover, the human $5-\mathrm{HT}_{7(\mathrm{~b})}$ and the rat $5-\mathrm{HT}_{7(\mathrm{~b})}$ and $5-\mathrm{HT}_{7(\mathrm{c})}$ receptor splice variants contain recognition sites for PDZ domain-containing proteins (Hamblin et al., 1998), suggesting that these splice variants may be targeted to active zones within cells and may couple to alternative signaling pathways.

Stimulation of the human $5-\mathrm{HT}_{7(\mathrm{a})}$ receptor in HEK293 cells coexpressed with various adenylyl cyclase isoforms revealed that this receptor not only activates the $\mathrm{G}_{\mathrm{s}}$-sensitive AC5 isoform but also the $\mathrm{G}_{\mathrm{s}}$-insensitive 
and $\mathrm{Ca}^{2+}$ /calmodulin-stimulated $\mathrm{AC} 1$ and $\mathrm{AC} 8$ isoforms (Nielsen et al., 1996; Xia and Storm, 1997; Baker et al., 1998).

$5-\mathrm{HT}_{7}$ receptor expression density does not appear to influence agonist or partial agonist potency (or efficacy), suggesting the absence of receptor reserve effects (Bruheim et al., 2003; Andressen et al., 2006) and implying independence from receptor- $\mathrm{G}_{\mathrm{s}}$ stoichiometry. This may also suggest the $5-\mathrm{HT}_{7}$ receptor is preassociated with $\mathrm{G}_{\mathrm{s}}$ (Adham et al., 1998; Alberts et al., 2001; Krobert et al., 2001), which was supported by a more recent study investigating receptor-immobilized fluorescence recovery after photobleaching and fluorescence resonance energy transfer (Andressen et al., 2018) to compare the $\mathrm{G}_{\mathrm{s}}$ coupling of the $5-\mathrm{HT}_{7}$ and $5-\mathrm{HT}_{4}$ receptors.

Prolonged stimulation by 5 -HT induces both homoand heterologous desensitization of $\mathrm{G}_{\mathrm{s}}$ signaling in HEK293 cells. A similar effect is seen on prolonged incubation with the inverse agonists SB-269970 and methiothepin, implying that desensitization is independent of $\mathrm{G}_{\mathrm{s}}$ activation (Krobert et al., 2006).

Clozapine and olanzapine, which are $5-\mathrm{HT}_{7}$ receptor inverse agonists [see Krobert and Levy (2002)], display functional selectivity at the human $5-\mathrm{HT}_{7}$ receptor (i.e., different ligands at the same receptor elicit different functional effects) (Andressen et al., 2015). Thus, clozapine and olanzapine downregulate $5-\mathrm{HT}_{7}$ receptors expressed in HEK293 cells, an effect normally evident for agonists but not for antagonists or inverse agonists. This inverse agonist-mediated receptor downregulation may be mediated by interaction with the G protein-associated sorting protein GASP-1 (Manfra et al., 2015).

In rat hippocampal neurons, 5-HT stimulation leads to the activation of serine/threonine kinases ERK1 and ERK2, and most of this activity is mediated by $5-\mathrm{HT}_{7}$ receptors (Errico et al., 2001). A PKA-dependent pathway for $5-\mathrm{HT}_{7}$ receptor-mediated ERK1 and ERK2 activation has been proposed (Norum et al., 2003, 2005). $5-\mathrm{HT}_{7}$ receptor activation increases intracellular cAMP levels to activate PKA, which phosphorylates the guanine nucleotide exchange factor (GEF) Ras-GRF1 that controls the activity of Ras, an upstream activator of c-Raf (or Raf-1; a member of the Raf kinase family; Norum et al., 2003). Consequently, c-Raf phosphorylates and activates various kinases, including MEK1 and, further downstream, ERK1/2. An alternative pathway could involve the activation of GEF proteins Epac1 and Epac2 by cAMP, which in turn activate the Rap1 proteins through GDP-GTP exchange. GTP-bound Rap1 proteins can bind and activate different members of the Raf kinase family (i.e., B-Raf, A-Raf, and c-Raf), leading to ERK1/2 activation (Norum et al., 2005). The contribution of these GEFs in the ERK1/2 activation pathway mediated by $5-\mathrm{HT}_{7}$ receptor has been demonstrated in the pheochromocytoma PC12 cells stably overexpressing
$5-\mathrm{HT}_{7}$ receptor and in rat hippocampal neurons (Lin et al., 2003; Johnson-Farley et al., 2005). Moreover, ERK1/2 seems to be required for normal neuronal function, such as neurotrophin-stimulated neuronal differentiation and neuroprotection as well as regulation of neurite outgrowth and formation of neuronal networks (Hetman et al., 1999; Speranza et al., 2013, 2015).

Stimulation of 5-HT 7 receptor expressed in HEK293 cells increases intracellular $\mathrm{Ca}^{2+}$ levels (Baker et al., 1998). However, the exact mechanism for this increase is not known. In rat adrenal glomerulosa cells, this $5-\mathrm{HT}_{7}$ receptor-mediated increase of intracellular $\mathrm{Ca}^{2+}$ levels is mediated by T-type $\mathrm{Ca}^{2+}$ channels in a cAMPPKA-dependent manner (Lenglet et al., 2002a,b), which is likely to contribute to ERK1/2 activation (Lin et al., 2003; Norum et al., 2003; Johnson-Farley et al., 2005).

The $5-\mathrm{HT}_{7}$ receptor interacts with the $\mathrm{G}_{12}$ member of the G protein family (Kvachnina et al., 2005; Kobe et al., 2012), which can activate multiple signaling pathways. The prominent downstream effectors are members of the Rho family of small GTPases (Rho, Rac, and Cdc42). $5-\mathrm{HT}_{7}$ receptor-mediated stimulation of $\mathrm{G}_{12}$ protein results in Rho-dependent activation of the transcription factor serum response factor, which binds to the serum response element (SRE). The stimulation of $5-\mathrm{HT}_{7}$ receptor increases SRE-driven gene expression even in the presence of a PKA inhibitor or pertussis toxin, suggesting that the receptor-mediated SRE activation is not PKA-dependent (Kvachnina et al., 2005). Stimulation of $5-\mathrm{HT}_{7}$ receptor/ $\mathrm{G}_{12}$ signaling pathway selectively activates both RhoA and Cdc42 (Kvachnina et al., 2005), suggesting a cross talk between Cdc 42 and RhoA pathways. The $5-\mathrm{HT}_{7}$ receptor/ $\mathrm{G}_{12}$ signaling pathway in cultured hippocampal neurons promotes formation of dendritic spines and accelerates synaptogenesis, leading to enhanced spontaneous synaptic activity (Kobe et al., 2012). A morphogenic action of the $5-\mathrm{HT}_{7}$ receptor is confirmed in neuronal primary cultures from the cortex, hippocampus, and striatal complex of embryonic rat or mouse brain (Speranza et al., 2013, 2015) and postnatal cortical and striatal neurons (Speranza et al., 2017). The involvement of mTOR, Cdc42, Cdk5, and ERK in this process suggests these proteins to be downstream targets of $\mathrm{G}_{12}$ (Speranza et al., 2013, 2015). In the hippocampus, the $5-\mathrm{HT}_{7}$ receptor $/ \mathrm{G}_{12}$ signaling pathway undergoes strong developmental regulation. In organotypic hippocampal cultures from juvenile mice, $\mathrm{G}_{12}$ signaling potentiates formation of dendritic spines, increases the basal neuronal excitability, and modulates synaptic plasticity. In contrast, in preparations from older mice, $5-\mathrm{HT}_{7}$ receptor stimulation had no effect on neuronal morphology, synaptogenesis, and synaptic plasticity (Kobe et al., 2012). Consistently, the expression level of both $5-\mathrm{HT}_{7}$ receptor and $\mathrm{G}_{12}$ proteins in the hippocampus 
progressively decreases during postnatal development (Kobe et al., 2012).

\section{F. Post-translational Modifications}

1. Regulatory Mechanisms. The $5-\mathrm{HT}_{7}$ receptor appears to undergo $N$-glycosylation and palmitoylation. The receptor is $N$-glycosylated at the asparagine residues N5 and N66 (Gellynck et al., 2012), but this does not appear to influence agonist binding, potency, or efficacy. Furthermore, immunocytochemical studies revealed the presence of the $N$-glycosylation mutants at the cell surface.

The mouse $5-\mathrm{HT}_{7}$ receptor expressed in $\mathrm{Sf9}$ insect cells undergoes dynamic palmitoylation in an agonistdependent manner (Kvachnina et al., 2009). Mutation analysis shows that cysteines located in the C-terminal receptor domain at positions 404, 438, and 441 represent the main potential palmitoylation sites. Palmitoylationdeficient mutants reveal that agonist-induced activation of $\mathrm{G}_{\mathrm{s}}$ and $\mathrm{G}_{12}$ proteins is unaffected. Instead, mutation of the Cys404 alone or in combination with Cys438/Cys441 increases $\mathrm{G}_{\mathrm{s}}$-mediated constitutive activity of the $5-\mathrm{HT}_{7}$ receptor (agonist-independent), whereas the activation of $\mathrm{G}_{12}$ protein is not affected. Thus, palmitoylation of $5-\mathrm{HT}_{7}$ receptors might be directly involved in the isomerization of the receptor from the inactive to the active form in the absence of agonists. Considering that the $5-\mathrm{HT}_{7}$ receptor is coupled to both $\mathrm{G}_{\mathrm{s}}$ and $\mathrm{G}_{12}$ proteins, dynamic palmitoylation may represent a molecular mechanism responsible for selective $\mathrm{G}_{\mathrm{s}^{-}}$or $\mathrm{G}_{12}$-mediated signaling.

2. Interacting Proteins. Apart from $\mathrm{G}$ proteins, only a few $5-\mathrm{HT}_{7}$ receptor-interacting proteins have been described. Interacting proteins mostly act as adaptor or scaffolding proteins and help in trafficking of the receptor, not only to the plasma membrane but also in receptor internalization, recycling, and degradation. Among the many regulatory proteins that are involved in GPCR desensitization and downregulation, GPCRassociated sorting proteins (GASPs) participate in the sorting of several receptors toward the degradation pathway (Bornert et al., 2013). GASP-1 and GASP-2 interact with several GPCRs, including $5-\mathrm{HT}_{7}$ receptors, through interaction of C-terminal tails containing two critical amino acid residues within the sequence that corresponds to helix 8 in the three-dimensional structure of rhodopsin (Simonin et al., 2004).

PLAC-24 (protein that localizes at cell-cell contacts), also known as the eukaryotic initiation of translation factor 3 , subunit $\mathrm{k}$, is another intracellular interaction partner for all three splice variants of the human $5-\mathrm{HT}_{7}$ receptor (De Martelaere et al., 2007). PLAC-24 might be involved in the transport of newly synthesized $5-\mathrm{HT}_{7}$ receptors toward the plasma membrane, as this transport is hampered by the overexpression of certain domain constructs of PLAC-24. PLAC-24 has been proposed to be additionally involved in the stabilization of the receptor at the cell surface by anchoring it at the actin cytoskeleton, as PLAC-24 might be part of a multisubunit complex that links the actin and microtubule cytoskeleton and causes an increase in the expression of the receptor.

Periplakin (an actin- and intermediate filamentbinding protein) and the neurite-outgrowth promoting protein, neurochondrin, strongly interact with the C-terminal tail of 5- $\mathrm{HT}_{7}$ receptor. The functional consequences of these specific interactions are not yet known (Ward et al., 2009).

RhoBTB3, a member of the Ras superfamily of small GTPases, is expressed in several brain regions where the $5-\mathrm{HT}_{7}$ receptor is also localized, including hippocampus and nucleus accumbens. The physical interaction between the $5-\mathrm{HT}_{7 \mathrm{a}}$ receptor and RhoBTB3 has been demonstrated through yeast two hybrid, GST pulldown, and coimmunoprecipitation assays (Matthys et al., 2012). Not only the C-terminal tail but also the third intracellular loop of the $5-\mathrm{HT}_{7 \mathrm{a}}$ receptor seem to be involved in the interaction. The $5-\mathrm{HT}_{7 \mathrm{a}}$ receptor may be targeted for proteasomal degradation following endocytosis at the plasma membrane, and RhoBTB3 appears to strongly inhibit proteasomal degradation of the receptor. $\mathrm{S} 100 \mathrm{~B}$ is a $\mathrm{Ca}^{2+}$-regulatory protein that controls $\mathrm{Ca}^{2+}$ homeostasis in various cell types, including astrocytes. S100B also regulates the activity of adenylyl cyclase in preparations from rat brain and skeletal muscle (Donato et al., 2009). S100B physically interacts with $5-\mathrm{HT}_{7}$ receptors; it negatively regulates cAMP accumulation in $5-\mathrm{HT}_{7}$-transfected HeLa cells and mouse cortical astrocytes. Overexpression of S100B causes brain region-specific dysregulation of cAMP pathways in vivo that may relate to depressive-like behavior, which can be normalized by $5-\mathrm{HT}_{7}$ receptor blockade by SB-269970 (Stroth and Svenningsson, 2015).

For further discussion of interacting proteins, see XVII. B. A Survey of 5-HT Receptor GIPs.

3. Homo- and Heteromeric Receptor Associations. GPCRs can form oligomers, and it is now widely accepted that homo- and heterodimerization provides an additional mechanism for regulating cellular processes through the fine tuning of receptor-mediated signaling (Devi, 2001; Bulenger et al., 2005). The 5-HT receptor forms homodimers in both intact HEK293 cells and neuroblastoma N1E-115 cells transfected with $5-\mathrm{HT}_{7}$ receptor and rat cortical astrocytes (Teitler et al., 2010; Smith et al., 2011; Renner et al., 2012; Teitler and Klein, 2012).

Heterodimerization between $5-\mathrm{HT}_{1 \mathrm{~A}}$ and $5-\mathrm{HT}_{7}$ receptors has been demonstrated by coimmunoprecipitation and by fluorescence resonance energy transfer approaches (Renner et al., 2012); the coimmunoprecipitation studies in mouse brain provide direct evidence that $5-\mathrm{HT}_{1 \mathrm{~A}}$ and 5 - $\mathrm{HT}_{7}$ receptors can form heterodimers in vivo. Such heterodimerization alters the signaling properties of the $5-\mathrm{HT}_{1 \mathrm{~A}}$ receptor by attenuating the ability of $5-\mathrm{HT}_{1 \mathrm{~A}}$ 
receptor to activate $G_{i}$ protein, in contrast to $5-\mathrm{HT}_{7}$ receptor-mediated activation of Gs protein, which is not affected. In addition, heterodimerization reduces the ability of $5-\mathrm{HT}_{1 \mathrm{~A}}$ receptors to activate GIRK channels, an effect mediated through the $\mathrm{G} \beta \gamma$ subunits of $\mathrm{G}_{\mathrm{i}}$ proteins (Reuveny et al., 1994; Kofuji et al., 1995). The inhibitory effect of heterodimerization on GIRK currents is also evident in mouse hippocampal neurons, suggesting a physiologic relevance in vivo.

Heterodimerization between the $5-\mathrm{HT}_{1 \mathrm{~A}}$ and $5-\mathrm{HT}_{7}$ receptors appears to promote agonist-mediated internalization of the $5-\mathrm{HT}_{1 \mathrm{~A}}$ receptor $\left(5-\mathrm{HT}_{1 \mathrm{~A}}\right.$ receptors expressed alone are relatively resistant to the agonistinduced internalization). The pharmacological blockade of $5-\mathrm{HT}_{7}$ receptors, but not of $5-\mathrm{HT}_{1 \mathrm{~A}}$ receptors, abolishes internalization of both $5-\mathrm{HT}_{7}$ homo- and heterodimers, suggesting that $5-\mathrm{HT}_{7}$ receptor-mediated signaling is an initial step responsible for $5-\mathrm{HT}_{1 \mathrm{~A}}$ receptor cointernalization. Once internalized, $5-\mathrm{HT}_{1 \mathrm{~A}}$ receptors can activate $\mathrm{G}$ protein-independent signaling pathways such as a $\beta$-arrestin-mediated coupling to MAPK. Thus, depending on the relative amount of $5-\mathrm{HT}_{1 \mathrm{~A}}$ receptors participating in dimers, stimulation by 5 -HT can activate distinct ERK-mediated pathways (i.e., G proteindependent or $\beta$-arrestin-dependent), further implicating the physiologic relevance of heterodimerization.

\section{G. Function}

Hedlund et al. (2003) first reported on the generation of $5-\mathrm{HT}_{7} \mathrm{KO}$ mice by targeted disruption within exon II of the $5-\mathrm{HT}_{7}$ receptor gene, thus inactivating all known splice variants of the receptor. 5 - $\mathrm{HT}_{7} \mathrm{KO}$ mice (Roberts et al., 2004a; Guscott et al., 2005) grow and reproduce, normally suggesting that the receptor does not play an essential role during development. These mice also have normal body weight and basal rectal temperature and appear to be in good health (Guscott et al., 2005). No differences are detected between $5-\mathrm{HT}_{7} \mathrm{KO}$ mice and the wild-type littermates in general motor ability, visual acuity, pain sensitivity, anxiety-like behavior, or the capacity to show freezing behavior in the habituation, conditioning, or cued components of the cued and contextual conditioning procedure (Roberts et al., 2004a). Also, in the prepulse inhibition paradigm, no difference is observed in the $5-\mathrm{HT}_{7}$ receptor $\mathrm{KO}$ mice (Guscott et al., 2005; Semenova et al., 2008).

1. Thermoregulation. $5-\mathrm{HT}_{7}$ agonists induce a considerable hypothermic response in vivo in various species (Yamada et al., 1988; Won and Lin, 1988; Sugimoto et al., 1991; Guscott et al., 2003; Hedlund et al., 2003, 2004; Naumenko et al., 2011). Initially, the $5-\mathrm{HT}_{1 \mathrm{~A}}$ receptor was thought responsible, largely on the basis of data obtained using the 5 - $\mathrm{HT}_{1 \mathrm{~A}}$ receptor agonist 8-OH-DPAT (Hjorth, 1985) before this drug was also recognized as a $5-\mathrm{HT}_{7}$ receptor agonist (Guscott et al., 2003; Hedlund et al., 2003, 2004). It appears the $5-\mathrm{HT}_{7}$ receptor is more important at lower 5 -HT concentrations, playing a role in the fine tuning of temperature homeostasis, whereas the $5-\mathrm{HT}_{1 \mathrm{~A}}$ receptor is activated at higher 5-HT concentrations, possibly as a defense against hyperthermia (Hedlund et al., 2004), such that both 5-HT $1 \mathrm{~A}$ and $5-\mathrm{HT}_{7}$ receptors are important (Brenchat et al., 2012a).

2. Learning and Memory. $5-\mathrm{HT}_{7}$ receptor $\mathrm{KO}$ mice under certain types of examination can display specific impairments in contextual learning. Two forms of place learning, spatial (Barnes maze) and contextual (fear conditioning), in addition to three hippocampusdependent learning tests have been studied (motor, cued conditioning, and operant conditioning) to demonstrate effects of $5-\mathrm{HT}_{7}$ receptor $\mathrm{KO}$ mice in contextual fear conditioning, whereas there was no evident effect in the other learning tests. Of potential relevance, electrophysiological studies on hippocampal slices from $5-\mathrm{HT}_{7}$ receptor $\mathrm{KO}$ mice demonstrate deficits in longterm potentiation (Roberts et al., 2004).

Further behavioral studies demonstrate hippocampus-associated spatial memory deficits in $5-\mathrm{HT}_{7}$ receptor KO mice (impairments in memory compilation required for resolving spatial tasks), which result in impaired hippocampus-dependent allocentric memory (Sarkisyan and Hedlund, 2009), whereas no effect was evident in the novel object recognition test. Egocentric spatial memory, which is striatum-dependent, remains intact. On the other hand, $5-\mathrm{HT}_{7}$ receptor $\mathrm{KO}$ mice do not exhibit learning impairments and/or dysfunctions in short-term memory if the environment remains static, such as in the Barnes maze test. In the same test, $5-\mathrm{HT}_{7}$ receptor $\mathrm{KO}$ mice have no impairment in long-term memory or memory consolidation.

3. Antipsychotic Potential. 5- $\mathrm{HT}_{7}$ receptor antagonists have been evaluated in animal models used to test antipsychotic-like activity. The selective 5 - $\mathrm{HT}_{7}$ receptor antagonist SB-258741 reverses hyperactivity induced by PCP in rats (Pouzet et al., 2002). SB-269970 partially but significantly blocks hyperactivity induced by ketamine in mice (Galici et al., 2008). Furthermore, $5-\mathrm{HT}_{7}$ receptor $\mathrm{KO}$ mice display less pronounced deficits in the PCP-induced prepulse inhibition compared with WT mice (Semenova et al., 2008), although this effect was not replicated by SB-269970 treatment (Semenova et al., 2008). Collectively, the available data suggest that the antipsychotic-like activity elicited by selective $5-\mathrm{HT}_{7}$ receptor blockade is weaker than that obtained with clinically proven antipsychotic drugs (Thomas and Hagan, 2004).

Current antipsychotic drugs are not very effective to reverse the cognitive deficits associated with schizophrenia. Cognitive impairments induced by subchronic PCP administration in rats are believed to mimic cognitive deficits in schizophrenia (Javitt and Zukin, 1991; Jentsch and Roth, 1999). PCP selectively impairs performance in reversal learning test (Abdul-Monim et al., 2006, 2007; McLean et al., 2009a), attentional setshifting test (McLean et al., 2008), and novel object 
recognition test (a paradigm for studying visual episodic memory) (Grayson et al., 2007). The acute administration of SB-269970 reverses subchronic PCP-induced deficits in a reversal learning task in rats (McLean et al., 2009b) and in the novel object recognition test in rats (Horiguchi et al., 2011). Pretreatment with SB269970 or lurasidone reverses the subchronic PCPinduced deficit in reversal learning in mice (Rajagopal et al., 2016). This effect was not elicited by the agonist AS-19, confirming that antagonism, but not agonism, at $5-\mathrm{HT}_{7}$ receptors restores function in principal cortical neurons impaired by NMDA receptor blockade.

Cognitive deficits in mice induced by dizocilpine are also used to model impaired working memory in schizophrenia. SB-269970 reverts dizocilpine-induced cognitive deficits in a translational behavioral model of working memory, the delayed nonmatching to position task. At a neurochemical level, SB-269970 normalizes the dizocilpine-induced glutamate efflux but not dizocilpine-induced dopamine extracellular levels in the cortex of freely moving rats (Bonaventure et al., 2011). SB-269970 also reverses dizocilpine-induced memory deficits in an autoshaping Pavlovian instrumental learning task in rats (Meneses, 2004). Moreover, 5- $\mathrm{HT}_{7}$ receptor blockade by another antagonist, SB-656104, reverses dizocilpine-induced learning and memory impairments in the passive avoidance and Morris water maze tests in rats (Horisawa et al., 2011).

Ketamine-based animal models represent a valuable tool in preclinical research because ketamine is commonly used in the clinic to model the transient neurocognitive impairments in healthy volunteers (Krystal et al., 1994). Acute administration of SB-269970 in rats ameliorates ketamine-induced cognitive deficits in the attentional set-shifting task (a measure of cognitive flexibility) and the novel object recognition test (Nikiforuk et al., 2013). SB-269970 reverses memory deficits in an autoshaping Pavlovian instrumental learning task in rats after an intraprefrontal infusion of ketamine (Liy-Salmeron and Meneses, 2008).

Experimental evidences suggest a role of $5-\mathrm{HT}_{7}$ receptor blockade in the procognitive actions of the atypical antipsychotics amisulpride and lurasidone. Both drugs ameliorate the PCP-induced deficits in the novel object recognition task in rats (Horiguchi et al., 2011). This effect is reversed by coadministration of the selective $5-\mathrm{HT}_{7}$ agonist AS-19. Lurasidone attenuates the dizocilpine-induced deficits in the passive avoidance test in rats. Also, in this case, AS-19 abolishes the effect of lurasidone (Horisawa et al., 2013).

The pharmacological blockade of $5-\mathrm{HT}_{7}$ receptors may also have therapeutic implications for the treatment of negative symptoms in schizophrenia because SB-269970 ameliorates ketamine-induced social withdrawal in rats (Nikiforuk and Popik, 2013). Consistently, acute administration of amisulpride reverses ketamine-induced social withdrawal. The prosocial efficacy of amisulpride is abolished by the agonist AS-19. Finally, coadministration of subactive doses of SB-269970 and amisulpride results in prosocial effects in rats (Hołuj et al., 2015).

4. Antidepressant-Like Behavior. 5- $\mathrm{HT}_{7}$ receptor KO mice have an antidepressant-like behavior, with reduced immobility in commonly used preclinical animal models of depression, such as the tail suspension test (TST) and the forced swim test (Guscott et al., 2005; Hedlund et al., 2005; Sarkisyan et al., 2010). The decreased immobility in both models is most likely not due to a general increase in motor activity, as no genotype difference in locomotor activity or motor learning were evident between $5-\mathrm{HT}_{7}$ receptor $\mathrm{KO}$ and WT mice (Roberts et al., 2004).

Because 5- $\mathrm{HT}_{7}$ receptor $\mathrm{KO}$ mice display an antidepressant-like behavior, the potential role of the $5-\mathrm{HT}_{7}$ receptor was also investigated in OCD models: it is recognized OCD involves the 5-HT system and patients may benefit from antidepressant therapy. Thus, $5-\mathrm{HT}_{7}$ receptor $\mathrm{KO}$ mice have been tested in three models believed to mimic some of the stereotypic aspects of OCD (Hedlund and Sutcliffe, 2007). Inactivation of the $5-\mathrm{HT}_{7}$ receptor leads to decreased marble burying, a model linked to OCD and anxiety. However, there is no difference between $5-\mathrm{HT}_{7}$ receptor $\mathrm{KO}$ and $\mathrm{WT}$ mice in the two other models (i.e., head dipping and plasticmesh screen chewing models). Thus, a possible role of the receptor in OCD remains an open question.

5. Sleep. Overall, a normal sleep pattern is observed in $5-\mathrm{HT}_{7}$ receptor $\mathrm{KO}$ mice, although during rest, $5-\mathrm{HT}_{7}$ receptor KO mice spend less time in REM sleep (with less frequent but longer REM episodes) compared with WT mice (Hedlund et al., 2005). There is no difference between the genotypes in time spent awake or in slow wave sleep, and the frequency of slow wave sleep episodes is not altered. These sleep patterns of $5-\mathrm{HT}_{7}$ receptor $\mathrm{KO}$ mice are in agreement with the antidepressant-like profile observed in this genotype.

A variety of circadian parameters in $5-\mathrm{HT}_{7}$ receptor $\mathrm{KO}$ mice, including rate of entrainment and photic responsiveness, have been investigated. There are no evident differences in the average number of days that $5-\mathrm{HT}_{7}$ receptor $\mathrm{KO}$ mice need to reach entrainment to an advance of 6 hours in the light/dark cycle compared with WT mice (Gardani and Biello, 2008). Both groups of mice display minimal effects to light stimulation during the subjective day, whereas, during the early night, light induces phase delays and, later in the subjective night, results in advances of the circadian phase.

Similarly, administration of the $5-\mathrm{HT}_{7}$ receptor antagonists SB-269970 and SB-656104 to rats reduces the total amount of REM sleep, whereas wake and slow wave sleep are not affected (Hagan et al., 2000; Thomas et al., 2003; Monti and Jantos, 2006). Furthermore, both 
genetic inactivation and pharmacological blockade of $5-\mathrm{HT}_{7}$ receptor augmented the effects of SSRIs on REM sleep suppression (Bonaventure et al., 2007; Shelton et al., 2009).

As for the effect of $5-\mathrm{HT}_{7}$ receptor agonists on sleep, systemic administration of LP-211 during the light phase increases wakefulness in rats and reduces REM sleep duration and periods. To assess the potential neural sites that mediate the changes in REM and wake in the rat, LP-211 was microinjected into the brain regions involved in sleep-wake regulation. Local administration of LP-211 into the DRN, locus coeruleus, lateral basal forebrain, and laterodorsal tegmental nucleus suppressed REM sleep, and microinjection of LP-211 into the basal forebrain augmented wake (Monti et al., 2014). The authors proposed that activation of $5-\mathrm{HT}_{7}$ receptors expressed by GABAergic interneurons decreases the activity of REM sleep-promoting cholinergic neurons in the laterodorsal and pedunculopontine tegmental nuclei and reduces REM sleep. Suppression of REM sleep was observed also when LP-44, another $5-\mathrm{HT}_{7}$ receptor agonist, was microinjected into the DRN (Monti et al., 2008).

A possible explanation for these apparently contradictory findings is that $5-\mathrm{HT}_{7}$ receptors can stimulate GABAergic neurons only in the absence and/or at low concentrations of 5-HT, whereas at high 5-HT concentrations, $5-\mathrm{HT}_{7}$ receptors inhibit these GABAergic neurons. Therefore, a concentration-dependent switch in $5-\mathrm{HT}_{7}$ receptor signaling could explain why inhibition of $5-\mathrm{HT}_{7}$ receptor activity, elevated 5-HT concentrations, or administration of $5-\mathrm{HT}_{7}$ receptor agonist at high concentrations prevent $5-\mathrm{HT}_{7}$ receptor-mediated stimulation of the REM stimulatory GABAergic neurons.

$5-\mathrm{HT}_{7}$ receptors have also been implicated in the regulation of the mammalian circadian clock located in the suprachiasmatic nucleus. Studies have demonstrated that 8-OH-DPAT induces nonphotic phase resetting through activation of $5-\mathrm{HT}_{7}$ receptors in vitro and in vivo. This effect is reversed by genetic inactivation or pharmacological blockade by the antagonists SB-269970, DR-4004, and JNJ-18038683 (Sprouse et al., 2004; Guscott et al., 2005; Shelton et al., 2015). Consistently, the agonist LP-211 induced a phase advancement of the circadian rhythm in mice (Adriani et al., 2012). Moreover, activation of $5-\mathrm{HT}_{7}$ receptors by the partial agonist AS19 shortens the period length of oscillation of clock gene period circadian protein homo$\log 2$ expression in the suprachiasmatic nucleus. Period circadian protein homolog 2 expression is used to monitor changes in circadian period length and amplitude (Westrich et al., 2013).

6. Autism Spectrum Disorders. Clinical studies suggest a deficient brain 5 -HT system as a causal mechanism in autism spectrum disorders (McDougle et al., 1996; Boccuto et al., 2013). Moreover, the lack of
5-HT during early stages of development may contribute to disrupt the wiring architecture of the brain (Azmitia et al., 2011).

$5-\mathrm{HT}_{7}$ receptor activation corrects molecular, electrophysiological, and behavioral manifestations in mice models of Fragile X syndrome (FXS) and Rett syndrome (RTT), both genetic forms of intellectual disabilities associated with autistic behavior (Costa et al., 2012, 2015; De Filippis et al., 2014, 2015). FXS is the most common inherited intellectual disability; it is caused by silencing of the Fmr1 gene coding for the Fragile X Mental Retardation Protein (Pieretti et al., 1991).

Activation of $5-\mathrm{HT}_{7}$ receptors by the agonists $8-\mathrm{OH}-$ DPAT and LP-211 rescues mGluR-LTD in Fmr1 knockout mice and restores LTD levels to those of WT mice (Costa et al., 2012, 2015). This might have important functional consequences, as long-term synaptic plasticity plays a fundamental role in shaping the structure and function of brain circuits. LTD is crucially involved in learning and memory, in novelty detection, and in the extinction of previously acquired memories, and it is believed to underlie behavioral flexibility (Collingridge et al., 2010). On that basis, Costa et al. (2012, 2015) suggested that selective activation of $5-\mathrm{HT}_{7}$ receptors, by restoring mGluR-mediated synaptic plasticity to normal levels, might also rescue cognitive functions and behavioral flexibility in the mouse model of FXS.

De Filippis et al. (2014) have demonstrated that the selective $5-\mathrm{HT}_{7}$ agonist LP-211 rescues the behavioral impairments in MeCP2-308 male mice, a mouse model of RTT. RTT is a rare neurodevelopmental disorder characterized by severe behavioral symptoms, including autistic-like behaviors, anxiety, motor disturbances, stereotypic hand movements, and severe cognitive dysfunction (Hagberg, 2002; Ricceri et al., 2013). Mutations in the methyl-CpG-binding protein 2 (MeCP2) gene have been identified as the main genetic cause of RTT. MeCP2 encodes a multifunctional protein that binds to methylated DNA and mainly acts as a key transcriptional regulator. Systemic treatment with LP-211 rescues RTT-related defective performance: anxiety-related profiles in a light/dark test, motor abilities in a dowel test, the exploratory behavior in the marble burying test, and memory in the novelty preference task. At a molecular level, LP-211 administration in MeCP2-308 mice restores levels of the Rho GTPases effector molecules p21 activated kinases and cofilin, which both are key regulators of actin cytoskeleton dynamics and, thus, crucially involved in neuronal plasticity. A follow-up study reported similar effects in MeCP2-308 heterozygous female mice; the genetic and hormonal milieus of these mice more closely resemble those of RTT patients (De Filippis et al., 2015). In addition, targeting $5-\mathrm{HT}_{7}$ receptors can rescue brain mitochondrial dysfunction in heterozygous female MeCP2-308 and MeCP2-Bird mice (a more severely affected model). Moreover, LP-211 treatment 
completely restores the radical species overproduction by brain mitochondria in the MeCP2-308 model and partially recovers the oxidative imbalance in MeCP2-Bird mice (Valenti et al., 2017).

A core symptom of autism spectrum disorder is repetitive and stereotypic behavior. The dual $5-\mathrm{HT}_{1 \mathrm{~A}} /$ 5 - $\mathrm{HT}_{7}$ partial agonist (+)-5-(2'-fluorophenyl)-N,Ndimethyl-1,2,3,4-tetrahydronaphthalen-2-amine reduces or eliminates stereotypy in three different mouse models of stereotypy: idiopathic jumping, repetitive body rotations after treatment with the NMDA antagonist dizocilpine, and repetitive head-twitching after treatment with the $5-\mathrm{HT}_{2}$ receptor agonist DOI (Canal et al., 2015) without altering locomotor behavior.

Finally, it has been proposed that the reduced behavioral inflexibility elicited by $5-\mathrm{HT}_{7}$ receptor antagonists (Nikiforuk, 2012; Nikiforuk and Popik, 2013) might be of relevance in autism spectrum disorder, as reduced behavioral flexibility (i.e., a reduced ability to replace a previously acquired rule with a new one in adaptation to a new environmental context) is a typical feature of this pathology (Ciranna and Catania, 2014).

There is a suggestive link between a HTR7 genetic abnormality, which encodes the $5-\mathrm{HT}_{7}$ receptor, and neurodevelopmental disorders (Helsmoortel et al., 2016). The whole-genome sequencing of a severely affected dizygotic twin with an autism spectrum disorder and intellectual disability revealed a compound heterozygous mutation in the HTR7 gene as the only variation.

7. Epilepsy. The involvement of $5-\mathrm{HT}_{7}$ receptors in epilepsy has been actively investigated. The $5-\mathrm{HT}_{7}$ receptor antagonist SB-258719 reduces spontaneous epileptic activity in the WAG/Rij rat model of absence epilepsy (Graf et al., 2004). In pilocarpine-induced rat models of temporal lobe epilepsy, SB-269970 also reduces the number of seizures (Yang et al., 2012). Consistently, in epileptic rats, the presumed activation of $5-\mathrm{HT}_{7}$ receptors by AS-19 increases the number of seizures (Yang et al., 2012). In contrast to the above data, inactivation of the $5-\mathrm{HT}_{7}$ receptor gene caused a generalized threshold reduction in electrical- or chemical-induced seizures (Witkin et al., 2007).

It has been suggested that the evident seizureprone phenotype of $5-\mathrm{HT}_{7}$ receptor $\mathrm{KO}$ mice may be due to adaptive changes to the loss of perinatal $5-\mathrm{HT}_{7}$ receptor-induced depolarization. In line with these data, the $5-\mathrm{HT}_{7} / 5-\mathrm{HT}_{1 \mathrm{~A}}$ receptor agonist 5 -CT increased the seizure threshold for picrotoxin in stressed mice (Pericic and Svob Strac, 2007), which is abolished by SB-269970 but not by the $5-\mathrm{HT}_{1 \mathrm{~A}}$ receptor antagonist WAY-100635 (Pericic and Svob Strac, 2007).

8. Drug Abuse. The link between the $5-\mathrm{HT}_{7}$ receptor and substance abuse has been under explored. Hauser et al. (2015) suggest that $5-\mathrm{HT}_{7}$ receptors may play a key role in addiction on the basis of neuroanatomical, biochemical, physiologic, and behavioral observations.
Interestingly, genomic studies in humans suggest a link between variants in the gene encoding the $5-\mathrm{HT}_{7}$ receptor and alcoholism (Zlojutro et al., 2011; Kim et al., 2014). In this respect, mice exposed to alcohol vapors present increased expression of $5-\mathrm{HT}_{7}$ receptors in brain areas specifically involved in dependence (Yoshimoto et al., 2012). However, blockade of 5- $\mathrm{HT}_{7}$ receptors with SB-258719 does not alter alcohol drinking behavior in the mice exposed to alcohol vapor (Yoshimoto et al., 2012).

9. Pain. Much effort has been made to investigate the potential (patho)physiologic role of $5-\mathrm{HT}_{7}$ receptors in nociception and chronic pain. Early studies suggested a peripheral pronociceptive action of 5-HT through $5-\mathrm{HT}_{7}$ receptor activation (Meuser et al., 2002). The pain-promoting effect of 5-HT or 5-CT injection into a hindpaw on formalin-induced local nociceptive responses is blocked by SB-269970 (Rocha-González et al., 2005).

In rat models of neuropathic pain (i.e., chronic constriction injury to the sciatic nerve or spinal nerve ligation) systemic administration of SB-269970 reduces hyperalgesia and tactile allodynia (Amaya-Castellanos et al., 2011; Viguier et al., 2012). Intrathecal administration of SB-269970 also reduces tactile allodynia in spinal nerve-ligated rats, suggesting the involvement of $5-\mathrm{HT}_{7}$ receptors in pronociceptive mechanisms at the spinal level (Amaya-Castellanos et al., 2011). A pronociceptive effect of $5-\mathrm{HT}_{7}$ receptor stimulation has been reported at the trigeminal level. SB-656104 significantly decreases the c-Fos immunostaining in the spinal nucleus of the trigeminal nerve in response to intracisternal injection of capsaicin (Martínez-García et al., 2011).

However, such findings appear in contradiction with the data from Brenchat et al. $(2009,2010)$, in which systemic administration of SB-269970 or SB-258719 enhance mechanical hypersensitivity associated with capsaicin-induced hyperalgesia or nerve injury in mice. Interestingly, local injection of SB-269970 or SB-258719 in control mice does not promote hypersensitivity, suggesting that $5-\mathrm{HT}_{7}$ receptors might be involved in some pronociceptive modulatory mechanisms only under neuronal sensitization conditions.

In addition to possible species differences, the selected model of neuropathic pain might also have relevance with respect to the aforementioned contradictions.

The antinociceptive potential of $5-\mathrm{HT}_{7}$ receptor antagonists would suggest a pronociceptive effect of $5-\mathrm{HT}_{7}$ receptor agonists for which there is some support (Brenchat et al., 2010; Martínez-García et al., 2011). However, other studies report $5-\mathrm{HT}_{7}$ receptors mediate antinociceptive effects. Thus, blockade of spinal $5-\mathrm{HT}_{7}$ receptors by intrathecal injection of SB-269970 prevents the antinociceptive effects of systemic administration of morphine, tramadol, or cannabinoids in the tail flick test (Dogrul and Seyrek, 2006; Dogrul et al., 2009; Yanarates 
et al., 2010), and intrathecal administration of E-57431 and E-55888 inhibit mechanical hypersensitivity caused by capsaicin injection or nerve injury-induced mechanical hypersensitivity in both mice and rats (Brenchat et al., 2011; Viguier et al., 2012). Furthermore, systemic treatment with $5-\mathrm{HT}_{7}$ receptor agonists produce marked reductions in mechanical and thermal hypersensitivity in various chronic pain models with central and/or peripheral sensitization (Brenchat et al., 2009, 2010, 2012a,b; Ulugol et al., 2012; Viguier et al., 2012, 2013).

\section{H. Clinical Relevance}

1. Depression. Multiple experimental approaches tend to support the hypothesis that $5-\mathrm{HT}_{7}$ receptor blockade or genetic inactivation displays an antidepressant-like activity (Guscott et al., 2005; Hedlund et al., 2005; Sarkisyan et al., 2010). In agreement with mouse KO data, the pharmacological blockade of $5-\mathrm{HT}_{7}$ receptors results in antidepressant-like effects in the TST (Hedlund et al., 2005; Wesołowska et al., 2006a; Bonaventure et al., 2007) and in the FST in both mice (Hedlund et al., 2005; Wesołowska et al., 2006b) and rats (Wesołowska and Kowalska et al., 2008; Mnie-Filali et al., 2011).

The $5-\mathrm{HT}_{7}$ receptor antagonist SB-269970 was assessed in the olfactory bulbectomy paradigm, which is considered as a "chronic" behavioral model of depression, in which classic antidepressants require the administration for 2 to 3 weeks before any antidepressant-like effects can be observed (Song and Leonard, 2005). SB-269970 induced a faster antidepressant-like response when compared with 1 week of treatment with the SSRI fluoxetine (Mnie-Filali et al., 2011). 5- $\mathrm{HT}_{7}$ receptor blockade may also augment the effects of antidepressant drugs; thus, the combination of an ineffective dose of SB-269970 with an ineffective dose of one of several antidepressants, results in a synergistic reduction in immobility in both FST and TST (Wesołowska et al., 2006b; Bonaventure et al., 2007; Wesołowska and Kowalska, 2008; Sarkisyan et al., 2010) that correlates with increases in 5 -HT release in the frontal cortex (Bonaventure et al., 2007; Wesołowska and Kowalska, 2008). Besides the prefrontal cortex, the hippocampus has also been implicated in the effects of SB-269970 and imipramine, as intrahippocampal SB-269970 administration reduces immobility in the rat FST (Wesołowska et al., 2006b).

Preclinical tests in mice suggest that the clinically established antidepressant effect of the atypical antipsychotic drugs amisulpride, aripiprazole, or lurasidone may be due to $5-\mathrm{HT}_{7}$ receptor blockade. Thus, amisulpride, aripiprazole, and lurasidone are potent but nonselective $5-\mathrm{HT}_{7}$ receptor antagonists that have clear antidepressant actions (Lecrubier et al., 1997; Smeraldi, 1998; Lawler et al., 1999; Shapiro et al., 2003; Nakamura et al., 2009; Ishibashi et al., 2010; Citrome, 2011) that reduce immobility in the TST and the FST in WT but not in $5-\mathrm{HT}_{7} \mathrm{KO}$ mice (Abbas et al., 2009a; Sarkisyan et al., 2010; Cates et al., 2013), strongly suggesting a role for the $5-\mathrm{HT}_{7}$ receptor.

The $5-\mathrm{HT}_{7}$ receptor antagonist JNJ-18038683 (Bonaventure et al., 2012) reduces immobility in mice in the TST. Coadministration of subeffective doses of citalopram and JNJ-18038683 elicits an antidepressant effect. However, JNJ-18038683, when tested in patients with major depressive disorder, produced no statistically significant improvement over placebo on the Montgomery-Ẩsberg Depression Rating Scale, although escitalopram in that same study was also inactive, complicating the interpretation.

2. Sleep. The potent and selective $5-\mathrm{HT}_{7}$ receptor antagonist JNJ-18038683 prolonged REM latency and decreased REM sleep duration in healthy volunteers (Bonaventure et al., 2012). Furthermore, JNJ-18038683 appeared to enhance REM sleep suppression induced by citalopram.

\section{High-Resolution Structure of 5-HT Receptors}

\section{A. 5-HT GPCRs}

Since the initial cloning of a 5-HT receptor in 1988 (Julius et al., 1988), it has been appreciated that the G protein-coupled 5-HT receptors would have a topology similar to other members of the GPCR superfamily (Kroeze et al., 2003). These features included a predicted seven-transmembrane helical arrangement with an orthosteric binding pocket near the upper one-third of the helical array (Choudhary et al., 1992, 1993, 1995). Indeed, early molecular models-bolstered by sitedirected mutagenesis studies-predicted that 5-HT and serotonergic drugs such as ergolines and ergopeptines would be anchored by a highly conserved aspartic acid in helix III and aromatic residues in helix VI (Choudhary et al., 1993, 1995; Wang et al., 1993; Sealfon et al., 1995).

These predictions were confirmed in 2013 with the publication of the first high-resolution structures of the human 5- $\mathrm{HT}_{1 \mathrm{~B}}$ (Wang et al., 2013) and 5- $\mathrm{HT}_{2 \mathrm{~B}}$ (Wacker et al., 2013) receptors-both in complex with the ergopeptine ergotamine (Fig. 28). Additionally, the $5-\mathrm{HT}_{1 \mathrm{~B}}$ receptor was also solved in complex with dihydroergotamine (Wang et al., 2013), revealing an essentially identical ligand orientation. Perhaps not surprisingly, and as predicted many years ago (Choudhary et al., 1995), ergotamine was anchored by the highly conserved TMIII aspartic acid residue and stabilized by hydrophobic and edge-on-face interactions with aromatic residues in helix VI (Wacker et al., 2013; Wang et al., 2013).

Given the large differences between $5-\mathrm{HT}_{1 \mathrm{~B}}$ and $5-\mathrm{HT}_{2 \mathrm{~B}}$ receptors in terms of pharmacology, signal transduction, and amino acid sequence, the high-resolution structures of both receptors allowed the investigators to 

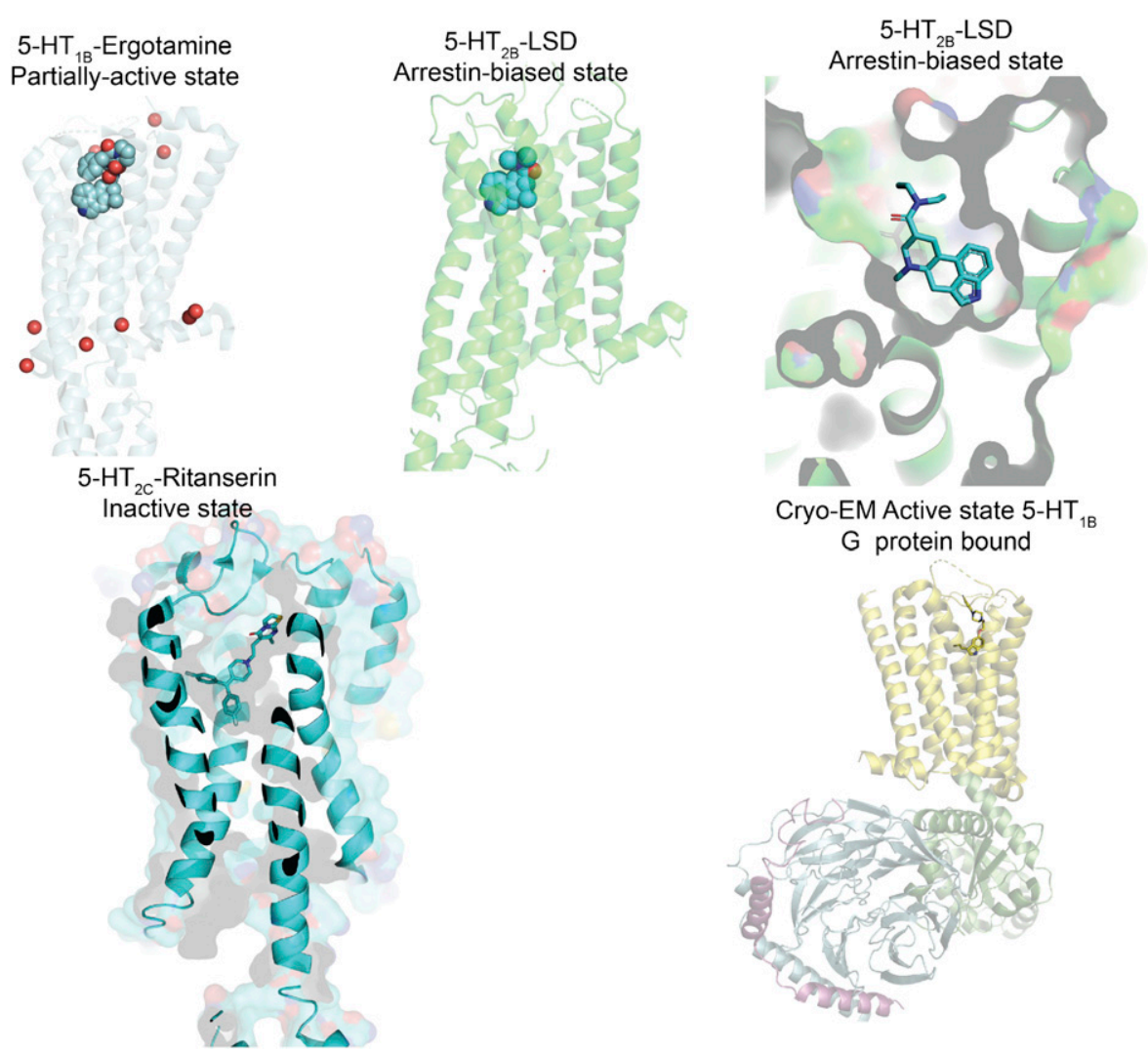

Fig. 28. Structures of 5- $\mathrm{HT}_{1 \mathrm{~B}}, 5-\mathrm{HT}_{2 \mathrm{~B}}$, and $5-\mathrm{HT}_{2 \mathrm{C}}$ receptors. PyMol renderings of the $5-\mathrm{HT}_{1 \mathrm{~B}}$ receptor in complex with ergotamine (Left: Wang et al., 2013; Wacker et al., 2013) and the 5-HT ${ }_{2 \mathrm{~B}}$ receptor in complex with LSD (Wacker et al., 2017) demonstrating different binding pockets for ergotamine and LSD [see Wacker et al. (2017) for details]. The figure also shows inactive-state structure of the 5-HT $2 \mathrm{C}$ receptor (Peng et al., 2018) and the G protein-coupled state of the $5-\mathrm{HT}_{1 \mathrm{~B}}$ receptor (Garcia-Nafria et al., 2018)

identify both important structural commonalities and dissimilarities between these two distinct 5 -HT receptor families (Wacker et al., 2013; Wang et al., 2013); the orthosteric binding pockets of both receptors are nearly identical, with only two amino acids in the conserved orthosteric binding site differing (Wang et al., 2013). This high degree of conservation readily explains why many serotonergic drugs are promiscuous. Indeed, LSD was found to be a potent agonist at every $\mathrm{G}$ protein-coupled 5-HT receptor except the 5- $\mathrm{HT}_{7}$ (Wacker et al., 2013).

Subtle differences in the general region of the binding pocket were able to explain heretofore puzzling aspects of 5-HT receptor pharmacology. For instance, the apparent preference of rodent versions of the $5-\mathrm{HT}_{1 \mathrm{~B}}$, $5-\mathrm{HT}_{1 \mathrm{D}}, 5-\mathrm{ht}_{1 \mathrm{e}}$, and $5-\mathrm{HT}_{1 \mathrm{~F}}$ receptors for $\beta$-adrenergic antagonists (Hoyer and Middlemiss, 1989; Adham et al., 1994) was now apparent based on structural, mutagenesis, and modeling studies (Wang et al., 2013). Thus, a $\mathrm{Thr}^{7.39} \mathrm{Asn}^{7.39}$ to mutation, changing the human to a rodent version, led to the formation of a polar interaction network now favoring the binding of the propanolamine moiety of adrenergic antagonists. Additionally, the high affinity of norfenfluramine for 5 - $\mathrm{HT}_{2 \mathrm{~B}}$ receptors, which may lead to valvular heart disease (Rothman et al., 2000), was explained by the orientation of a nonconserved methionine residue $\left(\mathrm{M}^{5.39}\right)$ that was oriented in the binding pocket in the $5-\mathrm{HT}_{2 \mathrm{~B}}$ receptor and absent in all other 5-HT receptors (Wang et al., 2013). Finally, distinctly different patterns of signaling by ergotamine at $5-\mathrm{HT}_{1 \mathrm{~B}}$ receptors, where it is unbiased, and $5-\mathrm{HT}_{2 \mathrm{~B}}$ receptors, where it shows arrestin bias, led to explication of the structural features responsible for functional selectivity (Wacker et al., 2013). Thus, the apparent arrestin-biased signaling by ergotamine at $5-\mathrm{HT}_{2 \mathrm{~B}}$ receptors is due to a preferential stabilization of inactive states of particular $G$ protein conformational microswitches (which are essential for mediating canonical signaling) and the preferential allowance of conformations responsible for arrestindependent signaling (Wacker et al., 2013).

More recent studies have clarified the mechanisms responsible for the differential activation of $G$ protein versus arrestin signaling (Wacker et al., 2017a) at $5-\mathrm{HT}_{2 \mathrm{~A}}$ (Wacker et al., 2017b) and 5- $\mathrm{HT}_{2 \mathrm{~B}}$ receptors (Wacker et al., 2017b; McCorvy et al., 2018). In particular, a detailed study of several $5-\mathrm{HT}_{2 \mathrm{~B}}$ receptor structures (Wacker et al., 2017b; McCorvy et al., 2018) disclosed that key interactions with $\mathrm{A}^{5.46}$ and $\mathrm{T}^{3.37}$ are essential for canonical $G$ protein signaling, whereas interactions with extracellular loop residue $L^{7.35}$ are essential for arrestin-ergic signaling. Additionally, other structures of an intermediate-active state of the $5-\mathrm{HT}_{2 \mathrm{C}}$ receptor (Peng et al., 2018; Fig. 28) and the G protein heterotrimer-stabilized active state of the 
$5-\mathrm{HT}_{1 \mathrm{~B}}$ receptor (Garcia-Nafria et al., 2018) implicated a key "trigger motif" P-I-F as being essential for the active-inactive switch and biased signaling (Wacker et al., 2017a; McCorvy et al., 2018).

\section{B. 5-HT Ligand-Gated Ion Channels}

$5-\mathrm{HT}_{3}$ receptors are ion channels of the Cys-loop receptor family (Thompson et al., 2010; Corringer et al., 2012). Thus, they share a common architecture with other members, such as nicotinic acetylcholine, ionotropic $\gamma$-aminobutyric, and glycine receptors. All of them are composed of five subunits, symmetrically disposed around a central ionic pore axis, forming an urn-like architecture (Fig. 29). Each subunit has three functional domains (Fig. 29): a large extracellular domain harboring the neurotransmitter binding pocket, a four-helix transmembrane domain establishing the ion channel, and an intracellular domain that mediates the receptor interaction with intracellular proteins.

Recent years have seen the emergence of a solid structural framework to help interpret functional and pharmacological studies. First, 5-HT, granisetron, and palonosetron have been crystallized in complex with a soluble model protein (termed 5-HTBP; Kesters et al., 2013; Price et al., 2016), providing possible orientations of ligands and adding up to the huge variety of nicotinic receptor ligands cocrystallized with the same type of model protein. Second, the initial mouse $5-\mathrm{HT}_{3} \mathrm{~A}$ receptor X-ray structure (Hassaïne et al., 2014) has provided an almost complete picture $(\sim 60$ unstructured residues missing in the intracellular domain) of a $5-\mathrm{HT}_{3}$ receptor but with empty neurotransmitter sites capped by stabilizing llama antibodies instrumental to crystallization. Third, a series of distinct conformations of the full-length murine receptor imaged by Cryo-Electron Microscopy (Basak et al., 2018a,b; Polovinkin et al., 2018) has shed light on its gating mechanism and revealed how 5 -HT and antiemetic drugs such as tropisetron bind in the neurotransmitter site. Specialized reviews discuss Cys-loop receptor structure at length (daCosta and Baenziger, 2013; Nys et al., 2013; Sauguet et al., 2015; Wu et al., 2015; Nemecz et al., 2016).

The five equivalent neurotransmitter binding pockets of the homopentameric $5-\mathrm{HT}_{3} \mathrm{~A}$ receptor are located in electronegative clefts at interfaces between two adjacent subunits (Fig. 30). Three loops of the principal subunit and four portions of beta strands of the complementary subunit contribute to the pocket (Fig. 30). Therefore, the shape of the binding pocket arises from the combination of the quaternary arrangement (how one subunit is oriented relative to its neighbor) and of the local conformation of loops and side chains. During activation of Cys-loop receptors and gating of the channel, both global subunit/subunit orientation and more local conformation changes take place (Sauguet et al., 2013; Du et al., 2015; Basak et al., 2018a; Polovinkin et al., 2018). The 5-HTBP and other model proteins present a stiff quaternary structure in which the subunit/subunit orientation is fixed, and in that respect, they are imperfect models for ligand binding.

The binding cleft of the $5-\mathrm{HT}_{3} \mathrm{~A}$ receptor is surrounded by aromatic residues forming a $10-\AA$ A wide box, including W156 (loop B), W63 (loop D), Y126 (loop E), F199, and Y207 (loop C). W156 (W145 in 5-HTBP) lies at the bottom of the cleft and has cation-Pi interaction with 5-HT
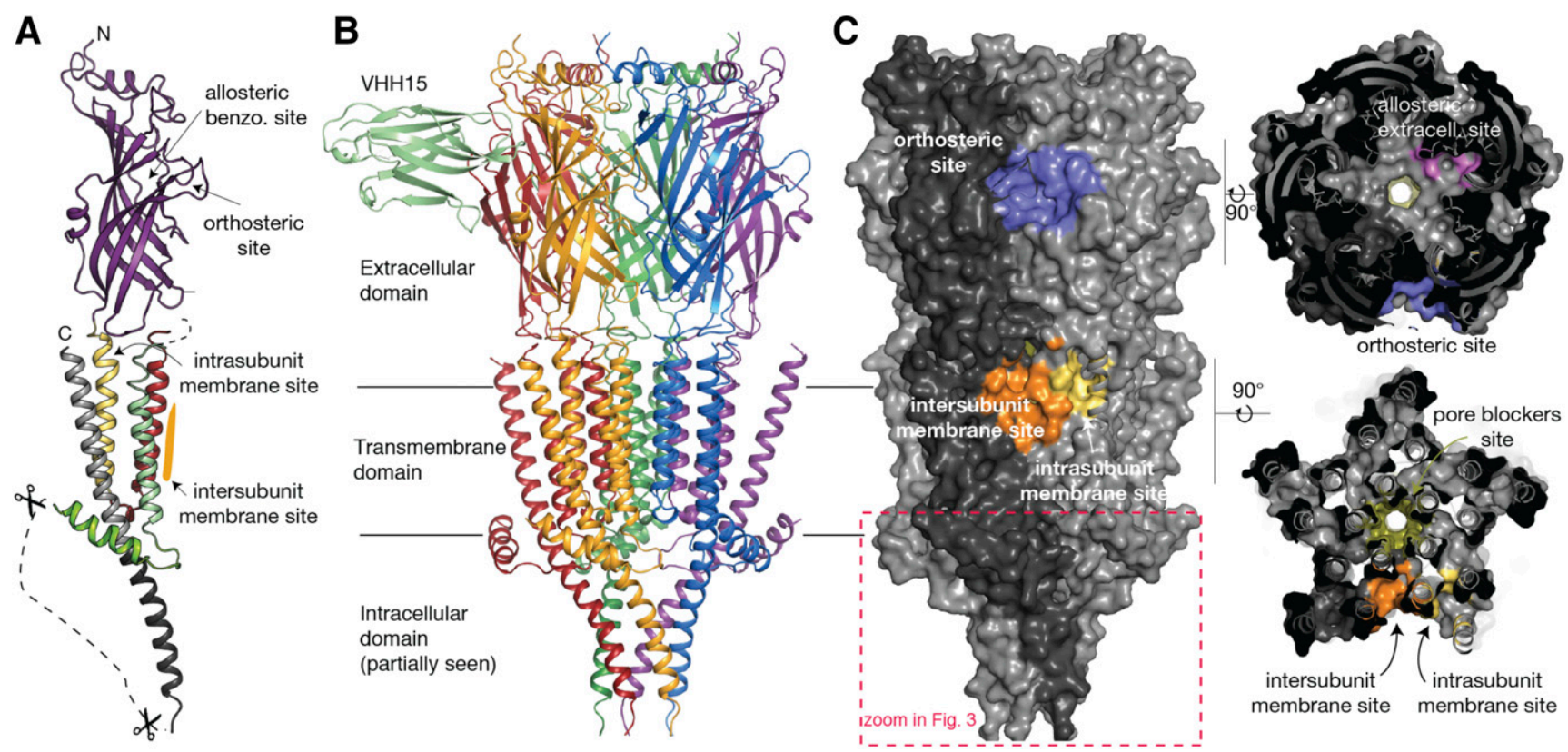

Fig. 29. Architecture and ligand binding sites of 5-HT 3 receptors. (A) Cartoon representation of a single subunit viewed parallel to the plane of the membrane. (B) Cartoon representation of the entire pentameric receptor, in the same orientation [the subunit of (A) is equivalent to the yellow subunit]. One out of the five stabilizing VHH15 single-chain llama antibodies is shown in pale green and labeled VHH15. (C) Surface representation of the receptor highlighting binding clefts in blue (neurotransmitter site), yellow (anesthetics intrasubunit site), orange (PU-02 and anesthetics intersubunit site), purple (extracellular allosteric pocket), and olive (pore blockers site). The subunit equivalent to the one of (A) appears in darker gray. 
A

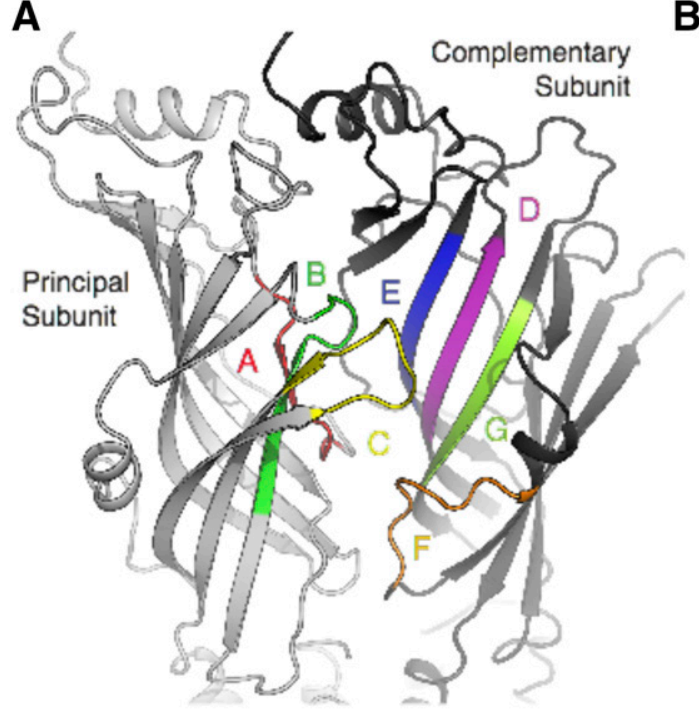

C

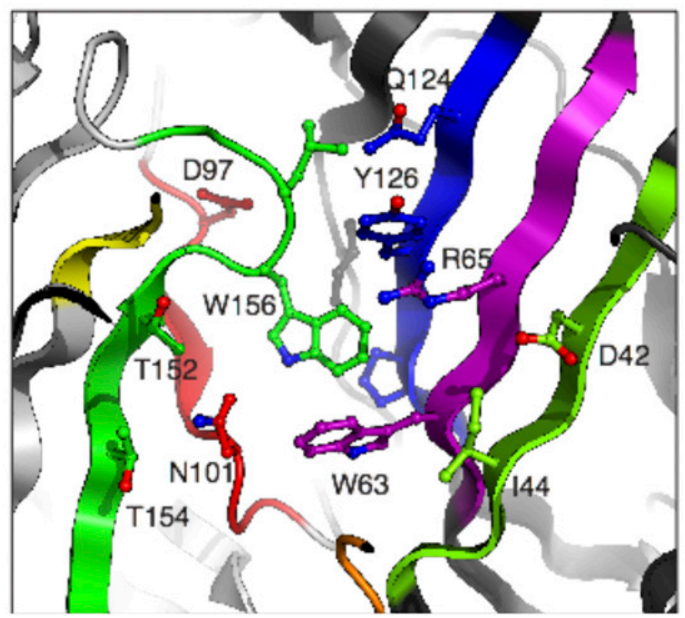

B
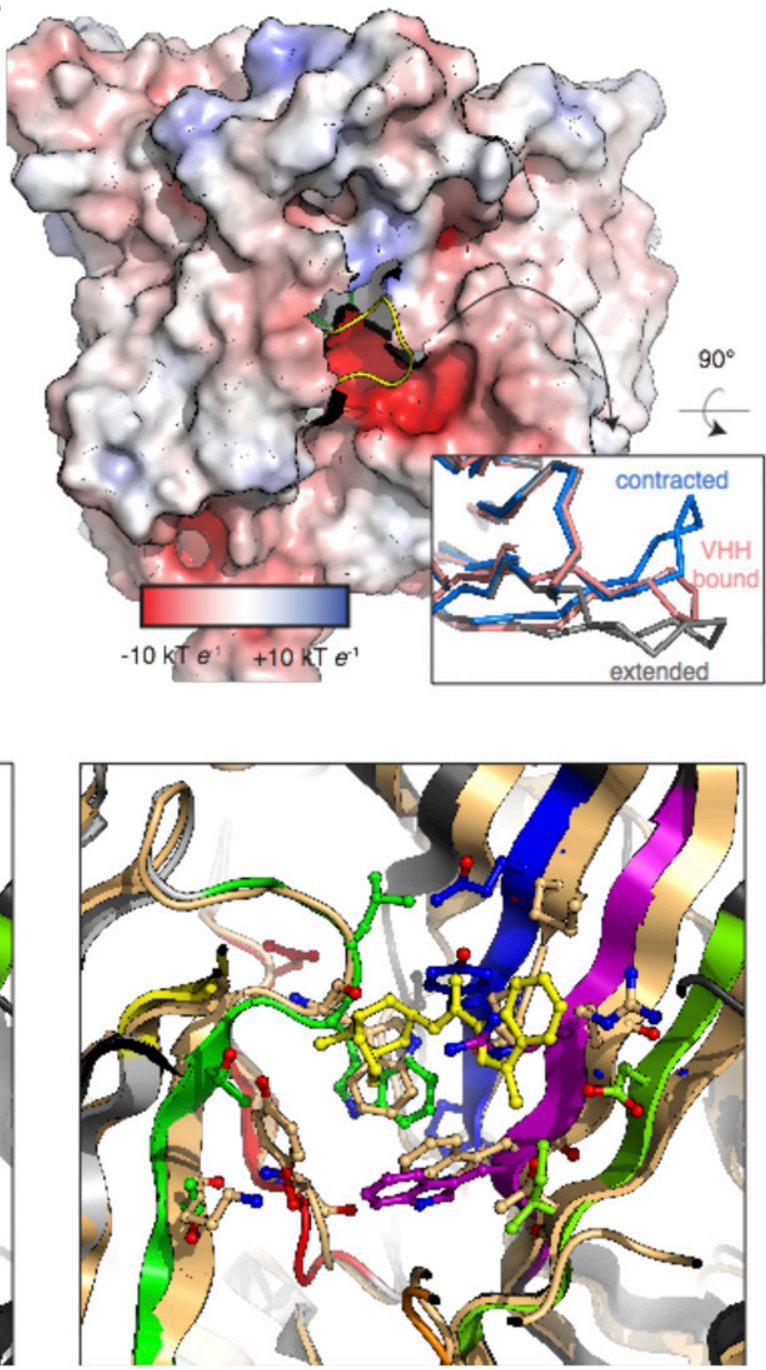

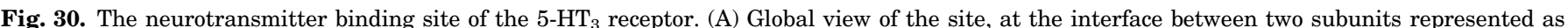

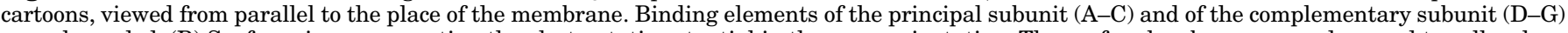

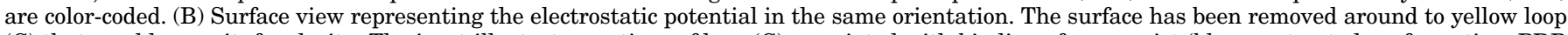

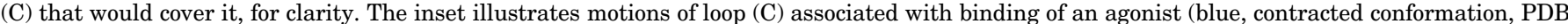

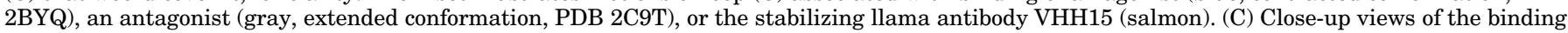

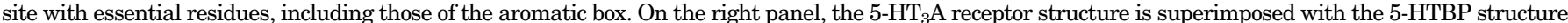

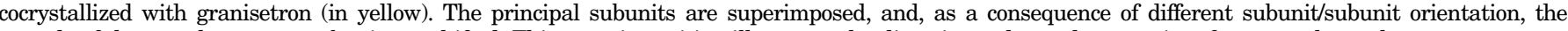
strands of the complementary subunit are shifted. This superimposition illustrates the diversity and complementarity of structural templates.

(Beene et al., 2002). This part of the site looks rigid with many intra- and intersubunit interactions. In contrast, the mouth of the cleft seems prone to reorganization. The C loop adopts different conformations in the apo, the antagonist-bound, and 5-HT-bound (Fig. 30). Other important residues lining the site include N101 (loop A), T152 and T154 (loop B), R65 (loop D), D177, S179, I180 (loop F), D42, and I44 (loop G).

A picture of the molecular mechanism of $5-\mathrm{HT}_{3}$ receptors starts to emerge from the accumulated structural data. The closed apo conformation resembles those of the receptor inhibited by small molecules (antiemetics such as tropisetron) or by the inhibitory VHH15. Upon 5-HT binding, the receptors undergo a transition to the open state characterized by 1) a compaction of the neurotransmitter pocket because of quaternary reorganization of the extracellular domain and 2) an opening of the transmembrane pore linked to the pivot of each subunit transmembrane domain. Two independent cryo-EM studies have captured a second 5-HT-bound state featuring a closed pore similar to that of the resting state (Basak et al., 2018a; Polovinkin et al., 2018). Based on functional experiments, this state was tentatively described as preactive rather than desensitized (Polovinkin et al., 2018).

There is no direct structural data on allosteric modulation sites of $5-\mathrm{HT}_{3}$ receptors. Nevertheless, allosteric sites identified on homologous Cys-loop receptors are relevant to the $5-\mathrm{HT}_{3}$ pharmacology. For instance, PU-02, a selective inhibitor of the $5-\mathrm{HT}_{3}$ receptor acting in the micromolar range, binds to a transmembrane intersubunit site (orange in Fig. 29) 
that correlates to the ivermectin site of the C. elegans glutamate-gated chloride channels receptor (Hibbs and Gouaux, 2011) and to the ethanol and bromoform sites of the model bacterial GLIC receptor (Sauguet et al., 2013). In the $5-\mathrm{HT}_{3} \mathrm{~A}$ receptor structure, a deep cleft between subunits is indeed accessible from the lipid bilayer and lined by residues determining PU-02 activity [16]: L266, S270, G282, and V288 on the (+) side and S226, I268, and T272 on the (-) side (Fig. 29). A second membrane-accessible site, this time located within a single subunit (Fig. 29), has been identified as the site of action of the positive allosteric modulator TMPPAA (Gasiorek et al., 2016; Polovinkin et al., 2018) and might be involved in anesthetics inhibition (Lopreato et al., 2003). Some compounds acting as physical blockers of the ion flux bind directly in the channel lumen. A variety of sites have been identified at different depths in the pore, spanning almost the whole transmembrane part, from divalent cations binding close to the intracellular mouth to TEA and lidocaine in the middle (Hilf et al., 2010) and mementine that binds close to the extracellular mouth (between 13' and 16') (Rammes et al., 2001; Ulens et al., 2014).

The $5-\mathrm{HT}_{3}$ receptor structures also shed light on the neglected intracellular domain. Only part of it is seen in the structures: a short helical stretch after the M3 transmembrane helix and a long helix MA continuous with the M4 transmembrane helix (Figs. 29 and 31). At their N-terminal side, MA helices form a tight pentameric bundle stabilized by hydrophobic interactions (Fig. 31). Further up, and closer to the mouth of the transmembrane pore, they carry charged residues whose mutations were shown to profoundly affect the channel conductance. At this level, the spacing between MA helices results in lateral fenestrations, plugged in the closed-pore structures by the loop linking M3 and MA (Fig. 31). Recent cryo-EM structures have shown that this intracellular region is drastically reorganized in the openpore state, with wide portals, and displays flexibility. The ion exit pathway and the way in which the ion flux depends on the flexibility and the local electrostatic environment remain to be fully described (Di Maio et al., 2015).

Molecular dynamic simulations established the existence of a dewetted zone in the transmembrane pore in the closed-pore conformations and its conversion to a fully hydrated pore permeant to cations in the open conformations (Yuan et al., 2016; Polovinkin et al., 2018).

\section{5-HT GPCRs and Their Interacting Proteins}

\section{A. Introduction}

The history of cell signaling started more than 60 years ago with the seminal discovery of cAMP by Earl Sutherland (Nobel prize in 1971). The mechanisms by which some receptors activate the production of second messengers has been revealed by Martin Rodbell (Nobel Prize 1994) in the 1970s when he showed that
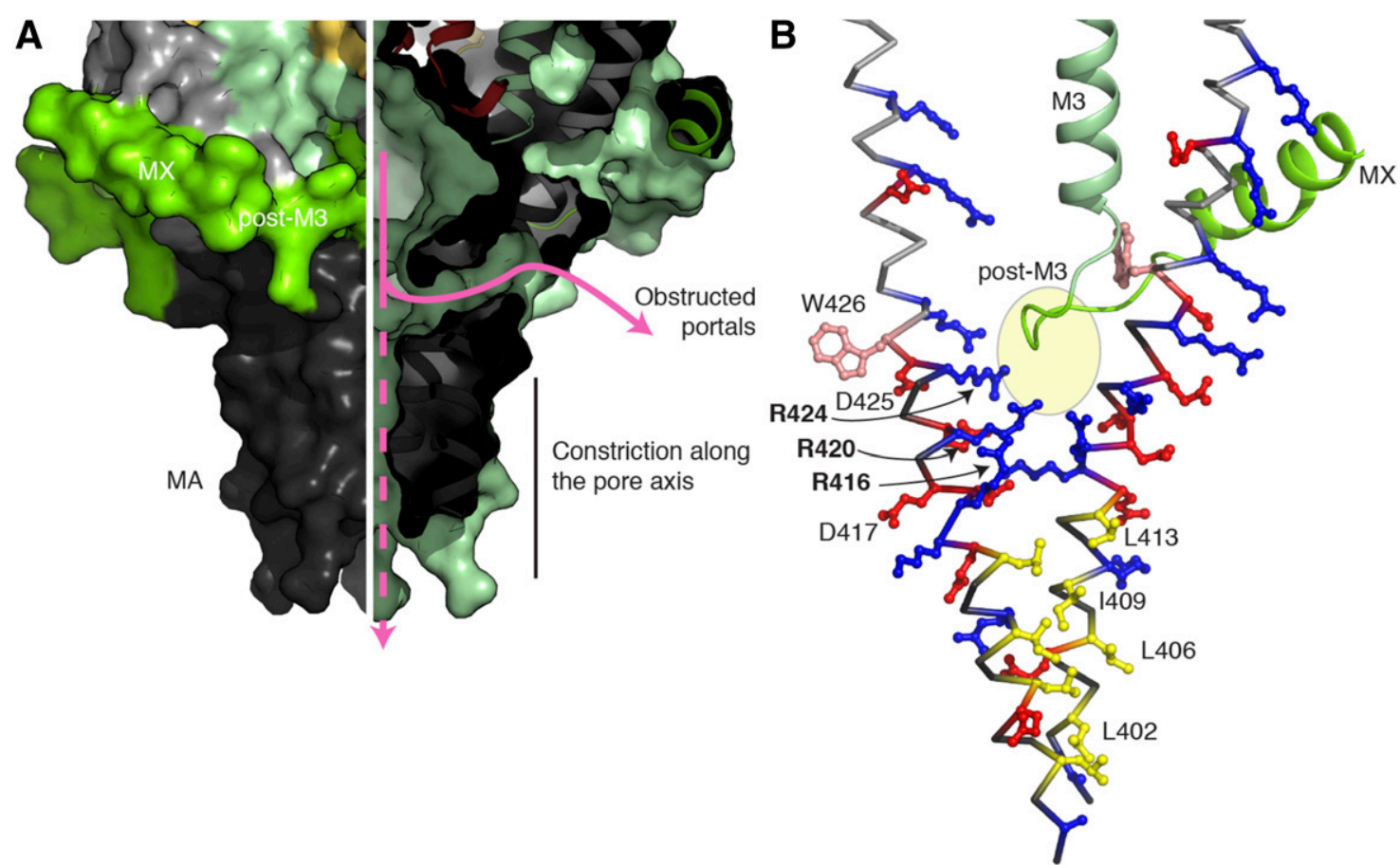

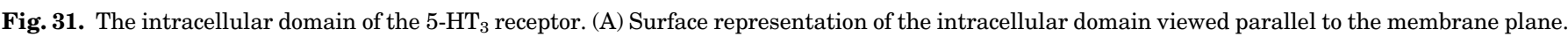

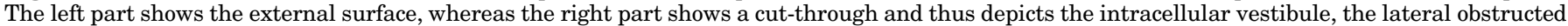

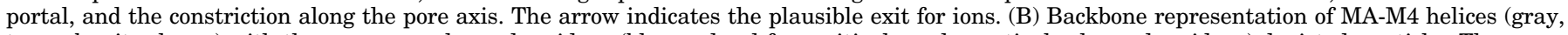

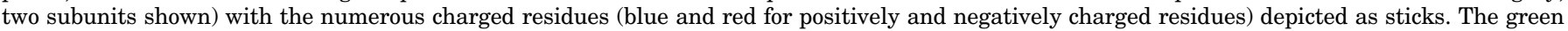

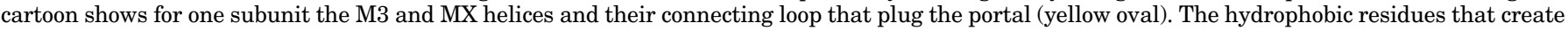
the tight bundle of MA helices are in yellow, and the triplet of arginine determinant for channel conductance are labeled in bold font. 
the receptors do not directly stimulate second messenger synthetizing enzymes but indirectly, via an allosteric activation of $\mathrm{G}$ proteins. The GPCR ternary complex consisting of a receptor, a G protein, and an effector, enzyme, or channel was born. Surprisingly, five decades later, the nature and functions of the huge protein complexes comprising GPCRs and GPCR-interacting proteins (GIPs) still remain poorly characterized. During their cellular journey, GPCRs are assisted by GIPs for their proper folding, targeting proper subcellular compartments, trafficking to and out of the plasma membrane, and select several alternative signaling pathways, including G protein-independent pathways. In addition, GIPs are able to allosterically modify the pharmacology of associated GPCR and even activate some GPCRs in the absence of ligands. This section of the review is dedicated to GIPs of 5-HT receptors, which are among the GPCRs for which those proteins are the most extensively characterized, mainly thanks to proteomics screens. Given the large number of 5-HT receptor GIPs identified, it provides a wide overview of their role in GPCR physiology. Recent advances in the role of GIPs in fine-tuning $5-\mathrm{HT}_{6}$ receptor signaling and associated physiologic functions, including neurodevelopment and cognition, are particularly highlighted.

The evolution of multicellular organisms has been closely linked to their capacity to communicate with their environment and to develop sophisticated communications between their own cells. Most of these communications involve chemical messengers (e.g., hormones, neurotransmitters, growth factors) that interact with one or several transmembrane receptors. Among those receptors, GPCRs are the most numerous ones (Bockaert and Pin, 1999). Around 1000 genes encode such receptors in the human genome (representing $3 \%$ to $4 \%$ of the genome), of which $\sim 300$ are nonolfactory receptors (Fredriksson et al., 2003). 5-HT receptors are particularly well represented in this important receptor family. The diversity of 5-HT GPCRs is certainly due to molecular tinkering from one ancestral gene and has been instrumental for the implication of 5-HT in a large number of physiologic and pathophysiological functions both in the CNS and peripheral tissues. Because of their structural diversity, 5-HT receptors are able to trigger a large panel of signaling events (Marin et al., 2012). Many of them are transduced by different $G$ proteins. In addition, signaling events elicited by 5 -HT receptor activation as well as by many GPCRs are triggered or finely modulated through their interaction with multiple intracellular proteins, "GIPs," and are assembled into functional complexes designated as "receptosomes" (Bockaert et al., 2003, 2004b, 2010b; Maurice et al., 2011; Marin et al., 2012). GIPs are not only involved in GPCR signaling but also in their targeting to subcellular compartments, including axonal and dendritic compartments, in their trafficking in and out of the plasma membrane through the endoplasmic reticulum, Golgi apparatus, endosomal, and lysosomal compartments (Bockaert et al., 2003, 2004b, 2010; Maurice et al., 2011; Marin et al., 2012). Several reviews have been published on GIPs, including two dedicated to 5-HT receptor GIPs (Allen et al., 2008; Marin et al., 2012). Accordingly, only a brief description of the nature, cellular, and physiologic functions of 5-HT receptor GIPs will be provided here (see Table 21), focusing on intracellular GIPs and not considering 5-HT receptor association with other GPCRs (homodimer/heteromer formation). A more detailed account of proteins interacting with the $5-\mathrm{HT}_{6}$ receptor is presented to highlight the interest of a comprehensive description of GIPs for a given receptor to unravel novel mechanisms underlying GPCR activation and physiologic functions controlled by those receptors.

\section{B. A Survey of 5-HT Receptor GIPs}

1. 5-HT $T_{1 \mathrm{~A}}$ Receptor. The $5-\mathrm{HT}_{1 \mathrm{~A}}$ receptor recruits and activates both $\mathrm{G}_{\mathrm{i} 3}$ and $\mathrm{G}_{\mathrm{o}}$ (Bockaert et al., 2006; Marin et al., 2012). Coupling to $\mathrm{G}_{\mathrm{i} 3}$ is predominant in the soma of 5-HT raphe neurons and mainly leads to adenylyl cyclase (AC) inhibition, whereas coupling to $G_{o}$ prevails in hippocampus and leads to inhibition of GIRK channels (Mannoury la Cour et al., 2006); see also Marin et al. (2012) for a detailed review of $\mathrm{G}_{\mathrm{i}} / \mathrm{G}_{\mathrm{o}}$-mediated signaling events elicited by $5-\mathrm{HT}_{1 \mathrm{~A}}$ receptor and their physiologic impact. The molecular basis of the difference in G protein coupling is unknown. Only two GIPs are known to interact with $5-\mathrm{HT}_{1 \mathrm{~A}}$ receptors, namely calmodulin (Della Rocca et al., 1999; Turner et al., 2004) and Yif1B (Carrel et al., 2008; Al Awabdh et al., 2012; Alterio et al., 2015). The $\mathrm{Ca}^{2+}$-calmodulin complex binds to two distinct sites located in the third intracellular loop $\left(i_{3}\right)$ of the receptor (Turner et al., 2004), whereas Yif1B (Yip1 interacting factor homolog B) associates with its short C-terminal domain $(\mathrm{Ct}) . \mathrm{Ca}^{2+}$ calmodulin is implicated in receptor internalization, Erk1/2 activation, and modulation of PKC-dependent receptor phosphorylation (Della Rocca et al., 1999; Turner et al., 2004). In addition, $\mathrm{Ca}^{2+}$-calmodulin contributes to receptor-operated Janus kinase 2 (Jak2) and type 1 sodium-proton exchanger (NHE-1) activation (Turner et al., 2007). 5- $\mathrm{HT}_{1 \mathrm{~A}}$ receptor activation leads to the assembly of a ternary signaling complex that includes activated Jak2, $\mathrm{Ca}^{2+}$-calmodulin, and NHE-1, in which calmodulin is activated by tyrosine phosphorylation instead of cellular $\mathrm{Ca}^{2+}$ elevation. This results in tighter interaction of calmodulin with NHE-1, NHE-1 conformational change, and increased NHE-1 transport activity (Turner et al., 2007). Yif1B is a protein implicated in the traffic of proteins from the endoplasmic reticulum (ER) to the Golgi (Alterio et al., 2015) that plays a key role in the selective targeting of $5-\mathrm{HT}_{1 \mathrm{~A}}$ receptors to dendrites (Carrel et al., 2008). It has been proposed that Yif1B serves as a scaffold allowing the recruitment of $5-\mathrm{HT}_{1 \mathrm{~A}}$ receptor to a complex comprising 
TABLE 21

5-HT receptor-interacting proteins and their cellular and physiologic functions

For each receptor, the nature of identified GIPs, their site of interaction, the function of their interaction with the receptor (if known) at the cellular (receptor targeting, trafficking, and signal transduction) and physiologic levels as well as their role in pathologies are indicated. The question marks indicate that the site of interaction of the GIP in the receptor sequence or the physiologic/pathologic functions of its interaction with the receptor remain unknown.

\begin{tabular}{|c|c|c|c|c|c|}
\hline Receptor & GIP & $\begin{array}{l}\text { Site of } \\
\text { Interaction }\end{array}$ & Cellular Functions & Physiologic/Pathologic Functions & References \\
\hline \multirow[t]{2}{*}{$5-\mathrm{HT}_{1 \mathrm{~A}}$} & Calmodulin & $\mathrm{i}_{3} / \mathrm{Ct}$ & $\begin{array}{c}\text { Endocytosis } \\
\text { PKC-dependent receptor } \\
\text { phosphorylation } \\
\text { Erk1,2 and Jun kinase } \\
\text { activation } \\
\text { NHE-1 activation }\end{array}$ & $?$ & $\begin{array}{l}\text { Della Rocca et al., 1999; } \\
\text { Turner et al., 2004, } 2007\end{array}$ \\
\hline & Yif1B & $\mathrm{Ct}$ & $\begin{array}{l}\text { Anterograde trafficking } \\
\text { Dendritic targeting }\end{array}$ & $?$ & $\begin{array}{c}\text { Al Awabdh et al., 2012; Alterio } \\
\text { et al., 2015 }\end{array}$ \\
\hline $5-\mathrm{HT}_{1 \mathrm{~B} / \mathrm{D}}$ & $\mathrm{p} 11$ & $\mathrm{i}_{3}$ & $\begin{array}{l}\text { Aell surface density and } \\
\text { signaling }\end{array}$ & $\begin{array}{l}\text { Depression in rodent models } \\
\text { 、Emotional memory in } \\
\text { rodents }\end{array}$ & $\begin{array}{l}\text { Svenningsson et al., 2006; } \\
\text { Eriksson et al., } 2013\end{array}$ \\
\hline \multirow[t]{5}{*}{$5-\mathrm{HT}_{2 \mathrm{~A}}$} & $\beta$-arrestin 2 & $?$ & $\begin{array}{l}\text { ^PI3K/Src/Akt signaling } \\
\text { Delayed recycling (human } \\
\text { receptor) }\end{array}$ & $\begin{array}{l}\text { Hallucinogenic effects induced } \\
\text { by high } 5 \text {-HT concentration }\end{array}$ & $\begin{array}{c}\text { Schmid et al., 2008; } \\
\text { Bhattacharya et al., 2010; } \\
\text { Schmid and Bohn, } 2010\end{array}$ \\
\hline & MAP1A & $?$ & $\begin{array}{c}\text { Trafficking in apical } \\
\text { dendrites }\end{array}$ & & Allen et al., 2008 \\
\hline & Arf1-6 & $\mathrm{i}_{3} / \mathrm{Ct}$ & $\begin{array}{c}\text { Coupling to phospholipase } \\
\text { D }\end{array}$ & & Robertson et al., 2003 \\
\hline & Jak/STAT3 & $?$ & $\rtimes$ Transcription & & Guillet-Deniau et al., 1997 \\
\hline & RSK2 & i3 & $\begin{array}{l}\text { Receptor phosphorylation } \\
\text { and desensitization }\end{array}$ & $\begin{array}{c}\text { Putative implication in } \\
\text { psychiatric disorders (Coffin- } \\
\text { Lowry syndrome) }\end{array}$ & $\begin{array}{c}\text { Sheffler et al., 2006; Allen } \\
\text { et al., 2008; Strachan et al., } \\
2009\end{array}$ \\
\hline \multirow[t]{7}{*}{$5-\mathrm{HT}_{2 \mathrm{~A}}$} & $\begin{array}{l}\text { Calmodulin } \\
\text { Caveolins }\end{array}$ & $\begin{array}{c}\mathrm{i}_{2} / \mathrm{Ct} \\
?\end{array}$ & $\begin{array}{l}\text { \Gq coupling } \\
\text { Targeting to lipid rafts } \\
\text { Endocytosis }\end{array}$ & & $\begin{array}{l}\text { Turner and Raymond, } 2005 \\
\text { Bhatnagar et al., } 2004\end{array}$ \\
\hline & PSD-95 & $\begin{array}{c}\mathrm{Ct}(\mathrm{PDZ} \\
\text { ligand-SCV) }\end{array}$ & $\begin{array}{l}\text { Dendritic targeting } \\
\text { Postsynaptic localization } \\
\text { ^Phospholipase C } \\
\text { ^Endocytosis } \\
\text { Cell surface density }\end{array}$ & $\begin{array}{l}\text { Hallucinogen effects in mice } \\
\text { Antipsychotic drug effects } \\
\text { vInflammatory and } \\
\text { neuropathic pain }\end{array}$ & $\begin{array}{c}\text { Xia et al., 2003; Becamel } \\
\text { et al., 2004; Abbas et al., 2009; } \\
\text { Pichon et al., 2010; Vogrig } \\
\text { et al., 2013; Wattiez et al., } \\
2013\end{array}$ \\
\hline & SAP97 & $\begin{array}{c}\mathrm{Ct}(\mathrm{PDZ} \\
\text { ligand-SCV) }\end{array}$ & $\begin{array}{l}\text { TGq signaling } \\
\text { Endocytosis }\end{array}$ & $?$ & Allen et al., 2008 \\
\hline & MUPP1 & $\begin{array}{l}\mathrm{Ct}(\mathrm{PDZ} \\
\text { ligand-SCV) }\end{array}$ & $\begin{array}{l}\text { Postsynaptic localization } \\
\quad \text { Cell surface density }\end{array}$ & Drug dependence & $\begin{array}{c}\text { Jones et al., 200; Becamel } \\
\text { et al., 2001; Shirley et al., } \\
2004\end{array}$ \\
\hline & MAGI2 & $\begin{array}{c}\mathrm{Ct}(\mathrm{PDZ} \\
\text { ligand-SCV) }\end{array}$ & Postsynaptic localization & $?$ & Bécamel et al., 2004 \\
\hline & CIPP & $\begin{array}{c}\mathrm{Ct}(\mathrm{PDZ} \\
\text { ligand-SCV) }\end{array}$ & Postsynaptic localization & $?$ & Bécamel et al., 2004 \\
\hline & NHERF3 & $?$ & $\begin{array}{l}\text { Gq signaling } \\
\text { Endocytosis }\end{array}$ & $?$ & Walther et al., 2015 \\
\hline \multirow[t]{2}{*}{$5-\mathrm{HT}_{2 \mathrm{~B}}$} & MUPP1 & $\begin{array}{l}\mathrm{Ct}(\mathrm{PDZ} \\
\text { ligand- } \\
\mathrm{SYV} / \mathrm{I})\end{array}$ & ? & $?$ & Becamel et al., 2001 \\
\hline & PDZ protein & $\begin{array}{l}\mathrm{Ct}(\mathrm{PDZ} \\
\text { ligand- } \\
\mathrm{SYV} / \mathrm{I})\end{array}$ & NO synthesis & $?$ & Manivet et al., 2000 \\
\hline \multirow[t]{6}{*}{$5-\mathrm{HT}_{2 \mathrm{C}}$} & Calmodulin & $\mathrm{Ct}$ & ^Erk1/2 signaling & $?$ & $\begin{array}{l}\text { Bécamel et al., 2002; } \\
\text { Labasque et al., } 2008\end{array}$ \\
\hline & $\beta$-arrestins & $\mathrm{i}_{2} / ?$ & $\begin{array}{l}\text { AErk } 1 / 2 \text { signaling } \\
\text { Constitutive and agonist- } \\
\text { dependent endocytosis }\end{array}$ & $?$ & $\begin{array}{l}\text { Labasque et al., 2008, 2010; } \\
\text { Marion et al., } 2004\end{array}$ \\
\hline & MUPP1 & $\begin{array}{c}\mathrm{Ct}(\mathrm{PDZ} \\
\text { ligand-SSV) }\end{array}$ & $?$ & $?$ & $\begin{array}{c}\text { Becamel et al., 2001; Parker } \\
\text { et al., 2003 }\end{array}$ \\
\hline & PSD-95 & $\begin{array}{c}\mathrm{Ct}(\mathrm{PDZ} \\
\text { ligand-SSV) }\end{array}$ & $\begin{array}{l}\text { Endocytosis } \\
\text { Signaling }\end{array}$ & $?$ & $\begin{array}{c}\text { Bécamel et al., 2002; Gavarini } \\
\text { et al., 2006 }\end{array}$ \\
\hline & MPP3 & $\begin{array}{c}\mathrm{Ct}(\mathrm{PDZ} \\
\text { ligand-SSV) }\end{array}$ & $\mathbf{v E n d o c y t o s i s}$ & $?$ & $\begin{array}{c}\text { Bécamel et al., 2002; Gavarini } \\
\text { et al., 2006 }\end{array}$ \\
\hline & $\begin{array}{l}\text { Veli3/CASK/MintMAGI2, } \\
\text { SAP102, PSD93 }\end{array}$ & $\begin{array}{c}\mathrm{Ct}(\mathrm{PDZ} \\
\text { ligand-SSV) }\end{array}$ & $?$ & $?$ & Bécamel et al., 2002 \\
\hline \multirow[t]{2}{*}{$5-\mathrm{HT}_{2 \mathrm{C}}$} & PICOT & $\mathrm{Ct}$ & $?$ & $?$ & Bécamel et al., 2002 \\
\hline & PTEN & $i_{3}$ & $?$ & $\begin{array}{c}\text { Rewarding effects of THC and } \\
\text { nicotine }\end{array}$ & Ji et al., 2006 \\
\hline \multirow[t]{4}{*}{$5-\mathrm{HT}_{4}$} & Src & $?$ & $\begin{array}{c}\rtimes \text { Erk1/2 signaling } \\
\rtimes \mathrm{PLC} \gamma 1\end{array}$ & $?$ & $\begin{array}{l}\text { Gill et al., 2005; Barthet et al., } \\
\text { 2007; Barthet et al., } 2009\end{array}$ \\
\hline & p11 & $\mathrm{i}_{3}$ & $\begin{array}{c}\star \text { Cell surface localization } \\
\star \text { Signaling }\end{array}$ & $\mathbf{v}$ Depression in rodent models & Warner-Schmidt et al., 2009 \\
\hline & ADAM10 & $?$ & $1 \mathrm{sAPP} \alpha$ release & $\begin{array}{l}\mathbf{\Delta} \beta \text {-amyloid plaques } \\
\mathbf{v} \text { Neuroinflammation }\end{array}$ & Cochet et al., 2013 \\
\hline & GRK5 & $\mathrm{Ct}$ & $\begin{array}{l}\text { \Src activation } \\
\text { Erk1/2 signaling }\end{array}$ & $?$ & Barthet et al., 2009 \\
\hline $5-\mathrm{HT}_{4(\mathrm{a})}$ & SNX27a & & Targeting to endosomes & $?$ & Joubert et al., 2004 \\
\hline
\end{tabular}


TABLE 21-Continued

\begin{tabular}{|c|c|c|c|c|c|}
\hline Receptor & GIP & $\begin{array}{c}\text { Site of } \\
\text { Interaction }\end{array}$ & Cellular Functions & Physiologic/Pathologic Functions & References \\
\hline & & $\begin{array}{c}\mathrm{Ct}(\mathrm{PDZ} \\
\text { ligand-SCF) }\end{array}$ & Receptor recycling? & & \\
\hline & NHERF & $\begin{array}{c}\mathrm{Ct}(\mathrm{PDZ} \\
\text { ligand-SCF) }\end{array}$ & $\begin{array}{l}\text { Targeting to microvilli } \\
\text { - interaction with Ezrin }\end{array}$ & $?$ & Joubert et al., 2004 \\
\hline & CRMP2 & $\mathrm{Ct}$ & Neuronal architecture & $?$ & Joubert et al., 2004 \\
\hline $5-\mathrm{HT}_{4(\mathrm{~b})}$ & PDE3A1, PDE4D3 & $?$ & $\begin{array}{c}\text { Regulation of cAMP } \\
\text { signaling }\end{array}$ & $?$ & Weninger et al., 2014 \\
\hline $5-\mathrm{HT}_{4(\mathrm{e})}$ & CIPP & $\begin{array}{c}\mathrm{Ct}(\mathrm{PDZ} \\
\text { ligand-VPV) }\end{array}$ & $?$ & $?$ & Joubert et al., 2004 \\
\hline $5-\mathrm{HT}_{4(\mathrm{e})}$ & nNOS & $\begin{array}{c}\mathrm{Ct}(\mathrm{PDZ} \\
\text { ligand-VPV) }\end{array}$ & $?$ & $?$ & Joubert et al., 2004 \\
\hline \multirow[t]{6}{*}{$5-\mathrm{HT}_{6}$} & Fyn & (PXHPXR) & $\begin{array}{c}\star \text { Gs signaling } \\
\star \text { Erk1/2 signaling } \\
\star \text { Cell surface expression }\end{array}$ & $?$ & Yun et al., 2007 \\
\hline & Jab1 & $\mathrm{i}_{3} / \mathrm{Ct}$ & $\begin{array}{l}\star \text { Gs signaling } \\
\star \text { Cell surface expression } \\
\rtimes \text { c-Jun phosphorylation }\end{array}$ & $\checkmark$ Cell death & Yun et al., 2010 \\
\hline & Map1B-LC1 & $\mathrm{Ct}$ & 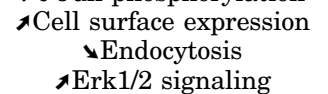 & $?$ & Kim et al., 2014 \\
\hline & SNX14 & $\mathrm{i}_{3}$ & $\begin{array}{l}\text { Endocytosis } \\
\text { Gs signaling }\end{array}$ & $?$ & Ha et al., 2015 \\
\hline & mTORC1 & Ct/unknown & ^mTOR signaling & $\begin{array}{c}\text { Cognitive impairment in } \\
\text { neurodevelopmental models of } \\
\text { schizophrenia }\end{array}$ & Meffre et al., 2012 \\
\hline & Cdk5, p35 & $\mathrm{Ct}$ & $\begin{array}{l}\text { Receptor phosphorylation } \\
\text { Cdk5 signaling }\end{array}$ & $\begin{array}{l}\text { Neurite growth migration of } \\
\text { pyramidal neurons }\end{array}$ & $\begin{array}{c}\text { Duhr et al., 2014; } \\
\text { Jacobshagen et al., 2014; } \\
\text { Dayer et al., } 2015\end{array}$ \\
\hline \multirow[t]{3}{*}{$5-\mathrm{HT}_{7}$} & Neurochondrin & & $?$ & $?$ & Ward et al., 2009 \\
\hline & Periplakin & & $?$ & $?$ & Ward et al., 2009 \\
\hline & S100B & $\mathrm{i}_{3}$ & $\checkmark c A M P$ & Behavioral despair & $\begin{array}{c}\text { Stroth and Svenningsson, } \\
2015\end{array}$ \\
\hline
\end{tabular}

PICO, protein kinase $\mathrm{C}$ interacting cousin of thioredoxin.

Rab6, kinesin family member $5 \mathrm{~B}$, and dynein that coordinates its anterograde traffic to terminal dendrites (Al Awabdh et al., 2012).

2. 5-HT 1 Receptor. In addition to its coupling to $\mathrm{G}_{\mathrm{i}} / \mathrm{G}_{\mathrm{o}}$ (Bockaert et al., 2006; Marin et al., 2012), the $5-\mathrm{HT}_{1 \mathrm{~B}}$ receptor interacts via its $\mathrm{i}_{3}$ loop with a particularly interesting GIP, named p11 (Svenningsson et al., 2006; Svenningsson and Greengard, 2007). p11 (also known as S100A10) is a member of the S100 EF-hand protein family. S100 proteins are small acidic proteins (10-12 $\mathrm{kDa})$ characterized by two calcium-binding sites that have helix-loop-helix ("EF-hand type"). p11 increases cell surface density of $5-\mathrm{HT}_{1 \mathrm{~B}}$ receptor and, thus, receptor-operated signaling (Svenningsson et al., 2006). Reduction in p11 level has been found in postmortem human tissue from depressed individuals and suicide victims as well as in a rodent model of depression, whereas its level in rodent brain is increased by antidepressants or electroconvulsive therapy (Svenningsson et al., 2006; Svenningsson and Greengard, 2007). Furthermore, invalidation of the gene encoding p11 induces a depression-like phenotype, reduces response to antidepressants and emotional memory, and enhances dependence to cocaine (Svenningsson and Greengard, 2007; Eriksson et al., 2013; Svenningsson et al., 2013; Svenningsson, 2014).
3. 5-HT $T_{2 A}$ Receptor. The $5-\mathrm{HT}_{2 \mathrm{~A}}$ receptor is mainly coupled to $\mathrm{G}_{\mathrm{q}} / \mathrm{G}_{11}$ proteins. 5- $\mathrm{HT}_{2 \mathrm{~A}}$ receptors also engage $G_{i} / G_{0}$-mediated signaling upon stimulation by hallucinogenic agonists, including LSD and synthetic agonists such as DOI (Bockaert et al., 2006; GonzalezMaeso et al., 2007; Marin et al., 2012; Karaki et al., 2014). Like many GPCRs, the $5-\mathrm{HT}_{2 \mathrm{~A}}$ receptor also recruits $\beta$-arrestins following agonist stimulation (Bhattacharya et al., 2010). Intriguingly, it has been found that $\beta$-arrestin 2 is specifically involved in the hallucinogenic-like effects elicited by high concentrations of 5-HT (or its metabolites) but not in those induced by DOI (Schmid et al., 2008). These hallucinogenic-like effects are mediated by the activation, via $\beta$-arrestin 2 , of a PI3K/Src/Akt signaling cascade (Schmid and Bohn, 2010). Likewise, $\beta$-arrestins are required for Erk $1 / 2$ activation by 5 -HT but not by DOI (Schmid et al., 2008).

The 5- $\mathrm{HT}_{2 \mathrm{~A}}$ receptor (like several other 5-HT receptors, including $5-\mathrm{HT}_{2 \mathrm{~B}}$ and $5-\mathrm{HT}_{2 \mathrm{C}}$ receptors; see below) expresses a canonical recognition motif for PDZ domain-containing proteins at its C-terminal extremity. PDZ domain-containing proteins (or PDZ proteins) are scaffolding proteins containing one or several PDZ domains, in addition to other protein-protein interaction domains. PDZ domains have been classified according to their specificity for PDZ motifs (or PDZ ligands): 
class I PDZ domains preferentially bind to $-\mathrm{S} / \mathrm{Tx} \varphi$, class II to $-\varphi \mathrm{x} \varphi$, and class III to $-\mathrm{E} / \mathrm{Dx} \varphi$ motifs (where $\varphi$ represents a hydrophobic residue and $\mathrm{X}$ any residue), respectively. The $5-\mathrm{HT}_{2 \mathrm{~A}}$ receptor $\mathrm{PDZ}$ ligand (-SCV) clearly belongs to class I. Several PDZ proteins have been found to interact with the $5-\mathrm{HT}_{2 \mathrm{~A}}$ receptor. The majority of them have been identified thanks to affinity purification coupled to mass spectrometry (AP-MS) proteomic strategies or two-hybrid screens. These include Multi-PDZ protein1 (MUPP1), PSD-95, membraneassociated guanylate kinase with inverted domain structure2 (MAGI2), synapse-associated protein (SAP)97, channel interacting PDZ protein (CIPP), and MAGUK p55 subfamily member 2 (MPP2) and 3 (MPP3) (Becamel et al., 2001; Bécamel et al., 2004; Pichon et al., 2010). Among the 5- $\mathrm{HT}_{2 \mathrm{~A}}$ receptor GIPs identified, PSD-95 is certainly the most extensively studied with respect to the functional impact of its association with the receptor. PSD-95, which is located in postsynaptic spine membranes together with other receptor PDZ partners, is required for dendritic targeting of the receptor (Xia et al., 2003; Allen et al., 2008). In addition, microtubuleassociated protein (MAP)1A may scaffold the receptor to the microtubule cytoskeleton and facilitate its trafficking to apical dendrites (Allen et al., 2008). PSD-95, like SAP97 and MUPP1, increases receptor cell surface density likely by inhibiting receptor endocytosis (Allen et al., 2008; Jones et al., 2009). The impact of the 5-HT receptor/PSD-95 complex upon receptor-operated signaling is less clear. On the one hand, $5-\mathrm{HT}_{2 \mathrm{~A}}$ receptormediated downstream signaling is impaired in PSD-95deficient mice (Abbas et al., 2009), suggesting that the interaction promotes receptor-operated signal transduction. On the other hand, acute disruption of $5-\mathrm{HT}_{2 \mathrm{~A}}$ receptor/PSD-95 association with an interfering peptide increases receptor-mediated cytosolic $\mathrm{Ca}^{2+}$ increase and its antihyperalgesic effects in models of neuropathic and inflammatory pain in the rat (Pichon et al., 2010; Wattiez et al., 2013), suggesting that this interaction inhibits receptor-operated signaling. These opposite effects of sustained (PSD-95 knockout) and acute (interfering peptide) disruption of the $5-\mathrm{HT}_{2 \mathrm{~A}}$ receptor/PSD-95 interaction may reflect long-term adaptive changes in PSD-95 knockout mice. In line with the antihyperalgesic effects produced by disruption of 5- $\mathrm{HT}_{2 \mathrm{~A}}$ receptor/PSD-95 interaction with a peptide, docking simulation studies identified a series of substituted indoles as potential small-molecule inhibitors of this interaction. One of them efficiently inhibited mechanical hyperalgesia in an experimental model of traumatic neuropathic pain in the rat (Vogrig et al., 2013). Collectively, these studies identify the $5-\mathrm{HT}_{2 \mathrm{~A}}$ receptor/PSD-95 complex as a new therapeutic target for the treatment of neuropathic pain, which remains poorly controlled by currently available analgesics. Consistent with the inhibition of $5-\mathrm{HT}_{2 \mathrm{~A}}$ receptor-operated signaling in PSD-95 deficient mice, the hallucinogenic-like effects of drugs are impaired in these mice (Abbas et al., 2009). Likewise, deletion of PSD-95 renders ineffective atypical antipsychotics such as clozapine, which act as $5-\mathrm{HT}_{2 \mathrm{~A}}$ receptor inverse agonists, against PCP-induced disruption of prepulse inhibition, a widely used pharmacological model of schizophrenia (Abbas et al., 2009). $\mathrm{Na}^{+} / \mathrm{H}^{+}$exchanger regulatory factor (NHERF) 3 is another PDZ protein that interacts with the $5-\mathrm{HT}_{2 \mathrm{~A}}$ receptor but, surprisingly, in a PDZ-independent manner (Walther et al., 2015). NHERF3 negatively regulates $5-\mathrm{HT}_{2 \mathrm{~A}}$ receptor endocytosis and positively influences $5-\mathrm{HT}_{2 \mathrm{~A}}$ receptor-stimulated inositol phosphate formation (Walther et al., 2015).

Several $5-\mathrm{HT}_{2 \mathrm{~A}}$ receptor-interacting proteins have been identified in addition to PDZ proteins. Targeting of $5-\mathrm{HT}_{2 \mathrm{~A}}$ receptor to caveolae microdomains is ensured by its interaction with the multifunctional proteins caveolins (Allen et al., 2008). Moreover, association of the receptor with caveolins has a profound impact on receptor-operated signal transduction and functions; interaction of $5-\mathrm{HT}_{2 \mathrm{~A}}$ receptor with caveolin-1 within lipid raft/caveolae membranes enhances receptor-mediated signal transduction by facilitating its coupling to $\mathrm{G} \alpha \alpha_{\mathrm{q}}$ protein in $\mathrm{C} 6$ glioma cells (Bhatnagar et al., 2004), whereas its interaction with caveolin-3, the predominant caveolin isoform in heart, upon 5-HT stimulation, negatively regulates receptormediated hypertrophy in cardiomyoblasts and neonatal cardiomyocytes (Mialet-Perez et al., 2012).

ARF1 and, to a lesser extent, ARF6, associate with the $\mathrm{i}_{3}$ loop and $\mathrm{Ct}$ of the $5-\mathrm{HT}_{2 \mathrm{~A}}$ receptor (Robertson et al., 2003). This association is enhanced by GTP loading and is essential for $5-\mathrm{HT}_{2 \mathrm{~A}}$ receptor-mediated PLD activation, which seems to be independent of $G_{q / 11}$ (Robertson et al., 2003). 5- $\mathrm{HT}_{2 \mathrm{~A}}$ receptors also bind to the tyrosine kinase Jak2 in fetal myoblasts (GuilletDeniau et al., 1997). This is accompanied by Jak2 autophosphorylation, the recruitment of the transcription factor signal transducer and activator of transcription (STAT)3, and its translocation to the nucleus (Guillet-Deniau et al., 1997). P90 ribosomal S6 kinase 2 (RSK2) interacts with $5-\mathrm{HT}_{2 \mathrm{~A}}$ receptor $\mathrm{i}_{3}$ loop and exerts a tonic break on receptor-operated signaling (Sheffler et al., 2006; Allen et al., 2008). RSK2 phosphorylates $5-\mathrm{HT}_{2 \mathrm{~A}}$ receptor at $\mathrm{Ser}^{314}$ located in the $\mathrm{i}_{3}$ loop. Ser ${ }^{314}$ phosphorylation underlies heterologous desensitization of the receptor elicited by growth factors (Allen et al., 2008; Strachan et al., 2009). A role of 5- $\mathrm{HT}_{2 \mathrm{~A}}$ receptors in symptoms associated with Coffin-Lowry syndrome (because of null mutations in RSK2 gene), such as moderate to severe mental retardation, movement disorders, and schizophrenia-like psychosis, in heterozygote females has been proposed (Allen et al., 2008). Calmodulin interacts in a $\mathrm{Ca}^{2+}$-dependent manner with consensus binding motifs located in $5-\mathrm{HT}_{2 \mathrm{~A}}$ receptor $i_{2}$ loop and $C t$. This association inhibits receptor coupling to $\mathrm{G}_{\mathrm{q}}$ (Turner and Raymond, 2005).

4. 5-HT $T_{2 B}$ Receptor. The $5-\mathrm{HT}_{2 \mathrm{~B}}$ receptor is mainly coupled to $\mathrm{G}_{\mathrm{q}}$ [see also Bockaert et al. (2006), Marin 
et al. (2012) for detailed review of $\mathrm{G}_{\mathrm{i}} / \mathrm{G}_{\mathrm{o}}$-mediated signaling events elicited by this receptor].

A number of recognized signaling proteins interact with the $5-\mathrm{HT}_{2 \mathrm{~B}}$ receptor, including constitutive and inducible NOS and the G proteins $\mathrm{G} \alpha \mathrm{q}, \mathrm{G} \alpha 11$, and $\mathrm{G} \alpha 13$. The $5-\mathrm{HT}_{2 \mathrm{~B}}$ receptor also binds to the multivalent PDZ scaffold protein, MUPP1; this is in common with the other $5-\mathrm{HT}_{2}$ receptors $5-\mathrm{HT}_{2 \mathrm{~A}}$ and $5-\mathrm{HT}_{2 \mathrm{C}} \cdot 5-\mathrm{HT}_{2 \mathrm{~A}}$ and $5-\mathrm{HT}_{2 \mathrm{~B}}$ receptors also bind MUPP1-PDZ domains in vitro and share the C-terminal $-\mathrm{E}-\mathrm{X}-\mathrm{V} / \mathrm{I}-\mathrm{S}-\mathrm{X}-\mathrm{V}$ sequence (Becamel et al., 2001). This PDZ motif is also required for the recruitment of the constitutive NO synthase cNOS (Manivet et al., 2000).

Ubiquitin E3 ligases (E3s) confer specificity to ubiquitination by recognizing target substrates. The ligand of numb protein X (LNX) family of E3s is a group of PDZ domain-containing RING-type E3 ubiquitin ligases. The substrate recognition mechanism of LNX E3s involves their specific PDZ domains by binding to the $\mathrm{C}$ termini of the target proteins. The human C-terminal LNX1 PDZ3-binding motifs of the $5-\mathrm{HT}_{2 \mathrm{~B}}$ receptor promotes ubiquitination by LNX1 $1 \mathrm{PDZ} 4$ (Guo et al., 2012).

5. 5-HT $T_{2 C}$ Receptor. The $5-\mathrm{HT}_{2 \mathrm{C}}$ receptor activates phospholipase $\mathrm{C}$ (PLC) via $\mathrm{G}_{\mathrm{q} / 11}, \mathrm{PLD}$ via $\mathrm{G}_{13}$, phospholipase A2 (PLA2), and Akt/glycogen synthase kinase (GSK) $3 \beta$ via $\mathrm{Gi}_{3}$ (Bockaert et al., 2006). $5-\mathrm{HT}_{2 \mathrm{C}}$ receptors also activate Erk1/2 signaling via a mechanism entirely independent of $\mathrm{G}$ proteins but dependent of their interaction with both $\mathrm{Ca}^{2+} /$ calmodulin and $\beta$-arrestin 2 (Labasque et al., 2008; Marin et al., 2012). As already mentioned, the receptor expresses a canonical class I PDZ ligand at its C-terminal extremity. MUPP1 was the first PDZ protein identified as a partner of the $5-\mathrm{HT}_{2 \mathrm{C}}$ receptor in 1998 , using the yeast two hybrid system (Ullmer et al., 1998). MUPP1 contains 13 PDZ domains (it is the PDZ protein that contains the largest number of PDZ domains identified) and selectively interacts with the receptor via its 10th PDZ domain (Becamel et al., 2001). This interaction is dynamically regulated by agonist-dependent receptor phosphorylation at $\operatorname{Ser}^{458}$ located in the PDZ binding motif (Parker et al., 2003). The gene encoding MUPP1 ( $M p d z)$ has been identified as a quantitative trait underlying physical dependence to drugs of abuse (Shirley et al., 2004). Additional $\mathrm{PDZ}$ partners of $5-\mathrm{HT}_{2 \mathrm{C}}$ receptor have been identified by means of AP-MS proteomic strategies (Bécamel et al., 2002, 2004). These include PSD-95, SAP102, MPP3, and the ternary complex Veli3/CASK/ Mint1. These studies revealed that in spite of their similar PDZ binding motifs, $5-\mathrm{HT}_{2 \mathrm{~A}}$ and $5-\mathrm{HT}_{2 \mathrm{C}}$ receptors bind to different sets of PDZ proteins that differ in their synaptic localizations: $5-\mathrm{HT}_{2 \mathrm{~A}}$ receptors preferentially interact with PDZ proteins exclusively located at the postsynapse (e.g., PSD-95, SAP97, and CIPP), whereas $5-\mathrm{HT}_{2 \mathrm{C}}$ receptors associate with PDZ proteins exhibiting both presynaptic and postsynaptic localizations such as the ternary complex Veli3/CASK/Mint1, consistent with their different distribution at the synapse (Bécamel et al., 2004). $5-\mathrm{HT}_{2 \mathrm{C}}$ receptor $\mathrm{PDZ}$ partners differentially regulate receptor endocytosis and desensitization: PSD-95 increases both constitutive and agonist-induced receptor endocytosis and desensitization, whereas MPP3 stabilizes the receptor at the plasma membrane and prevents its desensitization (Gavarini et al., 2006). Note that PSD-95 has an opposite effect on $5-\mathrm{HT}_{2 \mathrm{~A}}$ and $5-\mathrm{HT}_{2 \mathrm{C}}$ receptor endocytosis (Xia et al., 2003; Gavarini et al., 2006).

$5-\mathrm{HT}_{2 \mathrm{C}}$ receptors also interact via their $\mathrm{i}_{3}$ loop with PTEN, a phosphatase that negatively controls the Akt/PkB signaling pathway and thus is a tumor suppressor (Ji et al., 2006). The 5- $\mathrm{HT}_{2 \mathrm{C}}$ receptor/PTEN interaction was established in the VTA, the site of inhibition of the rewarding effects of many drugs of abuse by $5-\mathrm{HT}_{2 \mathrm{C}}$ receptor agonists. This inhibition is linked to the ability of receptors to prevent the increase in the firing rate of VTA dopaminergic neurons projecting to the nucleus accumbens elicited by drugs. Disrupting the $5-\mathrm{HT}_{2 \mathrm{C}}$ receptor-PTEN interaction with a cell-penetrating interfering peptide reduced the firing rate of VTA dopaminergic neurons and prevented rewarding effects of drugs of abuse such as THC and nicotine, suggesting that this interaction might be a relevant target for the treatment of drug addiction (Ji et al., 2006). 5- $\mathrm{HT}_{2 \mathrm{C}}$ receptors also interact with protein kinase $\mathrm{C}$ interacting cousin of thioredoxin, a PKC theta-interacting protein with a thioredoxin homology domain involved in the regulation of the thioredoxin system (Bécamel et al., 2002). The functional consequence of this interaction remains to be established.

6. 5-HT 4 Receptors. 5- $\mathrm{HT}_{4}$ receptors engage signaling pathways through multiple $G$ proteins, especially $\mathrm{G}_{\mathrm{S}}$ and in some cell lines $\mathrm{G}_{13}, \mathrm{G}_{\mathrm{q}}$, and $\mathrm{G}_{\mathrm{i}}$ [for reviews, see Coupar et al. (2007), Bockaert et al. (2008)]. In addition, $5-\mathrm{HT}_{4}$ receptors stimulate Erk1/2 in a G protein- and $\beta$-arrestin-independent mechanism that requires activation of the tyrosine kinase Src constitutively associated with $5-\mathrm{HT}_{4}$ receptor (Gill et al., 2005; Barthet et al., 2007; Bockaert et al., 2011). This pathway is also implicated in the activation of PLC $\gamma 1$-mediated inhibition of NHE-1 in intestinal epithelial cells (Gill et al., 2005). Furthermore, GRK5 interacts with the proximal $\mathrm{Ct}$ of $5-\mathrm{HT}_{4}$ receptors and phosphorylates $\beta$-arrestin 1 . This prevents Src activation and underlies desensitization of Src-dependent Erk1/2 activation by $5-\mathrm{HT}_{4}$ receptors (Bockaert et al., 2008; Barthet et al., 2009).

Like 5- $\mathrm{HT}_{1 \mathrm{~B}}$ receptors, $5-\mathrm{HT}_{4}$ receptors interact with p11 via their $i_{3}$ loop (Warner-Schmidt et al., 2009). p11 enhances receptor cell surface localization and signal transduction (Warner-Schmidt et al., 2009). Given the extensive data showing that p11 is downregulated in depressive states (Svenningsson and Greengard, 2007) and that activation of $5-\mathrm{HT}_{4}$ receptors has antidepressant effects (Ge and Barnes, 1996; Bockaert et al., 2011), 
this interaction might be of particular interest for the treatment of depression.

The $5-\mathrm{HT}_{4}$ receptor interacts, directly or indirectly, with the $\alpha$-secretase ADAM10. This interaction might be an important step in the constitutive (agonistindependent) activation of nonamyloidogenic cleavage of amyloid precursor protein (APP) and release of soluble $\operatorname{APP} \alpha(\operatorname{sAPP} \alpha)$ fragment elicited by the receptor (Cochet et al., 2013). $\operatorname{sAPP} \alpha$ has neurotrophic and neuroprotective properties, and its release on constitutive (and agonist-dependent) receptor activation might contribute to receptor-mediated reduction of amyloid pathology observed in several mouse models of Alzheimer disease (Cochet et al., 2013; Tesseur et al., 2013; Pimenova et al., 2014; Claeysen et al., 2015).

The $5-\mathrm{HT}_{4}$ receptor is one of the GPCRs for which alternative mRNA splicing generates the most variants that differ in their $\mathrm{Ct}$, with some variants (a, e, and f) expressing canonical PDZ ligands, suggesting that these receptors may recruit specific GIPs, including different sets of PDZ partners. Ten proteins have been shown to interact with the $\mathrm{Ct}$ of the $5-\mathrm{HT}_{4(\mathrm{a})}$ receptor. Most of them are PDZ proteins that associate with its canonical class I PDZ motif (-SCF) (Joubert et al., 2004). These include SNX27a, a member of the sorting nexin family, which targets 5 - $\mathrm{HT}_{4(\mathrm{a})}$ receptors to early endosomes in cell lines (Joubert et al., 2004). A more recent study showed that SNX27 associates with $\beta_{2}$-adrenergic receptor PDZ ligand and that this interaction is essential for PDZ-directed receptor recycling (Temkin et al., 2011). It also showed that SNX27 serves as an essential adaptor protein linking PDZ motif containing cargo to the retromer. SNX27 also directly interacts with endosomes through its lipid-binding phox homology (PX) domain. A similar role of SNX27a in endocytic 5-HT receptor trafficking is likely. The interaction of the $5-\mathrm{HT}_{4(\mathrm{a})}$ receptor with the PDZ protein NHERF promotes its recruitment to microvilli, where it localizes with activated ezrin, consistent with a role of $5-\mathrm{HT}_{4}$ receptors in cytoskeleton remodeling (Joubert et al., 2004). The $\mathrm{Ct}$ of the $5-\mathrm{HT}_{4(\mathrm{a})}$ receptor also recruits CRMP2, a member of the collapsing response mediator protein (CRMP) family through a PDZ-independent mechanism (Joubert et al., 2004). 5- $\mathrm{HT}_{4}$ receptors cause $\mathrm{G}_{13^{-}}$and RhoA-dependent neurite retraction and cell rounding in neuroblastoma cells (Ponimaskin et al., 2002b). Their association with CRMP2 might also contribute to regulation of neuronal architecture.

Three GIPs associate with the class II PDZ ligand (-VPV) of the 5- $\mathrm{HT}_{4(\mathrm{e})}$ receptor. These include two PDZ partners, namely CIPP and nNOS, the only NOS isoform expressing a PDZ domain. The third protein that binds to the $\mathrm{Ct}$ of $5-\mathrm{HT}_{4(\mathrm{e})}$ receptor is $\mathrm{Sec} 23 \mathrm{~A}$, a protein of the COPII complex, which is likely involved in its trafficking from the ER to the Golgi (Joubert et al., 2004). The $5-\mathrm{HT}_{4(\mathrm{~b})}$ receptor interacts with the phosphodiesterases PDE3A1 and PDE4D3, which may thereby regulate receptor-operated cAMP signaling (Weninger et al., 2014).

7. 5-HT 7 Receptor. The 5- $\mathrm{HT}_{7}$ receptor is coupled to $\mathrm{G}_{\mathrm{s}}$ and $\mathrm{G}_{12}$ (Bard et al., 1993; Ruat et al., 1993b). $5-\mathrm{HT}_{7}$ receptor stimulation promotes neurite outgrowth and SRE-mediated gene transcription through $\mathrm{G} \alpha_{12^{-}}$ dependent activation of RhoA and Cdc42 GTPases (Kvachnina et al., 2005; Guseva et al., 2014b). The $5-\mathrm{HT}_{7}$ receptor $\mathrm{Ct}$ interacts with neurochondrin, a protein expressed in bone and brain that promotes neurite growth. Neurochondrin interacts with several GPCRs, including melanin-concentrating hormone receptor 1 , orexin-1 and thromboxane A2 receptors, and the mGlu5 metabotropic glutamate receptor (Ward et al., 2009; Marin et al., 2012). Generally, neurochondrin inhibits GPCR coupling to $\mathrm{G}$ proteins. The $5-\mathrm{HT}_{7}$ receptor $\mathrm{Ct}$ also recruits the intermediate filament periplakin, which, like neurochondrin, inhibits receptor-operated $\mathrm{Ca}^{2+}$ signaling (Ward et al., 2009). The role of neurochondrin in neurite outgrowth elicited by $5-\mathrm{HT}_{7}$ receptor stimulation remains unexplored.

$5-\mathrm{HT}_{7}$ receptors, via their $\mathrm{i}_{3}$ loop, interact with S100B, a member of the S100 family, and S100B negatively regulates $5-\mathrm{HT}_{7}$ receptor-induced cAMP production (Stroth and Svenningsson, 2015). S100B seems to play a role in the antidepressant effects of fluoxetine (Baudry et al., 2010), and its serum concentration may serve as a biomarker predicting response to antidepressant treatment (Arolt et al., 2003). Notably, $5-\mathrm{HT}_{7}$ receptor antagonists have been reported to display rapid antidepressant action, making the receptor a promising target for antidepressants with improved onset of clinical efficacy compared with most of the currently available treatments (Mnie-Filali et al., 2011). Suggestive of a possible influence of $5-\mathrm{HT}_{7}$ receptor/S100B interaction in the pathogenesis of mood disorders and their treatment, transgenic female mice overexpressing S100B show depressive-like behavior that is normalized by administration of a $5-\mathrm{HT}_{7}$ receptor antagonist (Stroth and Svenningsson, 2015).

The human and rat genes coding for the $5-\mathrm{HT}_{7}$ receptors generate different splice variants (Heidmann et al., 1997). One of them (5- $\mathrm{HT}_{7(b)}$ receptor) is common to rat and human and expresses at its extreme $\mathrm{Ct}$ a canonical class II PDZ ligand (-FVL). To date, no PDZ partner of $5-\mathrm{HT}_{7(\mathrm{~b})}$ receptor has been identified.

\section{5-HT ${ }_{6}$ Receptor Receptosome: Toward New Signaling Mechanisms Underlying Its Control of Cognition and Neurodevelopmental Processes}

1. Introduction. The $5-\mathrm{HT}_{6}$ receptor has early been considered as a promising target for psychiatric diseases in line with its near exclusive expression in the central nervous system (Hirst et al., 2003). Although initial studies suggested that $5-\mathrm{HT}_{6}$ receptors are almost exclusively localized on GABA interneurons, more recent studies, including some in human brain, 
indicate that they are also present on pyramidal glutamatergic neurons in prefrontal cortex and hippocampus (Woolley et al., 2004; Marazziti et al., 2013b). A more detailed study of $5-\mathrm{HT}_{6}$ receptor mRNA distribution showed highest expression in both $\mathrm{D}_{1}$ and $\mathrm{D}_{2}$ receptorcontaining medium-size spiny neurons of caudate putamen and nucleus accumbens and confirmed consistent expression in glutamatergic neurons of hippocampus and cerebral cortex expressing vGluT1 (Helboe et al., 2015). It also showed the presence of $5-\mathrm{HT}_{6}$ receptor mRNA in a minor fraction of GABAergic cortical neurons, including mainly neurons coexpressing $5-\mathrm{HT}_{3 \mathrm{~A}}$ receptor and a subset of calbindin- and calretininpositive neurons (Helboe et al., 2015). 5- $\mathrm{HT}_{6}$ receptors thus display an ideal distribution to regulate the balance between excitatory and inhibitory signaling in brain regions implicated in cognition, which is altered in schizophrenia (Uhlhaas and Singer, 2010). The pharmacology of $5-\mathrm{HT}_{6}$ receptors includes a great number of ligands exhibiting agonist or antagonist activities. Some of them have shown putative interest for treating cognitive deficits, depression, anxiety, sleep, and feeding disorders as well as pain (Mitchell and Neumaier, 2005; Svenningsson et al., 2007; Fone, 2008; Ly et al., 2013; Wilkinson et al., 2014; Claeysen et al., 2015; Karila et al., 2015; Pereira et al., 2015). Unfortunately, phase III clinical trial results for treating cognitive impairment have been disappointing. An increase in our understanding of how the cellular and molecular events associated with the $5-\mathrm{HT}_{6}$ receptor translate to behavioral responses may inform and support stratified medicine approaches.
The $5-\mathrm{HT}_{6}$ receptor is positively coupled to $\mathrm{G}_{\mathrm{s}}$ and, like many GPCRs, activates Erk1/2 (Ruat et al., 1993a; Sebben et al., 1994) (Fig. 32). As $\mathrm{G}_{\mathrm{s}} / \mathrm{cAMP}$ and Erk1/2 pathways can have a positive influence on cognition, it was unlikely that their inhibition would mediate the procognitive effects of $5-\mathrm{HT}_{6}$ receptor antagonists. This suggested that alternative coupling mechanisms might be involved. Likewise, the cellular mechanisms controlling $5-\mathrm{HT}_{6}$ receptor functional activity remained largely unexplored until the use of unbiased strategies to identify $5-\mathrm{HT}_{6}$ receptor-interacting proteins. These included two-hybrid screens (Yun et al., 2007, 2010; Kim et al., 2014) and AP-MS proteomic strategies based on different methods to purify receptor partners, such as coimmunoprecipitation (Meffre et al., 2012) or pulldown assays using particular receptor sequences as baits (Duhr et al., 2014; Ha et al., 2015).

2. Fine-Tuning of $5-H T_{6}$ Receptor Trafficking and Signal Transduction by GIPs. The nonreceptor tyrosine kinase Fyn was the first GIP discovered for $5-\mathrm{HT}_{6}$ receptor, thanks to a two-hybrid screen using the receptor Ct as bait (Fig. 32). Fyn is a member of the Src family of tyrosine kinases that are highly expressed in brain and involved in synaptic plasticity. Several lines of evidence suggest that Fyn might be implicated in Alzheimer disease pathogenesis: Fyn phosphorylates Tau at $\mathrm{Tyr}^{18}$ and controls its association with microtubules (Lee et al., 2004); it has also been involved in $\mathrm{A} \beta$-induced synaptic deficits and neurotoxicity (Yang et al., 2011). In addition, Fyn plays a key role in neurodevelopmental processes: in combination with Src, Fyn controls cortical lamination, the formation of

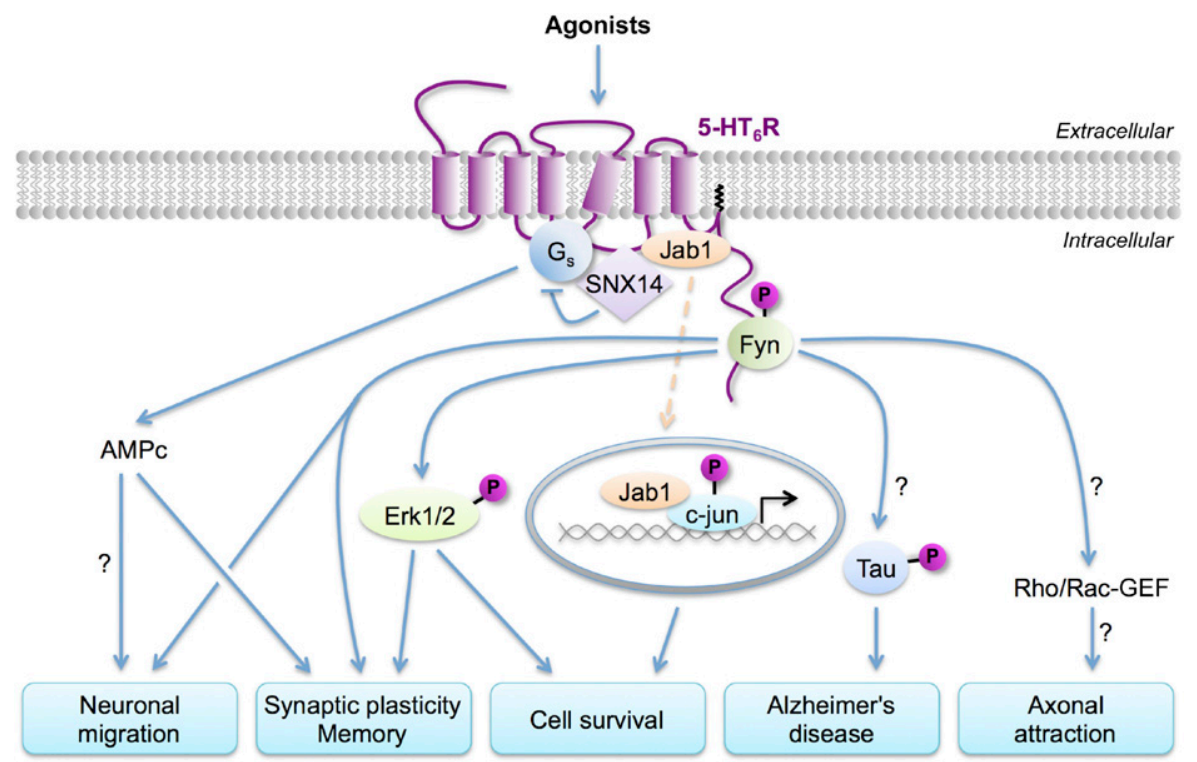

Fig. 32. Role of Fyn, Jab1, and SNX 1 recruitment by 5-HT 6 receptor in receptor-operated signaling and functions. Association of Fyn with 5 -HT 6 receptor Ct increases receptor cell surface localization and, consequently, receptor-operated G protein signaling. Fyn is also involved in Erk1/2 activation by $5-\mathrm{HT}_{6}$ receptors. Fyn phosphorylates Tau to control its association with microtubules and is involved in neuronal migration and $\mathrm{A} \beta$ induced synaptic deficits and neurotoxicity. Association of 5- $\mathrm{HT}_{6}$ receptor with Jab1 stabilizes surface expression of the receptor and is essential for its activity. $5-\mathrm{HT}_{6}$ receptor stimulation increases nuclear translocation of Jab1, a process that might reduce cell death induced by hypoxia. The 5-HT 6 receptor also interacts with SNX14, which inhibits receptor functions by sequestering $\mathrm{G} \alpha_{\mathrm{s}}$ and promoting receptor endocytosis and degradation. 
the Purkinje cell plate, and, thus, neuronal migration (Kuo et al., 2005). It is involved in netrin-1-mediated axon attraction of cortical neurons via the phosphorylation of Trio, a Rho/Rac-GEF (DeGeer et al., 2013), and in the maturation of GABAergic synapses elicited by neural cell adhesion molecule (Chattopadhyaya et al., 2013). Fyn binds to $5-\mathrm{HT}_{6}$ receptor Ct (likely to the conserved polyproline sequence PXhPXR, where $\mathrm{X}$ represents any amino acid and $\mathrm{h}$ any hydrophobic amino acid) via its SH3 domain (Yun et al., 2007). Functional studies showed that Fyn increases $5-\mathrm{HT}_{6}$ receptor cell surface localization and, consequently, receptor-operated G protein signaling (Yun et al., 2007). Conversely, $5-\mathrm{HT}_{6}$ receptor activation triggers Fyn phosphorylation, as assessed by an increase in $\mathrm{Tyr}^{420}$ phosphorylation, an event contributing to $5-\mathrm{HT}_{6}$ receptor-induced activation of the Ras/Erk1/2 pathway (Fig. 32) (Yun et al., 2007). Whether 5- $\mathrm{HT}_{6}$ receptormediated Fyn activation is involved in neuronal migration, attraction, and maturation of GABAergic synapses remains to be elucidated.

Further two-hybrid screens identified two other $5-\mathrm{HT}_{6}$ receptor-interacting proteins that control receptor trafficking. The first one is Jun activation domain-binding protein (Jab)1, a protein initially isolated as a c-Jun and Jun D binding partner that stabilizes their binding to activator protein 1 (AP-1) sites and potentiates them as transcription factors (Claret et al., 1996; Yun et al., 2010). Jab1 interacts with both $\mathrm{i}_{3}$ loop and $\mathrm{Ct}$ of the receptor (Yun et al., 2010). Jab1 stabilizes surface expression of $5-\mathrm{HT}_{6}$ receptor and is necessary to maintain activity of endogenous receptors. In turn, $5-\mathrm{HT}_{6}$ receptor stimulation increases nuclear translocation of Jab1, suggesting that they may play a role in the regulation of gene expression via Jab1 (Fig. 32) (Yun et al., 2010). Furthermore, 5-HT receptors and Jab1 are upregulated following middle cerebral artery occlusion-induced focal cerebral ischemia in rats. Likewise, exposure of cultured cells to hypoxic insults increased expression of both protein partners, which in turn reduce cell death induced by hypoxia (Fig. 32) (Yun et al., 2010). The second protein identified is light chain 1 (LC1) subunit of MAP1B protein (MAP1B-LC1), a microtubule-associated protein highly expressed in the brain (Kim et al., 2014). MAP1B-LC1 interacts with the $\mathrm{Ct}$ of the receptor and reduces receptor endocytosis, thereby increasing its cell surface expression and signal transduction activity $\left(\mathrm{G}_{\mathrm{S}}\right.$ coupling and Erk1/2 activation) (Kim et al., 2014).

The $5-\mathrm{HT}_{6}$ receptor $\mathrm{i}_{3}$ loop recruits several proteins of the endocytic machinery, such as dynamin, AP-2, amphiphysin, and epsin as well as SNX14 (Ha et al., 2015). Like SNX27, SNX14 belongs to the sorting nexin family, predicted to have a role in protein sorting and vesicular trafficking (Carlton et al., 2005). It contains a putative RGS domain and a phox homology (PX) domain, an $\mathrm{N}$-terminal hydrophobic region, and a PX-associated domain of unknown function. SNX14 is expressed at high levels in the nervous system (Carroll et al., 2001) and plays a critical role in both excitatory and inhibitory transmissions (Huang et al., 2014). SNX14 was found to inhibit $5-\mathrm{HT}_{6}$ receptordependent signaling via two different mechanisms: 1) it specifically binds to and sequesters $\mathrm{G} \alpha_{\mathrm{s}}$, thus inhibiting the $\mathrm{G}_{\mathrm{s}}$-cAMP pathway; and 2) it promotes $5-\mathrm{HT}_{6}$ receptor endocytosis and degradation (Fig. 32) (Ha et al., 2015). Furthermore, PKA phosphorylates SNX14 at two serine residues located in the RGS domain. SNX14 phosphorylation strongly reduces its affinity for $\mathrm{G} \alpha_{\mathrm{s}}$ and thereby prevents $\mathrm{G} \alpha_{\mathrm{s}}$ sequestration. Accordingly, phosphorylated SNX14 preferentially associates with $5-\mathrm{HT}_{6}$ receptor and can thereby enhance receptor internalization (Ha et al., 2015). Therefore, SNX14 has been considered as a dual, sequential, negative regulator of $5-\mathrm{HT}_{6}$ receptoroperated signaling, first by sequestering $\mathrm{G} \alpha_{\mathrm{s}}$ and second by inducing receptor endocytosis (Ha et al., 2015). Collectively, these findings indicate that $5-\mathrm{HT}_{6}$ receptor functional activity is finely modulated by its association with GIPs that exert contrasting effects on receptor trafficking and receptor-mediated signal transduction.

3. Recruitment of mTOR Complex 1 by $5-H T_{6}$ Receptor: Potential Role in Cognitive Deficits Associated with Schizophrenia. Using a proteomics strategy combining coimmunoprecipitation of full-length receptor and tandem mass spectrometry, Meffre et al. (2012) identified 28 proteins that specifically associate with the $5-\mathrm{HT}_{6}$ receptor. This "receptosome" showed a remarkable enrichment in proteins of the mTOR pathway (Meffre et al., 2012). These include mTOR itself; Raptor (regulatory associated protein of TOR), an activator of mTOR that together with mTOR and proline-rich Akt substrate of $40 \mathrm{kDa}$ constitutes the mTOR complex 1 (mTORC1); the small GTPase Rheb (Ras homolog enriched in brain), which directly activates mTOR when bound to GTP; the Tti1/Tel2 complex, required for assembly and stability of mTOR complexes; and the Ras GTPase activating protein neurofibromin, an upstream negative regulator of the pathway leading to mTOR activation (Fig. 33) (Meffre et al., 2012). This "receptosome" also includes Vps34, a protein of the class III PI3K family implicated in autophagosome formation (Bockaert and Marin, 2015). In line with this remarkable enrichment of the $5-\mathrm{HT}_{6}$ receptor complex in proteins of the mTOR pathway, agonist stimulation of the receptor results in the activation of the mTOR pathway both in a transfected cell line and in rodent brain, particularly in prefrontal cortex and striatum (Meffre et al., 2012). Notably, 5- $\mathrm{HT}_{6}$ receptor-elicited mTOR activation depends on both its physical association with mTOR and the canonical PI3K/Akt/TSC/Rheb pathway involved in activation of mTORC1 by tyrosine kinase receptors (Fig. 33) (Meffre et al., 2012).

An overactivation of mTOR is observed in many genetic diseases in which mental retardation or 


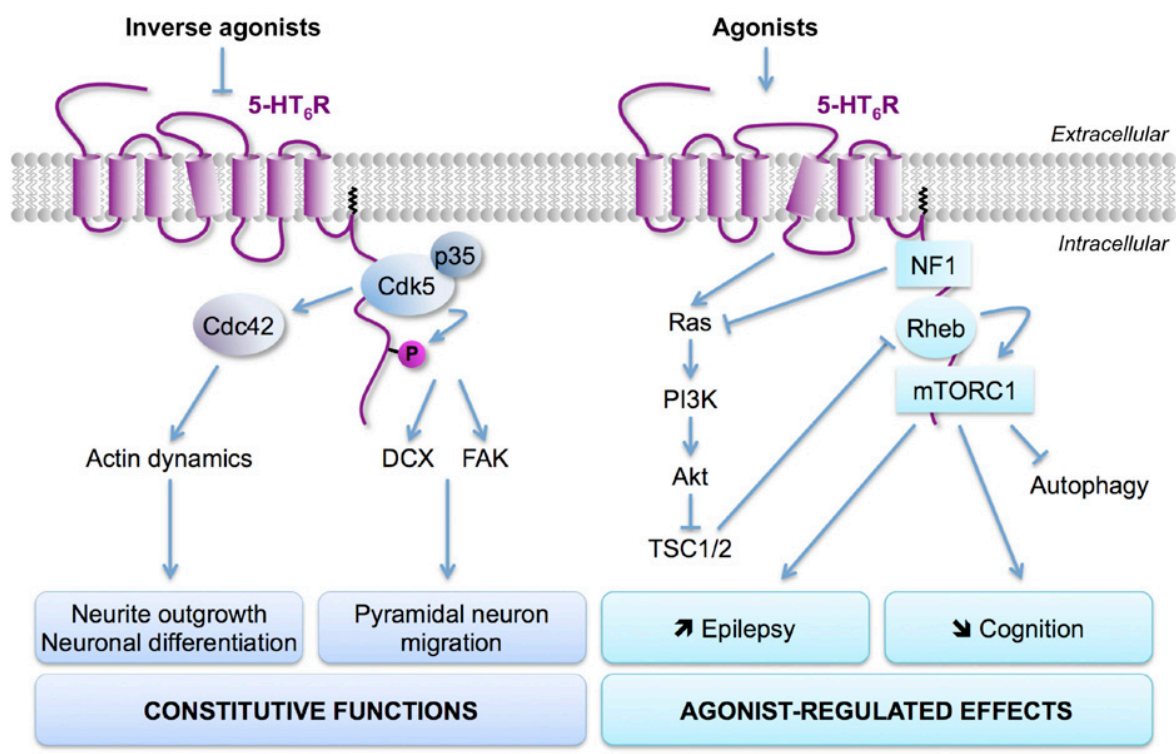

Fig. 33. Engagement of Cdk5 and mTOR signaling pathways by $5-\mathrm{HT}_{6}$ receptor and their role in neurodevelopmental processes and cognition. Left panel: The $5-\mathrm{HT}_{6}$ receptor constitutively interacts with Cdk5 (and its activator p35), which phosphorylates the receptor at Ser ${ }^{350}$. This enables 5 -HT 6 receptor to promote neurite growth via the activation of the Rho GTPase Cdc42. Cdk5 activity, under the control of 5-HT 6 receptor, also enables migration of pyramidal cortical neurons, likely via the phosphorylation of doublecortin (DCX) and focal adhesion kinase (FAK). These effects are agonist-independent and prevented by inverse agonists. Right panel: The 5 - $\mathrm{HT}_{6}$ receptor recruits several proteins of the mTOR pathway, including mTOR itself and Raptor, two protein components of the mTORC1 complex, neurofibromin (NF1), Vps34, and Rheb. Prefrontal 5-HT 6 receptors engage mTOR signaling upon agonist stimulation and in rat neurodevelopmental models of schizophrenia to compromise social cognition and episodic memory, whereas $5-\mathrm{HT}_{6}$ receptor blockade by antagonists or direct mTOR inhibition by rapamycin rescue cognitive deficits in these models.

cognitive deficits are observed [for a review, see Bockaert and Marin (2015)]. One classic example is tuberous sclerosis (TSC) caused by mutations in the TSC1 or TSC2 genes, which encode proteins of the TSC complex, namely, hamartin and tuberin, respectively. The TSC complex is the main GTPase activating protein for Rheb. Mutations in TSC1 or TSC2 result in inactivation of TSC, a process leading to nonphysiologic mTOR activation. About $50 \%$ of TSC patients show intellectual disabilities as well as deficits in memory, attention, and executive functions, and 20\%-60\% display ASD (Bockaert and Marin, 2015). Moreover, the mTORC1 inhibitor rapamycin rescues cognitive deficits in a mouse model of TSC (Tsc2 $2^{+/-}$mice). Likewise, systemic administration of rapamycin prevents deficits in social cognition and novel object recognition induced by a $5-\mathrm{HT}_{6}$ receptor agonist in the rat (Meffre et al., 2012). In two neurodevelopmental rodent models of schizophrenia, the neonatal PCP model and the social isolation model (isolation after weaning), a sustained 5 - $\mathrm{HT}_{6}$ receptor-mediated mTOR activation that persists at the adult stage occurs specifically in prefrontal cortex (Meffre et al., 2012). Again, cognitive impairment observed in both models is reversed by an acute injection of rapamycin at the adult stage (Meffre et al., 2012). These findings suggest a critical role of mTOR activation not only in rare autism-related genetic disorders, such as TSC, but also in schizophrenia, a more frequent, multifactorial, and debilitating disorder. The mechanisms by which nonphysiologic mTORC1 activation induces cognitive deficits remain largely unknown.
A recent report has shown that enhanced activity of mTORC1 in postmortem brain of ASD patients is associated with a decrease in autophagy, an increase in spine density, and a reduction of developmental spine pruning in layer $\mathrm{V}$ pyramidal neurons (Tang et al., 2014). Spine defects are likewise observed in $T s c 2^{+/-}$mice (Bockaert and Marin, 2015). Whether inhibition of mTOR pathway contributes to the procognitive effects of $5-\mathrm{HT}_{6}$ receptor antagonists in patients with Alzheimer disease remains to be explored. Nonphysiologic mTOR activation, under the control of $5-\mathrm{HT}_{6}$ receptor, might also be involved in epilepsy. Indeed, an increase in $5-\mathrm{HT}_{6}$ receptor expression was found both in human epileptic tissue and the brain of rats treated with pilocarpine, a model of temporal lobe epilepsy (Wang et al., 2014). mTOR is also overactivated in the pilocarpine model, and a $5-\mathrm{HT}_{6}$ receptor antagonist prevents mTOR activation, increases latency of seizures, and reduces their severity (Wang et al., 2014). This suggests that blocking the $5-\mathrm{HT}_{6} / \mathrm{mTOR}$ pathway might be a valuable therapeutic strategy for epilepsy treatment.

4. Recruitment of Cyclin-Dependent Kinase 5 by

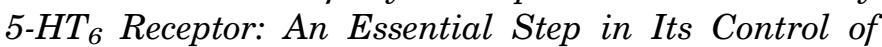
Neuronal Migration and Differentiation. The $5-\mathrm{HT}_{6}$ receptor is implicated in early steps of brain development, including neurulation and neuronal migration within the cortex (Jacobshagen et al., 2014; Dayer et al., 2015). Although the cAMP pathway contributes to the control of neuronal migration by $5-\mathrm{HT}_{6}$ receptors, a PKA inhibitor only partially reversed the effect of its stimulation upon neuronal migration (Riccio et al., 2009), 
suggesting that other signaling pathways might be involved. Cyclin-dependent kinase (Cdk)5, which has been identified as a $5-\mathrm{HT}_{6}$ receptor partner by different AP-MS proteomics strategies (Fig. 33; Meffre et al., 2012; Duhr et al., 2014), was an obvious candidate. Indeed, Cdk5 is known to control actin cytoskeleton dynamics and various neurodevelopmental processes, such as neuronal migration (including migration of cortical pyramidal neurons), neurite growth, and synapse morphogenesis (Jessberger et al., 2009; Lalioti et al., 2010). Moreover, the $5-\mathrm{HT}_{6}$ receptor recruits, via its Ct, not only Cdk5 and its activator p35 but also a network of proteins functionally connected with Cdk5, including Wiskott-Aldrich syndrome protein-family verprolin homologous protein 1 (WAVE-1) and G protein inducer of neurite growth 1 , two Cdk5 substrates; phosphatase $2 \mathrm{~A}$, which dephosphorylates and activates WAVE-1; and the Arp2/3 complex, which is also known to be activated by WAVE-1 (Duhr et al., 2014). Several lines of evidence indicate a role of Cdk5, under the control of the $5-\mathrm{HT}_{6}$ receptor, in the migration of pyramidal neurons: in utero electroporation of a $5-\mathrm{HT}_{6}$ receptor short hairpin RNA at E14.5 induces a mispositioning of these neurons, which can be rescued by electroporation of plasmids encoding wild-type $5-\mathrm{HT}_{6}$ receptor or $5-\mathrm{HT}_{6}$ receptors unable to couple to $\mathrm{G}_{\mathrm{s}}$ or to bind to 5-HT (Jacobshagen et al., 2014). This indicates that the effect of $5-\mathrm{HT}_{6}$ receptors on pyramidal neuron migration is agonist-independent and is not mediated by the $\mathrm{G}_{\mathrm{s}}$-adenylyl cyclase pathway. Defect in migration elicited by silencing $5-\mathrm{HT}_{6}$ receptor expression is rescued by electroporation of plasmids expressing Cdk5 and its activator p35 (Jacobshagen et al., 2014). Moreover, $5-\mathrm{HT}_{6}$ receptor knockdown significantly reduces phosphorylation of doublecortin (at $\mathrm{Ser}^{297}$ ) and focal adhesion kinase (at $\mathrm{Ser}^{732}$ ) in primary cortical neurons, two Cdk5 substrates known to control migration of pyramidal neurons (Xie et al., 2003; Tanaka et al., 2004). Collectively, these findings indicate that $5-\mathrm{HT}_{6}$ receptors control migration of cortical pyramidal neurons through an agonist-independent, Cdk5-dependent mechanism (Jacobshagen et al., 2014; Dayer et al., 2015).

Beyond neuronal migration, the $5-\mathrm{HT}_{6} / \mathrm{Cdk} 5$ complex also controls neurite outgrowth and neuronal differentiation (Fig. 33). Its role in neurite growth was not only established in neuroblastoma-glioma NG108-15 cells, a commonly used cellular mode for investigating mechanisms underlying neuronal development, but also in primary neurons and brain explants (Duhr et al., 2014; Seo and Tsai, 2014). Reminiscent of its control of neuronal migration, the growth-promoting effects of the receptor is $\mathrm{G}_{\mathrm{s}^{-}}$and agonist-independent. They are reversed by the selective $5-\mathrm{HT}_{6}$ receptor antagonist SB258585, which thus behaves as an inverse agonist in this model (Duhr et al., 2014). Likewise, SB258585 inhibits $\mathrm{Cdk} 5$ association with the $5-\mathrm{HT}_{6}$ receptor, indicating a specific recruitment of Cdk5 by a constitutively active receptor conformation. 5 - $\mathrm{HT}_{6}$ receptor-elicited neurite growth also depends on receptor phosphorylation at Ser $^{350}$ by associated Cdk5. This suggests a reciprocal interplay between $5-\mathrm{HT}_{6}$ receptor and $\mathrm{Cdk} 5$, whereby the receptor stimulates Cdk5 activity and is itself a Cdk5 substrate. The signaling events downstream of the $5-\mathrm{HT}_{6} / \mathrm{Cdk} 5$ complex contributing to neurite growth have been partially characterized and involve Cdk5-dependent activation of the Rho GTPase cell division cycle (Cdc)42, a key regulator of actin cytoskeleton dynamics (Fig. 33) (Duhr et al., 2014). The precise mechanisms that control $5-\mathrm{HT}_{6}$ receptor/Cdk5 interaction, including the potential influence of other receptor partners, and the cellular events downstream of the $5-\mathrm{HT}_{6} / \mathrm{Cdk} 5 / \mathrm{Cdc} 42$ pathway remain to be explored. As already mentioned, the regulatory role of Cdk5 during brain development extends to synapse formation. Whether $5-\mathrm{HT}_{6}$ receptor-dependent activation of Cdk5 controls synaptogenesis in addition to neuron migration and shaping also remains to be investigated.

\section{5-HT Receptors and the Brain}

\section{A. Introduction}

The diversity of 5-HT receptor signaling pathways and associated functional complexity in the brain is greater than any other tissue or organ. For historical perspectives on the contribution of neurophysiology, pharmacology, and molecular biology to the discovery of 5 -HT receptor subtypes in the brain, see reviews in Bradley et al. (1986), Barnes and Sharp (1999), and Bockaert et al. (2010).

\section{B. 5-HT Receptor Signaling in Neurons}

All 5-HT receptor subtypes found in the brain are also found in the periphery except $5-\mathrm{ht}_{1 \mathrm{e}}, 5-\mathrm{HT}_{2 \mathrm{C}}$, and $5-\mathrm{HT}_{6}$ receptors, for which there is little evidence for functional expression outside the CNS. The signaling properties of 5-HT receptors in the brain are identical to those in the periphery. Thus, the metabotropic 5-HT receptors couple to the three canonical signaling pathways, namely $G_{i}, G_{s}$, and $G_{q / 11}$, which elicit the expected second messenger cascades, and this is proven to occur in neurons in most cases.

The $\mathrm{G}_{\mathrm{i}}$-coupled 5-HT receptors that inhibit adenylyl cyclase and cause a fall in cAMP encompass the $5-\mathrm{HT}_{1}$ receptor family, comprising $5-\mathrm{HT}_{1 \mathrm{~A}}, 5-\mathrm{HT}_{1 \mathrm{~B}}, 5-\mathrm{HT}_{1 \mathrm{D}}$, $5-\mathrm{ht}_{1 \mathrm{E}}$, and $5-\mathrm{HT}_{1 \mathrm{~F}}$ subtypes. Evidence suggests that the $5-\mathrm{HT}_{5}$ receptor family, $5-\mathrm{HT}_{5 \mathrm{~A}}$ and $5-\mathrm{ht} \mathrm{t}_{5 \mathrm{~b}}$, is also $\mathrm{G}_{\mathrm{i}}$-coupled, although, to date, this has only been demonstrated in cultured cells and not native neurons. Excellent reviews on the signaling (Hannon and Hoyer, 2008; Bockaert et al., 2010; McCorvy and Roth, 2015) and consequent electrophysiological (Lamb and Aghajanian, 2006; Andrade and Beck, 2010; Marek, 
2010) properties of $5-\mathrm{HT}_{1}$ receptors can be found elsewhere.

Independent of the involvement of a decrease in cAMP, $5-\mathrm{HT}_{1}$ receptors also open GIRKs to hyperpolarize neurons and inhibit the opening of voltage-gated calcium channels; this is best understood for $5-\mathrm{HT}_{1 \mathrm{~A}}$ receptors (e.g., Montalbano et al., 2015). 5-HT 1 receptors are also likely to elicit other (noncanonical) $\mathrm{G}$ protein-dependent signals, including via ERK and Akt kinase, again as exemplified by studies of the $5-\mathrm{HT}_{1 \mathrm{~A}}$ receptor. Adding further complexity, it is well established that $5-\mathrm{HT}_{1 \mathrm{~A}}$ receptors have different properties depending on their pre- or postsynaptic localization. In particular, agonists tend to have greater efficacy at presynaptic 5 - $\mathrm{HT}_{1 \mathrm{~A}}$ receptors, and the latter have greater tendency to desensitize than postsynaptic $5-\mathrm{HT}_{1 \mathrm{~A}}$ receptors. The reasons for these differences are uncertain but, as discussed elsewhere (Clarke et al., 1996; Barnes and Sharp, 1999; Mannoury la Cour et al., 2006; GarciaGarcia et al., 2014), could relate to presynaptic versus postsynaptic differences in $5-\mathrm{HT}_{1 \mathrm{~A}}$ receptor reserve, efficiency of $G$ protein coupling, non-G protein-dependent signaling, or even biased agonism - that is, the generation of signals that are ligand-dependent. Regarding the latter, emerging data strongly support the view that selective $5-\mathrm{HT}_{1 \mathrm{~A}}$ receptor agonists can preferentially direct receptor signaling to particular intracellular pathways in a brain region-specific manner (Becker et al., 2016).

The $5-\mathrm{HT}_{2}$ receptor family, $5-\mathrm{HT}_{2 \mathrm{~A}}, 5-\mathrm{HT}_{2 \mathrm{~B}}$, and $5-\mathrm{HT}_{2 \mathrm{C}}$, comprise $\mathrm{G}_{\mathrm{q} / 11^{-}}$-coupled receptors that activate phospholipase $\mathrm{C}$, leading to increased formation of inositol trisphosphate and diacylglycerol and then mobilization of intracellular calcium and PKC activation. $5-\mathrm{HT}_{2}$ receptor stimulation also results in neuronal excitation in a variety of brain regions, likely involving the closure of potassium channels. A 5- $\mathrm{HT}_{2}$ receptor-mediated increase in excitatory postsynaptic currents is also often observed, which is thought to be mediated either directly or indirectly through increased release of glutamate (Lambe and Aghajanian, 2006; Marek, 2010).

It is now recognized that $5-\mathrm{HT}_{2}$ receptor signaling goes well beyond activation of the phospholipase C/PKC pathway. For instance, noncanonical signaling pathways associated with $5-\mathrm{HT}_{2 \mathrm{~A}}$ receptor activation include phospholipase $\mathrm{A}_{2}$, the ERK pathway, and signaling via small $\mathrm{G}$ proteins (e.g., Rho A and Rab4), and there are similar such findings for $5-\mathrm{HT}_{2 \mathrm{~B}}$ and $5-\mathrm{HT}_{2 \mathrm{C}}$ receptors [for review, see Bockaert et al. (2010), Halberstadt (2015), McCorvy and Roth (2015), Maroteaux et al. (2017)]. Interesting findings are emerging regarding noncanonical signaling by $5-\mathrm{HT}_{2}$ receptors. Specifically, the $5-\mathrm{HT}_{2 \mathrm{C}}$ receptor is able to activate ERK via a G proteinindependent mechanism through recruitment of calmodulin and $\beta$-arrestin (Labasque et al., 2008). Furthermore, recent studies on noncanonical signaling by the $5-\mathrm{HT}_{2 \mathrm{~B}}$ receptor found evidence of liganddependent signals and then used the crystal structure of the receptor to identify high-resolution, structural basis for the biased signaling (Wacker et al., 2013, $2017 a, b)$. This evidence of ligand-dependent signaling through $5-\mathrm{HT}_{2}$ receptors has relevance to the psychotropic effects of $5-\mathrm{HT}_{2 \mathrm{~A}}$ receptor agonists, some of which are hallucinogenic but not all (Gonzalez-Maeso et al., 2007), and may also explain the long-lasting effects of LSD that are difficult to explain on the basis of pharmacokinetics alone (Wacker et al., 2017). However, the signaling pathways mediating the characteristic effects of hallucinogens have not been identified conclusively. Biased agonism at $5-\mathrm{HT}_{2}$ receptors offers intriguing possibilities for therapeutic potential (e.g., avoidance of hallucinogenic properties), although this is yet to be explored, keeping in mind that $5-\mathrm{HT}_{2 \mathrm{~A}}$ receptor agonists have profound effects on vascular and other smooth muscle in addition to their psychotropic effects. Also, findings of the existence of constitutive activity at $5-\mathrm{HT}_{2 \mathrm{~A}}$ and $5-\mathrm{HT}_{2 \mathrm{C}}$ receptors, and $5-\mathrm{HT}_{2}$ receptor ligands with inverse agonist properties, provides further avenues for $5-\mathrm{HT}_{2}$ receptor drug development (e.g., Aloyo et al., 2009).

The remaining metabotropic 5 -HT receptors to be considered, specifically $5-\mathrm{HT}_{4}, 5-\mathrm{HT}_{6}$, and $5-\mathrm{HT}_{7}$ receptors, are $\mathrm{G}_{\mathrm{s}}$ coupled and thus activate adenylyl cyclase to increase cAMP. At the electrophysiological level, $5-\mathrm{HT}_{4}$ receptor activation on neurons is associated with a slow membrane depolarization mediated by a reduction of a slow after-hyperpolarization potential and facilitation of L-type calcium channels through protein kinase A activation (Andrade and Chaput, 1991; Birnstiel and Beck, 1995). Similarly, the neuronal $5-\mathrm{HT}_{7}$ receptor is also frequently associated with a direct depolarizing or excitatory effect, also likely mediated by actions on slow after-hyperpolarization and L-type calcium channels (Bacon and Beck, 2000; Andrade, 2006).

As with the other metabotropic 5-HT receptors, the $5-\mathrm{HT}_{4}$ receptor generates a diversity of signals independent of the second messenger. In addition, both the $5-\mathrm{HT}_{4}$ and $5-\mathrm{HT}_{6}$ receptors provide further examples of metabotropic 5-HT receptors that are capable of noncanonical signaling. For example, $5-\mathrm{HT}_{4}$ receptor stimulation activated ERK in cultured cells and neurons in a manner that was $G$ protein-independent $\left(G_{q}, G_{i}, G_{o}\right)$ but dependent on Src tyrosine kinase (Barthet et al., 2007; Bockaert et al., 2010), and there are analogous observations for $5-\mathrm{HT}_{6}$ receptors (Yun et al., 2007).

As a complement to the slow signaling elicited by metabotropic 5-HT receptors, the ionotropic $5-\mathrm{HT}_{3}$ receptor mediates rapid synaptic transmission. All five human $5-\mathrm{HT}_{3}$ receptor genes $(5-H T 3 A-3 E)$ are homologous with other members of the Cys-Cys loop ligandgated channel superfamily (e.g., nicotinic, $\mathrm{GABA}_{\mathrm{A}}$, glutamate, or glycine receptors) (Barnes et al., 2009). Although there is uncertainty regarding the composition of the native $5-\mathrm{HT}_{3}$ receptors in the brain, pentameric coassemblies of $5-\mathrm{HT}_{3 \mathrm{~A}}$ and $5-\mathrm{HT}_{3 \mathrm{~B}}$ subunits is 
a likely common occurrence [for reviews, see Niesler (2011) and Thompson and Lummis (2013)]. Allosteric modulators of the $5-\mathrm{HT}_{3}$ receptor are emerging to add to the possibilities for $5-\mathrm{HT}_{3}$ receptor manipulation for therapeutic benefit (e.g., Trattnig et al., 2012 and Newman et al., 2013).

Overall, the complexity of neuronal signaling events elicited by 5 -HT receptors is yet to be fully revealed. The metabotropic 5-HT receptors are clearly capable of both $\mathrm{G}$ protein-dependent and $\mathrm{G}$ protein-independent signaling, and it is also clear that the diverse signals generated by these receptors can be biased according to the agonist used. Moreover, as covered elsewhere, further complexity arises from the large number of protein partners influencing cellular localization and trafficking as well as signal tuning of 5-HT receptors, their homo- or heterodimerization with other GPCRs, and the alternative RNA splicing and editing of certain 5 - $\mathrm{HT}$ receptors (especially $5-\mathrm{HT}_{2 \mathrm{C}}, 5-\mathrm{HT}_{4}$, and $5-\mathrm{HT}_{7}$ receptors) to generate variability in function (Hannon and Hoyer, 2008; Bockaert et al., 2010; McCorvy and Roth, 2015).

\section{Expression of 5-HT Receptors in the Brain}

Application of a combination of techniques such as receptor autoradiography, in situ hybridization, and immunocytochemistry has revealed maps of 5-HT receptor subtype distribution in the brain that are largely similar across a range of vertebrate species (although of note, the $5-\mathrm{ht}_{1 \mathrm{e}}$ receptor is not expressed in rodents, forebrain $5-\mathrm{HT}_{3}$ receptors are differentially expressed across species, and the full-length $5-\mathrm{ht}_{5 \mathrm{~b}}$ receptor is not expressed in man). The use of BAC transgenic mice engineered to express a fluorescent or colored reporter genes under the control of specific 5 -HT receptor promoters, such as in the case of $5-\mathrm{HT}_{2 \mathrm{~A}}$ receptor (Weber and Andrade, 2010), reveals further anatomic detail of 5-HT receptor distribution. Although the 5-HT receptor maps are largely based on data collected from the rodent brain, a high-resolution PET atlas of four 5 -HT receptors $\left(5-\mathrm{HT}_{1 \mathrm{~A}}, 5-\mathrm{HT}_{1 \mathrm{~B}}, 5-\mathrm{HT}_{2 \mathrm{~A}}\right.$, and $5-\mathrm{HT}_{4}$ receptors) and the 5-HT transporter was recently described for the human brain (Beliveau et al., 2017). It is now clear from these mapping studies that each 5-HT receptor subtype has a unique distribution pattern in the brain but one that often overlaps with that of other 5 -HT receptor subtypes. These differential distribution patterns suggest that different 5-HT receptor subtypes are likely associated with distinct CNS functions amenable to manipulation using 5-HT receptor subtype selective pharmacological agents.

\section{Presynaptic 5-HT Receptors}

Two of the 145 -HT receptors are highly expressed presynaptically (i.e., expressed by 5 -HT neurons themselves). Thus, $5-\mathrm{HT}_{1 \mathrm{~A}}$ receptors are located on the soma and dendrites of 5 - $\mathrm{HT}$ neurons, whereas $5-\mathrm{HT}_{1 \mathrm{~B}}$ receptors are expressed at the soma but then trafficked down the axons to the terminals (Riad et al., 2000). It is firmly established from both in vitro and in vivo models that $5-\mathrm{HT}_{1 \mathrm{~A}}$ and $5-\mathrm{HT}_{1 \mathrm{~B}}$ receptors function as autoreceptors and exert direct inhibitory control over the firing of 5-HT neurons and terminal 5-HT release, respectively. Thus, studies over 40 years ago finding that 5-HT itself, or nonselective 5-HT agonists such as LSD, inhibited the efflux of preloaded radiolabeled 5-HT from rodent brain slice preparations were followed up by extensive pharmacological analysis that identified that this effect was mediated by $5-\mathrm{HT}_{1 \mathrm{~B}}$ receptors located on 5-HT nerve terminals (Gothert and Weinheimer, 1979; Mounsey et al., 1982; Engel et al., 1986; Fink and Gothert, 2007). Similarly detailed pharmacological studies using electrophysiological recordings of 5 -HT neurons and in vivo microdialysis measurements of 5-HT release characterized the autoreceptor function of somatodendritic $5-\mathrm{HT}_{1 \mathrm{~A}}$ receptors (e.g., Vandermaelen and Aghajanian, 1983; Sharp et al., 1989; and Adell and Artigas, 1998).

There are more recent reports of the presence of other 5 -HT receptor subtypes in the midbrain raphe nuclei, particularly $5-\mathrm{HT}_{1 \mathrm{D}}, 5-\mathrm{HT}_{1 \mathrm{~F}}, 5-\mathrm{HT}_{2 \mathrm{~B}}, 5-\mathrm{HT}_{2 \mathrm{C}}$, and $5-\mathrm{HT}_{5 \mathrm{~A}}$. However, with the exception of $5-\mathrm{HT}_{2 \mathrm{C}}$ (located on raphe GABAergic interneurons and not 5-HT neurons), expression levels of these receptors in the midbrain raphe are low, and their functional significance in terms of 5-HT neuron control is not certain. Nevertheless, recent findings demonstrate that feedback control of 5 -HT neurons is not likely limited to $5-\mathrm{HT}_{1}$ autoreceptors; instead, it includes 5-HT receptors located on postsynaptic targets that have the physiologic effects of 5-HT autoreceptors but use additional 5-HT receptor subtypes and operate via neural inputs to 5-HT neurons. For example, evidence supports a role for postsynaptic $5 \mathrm{HT}_{1 \mathrm{~A}}, 5-\mathrm{HT}_{2 \mathrm{~A}}$, and $5-\mathrm{HT}_{2 \mathrm{C}}$ receptors in the inhibitory control of 5-HT neurons, whereas $5-\mathrm{HT}_{4}$ and $5-\mathrm{HT}_{6}$ receptors are excitatory in this regard (Ge and Barnes, 1996; Sharp et al., 2007; Sharp, 2010; Brouard et al., 2015). Many of these feedback pathways appear to be localized on cortical pathways projecting back to the midbrain raphe nuclei $\left(5-\mathrm{HT}_{1 \mathrm{~A}}, 5-\mathrm{HT}_{2 \mathrm{~A}}, 5-\mathrm{HT}_{4}\right.$, and $5-\mathrm{HT}_{6}$ receptors), although contributions from non5-HT neurons such as habenula inputs to the raphe (5- $\mathrm{HT}_{2 \mathrm{C}}$ receptors) further emphasize the complexity of 5-HT neuron control.

\section{E. Postsynaptic 5-HT Receptors}

5-HT receptor mapping studies demonstrate that the majority of 5-HT receptor subtypes are located postsynaptically (i.e., expressed by non-5-HT neurons, sometimes referred to as heteroceptors, including the receptor subtypes involved in feedback control of 5-HT neurons) and that each 5-HT receptor subtype has an expression pattern that is distinct but often overlaps with that of other 5-HT receptors. Even 5-HT receptors 
from the same family have different CNS distributions (e.g., $5-\mathrm{HT}_{2 \mathrm{~A}}$ vs. $5-\mathrm{HT}_{2 \mathrm{C}}$ and $5-\mathrm{HT}_{1 \mathrm{~A}}$ vs. 5 - $\mathrm{HT}_{1 \mathrm{~B}}$ ). Some 5 -HT receptors are expressed at higher levels than others; in particular, $5-\mathrm{HT}_{1 \mathrm{~A}}$ and $5-\mathrm{HT}_{2 \mathrm{~A}}$ receptors are among the most abundant, whereas in comparison, levels of $5-\mathrm{HT}_{1 \mathrm{D}}, 5-\mathrm{ht}_{1 \mathrm{E}}, 5-\mathrm{HT}_{1 \mathrm{~F}}, 5-\mathrm{HT}_{2 \mathrm{~B}}$, and $5-\mathrm{HT}_{5 \mathrm{~A}}$ receptors are much less abundant. Detailed maps of 5 -HT receptor binding sites and protein and mRNA distribution in the brain are reported in a number of review articles (Mengod et al., 2006, 2010; Palacios, 2016).

At the macrolevel, and in keeping with the widespread 5-HT innervation of the brain, 5-HT receptors of different types are expressed in many brain regions that play key roles in numerous CNS functions. For example, regions rich in 5-HT receptors include cortical and limbic areas $\left(5-\mathrm{HT}_{1 \mathrm{~A}}, 5-\mathrm{HT}_{2 \mathrm{~A} / 2 \mathrm{C}}, 5-\mathrm{HT}_{3}, 5-\mathrm{HT}_{4}\right.$, and $5-\mathrm{HT}_{6}$ receptors), the basal ganglia $\left(5-\mathrm{HT}_{1 \mathrm{~B}}, 5-\mathrm{HT}_{4}\right.$, and $5-\mathrm{HT}_{6}$ receptors), mesolimbic pathways $\left(5-\mathrm{HT}_{1 \mathrm{~B}}\right.$, $5-\mathrm{HT}_{2 \mathrm{~A} / 2 \mathrm{C}}$, and $5-\mathrm{HT}_{4}$ receptors), hypothalamus (e.g., paraventricular and arcuate nuclei; $5-\mathrm{HT}_{2 \mathrm{C}}$ receptor), suprachiasmatic nucleus $\left(5-\mathrm{HT}_{7}\right.$ receptor), trigeminal nucleus $\left(5-\mathrm{HT}_{1 \mathrm{~B} / 1 \mathrm{D}}\right.$ receptors), dorsal vagal complex (encompassing the area postrema and nucleus tractus solitarus; $5-\mathrm{HT}_{3}$ receptor), and the spinal cord (dorsal root ganglia; $5-\mathrm{HT}_{2 \mathrm{~B} / 2 \mathrm{C}}$ and $5-\mathrm{HT}_{3}$ receptors). This list depicting 5-HT receptor distribution is of course not exclusive and does not take into account the relative density of receptors in the different regions [e.g., in many regions, $5-\mathrm{HT}_{2 \mathrm{C}}$ receptors are present at much lower densities than $5-\mathrm{HT}_{2 \mathrm{~A}}$ receptors (with the remarkable exception of the choroid plexus), and this is also the case for $5-\mathrm{HT}_{1 \mathrm{D}}$ compared with $5-\mathrm{HT}_{1 \mathrm{~B}}$ receptors].

\section{F. Cellular Localization of Central Nervous System 5-HT Receptors}

The principal cellular location of CNS 5-HT receptors is neurons; indeed, evidence for the expression of 5-HT receptors by adult native nonneural cells such as glial cells is, at best, inconsistent. For example, reports of glial cell expression of $5-\mathrm{HT}_{1 \mathrm{~A}}$ and $5-\mathrm{HT}_{2 \mathrm{~A}}$ receptors appear to be dependent on the antibody used. However, emerging evidence suggests that activated microglia may express $5-\mathrm{HT}_{2 \mathrm{~B}}$ and other 5 - $\mathrm{HT}$ receptors (Krabbe et al., 2012; Kolodziejczak et al., 2015). Nevertheless, 5 -HT receptors are undoubtedly present in cells of the cerebrovasculature, as most evident for $5-\mathrm{HT}_{1 \mathrm{~B}}$ receptors (Riad et al., 1998).

On the whole, the expression of specific 5-HT receptors is not restricted to particular neuron types. For example, among the complex microcircuitry of the cerebral cortex, hippocampus, and amygdala, $5-\mathrm{HT}_{1 \mathrm{~A}}$ and $5-\mathrm{HT}_{2 \mathrm{~A}}$ receptors are expressed both on pyramidal neurons (glutamatergic) and certain classes of GABAergic interneurons (particularly those expressing parvalbumin). Elsewhere in the brain, $5-\mathrm{HT}_{1 \mathrm{~A}}$ receptors are localized on 5-HT neurons in the raphe nuclei (see above) and cholinergic neurons in the septum, whereas $5-\mathrm{HT}_{2 \mathrm{~A}}$ receptors are expressed by midbrain dopamine neurons. On the other hand, $5-\mathrm{HT}_{3}$ receptors in rodent cortex and hippocampus mark a specific population of GABA interneurons with distinct chemical, morphologic, and anatomic properties (Lee et al., 2010), and these receptors are also present in pyramidal neurons, particularly in humans (Brady et al., 2007). In comparison, cortical $5-\mathrm{HT}_{6}$ receptors are preferentially (although not exclusively) expressed by pyramidal cells (Helboe et al., 2015).

Not surprisingly, there are multiple interactions between 5-HT and other neurotransmitter systems, and particular attention has been paid to 5-HT interactions with the other monoamines, noradrenaline and dopamine. These interactions are highly complex, involving multiple 5 -HT receptor subtypes located at preand postsynaptic sites within complicated, overlapping circuitry, such that prediction of the overall effect of 5-HT is often not possible. However, at the level of individual receptors, the rules can be more straightforward. For example, the distribution of $5-\mathrm{HT}_{2 \mathrm{~A}}$ and $5-\mathrm{HT}_{2 \mathrm{C}}$ receptors within the mesolimbic dopamine system has allowed the general consensus that $5-\mathrm{HT}_{2 \mathrm{~A}}$ receptors stimulate and $5-\mathrm{HT}_{2 \mathrm{C}}$ receptors inhibit dopamine transmission (Howell and Cunningham, 2015).

Given the differential expression patterns of the 5-HT receptors, it is highly unlikely that all 145 -HT receptors are expressed by a single neuron. Evidence from earlier double- and triple-labeling in situ hybridization studies support the idea that a single postsynaptic synapse may express a combination of two to three 5-HT receptors (Mengod et al., 2010). Studies combining whole-cell patch clamp recordings with single-cell reverse transcriptase polymerase chain reaction (RT-PCR) to characterize 5-HT receptor expression are in keeping with this idea. Thus, analysis of the 5-HT receptor mRNA content of neurons of the bed nucleus of the stria terminalis revealed that individual neurons could be subdivided according to the prominent expression of two to three distinct 5-HT receptor transcripts in largely excitatory/inhibitory combinations (e.g., $5-\mathrm{HT}_{1 \mathrm{~A}} / 5-\mathrm{HT}_{7}$, $5-\mathrm{HT}_{3} / 5-\mathrm{HT}_{7}, \quad 5-\mathrm{HT}_{1 \mathrm{~B}} / 5-\mathrm{HT}_{4}, \quad 5-\mathrm{HT}_{1 \mathrm{~A}} / 5-\mathrm{HT}_{1 \mathrm{~B}} / 5-\mathrm{HT}_{2 \mathrm{~A}}$, and $5-\mathrm{HT}_{1 \mathrm{~A}} / 5-\mathrm{HT}_{2 \mathrm{~A}}$ receptors) that matched electrophysiological observations (Hazra et al., 2012). A similar analysis of the 5-HT receptor mRNA content of single neurons of the preoptic nucleus revealed two types of neurons that predominantly expressed a combination of inhibitory $\left(5-\mathrm{HT}_{1 \mathrm{~A}}\right)$ and excitatory $\left(5-\mathrm{HT}_{2 \mathrm{C}}\right.$, $\left.5-\mathrm{HT}_{4}, 5-\mathrm{HT}_{7}\right) 5$-HT receptors, whereas others expressed excitatory 5-HT receptors alone, again in keeping with electrophysiological findings (Sangare et al., 2016). This evidence of 5-HT receptor expression conferring both excitatory and inhibitory signaling effects of 5-HT at the single-cell level is born out more generally in electrophysiological experiments recording the effects of either bath application of 5-HT or electrical and optogenetic 
activation of 5-HT neurons (Andrade, 2006; Andrade and Beck, 2010; Sengupta et al., 2017).

Generally speaking, there is a very good match between 5-HT receptor mRNA and protein (e.g., Mengod et al., 2010), suggesting that the majority of 5 -HT receptor proteins are not trafficked significantly along axons and reside largely at the levels of the neuronal soma and dendrites. Notable exceptions to this rule are $5-\mathrm{HT}_{1 \mathrm{~B}}$ and $5-\mathrm{HT}_{3}$ receptors. The former are trafficked either to nerve terminals of 5-HT neurons where they function as autoreceptors or to nerve terminals of other neurons and especially GABA neurons where they modulate GABA release. On the other hand, it is estimated that about $70 \%-80 \%$ of the $5-\mathrm{HT}_{3}$ receptors are located on nerve endings, where their role is also to modulate neurotransmitter release (e.g., dopamine, cholecystokinin, glutamate, acetylcholine, and GABA) (Hannon and Hoyer, 2008; Walstab et al., 2010). A final point of note is that, unusually, $5-\mathrm{HT}_{6}$ receptors are expressed on neuronal primary cilia (Hamon et al., 1999), the functions of which remain obscure.

At the ultrastructural level, electron microscopy studies show that all metabotropic 5-HT receptors visualized thus far are located extrasynaptically, which has reinforced the idea that 5-HT principally signals via volume transmission (Descarries et al., 2006). However, synaptic localization of 5-HT receptors cannot be excluded, as these are challenging studies that are often limited by the properties and specificity of available antibodies. Moreover, it is beyond doubt that 5 -HT is present in vesicles that are synaptic as well as nonsynaptic. An additional complexity in signaling at 5 -HT synapses is cotransmission, with coreleased glutamate emerging as a key player (e.g., Sengupta et al., 2017).

\section{G. Behavioral Roles of 5-HT Receptors in the Brain}

1. Introduction. Knowledge of the regional and cellular location of 5-HT receptors in the brain has been immensely helpful in understanding a vast literature on the behavioral effects of pharmacological and genetic manipulation of 5-HT receptors. Collectively, these developments are casting light on the likely behavioral functions of 5-HT receptors. So far, no behavioral response can be confidently ascribed to activation of the CNS $5-\mathrm{HT}_{1 \mathrm{D}}, 5-\mathrm{ht}_{1 \mathrm{e}}, 5-\mathrm{HT}_{1 \mathrm{~F}}$, or $5-\mathrm{HT}_{5}$ receptors.

2. 5-HT $T_{1}$ Receptor Family.

a. 5-HT $1 \mathrm{~A}$ receptors. The behavioral functions of $5-\mathrm{HT}_{1 \mathrm{~A}}$ receptors have been the focus of much research given the widespread and high CNS expression of these receptors, combined with the availability of a large number of selective $5-\mathrm{HT}_{1 \mathrm{~A}}$ receptor ligands. It has long been known that in rodents, administration of 8-OHDPAT and other $5 \mathrm{HT}_{1 \mathrm{~A}}$ receptor agonists causes a wide range of behavioral and physiologic effects, including changes in motor function (especially induction of the 5-HT behavioral syndrome), hyperphagia, hypothermia, altered sexual behavior, and changes in pain threshold. Also, there is a large literature demonstrating that $5-\mathrm{HT}_{1 \mathrm{~A}}$ receptor agonists have antidepressant and anxiolytic activity and influence a range of cognitive domains relevant to symptoms of schizophrenia (for reviews, see Traber and Glaser, 1987; Handley, 1995; and NewmanTancredi, 2010). These findings accord with preclinical and clinical evidence implicating changes in $5-\mathrm{HT}_{1 \mathrm{~A}}$ receptors in the pathophysiology of a variety of psychiatric illnesses, including depression, anxiety and other stress-related disorders, and schizophrenia. Appropriate $5-\mathrm{HT}_{1 \mathrm{~A}}$ receptor function also appears critical for antidepressant drug efficacy (Richardson-Jones et al., 2010; Samuels et al., 2016). The diverse behavioral effects of 5- $\mathrm{HT}_{1 \mathrm{~A}}$ receptor agonists are likely to involve an action at $5-\mathrm{HT}_{1 \mathrm{~A}}$ receptors in multiple forebrain and midbrain sites; the contribution of presynaptic and postsynaptic 5- $\mathrm{HT}_{1 \mathrm{~A}}$ receptors to specific behavioral effects of $5-\mathrm{HT}_{1 \mathrm{~A}}$ receptor agonists is not always certain, and indirect effects on other transmitter systems, particularly noradrenaline and dopamine, may often be involved.

Despite these complexities, a significant body of evidence links the decrease in 5-HT transmission evoked by $5-\mathrm{HT}_{1 \mathrm{~A}}$ autoreceptor activation to anxiolytic effects, whereas an increase in 5-HT transmission evoked by activation of postsynaptic $5-\mathrm{HT}_{1 \mathrm{~A}}$ receptors is associated with antidepressant effects [see Barnes and Sharp (1999) and II. 5-HT ${ }_{1 A}$ Receptor in the present review]. Much of the evidence for this has come from psychopharmacological studies in animals and humans, and it is being increasingly reinforced by studies using advanced genetic mouse models that have the power to make targeted manipulation of pre- versus postsynaptic $5-\mathrm{HT}_{1 \mathrm{~A}}$ receptors. In particular, genetic mouse constructs with selective knockdown of 5 - $\mathrm{HT}_{1 \mathrm{~A}}$ autoreceptor expression generate an increase in anxiety phenotypes (Richardson-Jones et al., 2011). In contrast, selective knockdown of postsynaptic $5-\mathrm{HT}_{1 \mathrm{~A}}$ receptors is associated with depressivelike phenotype, suggesting a differential impact of pre- versus postsynaptic $5-\mathrm{HT}_{1 \mathrm{~A}}$ receptors on anxiety and depression mechanisms. Paradoxically, although these phenotypes associated with genetic manipulation can be reproduced by pharmacological means, they are only observed when $5-\mathrm{HT}_{1 \mathrm{~A}}$ receptor suppression is initiated in early life and not during adulthood. Thus, these data point to a developmental mechanism, that is, altered pre- and postsynaptic $5-\mathrm{HT}_{1 \mathrm{~A}}$ receptor signaling during development, causing an adult behavioral phenotype through impacting the normal formation of anxiety/depression circuitry (Richardson-Jones et al., 2011; Garcia-Garcia et al., 2014, 2016). An analogous theory has been posited to explain the behavioral phenotype of 5-HT transporter mutant mice (Ansorge et al., 2004). Consideration of developmental mechanisms may therefore be appropriate when interpreting the behavioral phenotype of other mouse models with 
altered 5-HT receptor expression (Gingrich et al., 2003; Berger and Tecott, 2006; O'Leary and Cryan, 2010).

Aside from the interesting picture emerging through genetic models, there is increasing evidence that behavioral effects of $5-\mathrm{HT}_{1 \mathrm{~A}}$ agonist administration are dependent on the agonist used. Divergent effects of certain $5-\mathrm{HT}_{1 \mathrm{~A}}$ agonists have been reported across a range of models of cognition and emotional behavior as well as in relevant neurochemical and neurophysiological paradigms. These findings raise the possibility that different behaviors are being evoked by different signals because of biased agonism, and differential sensitivity of pre- and postsynaptic $5-\mathrm{HT}_{1 \mathrm{~A}}$ receptors to the agonists may be a contributing factor. Thus, functionally and anatomically distinct subpopulations of $5-\mathrm{HT}_{1 \mathrm{~A}}$ receptors, combined with an emerging diversity of biased $5-\mathrm{HT}_{1 \mathrm{~A}}$ receptor agonists, forecasts new categories of $5-\mathrm{HT}_{1 \mathrm{~A}}$ drugs for selective behavioral manipulation and thereby potential multiple therapeutic applications.

b. 5-HT $1 B$ receptors. Preclinical studies on the behavioral effects of the $5-\mathrm{HT}_{1 \mathrm{~B}}$ receptor ligands have been hampered by the lack of drug tools with sufficient selectivity or brain penetration, and this continues to be somewhat problematic in the case of $5-\mathrm{HT}_{1 \mathrm{~B}}$ receptor agonists. Early studies on the behavioral effects of $5-\mathrm{HT}_{1 \mathrm{~B}}$ receptor agonists and antagonists in rodents have been extensively reviewed (Lucki, 1992; Middlemiss and Tricklebank, 1992; Barnes and Sharp, 1999). These earlier findings, combined with more recent preclinical and clinical studies, emphasize a role for $5-\mathrm{HT}_{1 \mathrm{~B}}$ receptors in depression and anxiety behaviors on the one hand [for review, see Ruf and Bhagwagar (2009) and Fakhoury (2016)] and aggression and impulse control on the other [for review, see Nautiyal et al. (2015)]. Moreover, the role of pre- versus postsynaptic $5-\mathrm{HT}_{1 \mathrm{~B}}$ receptors in these behaviors is beginning to be addressed using tissuespecific and time-dependent conditional $5-\mathrm{HT}_{1 \mathrm{~B}}$ receptor mutant mice.

Evidence from earlier neuropharmacological studies suggests on the whole that $5-\mathrm{HT}_{1 \mathrm{~B}}$ receptor agonists have antidepressant effects in animal models, whereas $5-\mathrm{HT}_{1 \mathrm{~B}}$ receptor antagonists are anxiolytic (Fakhoury, 2016). The findings with $5-\mathrm{HT}_{1 \mathrm{~B}}$ receptor antagonists are to some extent consistent with evidence that mice with a global $5-\mathrm{HT}_{1 \mathrm{~B}}$ receptor knockout demonstrate anxiolytic and antidepressant-like phenotypes (Mayorga et al., 2001; Jones and Lucki, 2005; Bechtholt et al., 2008). Moreover, it is reported these phenotypic effects can be recapitulated in genetic mice with selective loss of 5 -HT 1 в autoreceptors (Nautiyal et al., 2015). The latter group argue that relative to $5-\mathrm{HT}_{1 \mathrm{~B}}$ autoreceptors, postsynaptic $5-\mathrm{HT}_{1 \mathrm{~B}}$ receptors may have an opposing effect on anxiety and depressive behaviors, thereby potentially accounting for the divergent actions of $5-\mathrm{HT}_{1 \mathrm{~B}}$ receptor agonists and antagonists noted above. Importantly, an anxiolytic and antidepressant-like phenotype was generated by knockout of $5-\mathrm{HT}_{1 \mathrm{~B}}$ autoreceptors in adulthood and not during early postnatal life, thereby making a developmental mechanism unlikely (Nautiyal et al., 2015). Collectively, these data suggest that drugs that selectively block $5-\mathrm{HT}_{1 \mathrm{~B}}$ autoreceptors may be useful for the treatment of anxiety and depression. Currently, there are no drugs with this property, although developments with biased $5-\mathrm{HT}_{1 \mathrm{~A}}$ receptor agonists (see above) offer the potential for such agents in the future.

Another interesting phenotype of mice with a global $5-\mathrm{HT}_{1 \mathrm{~B}}$ receptor knockout is increased aggression and impulsivity. This finding fits in with earlier evidence that certain $5-\mathrm{HT}_{1 \mathrm{~B}}$ receptor agonists ("serenics") have antiaggressive properties (Olivier et al., 1995). Moreover, these data fit with a consistent line of evidence associating reduced brain 5-HT transmission with high levels of impulsivity and aggression. The recently available conditional $5-\mathrm{HT}_{1 \mathrm{~B}}$ receptor knockout mouse has allowed for further examination of the role of pre- versus postsynaptic $5-\mathrm{HT}_{1 \mathrm{~B}}$ receptors in aggression and impulsivity (Nautiyal et al., 2015). It was found that heightened aggression and impulsivity was linked to loss postsynaptic $5-\mathrm{HT}_{1 \mathrm{~B}}$ receptors and not $5-\mathrm{HT}_{1 \mathrm{~B}}$ autoreceptors. However, although the increase in aggression involved a development mechanism (i.e., recapitulated by early life knockout), the increase in impulsivity was separable and was linked to loss of postsynaptic $5-\mathrm{HT}_{1 \mathrm{~B}}$ receptors in adulthood. These data raise the possibility that pharmacologic agents targeting $5-\mathrm{HT}_{1 \mathrm{~B}}$ receptors may be therapeutically effective in disorders associated with loss of impulse control. At least in the case of $5-\mathrm{HT}_{1 \mathrm{~B}}$ receptor agonists, these agents have been widely used in the clinic since the first development of sumatriptan for the acute treatment of migraine (Humphrey, 2008). It may be argued at length whether the effects of triptans in migraine involve a neuronal component versus vascular/inflammatory mechanisms (Humphrey and Goadsby, 1994) and whether triptans are considered safe in terms of CNS adverse effects.

3. 5-HT $\mathrm{T}_{2}$ Receptor Family. The behavioral effects of $5-\mathrm{HT}_{2}$ receptor agonists in rodents are many, ranging from changes in both unconditioned (e.g., head-twitches, increased motor activity, hypophagia, and hyperthermia) and conditioned responses (e.g., punished responding and drug discrimination) [for review, see Koek et al. (1992), Barnes and Sharp (1999), and Halberstadt (2015)]. It has become possible to identify the role of the different $5-\mathrm{HT}_{2}$ receptor subtypes in these behaviors with some degree of confidence through the availability of highly selective antagonists (for each of $5-\mathrm{HT}_{2 \mathrm{~A}}$, $5-\mathrm{HT}_{2 \mathrm{~B}}$, and $5-\mathrm{HT}_{2 \mathrm{C}}$ receptors) and agonists (especially $5-\mathrm{HT}_{2 \mathrm{C}}$ receptor agonists) as well as mutant mice with the different receptors selectively knocked out [for review, see Berger and Tecott (2006), O'Leary and Cryan (2010), Halberstadt (2015), and Di Giovanni and De Deurwaerdere (2016)]. 
a. $5-H T_{2 A}$ receptors. It is clear from detailed pharmacological analysis that the $5-\mathrm{HT}_{2 \mathrm{~A}}$ receptor mediates the effects of serotonergic hallucinogens such as LSD and psilocybin in various behavioral models in animals, including drug discrimination, the head-twitch response, and locomotion (Halberstadt, 2015). The evidence is equally strong that the $5-\mathrm{HT}_{2 \mathrm{~A}}$ receptor mediates the hallucinogenic effects of these drugs in humans. Prior to their prohibition in the late 1960s, psychedelic drugs such as LSD and psilocybin were used extensively in the treatment of major depression as well as anxiety-related disorders and addictions, and results were generally encouraging. Despite the restrictions that remain in place around these agents, there has been renewed interest in their use for experimental medicine studies and therapeutic purposes. Psilocybin in particular has been subject to investigation in a range of human psychopharmacological and brain imaging studies, which have contributed proof-of-principle and dose/safety data for clinical trials (Nutt, 2016). Moreover, recent clinical data demonstrate that acute administration of psilocybin (combined with psychologic support) causes a sustained lowering of depression and anxiety ratings in cancer patients (Griffiths et al., 2016; Ross et al., 2016) and treatment resistant-depression (Carhart-Harris et al., 2016), which is likely to encourage further studies in these and other patient groups.

The potent $5-\mathrm{HT}_{2 \mathrm{~A}}$ receptor antagonist properties of many second-generation antipsychotics has been linked to the reported superior antipsychotic efficacy and reduced side-effect profile of these agents compared with early drugs (Meltzer and Massey, 2011). Although selective $5-\mathrm{HT}_{2 \mathrm{~A}}$ receptor blockade is unlikely to be sufficient to generate a useful antipsychotic effect per se, evidence that the $5-\mathrm{HT}_{2 \mathrm{~A}}$ receptor inverse agonist pimavanserin has antipsychotic actions in relevant animal models (Vanover et al., 2006) and in certain patient populations (Fox, 2014) suggests a novel alternative way to treat psychosis.

Recent reports that $5-\mathrm{HT}_{2 \mathrm{~A}}$ receptor antagonists augment the effect of 5-HT uptake inhibitors in preclinical models (Marek et al., 2003, 2005; Boothman et al., 2006) may link to evidence that drugs with $5-\mathrm{HT}_{2 \mathrm{~A}}$ receptor antagonist properties are helpful as augmenting agents in treatment-resistant depression (Marek et al., 2003). Although the mechanism behind this effect of $5-\mathrm{HT}_{2 \mathrm{~A}}$ receptor blockade is not certain, it may link to evidence of an inhibitory $5-\mathrm{HT}_{2 \mathrm{~A}}$ receptormediated feedback on 5-HT neurons (Sharp et al., 2007). $5-\mathrm{HT}_{2 \mathrm{~A}}$ receptor blockade has also been associated with impulse control; thus, selective $5-\mathrm{HT}_{2 \mathrm{~A}}$ receptor antagonists decrease impulsivity in animal models (Winstanley et al., 2004; Winstanley, 2011), and there is support for this action from psychopharmacological studies in humans (Rock et al., 2013). Interestingly, both lithium and the organoselenium compound, ebselen, which like lithium blocks signaling through phosphoinositide pathway, inhibit $5-\mathrm{HT}_{2 \mathrm{~A}}$ receptor function, and both agents reduce impulsivity in animal models and humans (Singh et al., 2013; Masaki et al., 2016). This raises the possibility that $5-\mathrm{HT}_{2 \mathrm{~A}}$ receptor antagonists/inverse agonists as well as novel lithium mimetics may have utility in the control of disorders of impulse control.

b. $5-H T_{2 B}$ receptors. The combination of low $5-\mathrm{HT}_{2 \mathrm{~B}}$ receptor expression in the brain and the lack of selective $5-\mathrm{HT}_{2 \mathrm{~B}}$ receptor ligands has hampered progress in establishing whether these receptors are able to elicit robust behavioral effects. This situation has moved forward with the development of $5-\mathrm{HT}_{2 \mathrm{~B}}$ knockout mice, which have striking phenotypes across a range of modalities, including deficits in sensorimotor gating, social interaction, attention, learning, and memory as well as elevated impulsivity and altered sleep patterns (Pitychoutis et al., 2015). Furthermore, some of these effects (sleep and sensorimotor gating) can be phenocopied by administration of a selective $5-\mathrm{HT}_{2 \mathrm{~B}}$ receptor antagonist. However, $5-\mathrm{HT}_{2 \mathrm{~B}}$ knockout is also associated with severe cardiac abnormalities and embryonic and postnatal lethality, which might lead to neurodevelopment issues in surviving animals that could confound the interpretation of these adult CNS phenotypes (as noted above). Although studies involving conditional $5-\mathrm{HT}_{2 \mathrm{~B}}$ knockout strategies and further pharmacological phenocopying are awaited, these data raise interesting possibilities regarding the functional role of CNS $5-\mathrm{HT}_{2 \mathrm{~B}}$ receptors. As noted elsewhere (Hutcheson et al., 2011), 5- $\mathrm{HT}_{2 \mathrm{~B}}$ receptor agonism as a therapeutic approach is fraught by clinical evidence that such agents may induce valvulopathies, pulmonary hypertension that can have lethal consequences; thus, many therapeutic agents with $5-\mathrm{HT}_{2 \mathrm{~B}}$ receptor agonist properties (e.g., fenfluramine, pergolide, and cabergoline) have now been withdrawn from the market (Hutcheson et al., 2011). Nevertheless, recent data showing biased agonism at the 5- $\mathrm{HT}_{2 \mathrm{~B}}$ receptor (Wacker et al., 2013) offers the potential for future $5-\mathrm{HT}_{2 \mathrm{~B}}$ receptor agonists that may be devoid of these systemic adverse effects.

c. $5-H_{2} T_{2 C}$ receptors. Early studies recognized that several behavioral responses were likely associated with activation of central $5-\mathrm{HT}_{2 \mathrm{C}}$ receptors, including hypolocomotion, hypophagia, anxiety, penile erection, and hyperthermia [for review, see Barnes and Sharp (1999)]. Initially, these associations were largely based on observations using nonselective $5-\mathrm{HT}_{2 \mathrm{C}}$ receptor ligands. However, with increased availability of $5-\mathrm{HT}_{2 \mathrm{C}}$ receptor-selective compounds and the creation of $5-\mathrm{HT}_{2 \mathrm{C}}$ knockout mice, evidence for the involvement of the $5-\mathrm{HT}_{2 \mathrm{C}}$ receptor in many of these responses is now compelling [for review, see Di Giovanni and De Deurwaerdere (2016)]. Moreover, these developments expanded the CNS processes likely to be under $5-\mathrm{HT}_{2 \mathrm{C}}$ receptor control to include various behaviors and cognitions linked to compulsive drug- and food-seeking as well as the central control of energy homeostasis, 
oral dyskinesia, wakefulness, and even control seizure threshold.

In the last decade or so, there has been considerable research interest in the link between $5-\mathrm{HT}_{2 \mathrm{C}}$ receptors and addictive behaviors associated with food and psychostimulant drugs (Higgins and Fletcher, 2015; Howell and Cunningham, 2015). It is now clear that $5-\mathrm{HT}_{2 \mathrm{C}}$ receptor agonists reduce palatable food consumption and other effects associated with obesity (increased body mass and fat content; Heisler et al., 2006, 2007a,b; Lam et al., 2008; Higgs et al., 2011, 2016). These agents can also disrupt various steps in the sequence of events leading up to compulsive use of addictive drugs such as cocaine and nicotine (including stimulant action, positive reinforcement, behavioral sensitization, and reinstatement). The mechanism is, in part, likely to involve a $5-\mathrm{HT}_{2 \mathrm{C}}$ receptor-mediated decrease in mesolimbic dopamine function, but interactions with other transmitter systems (especially cortical glutamate) are likely to play a role. In addition, the lowering of food intake and metabolism by $5-\mathrm{HT}_{2 \mathrm{C}}$ receptor agonists is likely to involve an action on hypothalamic nuclei that promotes satiety and regulates energy balance pathways (Heisler et al., 2006, 2007; Lam et al., 2008).

Interestingly, separate studies have revealed a link between $5-\mathrm{HT}_{2 \mathrm{C}}$ receptors and impulse control; thus, $5-\mathrm{HT}_{2 \mathrm{C}}$ receptor agonists reduce premature responses, whereas $5-\mathrm{HT}_{2 \mathrm{C}}$ receptor antagonists have the opposite effect (Higgins et al., 2003; Winstanley et al., 2004; Fletcher et al., 2007). Given that impulsivity may influence many aspects of addictive behavior, $5-\mathrm{HT}_{2 \mathrm{C}}$ receptors may modulate addiction indirectly via its effects on impulsive behavior.

Many of these experiments detect opposing interactions between $5-\mathrm{HT}_{2 \mathrm{C}}$ receptors and $5-\mathrm{HT}_{2 \mathrm{~A}}$ receptors (e.g., $5-\mathrm{HT}_{2 \mathrm{~A}}$ receptor antagonists also lower impulsivity) that were detected in earlier neuropharmacological studies (Berendsen and Broekkamp, 1990). This opposing interaction between $5-\mathrm{HT}_{2 \mathrm{C}}$ and $5-\mathrm{HT}_{2 \mathrm{~A}}$ receptors could explain the poor efficacy in drug addiction models of drugs that elevate 5-HT itself (SSRIs, fenfluramine). Consequently, it is proposed that an optimal way to control addictive behavior (and also avoid potential adverse effects associated with $5-\mathrm{HT}_{2 \mathrm{C}}$ receptor agonists that have off-target effects at $5-\mathrm{HT}_{2 \mathrm{~A}}$ and $5-\mathrm{HT}_{2 \mathrm{~B}}$ receptors) may be a drug that combines in the same molecule agonist activity at the $5-\mathrm{HT}_{2 \mathrm{C}}$ receptor and antagonist activity at the $5-\mathrm{HT}_{2 \mathrm{~A}}$ receptor (Anastasio et al., 2015; Higgins and Fletcher, 2015). Additional approaches for future investigation could include 5 - $\mathrm{HT}_{2 \mathrm{C}}$ receptor agonists with biased agonist properties or positive allosteric modulators of the $5-\mathrm{HT}_{2 \mathrm{C}}$ receptor.

4. 5-HT $\mathrm{T}_{3}$ Receptors. Outside of the well established role of central (as well as peripheral) $5-\mathrm{HT}_{3}$ receptors in the control of emesis, $5-\mathrm{HT}_{3}$ receptors have been linked to multiple behavioral effects, ranging from changes in anxiety and cognition to altered pain processing and sensitivity to addictive drugs. Most of the original evidence for this comes from reports of the behavioral effects of $5-\mathrm{HT}_{3}$ receptor ligands (mostly antagonists) in animal models; these and more recent findings are extensively reviewed elsewhere (Costall and Naylor, 1992; Bentley and Barnes, 1995; Barnes and Sharp, 1999; Walstab et al., 2010; Gupta et al., 2016). However, many of the behavioral effects observed in preclinical investigations are not confirmed by studies of selective $5-\mathrm{HT}_{3}$ receptor antagonists in clinical populations (Bentley and Barnes, 1995; Walstab et al., 2010). The apparent failure for the translation of these preclinical findings could, in part, be explained by suboptimal clinical dosing, as bell-shaped dose-response curves are often observed for $5-\mathrm{HT}_{3}$ receptor antagonists, particularly in relation to CNS effects. Nevertheless, the involvement of $5-\mathrm{HT}_{3}$ receptors in some of these behaviors receives support from more recent studies of mutant mice with altered $5-\mathrm{HT}_{3 \mathrm{~A}}$ receptor expression. In particular, support for a role for $5-\mathrm{HT}_{3}$ receptors in depression/anxiety-related behaviors, learning and memory, and pain processing comes from the phenotypic analysis of transgenic mice with $5-\mathrm{HT}_{3 \mathrm{~A}}$ receptor knockout or overexpression (Harrell and Allan, 2003; Kelley et al., 2003; Berger and Tecott, 2006). However, interpretation of the phenotypes of these mice is complicated by findings that 1) they are not always phenocopied by pharmacological agents, 2) they are dependent on the mouse background strain, and 3) overexpression and deletion of the $5-\mathrm{HT}_{3 \mathrm{~A}}$ receptor sometimes produced similar effects [for review, see Berger and Tecott (2006) and O'Leary and Cryan (2010)].

More recent evidence associating $5-\mathrm{HT}_{3}$ receptors with emotional behaviors and cognition comes from findings with vortioxetine, which has a complex pharmacology leading to potent inhibition of $5-\mathrm{HT}_{3}$ receptors, although the drug is also a $5-\mathrm{HT}_{7}$ and $5-\mathrm{HT}_{1 \mathrm{D}}$ receptor antagonist, $5-\mathrm{HT}_{1 \mathrm{~B}}$ receptor partial agonist, $5-\mathrm{HT}_{1 \mathrm{~A}}$ receptor agonist, and 5-HT transporter inhibitor. Vortioxetine has significant antidepressant and procognitive activity in both rodent models and clinical trials (Mørk et al., 2012; Sanchez et al., 2015) and is currently marketed as an antidepressant with cognitionenhancing properties. Despite vortioxetine's polymodal pharmacology, inhibition of $5-\mathrm{HT}_{3}$ receptors is thought to play a prominent role in its mechanism of action. Thus, in rodents, vortioxetine preferentially occupies $5 \mathrm{HT}_{3}$ receptors and the 5-HT transporter at low doses, and either $5-\mathrm{HT}_{3}$ receptor blockade alone produces similar effects to vortioxetine or effects of vortioxetine can be replicated by coadministration of an SSRI and a $5-\mathrm{HT}_{3}$ receptor antagonist (Mørk et al., 2012; Sanchez et al., 2015). One current mechanistic explanation of these findings is that blockade of $5-\mathrm{HT}_{3}$ receptors on specific populations of 
GABA interneurons in the cerebral cortex contributes to vortioxetine's action (Riga et al., 2016).

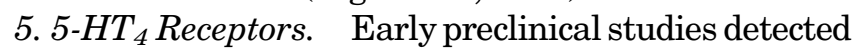
positive effects of $5-\mathrm{HT}_{4}$ receptor agonists on cognitive performance as well as a reduction in anxiety-related behaviors [for review, see Barnes and Sharp (1999)], and these observations have proven to be consistent in later work as recently reviewed by others (Bockaert et al., 2011; Claeysen et al., 2015; Hagena and Manahan-Vaughan, 2017). Stemming in part from studies of $5-\mathrm{HT}_{4}$ knockout mice (Compan et al., 2004), a role of $5-\mathrm{HT}_{4}$ receptors in feeding behavior also seems clear, with $5-\mathrm{HT}_{4}$ receptor agonists and antagonists having hypo- and hyperphagic properties, respectively (Jean et al., 2007; Bockaert et al., 2011).

Procognitive effects of $5-\mathrm{HT}_{4}$ receptor agonists have been described across a range of species and in a variety of experimental paradigms that model different aspects of short- and long-term memory, many of them dependent on the hippocampus where $5-\mathrm{HT}_{4}$ receptors are reasonably abundant (Hagena and Manahan-Vaughan, 2017). These agents also reverse the cognitive deficits induced by factors such as ageing, pharmacological interventions (e.g., muscarinic antagonists), and Alzheimer disease-like pathology. The mechanisms underlying the procognitive effects of 5 - $\mathrm{HT}_{4}$ receptor agonists are not certain but may be mediated by one or more of increased release of acetylcholine, induction of synaptic plasticity, increased synaptic spine formation, and altered hippocampal network properties [see Boddeke and Kalkman (1990), Claeysen et al. (2015), and Hagena and ManahanVaughan (2017)]. Administration of 5- $\mathrm{HT}_{4}$ receptor agonists is also associated with increased amyloid precursor protein cleavage, which has led to speculation that these agents may be useful in the management of Alzheimer disease (Claeysen et al., 2015). A contribution from $5-\mathrm{HT}_{4}$ receptors in hippocampus seems likely as noted above, but a role for other circuits such as corticostriatal connectivity, which is abundant in $5-\mathrm{HT}_{4}$ receptors, seems likely.

Administration of $5-\mathrm{HT}_{4}$ receptor agonists is also associated with rapid antidepressant effects in animal models (Lucas et al., 2007), and there is preclinical evidence that $5-\mathrm{HT}_{4}$ receptor activation plays an important role in the action of SSRIs (Mendez-David et al., 2014). Thus, $5-\mathrm{HT}_{4}$ receptor agonists induce a number of responses in common with repeated antidepressant treatment (e.g., efficacy in models of depression or increased expression of neural plasticity markers) but with a rapid onset of action (Vidal et al., 2014b; Samuels et al., 2016). Moreover, antidepressant administration causes adaptive changes in 5 - $\mathrm{HT}_{4}$ receptor expression and function (Licht et al., 2010a). Part of the mechanism involved in the antidepressant effects of $5-\mathrm{HT}_{4}$ receptor agonists may be the activation of a positive feedback control of midbrain 5 -HT neurons via $5-\mathrm{HT}_{4}$ receptor located in the frontal cortex (Lucas et al., 2005; Licht et al., 2010b).

The full interpretation of this literature on the behavioral effects of 5 - $\mathrm{HT}_{4}$ receptor ligands is somewhat hampered by the current lack of reports concerning the effect of these agents on mood or cognitive performance in humans, although there is early evidence that a $5-\mathrm{HT}_{4}$ receptor agonist improved the cognitive performance in nonhuman primates (Terry et al., 1998). Concerns about the potential for $5-\mathrm{HT}_{4}$ receptor agonists to elicit adverse gastrointestinal and cardiac effects are likely to have held back the transition to clinical studies, but these do not appear to be effects common to all $5-\mathrm{HT}_{4}$ receptor agonists (Claeysen et al., 2015), which is encouraging for future clinical studies.

6. 5-HT $T_{5}$ Receptors. To date, there are few studies on the CNS effects of 5- $\mathrm{HT}_{5}$ receptor ligands, and the main indications regarding the functions of this receptor currently come from studies on the phenotype of $5-\mathrm{HT}_{5 \mathrm{~A}}$ receptor knockout mice (Grailhe et al., 1999). It is reported that these mice display increased exploratory activity in the open field and various other tests without evidence of altered anxiety levels. Without data from phenocopying experiments using $5-\mathrm{HT}_{5}$ receptor antagonists or other controls for developmental origins of the phenotype, it remains uncertain whether these behaviors are driven by the absence of $5-\mathrm{HT}_{5}$ receptor in the adult brain. Intriguingly, in $5-\mathrm{HT}_{5 \mathrm{~A}}$ receptor knockout mice the locomotor activation induced by LSD was blunted, suggesting that $5-\mathrm{HT}_{5 \mathrm{~A}}$ receptor activation might contribute to the psychotropic effects of psychedelic agents.

7. 5-HT $\mathrm{T}_{6}$ Receptors. Despite the identification of the $5-\mathrm{HT}_{6}$ receptor over 20 years ago, the functions of this receptor have been somewhat obscure until recently. Largely through studies on the effects of $5-\mathrm{HT}_{6}$ receptor ligands (agonists and antagonists) in animal behavioral models, it has been discovered that the receptor likely plays an important role in cognition.

The evidence for procognitive effects of $5-\mathrm{HT}_{6}$ receptor ligands is in keeping with the predominant localization of $5-\mathrm{HT}_{6}$ receptors in corticostriatal circuitry and is reviewed elsewhere (King et al., 2008; Codony et al., 2011; Meneses, 2015; see also XIV. 5-HT Receptors). There are consistent findings that $5-\mathrm{HT}_{6}$ receptor antagonists enhance learning and memory mechanisms in a variety of preclinical models ranging from novel object and social recognition to spatial memory tasks. These effects are observed in naive animals and in those with memory deficits induced by, for example, pharmacological means such as cholinergic antagonists.

The mechanism underlying this effect of $5-\mathrm{HT}_{6}$ receptor blockade is uncertain. An interaction with the cholinergic system was proposed in early studies, and this is supported by more recent data. In particular, treatment with a $5-\mathrm{HT}_{6}$ receptor antagonist augments 
the effects of an acetylcholinesterase inhibitor on cognitive measures in both animal models and patients with Alzheimer disease (Wilkinson et al., 2014; Kucinski et al., 2017; although 5- $\mathrm{HT}_{6}$ receptor antagonists have failed in larger phase III clinical trial of patients with pathologic cognitive deficits), and there is neurophysiological and neurochemical evidence that this drug combination has a synergistic effect on cholinergic function (Herrik et al., 2016). However, recent data show that $5-\mathrm{HT}_{6}$ receptors are not expressed by cholinergic neurons (Helboe et al., 2015), which would invoke an indirect mechanism. A mechanism involving increased information processing through corticostriatal circuits was recently proposed (Kucinski et al., 2017).

A further complication in understanding the procognitive effects of $5-\mathrm{HT}_{6}$ receptor antagonists is the paradoxical observation that $5-\mathrm{HT}_{6}$ receptor agonists are also reported to have precognitive effects in some, albeit not all, studies (e.g., Schechter et al., 2008; Burnham et al., 2010; Kendall et al., 2011; Meneses et al., 2011). It is difficult to see how this paradox can be reconciled by inferring subtleties in subpopulations of $5-\mathrm{HT}_{6}$ receptor at the neural circuit level. Part of the explanation could lie in the cognitive domain being measured, and to date, few studies have systematically compared $5-\mathrm{HT}_{6}$ receptor agonists and antagonists in the same model. There also remains the intriguing possibility that the full answer lies in the pharmacology of $5-\mathrm{HT}_{6}$ receptor ligands and that their categorization in terms of partial agonist, inverse agonist, and even biased agonist is not yet complete (e.g., Romero et al., 2006).

8. 5-HT 7 Receptors. As with the 5- $\mathrm{HT}_{6}$ receptor, the functions of the $5-\mathrm{HT}_{7}$ receptor are only now beginning to be revealed. This has largely come about through developments in 5- $\mathrm{HT}_{7}$ receptor pharmacology and genetic mouse models. Preclinical data link the $5-\mathrm{HT}_{7}$ receptor to a variety of CNS processes, including regulation of circadian rhythms, body temperature, mood, cognitions, seizure threshold, and pain processing as well as mechanisms of addiction, and this is extensively reviewed elsewhere and will only be briefly discussed here (Hedlund, 2009; Hauser et al., 2015; see also $X V$. 5-HT 7 Receptors).

The link between the $5-\mathrm{HT}_{7}$ receptor and circadian rhythms was established in early studies, which recognized that the circadian phase shift of neurons of the suprachiasmatic nucleus evoked by the $5-\mathrm{HT}_{1 \mathrm{~A}}$ receptor agonist 8-OH-DPAT was mediated by $5-\mathrm{HT}_{7}$ and not $5-\mathrm{HT}_{1 \mathrm{~A}}$ receptors (Lovenberg et al., 1993). Indeed, in this light, re-evaluation of the hypothermic effect of 8-OH-DPAT using $5-\mathrm{HT}_{7}$ receptor knockout mice and selective antagonists revealed the involvement of $5-\mathrm{HT}_{7}$ receptors, although $5-\mathrm{HT}_{1 \mathrm{~A}}$ receptors appear to mediate the hypothermic effect of higher doses of the drug (Hedlund et al., 2004). This hypothermic effect of
$5-\mathrm{HT}_{7}$ receptor activation is sufficiently robust to make it a useful test of 5- $\mathrm{HT}_{7}$ receptor agonist activity in vivo (Di Pilato et al., 2014).

The discovery that $5-\mathrm{HT}_{7}$ receptor knockout mice have an antidepressant-like phenotype contributed to evidence that $5-\mathrm{HT}_{7}$ receptors have a role in emotional control. This feature of the mice is phenocopied by selective $5-\mathrm{HT}_{7}$ receptor antagonists that were shown to have antidepressant effects in a range of models in rats and mice. These agents also augment the effect of SSRI and other antidepressants in behavioral and neurochemical models. These findings have translated into clinical trials of the $5-\mathrm{HT}_{7}$ receptor antagonist JNJ18038683 (Bonaventure et al., 2012), although a clear conclusion regarding efficacy of this agent has not yet been reached. It is interesting that in animal models, the antidepressant efficacy of amisulpiride is $5-\mathrm{HT}_{7}$ receptor-dependent. Many other antidepressant and antipsychotic drugs (tricyclics, lurasidone, aripiprazole, etc.) in clinical use have $5-\mathrm{HT}_{7}$ receptor antagonist properties, though the contribution of this receptor to their clinical effects is not known.

As a final point of interest, selective brain penetrant $5-\mathrm{HT}_{7}$ receptor agonists are becoming available as pharmacological tools (Di Pilato et al., 2014) to help further define the function of the $5-\mathrm{HT}_{7}$ receptor and open new therapeutic avenues.

\section{5-HT Receptors and the Cardiovascular System}

\section{A. Introduction}

Cardiovascular effects of 5-HT are complex: when infused into the rat circulation, 5 -HT produces a triphasic response with a short-lasting hypotensive phase, followed by a hypertensive phase and then a longlasting hypotensive phase mediated by, respectively, $5-\mathrm{HT}_{3}, 5-\mathrm{HT}_{2}$, and $5-\mathrm{HT}_{1}$ receptors (Kalkman et al., 1984). The cardiovascular effects of 5 -HT have been known since the middle ages when ergots produced devastating peripheral vasoconstriction, which resulted in gangrene and limb loss because of consumption of rye bread polluted with fungi that produced ergots. For a long time, the general view was that $5-\mathrm{HT}_{2}$ receptors are largely responsible for vasoconstrictor effects, which would be blocked by $5-\mathrm{HT}_{2}$ receptor antagonists, such as ketanserin. However, the situation was much more complex, and it was known that depending on vessel and species, compounds such as the ergolines (ergotamine, DHE, and metergoline) would produce very complex responses: often vasoconstriction, but not infrequently vasodilation, could be observed as well. Even before the full repertoire of 5-HT receptors were known, it was suspected that " $5-\mathrm{HT}_{1}$ like" receptors would at least mediate some of these effects. One of the most important tools for probing " $5-\mathrm{HT}_{1}$ like receptor"mediated effects was 5-carboxamidotryptamine 
(5-CT), which became available in the early 1980s. 5-CT 1) potently contracted the dog saphenous vein (Feniuk et al., 1981); 2) inhibited the release of noradrenaline and 5-HT from sympathetic and central 5-HT neurons, respectively (Feniuk et al., 1981; Engel et al., 1983); and 3 ) displayed nanolomar affinity for the $5-\mathrm{HT}_{1}$ receptor recognition sites (Engel et al., 1983). Furthermore, several 5 -CT-induced responses (associated with " 5 - $\mathrm{HT}_{1}$-like" receptor recognition sites) were blocked by methiothepin and/or methysergide, but not by ketanserin, including relaxation of smooth muscle, contraction of dog saphenous vein, long-lasting hypotension in the rat, and tachycardia in the cat [see Kalkman et al. (1984), Bradley et al. (1986), Saxena and Villalón (1990)]. The migraine program led by Pat Humphrey at Glaxo used 5-CT as a template to study such effects with the idea to develop a new migraine medication that would be selective for the craniovascular bed (Humphrey et al., 1991). This research culminated with the discovery and development of sumatriptan (and other "triptans" that followed). It was then realized that sumatriptan had high affinity and potency at $5-\mathrm{HT}_{1 \mathrm{D}}$ receptor sites before the actual receptors were cloned (Peroutka et al., 1989; Schoeffter and Hoyer, 1989a,b; Hoyer et al., 1990). The high affinity of sumatriptan for $5-\mathrm{HT}_{1 \mathrm{D}}$ receptor recognition sites suggested that the sumatriptan-induced vasoconstriction was mediated by 5 - $\mathrm{HT}_{1}$-like receptors resembling the $5-\mathrm{HT}_{1 \mathrm{D}}$ receptor subtype (Martin, 1994). However, the concept of 5- $\mathrm{HT}_{1-}$ like receptor remained alive for some time (Hoyer et al., 1994). One of the main reasons for this uncertainty was that metergoline, a potent $5-\mathrm{HT}_{1 \mathrm{D}}$ receptor ligand, was less active as an antagonist both in vitro (e.g., canine, human, and rabbit saphenous vein and rabbit renal and cerebral arteries; Deckert et al., 1994; Hoyer et al., 1994) and in vivo (porcine and canine carotid vascular beds; Den Boer et al., 1992; Villalón et al., 1995) than methiothepin, as may have been anticipated from metergoline's affinity at the then defined 5 - $\mathrm{HT}_{1 \mathrm{D}}$ receptor recognition sites. However, the experimental conditions used to detect $5-\mathrm{HT}_{1 \mathrm{D}}$ receptor binding (Waeber et al., 1988) allowed binding to, at the time unknown, $5-\mathrm{ht}_{1 \mathrm{e}}, 5-\mathrm{HT}_{1 \mathrm{~F}}$, and $5-\mathrm{HT}_{7}$ receptors, which clearly complicated interpretation. The cloning of $5-\mathrm{HT}_{1 \mathrm{D} \alpha}$ and 5 - $\mathrm{HT}_{1 \mathrm{D} \beta}$ receptors combined with their relatively high affinity for sumatriptan, and the eventual distinction between $5-\mathrm{HT}_{1 \mathrm{~B}}$ and $5-\mathrm{HT}_{1 \mathrm{D}}$ receptors, including the species differences, allowed some order to the complexity (Weinshank et al., 1992) along with an appreciation of a need for subtypeselective $5-\mathrm{HT}_{1}$ receptor agonists and antagonists. Eventually it was realized that the loosely defined " $5-\mathrm{HT}_{1}-$ like receptor" covered at least three structurally distinct receptors, namely, the $5-\mathrm{HT}_{1 \mathrm{~B}}, 5-\mathrm{HT}_{1 \mathrm{D}}$, and $5-\mathrm{HT}_{7}$ receptors. Here, basic and more recent knowledge as to the involvement of each 5-HT receptor in the cardiovascular system in normal physiological and pathophysiological conditions will be discussed (the cardiovascular system to include the heart, blood, vasculature, kidneys, and adrenals as well as the peripheral and central nervous systems involved in cardiovascular system regulation).

\section{B. 5-HT in Cardiovascular Tissues}

The majority of 5 -HT in the body is made by 1 ) the gastrointestinal system and 2) the neurons of the raphe complexes in the brainstem. 5-HT makes its way to all body organs by storage in blood platelets following SERT uptake and through free 5-HT being released from the enterochromaffin cells of the intestine. Free 5-HT-external to the platelet-is measurable in the plasma of all species examined (Watts et al., 2012). 5-HT has been detected in all rat tissues examined (Linder et al., 2009) and cannot be accounted for by the presence of platelets given that electron microscopic images show no platelet adhesion to the tissues used for measuring 5-HT. Moreover, 5-hydroxyindole acetic acid (5-HIAA) can be detected in these same tissues. 5-HIAA is a metabolite of $5-\mathrm{HT}$, the product of monoamine oxidase, a mitochondrial enzyme (i.e., 5-HT has to be inside the cell to be converted to 5-HIAA). Interestingly, many cardiovascular tissues express SERT, and, at least in the rat, SERT-dependent uptake of 5-HT takes place in peripheral tissues that include arteries, heart, and adrenals (Linder et al., 2009). The SERT KO rat, created by Edwin Cuppen (Homberg et al., 2007), has been particularly useful in these studies. Moreover, certain tissues of the cardiovascular system synthesize 5-HT, independent of the gastrointestinal system and brain, using tryptophan hydroxyalase (TPH), of which two forms exist, TPH1 and TPH2, the latter being neuron-specific. This includes vascular smooth muscle (Ni et al., 2004, 2008), endothelial cells (Morecroft et al., 2007), kidney (Hafdi et al., 1996; Sole et al., 1986; Stier and Itskovitz, 1985; Stier et al, 1985), cardiomyocytes (Ikeda et al., 2005; Pönicke et al., 2012) and potentially adrenal glands (Brownfield et al., 1985; Csaba and Sudar, 1978; Delarue et al., 1992; Holzwarth and Brownfield, 1985; Holzwarth et al., 1984; Pönicke et al., 2012; Verhofstad and Jonsson, 1983).

\section{Cardiovascular Effects Mediated by 5-HT Receptors}

1. 5-HT ${ }_{1 A}$ Receptors. One of the best-known peripheral actions of $5-\mathrm{HT}_{1 \mathrm{~A}}$ receptor stimulation in rodents is inhibition of stress-evoked cardiovascular responses, reducing the tachycardia and renal sympathoexcitation that accompany stress (Horiuchi et al., 2005, 2011; Nalivaiko and Sgoifo, 2009). Stress models investigated include restraint stress, fear-conditioned stress, cold exposure, and elevated plus maze (anxiety-producing). Interestingly, $5-\mathrm{HT}_{1 \mathrm{~A}}$ receptor agonists can be given systemically to produce their anxiolytic effects independent of sympathoinhibition (Vianna and Carrive, 2009). 5- $\mathrm{HT}_{1 \mathrm{~A}}$ receptors also mediate increased vagal drive (Ramage, 1990).

$5-\mathrm{HT}_{1 \mathrm{~A}}$ receptor agonists lower blood pressure in the normal (nonhemorrhaged, nonstressed) rat. 8-OHDPAT given in the ventral medulla of the normal rat causes hypotension and bradycardia (Helke et al., 
1993). Similarly, 8-OH-DPAT, flesinoxan, and other $5-\mathrm{HT}_{1 \mathrm{~A}}$ receptor agonists reduce blood pressure in both the spontaneously hypertensive rat and Wistar Kyoto rat (see, e.g., Doods et al., 1988). The 5- $\mathrm{HT}_{1 \mathrm{~A}}$ receptor agonist flesinoxan has been suggested to inhibit sympathetic nerve activity, at least in part, through renal nerves and to lower blood pressure in rats (Chamienia and Johns, 1994) and in cats (Wouters et al., 1988; Ramage et al., 1992). Collectively, these studies point to the central role of 5- $\mathrm{HT}_{1 \mathrm{~A}}$ receptors modifying autonomic responses as one of the greatest contributions made by this receptor subtype. Interestingly, peripheral $5-\mathrm{HT}_{1 \mathrm{~A}}$ receptors can also mediate inhibition of the sympathetic vasopressor outflow in pithed rats (Villalón et al., 1998; Morán et al., 1998).

In contrast to the decrease in blood pressure caused in a normal rat, 8-OH-DPAT increases whole-body venous tone to protect against hemorrhagic shock (Tiniakov and Scrogin, 2009), described as a sympathetic medicated venoconstriction. $5-\mathrm{HT}_{1 \mathrm{~A}}$ receptors are not highly expressed in the vasculature, and direct effects within the vasculature are uncommon (Villalón and Centurión, 2007; Ramage and Villalón, 2008). Flesinoxan and other $5-\mathrm{HT}_{1 \mathrm{~A}}$ receptor agonists have been developed as blood pressure-lowering agents, but no clinical success has been reported, and these programs were abandoned.

2. 5-HT $T_{1 B}$ Receptors. 5- $\mathrm{HT}_{1 \mathrm{~B}}$ receptors are found on cerebral arteries and other vascular tissues mediating direct vasoconstriction [see Villalón et al. (2003) and Villalón and Centurión (2007)]. Furthermore, it seems that the receptor may be silent and may become responsive in conditions such as atherosclerosis (Geerts et al., 2000; Ishida et al., 2001). Peripheral effects in rats have been described, such as 1) inhibition of noradrenaline release from sympathetic nerves in vena cava (Göthert et al., 1986) and systemic vasculature (Villalón et al., 1998) and 2) inhibition of plasma extravasation produced by trigeminal ganglion stimulation (Buzzi and Moskowitz, 1991). 5- $\mathrm{HT}_{1 \mathrm{~B}}$ receptors also mediate vasoconstriction in the rat caudal arteries (Craig and Martin, 1993) and the canine external carotid circulation (De Vries et al., 1998).

$5-\mathrm{HT}_{1 \mathrm{~B}}$ receptors are expressed in vascular smooth muscle of several different arteries, including rat aorta (Banes and Watts, 2003), aortic vasavasorum (Cohen et al., 2002), tail artery (Craig and Martin, 1993), and middle cerebral artery (Kovács et al., 2012); human arteries and veins, including central, pulmonary, and coronary arteries (Verheggen et al., 1998, 2004; Morecroft et al., 1999; Nilsson et al., 1999a,b; van den Broek et al., 2002; Tanaka et al., 2008b) as well as coronary endothelial cells (Ishida et al., 1998); canine internal (Centurión et al., 2001) and external (Centurión et al., 2001, Valdivia et al., 2004) carotid artery beds; rabbit saphenous vein, basilar artery (Bhattacharya et al., 2004), and renal artery (Hill et al., 2000); porcine coronary artery (Schoeffter and Hoyer, 1989, 1990); bovine pulmonary artery (McKenzie et al., 2010); and guinea pig isolated iliac artery (Sahin Erdemli et al., 1991; Jahnichen et al., 2004). Next to the $5-\mathrm{HT}_{2 \mathrm{~A}}$ receptor, the $5-\mathrm{HT}_{1 \mathrm{~B}}$ receptor is the best studied and most frequently reported in the vasculature. Expression in cerebral arteries has been a significant focus given the potential involvement of these receptors in the pathophysiology of migraine (e.g., Villalón et al., 2003; Villalón and Centurión, 2007).

The $5-\mathrm{HT}_{1 \mathrm{~B}}$ receptor mediates vasoconstriction in a variety of blood vessels, although some $5-\mathrm{HT}_{1 \mathrm{~B}}$ receptors have been described as "silent," meaning that a vessel needs to be primed with a depolarizing stimulus such as high $\mathrm{K}^{+}$before a functional receptor is observed ("unmasking") (Movahedi and Purdy, 1998; Froldi et al., 2008). By contrast, functional $5-\mathrm{HT}_{1 \mathrm{~B}}$ receptors, coupled to nitric oxide synthase, have been reported in cultured bovine aortic endothelial cells (McDuffie et al., 1999). There is thus the potential for $5-\mathrm{HT}_{1 \mathrm{~B}}$ receptors to serve opposing actions in the blood vessel: contraction through smooth muscle and relaxation through the endothelium (Schoeffter and Hoyer, 1989, 1990; Sahin Erdemli et al., 1991).

Functional $5-\mathrm{HT}_{1 \mathrm{~B}}$ receptors are also found in the trigeminocervical complex of cats and dogs, where activation of the receptor inhibits 1) the "nociceptive traffic" within this complex in the former (Goadsby and Classey, 2003) and 2) capsaicin-sensitive trigeminal sensory nerves innervating the external carotid bed in the latter (Muñoz-Islas et al., 2006, 2009). 5- $\mathrm{HT}_{1 \mathrm{~B}}$ receptor agonists inhibit the release of sensory neuropeptides (particularly calcitonin gene-related peptide) in migraine, providing the basis for an effective treatment in addition to the craniovascular vasoconstrictor effects (Ma et al., 2001; Villalón and Olesen, 2009; Gupta and Villalón, 2010). Finally, prejunctional $5-\mathrm{HT}_{1 \mathrm{~B}}$ receptors inhibit (by peripheral mechanisms) 1) norepinephrine release in blood vessels (Molderings et al., 1990, 1996; Villalón et al., 2001), 2) the vasopressor (Villalón et al., 1998) and cardioaccelerator (Sánchez-López et al., 2004) sympathetic outflow, and 3) the vasodepressor sensory CGRPergic outflow in rats (González-Hernández et al., 2011). Thus, the expression and function of $5-\mathrm{HT}_{1 \mathrm{~B}}$ receptors is complex and at multiple levels, even within just the vasculature.

In the vasculature, the $5-\mathrm{HT}_{1 \mathrm{~B}}$ receptor is best known for its upregulation and elevated function in pulmonary hypertension (Keegan et al., 2001). The $5-\mathrm{HT}_{1 \mathrm{~B}}$ receptor contractile function is also enhanced in rabbit atherosclerotic coronary arteries (Ishida et al., 2001) and rabbit carotid arteries from animals subjected to a carotid collar (Geerts et al., 2000). Also well established is the use of $5-\mathrm{HT}_{1 \mathrm{~B} / 1 \mathrm{D} / 1 \mathrm{~F}}$ receptor agonists (the triptans) for the abortive treatment of migraine attacks (e.g., Villalón et al., 2003). Though useful in causing a cerebral vasoconstriction that is thought to be associated with improved symptoms, the triptans can also cause a coronary artery constriction that limits their use in the treatment of migraine in patients with a cardiac 
condition; however, long-term surveillance shows a remarkably low incidence of serious side effects (Chan et al., 2011). Exploration for antimigraine mechanisms have expanded beyond the $5-\mathrm{HT}_{1 \mathrm{~B}}$ receptor (there are a multitude of triptans available) with interest on the role of the $5-\mathrm{HT}_{1 \mathrm{~F}}$ receptor playing a potentially nonvascular role (Chan et al., 2011; Rizzoli, 2014) with compounds such as lasmiditan.

3. 5-HT $T_{1 D}$ Receptors. The external carotid vasoconstrictor responses to 5-HT and sumatriptan are antagonized by the selective $5-\mathrm{HT}_{1 \mathrm{~B}}$ receptor antagonist SB224289 but not the selective $5-\mathrm{HT}_{1 \mathrm{D}}$ receptor antagonist BRL15572 (De Vries et al., 1998), indicating that $5-\mathrm{HT}_{1 \mathrm{~B}}$ receptors mediate this vasoconstrictor response. It must be noted that sumatriptan and second-generation triptans do not distinguish between $5-\mathrm{HT}_{1 \mathrm{~B}}$ and $5-\mathrm{HT}_{1 \mathrm{D}}$ receptors (Villalón et al., 2003; Villalón and Centurión, 2007).

A series of isochroman-6-carboxamide derivatives, including PNU-109291 and PNU-142633, have been described as highly selective $5-\mathrm{HT}_{1 \mathrm{D}}$ receptor agonists (Ennis et al., 1998; McCall et al., 2002). These 5-HT $1 \mathrm{D}$ receptor agonists do not produce vasoconstriction in in vivo (Centurión et al., 2001) or in vitro preparations (cerebral arteries; Bouchelet et al., 2000).

At the peripheral level, the presence of $5-\mathrm{HT}_{1 \mathrm{D}}$ receptors seems to be rather limited to autonomic and trigeminal nerve terminals/ganglia (Jones et al., 1995; Molderings et al., 1996; Shepheard et al., 1997; Villalón et al., 1998).

There were attempts to develop $5-\mathrm{HT}_{1 \mathrm{D}}$ receptor agonists for migraine therapy [for references, see Villalón et al. (2003) and Chan et al. (2011)]; these compounds are active in the trigeminal inflammation/ plasma extravasation models yet would presumably be less prone to side effects, as the cardiovascular effects are largely negligible (Villalón et al., 2003; Chan et al., 2011). However, when tested in the clinic to treat migraine, there was little success, and development has been abandoned.

4. 5-ht $t_{1 e}$ Receptors. The receptor has been immunohistochemically localized to the cerebral vasculature of humans, but mice and rats do not express a functional 5 -ht $_{1 \mathrm{e}}$ receptor (Klein and Teitler, 2012). There is no evidence for a physiologic role for $5-\mathrm{ht}_{1 \mathrm{e}}$ receptors (Hoyer et al., 1994; Hoyer and Martin, 1997; Villalón and Centurión, 2007; Ramage and Villalón, 2008).

5. 5-HT $T_{1 F}$ Receptors. 5-HT $1 \mathrm{~F}$ receptor mRNA and the corresponding protein is preferentially expressed in neuronal tissues rather than vascular smooth muscle (Ullmer et al., 1995; Bouchelet et al., 1996). Accordingly, $5-\mathrm{HT}_{1 \mathrm{~F}}$ receptor agonists appear devoid of direct vasoconstrictor properties (Johnson et al., 1998; Cohen et al., 1999; Villalón et al., 1999).

Most recently, lasmiditan was developed as a $5-\mathrm{HT}_{1 \mathrm{~F}}$ receptor agonist (Rizzoli, 2014); it did not contract rabbit saphenous vein, which is frequently used as a surrogate for the human coronary artery for which crossover effects of migraine drugs (triptans) can be identified (Nelson et al., 2010). This is consistent with a lack of contractile response via the $5-\mathrm{HT}_{1 \mathrm{~F}}$ receptor generally in this preparation (Cohen and Schenck, 2000) as well as with human cerebral and meningeal arteries (Razzaque et al., 1999; Bouchelet et al., 2000).

6. $5-H T_{2 A}$ Receptors. The $5-\mathrm{HT}_{2 \mathrm{~A}}$ receptor is the original "D" receptor of Gaddum and Picarreli (1957). It is expressed in vascular smooth muscle, cardiac muscle, and platelets in multiple species, including humans (Ullmer et al., 1995; Derangeon et al., 2010; Watts et al., 2012).

The $5-\mathrm{HT}_{2 \mathrm{~A}}$ receptor mediates contraction in arteries and veins from most species (Villalón and Centurión, 2007), including rat (Sung et al., 2013), both directly and indirectly through regulation of sympathetic nerves (Blessing and Seaman, 2003). It promotes platelet aggregation and gap junctional coupling in heart myocytes (Derangeon et al., 2010), induces the activation of cardiac fibroblasts (Yabanoglu et al., 2009), and, within the nucleus tractus solitarius, stimulates a depressor and bradycardic response (Comet et al., 2007). Moreover, the direct component of 5-HT-induced tachycardia in reserpinized pithed rats is mediated by activation of $5-\mathrm{HT}_{2 \mathrm{~A}}$ receptors (Centurión et al., 2002). The receptor mediates increases in contractility in rat cardiac atrium (Läer et al., 1998) and ventricle but the latter only in heart failure and cardiac hypertrophy (Läer et al., 1998; Qvigstad et al., 2005c; Birkeland et al., 2007b; Brattelid et al., 2007a,b).

In most vascular diseases, isolated blood vessels are hyper-responsive to $5-\mathrm{HT}$ via the $5-\mathrm{HT}_{2 \mathrm{~A}}$ receptor. Similar to the $5-\mathrm{HT}_{1 \mathrm{~B}}$ receptor, upregulation of the 5 - $\mathrm{HT}_{2 \mathrm{~A}}$ receptor has been implicated in elevated vascular tone in pulmonary hypertension (Delaney et al., 2013). The $5-\mathrm{HT}_{2 \mathrm{~A}}$ receptor antagonist sarpogrelate blocked the development of pulmonary hypertension induced by monocrotaline and increased survival rate for this highly fatal disease (Hironaka et al., 2003).

The $5-\mathrm{HT}_{2 \mathrm{~A}}$ receptor has been targeted for the treatment of hypertension; thus, ketanserin had been developed for this indication, but further research revealed that the antihypertensive effects of ketanserin were actually mediated by $\alpha_{1}$-adrenoceptor blockade. Interestingly, relatively selective $5-\mathrm{HT}_{2 \mathrm{~A}}$ receptor antagonists (e.g., ritanserin) are devoid of antihypertensive potential in humans.

7. 5-HT $T_{2 B}$ Receptors. The $5-\mathrm{HT}_{2 \mathrm{~B}}$ receptor, originally described in the stomach fundus, is expressed throughout the cardiovascular system, including vascular smooth muscle (many beds), endothelial cells, cardiac myocytes, fibroblast, and valves (Choi and Maroteaux, 1996; Jaffré et a., 2009).

In systemic arteries from normotensive rats, the $5-\mathrm{HT}_{2 \mathrm{~B}}$ receptor is expressed but is apparently not functional (Banes and Watts, 2002, 2003). The endothelial $5-\mathrm{HT}_{2 \mathrm{~B}}$ receptor mediates a nitric oxide-mediated relaxation in normal vessels (Ellis et al., 1995; Glusa and 
Pertz, 2000; Jahnichen et al., 2005). Strong support for the interaction of the $5-\mathrm{HT}_{2 \mathrm{~B}}$ receptor with NOS was provided by Manivet et al., (2000). In endothelial cells isolated from human coronary artery, 5 -HT elevates nitric oxide production through the $5-\mathrm{HT}_{2 \mathrm{~B}}$ receptor (Ishida et al., 1998). The receptor also mediates calcium release in human pulmonary arterial endothelial cells (Ullmer et al., 1996). The $5-\mathrm{HT}_{2 \mathrm{~B}}$ receptor would appear necessary for cardiomyocyte survival (Nebigil et al., 2003a,b); receptor ablation leads to a cardiomyopathy without hypertrophy (Nebigil et al., 2000, 2001).

The 5- $\mathrm{HT}_{2 \mathrm{~B}}$ receptor is critical to development of hypoxia-induced pulmonary hypertension (Launay et al., 2002; Esteve et al., 2007) and monocrotalineinduced pulmonary hypertension (Zopf et al., 2011) and becomes functional in a number of models of experimental hypertension (Watts et al., 1995, 1996; Watts and Fink, 1999; Banes and Watts, 2002, 2003; Russell et al., 2002). Inhibition of the $5-\mathrm{HT}_{2 \mathrm{~B}}$ receptor appears to block valvular myofibroblast differentiation, a process involved in calcification of the aortic valves (Hutcheson et al., 2012). The question remains whether this role of the $5-\mathrm{HT}_{2 \mathrm{~B}}$ receptor also applies to pulmonary hypertension in humans, in which the $5-\mathrm{HT}_{1 \mathrm{~B}}$ receptor seems to have a central role (Maclean and Dempsie, 2010). However, the use of the anorectic combination fenfluramine-phentermine precipitated pulmonary hypertension and valvular heart disease, with evidence of mediation via the $5-\mathrm{HT}_{2 \mathrm{~B}}$ receptor (Fitzgerald et al., 2000; Rothman et al., 2000). Valvulopathy is also observed with other $5-\mathrm{HT}_{2 \mathrm{~B}}$ receptor agonists (e.g., norfenfluramine, benfluorex, pergolide, cabergoline, and ergotamine, most of which have been withdrawn from a majority of markets because of concerns around these adverse side-effects). As a consequence of these findings, preclinical safety screens for $5-\mathrm{HT}_{2 \mathrm{~B}}$ receptor agonism have become mandatory in an attempt to avoid the potential risk of valvulopathy (Hutcheson et al., 2011; Reid et al., 2013). Valvulopathy induced by serotonergic compounds did not begin with fenfluraminephentermine; it has been observed with ergots over the centuries in central and eastern Europe and even in ancient Egypt (Hauck et al., 1990; Eadie, 2003) as well as in patients with carcinoid tumors (Druce et al., 2009). Finally, 5- $\mathrm{HT}_{2 \mathrm{~B}}$ receptors appear essential for isoproterenol-induced cardiac hypertrophy in the mouse (Jaffre et al., 2004), and overexpression of the $5-\mathrm{HT}_{2 \mathrm{~B}}$ receptor led to cardiac hypertrophy in the mouse (Nebigil et al., 2003b). It should also be kept in mind that MDMA (ecstasy) and its metabolite MDA, as well as a number of MDMA analogs, act as $5-\mathrm{HT}_{2 \mathrm{~B}}$ receptor agonists and thus carry the risk of valvulopathies if consumed (Setola et al., 2003).

8. $5-H T_{2 C}$ Receptors. This receptor has not been localized to peripheral tissues with confidence, though a few reports suggest this may be so. The $5-\mathrm{HT}_{2 \mathrm{C}}$ receptor is, however, expressed in cardiovascularcontrolling areas of the central nervous system (e.g., nucleus tractus solitarius) and may elevate blood pressure (Ferreira et al., 2005; Austgen et al., 2012).

9. 5-HT $3 A$ and 5-HT $T_{3 A B}$ Receptors. An important action of $5-\mathrm{HT}_{3}$ receptors in the cardiovascular system is the ability to elicit the neuronally mediated transient von Bezold-Jarisch reflex [for references, see Kalkman et al. (1984), Saxena and Villalón (1990), and Villalón and Centurión (2007)].

Alternatively, activation of some peripheral $5-\mathrm{HT}_{3}$ receptors evokes tachycardic responses that may involve 1) noradrenaline release from postganglionic cardiac sympathetic neurons (Saxena and Villalón, 1990), 2) a direct action on the cardiac pacemaker (Wilson et al., 1990), and 3) CGRP release from cardiac sensory nerves (Nishio et al., 2002).

$5-\mathrm{HT}_{3}$ receptors in sympathetic ganglia may sustain chronic stress-induced hypertension in the rat (Nalivaiko and Sgoifo, 2009).

10. $5-H T_{4}$ Receptors. Cardiac expression is well established for the $5-\mathrm{HT}_{4}$ receptor, with earliest papers of $5-\mathrm{HT}_{4}$-like receptors in human atria dating back to 1989 (Kaumann and Levy, 2006). The $5-\mathrm{HT}_{4}$ receptor is functional in fetal hearts (Brattelid et al., 2012), normally expressed in human and porcine atrium and ventricle (Bach et al., 2001; Brattelid et al., 2004a,b; Weninger et al., 2012), and splice variants of the receptor exist in the human heart (Bach et al., 2001; Brattelid et al., 2004a; Krobert et al., 2005; Kaumann and Levy, 2006). Endothelial cells also express 5- $\mathrm{HT}_{4}$ receptors (Nishikawa et al., 2010; Machida et al., 2013), as does the adrenal gland (Vilaró et al., 2002).

5 -HT $\mathrm{H}_{4}$ receptors mediate positive inotropic, chronotropic, and lusitropic effects in human and porcine atrium (Kaumann, 1990; Kaumann et al., 1990, 1993; Villalón et al., 1990, 1991; Krobert et al., 2005; De Maeyer et al., 2006; Kaumann and Levy, 2006; Gergs et al., 2009; Chai et al., 2012; Weninger et al., 2012) and positive inotropic and lusitropic effects in human and porcine ventricular myocardium (Brattelid et al., 2004b; Afzal et al., 2008).

$5-\mathrm{HT}_{4}$ receptors also mediate arrhythmogenesis in human atria (Kaumann, 1994; Pino et al., 1998), modulation of angiogenesis in cultured human umbilical vein endothelial cells (Nishikawa et al., 2010; Profirovic et al., 2013), and aldosterone secretion from the adrenal gland (Lefebvre et al., 1998, 2000). Interestingly, a model of cardiac overexpression of the human $5-\mathrm{HT}_{4}$ receptor in the mouse heart has been developed to test for arrhythmogenesis as a cardiac side effect (Gergs et al., 2010).

As pointed out earlier, only $5-\mathrm{HT}_{2 \mathrm{~A}}$ receptors mediate 5 -HT-induced cardiostimulation in healthy rats (Centurión et al., 2002), but both $5-\mathrm{HT}_{4}$ and $5-\mathrm{HT}_{2 \mathrm{~A}}$ receptors mediate this effect after development of congestive heart failure (Qvigstad et al., 2005a,c). Accordingly, 5- $\mathrm{HT}_{4}$ receptors 1) become functional in ventricles during heart failure (Brattelid et al., 2004b, 2007a, 2012; Qvigstad et al., 2005a,c; Birkeland et al., 2007b) and 2) may contribute to human atrial 
fibrillation (Kaumann et al., 1994; Lezoualc'h et al., 2007). Thus, $5-\mathrm{HT}_{4}$ receptor antagonists may have potential therapeutic usefulness for improvement of cardiac function. In line with a proposed arrhythmogenic effect of stimulation of atrial $5-\mathrm{HT}_{4}$ receptors (Kaumann, 1994), antiarrhythmic effects of a $5-\mathrm{HT}_{4}$ antagonist were demonstrated in a porcine model of atrial fibrillation (Rahme et al., 1999). However, although atrial $5-\mathrm{HT}_{4}$ expression levels increase in human chronic atrial fibrillation (Lezoualc'h et al., 2007), the arrhythmic potential of $5-\mathrm{HT}_{4}$ receptors may be reduced in established human atrial fibrillation (Christ et al., 2014).

By analogy with the use of betablockers to improve prognosis in heart failure (Lohse et al., 2003), the use of $5-\mathrm{HT}_{4}$ receptor antagonists was proposed (Qvigstad et al., 2005b; Levy et al., 2008) and delivered improvement in a rat model (Birkeland et al., 2007a). 5- $\mathrm{HT}_{4}$ receptors are functional in human failing ventricle (Brattelid et al., 2004b; Afzal et al., 2008), and apparent clinical benefits of $5-\mathrm{HT}_{4}$ receptor antagonism have been detected (Kjekshus et al., 2009).

11. 5-HT $T_{5}$ Receptors. The knowledge about cardiovascular responses mediated by $5-\mathrm{HT}_{5}$ receptors is very limited [see Ramage and Villalón (2008)]. It is suggested that putative $5-\mathrm{HT}_{5}$ receptors can mediate 1 ) the 5-HT-induced cardiac sympathoinhibition (together with $5-\mathrm{HT}_{1 \mathrm{~B} / 1 \mathrm{D}}$ ) receptors in pithed rats (Sánchez-López et al., 2003) and 2) the GR-127935sensitive mechanism mediating hypotension in anesthetized rats (Sánchez-Maldonado et al., 2015).

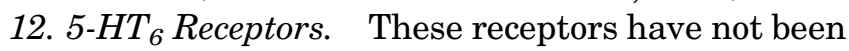
localized or found to be functionally relevant within the cardiovascular system (Villalón and Centurión, 2007; Ramage and Villalón, 2008).

13. 5-HT 7 Receptors. The $5-\mathrm{HT}_{7}$ receptor most probably is encompassed with the originally designated "5-HT $\mathrm{H}_{1}$-like" receptor that mediates direct (endotheliumindependent) vasorelaxation, the late vasodepressor response (i.e., the tertiary component of the triphasic response) following intravenous administration of 5-HT (Kalkman et al., 1984; Saxena and Villalón, 1990, 1991).

$5-\mathrm{HT}_{7}$ receptors are primarily located in vascular smooth muscle of most species (Ullmer et al., 1995; Villalón and Centurión, 2007; Ramage and Villalón, 2008). The $5-\mathrm{HT}_{7}$ receptor mediates direct vasorelaxation in multiple vascular beds (e.g., Cushing et al., 1996; Terrón, 1996; Villalón et al., 1997a, 2001; Jahnichen et al., 2005; Seto et al., 2009; Watts et al., 2015).

14. Receptor-Independent Actions of 5-HT. It is recognized that 5-HT can exert a (patho)physiologic role that is independent of cell surface 5-HT receptors.

For instance, various groups have reported that animals lacking SERT, or those in which SERT was pharmacologically inhibited, are protected from pulmonary hypertension (Fanburg and Lee, 2000; Marcos et al., 2003; Guignabert et al., 2005; Elangbam et al., 2008; Wang et al., 2012). Similarly, rodents overexpressing
SERT develop pulmonary hypertension (Guignabert et al., 2006). It is known that intracellular 5-HT is able to modify proteins, a phenomenon known as "serotonylation" of proteins (Lin et al., 2014). Such protein modification may mediate mitogenic and profibrotic effects of 5 -HT independent of receptor activation (Guilluy et al., 2009; Liu et al., 2011; Wei et al., 2012; Penumatsa and Fanburg, 2014). This covalent modification of target proteins by 5 -HT is mediated by the enzyme transglutaminase, of which the tissue transglutaminase isoform (TG II, tTG) is abundant in vascular tissue. Targets for serotonylation include Akt (Penumatsa et al., 2014); small GTPases such as Ras, Rab 4, and Rho (Ahmed et al., 2008; Mercado et al., 2011; Walther et al., 2003b, 2011; Lin et al., 2013); fibronectin (Liu et al., 2011; Hummerich et al., 2012); and smooth muscle $\alpha$-actin (Watts et al., 2009).

\section{5-HT Receptors and the Gastrointestinal Tract}

\section{A. Introduction}

The GI tracts of mammals contain a huge store of 5-HT (Gershon and Tack, 2007), melatonin (a derivative of 5-HT; Stone and Darlington, 2002), and kynurenine derivatives of tryptophan, which can interact with 5-HT receptors on GI muscle (Pomfret et al., 1987). This 5-HT is released to act within the GI tract (all known 5-HT receptors are expressed within the GI tract; see below) and externally into the blood, playing various roles in metabolism, osteogenesis, immunity, neurogenesis, and neuroprotection (Gershon, 2012, 2013). Indeed, about 95\% of the 5-HT in the human body the GI tract, with $90 \%$ being in enterochromaffin (EC) cells in the mucosal epithelium and 5\% in the neural structures intrinsic to the bowel wall; in common with the rest of the epithelium, EC cells are continually shed and replaced. Large amounts of 5-HT are also present in mast cells of rats and mice, but human intestinal mast cells usually contain no 5-HT (Buhner and Schemann, 2012); a subset of mast cells in patients with colon carcinoma and ulcerative colitis has been reported to contain 5-HT (Stoyanova and Gulubova, 2002). In the human GI tract, the highest amounts of 5-HT are present in the duodenum and rectum, whereas the lowest is found in the esophagus and ileum (Spiller, 2008a). In rats, the greatest amount of 5-HT is in the cecum (Hansen and Witte, 2008). 5-HT is also present in a limited (2\% to 3\%) number of myenteric descending interneurons (with variation among species; Gershon, 2003; Gershon and Tack, 2007), potentially regulating secretion and circular muscle movements in guinea pig jejunum (Neal and Bornstein, 2007), and in enteric sensory and motor neurons of mouse colon (Okamoto et al., 2014).

There are two GI 5-HT pools, each dependent on a different isoform of TPH ( $\mathrm{Li}$ et al., 2011b). The larger pool is present in EC cells and is TPH1-dependent. The smaller pool, present in neurons, is TPH2-dependent, as is CNS 5-HT. These two pools can thus be selectively 
depleted. Thus, TPH1 KO depletes EC cells, whereas TPH2 KO depletes neuronal 5-HT.

5 -HT is released from EC cells by mechanical and chemical stimuli (e.g., pH, bile acids, and nutrients such as glucose and short-chain fatty acids) applied to the luminal surface of the bowel. 5-HT release is modulated by neuronal and hormonal inputs acting at numerous receptors (including 5-HT receptors; see below) expressed by EC cells (Gershon, 2003; Hansen and Witte, 2008). The junctions between EC cells and intrinsic and extrinsic sensory nerve terminals in the mucosa are not morphologically like traditional synapses (Wade and Westfall, 1985). Indeed, 5-HT secreted by EC cells acts locally in a paracrine fashion, although the nerves it activates may be situated far from the EC cells (Wade and Westfall, 1985). In addition, EC cells are in constant motion from the crypts to the surface; they turn over and are replaced by stem cells both in the small and large intestines. As a result of the movement and transient nature of EC cells, traditional synapses are not found (nerves are not good at innervating moving targets) and EC cells do not focus the 5-HT released as precisely as do neurons [see Gershon and Tack (2007)]. Similarly, EC cells are located in relatively close proximity to mucosal lymphocytes (Yang and Lackner, 2004).

The 5-HT released into the mucosa and/or lumen does not normally penetrate to the muscle of the GI tract because of two reasons: first, 5 -HT has poor ability to cross lipid layers of cell membranes, and second, 5-HT is readily taken up by neurons and enterocytes via either SERT or organic cation transporters (Wade et al., 1996; Chen et al., 1998). 5-HT is also removed by the vasculature where it is taken up into blood platelets, which lack TPH and thus cannot synthesize 5-HT. Mucosal 5-HT thus does not gain access to the muscle layers of the bowel, except in pathologic conditions in which high plasma concentrations are reached (Sanger, 2008).

The released 5-HT can potentially act at multiple 5-HT receptors [see Costa et al. (2003), Beattie and Smith (2008), Hansen and Witte (2008), Sanger (2008), Chetty et al. (2009), Li et al. (2011b), Hoffman et al. (2012), and Alexander et al. (2015a,c)], which are expressed by several elements of the GI tract:

- Isolated enteric crest-derived cells (mRNA for all known 5-HT receptors)

- EC cells $\left(5-\mathrm{HT}_{2 \mathrm{C}}, 5-\mathrm{HT}_{3}, 5-\mathrm{HT}_{4}\right)$

- Goblet cells $\left(5-\mathrm{HT}_{4}\right)$

- Enterocytes $\left(5-\mathrm{HT}_{1 \mathrm{~A}}, 5-\mathrm{HT}_{2 \mathrm{~A}}, 5-\mathrm{HT}_{3}, 5-\mathrm{HT}_{4}\right)$

- Muscle $\left(5-\mathrm{HT}_{1 \mathrm{~B} / 1 \mathrm{D}}, 5-\mathrm{HT}_{2 \mathrm{~A}}, 5-\mathrm{HT}_{2 \mathrm{~B}}, 5-\mathrm{HT}_{4}, 5-\mathrm{HT}_{7}\right)$

- Interstitial cells of Cajal $\left(5-\mathrm{HT}_{3}, 5-\mathrm{HT}_{4}\right)$

- Motor $\left(5-\mathrm{HT}_{1 \mathrm{~A}}, 5-\mathrm{HT}_{1 \mathrm{~B} / 1 \mathrm{D}}, 5-\mathrm{HT}_{2 \mathrm{~A}}, 5-\mathrm{HT}_{2 \mathrm{~B}}, 5-\mathrm{HT}_{3}\right.$, $\left.5-\mathrm{HT}_{4}\right)$ and sensory $\left(5-\mathrm{HT}_{3}, 5-\mathrm{HT}_{4}, 5-\mathrm{HT}_{7}\right)$ neurons of the myenteric and submucosal plexus

- Terminals of GI extrinsic sympathetic and/or parasympathetic nerves $\left(5-\mathrm{HT}_{1 \mathrm{~A}}, 5-\mathrm{HT}_{3}, 5-\mathrm{HT}_{4}\right.$ in rodents)
The genes encoding the $5-\mathrm{HT}_{3 \mathrm{~A}}$ and $5-\mathrm{HT}_{3 \mathrm{~B}}$ subunits of the $5-\mathrm{HT}_{3}$ receptor are widely expressed by different mammalian tissues. In humans, expression of $5-\mathrm{HT}_{3 \mathrm{C}}$ and $5-\mathrm{HT}_{3 \mathrm{E}} \mathrm{mRNA}$ is greatest within the GI tract $\left(5-\mathrm{HT}_{3 \mathrm{C}}\right.$ is also present elsewhere), whereas 5-HT3D mRNA is largely restricted to the kidney, colon, and liver (Niesler et al., 2003; Holbrook et al., 2009; Yaakob et al., 2015). Notably, genes encoding $5-\mathrm{HT}_{3 \mathrm{C}}, 5-\mathrm{HT}_{3 \mathrm{D}}$, and $5-\mathrm{HT}_{3 \mathrm{E}}$ are found in humans and other mammals but not in rodents (Holbrook et al., 2009).

5-HT3A mRNA has been found in the mucosa and circular and longitudinal (taenia) muscle of human colon, whereas $5-\mathrm{HT}_{3 \mathrm{~B}}$ mRNA may be more common in muscle and $5-\mathrm{HT}_{3 \mathrm{E}} \mathrm{mRNA}$ in the mucosa (Chetty et al., 2009; Yaakob et al., 2015). Importantly, 5- $\mathrm{HT}_{3 \mathrm{~A}}$ and $5-\mathrm{HT}_{3 \mathrm{~B}} \mathrm{mRNA}$ and immunoreactivity are coexpressed with neuronal cell markers in the submucosal plexus of human intestine and therefore potentially form heteromeric $5-\mathrm{HT}_{3 \mathrm{AB}}$ receptors in these nerves (Michel et al., 2005). Others report that in cell bodies of human colon myenteric neurons, $5-\mathrm{HT}_{3 \mathrm{C}}, 5-\mathrm{HT}_{3 \mathrm{D}}$, and $5-\mathrm{HT}_{3 \mathrm{E}}$ mRNA coexpress with $5-\mathrm{HT}_{3 \mathrm{~A}}$, whereas mRNA for $5-\mathrm{HT}_{3 \mathrm{~A}}$ and $5-\mathrm{HT}_{3 \mathrm{D}}$ coexpress in the submucosal plexus (Kapeller et al., 2011). The physiologic significance of these different expression patterns is not clear. However, the absence of genes encoding $5-\mathrm{HT}_{3 \mathrm{C}}$, $5-\mathrm{HT}_{3 \mathrm{D}}$, and $5-\mathrm{HT}_{3 \mathrm{E}}$ in rodents has been linked to the specific divergence of rodents away from the primate evolutionary line and the peculiar lack of an emetic reflex in rodents (a function strongly linked in humans with $5-\mathrm{HT}_{3}$ receptors; see below and Holbrook et al., 2009). Here it may be of interest to note that selective 5 - $\mathrm{HT}_{3}$ receptor antagonists do not necessarily affect GI functions in the same way (e.g., Banner and Sanger, 1995), but whether such anomalies are explained by an ability to distinguish between different $5-\mathrm{HT}_{3}$ receptor subunits [see Thompson and Lummis (2013) for examples] is still unknown.

Among the 5-HT GPCRs, splice variants exist in human colon for $5-\mathrm{HT}_{2 \mathrm{~B}}, 5-\mathrm{HT}_{7}$, and $5-\mathrm{HT}_{4}$ receptors (Coupar et al., 2007; Chetty et al., 2009; Yaakob et al., 2015), although their roles are poorly understood. It has been speculated that the efficiency of $5-\mathrm{HT}_{4}$ receptor intracellular coupling and/or the desensitization liability and affinity of this receptor for particular ligands depends on which $\mathrm{COOH}$-terminal splice variant is expressed by a particular cell (Coupar et al., 2007; Beattie and Smith, 2008; Sanger, 2009). This would explain why $5-\mathrm{HT}_{4}$ receptor agonists facilitate GI cholinergic functions with high intrinsic activity (leading to increased GI motility), whereas in cardiac muscle and other tissues, the intrinsic activity of the same agonist is low (De Maeyer et al., 2006). Notably, the 5 - $\mathrm{HT}_{4(\mathrm{~d})}$ isoform is specifically expressed within human intestine (in addition to $5-\mathrm{HT}_{4(\mathrm{~b})}$ and $5-\mathrm{HT}_{4(\mathrm{a})}$, which are widely expressed), and the GI prokinetic renzapride (a nonselective 5- $\mathrm{HT}_{4}$ receptor agonist; Sanger, 1987a) 
acts as a full agonist at this isoform but only as a partial agonist at the 5- $\mathrm{HT}_{4(\mathrm{~g})}$ isoform (Mialet et al., 2000).

Certain 5-HT GPCRs may modulate ion channel functions within the GI tract. Sugiuar et al. (2004) showed that in mouse colon, the functions of transient receptor potential cation channel subfamily $\mathrm{V}$ member 1 channels were facilitated by both $5-\mathrm{HT}_{2 \mathrm{~A}}$ and $5-\mathrm{HT}_{4}$ receptor activation. In rat colon, a synergistic link between $5-\mathrm{HT}_{4}$ and $5-\mathrm{HT}_{3}$ receptors has been suggested (Smith et al., 1999). A proposed intracellular "cross talk" between $5-\mathrm{HT}_{3}$ and $\mathrm{NK}_{1}$ receptors may also provide a pathway via which certain selective $5-\mathrm{HT}_{3}$ receptor antagonists can influence the receptor in an allosteric manner (e.g., palonsetron) to inhibit substance P-mediated responses and thereby exert greater antiemetic activity (Rojas et al., 2014; see later).

Finally, it should be noted that 5-hydroxyindalpine, an agonist mimicking certain atypical 5-HT-mediated responses [said to be mediated by a putative $5-\mathrm{HT}_{1 \mathrm{P}}$ receptor, as yet undefined as a molecular entity despite considerable research; see Galligan (2007)], facilitated peristalsis in mouse colon but had no meaningful affinity for human $5-\mathrm{HT}_{1 \mathrm{~A}}, 1 \mathrm{~B}, 1 \mathrm{D}, 2 \mathrm{~A}, 2 \mathrm{~B}, 2 \mathrm{C},{ }_{3},{ }_{4}, 6$, and 7 receptors or for other monoamine (adrenoceptor, dopamine, and histamine) receptors (Mitchell et al., 2009). It has been speculated that at least some "atypical 5-HT responses" may be the result of ligands acting at allosteric binding sites and/or at GPCR heterodimers, such as a $5-\mathrm{HT}_{1 \mathrm{~B} / 1 \mathrm{D}}$ and dopamine $\mathrm{D}_{2}$ receptor heterodimer (Galligan, 2007).

\section{B. Functions of 5-HT}

Of the many proposed roles for endogenous 5-HT in GI physiology, the most widely studied relate to its involvement in GI movements, secretion, reflex functions, and sensations. Several of these functions are mediated via $5-\mathrm{HT}_{3}$ and $5-\mathrm{HT}_{4}$ receptors; other receptors may also have important roles, although the available data are often limited. It is important to appreciate that GI functions can differ markedly between species, especially between rodents and humans (Sanger et al., $2011 \mathrm{~b}, 2013 \mathrm{~b}$ ), and this can greatly change the functions of 5-HT and thereby complicate the translational value of certain animal models.

Additional developmental roles for endogenous 5-HT have also been reported, acting as an enteric neurotrophic or neuroprotective agent via $5-\mathrm{HT}_{2 \mathrm{~B}}$ and $5-\mathrm{HT}_{4}$ receptors or when released from enteric neurons, to promote epithelial growth via $5-\mathrm{HT}_{2 \mathrm{~A}}$ receptors on submucosal cholinergic neurons (Fiorica-Howells et al., 2000; Liu et al., 2009; Li et al., 2011b; Gross et al., 2012; Gershon, 2013; Mawe and Hoffman, 2013; Takaki et al., 2014). The absence of neuronal 5-HT during development in mice lacking TPH2, for example, is associated with a profound ENS hypoplasia and slow GI transit (Li et al., 2011b). Neurons that are born (become postmitotic) after enteric serotonergic neurons, in the sequence of ENS neurogenesis, are 5-HTdependent and are particularly deficient in these animals. Thus, 5-HT is a growth factor that is required for enteric neuronal development. The mucosa was also defective in TPH2KO mice, suggesting that neuronal 5-HT promotes division of transit-amplifying cells in intestinal crypts (Gross et al., 2012). Furthermore, the normal postnatal accretion of enteric neurons and growth of mice during the first 4 months of life also does not occur in animals in which $5-\mathrm{HT}_{4}$ receptors have been deleted (Liu et al., 2009).

One possibility is that neuroprotective functions of neuronal 5-HT might be integrated with a proinflammatory role of mucosal 5-HT. For example, mucosal 5 -HT enhances and triggers inflammation (Bischoff et al., 2009; Ghia et al., 2009; Haub et al., 2010; Li et al., 2011a; Margolis et al., 2014), probably by stimulating dendritic cells (Li et al., 2011a). Inflammation is potentially toxic to enteric neurons (Gulbransen et al., 2012), but it is also important in protecting the bowel from microbial invasion. Mucosal 5-HT may therefore enhance the strength of the innate immune response to danger, while at the same time, neuronal 5-HT may protect enteric neurons from being damaged by the response; 5-HT can thus serve both as a sword and a shield of the gut (Gershon, 2012).

1. Movements of the Hungry Stomach. During hunger, the release of 5-HT from the upper GI tract, together with the hormone motilin, has a potential role in initiating a repeating pattern of upper GI movements known as the migrating motor complex, also associated with changes in blood flow, gall-bladder emptying, and gastric and pancreatic secretions.

The migrating motor complex, which in humans repeats every $80-120$ minutes, is characterized by a relatively long period of quiescence (phase I), irregular nonpropulsive movements (phase II), and then a short burst (5-8 minutes) of high-amplitude propulsive contractions (phase III) initiated by the vagus nerve in stomach, duodenum, and jejunum but rapidly recovering (phase IV) while migrating to the terminal ileum, where the movement is terminated. Phase III removes undigested material and prevents bacterial overgrowth; it can be disrupted by disease and may help develop feelings of hunger (Sanger and Lee, 2008; Sanger et al., 2011a; Deloose et al., 2012; Tack et al., 2014). In dogs (Nakajima et al., 2010), a gradual release of 5-HT from duodenal enterochromaffin cells during phase I eventually activates $5-\mathrm{HT}_{4}$ receptors within the myenteric plexus to increase GI motility (phase II), releasing more 5-HT from enterochromaffin cells to initiate phase III via $5-\mathrm{HT}_{3}$ receptors in the stomach (also Morita et al., 2013) and in humans (Wilmer et al., 1993; Luiking et al., 2002) and $5-\mathrm{HT}_{4}$ receptors in the intestine (dogs: Davidson et al., 1990; Nakajima et al., 2010). The vagus also increases motilin release from human mucosal 
enteroendocrine cells (Wilmer et al., 1993) to re-enforce gastric phase III activity by greatly facilitating cholinergic motor nerve activity in a short-lasting manner (Broad et al., 2012).

2. Movements and Sensations of the Stomach and Duodenum after Meals. In healthy volunteers, little or no influence of endogenous 5-HT has been detected on gastric accommodation, compliance, sensation and motility, or on the rate of gastric emptying after ingestion of a meal, at least by acting at 5 - $\mathrm{HT}_{3}$ (e.g., Gore et al., 1990; Kuo et al., 2002; Netzer et al., 2002; Janssen et al., 2011b; Kusakabe et al., 2014) or $5-\mathrm{HT}_{4}$ receptors (e.g., Bharucha et al., 2000). In contrast, $5-\mathrm{HT}_{3}$ receptor antagonism can increase gastric emptying in rodents (e.g., Costall et al., 1987; Miyata et al., 1995), although an ability of ondansetron, a racemate, to facilitate cholinergic activity in guinea pig ileum via an unknown, non-5- $\mathrm{HT}_{3}$-mediated mechanism should also be noted (Miyata et al., 1995; González and Puig, 1997). However, in the mouse, elimination of neuronal 5-HT as a result of the knockout of TPH2 accelerates gastric emptying ( $\mathrm{Li}$ et al., 2011b), and 5-HT deletion or antagonism impairs vagal relaxation of the guinea pig stomach (Bülbring and Gershon, 1967).

If a meal is rich in glucose, amino acids, and/or lipids, high concentrations of these nutrients and/or gastric acid within the lumen of the duodenum can release 5-HT from enterochromaffin cells (and other mediators such as cholecystokinin, potentially acting synergistically together; Hayes and Covasa, 2005) to activate $5-\mathrm{HT}_{3}$ receptors upon abdominal vagal nerve terminals to induce satiety (Feinle and Read, 1996; Savastano and Covasa, 2007) and, if necessary, nausea (see below). In rodents, a clear reduction in gastric emptying has also been observed, but in humans, intraduodenal infusion of glucose or a high-fat meal caused only a small $5-\mathrm{HT}_{3}$ receptor-mediated reduction in gastric antrum movements and gastric emptying (Stacher et al., 1990; Raybould et al., 2003; Savoye et al., 2007). In rats, $5-\mathrm{HT}_{4}$ receptors on intrinsic cholinergic neurons may be activated to increase duodenal bicarbonate secretion for a neutralizing action against gastric acid (Akiba et al., 2015).

3. Movements of the Small Intestine. It has long been known that 5 -HT is released into the intestinal lumen by mechanical stimuli to the mucosa, leading to facilitation of the peristaltic reflex (e.g., Bülbring and Lin, 1958; Foxx-Orenstein et al., 1996; (Bertrand et al., 2000, 2008; Pan and Gershon, 2000; Patel et al., 2007). However, it seems unlikely that this mechanism has a major physiologic influence on human small-intestinal movements, at least via $5-\mathrm{HT}_{3}$ (Gore et al., 1990; Houghton et al., 2000) and 5- $\mathrm{HT}_{4}$ receptors (Bharucha et al., 2000). Nevertheless, this does not rule out the possibility that under certain nonphysiologic conditions (e.g., prevention of 5-HT reuptake by use of an SSRI), small-intestinal movements can be stimulated by the released 5-HT (Grover and Camilleri, 2013; Bundeff and Woodis, 2014; see XX. C. 5-HT in GI Pathology for discussion). Furthermore, it should be noted that 5-HT is probably released from EC cells into the lamina propria underlying these cells. Nerve fibers from intrinsic primary afferent neurons are found in this location, as are sensory nerves derived from the vagus and dorsal root ganglia. Because the entire enteroendocrine system, including EC cells, secretes basolaterally, not apically, the luminal appearance of 5-HT is likely to result from spillover (5-HT is a relatively small molecule so it can diffuse into the lumen after its release into the lamina propria). It might thus be expected that endogenous 5-HT release in the small intestine would not affect motility.

4. Movements of the Colon. Endogenous 5-HT acting at $5-\mathrm{HT}_{3}$ receptors plays a physiologic role in controlling normal movements of the colon via extrinsic and/or intrinsic nerve pathways, depending on the species of mammal. Additionally, and in certain species, $5-\mathrm{HT}_{2 \mathrm{~B}}$ and $5-\mathrm{HT}_{7}$ receptors may play similar roles (see below). However, the exact role of 5-HT on movements of the colon remain uncertain due, in part, to the high complexity of both the 5-HT system and the movements of colon in different species. This uncertainty has been discussed in a series of "cross talk" articles (Heredia et al., 2013; Smith and Gershon, 2015a,b; Spencer et al., $2015 \mathrm{a}, \mathrm{b})$.

a. 5-HT $T_{2 A}$ receptors. $5-\mathrm{HT}_{2 \mathrm{~A}}$ receptor knockout mice, from which 5-HT can no longer cause contraction of the isolated colon, display apparently normal GI transit and colorectal motility patterns (Fiorica-Howells et al., 2002).

b. 5-HT $T_{2 B}$ receptors. Propulsive movements of the colon and fecal output in vivo are reduced by $5-\mathrm{HT}_{2 \mathrm{~B}}$ receptor antagonism in rodents (Bassil et al., 2009) but not in dogs (Morita et al., 2013). The receptor has been implicated in enteric nerve and in ICC development (Fiorica-Howells et al., 2000; Tharayil et al., 2010). Although exogenously applied 5-HT can cause contraction of human colon via $5-\mathrm{HT}_{2 \mathrm{~B}}$ receptor activation (Borman et al., 2002), a role for endogenous 5-HT acting at the $5-\mathrm{HT}_{2 \mathrm{~B}}$ receptor to affect human colonic functions has yet to be established.

c. 5-HT $\mathrm{H}_{3}$ receptors. $5-\mathrm{HT}_{3}$ receptor antagonists slow colonic motility and induce mild constipation in several species, but the mechanisms of action may vary. In humans, the ability to slow colonic motility (e.g., Gore et al., 1990; Talley et al., 1990; Houghton et al., 2000) is at least partly due to inhibition of the gastrocolic reflex, thought to be a vagus nerve-mediated colonic contractile response associated with eating but specifically evoked by distension of the gastric antrum or inclusion of lipids within the lumen of the duodenum (Prior and Read, 1993; von der Ohe et al., 1994; Björnsson et al., 1998, 2002). In these studies, the ascending and descending components of the peristaltic reflex were unaffected by $5-\mathrm{HT}_{3}$ receptor antagonism. The latter is 
consistent with an inability to detect 5-HT-mediated fast synaptic potentials in the myenteric plexus of human colon (Brookes et al., 1987) but seems at variance with the ability of local application of 5-HT to excite submucosal neurons (but not chloride ion secretion) in human small and large intestine via $5-\mathrm{HT}_{3}$ receptors (where 5-HT3A and 5-HT3B receptor subunits are expressed; Michel et al., 2005).

In rodents, $5-\mathrm{HT}_{3}$ receptors appear to influence colonic movements via more "local" mechanisms. Thus, the ability of $5-\mathrm{HT}_{3}$ receptor antagonists (granisetron and tropisetron but not ondansetron) to dose-dependently inhibit fecal pellet excretion by guinea pigs could be at least partly mimicked in guinea pig mid-to-distal isolated colon, in which granisetron and tropisetron prevented movement and expulsion of endogenous fecal pellets (recovered by application of naloxone; Sanger and Wardle, 1994). Similar data were reported by Jin et al. (1999) using artificial fecal pellets and approximately the same region of colon after application of different $5-\mathrm{HT}_{3}$ and $5-\mathrm{HT}_{4}$ receptor antagonists. However, in guinea pig distal colon, movements of artificially inserted fecal pellets were unaffected or only transiently reduced when $5-\mathrm{HT}_{4}$ or $5-\mathrm{HT}_{3}$ receptor antagonists (including granisetron and ondansetron) were applied individually but were inhibited, albeit for only a short period of time, when the antagonists were given together (Kadowaki et al., 1996). In rats, proximal colon transit (measured via an indwelling cannula) and 5-HT-induced diarrhea in mice were unaffected by $5-\mathrm{HT}_{4}$ or $5-\mathrm{HT}_{3}$ receptor antagonists (ondansetron) applied separately but were inhibited when applied together (Nagakura et al., 1997). In contrast, Yu et al. (2015) demonstrated an ability of 5 - $\mathrm{HT}_{3}$ receptor antagonism to abolish propulsive movements of rat isolated colon, again supporting a local role for 5-HT in the control of rodent colonic movements.

More recent studies confirmed a local release of 5-HT from mouse colon in response to a maintained presence of a fecal pellet, an ability of $5-\mathrm{HT}_{3}$ receptor activation to promote pacemaker activity generated in mouse ileum by the interstitial cells of Cajal (Liu et al., 2011), and an ability of $5-\mathrm{HT}_{3}$ receptor antagonism to prevent colonic migrating motor contractions (e.g., Bush et al., 2001; Heredia et al., 2009, 2013; Dickson et al., 2010). The question of whether the 5-HT comes from interneurons or from enterochromaffin cells to evoke these movements-or even if endogenous 5-HT is required at all-is the subject of debate, raising interesting questions about methods, the role of mucosal versus stretch-induced reflexes, putative constitutive expression of receptors (Smith et al., 2010, 2014; Heredia et al., 2013; Sia et al., 2013), and mouse strain differences (Neal et al., 2009). Despite the controversy surrounding the function of colonic 5-HT, myenteric 5 -HT neurons project so extensively in the colon that these cells have been called "the central processing unit in the colon" (Okamoto et al., 2014). d. 5-HT $\mathrm{H}_{4}$ receptors. $5-\mathrm{HT}_{4}$ receptor antagonists have little (Morita et al., 2013) or no ability to inhibit colon movements in dogs (Nagakura et al., 1996) or rodents (Kadowaki et al., 1996; Nagakura et al., 1997; Sanger et al., 1998, 2000), although reduced GI activity was observed in $5-\mathrm{HT}_{4}$ receptor knockout mice, arguably related to loss of 5- $\mathrm{HT}_{4}$ receptor-mediated promotion of survival of enteric neurons (Gershon and Liu, 2007). In human volunteers, there were no changes in colonic transit (a trend toward delayed transit was not statistically significant), fasting or postprandial motor activity, compliance, or sensations evoked by transverse and sigmoid colon distension after 10-12 days administration with pharmacologically effective doses of a $5-\mathrm{HT}_{4}$ receptor antagonist (Bharucha et al., 2000).

e. $5-\mathrm{HT}_{7}$ receptors. Activation of $5-\mathrm{HT}_{7}$ receptors expressed by human intestinal muscle causes muscle relaxation (Prins et al., 1999; Coupar et al., 2007; Irving et al., 2007). In guinea pig ileum, $5-\mathrm{HT}_{7}$ receptors are localized both to muscle and to myenteric and submucosal neurons (Tonini et al., 2005). In this tissue, the release of 5-HT from enterochromaffin cells is thought to activate $5-\mathrm{HT}_{7}$ receptors on intrinsic sensory neurons (defined as Dogiel type II neurons) to evoke slow depolarization (Monro et al., 2005) and perhaps also to facilitate a descending inhibitory motor pathway to relax the muscle, increasing its ability to accommodate and thereby reducing the likelihood of inducing peristalsis by intraluminal distension (Tuladhar et al., 2003; Tonini et al., 2005). By a similar process, endogenous 5-HT may activate $5-\mathrm{HT}_{7}$ receptors in mouse colon to promote descending inhibitory interneurons and contribute to the generation of spontaneous colonic migrating motor complex (Dickson et al., 2010).

\section{5-HT in Gastrointestinal Pathology}

The large amount of 5-HT in the GI tract and the expression of all 5-HT receptors on several, functionally different types of GI cells (see above) creates the interesting situation of being able to use selective 5 -HT receptor antagonists to treat disease caused by release of endogenous 5-HT and also use 5-HT receptor agonists ("exogenous 5-HT") to treat other diseases. This section discusses the involvement of endogenous 5 -HT in the mechanisms of disease.

Increased release or availability of 5-HT from EC cells is associated with various GI disorders, including diarrhea (e.g., induced by cholera and other bacterial toxins and also by carcinoid tumors), inflammatory bowel disease, and functional disorders such as IBS [Gershon and Tack, 2007; Spiller, 2008b, 2011; Bertrand and Bertrand, 2010; for discussion on expression of 5-HT receptors by human dendritic and immune cells, see Idzko et al. (2004) and Shajib and Khan (2015)]. More recently, the release of 5-HT from enterochromaffin cells of the rat duodenum has been shown to increase following exposure to short-chain fatty acids (Akiba et al., 2015), 
potentially caused by increased TPH1 transcription (Reigstad et al., 2015). 5-HT release is also increased by cytotoxic anticancer treatments following generation of free radicals in enterochromaffin cells (Minami et al., 2003) and acute stress via agents such as corticotropinreleasing factor (Sanger et al., 2000; Von Mentzer et al., 2007). Increases in 5-HT availability in 5-HT transporter knockout mice can change the level of expression and sensitivity of enteric 5- $\mathrm{HT}_{3}$ receptors (Gershon, 2003).

In GI disease, an increased availability of 5-HT has marked effects on certain autonomic functions (e.g., emesis), GI movements (e.g., diarrhea), and, perhaps, conscious perceptions of discomfort and/or pain. Several studies have investigated the role of 5-HT release into the circulation, 5-HT in tissue (typically by immunohistochemistry), and mRNA expression of 5-HTTLPR gene (which determines SERT levels) in rectal mucosa and platelets and DNA polymorphisms in 5-HTTLPR gene. In summary, the most consistent findings are elevated postprandial plasma 5-HT in IBS-D and reduced levels in IBS with constipation (IBS-C) (Spiller, 2008a,b; ElSalhy et al., 2012; Mawe and Hoffman, 2013; Camilleri, 2014; Zhang et al., 2014).

1. Emesis. There are no "universal" antiemetic drugs, and multiple stimuli evoke emesis via different pathways, not all of which involve the release of 5-HT. The stimuli that involve the release of 5-HT and that have been studied most often are discussed below. In this discussion, the term "emesis" is taken to represent the combined act of vomiting (and dry retching) as well as nausea. It is, however, increasingly appreciated that the sensation of nausea is not fully explained by the pathways that induce vomiting. For example, $5-\mathrm{HT}_{3}$ and $\mathrm{NK}_{1}$ receptor antagonists are both more effective against vomiting than they are against nausea, implying that different mechanisms are involved (Andrews and Sanger, 2014) and, hence, different approaches to treatment are required (Sanger et al., 2013).

Since the pioneering studies with animals (Costall et al., 1986; Miner and Sanger, 1986; Miner et al., 1987), the use of selective $5-\mathrm{HT}_{3}$ receptor antagonists as antiemetic drugs has revolutionized treatment of cancer by making chemo- and radiotherapeutic treatments more tolerable (emesis is now viewed as something that can be treated rather than needs to be tolerated, and anticancer drugs can now be given in family-orientated outpatient clinics) by enabling the delivery of more aggressive treatments and by actually reducing health care costs (Currow et al., 1997; Warr and DeAngelis, 2009). Following identification of this role for the $5-\mathrm{HT}_{3}$ receptor, it rapidly became standard practice to coadminister a $5-\mathrm{HT}_{3}$ receptor antagonist with the corticosteroid dexamethasone to achieve even better relief from emesis evoked by moderate to severe emetogenic treatments. Later, the "triple-therapy" of $5-\mathrm{HT}_{3}$ receptor antagonism, dexamethasone, and $\mathrm{NK}_{1}$ receptor antagonism achieved a further benefit in patients receiving treatments classified as "highly emetogenic," not only controlling the appearance of "acute" emesis (during the first 24 hours after initiation of treatment) but also, even more importantly, now controlling the "delayed emesis," which in these patients can occur 24-48 hours after the start of treatment (Warr, 2012).

5- $\mathrm{HT}_{3}$ receptor antagonists prevent cytotoxic-associated vomiting by blocking the ability of released 5-HT (Barnes et al., 1990; Cubeddu et al., 1990), likely from EC cells, to activate $5-\mathrm{HT}_{3}$ receptors on abdominal vagal nerve terminals and thereby effectively "desensitize" the vagus to the proemetic stimulatory actions of other substances (e.g., prostanoids) released during the cytotoxic treatment (see Sanger and Andrews, 2006). Most recently, evidence is emerging that a long-lasting $5-\mathrm{HT}_{3}$ receptor antagonist (palonosetron) may provide further improvements in emesis control by a mechanism not yet clearly understood but argued to involve inhibition of substance $\mathrm{P}$-mediated responses via a unique interaction with the 5- $\mathrm{HT}_{3}$ receptor (Rojas et al., 2014).

Depending partly on the population studied, a minority of patients treated with moderate to highly emetogenic chemotherapy do not respond well to treatment with a $5-\mathrm{HT}_{3}$ receptor antagonist. This may be due to mutations in a P-glycoprotein efflux transporter in intestinal epithelia and capillaries of the blood-brain barrier, affecting the availability and target engagement of these and other drugs (Perwitasari et al., 2011; Tsuji et al., 2013; He et al., 2014; Zoto et al., 2015), and/or differences in rates of metabolism of ondansetron and tropisetron associated with polymorphisms of the gene encoding CYP2D6 (Kaiser et al., 2002). Genetic variants of the $5-\mathrm{HT}_{3 \mathrm{~B}}$, but not the $5-\mathrm{HT}_{3 \mathrm{~A}}$ subunit, are also reported to alter antiemetic efficacy in a small number of patients (Tremblay et al., 2003; Kaiser et al., 2004; de Wit et al., 2005).

In patients at the end of life, perhaps with faradvanced cancer for which chemo- or radiotherapy is no longer provided, emesis can remain a severe problem for reasons associated with the use of drugs; cranial, electrolytic, or metabolic causes; and bowel obstruction, uremia, and/or sepsis. In these patients, $5-\mathrm{HT}_{3}$ receptor antagonists have often provided effective control of emesis (e.g., Currow et al., 1997; Mystakidou et al., 1998; Buchanan and Muirhead, 2007). Exactly where the 5 -HT comes from is not always clear, and $5-\mathrm{HT}_{3}$ receptors expressed both peripherally (vagus nerve terminals) and centrally within the brainstem are likely to be involved (Sanger and Andrews, 2006).

SSRIs can induce nausea and vomiting that is reduced by $5-\mathrm{HT}_{3}$ receptor antagonism and associated with polymorphisms of the HTR $3 B$ gene but not with genes encoding the 5 -HT transporter, the $5-\mathrm{HT}_{2 \mathrm{~A}}$ receptor, or the $5-\mathrm{HT}_{3 \mathrm{~A}}$ receptor subunit (Sugai et al., 2006; Tanaka et al., 2008). Such drugs also stimulate small but not large bowel motility and have 
been evaluated as potential treatments of IBS, improving general well-being (Grover and Camilleri, 2013; Bundeff and Woodis, 2014).

Notably, there are many drugs and experimental tools other than the SSRIs that increase (e.g., 5-hydroxytryptophan, nonselective SSRIs, and monoamine oxidase inhibitors) or decrease 5-HT availability (e.g., fenfluramine; depletion following the initial increase), sometimes with additional abilities to antagonize certain 5 -HT receptors, and these can induce or reduce emesis. The receptors include $5-\mathrm{HT}_{1 \mathrm{~A}}, 5-\mathrm{HT}_{2 \mathrm{~A}}$, and $5-\mathrm{HT}_{3}$, but which receptors are involved is not always clear, and studies with more selective ligands are required to understand mechanisms of action (Johnston et al., 2014).

Postoperative vomiting (POV) is caused by multiple stimuli but can be reduced by $5-\mathrm{HT}_{3}$ receptor antagonism (e.g., Chun et al., 2014). The exact mechanism is not clear (Horn et al., 2014). Genetic variations in the HTR3A and HTR3B genes may be associated with the risk of developing POV, but given the multifactorial causes of POV, larger studies are required to determine the true clinical significance of these observations (Rueffert et al., 2009; Ma et al., 2013).

2. Eating Disorders. The 5- $\mathrm{HT}_{3}$ receptor antagonist ondansetron reduces binge-eating, vomiting, and depressive symptoms in patients with severe bulimia nervosa, leading to a return of normal eating, possibly by modulating cyclic increases in vagal nerve activity (Faris et al., 2006). Arguably, an ability of 5 - $\mathrm{HT}_{3}$ receptor antagonism to increase the threshold before satiation is reached (Janssen et al., 2011b) could also play a role. Variants of the HTR3B gene have been associated with the restrictive subtype of anorexia nervosa (Hammer et al., 2009). It may also be possible to achieve long-term regulation of body weight by modulating different aspects of gastric motility (Janssen et al., 2011), perhaps with drugs that act at different 5-HT receptors (see below).

3. Carcinoid Diarrhea. Carcinoid tumors in the colon can generate high levels of circulating 5 - $\mathrm{HT}$, causing diarrhea by stimulating colonic motor functions (von der Ohe et al., 1993) via $5-\mathrm{HT}_{3}$ receptors (see above) and chloride ion secretion in human colon via $5-\mathrm{HT}_{2 \mathrm{~A}}$ and $5-\mathrm{HT}_{4}$ (ascending colon) and $5-\mathrm{HT}_{2 \mathrm{~A}}$ (descending colon) receptors (Borman and Burleigh, 1996). This is primarily treated with loperamide or a somatostatin analog, such as octreotide, but $5-\mathrm{HT}_{3}$ receptor antagonists have helped, at least when given acutely, as have $5-\mathrm{HT}_{2 \mathrm{~A}}$ (ketanserin) receptor antagonists and methysergide, a nonselective $5-\mathrm{HT}_{1} / 5$ $\mathrm{HT}_{2}$ receptor agonist/antagonist (Camilleri and von der Ohe, 1994; Schwörer et al., 1995; Spiller, 2008a). Given that TPH1 is responsible for 5 -HT production, perhaps its inhibition may represent a new treatment paradigm in carcinoid tumors (see Camilleri, 2011).
4. Functional Gastrointestinal Disorders. These are a grouping of GI disorders that cannot be explained by structural or tissue abnormalities and as such are defined by symptoms. They include functional dyspepsia, IBS, and several others (Longstreth et al., 2006).

5. Functional Dyspepsia. The rationale for treatment of functional dyspepsia with a 5-HT receptor antagonist has not been established. Single doses of a $5-\mathrm{HT}_{4}$ receptor antagonist did not affect symptoms (Van Lelyveld et al., 2006), although an ability of 5- $\mathrm{HT}_{4}$ receptor antagonism to prevent $\mathrm{HCO}_{3}^{-}$release in rat duodenum by SCFAs has suggested a role when high levels of SCFAs occur in the upper GI tract during bacterial overgrowth (Akiba et al., 2015). More promisingly, a pilot study with patients dosed for 12 weeks with a $5-\mathrm{HT}_{3}$ receptor antagonist showed some improvement in "adequate relief of pain or discomfort" (Talley et al., 2001), and an association between symptoms and 5-HT3A receptor gene polymorphism has been suggested (Mujakovic et al., 2011). Arguably, these data find some consistency with an ability of $5-\mathrm{HT}_{3}$ receptor antagonism to prevent the experience of nausea in healthy volunteers induced by intraduodenal infusion of lipids [see Gershon and Tack (2007)], as early satiety and nausea are common symptoms in this group of patients (Vanheel et al., 2013) but are at variance with the lack of ability of $5-\mathrm{HT}_{3}$ receptor antagonism to change sensitivity to gastric distension [see Gershon and Tack (2007)].

6. Irritable Bowel Syndrome. In some pilot studies, $5-\mathrm{HT}_{3}$ receptor antagonism reduced sensations caused by bowel distension in patients with IBS [e.g., Prior and Read (1993) and Goldberg et al. (1996)], perhaps as a consequence of increased compliance to distension (Delvaux et al., 1998). These studies, together with the known ability to reduce colonic movements, prompted the evaluation and initial success of the $5-\mathrm{HT}_{3}$ receptor antagonist alosetron as a treatment for patients with IBS with symptoms of diarrhea as well as abdominal discomfort and/or pain. The subsequent occurrence of ischemic colitis in a small number of treated patients restricted use of alosetron and almost entirely stopped research into this area. It has since been concluded that ischemic colitis is two- to four-times more likely to occur in patients with IBS regardless of treatment (Lewis, 2011), suggesting that any future treatments of this form of IBS should not induce severe constipation to potentially exacerbate such a liability. Furthermore, it should be noted that an ability of $5-\mathrm{HT}_{3}$ receptor antagonists to reduce sensations evoked by bowel distension has not been consistently observed [e.g., Hammer et al. (1993) and Zighelboim et al. (1995) in patients without "psychologic disorders"), perhaps arguing for greater emphasis of future research on colonic movement disorders. Any association between IBS and HTR3 subunit gene mutations remains uncertain 
(Niesler, 2011). Nevertheless, in patients with diarrheapredominant IBS, the ability of alosetron to reduce colonic transit may be associated with long (LL) polymorphisms of the 5-HT transporter gene 5-HTTLPR, which is associated with increased synthesis of SERT (SLC6A4) and inactivation of endogenous 5-HT (Camilleri et al., 2002). Also, in this group of patients with IBS, symptoms were improved in a pilot study using the $5-\mathrm{HT}_{3}$ receptor antagonist ramosetron, an activity correlating with increased expression of TPH1 and with TPH1 gene polymorphism (Shiotani et al., 2015).

The $5-\mathrm{HT}_{4}$ receptor antagonist SB-207266 reduced stress-induced defecation in mice (Sanger et al., 2000), and in a pilot study with diarrhea-predominant IBS patients, it tended to reduce rectal sensitivity and reduced small-intestinal transit (Houghton et al., 1999). However, lack of significant efficacy in larger studies stopped further development for this indication (De Ponti, 2004).

In some countries, the $5-\mathrm{HT}_{4}$ receptor agonist tegaserod was registered for treatment of IBS and chronic constipation (see below for discussion on the potential use of $5-\mathrm{HT}_{4}$ receptor agonists in the treatment of IBS) but was then withdrawn because of potential cardiovascular liability and poor overall efficacy (Schiller and Johnson, 2008). Tegaserod has since been shown to act as a potent $5-\mathrm{HT}_{2 \mathrm{~B}}$ receptor antagonist (Beattie et al., 2004), reducing colonic motility (in rodents, not dogs; see above) and exerting a visceral antinociceptive activity in rodents (Ohashi-Doi et al., 2010; O'Mahony et al., 2010). The extent to which each of these different activities translates to humans and/or patients with IBS is not clear. In parallel with the evidence that LL polymorphisms of the 5-HT transporter gene 5-HTTLPR result in greater changes in colonic transit with alosetron, a clinical trial has shown that LL polymorphism is associated with reduced clinical efficacy of tegaserod in patients with constipation $(\mathrm{Li}$ et al., 2007).

LX1031, a locally acting TPH inhibitor, that does not cross the blood-brain barrier, has been found to be safe and well tolerated in an exploratory 4-week phase 2 study in patients with symptomatic, nonconstipating IBS (Brown et al., 2011). Thus, reduction of mucosaderived 5-HT may positively influence symptoms common to nonconstipating IBS. A relationship was observed between symptom improvement and a reduction in 24-hour urinary 5-HIAA; thus, 5-HIAA can serve as a biomarker to estimate the rate of 5-HT synthesis and target engagement by the TPH inhibitor LX1031. However, data from any further clinical development of this drug is lacking, and the company Lexicon have confirmed development has been terminated.

Any involvement of the $5-\mathrm{HT}_{7}$ receptor in the mechanisms of visceral pain, following a proposed role in somatic pain (Andrews and O'Neill, 2011), is as yet unknown. Similarly, any involvement of 5-HT in the mechanisms of mucosal inflammation (see earlier) in patients with IBS has yet to be demonstrated.

7. Other Gastrointestinal Disorders. In colon from patients with diverticular disease, $5-\mathrm{HT}_{4} \mathrm{mRNA}$ expression was reduced in the muscle but increased in the mucosa; expression of $5-\mathrm{HT}_{2 \mathrm{~B}}$ and $5-\mathrm{HT}_{3} \mathrm{~A}$ mRNA was unchanged. The authors speculate that these changes could influence the intestinal motor disturbances associated with this disease (Böttner et al., 2013).

\section{Therapeutic Benefits of 5-HT Receptor Agonists and Antagonists}

This section discusses the use of 5 -HT receptor agonists ("exogenous 5-HT") to treat diseases where any involvement of endogenous $5-\mathrm{HT}$ in the mechanism of the disease is absent or unclear. The class of $5-\mathrm{HT}_{3}$ receptor antagonists (e.g., alosetron or ondansetron) for IBS-D and 5- $\mathrm{HT}_{4}$ receptor agonists for chronic constipation or IBS-C (e.g., prucalopride) are extensively used in clinical practice and constitute first- or second-line therapeutic agents for these conditions. Efficacy and safety are documented by systematic reviews and meta-analyses (Andresen et al., 2008; Ford et al., 2009; Shin et al., 2014). The risk of ischemic colitis with alosetron (not observed with ondansetron) is estimated at about 1 in 1000 patients; however, there is also evidence that IBS itself is a risk factor for the development of ischemic colitis (Huerta et al., 2011).

1. 5-HT 4 Receptor Agonists. At present, $5-\mathrm{HT}_{4}$ receptors appear to have little or no major roles in disorders of GI hypomotility; for example, in idiopathic gastroparesis, there were no overall changes in $5-\mathrm{HT}_{4}$ receptor expression apart from a reduced expression of the 5-HT 4 (c) splice variant (van Lelyveld et al., 2008), yet $5-\mathrm{HT}_{4}$ receptor agonists have long been used to treat such disorders. This began with metoclopramide, a derivative of procaine found to have surprising antiemetic and gastric prokinetic properties. Understanding the mechanisms of action of metoclopramide directly led to the discovery of the antiemetic role of the $5-\mathrm{HT}_{3}$ receptor (Miner and Sanger, 1986) and in the description of a novel "5-HT-like" receptor affecting GI motility (Sanger, 1987b), later named as the $5-\mathrm{HT}_{4}$ receptor by Bockaert and colleagues who used similar ligands in CNS studies (Dumuis et al., 1988). Subsequently, a number of different $5-\mathrm{HT}_{4}$ receptor agonists were launched as prokinetic agents, but none of the early examples are selective in their action, leading to cardiovascular complications (Sanger, 2009). Nevertheless, the selective 5- $\mathrm{HT}_{4}$ receptor agonist prucalopride is now marketed as a treatment of chronic idiopathic constipation; others are in development, and the potential use of such agents in the treatment of upper GI disorders associated with gastric and/or esophageal hypomotility is still being explored (Sanger, 2009; Broad et al., 2014a,b; Kessing et al., 2014). Interestingly, a low dose of the $5-\mathrm{HT}_{4}$ receptor agonist 
mosapride has been shown to increase human gastric accommodation in healthy volunteers (Amano et al., 2015), perhaps reflecting the ability of $5-\mathrm{HT}_{4}$ receptor agonists to increase nitrergic as well as cholinergic activity (Cellek et al., 2006), the former potentially increasing gastric fundus accommodation and the latter, gastric antrum motility and emptying. Because impaired gastric accommodation may contribute to the etiology of symptoms in patients with postprandial functional dyspepsia (e.g., early satiety and/or nausea; Talley, 2015), these data support the argument that such symptoms can be relieved by selective $5-\mathrm{HT}_{4}$ receptor agonists (Janssen et al., 2011a; Sanger et al., 2013).

In human colon, 5 - $\mathrm{HT}_{4}$ receptor activation is an effective prokinetic principle, as it facilitates excitatory cholinergic and inhibitory nitrergic motor nerve activities (representing the ascending excitatory and descending inhibitory components of a peristaltic reflex), decreases muscle tension, and increases chloride secretion from the mucosa into the lumen (Borman and Burleigh, 1996; Prins et al., 2000; Cellek et al., 2006; Broad et al., 2013). Evidence for facilitation of enteric sensory nerve activity remains uncertain (Gershon and Tack, 2007). More recent attention has been drawn to the possibility that $5-\mathrm{HT}_{4}$ receptor activation might stimulate bicarbonate secretion in rat proximal colon (Kaji et al., 2015) and might also reduce nociception in rats exposed to colorectal distension (Hoffman et al., 2012; Gilet et al., 2014). The latter activity could depend on a synergistic interaction with $5-\mathrm{HT}_{3}$ receptors in the mechanisms of allodynia (Smith et al., 1999) but also contrasts with the findings of Sugiuar et al. (2004), who showed that the nociceptive functions of transient receptor potential cation channel subfamily $\mathrm{V}$ member 1 channels were facilitated by $5-\mathrm{HT}_{4}$ receptor activation in mouse colon. Similar responses have not yet been confirmed to occur in human colon, but if successfully translated, $5-\mathrm{HT}_{4}$ agonists may be useful as suppositories or enemas for treating IBS (Kale-Pradhan and Wilhelm, 2007; Mawe and Hoffman, 2013). To date, only the $5-\mathrm{HT}_{4}$ receptor agonist tegaserod has been fully tested as a potential treatment of IBS, but poor efficacy at the $5-\mathrm{HT}_{4}$ receptor, potential confounding cardiovascular complications, and the existence of additional ability to antagonist at the $5-\mathrm{HT}_{2 \mathrm{~B}}$ receptor (see above for discussion) greatly complicate the use of such data to argue for or against the use of $5-\mathrm{HT}_{4}$ receptor agonists as a treatment of any form of IBS.

Finally, the possibility that $5-\mathrm{HT}_{4}$ receptor activation might promote neurogenesis in adults has received support from studies using mice (increased bromodeoxyuridine incorporation into neurons, neural precursors, or stem cells; Liu et al., 2011), guinea pigs, and rats (regeneration of neural circuitry or recovery of reflex activity after rectal transection and anastomosis, accompanied by increased neurofilament and neural stem cell markers; Takaki et al.,
2014), suggesting potential use of $5-\mathrm{HT}_{4}$ receptor agonists in treatments of disorders associated with intestinal aganglia.

2. Other 5-HT Receptor Agonists. Different 5- $\mathrm{HT}_{1 \mathrm{~A}}$ receptor agonists, including buspirone, may reduce emesis induced by different stimuli in animals, including cisplatin and motion, although species differences in actions complicates the interpretation of data (Johnston et al., 2014). In patients with functional dyspepsia, repeat-dosing with the $5-\mathrm{HT}_{1 \mathrm{~A}}$ receptor agonist R137696 did not reduce dyspeptic symptoms or gastric accommodation (Tack et al., 2009).

When given acutely after meals to patients with functional dyspepsia, the $5-\mathrm{HT}_{1 \mathrm{~B} / 1 \mathrm{D}}$ receptor agonist sumatriptan delayed gastric emptying, improved gastric accommodation, and reduced the perception of gastric distension and early satiety (Tack et al., 2004). The suggestion that this receptor may be involved in the mechanisms of vomiting has not yet been resolved (Johnston et al., 2014), especially as sumatriptan may act on the yet to be defined $5-\mathrm{HT}_{1 \mathrm{P}}$ receptor.

Partial 5- $\mathrm{HT}_{3}$ receptor agonists (e.g., pumosetrag; CSTI-300) have been identified for treatment of patients with diarrhea-predominant IBS (e.g., Moore et al., 2013; Roberts et al., 2020). CSTI-300 displays comparable efficacy to alosetron in a rat model of colon distension (Roberts et al., 2020). Pumosetrag has been evaluated in patients with gastroesophageal reflux disease (Choung et al., 2014), reducing the rate of acid reflux events but not symptoms.

A summary of some 5-HT drugs in development for GI therapeutics is summarized in Table 22 and reviewed elsewhere (Valentin et al., 2015).

\section{5-HT Receptors and the Immune System}

\section{A. Introduction}

The defense against pathogens is mediated by innate and adaptive immune mechanisms that act in the periphery and the CNS. 5-HT regulates inflammation and immunity by acting on 5 -HT receptors that are differentially expressed on immune cells, both in rodents and humans. 5-HT acts as a potent chemoattractant, recruiting innate immune cells to sites of inflammation. 5-HT also alters the production and release of cytokines and cell activation/proliferation. Some immune cells, including mast cells and T lymphocytes, have the capacity to synthesize and release 5-HT, expanding the range of tissues for 5-HT signaling.

\section{B. How Do Immune Cells Encounter 5-HT?}

Although 5-HT is largely studied as a neurotransmitter, enterochromaffin cells of the gut produce most of the body's 5-HT that functions as a local hormone. These cells express tryptophan hydroxylase TPH1, a ratelimiting enzyme for 5-HT production (Walther et al., 2003). A second TPH isoform, TPH2, synthesizes 5-HT 
TABLE 22

Some novel 5-HT agents for GI indications

\begin{tabular}{|c|c|c|c|c|c|}
\hline Drug Class & Example & Putative Action in Humans & Pharmacodynamic in Humans & $\begin{array}{l}\text { Clinical Efficacy: Phase IIB } \\
\text { or III }\end{array}$ & Safety Issues, Approval, Other \\
\hline $\begin{array}{l}\mathrm{TPH}_{1} \\
\text { blocker }\end{array}$ & LX-1031 & $\begin{array}{c}\text { Inhibits synthesis of } 5-\mathrm{HT} \\
\text { by blocking } \mathrm{TPH}_{1}\end{array}$ & $\begin{array}{l}\text { Inhibition of urine 5-HIAA } \\
\text { excretion; no studies of PD } \\
\text { efficacy }\end{array}$ & $\begin{array}{l}\text { Phase IIB trial in non-C- } \\
\text { IBS: } 1000-\text { mg dose, } \\
\text { improved adequate relief, } \\
\text { stool consistency }\end{array}$ & Reported to be discontinued \\
\hline $\begin{array}{l}5-\mathrm{HT}_{3} \\
\text { receptor } \\
\text { antagonist }\end{array}$ & Ramosetron & $\begin{array}{l}\text { Inhibits secretion, motility, } \\
\text { nociception }\end{array}$ & ND & $\begin{array}{l}\text { Phase IIB } 5-\text { and } 10-\mu \mathrm{g} \text { dose } \\
\text { studies in IBS-D: benefit on } \\
\text { global relief and bowel } \\
\text { function }\end{array}$ & $\begin{array}{c}\text { Approved in Asia, under } \\
\text { investigation elsewhere; } \\
\text { ischemic colitis with same } \\
\text { drug class }\end{array}$ \\
\hline $\begin{array}{l}5-\mathrm{HT}_{4} \\
\text { receptor } \\
\text { agonist }\end{array}$ & Prucalopride & $\begin{array}{c}\text { Selective } 5-\mathrm{HT}_{4} \text { receptor } \\
\text { agonist; stimulates colonic } \\
\text { motility }\end{array}$ & $\begin{array}{c}\text { Accelerated CT in health } \\
\text { and CC }\end{array}$ & $\begin{array}{l}\text { Multiple phase II/III trials } \\
\text { completed; open label } \\
\text { experience of } \sim 1000 \\
\text { cumulative patient-years; } \\
\text { efficacy in CC (males and } \\
\text { females in phase III and IV } \\
\text { clinical trials), with } \\
\text { consistent benefits shown } \\
\text { by meta-analyses }\end{array}$ & $\begin{array}{l}\text { No clinical cardiac AEs in } \\
\text { clinical trials of }>4000 \\
\text { humans; approved in } \\
\text { virtually all countries } \\
\text { except United States }\end{array}$ \\
\hline $\begin{array}{l}5-\mathrm{HT}_{4} \\
\text { receptor } \\
\text { agonist }\end{array}$ & Velusetrag & $\begin{array}{c}\text { Selective } 5-\mathrm{HT}_{4} \text { receptor } \\
\text { agonist; stimulates colonic } \\
\text { motility }\end{array}$ & $\begin{array}{l}\text { Accelerated CT in health in } \\
\text { dose-related fashion }\end{array}$ & $\begin{array}{l}\text { Phase IIB efficacy; no effect } \\
\text { on QT in health or } \\
400 \text { patients with } \\
\text { constipation }\end{array}$ & $\begin{array}{c}\text { Under investigation } \\
\text { (although last report 2017) }\end{array}$ \\
\hline $\begin{array}{l}5-\mathrm{HT}_{4} \\
\text { receptor } \\
\text { agonist }\end{array}$ & Naronapride & $\begin{array}{l}\text { Selective } 5-\mathrm{HT}_{4} \text { receptor } \\
\text { agonist; stimulates colonic } \\
\text { motility }\end{array}$ & Accelerated CT in health & Under investigation & $\begin{array}{c}\text { Under investigation } \\
\text { (although last report 2018) }\end{array}$ \\
\hline $\begin{array}{l}5-\mathrm{HT}_{4} \\
\text { receptor } \\
\text { agonist }\end{array}$ & Relenopride & $\begin{array}{c}\text { Selective } 5 \text { - } \mathrm{HT}_{4} \text { receptor } \\
\text { agonist; stimulates colonic } \\
\text { motility }\end{array}$ & $\begin{array}{c}\text { Accelerated CT in } \\
\text { functional constipation }\end{array}$ & $\begin{array}{l}\text { Phase II studies ongoing in } \\
\text { IBS-C patients } \\
\text { (ClinicalTrials.gov trial } \\
\text { NCT02082457). }\end{array}$ & $\begin{array}{l}\text { May be discontinued (last } \\
\text { active report 2015) }\end{array}$ \\
\hline
\end{tabular}

AEs, adverse events; CC, chronic constipation; CT, colonic transit; ND, not determined.

in the CNS and gut enteric nerves (Walther et al., 2003). 5-HT concentrations in blood and tissues are normally kept relatively low. Immune cells, however, may encounter 5-HT released in the gut mucosa or from platelets that sequestered 5-HT via the 5-HT transporter SERT (SLC6A4). In turn, platelets can release accumulated 5-HT at sites of injury and inflammation. Platelet-derived 5-HT is important for attracting innate immune cells such as neutrophils to inflamed tissue (Duerschmied et al., 2013). In addition to platelets, dendritic cells (professional antigen-presenting cells) and B lymphocytes express SERT and, thus, accumulate and release 5-HT. Interestingly, recent studies indicate that some immune cells are capable of 5-HT biosynthesis. Mast cells (tissue-resident cells) in rodents and humans express TPH1, and levels of 5-HT are elevated in patients with mastocytosis, who have greatly elevated mast cell numbers (Kushnir-Sukhov et al. 2007; Nowak et al., 2012). Furthermore, T lymphocytes (O'Connell et al., 2006; León-Ponte et al. 2007; Urbina et al., 2014) also express TPH1 upon mitogen or T-cell receptor activation and can synthesize 5-HT. Interestingly, expression of TPH1 and 5-HT production is greater in $\mathrm{CD} 8^{+}$compared with $\mathrm{CD} 4^{+} \mathrm{T}$ cells (Chen et al., 2015).

\section{5-HT and Hematopoiesis}

It has been proposed that 5 -HT acts at hematopoietic stem cell progenitors directly or via modulation of the bone marrow microenvironment (Yang et al., 2007). Mice deficient in peripheral 5-HT $\left(T p h 1^{-1-}\right)$ display morphologic and cellular features reminiscent of ineffective erythropoiesis (Amireault et al., 2011). Other data show that the bone marrow composition of $\mathrm{Htr}_{2 B}^{-1-}$ mice displays a significant increase in $\mathrm{Cd} 11 \mathrm{~b}+/ \mathrm{Gr}+$ cells that represents granulocyte precursors. This is associated with a significant reduction in $\mathrm{Cd} 11 \mathrm{~b}-/ \mathrm{Cd} 31+$ population that corresponds to immature endothelial progenitor cells in 5- $\mathrm{HT}_{2 \mathrm{~B}}^{-1-}$ mice (Launay et al., 2012). These observations support the hypothesis that 5 -HT signaling controls the differentiation of myeloid precursor cells, particularly in the monocyte/macrophage lineages.

\section{5-HT and the Immune Tolerance}

One well documented way to control immunity and tolerance is through the regulation of nutrients in the microenvironment of immune cells. Best described is tryptophan deficiency mediated by the catabolic enzyme indoleamine 2,3-dioxygenase (IDO), which locally depletes tryptophan and liberates immunoregulatory metabolites known as kynurenines. T-cell activation is exquisitely sensitive to local tryptophan catabolism, and thus this enzyme exerts profound protective effects in allo-fetal rejection, autoimmunity, and inflammation (Munn and Mellor, 2013). Although IDO is thought to be the major tryptophan-catabolizing enzyme outside of the liver, TPH1 shares a similar $K_{\mathrm{M}}$ to IDO ( $\sim 20 \mu \mathrm{M})$ (Mckinney et al., 2005$)$ and can also 
potentially exhaust tryptophan to regulate immune tolerance. Indeed, in models of skin allograft tolerance, tumor growth, and experimental autoimmune encephalomyelitis (multiple sclerosis), Tph1 deficiency was shown to break allograft tolerance, to induce tumor remission, and to intensify neuroinflammation independent of the downstream product 5-HT (Nowak et al., 2012).

\section{E. 5-HT and the Innate Immune Response}

Innate immune system function involves monocytes, macrophages, dendritic cells, neutrophils, eosinophils, mast cells, and natural killer cells that act immediately in the area of infection, leading to the destruction of pathogens. Innate immunity is primarily responsible for recognizing and eradicating "nonself" molecules presented by pathogens and is therefore confined to recognizing extracellular pathogens (bacteria vs. viruses). This response is nonspecific with respect to particular invaders but provides immediate host defense against pathogens via pattern recognition by tolllike receptors (TLRs). Pathogen-associated molecular patterns (e.g., peptidoglycans, bacterial LPS, and double-stranded viral RNAs) bind TLRs on antigenpresenting cells, namely, dendritic cells and macrophages. Antigen-presenting cells then phagocytose pathogens and display pathogen-derived peptides via the major histocompatibility complex on their cell surface for recognition by leukocytes of the "adaptive" immune system. Antigen-presenting cells also secrete proinflammatory cytokines (e.g., IL1 $\beta$, IL-6, and $\mathrm{TNF} \alpha$ ), prostaglandins, and histamine, which further activate physiologic responses, alerting the body to infection/invasion. In addition to cellular protective mechanisms, innate immunity also includes the complement system, activated by foreign substances, antigen-antibody complexes (classic pathway), and Gram-negative bacteria (alternative pathway). This system leads to cell lysis, increased vascular permeability (allowing antibodies, innate immune cells, and fluid to enter tissues), and chemotaxis. The complement system also helps to activate antigen-presenting cells, namely, dendritic cells and $\mathrm{B}$ cells, during specific immune responses. Innate immunity also functions to communicate the presence of pathogens to cells involved in adaptive immune responses (Baganz and Blakely, 2013). The local environment and the presence of stimulatory signals determine whether monocytes acquire dendritic cell or macrophage characteristics and functions. 5-HT receptors are expressed by a broad range of inflammatory cell types, including monocytes, macrophages, and dendritic cells.

Neutrophils are the most abundant white blood cell and serve an essential role in innate immunity, particularly against bacteria. Duerschmied et al. (2013) reported that $T p h 1^{-1-}$ mice show mild leukocytosis (e.g., elevated white blood cells) numbers compared with WT mice, primarily driven by an elevated neutrophil count. Despite this, 50\% fewer leukocytes rolled on unstimulated mesenteric venous endothelium of $T p h 1^{-1-}$ mice. Diminished rolling in $T p h 1^{-/-}$mice resulted in reduced firm adhesion of leukocytes after LPS treatment, and neutrophil extravasation into lung, peritoneum, and skin wounds was reduced in $T p h 1^{-1-}$ mice. 5-HT alone did not induce neutrophil migration in vitro, suggesting that endothelial adhesion was the primary deficit. Consequently, survival from LPSinduced endotoxic shock was improved in $T p h 1^{-1-}$ mice. In conclusion, platelet 5 -HT promotes the recruitment of neutrophils in acute inflammation (Duerschmied et al., 2013); however, the nature of the 5-HT receptors underlying these effects is unknown.

In human CD14 monocytes, mRNA expression of $5-\mathrm{HT}_{1 \mathrm{E}}, 5-\mathrm{HT}_{2 \mathrm{~A}}, 5-\mathrm{HT}_{3}, 5-\mathrm{HT}_{4}$, and $5-\mathrm{HT}_{7}$ receptors has been revealed (Dürk et al., 2005). 5-HT modulates the release of IL- $1 \beta$, IL-6, IL-8/CXCL8, IL-12p40, and TNF- $\alpha$, whereas it has no effect on the production of IL-18 and IFN- $\gamma$ in LPS-stimulated human blood monocytes. Moreover, 5 -HT modulates mRNA levels of IL- 6 and IL-8/CXCL8 but not of IL- $1 \beta$ and TNF- $\alpha$. Pharmacologic experiments suggested that signaling through the $5-\mathrm{HT}_{3}$ receptor upregulates the LPSinduced production of IL-1 $\beta$, IL-6, and IL-8/CXCL8 but not that of TNF- $\alpha$ and IL-12p40. Furthermore, activation of the Gs-coupled $5-\mathrm{HT}_{4}$ and $5-\mathrm{HT}_{7}$ receptors increases secretion of IL-1 $\beta$, IL-6, IL-12p40, and IL-8/CXCL8, but in contrast, it inhibits LPS-induced $\mathrm{TNF}-\alpha$ release. Interestingly, $5-\mathrm{HT}_{1 \mathrm{E}}$ and $5-\mathrm{HT}_{2 \mathrm{~A}}$ receptor agonists do not modulate the LPS-induced cytokine production in human monocytes (Dürk et al., 2005). Instead, 5-HT modulates cytokine production via activation of $5-\mathrm{HT}_{3}, 5-\mathrm{HT}_{4}$, and $5-\mathrm{HT}_{7}$ receptors.

5 -HT has been shown to upregulate the activity of peritoneal macrophages and to increase the in vitro activity of phagocytosis in a concentration-dependent manner via $5-\mathrm{HT}_{1 \mathrm{~A} / 7}$ receptors and $\mathrm{NF}-\kappa \mathrm{B}$ (FreireGarabal et al., 2003). Gene expression profiling of proinflammatory M1 (granulate-macrophage colonystimulating factor) and anti-inflammatory M2 (macrophage colony-stimulating factor) macrophages revealed that $5-\mathrm{HT}_{2 \mathrm{~B}}$ and $5-\mathrm{HT}_{7}$ receptor mRNAs are preferentially expressed by M2 macrophages, whereas the $5-\mathrm{HT}_{7}$ receptor is the only 5 -HT receptor expressed in M1 macrophages (de Las Casas-Engel et al., 2013). The $5-\mathrm{HT}_{2 \mathrm{~B}}$ receptor is preferentially expressed by antiinflammatory M2 macrophages and is also detected in vivo in liver Kupffer cells and in tumor-associated macrophages. Expression of $5-\mathrm{HT}_{2 \mathrm{C}}$ receptors was also reported in alveolar macrophages, where 5 -HT induces a rise in intracellular $\mathrm{Ca}^{2+}$ concentration and an increased expression of CCL2 (monocyte chemoattractant protein-1) mRNA (Mikulski et al., 2010). LPS, the archetypal macrophage-activating stimulus that 
signals via TLR4, was shown to regulate the expression of $5-\mathrm{HT}_{2 \mathrm{~B}}$ receptors in mouse macrophages. 5 - $\mathrm{HT}_{2 \mathrm{~B}}$ receptor mRNA is increased 20-fold in murine thioglycollate-elicited peritoneal macrophages (Lattin et al., 2008). 5-HT was shown to inhibit the LPS-induced release of proinflammatory cytokines, to upregulate expression of macrophage M2 polarization-associated genes, and to reduce the expression of M1-associated genes. Only $5-\mathrm{HT}_{7}$ receptors mediate the inhibitory action of 5-HT on the release of proinflammatory cytokines. Both $5-\mathrm{HT}_{2 \mathrm{~B}}$ and $5-\mathrm{HT}_{7}$ receptors mediate the pro-M2 skewing effect of 5-HT. Blockade of both receptors during in vitro monocyte-to-macrophage differentiation preferentially modulates the acquisition of M2 polarization markers (de Las Casas-Engel et al., 2013).

In mice, it has been established that 5 -HT is an important regulator of microglia, the brain resident macrophages, which derive from yolk sac hematopoietic stem cell precursors. In the presence of 5 -HT, the microglial processes moved more rapidly toward a lesion, which is considered a chemotactic response. Similarly, the chemotactic response of cultured microglia to ATP is enhanced by 5-HT. Phagocytic activity determined by the uptake of microspheres reveals that 5-HT application decreases phagocytic activity of amoeboid microglia. The presence of microglial $5-\mathrm{HT}_{2 \mathrm{~B}}$, $5-\mathrm{HT}_{5 \mathrm{~A}}$, and $5-\mathrm{HT}_{7}$ receptors was confirmed by patchclamp experiments in culture and amoeboid microglia and by qPCR analysis of RNA isolated from primary cultured and acutely isolated adult microglia (Krabbe et al., 2012). This was recently confirmed by two-photon microscopy, showing that microglial processes moved rapidly toward the source of 5-HT via activation of the $5-\mathrm{HT}_{2 \mathrm{~B}}$ receptor (Kolodziejczak et al., 2015). Modulation of microglial functions such as phagocytosis and migration is fundamental for the CNS, as microglia can influence the balance of synaptogenesis and neuronal death during development and in pathology.

Platelet activation was reported in patients with various allergic disorders. Platelet-derived factors may influence monocytic differentiation into dendritic cells. Indeed, 5-HT alters differentiation of monocytes into dendritic cells (triggered by granulocyte-macrophage colony-stimulating factor and IL-4), leading to dendritic cells with reduced expression of costimulatory molecules and CD1a and higher expression of CD14. These 5-HT-triggered dendritic cells exhibit significantly reduced stimulatory activity toward allogeneic $\mathrm{T}$ cells. However, they show enhanced cytokine-producing capacity, including for IL-10 but not IL-12. 5-HT-induced alteration of the dendritic cells phenotype and the reduction in antigen-presenting capacity are mediated via $5-\mathrm{HT}_{1 \mathrm{E}} / 5-\mathrm{HT}_{7}$ receptors (Katoh et al., 2006).

Immature dendritic cells preferentially express mRNA for $5-\mathrm{HT}_{1 \mathrm{~B}}, 5-\mathrm{HT} 1 \mathrm{E}$, and $5-\mathrm{HT}_{2 \mathrm{~B}}$ receptors, whereas mature dendritic cells mostly express $5-\mathrm{HT}_{4}$ and $5-\mathrm{HT}_{7}$ receptors. The mRNA expression level of the ligand-gated cation channel $5-\mathrm{HT}_{3}$ and the GPCR $5-\mathrm{HT}_{2 \mathrm{~A}}$ receptors are not modified during maturation. 5-HT stimulates 5 - $\mathrm{HT}_{3}$-dependent $\mathrm{Ca}^{2+}$ influx in both immature and mature dendritic cells. The $5-\mathrm{HT}_{1 \mathrm{~B} / 1 \mathrm{E}}$ and $5-\mathrm{HT}_{2 \mathrm{~A} / 2 \mathrm{~B}}$ receptor stimulation induces intracellular $\mathrm{Ca}^{2+}$ mobilization via Gi/Gq proteins in immature, but not mature, dendritic cells. Activation of $5-\mathrm{HT}_{4 / 7}$ receptors induces cAMP elevation in mature dendritic cells. Functional studies indicate that activation of $5-\mathrm{HT}_{4}$ and $5-\mathrm{HT}_{7}$ receptors enhances the release of the cytokines IL- $1 \beta$ and IL- 8 while reducing the secretion of IL-12 and TNF- $\alpha$ in mature dendritic cells (Idzko et al., 2004).

5 -HT is able to induce oriented migration in immature but not in LPS-matured dendritic cells via activation of $5-\mathrm{HT}_{1 \mathrm{~B} / 1 \mathrm{E}}$ and $5-\mathrm{HT}_{2 \mathrm{~A} / 2 \mathrm{~B}}$ receptors. Accordingly, 5 -HT also increases migration of pulmonary dendritic cells to draining lymph nodes in vivo. By binding to $5-\mathrm{HT}_{3}, 5-\mathrm{HT}_{4}$, and $5-\mathrm{HT}_{7}$ receptors, 5 - $\mathrm{HT}$ upregulates the production of the proinflammatory cytokine IL-6. Additionally, 5-HT influenced chemokine release by human monocyte-derived dendritic cells: production of the potent T-helper cells Th1 chemoattractant IP-10/ CXCL10 was inhibited in mature dendritic cells, whereas CCL22/ macrophage-derived chemokine secretion was upregulated in both immature and mature dendritic cells. Furthermore, dendritic cells matured in the presence of 5-HT switched to a high IL-10 - and low IL-12p70secreting phenotype. Consistently, 5-HT favored the outcome of a Th2 immune response both in vitro and in vivo (Müller et al., 2009). A recent study using $\mathrm{Htr}_{7}^{-{ }^{-1}}$ mice confirmed $5-\mathrm{HT}_{7}$ receptor expression in $\mathrm{CD}_{103}{ }^{+} \mathrm{CD} 11 \mathrm{c}^{+}$ dendritic cells found in colon (and spleen) and its importance in immune activation and gut inflammation (Kim et al., 2013).

Interestingly, like platelets, dendritic cells can take up 5-HT from the microenvironment, and the antidepressant fluoxetine inhibits this uptake. Expression of 5-HT transporters (SERTs) is regulated by dendritic cell maturation, exposure to microbial stimuli, and physical interactions with T cells. Significantly, 5-HT sequestered by dendritic cells is stored within LAMP-1+ vesicles and subsequently released via $\mathrm{Ca}^{2+}$-dependent exocytosis, as confirmed by amperometric recordings (O'Connell et al., 2006).

5 -HT is chemotactic for eosinophils. Notably, allergic asthma is characterized by infiltration of eosinophils, and plasma levels of 5-HT are elevated in symptomatic asthma patients. There is solid evidence that $5-\mathrm{HT}$ contributes to this eosinophil recruitment. Indeed, 5-HT alone can stimulate in vitro migration of murine and human eosinophils (Boehme et al., 2004; Kang et al., 2013). Although several 5-HT receptor subtypes are expressed, $5-\mathrm{HT}_{2 \mathrm{~A}}$ is the most prominent, and $5-\mathrm{HT}_{2 \mathrm{~A}}$ receptor antagonists inhibit 5-HT-induced but not eotaxin-induced migration. Furthermore, eosinophils roll in response to 5-HT in venules under conditions of 
physiologic shear stress (Boehme et al., 2004; Kang et al., 2013). Signaling via $5-\mathrm{HT}_{2 \mathrm{~A}}$ receptors is associated with changes in cell shape/morphology via activation of specific intracellular signaling molecules (ROCK, MAPK, PI3K, and the PKC-calmodulin pathway) (Kang et al., 2013).

Mast cells have the capacity to synthesize and accumulate 5-HT (Kushnir-Sukhov et al., 2007). In turn, this stored 5-HT can be released upon IgE crosslinking. Furthermore, mast cells express mRNA for multiple 5-HT receptors, including $5-\mathrm{HT}_{1 \mathrm{~A}}, 5-\mathrm{HT}_{1 \mathrm{~B}}$, $5-\mathrm{HT}_{1 \mathrm{D}}, 5-\mathrm{HT}_{2 \mathrm{~A}}, 5-\mathrm{HT}_{2 \mathrm{~B}}, 5-\mathrm{HT}_{6}$, and $5-\mathrm{HT}_{7}$ receptors (Kushnir-Sukhov et al., 2006). 5-HT can induce mast cell adherence to fibronectin and stimulate cell migration. However, there is no evidence that 5-HT degranulates mast cells or modulates their activation by IgE. Mast cells from the $5-\mathrm{HT}_{1 \mathrm{~A}}$ receptor knockout mouse $\left(H \mathrm{Hr}_{1 A}^{-1-}\right)$ do not respond to 5-HT, indicating a principal role for this receptor. Importantly, 5-HT attracts mast cells to sites of inflammation; injection of 5 -HT into the skin enhances the accumulation of mast cells in wild-type but not in $5-\mathrm{HT}_{1 \mathrm{~A}}$ receptor-null mice.

Natural killer cells are large lymphocytes with innate killing capacity. Addition of 5-HT to mixtures of target cells and $\mathrm{CD} 6^{+}$natural killer-enriched human mononuclear cells strongly augmented natural killer cell cytotoxicity via 5 - $\mathrm{HT}_{1 \mathrm{~A}}$ receptors. This effect was indirect and involved 5-HT signaling at accessory monocytes. The cytotoxicity-enhancing effect of 5 -HT was additive to that induced by IFN- $\alpha$, IFN- $\gamma$, or IL- 2 but not to histamine (Hellstrand and Hermodsson, 1987).

\section{F. 5-HT and Adaptive Immunity}

The response of a second immune system division, termed the adaptive, or specific, immune system, occurs within hours of an infection and involves antigenspecific recognition and destruction of pathogens by $\mathrm{T}$ and B lymphocytes. The two components of the adaptive immune system involve cell-mediated and humoral immunity. Cell-mediated immunity is carried out by $\mathrm{T}$ cells located in the thymus, lymph nodes, and circulation. Antigen-presenting cells that migrate to lymph nodes will prime and educate $\mathrm{T}$ cells as to the nature of the pathogen. $\mathrm{T}$ cells then proliferate and differentiate into, for example, $\mathrm{CD} 4^{+}$T-helper inflammatory cells (Th1) that activate macrophages, CD4 ${ }^{+}$ Th2 cells that aid antibody responses, or $\mathrm{CD}^{+}$cytotoxic cells that target cells infected with intracellular microbes. The second component of adaptive immunity involves the contributions of B cells, located in lymph tissue, spleen, and in the circulation. Upon stimulation, B cells become plasma cells (with or without the help of Th2) that produce and secrete antibodies (immunoglobulins). Memory $\mathrm{T}$ and $\mathrm{B}$ cells recognize specific antigens and respond quickly. Thus, the adaptive immune system is distinguished from the innate immune system by its ability to identify, remember, and eliminate pathogens that have been designated as nonself. Adaptive immunity is triggered at the immune synapse, where peptide major histocompatibility complexes and costimulatory molecules expressed by dendritic cells are physically presented to $\mathrm{T}$ cells (Baganz and Blakely, 2013).

The mRNA expression of 5-HT receptors in lymphoid tissues of the rat, ex vivo isolated spleen, thymus, and peripheral blood lymphocytes include $5-\mathrm{HT}_{1 \mathrm{~B}}, 5-\mathrm{HT}_{1 \mathrm{~F}}$, $5-\mathrm{HT}_{2 \mathrm{~A}}, 5-\mathrm{HT}_{2 \mathrm{~B}}, 5-\mathrm{HT}_{6}$, and $5-\mathrm{HT}_{7}$ receptor mRNAs. Mitogen-stimulated spleen cells additionally expressed mRNA corresponding to the $5-\mathrm{HT}_{3}$ receptor (Stefulj et al., 2000). In the rhesus macaque, SERT-positive cells were found among $\mathrm{CD} 4^{+}, \mathrm{CD}^{+}$, and $\mathrm{CD}_{3}^{+} \mathrm{CD}^{+}$ lymphocytes, respectively (Yang et al., 2007). Fluoxetine significantly increases the number of lymphocytes expressing SERT and stimulates an enrichment of $\mathrm{CD}^{+} \mathrm{T}$ cells, decreasing the $\mathrm{CD} 4^{+} / \mathrm{CD}^{+}$ratio. Fluoxetine administration elevates the levels of IL-4 at 1, 2, and 3 weeks and of IL-2 at 2 and 3 weeks. The IL-4/IL-2 ratio is significantly increased in fluoxetine group compared with the controls and is similar during the 3 weeks of treatment (Fazzino et al., 2009).

There is long-standing evidence that 5-HT can influence T-cell activation. Notably, mice treated with a selective, irreversible inhibitor of TPH1, parachlorophenylalanine, exhibit a reduction in the number of CD25-positive T cells (Young et al., 1993; León-Ponte et al., 2007), suggesting that 5-HT contributes physiologically to T-cell activation. A screen for 5 -HT receptor subtypes in murine $\mathrm{T}$ cells revealed expression of three subtypes; naive $\mathrm{T}$ cells selectively express $5-\mathrm{HT}_{7}$ receptors, whereas following T-cell activation, there is a strong upregulation of $5-\mathrm{HT}_{1 \mathrm{~B}}$ and $5-\mathrm{HT}_{2 \mathrm{~A}}$ receptors (León-Ponte et al. 2007). Significantly, exogenous 5-HT induces rapid phosphorylation of ERK1/2 and $\mathrm{I} \kappa \mathrm{B} \alpha$ in naive $\mathrm{T}$ cells that is inhibited by preincubation with a selective $5-\mathrm{HT}_{7}$ receptor antagonist. Thus, 5-HT signaling via the $5-\mathrm{HT}_{7}$ receptor may contribute to early T-cell activation. Yin et al. (2006) showed that $5-\mathrm{HT}_{1 \mathrm{~B}}$ receptor antagonists impaired the proliferation of helper $\mathrm{CD} 4^{+} \mathrm{T}$ cells in mouse and human. Inoue et al. (2011) showed that a $5-\mathrm{HT}_{2 \mathrm{~A}}$ receptor agonist enhanced Concavalin-A-induced activation of murine $\mathrm{CD}^{+}$and $\mathrm{CD}^{+} \mathrm{T}$ cells, whereas a $5-\mathrm{HT}_{2 \mathrm{~A}}$ receptor antagonist blocked T-cell receptor-mediated IL-2 and interferon- $\gamma$ production. Consistent with these data, Akiyoshi et al. (2006) showed that treatment with a $5-\mathrm{HT}_{2 \mathrm{~A}}$ receptor antagonist enhanced the survival of cardiac allograft in mice. Thus, these mouse data strongly support involvement of $5-\mathrm{HT}$ receptors $\left(5-\mathrm{HT}_{7}, 5-\mathrm{HT}_{1 \mathrm{~B}}\right.$, and $\left.5-\mathrm{HT}_{2 \mathrm{~A}}\right)$ during early- and late-stage T-cell activation.

Interestingly, although not detected in mouse, the $5-\mathrm{HT}_{2 \mathrm{~B}}$ receptor is found in human $\mathrm{T}$ cells. Gene expression profiles during human $\mathrm{CD} 4^{+} \mathrm{T}$-cell differentiation identified the $5-\mathrm{HT}_{2 \mathrm{~B}}$ receptor with 10 -fold greater expression in $\mathrm{CD} 3{ }^{\text {high }} \mathrm{CD} 4^{+} \mathrm{CD} 8^{-}$ 
SP4 thymocytes over intrathymic T progenitor cells, $\mathrm{CD}^{-} \mathrm{CD}^{+} \mathrm{CD}^{+}$"double positive" thymocytes, $\mathrm{CD}^{+}{ }^{+} \mathrm{CD} 4{ }^{+} \mathrm{CD}^{-}{ }^{-} \mathrm{CD} 45 \mathrm{RA}^{+} \mathrm{CD} 62 \mathrm{~L}^{+}$"naive" $\mathrm{T}$ cells from cord blood, and $\mathrm{CD} 3^{+} \mathrm{CD} 4^{+} \mathrm{CD} 8^{-} \mathrm{CD} 45 \mathrm{RA}^{+} \mathrm{CD} 62 \mathrm{~L}^{+}$ "naive" $\mathrm{T}$ cells from adult blood (Lee et al., 2004). Furthermore, 5- $\mathrm{HT}_{2 \mathrm{~B}}$ receptors are differentially expressed among Th subsets. In human umbilical cord blood, Th cells cultured in the presence of cytokines promoting Th2 differentiation were found to increase $5-\mathrm{HT}_{2 \mathrm{~B}}$ receptor expression along with $50 \mathrm{Th} 2$ differentially expressed genes (Aijö et al., 2012).

5 -HT may also modulate migration of human T cells. Human but not mouse $\mathrm{T}$ cells express functional $5-\mathrm{HT}_{3}$ receptors. $5-\mathrm{HT}_{3}$ receptor agonists selectively decrease T-cell migration toward gradients of the chemokine CXCL12 but not to other chemokines such as CCL2 and CCL5. Interestingly, CXCL12 is highly expressed on vascular endothelium and inhibits T-cell migration across endothelium and extravasation. In transmigration experiments, $5-\mathrm{HT}_{3}$ receptor stimulation reverses this effect of endothelial-bound CXCL12 on T-cell migration (Magrini et al., 2011). These data suggest that 5 -HT can stimulate trafficking of $\mathrm{T}$ cells from blood to tissues.

$\mathrm{T}$ cells have the capacity to synthesize 5 -HT, and levels of TPH1 expression increase following T-cell activation (O'Connell et al., 2006; León-Ponte et al. 2007; Urbina et al., 2014; Chen et al., 2015). The precise signaling role for T-cell-produced 5 -HT is uncertain. Conceivably, TPH1 activity in T cells could act to exhaust tryptophan, as has been proposed for mast cells (Nowak et al., 2012). On the other hand, 5-HT produced by $\mathrm{T}$ cells might act in an autocrine or paracrine manner. Indeed, $\mathrm{T}$ cells express the type 1 vesicular monoamine transporter responsible for vesicular storage of 5 -HT, and type 1 vesicular monoamine transporter expression increases following T-cell activation concomitant with TPH1. Furthermore, $\mathrm{Ca}^{2+}$ elevations in $\mathrm{T}$ cells can trigger secretion of $5-\mathrm{HT}$. Interestingly, levels of TPH1 and monoamine oxidase A, the principal catabolic enzyme for 5-HT, are greater in $\mathrm{CD}^{+}$compared with $\mathrm{CD} 4^{+} \mathrm{T}$ cells, suggesting a specific biologic role for 5-HT synthesis in this T-cell subset (Chen et al., 2015). B lymphocytes have the capacity to sense and sequester 5 -HT via SERT. 5 -HT increases mitogen-stimulated $\mathrm{CD}^{+}{ }^{+} \mathrm{B}$ lymphocyte proliferation in a concentration- and time-dependent manner. These effects are reproduced by a $5-\mathrm{HT}_{1 \mathrm{~A}}$ receptor agonist. 5-HT-induced increases in proliferation are blocked by $5-\mathrm{HT}_{1 \mathrm{~A}}$ receptor antagonists. Moreover, LPS-activated mouse spleen cells express specific binding sites for $5-\mathrm{HT}_{1 \mathrm{~A}}$ receptor, suggesting that 5 - $\mathrm{HT}$ upregulates mitogen-stimulated B lymphocyte proliferation through $5-\mathrm{HT}_{1 \mathrm{~A}}$ receptors (Iken et al., 1995). Furthermore, mitogen-activated B lymphocytes express higher levels of $5-\mathrm{HT}_{1 \mathrm{~A}}$ receptor $\mathrm{mRNA}$ and protein than resting cells. This upregulation is seemingly dependent on NF- $\kappa$ B transcription factors, as selective inhibitors of this pathway prevent the increase in mRNA expression for the 5-HT $1 \mathrm{~A}$ receptor (Abdouh et al., 2001).

B lymphocytes express SERT, and uptake of 5-HT leads to apoptosis of Burkitt lymphoma cells (Serafeim et al., 2002). 5-HT may induce apoptosis via the intracellular serotonylation signaling pathway. Furthermore, long-term treatment with SSRIs in humans leads to enhanced $(\sim 30 \%)$ numbers of B lymphocytes (Hernandez et al., 2010). Interestingly, higher doses of SSRIs directly promote apoptosis of Burkitt lymphoma cells by inhibiting DNA synthesis, whereas normal peripheral and tonsilar B cells are relatively resistant to SSRI-induced apoptosis (Serafeim et al., 2003). SERT has been detected in a variety of B-cell lines (Meredith et al., 2005), revealing SERT as a potential target for a broad range of B-cell malignancies.

\section{General Summary and Conclusions}

The first official IUPHAR review on 5-HT receptors (Hoyer et al., 1994) was a landmark for the then rather complex 5-HT receptor field: it has come of age and has been cited well over 3600 times (Google Scholar). It followed a number of initiatives and meetings in the late $1980 \mathrm{~s}$, when the 5 -HT receptor nomenclature committee was established (by our esteemed colleague and friend Paul Vanhoutte in 1987, who sadly died in 2019). The committee was constituted and met formally for the first time in 1990 at the occasion of the 5-HT meeting in Basel (a satellite to the 1990 IUPHAR main meeting); a number of recommendations were made adapting to the new findings in transduction mechanisms and molecular biology of the receptors over the subsequent decade (Humphrey et al., 1993a; Hoyer et al., 1994, 2002; Hartig et al., 1996; Hoyer and Martin, 1997; Martin et al., 1998). It is remarkable that the recommendations made at the time have been largely accepted by a community that was used to very different nomenclatures or even definitions of receptors and that very little needed to be changed or added to these recommendations (Alexander et al., 2015a,b,c; 2019). In the 1994 review, it was noted that the authors had a cumulated 100 years of active 5-HT research to share. A number of our colleagues have in the meantime retired from active research or have moved to other professional priorities. There is a lot of new "blood" now on board to reflect the growing diversity of the research, which is currently performed in many different academic and SME (small or medium enterprise) pharmaceutical centers; the combined years in 5-HT research accumulated by the authorship has increased because of the considerably greater number of authors on the present paper to address a more diverse range of complex issues.

What has clearly changed, though, is the relative representation from the industry, which compared with the 1994 version, is very much reduced. In 1994, there were six out of the eight authors who worked in "Big Pharma," whereas there are none for the present 
review. This is explained by the lesser interest for exploratory 5-HT research in the industry on the one hand, with less emphasis on 5-HT translational research and a shift of research toward small or medium enterprise/Biotech; on the other hand, there is an increased interest in very basic aspects of 5-HT research, such as structural biology or the more recent advances in the immunologic aspects, which were hardly addressed in the previous review of 1994. The shift in emphasis and thus authorship was very much needed, as the 5-HT receptor field has become more complex and possibly less the subject of "classical" pharmacologists as it was in the latter decades of the last century.

The apparent good news is that no new receptors have been identified, except for some additional $5-\mathrm{HT}_{3}$ receptor subunits whose function still remain to be defined clearly. On the other hand, there have been major advances with respect to $5-\mathrm{HT}_{1 \mathrm{~B} / 1 \mathrm{D}}$ receptors; as far as can be told, all triptans act as $5-\mathrm{HT}_{1 \mathrm{~B} / 1 \mathrm{D}}$ receptor agonists, and in the meantime, many different triptans have reached the market primarily for the acute treatment of migraine. Some of them, such as sumatriptan, may also act as $5-\mathrm{HT}_{1 \mathrm{~F}}$ receptor agonists. Thus, the $5-\mathrm{HT}_{1 \mathrm{~B}}$ receptor is most probably the main and sole target for triptans in the treatment of migraine, whereas the $5-\mathrm{HT}_{1 \mathrm{D}}$ receptor, which is comparatively less abundant, may only play a minor role. Indeed, a study in migraine with a selective $5-\mathrm{HT}_{1 \mathrm{D}}$ receptor agonist (PNU142633) was not conclusive; it can be argued that the compound was only a partial agonist and that target engagement may not have been optimal. Thus, the jury is still out to define a role for the $5-\mathrm{HT}_{1 \mathrm{D}}$ receptor in physiology and disease. Because of the triptans, of which many starting with sumatriptan have affinity, the $5-\mathrm{HT}_{1 \mathrm{~F}}$ receptor has attracted quite some attention, and there is clinical evidence (with lasmidi$\tan$ ) that this constitutes another target for the treatment of migraine. This is especially true for patients who want to avoid vascular side effects, as in contrast to the $5-\mathrm{HT}_{1 \mathrm{~B}}$ receptor, the $5-\mathrm{HT}_{1 \mathrm{~F}}$ receptor is not expressed in vascular tissues. The $5-\mathrm{HT}_{1 \mathrm{~A}}$ receptor is still actively investigated, especially because newer highly selective $5-\mathrm{HT}_{1 \mathrm{~A}}$ receptor ligands show very different patterns of pathway selectivity and thus may have clinical application in diseases as different as chronic pain, Parkinson disease, or Rett Syndrome and other forms of autistic disorders/mental retardation, as illustrated by the relatively recent FDA approval for compounds such as flibanserin, cariprazine, vortiotexine for the treatment of female sexual desire deficit, schizophrenia, and depression, respectively. Although these compounds have other activities, they all share $5-\mathrm{HT}_{1 \mathrm{~A}}$ receptor agonism with possible differences in receptor engagement in different brain regions. An interesting aspect with some of the newer $5-\mathrm{HT}_{1 \mathrm{~A}}$ receptorligands is their variety of activities at different transduction systems (i.e., these compounds have various degrees of biased agonism or signaling). This is not unique to $5-\mathrm{HT}_{1 \mathrm{~A}}$ receptors, as probably most $5-\mathrm{HT}$ GPCR agonists show different levels of biased signaling depending on their preferential activation of one or the other multiple combinations of receptor/G protein and accessory proteins. This has become even more evident now that crystal structures exist for both $5-\mathrm{HT}_{1 \mathrm{~B}}$ and $5-\mathrm{HT}_{2 \mathrm{~B}}$ receptors, which show that various ligands can occupy different conformation in the same orthosteric pocket, which may explain why certain $5-\mathrm{HT}_{2 \mathrm{~A}}$ receptor agonists produce hallucinations when others do not. In addition, it has become evident that the orthosteric binding pocket is not the unique target for ligands, since a number of ergolines (e.g., ergotamine or DHE) may bind an accessory (allosteric site?), which has been well described for some metabotropic GPCRs (e.g., mGlu or GABA $_{B}$ receptors), opening the possibility for allosteric 5-HT receptor modulators (some of which have already been proposed for, for example, $5-\mathrm{HT}_{1 \mathrm{~B} / 1 \mathrm{D}}$ or $5-\mathrm{HT}_{3}$ receptors).

The aspect of species differences is a recurrent theme, as illustrated by the amply documented and well accepted differences in the pharmacology of $5-\mathrm{HT}_{1 \mathrm{~B}}$ receptors (explained by a single amino acid change in the core structure of the ligand-binding site) or the multiple differences observed with splice variants of the $5-\mathrm{HT}_{4}$ or $5-\mathrm{HT}_{7}$ receptors. A potential function for the $5-\mathrm{ht}_{1 \mathrm{e}}$ receptor in native tissue or cells is still to be identified; absence from rodents hinders the research and has made 5 -ht $_{1 \mathrm{e}}$ receptor drug discovery relatively unattractive in the absence of a link to disease. A similar point can be made about the $5-\mathrm{HT}_{5}$ receptors, in which both a relative lack of tools and the absence of a link to disease also hinder progress, although recent advances in knowledge concerning the $5-\mathrm{HT}_{5 \mathrm{~A}}$ receptor may promote further research. However, as the $5-\mathrm{ht}_{5 \mathrm{~B}}$ receptor appears to be nonfunctional in humans, this likely prevents interest as a therapeutic target.

Significant progress has been made in the $5-\mathrm{HT}_{2}$ receptor family. The potential role played by $5-\mathrm{HT}_{2 \mathrm{~B}}$ receptors in valvulopathies led to many of the drugs acting as agonists at these receptors being withdrawn from the market since the early 2000s (fenfluramine, norfenfluramine, benfluorex, and pergolide), keeping in mind that MDMA ("ecstasy") and its active metabolites act as $5-\mathrm{HT}_{2 \mathrm{~B}}$ receptor agonists, as may also be the case for a number of "designer" drugs. As a consequence, there is significant emphasis on screening for $5-\mathrm{HT}_{2 \mathrm{~B}}$ receptor agonism in preclinical safety studies and the "red flag" on further clinical development of such compounds. It has been established that the $5-\mathrm{HT}_{2 \mathrm{C}}$ receptor comes in a variety of edited forms (up to 24 possible variants in the human brain) that may be linked to disease (e.g., depression, suicide, impulsivity, addiction, spinal cord injury, and obesity as induced by some antipsychotic drugs). The edited forms of the receptor can display different coupling ability, lower affinity for agonists, and lower constitutive activity 
compared with the nonedited isoform that can couple to multiple $\mathrm{G}$ proteins. In addition, both agonists (lorcaserin) and antagonists (agomelatine) have been/are being developed to treat obesity/schizophrenia/addiction and depression/generalized anxiety disorder, respectively. Interestingly, in spinal cord injury, the $5-\mathrm{HT}_{2 \mathrm{C}}$ receptor is less edited and expression is increased, resulting in constitutive activity and muscle spasms in the absence of any endogenous 5-HT, which can be reversed by inverse 5 - $\mathrm{HT}_{2 \mathrm{C}}$ receptor antagonists. The $5-\mathrm{HT}_{2 \mathrm{~A}}$ receptor may be less investigated, as early claims that linked $5-\mathrm{HT}_{2 \mathrm{~A}}$ to hypertension or sleep did not result in clinical success. However, it should be kept in mind that all three, $5-\mathrm{HT}_{2 \mathrm{~A}}, 5-\mathrm{HT}_{2 \mathrm{~B}}$, and $5-\mathrm{HT}_{1 \mathrm{~B}}$, receptors play a role in pulmonary hypertension, a disease with unmet need for treatment, as neither endothelin antagonists nor PDE inhibitors are highly effective, although commonly prescribed. On another note, $5-\mathrm{HT}_{2 \mathrm{~B}}$ receptors appear to play a significant role in fibrosis, be it in the lung, liver, and especially the heart. $5-\mathrm{HT}_{2 \mathrm{~A}}$ receptor antagonism is a major component of second-generation antipsychotics (in combination with dopamine $\mathrm{D}_{2}$ receptor antagonism and often many other pharmacological activities, e.g., blonanserin), and there is evidence that a $5-\mathrm{HT}_{2 \mathrm{~A}}$ receptor antagonist may show efficacy in certain subpopulations of schizophrenic patients. It may also be relevant that the 5-HT-glutamate link in schizophrenia may be related to the existence of heterodimers between $5-\mathrm{HT}_{2 \mathrm{~A}}$ and $\mathrm{mGlu}_{2}$ receptors, although in vivo proof of concept remains to be established. Along these lines, there is evidence that $5-\mathrm{HT}_{2 \mathrm{~A}}$ receptors are able to form homodimers, similarly to $5-\mathrm{HT}_{1 \mathrm{~B}}$ or $5-\mathrm{HT}_{1 \mathrm{D}}$ receptors; however, the latter two may also form heterodimers, which may explain the codistribution that has been consistently observed for these two receptors. The $5-\mathrm{HT}_{2 \mathrm{C}}$ receptor is also capable of dimerization in vitro; it may even form tetra or octamers, and it may form heteromers with the ghrelin or the melatonin 2 receptor.

Clearly, receptor homo- and heterodimerization is an ongoing subject of interest with respect to 5-HT receptors. In addition to information incorporated within relevant sections of this review, the reader is also directed to specialized papers on this subject (e.g., Lee et al., 2000; Herrick-Davis, 2013; Moreno et al., 2016; Moutkine et al., 2017; Maroteaux et al., 2019).

In the $5-\mathrm{HT}_{3}$ receptor field, similarly to what has been long known and accepted for other members of the Cysloop ligand-gated ion channel superfamily (e.g., nicotine acetylcholine receptors), homomeric and heteromeric $5-\mathrm{HT}_{3}$ receptors are evident, and new receptor molecular isoforms are still being investigated. Clinically, alosetron has been developed for the treatment of IBS with diarrhea, in contrast to $5-\mathrm{HT}_{4}$ receptor agonists, for which the primary indication remains IBS with constipation or primary constipation in spite of the withdrawal of tegaserod from most markets. Obviously, the antiemetic effects of $5-\mathrm{HT}_{3}$ receptor antagonists, whether in the short term or in the longer term following chemotherapy or possibly surgically induced, are still a very salient feature of these drugs, even if, in the meantime, combination therapy (with, e.g., NK1 receptor antagonists) becomes the accepted treatment. There has been a lot of research dealing with $5-\mathrm{HT}_{6}$ receptor antagonists in memory/dementia (e.g., idalopirdine), although the phase III clinical data has been disappointing, whereas the $5-\mathrm{HT}_{7}$ receptor is somewhat less actively investigated as a clinical target. The mystery of the putative $5-\mathrm{HT}_{1 \mathrm{P}}$ receptor in the gastrointestinal tract remains, although heterodimerization remains a favored potential explanation, albeit without clear direct evidence.

The more troubling news is that whereas receptors used to be defined based on structural, operational, and transductional features, it becomes clear that some refinements are needed:

1) In terms of structural knowledge, progress has been relatively slow. X-ray diffraction data from crystals exist for the $5-\mathrm{HT}_{3}$ receptor and also, for example, the $5-\mathrm{HT}_{1 \mathrm{~B}}$ and $5-\mathrm{HT}_{2 \mathrm{~B}}$ receptors. One of the limitations of this approach for GPCRs is that the conformation of the ligand-receptor complex is very much dependent on the $\mathrm{G}$ protein heterotrimer associated with the receptor. In more recent years, we have learned that many receptors are able to couple to various pathways and even are able to signal in the absence of $G$ proteins. In addition, there are multiple GPCRinteracting proteins that may affect both signal transduction and receptor-ligand conformation, thus the pharmacological signature.

2) The operational definition of a receptor (pharmacological profile based on rank orders of affinity of agonists and antagonists), which was the primary feature of receptors up to the 1990s, is now recognized as increasingly complex because of the dependence on the G protein associated with the receptor under study and other GPCR-interacting proteins. Indeed, a number of drugs will have different affinities and potencies depending on the transduction system studied. Such variations may seem artificial and linked to the expression of receptors and transduction components in engineered cells, but we know that an endogenously expressed receptor can react very differently to a given ligand in a cell- and system-dependent manner (e.g., $5-\mathrm{HT}_{4}$ receptors in the GIT). Thus, the concept of functional selectivity or biased agonism/antagonism is a reality (see so-called $\beta$-blockers, which have rather different clinical features depending on their signaling characteristics, e.g., carvedilol compared with propranolol, pindolol, and nadolol). In contrast to other receptors, such as 
muscarinic or GABA receptors, there is little research addressing allosteric modulation for 5 -HT receptors, with the possible exception of the $5-\mathrm{HT}_{3}$ receptor. However, it becomes clear from X-ray structural studies performed with some ergolines that in addition to the classic orthosteric binding pocket, some 5-HT receptors have an extended binding "site," which is very reminiscent of that described for muscarinic allosteric ligands. Such molecular targets may offer attractive strategies for novel therapeutics.

The relatively recently recognized importance of the microbiome continues to grow (Gilbert et al., 2018), and one aspect of this relevant to the present paper is the regulation of 5-HT receptors by bacteria-derived metabolites (e.g., Yano et al., 2015; Bhattarai et al., 2017; Cohen et al., 2017); understanding the "physiologic" and "pathologic" consequences of such modulation will no doubt provide impetus for developing therapeutic strategies harnessing these mechanisms.

In conclusion, it is a clear understatement to say a lot has been learned since 1994, but still some old questions remain unanswered, and many new questions will keep 5-HT researchers busy for years to come. Although 5-HT / serotonin / enteramine was only discovered and characterized a little more than 70-80 years ago (Viali and Erspamer, 1933; Rapport et al., 1947, 1948; Erspamer and Asero, 1952; Twarog and Page, 1953), 5-HT, its receptors, enzymes, transporters and multiple accessory proteins, constitute one of the oldest transmitter systems, estimated to have originated about 800 million years ago; hence it had time to develop a certain level of complexity. The appreciated complexity of the 5-HT system relates less to the number of 5 -HT receptor classes, families, and subtypes, which was, per se, a conceptual challenge for some researchers in the 1980 s and 1990s, than to the actual complex nature of the ligand/receptor/G protein/arrestin and/or other interacting protein complexes that vary according to species, organ, cells, gender, and disease state. This intricacy renders the pharmacological definition of a given receptor, or a ligand, challenging, as it may all depend on the nature and environment of the supramolecular complex, which is being specifically addressed.

\section{Acknowledgments}

We thank Dr. Michael Klein for contributing to the section concerning the 5 -ht $_{1 \mathrm{e}}$ receptor. We thank Gail Green, personal assistant to N.M.B., for help and support. R.M.H. and K.A.C. extend thanks to Marcy Bubar Jordan for her editorial assistance.

\section{Authorship Contributions}

Wrote or contributed to the writing of the manuscript: Barnes, Ahern, Becamel, Bockaert, Camilleri, Chaumont-Dubel, Claeysen, Cunningham, Fone, Gershon, Di Giovanni, Goodfellow, Halberstadt,
Hartley, Hassaine, Herrick-Davis, Hovius, Lacivita, Lambe, Leopoldo, Levy, Lummis, Marin, Maroteaux, McCreary, Nelson, Neumaier, Newman-Tancredi, Nury, Roberts, Roth, Roumier, Sanger, Teitler, Sharp, Villalón, Vogel, Watts, Hoyer.

\section{References}

Abbas AI, Hedlund PB, Huang XP, Tran TB, Meltzer HY, and Roth BL (2009a) Amisulpride is a potent 5-HT7 antagonist: relevance for antidepressant actions in vivo. Psychopharmacology (Berl) 205:119-128.

Abbas AI, Urban DJ, Jensen NH, Farrell MS, Kroeze WK, Mieczkowski P, Wang Z, and Roth BL (2010) Assessing serotonin receptor mRNA editing frequency by a novel ultra high-throughput sequencing method. Nucleic Acids Res 38:e118.

Abbas AI, Yadav PN, Yao WD, Arbuckle MI, Grant SG, Caron MG, and Roth BL (2009b) PSD-95 is essential for hallucinogen and atypical antipsychotic drug actions at serotonin receptors. J Neurosci 29:7124-7136.

Abdala AP, Bissonnette JM, and Newman-Tancredi A (2014a) Pinpointing brainstem mechanisms responsible for autonomic dysfunction in Rett syndrome: therapeutic perspectives for 5-HT1A agonists. Front Physiol 5:205.

Abdala AP, Dutschmann M, Bissonnette JM, and Paton JF (2010) Correction of respiratory disorders in a mouse model of Rett syndrome. Proc Natl Acad Sci USA 107:18208-18213.

Abdala AP, Lioy DT, Garg SK, Knopp SJ, Paton JF, and Bissonnette JM (2014b) Effect of Sarizotan, a 5-HT1a and D2-like receptor agonist, on respiration in three mouse models of Rett syndrome. Am J Respir Cell Mol Biol 50:1031-1039.

Abdouh M, Storring JM, Riad M, Paquette Y, Albert PR, Drobetsky E, and Kouassi E (2001) Transcriptional mechanisms for induction of 5-HT1A receptor mRNA and protein in activated B and T lymphocytes. J Biol Chem 276:4382-4388.

Abdul-Monim Z, Neill JC, and Reynolds GP (2007) Sub-chronic psychotomimetic phencyclidine induces deficits in reversal learning and alterations in parvalbuminimmunoreactive expression in the rat. $J$ Psychopharmacol 21:198-205.

Abdul-Monim Z, Reynolds GP, and Neill JC (2006) The effect of atypical and classical antipsychotics on sub-chronic PCP-induced cognitive deficits in a reversal-learning paradigm. Behav Brain Res 169:263-273.

Abramowski D, Rigo M, Duc D, Hoyer D, and Staufenbiel M (1995) Localization of the 5-hydroxytryptamine2C receptor protein in human and rat brain using specific antisera. Neuropharmacology 34:1635-1645.

Abramowski D and Staufenbiel M (1995) Identification of the 5-hydroxytryptamine2C receptor as a $60-\mathrm{kDa} \mathrm{N}$-glycosylated protein in choroid plexus and hippocampus. $J$ Neurochem 65:782-790.

Adam K and Oswald I (1989) Effects of repeated ritanserin on middle-aged poor sleepers. Psychopharmacology (Berl) 99:219-221.

Adayev T, Ray I, Sondhi R, Sobocki T, and Banerjee P (2003) The G protein-coupled 5 -HT1A receptor causes suppression of caspase-3 through MAPK and protein kinase Calpha. Biochim Biophys Acta 1640:85-96.

Adell A and Artigas F (1998) A microdialysis study of the in vivo release of 5-HT in the median raphe nucleus of the rat. Br J Pharmacol 125:1361-1367.

Adham N, Bard JA, Zgombick JM, Durkin MM, Kucharewicz S, Weinshank RL, and Branchek TA (1997) Cloning and characterization of the guinea pig 5-HT receptor subtype: a comparison of the pharmacological profile to the human species homolog. Neuropharmacology 36:569-576.

Adham N, Borden LA, Schechter LE, Gustafson EL, Cochran TL, Vaysse PJ, Weinshank RL, and Branchek TA (1993a) Cell-specific coupling of the cloned human $5-\mathrm{HT}_{1 \mathrm{~F}}$ receptor to multiple signal transduction pathways. Naunyn Schmiedebergs Arch Pharmacol 348:566-575.

Adham N, Kao HT, Schecter LE, Bard J, Olsen M, Urquhart D, Durkin M, Hartig PR, Weinshank RL, and Branchek TA (1993b) Cloning of another human serotonin receptor $\left(5-\mathrm{HT}_{1 \mathrm{~F}}\right)$ : a fifth $5-\mathrm{HT}_{1}$ receptor subtype coupled to the inhibition of adenylate cyclase. Proc Natl Acad Sci USA 90:408-412.

Adham N, Romanienko P, Hartig P, Weinshank RL, and Branchek T (1992) The rat 5-hydroxytryptamine $1 \mathrm{~B}$ receptor is the species homologue of the human 5-hydroxytryptamine ${ }_{1 \mathrm{D}}$ beta receptor. Mol Pharmacol 41:1-7.

Adham N, Tamm JA, Salon JA, Vaysse PJ, Weinshank RL, and Branchek TA (1994a) A single point mutation increases the affinity of serotonin $5-\mathrm{HT}_{1 \mathrm{D} \text { alpha }}, 5-\mathrm{HT}_{1 \mathrm{D}}$ beta, $5-\mathrm{HT}_{1 \mathrm{E}}$ and $5-\mathrm{HT}_{1 \mathrm{~F}}$ receptors for beta-adrenergic antagonists. Neuropharmacology 33:387-391.

Adham N, Vaysse PJ, Weinshank RL, and Branchek TA (1994b) The cloned human $5-\mathrm{HT}_{1 \mathrm{E}}$ receptor couples to inhibition and activation of adenylyl cyclase via two distinct pathways in transfected BS-C-1 cells. Neuropharmacology 33:403-410.

Adham N, Zgombick JM, Bard J, and Branchek TA (1998) Functional characterization of the recombinant human 5-hydroxytryptamine7(a) receptor isoform coupled to adenylate cyclase stimulation. J Pharmacol Exp Ther 287:508-514.

Adriani W, Travaglini D, Lacivita E, Saso L, Leopoldo M, and Laviola G (2012) Modulatory effects of two novel agonists for serotonin receptor 7 on emotion, motivation and circadian rhythm profiles in mice. Neuropharmacology 62:833-842.

Afzal F, Andressen KW, Mørk HK, Aronsen JM, Sjaastad I, Dahl CP, Skomedal T, Levy FO, Osnes JB, and Qvigstad E (2008) 5- $\mathrm{HT}_{4}$-elicited positive inotropic response is mediated by cAMP and regulated by PDE3 in failing rat and human cardiac ventricles. Br J Pharmacol 155:1005-1014.

Aghajanian GK and Marek GJ (1997) Serotonin induces excitatory postsynaptic potentials in apical dendrites of neocortical pyramidal cells. Neuropharmacology 36:589-599.

Ahn SK, Khalmuratova R, Jeon SY, Kim JP, Park JJ, Hur DG, and Balaban CD (2009) Colocalization of $5-\mathrm{HT}_{1 \mathrm{~F}}$ receptor and calcitonin gene-related peptide in rat vestibular nuclei. Neurosci Lett 465:151-156.

Aijö T, Edelman SM, Lönnberg T, Larjo A, Kallionpää H, Tuomela S, Engström E, Lahesmaa R, and Lähdesmäki H (2012) An integrative computational systems biology approach identifies differentially regulated dynamic transcriptome signatures which drive the initiation of human T helper cell differentiation. BMC Genomics 13:572. 
Aira Z, Buesa I, García del Caño G, Bilbao J, Doñate F, Zimmermann M, and Azkue JJ (2013) Transient, $5-\mathrm{HT}_{2 \mathrm{~B}}$ receptor-mediated facilitation in neuropathic pain: up-regulation of $\mathrm{PKC} \gamma$ and engagement of the NMDA receptor in dorsal horn neurons. Pain 154:1865-1877.

Aira Z, Buesa I, García del Caño G, Salgueiro M, Mendiable N, Mingo J, Aguilera L, Bilbao J, and Azkue JJ (2012) Selective impairment of spinal mu-opioid receptor mechanism by plasticity of serotonergic facilitation mediated by 5 -HT2A and $5-\mathrm{HT}_{2 \mathrm{~B}}$ receptors. Pain 153:1418-1425.

Aira Z, Buesa I, Rada D, Gómez-Esteban JC, and Azkue JJ (2014) Coupling of serotonergic input to NMDA receptor-phosphorylation following peripheral nerve injury via rapid, synaptic up-regulation of ND2. Exp Neurol 255:86-95.

Aira Z, Buesa I, Salgueiro M, Bilbao J, Aguilera L, Zimmermann M, and Azkue JJ (2010) Subtype-specific changes in 5-HT receptor-mediated modulation of C fibreevoked spinal field potentials are triggered by peripheral nerve injury. Neuroscience 168:831-841.

Akiba Y, Inoue T, Kaji I, Higashiyama M, Narimatsu K, Iwamoto K, Watanabe M, Guth PH, Engel E, Kuwahara A, et al. (2015) Short-chain fatty acid sensing in rat duodenum. J Physiol 593:585-599.

Akimova E, Lanzenberger R, and Kasper S (2009) The serotonin-1A receptor in anxiety disorders. Biol Psychiatry 66:627-635.

Akiyoshi T, Zhang Q, Inoue F, Aramaki O, Hatano M, Shimazu M, Kitajima M, Shirasugi N, and Niimi M (2006) Induction of indefinite survival of fully mismatched cardiac allografts and generation of regulatory cells by sarpogrelate hydrochloride. Transplantation 82:1051-1059.

Al Awabdh S, Miserey-Lenkei S, Bouceba T, Masson J, Kano F, Marinach-Patrice C, Hamon M, Emerit MB, and Darmon M (2012) A new vesicular scaffolding complex mediates the G-protein-coupled 5-HT1A receptor targeting to neuronal dendrites. J Neurosci 32:14227-14241.

Albert PR (2012) Transcriptional regulation of the 5-HT1A receptor: implications for mental illness. Philos Trans R Soc Lond B Biol Sci 367:2402-2415.

Albert PR and Fiori LM (2014) Transcriptional dys-regulation in anxiety and major depression: 5-HT1A gene promoter architecture as a therapeutic opportunity. Curr Pharm Des 20:3738-3750.

Albert PR and François BL (2010) Modifying 5-HT1A receptor gene expression as a new target for antidepressant therapy. Front Neurosci 4:35.

Albert PR, Vahid-Ansari F, and Luckhart C (2014) Serotonin-prefrontal cortical circuitry in anxiety and depression phenotypes: pivotal role of pre- and post-synaptic 5-HT1A receptor expression. Front Behav Neurosci 8:199.

Albert PR, Zhou QY, Van Tol HH, Bunzow JR, and Civelli O (1990) Cloning, functional expression, and mRNA tissue distribution of the rat 5-hydroxytryptamine1A receptor gene. J Biol Chem 265:5825-5832

Alberts GL, Chio CL, and Im WB (2001) Allosteric modulation of the human 5-HT(7A) receptor by lipidic amphipathic compounds. Mol Pharmacol 60 1349-1355.

Alberts GL, Pregenzer JF, Im WB, Zaworski PG, and Gill GS (1999) Agonist-induced GTPgamma35S binding mediated by human 5 -HT(2C) receptors expressed in human embryonic kidney 293 cells. Eur J Pharmacol 383:311-319.

Alex KD and Pehek EA (2007) Pharmacologic mechanisms of serotonergic regulation of dopamine neurotransmission. Pharmacol Ther 113:296-320.

Alexander SPH, Christopoulos A, Davenport AP, Kelly E, Mathie A, Peters JA, Veale EL, Armstrong JF, Pawson AJ, Faccenda E, Harding SD, Pawson AJ, Sharman JL, Southan C, and Davies JA; CGTP Collaborators (2019) he Concise Guide To Pharmacology 2019/20: G protein-coupled receptors. Br J Pharmacol 176 (Suppl 1): S21-S141.

Alexander SPH, Davenport AP, Kelly E, Marrion N, Peters JA, Benson HE, Faccenda E, Pawson AJ, Sharman JL, Southan C, et al.; CGTP Collaborators (2015a) The concise guide to pharmacology 2015/16: G protein-coupled receptors. Br J Pharmacol 172:5744-5869.

Alexander SPH, Kelly E, Marrion N, Peters JA, Benson HE, Faccenda E, Pawson AJ, Sharman JL, Southan C, Buneman OP, et al.; CGTP Collaborators (2015b) The concise guide to pharmacology 2015/16: overview. Br J Pharmacol 172:5729-5743.

Alexander SPH, Peters JA, Kelly E, Marrion N, Benson HE, Faccenda E, Pawson AJ, Sharman JL, Southan C, and Davies JA; CGTP Collaborators (2015c) The concise guide to pharmacology 2015/16: ligand-gated ion channels. $\mathrm{Br} J$ Pharmacol 172: $5870-5903$

Allen JA, Yadav PN, and Roth BL (2008) Insights into the regulation of 5-HT2A serotonin receptors by scaffolding proteins and kinases. Neuropharmacology $\mathbf{5 5}$ : 961-968.

Allen JA, Yost JM, Setola V, Chen X, Sassano MF, Chen M, Peterson S, Yadav PN, Huang XP, Feng B, et al. (2011) Discovery of $\beta$-arrestin-biased dopamine D2 ligands for probing signal transduction pathways essential for antipsychotic efficacy. Proc Natl Acad Sci USA 108:18488-18493.

Allers KA, Dremencov E, Ceci A, Flik G, Ferger B, Cremers TI, Ittrich C, and Sommer B (2010) Acute and repeated flibanserin administration in female rats modulates monoamines differentially across brain areas: a microdialysis study. $J$ Sex Med 7:1757-1767.

Almeida-Santos AF, Ferreira RC, Duarte ID, Aguiar DC, Romero TR, and Moreira FA (2015) The antipsychotic aripiprazole induces antinociceptive effects: possible role of peripheral dopamine D2 and serotonin 5-HT1A receptors. Eur J Pharmacol 765:300-306

Aloyo VJ, Berg KA, Spampinato U, Clarke WP, and Harvey JA (2009) Current status of inverse agonism at serotonin2A (5-HT2A) and 5-HT2C receptors. Pharmacol Ther 121:160-173.

Alper RH (1990) Hemodynamic and renin responses to (+-)-DOI, a selective 5-HT2 receptor agonist, in conscious rats. Eur J Pharmacol 175:323-332.

Alterio J, Masson J, Diaz J, Chachlaki K, Salman H, Areias J, Al Awabdh S, Emerit $\mathrm{MB}$, and Darmon M (2015) Yif1B is involved in the anterograde traffic pathway and the golgi architecture. Traffic 16:978-993.
Alvarez E, Perez V, Dragheim M, Loft H, and Artigas F (2012) A double-blind, randomized, placebo-controlled, active reference study of Lu AA21004 in patients with major depressive disorder. Int $J$ Neuropsychopharmacol 15:589-600

Amano T, Ariga H, Kurematsu A, Yamato S, Morioka S, Masaka A, Kanazawa M, and Fukudo S (2015) Effect of 5-hydroxytryptamine receptor 4 agonist mosapride on human gastric accommodation. Neurogastroenterol Motil 27:1303-1309.

Amaya-Castellanos E, Pineda-Farias JB, Castañeda-Corral G, Vidal-Cantú GC Murbartián J, Rocha-González HI, and Granados-Soto V (2011) Blockade of 5-HT7 receptors reduces tactile allodynia in the rat. Pharmacol Biochem Behav 99: 591-597.

American Psychiatric Association (2013) Diagnostic and Statistical Manual of Mental Disorders: DSM-5. American Psychiatric Association.

Amireault P, Hatia S, Bayard E, Bernex F, Collet C, Callebert J, Launay J-M, Hermine O, Schneider E, Mallet J, et al. (2011) Ineffective erythropoiesis with reduced red blood cell survival in serotonin-deficient mice. Proc Natl Acad Sci USA 108:13141-13146.

Amlaiky N, Ramboz S, Boschert U, Plassat JL, and Hen R (1992) Isolation of a mouse "5HT1E-like" serotonin receptor expressed predominantly in hippocampus. J Biol Chem 267:19761-19764.

Amrutkar DV, Ploug KB, Hay-Schmidt A, Porreca F, Olesen J, and Jansen-Olesen I (2012) mRNA expression of 5-hydroxytryptamine $1 \mathrm{~B}, 1 \mathrm{D}$, and $1 \mathrm{~F}$ receptors and their role in controlling the release of calcitonin gene-related peptide in the rat trigeminovascular system. Pain 153:830-838.

Anastasio NC, Gilbertson SR, Bubar MJ, Agarkov A, Stutz SJ, Jeng Y, Bremer NM, Smith TD, Fox RG, Swinford SE, et al. (2013) Peptide inhibitors disrupt the serotonin 5-HT2C receptor interaction with phosphatase and tensin homolog to allosterically modulate cellular signaling and behavior. J Neurosci 33:1615-1630.

Anastasio NC, Lanfranco MF, Bubar MJ, Seitz PK, Stutz SJ, McGinnis AG, Watson CS, and Cunningham KA (2010) Serotonin 5-HT2C receptor protein expression is enriched in synaptosomal and post-synaptic compartments of rat cortex. $\mathrm{J} \mathrm{Neu}$ rochem 113:1504-1515.

Anastasio NC, Liu S, Maili L, Swinford SE, Lane SD, Fox RG, Hamon SC, Nielsen DA, Cunningham KA, and Moeller FG (2014a) Variation within the serotonin (5$\mathrm{HT}$ ) $5-\mathrm{HT}_{2} \mathrm{C}$ receptor system aligns with vulnerability to cocaine cue reactivity. Transl Psychiatry 4:e369.

Anastasio NC, Stutz SJ, Fink LH, Swinford-Jackson SE, Sears RM, DiLeone RJ, Rice KC, Moeller FG, and Cunningham KA (2015) Serotonin (5-HT) 5-HT2A receptor (5HT2AR):5-HT2CR imbalance in medial prefrontal cortex associates with motor impulsivity. ACS Chem Neurosci 6:1248-1258.

Anastasio NC, Stutz SJ, Fox RG, Sears RM, Emeson RB, DiLeone RJ, O'Neil RT, Fink LH, Li D, Green TA, et al. (2014b) Functional status of the serotonin 5-HT2C receptor (5-HT2CR) drives interlocked phenotypes that precipitate relapse-like behaviors in cocaine dependence. Neuropsychopharmacology 39:370-382.

Andrade R (2006) Electrophysiological properties of g $\alpha$ s-coupled 5-HT receptors (5HT4, 5-HT6, 5-HT7), in The Serotonin Receptors; From Molecular Pharmacology to Human Therapeutics (Roth BL, ed) pp 481-494, Humana press, Totowa, NJ.

Andrade R, Barnes NM, Baxter G, et al. (2019) 5-Hydroxytryptamine receptors (version 2019.4) in the IUPHAR/BPS Guide to Pharmacology Database. IUPHAR / BPS Guide to Pharmacology CITE. 2019: doi: 10.2218/gtopdb/F1/2019.4.

Andrade R and Beck SG (2010) Cellular effects of serotonin in the CNS, in Handbook of the Behavioral Neurobiology of Serotonin (Muller CP and Jacobs B eds) pp 219-232, Elsevier Academic Press.

Andrade R and Chaput Y (1991) 5-Hydroxytryptamine4-like receptors mediate the slow excitatory response to serotonin in the rat hippocampus. $J$ Pharmacol Exp Ther 257:930-937.

Andrés AM, de Hemptinne C, and Bertranpetit J (2007) Heterogeneous rate of protein evolution in serotonin genes. Mol Biol Evol 24:2707-2715.

Andresen V, Montori VM, Keller J, West CP, Layer P, and Camilleri M (2008) Effects of 5-hydroxytryptamine (serotonin) type 3 antagonists on symptom relief and constipation in nonconstipated irritable bowel syndrome: a systematic review and meta-analysis of randomized controlled trials. Clin Gastroenterol Hepatol 6 $545-555$

Andressen KW, Manfra O, Brevik CH, Ulsund AH, Vanhoenacker P, Levy FO, and Krobert KA (2015) The atypical antipsychotics clozapine and olanzapine promote down-regulation and display functional selectivity at human $5-\mathrm{HT}_{7}$ receptors. Br J Pharmacol 172:3846-3860.

Andressen KW, Norum JH, Levy FO, and Krobert KA (2006) Activation of adenyly cyclase by endogenous $\mathrm{G}_{\mathrm{s}}$-coupled receptors in human embryonic kidney 293 cells is attenuated by $5-\mathrm{HT}_{7}$ receptor expression. Mol Pharmacol 69:207-215.

Andressen KW, Ulsund AH, Krobert KA, Lohse MJ, Bünemann M, and Levy FO (2018) Related GPCRs couple differently to $\mathrm{G}_{\mathrm{s}}$ : preassociation between $\mathrm{G}$ protein and $5-\mathrm{HT}_{7}$ serotonin receptor reveals movement of $\mathrm{G} \alpha_{\mathrm{s}}$ upon receptor activation. FASEB J 32:1059-1069.

Andrews N and O'Neill MF (2011) It might be a big family but the pain remains-last chance saloon for selective 5-HT receptor ligands? Curr Opin Pharmacol 11:39-44

Andrews PLR and Sanger GJ (2014) Nausea and the quest for the perfect antiemetic. Eur J Pharmacol 722:108-121.

Ansanay H, Dumuis A, Sebben M, Bockaert J, and Fagni L (1995) cAMP-dependent, long-lasting inhibition of a $\mathrm{K}+$ current in mammalian neurons. Proc Natl Acad Sci USA 92:6635-6639.

Ansanay H, Sebben M, Bockaert J, and Dumuis A (1992) Characterization of homologous 5-hydroxytryptamine4 receptor desensitization in colliculi neurons. Mol Pharmacol 42:808-816.

Ansorge MS, Zhou M, Lira A, Hen R, and Gingrich JA (2004) Early-life blockade of the 5-HT transporter alters emotional behavior in adult mice. Science 306:879-881.

Antonini A and Poewe W (2007) Fibrotic heart-valve reactions to dopamine-agonist treatment in Parkinson's disease. Lancet Neurol 6:826-829.

Applegate CD and Tecott LH (1998) Global increases in seizure susceptibility in mice lacking 5-HT2C receptors: a behavioral analysis. Exp Neurol 154:522-530. 
Araneda R and Andrade R (1991) 5-Hydroxytryptamine2 and 5-hydroxytryptamine $1 \mathrm{~A}$ receptors mediate opposing responses on membrane excitability in rat association cortex. Neuroscience 40:399-412.

Arias B, Collier DA, Gastó C, Pintor L, Gutiérrez B, Vallès V, and Fañanás L (2001) Genetic variation in the 5-HT5A receptor gene in patients with bipolar disorder and major depression. Neurosci Lett 303:111-114.

Arolt V, Peters M, Erfurth A, Wiesmann M, Missler U, Rudolf S, Kirchner H, and Rothermundt M (2003) S100B and response to treatment in major depression: a pilot study. Eur Neuropsychopharmacol 13:235-239.

Arslan AA, Gold LI, Mittal K, Suen TC, Belitskaya-Levy I, Tang MS, and Toniolo P (2005) Gene expression studies provide clues to the pathogenesis of uterine leiomyoma: new evidence and a systematic review. Hum Reprod 20:852-863.

Artigas F, Adell A, and Celada P (2006) Pindolol augmentation of antidepressant response. Curr Drug Targets 7:139-147.

Artigas F, Romero L, de Montigny C, and Blier P (1996) Acceleration of the effect of selected antidepressant drugs in major depression by 5-HT1A antagonists. Trends Neurosci 19:378-383.

Asada M, Ebihara S, Yamanda S, Niu K, Okazaki T, Sora I, and Arai H (2009) Depletion of serotonin and selective inhibition of ${ }_{2 \mathrm{~B}}$ receptor suppressed tumor angiogenesis by inhibiting endothelial nitric oxide synthase and extracellular signal-regulated kinase 1/2 phosphorylation. Neoplasia 11:408-417.

Asaoka N, Nagayasu K, Nishitani N, Yamashiro M, Shirakawa H, Nakagawa T, and Kaneko S (2015) Olanzapine augments the effect of selective serotonin reuptake inhibitors by suppressing GABAergic inhibition via antagonism of 5-HT(6) receptors in the dorsal raphe nucleus. Neuropharmacology 95:261-268.

Assetta B, Maginnis MS, Gracia Ahufinger I, Haley SA, Gee GV, Nelson CD, O'Hara BA, Allen Ramdial SA, and Atwood WJ (2013) 5-HT2 receptors facilitate JC polyomavirus entry. $J$ Virol 87:13490-13498.

Assié MB, Bardin L, Auclair AL, Carilla-Durand E, Depoortère R, Koek W, Kleven MS, Colpaert F, Vacher B, and Newman-Tancredi A (2010) F15599, a highly selective post-synaptic 5-HT(1A) receptor agonist: in-vivo profile in behavioural models of antidepressant and serotonergic activity. Int $J$ Neuropsychopharmacol 13:1285-1298.

Assié MB, Lomenech H, Ravailhe V, Faucillon V, and Newman-Tancredi A (2006) Rapid desensitization of somatodendritic 5-HT1A receptors by chronic administration of the high-efficacy 5-HT1A agonist, F13714: a microdialysis study in the rat. $\mathrm{Br}$ J Pharmacol 149:170-178.

Atanes P, Lacivita E, Rodríguez J, Brea J, Burgueño J, Vela JM, Cadavid MI, Loza MI, Leopoldo M, and Castro M (2013) The arylpiperazine derivatives N-(4-cyanophenylmethyl)-4-(2-diphenyl)-1-piperazinehexanamide and N-benzyl-4-(2-diphenyl)1-piperazinehexanamide exert a long-lasting inhibition of human serotonin 5-HT7 receptor binding and cAMP signaling. Pharmacol Res Perspect 1:e0013.

Aubert Y, Gustison ML, Gardner LA, Bohl MA, Lange JR, Allers KA, Sommer B, Datson NA, and Abbott DH (2012) Flibanserin and 8-OH-DPAT implicate serotonin in association between female marmoset monkey sexual behavior and changes in pair-bond quality. J Sex Med 9:694-707.

Auclair AL, Cathala A, Sarrazin F, Depoortère R, Piazza PV, Newman-Tancredi A and Spampinato U (2010) The central serotonin ${ }_{2 \mathrm{~B}}$ receptor: a new pharmacological target to modulate the mesoaccumbens dopaminergic pathway activity. $J$ Neurochem 114:1323-1332.

Audia JE, Evrard DA, Murdoch GR, Droste JJ, Nissen JS, Schenck KW, Fludzinski P, Lucaites VL, Nelson DL, and Cohen ML (1996) Potent, selective tetrahydrobeta-carboline antagonists of the serotonin ${ }_{2 \mathrm{~B}}\left(5 \mathrm{HT}_{2 \mathrm{~B}}\right)$ contractile receptor in the rat stomach fundus. $J$ Med Chem 39:2773-2780.

Austgen JR, Dantzler HA, Barger BK, and Kline DD (2012) 5-hydroxytryptamine 2C receptors tonically augment synaptic currents in the nucleus tractus solitarii. $J$ Neurophysiol 108:2292-2305.

Avesar D and Gulledge AT (2012) Selective serotonergic excitation of callosal projection neurons. Front Neural Circuits $6: 12$

Avila-Rojas SH, Velázquez-Lagunas I, Salinas-Abarca AB, Barragán-Iglesias P, Pineda-Farias JB, and Granados-Soto V (2015) Role of spinal 5-HT5A, and 5 -HT1A/1B/1D, receptors in neuropathic pain induced by spinal nerve ligation in rats. Brain Res 1622:377-385.

Ayme-Dietrich E, Lawson R, Gasser B, Dallemand R, Bischoff N, and Monassier L (2012) Mitral bioprosthesis hypertrophic scaring and native aortic valve fibrosis during benfluorex therapy. Fundam Clin Pharmacol 26:215-218.

Ayme-Dietrich E, Marzak H, Lawson R, Mokni W, Wendling O, Combe R, Becker J, El Fertak L, Champy MF, Matz R, et al. (2015) Contribution of serotonin to cardiac remodeling associated with hypertensive diastolic ventricular dysfunction in rats. J Hypertens 33:2310-2321.

Azim S, Banday AR, and Tabish M (2012) Identification of alternatively spliced multiple transcripts of 5-hydroxytryptamine receptor in mouse. Brain Res Bull 87: $250-258$.

Azmitia EC, Singh JS, and Whitaker-Azmitia PM (2011) Increased serotonin axons (immunoreactive to 5-HT transporter) in postmortem brains from young autism donors. Neuropharmacology 60:1347-1354.

Aznar S, Qian Z, Shah R, Rahbek B, and Knudsen GM (2003) The 5-HT1A serotonin receptor is located on calbindin- and parvalbumin-containing neurons in the rat brain. Brain Res 959:58-67.

Bach T, Syversveen T, Kvingedal AM, Krobert KA, Brattelid T, Kaumann AJ, and Levy FO (2001) $5-\mathrm{HT}_{4(\mathrm{a})}$ and $5-\mathrm{HT}_{4(\mathrm{~b})}$ receptors have nearly identical pharmacology and are both expressed in human atrium and ventricle. Naunyn Schmiedebergs Arch Pharmacol 363:146-160.

Backstrom JR, Price RD, Reasoner DT, and Sanders-Bush E (2000) Deletion of the serotonin 5-HT2C receptor PDZ recognition motif prevents receptor phosphorylation and delays resensitization of receptor responses. $J$ Biol Chem 275 $23620-23626$.

Backstrom JR, Westphal RS, Canton H, and Sanders-Bush E (1995) Identification of rat serotonin 5-HT2C receptors as glycoproteins containing N-linked oligosaccharides. Brain Res Mol Brain Res 33:311-318.
Bacon WL and Beck SG (2000) 5-Hydroxytryptamine(7) receptor activation decreases slow afterhyperpolarization amplitude in CA3 hippocampal pyramidal cells. $J$ Pharmacol Exp Ther 294:672-679.

Baganz NL and Blakely RD (2013) A dialogue between the immune system and brain, spoken in the language of serotonin. ACS Chem Neurosci 4:48-63.

Bagdy G, Kecskemeti V, Riba P, and Jakus R (2007) Serotonin and epilepsy. $J$ Neurochem 100:857-873.

Bai C-F, Liu J-C, Zhao R, Cao W, Liu S-B, Zhang X-N, Guo H-J, Yang Q, Yi D-H, and Zhao M-G (2010) Role of 5-HT 2B receptors in cardiomyocyte apoptosis in noradrenaline-induced cardiomyopathy in rats. Clin Exp Pharmacol Physiol 37: e145-e151.

Bai F, Yin T, Johnstone EM, Su C, Varga G, Little SP, and Nelson DL (2004) Molecular cloning and pharmacological characterization of the guinea pig 5-HT1E receptor. Eur J Pharmacol 484:127-139.

Bailer UF, Bloss CS, Frank GK, Price JC, Meltzer CC, Mathis CA, Geyer MA, Wagner A, Becker CR, Schork NJ, et al. (2011) 5 -HT $\mathrm{H}_{1} \mathrm{~A}$ receptor binding is increased after recovery from bulimia nervosa compared to control women and is associated with behavioral inhibition in both groups. Int $J$ Eat Disord 44:477-487.

Bailer UF, Frank GK, Henry SE, Price JC, Meltzer CC, Mathis CA, Wagner A Thornton L, Hoge J, Ziolko SK, et al. (2007) Exaggerated 5-HT1A but normal 5-HT2A receptor activity in individuals ill with anorexia nervosa. Biol Psychiatry 61:1090-1099.

Bailer UF and Kaye WH (2011) Serotonin: imaging findings in eating disorders. Curr Top Behav Neurosci 6:59-79.

Baker LP, Nielsen MD, Impey S, Metcalf MA, Poser SW, Chan G, Obrietan K, Hamblin MW, and Storm DR (1998) Stimulation of type 1 and type $8 \mathrm{Ca} 2+/ \mathrm{cal}$ modulin-sensitive adenylyl cyclases by the Gs-coupled 5-hydroxytryptamine subtype 5-HT7A receptor. J Biol Chem 273:17469-17476.

Banas SM, Doly S, Boutourlinsky K, Diaz SL, Belmer A, Callebert J, Collet C, Launay J-M, and Maroteaux L (2011) Deconstructing antiobesity compound action: requirement of serotonin $5-\mathrm{HT}_{2 \mathrm{~B}}$ receptors for dexfenfluramine anorectic effects. Neuropsychopharmacology 36:423-433.

Banes A, Florian JA, and Watts SW (1999) Mechanisms of 5-hydroxytryptamine $(2 \mathrm{~A})$ receptor activation of the mitogen-activated protein kinase pathway in vascular smooth muscle. J Pharmacol Exp Ther 291:1179-1187.

Banes AB and Watts SW (2002) Upregulation of arterial serotonin $1 \mathrm{~B}$ and $2 \mathrm{~B}$ receptors in deoxycorticosterone acetate-salt hypertension. Hypertension $\mathbf{3 9}$ 394-398.

Banes AK, Shaw SM, Tawfik A, Patel BP, Ogbi S, Fulton D, and Marrero MB (2005) Activation of the JAK/STAT pathway in vascular smooth muscle by serotonin. Am J Physiol Cell Physiol 288:C805-C812.

Banes AKL and Watts SW (2003) Arterial expression of 5-HT $\mathrm{HT}_{2 \mathrm{~B}}$ and 5-HT $\mathrm{H}_{1 \mathrm{~B}}$ receptors during development of DOCA-salt hypertension. BMC Pharmacol 3:12.

Bankson MG and Cunningham KA (2002) Pharmacological studies of the acute effects of (+)-3,4-methylenedioxymethamphetamine on locomotor activity: role of 5-HT(1B/1D) and 5-HT(2) receptors. Neuropsychopharmacology 26:40-52.

Banner SE and Sanger GJ (1995) Differences between 5-HT $\mathrm{H}_{3}$ receptor antagonists in modulation of visceral hypersensitivity. $\mathrm{Br} J$ Pharmacol 114:558-562.

Bantick RA, Montgomery AJ, Bench CJ, Choudhry T, Malek N, McKenna PJ, Quested DJ, Deakin JF, and Grasby PM (2004) A positron emission tomography study of the 5-HT1A receptor in schizophrenia and during clozapine treatment. $J$ Psychopharmacol 18:346-354.

Baptista-Hon DT, Deeb TZ, Othman NA, Sharp D, and Hales TG (2012) The 5-HT3B subunit affects high-potency inhibition of 5-HT3 receptors by morphine. $\mathrm{Br} J$ Pharmacol 165:693-704.

Barclay Z, Dickson L, Robertson DN, Johnson MS, Holland PJ, Rosie R, Sun L, Fleetwood-Walker S, Lutz EM, and Mitchell R (2011) 5-HT2A receptor signalling through phospholipase D1 associated with its C-terminal tail. Biochem $J$ 436: $651-660$

Bard JA, Zgombick J, Adham N, Vaysse P, Branchek TA, and Weinshank RL (1993) Cloning of a novel human serotonin receptor $\left(5-\mathrm{HT}_{7}\right)$ positively linked to adenylate cyclase. J Biol Chem 268:23422-23426.

Bardin L, Kleven MS, Barret-Grévoz C, Depoortère R, and Newman-Tancredi A (2006) Antipsychotic-like vs cataleptogenic actions in mice of novel antipsychotics having D2 antagonist and 5-HT1A agonist properties. Neuropsychopharmacology 31:1869-1879.

Bari A and Robbins TW (2013) Inhibition and impulsivity: behavioral and neural basis of response control. Prog Neurobiol 108:44-79.

Barnes NM, Ge J, Jones WG, Naylor RJ, and Rudd JA (1990) Cisplatin induced emesis: preliminary results indicative of changes in plasma levels of 5-hydroxytryptamine. $\mathrm{Br} J$ Cancer 62:862-864.

Barnes NM, Hales TG, Lummis SC, and Peters JA (2009) The 5-HT3 receptor-the relationship between structure and function. Neuropharmacology 56:273-284.

Barnes NM and Sharp T (1999) A review of central 5-HT receptors and their function. Neuropharmacology 38:1083-1152.

Barone P, Jordan D, Atger F, Kopp N, and Fillion G (1994) Quantitative autoradiography of 5-HT1D and 5-HT1E binding sites labelled by [3H]5-HT, in frontal cortex and the hippocampal region of the human brain. Brain Res 638:85-94.

Barr AJ and Manning DR (1997) Agonist-independent activation of Gz by the 5-hydroxytryptamine1A receptor co-expressed in Spodoptera frugiperda cells. Distinguishing inverse agonists from neutral antagonists. J Biol Chem 272 32979-32987.

Barrera NP, Herbert P, Henderson RM, Martin IL, and Edwardson JM (2005) Atomic force microscopy reveals the stoichiometry and subunit arrangement of 5-HT3 receptors. Proc Natl Acad Sci USA 102:12595-12600.

Barrondo S and Sallés J (2009) Allosteric modulation of 5-HT(1A) receptors by zinc: binding studies. Neuropharmacology 56:455-462.

Barthet G, Carrat G, Cassier E, Barker B, Gaven F, Pillot M, Framery B, Pellissier LP, Augier J, Kang DS, et al. (2009) Beta-arrestin1 phosphorylation by GRK5 
regulates G protein-independent 5-HT4 receptor signalling. EMBO J 28: $2706-2718$

Barthet G, Framery B, Gaven F, Pellissier L, Reiter E, Claeysen S, Bockaert J and Dumuis A (2007) 5-hydroxytryptamine 4 receptor activation of the extracellular signal-regulated kinase pathway depends on Src activation but not on G protein or beta-arrestin signaling. Mol Biol Cell 18:1979-1991.

Barthet G, Gaven F, Framery B, Shinjo K, Nakamura T, Claeysen S, Bockaert J, and Dumuis A (2005) Uncoupling and endocytosis of 5-hydroxytryptamine 4 receptors. Distinct molecular events with different GRK2 requirements. J Biol Chem 280:27924-27934.

Basak S, Gicheru Y, Rao S, Sansom MSP, and Chakrapani S (2018a) Cryo-EM reveals two distinct serotonin-bound conformations of full-length $5-\mathrm{HT}_{3 \mathrm{~A}}$ receptor. Nature 563:270-274.

Basak S, Gicheru Y, Samanta A, Molugu SK, Huang W, Fuente M, Hughes T, Taylor DJ, Nieman MT, Moiseenkova-Bell V, et al. (2018b) Cryo-EM structure of 5- $\mathrm{HT}_{3 \mathrm{~A}}$ receptor in its resting conformation. Nat Commun 9:514.

Basile VS, Masellis M, De Luca V, Meltzer HY, and Kennedy JL (2002) 759C/T genetic variation of $5 \mathrm{HT}(2 \mathrm{C})$ receptor and clozapine-induced weight gain. Lancet 360:1790-1791.

Basselin M, Ramadan E, and Rapoport SI (2012) Imaging brain signal transduction and metabolism via arachidonic and docosahexaenoic acid in animals and humans. Brain Res Bull 87:154-171.

Bassil AK, Taylor CM, Bolton VJ, Gray KM, Brown JD, Cutler L, Summerfield SG, Bruton G, Winchester WJ, Lee K, et al. (2009) Inhibition of colonic motility and defecation by RS-127445 suggests an involvement of the $5-\mathrm{HT}_{2 \mathrm{~B}}$ receptor in rodent large bowel physiology. $\mathrm{Br} J$ Pharmacol 158:252-258.

Baudry A, Bitard J, Mouillet-Richard S, Locker M, Poliard A, Launay J-M, and Kellermann O (2010a) Serotonergic 5-HT(2B) receptor controls tissue-nonspecific alkaline phosphatase activity in osteoblasts via eicosanoids and phosphatidylinositol-specific phospholipase C. J Biol Chem 285:26066-26073.

Baudry A, Mouillet-Richard S, Schneider B, Launay JM, and Kellermann O (2010b) miR-16 targets the serotonin transporter: a new facet for adaptive responses to antidepressants. Science 329:1537-1541.

Bayer H, Müller T, Myrtek D, Sorichter S, Ziegenhagen M, Norgauer J, Zissel G, and Idzko M (2007) Serotoninergic receptors on human airway epithelial cells. Am $J$ Respir Cell Mol Biol 36:85-93.

Beattie DT, Armstrong SR, Shaw JP, Marquess D, Sandlund C, Smith JA, Taylor JA, and Humphrey PP (2008) The in vivo gastrointestinal activity of TD-5108, a selective 5-HT(4) receptor agonist with high intrinsic activity. Naunyn Schmiedebergs Arch Pharmacol 378:139-147.

Beattie DT and Smith JA (2008) Serotonin pharmacology in the gastrointestinal tract: a review. Naunyn Schmiedebergs Arch Pharmacol 377:181-203.

Beattie DT, Smith JA, Marquess D, Vickery RG, Armstrong SR, Pulido-Rios T, McCullough JL, Sandlund C, Richardson C, Mai N, et al. (2004) The 5-HT $\mathrm{H}_{4}$ receptor agonist, tegaserod, is a potent $5-\mathrm{HT}_{2 \mathrm{~B}}$ receptor antagonist in vitro and in vivo. $\mathrm{Br} J$ Pharmacol 143:549-560.

Bécamel C, Alonso G, Galéotti N, Demey E, Jouin P, Ullmer C, Dumuis A, Bockaert J, and Marin P (2002) Synaptic multiprotein complexes associated with 5-HT(2C) receptors: a proteomic approach. EMBO J 21:2332-2342.

Becamel C, Figge A, Poliak S, Dumuis A, Peles E, Bockaert J, Lubbert H, and Ullmer $\mathrm{C}$ (2001) Interaction of serotonin 5-hydroxytryptamine type 2C receptors with PDZ10 of the multi-PDZ domain protein MUPP1. J Biol Chem 276:12974-12982.

Bécamel C, Gavarini S, Chanrion B, Alonso G, Galéotti N, Dumuis A, Bockaert J, and Marin P (2004) The serotonin 5-HT2A and 5-HT2C receptors interact with specific sets of PDZ proteins. J Biol Chem 279:20257-20266.

Bechara A (2005) Decision making, impulse control and loss of willpower to resist drugs: a neurocognitive perspective. Nat Neurosci 8:1458-1463.

Bechtholt AJ, Smith K, Gaughan S, and Lucki I (2008) Sucrose intake and fasting glucose levels in 5-HT(1A) and 5-HT(1B) receptor mutant mice. Physiol Behav 93: 659-665.

Becker G, Bolbos R, Costes N, Redouté J, Newman-Tancredi A, and Zimmer L (2016) Selective serotonin 5-HT1A receptor biased agonists elicitdistinct brain activation patterns: a pharmacoMRI study. Sci Rep 6:26633.

Beene DL, Brandt GS, Zhong W, Zacharias NM, Lester HA, and Dougherty DA (2002) Cation-pi interactions in ligand recognition by serotonergic (5-HT3A) and nicotinic acetylcholine receptors: the anomalous binding properties of nicotine. Biochemistry 41:10262-10269.

Beer MS, Heald MA, McAllister G, and Stanton JA (1998) Pharmacological characterisation of a cloned dog 5-HT1B receptor cell line. Eur J Pharmacol 360: 117-121.

Beer MS, Stanton JA, Hawkins LM, and Middlemiss DN (1993) 5-Carboxamidotryptamine-insensitive 5-HT1-like receptors are concentrated in guinea pig but not rat, claustrum. Eur J Pharmacol 236:167-169.

Béïque JC, Imad M, Mladenovic L, Gingrich JA, and Andrade R (2007) Mechanism of the 5-hydroxytryptamine $2 \mathrm{~A}$ receptor-mediated facilitation of synaptic activity in prefrontal cortex. Proc Natl Acad Sci USA 104:9870-9875.

Belelli D, Balcarek JM, Hope AG, Peters JA, Lambert JJ, and Blackburn TP (1995) Cloning and functional expression of a human 5-hydroxytryptamine type 3AS receptor subunit. Mol Pharmacol 48:1054-1062.

Belenky MA and Pickard GE (2001) Subcellular distribution of 5-HT(1B) and 5-HT(7) receptors in the mouse suprachiasmatic nucleus. J Comp Neurol 423:371-388.

Beliveau V, Ganz M, Feng L, Ozenne B, Højgaard L, Fisher PM, Svarer C, Greve DN and Knudsen GM (2017) A high-resolution in vivo atlas of the human brain's serotonin system. J Neurosci 37:120-128.

Bell R and Hobson H (1994) 5-HT1A receptor influences on rodent social and agonistic behavior: a review and empirical study. Neurosci Biobehav Rev 18:325-338.

Belmer A, Doly S, Setola V, Banas SM, Moutkine I, Boutourlinsky K, Kenakin T, and Maroteaux L (2014) Role of the $\mathrm{N}$-terminal region in $\mathrm{G}$ protein-coupled receptor functions: negative modulation revealed by $5-\mathrm{HT}_{2 \mathrm{~B}}$ receptor polymorphisms. Mol Pharmacol 85:127-138.
Bender E, Pindon A, van Oers I, Zhang YB, Gommeren W, Verhasselt P, Jurzak M, Leysen J, and Luyten W (2000) Structure of the human serotonin 5-HT4 receptor gene and cloning of a novel 5-HT4 splice variant. J Neurochem 74:478-489.

Benekareddy M, Goodfellow NM, Lambe EK, and Vaidya VA (2010) Enhanced function of prefrontal serotonin 5-HT(2) receptors in a rat model of psychiatric vulnerability. $J$ Neurosci 30:12138-12150.

Benjamin D, Lal H, and Meyerson LR (1990) The effects of 5-HT1B characterizing agents in the mouse elevated plus-maze. Life Sci 47:195-203.

Bennett JL and Aghajanian GK (1974) d-LSD binding to brain homogenates: possible relationship to serotonin receptors. Life Sci 15:1935-1944.

Bentley KR and Barnes JM (1995) Therapeutic potential of 5-HT3 receptor antagonists in neuropsychiatric disorders. CNS Drugs 3:363-392.

Bentley KR and Barnes NM (1998) 5-hydroxytryptamine 3 (5- $\left.\mathrm{HT}_{3}\right)$ receptor-mediated depolarisation of the rat isolated vagus nerve: modulation by trichloroethanol and related alcohols. Eur J Pharmacol 354:25-31.

Berbari NF, Johnson AD, Lewis JS, Askwith CC, and Mykytyn K (2008) Identification of ciliary localization sequences within the third intracellular loop of G protein-coupled receptors. Mol Biol Cell 19:1540-1547.

Berends AC, Luiten PG, and Nyakas C (2005) A review of the neuroprotective properties of the 5-HT1A receptor agonist repinotan $\mathrm{HCl}(\mathrm{BAY}$ 3702) in ischemic stroke. CNS Drug Rev 11:379-402.

Berendsen HH and Broekkamp CL (1990) Behavioural evidence for functional interactions between 5-HT-receptor subtypes in rats and mice. $\mathrm{Br} J$ Pharmacol 101:667-673.

Berg KA and Clarke WP (2006) Development of functionally selective agonists as novel therapeutic agents. Drug Discov Today Ther Strateg 3:421-428.

Berg KA and Clarke WP (2009) Functional selectivity at serotonin receptors, in Functional Selectivity of G Protein-Coupled Receptor Ligands (Neve KA ed) pp 155-176, Humana Press, New York.

Berg KA, Clarke WP, Cunningham KA, and Spampinato U (2008a) Fine-tuning serotonin2c receptor function in the brain: molecular and functional implications. Neuropharmacology 55:969-976.

Berg KA, Clarke WP, Sailstad C, Saltzman A, and Maayani S (1994) Signal transduction differences between 5 -hydroxytryptamine type $2 \mathrm{~A}$ and type $2 \mathrm{C}$ receptor systems. Mol Pharmacol 46:477-484.

Berg KA, Cropper JD, Niswender CM, Sanders-Bush E, Emeson RB, and Clarke WP (2001) RNA-editing of the 5-HT(2C) receptor alters agonist-receptor-effector coupling specificity. Br J Pharmacol 134:386-392.

Berg KA, Dunlop J, Sanchez T, Silva M, and Clarke WP (2008b) A conservative, single-amino acid substitution in the second cytoplasmic domain of the human Serotonin2C receptor alters both ligand-dependent and -independent receptor signaling. J Pharmacol Exp Ther 324:1084-1092.

Berg KA, Maayani S, and Clarke WP (1996) 5-hydroxytryptamine2C receptor activation inhibits 5-hydroxytryptamine1B-like receptor function via arachidonic acid metabolism. Mol Pharmacol 50:1017-1023.

Berg KA, Maayani S, Goldfarb J, and Clarke WP (1998a) Pleiotropic behavior of 5-HT2A and 5-HT2C receptor agonists. Ann N Y Acad Sci 861:104-110.

Berg KA, Maayani S, Goldfarb J, Scaramellini C, Leff P, and Clarke WP (1998b) Effector pathway-dependent relative efficacy at serotonin type $2 \mathrm{~A}$ and $2 \mathrm{C}$ receptors: evidence for agonist-directed trafficking of receptor stimulus. Mol Pharmacol 54:94-104.

Bergen SS Jr (1964) Appetite stimulating properties of cyproheptadine. Am J Dis Child 108:270-273

Berger M and Tecott LH (2006) Serotonin system gene knockouts: a story of mice with implications for man, in The Serotonin Receptors; From Molecular Pharmacology to Human Therapeutics (Roth BL ed) pp 537-575, Humana Press, Totowa, NJ.

Berglund ED, Liu C, Sohn JW, Liu T, Kim MH, Lee CE, Vianna CR, Williams KW, $\mathrm{Xu}$ Y, and Elmquist JK (2013) Serotonin 2C receptors in pro-opiomelanocortin neurons regulate energy and glucose homeostasis [published correction appears in $J$ Clin Invest (2014) 124:1868]. J Clin Invest 123:5061-5070.

Berrocoso E and Mico JA (2009) Role of serotonin 5-HT1A receptors in the antidepressant-like effect and the antinociceptive effect of venlafaxine in mice. Int $J$ Neuropsychopharmacol 12:61-71.

Bersani G, Grispini A, Marini S, Pasini A, Valducci M, and Ciani N (1990) 5-HT2 antagonist ritanserin in neuroleptic-induced parkinsonism: a double-blind comparison with orphenadrine and placebo. Clin Neuropharmacol 13:500-506.

Bertrand PP and Bertrand RL (2010) Serotonin release and uptake in the gastrointestinal tract. Auton Neurosci 153:47-57.

Bertrand PP, Hu X, Mach J, and Bertrand RL (2008) Serotonin (5-HT) release and uptake measured by real-time electrochemical techniques in the rat ileum. Am J Physiol Gastrointest Liver Physiol 295:G1228-G1236.

Bertrand PP, Kunze WAA, Furness JB, and Bornstein JC (2000) The terminals of myenteric intrinsic primary afferent neurons of the Guinea-pig ileum are excited by 5 -hydroxytryptamine acting at 5-hydroxytryptamine-3 receptors. Neuroscience 101:459-469.

Besson M, Pelloux Y, Dilleen R, Theobald DE, Lyon A, Belin-Rauscent A, Robbins TW, Dalley JW, Everitt BJ, and Belin D (2013) Cocaine modulation of frontostriatal expression of Zif268, D2, and 5-HT2c receptors in high and low impulsive rats. Neuropsychopharmacology 38:1963-1973.

Bevilacqua L, Doly S, Kaprio J, Yuan Q, Tikkanen R, Paunio T, Zhou Z, Wedenoja J, Maroteaux L, Diaz S, et al. (2010) A population-specific $\mathrm{HTR}_{2 \mathrm{~B}}$ stop codon predisposes to severe impulsivity. Nature 468:1061-1066.

Bezard E, Gerlach I, Moratalla R, Gross CE, and Jork R (2006) 5-HT1A receptor agonist-mediated protection from MPTP toxicity in mouse and macaque models of Parkinson's disease. Neurobiol Dis 23:77-86.

Bhagwagar Z, Hinz R, Taylor M, Fancy S, Cowen P, and Grasby P (2006) Increased 5 -HT(2A) receptor binding in euthymic, medication-free patients recovered from depression: a positron emission study with [(11)C]MDL 100,907. Am J Psychiatry 163:1580-1587. 
Bhalla P, Saxena PR, and Sharma HS (2002a) Molecular cloning and tissue distribution of mRNA encoding porcine 5-HT7 receptor and its comparison with the structure of other species. Mol Cell Biochem 238:81-88.

Bhalla P, Sharma HS, Wurch T, Pauwels PJ, and Saxena PR (2002b) Molecular cloning and expression of the porcine trigeminal ganglion cDNA encoding a $5-\mathrm{ht}\left({ }_{1 \mathrm{~F}}\right)$ receptor. Eur J Pharmacol 436:23-33.

Bharucha AE, Camilleri M, Haydock S, Ferber I, Burton D, Cooper S, Tompson D, Fitzpatrick K, Higgins R, and Zinsmeister AR (2000) Effects of a serotonin 5-HT( $\left.{ }_{4}\right)$ receptor antagonist SB-207266 on gastrointestinal motor and sensory function in humans. Gut 47:667-674.

Bhasin N, LaMantia AS, and Lauder JM (2004) Opposing regulation of cell proliferation by retinoic acid and the $\operatorname{serotonin}_{2 \mathrm{~B}}$ receptor in the mouse frontonasal mass. Anat Embryol (Berl) 208:135-143.

Bhatnagar A, Sheffler DJ, Kroeze WK, Compton-Toth B, and Roth BL (2004) Caveolin-1 interacts with 5-HT2A serotonin receptors and profoundly modulates the signaling of selected Galphaq-coupled protein receptors. J Biol Chem 279: 34614-34623.

Bhatnagar A, Willins DL, Gray JA, Woods J, Benovic JL, and Roth BL (2001) The dynamin-dependent, arrestin-independent internalization of 5-hydroxytryptamine 2A (5-HT2A) serotonin receptors reveals differential sorting of arrestins and 5-HT2A receptors during endocytosis. J Biol Chem 276:8269-8277.

Bhattacharya A, Dang H, Zhu QM, Schnegelsberg B, Rozengurt N, Cain G, Prantil R Vorp DA, Guy N, Julius D, et al. (2004a) Uropathic observations in mice expressing a constitutively active point mutation in the 5-HT3A receptor subunit. $J$ Neurosci 24:5537-5548.

Bhattacharya A, Sankar S, and Panicker MM (2010) Differences in the C-terminus contribute to variations in trafficking between rat and human $5-\mathrm{HT}(2 \mathrm{~A})$ receptor isoforms: identification of a primate-specific tripeptide ASK motif that confers GRK-2 and beta arrestin-2 interactions. J Neurochem 112:723-732.

Bhattacharya A, Schenck KW, Xu YC, Nisenbaum L, Galbreath E, and Cohen ML (2004b) 5-Hydroxytryptamine1B receptor-mediated contraction of rabbit saphenous vein and basilar artery: role of vascular endothelium. J Pharmacol Exp Ther 309:825-832.

Bhattarai Y, Schmidt BA, Linden DR, Larson ED, Grover M, Beyder A, Farrugia G, and Kashyap PC (2017) Human-derived gut microbiota modulates colonic secretion in mice by regulating $5-\mathrm{HT}_{3}$ receptor expression via acetate production. $\mathrm{Am} J$ Physiol Gastrointest Liver Physiol 313:G80-G87.

Bibbiani F, Oh JD, and Chase TN (2001) Serotonin 5-HT1A agonist improves motor complications in rodent and primate parkinsonian models. Neurology 57:1829-1834.

Bigford GE, Chaundry NS, Keane RW, and Holohean AM (2012) 5-Hydroxytryptamine 5HT2C receptors form a protein complex with N-methyl-D-Aspartate GLUN2A subunits and activate phosphorylation of Src protein to modulate motoneuronal depolarization. J Biol Chem 287:11049-11059.

Bilkei-Gorzo A, Gyertyan I, and Levay G (1998) mCPP-induced anxiety in the lightdark box in rats-a new method for screening anxiolytic activity. Psychopharmacology (Berl) 136:291-298.

Billard T, Le Bars D, and Zimmer L (2014) PET radiotracers for molecular imaging of serotonin 5-HT1A receptors. Curr Med Chem 21:70-81.

Birkeland JA, Sjaastad I, Brattelid T, Qvigstad E, Moberg ER, Krobert KA, Bjørnerheim R, Skomedal T, Sejersted OM, Osnes JB, et al. (2007a) Effects of treatment with a $5-\mathrm{HT}_{4}$ receptor antagonist in heart failure. $\mathrm{Br} J$ Pharmacol 150: 143-152.

Birkeland JA, Swift F, Tovsrud N, Enger U, Lunde PK, Qvigstad E, Levy FO, Sejersted OM, and Sjaastad I (2007b) Serotonin increases L-type $\mathrm{Ca}^{2+}$ current and $\mathrm{SR} \mathrm{Ca}^{2+}$ content through $5-\mathrm{HT}_{4}$ receptors in failing rat ventricular cardiomyocytes. Am J Physiol Heart Circ Physiol 293:H2367-H2376.

Birkett JT, Arranz MJ, Munro J, Osbourn S, Kerwin RW, and Collier DA (2000) Association analysis of the 5-HT5A gene in depression, psychosis and antipsychotic response. Neuroreport 11:2017-2020.

Birnstiel S and Beck SG (1995) Modulation of the 5-hydroxytryptamine4 receptormediated response by short-term and long-term administration of corticosterone in rat CA1 hippocampal pyramidal neurons. I Pharmacol Exp Ther 273:1132-1138.

Bischoff SC, Mailer R, Pabst O, Weier G, Sedlik W, Li Z, Chen JJ, Murphy DL, and Gershon MD (2009) Role of serotonin in intestinal inflammation: knockout of serotonin reuptake transporter exacerbates 2,4,6-trinitrobenzene sulfonic acid colitis in mice. Am J Physiol Gastrointest Liver Physiol 296:G685-G695.

Björnsson ES, Chey WD, Hooper F, Woods ML, Owyang C, and Hasler WL (2002) Impaired gastrocolonic response and peristaltic reflex in slow-transit constipation: role of 5-HT(3) pathways. Am J Physiol Gastrointest Liver Physiol 283:G400-G407.

Björnsson ES, Chey WD, Ladabaum U, Woods ML, Hooper FG, Owyang C, and Hasler WL (1998) Differential 5- $\mathrm{HT}_{3}$ mediation of human gastrocolonic response and colonic peristaltic reflex. Am J Physiol 275:G498-G505.

Blanpain C, Le Poul E, Parma J, Knoop C, Detheux M, Parmentier M, Vassart G, and Abramowicz MJ (2003) Serotonin 5-HT( ${ }_{2 \mathrm{~B}}$ ) receptor loss of function mutation in a patient with fenfluramine-associated primary pulmonary hypertension. Car diovasc Res 60:518-528.

Blessing WW and Seaman B (2003) 5-hydroxytryptamine(2A) receptors regulate sympathetic nerves constricting the cutaneous vascular bed in rabbits and rats. Neuroscience 117:939-948.

Bliziotes MM, Eshleman AJ, Zhang XW, and Wiren KM (2001) Neurotransmitter action in osteoblasts: expression of a functional system for serotonin receptor activation and reuptake. Bone 29:477-486.

Blomeley C and Bracci E (2005) Excitatory effects of serotonin on rat striatal cholinergic interneurones. $J$ Physiol 569:715-721.

Blomeley CP and Bracci E (2009) Serotonin excites fast-spiking interneurons in the striatum. Eur J Neurosci 29:1604-1614.

Blondel O, Gastineau M, Dahmoune Y, Langlois M, and Fischmeister R (1998) Cloning, expression, and pharmacology of four human 5-hydroxytryptamine 4 receptor isoforms produced by alternative splicing in the carboxyl terminus. J Neurochem 70:2252-2261.
Blondel O, Vandecasteele G, Gastineau M, Leclerc S, Dahmoune Y, Langlois M, and Fischmeister R (1997) Molecular and functional characterization of a 5-HT receptor cloned from human atrium. FEBS Lett 412:465-474.

Blough BE, Landavazo A, Decker AM, Partilla JS, Baumann MH, and Rothman RB (2014) Interaction of psychoactive tryptamines with biogenic amine transporters and serotonin receptor subtypes. Psychopharmacology (Berl) 231:4135-4144.

Blundell JE (1999) The control of appetite: basic concepts and practical implications. Schweiz Med Wochenschr 129:182-188.

Blundell JE, Lawton CL, and Halford JC (1995) Serotonin, eating behavior, and fat intake. Obes Res 3 (Suppl 4):471S-476S.

Bocchio M, Fucsina G, Oikonomidis L, McHugh SB, Bannerman DM, Sharp T, and Capogna M (2015) Increased serotonin transporter expression reduces fear and recruitment of parvalbumin interneurons of the amygdala. Neuropsychopharmacology 40:3015-3026.

Boccuto L, Chen CF, Pittman AR, Skinner CD, McCartney HJ, Jones K, Bochner BR, Stevenson RE, and Schwartz CE (2013) Decreased tryptophan metabolism in patients with autism spectrum disorders. Mol Autism 4:16.

Bockaert J, Claeysen S, Bécamel C, Dumuis A, and Marin P (2006) Neuronal 5-HT metabotropic receptors: fine-tuning of their structure, signaling, and roles in synaptic modulation. Cell Tissue Res 326:553-572.

Bockaert J, Claeysen S, Compan V, and Dumuis A (2004a) 5-HT4 receptors. Curr Drug Targets CNS Neurol Disord 3:39-51.

Bockaert J, Claeysen S, Compan V, and Dumuis A (2008) 5-HT(4) receptors: history, molecular pharmacology and brain functions. Neuropharmacology 55:922-931.

Bockaert J, Claeysen S, Compan V, and Dumuis A (2011) 5-HT(4) receptors, a place in the sun: act two. Curr Opin Pharmacol 11:87-93.

Bockaert J, Claeysen S, Dumuis A, and Marin P (2010a) Classification and signaling characteristics of 5-HT receptors, in Handbook of the Behavioural Neurobiology of Serotonin (Muller CP and Jacobs B eds) pp 103-122, Elesevier, London.

Bockaert J, Dumuis A, Bouhelal R, Sebben M, and Cory RN (1987) Piperazine derivatives including the putative anxiolytic drugs, buspirone and ipsapirone, are agonists at 5-HT1A receptors negatively coupled with adenylate cyclase in hippocampal neurons. Naunyn Schmiedebergs Arch Pharmacol 335:588-592.

Bockaert J, Dumuis A, Fagni L, and Marin P (2004b) GPCR-GIP networks: a first step in the discovery of new therapeutic drugs? Curr Opin Drug Discov Devel 7 : 649-657.

Bockaert J, Fagni L, and Dumuis A (1997) 5- $\mathrm{HT}_{4}$ Receptors: An update, in Serotoninergic Neurons and 5-HT Receptors in the CNS, Handbook of Experimental Pharmacology, (Baumgarten HG and Göthert M eds) pp 439-465, Spinger-Verlag, New York.

Bockaert J and Marin P (2015) mTOR in brain physiology and pathologies. Physiol Rev 95:1157-1187.

Bockaert J, Marin P, Dumuis A, and Fagni L (2003) The 'magic tail' of G proteincoupled receptors: an anchorage for functional protein networks. FEBS Lett 546: 65-72.

Bockaert J, Perroy J, Bécamel C, Marin P, and Fagni L (2010b) GPCR interacting proteins (GIPs) in the nervous system: roles in physiology and pathologies. Annu Rev Pharmacol Toxicol 50:89-109.

Bockaert J and Pin JP (1999) Molecular tinkering of G protein-coupled receptors: an evolutionary success. EMBO J 18:1723-1729.

Bockaert J, Sebben M, and Dumuis A (1990) Pharmacological characterization of 5 -hydroxytryptamine4(5-HT4) receptors positively coupled to adenylate cyclase in adult guinea pig hippocampal membranes: effect of substituted benzamide derivatives. Mol Pharmacol 37:408-411.

Boddeke HWGM, Hoffman BJ, Palacios JM, and Hoyer D (1993) Calcineurin inhibits desensitization of cloned rat 5-HT1C receptors. Naunyn Schmiedebergs Arch Pharmacol 348:221-224.

Boddeke HW and Kalkman HO (1990) Zacopride and BRL 24924 induce an increase in EEG-energy in rats. Br J Pharmacol 101:281-284.

Boehme SA, Lio FM, Sikora L, Pandit TS, Lavrador K, Rao SP, and Sriramarao P (2004) Cutting edge: serotonin is a chemotactic factor for eosinophils and functions additively with eotaxin. J Immunol 173:3599-3603.

Boess FG, Lummis SC, and Martin IL (1992) Molecular properties of 5-hydroxytryptamine3 receptor-type binding sites purified from NG108-15 cells. J Neurochem 59:1692-1701.

Bombardi C and Di Giovanni G (2013) Functional anatomy of 5-HT2A receptors in the amygdala and hippocampal complex: relevance to memory functions. Exp Brain Res 230:427-439.

Bonasera SJ, Chu HM, Brennan TJ, and Tecott LH (2006) A null mutation of the serotonin 6 receptor alters acute responses to ethanol. Neuropsychopharmacology 31:1801-1813.

Bonaventure P, Aluisio L, Shoblock J, Boggs JD, Fraser IC, Lord B, Lovenberg TW, and Galici R (2011) Pharmacological blockade of serotonin $5-\mathrm{HT}_{7}$ receptor reverses working memory deficits in rats by normalizing cortical glutamate neurotransmission. PLoS One 6: 20210.

Bonaventure P, Dugovic C, Kramer M, De Boer P, Singh J, Wilson S, Bertelsen K, Di J, Shelton J, Aluisio L, et al. (2012) Translational evaluation of JNJ-18038683, a 5-hydroxytryptamine type 7 receptor antagonist, on rapid eye movement sleep and in major depressive disorder. J Pharmacol Exp Ther 342:429-440.

Bonaventure P, Guo H, Tian B, Liu X, Bittner A, Roland B, Salunga R, Ma XJ, Kamme F, Meurers B, et al. (2002a) Nuclei and subnuclei gene expression profiling in mammalian brain. Brain Res 943:38-47.

Bonaventure P, Hall H, Gommeren W, Cras P, Langlois X, Jurzak M, and Leysen JE (2000) Mapping of serotonin 5-HT(4) receptor mRNA and ligand binding sites in the post-mortem human brain. Synapse 36:35-46.

Bonaventure P, Kelly L, Aluisio L, Shelton J, Lord B, Galici R, Miller K, Atack J, Lovenberg TW, and Dugovic C (2007) Selective blockade of 5-hydroxytryptamine (5-HT)7 receptors enhances 5-HT transmission, antidepressant-like behavior, and rapid eye movement sleep suppression induced by citalopram in rodents. $J$ Pharmacol Exp Ther 321:690-698. 
Bonaventure P, Nepomuceno D, Kwok A, Chai W, Langlois X, Hen R, Stark K, Carruthers N, and Lovenberg TW (2002b) Reconsideration of 5-hydroxytryptamine $(5-\mathrm{HT})(7)$ receptor distribution using $[(3) \mathrm{H}] 5$-carboxamidotryptamine and $[(3) \mathrm{H}] 8$ hydroxy-2-(di-n-propylamino)tetraline: analysis in brain of 5-HT(1A) knockout and 5-HT(1A/1B) double-knockout mice. J Pharmacol Exp Ther 302:240-248.

Bonaventure P, Schotte A, Cras P, and Leysen JE (1997) Autoradiographic mapping of 5-HT1B- and 5-HT1D receptors in human brain using [3H]alniditan, a new radioligand. Receptors Channels 5:225-230.

Bonhaus DW, Bach C, DeSouza A, Salazar FHR, Matsuoka BD, Zuppan P, Chan HW, and Eglen RM (1995) The pharmacology and distribution of human 5-hydroxytryptamine ${ }_{2 \mathrm{~B}}\left(5-\mathrm{HT}_{2 \mathrm{~B}}\right)$ receptor gene products: comparison with 5 -HT2A and 5-HT2C receptors. Br J Pharmacol 115:622-628.

Bonhaus DW, Flippin LA, Greenhouse RJ, Jaime S, Rocha C, Dawson M, Van Natta K, Chang LK, Pulido-Rios T, Webber A, et al. (1999) RS-127445: a selective, high affinity, orally bioavailable $5-\mathrm{HT}_{2 \mathrm{~B}}$ receptor antagonist. $\mathrm{Br} J$ Pharmacol 127: 1075-1082.

Bonhaus DW, Loury DN, Jakeman LB, To Z, DeSouza A, Eglen RM, and Wong EH (1993) [3H]BIMU-1, a 5-hydroxytryptamine3 receptor ligand in NG-108 cells, selectively labels sigma-2 binding sites in guinea pig hippocampus. J Pharmacol Exp Ther 267:961-970.

Bonhaus DW, Weinhardt KK, Taylor M, DeSouza A, McNeeley PM, Szczepanski K, Fontana DJ, Trinh J, Rocha CL, Dawson MW, et al. (1997) RS-102221: a novel high affinity and selective, 5-HT2C receptor antagonist. Neuropharmacology 36: $621-629$

Bonifati V, Fabrizio E, Cipriani R, Vanacore N, and Meco G (1994) Buspirone in levodopa-induced dyskinesias. Clin Neuropharmacol 17:73-82.

Bonn M, Schmitt A, Lesch KP, Van Bockstaele EJ, and Asan E (2013) Serotonergic innervation and serotonin receptor expression of NPY-producing neurons in the rat lateral and basolateral amygdaloid nuclei. Brain Struct Funct 218:421-435

Bonnin A, Peng W, Hewlett W, and Levitt P (2006) Expression mapping of 5-HT1 serotonin receptor subtypes during fetal and early postnatal mouse forebrain development. Neuroscience 141:781-794.

Bonnycastle DD, Giarman NJ, and Paasonen MK (1957) Anticonvulsant compounds and 5-hydroxytryptamine in rat brain. Br J Pharmacol Chemother 12:228-231.

Bonsi P, Cuomo D, Ding J, Sciamanna G, Ulrich S, Tscherter A, Bernardi G, Surmeier DJ, and Pisani A (2007) Endogenous serotonin excites striatal cholinergic interneurons via the activation of 5-HT 2C, 5-HT6, and 5-HT7 serotonin receptors: implications for extrapyramidal side effects of serotonin reuptake inhibitors. Neuropsychopharmacology 32:1840-1854.

Boothman LJ, Mitchell SN, and Sharp T (2006) Investigation of the SSRI augmentation properties of 5-HT(2) receptor antagonists using in vivo microdialysis Neuropharmacology 50:726-732.

Bootle DJ, Adcock JJ, and Ramage AG (1998) The role of central 5-HT receptors in the bronchoconstriction evoked by inhaled capsaicin in anaesthetised guinea-pigs. Neuropharmacology 37:243-250.

Borman RA and Burleigh DE (1996) Human colonic mucosa possesses a mixed population of 5-HT receptors. Eur J Pharmacol 309:271-274.

Borman RA, Tilford NS, Harmer DW, Day N, Ellis ES, Sheldrick RL, Carey J, Coleman RA, and Baxter GS (2002) $5-\mathrm{HT}_{2 \mathrm{~B}}$ ) receptors play a key role in mediating the excitatory effects of 5 -HT in human colon in vitro. $\mathrm{Br} J$ Pharmacol $\mathbf{1 3 5}$ $1144-1151$.

Bornert O, Møller TC, Boeuf J, Candusso MP, Wagner R, Martinez KL, and Simonin $\mathrm{F}$ (2013) Identification of a novel protein-protein interaction motif mediating interaction of GPCR-associated sorting proteins with G protein-coupled receptors. PLoS One 8:e56336.

Borroto-Escuela DO, Romero-Fernandez W, Tarakanov AO, Marcellino D, Ciruela F, Agnati LF, and Fuxe K (2010) Dopamine D2 and 5-hydroxytryptamine 5- $\mathrm{HT}_{2} \mathrm{~A}$ receptors assemble into functionally interacting heteromers. Biochem Biophys Res Commun 401:605-610.

Borsini F, Bordi F, Poggi A, and Di Matteo V (2015) Effects of ST1936, a selective serotonin-6 agonist, on electrical activity of putative mesencephalic dopaminergic neurons in the rat brain. $J$ Psychopharmacol 29:802-811.

Borsini F, Evans K, Jason K, Rohde F, Alexander B, and Pollentier S (2002) Pharmacology of flibanserin. CNS Drug Rev 8:117-142.

Bortolozzi A, Masana M, Díaz-Mataix L, Cortés R, Scorza MC, Gingrich JA, Toth M, and Artigas F (2010) Dopamine release induced by atypical antipsychotics in prefrontal cortex requires $5-\mathrm{HT}(1 \mathrm{~A})$ receptors but not 5 - $\mathrm{HT}(2 \mathrm{~A})$ receptors. Int $J$ Neuropsychopharmacol 13:1299-1314.

Böttner M, Barrenschee M, Hellwig I, Harde J, Egberts JH, Becker T, Zorenkov D, and Wedel T (2013) The enteric serotonergic system is altered in patients with diverticular disease. Gut 62:1753-1762

Bou J, Domènech T, Gras J, Beleta J, and Llenas J (1997) Pharmacological profile of almotriptan, a novel antimigraine agent. Cephalalgia 17:421-422.

Bouchelet I, Case B, Olivier A, and Hamel E (2000) No contractile effect for 5-HT and $5-\mathrm{HT}_{1 \mathrm{~F}}$ receptor agonists in human and bovine cerebral arteries: similarity with human coronary artery. Br J Pharmacol 129:501-508.

Bouchelet I, Cohen Z, Case B, Séguéla P, and Hamel E (1996) Differential expression of sumatriptan-sensitive 5-hydroxytryptamine receptors in human trigeminal ganglia and cerebral blood vessels. Mol Pharmacol 50:219-223.

Bouhelal R, Smounya L, and Bockaert J (1988) 5-HT1B receptors are negatively coupled with adenylate cyclase in rat substantia nigra. Eur J Pharmacol 151 189-196.

Boulay D, Depoortère R, Louis C, Perrault G, Griebel G, and Soubrie P (2004) SSR181507, a putative atypical antipsychotic with dopamine D2 antagonist and 5-HT1A agonist activities: improvement of social interaction deficits induced by phencyclidine in rats. Neuropharmacology 46:1121-1129.

Boulay D, Ho-Van S, Bergis O, Avenet P, and Griebel G (2013) Phencyclidine decreases tickling-induced $50-\mathrm{kHz}$ ultrasound vocalizations in juvenile rats: a putative model of the negative symptoms of schizophrenia? Behav Pharmacol 24: 543-551.
Boulenguez P, Segu L, Chauveau J, Morel A, Lanoir J, and Delaage M (1992) Biochemical and pharmacological characterization of serotonin-O carboxymethylglycyl[125I]iodotyrosinamide, a new radioiodinated probe for 5-HT1B and 5-HT1D binding sites. $J$ Neurochem 58:951-959.

Bourdon DM, Camden JM, Landon LA, Levy FO, and Turner JT (2000) Identification of the adenylyl cyclase-activating 5-hydroxytryptamine receptor subtypes expressed in the rat submandibular gland. Br J Pharmacol 130:104-108.

Bourson A, Borroni E, Austin RH, Monsma FJ Jr, and Sleight AJ (1995) Determination of the role of the 5-ht6 receptor in the rat brain: a study using antisense oligonucleotides. J Pharmacol Exp Ther 274:173-180.

Boyd GW, Doward AI, Kirkness EF, Millar NS, and Connolly CN (2003) Cell surface expression of 5-hydroxytryptamine type 3 receptors is controlled by an endoplasmic reticulum retention signal. J Biol Chem 278:27681-27687.

Bowersox SS, Lightning LK, Rao S, Palme M, Ellis D, Coleman R, Davies AM, Kumaraswamy P, and Druzgala P (2011) Metabolism and pharmacokinetics of naronapride (ATI-7505), a serotonin 5-HT(4) receptor agonist for gastrointestinal motility disorders. Drug Metab Dispos 39:1170-1180.

Bradley PB, Engel G, Feniuk W, Fozard JR, Humphrey PPA, Middlemiss DN, Mylecharane EJ, Richardson BP, and Saxena PR (1986) Proposals for the classification and nomenclature of functional receptors for 5-hydroxytryptamine. Neuropharmacology 25:563-576.

Brady CA, Dover TJ, Massoura AN, Princivalle AP, Hope AG, and Barnes NM (2007) Identification of 5-HT3A and 5-HT3B receptor subunits in human hippocampus. Neuropharmacology 52:1284-1290.

Brady CA, Stanford IM, Ali I, Lin L, Williams JM, Dubin AE, Hope AG, and Barnes NM (2001) Pharmacological comparison of human homomeric 5-HT3A receptors versus heteromeric 5-HT3A/3B receptors. Neuropharmacology 41:282-284.

Brailov I, Bancila M, Brisorgueil MJ, Miquel MC, Hamon M, and Vergé D (2000) Localization of 5-HT(6) receptors at the plasma membrane of neuronal cilia in the rat brain. Brain Res 872:271-275

Brattelid T, Kvingedal AM, Krobert KA, Andressen KW, Bach T, Hystad ME, Kaumann AJ, and Levy FO (2004a) Cloning, pharmacological characterisation and tissue distribution of a novel $5-\mathrm{HT}_{4}$ receptor splice variant, $5-\mathrm{HT}_{4(\mathrm{i})}$. Naunyn Schmiedebergs Arch Pharmacol 369:616-628.

Brattelid T, Qvigstad E, Birkeland JA, Swift F, Bekkevold SV, Krobert KA, Sejersted OM, Skomedal T, Osnes JB, Levy FO, et al. (2007a) Serotonin responsiveness through $5-\mathrm{HT}_{2 \mathrm{~A}}$ and $5-\mathrm{HT}_{4}$ receptors is differentially regulated in hypertrophic and failing rat cardiac ventricle. J Mol Cell Cardiol 43:767-779.

Brattelid T, Qvigstad E, Lynham JA, Molenaar P, Aass H, Geiran O, Skomedal T, Osnes JB, Levy FO, and Kaumann AJ (2004b) Functional serotonin 5-HT Hecep- $_{4}$ tors in porcine and human ventricular myocardium with increased 5 - $\mathrm{HT}_{4}$ mRNA in heart failure. Naunyn Schmiedebergs Arch Pharmacol 370:157-166.

Brattelid T, Qvigstad E, Moltzau LR, Bekkevold SV, Sandnes DL, Birkeland JA Skomedal T, Osnes JB, Sjaastad I, and Levy FO (2012) The cardiac ventricular $5-\mathrm{HT}_{4}$ receptor is functional in late foetal development and is reactivated in heart failure. PLoS One 7:e45489.

Brattelid T, Tveit K, Birkeland JA, Sjaastad I, Qvigstad E, Krobert KA, Hussain RI, Skomedal T, Osnes JB, and Levy FO (2007b) Expression of mRNA encoding G protein-coupled receptors involved in congestive heart failure-a quantitative RT-PCR study and the question of normalisation. Basic Res Cardiol 102:198-208.

Brenchat A, Ejarque M, Zamanillo D, Vela JM, and Romero L (2011) Potentiation of morphine analgesia by adjuvant activation of 5-HT7 receptors. J Pharmacol Sci 116:388-391.

Brenchat A, Nadal X, Romero L, Ovalle S, Muro A, Sánchez-Arroyos R, PortilloSalido E, Pujol M, Montero A, Codony X, et al. (2010) Pharmacological activation of 5-HT7 receptors reduces nerve injury-induced mechanical and thermal hypersensitivity. Pain 149:483-494.

Brenchat A, Rocasalbas M, Zamanillo D, Hamon M, Vela JM, and Romero L (2012a) Assessment of 5-HT(7) receptor agonists selectivity using nociceptive and thermoregulation tests in knockout versus wild-type mice. Adv Pharmacol Sci 2012: 312041

Brenchat A, Romero L, García M, Pujol M, Burgueño J, Torrens A, Hamon M, Baeyens JM, Buschmann H, Zamanillo D, et al. (2009) 5-HT7 receptor activation inhibits mechanical hypersensitivity secondary to capsaicin sensitization in mice. Pain 141:239-247.

Brenchat A, Zamanillo D, Hamon M, Romero L, and Vela JM (2012b) Role of peripheral versus spinal 5-HT(7) receptors in the modulation of pain undersensitizing conditions. Eur J Pain 16:72-81.

Briddon SJ, Leslie RA, and Elliott JM (1998) Comparative desensitization of the human 5-HT2A and 5-HT2C receptors expressed in the human neuroblastoma cell line SH-SY5Y. Br J Pharmacol 125:727-734.

Briejer MR, Schuurkes JA, and Sarna SK (1999) Idiopathic constipation: too few stools and too little knowledge. Trends Pharmacol Sci 20:1-3.

Broad J, Góralczyk A, Mannur K, Dukes GE, and Sanger GJ (2014a) Drugs acting at $5-\mathrm{HT}_{4}, \mathrm{D}_{2}$, motilin, and ghrelin receptors differ markedly in how they affect neuromuscular functions in human isolated stomach. Neurogastroenterol Motil 26: $851-861$

Broad J, Hughes F, Chin-Aleong J, Sifrim D, and Sanger GJ (2014b) Regionally dependent neuromuscular functions of motilin and 5- $\mathrm{HT}_{4}$ receptors in human isolated esophageal body and gastric fundus. Neurogastroenterol Motil 26: $1311-1322$

Broad J, Kung VWS, Boundouki G, Aziz Q, De Maeyer JH, Knowles CH, and Sanger GJ (2013) Cholinergic interactions between donepezil and prucalopride in human colon: potential to treat severe intestinal dysmotility. $\mathrm{Br} J$ Pharmacol 170 $1253-1261$

Broad J, Mukherjee S, Samadi M, Martin JE, Dukes GE, and Sanger GJ (2012) Regional- and agonist-dependent facilitation of human neurogastrointestinal functions by motilin receptor agonists. $\mathrm{Br} J$ Pharmacol 167:763-774.

Brodney MA, Johnson DE, Sawant-Basak A, Coffman KJ, Drummond EM, Hudson EL, Fisher KE, Noguchi H, Waizumi N, McDowell LL, et al. (2012) Identification of 
multiple 5- $\mathrm{HT}_{4}$ partial agonist clinical candidates for the treatment of Alzheimer's disease. $J$ Med Chem 55:9240-9254.

Brodsky M, Gibson AW, Smirnov D, Nair SG, and Neumaier JF (2016) Striatal 5-HT6 receptors regulate cocaine reinforcement in a pathway-selective manner. Neuropsychopharmacology 41:2377-2387.

Bromidge SM, Brown AM, Clarke SE, Dodgson K, Gager T, Grassam HL, Jeffrey PM, Joiner GF, King FD, Middlemiss DN, et al. (1999) 5-Chloro-N-(4-methoxy-3piperazin-1-yl- phenyl)-3-methyl-2-benzothiophenesulfon- amide (SB-271046): a potent, selective, and orally bioavailable 5-HT6 receptor antagonist. J Med Chem 42:202-205.

Bromidge SM, Duckworth M, Forbes IT, Ham P, King FD, Thewlis KM, Blaney FE, Naylor CB, Blackburn TP, Kennett GA, et al. (1997) 6-Chloro-5-methyl-1-[[2-[(2methyl-3-pyridyl)oxy]-5-pyridyl]carbamoyl]- indoline (SB-242084): the first selective and brain penetrant 5-HT2C receptor antagonist. J Med Chem 40:3494-3496.

Brookes S.J, Ewart WR, and Wingate DL (1987) Intracellular recordings from myenteric neurones in the human colon. J Physiol 390:305-318.

Brouard JT, Schweimer JV, Houlton R, Burnham KE, Quérée P, and Sharp T (2015) Pharmacological evidence for 5-HT6 receptor modulation of 5-HT neuron firing in vivo. ACS Chem Neurosci 6:1241-1247.

Brown AM, Avenell K, Young TJ, Ho M, Porter RA, and Vimal M (1998a) BRL 54443, a potent agonist with selectivity for human cloned 5-Ht1E and 5-Ht1F receptors. Br J Pharmacol 123:233.

Brown AM, Ho M, Thomas DR, and Parsons AA (1998c) Functional effects of frovatriptan (VML 251), sumatriptan and naratriptan on human recombinant 5-HT1 and 5-HT7 receptors. Headache 38:c376.

Brown AM, Hope AG, Lambert JJ, and Peters JA (1998b) Ion permeation and conduction in a human recombinant 5-HT3 receptor subunit (h5-HT3A). J Physiol 507: 653-665.

Brown AM, Patch TL, and Kaumann AJ (1991) The antimigraine drugs ergotamine and dihydroergotamine are potent 5 -HT1C receptor agonists in piglet choroid plexus. Br J Pharmacol 104:45-48.

Brown PM, Drossman DA, Wood AJ, Cline GA, Frazier KS, Jackson JI, Bronner J, Freiman J, Zambrowicz B, Sands A, et al. (2011) The tryptophan hydroxylase inhibitor LX1031 shows clinical benefit in patients with nonconstipating irritable bowel syndrome. Gastroenterology 141:507-516.

Brownfield MS, Poff BC, and Holzwarth MA (1985) Ultrastructural immunocytochemical co-localization of serotonin and PNMT in adrenal medullary vesicles. Histochemistry 83:41-46.

Brudeli B, Andressen KW, Moltzau LR, Nilsen NO, Levy FO, and Klaveness J (2013a) Acidic biphenyl derivatives: synthesis and biological activity of a new series of potent 5- $\mathrm{HT}_{4}$ receptor antagonists. Bioorg Med Chem 21:7134-7145.

Brudeli B, Moltzau LR, Andressen KW, Krobert KA, Klaveness J, and Levy FO (2010) Synthesis and pharmacological properties of novel hydrophilic 5 - $\mathrm{HT}_{4}$ receptor antagonists. Bioorg Med Chem 18:8600-8613.

Brudeli B, Moltzau LR, Nguyen CH, Andressen KW, Nilsen NO, Levy FO, and Klaveness J (2013b) Synthesis and pharmacological properties of a new hydrophilic and orally bioavailable 5-HT4 antagonist. Eur J Med Chem 64:629-637.

Brudeli B, Navaratnarajah M, Andressen KW, Manfra O, Moltzau LR, Nilsen NO, Levy FO, and Klaveness J (2014) Discovery and pharmacological profile of new hydrophilic 5- $\mathrm{HT}_{(4)}$ receptor antagonists. Bioorg Med Chem Lett 24:4598-4602.

Bruheim S, Krobert KA, Andressen KW, and Levy FO (2003) Unaltered agonist potency upon inducible $5-\mathrm{HT}_{7(\mathrm{a})}$ but not 5 - $\mathrm{HT}_{4(\mathrm{~b})}$ receptor expression indicates agonist-independent association of $5-\mathrm{HT}_{7(\mathrm{a})}$ receptor and $\mathrm{G}_{\mathrm{s}}$. Receptors Channels $\mathbf{9}$ : 107-116.

Bruins Slot LA, Kleven MS, and Newman-Tancredi A (2005) Effects of novel antipsychotics with mixed $\mathrm{D}(2)$ antagonist/5-HT(1A) agonist properties on PCP-induced social interaction deficits in the rat. Neuropharmacology 49:996-1006.

Bruinvels AT, Landwehrmeyer B, Gustafson EL, Durkin MM, Mengod G, Branchek TA, Hoyer D, and Palacios JM (1994a) Localization of 5-HT1B, 5-HT1D $\alpha, 5-H T 1 E$ and 5 -HT1F receptor messenger RNA in rodent and primate brain. Neurophar macology 33:367-386.

Bruinvels AT, Landwehrmeyer B, Moskowitz MA and Hoyer D (1992a) Evidence for the presence of 5-HT1B receptor messenger RNA in neurons of the rat trigeminal ganglia. Eur J Pharmacol 227:357-359.

Bruinvels AT, Landwehrmeyer B, Probst A, Palacios JM, and Hoyer D (1994b) A comparative autoradiographic study of 5-HT1D binding sites in human and guinea-pig brain using different radioligands. Brain Res Mol Brain Res 21:19-29

Bruinvels AT, Landwehrmeyer B, Waeber C, Palacios JM, and Hoyer D (1991) Homogeneous 5-HT1D recognition sites in the human substantia nigra identified with a new iodinated radioligand. Eur J Pharmacol 202:89-91.

Bruinvels AT, Lery H, Nozulak J, Palacios JM, and Hoyer D (1992b) 5-HT1D binding sites in various species: similar pharmacological profile in dog, monkey, calf, guinea-pig and human brain membranes. Naunyn Schmiedebergs Arch Pharmacol 346:243-248.

Bruinvels AT, Palacios JM, and Hoyer D (1993a) Autoradiographic characterisation and localisation of 5-HT1D compared to 5-HT1B binding sites in rat brain. Naunyn Schmiedebergs Arch Pharmacol 347:569-582.

Bruinvels AT, Palacios JM, and Hoyer D (1993b) 5-hydroxytryptamine1 recognition sites in rat brain: heterogeneity of non-5-hydroxytryptamine $1 \mathrm{~A} / 1 \mathrm{C}$ binding sites revealed by quantitative receptor autoradiography. Neuroscience 53:465-473.

Brüss M, Barann M, Hayer-Zillgen M, Eucker T, Göthert M, and Bönisch H (2000) Modified 5-HT3A receptor function by co-expression of alternatively spliced human 5-HT3A receptor isoforms. Naunyn Schmiedebergs Arch Pharmacol 362:392-401.

Bubar MJ and Cunningham KA (2006) Serotonin 5-HT2A and 5-HT2C receptors as potential targets for modulation of psychostimulant use and dependence. Curr Top Med Chem 6:1971-1985.

Bubar MJ and Cunningham KA (2007) Distribution of serotonin 5-HT2C receptors in the ventral tegmental area. Neuroscience 146:286-297.

Bubar MJ and Cunningham KA (2008) Prospects for serotonin 5-HT2R pharmacotherapy in psychostimulant abuse. Prog Brain Res 172:319-346.
Bubar MJ, Stutz SJ, and Cunningham KA (2011) 5-HT(2C) receptors localize to dopamine and GABA neurons in the rat mesoaccumbens pathway. PLoS One 6: e20508.

Buchanan D and Muirhead K (2007) Intractable nausea and vomiting successfully related with granisetron 5-hydroxytryptamine type 3 receptor antagonists in $\mathrm{Pal}$ liative Medicine. Palliat Med 21:725-726.

Bucholtz EC, Brown RL, Tropsha A, Booth RG, and Wyrick SD (1999) Synthesis, evaluation, and comparative molecular field analysis of 1-phenyl-3-amino-1,2,3,4tetrahydronaphthalenes as ligands for histamine $\left.\mathrm{H}_{1}\right)$ receptors. J Med Chem 42 3041-3054

Buckland PR, Hoogendoorn B, Guy CA, Smith SK, Coleman SL, and O'Donovan MC (2005) Low gene expression conferred by association of an allele of the 5-HT2C receptor gene with antipsychotic-induced weight gain. Am J Psychiatry 162: 613-615.

Buhner S and Schemann M (2012) Mast cell-nerve axis with a focus on the human gut. Biochim Biophys Acta 1822:85-92.

Buhot MC, Wolff M, Savova M, Malleret G, Hen R, and Segu L (2003) Protective effect of 5-HT1B receptor gene deletion on the age-related decline in spatia learning abilities in mice. Behav Brain Res 142:135-142.

Buiter HJ, Windhorst AD, Huisman MC, De Maeyer JH, Schuurkes JA, Lammertsma AA, and Leysen JE (2013) Radiosynthesis and preclinical evaluation of [11C]prucalopride as a potential agonist PET ligand for the 5-HT4 receptor. EJNMMI Res 3:24.

Bülbring E and Gershon MD (1967) 5-hydroxytryptamine participation in the vagal inhibitory innervation of the stomach. J Physiol 192:823-846.

Bülbring E and Lin RC (1958) The effect of intraluminal application of 5-hydroxytryptamine and 5-hydroxytryptophan on peristalsis; the local production of 5-HT and its release in relation to intraluminal pressure and propulsive activity. J Physiol 140:381-407.

Bulenger S, Marullo S, and Bouvier M (2005) Emerging role of homo- and heterodimerization in G-protein-coupled receptor biosynthesis and maturation. Trends Pharmacol Sci 26:131-137.

Bundeff AW and Woodis CB (2014) Selective serotonin reuptake inhibitors for the treatment of irritable bowel syndrome. Ann Pharmacother 48:777-784.

Burbassi S and Cervo L (2008) Stimulation of serotonin2C receptors influences cocaine-seeking behavior in response to drug-associated stimuli in rats. Psychopharmacology (Berl) 196:15-27.

Buritova J, Berrichon G, Cathala C, Colpaert F, and Cussac D (2009) Region-specific changes in 5-HT1A agonist-induced extracellular signal-regulated kinases 1/2 phosphorylation in rat brain: a quantitative ELISA study. Neuropharmacology $\mathbf{5 6}$ $350-361$.

Burke JE and Dennis EA (2009a) Phospholipase A2 biochemistry. Cardiovasc Drugs Ther 23:49-59.

Burke JE and Dennis EA (2009b) Phospholipase A2 structure/function, mechanism, and signaling. J Lipid Res 50 (Suppl):S237-S242.

Burke LK, Doslikova B, D’Agostino G, Greenwald-Yarnell M, Georgescu T, Chianese R, Martinez de Morentin PB, Ogunnowo-Bada E, Cansell C, Valencia-Torres L, et al. (2016) Sex difference in physical activity, energy expenditure and obesity driven by a subpopulation of hypothalamic POMC neurons. Mol Metab 5:245-252.

Burnet PW, Chen CP, McGowan S, Franklin M, and Harrison PJ (1996) The effects of clozapine and haloperidol on serotonin-1A, $-2 \mathrm{~A}$ and $-2 \mathrm{C}$ receptor gene expression and serotonin metabolism in the rat forebrain. Neuroscience 73:531-540.

Burnet PW, Eastwood SL, Lacey K, and Harrison PJ (1995) The distribution of 5-HT1A and 5-HT2A receptor mRNA in human brain. Brain Res 676:157-168.

Burnham KE, Baxter MG, Bainton JR, Southam E, Dawson LA, Bannerman DM and Sharp T (2010) Activation of 5-HT(6) receptors facilitates attentional set shifting. Psychopharmacology (Berl) 208:13-21.

Burns CM, Chu $\mathrm{H}$, Rueter SM, Hutchinson LK, Canton $\mathrm{H}$, Sanders-Bush $\mathrm{E}$, and Emeson RB (1997) Regulation of serotonin-2C receptor G-protein coupling by RNA editing. Nature 387:303-308.

Bush E, Fielitz J, Melvin L, Martinez-Arnold M, McKinsey TA, Plichta R, and Olson EN (2004) A small molecular activator of cardiac hypertrophy uncovered in a chemical screen for modifiers of the calcineurin signaling pathway. Proc Natl Acad Sci USA 101:2870-2875.

Bush TG, Spencer NJ, Watters N, Sanders KM, and Smith TK (2001) Effects of alosetron on spontaneous migrating motor complexes in murine small and large bowel in vitro. Am J Physiol Gastrointest Liver Physiol 281:G974-G983.

Buydens-Branchey L, Branchey M, Fergeson P, Hudson J, and McKernin C (1997) The meta-chlorophenylpiperazine challenge test in cocaine addicts: hormonal and psychological responses. Biol Psychiatry 41:1071-1086.

Buzzi MG and Moskowitz MA (1991) Evidence for 5-HT H $_{1 \mathrm{D}}$ receptors mediating the antimigraine effect of sumatriptan and dihydroergotamine. Cephalalgia 11: 165-168

Cahoy JD, Emery B, Kaushal A, Foo LC, Zamanian JL, Christopherson KS, Xing Y, Lubischer JL, Krieg PA, Krupenko SA, et al. (2008) A transcriptome database for astrocytes, neurons, and oligodendrocytes: a new resource for understanding brain development and function. J Neurosci 28:264-278.

Cai X, Flores-Hernandez J, Feng J, and Yan Z (2002) Activity-dependent bidirectiona regulation of GABA(A) receptor channels by the 5-HT(4) receptor-mediated signalling in rat prefrontal cortical pyramidal neurons. J Physiol 540:743-759.

Caillé F, Morley TJ, Tavares AA, Papin C, Twardy NM, Alagille D, Lee HS, Baldwin RM, Seibyl JP, Barret O, et al. (2013) Synthesis and biological evaluation of positron emission tomography radiotracers targeting serotonin 4 receptors in brain [18F]MNI-698 and [18F]MNI-699. Bioorg Med Chem Lett 23:6243-6247.

Calogero AE, Bagdy G, Szemeredi K, Tartaglia ME, Gold PW, and Chrousos GP (1990) Mechanisms of serotonin receptor agonist-induced activation of the hypothalamic-pituitary-adrenal axis in the rat. Endocrinology 126:1888-1894.

Camilleri M (2011) LX-1031, a tryptophan 5-hydroxylase inhibitor, and its potential in chronic diarrhea associated with increased serotonin. Neurogastroenterol Motil 23:193-200. 
Camilleri M (2014) Physiological underpinnings of irritable bowel syndrome: neurohormonal mechanisms. J Physiol 592:2967-2980.

Camilleri M, Atanasova E, Carlson PJ, Ahmad U, Kim HJ, Viramontes BE, McKinzie S, and Urrutia R (2002) Serotonin-transporter polymorphism pharmacogenetics in diarrhea-predominant irritable bowel syndrome. Gastroenterology 123:425-432.

Camilleri M, Vazquez-Roque MI, Burton D, Ford T, McKinzie S, Zinsmeister AR, and Druzgala P (2007) Pharmacodynamic effects of a novel prokinetic 5-HT receptor agonist, ATI-7505, in humans. Neurogastroenterol Motil 19:30-38.

Camilleri M and Von der Ohe MR (1994) Drugs affecting serotonin receptors. Baillieres Clin Gastroenterol 8:301-319.

Campbell BM and Merchant KM (2003) Serotonin 2C receptors within the basolateral amygdala induce acute fear-like responses in an open-field environment. Brain Res 993:1-9.

Canal CE, Booth RG, and Morgan D (2013) Support for 5-HT2C receptor functional selectivity in vivo utilizing structurally diverse, selective 5-HT2C receptor ligands and the 2,5-dimethoxy-4-iodoamphetamine elicited head-twitch response model. Neuropharmacology 70:112-121.

Canal CE, Cordova-Sintjago TC, Villa NY, Fang LJ, and Booth RG (2011) Drug discovery targeting human 5-HT(2C) receptors: residues S3.36 and Y7.43 impact ligand-binding pocket structure via hydrogen bond formation. Eur J Pharmacol 673:1-12.

Canal CE, Felsing DE, Liu Y, Zhu W, Wood JT, Perry CK, Vemula R, and Booth RG (2015) An orally active phenylaminotetralin-chemotype serotonin 5-HT7 and 5-HT1A receptor partial agonist that corrects motor stereotypy in mouse models. ACS Chem Neurosci 6:1259-1270.

Candura SM, Messori E, Franceschetti GP, D'Agostino G, Vicini D, Tagliani M, and Tonini M (1996) Neural 5-HT4 receptors in the human isolated detrusor muscle: effects of indole, benzimidazolone and substituted benzamide agonists and antagonists. Br J Pharmacol 118:1965-1970.

Canton H, Emeson RB, Barker EL, Backstrom JR, Lu JT, Chang MS, and SandersBush E (1996) Identification, molecular cloning, and distribution of a short variant of the 5-hydroxytryptamine ${ }_{2 \mathrm{C}}$ receptor produced by alternative splicing. Mol Pharmacol 50:799-807.

Cao BJ and Rodgers RJ (1997) Comparative behavioural profiles of buspirone and its metabolite 1-(2-pyrimidinyl)-piperazine (1-PP) in the murine elevated plus-maze. Neuropharmacology 36:1089-1097.

Carhart-Harris RL, Bolstridge M, Rucker J, Day CM, Erritzoe D, Kaelen M Bloomfield M, Rickard JA Forbes B, Feilding A et al (2016) Psilocybin with psychological support for treatment-resistant depression: an open-label feasibility study. Lancet Psychiatry 3:619-627.

Carlton J, Bujny M, Rutherford A, and Cullen P (2005) Sorting nexins-unifying trends and new perspectives. Traffic 6:75-82.

Carmel L, Koonin EV, and Dracheva S (2012) Dependencies among editing sites in serotonin 2C receptor mRNA. PLOS Comput Biol 8:e1002663.

Carr DB, Cooper DC, Ulrich SL, Spruston N, and Surmeier DJ (2002) Serotonin receptor activation inhibits sodium current and dendritic excitability in prefrontal cortex via a protein kinase C-dependent mechanism. $J$ Neurosci 22:6846-6855.

Carrel D, Masson J, Al Awabdh S, Capra CB, Lenkei Z, Hamon M, Emerit MB, and Darmon M (2008) Targeting of the 5-HT1A serotonin receptor to neuronal dendrites is mediated by Yif1B. J Neurosci 28:8063-8073.

Carroll P, Renoncourt Y, Gayet O, De Bovis B, and Alonso S (2001) Sorting nexin-14, a gene expressed in motoneurons trapped by an in vitro preselection method. Dev Dyn 221:431-442.

Carter BL and Tiffany ST (1999) Meta-analysis of cue-reactivity in addiction research. Addiction 94:327-340.

Cartier D, Jégou S, Parmentier F, Lihrmann I, Louiset E, Kuhn JM, Bastard C, Plouin PF, Godin M, Vaudry H, et al. (2005) Expression profile of serotonin4 (5HT4) receptors in adrenocortical aldosterone-producing adenomas. Eur $J$ Endocrinol 153:939-947.

Castillo M, Mulet J, Gutiérrez LM, Ortiz JA, Castelán F, Gerber S, Sala S, Sala F, and Criado M (2005) Dual role of the RIC-3 protein in trafficking of serotonin and nicotinic acetylcholine receptors. J Biol Chem 280:27062-27068.

Cates LN, Roberts AJ, Huitron-Resendiz S, and Hedlund PB (2013) Effects of lurasidone in behavioral models of depression. Role of the $5-\mathrm{HT}_{7}$ receptor subtype. Neuropharmacology 70:211-217.

Cathala A, Devroye C, Maitre M, Piazza PV, Abrous DN, Revest JM, and Spampinato U (2015) Serotonin2C receptors modulate dopamine transmission in the nucleus accumbens independently of dopamine release: behavioral, neurochemical and molecular studies with cocaine. Addict Biol 20:445-457.

Celada P, Puig M, Amargós-Bosch M, Adell A, and Artigas F (2004) The therapeutic role of 5-HT1A and 5-HT2A receptors in depression. J Psychiatry Neurosci 29:252-265.

Cellek S, John AK, Thangiah R, Dass NB, Bassil AK, Jarvie EM, Lalude O, Vivekanandan S, and Sanger GJ (2006) 5-HT4 receptor agonists enhance both cholinergic and nitrergic activities in human isolated colon circular muscle. Neurogastroenterol Motil 18:853-861.

Centurión D, Ortiz MI, Saxena PR, and Villalón CM (2002) The atypical 5-HT2 receptor mediating tachycardia in pithed rats: pharmacological correlation with the 5-HT2A receptor subtype. Br J Pharmacol 135:1531-1539.

Centurión D, Sánchez-López A, De Vries P, Saxena PR, and Villalón CM (2001) The GR127935 sensitive 5-HT(1) receptors mediating canine internal carotid vasoconstriction: resemblance of the 5-HT(1B) but not to the 5-HT (1D) or 5-ht $(1 \mathrm{~F})$, receptor subtypes. Br. J Pharmacol 132:991-998.

Cervantes-Durán C, Vidal-Cantú GC, Barragán-Iglesias P, Pineda-Farias JB, BravoHernández M, Murbartián J, and Granados-Soto V (2012) Role of peripheral and spinal 5-HT2B receptors in formalin-induced nociception. Pharmacol Biochem Behav 102:30-35.

Cettomai D and McArthur JC (2009) Mirtazapine use in human immunodeficiency virus-infected patients with progressive multifocal leukoencephalopathy. Arch Neurol 66:255-258
Chabbi-Achengli Y, Launay J-M, Maroteaux L, de Vernejoul MC, and Collet C (2013) Serotonin $2 \mathrm{~B}$ receptor (5-HT2B R) signals through prostacyclin and PPAR- $\beta / \delta$ in osteoblasts. PLoS One 8:e75783.

Chai W, Chan KY, de Vries R, van den Bogeardt AJ, de Maeyer JH, Schuurkes JA, Villalón CM, Saxena PR, Danser AH, and MaassenVanDenBrink A (2012) Inotropic effects of prokinetic agents with $5-\mathrm{HT}_{4}$ ) receptor agonist actions on human isolated myocardial trabeculae. Life Sci 90:538-544.

Chadha A, Sur C, Atack J, and Duty S (2000) The 5HT(1B) receptor agonist, CP-93129, inhibits [(3)H]-GABA release from rat globus pallidus slices and reverses akinesia following intrapallidal injection in the reserpine-treated rat. $\mathrm{Br} J$ Pharmacol 130:1927-1932.

Chalecka-Franaszek E, Chen H, and Chuang DM (1999) 5-Hydroxytryptamine2A receptor stimulation induces activator protein-1 and cyclic AMP-responsive element binding with cyclic AMP-responsive element-binding protein and Jun D as common components in cerebellar neurons. Neuroscience 88:885-898.

Chalmers DT and Watson SJ (1991) Comparative anatomical distribution of 5-HT1A receptor mRNA and 5-HT1A binding in rat brain-a combined in situ hybridisation/in vitro receptor autoradiographic study. Brain Res 561:51-60.

Chamienia AL and Johns EJ (1994) The renal functional responses to 5-HT1A receptor agonist, flesinoxan, in anaesthetized, normotensive rat. $\mathrm{Br} J$ Pharmaco 112:214-218.

Chan KY, Vermeersch S, de Hoon J, Villalón CM, and Maassenvandenbrink A (2011) Potential mechanisms of prospective antimigraine drugs: a focus on vascular (side) effects. Pharmacol Ther 129:332-351.

Chan SY and Loscalzo J (2008) Pathogenic mechanisms of pulmonary arterial hypertension. J Mol Cell Cardiol 44:14-30.

Chang FW, Burke JA, and Potter DE (1985) Mechanism of the ocular hypotensive action of ketanserin. $J$ Ocul Pharmacol 1:137-147.

Chang M, Zhang L, Tam JP, and Sanders-Bush E (2000) Dissecting G protein-coupled receptor signaling pathways with membrane-permeable blocking peptides. Endogenous 5-HT(2C) receptors in choroid plexus epithelial cells. J Biol Chem 275 7021-7029.

Chang S, Bezprozvannaya S, Li S, and Olson EN (2005) An expression screen reveals modulators of class II histone deacetylase phosphorylation. Proc Natl Acad Sci USA 102:8120-8125.

Chang WC, Ng JK, Nguyen T, Pellissier L, Claeysen S, Hsiao EC, and Conklin BR (2007) Modifying ligand-induced and constitutive signaling of the human 5-HT4 receptor. PLoS One 2:e1317.

Chaouche-Teyara K, Fournier B, Safar M, and Dabiré H (1994) Systemic and regional haemodynamic effects of 1-(2,5-dimethoxy-4-iodo-phenyl)-2-aminopropane (DOI) and alpha-methyl-5-HT, in the anaesthetised rat. Clin Exp Hypertens 16:779-798 Charest A, Wainer BH, and Albert PR (1993) Cloning and differentiation-induced expression of a murine serotonin1A receptor in a septal cell line. $J$ Neurosci 13: $5164-5171$

Chattopadhyaya B, Baho E, Huang ZJ, Schachner M, and Di Cristo G (2013) Neural cell adhesion molecule-mediated Fyn activation promotes GABAergic synapse maturation in postnatal mouse cortex. $J$ Neurosci 33:5957-5968.

Chen H, Qiang H, Fan K, Wang S, and Zheng Z (2014) The snoRNA MBII-52 regulates cocaine-induced conditioned place preference and locomotion in mice. PLoS One 9:e99986.

Chen JJ, Vasko MR, Wu X, Staeva TP, Baez M, Zgombick JM, and Nelson DL (1998a) Multiple subtypes of serotonin receptors are expressed in rat sensory neurons in culture. J Pharmacol Exp Ther 287:1119-1127.

Chen J-X, Pan H, Rothman TP, Wade PR, and Gershon MD (1998b) Guinea pig 5-HT transporter: cloning, expression, distribution, and function in intestinal sensory reception. Am J Physiol 275:G433-G448.

Chen K, Yang W, Grimsby J, and Shih JC (1992) The human 5-HT2 receptor is encoded by a multiple intron-exon gene. Brain Res Mol Brain Res 14:20-26.

Chen Y, Baez M, and Yu L (1994) Functional coupling of the 5-HT2C serotonin receptor to G proteins in Xenopus oocytes. Neurosci Lett 179:100-102.

Chen Y, Leon-Ponte M, Pingle SC, O'Connell PJ, and Ahern GP (2015) T lymphocytes possess the machinery for 5-HT synthesis, storage, degradation and release. Acta Physiol (Oxf) 213:860-867.

Cheng A, Bollan KA, Greenwood SM, Irving AJ, and Connolly CN (2007) Differential subcellular localization of RIC-3 isoforms and their role in determining 5-HT3 receptor composition. J Biol Chem 282:26158-26166.

Cheng A, McDonald NA, and Connolly CN (2005) Cell surface expression of 5 -hydroxytryptamine type 3 receptors is promoted by RIC-3. J Biol Chem 280: 22502-22507.

Cheng J, Giguere PM, Schmerberg CM, Pogorelov VM, Rodriguiz RM, Huang XP, Zhu H, McCorvy JD, Wetsel WC, Roth BL, et al. (2016) Further advances in optimizing (2-phenylcyclopropyl)methylamines as novel serotonin $2 \mathrm{C}$ agonists: effects on hyperlocomotion, prepulse inhibition, and cognition models. J Med Chem $\mathbf{5 9}$ 578-591.

Chenu F, Shim S, El Mansari M, and Blier P (2014) Role of melatonin, serotonin $2 \mathrm{~B}$, and serotonin $2 \mathrm{C}$ receptors in modulating the firing activity of rat dopamine neurons. J Psychopharmacol 28:162-167.

Chetty N, Coupar IM, Tan YY, Desmond PV, and Irving HR (2009) Distribution of serotonin receptors and interacting proteins in the human sigmoid colon. Neurogastroenterol Motil 21:551-558, e14-e15.

Childress AR, Mozley PD, McElgin W, Fitzgerald J, Reivich M, and O'Brien CP (1999) Limbic activation during cue-induced cocaine craving. Am J Psychiatry 156: $11-18$

Chinuck RS, Fortnum H, and Baldwin DR (2007) Appetite stimulants in cystic fibrosis: a systematic review. J Hum Nutr Diet 20:526-537.

Choi D-S, Birraux G, Launay J-M, and Maroteaux L (1994) The human serotonin 5 - $\mathrm{HT}_{2 \mathrm{~B}}$ receptor: pharmacological link between 5 -HT2 and 5 -HT1D receptors. FEBS Lett 352:393-399. 
Choi D-S and Maroteaux L (1996) Immunohistochemical localisation of the serotonin $5-\mathrm{HT}_{2 \mathrm{~B}}$ receptor in mouse gut, cardiovascular system, and brain. FEBS Lett 391: $45-51$.

Choi YH, Kang H, Lee WK, Kim T, Rhim H, and Yu YG (2007) An inhibitory compound against the interaction between $\mathrm{G}$ alpha(s) and the third intracellular loop region of serotonin receptor subtype 6 (5-HT6) disrupts the signaling pathway of 5-HT6. Exp Mol Med 39:335-342.

Choudhary MS, Craigo S, and Roth BL (1992) Identification of receptor domains that modify ligand binding to 5-hydroxytryptamine 2 and 5-hydroxytryptamine1c serotonin receptors. Mol Pharmacol 42:627-633.

Choudhary MS, Craigo S, and Roth BL (1993) A single point mutation (Phe340 $>$ Leu340) of a conserved phenylalanine abolishes 4-[125I]iodo-(2,5-dimethoxy)phenylisopropylamine and $[3 \mathrm{H}]$ mesulergine but not $[3 \mathrm{H}]$ ketanserin binding to 5-hydroxytryptamine2 receptors. Mol Pharmacol 43:755-761.

Choudhary MS, Sachs N, Uluer A, Glennon RA, Westkaemper RB, and Roth BL (1995) Differential ergoline and ergopeptine binding to 5-hydroxytryptamine2A receptors: ergolines require an aromatic residue at position 340 for high affinity binding [published erratum appears in Mol Pharmacol (1995) 48:568]. Mol Pharmacol 47:450-457.

Choung RS, Locke GR III, Francis DD, Katzka D, Winkle PJ, Orr WC, Crowell MD, Devault K, Harmsen WS, Zinsmeister AR, et al. (2014) Novel partial $5 \mathrm{HT}_{3}$ agonist pumosetrag reduces acid reflux events in uninvestigated GERD patients after a standard refluxogenic meal: a randomized, double-blind, placebo-controlled pharmacodynamic study. Neurogastroenterol Motil 26:13-20.

Christ T, Rozmaritsa N, Engel A, Berk E, Knaut M, Metzner K, Canteras M, Ravens U, and Kaumann A (2014) Arrhythmias, elicited by catecholamines and serotonin, vanish in human chronic atrial fibrillation. Proc Natl Acad Sci USA 111: 11193-11198.

Christianson JP, Ragole T, Amat J, Greenwood BN, Strong PV, Paul ED, Fleshner M, Watkins LR, and Maier SF (2010) 5-hydroxytryptamine 2C receptors in the basolateral amygdala are involved in the expression of anxiety after uncontrollable traumatic stress. Biol Psychiatry 67:339-345.

Christopoulos A, Changeux JP, Catterall WA, Fabbro D, Burris TP, Cidlowski JA Olsen RW, Peters JA, Neubig RR, Pin JP, et al. (2014) International Union of Basic and Clinical Pharmacology. XC. multisite pharmacology: recommendations for the nomenclature of receptor allosterism and allosteric ligands. Pharmacol Rev 66: 918-947.

Chun HR, Jeon IS, Park SY, Lee SJ, Kang SH, and Kim SI (2014) Efficacy of palonosetron for the prevention of postoperative nausea and vomiting: a randomized, double-blinded, placebo-controlled trial. Br J Anaesth 112:485-490.

Ciranna L and Catania MV (2014) 5-HT7 receptors as modulators of neuronal excitability, synaptic transmission and plasticity: physiological role and possible implications in autism spectrum disorders. Front Cell Neurosci 8:250.

Citrome L (2011) Iloperidone, asenapine, and lurasidone: a brief overview of 3 new second-generation antipsychotics. Postgrad Med 123:153-162.

Citrome L, Weiden PJ, McEvoy JP, Correll CU, Cucchiaro J, Hsu J, and Loebel A (2014) Effectiveness of lurasidone in schizophrenia or schizoaffective patients switched from other antipsychotics: a 6-month, open-label, extension study. CNS Spectr 19:330-339.

Claeysen S, Bockaert J, and Giannoni P (2015) Serotonin: a new hope in Alzheimer's disease? ACS Chem Neurosci 6:940-943.

Claeysen S, Faye P, Sebben M, Lemaire S, Bockaert J, Dumuis A, and Taviaux S (1997) Assignment of 5-hydroxytryptamine receptor (HTR4) to human chromosome 5 bands q31->q33 by in situ hybridization. Cytogenet Cell Genet 78:133-134.

Claeysen S, Sebben M, Becamel C, Bockaert J, and Dumuis A (1999) Novel brainspecific 5-HT4 receptor splice variants show marked constitutive activity: role of the C-terminal intracellular domain. Mol Pharmacol 55:910-920.

Claeysen S, Sebben M, Bécamel C, Eglen RM, Clark RD, Bockaert J, and Dumuis A (2000) Pharmacological properties of 5-Hydroxytryptamine(4) receptor antagonists on constitutively active wild-type and mutated receptors. Mol Pharmacol 58 $136-144$.

Claret FX, Hibi M, Dhut S, Toda T, and Karin M (1996) A new group of conserved coactivators that increase the specificity of AP-1 transcription factors. Nature 383 453-457.

Clarke DE, Craig DA, and Fozard JR (1989) The 5-HT4 receptor: naughty, but nice. Trends Pharmacol Sci 10:385-386.

Clarke WP, Yocca FD, and Maayani S (1996) Lack of 5-hydroxytryptamine1A-mediated inhibition of adenylyl cyclase in dorsal raphe of male and female rats. $J$ Pharmacol Exp Ther 277:1259-1266.

Classey JD, Bartsch T, and Goadsby PJ (2010) Distribution of 5-HT(1B), 5-HT(1D) and $5-\mathrm{HT}(1 \mathrm{~F})$ receptor expression in rat trigeminal and dorsal root ganglia neurons: relevance to the selective anti-migraine effect of triptans. Brain Res 1361: 76-85.

Claustre Y, Peretti DD, Brun P, Gueudet C, Allouard N, Alonso R, Lourdelet J, Oblin A, Damoiseau G, Francon D, et al. (2003) SSR181507, a dopamine D(2) receptor antagonist and 5-HT(1A) receptor agonist. I: neurochemical and electrophysiological profile. Neuropsychopharmacology 28:2064-2076.

Clayton AH, Dennerstein L, Pyke R, and Sand M (2010) Flibanserin: a potential treatment for Hypoactive Sexual Desire Disorder in premenopausal women. Womens Health (Lond) 6:639-653.

Clemett DA, Punhani T, Duxon MS, Blackburn TP, and Fone KC (2000) Immunohistochemical localisation of the 5-HT2C receptor protein in the rat CNS. Neuropharmacology 39:123-132.

Clifton PG, Lee MD, and Dourish CT (2000) Similarities in the action of Ro 60-0175, a 5-HT2C receptor agonist and d-fenfluramine on feeding patterns in the rat. Psychopharmacology (Berl) 152:256-267.

Clissold KA, Choi E, and Pratt WE (2013) Serotonin 1A, 1B, and 7 receptors of the rat medial nucleus accumbens differentially regulate feeding, water intake, and locomotor activity. Pharmacol Biochem Behav 112:96-103.
Clitherow JW, Scopes DI, Skingle M, Jordan CC, Feniuk W, Campbell IB, Carter MC, Collington EW, Connor HE, Higgins GA, et al. (1994) Evolution of a novel series of [(N,N-dimethylamino)propyl]- and piperazinylbenzanilides as the first selective 5-HT1D antagonists. J Med Chem 37:2253-2257.

Closse A (1983) [3H]Mesulergine, a selective ligand for serotonin-2 receptors. Life Sci 32:2485-2495.

Cochet M, Donneger R, Cassier E, Gaven F, Lichtenthaler SF, Marin P, Bockaert J, Dumuis A, and Claeysen S (2013) 5-HT4 receptors constitutively promote the nonamyloidogenic pathway of APP cleavage and interact with ADAM10. ACS Chem Neurosci 4:130-140.

Cockcroft V, Ortells M, and Lunt G (1995) Ligands, receptor models, and evolution. Ann N Y Acad Sci 757:40-47.

Codony X, Vela JM, and Ramírez MJ (2011) 5-HT(6) receptor and cognition. Curr Opin Pharmacol 11:94-100.

Cogolludo A, Moreno L, Lodi F, Frazziano G, Cobeño L, Tamargo J, and Perez-Vizcaino F (2006) Serotonin inhibits voltage-gated $\mathrm{K}+$ currents in pulmonary artery smooth muscle cells: role of 5-HT2A receptors, caveolin-1, and KV1.5 channel internalization. Circ Res 98:931-938.

Cohen LJ, Esterhazy D, Kim SH, Lemetre C, Aguilar RR, Gordon EA, Pickard AJ, Cross JR, Emiliano AB, Han SM, et al. (2017) Commensal bacteria make GPCR ligands that mimic human signalling molecules. Nature 549:48-53.

Cohen ML, Fuller RW, and Wiley KS (1981) Evidence for 5-HT 2 receptors mediating contraction in vascular smooth muscle. J Pharmacol Exp Ther 218:421-425.

Cohen ML, Galbreath EJ, Schenck KW, Li D, Hoffman BJ, and Bhattacharya A (2002) Lack of sumatriptan-induced aortic contraction or relaxation: 5- $\mathrm{HT}_{1 \mathrm{~B}}$ receptor protein detected in endothelium and smooth muscle of vasa vasorum but not aorta. Receptors Channels 8:71-78.

Cohen ML and Schenck K (1999) 5-Hydroxytryptamine ${ }_{1 \mathrm{~F}}$ ) receptors do not participate in vasoconstriction: lack of vasoconstriction to LY344864, a selective serotonin $(1 \mathrm{~F})$ receptor agonist in rabbit saphenous vein. J Pharmacol Exp Ther 290:935-939.

Cohen ML and Schenck K (2000) Contractile responses to sumatriptan and ergotamine in the rabbit saphenous vein: effect of selective $5-\mathrm{HT}\left({ }_{1 \mathrm{~F}}\right)$ receptor agonists and $\mathrm{PGF}_{(2,}$. Br J Pharmacol 131:562-568.

Cohen ML, Schenck KW, Mabry TE, Nelson DL, and Audia JE (1996) LY272015, a potent, selective and orally active $5-\mathrm{HT}_{2 \mathrm{~B}}$ receptor antagonist. J Serv Res 3:131-144.

Cohen P, Zhao C, Cai X, Montez JM, Rohani SC, Feinstein P, Mombaerts P, and Friedman JM (2001) Selective deletion of leptin receptor in neurons leads to obesity. J Clin Invest 108:1113-1121.

Cohen Z, Bouchelet I, Olivier A, Villemure JG, Ball R, Stanimirovic DB, and Hamel E (1999) Multiple microvascular and astroglial 5-hydroxytryptamine receptor subtypes in human brain: molecular and pharmacologic characterization. $J$ Cereb Blood Flow Metab 19:908-917.

Collet C, Schiltz C, Geoffroy V, Maroteaux L, Launay J-M, and de Vernejoul M-C (2008) The serotonin $5-\mathrm{HT}_{2 \mathrm{~B}}$ receptor controls bone mass via osteoblast recruitment and proliferation. FASEB J 22:418-427.

Collingridge GL, Peineau S, Howland JG, and Wang YT (2010) Long-term depression in the CNS. Nat Rev Neurosci 11:459-473.

Colpaert FC (2006) 5-HT(1A) receptor activation: new molecular and neuroadaptive mechanisms of pain relief. Curr Opin Investig Drugs 7:40-47.

Colpaert FC, Tarayre JP, Koek W, Pauwels PJ, Bardin L, Xu XJ, Wiesenfeld-Hallin Z, Cosi C, Carilla-Durand E, Assié MB, et al. (2002) Large-amplitude 5-HT1A receptor activation: a new mechanism of profound, central analgesia. Neuropharmacology 43:945-958

Comet MA, Bernard JF, Hamon M, Laguzzi R, and Sévoz-Couche C (2007) Activation of nucleus tractus solitarius $5-\mathrm{HT}_{2 \mathrm{~A}}$ but not other $5-\mathrm{HT}_{2}$ receptor subtypes inhibits the sympathetic activity in rats. Eur $J$ Neurosci 26:345-354.

Compan V, Daszuta A, Salin P, Sebben M, Bockaert J, and Dumuis A (1996) Lesion study of the distribution of serotonin 5-HT4 receptors in rat basal ganglia and hippocampus. Eur J Neurosci 8:2591-2598.

Compan V, Zhou M, Grailhe R, Gazzara RA, Martin R, Gingrich J, Dumuis A, Brunner D, Bockaert J, and Hen R (2004) Attenuated response to stress and novelty and hypersensitivity to seizures in 5-HT4 receptor knock-out mice. $J$ Neurosci 24:412-419.

Conn PJ, Christopoulos A, and Lindsley CW (2009) Allosteric modulators of GPCRs: a novel approach for the treatment of CNS disorders. Nat Rev Drug Discov 8:41-54

Conn PJ and Sanders-Bush E (1984) Selective 5HT-2 antagonists inhibit serotonin stimulated phosphatidylinositol metabolism in cerebral cortex. Neuropharmacology 23:993-996.

Conn PJ and Sanders-Bush E (1986a) Agonist-induced phosphoinositide hydrolysis in choroid plexus. $J$ Neurochem 47:1754-1760.

Conn PJ and Sanders-Bush E (1986b) Biochemical characterization of serotonin stimulated phosphoinositide turnover. Life Sci 38:663-669.

Conn PJ, Sanders-Bush E, Hoffman BJ, and Hartig PR (1986) A unique serotonin receptor in choroid plexus is linked to phosphatidylinositol turnover. Proc Natl Acad Sci USA 83:4086-4088.

Connolly HM, Crary JL, McGoon MD, Hensrud DD, Edwards BS, Edwards WD, and Schaff HV (1997) Valvular heart disease associated with fenfluramine-phentermine. $N$ Engl J Med 337:581-588.

Connor HE, Feniuk W, Beattie DT, North PC, Oxford AW, Saynor DA, and Humphrey PP (1997) Naratriptan: biological profile in animal models relevant to migraine. Cephalagia 17:145-152.

Contesse V, Lenglet S, Grumolato L, Anouar Y, Lihrmann I, Lefebvre H, Delarue C, and Vaudry H (1999) Pharmacological and molecular characterization of 5 -hydroxytryptamine(7) receptors in the rat adrenal gland. Mol Pharmacol 56 $552-561$

Cope DW, Di Giovanni G, Fyson SJ, Orbán G, Errington AC, Lorincz ML, Gould TM, Carter DA, and Crunelli V (2009) Enhanced tonic GABAA inhibition in typical absence epilepsy. Nat Med 15:1392-1398. 
Corbett DF, Heightman TD, Moss SF, Bromidge SM, Coggon SA, Longley MJ, Roa AM, Williams JA, and Thomas DR (2005) Discovery of a potent and selective 5-ht5A receptor antagonist by high-throughput chemistry. Bioorg Med Chem Lett 15:4014-4018

Cornea-Hébert V, Riad M, Wu C, Singh SK, and Descarries L (1999) Cellular and subcellular distribution of the serotonin 5-HT2A receptor in the central nervous system of adult rat. J Comp Neurol 409:187-209.

Cornea-Hébert V, Watkins KC, Roth BL, Kroeze WK, Gaudreau P, Leclerc N, and Descarries L (2002) Similar ultrastructural distribution of the 5-HT(2A) serotonin receptor and microtubule-associated protein MAP1A in cortical dendrites of adult rat. Neuroscience 113:23-35.

Corominas R, Sobrido MJ, Ribasés M, Cuenca-León E, Blanco-Arias P, Narberhaus B, Roig M, Leira R, López-González J, Macaya A, et al. (2010) Association study of the serotoninergic system in migraine in the Spanish population. Am J Med Genet B Neuropsychiatr Genet 153B:177-184.

Corradetti R, Mlinar B, Falsini C, Pugliese AM, Cilia A, Destefani C, and Testa R (2005) Differential effects of the 5-hydroxytryptamine (5-HT)1A receptor inverse agonists Rec 27/0224 and Rec 27/0074 on electrophysiological responses to 5-HT1A receptor activation in rat dorsal raphe nucleus and hippocampus in vitro. $J$ Pharmacol Exp Ther 315:109-117.

Corringer P-J, Poitevin F, Prevost MS, Sauguet L, Delarue M, and Changeux JP (2012) Structure and pharmacology of pentameric receptor channels: from bacteria to brain. Structure 20:941-956.

Cosi C and Koek W (2000) The putative < silent $>$ 5-HT(1A) receptor antagonist, WAY 100635, has inverse agonist properties at cloned human 5-HT(1A) receptors. Eur J Pharmacol 401:9-15.

Cosi C, Waget A, Rollet K, Tesori V, and Newman-Tancredi A (2005) Clozapine, ziprasidone and aripiprazole but not haloperidol protect against kainic acid-induced lesion of the striatum in mice, in vivo: role of 5-HT1A receptor activation. Brain Res 1043:32-41.

Costa L, Sardone LM, Lacivita E, Leopoldo M, and Ciranna L (2015) Novel agonists for serotonin 5-HT7 receptors reverse metabotropic glutamate receptor-mediated long-term depression in the hippocampus of wild-type and Fmr1 KO mice, a model of Fragile X Syndrome. Front Behav Neurosci 9:65.

Costa L, Spatuzza M, D’Antoni S, Bonaccorso CM, Trovato C, Musumeci SA, Leopoldo M, Lacivita E, Catania MV, and Ciranna L (2012) Activation of 5-HT7 serotonin receptors reverses metabotropic glutamate receptor-mediated synaptic plasticity in wild-type and Fmr1 knockout mice, a model of Fragile X syndrome. Biol Psychiatry 72:924-933.

Costa SK, Brain SD, Antunes E, De Nucci G, and Docherty RJ (2003) Phoneutria nigriventer spider venom activates $5-\mathrm{HT}_{4}$ receptors in rat-isolated vagus nerve. $\mathrm{Br}$ $J$ Pharmacol 139:59-64.

Costagliola C, Iuliano G, Rinaldi M, Russo V, Scibelli G, and Mastropasqua L (1993) Effect of topical ketanserin administration on intraocular pressure. $\mathrm{Br} J \mathrm{Oph}$ thalmol 77:344-348.

Costall B, Domeney AM, Naylor RJ, and Tattersall FD (1986) 5-Hydroxytryptamine M-receptor antagonism to prevent cisplatin-induced emesis. Neuropharmacology 25:959-961.

Costall B, Gunning SJ, Naylor RJ, and Tyers MB (1987) The effect of GR38032F, novel 5 - $\mathrm{HT}_{3}$-receptor antagonist on gastric emptying in the guinea-pig. $\mathrm{Br} J$ Pharmacol 91:263-264.

Costall B and Naylor RJ (1992) Anxiolytic potential of 5-HT3 receptor antagonists. Pharmacol Toxicol 70:157-162.

Coupar IM, Desmond PV, and Irving HR (2007) Human 5-HT(4) and 5-HT(7) receptor splice variants: are they important? Curr Neuropharmacol 5:224-231.

Couvineau A, Fabre C, Gaudin P, Maoret JJ, and Laburthe M (1996) Mutagenesis of $\mathrm{N}$-glycosylation sites in the human vasoactive intestinal peptide 1 receptor. Evidence that asparagine 58 or 69 is crucial for correct delivery of the receptor to plasma membrane. Biochemistry 35:1745-1752.

Craig DA and Clarke DE (1990) Pharmacological characterization of a neuronal receptor for 5-hydroxytryptamine in guinea pig ileum with properties similar to the 5-hydroxytryptamine receptor. J Pharmacol Exp Ther 252:1378-1386.

Craig DA and Martin GR (1993) 5-HT1B receptors mediate potent contractile responses to 5-HT in rat caudal artery. $\mathrm{Br} J$ Pharmacol 109:609-611.

Craige CP, Lewandowski S, Kirby LG, and Unterwald EM (2015) Dorsal raphe 5 -HT(2C) receptor and GABA networks regulate anxiety produced by cocaine withdrawal. Neuropharmacology 93:41-51.

Cremer SE, Moesgaard SG, Rasmussen CE, Zois NE, Falk T, Reimann MJ, Cirera S, Aupperle H, Oyama MA, and Olsen LH (2015a) Alpha-smooth muscle actin and serotonin receptors $2 \mathrm{~A}$ and ${ }_{2 \mathrm{~B}}$ in dogs with myxomatous mitral valve disease. Res Vet Sci 100:197-206.

Cremer SE, Zois NE, Moesgaard SG, Ravn N, Cirera S, Honge JL, Smerup MH, Hasenkam JM, Sloth E, Leifsson PS, et al. (2015b) Serotonin markers show altered transcription levels in an experimental pig model of mitral regurgitation. Vet $J$ 203:192-198

Cremers TI, Giorgetti M, Bosker FJ, Hogg S, Arnt J, Mørk A, Honig G, Bøgesø KP, Westerink BH, den Boer H, et al. (2004) Inactivation of 5-HT(2C) receptors potentiates consequences of serotonin reuptake blockade. Neuropsychopharmacology 29:1782-1789.

Cremers TI, Rea K, Bosker FJ, Wikström HV, Hogg S, Mørk A, and Westerink BH (2007) Augmentation of SSRI effects on serotonin by 5-HT2C antagonists: mechanistic studies. Neuropsychopharmacology 32:1550-1557.

Crow SJ and Mitchell JE (1994) Rational therapy of eating disorders. Drugs 48 372-379.

Crunelli V and Di Giovanni G (2014) Monoamine modulation of tonic GABAA in hibition. Rev Neurosci 25:195-206.

Crunelli V and Di Giovanni G (2015) Differential control by 5-HT and 5-HT1A, 2A, 2C receptors of phasic and tonic GABAA inhibition in the visual thalamus. CNS Neurosci Ther 21:967-970.

Cryan JF and Lucki I (2000) Antidepressant-like behavioral effects mediated by 5-Hydroxytryptamine(2C) receptors. J Pharmacol Exp Ther 295:1120-1126.
Csaba G and Sudár F (1978) Localization of radioactively labelled serotonin in the nucleus of adrenal medulla cells. Acta Anat (Basel) 100:237-240.

Cubeddu LX, Hoffmann IS, Fuenmayor NT, and Finn AL (1990) Efficacy of ondansetron (GR 38032F) and the role of serotonin in cisplatin-induced nausea and vomiting. N Engl J Med 322:810-816.

Cumberbatch MJ, Hill RG, and Hargreaves RJ (1998) The effects of 5-HT1A, 5-HT1B and 5-HT1D receptor agonists on trigeminal nociceptive neurotransmission in anaesthetized rats. Eur J Pharmacol 362:43-46.

Cumming-Hood PA, Strahlendorf HK, and Strahlendorf JC (1993) Effects of serotonin and the $5-\mathrm{HT}_{2 / 1 \mathrm{C}}$ receptor agonist DOI on neurons of the cerebellar dentate/interpositus nuclei: possible involvement of a GABAergic interneuron. Eur $J$ Pharmacol 236:457-465.

Cunningham KA and Anastasio NC (2014) Serotonin at the nexus of impulsivity and cue reactivity in cocaine addiction. Neuropharmacology 76:460-478.

Cunningham KA, Anastasio NC, Fox RG, Stutz SJ, Bubar MJ, Swinford SE, Watson CS, Gilbertson SR, Rice KC, Rosenzweig-Lipson S, et al. (2013) Synergism between a serotonin $5-\mathrm{HT}_{2 \mathrm{~A}}$ receptor $\left(5-\mathrm{HT}_{2 \mathrm{~A}} \mathrm{R}\right)$ antagonist and $5-\mathrm{HT}_{2 \mathrm{C}} \mathrm{R}$ agonist suggests new pharmacotherapeutics for cocaine addiction. ACS Chem Neurosci 4:110-121.

Cunningham KA, Fox RG, Anastasio NC, Bubar MJ, Stutz S.J, Moeller FG, Gilbertson SR, and Rosenzweig-Lipson S (2011) Selective serotonin 5-HT(2C) receptor activation suppresses the reinforcing efficacy of cocaine and sucrose but differentially affects the incentive-salience value of cocaine- vs. sucrose-associated cues. Neuropharmacology 61:513-523.

Curran MP and Robinson DM (2008) Mosapride in gastrointestinal disorders. Drugs 68:981-991.

Currow DC, Coughlan M, Fardell B, and Cooney NJ (1997) Use of ondansetron in palliative medicine. J Pain Symptom Manage 13:302-307.

Curtin PCP, Medan V, Neumeister H, Bronson DR, and Preuss T (2013) The 5-HT5A receptor regulates excitability in the auditory startle circuit: functional implications for sensorimotor gating. J Neurosci 33:10011-10020.

Cushing DJ, Zgombick JM, Nelson DL, and Cohen ML (1996) LY215840, a highaffinity 5-HT7 receptor ligand, blocks serotonin-induced relaxation in canine coronary artery. $J$ Pharmacol Exp Ther 277:1560-1566.

Cussac D, Boutet-Robinet E, Ailhaud MC, Newman-Tancredi A, Martel JC, Danty N, and Rauly-Lestienne I (2008) Agonist-directed trafficking of signalling at serotonin 5-HT2A, 5- $\mathrm{HT}_{2 \mathrm{~B}}$ and 5-HT2C-VSV receptors mediated $\mathrm{Gq} / 11$ activation and calcium mobilisation in CHO cells. Eur J Pharmacol 594:32-38.

Cussac D, Newman-Tancredi A, Quentric Y, Carpentier N, Poissonnet G, Parmentier JG, Goldstein S, and Millan MJ (2002) Characterization of phospholipase C activity at h5-HT2C compared with $\mathrm{h} 5-\mathrm{HT}_{2 \mathrm{~B}}$ receptors: influence of novel ligands upon membrane-bound levels of [3H]phosphatidylinositols. Naunyn Schmiedebergs Arch Pharmacol 365:242-252.

Cussac D, Rauly-Lestienne I, Heusler P, Finana F, Cathala C, Bernois S, and De Vries L (2012) $\mu$-Opioid and 5-HT1A receptors heterodimerize and show signalling crosstalk via G protein and MAP-kinase pathways. Cell Signal 24:1648-1657.

daCosta CJB and Baenziger JE (2013) Gating of pentameric ligand-gated ion channels: structural insights and ambiguities. Structure 21:1271-1283.

Dalley JW and Roiser JP (2012) Dopamine, serotonin and impulsivity. Neuroscience 215:42-58.

Dalton GL, Lee MD, Kennett GA, Dourish CT, and Clifton PG (2006) Serotonin 1B and $2 \mathrm{C}$ receptor interactions in the modulation of feeding behaviour in the mouse. Psychopharmacology (Berl) 185:45-57.

Damjanoska KJ, Muma NA, Zhang Y, D'Souza DN, Garcia F, Carrasco GA, Kindel GH, Haskins KA, Shankaran M, Petersen BR, et al. (2003) Neuroendocrine evidence that (S)-2-(chloro-5-fluoro-indol- 1-yl)-1-methylethylamine fumarate (Ro $60-0175$ ) is not a selective 5-hydroxytryptamine(2C) receptor agonist. J Pharmacol Exp Ther 304:1209-1216.

Dando SB, Skinner MR, Jordan D, and Ramage AG (1998) Modulation of the vagal bradycardia evoked by stimulation of upper airway receptors by central 5 -HT1 receptors in anaesthetized rabbits. Br J Pharmacol 125:409-417.

Dang H, England PM, Farivar SS, Dougherty DA, and Lester HA (2000) Probing the role of a conserved M1 proline residue in 5-hydroxytryptamine(3) receptor gating. Mol Pharmacol 57:1114-1122.

Danober L, Deransart C, Depaulis A, Vergnes M, and Marescaux C (1998) Pathophysiological mechanisms of genetic absence epilepsy in the rat. Prog Neurobiol 55: $27-57$.

Danysz W, Flik G, McCreary A, Tober C, Dimpfel W, Bizot JC, Kostrzewa R, Brown RW, Jatzke CC, Greco S, et al. (2015) Effects of sarizotan in animal models of ADHD: challenging pharmacokinetic-pharmacodynamic relationships. J Neural Transm (Vienna) 122:1221-1238.

da Roza Davis JM, Sharpley AL, and Cowen PJ (1992) Slow wave sleep and 5-HT2 receptor sensitivity in generalised anxiety disorder: a pilot study with ritanserin. Psychopharmacology (Berl) 108:387-389.

Das P and Dillon GH (2003) The 5-HT3B subunit confers reduced sensitivity to picrotoxin when co-expressed with the 5-HT3A receptor. Brain Res Mol Brain Res 119:207-212.

Daval G, Vergé D, Basbaum AI, Bourgoin S, and Hamon M (1987) Autoradiographic evidence of serotonin 1 binding sites on primary afferent fibres in the dorsal horn of the rat spinal cord. Neurosci Lett 83:71-76.

Davidson HI, Pilot M-A, and Thompson HH (1990) Involvement of 5-hydroxytryptamine in canine intestinal motility patterns. J Gastrointest Motil 2: $31-39$.

Davis JD, Smith GP, Singh B, and McCann DL (2001) The impact of sucrose-derived unconditioned and conditioned negative feedback on the microstructure of in gestive behavior. Physiol Behav 72:393-402.

Davies PA (2011) Allosteric modulation of the 5-HT(3) receptor. Curr Opin Pharmacol 11:75-80.

Davies PA, Pistis M, Hanna MC, Peters JA, Lambert JJ, Hales TG, and Kirkness EF (1999) The 5-HT3B subunit is a major determinant of serotonin-receptor function. Nature 397:359-363. 
Dawson LA (2011) The central role of 5-HT6 receptors in modulating brain neurochemistry. Int Rev Neurobiol 96:1-26.

Dawson LA and Watson JM (2009) Vilazodone: a 5-HT1A receptor agonist/serotonin transporter inhibitor for the treatment of affective disorders. CNS Neurosci Ther 15:107-117.

Dawson P, Opacka-Juffry J, Moffatt JD, Daniju Y, Dutta N, Ramsey J, and Davidson C (2014) The effects of benzofury (5-APB) on the dopamine transporter and 5-HT2dependent vasoconstriction in the rat. Prog Neuropsychopharmacol Biol Psychiatry 48:57-63.

Day M, Olson PA, Platzer J, Striessnig J, and Surmeier DJ (2002) Stimulation of 5 -HT(2) receptors in prefrontal pyramidal neurons inhibits $\mathrm{Ca}(\mathrm{v}) 1.2 \mathrm{~L}$ type $\mathrm{Ca}(2+)$ currents via a PLCbeta/IP3/calcineurin signaling cascade. J Neurophysiol 87: 2490-2504.

Dayer AG, Jacobshagen M, Chaumont-Dubel S, and Marin P (2015) 5-HT6 receptor: a new player controlling the development of neural circuits. ACS Chem Neurosci 6 951-960.

Dean B, Pavey G, Thomas D, and Scarr E (2006) Cortical serotonin , $_{1 \mathrm{D}}$ and $1 \mathrm{~F}$ receptors: effects of schizophrenia, suicide and antipsychotic drug treatment. Schizophr Res 88:265-274.

de Boer SF, Lesourd M, Mocaer E, and Koolhaas JM (2000) Somatodendritic 5 -HT(1A) autoreceptors mediate the anti-aggressive actions of 5-HT(1A) receptor agonists in rats: an ethopharmacological study with S-15535, alnespirone, and WAY-100635. Neuropsychopharmacology 23:20-33.

Deckert V, Pruneau D, and Elghazi JL (1994) Mediation by 5-HT1D receptors of 5 hydoxytryptamine-induced contractions of rabbit middle and posterior cerebral arteries. Br J Pharmacol 112:939-945

de Clerck F, David JL, and Janssen PAJ (1982) Inhibition of 5-hydroxytryptamineinduced and -amplified human platelet aggregation by ketanserin ( $\mathrm{R} 41468$ ), a selective 5-HT ${ }_{2}$-receptor antagonist. Agents Actions 12:388-397.

De Clerck F, Xhonneux B, Leysen J, and Janssen PAJ (1984) The involvement of 5-HT2-receptor sites in the activation of cat platelets. Thromb Res 33:305-321.

Dedeoğlu A and Fisher LA (1991) Central and peripheral injections of the 5-HT2 agonist, 1-(2,5-dimethoxy-4-iodophenyl)-2-aminopropane, modify cardiovascular function through different mechanisms. J Pharmacol Exp Ther 259:1027-1034.

Deeb TZ, Sharp D, and Hales TG (2009) Direct subunit-dependent multimodal 5-hydroxytryptamine3 receptor antagonism by methadone. Mol Pharmacol $\mathbf{7 5}$ : 908-917.

Dees C, Akhmetshina A, Zerr P, Reich N, Palumbo K, Horn A, Jüngel A, Beyer C, Krönke G, Zwerina J, et al. (2011) Platelet-derived serotonin links vascular disease and tissue fibrosis. J Exp Med 208:961-972.

De Filippis B, Chiodi V, Adriani W, Lacivita E, Mallozzi C, Leopoldo M, Domenici MR, Fuso A, and Laviola G (2015) Long-lasting beneficial effects of central serotonin receptor 7 stimulation in female mice modeling Rett syndrome. Front Behav Neurosci 9:86.

De Filippis B, Nativio P, Fabbri A, Ricceri L, Adriani W, Lacivita E, Leopoldo M, Passarelli F, Fuso A, and Laviola G (2014) Pharmacological stimulation of the brain serotonin receptor 7 as a novel therapeutic approach for Rett syndrome. Neuropsychopharmacology 39:2506-2518.

DeGeer J, Boudeau J, Schmidt S, Bedford F, Lamarche-Vane N, and Debant A (2013) Tyrosine phosphorylation of the Rho guanine nucleotide exchange factor Trio regulates netrin-1/DCC-mediated cortical axon outgrowth. Mol Cell Biol $\mathbf{3 3}$ 739-751.

Delaney C, Gien J, Roe G, Isenberg N, Kailey J, and Abman SH (2013) Serotonin contributes to high pulmonary vascular tone in a sheep model of persistent pulmonary hypertension of the newborn. Am J Physiol Lung Cell Mol Physiol 304: L894-L901.

Delarue C, Becquet D, Idres S, Hery F, and Vaudry H (1992) Serotonin synthesis in adrenochromaffin cells. Neuroscience 46:495-500.

de las Casas-Engel M, Domínguez-Soto A, Sierra-Filardi E, Bragado R, Nieto C, PuigKroger A, Samaniego R, Loza M, Corcuera MT, Gómez-Aguado F, et al. (2013) Serotonin skews human macrophage polarization through $\mathrm{HTR}_{2 \mathrm{~B}}$ and HTR7. $J$ Immunol 190:2301-2310.

Della Rocca GJ, Mukhin YV, Garnovskaya MN, Daaka Y, Clark GJ, Luttrell LM, Lefkowitz RJ, and Raymond JR (1999) Serotonin 5-HT1A receptor-mediated Erk activation requires calcium/calmodulin-dependent receptor endocytosis. $J$ Biol Chem 274:4749-4753.

Delmas P and Brown DA (2005) Pathways modulating neural KCNQ/M (Kv7) potassium channels. Nat Rev Neurosci 6:850-862.

Deloose E, Janssen P, Depoortere I, and Tack J (2012) The migrating motor complex: control mechanisms and its role in health and disease. Nat Rev Gastroenterol Hepatol 9:271-285.

de Luca C, Kowalski TJ, Zhang Y, Elmquist JK, Lee C, Kilimann MW, Ludwig T, Liu $\mathrm{SM}$, and Chua SC Jr (2005) Complete rescue of obesity, diabetes, and infertility in $\mathrm{db} / \mathrm{db}$ mice by neuron-specific LEPR-B transgenes. J Clin Invest 115:3484-3493.

De Lucchini S, Marracci S, and Nardi I (2001) The serotonin 5- $\mathrm{HT}_{2 \mathrm{~B}}$ receptor from the puffer fish Tetraodon fluviatilis: cDNA cloning, genomic organization and alternatively spliced variants. Brain Res Mol Brain Res 97:89-93.

De Lucchini S, Ori M, Cremisi F, Nardini M, and Nardi I (2005) 5- $\mathrm{HT}_{2 \mathrm{~B}}$-mediated serotonin signaling is required for eye morphogenesis in Xenopus. $\mathrm{Mol} \mathrm{Cell} \mathrm{Neu-}$ rosci 29:299-312

Delvaux M, Louvel D, Mamet JP, Campos-Oriola R, and Frexinos J (1998) Effect of alosetron on responses to colonic distension in patients with irritable bowel syndrome. Aliment Pharmacol Ther 12:849-855.

De Maeyer JH, Aerssens J, Verhasselt P, and Lefebvre RA (2008a) Alternative splicing and exon duplication generates 10 unique porcine 5-HT 4 receptor splice variants including a functional homofusion variant. Physiol Genomics 34:22-33.

De Maeyer JH, Lefebvre RA, and Schuurkes JA (2008b) 5-HT4 receptor agonists: similar but not the same. Neurogastroenterol Motil 20:99-112.

De Maeyer JH, Prins NH, Schuurkes JAJ, and Lefebvre RA (2006) Differential effects of 5-hydroxytryptamine ${ }_{4}$ receptor agonists at gastric versus cardiac receptors: an operational framework to explain and quantify organ-specific behavior. $J$ Pharmacol Exp Ther 317:955-964.

De Martelaere K, Lintermans B, Haegeman G, and Vanhoenacker P (2007) Novel interaction between the human 5-HT7 receptor isoforms and PLAC-24/eIF3k. Cell Signal 19:278-288.

De Vries P, Villalón CM, and Saxena PR (1999a) Pharmacological aspects of experimental headache models in relation to acute antimigraine therapy. Eur $J$ Pharmacol 375:61-74

De Vries P, Villalón CM, and Saxena PR (1999b) Pharmacology of triptans. Emerging Drugs 4:107-125.

Den Boer MO, Villalón CM, and Saxena PR (1992) 5?HT1?like receptor?mediated changes in porcine carotid haemodynamics: are 5?HT1D receptors involved?. Naunyn?Schmiedeberg's Arch. Pharmacol 345:509-515.

Deng PY and Lei S (2008) Serotonin increases GABA release in rat entorhinal cortex by inhibiting interneuron TASK-3 K+ channels. Mol Cell Neurosci 39:273-284.

Dentel C, Palamiuc L, Henriques A, Lannes B, Spreux-Varoquaux O, Gutknecht L, René F, Echaniz-Laguna A, Gonzalez de Aguilar J-L, Lesch KP, et al. (2013) Degeneration of serotonergic neurons in amyotrophic lateral sclerosis: a link to spasticity. Brain 136:483-493.

De Ponti F (2004) Pharmacology of serotonin: what a clinician should know. Gut 53: $1520-1535$

Depoortere I, Thijs T, and Peeters T (2006) The contractile effect of the ghrelin receptor antagonist, D-Lys3-GHRP-6, in rat fundic strips is mediated through 5-HT receptors. Eur J Pharmacol 537:160-165.

Depoortère R, Auclair AL, Bardin L, Bruins Slot L, Kleven MS, Colpaert F, Vacher B and Newman-Tancredi A (2007) F15063, a compound with D2/D3 antagonist, 5-HT $1 \mathrm{~A}$ agonist and D4 partial agonist properties. III. Activity in models of cognition and negative symptoms. Br J Pharmacol 151:266-277.

Depoortère R, Auclair AL, Bardin L, Colpaert FC, Vacher B, and Newman-Tancredi A (2010) F15599, a preferential post-synaptic 5-HT1A receptor agonist: activity in models of cognition in comparison with reference 5-HT1A receptor agonists. Eur Neuropsychopharmacol 20:641-654.

Depoortere R, Boulay D, Perrault G, Bergis O, Decobert M, Françon D, Jung M, Simiand J, Soubrié P, and Scatton B (2003) SSR181507, a dopamine D2 receptor antagonist and 5-HT1A receptor agonist. II: behavioral profile predictive of an atypical antipsychotic activity. Neuropsychopharmacology 28:1889-1902.

Deraet M, Manivet P, Janoshazi A, Callebert J, Guenther S, Drouet L, Launay JM and Maroteaux L (2005) The natural mutation encoding a $\mathrm{C}$ terminus-truncated 5-hydroxytryptamine ${ }_{2 \mathrm{~B}}$ receptor is a gain of proliferative functions. Mol Pharmacol 67:983-991.

Derangeon M, Bozon V, Defamie N, Peineau N, Bourmeyster N, Sarrouilhe D, Argibay JA, and Hervé J-C (2010) 5-HT4 and 5-HT2 receptors antagonistically influence gap junctional coupling between rat auricular myocytes. $J$ Mol Cell Cardiol 48:220-229. Dergacheva O, Wang X, Kamendi H, Cheng Q, Pinol RM, Jameson H, Gorini C, and Mendelowitz D (2008) 5HT2 receptor activation facilitates P2X receptor mediated excitatory neurotransmission to cardiac vagal neurons in the nucleus ambiguus. Neuropharmacology 54:1095-1102

Derkach V, Surprenant A, and North RA (1989) 5-HT3 receptors are membrane ion channels. Nature 339:706-709.

Descarries L, Cornea-Herbert V, and Riad M (2006) Cellular and subcellular localization of serotonin receptors in the central nervous system, in The Serotonin Receptors; From Molecular Pharmacology to Human Therapeutics (Roth BL ed) pp 277-317, Humana Press, Totowa, NJ

Devi LA (2001) Heterodimerization of G-protein-coupled receptors: pharmacology, signaling and trafficking. Trends Pharmacol Sci 22:532-537.

De Vivo M and Maayani S (1986) Characterization of the 5-hydroxytryptamine1a receptor-mediated inhibition of forskolin-stimulated adenylate cyclase activity in guinea pig and rat hippocampal membranes. J Pharmacol Exp Ther 238:248-253.

Devlin MG, Smith NJ, Ryan OM, Guida E, Sexton PM, and Christopoulos A (2004) Regulation of serotonin 5-HT2C receptors by chronic ligand exposure. Eur $J$ Pharmacol 498:59-69.

De Vries P, Apaydin S, Villalón CM, Heiligers JP, and Saxena PR (1997) Interactions of GR127935, a 5-HT(1B/D) receptor ligand, with functional 5-HT receptors. Naunyn Schmiedebergs Arch Pharmacol 355:423-430.

De Vries P, De Visser PA, Heiligers JP, Villalón CM, and Saxena PR (1999) Changes in systemic and regional haemodynamics during 5-HT7 receptor-mediated depressor responses in rats. Naunyn Schmiedebergs Arch Pharmacol 359:331-338.

De Vries P, Sánchez-López A, Centurión D, Heiligers JP, Saxena PR, and Villalón CM (1998) The canine external carotid vasoconstrictor 5-HT1 receptor: blockade by 5-HT1B (SB224289), but not by 5-HT1D (BRL15572) receptor antagonists. Eur J Pharmacol 362:69-72.

Devroye C, Cathala A, Di Marco B, Caraci F, Drago F, Piazza PV, and Spampinato U (2015) Central serotonin $(2 \mathrm{~B})$ receptor blockade inhibits cocaine-induced hyperlocomotion independently of changes of subcortical dopamine outflow. Neuropharmacology 97:329-337.

De Vry J, Benz U, Schreiber R, and Traber J (1993) Shock-induced ultrasonic vocalization in young adult rats: a model for testing putative anti-anxiety drugs. Eur $J$ Pharmacol 249:331-339.

De Vry J, Schreiber R, Melon C, Dalmus M, and Jentzsch KR (2004) 5-HT1A receptors are differentially involved in the anxiolytic- and antidepressant-like effects of 8-OH-DPAT and fluoxetine in the rat. Eur Neuropsychopharmacol 14:487-495.

de Wit R, Aapro M, and Blower PR (2005) Is there a pharmacological basis for differences in $5-\mathrm{HT}_{3}$-receptor antagonist efficacy in refractory patients? Cancer Chemother Pharmacol 56:231-238.

Diaz SL, Doly S, Narboux-Nême N, Fernández S, Mazot P, Banas SM, Boutourlinsky K, Moutkine I, Belmer A, Roumier A, et al. (2012) 5-HT( ${ }_{2 \mathrm{~B}}$ ) receptors are required for serotonin-selective antidepressant actions. Mol Psychiatry 17:154-163.

Diaz SL and Maroteaux L (2011) Implication of 5-HT( $\left(_{2 \mathrm{~B}}\right)$ receptors in the serotonin syndrome. Neuropharmacology 61:495-502. 
Dickson EJ, Heredia DJ, and Smith TK (2010) Critical role of 5- $\mathrm{HT}_{1 \mathrm{~A}}, 5-\mathrm{HT}_{3}$, and $5-\mathrm{HT}_{7}$ receptor subtypes in the initiation, generation, and propagation of the murine colonic migrating motor complex. Am J Physiol Gastrointest Liver Physiol 299: G144-G157.

Di Giovanni G and De Deurwaerdère P (2016) New therapeutic opportunities for 5-HT2C receptor ligands in neuropsychiatric disorders. Pharmacol Ther 157: $125-162$.

Di Giovanni G, De Deurwaerdére P, Di Mascio M, Di Matteo V, Esposito E, and Spampinato U (1999) Selective blockade of serotonin-2C/2B receptors enhances mesolimbic and mesostriatal dopaminergic function: a combined in vivo electrophysiological and microdialysis study. Neuroscience 91:587-597.

Di Giovanni G, Di Matteo V, La Grutta V, and Esposito E (2001) m-Chlorophenylpiperazine excites non-dopaminergic neurons in the rat substantia nigra and ventral tegmental area by activating serotonin-2C receptors. Neuroscience 103 $111-116$.

Di Giovanni G, Di Matteo V, Pierucci M, Benigno A, and Esposito E (2006) Central serotonin2C receptor: from physiology to pathology. Curr Top Med Chem 6 $1909-1925$

Di Giovanni G, Esposito E, and Di Matteo V (2010) 5-HT2C Receptors in the Pathophysiology of CNS Disease, Springer Science \& Business Media, New York.

Dijk DJ, Beersma DG, Daan S, and van den Hoofdakker RH (1989) Effects of seganserin, a 5-HT2 antagonist, and temazepam on human sleep stages and EEG power spectra. Eur J Pharmacol 171:207-218.

DiMagno L, Dascal N, Davidson N, Lester HA, and Schreibmayer W (1996) Serotonin and protein kinase $\mathrm{C}$ modulation of a rat brain inwardly rectifying $\mathrm{K}^{+}$channel expressed in xenopus oocytes. Pflugers Arch 431:335-340.

Di Maio D, Chandramouli B, and Brancato G (2015) Pathways and barriers for ion translocation through the 5-HT3A receptor channel. PLoS One 10:e140258.

Di Matteo V, Di Giovanni G, Di Mascio M, and Esposito E (1999) SB 242084, a selective serotonin2C receptor antagonist, increases dopaminergic transmission in the mesolimbic system. Neuropharmacology 38:1195-1205.

Di Matteo V, Di Giovanni G, Di Mascio M, and Esposito E (2000) Biochemical and electrophysiological evidence that RO 60-0175 inhibits mesolimbic dopaminergic function through serotonin(2C) receptors. Brain Res 865:85-90.

Dimitrova-Nakov S, Baudry A, Harichane Y, Collet C, Marchadier A, Kellermann O, and Goldberg M (2014) Deletion of serotonin ${ }_{2 B}$ receptor provokes structural alterations of mouse dental tissues. Calcif Tissue Int 94:293-300.

Di Narzo AF, Kozlenkov A, Ge Y, Zhang B, Sanelli L, May Z, Li Y, Fouad K, Cardozo C, Koonin EV, et al. (2015) Decrease of mRNA editing after spinal cord injury is caused by down-regulation of ADAR2 that is triggered by inflammatory response. Sci Rep 5:12615.

Di Narzo AF, Kozlenkov A, Roussos P, Hao K, Hurd Y, Lewis DA, Sibille E, Siever LJ, Koonin E, and Dracheva S (2014) A unique gene expression signature associated with serotonin $2 \mathrm{C}$ receptor RNA editing in the prefrontal cortex and altered in suicide. Hum Mol Genet 23:4801-4813.

Ding C, Bremer NM, Smith TD, Seitz PK, Anastasio NC, Cunningham KA, and Zhou $J$ (2012) Exploration of synthetic approaches and pharmacological evaluation of PNU-69176E and its stereoisomer as $5-\mathrm{HT}_{2 \mathrm{C}}$ receptor allosteric modulators. ACS Chem Neurosci 3:538-545.

Ding D, Toth M, Zhou Y, Parks C, Hoffman BJ, and Shenk T (1993) Glial cell-specific expression of the serotonin 2 receptor gene: selective reactivation of a repressed promoter. Brain Res Mol Brain Res 20:181-191.

Di Pilato P, Niso M, Adriani W, Romano E, Travaglini D, Berardi F, Colabufo NA, Perrone R, Laviola G, Lacivita E, et al. (2014) Selective agonists for serotonin 7 (5HT7) receptor and their applications in preclinical models: an overview. Rev Neurosci 25:401-415.

Dizeyi N, Bjartell A, Hedlund P, Taskén KA, Gadaleanu V, and Abrahamsson PA (2005) Expression of serotonin receptors ${ }_{2 B}$ and 4 in human prostate cancer tissue and effects of their antagonists on prostate cancer cell lines. Eur Urol 47:895-900.

Dizeyi N, Bjartell A, Nilsson E, Hansson J, Gadaleanu V, Cross N, and Abrahamsson PA (2004) Expression of serotonin receptors and role of serotonin in human prostate cancer tissue and cell lines. Prostate 59:328-336.

Doe CM, Relkovic D, Garfield AS, Dalley JW, Theobald DEH, Humby T, Wilkinson LS, and Isles AR (2009) Loss of the imprinted snoRNA mbii-52 leads to increased 5 htr2c pre-RNA editing and altered 5HT2CR-mediated behaviour. Hum Mol Genet 18:2140-2148

Dogrul A, Ossipov MH, and Porreca F (2009) Differential mediation of descending pain facilitation and inhibition by spinal 5HT-3 and 5HT-7 receptors. Brain Res 1280:52-59.

Dogrul A and Seyrek M (2006) Systemic morphine produce antinociception mediated by spinal 5-HT7, but not 5-HT1A and 5-HT2 receptors in the spinal cord. $\mathrm{Br} J$ Pharmacol 149:498-505.

Doherty MD and Pickel VM (2000) Ultrastructural localization of the serotonin 2A receptor in dopaminergic neurons in the ventral tegmental area. Brain Res $\mathbf{8 6 4}$ $176-185$.

Doly S, Bertran-Gonzalez J, Callebert J, Bruneau A, Banas SM, Belmer A, Boutourlinsky K, Hervé D, Launay JM, and Maroteaux L (2009) Role of serotonin via $5-\mathrm{HT}_{2 \mathrm{~B}}$ receptors in the reinforcing effects of MDMA in mice. PLoS One 4:e7952.

Doly S, Fischer J, Brisorgueil M-J, Vergé D, and Conrath M (2004) 5-HT5A receptor localization in the rat spinal cord suggests a role in nociception and control of pelvic floor musculature. J Comp Neurol 476:316-329.

Doly S, Fischer J, Brisorgueil M-J, Vergé D, and Conrath M (2005) Pre- and postsynaptic localization of the 5-HT7 receptor in rat dorsal spinal cord: immunocytochemical evidence. J Comp Neurol 490:256-269.

Doly S, Valjent E, Setola V, Callebert J, Hervé D, Launay JM, and Maroteaux L (2008) Serotonin 5- $\mathrm{HT}_{2 \mathrm{~B}}$ receptors are required for 3,4-methylenedioxymethamphetamine-induced hyperlocomotion and 5-HT release in vivo and in vitro. J Neurosci 28:2933-2940.
Doménech T, Beleta J, and Palacios JM (1997) Characterization of human serotonin $1 \mathrm{D}$ and $1 \mathrm{~B}$ receptors using [3H]-GR-125743, a novel radiolabelled serotonin 5HT1D/1B receptor antagonist. Naunyn Schmiedebergs Arch Pharmacol 356:328-334

Donaldson ZR, Piel DA, Santos TL, Richardson-Jones J, Leonardo ED, Beck SG, Champagne FA, and Hen R (2014) Developmental effects of serotonin 1A autoreceptors on anxiety and social behavior. Neuropsychopharmacology 39:291-302.

Donato R, Sorci G, Riuzzi F, Arcuri C, Bianchi R, Brozzi F, Tubaro C, and Giambanco I (2009) S100B's double life: intracellular regulator and extracellular signal. Biochim Biophys Acta 1793:1008-1022.

Donatsch P, Engel G, Richardson BP, and Stadler PA (1985) ICS 205-930: a hihgly selective adn potent antagonist at peripheral neuronal 5-hydroxytryptamine (5$\mathrm{HT}$ ) receptors. $\mathrm{Br} J$ Pharmacol 81:34P.

Doods HN, Boddeke HW, Kalkman HO, Hoyer D, Mathy MJ, and van Zwieten PA (1988) Central 5-HT $\mathrm{HT}_{1 \mathrm{~A}}$ receptors and the mechanism of the central hypotensive effect of (+)8-OH-DPAT, DP-5-CT, R28935, and urapidil. J Cardiovasc Pharmacol 11:432-437.

Doran N, McChargue D, and Spring B (2008) Effect of impulsivity on cardiovascular and subjective reactivity to smoking cues. Addict Behav 33:167-172.

Doran N, Spring B, and McChargue D (2007) Effect of impulsivity on craving and behavioral reactivity to smoking cues. Psychopharmacology (Berl) 194:279-288.

Dourish CT, Hutson PH, Kennett GA, and Curzon G (1986) 8-OH-DPAT-induced hyperphagia: its neural basis and possible therapeutic relevance. Appetite. 7 (Suppl):127-140.

Dourish CT, Kennett GA, and Curzon G (1987) The 5-HT1A agonists 8-OH-DPAT, buspirone and ipsapirone attenuate stress-induced anorexia in rats. $J$ Psychopharmacol 1:23-30.

Downie DL, Hope AG, Belelli D, Lambert JJ, Peters JA, Bentley KR, Steward LJ, Chen CY, and Barnes NM (1995) The interaction of trichloroethanol with murine recombinant 5- $\mathrm{HT}_{3}$ receptors. Br J Pharmacol 114:1641-1651.

Dracheva S, Chin B, and Haroutunian V (2008a) Altered serotonin 2C receptor RNA splicing in suicide: association with editing. Neuroreport 19:379-382.

Dracheva S, Elhakem SL, Marcus SM, Siever LJ, McGurk SR, and Haroutunian V (2003) RNA editing and alternative splicing of human serotonin $2 \mathrm{C}$ receptor in schizophrenia. J Neurochem 87:1402-1412.

Dracheva S, Lyddon R, Barley K, Marcus SM, Hurd YL, and Byne WM (2009) Editing of serotonin $2 \mathrm{C}$ receptor mRNA in the prefrontal cortex characterizes high-novelty locomotor response behavioral trait. Neuropsychopharmacology 34:2237-2251.

Dracheva S, Patel N, Woo DA, Marcus SM, Siever LJ, and Haroutunian V (2008b) Increased serotonin $2 \mathrm{C}$ receptor mRNA editing: a possible risk factor for suicide. Mol Psychiatry 13:1001-1010.

Druce M, Rockall A, and Grossman AB (2009) Fibrosis and carcinoid syndrome: from causation to future therapy. Nat Rev Endocrinol 5:276-283.

Drummond DC (2001) Theories of drug craving, ancient and modern. Addiction 96: 33-46.

Du J, Lü W, Wu S, Cheng Y, and Gouaux E (2015) Glycine receptor mechanism elucidated by electron cryo-microscopy. Nature 526:24-229.

Du YL, Wilcox BD, and Jeffrey JJ (1995) Regulation of rat 5-hydroxytryptamine type 2 receptor gene activity: identification of cis elements that mediate basal and 5-hydroxytryptamine-dependent gene activation. Mol Pharmacol 47:915-922.

Du YL, Wilcox BD, Teitler M, and Jeffrey JJ (1994) Isolation and characterization of the rat 5-hydroxytryptamine type 2 receptor promoter: constitutive and inducible activity in myometrial smooth muscle cells. Mol Pharmacol 45:1125-1131.

Dubertret C, Hanoun N, Adès J, Hamon M, and Gorwood P (2004) Family-based association studies between 5-HT5A receptor gene and schizophrenia. J Psychiatr Res 38:371-376.

Dubin AE, Huvar R, D’Andrea MR, Pyati J, Zhu JY, Joy KC, Wilson SJ, Galindo JE, Glass CA, Luo L, et al. (1999) The pharmacological and functional characteristics of the serotonin $5-\mathrm{HT}(3 \mathrm{~A})$ receptor are specifically modified by a $5-\mathrm{HT}(3 \mathrm{~B})$ receptor subunit. J Biol Chem 274:30799-30810.

Dubost E, Dumas N, Fossey C, Magnelli R, Butt-Gueulle S, Ballandonne C, Caignard DH, Dulin F, Sopkova de-Oliveira Santos J, Millet P, et al. (2012) Synthesis and structure-affinity relationships of selective high-affinity 5-HT(4) receptor antagonists: application to the design of new potential single photon emission computed tomography tracers. J Med Chem 55:9693-9707.

Dudek M, Marcinkowska M, Bucki A, Olczyk A, and Kolaczkowski M (2015) Idalopirdine - a small molecule antagonist of 5-HT6 with therapeutic potential against obesity. Metab Brain Dis 30:1487-1494.

Dudley MW, Weich NL, Miller FP, Carr AA, Cheng HC, Roebel LE, Doherty NS, Yamamura HI, Ursillo RC, and Palfreyman MG (1988) Pharmacological effects of MDL 11,939: a selective, centrally acting antagonist of $5-\mathrm{HT}_{2}$ receptors. Drug Dev Res 13.29-43.

Duerschmied D, Suidan GL, Demers M, Herr N, Carbo C, Brill A, Cifuni SM, Mauler M, Cicko S, Bader M, et al. (2013) Platelet serotonin promotes the recruitment of neutrophils to sites of acute inflammation in mice. Blood 121:1008-1015.

Duhr F, Déléris P, Raynaud F, Séveno M, Morisset-Lopez S, Mannoury la Cour C, Millan MJ, Bockaert J, Marin P, and Chaumont-Dubel S (2014) Cdk5 induces constitutive activation of 5-HT6 receptors to promote neurite growth. Nat Chem Biol 10:590-597.

Dukat M, Smith C, Herrick-Davis K, Teitler M, and Glennon RA (2004) Binding of tryptamine analogs at h5-HT1E receptors: a structure-affinity investigation. Bioorg Med Chem 12:2545-2552.

Duman RS and Monteggia LM (2006) A neurotrophic model for stress-related mood disorders. Biol Psychiatry 59:1116-1127.

Dumitrascu R, Kulcke C, Königshoff M, Kouri F, Yang X, Morrell N, Ghofrani HA, Weissmann N, Reiter R, Seeger W, et al. (2011) Terguride ameliorates monocrotaline-induced pulmonary hypertension in rats. Eur Respir J 37:1104-1118.

Dumuis A, Bouhelal R, Sebben M, Cory R, and Bockaert J (1988a) A nonclassical 5 -hydroxytryptamine receptor positively coupled with adenylate cyclase in the central nervous system. Mol Pharmacol 34:880-887. 
Dumuis A, Sebben M, and Bockaert J (1988b) Pharmacology of 5-hydroxytryptamine$1 \mathrm{~A}$ receptors which inhibit cAMP production in hippocampal and cortical neurons in primary culture. Mol Pharmacol 33:178-186.

Dumuis A, Sebben M, Monferini E, Nicola M, Turconi M, Ladinsky H, and Bockaert J (1991) Azabicycloalkyl benzimidazolone derivatives as a novel class of potent agonists at the 5-HT4 receptor positively coupled to adenylate cyclase in brain Naunyn Schmiedebergs Arch Pharmacol 343:245-251.

Duncan MJ and Franklin KM (2007) Expression of 5-HT7 receptor mRNA in the hamster brain: effect of aging and association with calbindin-D28K expression. Brain Res 1143:70-77.

Duncan MJ, Jennes L, Jefferson JB, and Brownfield MS (2000) Localization of serotonin(5A) receptors in discrete regions of the circadian timing system in the Syrian hamster. Brain Res 869:178-185.

Dunlop J, Marquis KL, Lim HK, Leung L, Kao J, Cheesman C, and RosenzweigLipson S (2006) Pharmacological profile of the 5-HT(2C) receptor agonist WAY 163909; therapeutic potential in multiple indications. CNS Drug Rev 12:167-177.

Dunlop J, Sabb AL, Mazandarani H, Zhang J, Kalgaonker S, Shukhina E, Sukoff S, Vogel RL, Stack G, Schechter L, et al. (2005) WAY-163909 [(7bR, 10aR) $1,2,3,4,8,9,10,10$ a-octahydro-7bH-cyclopenta-[b] [1,4]diazepino[6,7,1hi]indole], a novel 5-hydroxytryptamine $2 \mathrm{C}$ receptor-selective agonist with anorectic activity. $J$ Pharmacol Exp Ther 313:862-869.

Dunlop J, Watts SW, Barrett JE, Coupet J, Harrison B, Mazandarani H, Nawoschik S, Pangalos MN, Ramamoorthy S, Schechter L, et al. (2011) Characterization of vabicaserin (SCA-136), a selective 5-hydroxytryptamine $2 \mathrm{C}$ receptor agonist. $J$ Pharmacol Exp Ther 337:673-680.

Dunn HA, Walther C, Yuan GY, Caetano FA, Godin CM, and Ferguson SS (2014) Role of SAP97 in the regulation of 5-HT2AR endocytosis and signaling. Mol Pharmacol 86:275-283.

Dupuis DS, Pauwels PJ, Radu D, and Hall H (1999a) Autoradiographic studies of 5-HT1A-receptor-stimulated [35S]GTPgammaS-binding responses in the human and monkey brain. Eur J Neurosci 11:1809-1817.

Dupuis DS, Perez M, Halazy S, Colpaert FC, and Pauwels PJ (1999b) Magnitude of 5-HT1B and 5-HT1A receptor activation in guinea-pig and rat brain: evidence from sumatriptan dimer-mediated [35S]GTPgammaS binding responses. Brain Res Mol Brain Res 67:107-123.

Durgam S, Starace A, Li D, Migliore R, Ruth A, Németh G, and Laszlovszky I (2014) An evaluation of the safety and efficacy of cariprazine in patients with acute exacerbation of schizophrenia: a phase II, randomized clinical trial. Schizophr Res 152:450-457.

Dürk T, Panther E, Müller T, Sorichter S, Ferrari D, Pizzirani C, Di Virgilio F, Myrtek D, Norgauer J, and Idzko M (2005) 5-Hydroxytryptamine modulates cytokine and chemokine production in LPS-primed human monocytes via stimulation of different 5-HTR subtypes. Int Immunol 17:599-606.

Dutton AC, Massoura AN, Dover TJ, Andrews NA, and Barnes NM (2008) Identification and functional significance of $\mathrm{N}$-glycosylation of the 5-ht5A receptor. $\mathrm{Neu}$ rochem Int 52:419-425.

Duxon MS, Flanigan TP, Reavley AC, Baxter GS, Blackburn TP, and Fone KCF (1997) Evidence for expression of the 5-hydroxytryptamine-2B receptor protein in the rat central nervous system. Neuroscience 76:323-329.

Eadie MJ (2003) Convulsive ergotism: epidemics of the serotonin syndrome? Lancet Neurol 2:429-434.

Eberle-Wang K, Mikeladze Z, Uryu K, and Chesselet MF (1997) Pattern of expression of the serotonin ${ }_{2 \mathrm{C}}$ receptor messenger RNA in the basal ganglia of adult rats. $J$ Comp Neurol 384:233-247.

Ebrahimkhani MR, Oakley F, Murphy LB, Mann J, Moles A, Perugorria MJ, Ellis E, Lakey AF, Burt AD, Douglass A, et al. (2011) Stimulating healthy tissue regeneration by targeting the $5-\mathrm{HT}_{2} \mathrm{~B}$ receptor in chronic liver disease. Nat Med 17: 1668-1673.

Edwards E, Whitaker-Azmitia PM, and Harkins K (1990) 5-HT1A and 5-HT1B agonists play a differential role on the respiratory frequency in rats. Neuropsychopharmacology 3:129-136.

Egawa J, Endo T, Tamura R, Masuzawa N, Fukui N, Sugai T, and Someya T (2012) Influence of the 5-HTR1A C-1019G polymorphism on clinical phenotypes of autism spectrum disorders. Psychiatry Res 198:336-337.

Egeland M, Warner-Schmidt J, Greengard P, and Svenningsson P (2011) Co-expression of serotonin $5-\mathrm{HT}(1 \mathrm{~B})$ and $5-\mathrm{HT}(4)$ receptors in p11 containing cells in cerebral cortex, hippocampus, caudate-putamen and cerebellum. Neuropharmacology 61:442-450.

Eglen RM, Bonhaus DW, Clark RD, Johnson LG, Lee CH, Leung E, Smith WL, Wong EH, and Whiting RL (1994) (R) and (S) RS 56532: mixed 5-HT3 and 5-HT4 receptor ligands with opposing enantiomeric selectivity. Neuropharmacology $\mathbf{3 3}$ $515-526$.

Eglen RM, Bonhaus DW, Johnson LG, Leung E, and Clark RD (1995a) Pharmacological characterization of two novel and potent 5-HT4 receptor agonists, RS 67333 and RS 67506, in vitro and in vivo. Br J Pharmacol 115:1387-1392.

Eglen RM, Wong EH, Dumuis A, and Bockaert J (1995b) Central 5-HT4 receptors. Trends Pharmacol Sci 16:391-398.

Einstein R, Jordan H, Zhou W, Brenner M, Moses EG, and Liggett SB (2008) Alternative splicing of the $\mathrm{G}$ protein-coupled receptor superfamily in human airway smooth muscle diversifies the complement of receptors. Proc Natl Acad Sci USA 105:5230-5235.

Eison AS, Eison MS, Yocca FD, and Gianutsos G (1989) Effects of imipramine and serotonin-2 agonists and antagonists on serotonin-2 and beta-adrenergic receptors following noradrenergic or serotonergic denervation. Life Sci 44:1419-1427.

Elangbam CS, Job LE, Zadrozny LM, Barton JC, Yoon LW, Gates LD, and Slocum N (2008) 5-hydroxytryptamine (5HT)-induced valvulopathy: compositional valvular alterations are associated with 5HT2B receptor and 5HT transporter transcript changes in Sprague-Dawley rats. Exp Toxicol Pathol 60:253-262.
Ellis ES, Byrne C, Murphy OE, Tilford NS, and Baxter GS (1995) Mediation by 5-hydroxytryptamine ${ }_{2 \mathrm{~B}}$ receptors of endothelium-dependent relaxation in rat jugular vein. Br J Pharmacol 114:400-404.

Elphick GF, Querbes W, Jordan JA, Gee GV, Eash S, Manley K, Dugan A, Stanifer M, Bhatnagar A, Kroeze WK, et al. (2004) The human polyomavirus, JCV, uses serotonin receptors to infect cells. Science 306:1380-1383.

El-Salhy M, Gundersen D, Ostgaard H, Lomholt-Beck B, Hatlebakk JG, and Hausken T (2012) Low densities of serotonin and peptide YY cells in the colon of patients with irritable bowel syndrome. Dig Dis Sci 57:873-878.

Engel G, Göthert M, Hoyer D, Schlicker E, and Hillenbrand K (1986) Identity of inhibitory presynaptic 5-hydroxytryptamine (5-HT) autoreceptors in the rat brain cortex with 5-HT1B binding sites. Naunyn Schmiedebergs Arch Pharmacol 332: $1-7$.

Engel G, Gothert M, Muller-Schweinitzer E, Schlicker E, Sistonen L, and Stadler PA (1983) Evidence for common pharmacological properties of [3H]5-hydroxytryptamine autoreceptors in CNS and inhibitor presynaptic 5-hydroxytryptamine receptors on sympathetic nerves. Naunyn Schmiedebergs Arch Pharmacol 324: 116-124.

Engel G, Hoyer D, Berthold R, and Wagner H (1981) (+/-)[125Iodo] cyanopindolol, a new ligand for beta-adrenoceptors: identification and quantitation of subclasses of beta-adrenoceptors in guinea pig. Naunyn Schmiedebergs Arch Pharmacol 317 277-285.

Engel G, Hoyer D, Kalkman H, and Wick MB (1985) Pharmacological similarity between the 5HT-D-receptor on the guinea pig ileum and the $5-\mathrm{HT}_{2}$, binding site $\mathrm{Br}$ J Pharmacol 84:106P

Engel L, Kobel B, Ontsouka EC, Graber HU, Blum JW, Steiner A, and Meylan M (2006) Distribution of mRNA coding for 5-hydroxytryptamine receptor subtypes in the intestines of healthy dairy cows and dairy cows with cecal dilatation-dislocation. Am J Vet Res 67:95-101.

Ennis MD, Ghazal NB, Hoffman RL, Smith MW, Schlachter SK, Lawson CF, Im WB, Pregenzer JF, Svensson KA, Lewis RA, et al. (1998) Isochroman-6-carboxamides as highly selective 5-HT1D agonists: potential new treatment for migraine without cardiovascular side effects. J Med Chem. 41:2180-2183.

Erdmann J, Nöthen MM, Shimron-Abarbanell D, Rietschel M, Albus M, Borrmann M, Maier W, Franzek E, Körner J, Weigelt B, et al. (1996) The human serotonin 7 (5-HT7) receptor gene: genomic organization and systematic mutation screening in schizophrenia and bipolar affective disorder. Mol Psychiatry 1:392-397.

Erickson JD, Schafer MK, Bonner TI, Eiden LE, and Weihe E (1996) Distinct pharmacological properties and distribution in neurons and endocrine cells of two isoforms of the human vesicular monoamine transporter. Proc Natl Acad Sci USA 93:5166-5171.

Eriksson TM, Alvarsson A, Stan TL, Zhang X, Hascup KN, Hascup ER, Kehr J, Gerhardt GA, Warner-Schmidt J, Arango-Lievano M, et al. (2013) Bidirectional regulation of emotional memory by 5 -HT1B receptors involves hippocampal p11. Mol Psychiatry 18:1096-1105.

Erlander MG, Lovenberg TW, Baron BM, de Lecea L, Danielson PE, Racke M, Slone AL, Siegel BW, Foye PE, Cannon K, et al. (1993) Two members of a distinct subfamily of 5-hydroxytryptamine receptors differentially expressed in rat brain. Proc Natl Acad Sci USA 90:3452-3456.

Errico M, Crozier RA, Plummer MR, and Cowen DS (2001) 5-HT(7) receptors activate the mitogen activated protein kinase extracellular signal related kinase in cultured rat hippocampal neurons. Neuroscience 102:361-367.

Erspamer V and Asero B (1952) Identification of enteramine, the specific hormone of the enterochromaffin cell system, as 5-hydroxytryptamine. Nature 169:800-801.

Eskenazi D, Brodsky M, and Neumaier JF (2015) Deconstructing 5-HT6 receptor effects on striatal circuit function. Neuroscience 299:97-106.

Eskenazi D and Neumaier JF (2011a) Increased expression of 5-HT 6 receptors in dorsolateral striatum decreases habitual lever pressing, but does not affect learning acquisition of simple operant tasks in rats. Eur $J$ Neurosci 34:343-351.

Eskenazi D and Neumaier JF (2011b) Increased expression of the 5-HT6 receptor by viral mediated gene transfer into posterior but not anterior dorsomedial striatum interferes with acquisition of a discrete action-outcome task. J Psychopharmaco 25:944-951.

Eskow KL, Dupre KB, Barnum CJ, Dickinson SO, Park JY, and Bishop C (2009) The role of the dorsal raphe nucleus in the development, expression, and treatment of L-dopa-induced dyskinesia in hemiparkinsonian rats. Synapse 63:610-620.

Eskow KL, Gupta V, Alam S, Park JY, and Bishop C (2007) The partial 5-HT(1A) agonist buspirone reduces the expression and development of l-DOPA-induced dyskinesia in rats and improves l-DOPA efficacy. Pharmacol Biochem Behav 87: $306-314$

Eskow Jaunarajs KL, Dupre KB, Ostock CY, Button T, Deak T, and Bishop C (2010) Behavioral and neurochemical effects of chronic L-DOPA treatment on nonmotor sequelae in the hemiparkinsonian rat. Behav Pharmacol 21:627-637.

Esteve JM, Launay JM, Kellermann O, and Maroteaux L (2007) Functions of serotonin in hypoxic pulmonary vascular remodeling. Cell Biochem Biophys 47:33-44. Ettrup A, da Cunha-Bang S, McMahon B, Lehel S, Dyssegaard A, Skibsted AW, Jørgensen LM, Hansen M, Baandrup AO, Bache S, et al. (2014) Serotonin 2A receptor agonist binding in the human brain with $\left.{ }^{11} \mathrm{C}\right]$ Cimbi-36. J Cereb Blood Flow Metab 34:1188-1196.

Evans BA, Sato M, Sarwar M, Hutchinson DS, and Summers RJ (2010) Liganddirected signalling at beta-adrenoceptors. Br J Pharmacol 159:1022-1038.

Evans SM, Galdes A, and Gall M (1991) Molecular modeling of 5-HT3 receptor ligands. Pharmacol Biochem Behav 40:1033-1040.

Fabre A, Marchal-Sommé J, Marchand-Adam S, Quesnel C, Borie R, Dehoux M, Ruffié C, Callebert J, Launay J-M, Hénin D, et al. (2008) Modulation of bleomycininduced lung fibrosis by serotonin receptor antagonists in mice. Eur Respir $J \mathbf{3 2}$ $426-436$

Fakhoury M (2016) Revisiting the serotonin hypothesis: implications for major depressive disorders. Mol Neurobiol 53:2778-2786. 
Falkenberg VR, Gurbaxani BM, Unger ER, and Rajeevan MS (2011) Functional genomics of serotonin receptor 2A (HTR2A): interaction of polymorphism, methylation, expression and disease association. Neuromolecular Med 13:66-76.

Fanburg BL and Lee SL (1997) A new role for an old molecule: serotonin as a mitogen. Am J Physiol 272:L795-L806.

Fanburg BL and Lee SL (2000) A role for the serotonin transporter in hypoxiainduced pulmonary hypertension. J Clin Invest 105:1521-1523.

Fargin A, Raymond JR, Lohse MJ, Kobilka BK, Caron MG, and Lefkowitz RJ (1988) The genomic clone G-21 which resembles a beta-adrenergic receptor sequence encodes the 5-HT1A receptor. Nature 335:358-360.

Fargin A, Raymond JR, Regan JW, Cotecchia S, Lefkowitz RJ, and Caron MG (1989) Effector coupling mechanisms of the cloned 5-HT1A receptor. J Biol Chem 264: 14848-14852.

Faris PL, Eckert ED, Kim SW, Meller WH, Pardo JV, Goodale RL, and Hartman BK (2006) Evidence for a vagal pathophysiology for bulimia nervosa and the accompanying depressive symptoms. J Affect Disord 92:79-90.

Färkkilä M, Diener HC, Géraud G, Láinez M, Schoenen J, Harner N, Pilgrim A and Reuter U; COL MIG-202 study group (2012) Efficacy and tolerability of lasmiditan, an oral $5-\mathrm{HT}\left({ }_{1 \mathrm{~F}}\right)$ receptor agonist, for the acute treatment of migraine: a phase 2 randomised, placebo-controlled, parallel-group, dose-ranging study. Lancet Neurol 11:405-413.

Fasmer OB, Berge OG, Post C, and Hole K (1986) Effects of the putative 5-HT1A receptor agonist $8-\mathrm{OH}-2$-(di-n-propylamino)tetralin on nociceptive sensitivity in mice. Pharmacol Biochem Behav 25:883-888.

Fazzino F, Urbina M, Cedeño N, and Lima L (2009) Fluoxetine treatment to rats modifies serotonin transporter and cAMP in lymphocytes, CD4+ and CD8+ subpopulations and interleukins 2 and 4. Int Immunopharmacol 9:463-467.

Fei L, Abrardi L, and Mediati RD (2012) Unexpected effect of aripiprazole on nociceptive pain. Ther Adv Psychopharmacol 2:211-212.

Feinle C and Read NW (1996) Ondansetron reduces nausea induced by gastroduodenal stimulation without changing gastric motility. Am $J$ Physiol 271 G591-G597.

Felder CC, Kanterman RY, Ma AL, and Axelrod J (1990) Serotonin stimulates phospholipase A2 and the release of arachidonic acid in hippocampal neurons by a type 2 serotonin receptor that is independent of inositolphospholipid hydrolysis. Proc Natl Acad Sci USA 87:2187-2191.

Feng Z, Mohapatra S, Klimko PG, Hellberg MR, May JA, Kelly C, Williams G, McLaughlin MA, Klimko PG, and Sharif NA (2007) Novel benzodifuran analogs as potent 5-HT2A receptor agonists with ocular hypotensive activity. Bioorg Med Chem Lett 17:2998-3002.

Feniuk W, Humphrey PP, and Watts AD (1981) Modification of the vasomotor actions of methysergide in the femoral arterial bed of the anaesthetized dog by changes in sympathetic nerve activity. J Auton Pharmacol 1:127-132.

Fentress HM, Grinde E, Mazurkiewicz JE, Backstrom JR, Herrick-Davis K and Sanders-Bush E (2005) Pharmacological properties of the Cys23Ser single nucleotide polymorphism in human 5-HT2C receptor isoforms. Pharmacogenomics $J$ 5:244-254

Ferguson SM, Mitchell ES, and Neumaier JF (2008) Increased expression of 5-HT6 receptors in the nucleus accumbens blocks the rewarding but not psychomotor activating properties of cocaine. Biol Psychiatry 63:207-213.

Fernandez-Ranvier GG, Weng J, Yeh RF, Khanafshar E, Suh I, Barker C, Duh QY, Clark $\mathrm{OH}$, and Kebebew E (2008) Identification of biomarkers of adrenocortical carcinoma using genomewide gene expression profiling. Arch Surg 143:841-846, discussion 846 .

Ferreira HS, Oliveira E, Faustino TN, Silva EdeC, and Fregoneze JB (2005) Effect of the activation of central $5-\mathrm{HT}_{2 \mathrm{C}}$ receptors by the $5-\mathrm{HT}_{2 \mathrm{C}}$ agonist $\mathrm{mCPP}$ on blood pressure and heart rate in rats. Brain Res 1040:64-72

Ferrari MD, Färkkilä M, Reuter U, Pilgrim A, Davis C, Krauss M, and Diener HC European COL-144 Investigators (2010) Acute treatment of migraine with the selective $5-\mathrm{HT}_{1 \mathrm{~F}}$ receptor agonist lasmiditan-a randomised proof-of-concept trial. Cephalalgia 30:1170-1178.

Fiebich BL, Akundi RS, Seidel M, Geyer V, Haus U, Müller W, Stratz T, and Candelario-Jalil E (2004) Expression of 5-HT3A receptors in cells of the immune system. Scand J Rheumatol Suppl 119:9-11.

Fijał K, Pachuta A, McCreary AC, Wydra K, Nowak E, Papp M, Bieńkowski p, Kotlińska J, and Filip M (2010) Effects of serotonin (5-HT)6 receptor ligands on responding for cocaine reward and seeking in rats. Pharmacol Rep 62:1005-1014

Filip M and Cunningham KA (2002) Serotonin 5-HT(2C) receptors in nucleus accumbens regulate expression of the hyperlocomotive and discriminative stimulus effects of cocaine. Pharmacol Biochem Behav 71:745-756.

Filla SA, Mathes BM, Johnson KW, Phebus LA, Cohen ML, Nelson DL, Zgombick JM, Erickson JA, Schenck KW, Wainscott DB, et al. (2003) Novel potent 5-HT( $\left(_{1 F}\right)$ receptor agonists: structure-activity studies of a series of substituted N-[3-(1methyl-4-piperidinyl)-1H-pyrrolo[3,2-b]pyridin-5-yl]amides. $J$ Med Chem $\mathbf{4 6}$ 3060-3071.

Fillion G (2000) Potential of 5-HT-moduline as a drug target for affective disorders. Curr Opin Investig Drugs 1:104-109.

Fink KB and Göthert M (2007) 5-HT receptor regulation of neurotransmitter release. Pharmacol Rev 59:360-417.

Fink LH, Anastasio NC, Fox RG, Rice KC, Moeller FG, and Cunningham KA (2015) Individual differences in impulsive action reflect variation in the cortical serotonin 5-HT2A receptor system. Neuropsychopharmacology 40:1957-1968.

Fiorica-Howells E, Hen R, Gingrich J, Li Z, and Gershon MD (2002) 5-HT( $\left(_{2 A}\right)$ receptors: location and functional analysis in intestines of wild-type and 5-HT( $(2 \mathrm{~A}$ knockout mice. Am J Physiol Gastrointest Liver Physiol 282:G877-G893.

Fiorica-Howells E, Maroteaux L, and Gershon MD (2000) Serotonin and the 5-HT( $\left(_{2 \mathrm{~B}}\right)$ receptor in the development of enteric neurons. J Neurosci 20:294-305.

Fisas A, Codony X, Romero G, Dordal A, Giraldo J, Mercé R, Holenz J, Vrang N, Sørensen RV, Heal D, et al. (2006) Chronic 5-HT6 receptor modulation by E-6837 induces hypophagia and sustained weight loss in diet-induced obese rats [published correction appears in Br J Pharmacol (2007) 151:564]. Br J Pharmacol 148:973-983.

Fitzgerald LW, Burn TC, Brown BS, Patterson JP, Corjay MH, Valentine PA, Sun JH, Link JR, Abbaszade I, Hollis JM, et al. (2000) Possible role of valvular serotonin $5-\mathrm{HT}(2 \mathrm{~B})$ receptors in the cardiopathy associated with fenfluramine. $\mathrm{Mol}$ Pharmacol 57:75-81.

Fitzgerald LW, Iyer G, Conklin DS, Krause CM, Marshall A, Patterson JP, Tran DP, Jonak GJ, and Hartig PR (1999) Messenger RNA editing of the human serotonin 5-HT2C receptor. Neuropsychopharmacology 21(2 Suppl):82S-90S.

Fletcher A, Forster EA, Bill DJ, Brown G, Cliffe IA, Hartley JE, Jones DE, McLenachan A, Stanhope KJ, Critchley DJ, et al. (1996) Electrophysiological, biochemical, neurohormonal and behavioural studies with WAY-100635, a potent, selective and silent 5-HT1A receptor antagonist. Behav Brain Res 73:337-353.

Fletcher PJ, Chintoh AF, Sinyard J, and Higgins GA (2004) Injection of the 5-HT2C receptor agonist Ro60-0175 into the ventral tegmental area reduces cocaine-induced locomotor activity and cocaine self-administration. Neuropsychopharmacology 29:308-318

Fletcher PJ, Grottick AJ, and Higgins GA (2002a) Differential effects of the 5-HT(2A) receptor antagonist M100907 and the 5-HT(2C) receptor antagonist SB242084 on cocaine-induced locomotor activity, cocaine self-administration and cocaine-induced reinstatement of responding. Neuropsychopharmacology 27:576-586.

Fletcher PJ, Korth KM, Robinson SR, and Baker GB (2002b) Multiple 5-HT receptors are involved in the effects of acute MDMA treatment: studies on locomotor activity and responding for conditioned reinforcement. Psychopharmacology (Berl) 162 : 282-291.

Fletcher PJ, Rizos Z, Noble K, and Higgins GA (2011) Impulsive action induced by amphetamine, cocaine and MK801 is reduced by $5-\mathrm{HT}(2 \mathrm{C})$ receptor stimulation and 5-HT(2A) receptor blockade. Neuropharmacology 61:468-477.

Fletcher PJ, Rizos Z, Noble K, Soko AD, Silenieks LB, Lê AD, and Higgins GA (2012) Effects of the 5-HT2C receptor agonist Ro60-0175 and the 5-HT2A receptor antagonist M100907 on nicotine self-administration and reinstatement. Neuropharmacology 62:2288-2298.

Fletcher PJ, Rizos Z, Sinyard J, Tampakeras M, and Higgins GA (2008) The 5-HT2C receptor agonist Ro60-0175 reduces cocaine self-administration and reinstatement induced by the stressor yohimbine, and contextual cues. Neuropsychopharmacology 33:1402-1412.

Fletcher PJ, Tampakeras M, Sinyard J, and Higgins GA (2007) Opposing effects of $5-\mathrm{HT}(2 \mathrm{~A})$ and $5-\mathrm{HT}(2 \mathrm{C})$ receptor antagonists in the rat and mouse on premature responding in the five-choice serial reaction time test. Psychopharmacology (Berl) 195:223-234.

Flomen R, Knight J, Sham P, Kerwin R, and Makoff A (2004) Evidence that RNA editing modulates splice site selection in the 5-HT2C receptor gene. Nucleic Acids Res 32:2113-2122.

Florian JA and Watts SW (1998) Integration of mitogen-activated protein kinase kinase activation in vascular 5-hydroxytryptamine2A receptor signal transduction. $J$ Pharmacol Exp Ther 284:346-355.

Foguet M, Hoyer D, Pardo LA, Parekh A, Kluxen FW, Kalkman HO, Stühmer W, and Lübbert $\mathrm{H}$ (1992a) Cloning and functional characterization of the rat stomach fundus serotonin receptor. EMBO J 11:3481-3487.

Foguet M, Nguyen H, Le H, and Lübbert H (1992b) Structure of the mouse 5-HT1C, 5-HT2 and stomach fundus serotonin receptor genes. Neuroreport 3:345-348.

Fone KC (2008) An update on the role of the 5-hydroxytryptamine6 receptor in cognitive function. Neuropharmacology 55:1015-1022.

Fontana DJ, Daniels SE, Wong EH, Clark RD, and Eglen RM (1997) The effects of novel, selective 5-hydroxytryptamine (5-HT) 4 receptor ligands in rat spatial navigation. Neuropharmacology 36:689-696.

Forbes IT, Dabbs S, Duckworth DM, Jennings AJ, King FD, Lovell PJ, Brown AM, Collin L, Hagan JJ, Middlemiss DN, et al. (1998) (R)-3,N-dimethyl-N-[1-methyl-3(4-methyl-piperidin-1-yl) propyl]benzenesulfonamide: the first selective 5-HT7 receptor antagonist. J Med Chem 41:655-657.

Fornal CA, Litto WJ, Metzler CW, Marrosu F, Tada K, and Jacobs BL (1994) Singleunit responses of serotonergic dorsal raphe neurons to 5-HT1A agonist and antagonist drug administration in behaving cats. J Pharmacol Exp Ther 270:1345-1358.

Fornal CA, Metzler CW, Gallegos RA, Veasey SC, McCreary AC, and Jacobs BL (1996) WAY-100635, a potent and selective 5-hydroxytryptamine 1A $_{\text {A }}$ antagonist, increases serotonergic neuronal activity in behaving cats: comparison with (S) WAY-100135. J Pharmacol Exp Ther 278:752-762.

Ford AC, Brandt LJ, Young C, Chey WD, Foxx-Orenstein AE, and Moayyedi P (2009) Efficacy of 5-HT3 antagonists and 5-HT4 agonists in irritable bowel syndrome: systematic review and meta-analysis. Am J Gastroenterol 104:1831-1843; quiz 1844.

Fox SH (2014) Pimavanserin as treatment for Parkinson's disease psychosis. Lancet 383:494-496.

Foxx-Orenstein AE, Kuemmerle JF, and Grider JR (1996) Distinct 5-HT receptors mediate the peristaltic reflex induced by mucosal stimuli in human and guinea pig intestine. Gastroenterology 111:1281-1290.

Fozard JR (1984) MDL 72222: a potent and highly selective antagonist at neuronal 5-hydroxytryptamine receptors. Naunyn Schmiedebergs Arch Pharmacol 326: $36-44$

Francis PT, Pangalos MN, Pearson RC, Middlemiss DN, Stratmann GC, and Bowen DM (1992) 5-Hydroxytryptamine1A but not 5-hydroxytryptamine2 receptors are enriched on neocortical pyramidal neurones destroyed by intrastriatal volkensin. $J$ Pharmacol Exp Ther 261:1273-1281.

Francken BJ, Jurzak M, Vanhauwe JF, Luyten WH, and Leysen JE (1998) The human 5 -ht5A receptor couples to $\mathrm{Gi} / \mathrm{Go}$ proteins and inhibits adenylate cyclase in HEK 293 cells. Eur J Pharmacol 361:299-309.

Frank MG, Stryker MP, and Tecott LH (2002) Sleep and sleep homeostasis in mice lacking the 5-HT2c receptor. Neuropsychopharmacology 27:869-873.

Frankle WG, Lombardo I, Kegeles LS, Slifstein M, Martin JH, Huang Y, Hwang DR, Reich E, Cangiano C, Gil R, et al. (2006) Serotonin 1A receptor availability in patients with schizophrenia and schizo-affective disorder: a positron emission 
tomography imaging study with [11C]WAY 100635. Psychopharmacology (Berl) 189:155-164.

Frantz KJ, Hansson KJ, Stouffer DG, and Parsons LH (2002) 5-HT(6) receptor antagonism potentiates the behavioral and neurochemical effects of amphetamine but not cocaine. Neuropharmacol 42:170-180.

Fredriksson R, Lagerström MC, Lundin LG, and Schiöth HB (2003) The G-proteincoupled receptors in the human genome form five main families. Phylogenetic analysis, paralogon groups, and fingerprints. Mol Pharmacol 63:1256-1272.

Freire-Garabal M, Núñez MJ, Balboa J, López-Delgado P, Gallego R, García-Caballero T, Fernández-Roel MD, Brenlla J, and Rey-Méndez M (2003) Serotonin upregulates the activity of phagocytosis through 5-HT1A receptors. $\mathrm{Br} J$ Pharmacol 139:457-463.

Friedman J (2014) 20 years of leptin: leptin at 20: an overview. J Endocrinol 223: T1-T8.

Frohman MA (2015) The phospholipase D superfamily as therapeutic targets. Trends Pharmacol Sci 36:137-144.

Frokjaer VG, Mortensen EL, Nielsen FA, Haugbol S, Pinborg LH, Adams KH, Svarer C, Hasselbalch SG, Holm S, Paulson OB, et al. (2008) Frontolimbic serotonin 2A receptor binding in healthy subjects is associated with personality risk factors for affective disorder. Biol Psychiatry 63:569-576.

Froldi G, Montopoli M, Zanetti M, Dorigo P, and Caparrotta L (2008) 5-HT ${ }_{1 B}$ receptor subtype and aging in rat resistance vessels. Pharmacology 81:70-78.

Fugelli A, Moret C, and Fillion G (1997) Autoradiographic localization of 5-HT1E and 5-HT1F binding sites in rat brain: effect of serotonergic lesioning. J Recept Signal Transduct Res 17:631-645.

Fujiwara Y, Nelson DL, Kashihara K, Varga E, Roeske WR, and Yamamura HI (1990) The cloning and sequence analysis of the rat serotonin-1A receptor gene. Life Sci 47:PL127-PL132.

Fukuda M, Oyama Y, Nishitarumizu A, Omura M, Nose K, and Deshimaru M (2015) Identification of an RNA element for specific coordination of A-to-I RNA editing on HTR2C pre-mRNA. Genes Cells 20:834-846.

Fukumoto K, Iijima M, and Chaki S (2014) Serotonin-1A receptor stimulation mediates effects of a metabotropic glutamate $2 / 3$ receptor antagonist, $2 \mathrm{~S}$-2-amino2-(1S,2S-2-carboxycycloprop-1-yl)-3-(xanth-9-yl)propanoic acid (LY341495), and an N-methyl-D-aspartate receptor antagonist, ketamine, in the novelty-suppressed feeding test. Psychopharmacology (Berl) 231:2291-2298.

Furlotti G, Alisi MA, Apicella C, Capezzone de Joannon A, Cazzolla N, Costi R, Cuzzucoli Crucitti G, Garrone B, Iacovo A, Magarò G, et al. (2012) Discovery and pharmacological profile of new $1 \mathrm{H}$-indazole-3-carboxamide and $2 \mathrm{H}$-pyrrolo[3,4-c]quinoline derivatives as selective serotonin 4 receptor ligands. $J$ Med Chem $\mathbf{5 5}$ : 9446-9466.

Furrer K, Rickenbacher A, Tian Y, Jochum W, Bittermann AG, Käch A, Humar B, Graf R, Moritz W, and Clavien P-A (2011) Serotonin reverts age-related capillarization and failure of regeneration in the liver through a VEGF-dependent pathway. Proc Natl Acad Sci USA 108:2945-2950.

Futuro-Neto HA, Pires JG, Gilbey MP, and Ramage AG (1993) Evidence for the ability of central 5-HT1A receptors to modulate the vagal bradycardia induced by stimulating the upper airways of anesthetized rabbits with smoke. Brain Res $\mathbf{6 2 9}$ : 349-354.

Fuxe K, Borroto-Escuela DO, Romero-Fernandez W, Tarakanov AO, Calvo F, Garriga P, Tena M, Narvaez M, Millón C, Parrado C, et al. (2012) On the existence and function of galanin receptor heteromers in the central nervous system. Front Endocrinol (Lausanne) 3:127.

Gabelt BT, Okka M, Dean TR, Kaufman PL, et al. (2005) Aqueous humor dynamics in monkeys after topical R-DOI. Invest Ophthalmol Vis Sci 46:4691-4696.

Gaddum JH and Picarelli ZP (1957) Two kinds of tryptamine receptor. Br J Pharmacol 120(4 Suppl):134-139; discussion 132-133.

Gaggi R, Dall'Olio R, and Roncada P (1997) Effect of the selective 5-HT receptor agonists 8-OHePAT and DOI on behavior and brain biogenic amines of rats. Gen Pharmacol 28:583-587.

Gale JD, Grossman CJ, Whitehead JW, Oxford AW, Bunce KT, and Humphrey PP (1994) GR113808: a novel, selective antagonist with high affinity at the 5-HT4 receptor. Br J Pharmacol 111:332-338.

Galici R, Boggs JD, Miller KL, Bonaventure P, and Atack JR (2008) Effects of SB-269970, a 5-HT7 receptor antagonist, in mouse models predictive of antipsychotic-like activity. Behav Pharmacol 19:153-159.

Galligan JJ (2007) Actions of sumatriptan on myenteric neurones: relief from an old headache in the enteric nervous system? Neurogastroenterol Motil 19:1-3.

Galusca B, Costes N, Zito NG, Peyron R, Bossu C, Lang F, Le Bars D, and Estour B (2008) Organic background of restrictive-type anorexia nervosa suggested by increased serotonin $1 \mathrm{~A}$ receptor binding in right frontotemporal cortex of both lean and recovered patients: [18F]MPPF PET scan study. Biol Psychiatry 64 $1009-1013$

Garattini S, Caccia S, and Mennini T (1982) Notes on buspirone's mechanisms of action. J Clin Psychiatry 43:19-24.

García-Alcocer G, Rodríguez A, Moreno-Layseca P, Berumen LC, Escobar J, and Miledi R (2010) Serotonin receptor 5-HT5A in rat hippocampus decrease by leptin treatment. Neurosci Lett 486:171-173.

Garcia-Garcia AL, Meng Q, Richardson-Jones J, Dranovsky A, and Leonardo ED (2016) Disruption of 5-HT1A function in adolescence but not early adulthood leads to sustained increases of anxiety. Neuroscience 321:210-221.

Garcia-Garcia AL, Newman-Tancredi A, and Leonardo ED (2014) 5-HT(1A) [corrected] receptors in mood and anxiety: recent insights into autoreceptor versus heteroreceptor function. Psychopharmacology (Berl) 231:623-636.

Garcia-Ladona F, Amberg W, Kling A, Lange UEW, Hornberger W, Wernet W, Netz A, Ochse M, Mezler M, Meyer AH, et al. (2006) First potent and highly selective antagonists for the human 5-HT5A receptor. Program number 33.1/B73, in 2006 Neuroscience Meeting Planner. Society for Neuroscience, Atlanta, GA.

García-Nafría J, Nehmé R, Edwards PC, and Tate CG (2018) Cryo-EM structure of the serotonin 5-HT $\mathrm{H}_{1 \mathrm{~B}}$ receptor coupled to heterotrimeric $\mathrm{G}_{\mathrm{o}}$. Nature 558:620-623.
Gardani M and Biello SM (2008) The effects of photic and nonphotic stimuli in the 5-HT7 receptor knockout mouse. Neuroscience 152:245-253.

Garlow SJ, Chin AC, Marinovich AM, Heller MR, and Ciaranello RD (1994) Cloning and functional promoter mapping of the rat serotonin-2 receptor gene. Mol Cell Neurosci 5:291-300.

Garlow SJ and Ciaranello RD (1995) Transcriptional control of the rat serotonin-2 receptor gene. Brain Res Mol Brain Res 31:201-209.

Garratt JC, Alreja M, and Aghajanian GK (1993) LSD has high efficacy relative to serotonin in enhancing the cationic current Ih: intracellular studies in rat facial motoneurons. Synapse 13:123-134.

Garrett SM, Whitaker RM, Beeson CC, and Schnellmann RG (2014) Agonism of the 5 -hydroxytryptamine $1 \mathrm{~F}$ receptor promotes mitochondrial biogenesis and recovery from acute kidney injury. J Pharmacol Exp Ther 350:257-264.

Gartside SE, Clifford EM, Cowen PJ, and Sharp T (1999) Effects of (-)-tertatolol, (-)-penbutolol and (+/-)-pindolol in combination with paroxetine on presynaptic 5-HT function: an in vivo microdialysis and electrophysiological study. $\mathrm{Br} J$ Pharmacol 127:145-152.

Gasiorek A, Trattnig SM, Ahring PK, Kristiansen U, Frølund B, Frederiksen K, and Jensen AA (2016) Delineation of the functional properties and the mechanism of action of TMPPAA, an allosteric agonist and positive allosteric modulator of 5-HT3 receptors. Biochem Pharmacol 110-111:92-108.

Gaster LM, Ham P, Joiner GF, King FD, Mulholland KR, Wyman PA, Hagan JJ, Price GW, Roberts C, Routledge C, et al. (1998) The selective 5-HT1B receptor inverse agonist SB-224289, potently blocks terminal 5-HT autoreceptor function both in vitro and in vivo. Ann N Y Acad Sci 861:270-271.

Gatch MB (2003) Discriminative stimulus effects of m-chlorophenylpiperazine as a model of the role of serotonin receptors in anxiety. Life Sci 73:1347-1367.

Gautron L, Elmquist JK, and Williams KW (2015) Neural control of energy balance: translating circuits to therapies. Cell 161:133-145.

Gavarini S, Bécamel C, Altier C, Lory P, Poncet J, Wijnholds J, Bockaert J, and Marin P (2006) Opposite effects of PSD-95 and MPP3 PDZ proteins on serotonin 5-hydroxytryptamine2C receptor desensitization and membrane stability. Mol Biol Cell 17:4619-4631.

Gaven F, Pellissier LP, Queffeulou E, Cochet M, Bockaert J, Dumuis A, and Claeysen $\mathrm{S}$ (2013) Pharmacological profile of engineered 5- $\mathrm{HT}_{4}$ receptors and identification of 5- $\mathrm{HT}_{4}$ receptor-biased ligands. Brain Res 1511:65-72.

Ge $\mathrm{J}$ and Barnes NM (1996) $5-\mathrm{HT}_{4}$ receptor-mediated modulation of 5-HT release in the rat hippocampus in vivo. Br J Pharmacol 117:1475-1480.

Gee AD, Martarello L, Passchier J, Wishart M, Parker C, Matthews J, Comley R, Hopper R, and Gunn R (2008) Synthesis and evaluation of [11C]SB207145 as the first in vivo serotonin 5-HT4 receptor radioligand for PET imaging in man. Curr Radiopharm 1:110-114.

Geerts IS, De Meyer GR, and Bult H (2000) Collar-induced elevation of mRNA and functional activity of 5-HT(1B) receptor in the rabbit carotid artery. $\mathrm{Br} J$ Pharmacol 131:1723-1731.

Gelber EI, Kroeze WK, Willins DL, Gray JA, Sinar CA, Hyde EG, Gurevich V, Benovic J, and Roth BL (1999) Structure and function of the third intracellular loop of the 5-hydroxytryptamine2A receptor: the third intracellular loop is alpha-helical and binds purified arrestins. J Neurochem 72:2206-2214.

Gelernter J, Rao PA, Pauls DL, Hamblin MW, Sibley DR, and Kidd KK (1995) Assignment of the 5HT7 receptor gene (HTR7) to chromosome 10q and exclusion of genetic linkage with Tourette syndrome. Genomics 26:207-209.

Gelez H, Greggain-Mohr J, Pfaus JG, Allers KA, and Giuliano F (2013) Flibanserin treatment increases appetitive sexual motivation in the female rat. $J$ Sex Med 10: 1231-1239.

Gellynck E, Andressen KW, Lintermans B, Haegeman G, Levy FO, Vanhoenacker P, and Van Craenenbroeck K (2012) Biochemical and pharmacological study of $\mathrm{N}$-linked glycosylation of the human serotonin $5-\mathrm{HT}_{7(\mathrm{a})}$ receptor. $F E B S J \mathbf{2 7 9}$ : 1994-2003.

Gellynck E, Laenen K, Andressen KW, Lintermans B, De Martelaere K, Matthys A Levy FO, Haegeman G, Vanhoenacker P, and Van Craenenbroeck K (2008) Cloning, genomic organization and functionality of $5-\mathrm{HT}_{7}$ receptor splice variants from mouse brain. Gene 426:23-31

Gerald C, Adham N, Kao HT, Olsen MA, Laz TM, Schechter LE, Bard JA, Vaysse PJ, Hartig PR, Branchek TA, et al. (1995) The 5-HT4 receptor: molecular cloning and pharmacological characterization of two splice variants. EMBO J 14:2806-2815.

Gérard C, Martres MP, Lefêvre K, Miquel MC, Vergé D, Lanfumey L, Doucet E, Hamon M, and el Mestikawy S (1997) Immuno-localization of serotonin 5-HT6 receptor-like material in the rat central nervous system. Brain Res 746:207-219.

Gerfen CR and Surmeier DJ (2011) Modulation of striatal projection systems by dopamine. Annu Rev Neurosci 34:441-466.

Gergs U, Baumann M, Böckler A, Buchwalow IB, Ebelt H, Fabritz L, Hauptmann S, Keller N, Kirchhof P, Klöckner U, et al. (2010) Cardiac overexpression of the human 5-HT4 receptor in mice. Am J Physiol Heart Circ Physiol 299:H788-H798.

Gergs U, Neumann J, Simm A, Silber RE, Remmers FO, and Läer S (2009) Phosphorylation of phospholamban and troponin I through 5-HT 4 receptors in the isolated human atrium. Naunyn Schmiedebergs Arch Pharmacol 379:349-359.

Gershon MD (2003) Plasticity in serotonin control mechanisms in the gut. Curr Opin Pharmacol 3:600-607.

Gershon MD (2011) Behind an enteric neuron there may lie a glial cell. J Clin Invest 121:3386-3389.

Gershon MD (2012) Serotonin is a sword and a shield of the bowel: serotonin plays offense and defense. Trans Am Clin Climatol Assoc 123:268-280; discussion 280.

Gershon MD (2013) 5-Hydroxytryptamine (serotonin) in the gastrointestinal tract. Curr Opin Endocrinol Diabetes Obes 20:14-21.

Gershon MD and Liu MT (2007) Serotonin and neuroprotection in functional bowel disorders. Neurogastroenterol Motil 19 (Suppl 2):19-24.

Gershon MD and Tack J (2007) The serotonin signaling system: from basic understanding to drug development for functional GI disorders. Gastroenterology 132 : $397-414$. 
Gesty-Palmer D, Chen M, Reiter E, Ahn S, Nelson CD, Wang S, Eckhardt AE, Cowan CL, Spurney RF, Luttrell LM, et al. (2006) Distinct beta-arrestin- and G proteindependent pathways for parathyroid hormone receptor-stimulated ERK1/2 activation. J Biol Chem 281:10856-10864.

Gettys TW, Fields TA, and Raymond JR (1994) Selective activation of inhibitory G-protein alpha-subunits by partial agonists of the human 5-HT1A receptor. Biochemistry 33:4283-4290.

Geurts FJ, De Schutter E, and Timmermans JP (2002) Localization of 5-HT2A, 5-HT3, 5-HT5A and 5-HT7 receptor-like immunoreactivity in the rat cerebellum. $J$ Chem Neuroanat 24:65-74

Ghia JE, Li N, Wang H, Collins M, Deng Y, El-Sharkawy RT, Côté F, Mallet J, and Khan WI (2009) Serotonin has a key role in pathogenesis of experimental colitis. Gastroenterology 137:1649-1660.

Gibson WT, Ebersole BJ, Bhattacharyya S, Clayton P, Farooqi IS, Sealfon SC, and O'Rahilly S (2004) Mutational analysis of the serotonin receptor 5HT2c in severe early-onset human obesity. Can J Physiol Pharmacol 82:426-429.

Gigliucci V, O'Dowd G, Casey S, Egan D, Gibney S, and Harkin A (2013) Ketamine elicits sustained antidepressant-like activity via a serotonin-dependent mechanism. Psychopharmacology (Berl) 228:157-166.

Gilbert JA, Blaser MJ, Caporaso JG, Jansson JK, Lynch SV, and Knight R (2018) Current understanding of the human microbiome. Nat Med 24:392-400.

Gilbert F and Dourish CT (1987) Effects of the novel anxiolytics gepirone, buspirone and ipsapirone on free feeding and on feeding induced by 8-OH-DPAT. Psychopharmacology (Berl) 93:349-352.

Gilet M, Eutamene H, Han H, Kim HW, and Bueno L (2014) Influence of a new 5-HT receptor partial agonist, YKP10811, on visceral hypersensitivity in rats triggered by stress and inflammation. Neurogastroenterol Motil 26:1761-1770.

Gill RK, Saksena S, Tyagi S, Alrefai WA, Malakooti J, Sarwar Z, Turner JR, Ramaswamy K, and Dudeja PK (2005) Serotonin inhibits $\mathrm{Na}+/ \mathrm{H}+$ exchange activity via 5 -HT4 receptors and activation of PKC alpha in human intestinal epithelial cells. Gastroenterology 128:962-974.

Gingrich JA, Ansorge MS, Merker R, Weisstaub N, and Zhou M (2003) New lessons from knockout mice: the role of serotonin during development and its possible contribution to the origins of neuropsychiatric disorders. CNS Spectr 8:572-577.

Glatt CE, Snowman AM, Sibley DR, and Snyder SH (1995) Clozapine: selective labeling of sites resembling $5 \mathrm{HT} 6$ serotonin receptors may reflect psychoactive profile. Mol Med 1:398-406.

Glennon JC, Van Scharrenburg G, Ronken E, Hesselink MB, Reinders JH, Van Der Neut M, Long SK, Feenstra RW, and McCreary AC (2006) In vitro characterization of SLV308 (7-[4-methyl-1-piperazinyl]-2(3H)-benzoxazolone, monohydrochloride): a novel partial dopamine D2 and D3 receptor agonist and serotonin 5-HT1A receptor agonist. Synapse 60:599-608.

Glennon RA, Dukat M, el-Bermawy M, Law H, De los Angeles J, Teitler M, King A and Herrick-Davis K (1994) Influence of amine substituents on 5-HT2A versus 5 -HT2C binding of phenylalkyl- and indolylalkylamines. $J$ Med Chem 37: $1929-1935$.

Glennon RA, Bondarev ML, Khorana N, Young R, May JA, Hellberg MR, McLaughlin MA, and Sharif NA (2004) $\beta$-oxygenated analogues of the 5-HT2A serotonin receptor agonist 1-(4-Bromo-2,5-dimethoxyphenyl)-2-aminopropane. J Med Chem 47: $6034-6041$.

Glennon RA, Lee M, Rangisetty JB, Dukat M, Roth BL, Savage JE, McBride A, Rauser L, Hufeisen S, and Lee DK (2000) 2-Substituted tryptamines: agents with selectivity for 5-HT(6) serotonin receptors. J Med Chem 43:1011-1018.

Glennon RA, Raghupathi R, Bartyzel P, Teitler M, and Leonhardt S (1992a) Binding of phenylalkylamine derivatives at 5 -HT1C and 5-HT2 serotonin receptors: evidence for a lack of selectivity. J Med Chem 35:734-740.

Glennon RA, Seggel MR, Soine WH, Herrick-Davis K, Lyon RA, and Titeler M (1988) [125I]-1-(2,5-dimethoxy-4-iodophenyl)-2-amino-propane: an iodinated radioligand that specifically labels the agonist high-affinity state of 5-HT2 serotonin receptors. J Med Chem 31:5-7.

Glennon RA, Teitler M, and Sanders-Bush E (1992b) Hallucinogens and serotonergic mechanisms. NIDA Res Monogr 119:131-135.

Glusa E and Pertz HH (2000) Further evidence that 5-HT-induced relaxation of pig pulmonary artery is mediated by endothelial 5- $\mathrm{HT}\left({ }_{2 \mathrm{~B}}\right)$ receptors. $\mathrm{Br} J$ Pharmacol 130:692-698

Gobbi M, Parotti L, and Mennini T (1996) Are 5-hydroxytryptamine7 receptors involved in $[3 \mathrm{H}] 5$-hydroxytryptamine binding to 5 -hydroxytryptamine 1 nonA-nonB receptors in rat hypothalamus? Mol Pharmacol 49:556-559.

Gobert A, Rivet JM, Lejeune F, Newman-Tancredi A, Adhumeau-Auclair A, Nicolas JP, Cistarelli L, Melon C, and Millan MJ (2000) Serotonin(2C) receptors tonically suppress the activity of mesocortical dopaminergic and adrenergic, but not serotonergic, pathways: a combined dialysis and electrophysiological analysis in the rat. Synapse 36:205-221.

Goetz CG, Damier P, Hicking C, Laska E, Müller T, Olanow CW, Rascol O, and Russ H (2007) Sarizotan as a treatment for dyskinesias in Parkinson's disease: a doubleblind placebo-controlled trial. Mov Disord 22:179-186.

Gohla A, Offermanns S, Wilkie TM, and Schultz G (1999) Differential involvement of Galpha12 and Galpha13 in receptor-mediated stress fiber formation. J Biol Chem 274:17901-17907.

Gökben S, Ardıç UA, and Serdaroğlu G (2012) Use of buspirone and fluoxetine for breathing problems in Rett syndrome. Pediatr Neurol 46:192-194.

Goldberg PA, Kamm MA, Setti-Carraro P, van der Sijp JRM, and Roth C (1996) Modification of visceral sensitivity and pain in irritable bowel syndrome by $5-\mathrm{HT}_{3}$ antagonism (ondansetron). Digestion 57:478-483.

Goldstein DJ, Roon KI, Offen WW, Ramadan NM, Phebus LA, Johnson KW, Schaus JM, and Ferrari MD (2001) Selective seratonin 1F (5-HT(1)) receptor agonist LY334370 for acute migraine: a randomised controlled trial. Lancet 358:1230-1234. Goldstein RZ, Tomasi D, Rajaram S, Cottone LA, Zhang L, Maloney T, Telang F, Alia-Klein N, and Volkow ND (2007) Role of the anterior cingulate and medial orbitofrontal cortex in processing drug cues in cocaine addiction. Neuroscience 144 $1153-1159$

Gomez-Mancilla B, Cutler NR, Leibowitz MT, Spierings ELH, Klapper JA, Diamond S, Goldstein J, Smith T, Couch JR, Fleishaker J, et al. (2001) Safety and efficacy of PNU-142633, a selective 5-HT1D agonist, in patients with acute migraine. Cephalalgia 21:727-732.

González AA and Puig MM (1997) Ondansetron facilitates neuromuscular transmission in the guinea-pig ileum. Eur J Pharmacol 328:201-206.

Gonzalez R, Chávez-Pascacio K, and Meneses A (2013) Role of 5-HT5A receptors in the consolidation of memory. Behav Brain Res 252:246-251.

González-Hernández A, Manrique-Maldonado G, Lozano-Cuenca J, Muñoz-Islas E, Centurión D, Maassen VanDenBrink A, and Villalón CM (2011) The 5-HT( $\left.{ }_{1}\right)$ receptors inhibiting the rat vasodepressor sensory CGRPergic outflow: further involvement of 5-HT( $\left(_{1 \mathrm{~F})}\right.$, but not 5- $\mathrm{HT}\left({ }_{1 \mathrm{~A}}\right)$ or 5-HT( ${ }_{1 \mathrm{D})}$, subtypes. Eur J Pharmacol 659:233-243.

González-Maeso J, Ang RL, Yuen T, et al. (2008) Identification of a serotonin/glutamate receptor complex implicated in psychosis. Nature 452:93-97.

González-Maeso J, Rodríguez-Puertas R, Gabilondo AM, and Meana JJ (2000) Characterization of receptor-mediated [35S]GTPgammaS binding to cortical membranes from postmortem human brain. Eur J Pharmacol 390:25-36.

González-Maeso J, Weisstaub NV, Zhou M, Chan P, Ivic L, Ang R, Lira A, BradleyMoore M, Ge Y, Zhou Q, et al. (2007) Hallucinogens recruit specific cortical 5 -HT $(2 \mathrm{~A})$ receptor-mediated signaling pathways to affect behavior. Neuron $\mathbf{5 3}$ $439-452$.

Goodfellow NM, Bailey CDC, and Lambe EK (2012) The native serotonin 5-HT(5A) receptor: electrophysiological characterization in rodent cortex and 5-HT(1A)-mediated compensatory plasticity in the knock-out mouse. J Neurosci 32:5804-5809.

Goodfellow NM, Benekareddy M, Vaidya VA, and Lambe EK (2009) Layer II/III of the prefrontal cortex: inhibition by the serotonin 5-HT1A receptor in development and stress. $J$ Neurosci 29:10094-10103.

Goodfellow NM, Sargin D, Ansorge MS, Gingrich JA, and Lambe EK (2014) Mice with compromised 5-HTT function lack phosphotyrosine-mediated inhibitory control over prefrontal 5-HT responses. $J$ Neurosci 34:6107-6111.

Göoz M, Göoz P, Luttrell LM, and Raymond JR (2006) 5-HT2A receptor induces ERK phosphorylation and proliferation through ADAM-17 tumor necrosis factor-alphaconverting enzyme (TACE) activation and heparin-bound epidermal growth factorlike growth factor (HB-EGF) shedding in mesangial cells. J Biol Chem 281 21004-21012.

Gore S, Gilmore IT, Haigh CG, Brownless SM, Stockdale H, and Morris AI (1990) Colonic transit in man is slowed by ondansetron (GR38032F), a selective 5-hydroxytryptamine receptor (type 3) antagonist. Aliment Pharmacol Ther 4: $139-144$

Göthert M, Schlicker E, and Kollecker P (1986) Receptor-mediated effects of serotonin and 5-methoxytryptamine on noradrenaline release in the rat vena cava and in the heart of the pithed rat. Naunyn Schmiedebergs Arch Pharmacol 332:124-130.

Göthert M and Weinheimer G (1979) Extracellular 5-hydroxytryptamine inhibits 5-hydroxytryptamine release from rat brain cortex slices. Naunyn Schmiedebergs Arch Pharmacol 310:93-96.

Goto K, Kawahara I, Kuniyasu H, and Takaki M (2015) A protein tyrosine kinase receptor, c-RET signaling pathway contributes to the enteric neurogenesis induced by a 5-HT4 receptor agonist at an anastomosis after transection of the gut in rodents. J Physiol Sci 65:377-383.

Gould GG, Hensler JG, Burke TF, Benno RH, Onaivi ES, and Daws LC (2011) Density and function of central serotonin (5-HT) transporters, 5-HT1A and 5-HT2A receptors, and effects of their targeting on BTBR $\mathrm{T}+\mathrm{tf} / \mathrm{J}$ mouse social behavior. $J$ Neurochem 116:291-303.

Goyal R, Salahudeen AA, and Jansen M (2011) Engineering a prokaryotic Cys-loop receptor with a third functional domain. J Biol Chem 286:34635-34642.

Gozlan H, El Mestikawy S, Pichat L, Glowinski J, and Hamon M (1983) Identification of presynaptic serotonin autoreceptors using a new ligand: 3H-PAT. Nature 305: $140-142$.

Graf M, Jakus R, Kantor S, Levay G, and Bagdy G (2004) Selective 5-HT1A and 5-HT7 antagonists decrease epileptic activity in the WAG/Rij rat model of absence epilepsy. Neurosci Lett 359:45-48.

Grailhe R, Grabtree GW, and Hen R (2001) Human 5-HT(5) receptors: the 5-HT(5A) receptor is functional but the $5-\mathrm{HT}(5 \mathrm{~B})$ receptor was lost during mammalian evolution. Eur J Pharmacol 418:157-167.

Grailhe R, Waeber C, Dulawa SC, Hornung JP, Zhuang X, Brunner D, Geyer MA, and Hen R (1999) Increased exploratory activity and altered response to LSD in mice lacking the 5-HT(5A) receptor. Neuron 22:581-591.

Granados-Soto V, Argüelles CF, Rocha-González HI, Godínez-Chaparro B, FloresMurrieta FJ, and Villalón CM (2010) The role of peripheral 5-HT1A, 5-HT1B, 5-HT1D, 5-HT1E and 5-HT1F serotonergic receptors in the reduction of nociception in rats. Neuroscience 165:561-568.

Grauer SM, Graf R, Navarra R, Sung A, Logue SF, Stack G, Huselton C, Liu Z, Comery TA, Marquis KL, et al. (2009) WAY-163909, a 5-HT2C agonist, enhances the preclinical potency of current antipsychotics. Psychopharmacology (Berl) 204: $37-48$

Graveleau C, Paust H-J, Schmidt-Grimminger D, and Mukhopadhyay AK (2000) Presence of a 5-HT7 receptor positively coupled to adenylate cyclase activation in human granulosa-lutein cells. J Clin Endocrinol Metab 85:1277-1286.

Graves SM and Napier TC (2012) SB 206553, a putative 5-HT2C inverse agonist, attenuates methamphetamine-seeking in rats. BMC Neurosci 13:65.

Grayson B, Idris NF, and Neill JC (2007) Atypical antipsychotics attenuate a subchronic PCP-induced cognitive deficit in the novel object recognition task in the rat Behav Brain Res 184:31-38.

Green T, Stauffer KA, and Lummis SC (1995) Expression of recombinant homooligomeric 5-hydroxytryptamine 3 receptors provides new insights into their maturation and structure. J Biol Chem 270:6056-6061. 
Greene EL, Houghton O, Collinsworth G, Garnovskaya MN, Nagai T, Sajjad T, Bheemanathini V, Grewal JS, Paul RV, and Raymond JR (2000) 5-HT(2A) receptors stimulate mitogen-activated protein kinase via $\mathrm{H}(2) \mathrm{O}(2)$ generation in rat renal mesangial cells. Am J Physiol Renal Physiol 278:F650-F658.

Greuel JM and Glaser T (1992) The putative 5-HT1A receptor antagonists NAN-190 and BMY 7378 are partial agonists in the rat dorsal raphe nucleus in vitro. Eur $J$ Pharmacol 211:211-219.

Grider JR, Foxx-Orenstein AE, and Jin JG (1998) 5-Hydroxytryptamine4 receptor agonists initiate the peristaltic reflex in human, rat, and guinea pig intestine. Gastroenterology 115:370-380.

Griffiths RR, Johnson MW, Carducci MA, Umbricht A, Richards WA, Richards BD, Cosimano MP, and Klinedinst MA (2016) Psilocybin produces substantial and sustained decreases in depression and anxiety in patients with life-threatening cancer: a randomized double-blind trial. J Psychopharmacol 30:1181-1197.

Grimaldi B, Bonnin A, Fillion MP, Ruat M, Traiffort E, and Fillion G (1998) Characterization of 5-ht6 receptor and expression of 5-ht6 mRNA in the rat brain during ontogenetic development. Naunyn Schmiedebergs Arch Pharmacol 357:393-400.

Gross ER, Gershon MD, Margolis KG, Gertsberg ZV, Li Z, and Cowles RA (2012) Neuronal serotonin regulates growth of the intestinal mucosa in mice [published correction appears in Gastroenterology (2013) 144:249]. Gastroenterology 143: 408-417.e2.

Grossman CJ, Kilpatrick GJ, and Bunce KT (1993) Development of a radioligand binding assay for 5-HT4 receptors in guinea-pig and rat brain. $\mathrm{Br} J$ Pharmacol 109 $618-624$

Grottick AJ, Corrigall WA, and Higgins GA (2001) Activation of 5-HT(2C) receptors reduces the locomotor and rewarding effects of nicotine. Psychopharmacology (Berl) 157:292-298

Grottick AJ, Fletcher PJ, and Higgins GA (2000) Studies to investigate the role of 5 -HT(2C) receptors on cocaine- and food-maintained behavior. J Pharmacol Exp Ther 295:1183-1191.

Grottick AJ, Whelan K, Sanabria EK, Behan DP, Morgan M, and Sage C (2015) Investigating interactions between phentermine, dexfenfluramine, and 5-HT2C agonists, on food intake in the rat. Psychopharmacology (Berl) 232:1973-1982.

Grover M and Camilleri M (2013) Effects on gastrointestinal functions and symptoms of serotonergic psychoactive agents used in functional gastrointestinal diseases. $J$ Gastroenterol 48:177-181.

Grueb M, Wallenfels-Thilo B, Denk O, Mielke J, Reinthal E, Rohrbach JM, and Bartz-Schmidt KU (2006) Monoamine receptors in human corneal epithelium and endothelium. Acta Ophthalmol Scand 84:110-115.

Gudermann T, Levy FO, Birnbaumer M, Birnbaumer L, and Kaumann AJ (1993) Human S31 serotonin receptor clone encodes a 5-hydroxytryptamine ${ }_{1 \mathrm{E}}$-like serotonin receptor. Mol Pharmacol 43:412-418.

Guenther U, Wrigge H, Theuerkauf N, Boettcher MF, Wensing G, Zinserling J, Putensen C, and Hoeft A (2010) Repinotan, a selective 5-HT1A-R-agonist, antagonizes morphine-induced ventilatory depression in anesthetized rats. Anesth Analg 111:901-907.

Guiard BP and Di Giovanni G (2015) Central serotonin-2A (5-HT2A) receptor dysfunction in depression and epilepsy: the missing link? Front Pharmacol 6:46.

Guignabert C, Izikki M, Tu LI, Li Z, Zadigue P, Barlier-Mur AM, Hanoun N, Rodman D, Hamon M, Adnot S, et al. (2006) Transgenic mice overexpressing the 5-hydroxytryptamine transporter gene in smooth muscle develop pulmonary hypertension. Circ Res 98:1323-1330.

Guignabert C, Raffestin B, Benferhat R, Raoul W, Zadigue P, Rideau D, Hamon M, Adnot S, and Eddahibi S (2005) Serotonin transporter inhibition prevents and reverses monocrotaline-induced pulmonary hypertension in rats. Circulation 111: $2812-2819$.

Guillet-Deniau I, Burnol AF, and Girard J (1997) Identification and localization of a skeletal muscle secrotonin 5-HT2A receptor coupled to the Jak/STAT pathway. $J$ Biol Chem 272:14825-14829.

Guilluy C, Eddahibi S, Agard C, Guignabert C, Izikki M, Tu L, Savale L, Humbert M, Fadel E, Adnot S, et al. (2009) RhoA and Rho kinase activation in human pulmonary hypertension: role of 5-HT signaling. Am J Respir Crit Care Med 179: $1151-1158$.

Gulbransen BD, Bashashati M, Hirota SA, Gui X, Roberts JA, MacDonald JA, Muruve DA, McKay DM, Beck PL, Mawe GM, et al. (2012) Activation of neuronal $\mathrm{P}_{2} \mathrm{X}_{7}$ receptor-pannexin-1 mediates death of enteric neurons during colitis. Nat Med 18:600-604.

Günther S, Maroteaux L, and Schwarzacher SW (2006) Endogenous 5-HT ${ }_{2 \mathrm{~B}}$ receptor activation regulates neonatal respiratory activity in vitro. $J$ Neurobiol 66:949-961.

Gunthorpe MJ and Lummis SC (1999) Diltiazem causes open channel block of recombinant 5-HT3 receptors. J Physiol 519:713-722.

Gunthorpe MJ and Lummis SC (2001) Conversion of the ion selectivity of the 5 -HT(3a) receptor from cationic to anionic reveals a conserved feature of the ligandgated ion channel superfamily. J Biol Chem 276:10977-10983.

Gunthorpe MJ, Peters JA, Gill CH, Lambert JJ, and Lummis SC (2000) The 4'lysine in the putative channel lining domain affects desensitization but not the singlechannel conductance of recombinant homomeric 5-HT3A receptors. J Physiol $\mathbf{5 2 2}$ $187-198$

Guo Z, Song E, Ma S, Wang X, Gao S, Shao C, Hu S, Jia L, Tian R, Xu T, et al. (2012) Proteomics strategy to identify substrates of LNX, a PDZ domain-containing E3 ubiquitin ligase. J Proteome Res 11:4847-4862.

Gupta D, Prabhakar V, and Radhakrishnan M (2016) 5HT3 receptors: target for new antidepressant drugs. Neurosci Biobehav Rev 64:311-325.

Gupta S and Villalón CM (2010) The relevance of preclinical research models for the development of antimigraine drugs: focus on 5-HT(1B/1D) and CGRP receptors. Pharmacol Ther 128:170-190.

Guptan P, Dhingra A, and Panicker MM (1997) Multiple transcripts encode the $5-\mathrm{HT}_{1 \mathrm{~F}}$ receptor in rodent brain. Neuroreport 8:3317-3321.
Gurevich I, Englander MT, Adlersberg M, Siegal NB, and Schmauss C (2002a) Modulation of serotonin $2 \mathrm{C}$ receptor editing by sustained changes in serotonergic neurotransmission. J Neurosci 22:10529-10532.

Gurevich I, Tamir H, Arango V, Dwork AJ, Mann JJ, and Schmauss C (2002b) Altered editing of serotonin $2 \mathrm{C}$ receptor pre-mRNA in the prefrontal cortex of depressed suicide victims. Neuron 34:349-356.

Guscott M, Bristow LJ, Hadingham K, Rosahl TW, Beer MS, Stanton JA, Bromidge F, Owens AP, Huscroft I, Myers J, et al. (2005) Genetic knockout and pharmacological blockade studies of the 5-HT7 receptor suggest therapeutic potential in depression. Neuropharmacology 48:492-502.

Guscott MR, Egan E, Cook GP, Stanton JA, Beer MS, Rosahl TW, Hartmann S, Kulagowski J, McAllister G, Fone KC, et al. (2003) The hypothermic effect of 5-CT in mice is mediated through the 5-HT7 receptor. Neuropharmacology 44 1031-1037.

Guseva D, Holst K, Kaune B, Meier M, Keubler L, Glage S, Buettner M, Bleich A Pabst O, Bachmann O, et al. (2014a) Serotonin 5-HT7 receptor is critically involved in acute and chronic inflammation of the gastrointestinal tract. Inflamm Bowel Dis 20:1516-1529.

Guseva D, Wirth A, and Ponimaskin E (2014b) Cellular mechanisms of the 5-HT7 receptor-mediated signaling. Front Behav Neurosci 8:306.

Gustafson EL, Durkin MM, Bard JA, Zgombick J, and Branchek TA (1996) A receptor autoradiographic and in situ hybridization analysis of the distribution of the 5-ht7 receptor in rat brain. $\mathrm{Br} J$ Pharmacol 117:657-666.

Guthrie CR, Murray AT, Franklin AA, and Hamblin MW (2005) Differential agonistmediated internalization of the human 5-hydroxytryptamine 7 receptor isoforms. $J$ Pharmacol Exp Ther 313:1003-1010.

Ha CM, Park D, Kim Y, Na M, Panda S, Won S, Kim H, Ryu H, Park ZY, Rasenick MM, et al. (2015) SNX14 is a bifunctional negative regulator for neuronal 5-HT6 receptor signaling. J Cell Sci 128:1848-1861.

Haahr ME, Fisher P, Holst K, Madsen K, Jensen CG, Marner L, Lehel S, Baaré W, Knudsen G, and Hasselbalch S (2013) The 5-HT4 receptor levels in hippocampus correlates inversely with memory test performance in humans. Hum Brain Mapp 34:3066-3074

Hafdi Z, Couette S, Comoy E, Prie D, Amiel C, and Friedlander G (1996) Locally formed 5-hydroxytryptamine stimulates phosphate transport in cultured opossum kidney cells and in rat kidney. Biochem $J$ 320:615-621.

Hagan JJ, Price GW, Jeffrey P, Deeks NJ, Stean T, Piper D, Smith MI, Upton N, Medhurst AD, Middlemiss DN, et al. (2000) Characterization of SB-269970-A, a selective 5-HT(7) receptor antagonist. Br J Pharmacol 130:539-548.

Hagan JJ, Slade PD, Gaster L, Jeffrey P, Hatcher JP, and Middlemiss DN (1997) Stimulation of 5-HT1B receptors causes hypothermia in the guinea pig. Eur $J$ Pharmacol 331:169-174.

Hagberg B (2002) Clinical manifestations and stages of Rett syndrome. Ment Retard Dev Disabil Res Rev 8:61-65.

Hagberg GB, Blomstrand F, Nilsson M, Tamir H, and Hansson E (1998) Stimulation of 5-HT2A receptors on astrocytes in primary culture opens voltage-independent $\mathrm{Ca} 2+$ channels. Neurochem Int 32:153-162.

Hagena H and Manahan-Vaughan D (2017) The serotonergic 5-HT4 receptor: a unique modulator of hippocampal synaptic information processing and cognition. Neurobiol Learn Mem 138:145-153.

Halaas JL, Gajiwala KS, Maffei M, Cohen SL, Chait BT, Rabinowitz D, Lallone RL, Burley SK, and Friedman JM (1995) Weight-reducing effects of the plasma protein encoded by the obese gene. Science 269:543-546.

Halberstadt AL (2015) Recent advances in the neuropsychopharmacology of serotonergic hallucinogens. Behav Brain Res 277:99-120.

Halford JC and Blundell JE (2000) Separate systems for serotonin and leptin in appetite control. Ann Med 32:222-232.

Halberstadt AL, Sindhunata IS, Scheffers K, Flynn AD, Sharp RF, Geyer MA and Young JW (2016) Effect of 5-HT2A and 5-HT2C receptors on temporal discrimination by mice. Neuropharmacology 107:364-375.

Halford JC, Harrold JA, Boyland EJ, Lawton CL, and Blundell JE (2007) Serotonergic drugs: effects on appetite expression and use for the treatment of obesity. Drugs 67:27-55.

Halford JC, Lawton CL, and Blundell JE (1997) The 5-HT2 receptor agonist MK-212 reduces food intake and increases resting but prevents the behavioural satiety sequence. Pharmacol Biochem Behav 56:41-46.

Halford JC, Wanninayake SC, and Blundell JE (1998) Behavioral satiety sequence (BSS) for the diagnosis of drug action on food intake. Pharmacol Biochem Behav 61: 159-168.

Hall MD, el Mestikawy S, Emerit MB, Pichat L, Hamon M, and Gozlan H (1985) $[3 \mathrm{H}] 8$-hydroxy-2-(di-n-propylamino)tetralin binding to pre- and postsynaptic 5 -hydroxytryptamine sites in various regions of the rat brain. $J$ Neurochem 44 $1685-1696$

Hamblin MW, Guthrie CR, Kohen R, and Heidmann DE (1998) Gs protein-coupled serotonin receptors: receptor isoforms and functional differences. Ann N Y Acad Sci 861:31-37.

Hamblin MW and Metcalf MA (1991) Primary structure and functional characterization of a human 5-HT1D-type serotonin receptor. Mol Pharmacol 40:143-148.

Hamblin MW, Metcalf MA, McGuffin RW, and Karpells S (1992a) Molecular cloning and functional characterization of a human 5-HT1B serotonin receptor: a homologue of the rat 5-HT1B receptor with 5-HT1D-like pharmacological specificity. Biochem Biophys Res Commun 184:752-759.

Hamblin MW, McGuffin RW, Metcalf MA, Dorsa DM, and Merchant KM (1992b) Distinct 5-HT(1B) and 5-HT(1D) serotonin receptors in rat: structural and pharmacological comparison of the two cloned receptors. Mol Cell Neurosci 3:578-587.

Hamik A, Oksenberg D, Fischette C, and Peroutka SJ (1990) Analysis of tandospirone (SM-3997) interactions with neurotransmitter receptor binding sites. Biol Psychiatry 28:99-109.

Hammer C, Cichon S, Mühleisen TW, Haenisch B, Degenhardt F, Mattheisen M, Breuer R, Witt SH, Strohmaier J, Oruc L, et al. (2012) Replication of functiona 
serotonin receptor type $3 \mathrm{~A}$ and B variants in bipolar affective disorder: a European multicenter study. Transl Psychiatry 2:e103.

Hammer C, Kapeller J, Endele M, Fischer C, Hebebrand J, Hinney A, Friedel S, Gratacòs M, Estivill X, Fichter M, et al. (2009) Functional variants of the serotonin receptor type $3 \mathrm{~A}$ and $\mathrm{B}$ gene are associated with eating disorders. Pharmacogenet Genomics 19:790-799.

Hammer J, Phillips SF, Talley NJ, and Camilleri M (1993) Effect of a 5HT3-antagonist (ondansetron) on rectal sensitivity and compliance in health and the irritable bowel syndrome. Aliment Pharmacol Ther 7:543-551.

Hamon M, Bourgoin S, Le Bars D, and Cesselin F (1988) In vivo and in vitro release of central neurotransmitters in relation to pain and analgesia. Prog Brain Res $\mathbf{7 7}$ 431-444.

Hamon M, Doucet E, Lefèvre K, Miquel MC, Lanfumey L, Insausti R, Frechilla D, Del Rio J, and Vergé D (1999) Antibodies and antisense oligonucleotide for probing the distribution and putative functions of central 5-HT6 receptors. Neuropsychopharmacology 21(2 Suppl):68S-76S.

Hancock DB, Eijgelsheim M, Wilk JB, Gharib SA, Loehr LR, Marciante KD, Franceschini N, van Durme YM, Chen TH, Barr RG, et al (2010) Meta-analyses of genome-wide association studies identify multiple loci associated with pulmonary function. Nat Genet 42:45-52.

Handley SL (1995) 5-Hydroxytryptamine pathways in anxiety and its treatment. Pharmacol Ther 66:103-148.

Hannon J and Hoyer D (2008a) Molecular biology of 5-HT receptors. Behav Brain Res 195:198-213.

Hannon J and Hoyer D (2008b) Molecular biology of 5-HT receptors, in Serotonin and Sleep: Molecular, Functional and Clinical Aspects (Monti JM, Pandi-Perumal SR, Jacobs BL, and Nutt DJ eds). pp 155-182.

Hansen M, Phonekeo K, Paine JS, Leth-Petersen S, Begtrup M, Bräuner-Osborne H, and Kristensen JL (2014) Synthesis and structure-activity relationships of N-benzyl phenethylamines as 5- $\mathrm{HT}_{2 \mathrm{~A} / 2 \mathrm{C}}$ agonists. ACS Chem Neurosci 5:243-249.

Hansen MB and Witte A-B (2008) The role of serotonin in intestinal luminal sensing and secretion. Acta Physiol (Oxf) 193:311-323.

Harada K, Aota M, Inoue T, Matsuda R, Mihara T, Yamaji T, Ishibashi K, and Matsuoka N (2006) Anxiolytic activity of a novel potent serotonin 5-HT2C receptor antagonist FR260010: a comparison with diazepam and buspirone. Eur $J$ Pharmacol 553:171-184

Harrell AV and Allan AM (2003) Improvements in hippocampal-dependent learning and decremental attention in 5-HT(3) receptor overexpressing mice. Learn Mem 10:410-419.

Hartig PR, Branchek TA, and Weinshank RL (1992) A subfamily of 5-HT1D receptor genes. Trends Pharmacol Sci 13:152-159.

Hartig PR, Hoffman BJ, Kaufman MJ, and Hirata F (1990) The 5-HT 1 receptor. Ann N Y Acad Sci 600:149-166; discussion 166-167.

Hartig PR, Hoyer D, Humphrey PPA, and Martin GR (1996) Alignment of receptor nomenclature with the human genome: classification of 5-HT1B and 5-HT1D receptor subtypes. Trends Pharmacol Sci 17:103-105.

Hartner JC, Schmittwolf C, Kispert A, Müller AM, Higuchi M, and Seeburg PH (2004) Liver disintegration in the mouse embryo caused by deficiency in the RNAediting enzyme ADAR1. J Biol Chem 279:4894-4902.

Harvey-Lewis C, Li Z, Higgins GA, and Fletcher PJ (2016) The 5-HT(2C) receptor agonist lorcaserin reduces cocaine self-administration, reinstatement of cocaineseeking and cocaine induced locomotor activity. Neuropharmacology 101:237-245.

Hassaine G, Deluz C, Grasso L, Wyss R, Tol MB, Hovius R, Graff A, Stahlberg H, Tomizaki T, Desmyter A, et al. (2014) X-ray structure of the mouse serotonin 5-HT3 receptor. Nature 512:276-281.

Haub S, Ritze Y, Bergheim I, Pabst O, Gershon MD, and Bischoff SC (2010) Enhancement of intestinal inflammation in mice lacking interleukin 10 by deletion of the serotonin reuptake transporter. Neurogastroenterol Motil 22:826-834, e229.

Hauck AJ, Edwards WD, Danielson GK, Mullany CJ, and Bresnahan DR (1990) Mitral and aortic valve disease associated with ergotamine therapy for migraine. Report of two cases and review of literature. Arch Pathol Lab Med 114:62-64.

Hauser SR, Hedlund PB, Roberts AJ, Sari Y, Bell RL, and Engleman EA (2015) The 5-HT7 receptor as a potential target for treating drug and alcohol abuse. Front Neurosci 8:448.

Hayasaka Y, Purgato M, Magni LR, Ogawa Y, Takeshima N, Cipriani A, Barbui C, Leucht S, and Furukawa TA (2015) Dose equivalents of antidepressants: evidencebased recommendations from randomized controlled trials. J Affect Disord 180 179-184.

Hayes MR and Covasa M (2005) CCK and 5-HT act synergistically to suppress food intake through simultaneous activation of CCK-1 and 5- $\mathrm{HT}_{3}$ receptors. Peptides 26 : $2322-2330$.

Hazra R, Guo JD, Dabrowska J, and Rainnie DG (2012) Differential distribution of serotonin receptor subtypes in BNST(ALG) neurons: modulation by unpredictable shock stress. Neuroscience 225:9-21.

He H, Yin JY, Xu YJ, Li X, Zhang Y, Liu ZG, Zhou F, Zhai M, Li Y, Li XP, et al. (2014) Association of ABCB1 polymorphisms with the efficacy of ondansetron in chemotherapy-induced nausea and vomiting. Clin Ther 36:1242-1252.e2.

Heal DJ, Smith SL, Fisas A, Codony X, and Buschmann H (2008) Selective 5-HT6 receptor ligands: progress in the development of a novel pharmacological approach to the treatment of obesity and related metabolic disorders. Pharmacology \& therapeutics 117:207-231.

Hedlund PB (2009) The 5-HT7 receptor and disorders of the nervous system: an overview. Psychopharmacology (Berl) 206:345-354.

Hedlund PB, Carson MJ, Sutcliffe JG, and Thomas EA (1999) Allosteric regulation by oleamide of the binding properties of 5-hydroxytryptamine7 receptors. Biochem Pharmacol 58:1807-1813.

Hedlund PB, Danielson PE, Thomas EA, Slanina K, Carson MJ, and Sutcliffe JG (2003) No hypothermic response to serotonin in 5-HT7 receptor knockout mice. Proc Natl Acad Sci USA 100:1375-1380.
Hedlund PB, Huitron-Resendiz S, Henriksen SJ, and Sutcliffe JG (2005) 5-HT7 receptor inhibition and inactivation induce antidepressantlike behavior and sleep pattern. Biol Psychiatry 58:831-837.

Hedlund PB, Kelly L, Mazur C, Lovenberg T, Sutcliffe JG, and Bonaventure P (2004) 8-OH-DPAT acts on both 5-HT1A and 5-HT7 receptors to induce hypothermia in rodents. Eur J Pharmacol 487:125-132.

Hedlund PB, Leopoldo M, Caccia S, Sarkisyan G, Fracasso C, Martelli G, Lacivita E, Berardi F, and Perrone R (2010) LP-211 is a brain penetrant selective agonist for the serotonin 5-HT(7) receptor. Neurosci Lett 481:12-16.

Hedlund PB and Sutcliffe JG (2007) The 5-HT7 receptor influences stereotypic behavior in a model of obsessive-compulsive disorder. Neurosci Lett 414:247-251.

Hegde SS and Eglen RM (1996) Peripheral 5-HT4 receptors. FASEB J 10:1398-1407.

Hegener O, Prenner L, Runkel F, Baader SL, Kappler J, and Häberlein H (2004) Dynamics of beta2-adrenergic receptor-ligand complexes on living cells. Biochemistry 43:6190-6199.

Heidmann DE, Metcalf MA, Kohen R, and Hamblin MW (1997) Four 5-hydroxytryptamine7 (5-HT7) receptor isoforms in human and rat produced by alternative splicing: species differences due to altered intron-exon organization. $J$ Neurochem 68:1372-1381.

Heidmann DE, Szot P, Kohen R, and Hamblin MW (1998) Function and distribution of three rat 5-hydroxytryptamine7 (5-HT7) receptor isoforms produced by alternative splicing. Neuropharmacology 37:1621-1632.

Heisler LK, Chu HM, Brennan TJ, Danao JA, Bajwa P, Parsons LH, and Tecott LH (1998a) Elevated anxiety and antidepressant-like responses in serotonin 5-HT1A receptor mutant mice. Proc Natl Acad Sci USA 95:15049-15054.

Heisler LK, Chu HM, and Tecott LH (1998b) Epilepsy and obesity in serotonin 5- $\mathrm{HT}_{2 \mathrm{C}}$ receptor mutant mice. Ann N Y Acad Sci 861:74-78.

Heisler LK, Cowley MA, Tecott LH, Fan W, Low MJ, Smart JL, Rubinstein M, Tatro JB, Marcus JN, Holstege H, et al. (2002) Activation of central melanocortin pathways by fenfluramine. Science 297:609-611.

Heisler LK, Jobst EE, Sutton GM, Zhou L, Borok E, Thornton-Jones Z, Liu HY, Zigman JM, Balthasar N, Kishi T, et al. (2006) Serotonin reciprocally regulates melanocortin neurons to modulate food intake. Neuron 51:239-249.

Heisler LK, Pronchuk N, Nonogaki K, Zhou L, Raber J, Tung L, Yeo GS, O'Rahilly S, Colmers WF, Elmquist JK, et al. (2007a) Serotonin activates the hypothalamic-pituitary-adrenal axis via serotonin $2 \mathrm{C}$ receptor stimulation. J Neurosci 27:6956-6964.

Heisler LK, Zhou L, Bajwa P, Hsu J, and Tecott LH (2007b) Serotonin 5-HT(2C) receptors regulate anxiety-like behavior. Genes Brain Behav 6:491-496.

Helboe L, Egebjerg J, and de Jong IE (2015) Distribution of serotonin receptor 5-HT6 mRNA in rat neuronal subpopulations: a double in situ hybridization study. Neuroscience 310:442-454.

Helekar SA and Patrick J (1997) Peptidyl prolyl cis-trans isomerase activity of cyclophilin A in functional homo-oligomeric receptor expression. Proc Natl Acad Sci USA 94:5432-5437.

Helke CJ, McDonald CH, and Phillips ET (1993) Hypotensive effects of 5-HT $1 \mathrm{~A}$ receptor activation: ventral medullary sites and mechanisms of action in the rat. $J$ Auton Nerv Syst 42:177-188.

Hellstrand K and Hermodsson S (1987) Role of serotonin in the regulation of human natural killer cell cytotoxicity. J Immunol 139:869-875.

Helsmoortel C, Swagemakers SM, Vandeweyer G, Stubbs AP, Palli I, Mortier G, Kooy RF, and van der Spek PJ (2016) Whole genome sequencing of a dizygotic twin suggests a role for the serotonin receptor HTR7 in autism spectrum disorder. Am J Med Genet B Neuropsychiatr Genet 171:1049-1056.

Helton LA, Thor KB, and Baez M (1994) 5-hydroxytryptamine2A 5 -hydroxytryptamine ${ }_{2 \mathrm{~B}}$, and 5-hydroxytryptamine $2 \mathrm{C}$ receptor mRNA expression in the spinal cord of rat, cat, monkey and human. Neuroreport 5:2617-2620.

Hemedah M, Coupar IM, and Mitchelson FJ (1999) [3H]-Mesulergine labels 5-HT7 sites in rat brain and guinea-pig ileum but not rat jejunum. $\mathrm{Br} J$ Pharmacol 126: $179-188$.

Hendrikx M, Van Dorpe J, Flameng W, and Daenen W (1996) Aortic and mitral valve disease induced by ergotamine therapy for migraine: a case report and review of the literature. $J$ Heart Valve Dis 5:235-237.

Hensler JG (2003) Regulation of 5-HT1A receptor function in brain following agonist or antidepressant administration. Life Sci 72:1665-1682.

Heredia DJ, Dickson EJ, Bayguinov PO, Hennig GW, and Smith TK (2009) Localized release of serotonin (5-hydroxytryptamine) by a fecal pellet regulates migrating motor complexes in murine colon. Gastroenterology 136:1328-1338.

Heredia DJ, Gershon MD, Koh SD, Corrigan RD, Okamoto T, and Smith TK (2013) Important role of mucosal serotonin in colonic propulsion and peristaltic reflexes: in vitro analyses in mice lacking tryptophan hydroxylase 1 . J Physiol 591: $5939-5957$.

Hernandez ME, Martinez-Fong D, Perez-Tapia M, Estrada-Garcia I, Estrada-Parra S, and Pavón L (2010) Evaluation of the effect of selective serotonin-reuptake inhibitors on lymphocyte subsets in patients with a major depressive disorder. Eur Neuropsychopharmacol 20:88-95.

Herrick-Davis K (2013) Functional significance of serotonin receptor dimerization. Exp Brain Res 230:375-386.

Herrick-Davis K and Farrington DT (2011) 5-HT2C Receptor Dimerization, in 5-HT2C Receptors in the Pathophysiology of CNS Disease, pp 129-155, Springer.

Herrick-Davis K, Grinde E, Cowan A, and Mazurkiewicz JE (2013) Fluorescence correlation spectroscopy analysis of serotonin, adrenergic, muscarinic, and dopamine receptor dimerization: the oligomer number puzzle. Mol Pharmacol 84 $630-642$

Herrick-Davis K, Grinde E, Harrigan TJ, and Mazurkiewicz JE (2005) Inhibition of serotonin 5-hydroxytryptamine2c receptor function through heterodimerization: receptor dimers bind two molecules of ligand and one G-protein. J Biol Chem $\mathbf{2 8 0}$ 40144-40151.

Herrick-Davis K, Grinde E, Lindsley T, Cowan A, and Mazurkiewicz JE (2012) Oligomer size of the serotonin 5-hydroxytryptamine 2C (5-HT2C) receptor revealed by fluorescence correlation spectroscopy with photon counting histogram analysis: 
evidence for homodimers without monomers or tetramers. J Biol Chem 287: 23604-23614.

Herrick-Davis K, Grinde E, Lindsley T, Teitler M, Mancia F, Cowan A, and Mazurkiewicz JE (2015) Native serotonin 5-HT2C receptors are expressed as homodimers on the apical surface of choroid plexus epithelial cells. Mol Pharmacol 87:660-673.

Herrick-Davis K, Grinde E, and Mazurkiewicz JE (2004) Biochemical and biophysical characterization of serotonin 5-HT2C receptor homodimers on the plasma membrane of living cells. Biochemistry 43:13963-13971.

Herrick-Davis K, Grinde E, and Niswender CM (1999) Serotonin 5-HT2C receptor RNA editing alters receptor basal activity: implications for serotonergic signal transduction. $J$ Neurochem 73:1711-1717.

Herrick-Davis K, Grinde E, and Teitler M (2000) Inverse agonist activity of atypical antipsychotic drugs at human 5-hydroxytryptamine2C receptors. J Pharmacol Exp Ther 295:226-232.

Herrick-Davis K, Grinde E, and Weaver BA (2007) Serotonin 5-HT(2C) receptor homodimerization is not regulated by agonist or inverse agonist treatment. Eur $J$ Pharmacol 568:45-53.

Herrick-Davis K, Weaver BA, Grinde E, and Mazurkiewicz JE (2006) Serotonin 5-HT2C receptor homodimer biogenesis in the endoplasmic reticulum: real-time visualization with confocal fluorescence resonance energy transfer. $J$ Biol Chem 281:27109-27116.

Herrik KF, Mørk A, Richard N, Bundgaard C, Bastlund JF, and de Jong IEM (2016) The 5-HT6 receptor antagonist idalopirdine potentiates the effects of acetylcholinesterase inhibition on neuronal network oscillations and extracellular acetylcholine levels in the rat dorsal hippocampus. Neuropharmacology 107: 351-363.

Hershenson MB, Chao TS, Abe MK, Gomes I, Kelleher MD, Solway J, and Rosner MR (1995) Histamine antagonizes serotonin and growth factor-induced mitogen-activated protein kinase activation in bovine tracheal smooth muscle cells. $J$ Biol Chem 270:19908-19913.

Herth MM and Knudsen GM (2015) Current radiosynthesis strategies for 5-HT2A receptor PET tracers. J Labelled Comp Radiopharm 58:265-273.

Hervás A, Toma C, Romarís P, Ribasés M, Salgado M, Bayes M, Balmaña N, Cormand B, Maristany M, Guijarro S, et al. (2014) The involvement of serotonin polymorphisms in autistic spectrum symptomatology. Psychiatr Genet 24:158-163.

Hetman M, Kanning K, Cavanaugh JE, and Xia Z (1999) Neuroprotection by brainderived neurotrophic factor is mediated by extracellular signal-regulated kinase and phosphatidylinositol 3-kinase. J Biol Chem 274:22569-22580.

Heusler P, Bruins Slot L, Rauly-Lestienne I, Palmier C, Tardif S, Tourette A, Ailhaud $\mathrm{MC}$, and Cussac D (2009) Activation of G proteins and extracellular signal-regulated kinase 1/2 phosphorylation via human dopamine D4.4 receptors: differentia pathway-dependent potencies of receptor agonists. Naunyn Schmiedebergs Arch Pharmacol 379:87-99.

Hewitt KN, Lee MD, Dourish CT, and Clifton PG (2002) Serotonin 2C receptor agonists and the behavioural satiety sequence in mice. Pharmacol Biochem Behav 71:691-700.

Hibbs RE and Gouaux E (2011) Principles of activation and permeation in an anionselective Cys-loop receptor. Nature 474:54-60.

Hietala J, Kuonnamäki M, Pälvimäki EP, Laakso A, Majasuo H, and Syvälahti E (2001) Sertindole is a serotonin 5-HT2c inverse agonist and decreases agonist but not antagonist binding to 5-HT2c receptors after chronic treatment. Psychopharmacology (Berl) 157:180-187.

Higgins GA, Enderlin M, Haman M, and Fletcher PJ (2003) The 5-HT2A receptor antagonist M100,907 attenuates motor and 'impulsive-type' behaviours produced by NMDA receptor antagonism. Psychopharmacology (Berl) 170:309-319.

Higgins GA and Fletcher PJ (2015) Therapeutic potential of 5-HT2C receptor agonists for addictive disorders. ACS Chem Neurosci 6:1071-1088.

Higgins GA, Fletcher PJ, and Shanahan WR (2020) Lorcaserin: a review of its preclinical and clinical pharmacology and therapeutic potential. Pharmacol Ther $\mathbf{2 0 5}$ 107417.

Higgins GA, Silenieks LB, Rossmann A, Rizos Z, Noble K, Soko AD, and Fletcher PJ (2012) The 5- $\mathrm{HT}_{2 \mathrm{C}}$ receptor agonist lorcaserin reduces nicotine self-administration, discrimination, and reinstatement: relationship to feeding behavior and impulse control. Neuropsychopharmacology 37:1177-1191.

Higgs S, Cooper AJ, and Barnes NM (2011) Reversal of sibutramine-induced anorexia with a selective 5-HT(2C) receptor antagonist. Psychopharmacology (Berl) 214:941-947.

Higgs S, Cooper AJ, and Barnes NM (2016) The $5-\mathrm{HT}_{2} \mathrm{C}$ receptor agonist, lorcaserin, and the $5-\mathrm{HT}_{6}$ receptor antagonist, SB-742457, promote satiety; a microstructural analysis of feeding behaviour. Psychopharmacology (Berl) 233:417-424.

Hilf RJC, Bertozzi C, Zimmermann I, Reiter A, Trauner D, and Dutzler R (2010) Structural basis of open channel block in a prokaryotic pentameric ligand-gated ion channel. Nat Struct Mol Biol 17:1330-1336.

Hill PB, Dora KA, Hughes AD, and Garland CJ (2000) The involvement of intracellular $\mathrm{Ca}^{2+}$ ) in 5-HT(1B/1D) receptor-mediated contraction of the rabbit isolated renal artery. Br J Pharmacol 130:835-842.

Hirai T, Tokumo K, Tsuchiya D, and Nishio H (2009) Expression of mRNA for 5-HT2 receptors and proteins related to inactivation of 5-HT in mouse osteoblasts. $J$ Pharmacol Sci 109:319-323.

Hirani E, Opacka-Juffry J, Gunn R, Khan I, Sharp T, and Hume S (2000) Pindolol occupancy of 5-HT(1A) receptors measured in vivo using small animal positron emission tomography with carbon-11 labeled WAY 100635. Synapse 36: $330-341$

Hironaka E, Hongo M, Sakai A, Mawatari E, Terasawa F, Okumura N, Yamazaki A Ushiyama Y, Yazaki Y, and Kinoshita O (2003) Serotonin receptor antagonist inhibits monocrotaline-induced pulmonary hypertension and prolongs survival in rats. Cardiovasc Res 60:692-699.
Hirose A, Sasa M, Akaike A, and Takaori S (1990) Inhibition of hippocampal CA1 neurons by 5 -hydroxytryptamine, derived from the dorsal raphe nucleus and the 5-hydroxytryptamine1A agonist SM-3997. Neuropharmacology 29:93-101.

Hirst WD, Abrahamsen B, Blaney FE, Calver AR, Aloj L, Price GW, and Medhurst $\mathrm{AD}$ (2003) Differences in the central nervous system distribution and pharmacology of the mouse 5-hydroxytryptamine-6 receptor compared with rat and human receptors investigated by radioligand binding, site-directed mutagenesis, and molecular modeling. Mol Pharmacol 64:1295-1308.

Hirst WD, Cheung NY, Rattray M, Price GW, and Wilkin GP (1998) Cultured astrocytes express messenger RNA for multiple serotonin receptor subtypes, without functional coupling of $5-\mathrm{HT}_{1}$ receptor subtypes to adenylyl cyclase. Brain Res Mol Brain Res 61:90-99.

Hirst WD, Stean TO, Rogers DC, Sunter D, Pugh P, Moss SF, Bromidge SM, Riley G, Smith DR, Bartlett S, et al. (2006) SB-399885 is a potent, selective 5-HT6 receptor antagonist with cognitive enhancing properties in aged rat water maze and novel object recognition models. Eur J Pharmacol 553:109-119.

Hisadome K, Smith MA, Choudhury AI, Claret M, Withers DJ, and Ashford ML (2009) 5-HT inhibition of rat insulin 2 promoter Cre recombinase transgene and proopiomelanocortin neuron excitability in the mouse arcuate nucleus. Neuroscience 159:83-93.

Hjorth S (1985) Hypothermia in the rat induced by the potent serotoninergic agent 8-OH-DPAT. J Neural Transm (Vienna) 61:131-135.

Hjorth S, Carlsson A, Lindberg P, et al. (1982) 8-Hydroxy-2-(di- n-propylamino)tetralin, 8-OH-DPAT, a potent and selective sim- plifies ergot congener with central 5HT receptor stimulating activity. J Neural Transm 55:169-188.

Hobson RJ, Geng J, Gray AD, and Komuniecki RW (2003) Ser-7b, a constitutively active G $\alpha$ s coupled 5-HT7-like receptor expressed in the Caenorhabditis elegans M4 pharyngeal motor neuron. J Neurochem 87:22-29.

Hodge E, Nelson CP, Miller S, Billington CK, Stewart CE, Swan C, Malarstig A, Henry AP, Gowland C, Melén E, et al. (2013a) HTR4 gene structure and altered expression in the developing lung. Respir Res 14:77.

Hodge JM, Wang Y, Berk M, Collier FM, Fernandes TJ, Constable MJ, Pasco JA, Dodd S, Nicholson GC, Kennedy RL, et al. (2013b) Selective serotonin reuptake inhibitors inhibit human osteoclast and osteoblast formation and function. Biol Psychiatry 74:32-39.

Hodos W and Kalman G (1963) Effects of increment size and reinforcer volume on progressive ratio performance. J Exp Anal Behav 6:387-392.

Hoffman BJ and Mezey E (1989) Distribution of serotonin 5-HT1C receptor mRNA in adult rat brain. FEBS Lett 247:453-462.

Hoffman JM, Tyler K, MacEachern SJ, Balemba OB, Johnson AC, Brooks EM, Zhao H, Swain GM, Moses PL, Galligan JJ, et al. (2012) Activation of colonic mucosal 5 -HT(4) receptors accelerates propulsive motility and inhibits visceral hypersensitivity. Gastroenterology 142:844-854.e4.

Hoger JH, Walter AE, Vance D, Yu L, Lester HA, and Davidson N (1991) Modulation of a cloned mouse brain potassium channel. Neuron 6:227-236.

Holbrook JD, Gill CH, Zebda N, Spencer JP, Leyland R, Rance KH, Trinh H, Balmer G, Kelly FM, Yusaf SP, et al. (2009) Characterisation of 5-HT3C, 5-HT3D and 5-HT3E receptor subunits: evolution, distribution and function. J Neurochem 108:384-396.

Holohean AM and Hackman JC (2004) Mechanisms intrinsic to 5-HT $\mathrm{H}_{2 \mathrm{~B}}$ receptorinduced potentiation of NMDA receptor responses in frog motoneurones. $\mathrm{Br} J$ Pharmacol 143:351-360.

Holst K, Guseva D, Schindler S, Sixt M, Braun A, Chopra H, Pabst O, and Ponimaskin E (2015) Serotonin receptor 5- $\mathrm{HT}_{7} \mathrm{R}$ regulates the morphology and migratory properties of dendritic cells. J Cell Sci 128:2866-2880.

Hołuj M, Popik P, and Nikiforuk A (2015) Improvement of ketamine-induced social withdrawal in rats: the role of 5-HT7 receptors. Behav Pharmacol 26:766-775.

Holzwarth MA and Brownfield MS (1985) Serotonin coexists with epinephrine in rat adrenal medullary cells. Neuroendocrinology 41:230-236.

Holzwarth MA, Sawetawan C, and Brownfield MS (1984) Serotonin-immunoreactivity in the adrenal medulla: distribution and response to pharmacological manipulation. Brain Res Bull 13:299-308.

Homberg JR, Olivier JDA, Smits BMG, Mul JD, Mudde J, Verheul M, Nieuwenhuizen OFM, Cools AR, Ronken E, Cremers T, et al. (2007) Characterization of the serotonin transporter knockout rat: a selective change in the functioning of the serotonergic system. Neuroscience 146:1662-1676.

Hope AG, Downie DL, Sutherland L, Lambert JJ, Peters JA, and Burchell B (1993) Cloning and functional expression of an apparent splice variant of the murine 5-HT3 receptor A subunit. Eur J Pharmacol 245:187-192.

Horiguchi M, Huang M, and Meltzer HY (2011) The role of 5-hydroxytryptamine 7 receptors in the phencyclidine-induced novel object recognition deficit in rats. $J$ Pharmacol Exp Ther 338:605-614.

Horiguchi M and Meltzer HY (2012) The role of 5-HT1A receptors in phencyclidine (PCP)-induced novel object recognition (NOR) deficit in rats. Psychopharmacology (Berl) 221:205-215.

Horiguchi M and Meltzer HY (2013) Blonanserin reverses the phencyclidine (PCP)induced impairment in novel object recognition (NOR) in rats: role of indirect 5-HT(1A) partial agonism. Behav Brain Res 247:158-164

Horisawa T, Ishibashi T, Nishikawa H, Enomoto T, Toma S, Ishiyama T, and Taiji M (2011) The effects of selective antagonists of serotonin 5-HT7 and 5-HT1A receptors on MK-801-induced impairment of learning and memory in the passive avoidance and Morris water maze tests in rats: mechanistic implications for the beneficial effects of the novel atypical antipsychotic lurasidone. Behav Brain Res 220:83-90.

Horisawa T, Nishikawa H, Toma S, Ikeda A, Horiguchi M, Ono M, Ishiyama T, and Taiji M (2013) The role of 5-HT7 receptor antagonism in the amelioration of MK-801-induced learning and memory deficits by the novel atypical antipsychotic drug lurasidone. Behav Brain Res 244:66-69.

Horiuchi J, Atik A, Iigaya K, McDowall LM, Killinger S, and Dampney RA (2011) Activation of 5-hydroxytryptamine-1A receptors suppresses cardiovascular 
responses evoked from the paraventricular nucleus. Am J Physiol Regul Integr Comp Physiol 301:R1088-R1097.

Horiuchi J, Wakabayashi S, and Dampney RA (2005) Activation of 5-hydroxytryptamine ${ }_{1 \mathrm{~A}}$ receptors suppresses the cardiovascular response evoked from the dorsomedial hypothalamic nucleus. Hypertension 46:173-179.

Horn CC, Wallisch WJ, Homanics GE, and Williams JP (2014) Pathophysiological and neurochemical mechanisms of postoperative nausea and vomiting. Eur $J$ Pharmacol 722:55-66.

Horvath J, Fross RD, Kleiner-Fisman G, Lerch R, Stalder H, Liaudat S, Raskoff WJ, Flachsbart KD, Rakowski H, Pache JC, et al. (2004) Severe multivalvular heart disease: a new complication of the ergot derivative dopamine agonists. Mov Disord 19:656-662.

Hou M, Kanje M, Longmore J, Tajti J, Uddman R, and Edvinsson L (2001) 5-HT(1B) and 5-HT(1D) receptors in the human trigeminal ganglion: co-localization with calcitonin gene-related peptide, substance $\mathrm{P}$ and nitric oxide synthase. Brain Res 909:112-120.

Houghton LA, Foster JM, and Whorwell PJ (2000) Alosetron, a 5-HT 3 receptor antagonist, delays colonic transit in patients with irritable bowel syndrome and healthy volunteers. Aliment Pharmacol Ther 14:775-782

Houghton LA, Jackson NA, Whorwell PJ, and Cooper SM (1999) 5-HT Teceptor $_{4}$ antagonism in irritable bowel syndrome: effect of SB-207266-A on rectal sensitivity and small bowel transit. Aliment Pharmacol Ther 13:1437-1444.

House JS, Li H, DeGraff LM, Flake G, Zeldin DC, and London SJ (2015) Genetic variation in HTR4 and lung function: GWAS follow-up in mouse. FASEB J 29:323-335.

Howell LL and Cunningham KA (2015) Serotonin 5-HT2 receptor interactions with dopamine function: implications for therapeutics in cocaine use disorder. Pharmacol Rev 67:176-197.

Howes SR, Dalley JW, Morrison CH, Robbins TW, and Everitt BJ (2000) Leftward shift in the acquisition of cocaine self-administration in isolation-reared rats: relationship to extracellular levels of dopamine, serotonin and glutamate in the nucleus accumbens and amygdala-striatal FOS expression. Psychopharmacology (Berl) 151:55-63.

Hoyer D (1988a) Functional correlates of serotonin 5-HT 1 recognition sites. J Recept Res 8:59-81.

Hoyer D (1988b) Molecular pharmacology and biology of 5-HT $\mathrm{HC}_{1 \mathrm{C}}$ receptors. Trends Pharmacol Sci 9:89-94.

Hoyer D, Clarke DE, Fozard JR, Hartig PR, Martin GR, Mylecharane EJ, Saxena PR, and Humphrey PPA (1994) International Union of Pharmacology classification of receptors for 5-hydroxytryptamine (Serotonin). Pharmacol Rev 46:157-203.

Hoyer D, Engel G, and Kalkman HO (1985a) Characterization of the 5-HT1B recognition site in rat brain: binding studies with (-)[125I]iodocyanopindolol. Eur $J$ Pharmacol 118:1-12.

Hoyer D, Engel G, and Kalkman HO (1985b) Molecular pharmacology of 5-HT1 and 5 -HT2 recognition sites in rat and pig brain membranes: radioligand binding studies with [3H]5-HT, [3H]8-OH-DPAT, (-)[125I]iodocyanopindolol, [3H]mesulergine and [3H]ketanserin. Eur J Pharmacol 118:13-23.

Hoyer D, Hannon JP, and Martin GR (2002) Molecular, pharmacological and functional diversity of 5-HT receptors. Pharmacol Biochem Behav 71:533-554.

Hoyer D, Lery H, Waeber C, Bruinvels AT, Nozulak J, and Palacios JM (1992) "5HT1R" or 5-HT1D sites? Evidence for 5-HT1D binding sites in rabbit brain. Naunyn Schmiedebergs Arch Pharmacol 346:249-254.

Hoyer D and Martin GR (1996) Classification and nomenclature of 5-HT receptors: a comment on current issues. Behav Brain Res 73:263-268.

Hoyer D and Martin G (1997) 5-HT receptor classification and nomenclature: towards a harmonization with the human genome. Neuropharmacology 36:419-428.

Hoyer D and Middlemiss DN (1989) Species differences in the pharmacology of terminal 5-HT autoreceptors in mammalian brain. Trends Pharmacol Sci 10:130-132.

Hoyer D, Pazos A, Probst A, and Palacios JM (1986a) Serotonin receptors in the human brain. I. Characterization and autoradiographic localization of 5-HT1A recognition sites. Apparent absence of 5-HT1B recognition sites. Brain Res 376 85-96.

Hoyer D, Pazos A, Probst A, and Palacios JM (1986b) Serotonin receptors in the human brain. II. Characterization and autoradiographic localization of 5-HT1C and 5-HT2 recognition sites. Brain Res 376:97-107.

Hoyer D and Schoeffter P (1988) 5-HT1D receptor-mediated inhibition of forskolinstimulated adenylate cyclase activity in calf substantia nigra. Eur J Pharmacol 147:145-147.

Hoyer D and Schoeffter P (1991) 5-HT receptors: subtypes and second messengers. $J$ Recept Res 11:197-214

Hoyer D, Schoeffter P, and Gray JA (1989a) A comparison of the interactions of dihydroergotamine, ergotamine and GR 43175 with $5-\mathrm{HT}_{1}$ receptor subtypes. Cephalalgia 9:340-341.

Hoyer D, Waeber C, Karpf A, Neijt H, and Palacios JM (1989b) [ ${ }^{3}$ H]ICS 205-930 labels $5-\mathrm{HT}_{3}$ recognition sites in membranes of cat and rabbit vagus nerve and superior cervical ganglion. Naunyn Schmiedebergs Arch Pharmacol 340:396-402.

Hoyer D, Schoeffter P, Waeber C, and Palacios JM (1990) Serotonin 5-HT1D receptors. Ann NY Acad Sci 600:168-181.

Hoyer D, Waeber C, Pazos A, Probst A, and Palacios JM (1988) Identification of a 5-HT1 recognition site in human brain membranes different from 5-HT1A 5-HT1B and 5-HT1C sites. Neurosci Lett 85:357-362.

Hoyer D, Waeber C, Schoeffter P, Palacios JM, and Dravid A (1989c) 5-HT1C receptor-mediated stimulation of inositol phosphate production in pig choroid plexus. A pharmacological characterization. Naunyn Schmiedebergs Arch Pharmacol 339: 252-258.

Hsiao CF, Trueblood PR, Levine MS, and Chandler SH (1997) Multiple effects of serotonin on membrane properties of trigeminal motoneurons in vitro. J Neurophysiol 77:2910-2924.

Hsiung SC, Tamir H, Franke TF, and Liu KP (2005) Roles of extracellular signalregulated kinase and Akt signaling in coordinating nuclear transcription factor-
kappaB-dependent cell survival after serotonin $1 \mathrm{~A}$ receptor activation. J Neurochem 95:1653-1666.

Huang HS, Yoon BJ, Brooks S, Bakal R, Berrios J, Larsen RS, Wallace ML, Han JE, Chung EH, Zylka MJ, et al. (2014a) Snx14 regulates neuronal excitability, promotes synaptic transmission, and is imprinted in the brain of mice. PLoS One $\mathbf{9}$ : e98383.

Huang M, Horiguchi M, Felix AR, and Meltzer HY (2012) 5-HT1A and 5-HT7 receptors contribute to lurasidone-induced dopamine efflux. Neuroreport 23: 436-440.

Huang M, Panos JJ, Kwon S, Oyamada Y, Rajagopal L, and Meltzer HY (2014b) Comparative effect of lurasidone and blonanserin on cortical glutamate, dopamine, and acetylcholine efflux: role of relative serotonin (5-HT)2A and DA D2 antagonism and 5-HT1A partial agonism. J Neurochem 128:938-949.

Huang XP, Setola V, Yadav PN, Allen JA, Rogan SC, Hanson BJ, Revankar C, Robers M, Doucette C, and Roth BL (2009) Parallel functional activity profiling reveals valvulopathogens are potent 5-hydroxytryptamine $(2 \mathrm{~B})$ receptor agonists: implications for drug safety assessment. Mol Pharmacol 76:710-722.

Huerta C, Rivero E, Montoro MA, and García-Rodriguez LA (2011) Risk factors for intestinal ischaemia among patients registered in a UK primary care database: a nested case-control study. Aliment Pharmacol Ther 33:969-978.

Hughes ZA, Starr KR, Scott CM, Newson MJ, Sharp T, Watson JM, Hagan JJ, and Dawson LA (2007) Simultaneous blockade of 5-HT1A/B receptors and 5-HT transporters results in acute increases in extracellular 5-HT in both rats and guinea pigs: in vivo characterization of the novel 5-HT1A/B receptor antagonist/5-HT transport inhibitor SB-649915-B. Psychopharmacology (Berl) 192: 121-133.

Huidobro-Toro JP and Harris RA (1996a) Brain lipids that induce sleep are novel modulators of 5-hydroxytrypamine receptors. Proc Natl Acad Sci 93:8078-8082.

Huidobro-Toro JP, Valenzuela CF, and Harris RA (1996b) Modulation of GABA receptor function by $\mathrm{G}$ protein-coupled $5-\mathrm{HT}_{2 \mathrm{C}}$ receptors. Neuropharmacology $\mathbf{3 5}$ : $1355-1363$

Hummerich R, Thumfart JO, Findeisen P, Bartsch D, and Schloss P (2012) Transglutaminase-mediated transamidation of serotonin, dopamine and noradrenaline to fibronectin: evidence for a general mechanism of monoaminylation. FEBS Lett 586:3421-3428.

Humphrey PP (2008) The discovery and development of the triptans, a major therapeutic breakthrough. Headache 48:685-687.

Humphrey PPA (2007) The discovery of a new drug class for the acute treatment of migraine. Headache 47 (Suppl 1):S10-S19.

Humphrey PP and Goadsby PJ (1994) The mode of action of sumatriptan is vascular? A debate. Cephalalgia 14:401-410, discussion 393.

Humphrey PPA, Hartig P, and Hoyer D (1993a) A proposed new nomenclature for 5-HT receptors. Trends Pharmacol Sci 14:233-236.

Humphrey PPA, Hartig P, and Hoyer D (1993b) A reappraisal of 5-HT receptor classification in Serotonin: From Cell Biology to Pharmacology and TherapeuticsVanhoutte PMSaxena PR and Paoletti R eds) vol 5, pp 41-47.

Hung BC, Loo DD, and Wright EM (1993) Regulation of mouse choroid plexus apical $\mathrm{Cl}-$ and $\mathrm{K}+$ channels by serotonin. Brain Res 617:285-295.

Huot P (2015) L-DOPA-induced dyskinesia, is striatal dopamine depletion a requisite? J Neurol Sci 351:9-12.

Hurley PT, McMahon RA, Fanning P, O’Boyle KM, Rogers M, and Martin F (1998) Functional coupling of a recombinant human 5-HT5A receptor to G-proteins in HEK-293 cells. Br J Pharmacol 124:1238-1244.

Hutcheson JD, Ryzhova LM, Setola V, and Merryman WD (2012) 5-HT( ${ }_{2 \mathrm{~B}}$ ) antagonism arrests non-canonical TGF- $\beta 1$-induced valvular myofibroblast differentiation. $J$ Mol Cell Cardiol 53:707-714

Hutcheson JD, Setola V, Roth BL, and Merryman WD (2011) Serotonin receptors and heart valve disease-it was meant 2B. Pharmacol Ther 132:146-157.

Iderberg H, McCreary AC, Varney MA, Cenci MA, and Newman-Tancredi A (2015) Activity of serotonin 5-HT(1A) receptor 'biased agonists' in rat models of Parkinson's disease and L-DOPA-induced dyskinesia. Neuropharmacology 93:52-67.

Idzikowski C, Mills FJ, and James RJ (1991) A dose-response study examining the effects of ritanserin on human slow wave sleep. Br J Clin Pharmacol 31:193-196.

Idzko M, Panther E, Stratz C, Müller T, Bayer H, Zissel G, Dürk T, Sorichter S, Di Virgilio F, Geissler M, et al. (2004) The serotoninergic receptors of human dendritic cells: identification and coupling to cytokine release. J Immunol 172:6011-6019.

Iizuka N, Oka M, Yamada-Okabe H, Hamada K, Nakayama H, Mori N, Tamesa T, Okada T, Takemoto N, Matoba K, et al. (2004) Molecular signature in three types of hepatocellular carcinoma with different viral origin by oligonucleotide microarray. Int $J$ Oncol 24:565-574.

Ikeda K, Tojo K, Otsubo C, Udagawa T, Kumazawa K, Ishikawa M, Tokudome G, Hosoya T, Tajima N, Claycomb WC, et al. (2005) 5-hydroxytryptamine synthesis in HL-1 cells and neonatal rat cardiocytes. Biochem Biophys Res Commun 328: $522-525$.

Iken K, Chheng S, Fargin A, Goulet AC, and Kouassi E (1995) Serotonin upregulates mitogen-stimulated B lymphocyte proliferation through 5-HT1A receptors. Cell Immunol 163:1-9.

Im WB, Chio CL, Alberts GL, and Dinh DM (2003) Positive allosteric modulator of the human 5- $\mathrm{HT}_{2 \mathrm{C}}$ receptor. $\mathrm{Mol}$ Pharmacol 64:78-84.

Impellizzeri AA, Pappalardo M, Basile L, Manfra O, Andressen KW, Krobert KA, Messina A, Levy FO, and Guccione S (2015) Identification of essential residues for binding and activation in the human $5-\mathrm{HT}_{7(\mathrm{a})}$ serotonin receptor by molecular modeling and site-directed mutagenesis. Front Behav Neurosci 9:92.

Inoue-Matsuhisa E, Moroi SE, Takenaka H, Sogo S, and Mano T (2003) 5-HT(2) receptor-mediated phosphoinositide hydrolysis in bovine ciliary epithelium. $J$ Ocul Pharmacol Ther 19:55-62.

Inoue M, Okazaki T, Kitazono T, Mizushima M, Omata M, and Ozaki S (2011) Regulation of antigen-specific CTL and Th1 cell activation through 5-Hydroxytryptamine 2A receptor. Int Immunopharmacol 11:67-73. 
Invernizzi RW, Pierucci M, Calcagno E, Di Giovanni G, Di Matteo V, Benigno A, and Esposito E (2007) Selective activation of 5-HT(2C) receptors stimulates GABAergic function in the rat substantia nigra pars reticulata: a combined in vivo electrophysiological and neurochemical study. Neuroscience 144:1523-1535.

Irving HR, Tan YY, Tochon-Danguy N, Liu H, Chetty N, Desmond PV, Pouton CW, and Coupar IM (2007) Comparison of 5- $\mathrm{HT}_{4}$ and $5-\mathrm{HT}_{7}$ receptor expression and function in the circular muscle of the human colon. Life Sci 80:1198-1205.

Isaac M (2005) Serotonergic 5-HT2C receptors as a potential therapeutic target for the design antiepileptic drugs. Curr Top Med Chem 5:59-67.

Ishibashi T, Horisawa T, Tokuda K, Ishiyama T, Ogasa M, Tagashira R, Matsumoto K, Nishikawa H, Ueda Y, Toma S, et al. (2010) Pharmacological profile of lurasidone, a novel antipsychotic agent with potent 5-hydroxytryptamine 7 (5-HT7) and 5-HT1A receptor activity. $J$ Pharmacol Exp Ther 334:171-181.

Ishida T, Hirata K, Sakoda T, Kawashima S, Akita H, and Yokoyama M (1999) Identification of mRNA for $5-\mathrm{HT}_{1}$ and $5-\mathrm{HT}_{2}$ receptor subtypes in human coronary arteries. Cardiovasc Res 41:267-274.

Ishida T, Kawashima S, Hirata Ki, Sakoda T, Shimokawa Y, Miwa Y, Inoue N, Ueyama T, Shiomi M, Akita H, et al. (2001) Serotonin-induced hypercontraction through 5-hydroxytryptamine $1 \mathrm{~B}$ receptors in atherosclerotic rabbit coronary arteries. Circulation 103:1289-1295.

Ishida T, Kawashima S, Hirata K, and Yokoyama M (1998) Nitric oxide is produced via $5-\mathrm{HT} 1 \mathrm{~B}$ and $5-\mathrm{HT}_{2 \mathrm{~B}}$ receptor activation in human coronary artery endothelial cells. Kobe J Med Sci 44:51-63.

Ishii Y, Blundell JE, Halford JC, and Rodgers RJ (2003) Palatability, food intake and the behavioural satiety sequence in male rats. Physiol Behav 80:37-47.

Ishizuka T, Goshima H, Ozawa A, and Watanabe Y (2014) Stimulation of 5-HT4 receptor enhances differentiation of mouse induced pluripotent stem cells into neural progenitor cells. Clin Exp Pharmacol Physiol 41:345-350.

Islam A, Thompson KSJ, Akhtar S, and Handley SL (2004) Increased 5-HT2A receptor expression and function following central glucocorticoid receptor knockdown in vivo. Eur J Pharmacol 502:213-220.

Ismaiel AM, De Los Angeles J, Teitler M, Ingher S, and Glennon RA (1993) Antagonism of 1-(2,5-dimethoxy-4-methylphenyl)-2-aminopropane stimulus with a newly identified 5- $\mathrm{HT}_{2}$ - versus 5-HT $\mathrm{HC}_{1 \mathrm{C}}$-selective antagonist. J Med Chem 36:2519-2525. Ismaiel AM, Titeler M, Miller KJ, Smith TS, and Glennon RA (1990) 5-HT1 and 5 -HT2 binding profiles of the serotonergic agents alpha-methylserotonin and 2-methylserotonin. J Med Chem 33:755-758.

Itoh T and Kajikuri J (2011) Characteristics of the actions by which 5-HT affects electrical and mechanical activities in rabbit jugular vein. $\mathrm{Br} J$ Pharmacol 164: 979-991.

Iversen L, Gibbons S, Treble R, Setola V, Huang X-P, and Roth BL (2013) Neurochemical profiles of some novel psychoactive substances. Eur J Pharmacol 700: 147-151.

Iwamoto K, Bundo M, and Kato T (2011) RNA editing of 5-HT2C receptor and neuropsychiatric diseases, in 5-HT2C receptors in the pathophysiology of CNS disease (Di Giovanni G, Esposito E, Di Matteo V eds) pp 157-167, Humana Press.

Iwamoto K and Kato T (2003) RNA editing of serotonin 2C receptor in human postmortem brains of major mental disorders. Neurosci Lett 346:169-172.

Iwata N, Ozaki N, Inada T, and Goldman D (2001) Association of a 5-HT(5A) receptor polymorphism, Pro15Ser, to schizophrenia. Mol Psychiatry 6:217-219.

Iwata N, Virkkunen M, Linnoila M, and Goldman D (1998) Identification of a naturally occurring Pro15-Ser15 substitution in the serotonin5A receptor gene in alcoholics and healthy volunteers. Brain Res Mol Brain Res 58:217-220.

Jacobs BL and Azmitia EC (1992) Structure and function of the brain serotonin system. Physiol Rev 72:165-229.

Jacobshagen M, Niquille M, Chaumont-Dubel S, Marin P, and Dayer A (2014) The serotonin 6 receptor controls neuronal migration during corticogenesis via a ligandindependent Cdk5-dependent mechanism. Development 141:3370-3377.

Jaffré F, Bonnin P, Callebert J, Debbabi H, Setola V, Doly S, Monassier L, Mettauer B, Blaxall BC, Launay JM, et al. (2009) Serotonin and angiotensin receptors in cardiac fibroblasts coregulate adrenergic-dependent cardiac hypertrophy. Circ Res 104:113-123.

Jaffré F, Callebert J, Sarre A, Etienne N, Nebigil CG, Launay JM, Maroteaux L, and Monassier L (2004) Involvement of the serotonin $5-\mathrm{HT}_{2 \mathrm{~B}}$ receptor in cardiac hypertrophy linked to sympathetic stimulation: control of interleukin-6, interleukin-1beta, and tumor necrosis factor-alpha cytokine production by ventricular fibroblasts. Circulation 110:969-974.

Jahnel U, Rupp J, Ertl R, and Nawrath H (1992) Positive inotropic response to 5-HT in human atrial but not in ventricular heart muscle. Naunyn Schmiedebergs Arch Pharmacol 346:482-485.

Jähnichen S, Glusa E, and Pertz HH (2005) Evidence for 5-HT2B and 5-HT7 receptor-mediated relaxation in pulmonary arteries of weaned pigs. Naunyn Schmiedebergs Arch Pharmacol 371:89-98.

Jähnichen S, Radtke OA, and Pertz HH (2004) Involvement of 5-HT 1 B receptors in triptan-induced contractile responses in guinea-pig isolated iliac artery. Naunyn Schmiedebergs Arch Pharmacol 370:54-63.

Jakeman LB, To ZP, Eglen RM, Wong EH, and Bonhaus DW (1994) Quantitative autoradiography of 5-HT4 receptors in brains of three species using two structurally distinct radioligands, [3H]GR113808 and [3H]BIMU-1. Neuropharmacology 33:1027-1038.

Jakus R and Bagdy G (2011) The Role of 5-HT2C Receptor in Epilepsy. In: 5-HT $\mathrm{H}_{2 \mathrm{C}}$ Receptors in the Pathophysiology of CNS Disease, in 5-HT2C Receptors in the Pathophysiology of CNS Disease (Di Giovanni G, Esposito E, and Di Matteo V eds) pp 429-444, Springer-Verlag, Wien, Austria.

Jakus R, Graf M, Juhasz G, Gerber K, Levay G, Halasz P, and Bagdy G (2003) 5HT2C receptors inhibit and 5-HT1A receptors activate the generation of spikewave discharges in a genetic rat model of absence epilepsy. Exp Neurol 184: 964-972.
Janno S, Holi M, Tuisku K, and Wahlbeck K (2004) Prevalence of neuroleptic-induced movement disorders in chronic schizophrenia inpatients. Am J Psychiatry 161: 160-163.

Janoshazi A, Deraet M, Callebert J, Setola V, Guenther S, Saubamea B, Manivet P, Launay JM, and Maroteaux L (2007) Modified receptor internalization upon coexpression of 5 -HT1B receptor and $5-\mathrm{HT}_{2 \mathrm{~B}}$ receptors. Mol Pharmacol 71: 1463-1474.

Jansen M, Bali M, and Akabas MH (2008) Modular design of Cys-loop ligand-gated ion channels: functional 5-HT3 and GABA rho1 receptors lacking the large cytoplasmic M3M4 loop. J Gen Physiol 131:137-146.

Janssen P, Vanden Berghe P, Verschueren S, Lehmann A, Depoortere I, and Tack J (2011a) Review article: the role of gastric motility in the control of food intake. Aliment Pharmacol Ther 33:880-894.

Janssen P, Vos R, Van Oudenhove L, and Tack J (2011b) Influence of the 5-HT receptor antagonist ondansetron on gastric sensorimotor function and nutrient tolerance in healthy volunteers. Neurogastroenterol Motil 23:444-449, e175.

Janssen W, Schymura Y, Novoyatleva T, Kojonazarov B, Boehm M, Wietelmann A Luitel H, Murmann K, Krompiec DR, Tretyn A, et al. (2015) 5-HT $2 \mathrm{~B}$ receptor antagonists inhibit fibrosis and protect from RV heart failure. BioMed Res Int 2015:438403

Jastrzebska-Wiesek M, Siwek A, Kazek G, Nawiesniak B, Partyka A, Marcinkowska M, Kolaczkowski M, and Wesolowska A (2013) Partial agonist efficacy of EMD386088, a 5-HT6 receptor ligand, in functional in vitro assays. Pharmacol Rep 65:998-1005.

Javitt DC and Zukin SR (1991) Recent advances in the phencyclidine model of schizophrenia. Am J Psychiatry 148:1301-1308.

Jayne C, Simon JA, Taylor LV, Kimura T, and Lesko LM; SUNFLOWER study investigators (2012) Open-label extension study of flibanserin in women with hypoactive sexual desire disorder. J Sex Med 9:3180-3188.

Jean A, Conductier G, Manrique C, Bouras C, Berta P, Hen R, Charnay Y, Bockaert $\mathrm{J}$, and Compan V (2007) Anorexia induced by activation of serotonin 5-HT4 receptors is mediated by increases in CART in the nucleus accumbens. Proc Natl Acad Sci USA 104:16335-16340.

Jean A, Laurent L, Bockaert J, Charnay Y, Dusticier N, Nieoullon A, Barrot M, Neve $\mathrm{R}$, and Compan V (2012) The nucleus accumbens 5 -HTR 4 -CART pathway ties anorexia to hyperactivity. Transl Psychiatry 2:e203.

Jenck F, Bös M, Wichmann J, Stadler H, Martin JR, and Moreau JL (1998) The role of 5-HT2C receptors in affective disorders. Expert Opin Investig Drugs 7: $1587-1599$

Jenner P, McCreary AC, and Scheller DK (2011) Continuous drug delivery in earlyand late-stage Parkinson's disease as a strategy for avoiding dyskinesia induction and expression. J Neural Transm (Vienna) 118:1691-1702.

Jensen TN, Nielsen J, Frederiksen K, and Ebert B (2006) Molecular cloning and pharmacological characterization of serotonin 5-HT(3A) receptor subtype in dog. Eur J Pharmacol 538:23-31.

Jentsch JD and Roth RH (1999) The neuropsychopharmacology of phencyclidine: from NMDA receptor hypofunction to the dopamine hypothesis of schizophrenia. Neuropsychopharmacology 20:201-225.

Jeong HJ, Chenu D, Johnson EE, Connor M, and Vaughan CW (2008) Sumatriptan inhibits synaptic transmission in the rat midbrain periaqueductal grey. Mol Pain 4:54-64.

Jerman JC, Brough SJ, Gager T, Wood M, Coldwell MC, Smart D, and Middlemiss DN (2001) Pharmacological characterisation of human 5-HT2 receptor subtypes. Eur J Pharmacol 414:23-30.

Jessberger S, Gage FH, Eisch AJ, and Lagace DC (2009) Making a neuron: Cdk5 in embryonic and adult neurogenesis. Trends Neurosci 32:575-582

Ji SP, Zhang Y, Van Cleemput J, Jiang W, Liao M, Li L, Wan Q, Backstrom JR, and Zhang X (2006) Disruption of PTEN coupling with 5-HT2C receptors suppresses behavioral responses induced by drugs of abuse. Nat Med 12:324-329.

Jiang X, Xing G, Yang C, Verma A, Zhang L, and Li H (2009) Stress impairs 5-HT2A receptor-mediated serotonergic facilitation of GABA release in juvenile rat basolateral amygdala. Neuropsychopharmacology 34:410-423.

Jiménez-Ferrer E, Herrera-Ruiz M, Ramírez-García R, Herrera-Arellano A, and Tortoriello $\mathrm{J}$ (2011) Interaction of the natural anxiolytic Galphimine-B with serotonergic drugs on dorsal hippocampus in rats. J Ethnopharmacol 137:724-729.

Jin HK, Bae JS, Furuya S, and Carter JE (2009) Amyloid beta-derived neuroplasticity in bone marrow-derived mesenchymal stem cells is mediated by NPY and $5-\mathrm{HT}_{2 \mathrm{~B}}$ receptors via ERK1/2 signalling pathways. Cell Prolif 42:571-586.

Jin JG, Foxx-Orenstein AE, and Grider JR (1999) Propulsion in guinea pig colon induced by 5 -hydroxytryptamine (HT) via $5-\mathrm{HT}_{4}$ and $5-\mathrm{HT}_{3}$ receptors. $J$ Pharmacol Exp Ther 288:93-97.

Johns GW, Pauwels PJ, Perez M, et al. (1999) F 11356, a novel 5-hydroxytryptamine (5-HT) derivative with potent, selective, and unique high intrinsic activity at 5 HT1B/1D receptors in models relevant to migraine. J Pharmacol Exp Ther. 290: $83-95$.

Johnson KW, Nelson DL, Dieckman DK, Wainscott DB, Lucaites VL, Audia JE, Owton WM, and Phebus LA (2003) Neurogenic dural protein extravasation induced by meta-chlorophenylpiperazine $(\mathrm{mCPP})$ involves nitric oxide and $5-\mathrm{HT}_{2 \mathrm{~B}}$ receptor activation. Cephalalgia 23:117-123.

Johnson KW, Phebus LA, and Cohen ML (1998) Serotonin in migraine: theories, animal models and emerging therapies. Prog Drug Res 51:219-244.

Johnson KW, Schaus JM, Durkin MM, Audia JE, Kaldor SW, Flaugh ME, Adham N, Zgombick JM, Cohen ML, Branchek TA, et al. (1997a) 5-HT HF $_{1 \mathrm{~F}}$ receptor agonists inhibit neurogenic dural inflammation in guinea pigs. Neuroreport 8:2237-2240.

Johnson MP, Baez M, Kursar JD, and Nelson DL (1995) Species differences in 5-HT2A receptors: cloned pig and rhesus monkey 5-HT2A receptors reveal conserved transmembrane homology to the human rather than rat sequence. Biochim Biophys Acta 1236:201-206. 
Johnson MS, Roberston DN, Holland PJ, Lutz EM, and Mitchell R (2006) Role of the conserved NPxxY motif of the 5-HT2A receptor in determining selective interaction with isoforms of ADP-ribosylation factor (ARF). Cell Signal 18:1793-1800.

Johnson RG, Fiorella D, Winter JC, and Rabin RA (1997b) [3H]8-OH-DPAT labels a 5-HT site coupled to inhibition of phosphoinositide hydrolysis in the dorsal raphe. Eur J Pharmacol 329:99-106.

Johnson SW, Mercuri NB, and North RA (1992) 5-hydroxytryptamine1B receptors block the GABAB synaptic potential in rat dopamine neurons. $J$ Neurosci 12 2000-2006.

Johnson-Farley NN, Kertesy SB, Dubyak GR, and Cowen DS (2005) Enhanced activation of Akt and extracellular-regulated kinase pathways by simultaneous occupancy of Gq-coupled 5-HT2A receptors and Gs-coupled 5-HT7A receptors in PC12 cells. J Neurochem 92:72-82.

Johnston KD, Lu Z, and Rudd JA (2014) Looking beyond 5-HT( ${ }_{3}$ ) receptors: a review of the wider role of serotonin in the pharmacology of nausea and vomiting. Eur $J$ Pharmacol 722:13-25.

Jones JF, Martin GR, and Ramage AG (1995) Evidence that 5-HT1D receptors mediate inhibition of sympathetic ganglionic transmission in anaesthetized cats. $\mathrm{Br} J$ Pharmacol 116:1715-1717.

Jones KA, Srivastava DP, Allen JA, Strachan RT, Roth BL, and Penzes P (2009) Rapid modulation of spine morphology by the 5-HT2A serotonin receptor through kalirin-7 signaling. Proc Natl Acad Sci USA 106:19575-19580.

Jones MD and Lucki I (2005) Sex differences in the regulation of serotonergic transmission and behavior in 5-HT receptor knockout mice. Neuropsychopharmacology 30:1039-1047.

Jongen-Relo AL, Bespalov AY, Rueter LE, et al. (2006) Behavioral pharmacological characterization of 5-HT5A receptor antagonists in antipsychotic drug tests, in 36th Annu. Meet. Soc. Neurosci.; 2006 Oct 14-18; Atlanta, GA. Abst.529.26.

Jordan D (2005) Vagal control of the heart: central serotonergic (5-HT) mechanisms. Exp Physiol 90:175-181.

Joubert L, Claeysen S, Sebben M, Bessis AS, Clark RD, Martin RS, Bockaert J, and Dumuis A (2002) A 5-HT4 receptor transmembrane network implicated in the activity of inverse agonists but not agonists. $J$ Biol Chem 277: $25502-25511$.

Joubert L, Hanson B, Barthet G, Sebben M, Claeysen S, Hong W, Marin P, Dumuis A, and Bockaert J (2004) New sorting nexin (SNX27) and NHERF specifically interact with the 5-HT4a receptor splice variant: roles in receptor targeting. $J$ Cell Sci 117:5367-5379.

Julius D, Huang KN, Livelli TJ, Axel R, and Jessell TM (1990) The 5HT2 receptor defines a family of structurally distinct but functionally conserved serotonin receptors. Proc Natl Acad Sci USA 87:928-932.

Julius D, Livelli TJ, Jessell TM, and Axel R (1989) Ectopic expression of the serotonin 1c receptor and the triggering of malignant transformation. Science $\mathbf{2 4 4}$ $1057-1062$

Julius D, MacDermott AB, Axel R, and Jessell TM (1988) Molecular characterization of a functional cDNA encoding the serotonin 1c receptor. Science 241:558-564.

Juncosa JI Jr, Hansen M, Bonner LA, Cueva JP, Maglathlin R, McCorvy JD, MaronaLewicka D, Lill MA, and Nichols DE (2013) Extensive rigid analogue design maps the binding conformation of potent $N$-benzylphenethylamine $5-\mathrm{HT}_{2 \mathrm{~A}}$ serotonin receptor agonist ligands. ACS Chem Neurosci 4:96-109.

Juruena MF, de Sena EP, and de Oliveira IR (2011) Sertindole in the management of schizophrenia. J Cent Nerv Syst Dis 3:75-85.

Kadowaki M, Wade PR, and Gershon MD (1996) Participation of $5-\mathrm{HT}_{3}, 5-\mathrm{HT}_{4}$, and nicotinic receptors in the peristaltic reflex of guinea pig distal colon. Am J Physiol 271:G849-G857.

Kahn RS and Wetzler S (1991) m-Chlorophenylpiperazine as a probe of serotonin function. Biol Psychiatry 30:1139-1166.

Kaiser R, Sezer O, Papies A, Bauer S, Schelenz C, Tremblay PB, Possinger K, Roots I, and Brockmöller J (2002) Patient-tailored antiemetic treatment with 5-hydroxytryptamine type 3 receptor antagonists according to cytochrome P-450 2D6 genotypes. J Clin Oncol 20:2805-2811.

Kaiser R, Tremblay PB, Sezer O, Possinger K, Roots I, and Brockmöller J (2004) Investigation of the association between $5-\mathrm{HT}_{3} \mathrm{~A}$ receptor gene polymorphisms and efficiency of antiemetic treatment with $5-\mathrm{HT}_{3}$ receptor antagonists. Pharmacogenetics 14:271-278.

Kaji I, Akiba Y, Said H, Narimatsu K, and Kaunitz JD (2015) Luminal 5-HT stimulates colonic bicarbonate secretion in rats. $\mathrm{Br}$ J Pharmacol 172:4655-4670.

Kale-Pradhan PB and Wilhelm SM (2007) Tegaserod for constipation-predominant irritable bowel syndrome. Pharmacotherapy 27:267-277.

Kalivas PW and Volkow ND (2005) The neural basis of addiction: a pathology of motivation and choice. Am J Psychiatry 162:1403-1413.

Kalkman HO, Engel G, and Hoyer D (1984) Three distinct subtypes of serotonergic receptors mediate the triphasic blood pressure response to 5 -HT in rats. $J$ Hypertens 2:143-145.

Kamal M, Gbahou F, Guillaume JL, Daulat AM, Benleulmi-Chaachoua A, Luka M, Chen P, Kalbasi Anaraki D, Baroncini M, Mannoury la Cour C, et al. (2015) Convergence of melatonin and serotonin (5-HT) signaling at MT2/5-HT2C receptor heteromers. J Biol Chem 290:11537-11546.

Kang BN, Ha SG, Bahaie NS, Hosseinkhani MR, Ge XN, Blumenthal MN, Rao SP, and Sriramarao $\mathrm{P}$ (2013) Regulation of serotonin-induced trafficking and migration of eosinophils. PLoS One 8:e54840.

Kannari K, Kurahashi K, Tomiyama M, Maeda T, Arai A, Baba M, Suda T, and Matsunaga M (2002) [Tandospirone citrate, a selective 5-HT1A agonist, alleviates L-DOPA-induced dyskinesia in patients with Parkinson's disease]. No To Shinkei 54:133-137.

Kanner AM, Schachter SC, Barry JJ, Hesdorffer DC, Mula M, Trimble M, Hermann B, Ettinger AE, Dunn D, Caplan R, et al. (2012) Depression and epilepsy: epidemiologic and neurobiologic perspectives that may explain their high comorbid occurrence. Epilepsy Behav 24:156-168.
Kantor S, Jakus R, Balogh B, Benko A, and Bagdy G (2004) Increased wakefulness, motor activity and decreased theta activity after blockade of the $5-\mathrm{HT}_{2 \mathrm{~B}}$ receptor by the subtype-selective antagonist SB-215505. Br J Pharmacol 142:1332-1342.

Kapeller J, Houghton LA, Mönnikes H, Walstab J, Möller D, Bönisch H, Burwinkel B, Autschbach F, Funke B, Lasitschka F, et al. (2008) First evidence for an association of a functional variant in the microRNA-510 target site of the serotonin receptortype $3 \mathrm{E}$ gene with diarrhea predominant irritable bowel syndrome. Hum Mol Genet 17:2967-2977.

Kapeller J, Möller D, Lasitschka F, Autschbach F, Hovius R, Rappold G, Brüss M, Gershon MD, and Niesler B (2011) Serotonin receptor diversity in the human colon: expression of serotonin type 3 receptor subunits 5-HT3C, 5-HT3D, and 5-HT3E. J Comp Neurol 519:420-432.

Karaki S, Becamel C, Murat S, Mannoury la Cour C, Millan MJ, Prézeau L, Bockaert J, Marin P, and Vandermoere F (2014) Quantitative phosphoproteomics unravels biased phosphorylation of serotonin 2 A receptor at Ser280 by hallucinogenic versus nonhallucinogenic agonists. Mol Cell Proteomics 13:1273-1285.

Karila D, Freret T, Bouet V, Boulouard M, Dallemagne P, and Rochais C (2015) Therapeutic Potential of 5-HT6 Receptor Agonists. J Med Chem 58:7901-7912.

Kasho M, Sakai M, Sasahara T, Anami Y, Matsumura T, Takemura T, Matsuda H, Kobori S, and Shichiri M (1998) Serotonin enhances the production of type IV collagen by human mesangial cells. Kidney Int 54:1083-1092.

Kasper J, Tikamdas R, Kim MS, Macfadyen K, Aramini R, Ladd J, Bisceglia S, Booth $\mathrm{R}$, and Peris $\mathrm{J}$ (2013) The serotonin-2 receptor modulator, (-)-trans-PAT, decreases voluntary ethanol consumption in rats. Eur $J$ Pharmacol 718:98-104.

Kasper S, Tauscher J, Willeit M, Stamenkovic M, Neumeister A, Küfferle B, Barnas C, Stastny J, Praschak-Rieder N, Pezawas L, et al. (2002) Receptor and transporter imaging studies in schizophrenia, depression, bulimia and Tourette's disorderimplications for psychopharmacology. World J Biol Psychiatry 3:133-146.

Kassai F, Schlumberger C, Kedves R, Pietraszek M, Jatzke C, Lendvai B, Gyertyán I, and Danysz W (2012) Effect of 5-HT5A antagonists in animal models of schizophrenia, anxiety and depression. Behav Pharmacol 23:397-406.

Katoh N, Soga F, Nara T, Tamagawa-Mineoka R, Nin M, Kotani H, Masuda K, and Kishimoto S (2006) Effect of serotonin on the differentiation of human monocytes into dendritic cells. Clin Exp Immunol 146:354-361.

Katz M, DeRogatis LR, Ackerman R, Hedges P, Lesko L, Garcia M Jr, and Sand M BEGONIA trial investigators (2013) Efficacy of flibanserin in women with hypoactive sexual desire disorder: results from the BEGONIA trial. $J$ Sex Med 10 $1807-1815$

Kaufman MJ, Hartig PR, and Hoffman BJ (1995) Serotonin 5- $\mathrm{HT}_{2 \mathrm{C}}$ receptor stimulates cyclic GMP formation in choroid plexus. $J$ Neurochem 64:199-205.

Kaumann AJ (1990) Piglet sinoatrial 5-HT receptors resemble human atrial 5-HT4like receptors. Naunyn Schmiedebergs Arch Pharmacol 342:619-622.

Kaumann AJ (1994) Do human atrial 5-HT4 receptors mediate arrhythmias? Trends Pharmacol Sci 15:451-455.

Kaumann AJ, Frenken M, Posival H, and Brown AM (1994) Variable participation of 5-HT1-like receptors and 5-HT2 receptors in serotonin-induced contraction of human isolated coronary arteries. 5-HT1-like receptors resemble cloned 5-HT1D beta receptors. Circulation 90:1141-1153.

Kaumann AJ and Levy FO (2006) 5-hydroxytryptamine receptors in the human cardiovascular system. Pharmacol Ther 111:674-706.

Kaumann AJ, Lynham JA, and Brown AM (1995) Labelling with [125I]-SB 207710 of a small 5-HT4 receptor population in piglet right atrium: functional relevance. $\mathrm{Br} J$ Pharmacol 115:933-936.

Kaumann AJ, Parsons AA, and Brown AM (1993) Human arterial constrictor serotonin receptors. Cardiovasc Res 27:2094-2103.

Kaumann AJ, Sanders L, Brown AM, Murray KJ, and Brown MJ (1990) A 5-hydroxytryptamine receptor in human atrium. Br J Pharmacol 100:879-885.

Kaumann AJ, Sanders L, Brown AM, Murray KJ, and Brown MJ (1991) A 5-HT4-like receptor in human right atrium. Naunyn Schmiedebergs Arch Pharmacol 344: 150-159.

Kawahara I, Kuniyasu H, Matsuyoshi H, Goto K, Obata K, Misawa H, Fujii H, and Takaki M (2012) Comparison of effects of a selective 5-HT reuptake inhibitor versus a 5-HT4 receptor agonist on in vivo neurogenesis at the rectal anastomosis in rats. Am J Physiol Gastrointest Liver Physiol 302:G588-G597.

Kawahara Y, Grimberg A, Teegarden S, Mombereau C, Liu S, Bale TL, Blendy JA, and Nishikura K (2008) Dysregulated editing of serotonin 2C receptor mRNAs results in energy dissipation and loss of fat mass. J Neurosci 28:12834-12844.

Kaya N, Shen T, Lu SG, Zhao FL, and Herness S (2004) A paracrine signaling role for serotonin in rat taste buds: expression and localization of serotonin receptor subtypes. Am J Physiol Regul Integr Comp Physiol 286:R649-R658.

Kaye WH, Frank GK, Bailer UF, Henry SE, Meltzer CC, Price JC, Mathis CA and Wagner A (2005) Serotonin alterations in anorexia and bulimia nervosa: new insights from imaging studies. Physiol Behav 85:73-81.

Keegan A, Morecroft I, Smillie D, Hicks MN, and MacLean MR (2001) Contribution of the 5-HT(1B) receptor to hypoxia-induced pulmonary hypertension: converging evidence using 5-HT(1B)-receptor knockout mice and the 5-HT(1B/1D)-receptor antagonist GR127935. Circ Res 89:1231-1239.

Kehne JH, Baron BM, Carr AA, Chaney SF, Elands J, Feldman DJ, Frank RA, van Giersbergen PL, McCloskey TC, Johnson MP, et al. (1996) Preclinical characterization of the potential of the putative atypical antipsychotic MDL 100,907 as a potent $5-\mathrm{HT}_{2 \mathrm{~A}}$ antagonist with a favorable CNS safety profile. J Pharmacol Exp Ther 277:968-981.

Kelley SP, Bratt AM, and Hodge CW (2003a) Targeted gene deletion of the 5-HT3A receptor subunit produces an anxiolytic phenotype in mice. Eur J Pharmacol 461:19-25. Kelley SP, Dunlop JI, Kirkness EF, Lambert JJ, and Peters JA (2003b) A cytoplasmic region determines single-channel conductance in 5-HT3 receptors. Nature 424: $321-324$

Kelly CR and Sharif NA (2006) Pharmacological evidence for a functional serotonin-2B receptor in a human uterine smooth muscle cell line. J Pharmacol Exp Ther 317:1254-1261. 
Kemp A and Manahan-Vaughan D (2004) Hippocampal long-term depression and long-term potentiation encode different aspects of novelty acquisition. Proc Natl Acad Sci USA 101:8192-8197.

Kenakin TP (2009) '7TM receptor allostery: putting numbers to shapeshifting proteins. Trends Pharmacol Sci 30:460-469.

Kenakin T (2010) G protein coupled receptors as allosteric proteins and the role of allosteric modulators. $J$ Recept Signal Transduct Res 30:313-321.

Kenakin T and Christopoulos A (2013) Signalling bias in new drug discovery: detection, quantification and therapeutic impact. Nat Rev Drug Discov 12:205-216.

Kenakin T and Miller LJ (2010) Seven transmembrane receptors as shapeshifting proteins: the impact of allosteric modulation and functional selectivity on new drug discovery. Pharmacol Rev 62:265-304.

Kendall DA and Nahorski SR (1985) 5-Hydroxytryptamine-stimulated inositol phospholipid hydrolysis in rat cerebral cortex slices: pharmacological characterization and effects of antidepressants. J Pharmacol Exp Ther 233:473-479.

Kendall I, Slotten HA, Codony X, Burgueño J, Pauwels PJ, Vela JM, and Fone KC (2011) E-6801, a 5-HT6 receptor agonist, improves recognition memory by combined modulation of cholinergic and glutamatergic neurotransmission in the rat. Psychopharmacology (Berl) 213:413-430.

Kennett G, Lightowler S, Trail B, Bright F, and Bromidge S (2000) Effects of RO 600175 , a 5-HT(2C) receptor agonist, in three animal models of anxiety. Eur $J$ Pharmacol 387:197-204.

Kennett GA, Ainsworth K, Trail B, and Blackburn TP (1997a) BW 723C86, a 5- $\mathrm{HT}_{2 \mathrm{~B}}$ receptor agonist, causes hyperphagia and reduced grooming in rats. Neuropharmacology 36:233-239.

Kennett GA, Bailey F, Piper DC, and Blackburn TP (1995) Effect of SB 200646A, a $5-\mathrm{HT} 2 \mathrm{C} / 5-\mathrm{HT}_{2 \mathrm{~B}}$ receptor antagonist, in two conflict models of anxiety. Psychopharmacology (Berl) 118:178-182.

Kennett GA, Bright F, Trail B, Baxter GS, and Blackburn TP (1996a) Effects of the $5-\mathrm{HT}_{2 \mathrm{~B}}$ receptor agonist, $\mathrm{BW} 723 \mathrm{C} 86$, on three rat models of anxiety. $\mathrm{Br} J \mathrm{Phar}$ macol 117:1443-1448.

Kennett GA and Curzon G (1988) Evidence that hypophagia induced by mCPP and TFMPP requires 5-HT1C and 5-HT1B receptors; hypophagia induced by RU 24969 only requires 5-HT1B receptors. Psychopharmacology (Berl) 96:93-100

Kennett GA, Pittaway K, and Blackburn TP (1994) Evidence that 5-HT 2 receptor antagonists are anxiolytic in the rat Geller-Seifter model of anxiety. Psychopharmacology (Berl) 114:90-96.

Kennett GA, Trail B, and Bright F (1998) Anxiolytic-like actions of BW 723 C86 in the rat Vogel conflict test are $5-\mathrm{HT}_{2 \mathrm{~B}}$ receptor mediated. Neuropharmacology 37 $1603-1610$

Kennett GA, Whitton P, Shah K, and Curzon G (1989) Anxiogenic-like effects of $\mathrm{mCPP}$ and TFMPP in animal models are opposed by 5 -HT1C receptor antagonists. Eur J Pharmacol 164:445-454.

Kennett GA, Wood MD, Bright F, Cilia J, Piper DC, Gager T, Thomas D, Baxter GS Forbes IT, Ham P, et al. (1996b) In vitro and in vivo profile of SB 206553, a potent $5-\mathrm{HT}_{2 \mathrm{C}} / 5-\mathrm{HT}_{2 \mathrm{~B}}$ receptor antagonist with anxiolytic-like properties. Br J Pharmacol 117:427-434

Kennett GA, Wood MD, Bright F, Trail B, Riley G, Holland V, Avenell KY, Stean T, Upton N, Bromidge S, et al. (1997b) SB 242084, a selective and brain penetrant 5-HT2C receptor antagonist. Neuropharmacology 36:609-620.

Kessing BF, Smout AJPM, Bennink RJ, Kraaijpoel N, Oors JM, and Bredenoord AJ (2014) Prucalopride decreases esophageal acid exposure and accelerates gastric emptying in healthy subjects. Neurogastroenterol Motil 26:1079-1086.

Kesters D, Thompson AD, Brams M, van Elk R, Spurny R, Geitmann M, Villalgordo JM, Guskov A, Danielson H, Lummis SCR, et al. (2013) Structural basis of ligand recognition in 5-HT3 receptors. EMBO Rep 14:49-56.

Khater-Boidin J, Rose D, and Duron B (1996) Central effects of 5-HT on activity of respiratory and hypoglossally innervated muscles in newborn kittens. $J$ Physiol 495:255-265

Khater-Boidin J, Rose D, Glérant JC, and Duron B (1999) Central effects of 5-HT on respiratory rhythm in newborn rats in vivo. Eur $J$ Neurosci 11:3433-3440.

Khawaja X (1995) Quantitative autoradiographic characterisation of the binding of [3H]WAY-100635, a selective 5-HT1A receptor antagonist. Brain Res 673: $217-225$.

Kilpatrick GJ, Butler A, Burridge J, and Oxford AW (1990) 1-(m-chlorophenyl)biguanide, a potent high affinity 5-HT3 receptor agonist. Eur $J$ Pharmacol 182 193-197.

Kim H, Toyofuku Y, Lynn FC, Chak E, Uchida T, Mizukami H, Fujitani Y, Kawamori R, Miyatsuka T, Kosaka Y, et al. (2010) Serotonin regulates pancreatic beta cell mass during pregnancy. Nat Med 16:804-808.

Kim JH, Park BL, Cheong HS, Bae JS, Kim LH, Kim JW, Lee BC, Seo CH, Kang TC, Park SH, et al. (2014a) Association between HTR7 genetic polymorphisms and alcohol dependence, using the alcohol use disorders identification test (AUDIT). Alcohol Clin Exp Res 38:2354-2361.

Kim JJ, Bridle BW, Ghia JE, Wang H, Syed SN, Manocha MM, Rengasamy P, Shajib MS, Wan Y, Hedlund PB, et al. (2013) Targeted inhibition of serotonin type 7 (5HT7) receptor function modulates immune responses and reduces the severity of intestinal inflammation. J Immunol 190:4795-4804.

Kim SH, Kim DH, Lee KH, Im SK, Hur EM, Chung KC, and Rhim H (2014b) Direct interaction and functional coupling between human 5-HT6 receptor and the light chain 1 subunit of the microtubule-associated protein 1B (MAP1B-LC1). PLoS One 9:e91402.

King MV, Marsden CA, and Fone KC (2008) A role for the 5-HT(1A), 5-HT4 and 5-HT6 receptors in learning and memory. Trends Pharmacol Sci 29:482-492.

Kinsey AM, Wainwright A, Heavens R, Sirinathsinghji DJ, and Oliver KR (2001) Distribution of 5-ht(5A), 5-ht(5B), 5-ht(6) and 5-HT(7) receptor mRNAs in the rat brain. Brain Res Mol Brain Res 88:194-198.

Kirk SL, Glazebrook J, Grayson B, Neill JC, and Reynolds GP (2009) Olanzapineinduced weight gain in the rat: role of 5-HT2C and histamine H1 receptors. Psychopharmacology (Berl) 207:119-125.
Kishi T, Meltzer HY, and Iwata N (2013) Augmentation of antipsychotic drug action by azapirone 5-HT1A receptor partial agonists: a meta-analysis. Int $J$ Neuropsychopharmacol 16:1259-1266.

Kishi T, Tsunoka T, Ikeda M, Kitajima T, Kawashima K, Okochi T, Okumura T, Yamanouchi Y, Kinoshita Y, Ujike H, et al. (2010) Serotonin 1A receptor gene is associated with Japanese methamphetamine-induced psychosis patients. Neuropharmacology 58:452-456.

Kishore S, Khanna A, Zhang Z, Hui J, Balwierz PJ, Stefan M, Beach C, Nicholls RD, Zavolan M, and Stamm S (2010) The snoRNA MBII-52 (SNORD 115) is processed into smaller RNAs and regulates alternative splicing. Hum Mol Genet 19: $1153-1164$

Kishore S and Stamm S (2006) The snoRNA HBII-52 regulates alternative splicing of the serotonin receptor 2C. Science 311:230-232.

Kiss B, Horváth A, Némethy Z, Schmidt E, Laszlovszky I, Bugovics G, Fazekas K Hornok K, Orosz S, Gyertyán I, et al. (2010) Cariprazine (RGH-188), a dopamine $\mathrm{D}(3)$ receptor-preferring, $\mathrm{D}(3) / \mathrm{D}(2)$ dopamine receptor antagonist-partial agonist antipsychotic candidate: in vitro and neurochemical profile. J Pharmacol Exp Ther 333:328-340.

Kitazawa T, Nakagoshi K, Teraoka H, and Taneike T (2001) 5-HT(7) receptor and beta(2)-adrenoceptor share in the inhibition of porcine uterine contractility in a muscle layer-dependent manner. Eur J Pharmacol 433:187-197.

Kjekshus JK, Torp-Pedersen C, Gullestad L, Køber L, Edvardsen T, Olsen IC Sjaastad I, Qvigstad E, Skomedal T, Osnes JB, et al. (2009) Effect of piboserod, a 5-HT4 serotonin receptor antagonist, on left ventricular function in patients with symptomatic heart failure. Eur J Heart Fail 11:771-778.

Kleene R, Chaudhary H, Karl N, Katic J, Kotarska A, Guitart K, Loers G, and Schachner M (2015) Interaction between CHL1 and serotonin receptor 2c regulates signal transduction and behavior in mice. $J$ Cell Sci 128:4642-4652.

Klein D, Demory A, Peyre F, Kroll J, Géraud C, Ohnesorge N, Schledzewski K, Arnold B, and Goerdt S (2009) Wnt2 acts as an angiogenic growth factor for nonsinusoidal endothelial cells and inhibits expression of stanniocalcin-1. Angiogenesis 12:251-265.

Klein MT, Dukat M, Glennon RA, and Teitler M (2011) Toward selective drug development for the human 5-hydroxytryptamine $1 \mathrm{E}$ receptor: a comparison of 5-hydroxytryptamine $1 \mathrm{E}$ and $1 \mathrm{~F}$ receptor structure-affinity relationships. J Pharmacol Exp Ther 337:860-867.

Klein MT and Teitler M (2012) Distribution of 5-ht(1E) receptors in the mammalian brain and cerebral vasculature: an immunohistochemical and pharmacological study. Br J Pharmacol 166:1290-1302.

Kleven MS, Barret-Grévoz C, Bruins Slot L, and Newman-Tancredi A (2005) Novel antipsychotic agents with 5-HT(1A) agonist properties: role of 5-HT(1A) receptor activation in attenuation of catalepsy induction in rats. Neuropharmacology 49 : 135-143.

Knight AR, Misra A, Quirk K, Benwell K, Revell D, Kennett G, and Bickerdike M (2004) Pharmacological characterisation of the agonist radioligand binding site of 5-HT(2A), 5-HT( $\left.{ }_{2 \mathrm{~B}}\right)$ and 5-HT(2C) receptors. Naunyn Schmiedebergs Arch Pharmacol 370:114-123.

Kobayashi K, Ikeda Y, Sakai A, Yamasaki N, Haneda E, Miyakawa T, and Suzuki H (2010) Reversal of hippocampal neuronal maturation by serotonergic antidepressants. Proc Natl Acad Sci USA 107:8434-8439.

Kobe F, Guseva D, Jensen TP, Wirth A, Renner U, Hess D, Müller M, Medrihan L, Zhang W, Zhang M, et al. (2012) 5-HT7R/G12 signaling regulates neuronal morphology and function in an age-dependent manner. $J$ Neurosci 32:2915-2930.

Kobilka BK, Frielle T, Collins S, Yang-Feng T, Kobilka TS, Francke U, Lefkowitz RJ, and Caron MG (1987) An intronless gene encoding a potential member of the family of receptors coupled to guanine nucleotide regulatory proteins. Nature 329: $75-79$

Koe BK (1976) Molecular geometry of inhibitors of the uptake of catecholamines and serotonin in synaptosomal preparations of rat brain. J Pharmacol Exp Ther 199: $649-661$.

Koek W, Jackson A, and Colpaert FC (1992) Behavioral pharmacology of antagonists at 5-HT2/5-HT1C receptors. Neurosci Biobehav Rev 16:95-105.

Kofuji P, Davidson N, and Lester HA (1995) Evidence that neuronal G-protein-gated inwardly rectifying $\mathrm{K}+$ channels are activated by $\mathrm{G}$ beta gamma subunits and function as heteromultimers. Proc Natl Acad Sci USA 92:6542-6546.

Kohen R, Fashingbauer LA, Heidmann DE, Guthrie CR, and Hamblin MW (2001) Cloning of the mouse 5-HT6 serotonin receptor and mutagenesis studies of the third cytoplasmic loop. Brain Res Mol Brain Res 90:110-117.

Kohen R, Metcalf MA, Khan N, Druck T, Huebner K, Lachowicz JE, Meltzer HY, Sibley DR, Roth BL, and Hamblin MW (1996) Cloning, characterization, and chromosomal localization of a human 5-HT6 serotonin receptor. J Neurochem 66 : $47-56$

Kolodziejczak M, Béchade C, Gervasi N, Irinopoulou T, Banas SM, Cordier C, Rebsam A, Roumier A, and Maroteaux L (2015) Serotonin modulates developmental microglia via $5-\mathrm{HT}_{2 \mathrm{~B}}$ receptors: potential implication during synaptic refinement of retinogeniculate projections. ACS Chem Neurosci 6:1219-1230.

Komada T, Matsuura T, Mikami T, Suzuki K, Sugimoto H, Kimura N, Ohmi T, Toga T, Nakai Y, Eda H, et al. (2009) Pharmacological characterization and determination of pharmacokinetic and pharmacodynamic relationship of PF-00885706, a novel partial agonist selective for the 5-HT(4) receptor. Pharmacol Res 60:237-246.

Königshoff M, Dumitrascu R, Udalov S, Amarie OV, Reiter R, Grimminger F, Seeger W, Schermuly RT, and Eickelberg O (2010) Increased expression of 5-hydroxytryptamine2A/B receptors in idiopathic pulmonary fibrosis: a rationale for therapeutic intervention. Thorax 65:949-955.

Kongsamut S, Roehr JE, Cai J, Hartman HB, Weissensee P, Kerman LL, Tang L, and Sandrasagra A (1996) Iloperidone binding to human and rat dopamine and 5HT receptors. Eur J Pharmacol 317:417-4236.

Koob GF and Volkow ND (2010) Neurocircuitry of addiction. Neuropsychopharmacology 35:217-238. 
Kopparapu PK, Tinzl M, Anagnostaki L, Persson JL, and Dizeyi N (2013) Expression and localization of serotonin receptors in human breast cancer. Anticancer Res 33: $363-370$

Kornum BR, Lind NM, Gillings N, Marner L, Andersen F, and Knudsen GM (2009) Evaluation of the novel 5-HT4 receptor PET ligand [11C]SB207145 in the Göttingen minipig. J Cereb Blood Flow Metab 29:186-196.

Korte SM, Meijer OC, de Kloet ER, Buwalda B, Keijser J, Sluyter F, van Oortmerssen G, and Bohus B (1996) Enhanced 5-HT1A receptor expression in forebrain regions of aggressive house mice. Brain Res 736:338-343.

Kovács A, Hársing LG Jr, and Szénási G (2012) Vasoconstrictor 5-HT receptors in the smooth muscle of the rat middle cerebral artery. Eur J Pharmacol 689:160-164.

Koya E, Uejima JL, Wihbey KA, Bossert JM, Hope BT, and Shaham Y (2009) Role of ventral medial prefrontal cortex in incubation of cocaine craving. Neuropharmacology 56 (Suppl 1):177-185.

Krabbe G, Matyash V, Pannasch U, Mamer L, Boddeke HWGM, and Kettenmann H (2012) Activation of serotonin receptors promotes microglial injury-induced motility but attenuates phagocytic activity. Brain Behav Immun 26:419-428.

Krobert KA, Andressen KW, and Levy FO (2006) Heterologous desensitization is evoked by both agonist and antagonist stimulation of the human 5 - $\mathrm{HT}_{7}$ serotonin receptor. Eur J Pharmacol 532:1-10.

Krobert KA, Bach T, Syversveen T, Kvingedal AM, and Levy FO (2001) The cloned human $5-\mathrm{HT}_{7}$ receptor splice variants: a comparative characterization of their pharmacology, function and distribution. Naunyn Schmiedebergs Arch Pharmacol 363:620-632.

Krobert KA, Brattelid T, Levy FO, and Kaumann AJ (2005) Prucalopride is a partial agonist through human and porcine atrial $5-\mathrm{HT}_{4}$ receptors: comparison with recombinant human $5-\mathrm{HT}_{4}$ splice variants. Naunyn Schmiedebergs Arch Pharmacol 371:473-479.

Krobert KA and Levy FO (2002) The human $5-\mathrm{HT}_{7}$ serotonin receptor splice variants: constitutive activity and inverse agonist effects. Br J Pharmacol 135:1563-1571.

Kroeze WK, Sheffler DJ, and Roth BL (2003) G-protein-coupled receptors at a glance. $J$ Cell Sci 116:4867-4869.

Krystal JH, Karper LP, Seibyl JP, Freeman GK, Delaney R, Bremner JD, Heninger GR, Bowers MB Jr, and Charney DS (1994) Subanesthetic effects of the noncompetitive NMDA antagonist, ketamine, in humans. Psychotomimetic, perceptual, cognitive, and neuroendocrine responses. Arch Gen Psychiatry 51:199-214.

Krzywkowski K (2006) Do polymorphisms in the human 5-HT3 genes contribute to pathological phenotypes? Biochem Soc Trans 34:872-876

Krzywkowski K, Davies PA, Feinberg-Zadek PL, Bräuner-Osborne H, and Jensen AA (2008) High-frequency HTR3B variant associated with major depression dramatically augments the signaling of the human 5-HT3AB receptor. Proc Natl Acad Sci USA 105:722-727.

Krzywkowski K, Jensen AA, Connolly CN, and Bräuner-Osborne H (2007) Naturally occurring variations in the human 5-HT3A gene profoundly impact 5-HT3 receptor function and expression. Pharmacogenet Genomics 17:255-266.

Kuca B, Silberstein SD, Wietecha L, Berg PH, Dozier G, and Lipton RB; COL MIG301 Study Group (2018) Lasmiditan is an effective acute treatment for migraine: a phase 3 randomized study. Neurology 91:e2222-e2232.

Kucinski A, de Jong IE, and Sarter M (2017) Reducing falls in Parkinson's disease: interactions between donepezil and the $5-\mathrm{HT}_{6}$ receptor antagonist idalopirdine on falls in a rat model of impaired cognitive control of complex movements. Eur $J$ Neurosci 45:217-231.

Kulla A and Manahan-Vaughan D (2002) Modulation by serotonin 5-HT(4) receptors of long-term potentiation and depotentiation in the dentate gyrus of freely moving rats. Cereb Cortex 12:150-162.

Kullmann FA, Kurihara R, Ye L, Wells GI, McKenna DG, Burgard EC, and Thor KB (2013) Effects of the 5-HT4 receptor agonist, cisapride, on neuronally evoked responses in human bladder, urethra, and ileum. Auton Neurosci 176:70-77.

Kung MP, Frederick D, Mu M, Zhuang ZP, and Kung HF (1995) 4-(2'-Methoxyphenyl)-1-[2'-(n-2"-pyridinyl)-p-iodobenzamido]-ethyl- piperazine ([125I]p-MPPI) as a new selective radioligand of serotonin-1A sites in rat brain: in vitro binding and autoradiographic studies. J Pharmacol Exp Ther 272:429-437.

Kuo B, Camilleri M, Burton D, Viramontes B, McKinzie S, Thomforde G, O'Connor MK, and Brinkmann BH (2002) Effects of 5-HT(3) antagonism on postprandial gastric volume and symptoms in humans. Aliment Pharmacol Ther 16:225-233.

Kuo G, Arnaud L, Kronstad-O'Brien P, and Cooper JA (2005) Absence of Fyn and Src causes a reeler-like phenotype. $J$ Neurosci 25:8578-8586.

Kurrasch-Orbaugh DM, Parrish JC, Watts VJ, and Nichols DE (2003a) A complex signaling cascade links the serotonin2A receptor to phospholipase A2 activation: the involvement of MAP kinases. $J$ Neurochem 86:980-991.

Kurrasch-Orbaugh DM, Watts VJ, Barker EL, and Nichols DE (2003b) Serotonin 5-hydroxytryptamine $2 \mathrm{~A}$ receptor-coupled phospholipase C and phospholipase A2 signaling pathways have different receptor reserves. J Pharmacol Exp Ther 304: $229-237$.

Kursar JD, Nelson DL, Wainscott DB, and Baez M (1994) Molecular cloning, functional expression, and mRNA tissue distribution of the human 5-hydroxytryptamine ${ }_{2 \mathrm{~B}}$ receptor. Mol Pharmacol 46:227-234.

Kursar JD, Nelson DL, Wainscott DB, Cohen ML, and Baez M (1992) Molecular cloning, functional expression, and pharmacological characterization of a novel serotonin receptor (5-hydroxytryptamine2F) from rat stomach fundus. Mol Pharmacol 42:549-557.

Kusakabe A, Nonaka T, Sekino Y, Iida H, Endo H, Koide T, Takahashi H, Fujita K, Yoneda M, Goto A, et al. (2014) Effects of ramosetron oral disintegrating tablets on gastric emptying: crossover study using the ${ }^{13} \mathrm{C}$-acetic acid breath test. Hepatogastroenterology 61:1279-1282.

Kushnir-Sukhov NM, Brown JM, Wu Y, Kirshenbaum A, and Metcalfe DD (2007) Human mast cells are capable of serotonin synthesis and release. J Allergy Clin Immunol 119:498-499.
Kushnir-Sukhov NM, Gilfillan AM, Coleman JW, Brown JM, Bruening S, Toth M, and Metcalfe DD (2006) 5-hydroxytryptamine induces mast cell adhesion and migration. J Immunol 177:6422-6432.

Kvachnina E, Dumuis A, Wlodarczyk J, Renner U, Cochet M, Richter DW, and Ponimaskin E (2009) Constitutive Gs-mediated, but not G12-mediated, activity of the 5-hydroxytryptamine 5-HT7(a) receptor is modulated by the palmitoylation of its C-terminal domain. Biochim Biophys Acta 1793:1646-1655.

Kvachnina E, Liu G, Dityatev A, Renner U, Dumuis A, Richter DW, Dityateva G, Schachner M, Voyno-Yasenetskaya TA, and Ponimaskin EG (2005) 5-HT7 receptor is coupled to $\mathrm{G}$ alpha subunits of heterotrimeric G12-protein to regulate gene transcription and neuronal morphology. J Neurosci 25:7821-7830.

Labasque M, Meffre J, Carrat G, Becamel C, Bockaert J, and Marin P (2010) Constitutive activity of serotonin $2 \mathrm{C}$ receptors at $\mathrm{G}$ protein-independent signaling: modulation by RNA editing and antidepressants. Mol Pharmacol 78:818-826.

Labasque M, Reiter E, Becamel C, Bockaert J, and Marin P (2008) Physical interaction of calmodulin with the 5-hydroxytryptamine $2 \mathrm{C}$ receptor C-terminus is essential for G protein-independent, arrestin-dependent receptor signaling. Mol Biol Cell 19:4640-4650.

Lachyankar MB, Sultana N, Schonhoff CM, Mitra P, Poluha W, Lambert S, Quesenberry PJ, Litofsky NS, Recht LD, Nabi R, et al. (2000) A role for nuclear PTEN in neuronal differentiation. $J$ Neurosci 20:1404-1413.

Lacivita E and Leopoldo M (2012) Editorial: "fluorescent probes: from bench to bedside". Curr Med Chem 19:4721.

Läer S, Remmers F, Scholz H, Stein B, Müller FU, and Neumann J (1998) Receptor mechanisms involved in the 5-HT-induced inotropic action in the rat isolated atrium. Br J Pharmacol 123:1182-1188.

Lalioti V, Pulido D, and Sandoval IV (2010) Cdk5, the multifunctional surveyor. Cell Cycle 9:284-311.

Lam DD, Przydzial MJ, Ridley SH, Yeo GSH, Rochford JJ, O’Rahilly S, and Heisler LK (2008) Serotonin 5-HT2C receptor agonist promotes hypophagia via downstream activation of melanocortin 4 receptors. Endocrinology 149:1323-1328.

Lamb EK and Aghajanian GK (2006) Electrophysiology of 5-HT2A receptors and relevance for hallucinogen and atypical antipsychotic drug actions, in The Serotonin Receptors; From Molecular Pharmacology to Human Therapeutics (Roth BL ed) pp 403-418, Humana Press, Totowa, NJ.

Lambe EK and Aghajanian GK (2001) The role of Kv1.2-containing potassium channels in serotonin-induced glutamate release from thalamocortical terminals in rat frontal cortex. J Neurosci 21:9955-9963.

Lambe EK and Aghajanian GK (2006) Hallucinogen-induced UP states in the brain slice of rat prefrontal cortex: role of glutamate spillover and NR2B-NMDA receptors. Neuropsychopharmacology 31:1682-1689.

Lambe EK and Aghajanian GK (2007) Prefrontal cortical network activity: opposite effects of psychedelic hallucinogens and D1/D5 dopamine receptor activation. Neuroscience 145:900-910.

Lambe EK, Fillman SG, Webster MJ, and Shannon Weickert C (2011) Serotonin receptor expression in human prefrontal cortex: balancing excitation and inhibition across postnatal development. PLoS One 6:e22799.

Lamirault L and Simon H (2001) Enhancement of place and object recognition memory in young adult and old rats by RS 67333 , a partial agonist of 5 -HT4 receptors. Neuropharmacology 41:844-853.

Lampron A, Bourdeau I, Hamet P, Tremblay J, and Lacroix A (2006) Whole genome expression profiling of glucose-dependent insulinotropic peptide (GIP)- and adrenocorticotropin-dependent adrenal hyperplasias reveals novel targets for the study of GIP-dependent Cushing's syndrome. J Clin Endocrinol Metab 91:3611-3618.

Land H, Parada LF, and Weinberg RA (1983) Tumorigenic conversion of primary embryo fibroblasts requires at least 2 cooperating oncogenes. Nature 304:596-602. Landolt HP, Meier V, Burgess HJ, Finelli LA, Cattelin F, Achermann P, and Borbély AA (1999) Serotonin-2 receptors and human sleep: effect of a selective antagonist on EEG power spectra. Neuropsychopharmacology 21:455-466.

Lanfranco MF, Seitz PK, Morabito MV, Emeson RB, Sanders-Bush E, and Cunningham KA (2009) An innovative real-time PCR method to measure changes in RNA editing of the serotonin $2 \mathrm{C}$ receptor $\left(5-\mathrm{HT}\left({ }_{2 \mathrm{C}} \mathrm{R}\right)\right.$ in brain. $J \mathrm{Neu}$ rosci Methods 179:247-257.

Langlois M and Fischmeister R (2003) 5-HT4 receptor ligands: applications and new prospects. J Med Chem 46:319-344.

Lankiewicz S, Lobitz N, Wetzel CH, Rupprecht R, Gisselmann G, and Hatt H (1998) Molecular cloning, functional expression, and pharmacological characterization of 5 -hydroxytryptamine3 receptor cDNA and its splice variants from guinea pig. Mol Pharmacol 53:202-212.

Laporte AM, Doyen C, Nevo IT, Chauveau J, Hauw JJ, and Hamon M (1996) Autoradiographic mapping of serotonin 5-HT1A, 5-HT1D, 5-HT2A and 5-HT3 receptors in the aged human spinal cord. J Chem Neuroanat 11:67-75.

Lappalainen J, Zhang L, Dean M, Oz M, Ozaki N, Yu DH, Virkkunen M, Weight F, Linnoila M, and Goldman D (1995) Identification, expression, and pharmacology of a Cys23-Ser23 substitution in the human 5-HT2c receptor gene (HTR2C) Genomics 27:274-279.

Laranjeira C, Sandgren K, Kessaris N, Richardson W, Potocnik A, Vanden Berghe P, and Pachnis V (2011) Glial cells in the mouse enteric nervous system can undergo neurogenesis in response to injury. $J$ Clin Invest 121:3412-3424.

Larkman PM and Kelly JS (1998) Characterization of 5-HT-sensitive potassium conductances in neonatal rat facial motoneurones in vitro. $J$ Physiol 508:67-81.

Larkman PM and Perkins EM (2005) A TASK-like pH- and amine-sensitive 'leak' K+ conductance regulates neonatal rat facial motoneuron excitability in vitro. Eur $J$ Neurosci 21:679-691.

Lattin JE, Schroder K, Su AI, Walker JR, Zhang J, Wiltshire T, Saijo K, Glass CK, Hume DA, Kellie S, et al. (2008) Expression analysis of G Protein-Coupled Receptors in mouse macrophages. Immunome Res 4:5.

Lauffer L, Glas E, Gudermann T, and Breit A (2016) Endogenous 5-HT2C receptors phosphorylate the cAMP response element binding protein via protein kinase 
C-promoted activation of extracellular-regulated kinases-1/2 in hypothalamic mHypoA-2/10 cells. J Pharmacol Exp Ther 358:39-49.

Launay J-M, Birraux G, Bondoux D, Callebert J, Choi D-S, Loric S, and Maroteaux L (1996) Ras involvement in signal transduction by the serotonin $5-\mathrm{HT}_{2 \mathrm{~B}}$ receptor. $J$ Biol Chem 271:3141-3147.

Launay J-M, Hervé P, Callebert J, Mallat Z, Collet C, Doly S, Belmer A, Diaz SL, Hatia S, Côté F, et al. (2012) Serotonin $5-\mathrm{HT}_{2 \mathrm{~B}}$ receptors are required for bonemarrow contribution to pulmonary arterial hypertension. Blood 119:1772-1780.

Launay JM, Hervé P, Peoc'h K, Tournois C, Callebert J, Nebigil CG, Etienne N, Drouet L, Humbert M. Simonneau G, et al. (2002) Function of the serotonin 5-hydroxytryptamine ${ }_{2 \mathrm{~B}}$ receptor in pulmonary hypertension. Nat Med 8:1129-1135.

Launay JM, Schneider B, Loric S, Da Prada M, and Kellermann O (2006) Serotonin transport and serotonin transporter-mediated antidepressant recognition are controlled by $5-\mathrm{HT}_{2 \mathrm{~B}}$ receptor signaling in serotonergic neuronal cells. FASEB $J$ 20:1843-1854.

Lawler CP, Prioleau C, Lewis MM, Mak C, Jiang D, Schetz JA, Gonzalez AM, Sibley DR, and Mailman RB (1999) Interactions of the novel antipsychotic aripiprazole (OPC14597 ) with dopamine and serotonin receptor subtypes. Neuropsychopharmacology 20 $612-627$.

Le Coniat M, Choi DS, Maroteaux L, Launay JM, and Berger R (1996) The 5- $\mathrm{HT}_{2 \mathrm{~B}}$ receptor gene maps to 2q36.3-2q37.1. Genomics 32:172-173.

Lecoutey C, Hedou D, Freret T, Giannoni P, Gaven F, Since M, Bouet V, Ballandonne C, Corvaisier S, Malzert Fréon A, et al. (2014) Design of donecopride, a dual serotonin subtype 4 receptor agonist/acetylcholinesterase inhibitor with potential interest for Alzheimer's disease treatment. Proc Natl Acad Sci USA 111:E3825-E3830.

Lecrubier Y, Boyer P, Turjanski S, and Rein W; Amisulpride Study Group (1997) Amisulpride versus imipramine and placebo in dysthymia and major depression. $J$ Affect Disord 43:95-103.

Lee G, Thangavel R, Sharma VM, Litersky JM, Bhaskar K, Fang SM, Do LH, Andreadis A, Van Hoesen G, and Ksiezak-Reding H (2004a) Phosphorylation of tau by fyn: implications for Alzheimer's disease. J Neurosci 24:2304-2312.

Lee MA and Meltzer HY (1994) Blunted oral body temperature response to MK-212 in cocaine addicts. Drug Alcohol Depend 35:217-222.

Lee MS, Hanspers K, Barker CS, Korn AP, and McCune JM (2004b) Gene expression profiles during human CD4+ T cell differentiation. Int Immunol 16:1109-1124.

Lee S, Hjerling-Leffler J, Zagha E, Fishell G, and Rudy B (2010) The largest group of superficial neocortical GABAergic interneurons expresses ionotropic serotonin receptors. J Neurosci 30:16796-16808.

Lee SP, Xie Z, Varghese G, Nguyen T, O'Dowd BF, and George SR (2000) Oligomerization of dopamine and serotonin receptors. Neuropsychopharmacology $\mathbf{2 3}$ (4 Suppl):S32-S40.

Lefebvre H, Cartier D, Duparc C, Contesse V, Lihrmann I, Delarue C, Vaudry H, Fischmeister R, and Kuhn JM (2000) Effect of serotonin4 (5-HT4) receptor agonists on aldosterone secretion in idiopathic hyperaldosteronism. Endocr Res 26:583-587.

Lefebvre H, Contesse V, Delarue C, Feuilloley M, Hery F, Grise P, Raynaud G, Verhofstad AA, Wolf LM, and Vaudry H (1992) Serotonin-induced stimulation of cortisol secretion from human adrenocortical tissue is mediated through activation of a serotonin4 receptor subtype. Neuroscience 47:999-1007.

Lefebvre H, Contesse V, Delarue C, Vaudry H, and Kuhn JM (1998a) Serotonergic regulation of adrenocortical function. Horm Metab Res 30:398-403.

Lefebvre H, Duparc C, Prévost G, Zennaro MC, Bertherat J, and Louiset E (2015) Paracrine control of steroidogenesis by serotonin in adrenocortical neoplasms. Mol Cell Endocrinol 408:198-204.

Lefebvre H, Gonzalez KN, Contesse V, Delarue C, Vaudry H, and Kuhnl JM (1998b) Effect of prolonged administration of the serotonin4 (5-HT4) receptor agonist cisapride on aldosterone secretion in healthy volunteers. Endocr Res 24:749-752.

Leggett JD, Aspley S, Beckett SR, D'Antona AM, Kendall DA, and Kendall DA (2004) Oleamide is a selective endogenous agonist of rat and human CB1 cannabinoid receptors. Br J Pharmacol 141:253-262.

Leggio GM, Cathala A, Moison D, Cunningham KA, Piazza PV, and Spampinato U (2009a) Serotonin2C receptors in the medial prefrontal cortex facilitate cocaineinduced dopamine release in the rat nucleus accumbens. Neuropharmacology 56: 507-513.

Leggio GM, Cathala A, Neny M, Rouge-Pont F, Drago F, Piazza PV, and Spampinato $\mathrm{U}(2009 \mathrm{~b})$ In vivo evidence that constitutive activity of serotonin $2 \mathrm{C}$ receptors in the medial prefrontal cortex participates in the control of dopamine release in the rat nucleus accumbens: differential effects of inverse agonist versus antagonist. $J$ Neurochem 111:614-623.

Lelong V, Dauphin F, and Boulouard M (2001) RS 67333 and D-cycloserine accelerate learning acquisition in the rat. Neuropharmacology 41:517-522.

Lelong V, Lhonneur L, Dauphin F, and Boulouard M (2003) BIMU 1 and RS 67333, two 5-HT4 receptor agonists, modulate spontaneous alternation deficits induced by scopolamine in the mouse. Naunyn Schmiedebergs Arch Pharmacol 367:621-628.

Lemaitre S, Lepailleur A, Bureau R, Butt-Gueulle S, Lelong-Boulouard V, Duchatelle P, Boulouard M, Dumuis A, Daveu C, Lezoualc'h F, et al. (2009) Novel antagonists of serotonin-4 receptors: synthesis and biological evaluation of pyrrolothienopyrazines. Bioorg Med Chem 17:2607-2622.

Lemoine L, Becker G, Vacher B, Billard T, Lancelot S, Newman-Tancredi A, and Zimmer L (2012) Radiosynthesis and preclinical evaluation of 18F-F13714 as a fluorinated 5-HT1A receptor agonist radioligand for PET neuroimaging. $J$ Nucl Med 53:969-976.

Lemoine L, Verdurand M, Vacher B, Blanc E, Le Bars D, Newman-Tancredi A and Zimmer L (2010) [18F]F15599, a novel 5-HT1A receptor agonist, as a radioligand for PET neuroimaging. Eur J Nucl Med Mol Imaging 37:594-605.

Lemonde S, Du L, Bakish D, Hrdina P, and Albert PR (2004) Association of the C( 1019)G 5-HT1A functional promoter polymorphism with antidepressant response. Int $J$ Neuropsychopharmacol 7:501-506.

Lemonde S, Turecki G, Bakish D, Du L, Hrdina PD, Bown CD, Sequeira A, Kushwaha N, Morris SJ, Basak A, et al. (2003) Impaired repression at a 5-hydroxytryptamine $1 \mathrm{~A}$ receptor gene polymorphism associated with major depression and suicide. J Neurosci 23:8788-8799.

Lenglet S, Delarue C, Lefebvre H, Vaudry H, and Contesse V Rat glomerulosa cells express functional 5-HT7 receptors. Endocr Res 26:597-602

Lenglet S, Louiset E, Delarue C, Vaudry H, and Contesse V (2002a) Activation of 5 -HT(7) receptor in rat glomerulosa cells is associated with an increase in adenylyl cyclase activity and calcium influx through T-type calcium channels. Endocrinology 143:1748-1760.

Lenglet S, Louiset E, Delarue C, Vaudry H, and Contesse V (2002b) Involvement of T-type calcium channels in the mechanism of action of 5-HT in rat glomerulosa cells: a novel signaling pathway for the 5-HT7 receptor. Endocr Res 28:651-655.

Lentes KU, Hinney A, Ziegler A, Rosenkranz K, Wurmser H, Barth N, Jacob K, Coners H, Mayer H, Grzeschik KH, et al. (1997) Evaluation of a Cys23Ser mutation within the human 5-HT2C receptor gene: no evidence for an association of the mutant allele with obesity or underweight in children, adolescents and young adults. Life Sci 61:PL9-PL16.

Leonardo ED and Hen R (2008) Anxiety as a developmental disorder. Neuropsychopharmacology 33:134-140.

Leonhardt S, Herrick-Davis K, and Titeler M (1989) Detection of a novel serotonin receptor subtype (5-HT1E) in human brain: interaction with a GTP-binding protein. $J$ Neurochem 53:465-471.

León-Ponte M, Ahern GP, and O'Connell PJ (2007) Serotonin provides an accessory signal to enhance T-cell activation by signaling through the 5-HT7 receptor. Blood 109:3139-3146.

Leopoldo M, Lacivita E, De Giorgio P, Fracasso C, Guzzetti S, Caccia S, Contino M, Colabufo NA, Berardi F, and Perrone R (2008) Structural modifications of $\mathrm{N}$-(1,2,3,4-tetrahydronaphthalen-1-yl)-4-aryl-1-piperazinehexanamides: influence on lipophilicity and 5-HT7 receptor activity. Part III. J Med Chem 51:5813-5822.

Lepailleur A, Freret T, Lemaître S, Boulouard M, Dauphin F, Hinschberger A, Dulin F, Lesnard A, Bureau R, and Rault S (2014) Dual histamine H3R/serotonin 5-HT4R ligands with antiamnesic properties: pharmacophore-based virtual screening and polypharmacology. J Chem Inf Model 54:1773-1784.

Lerond J, Lothe A, Ryvlin P, Bouvard S, d'Amato T, Ciumas C, Daléry J, Poulet E, and Saoud M (2013) Effects of aripiprazole, risperidone, and olanzapine on 5-HT1A receptors in patients with schizophrenia. J Clin Psychopharmacol 33:84-89.

Lesch KP and Gutknecht L (2004) Focus on The 5-HT1A receptor: emerging role of a gene regulatory variant in psychopathology and pharmacogenetics. Int $\mathrm{J} \mathrm{Neu}$ ropsychopharmacol 7:381-385.

Lesurtel M, Graf R, Aleil B, Walther DJ, Tian Y, Jochum W, Gachet C, Bader M, and Clavien PA (2006) Platelet-derived serotonin mediates liver regeneration. Science 312:104-107.

Levin ED, Johnson JE, Slade S, Wells C, Cauley M, Petro A, and Rose JE (2011) Lorcaserin, a 5-HT2C agonist, decreases nicotine self-administration in female rats. J Pharmacol Exp Ther 338:890-896.

Levin OS (2015) [The use of buspirone in clinical practice]. Zh Nevrol Psikhiatr Im S $S$ Korsakova 115:83-87.

Levitt ES, Hunnicutt BJ, Knopp SJ, Williams JT, and Bissonnette JM (2013) A selective 5-HT1a receptor agonist improves respiration in a mouse model of Rett syndrome. J Appl Physiol (1985) 115:1626-1633.

Levy FO, Gudermann T, Birnbaumer M, Kaumann AJ, and Birnbaumer L (1992a) Molecular cloning of a human gene (S31) encoding a novel serotonin receptor mediating inhibition of adenylyl cyclase. FEBS Lett 296:201-206.

Levy FO, Gudermann T, Perez-Reyes E, Birnbaumer M, Kaumann AJ, and Birnbaumer L (1992b) Molecular cloning of a human serotonin receptor (S12) with a pharmacological profile resembling that of the 5- $\mathrm{HT}_{1 \mathrm{D}}$ subtype. J Biol Chem 267:7553-7562.

Levy FO, Holtgreve-Grez H, Taskén K, Solberg R, Ried T, and Gudermann T (1994) Assignment of the gene encoding the 5-HT1E serotonin receptor (S31) (locus $\mathrm{HTR}_{1 \mathrm{E}}$ ) to human chromosome 6q14-q15. Genomics 22:637-640.

Levy FO, Qvigstad E, Krobert KA, Skomedal T, and Osnes JB (2008) Effects of serotonin in failing cardiac ventricle: signalling mechanisms and potential therapeutic implications. Neuropharmacology 55:1066-1071.

Lewis JH (2011) The risk of ischaemic colitis in irritable bowel syndrome patients treated with serotonergic therapies. Drug Saf 34:545-565.

Leysen JE, Awouters F, Kennis L, Laduron PM, Vandenberk J, and Janssen PA (1981) Receptor binding profile of $\mathrm{R} 41468$, a novel antagonist at 5-HT $\mathrm{H}_{2}$ receptors. Life Sci 28:1015-1022.

Leysen JE, Gommeren W, Heylen L, Luyten WH, Van de Weyer I, Vanhoenacker P, Haegeman G, Schotte A, Van Gompel P, Wouters R, et al. (1996) Alniditan, a new 5-hydroxytryptamine ${ }_{1 \mathrm{D}}$ agonist and migraine-abortive agent: ligand-binding properties of human 5-hydroxytryptamine ${ }_{1 \mathrm{D} \alpha}$, human 5-hydroxytryptamine ${ }_{1 \mathrm{D}} \beta$, and calf 5 -hydroxytryptamine 1 D receptors investigated with $\left[{ }^{3} \mathrm{H}\right] 5$-hydroxytryptamine and $\left[{ }^{3} \mathrm{H}\right]$ alniditan. Mol Pharmacol 50:1567-1580.

Leysen JE, Van Gompel P, Gommeren W, Woestenborghs R, and Janssen PA (1986) Down regulation of serotonin-S2 receptor sites in rat brain by chronic treatment with the serotonin-S2 antagonists: ritanserin and setoperone. Psychopharmacology (Berl) 88:434-444.

Lezoualc'h F and Robert SJ (2003) The serotonin 5-HT4 receptor and the amyloid precursor protein processing. Exp Gerontol 38:159-166.

Lezoualc'h F, Steplewski K, Sartiani L, Mugelli A, Fischmeister R, and Bril A (2007) Quantitative mRNA analysis of serotonin 5- $\mathrm{HT}_{4}$ receptor isoforms, calcium handling proteins and ion channels in human atrial fibrillation. Biochem Biophys Res Commun 357:218-224.

Li N, Ghia JE, Wang H, McClemens J, Cote F, Suehiro Y, Mallet J, and Khan WI (2011a) Serotonin activates dendritic cell function in the context of gut inflammation. Am J Pathol 178:662-671.

Li T, Weng S-G, Leng X-S, Peng J-R, Wei Y-H, Mou D-C, and Wang W-X (2006) Effects of 5-hydroxytamine and its antagonists on hepatic stellate cells. Hepatobiliary Pancreat Dis Int 5:96-100. 
Li X, Zhu W, Roh MS, Friedman AB, Rosborough K, and Jope RS (2004) In vivo regulation of glycogen synthase kinase-3beta (GSK3beta) by serotonergic activity in mouse brain. Neuropsychopharmacology 29:1426-1431.

Li Y, Nie Y, Xie J, Tang W, Liang P, Sha W, Yang H, and Zhou Y (2007) The association of serotonin transporter genetic polymorphisms and irritable bowel syndrome and its influence on tegaserod treatment in Chinese patients. Dig Dis Sci 52:2942-2949.

Li Z, Chalazonitis A, Huang YY, Mann JJ, Margolis KG, Yang QM, Kim DO, Côté F, Mallet J, and Gershon MD (2011b) Essential roles of enteric neuronal serotonin in gastrointestinal motility and the development/survival of enteric dopaminergic neurons. J Neurosci 31:8998-9009.

Liang C, Chen W, Zhi X, Ma T, Xia X, Liu H, Zhang Q, Hu Q, Zhang Y, Bai X, et al. (2013) Serotonin promotes the proliferation of serum-deprived hepatocellular carcinoma cells via upregulation of FOXO3a. Mol Cancer 12:14.

Liang YJ, Lai LP, Wang BW, Juang SJ, Chang CM, Leu JG, and Shyu KG (2006) Mechanical stress enhances serotonin ${ }_{2 \mathrm{~B}}$ receptor modulating brain natriuretic peptide through nuclear factor-kappaB in cardiomyocytes. Cardiovasc Res $\mathbf{7 2}$ 303-312.

Libert F, Parmentier M, Lefort A, Dumont JE, and Vassart G (1990) Complete nucleotide sequence of a putative G protein coupled receptor: RDC4. Nucleic Acids Res 18:1916

Licht CL, Kirkegaard L, Zueger M, Chourbaji S, Gass P, Aznar S, and Knudsen GM (2010a) Changes in 5-HT4 receptor and 5-HT transporter binding in olfactory bulbectomized and glucocorticoid receptor heterozygous mice. Neurochem Int $\mathbf{5 6}$ 603-610.

Licht CL, Knudsen GM, and Sharp T (2010b) Effects of the 5-HT(4) receptor agonist RS67333 and paroxetine on hippocampal extracellular 5-HT levels. Neurosci Lett 476:58-61.

Lieben CK, Blokland A, Sik A, Sung E, van Nieuwenhuizen P, and Schreiber R (2005) The selective 5-HT6 receptor antagonist Ro4368554 restores memory performance in cholinergic and serotonergic models of memory deficiency in the rat. Neuropsychopharmacology 30:2169-2179.

Lim C-S, Hoang ET, Viar KE, Stornetta RL, Scott MM, and Zhu JJ (2014) Pharmacological rescue of Ras signaling, GluA1-dependent synaptic plasticity, and learning deficits in a fragile X model. Genes Dev 28:273-289.

Lin JC, Chou CC, Gao S, Wu SC, Khoo KH, and Lin CH (2013) An in vivo tagging method reveals that Ras undergoes sustained activation upon transglutaminasemediated protein serotonylation. ChemBioChem 14:813-817.

Lin JC, Chou CC, Tu Z, Yeh LF, Wu SC, Khoo KH, and Lin CH (2014) Characterization of protein serotonylation via bioorthogonal labeling and enrichment. $J$ Proteome Res 13:3523-3529.

Lin SL, Johnson-Farley NN, Lubinsky DR, and Cowen DS (2003) Coupling of neuronal 5-HT7 receptors to activation of extracellular-regulated kinase through a protein kinase A-independent pathway that can utilize Epac. J Neurochem 87: 1076-1085.

Lin S-Y, Chang W-J, Lin C-S, Huang C-Y, Wang H-F, and Sun W-H (2011) Serotonin receptor $5-\mathrm{HT}_{2 \mathrm{~B}}$ mediates serotonin-induced mechanical hyperalgesia. $J$ Neurosci 31:1410-1418.

Lin Z, Walther D, Yu X-Y, Drgon T, and Uhl GR (2004) The human serotonin receptor ${ }_{2 \mathrm{~B}}$ : coding region polymorphisms and association with vulnerability to illegal drug abuse. Pharmacogenetics 14:805-811.

Linder AE, Beggs KM, Burnett RJ, and Watts SW (2009) Body distribution of infused serotonin in rats. Clin Exp Pharmacol Physiol 36:599-601.

Liu H, Irving HR, and Coupar IM (2001) Expression patterns of 5-HT7 receptor isoforms in the rat digestive tract. Life Sci 69:2467-2475.

Liu H-N, Ohya S, Nishizawa Y, Sawamura K, Iino S, Syed MM, Goto K, Imaizumi Y, and Nakayama S (2011a) Serotonin augments gut pacemaker activity via $5-\mathrm{HT}_{3}$ receptors. PLoS One 6:e24928.

Liu M, Geddis MS, Wen Y, Setlik W, and Gershon MD (2005a) Expression and function of 5-HT4 receptors in the mouse enteric nervous system. Am J Physiol Gastrointest Liver Physiol 289:G1148-G1163.

Liu MT, Kuan YH, Wang J, Hen R, and Gershon MD (2009) 5-HT4 receptor-mediated neuroprotection and neurogenesis in the enteric nervous system of adult mice. $J$ Neurosci 29:9683-9699.

Liu S, Bubar MJ, Lanfranco MF, Hillman GR, and Cunningham KA (2007) Seroto$\operatorname{nin}_{2 \mathrm{C}}$ receptor localization in GABA neurons of the rat medial prefrontal cortex: implications for understanding the neurobiology of addiction. Neuroscience 146 $1677-1688$.

Liu S, Lane SD, Schmitz JM, Green CE, Cunningham KA, and Moeller FG (2012a) Increased intra-individual reaction time variability in cocaine-dependent subjects: role of cocaine-related cues. Addict Behav 37:193-197.

Liu S, Lane SD, Schmitz JM, Waters AJ, Cunningham KA, and Moeller FG (2011b) Relationship between attentional bias to cocaine-related stimuli and impulsivity in cocaine-dependent subjects. Am J Drug Alcohol Abuse 37:117-122.

Liu W, Wacker D, Gati C, Han GW, James D, Wang D, Nelson G, Weierstall U, Katritch V, Barty A, et al. (2013a) Serial femtosecond crystallography of G proteincoupled receptors. Science 342:1521-1524.

Liu XY, Wu SX, Wang YY, Wang W, Zhou L, and Li YQ (2005b) Changes of 5-HT receptor subtype mRNAs in rat dorsal root ganglion by bee venom-induced inflammatory pain. Neurosci Lett 375:42-46.

Liu Y, Emeson RB, and Samuel CE (1999) Serotonin-2C receptor pre-mRNA editing in rat brain and in vitro by splice site variants of the interferon-inducible doublestranded RNA-specific adenosine deaminase ADAR1. J Biol Chem 274: 18351-18358.

Liu Y, Tian H, Yan X, Fan F, Wang W, and Han J (2013b) Serotonin inhibits apoptosis of pulmonary artery smooth muscle cells through $5-\mathrm{HT}_{2 \mathrm{~A}}$ receptors involved in the pulmonary artery remodeling of pulmonary artery hypertension. Exp Lung Res 39:70-79.

Liu Y, Tian XY, Mao G, Fang X, Fung ML, Shyy JY, Huang Y, and Wang N (2012b) Peroxisome proliferator-activated receptor- $\gamma$ ameliorates pulmonary arterial hypertension by inhibiting 5-hydroxytryptamine $2 \mathrm{~B}$ receptor. Hypertension $\mathbf{6 0}$ : 1471-1478.

Liu Y, Wei L, Laskin DL, and Fanburg BL (2011c) Role of protein transamidation in serotonin-induced proliferation and migration of pulmonary artery smooth muscle cells. Am J Respir Cell Mol Biol 44:548-555.

Liu YS and Yang M (2006) The effect of 5-hydroxtryptamine on the regulation of megakaryocytopoiesis. Hematology 11:53-56.

Livesey MR, Cooper MA, Deeb TZ, Carland JE, Kozuska J, Hales TG, Lambert JJ, and Peters JA (2008) Structural determinants of $\mathrm{Ca} 2+$ permeability and conduction in the human 5-hydroxytryptamine type 3A receptor. $J$ Biol Chem 283 : 19301-19313.

Livesey MR, Cooper MA, Lambert JJ, and Peters JA (2011) Rings of charge within the extracellular vestibule influence ion permeation of the 5-HT3A receptor. J Biol Chem 286:16008-16017.

Liy-Salmeron G and Meneses A (2008) Effects of 5-HT drugs in prefrontal cortex during memory formation and the ketamine amnesia-model. Hippocampus 18: 965-974.

Lladó-Pelfort L, Assié MB, Newman-Tancredi A, Artigas F, and Celada P (2010) Preferential in vivo action of $\mathrm{F} 15599$, a novel 5-HT(1A) receptor agonist, at postsynaptic 5-HT(1A) receptors. Br J Pharmacol 160:1929-1940.

Lladó-Pelfort L, Assié MB, Newman-Tancredi A, Artigas F, and Celada P (2012) In vivo electrophysiological and neurochemical effects of the selective 5-HT1A receptor agonist, F13640, at pre- and postsynaptic 5-HT1A receptors in the rat. Psychopharmacology (Berl) 221:261-272.

Lochner M and Lummis SC (2010) Agonists and antagonists bind to an A-A interface in the heteromeric 5-HT3AB receptor. Biophys $J$ 98:1494-1502.

Locker M, Bitard J, Collet C, Poliard A, Mutel V, Launay JM, and Kellermann O (2006) Stepwise control of osteogenic differentiation by $5-\mathrm{HT}\left({ }_{2 \mathrm{~B}}\right)$ receptor signaling: nitric oxide production and phospholipase A2 activation. Cell Signal 18:628-639.

Loebel A, Cucchiaro J, Silva R, Kroger H, Hsu J, Sarma K, and Sachs G (2014a) Lurasidone monotherapy in the treatment of bipolar I depression: a randomized, double-blind, placebo-controlled study. Am J Psychiatry 171:160-168.

Loebel A, Cucchiaro J, Silva R, Kroger H, Sarma K, Xu J, and Calabrese JR (2014b) Lurasidone as adjunctive therapy with lithium or valproate for the treatment of bipolar I depression: a randomized, double-blind, placebo-controlled study. Am $J$ Psychiatry 171:169-177.

Logue SF and Gould TJ (2014) The neural and genetic basis of executive function: attention, cognitive flexibility, and response inhibition. Pharmacol Biochem Behav 123:45-54

Lohse MJ, Engelhardt S, and Eschenhagen T (2003) What is the role of beta-adrenergic signaling in heart failure? Circ Res 93:896-906.

Loiseau F, Dekeyne A, and Millan MJ (2008) Pro-cognitive effects of 5-HT6 receptor antagonists in the social recognition procedure in rats: implication of the frontal cortex. Psychopharmacology (Berl) 196:93-104

Long DD, Armstrong SR, Beattie DT, Choi SK, Fatheree PR, Gendron RA, Goldblum AA, Humphrey PP, Marquess DG, Shaw JP, et al. (2012) Discovery, oral pharmacokinetics and in vivo efficacy of a highly selective 5-HT4 receptor agonist: clinical compound TD-2749. Bioorg Med Chem Lett 22:4849-4853.

Longmore J, Shaw D, Smith D, Hopkins R, McAllister G, Pickard JD, Sirinathsinghji DJ, Butler AJ, and Hill RG (1997) Differental distribution of 5- $\mathrm{HT}_{1 \mathrm{~B}^{-}}$and 5-HT immunoreactivity within the human trigemino-cerebrovascular system: implications for the discovery of new antimigraine drugs. Cephalalgia 17:833-842.

Longstreth GF, Thompson WG, Chey WD, Houghton LA, Mearin F, and Spiller RC (2006) Functional bowel disorders [published correction appears in Gastroenterology (2006) 131:688]. Gastroenterology 130:1480-1491.

Loo LS, Ailani J, Schim J, Baygani S, Hundemer H-P, Port M, and Krege JH (2019) Efficacy and safety of lasmiditan in patients using concomitant migraine preventive medications: findings from SAMURAI and SPARTAN, two randomized phase 3 trials. $J$ Headache Pain 20:84.

Lopez-Esparza S, Berumen LC, Padilla K, Miledi R, and García-Alcocer G (2015) Expression of hippocampal serotonin receptors 5-HT2C and 5-HT5A in a rat model of diet-induced obesity supplemented with tryptophan. Int $J$ Dev Neurosci 42: $80-85$.

López-Giménez JF, Mengod G, Palacios JM, and Vilaró MT (1997) Selective visualization of rat brain 5-HT2A receptors by autoradiography with [3H]MDL 100,907. Naunyn Schmiedebergs Arch Pharmacol 356:446-454.

López-Giménez JF, Mengod G, Palacios JM, and Vilaró MT (2001) Regional distribution and cellular localization of 5-HT2C receptor mRNA in monkey brain: comparison with $[3 \mathrm{H}]$ mesulergine binding sites and choline acetyltransferase mRNA. Synapse 42:12-26.

Lopreato GF, Banerjee P, and Mihic SJ (2003) Amino acids in transmembrane domain two influence anesthetic enhancement of serotonin-3A receptor function. Brain Res Mol Brain Res 118:45-51.

Loric S, Launay J-M, Colas J-F, and Maroteaux L (1992) New mouse 5-HT2-like receptor. Expression in brain, heart and intestine. FEBS Lett 312:203-207.

Lorke DE, Lu G, Cho E, and Yew DT (2006) Serotonin 5-HT2A and 5-HT6 receptors in the prefrontal cortex of Alzheimer and normal aging patients. BMC Neurosci 7: 36 .

Lovell KM, Frankowski KJ, Stahl EL, Slauson SR, Yoo E, Prisinzano TE, Aube J, and Bohn LM (2015) Structure-activity relationship studies of functionally selective kappa opioid receptor agonists that modulate ERK 1/2 phosphorylation while preserving G protein over BArrestin2 signaling bias. ACS Chem Neurosci 6: $1411-1419$

Lovell PJ, Bromidge SM, Dabbs S, Duckworth DM, Forbes IT, Jennings AJ, King FD, Middlemiss DN, Rahman SK, Saunders DV, et al. (2000) A novel, potent, and selective 5-HT(7) antagonist: (R)-3-(2-(2-(4-methylpiperidin-1-yl)ethyl)pyrrolidine1-sulfonyl) phen ol (SB-269970). J Med Chem 43:342-345.

Lovenberg TW, Baron BM, de Lecea L, Miller JD, Prosser RA, Rea MA, Foye PE, Racke M, Slone AL, Siegel BW, et al. (1993a) A novel adenylyl cyclase-activating 
serotonin receptor (5-HT7) implicated in the regulation of mammalian circadian rhythms. Neuron 11:449-458.

Lovenberg TW, Erlander MG, Baron BM, Racke M, Slone AL, Siegel BW, Craft CM, Burns JE, Danielson PE, and Sutcliffe JG (1993b) Molecular cloning and functional expression of 5-HT1E-like rat and human 5-hydroxytryptamine receptor genes. Proc Natl Acad Sci USA 90:2184-2188.

Lowy MT and Meltzer HY (1988) Stimulation of serum cortisol and prolactin secretion in humans by MK-212, a centrally active serotonin agonist. Biol Psychiatry 23: $818-828$.

Lübbert H, Hoffman BJ, Snutch TP, van Dyke T, Levine AJ, Hartig PR, Lester HA, and Davidson N (1987) cDNA cloning of a serotonin 5-HT1C receptor by electrophysiological assays of mRNA-injected Xenopus oocytes. Proc Natl Acad Sci USA 84:4332-4336

Lucaites VL, Nelson DL, Wainscott DB, and Baez M (1996) Receptor subtype and density determine the coupling repertoire of the 5-HT2 receptor subfamily. Life Sci 59:1081-1095.

Lucas G (2009) Serotonin receptors, type 4: a new hope? Curr Drug Targets 10: $1085-1095$.

Lucas G, Compan V, Charnay Y, Neve RL, Nestler EJ, Bockaert J, Barrot M, and Debonnel G (2005) Frontocortical 5-HT4 receptors exert positive feedback on serotonergic activity: viral transfections, subacute and chronic treatments with 5-HT4 agonists. Biol Psychiatry 57:918-925.

Lucas G and Debonnel G (2002) 5-HT4 receptors exert a frequency-related facilitatory control on dorsal raphé nucleus 5-HT neuronal activity. Eur $J$ Neurosci 16: 817-822.

Lucas G, Rymar VV, Du J, Mnie-Filali O, Bisgaard C, Manta S, Lambas-Senas L, Wiborg O, Haddjeri N, Piñeyro G, et al. (2007) Serotonin(4) (5-HT(4)) receptor agonists are putative antidepressants with a rapid onset of action. Neuron 55:712-725 Lucki I (1992) 5-HT1 receptors and behavior. Neurosci Biobehav Rev 16:83-93.

Lucki I (1998) The spectrum of behaviors influenced by serotonin. Biol Psychiatry 44: 151-162

Luiking YC, Akkermans LMA, Peeters TL, Cnossen PJ, Nieuwenhuijs VB, and Vanberge -Henegouwen GP (2002) Effects of motilin on human interdigestive gastrointestinal and gallbladder motility, and involvement of $5 \mathrm{HT}_{3}$ receptors. Neurogastroenterol Motil 14:151-159.

Łukasiewicz S, Błasiak E, Faron-Górecka A, Polit A, Tworzydło M, Górecki A Wasylewski Z, and Dziedzicka-Wasylewska M (2007) Fluorescence studies of homooligomerization of adenosine A2A and serotonin 5-HT1A receptors reveal the specificity of receptor interactions in the plasma membrane. Pharmacol Rep $\mathbf{5 9}$ 379-392.

Lukasiewicz S, Polit A, Kedracka-Krok S, Wedzony K, Maćkowiak M, and Dziedzicka-Wasylewska M (2010) Hetero-dimerization of serotonin 5-HT( $\left(_{2 A}\right)$ and dopamine $\left.\mathrm{D}_{2}\right)$ receptors. Biochim Biophys Acta 1803:1347-1358.

Luoni A, Hulsken S, Cazzaniga G, Racagni G, Homberg JR, and Riva MA (2013) Behavioural and neuroplastic properties of chronic lurasidone treatment in serotonin transporter knockout rats. Int J Neuropsychopharmacol 16:1319-1330.

Lutsep HL (2002) Repinotan Bayer. Curr Opin Investig Drugs 3:924-927.

Lüttgen M, Elvander E, Madjid N, and Ogren SO (2005) Analysis of the role of 5 -HT1A receptors in spatial and aversive learning in the rat. Neuropharmacology 48:830-852.

Luttrell LM, Maudsley S, and Bohn LM (2015) Fulfilling the promise of "biased" G protein-coupled receptor agonism. Mol Pharmacol 88:579-588.

Ly S, Pishdari B, Lok LL, Hajos M, and Kocsis B (2013) Activation of 5-HT6 receptors modulates sleep-wake activity and hippocampal theta oscillation. ACS Chem Neurosci 4:191-199.

Lyddon R, Cuppen E, Haroutunian V, Siever LJ, and Dracheva S (2010) No link of serotonin 2C receptor editing to serotonin transporter genotype. Neuroreport 21:1080-1084.

Lyddon R, Dwork AJ, Keddache M, Siever LJ, and Dracheva S (2013) Serotonin 2c receptor RNA editing in major depression and suicide. World J Biol Psychiatry 14: $590-601$.

Lyon RA, Davis KH, and Titeler M (1987) ${ }^{3} \mathrm{H}-\mathrm{DOB}$ (4-bromo-2,5-dimethoxyphenylisopropylamine) labels a guanyl nucleotide-sensitive state of cortical 5-HT receptors. Mol Pharmacol 31:194-199.

Ma QP (2001) Co-localization of 5-HT( $(1 \mathrm{~B} / 1 \mathrm{D} / 1 \mathrm{~F})$ receptors and glutamate in trigeminal ganglia in rats. Neuroreport 12:1589-1591.

Ma QP, Hill R, and Sirinathsinghji D (2001) Colocalization of CGRP with 5-HT1B/1D receptors and substance $\mathrm{P}$ in trigeminal ganglion neurons in rats. Eur $J$ Neurosci 13:2099-2104

Ma XX, Chen QX, Wu SJ, Hu Y, and Fang XM (2013) Polymorphisms of the HTR3B gene are associated with post-surgery emesis in a Chinese Han population. J Clin Pharm Ther 38:150-155.

Ma YY, Lee BR, Wang X, Guo C, Liu L, Cui R, Lan Y, Balcita-Pedicino JJ, Wolf ME, Sesack SR, et al. (2014) Bidirectional modulation of incubation of cocaine craving by silent synapse-based remodeling of prefrontal cortex to accumbens projections. Neuron 83:1453-1467.

Maas S, Patt S, Schrey M, and Rich A (2001) Underediting of glutamate receptor GluR-B mRNA in malignant gliomas. Proc Natl Acad Sci USA 98:14687-14692.

Maassen VanDenBrink A, Vergouwe MN, Ophoff RA, Naylor SL, Dauwerse HG, Saxena PR, Ferrari MD, and Frants RR (1998) Chromosomal localization of the $5-\mathrm{HT}_{1 \mathrm{~F}}$ receptor gene: no evidence for involvement in response to sumatriptan in migraine patients. Am J Med Genet 77:415-420.

Maayani S, Wilkinson CW, and Stollak JS (1984) 5-Hydroxytryptamine receptor in rabbit aorta: characterization by butyrophenone analogs. J Pharmacol Exp Ther 229:346-350

MacFarlane PM, Vinit S, and Mitchell GS (2011) Serotonin 2A and ${ }_{2 B}$ receptorinduced phrenic motor facilitation: differential requirement for spinal NADPH oxidase activity. Neuroscience 178:45-55.

MacFarlane PM, Vinit S, and Mitchell GS (2014) Spinal nNOS regulates phrenic motor facilitation by a $5-\mathrm{HT}_{2 \mathrm{~B}}$ receptor- and $\mathrm{NADPH}$ oxidase-dependent mechanism. Neuroscience 269:67-78.
Machida T, Iizuka K, and Hirafuji M (2013) 5-hydroxytryptamine and its receptors in systemic vascular walls. Biol Pharm Bull 36:1416-1419.

Machu TK (2011) Therapeutics of 5-HT3 receptor antagonists: current uses and future directions. Pharmacol Ther 130:338-347.

Maclean MR and Dempsie Y (2010) The serotonin hypothesis of pulmonary hypertension revisited. Adv Exp Med Biol 661:309-322.

MacLeod AM, Street LJ, Reeve AJ, Jelley RA, Sternfeld F, Beer MS, Stanton JA, Watt AP, Rathbone D, and Matassa VG (1997) Selective, orally active 5-HT1D receptor agonists as potential antimigraine agents. J Med Chem 40:3501-3503.

Madjid N, Tottie EE, Lüttgen M, Meister B, Sandin J, Kuzmin A, Stiedl O, and Ogren SO (2006) 5-Hydroxytryptamine $1 \mathrm{~A}$ receptor blockade facilitates aversive learning in mice: interactions with cholinergic and glutamatergic mechanisms. J Pharmacol Exp Ther 316:581-591.

Madsen K, Neumann WJ, Holst K, Marner L, Haahr MT, Lehel S, Knudsen GM, and Hasselbalch SG (2011) Cerebral serotonin 4 receptors and amyloid- $\beta$ in early Alzheimer's disease. J Alzheimers Dis 26:457-466.

Maekawa T, Kim S, Nakai D, Makino C, Takagi T, Ogura H, Yamada K, Chatton B, and Ishii S (2010) Social isolation stress induces ATF-7 phosphorylation and impairs silencing of the 5-HT 5B receptor gene. EMBO J 29:196-208.

Maenhaut C, Vansande J, Massart C, Dinsart C, Libert F, Monferini E, Giraldo E Ladinsky H, Vassart G, and Dumont JE (1991) The orphan receptor cDNA RDC4 encodes a 5-HT1D serotonin receptor. Biochem Biophys Res Commun 80:1460-1468.

Magee JA, Araki T, Patil S, Ehrig T, True L, Humphrey PA, Catalona WJ, Watson MA, and Milbrandt J (2001) Expression profiling reveals hepsin overexpression in prostate cancer. Cancer Res 61:5692-5696.

Maginnis MS, Haley SA, Gee GV, and Atwood WJ (2010) Role of N-linked glycosylation of the 5-HT2A receptor in JC virus infection. $J$ Virol 84:9677-9684.

Magrini E, Szabò I, Doni A, Cibella J, and Viola A (2011) Serotonin-mediated tuning of human helper $\mathrm{T}$ cell responsiveness to the chemokine CXCL12. PLoS One 6: e22482.

Maillet JC, Zhang Y, Li X, and Zhang X (2008) PTEN-5-HT2C coupling: a new target for treating drug addiction. Prog Brain Res 172:407-420.

Manfra O, Van Craenenbroeck K, Skieterska K, Frimurer T, Schwartz TW, Levy FO, and Andressen KW (2015) Downregulation of $5-\mathrm{HT}_{7}$ serotonin receptors by the atypical antipsychotics clozapine and olanzapine. Role of motifs in the C-terminal domain and interaction with GASP-1. ACS Chem Neurosci 6:1206-1218.

Manivet P, Mouillet-Richard S, Callebert J, Nebigil CG, Maroteaux L, Hosoda S, Kellermann O, and Launay J-M (2000) PDZ-dependent activation of nitric-oxide synthases by the serotonin $_{2 \mathrm{~B}}$ receptor. J Biol Chem 275:9324-9331.

Manning DD, Cioffi CL, Usyatinsky A, Fitzpatrick K, Masih L, Guo C, Zhang Z, Choo $\mathrm{SH}$, Sikkander MI, Ryan KN, et al. (2011) Novel serotonin type 3 receptor partial agonists for the potential treatment of irritable bowel syndrome. Bioorg Med Chem Lett 21:58-61.

Manning DD, Guo C, Zhang Z, Ryan KN, Naginskaya J, Choo SH, Masih L, Earley WG, Wierschke JD, Newman AS, et al. (2014) The discovery of diazepinone-based 5-HT3 receptor partial agonists. Bioorg Med Chem Lett 24:2578-2581.

Mannoury la Cour C, El Mestikawy S, Hanoun N, Hamon M, and Lanfumey L (2006) Regional differences in the coupling of 5-hydroxytryptamine-1A receptors to $\mathrm{G}$ proteins in the rat brain. Mol Pharmacol 70:1013-1021.

Manuel-Apolinar L, Rocha L, Pascoe D, Castillo E, Castillo C, and Meneses A (2005) Modifications of 5-HT4 receptor expression in rat brain during memory consolidation. Brain Res 1042:73-81.

Manvich DF, Kimmel HL, Cooper DA, and Howell LL (2012a) The serotonin 2C receptor antagonist SB 242084 exhibits abuse-related effects typical of stimulants in squirrel monkeys. J Pharmacol Exp Ther 342:761-769.

Manvich DF, Kimmel HL, and Howell LL (2012b) Effects of serotonin 2C receptor agonists on the behavioral and neurochemical effects of cocaine in squirrel monkeys. J Pharmacol Exp Ther 341:424-434.

Manzke T, Guenther U, Ponimaskin EG, Haller M, Dutschmann M, Schwarzacher S, and Richter DW (2003) 5-HT4(a) receptors avert opioid-induced breathing depression without loss of analgesia. Science 301:226-229.

Marazziti D, Baroni S, Borsini F, Picchetti M, Vatteroni E, Falaschi V, and CatenaDell'Osso M (2013a) Serotonin receptors of type 6 (5-HT6): from neuroscience to clinical pharmacology. Curr Med Chem 20:371-377.

Marazziti D, Baroni S, Pirone A, Giannaccini G, Betti L, Testa G, Schmid L, Palego L Borsini F, Bordi F, et al. (2013b) Serotonin receptor of type 6 (5-HT6) in human prefrontal cortex and hippocampus post-mortem: an immunohistochemical and immunofluorescence study. Neurochem Int 62:182-188.

Marchetti E, Dumuis A, Bockaert J, Soumireu-Mourat B, and Roman FS (2000) Differential modulation of the 5-HT(4) receptor agonists and antagonist on rat learning and memory. Neuropharmacology 39:2017-2027.

Marchetti E, Jacquet M, Escoffier G, Miglioratti M, Dumuis A, Bockaert J, and Roman FS (2011) Enhancement of reference memory in aged rats by specific activation of 5-HT(4) receptors using an olfactory associative discrimination task. Brain Res 1405:49-56.

Marcoli M, Maura G, Tortarolo M, and Raiteri M (1997) Serotonin inhibition of the NMDA receptor/nitric oxide/cyclic GMP pathway in rat cerebellum: involvement of 5-hydroxytryptamine ${ }_{2 \mathrm{C}}$ receptors. $J$ Neurochem 69:427-430.

Marcos E, Adnot S, Pham MH, Nosjean A, Raffestin B, Hamon M, and Eddahibi S (2003) Serotonin transporter inhibitors protect against hypoxic pulmonary hypertension. Am J Respir Crit Care Med 168:487-493.

Marek GJ (2010) Electrophysiology of serotonin receptors, in Handbook of the Behavioral Neurobiology of Serotonin (Muller CP and Jacobs B eds) pp. 163-182, Elsevier Academic Press.

Marek GJ and Aghajanian GK (1996) LSD and the phenethylamine hallucinogen DOI are potent partial agonists at 5-HT2A receptors on interneurons in rat piriform cortex. J Pharmacol Exp Ther 278:1373-1382.

Marek GJ, Carpenter LL, McDougle CJ, and Price LH (2003) Synergistic action of 5 -HT2A antagonists and selective serotonin reuptake inhibitors in neuropsychiatric disorders. Neuropsychopharmacology 28:402-412. 
Marek GJ, Martin-Ruiz R, Abo A, and Artigas F (2005) The selective 5-HT2A receptor antagonist M100907 enhances antidepressant-like behavioral effects of the SSRI fluoxetine. Neuropsychopharmacology 30:2205-2215.

Margolis KG, Stevanovic K, Li Z, Yang QM, Oravecz T, Zambrowicz B, Jhaver KG, Diacou A, and Gershon MD (2014) Pharmacological reduction of mucosal but not neuronal serotonin opposes inflammation in mouse intestine. Gut 63: 928-937.

Maricq AV, Peterson AS, Brake AJ, Myers RM, and Julius D (1991) Primary structure and functional expression of the 5HT3 receptor, a serotonin-gated ion channel. Science 254:432-437.

Marin P, Becamel C, Dumuis A, and Bockaert J (2012) 5-HT receptor-associated protein networks: new targets for drug discovery in psychiatric disorders? Curr Drug Targets 13:28-52.

Marion S, Weiner DM, and Caron MG (2004) RNA editing induces variation in desensitization and trafficking of 5-hydroxytryptamine 2c receptor isoforms. $J$ Biol Chem 279:2945-2954.

Markstein R, Hoyer D, and Engel G (1986) 5-HT1A-receptors mediate stimulation of adenylate cyclase in rat hippocampus. Naunyn Schmiedebergs Arch Pharmacol 333:335-341.

Marner L, Gillings N, Comley RA, Baaré WF, Rabiner EA, Wilson AA, Houle S, Hasselbalch SG, Svarer C, Gunn RN, et al. (2009) Kinetic modeling of 11CSB207145 binding to 5-HT4 receptors in the human brain in vivo. J Nucl Med 50: 900-908

Maroteaux L (2013) Overexpression of 5-hydroxytryptamine ${ }_{2 \mathrm{~B}}$ receptor gene in pulmonary hypertension: still a long way to understand its transcriptional regulation. Hypertension 61:e28-e29.

Maroteaux L, Ayme-Dietrich E, Aubertin-Kirch G, Banas S, Quentin E, Lawson R, and Monassier L (2017) New therapeutic opportunities for 5-HT2 receptor ligands. Pharmacol Ther 170:14-36.

Maroteaux L, Béchade C, and Roumier A (2019) Dimers of serotonin receptors: impact on ligand affinity and signaling. Biochimie 161:23-33.

Maroteaux L, Saudou F, Amlaiky N, Boschert U, Plassat JL, and Hen R (1992) Mouse 5HT1B serotonin receptor: cloning, functional expression, and localization in motor control centers. Proc Natl Acad Sci USA 89:3020-3024.

Marquis KL, Sabb AL, Logue SF, Brennan JA, Piesla MJ, Comery TA, Grauer SM, Ashby CR Jr, Nguyen HQ, Dawson LA, et al. (2007) WAY-163909 [(7bR,10aR) 1,2,3,4,8,9,10,10a-octahydro-7bH-cyclopenta-[b] [1,4]diazepino[6,7,1hi]indole]: a novel 5-hydroxytryptamine $2 \mathrm{C}$ receptor-selective agonist with preclinical antipsychotic-like activity. J Pharmacol Exp Ther 320:486-496.

Marsden CA, King MV, and Fone KC (2011) Influence of social isolation in the rat on serotonergic function and memory-relevance to models of schizophrenia and the role of 5- $\mathrm{HT}_{6}$ receptors. Neuropharmacology 61:400-407.

Martel JC, Ormière AM, Leduc N, Assié MB, Cussac D, and Newman-Tancredi A (2007) Native rat hippocampal 5-HT1A receptors show constitutive activity. Mol Pharmacol 71:638-643.

Martin CB, Hamon M, Lanfumey L, and Mongeau R (2014a) Controversies on the role of 5-HT(2C) receptors in the mechanisms of action of antidepressant drugs Neurosci Biobehav Rev 42:208-223.

Martin CB, Martin VS, Trigo JM, Chevarin C, Maldonado R, Fink LH, Cunningham KA, Hamon M, Lanfumey L, and Mongeau R (2014b) 5-HT2C receptor desensitization moderates anxiety in 5-HTT deficient mice: from behavioral to cellular evidence. Int $J$ Neuropsychopharmacol 18:pyu056.

Martin CB, Ramond F, Farrington DT, Aguiar AS Jr, Chevarin C, Berthiau AS, Caussanel S, Lanfumey L, Herrick-Davis K, Hamon M, et al. (2013) RNA splicing and editing modulation of $5-\mathrm{HT}(2 \mathrm{C})$ receptor function: relevance to anxiety and aggression in VGV mice. Mol Psychiatry 18:656-665.

Martin G (1997) Pre-clinical pharmacology of zolmitriptan (ZomigTM; formerly 311C90), a centrally and peripherally acting 5HT1B/1D agonist for migraine. Cephalalgia. 17:4-14

Martin GR (1994) Vascular receptors for 5-hydroxytryptamine: distribution, function and classification. Pharmacol Ther 62:283-324.

Martin JR, Bös M, Jenck F, Moreau J, Mutel V, Sleight A.J, Wichmann J, Andrews JS, Berendsen HHG, Broekkamp CLE, et al. (1998) 5 - $\mathrm{HT}_{2 \mathrm{C}}$ receptor agonists: pharmacological characteristics and therapeutic potential. J Pharmacol Exp Ther 286:913-924.

Martin LL, Bouchal RL, and Smith DJ (1982) Ketamine inhibits serotonin uptake in vivo. Neuropharmacology 21:113-118.

Martin LL and Smith DJ (1982) Ketamine inhibits serotonin synthesis and metabolism in vivo. Neuropharmacology 21:119-125.

Martín-Cora FJ and Pazos A (2004) Autoradiographic distribution of 5-HT7 receptors in the human brain using [3H]mesulergine: comparison to other mammalian species. Br J Pharmacol 141:92-104.

Martinez D, Hwang D, Mawlawi O, Slifstein M, Kent J, Simpson N, Parsey RV Hashimoto T, Huang Y, Shinn A, et al. (2001) Differential occupancy of somatodendritic and postsynaptic $5 \mathrm{HT}(1 \mathrm{~A})$ receptors by pindolol: a dose-occupancy study with [11C]WAY 100635 and positron emission tomography in humans. Neuropsychopharmacology 24:209-229.

Martínez-García E, Leopoldo M, Lacivita E, and Terrón JA (2011) Increase of capsaicin-induced trigeminal Fos-like immunoreactivity by 5 -HT(7) receptors. Headache 51:1511-1519.

Martí-Solano M, Iglesias A, de Fabritiis G, Sanz F, Brea J, Loza MI, Pastor M, and Selent J (2015) Detection of new biased agonists for the serotonin 5-HT2A receptor: modeling and experimental validation. Mol Pharmacol 87:740-746.

Martí-Solano M, Sanz F, Pastor M, and Selent J (2014) A dynamic view of molecular switch behavior at serotonin receptors: implications for functional selectivity. PLoS One 9:e109312.

Masaki C, Sharpley AL, Cooper CM, Godlewska BR, Singh N, Vasudevan SR, Harmer CJ, Churchill GC, Sharp T, Rogers RD, et al. (2016) Effects of the potential lithium-mimetic, ebselen, on impulsivity and emotional processing. Psychopharmacology (Berl) 233:2655-2661.
Masellis M, Basile VS, Meltzer HY, Lieberman JA, Sevy S, Goldman DA, Hamblin MW, Macciardi FM, and Kennedy JL (2001) Lack of association between the T-- $>$ C 267 serotonin 5-HT6 receptor gene (HTR6) polymorphism and prediction of response to clozapine in schizophrenia. Schizophr Res 47:49-58.

Masri B, Salahpour A, Didriksen M, Ghisi V, Beaulieu JM, Gainetdinov RR, and Caron MG (2008) Antagonism of dopamine D2 receptor/beta-arrestin 2 interaction is a common property of clinically effective antipsychotics. Proc Natl Acad Sci USA 105:13656-13661.

Massoura AN, Dover TJ, Newman AS, and Barnes NM (2011) The identification of $N$ glycosylated residues of the human 5-HT3B receptor subunit: importance for cell membrane expression. $J$ Neurochem 116:975-983

Mastropasqua L, Ciancaglini M, Carpineto P, and Costagliola C (1997) Ocular hypotensive effect of topical ketanserin in timolol users. Graefes Arch Clin Exp Ophthalmol 235:130-135.

Mathes BM, Hudziak KJ, Schaus JM, Xu YC, Nelson DL, Wainscott DB, Nutter SE Gough WH, Branchek TA, Zgombick JM, et al. (2004) Substituted furo[3,2-b]pyridines: novel bioisosteres of $5-\mathrm{HT}{ }_{1 \mathrm{~F}}$ receptor agonists. Bioorg Med Chem Lett 14:167-170.

Matsuda A, Suzuki Y, Honda G, Muramatsu S, Matsuzaki O, Nagano Y, Doi T, Shimotohno K, Harada T, Nishida E, et al. (2003) Large-scale identification and characterization of human genes that activate NF-kappaB and MAPK signaling pathways. Oncogene 22:3307-3318.

Matsumura N, Mandai M, Miyanishi M, Fukuhara K, Baba T, Higuchi T, Kariya M, Takakura K, and Fujii S (2006) Oncogenic property of acrogranin in human uterine leiomyosarcoma: direct evidence of genetic contribution in in vivo tumorigenesis. Clin Cancer Res 12:1402-1411.

Matsuyoshi H, Kuniyasu H, Okumura M, Misawa H, Katsui R, Zhang GX, Obata K, and Takaki M (2010) A 5-HT(4)-receptor activation-induced neural plasticity enhances in vivo reconstructs of enteric nerve circuit insult. Neurogastroentero Motil 22:806-813, e226.

Matthes H, Boschert U, Amlaiky N, Grailhe R, Plassat JL, Muscatelli F, Mattei MG, and Hen R (1993) Mouse 5-hydroxytryptamine5A and 5-hydroxytryptamine5B receptors define a new family of serotonin receptors: cloning, functional expression, and chromosomal localization. Mol Pharmacol 43:313-319.

Matthys A, Van Craenenbroeck K, Lintermans B, Haegeman G, and Vanhoenacker P (2012) RhoBTB3 interacts with the 5-HT7a receptor and inhibits its proteasomal degradation. Cell Signal 24:1053-1063.

Mattsson C, Sonesson C, Sandahl A, Greiner HE, Gassen M, Plaschke J, Leibrock J, and Bottcher H (2005) 2-Alkyl-3-(1,2,3,6-tetrahydropyridin-4-yl)-1H-indoles as novel 5-HT6 receptor agonists. Bioorganic \& medicinal chemistry letters 15: $4230-4234$

Mauler F and Horváth E (2005) Neuroprotective efficacy of repinotan HCl, a 5-HT1A receptor agonist, in animal models of stroke and traumatic brain injury. $J$ Cereb Blood Flow Metab 25:451-459.

Maura G and Raiteri M (1986) Cholinergic terminals in rat hippocampus possess 5-HT1B receptors mediating inhibition of acetylcholine release. Eur J Pharmacol 129:333-337.

Maurel S, De Vry J, and Schreiber R (1999) 5-HT receptor ligands differentially affect operant oral self-administration of ethanol in the rat. Eur $J$ Pharmacol $\mathbf{3 7 0}$ 217-223

Maurice P, Guillaume JL, Benleulmi-Chaachoua A, Daulat AM, Kamal M, and Jockers R (2011) GPCR-interacting proteins, major players of GPCR function. Adv Pharmacol 62:349-380.

Mawe GM and Hoffman JM (2013) Serotonin signalling in the gut-functions, dysfunctions and therapeutic targets. Nat Rev Gastroenterol Hepatol 10:473-486.

May JA, McLaughlin MA, Sharif NA, Hellberg MR, and Dean TR (2003) Evaluation of the ocular hypotensive response of serotonin 5-HT1A and 5-HT2 receptor ligands in conscious ocular hypertensive cynomolgus monkeys. $J$ Pharmacol Exp Ther 306: 301-309.

May JA, Sharif NA, McLaughlin MA, Chen H-H, Severns BS, Kelly CR, Holt WF, Young R, Glennon RA, Hellberg MR, and Dean TR (2015) Ocular hypotensive response in nonhuman primates of (8R)-1-[(2S)-2-Aminopropyl]-8,9-dihydro-7Hpyrano[2,3-g]indazol-8-ol a Selective 5-HT2 receptor agonist. $J$ Med Chem 58 $8818-8833$

Mayorga AJ, Dalvi A, Page ME, Zimov-Levinson S, Hen R, and Lucki I (2001) Antidepressant-like behavioral effects in 5-hydroxytryptamine(1A) and 5-hydroxytryptamine(1B) receptor mutant mice. J Pharmacol Exp Ther 298: 1101-1107.

McAllister G, Charlesworth A, Snodin C, Beer MS, Noble AJ, Middlemiss DN, Iversen LL, and Whiting $\mathrm{P}$ (1992) Molecular cloning of a serotonin receptor from human brain (5HT1E): a fifth 5HT1-like subtype. Proc Natl Acad Sci USA 89: $5517-5521$

McCall RB (1997) Trigeminal ganglion elicited increases in nucleus trigeminal caudalis blood flow: a novel migraine model. Brain Res 775:189-192.

McCall RB, Huff R, Chio CL, TenBrink R, Bergh CL, Ennis MD, Ghazal NB, Hoffman RL, Meisheri K, Higdon NR, et al. (2002) Preclinical studies characterizing the anti-migraine and cardiovascular effects of the selective 5-HT1D receptor agonist PNU-142633. Cephalalgia 22:799-806.

McCall RB, Patel BN, and Harris LT (1987) Effects of serotonin1 and serotonin2 receptor agonists and antagonists on blood pressure, heart rate and sympathetic nerve activity. J Pharmacol Exp Ther 242:1152-1159.

McCormick DA and Wang Z (1991) Serotonin and noradrenaline excite GABAergic neurones of the guinea-pig and cat nucleus reticularis thalami. $J$ Physiol 442: $235-255$.

McCorvy JD and Roth BL (2015) Structure and function of serotonin G proteincoupled receptors. Pharmacol Ther 150:129-142.

McCorvy JD, Wacker D, Wang S, Agegnehu B, Liu J, Lansu K, Tribo AR, Olsen RHJ, Che T, Jin J, et al. (2018) Structural determinants of $5-\mathrm{HT}_{2 \mathrm{~B}}$ receptor activation and biased agonism. Nat Struct Mol Biol 25:787-796. 
McCreary AC, Glennon JC, Ashby CR Jr, Meltzer HY, Li Z, Reinders JH, Hesselink MB, Long SK, Herremans AH, van Stuivenberg H, et al. (2007) SLV313 (1-(2,3dihydro-benzo[1,4]dioxin-5-yl)-4- [5-(4-fluoro-phenyl)-pyridin-3-ylmethyl]-piperazine monohydrochloride): a novel dopamine D2 receptor antagonist and 5-HT1A receptor agonist potential antipsychotic drug. Neuropsychopharmacology 32: $78-94$.

McCreary AC and Newman-Tancredi A (2015) Serotonin 5-HT1A receptors and antipsychotics - an update in light of new concepts and drugs. Curr Pharm Des 21: 3725-3731.

McDevitt RA and Neumaier JF (2011) Regulation of dorsal raphe nucleus function by serotonin autoreceptors: a behavioral perspective. $J$ Chem Neuroanat 41:234-246

McDougle CJ, Naylor ST, Cohen DJ, Aghajanian GK, Heninger GR, and Price LH (1996) Effects of tryptophan depletion in drug-free adults with autistic disorder. Arch Gen Psychiatry 53:993-1000.

McDuffie JE, Coaxum SD, and Maleque MA (1999) 5-hydroxytryptamine evokes endothelial nitric oxide synthase activation in bovine aortic endothelial cell cultures. Proc Soc Exp Biol Med 221:386-390.

McGrew L, Chang MS, and Sanders-Bush E (2002) Phospholipase D activation by endogenous 5-hydroxytryptamine $2 \mathrm{C}$ receptors is mediated by Galpha13 and pertussis toxin-insensitive Gbetagamma subunits. Mol Pharmacol 62:1339-1343.

McGrew L, Price RD, Hackler E, Chang MS, and Sanders-Bush E (2004) RNA editing of the human serotonin 5-HT2C receptor disrupts transactivation of the small G-protein RhoA. Mol Pharmacol 65:252-256.

McKenzie C, Alapati VR, MacDonald A, and Shaw AM (2010) Mechanisms involved in the regulation of bovine pulmonary vascular tone by the $5-\mathrm{HT}_{1 \mathrm{~B}}$ receptor. $\mathrm{Br} J$ Pharmacol 159:188-200.

McKinnell RM, Armstrong SR, Beattie DT, Choi SK, Fatheree PR, Gendron RA, Goldblum A, Humphrey PP, Long DD, Marquess DG, et al. (2009) A multivalent approach to the design and discovery of orally efficacious 5-HT4 receptor agonists. J Med Chem 52:5330-5343.

McKinnell RM, Armstrong SR, Beattie DT, Fatheree PR, Long DD, Marquess DG, Shaw JP, and Vickery RG (2013) Discovery of TD-8954, a clinical stage 5-HT(4) receptor agonist with gastrointestinal prokinetic properties. Bioorg Med Chem Lett 23:4210-4215.

McKinney J, Knappskog PM, and Haavik J (2005) Different properties of the central and peripheral forms of human tryptophan hydroxylase. J Neurochem 92:311-320.

McLean PG, Coupar IM, and Molenaar P (1995) A comparative study of functional 5 -HT4 receptors in human colon, rat oesophagus and rat ileum. Br J Pharmacol 115:47-56.

McLean SL, Beck JP, Woolley ML, and Neill JC (2008) A preliminary investigation into the effects of antipsychotics on sub-chronic phencyclidine-induced deficits in attentional set-shifting in female rats. Behav Brain Res 189:152-158.

McLean SL, Idris NF, Woolley ML, and Neill JC (2009a) D(1)-like receptor activation improves PCP-induced cognitive deficits in animal models: implications for mechanisms of improved cognitive function in schizophrenia. Eur Neuropsychopharmacol 19:440-450.

McLean SL, Woolley ML, Thomas D, and Neill JC (2009b) Role of 5-HT receptor mechanisms in sub-chronic PCP-induced reversal learning deficits in the rat. Psychopharmacology (Berl) 206:403-414.

McLoughlin DJ and Strange PG (2000) Mechanisms of agonism and inverse agonism at serotonin 5-HT1A receptors. $J$ Neurochem 74:347-357.

McKinnon NK, Reeves DC, and Akabas MH (2011) 5-HT3 receptor ion size selectivity is a property of the transmembrane channel, not the cytoplasmic vestibule portals. $J$ Gen Physiol 138:453-466.

McKinsey TA and Olson EN (2005) Toward transcriptional therapies for the failing heart: chemical screens to modulate genes. J Clin Invest 115:538-546.

McKune CM and Watts SW (2001) Characterization of the serotonin receptor mediating contraction in the mouse thoracic aorta and signal pathway coupling. $J$ Pharmacol Exp Ther 297:88-95.

Meffre J, Chaumont-Dubel S, Mannoury la Cour C, Loiseau F, Watson DJ, Dekeyne A, Séveno M, Rivet JM, Gaven F, Déléris P, et al. (2012) 5-HT(6) receptor recruitment of mTOR as a mechanism for perturbed cognition in schizophrenia EMBO Mol Med 4:1043-1056.

Meller E, Chalfin M, and Bohmaker K (1992) Serotonin 5-HT1A receptor-mediated hypothermia in mice: absence of spare receptors and rapid induction of tolerance. Pharmacol Biochem Behav 43:405-411.

Meller E, Goldstein M, and Bohmaker K (1990) Receptor reserve for 5-hydroxytryptamine1A-mediated inhibition of serotonin synthesis: possible relationship to anxiolytic properties of 5-hydroxytryptamine1A agonists. Mol Pharmacol 37:231-237.

Meltzer HY (1999) The role of serotonin in antipsychotic drug action. Neuropsychopharmacology 21:106S-115S

Meltzer HY (2012) Serotonergic mechanisms as targets for existing and novel antipsychotics. Handb Exp Pharmacol 212:87-124.

Meltzer HY and Massey BW (2011) The role of serotonin receptors in the action of atypical antipsychotic drugs. Curr Opin Pharmacol 11:59-67.

Meltzer HY and Roth BL (2013) Lorcaserin and pimavanserin: emerging selectivity of serotonin receptor subtype-targeted drugs. J Clin Invest 123:4986-4991.

Meltzer HY and Sumiyoshi T (2008) Does stimulation of 5-HT(1A) receptors improve cognition in schizophrenia? Behav Brain Res 195:98-102.

Mendelson SD and Gorzalka BB (1986) 5-HT1A receptors: differential involvement in female and male sexual behavior in the rat. Physiol Behav 37:345-351.

Mendez-David I, David DJ, Darcet F, Wu MV, Kerdine-Römer S, Gardier AM, and Hen R (2014) Rapid anxiolytic effects of a 5-HT 4 receptor agonist are mediated by a neurogenesis-independent mechanism. Neuropsychopharmacology 39:1366-1378.

Meneses A (2004) Effects of the 5-HT7 receptor antagonists SB-269970 and DR 4004 in autoshaping Pavlovian/instrumental learning task. Behav Brain Res 155:275-282.

Meneses A (2015) Serotonin, neural markers, and memory. Front Pharmacol 6:143.

Meneses A, Perez-Garcia G, Liy-Salmeron G, Flores-Galvez D, Castillo C, and Castillo E (2008) The effects of the 5-HT(6) receptor agonist EMD and the
5-HT(7) receptor agonist AS19 on memory formation. Behav Brain Res 195: $112-119$.

Meneses A, Pérez-García G, Ponce-Lopez T, and Castillo C (2011) 5-HT6 receptor memory and amnesia: behavioral pharmacology-learning and memory processes. Int Rev Neurobiol 96:27-47.

Mengod G, Cortés R, Vilaró MT, and Hoyer D (2010) Distribution of 5-HT receptors in the central nervous system, in Handbook of the Behavioral Neurobiology of Serotonin (Muller CP and Jacobs B eds) pp. 123-138, Elsevier Academic Press.

Mengod G, Nguyen H, Le H, Waeber C, Lübbert H, and Palacios JM (1990a) The distribution and cellular localization of the serotonin $1 \mathrm{C}$ receptor mRNA in the rodent brain examined by in situ hybridization histochemistry. Comparison with receptor binding distribution. Neuroscience 35:577-591.

Mengod G, Palacios JM, and Cortés R (2015) Cartography of 5-HT1A and 5-HT2A receptor subtypes in prefrontal cortex and its projections. ACS Chem Neurosci 6: 1089-1098.

Mengod G, Pompeiano M, Martínez-Mir MI, and Palacios JM (1990b) Localization of the mRNA for the 5-HT2 receptor by in situ hybridization histochemistry. Correlation with the distribution of receptor sites. Brain Res 524:139-143.

Mengod G, Vilaro MT, Cortes R, Lopez-Gimenez JF, Raurich A, and Palacios JM (2006) Chemical neuroanatomy of 5-HT receptor subtypes in the mammalian brain, in The Serotonin Receptors; From Molecular Pharmacology to Human Therapeutics (Roth BL ed) pp 319-364, Humana Press, Totowa, NJ.

Mengod G, Vilaró MT, Raurich A, López-Giménez JF, Cortés R, and Palacios JM (1996) 5-HT receptors in mammalian brain: receptor autoradiography and in situ hybridization studies of new ligands and newly identified receptors. Histochem $J$ 28:747-758.

Mercado CP, Ziu E, and Kilic F (2011) Communication between 5-HT and small GTPases. Curr Opin Pharmacol 11:23-28.

Meredith EJ, Holder MJ, Chamba A, Challa A, Drake-Lee A, Bunce CM, Drayson MT, Pilkington G, Blakely RD, Dyer MJ, et al. (2005) The serotonin transporter (SLC6A4) is present in B-cell clones of diverse malignant origin: probing a potential anti-tumor target for psychotropics. FASEB J 19:1187-1189.

Meschin P, Demion M, Cazorla O, Finan A, Thireau J, Richard S, and Lacampagne A (2015) p11 modulates calcium handling through $5-\mathrm{HT}_{4} \mathrm{R}$ pathway in rat ventricular cardiomyocytes. Cell Calcium 58:549-557.

Metwally KA, Dukat M, Egan CT, Smith C, DuPre A, Gauthier CB, Herrick-Davis K, Teitler M, and Glennon RA (1998) Spiperone: influence of spiro ring substituents on 5-HT2A serotonin receptor binding. J Med Chem 41:5084-5093.

Meunier CN, Amar M, Lanfumey L, Hamon M, and Fossier P (2013) 5-HT(1A) receptors direct the orientation of plasticity in layer 5 pyramidal neurons of the mouse prefrontal cortex. Neuropharmacology 71:37-45.

Meuser T, Pietruck C, Gabriel A, Xie GX, Lim KJ, and Pierce Palmer P (2002) 5-HT7 receptors are involved in mediating 5 -HT-induced activation of rat primary afferent neurons. Life Sci 71:2279-2289.

Meyer JH (2013) Neurochemical imaging and depressive behaviours. Curr Top Behav Neurosci 14:101-134.

Meyer JH, McMain S, Kennedy SH, Korman L, Brown GM, DaSilva JN, Wilson AA, Blak T, Eynan-Harvey R, Goulding VS, et al. (2003) Dysfunctional attitudes and 5-HT2 receptors during depression and self-harm. Am J Psychiatry 160:90-99.

Meyer M, Kircher M, Gansauge M-T, Li H, Racimo F, Mallick S, Schraiber JG, Jay F, Prüfer K, de Filippo C, et al. (2012) A high-coverage genome sequence from an archaic Denisovan individual. Science 338:222-226.

Meyerhof W, Obermüller F, Fehr S, and Richter D (1993) A novel rat serotonin receptor: primary structure, pharmacology, and expression pattern in distinct brain regions. DNA Cell Biol 12:401-409.

Mialet J, Berque-Bestel I, Sicsic S, Langlois M, Fischmeister R, and Lezoualc'h F (2000) Pharmacological characterization of the human $5-\mathrm{HT}\left({ }_{4(\mathrm{~d})}\right)$ receptor splice variant stably expressed in Chinese hamster ovary cells. $\mathrm{Br} J$ Pharmacol 131: 827-835.

Mialet-Perez J, D’Angelo R, Villeneuve C, Ordener C, Nègre-Salvayre A, Parini A, and Vindis $\mathrm{C}(2012)$ Serotonin $5-\mathrm{HT}_{2 \mathrm{~A}}$ receptor-mediated hypertrophy is negatively regulated by caveolin-3 in cardiomyoblasts and neonatal cardiomyocytes. $\mathrm{J} \mathrm{Mol}$ Cell Cardiol 52:502-510.

Michel K, Zeller F, Langer R, Nekarda H, Kruger D, Dover TJ, Brady CA, Barnes NM, and Schemann M (2005) Serotonin excites neurons in the human submucous plexus via 5- $\mathrm{HT}_{3}$ receptors. Gastroenterology 128:1317-1326.

Michineau S, Muller L, Pizard A, Alhenc-Gélas F, and Rajerison RM (2004) N-linked glycosylation of the human bradykinin B2 receptor is required for optimal cellsurface expression and coupling. Biol Chem 385:49-57.

Middlemiss DN, Blakeborough L, and Leather SR (1977) Direct evidence for an interaction of beta-adrenergic blockers with the 5-HT receptor. Nature 267:289-290.

Middlemiss DN and Fozard JR (1983) 8-Hydroxy-2-(di-n-propylamino)-tetralin discriminates between subtypes of the 5-HT1 recognition site. Eur J Pharmacol 90: 151-153.

Middlemiss DN, Göthert M, Schlicker E, Scott CM, Selkirk JV, Watson J, Gaster LM, Wyman P, Riley G, and Price GW (1999) SB-236057, a selective 5-HT1B receptor inverse agonist, blocks the 5-HT human terminal autoreceptor. Eur J Pharmacol 375:359-365.

Middlemiss DN and Tricklebank MD (1992) Centrally active 5-HT receptor agonists and antagonists. Neurosci Biobehav Rev 16:75-82.

Milatovich A, Hsieh CL, Bonaminio G, Tecott L, Julius D, and Francke U (1992) Serotonin receptor 1c gene assigned to $\mathrm{X}$ chromosome in human (band q24) and mouse (bands D-F4). Hum Mol Genet 1:681-684.

Miles TF, Dougherty DA, and Lester HA (2013) The 5-HT3AB receptor shows an stoichiometry at the plasma membrane. Biophys $J$ 105:887-898.

Mikami T, Komada T, Sugimoto H, Suzuki K, Ohmi T, Kimura N, Naganeo R, Nakata E, Nakatani K, Toga T, et al. (2009) In vitro and in vivo pharmacological characterization of PF-01354082, a novel partial agonist selective for the 5-HT(4) receptor. Eur J Pharmacol 609:5-12. 
Mikulski Z, Zaslona Z, Cakarova L, Hartmann P, Wilhelm J, Tecott LH, Lohmeyer J, and Kummer W (2010) Serotonin activates murine alveolar macrophages through 5-HT2C receptors. Am J Physiol Lung Cell Mol Physiol 299:L272-L280.

Millan MJ (1994) Serotonin and pain: evidence that activation of 5-HT1A receptors does not elicit antinociception against noxious thermal, mechanical and chemical stimuli in mice. Pain 58:45-61.

Millan MJ (2002) Descending control of pain. Prog Neurobiol 66:355-474.

Millan MJ (2003) The neurobiology and control of anxious states. Prog Neurobiol 70: 83-244.

Millan MJ (2005) Serotonin 5-HT2C receptors as a target for the treatment of depressive and anxious states: focus on novel therapeutic strategies. Therapie 60:441-460.

Millan MJ (2006) Multi-target strategies for the improved treatment of depressive states: conceptual foundations and neuronal substrates, drug discovery and therapeutic application. Pharmacol Ther 110:135-370.

Millan MJ, Brocco M, Gobert A, and Dekeyne A (2005) Anxiolytic properties of agomelatine, an antidepressant with melatoninergic and serotonergic properties: role of 5-HT2C receptor blockade. Psychopharmacology (Berl) 177:448-458.

Millan MJ, Brocco M, Veiga S, Cistarelli L, Melon C, and Gobert A (1998) WAY 100,635 enhances both the 'antidepressant' actions of duloxetine and its influence on dialysate levels of serotonin in frontal cortex. Eur J Pharmacol 341:165-167.

Millan MJ, Gobert A, Lejeune F, Dekeyne A, Newman-Tancredi A, Pasteau V, Rive J-M, and Cussac D (2003) The novel melatonin agonist agomelatine (S20098) is an antagonist at 5-hydroxytryptamine $2 \mathrm{C}$ receptors, blockade of which enhances the activity of frontocortical dopaminergic and adrenergic pathways. J Pharmacol Exp Ther 306:954-964

Millan MJ, Gobert A, Roux S, Porsolt R, Meneses A, Carli M, Di Cara B, Jaffard R, Rivet JM, Lestage P, et al. (2004) The serotonin1A receptor partial agonist S15535 [4-(benzodioxan-5-yl)1-(indan-2-yl)piperazine] enhances cholinergic transmission and cognitive function in rodents: a combined neurochemical and behavioral analysis. J Pharmacol Exp Ther 311:190-203.

Millan MJ, Hjorth S, Samanin R, Schreiber R, Jaffard R, De Ladonchamps B, Veiga S, Goument B, Peglion JL, Spedding M, et al. (1997) S 15535, a novel benzodioxopiperazine ligand of serotonin (5-HT)1A receptors: II. Modulation of hippocampal serotonin release in relation to potential anxiolytic properties. $J$ Pharmacol Exp Ther 282:148-161.

Millan MJ, Marin P, Bockaert J, and Mannoury la Cour C (2008) Signaling at G-protein-coupled serotonin receptors: recent advances and future research directions. Trends Pharmacol Sci 29:454-464.

Millan MJ, Marin P, Kamal M, Jockers R, Chanrion B, Labasque M, Bockaert J, and Mannoury la Cour C (2011) The melatonergic agonist and clinically active antidepressant, agomelatine, is a neutral antagonist at 5-HT(2C) receptors. Int $\mathrm{J}$ Neuropsychopharmacol 14:768-783.

Millan MJ, Seguin L, Honoré P, Girardon S, and Bervoets K (1996) Pro- and antinociceptive actions of serotonin (5-HT)1A agonists and antagonists in rodents: relationship to algesiometric paradigm. Behav Brain Res 73:69-77.

Millar ID, Bruce JIe, and Brown PD (2007) Ion channel diversity, channel expression and function in the choroid plexuses. Cerebrospinal Fluid Res 4:8.

Miller KJ (2005) Serotonin 5-ht2c receptor agonists: potential for the treatment of obesity. Mol Interv 5:282-291.

Miller KJ, Mariano CL, and Cruz WR (1997) Serotonin 5HT2A receptor activation inhibits inducible nitric oxide synthase activity in C6 glioma cells. Life Sci 61:1819-1827.

Miller KJ and Teitler M (1992) Quantitative autoradiography of 5-CT-sensitive (5HT1D) and 5-CT-insensitive (5-HT1E) serotonin receptors in human brain. Neurosci Lett 136:223-226.

Milligan G (2010) The role of dimerisation in the cellular trafficking of G-proteincoupled receptors. Curr Opin Pharmacol 10:23-29.

Mills A and Martin GR (1995) Autoradiographic mapping of [3H] sumatriptan binding in cat brain stem and spinal cord. Eur $J$ Pharmacol 280:175-178.

Minami M, Endo T, Hirafuji M, Hamaue N, Liu Y, Hiroshige T, Nemoto M, Saito H, and Yoshioka M (2003) Pharmacological aspects of anticancer drug-induced emesis with emphasis on serotonin release and vagal nerve activity. Pharmacol Ther $\mathbf{9 9}$ $149-165$

Miner WD and Sanger GJ (1986) Inhibition of cisplatin-induced vomiting by selective 5-hydroxytryptamine M-receptor antagonism. Br J Pharmacol 88:497-499.

Miner WD, Sanger GJ, and Turner DH (1987) Evidence that 5-hydroxytryptamine receptors mediate cytotoxic drug and radiation-evoked emesis. $\mathrm{Br} J$ Cancer $\mathbf{5 6}$ : $159-162$

Miquel MC, Doucet E, Riad M, Adrien J, Vergé D, and Hamon M (1992) Effect of the selective lesion of serotoninergic neurons on the regional distribution of 5-HT1A receptor mRNA in the rat brain. Brain Res Mol Brain Res 14:357-362.

Mitchell ES, McDevitt RA, and Neumaier JF (2009a) Adaptations in 5-HT receptor expression and function: implications for treatment of cognitive impairment in aging. $J$ Neurosci Res 87:2803-2811.

Mitchell ES and Neumaier JF (2005) 5-HT6 receptors: a novel target for cognitive enhancement. Pharmacol Ther 108:320-333.

Mitchell ES, Sexton T, and Neumaier JF (2007) Increased expression of 5-HT6 receptors in the rat dorsomedial striatum impairs instrumental learning. Neuropsychopharmacology 32:1520-1530.

Mitchell NA, Pepperell E, Ociepka S, Brown JD, Witherington J, Tuladhar B, Sanger GJ, Lee K, and Cellek S (2009b) 5-hydroxyindalpine, an agonist at the putative 5 -HT receptor, has no activity on human recombinant monoamine receptors but accelerates distension-induced peristalsis in mouse isolated colon. Neurogastroenterol Motil 21:760-768.

Mitsikostas DD, Sanchez del Rio M, Moskowitz MA, and Waeber C (1999) Both $5-\mathrm{HT}_{1 \mathrm{~B}}$ and $5-\mathrm{HT}_{1 \mathrm{~F}}$ receptors modulate $c$-fos expression within rat trigeminal nucleus caudalis. Eur J Pharmacol 369:271-277.

Mitsikostas DD, Sanchez del Rio M, and Waeber C (2002) 5-Hydroxytryptamine( $\mathrm{B} / 1 \mathrm{D})$ and 5-hydroxytryptamine ${ }_{1 \mathrm{~F}}$ receptors inhibit capsaicin-induced $c$-fos immunoreactivity within mouse trigeminal nucleus caudalis. Cephalalgia 22:384-394
Miyake A, Mochizuki S, Takemoto Y, and Akuzawa S (1995) Molecular cloning of human 5-hydroxytryptamine3 receptor: heterogeneity in distribution and function among species. Mol Pharmacol 48:407-416.

Miyata K, Yamano M, Kamato T, and Akuzawa S (1995) Effect of serotonin (5-HT) receptor antagonists YM060, YM114 (KAE-393), ondansetron and granisetron on 5- $\mathrm{HT}_{4}$ receptors and gastric emptying in rodents. Jpn J Pharmacol 69:205-214.

Miyazaki I, Asanuma M, Murakami S, Takeshima M, Torigoe N, Kitamura Y, and Miyoshi K (2013) Targeting 5-HT(1A) receptors in astrocytes to protect dopaminergic neurons in Parkinsonian models. Neurobiol Dis 59:244-256.

Miyazawa A, Fujiyoshi Y, and Unwin N (2003) Structure and gating mechanism of the acetylcholine receptor pore. Nature 423:949-955.

Mnie-Filali O, Amraei MG, Benmbarek S, Archer-Lahlou E, Peñas-Cazorla R, Vilaró MT, Boye SM, and Piñeyro G (2010) Serotonin 4 receptor (5-HT4R) internalization is isoform-specific: effects of 5-HT and RS67333 on isoforms A and B. Cell Signal 22:501-509.

Mnie-Filali O, Faure C, Lambás-Señas L, El Mansari M, Belblidia H, Gondard E, Etiévant A, Scarna H, Didier A, Berod A, et al. (2011) Pharmacological blockade of 5-HT7 receptors as a putative fast acting antidepressant strategy. Neuropsychopharmacology 36:1275-1288.

Mocci G, Jiménez-Sánchez L, Adell A, Cortés R, and Artigas F (2014) Expression of 5-HT2A receptors in prefrontal cortex pyramidal neurons projecting to nucleus accumbens. Potential relevance for atypical antipsychotic action. Neuropharmacology 79:49-58

Mochizuki S, Watanabe T, Miyake A, Saito M, and Furuichi K (2000) Cloning, expression, and characterization of ferret 5-HT(3) receptor subunit. Eur J Pharmaco 399:97-106.

Mochizuki D, Yuyama Y, Tsujita R, Komaki H, and Sagai H (1992) Cloning and expression of the human 5-HT1B-type receptor gene. Biochem Biophys Res Commun 185:517-523.

Moeller FG, Barratt ES, Dougherty DM, Schmitz JM, and Swann AC (2001a) Psychiatric aspects of impulsivity. Am J Psychiatry 158:1783-1793.

Moeller FG, Dougherty DM, Barratt ES, Schmitz JM, Swann AC, and Grabowski J (2001b) The impact of impulsivity on cocaine use and retention in treatment. $J$ Subst Abuse Treat 21:193-198.

Mogha A, Guariglia SR, Debata PR, Wen GY, and Banerjee P (2012) Serotonin 1A receptor-mediated signaling through ERK and $\mathrm{PKC} \alpha$ is essential for normal synaptogenesis in neonatal mouse hippocampus. Transl Psychiatry 2:e66.

Mohammadi MR, Hafezi P, Galeiha A, Hajiaghaee R, and Akhondzadeh S (2012) Buspirone versus methylphenidate in the treatment of children with attentiondeficit/ hyperactivity disorder: randomized double-blind study. Acta Med Iran 50: $723-728$

Mohler EG, Shacham S, Noiman S, Lezoualc'h F, Robert S, Gastineau M, Rutkowski J, Marantz Y, Dumuis A, Bockaert J, et al. (2007) VRX-03011, a novel 5-HT4 agonist, enhances memory and hippocampal acetylcholine efflux. Neuropharmacology 53: $563-573$.

Molderings GJ, Frölich D, Likungu J, and Göthert M (1996) Inhibition of noradrenaline release via presynaptic $5-\mathrm{HT}_{1 \mathrm{D}}$ alpha receptors in human atrium. Naunyn Schmiedebergs Arch Pharmacol 353:272-280.

Molderings GJ, Werner K, Likungu J, and Göthert M (1990) Inhibition of noradrenaline release from the sympathetic nerves of the human saphenous vein via presynaptic 5-HT receptors similar to the 5-HT ${ }_{1 \mathrm{D}}$ subtype. Naunyn Schmiedebergs Arch Pharmacol 342:371-377.

Molineaux SM, Jessell TM, Axel R, and Julius D (1989) 5-HT1c receptor is a prominent serotonin receptor subtype in the central nervous system. Proc Natl Acad Sci USA 86:6793-6797.

Møller TC, Wirth VF, Roberts NI, Bender J, Bach A, Jacky BP, Strømgaard K, Deussing JM, Schwartz TW, and Martinez KL (2013) PDZ domain-mediated interactions of $\mathrm{G}$ protein-coupled receptors with postsynaptic density protein 95 : quantitative characterization of interactions. PLoS One 8:e63352.

Monassier L, Laplante MA, Ayadi T, Doly S, and Maroteaux L (2010) Contribution of gene-modified mice and rats to our understanding of the cardiovascular pharmacology of serotonin. Pharmacol Ther 128:559-567.

Monassier L, Laplante MA, Jaffré F, Bousquet P, Maroteaux L, and de Champlain J (2008) Serotonin 5-HT( ${ }_{2 \mathrm{~B}}$ ) receptor blockade prevents reactive oxygen species-induced cardiac hypertrophy in mice. Hypertension 52:301-307.

Monk SA, Williams JM, Hope AG, and Barnes NM (2004) Identification and importance of N-glycosylation of the human 5-hydroxytryptamine3A receptor subunit. Biochem Pharmacol 68:1787-1796.

Monro RL, Bornstein JC, and Bertrand PP (2005) Slow excitatory post-synaptic potentials in myenteric $\mathrm{AH}$ neurons of the guinea-pig ileum are reduced by the 5-hydroxytryptamine ${ }_{7}$ receptor antagonist SB 269970. Neuroscience 134:975-986.

Monsma FJ Jr, Shen Y, Ward RP, Hamblin MW, and Sibley DR (1993) Cloning and expression of a novel serotonin receptor with high affinity for tricyclic psychotropic drugs. Mol Pharmacol 43:320-327.

Montalbano A, Corradetti R, and Mlinar B (2015) Pharmacological characterization of 5-HT1A autoreceptor-coupled GIRK channels in rat dorsal raphe 5-HT neurons. PLoS One 10:e140369.

Monti JM (2011) Serotonin control of sleep-wake behavior. Sleep Med Rev 15: $269-281$.

Monti JM and Jantos H (2006) Effects of the 5-HT(7) receptor antagonist SB-269970 microinjected into the dorsal raphe nucleus on REM sleep in the rat. Behav Brain Res 167:245-250.

Monti JM, Jantos H, and Schechter LE (2013) The effects of systemic and local microinjection into the central nervous system of the selective serotonin 5-HT6 receptor agonist WAY-208466 on sleep and wakefulness in the rat. Behav Brain Res 249:65-74.

Monti JM, Leopoldo M, and Jantos H (2008) The serotonin 5-HT7 receptor agonist LP-44 microinjected into the dorsal raphe nucleus suppresses REM sleep in the rat. Behav Brain Res 191:184-189. 
Monti JM, Leopoldo M, and Jantos H (2014) Systemic administration and local microinjection into the central nervous system of the 5-HT(7) receptor agonist LP-211 modify the sleep-wake cycle in the rat. Behav Brain Res 259:321-329.

Moore NA, Sargent BJ, Manning DD, and Guzzo PR (2013) Partial agonism of 5-HT receptors: a novel approach to the symptomatic treatment of IBS-D. ACS Chem Neurosci 4:43-47.

Moutkine I, Quentin E, Guiard BP, Maroteaux L, and Doly S (2017) Heterodimers of serotonin receptor subtypes 2 are driven by $5-\mathrm{HT}_{2 \mathrm{C}}$ protomers. J Biol Chem 292 $6352-6368$

Morabito MV, Abbas AI, Hood JL, Kesterson RA, Jacobs MM, Kump DS, Hachey DL, Roth BL, and Emeson RB (2010a) Mice with altered serotonin 2C receptor RNA editing display characteristics of Prader-Willi syndrome. Neurobiol Dis 39: $169-180$.

Morabito MV, Ulbricht RJ, O’Neil RT, Airey DC, Lu P, Zhang B, Wang L, and Emeson RB (2010b) High-throughput multiplexed transcript analysis yields enhanced resolution of 5-hydroxytryptamine $2 \mathrm{C}$ receptor mRNA editing profiles. Mol Pharmacol 77:895-902.

Morán A, Fernandez MM, Velasco C, Martin ML, and San Roman L (1998) Characterization of prejunctional 5-HT1 receptors that mediate the inhibition of pressor effects elicited by sympathetic stimulation in the pithed rat. $\mathrm{Br} J$ Pharmacol 123 : 1205-113.

Morán A, Ortiz de Urbina AV, Martín ML, García M, Rodriguez-Barbero A, Dorado F, and San Román L (2008) Characterization of contractile 5-hydroxytryptamine receptor subtypes in the in situ autoperfused kidney in the anaesthetized rat. Eur $J$ Pharmacol 592:133-137.

Moreau JL, Bos M, Jenck F, Martin JR, Mortas P, and Wichmann J (1996) 5HT2C receptor agonists exhibit antidepressant-like properties in the anhedonia model of depression in rats. Eur Neuropsychopharmacol 6:169-175.

Morecroft I, Dempsie Y, Bader M, Walther DJ, Kotnik K, Loughlin L, Nilsen M, and MacLean MR (2007) Effect of tryptophan hydroxylase 1 deficiency on the development of hypoxia-induced pulmonary hypertension. Hypertension 49:232-236.

Morecroft I, Heeley RP, Prentice HM, Kirk A, and MacLean MR (1999) 5-hydroxytryptamine receptors mediating contraction in human small muscular pulmonary arteries: importance of the 5-HT $1 \mathrm{~B}$ receptor. $\mathrm{Br} J$ Pharmacol 128:730-734.

Moreno JL, Holloway T, Umali A, Rayannavar V, Sealfon SC, and González-Maeso J (2013) Persistent effects of chronic clozapine on the cellular and behavioral responses to LSD in mice. Psychopharmacology (Berl) 225:217-226.

Moreno JL, Miranda-Azpiazu P, García-Bea A, Younkin J, Cui M, Kozlenkov A, BenEzra A, Voloudakis G, Fakira AK, Baki L, et al. (2016) Allosteric signaling through an mGlu2 and 5-HT2A heteromeric receptor complex and its potential contribution to schizophrenia. Sci Signal 9:ra5.

Moret C, Grimaldi B, Massot O, and Fillion G (2003) The role and therapeutic potential of 5-HT-moduline in psychiatry. Semin Clin Neuropsychiatry 8:137-146.

Morici JF, Ciccia L, Malleret G, Gingrich JA, Bekinschtein P, and Weisstaub NV (2015) Serotonin 2a receptor and serotonin 1a receptor interact within the medial prefrontal cortex during recognition memory in mice. Front Pharmacol 6:298.

Morilak DA, Somogyi P, Lujan-Miras R, and Ciaranello RD (1994) Neurons expressing 5-HT2 receptors in the rat brain: neurochemical identification of cell types by immunocytochemistry. Neuropsychopharmacology 11:157-166.

Morikawa H, Manzoni OJ, Crabbe JC, and Williams JT (2000) Regulation of central synaptic transmission by 5-HT(1B) auto- and heteroreceptors. Mol Pharmacol 58 $1271-1278$.

Morita H, Mochiki E, Takahashi N, Kawamura K, Watanabe A, Sutou T, Ogawa A, Yanai M, Ogata K, Fujii T, et al. (2013) Effects of 5- $\mathrm{HT}_{2 \mathrm{~B}}, 5-\mathrm{HT}_{3}$ and $5-\mathrm{HT}_{4}$ receptor antagonists on gastrointestinal motor activity in dogs. World $J$ Gastroenterol 19:6604-6612.

Mork A, Brennum LT, Fallon SM, Bisulco S, Frederiksen K, Bang-Andersen B, Lassen AB, Zhong H, Patel JG, Poon P, et al. (2009) Pharmacological profile of Lu AA21004, a novel multitarget drug for the treatment of mood disorders, in Society for Neuroscience - 39th Annual Meeting; 2009 Oct 17-21; Chicago, IL, pp. Poster 549.10 .

Mørk A, Pehrson A, Brennum LT, Nielsen SM, Zhong $\mathrm{H}$, Lassen AB, Miller S, Westrich L, Boyle NJ, Sánchez C, et al. (2012) Pharmacological effects of Lu AA21004: a novel multimodal compound for the treatment of major depressive disorder. $J$ Pharmacol Exp Ther 340:666-675.

Mos J, Olivier B, Poth M, Van Oorschot R, and Van Aken H (1993) The effects of dorsal raphe administration of eltoprazine, TFMPP and 8-OH-DPAT on resident intruder aggression in the rat. Eur J Pharmacol 238:411-415.

Moser PC, Bergis OE, Jegham S, Lochead A, Duconseille E, Terranova JP, Caille D, Berque-Bestel I, Lezoualc'h F, Fischmeister R, et al. (2002) SL65.0155, a novel 5-hydroxytryptamine(4) receptor partial agonist with potent cognition-enhancing properties. J Pharmacol Exp Ther 302:731-741.

Mota A, Bento A, Peñalva A, Pombo M, and Dieguez C (1995) Role of the serotonin receptor subtype 5-HT1D on basal and stimulated growth hormone secretion. $J$ Clin Endocrinol Metab 80:1973-1977.

Mounsey I, Brady KA, Carroll J, Fisher R, and Middlemiss DN (1982) K+-evoked $[3 \mathrm{H}]-5-\mathrm{HT}$ release from rat frontal cortex slices: the effect of 5-HT agonists and antagonists. Biochem Pharmacol 31:49-53.

Movahedi H and Purdy RE (1998) Pharmacological characterization of the "silent" 5- $\mathrm{HT}_{1 \mathrm{~B}}$-like receptors of rabbit ear artery. Ann N Y Acad Sci 861:258.

Moya PR, Berg KA, Gutiérrez-Hernandez MA, Sáez-Briones P, Reyes-Parada M, Cassels BK, and Clarke WP (2007) Functional selectivity of hallucinogenic phenethylamine and phenylisopropylamine derivatives at human 5-hydroxytryptamine (5-HT)2A and 5-HT2C receptors. J Pharmacol Exp Ther 321:1054-1061.

Moya PR, Fox MA, Jensen CL, Laporte JL, French HT, Wendland JR, and Murphy DL (2011) Altered 5-HT2C receptor agonist-induced responses and 5-HT2C receptor RNA editing in the amygdala of serotonin transporter knockout mice. BMC Pharmacol 11:3.

Mujakovic S, ter Linde JJ, de Wit NJ, van Marrewijk CJ, Fransen GA, Onland-Moret NC, Laheij RJ, Muris JW, Grobbee DE, Samsom M, et al. (2011) Serotonin receptor
3A polymorphism c. $-42 \mathrm{C}>\mathrm{T}$ is associated with severe dyspepsia. BMC Med Genet 12:140

Müller CP and Carey RJ (2006) Intracellular 5-HT 2C-receptor dephosphorylation: a new target for treating drug addiction. Trends Pharmacol Sci 27:455-458.

Müller CP and Homberg JR (2015) The role of serotonin in drug use and addiction. Behav Brain Res 277:146-192.

Müller MJ, Rossbach W, Mann K, Röschke J, Müller-Siecheneder F, Blümler M, Wetzel H, Russ H, Dittmann RW, and Benkert O (2004) Subchronic effects of olanzapine on sleep EEG in schizophrenic patients with predominantly negative symptoms. Pharmacopsychiatry 37:157-162.

Müller T, Dürk T, Blumenthal B, Grimm M, Cicko S, Panther E, Sorichter S, Herouy Y, Di Virgilio F, Ferrari D, et al. (2009) 5-hydroxytryptamine modulates migration, cytokine and chemokine release and T-cell priming capacity of dendritic cells in vitro and in vivo. PLoS One 4:e6453.

Munn DH and Mellor AL (2013) Indoleamine 2,3 dioxygenase and metabolic control of immune responses. Trends Immunol 34:137-143.

Muñoz A, Carlsson T, Tronci E, Kirik D, Björklund A, and Carta M (2009) Serotonin neuron-dependent and -independent reduction of dyskinesia by 5-HT1A and 5-HT1B receptor agonists in the rat Parkinson model. Exp Neurol 219:298-307.

Muñoz-Islas E, Gupta L, Jimenez-Mena LR, Lozano-Cuenca J, Sanchez-Lopez A, Centurion D, Mehrotra S, MaassenvVanDenBrink A, and Villalón CM (2006) Donitriptan, but not sumatriptan, inhibits capsaicin-induced canine external carotid vasodilatation via 5-HT1B rather than 5-HT1D receptors. $\mathrm{Br} J$ Pharmacol 149:82-91.

Muñoz-Islas E, Lozano-Cuenca J, González-Hernández A, Ramirez-Rosas MB, Sanchez-Lopez A, Centurion D, Maassenvandenbrink A, and Villalón CM (2009) Spinal sumatriptan inhibits capsaicin-induced canine external carotid vasodilatation via 5-HT1B rather than 5-HT1D receptors. Eur J Pharmacol 615:133-138.

Muñoz-Islas E, Vidal-Cantú GC, Bravo-Hernández M, Cervantes-Durán C, Quiñonez-Bastidas GN, Pineda-Farias JB, Barragán-Iglesias P, and Granados-Soto V 2014) Spinal 5- $\mathrm{HT}_{5} \mathrm{~A}$ receptors mediate 5-HT-induced antinociception in several pain models in rats. Pharmacol Biochem Behav 120:25-32.

Murotani T, Ishizuka T, Isogawa Y, Karashima M, and Yamatodani A (2011) Possible involvement of serotonin 5-HT2 receptor in the regulation of feeding behavior through the histaminergic system. Neuropharmacology 61:228-233.

Murray KC, Stephens MJ, Ballou EW, Heckman CJ, and Bennett DJ (2011) Motoneuron excitability and muscle spasms are regulated by $5-\mathrm{HT}_{2 \mathrm{~B}}$ and 5 -HT2C receptor activity. J Neurophysiol 105:731-748.

Mystakidou K, Befon S, Liossi C, and Vlachos L (1998) Comparison of the efficacy and safety of tropisetron, metoclopramide, and chlorpromazine in the treatment of emesis associated with far advanced cancer. Cancer 83:1214-1223.

Nagai F, Nonaka R, and Satoh Hisashi Kamimura K (2007) The effects of nonmedically used psychoactive drugs on monoamine neurotransmission in rat brain. Eur J Pharmacol 559:132-137.

Nagakura Y, Kamato T, Nishida A, Ito H, Yamano M, and Miyata K (1996) Characterization of 5-hydroxytryptamine (5-HT) receptor subtypes influencing colonic motility in conscious dogs. Naunyn Schmiedebergs Arch Pharmacol 353:489-498.

Nagakura Y, Kontoh A, Tokita K, Tomoi M, Shimomura K, and Kadowaki M (1997) Combined blockade of $5-\mathrm{HT}_{3}-$ and 5 - $\mathrm{HT}_{4}$-serotonin receptors inhibits colonic functions in conscious rats and mice. J Pharmacol Exp Ther 281:284-290.

Nakajima H, Mochiki E, Zietlow A, Ludwig K, and Takahashi T (2010) Mechanism of interdigestive migrating motor complex in conscious dogs. $J$ Gastroenterol 45: 506-514.

Nakamura K, Suzuki K, McCreary AC, and Ashby CR Jr (2006) The acute and chronic administration of (+/-)-8-hydroxy-2-(Di-n-propylamino)tetralin significantly alters the activity of spontaneously active midbrain dopamine neurons in rats: an in vivo electrophysiological study. Synapse 59:359-367.

Nakamura M, Ogasa M, Guarino J, Phillips D, Severs J, Cucchiaro J, and Loebel A (2009) Lurasidone in the treatment of acute schizophrenia: a double-blind, placebocontrolled trial. J Clin Psychiatry 70:829-836.

Nalivaiko E and Sgoifo A (2009) Central 5-HT receptors in cardiovascular contro during stress. Neurosci Biobehav Rev 33:95-106.

Napier C, Stewart M, Melrose H, Hopkins B, McHarg A, and Wallis R (1999) Characterisation of the 5 -HT receptor binding profile of eletriptan and kinetics of $[3 \mathrm{H}]$ eletriptan binding at human 5-HT1B and 5-HT1D receptors. Eur J Pharmacol 368:259-268.

Naumenko VS, Kondaurova EM, and Popova NK (2011) On the role of brain 5-HT7 receptor in the mechanism of hypothermia: comparison with hypothermia mediated via 5-HT1A and 5-HT3 receptor. Neuropharmacology 61:1360-1365.

Naumenko VS, Popova NK, Lacivita E, Leopoldo M, and Ponimaskin EG (2014) Interplay between serotonin 5-HT1A and 5-HT7 receptors in depressive disorders. CNS Neurosci Ther 20:582-590.

Nautiyal KM, Tanaka KF, Barr MM, Tritschler L, Le Dantec Y, David DJ, Gardier AM, Blanco C, Hen R, and Ahmari SE (2015) Distinct circuits underlie the effects of 5-HT1B receptors on aggression and impulsivity. Neuron 86:813-826.

Navailles $S$, De Deurwaerdère $P$, Porras $G$, and Spampinato $U$ (2004) In vivo evidence that 5-HT2C receptor antagonist but not agonist modulates cocaine-induced dopamine outflow in the rat nucleus accumbens and striatum. Neuropsychopharmacology 29:319-326.

Navailles S, Lagière M, Le Moine C, and De Deurwaerdère P (2013a) Role of 5-HT2C receptors in the enhancement of c-Fos expression induced by a 5 -HT2B/2C inverse agonist and 5-HT 2 agonists in the rat basal ganglia. Exp Brain Res 230:525-535. Navailles S, Lagiere M, Roumegous A, Polito M, Boujema MB, Cador M, Dunlop J, Chesselet MF, Millan MJ, and De Deurwaerdere P (2013b) Serotonin2C ligands exhibiting full negative and positive intrinsic activity elicit purposeless ora movements in rats: distinct effects of agonists and inverse agonists in a rat model of Parkinson's disease. Int J Neuropsychopharmacol 16:593-606.

Navailles S, Moison D, Cunningham KA, and Spampinato U (2008) Differential regulation of the mesoaccumbens dopamine circuit by serotonin $2 \mathrm{C}$ receptors in the ventral tegmental area and the nucleus accumbens: an in vivo microdialysis study with cocaine. Neuropsychopharmacology 33:237-246. 
Navarra R, Comery TA, Graf R, Rosenzweig-Lipson S, and Day M (2008) The 5-HT(2C) receptor agonist WAY-163909 decreases impulsivity in the 5-choice serial reaction time test. Behav Brain Res 188:412-415.

Neal KB and Bornstein JC (2007) Mapping 5-HT inputs to enteric neurons of the guinea-pig small intestine. Neuroscience 145:556-567.

Neal KB, Parry LJ, and Bornstein JC (2009) Strain-specific genetics, anatomy and function of enteric neural serotonergic pathways in inbred mice. J Physiol 587:567-586.

Nebigil CG, Choi DS, Dierich A, Hickel P, Le Meur M, Messaddeq N, Launay JM, and Maroteaux L (2000a) Serotonin 2B receptor is required for heart development. Proc Natl Acad Sci USA 97:9508-9513.

Nebigil CG, Etienne N, Messaddeq N, and Maroteaux L (2003a) Serotonin is a novel survival factor of cardiomyocytes: mitochondria as a target of $5-\mathrm{HT}_{2 \mathrm{~B}}$ receptor signaling. FASEB J 17:1373-1375.

Nebigil CG, Hickel P, Messaddeq N, Vonesch JL, Douchet MP, Monassier L, György K, Matz R, Andriantsitohaina R, Manivet P, et al. (2001) Ablation of serotonin 5 -HT(2B) receptors in mice leads to abnormal cardiac structure and function. Circulation 103:2973-2979.

Nebigil CG, Jaffré F, Messaddeq N, Hickel P, Monassier L, Launay JM, and Maroteaux L (2003b) Overexpression of the serotonin 5-HT2B receptor in heart leads to abnormal mitochondrial function and cardiac hypertrophy. Circulation 107:3223-3229.

Nebigil CG, Launay J-M, Hickel P, Tournois C, and Maroteaux L (2000b) 5-hydroxytryptamine ${ }_{2 \mathrm{~B}}$ receptor regulates cell-cycle progression: cross-talk with tyrosine kinase pathways. Proc Natl Acad Sci USA 97:2591-2596.

Neelakantan H, Holliday ED, Fox RG, Stutz SJ, Comer SD, Haney M, Anastasio NC Moeller FG, and Cunningham KA (2017) Lorcaserin suppresses oxycodone selfadministration and relapse vulnerability in rats. ACS Chem Neurosci 8:1065-1073.

Neisewander JL and Acosta JI (2007) Stimulation of 5-HT2C receptors attenuates cue and cocaine-primed reinstatement of cocaine-seeking behavior in rats. Behav Pharmacol 18:791-800.

Nelson AD, Camilleri M, Chirapongsathorn S, Vijayvargiya P, Valentin N, Shin A Erwin PJ, Wang Z, and Murad MH (2017) Comparison of efficacy of pharmacological treatments for chronic idiopathic constipation: a systematic review and network meta-analysis. Gut 66:1611-1622.

Nelson CS, Cone RD, Robbins LS, Allen CN, and Adelman JP (1995) Cloning and expression of a 5HT7 receptor from Xenopus laevis. Receptors Channels 3:61-70.

Nelson DL, Lucaites VL, Wainscott DB, and Glennon RA (1999) Comparisons of hallucinogenic phenylisopropylamine binding affinities at cloned human 5-HT2A -HT(2B) and 5-HT2C receptors. Naunyn Schmiedebergs Arch Pharmacol 359:1-6.

Nelson DL, Phebus LA, Johnson KW, Wainscott DB, Cohen ML, Calligaro DO, and Xu YC (2010) Preclinical pharmacological profile of the selective 5-HT $\mathrm{H}_{1 \mathrm{~F}} \mathrm{re}$ ceptor agonist lasmiditan. Cephalalgia 30:1159-1169.

Nelson RK and Frohman MA (2015) Physiological and pathophysiological roles for phospholipase D. J Lipid Res 56:2229-2237.

Nemecz Á, Prevost MS, Menny A, and Corringer P-J (2016) Emerging molecular mechanisms of signal transduction in pentameric ligand-gated ion channels Neuron 90:452-470.

Netzer P, Gaia C, Lourens ST, Reber P, Wildi S, Noelpp U, Ritter EP, Ledermann H, Lüscher D, Varga L, et al. (2002) Does intravenous ondansetron affect gastric emptying of a solid meal, gastric electrical activity or blood hormone levels in healthy volunteers? Aliment Pharmacol Ther 16:119-127.

Neumaier JF, Sexton TJ, Yracheta J, Diaz AM, and Brownfield M (2001) Localization of 5-HT(7) receptors in rat brain by immunocytochemistry, in situ hybridization, and agonist stimulated $\mathrm{cF}$ os expression. $J$ Chem Neuroanat 21:63-73.

Newman AS, Batis N, Grafton G, Caputo F, Brady CA, Lambert JJ, Peters JA Gordon J, Brain KL, Powell AD, et al. (2013) 5-Chloroindole: a potent allosteric modulator of the 5- $\mathrm{HT}_{3}$ receptor. Br J Pharmacol 169:1228-1238.

Newman-Tancredi A (2010) The importance of 5-HT1A receptor agonism in antipsychotic drug action: rationale and perspectives. Curr Opin Investig Drugs 11:802-812.

Newman-Tancredi A and Albert PR (2012) Gene polymorphism at serotonin 5-HT1A receptors: moving towards personalized medicine for psychosis and mood deficits?, in Schizophrenia Research: Recent Advances (Sumiyoshi T ed) pp. 339-360, Nova Science Publishers Inc., New York.

Newman-Tancredi A, Assié MB, Leduc N, Ormière AM, Danty N, and Cosi C (2005) Novel antipsychotics activate recombinant human and native rat serotonin 5-HT1A receptors: affinity, efficacy and potential implications for treatment of schizophrenia. Int $J$ Neuropsychopharmacol 8:341-356.

Newman-Tancredi A, Auclair A, Barret-Grévoz C, Galinier A, Barreto M, and Depoortère R (2009a) F15599, a selective 5-HT1A agonist: frontal cortex and dorsal Raphe microinjections reveal low- and high-dose forced swim test effects, in Society for Neuroscience - 39th Annual Meeting, Chicago, IL, Program number 516.2 .

Newman-Tancredi A, Chaput C, Verriele L, and Millan MJ (1996a) Clozapine is a partial agonist at cloned, human serotonin 5-HT1A receptors. Neuropharmacology 35:119-121.

Newman-Tancredi A, Chaput C, Verrièle L, and Millan MJ (1996b) S 15535 and WAY 100,635 antagonise 5-HT-stimulated [35S]GTP gamma S binding at cloned human 5-HT1A receptors. Eur J Pharmacol 307:107-111.

Newman-Tancredi A, Conte C, Chaput C, Spedding M, and Millan MJ (1997a) Inhibition of the constitutive activity of human 5-HT1A receptors by the inverse agonist, spiperone but not the neutral antagonist, WAY 100,635. Br J Pharmacol 120:737-739.

Newman-Tancredi A, Conte C, Chaput C, Verrièle L, Audinot-Bouchez V, Lochon S, Lavielle G, and Millan MJ (1997b) Agonist activity of antimigraine drugs at recombinant human 5-HT1A receptors: potential implications for prophylactic and acute therapy. Naunyn Schmiedebergs Arch Pharmacol 355:682-688.

Newman-Tancredi A, Conte C, Chaput C, Verrièle L, and Millan MJ (1997c) Agonist and inverse agonist efficacy at human recombinant serotonin 5-HT1A receptors as a function of receptor:G-protein stoichiometry. Neuropharmacology 36:451-459.
Newman-Tancredi A, Cussac D, Marini L, and Millan MJ (2002) Antibody capture assay reveals bell-shaped concentration-response isotherms for h5-HT(1A) receptormediated Galpha(i3) activation: conformational selection by high-efficacy agonists, and relationship to trafficking of receptor signaling. Mol Pharmacol 62:590-601.

Newman-Tancredi A, Gavaudan S, Conte C, Chaput C, Touzard M, Verrièle L, Audinot V, and Millan MJ (1998) Agonist and antagonist actions of antipsychotic agents at 5-HT1A receptors: a [35S]GTPgammaS binding study. Eur J Pharmacol 355:245-256.

Newman-Tancredi A, Martel JC, Assié MB, Buritova J, Lauressergues E, Cosi C, Heusler P, Bruins Slot L, Colpaert FC, Vacher B, et al. (2009b) Signal transduction and functional selectivity of F15599, a preferential post-synaptic 5-HT1A receptor agonist. Br J Pharmacol 156:338-353.

Newman-Tancredi A, Rivet JM, Cussac D, Touzard M, Chaput C, Marini L, and Millan MJ (2003) Comparison of hippocampal G protein activation by 5-HT(1A) receptor agonists and the atypical antipsychotics clozapine and S16924. Naunyn Schmiedebergs Arch Pharmacol 368:188-199.

Newton RA, Phipps SL, Flanigan TP, Newberry NR, Carey JE, Kumar C, McDonald B, Chen C, and Elliott JM (1996) Characterisation of human 5-hydroxytryptamine2A and 5-hydroxytryptamine2C receptors expressed in the human neuroblastoma cell line SH-SY5Y: comparative stimulation by hallucinogenic drugs. J Neurochem 67:2521-2531. Ni W, Geddes TJ, Priestley JR, Szasz T, Kuhn DM, and Watts SW (2008) The existence of a local 5-hydroxytryptaminergic system in peripheral arteries. $\mathrm{Br} J$ Pharmacol 154:663-674.

Ni W, Thompson JM, Northcott CA, Lookingland K, and Watts SW (2004) The serotonin transporter is present and functional in peripheral arterial smooth muscle. $J$ Cardiovasc Pharmacol 43:770-781.

Nic Dhonnchadha BA, Bourin M, and Hascoët M (2003) Anxiolytic-like effects of 5-HT2 ligands on three mouse models of anxiety. Behav Brain Res 140:203-214.

Nichols DE (2004) Hallucinogens. Pharmacol Ther 101:131-181.

Nichols DE, Sassano MF, Halberstadt AL, Klein LM, Brandt SD, Elliott SP, and Fiedler WJ (2015) N-Benzyl-5-methoxytryptamines as potent serotonin 5-HT2 receptor family agonists and comparison with a series of phenethylamine analogues. ACS Chem Neurosci 6:1165-1175.

Nicholson R, Small J, Dixon AK, Spanswick D, and Lee K (2003) Serotonin receptor mRNA expression in rat dorsal root ganglion neurons. Neurosci Lett 337:119-122.

Niebert M, Vogelgesang S, Koch UR, Bischoff A-M, Kron M, Bock N, and Manzke T (2011) Expression and function of serotonin 2A and ${ }_{2 \mathrm{~B}}$ receptors in the mammalian respiratory network. PLoS One 6:e21395

Niebert S, van Belle GJ, Vogelgesang S, Manzke T, and Niebert M (2017) The serotonin receptor subtype $5 \mathrm{~b}$ specifically interacts with serotonin receptor subtype 1A. Front Mol Neurosci 10:299.

Nielsen MD, Chan GC, Poser SW, and Storm DR (1996) Differential regulation of type I and type VIII Ca2+-stimulated adenylyl cyclases by Gi-coupled receptors in vivo. $J$ Biol Chem 271:33308-33316.

Niesler B (2011) 5-HT(3) receptors: potential of individual isoforms for personalised therapy. Curr Opin Pharmacol 11:81-86.

Niesler B, Flohr T, Nöthen MM, Fischer C, Rietschel M, Franzek E, Albus M, Propping P, and Rappold GA (2001) Association between the 5' UTR variant C178T of the serotonin receptor gene HTR3A and bipolar affective disorder. Pharmacogenetics 11:471-475.

Niesler B, Frank B, Kapeller J, and Rappold GA (2003) Cloning, physical mapping and expression analysis of the human 5-HT3 serotonin receptor-like genes HTR3C HTR3D and HTR3E. Gene 310:101-111.

Niesler B, Kapeller J, Hammer C, and Rappold G (2008) Serotonin type 3 receptor genes: HTR3A, B, C, D, E. Pharmacogenomics 9:501-504

Nikiforuk A (2012) Selective blockade of 5-HT7 receptors facilitates attentional setshifting in stressed and control rats. Behav Brain Res 226:118-123.

Nikiforuk A, Hołuj M, Kos T, and Popik P (2016) The effects of a 5-HT5A receptor antagonist in a ketamine-based rat model of cognitive dysfunction and the negative symptoms of schizophrenia. Neuropharmacology 105:351-360.

Nikiforuk A, Kos T, Fijał K, Hołuj M, Rafa D, and Popik P (2013) Effects of the selective 5-HT7 receptor antagonist SB-269970 and amisulpride on ketamine-induced schizophrenia-like deficits in rats. PLoS One 8:e66695.

Nikiforuk A and Popik P (2013) Amisulpride promotes cognitive flexibility in rats: the role of 5-HT7 receptors. Behav Brain Res 248:136-140.

Nilsson T, Longmore J, Shaw D, Olesen IJ, and Edvinsson L (1999a) Contractile 5 - $\mathrm{HT}_{1 \mathrm{~B}}$ receptors in human cerebral arteries: pharmacological characterization and localization with immunocytochemistry. Br J Pharmacol 128:1133-1140.

Nilsson T, Longmore J, Shaw D, Pantev E, Bard JA, Branchek T, and Edvinsson L (1999b) Characterisation of 5-HT receptors in human coronary arteries by molecular and pharmacological techniques. Eur J Pharmacol 372:49-56.

Nishikawa T, Tsuno NH, Shuno Y, Sasaki K, Hongo K, Okaji Y, Sunami E, Kitayama J, Takahashi K, and Nagawa H (2010) Antiangiogenic effect of a selective 5-HT receptor agonist. J Surg Res 159:696-704.

Nishio H, Morimoto Y, Hisaoka K, Nakata Y, and Watanabe T (2002) 5-HT-induced, $5-\mathrm{HT}_{3}$ receptor-mediated, and ruthenium red- and capsaicin-sensitive positive chronotropic effects in the isolated guinea pig atrium. Jpn J Pharmacol 89:242-248.

Niswender CM, Copeland SC, Herrick-Davis K, Emeson RB, and Sanders-Bush E (1999) RNA editing of the human serotonin 5-hydroxytryptamine 2C receptor silences constitutive activity. $J$ Biol Chem 274:9472-9478.

Niswender CM, Herrick-Davis K, Dilley GE, Meltzer HY, Overholser JC, Stockmeier CA, Emeson RB, and Sanders-Bush E (2001) RNA editing of the human serotonin 5-HT2C receptor. alterations in suicide and implications for serotonergic pharmacotherapy. Neuropsychopharmacology 24:478-491.

Nocito A, Dahm F, Jochum W, Jang JH, Georgiev P, Bader M, Graf R, and Clavien PA (2008) Serotonin regulates macrophage-mediated angiogenesis in a mouse model of colon cancer allografts. Cancer Res 68:5152-5158.

Nocjar C, Alex KD, Sonneborn A, Abbas AI, Roth BL, and Pehek EA (2015) Serotonin$2 \mathrm{C}$ and $-2 \mathrm{a}$ receptor co-expression on cells in the rat medial prefrontal cortex. Neuroscience 297:22-37. 
Nocjar C, Roth BL, and Pehek EA (2002) Localization of 5- $\mathrm{HT}_{2 \mathrm{~A}}$ receptors on dopamine cells in subnuclei of the midbrain A10 cell group. Neuroscience 111:163-176.

Noda M, Yasuda S, Okada M, Higashida H, Shimada A, Iwata N, Ozaki N, Nishikawa K, Shirasawa S, Uchida M, et al. (2003) Recombinant human serotonin 5A receptors stably expressed in $\mathrm{C} 6$ glioma cells couple to multiple signal transduction pathways. $J$ Neurochem 84:222-232.

Nofzinger EA, van Kammen DP, Gilbertson MW, Gurklis JA, and Peters JL (1993) Electroencephalographic sleep in clinically stable schizophrenic patients: twoweeks versus six-weeks neuroleptic-free. Biol Psychiatry 33:829-835.

Nonogaki K, Ohba Y, Sumii M, and Oka Y (2008) Serotonin systems upregulate the expression of hypothalamic NUCB2 via 5-HT2C receptors and induce anorexia via a leptin-independent pathway in mice. Biochem Biophys Res Commun 372:186-190.

North RA and Uchimura N (1989) 5-Hydroxytryptamine acts at 5-HT2 receptors to decrease potassium conductance in rat nucleus accumbens neurones. $J$ Physiol 417:1-12.

Norum JH, Hart K, and Levy FO (2003) Ras-dependent ERK activation by the human $\mathrm{G}_{\mathrm{s}}$-coupled serotonin receptors $5-\mathrm{HT}_{4(\mathrm{~b})}$ and $5-\mathrm{HT}_{7(\mathrm{a})}$. J Biol Chem 278: 3098-3104.

Norum JH, Méthi T, Mattingly RR, and Levy FO (2005) Endogenous expression and protein kinase A-dependent phosphorylation of the guanine nucleotide exchange factor Ras-GRF1 in human embryonic kidney 293 cells. FEBS $J$ 272:2304-2316.

Nowak EC, de Vries VC, Wasiuk A, Ahonen C, Bennett KA, Le Mercier I, Ha D-G, and Noelle RJ (2012) Tryptophan hydroxylase-1 regulates immune tolerance and inflammation. J Exp Med 209:2127-2135.

Nutt D (2016) Psilocybin for anxiety and depression in cancer care? Lessons from the past and prospects for the future. J Psychopharmacol 30:1163-1164.

Nys M, Kesters D, and Ulens C (2013) Structural insights into Cys-loop receptor function and ligand recognition. Biochem Pharmacol 86:1042-1053.

O'Brien CP, Childress AR, Ehrman R, and Robbins SJ (1998) Conditioning factors in drug abuse: can they explain compulsion? J Psychopharmacol 12:15-22.

O'Connell MT and Curzon G (1996) A comparison of the effects of 8-OH-DPAT pretreatment of different behavioural responses to 8-OH-DPAT. Eur J Pharmacol 312 137-143.

O'Connell PJ, Wang X, Leon-Ponte M, Griffiths C, Pingle SC, and Ahern GP (2006) A novel form of immune signaling revealed by transmission of the inflammatory mediator serotonin between dendritic cells and T cells. Blood 107:1010-1017.

Odagaki Y and Toyoshima R (2005a) 5-HT1A receptor-mediated G protein activation assessed by [35S]GTPgammaS binding in rat cerebral cortex. Eur $J$ Pharmacol 521:49-58.

Odagaki Y and Toyoshima R (2005b) Detailed pharmacological characterization of 5-HT1A-receptor-mediated [35S]GTP gamma S binding in rat hippocampal membranes. J Pharmacol Sci 98:66-76.

Odagaki Y and Toyoshima R (2007) 5-HT1A receptor agonist properties of antipsychotics determined by [35S]GTPgammaS binding in rat hippocampal membranes. Clin Exp Pharmacol Physiol 34:462-466.

Ogren SO, Eriksson TM, Elvander-Tottie E, D’Addario C, Ekström JC, Svenningsson P, Meister B, Kehr J, and Stiedl O (2008) The role of 5-HT(1A) receptors in learning and memory. Behav Brain Res 195:54-77.

Oh CK, Drescher MJ, Hatfield JS, and Drescher DG (1999) Selective expression of serotonin receptor transcripts in the mammalian cochlea and its subdivisions. Brain Res Mol Brain Res 70:135-140

O'Hara BA and Atwood WJ (2008) Interferon beta1-a and selective anti-5HT(2a) receptor antagonists inhibit infection of human glial cells by JC virus. Virus Res 132:97-103.

Ohashi-Doi K, Himaki D, Nagao K, Kawai M, Gale JD, Furness JB, and Kurebayashi $\mathrm{Y}(2010)$ A selective, high affinity $5-\mathrm{HT}_{2 \mathrm{~B}}$ receptor antagonist inhibits visceral hypersensitivity in rats. Neurogastroenterol Motil 22:e69-e76.

Ohta Y, Kosaka Y, Kishimoto N, Wang J, Smith SB, Honig G, Kim H, Gasa RM, Neubauer N, Liou A, et al. (2011) Convergence of the insulin and serotonin programs in the pancreatic $\beta$-cell. Diabetes 60:3208-3216.

Ohyashiki JH, Hamamura R, Kobayashi C, Zhang Y, and Ohyashiki K (2008) A network biology approach evaluating the anticancer effects of bortezomib identifies SPARC as a therapeutic target in adult T-cell leukemia cells. Adv Appl Bioinform Chem 1:85-98.

Okada M, Northup JK, Ozaki N, Russell JT, Linnoila M, and Goldman D (2004) Modification of human 5-HT(2C) receptor function by Cys23Ser, an abundant, naturally occurring amino-acid substitution. Mol Psychiatry 9:55-64.

Okamoto T, Barton MJ, Hennig GW, Birch GC, Grainger N, Corrigan RD, Koh SD, Sanders KM, and Smith TK (2014) Extensive projections of myenteric serotonergic neurons suggest they comprise the central processing unit in the colon. Neurogastroenterol Motil 26:556-570.

Okita K, Shiina A, Nakazato M, and Iyo M (2013) Tandospirone, a 5-HT1A partial agonist is effective in treating anorexia nervosa: a case series. Ann Gen Psychiatry 12:7.

O'Leary OF and Cryan JF (2010) The Behavioral Genetics of Serotonin: Relevance to Anxiety and Depression, $\mathrm{n}$ Handbook of the Behavioral Neurobiology of Serotonin (Muller CP and Jacobs B eds) pp. 139-154, Elsevier Academic Press.

Olanow CW, Damier P, Goetz CG, Mueller T, Nutt J, Rascol O, Serbanescu A Deckers F, and Russ H (2004) Multicenter, open-label, trial of sarizotan in Parkinson disease patients with levodopa-induced dyskinesias (the SPLENDID Study). Clin Neuropharmacol 27:58-62.

Olivier B, Chan JS, Snoeren EM, Olivier JD, Veening JG, Vinkers CH, Waldinger MD, and Oosting RS (2011) Differences in sexual behaviour in male and female rodents: role of serotonin. Curr Top Behav Neurosci 8:15-36.

Olivier B and Mos J (1992) Rodent models of aggressive behavior and serotonergic drugs. Prog Neuropsychopharmacol Biol Psychiatry 16:847-870.

Olivier B, Mos J, van Oorschot R, and Hen R (1995) Serotonin receptors and animal models of aggressive behavior. Pharmacopsychiatry 28 (Suppl 2):80-90.

Oliver KR, Kinsey AM, Wainwright A, and Sirinathsinghji DJ (2000) Localization of 5-ht(5A) receptor-like immunoreactivity in the rat brain. Brain Res 867:131-142.
Olsen MA, Nawoschik SP, Schurman BR, Schmitt HL, Burno M, Smith DL, and Schechter LE (1999) Identification of a human 5-HT6 receptor variant produced by alternative splicing. Brain Res Mol Brain Res 64:255-263.

O’Mahony SM, Bulmer DC, Coelho A-M, Fitzgerald P, Bongiovanni C, Lee K, Winchester W, Dinan TG, and Cryan JF (2010) 5- $\mathrm{HT}(2 \mathrm{~B})$ receptors modulate visceral hypersensitivity in a stress-sensitive animal model of brain-gut axis dysfunction. Neurogastroenterol Motil 22:573-578, e124.

O'Neil RT and Emeson RB (2012) Quantitative analysis of $5 \mathrm{HT}(2 \mathrm{C})$ receptor RNA editing patterns in psychiatric disorders. Neurobiol Dis 45:8-13.

O'Neill MF, Heron-Maxwell CL, and Shaw G (1999) 5-HT2 receptor antagonism reduces hyperactivity induced by amphetamine, cocaine, and MK-801 but not D1 agonist C-APB. Pharmacol Biochem Behav 63:237-243.

Onimaru H, Shamoto A, and Homma I (1998) Modulation of respiratory rhythm by 5-HT in the brainstem-spinal cord preparation from newborn rat. Pflugers Arch 435:485-494.

Onken MD, Worley LA, Tuscan MD, and Harbour JW (2010) An accurate, clinically feasible multi-gene expression assay for predicting metastasis in uveal melanoma. $J$ Mol Diagn 12:461-468.

Oosterink BJ, Korte SM, Nyakas C, Korf J, and Luiten PG (1998) Neuroprotection against N-methyl-D-aspartate-induced excitotoxicity in rat magnocellular nucleus basalis by the 5-HT1A receptor agonist 8-OH-DPAT. Eur J Pharmacol 358: 147-152.

Orban G, Bombardi C, Marino Gammazza A, Colangeli R, Pierucci M, Pomara C, Pessia M, Bucchieri F, Benigno A, Smolders I, et al. (2014) Role(s) of the 5-HT2C receptor in the development of maximal dentate activation in the hippocampus of anesthetized rats [published correction appears in CNS Neurosci Ther (2014) 20: 950]. CNS Neurosci Ther 20:651-661.

Orban G, Pierucci M, Benigno A, Pessia M, Galati S, Valentino M, Muscat R, and Di Giovanni G (2013) High dose of 8-OH-DPAT decreases maximal dentate gyrus activation and facilitates granular cell plasticity in vivo. Exp Brain Res 230:441-451.

Osredkar D and Kržan M (2009) Expression of serotonin receptor subtypes in rat brain and astrocyte cell cultures: an age and tissue-dependent process. Period Biol 111:129-135.

O'Sullivan RJ, Brown IG, and Pender MP (2008) Apneusis responding to buspirone in multiple sclerosis. Mult Scler 14:705-707.

Ou XM, Storring JM, Kushwaha N, and Albert PR (2001) Heterodimerization of mineralocorticoid and glucocorticoid receptors at a novel negative response element of the 5-HT1A receptor gene. J Biol Chem 276:14299-14307.

Ouadid H, Seguin J, Dumuis A, Bockaert J, and Nargeot J (1992) Serotonin increases calcium current in human atrial myocytes via the newly described 5-hydroxytryptamine4 receptors. Mol Pharmacol 41:346-351.

Padayatti PS, Wang L, Gupta S, Orban T, Sun W, Salom D, Jordan SR, Palczewski K, and Chance MR (2013) A hybrid structural approach to analyze ligand binding by the serotonin type 4 receptor (5-HT4). Mol Cell Proteomics 12:1259-1271.

Pai VP, Marshall AM, Hernandez LL, Buckley AR, and Horseman ND (2009) Altered serotonin physiology in human breast cancers favors paradoxical growth and cell survival. Breast Cancer Res 11:R81.

Palacios JM (2016) Serotonin receptors in brain revisited. Brain Res 1645:46-49.

Palacios JM, Markstein R, and Pazos A (1986) Serotonin-1C sites in the choroid plexus are not linked in a stimulatory or inhibitory way to adenylate cyclase. Brain Res 380:151-154.

Palacios JM, Pazos A, and Hoyer D (2017) A short history of the 5-HT 2 C receptor: from the choroid plexus to depression, obesity and addiction treatment. Psychopharmacology (Berl) 234:1395-1418.

Palacios JM, Waeber C, Bruinvels AT, and Hoyer D (1992) Direct visualization of serotonin1D receptors in the human brain using a new iodinated radioligand. Brain Res Mol Brain Res 13:175-178.

Palfreyman MG, Schmidt CJ, Sorensen SM, Dudley MW, Kehne JH, Moser P, Gittos MW, and Carr AA (1993) Electrophysiological, biochemical and behavioral evidence for $5-\mathrm{HT}_{2}$ and $5-\mathrm{HT}_{3}$ mediated control of dopaminergic function. Psychopharmacology (Berl) 112 (1 Suppl):S60-S67.

Pan $\mathrm{H}$ and Gershon MD (2000) Activation of intrinsic afferent pathways in submucosal ganglia of the guinea pig small intestine. J Neurosci 20:3295-3309.

Panicker MM, Parker I, and Miledi R (1991) Receptors of the serotonin 1C subtype expressed from cloned DNA mediate the closing of $\mathrm{K}^{+}$membrane channels encoded by brain mRNA. Proc Natl Acad Sci USA 88:2560-2562.

Panicker S, Cruz H, Arrabit C, and Slesinger PA (2002) Evidence for a centrally located gate in the pore of a serotonin-gated ion channel. J Neurosci 22:1629-1639. Papadimas GK, Tzirogiannis KN, Panoutsopoulos GI, Demonakou MD, Skaltsas SD, Hereti RI, Papadopoulou-Daifoti Z, and Mykoniatis MG (2006) Effect of serotonin receptor 2 blockage on liver regeneration after partial hepatectomy in the rat liver. Liver Int 26:352-361.

Papageorgiou A and Denef C (2007) Stimulation of growth hormone release by 5 -hydroxytryptamine (5-HT) in cultured rat anterior pituitary cell aggregates: evidence for mediation by 5 - $\mathrm{HT}_{2 \mathrm{~B}}$, 5-HT7, 5-HT1B, and ketanserin-sensitive receptors. Endocrinology 148:4509-4522.

Paquette AG and Marsit CJ (2014) The developmental basis of epigenetic regulation of HTR2A and psychiatric outcomes. $J$ Cell Biochem 115:2065-2072.

Park JH, Ryoo S, Noh HJ, Seo JM, Kang HH, Shin JS, Seo SW, and Na DL (2011a) Dual therapy with cidofovir and mirtazapine for progressive multifocal leukoencephalopathy in a sarcoidosis patient. Case Rep Neurol 3:258-262.

Park K-S, Sin P-J, Lee DH, Cha S-K, Kim M-J, Kim N-H, Baik S-K, Jeong S-W, and Kong ID (2011b) Switching-on of serotonergic calcium signaling in activated hepatic stellate cells. World J Gastroenterol 17:164-173.

Park YH, Lee KK, Kwon HJ, Ha M, Kim EJ, Yoo SJ, Paik KC, and Lim MH (2013) Association between HTR1A gene polymorphisms and attention deficit hyperactivity disorder in Korean children. Genet Test Mol Biomarkers 17:178-182.

Parker CA, Gunn RN, Rabiner EA, Slifstein M, Comley R, Salinas C, Johnson CN, Jakobsen S, Houle S, Laruelle M, et al. (2012) Radiosynthesis and characterization 
of $11 \mathrm{C}-\mathrm{GSK} 215083$ as a PET radioligand for the 5-HT6 receptor. J Nucl Med $\mathbf{5 3}$ 295-303.

Parker CA, Rabiner EI, Gunn R, Searle G, Martarello L, Comley R, Davy M, Wilson AA, Houle S, Mizrahi R, et al. (2015) Human kinetic modeling of the 5HT6 PET radioligand 11C-GSK215083 and its utility for determining occupancy at both $5 \mathrm{HT} 6$ and 5HT2A receptors by SB742457 as a potential therapeutic mechanism of action in Alzheimer disease. J Nucl Med 56:1901-1909.

Parker LL, Backstrom JR, Sanders-Bush E, and Shieh BH (2003) Agonist-induced phosphorylation of the serotonin 5-HT2C receptor regulates its interaction with multiple PDZ protein 1. J Biol Chem 278:21576-21583.

Parker RM, Barnes JM, Ge J, Barber PC, and Barnes NM (1996a) Autoradiographic distribution of $[3 \mathrm{H}]$-(S)-zacopride-labelled $5-\mathrm{HT}_{3}$ receptors in human brain. $J$ Neurol Sci 144:119-127.

Parker RM, Bentley KR, and Barnes NM (1996b) Allosteric modulation of 5-HT3 receptors: focus on alcohols and anaesthetic agents. Trends Pharmacol Sci 17: 95-99.

Parrish JC and Nichols DE (2006) Serotonin 5-HT( $\left(_{2 \mathrm{~A}}\right)$ receptor activation induces 2 -arachidonoylglycerol release through a phospholipase c-dependent mechanism. $J$ Neurochem 99:1164-1175.

Parsey RV, Olvet DM, Oquendo MA, Huang YY, Ogden RT, and Mann JJ (2006) Higher 5-HT1A receptor binding potential during a major depressive episode predicts poor treatment response: preliminary data from a naturalistic study. Neuropsychopharmacology 31:1745-1749.

Parsons LH and Justice JB Jr (1993) Perfusate serotonin increases extracellular dopamine in the nucleus accumbens as measured by in vivo microdialysis. Brain Res 606:195-199.

Parsons LH, Koob GF, and Weiss F (1996) Extracellular serotonin is decreased in the nucleus accumbens during withdrawal from cocaine self-administration. Behav Brain Res 73:225-228.

Pascual-Brazo J, Castro E, Díaz A, Valdizán EM, Pilar-Cuéllar F, Vidal R, Treceño B, and Pazos A (2012) Modulation of neuroplasticity pathways and antidepressantlike behavioural responses following the short-term ( 3 and 7 days) administration of the 5- $\mathrm{HT}_{4}$ receptor agonist RS67333. Int $J$ Neuropsychopharmacol 15:631-643.

Pasqualetti M, Ori M, Marazziti D, Castagna M, and Nardi I (1998a) Distribution of 5-HT2c and 5-ht5a receptor mRNA in human brain. Ann N Y Acad Sci 861:245.

Pasqualetti M, Ori M, Nardi I, Castagna M, Cassano GB, and Marazziti D (1998b) Distribution of the 5-HT5A serotonin receptor mRNA in the human brain. Brain Res Mol Brain Res 56:1-8.

Patel BA, Bian X, Quaiserová-Mocko V, Galligan JJ, and Swain GM (2007) In vitro continuous amperometric monitoring of 5-hydroxytryptamine release from enterochromaffin cells of the guinea pig ileum. Analyst (Lond) 132:41-47.

Paterson LM, Kornum BR, Nutt DJ, Pike VW, and Knudsen GM (2013) 5-HT radioligands for human brain imaging with PET and SPECT. Med Res Rev 33:54-111.

Patkar AA, Mannelli P, Peindl K, Hill KP, Gopalakrishnan R, and Berrettini WH (2006) Relationship of disinhibition and aggression to blunted prolactin response to meta-chlorophenylpiperazine in cocaine-dependent patients. Psychopharmacology (Berl) 185:123-132.

Pauwels PJ and Colpaert FC (2003) Ca2 + responses in Chinese hamster ovary-K1 cells demonstrate an atypical pattern of ligand-induced 5-HT1A receptor activation. J Pharmacol Exp Ther 307:608-614.

Pauwels PJ, Tardif S, Wurch T, and Colpaert FC (1997) Stimulated [35S]GTP gamma $\mathrm{S}$ binding by 5 -HT1A receptor agonists in recombinant cell lines. Modulation of apparent efficacy by G-protein activation state. Naunyn Schmiedebergs Arch Pharmacol 356:551-561.

Pazos A, Cortés R, and Palacios JM (1985) Quantitative autoradiographic mapping of serotonin receptors in the rat brain. II. Serotonin-2 receptors. Brain Res 346 231-249.

Pazos A, Hoyer D, and Palacios JM (1984a) Mesulergine, a selective serotonin-2 ligand in the rat cortex, does not label these receptors in porcine and human cortex: evidence for species differences in brain serotonin-2 receptors. Eur $J$ Pharmacol 106:531-538.

Pazos A, Hoyer D, and Palacios JM (1984b) The binding of serotonergic ligands to the porcine choroid plexus: characterization of a new type of serotonin recognition site. Eur J Pharmacol 106:539-546.

Pazos A and Palacios JM (1985) Quantitative autoradiographic mapping of serotonin receptors in the rat brain. I. Serotonin-1 receptors. Brain Res 346:205-230.

Pazos A, Probst A, and Palacios JM (1987a) Serotonin receptors in the human brainIII. Autoradiographic mapping of serotonin-1 receptors. Neuroscience 21:97-122.

Pazos A, Probst A, and Palacios JM (1987b) Serotonin receptors in the human brainIV. Autoradiographic mapping of serotonin-2 receptors. Neuroscience 21:123-139.

Pedigo NW, Yamamura HI, and Nelson DL (1981) Discrimination of multiple [3H]5hydroxytryptamine binding sites by the neuroleptic spiperone in rat brain. $J$ Neurochem 36:220-226

Pehek EA, Nocjar C, Roth BL, Byrd TA, and Mabrouk OS (2006) Evidence for the preferential involvement of 5-HT2A serotonin receptors in stress- and drug-induced dopamine release in the rat medial prefrontal cortex. Neuropsychopharmacology 31:265-277.

Pelloux Y, Dilleen R, Economidou D, Theobald D, and Everitt BJ (2012) Reduced forebrain serotonin transmission is causally involved in the development of compulsive cocaine seeking in rats. Neuropsychopharmacology 37:2505-2514.

Peñas-Cazorla R and Vilaró MT (2015) Serotonin 5-HT4 receptors and forebrain cholinergic system: receptor expression in identified cell populations. Brain Struct Funct 220:3413-3434.

Peng Y, McCorvy JD, Harpsøe K, Lansu K, Yuan S, Popov P, Qu L, Pu M, Che T, Nikolajsen LF, et al. (2018) 5-HT2C receptor structures reveal the structural basis of GPCR polypharmacology. Cell 172:719-730.e14.

Pentkowski NS, Duke FD, Weber SM, Pockros LA, Teer AP, Hamilton EC, Thiel KJ, and Neisewander JL (2010) Stimulation of medial prefrontal cortex serotonin $2 \mathrm{C}$ $(5-\mathrm{HT}(2 \mathrm{C}))$ receptors attenuates cocaine-seeking behavior. Neuropsychopharmacology 35:2037-2048.
Penumatsa K, Abualkhair S, Wei L, Warburton R, Preston I, Hill NS, Watts SW, Fanburg BL, and Toksoz D (2014) Tissue transglutaminase promotes serotonininduced AKT signaling and mitogenesis in pulmonary vascular smooth muscle cells. Cell Signal 26:2818-2825.

Penumatsa KC and Fanburg BL (2014) Transglutaminase 2-mediated serotonylation in pulmonary hypertension. Am J Physiol Lung Cell Mol Physiol 306:L309-L315.

Pereira M, Martynhak BJ, Andreatini R, and Svenningsson P (2015) 5-HT6 receptor agonism facilitates emotional learning. Front Pharmacol 6:200.

Pericić D and Svob Strac D (2007) The role of 5-HT(7) receptors in the control of seizures. Brain Res 1141:48-55.

Peroutka SJ (1985) Selective interaction of novel anxiolytics with 5-hydroxytryptamine1A receptors. Biol Psychiatry 20:971-979.

Peroutka SJ and Snyder SH (1979) Multiple serotonin receptors: differential binding of $[3 \mathrm{H}] 5$-hydroxytryptamine, $[3 \mathrm{H}]$ lysergic acid diethylamide and $[3 \mathrm{H}]$ spiroperidol. Mol Pharmacol 16:687-699.

Peroutka SJ, Switzer JA, and Hamik A (1989) Identification of 5-hydroxytryptamine1D binding sites in human brain membranes. Synapse 3:61-66.

Perwitasari DA, Wessels JA, van der Straaten RJ, Baak-Pablo RF, Mustofa M, Hakimi M, Nortier JW, Gelderblom H, and Guchelaar HJ (2011) Association of $\mathrm{ABCB} 1,5-\mathrm{HT}_{3} \mathrm{~B}$ receptor and CYP2D6 genetic polymorphisms with ondansetron and metoclopramide antiemetic response in Indonesian cancer patients treated with highly emetogenic chemotherapy. Jpn J Clin Oncol 41:1168-1176.

Pessia M, Jiang ZG, North RA, and Johnson SW (1994) Actions of 5 -hydroxytryptamine on ventral tegmental area neurons of the rat in vitro. Brain Res 654:324-330.

Peters JA, Hales TG, and Lambert JJ (2005) Molecular determinants of singlechannel conductance and ion selectivity in the Cys-loop family: insights from the 5-HT3 receptor. Trends Pharmacol Sci 26:587-594.

Peters J-U, Lübbers T, Alanine A, Kolczewski S, Blasco F, and Steward L (2008) Cyclic guanidines as dual 5-HT5A/5-HT7 receptor ligands: optimising brain penetration. Bioorg Med Chem Lett 18:262-266.

Peyron C, Petit JM, Rampon C, Jouvet M, and Luppi PH (1998) Forebrain afferents to the rat dorsal raphe nucleus demonstrated by retrograde and anterograde tracing methods. Neuroscience 82:443-468.

Phebus LA, Johnson KW, Zgombick JM, Gilbert PJ, Van Belle K, Mancuso V, Nelson DL, Calligaro DO, Kiefer AD Jr, Branchek TA, et al. (1997) Characterization of LY344864 as a pharmacological tool to study $5-\mathrm{HT}_{1 \mathrm{~F}}$ receptors: binding affinities, brain penetration and activity in the neurogenic dural inflammation model of migraine. Life Sci 61:2117-2126.

Pichon X, Wattiez AS, Becamel C, Ehrlich I, Bockaert J, Eschalier A, Marin P, and Courteix C (2010) Disrupting 5-HT(2A) receptor/PDZ protein interactions reduces hyperalgesia and enhances SSRI efficacy in neuropathic pain. Mol Ther 18:1462-1470.

Pierce PA, Xie GX, Levine JD, and Peroutka SJ (1996) 5-Hydroxytryptamine receptor subtype messenger RNAs in rat peripheral sensory and sympathetic ganglia: a polymerase chain reaction study. Neuroscience 70:553-559.

Pierce PA, Xie GX, Meuser T, and Peroutka SJ (1997) 5-Hydroxytryptamine receptor subtype messenger RNAs in human dorsal root ganglia: a polymerase chain reaction study. Neuroscience 81:813-819.

Pieretti M, Zhang FP, Fu YH, Warren ST, Oostra BA, Caskey CT, and Nelson DL (1991) Absence of expression of the FMR-1 gene in fragile X syndrome. Cell $\mathbf{6 6}$ : 817-822.

Pike VW, McCarron JA, Lammerstma AA, Hume SP, Poole K, Grasby PM, Malizia A Cliffe IA, Fletcher A, and Bench CJ (1995) First delineation of 5-HT1A receptors in human brain with PET and [11C]WAY-100635. Eur J Pharmacol 283:R1-R3.

Pimenova AA, Thathiah A, De Strooper B, and Tesseur I (2014) Regulation of amyloid precursor protein processing by serotonin signaling. PLoS One 9:e87014.

Pindon A, van Hecke G, van Gompel P, Lesage AS, Leysen JE, and Jurzak M (2002) Differences in signal transduction of two 5-HT4 receptor splice variants: compound specificity and dual coupling with Galphas- and Galphai/o-proteins. Mol Pharmacol 61:85-96.

Piñeyro G, de Montigny C, and Blier P (1995) 5-HT1D receptors regulate 5-HT release in the rat raphe nuclei. In vivo voltammetry and in vitro superfusion studies. Neuropsychopharmacology 13:249-260.

Pino R, Cerbai E, Calamai G, Alajmo F, Borgioli A, Braconi L, Cassai M, Montesi GF, and Mugelli A (1998) Effect of 5-HT4 receptor stimulation on the pacemaker current $\mathrm{I}(\mathrm{f})$ in human isolated atrial myocytes. Cardiovasc Res 40:516-522.

Pitychoutis PM, Belmer A, Moutkine I, Adrien J, and Maroteaux L (2015) Mice lacking the serotonin Htr2B receptor gene present an antipsychotic-sensitive schizophrenic-like phenotype. Neuropsychopharmacology 40:2764-2773.

Piva F, Giulietti M, Baldelli L, Nardi B, Bellantuono C, Armeni T, Saccucci F, and Principato G (2011) Bioinformatic analyses to select phenotype affecting polymorphisms in HTR2C gene. Hum Psychopharmacol 26:365-372.

Plassat JL, Amlaiky N, and Hen R (1993) Molecular cloning of a mammalian serotonin receptor that activates adenylate cyclase. Mol Pharmacol 44:229-236.

Plassat JL, Boschert U, Amlaiky N, and Hen R (1992) The mouse 5HT5 receptor reveals a remarkable heterogeneity within the $5 \mathrm{HT} 1 \mathrm{D}$ receptor family. EMBO $J$ 11:4779-4786.

Pockros LA, Pentkowski NS, Conway SM, Ullman TE, Zwick KR, and Neisewander JL (2012) 5-HT(2A) receptor blockade and 5-HT(2C) receptor activation interact to reduce cocaine hyperlocomotion and Fos protein expression in the caudate-putamen. Synapse 66:989-1001.

Politis M (2010) Dyskinesias after neural transplantation in Parkinson's disease: what do we know and what is next? BMC Med 8:80.

Polovinkin L, Hassaine G, Perot J, Neumann E, Jensen AA, Lefebvre SN, Corringer P-J, Neyton J, Chipot C, Dehez F, et al. (2018) Conformational transitions of the serotonin 5- $\mathrm{HT}_{3}$ receptor. Nature 563:275-279.

Polter AM and Li X (2010) 5-HT1A receptor-regulated signal transduction pathways in brain. Cell Signal 22:1406-1412. 
Pomfret DW, Schenck KW, Fludzinski P, and Cohen ML (1987) Interaction of 5-hydroxykynurenamine, L-kynurenine and kynuramine with multiple serotonin receptors in smooth muscle. J Pharmacol Exp Ther 241:465-471.

Pompeiano M, Palacios JM, and Mengod G (1992) Distribution and cellular localization of mRNA coding for 5-HT1A receptor in the rat brain: correlation with receptor binding. $J$ Neurosci 12:440-453.

Pompeiano M, Palacios JM, and Mengod G (1994) Distribution of the serotonin 5-HT receptor family mRNAs: comparison between $5-\mathrm{HT}_{2 \mathrm{~A}}$ and $5-\mathrm{HT}_{2 \mathrm{C}}$ receptors. Brain Res Mol Brain Res 23:163-178.

Pompili M, Serafini G, Innamorati M, Venturini P, Fusar-Poli P, Sher L, Amore M, and Girardi P (2013) Agomelatine, a novel intriguing antidepressant option enhancing neuroplasticity: a critical review. World J Biol Psychiatry 14:412-431.

Pönicke K, Gergs U, Buchwalow IB, Hauptmann S, and Neumann J (2012) On the presence of serotonin in mammalian cardiomyocytes. Mol Cell Biochem 365: 301-312.

Ponimaskin EG, Heine M, Joubert L, Sebben M, Bickmeyer U, Richter DW, and Dumuis A (2002a) The 5-hydroxytryptamine(4a) receptor is palmitoylated at two different sites, and acylation is critically involved in regulation of receptor constitutive activity. J Biol Chem 277:2534-2546.

Ponimaskin EG, Profirovic J, Vaiskunaite R, Richter DW, and Voyno-Yasenetskaya TA (2002b) 5-Hydroxytryptamine 4(a) receptor is coupled to the Galpha subunit of heterotrimeric G13 protein. J Biol Chem 277:20812-20819.

Poole DP, Xu B, Koh SL, Hunne B, Coupar IM, Irving HR, Shinjo K, and Furness JB (2006) Identification of neurons that express 5-hydroxytryptamine4 receptors in intestine. Cell Tissue Res 325:413-422.

Pooley EC, Fairburn CG, Cooper Z, Sodhi MS, Cowen PJ, and Harrison PJ (2004) A 5 -HT2C receptor promoter polymorphism (HTR2C - 759C/T) is associated with obesity in women, and with resistance to weight loss in heterozygotes. Am J Med Genet B Neuropsychiatr Genet 126B:124-127.

Popa D, Léna C, Fabre V, Prenat C, Gingrich J, Escourrou P, Hamon M, and Adrien J (2005) Contribution of 5-HT2 receptor subtypes to sleep-wakefulness and respiratory control, and functional adaptations in knock-out mice lacking 5-HT2A receptors. J Neurosci 25:11231-11238.

Popovic M, Stanojevic Z, Tosic J, Isakovic A, Paunovic V, Petricevic S, Martinovic T, Ciric D, Kravic-Stevovic T, Soskic V, et al. (2015) Neuroprotective arylpiperazine dopaminergic/serotonergic ligands suppress experimental autoimmune encephalomyelitis in rats. J Neurochem 135:125-138.

Portella MJ, de Diego-Adeliño J, Ballesteros J, Puigdemont D, Oller S, Santos B, Álvarez E, Artigas F, and Pérez V (2011) Can we really accelerate and enhance the selective serotonin reuptake inhibitor antidepressant effect? A randomized clinical trial and a meta-analysis of pindolol in nonresistant depression. J Clin Psychiatry 72:962-969.

Porter RH, Benwell KR, Lamb H, Malcolm CS, Allen NH, Revell DF, Adams DR, and Sheardown MJ (1999) Functional characterization of agonists at recombinant human 5-HT2A, 5-HT 2 B and 5-HT2C receptors in CHO-K1 cells. Br J Pharmacol 128:13-20.

Porter RH, Malcolm CS, Allen NH, Lamb H, Revell DF, and Sheardown MJ (2001) Agonist-induced functional desensitization of recombinant human 5-HT2 receptors expressed in CHO-K1 cells. Biochem Pharmacol 62:431-438.

Porvasnik SL, Germain S, Embury J, Gannon KS, Jacques V, Murray J, Byrne BJ, Shacham S, and Al-Mousily F (2010) PRX-08066, a novel 5-hydroxytryptamine receptor $2 \mathrm{~B}$ antagonist, reduces monocrotaline-induced pulmonary arterial hypertension and right ventricular hypertrophy in rats. J Pharmacol Exp Ther 334:364-372.

Potrebic S, Ahn AH, Skinner K, Fields HL, and Basbaum AI (2003) Peptidergic nociceptors of both trigeminal and dorsal root ganglia express serotonin 1D receptors: implications for the selective antimigraine action of triptans. $J$ Neurosci 23:10988-10997.

Pouzet B, Didriksen M, and Arnt J (2002) Effects of the 5-HT(7) receptor antagonist SB-258741 in animal models for schizophrenia. Pharmacol Biochem Behav 71: $655-665$.

Powell AD, Grafton G, Roberts A, Larkin S, O’Neill N, Palandri J, Otvos R, Cooper AJ, Ulens C, and Barnes NM (2016) Novel mechanism of modulation at a ligandgated ion channel; action of 5-Cl-indole at the 5-HT ${ }_{3}$ A receptor. $\mathrm{Br} J$ Pharmacol 173:3467-3479.

Pranzatelli MR (1991) Regulation of 5-HT2 receptors in rat cortex. Studies with a putative selective agonist and an antagonist. Biochem Pharmacol 42:1099-1105.

Pratt GD, Bowery NG, Kilpatrick GJ, Leslie RA, Barnes NM, Naylor RJ, Jones BJ, Nelson DR, Palacids JM, Slater P, et al. (1990) Consensus meeting agrees distribution of 5-HT3 receptors in mammalian hindbrain. Trends Pharmacol Sci 11 135-137.

Pratt WE, Blackstone K, Connolly ME, and Skelly MJ (2009) Selective serotonin receptor stimulation of the medial nucleus accumbens causes differential effects on food intake and locomotion. Behav Neurosci 123:1046-1057.

Pratt WE, Schall MA, and Choi E (2012) Selective serotonin receptor stimulation of the medial nucleus accumbens differentially affects appetitive motivation for food on a progressive ratio schedule of reinforcement. Neurosci Lett 511:84-88.

Preece MA, Dalley JW, Theobald DE, Robbins TW, and Reynolds GP (2004) Region specific changes in forebrain 5-hydroxytryptamine1A and 5-hydroxytryptamine2A receptors in isolation-reared rats: an in vitro autoradiography study. Neuroscience 123:725-732

Pregenzer JF, Alberts GL, Im WB, Slightom JL, Ennis MD, Hoffman RL, Ghazal NB, and Tenbrink RE (1999) Differential pharmacology between the guinea-pig and the gorilla 5-HT1D receptor as probed with isochromans (5-HT1D-selective ligands). Br J Pharmacol 127:468-472.

Price GW, Burton MJ, Collin LJ, Duckworth M, Gaster L, Göthert M, Jones BJ, Roberts C, Watson JM, and Middlemiss DN (1997) SB-216641 and BRL-15572compounds to pharmacologically discriminate $\mathrm{h} 5-\mathrm{HT}_{1 \mathrm{~B}}$ and $\mathrm{h} 5-\mathrm{HT}_{1 \mathrm{D}}$ receptors. Naunyn Schmiedebergs Arch Pharmacol 356:312-320.
Price KL, Lillestol RK, Ulens C, and Lummis SCR (2016) Palonosetron-5-HT $\mathrm{H}_{3}$ receptor interactions as shown by a binding protein cocrystal structure. ACS Chem Neurosci 7:1641-1646.

Price RD, Weiner DM, Chang MS, and Sanders-Bush E (2001) RNA editing of the human serotonin 5-HT2C receptor alters receptor-mediated activation of G13 protein. J Biol Chem 276:44663-44668.

Priem EK, De Maeyer JH, Vandewoestyne M, Deforce D, and Lefebvre RA (2013) Predominant mucosal expression of $5-\mathrm{HT}_{4}(+\mathrm{h})$ receptor splice variants in pig stomach and colon. World J Gastroenterol 19:3747-3760.

Prins NH, Briejer MR, Van Bergen PJ, Akkermans LM, and Schuurkes JA (1999) Evidence for $5-\mathrm{HT}_{7}$ receptors mediating relaxation of human colonic circular smooth muscle. $\mathrm{Br}$ J Pharmacol 128:849-852.

Prins NH, Shankley NP, Welsh NJ, Briejer MR, Lefebvre RA, Akkermans LMA, and Schuurkes JA (2000) An improved in vitro bioassay for the study of 5-HT(4) receptors in the human isolated large intestinal circular muscle. $\mathrm{Br} J$ Pharmacol 129:1601-1608.

Prinssen EP, Colpaert FC, and Koek W (2002) 5-HT1A receptor activation and anticataleptic effects: high-efficacy agonists maximally inhibit haloperidol-induced catalepsy. Eur J Pharmacol 453:217-221.

Prinssen EP, Koek W, Colpaert FC, and Kleven MS (2000) Repeated treatment with 8-OH-DPAT induces tolerance to its ability to produce the 5-HT1A behavioural syndrome, but not to its ability to attenuate haloperidol-induced catalepsy. Behav Pharmacol 11:299-305.

Prior A and Read NW (1993) Reduction of rectal sensitivity and post-prandial motility by granisetron, a $5 \mathrm{HT}_{3}$-receptor antagonist, in patients with irritable bowel syndrome. Aliment Pharmacol Ther 7:175-180.

Prisco S and Esposito E (1995) Differential effects of acute and chronic fluoxetine administration on the spontaneous activity of dopaminergic neurones in the ventral tegmental area. $\mathrm{Br} J$ Pharmacol 116:1923-1931.

Prisco S, Pagannone S, and Esposito E (1994) Serotonin-dopamine interaction in the rat ventral tegmental area: an electrophysiological study in vivo. J Pharmacol Exp Ther 271:83-90.

Pritchett DB, Bach AW, Wozny M, Taleb O, Dal Toso R, Shih JC, and Seeburg PH (1988) Structure and functional expression of cloned rat serotonin 5HT-2 receptor. EMBO J 7:4135-4140.

Profirovic J, Strekalova E, Urao N, Krbanjevic A, Andreeva AV, Varadarajan S, Fukai T, Hen R, Ushio-Fukai M, and Voyno-Yasenetskaya TA (2013) A nove regulator of angiogenesis in endothelial cells: 5-hydroxytriptamine 4 receptor. Angiogenesis 16:15-28.

Puig MV, Watakabe A, Ushimaru M, Yamamori T, and Kawaguchi Y (2010) Serotonin modulates fast-spiking interneuron and synchronous activity in the rat prefrontal cortex through 5-HT1A and 5-HT2A receptors. $J$ Neurosci 30: 2211-2222

Purohit A, Herrick-Davis K, and Teitler M (2003) Creation, expression, and characterization of a constitutively active mutant of the human serotonin 5-HT6 receptor. Synapse 47:218-224.

Qiu J, Fang Y, Rønnekleiv OK, and Kelly MJ (2010) Leptin excites proopiomelanocortin neurons via activation of TRPC channels. J Neurosci 30:1560-1565.

Qiu J, Xue C, Bosch MA, Murphy JG, Fan W, Rønnekleiv OK, and Kelly MJ (2007) Serotonin 5-hydroxytryptamine2C receptor signaling in hypothalamic proopiomelanocortin neurons: role in energy homeostasis in females. Mol Pharmacol 72: $885-896$

$\mathrm{Qu}$ Y, Villacreses N, Murphy DL, and Rapoport SI (2005) 5-HT2A/2C receptor signaling via phospholipase A2 and arachidonic acid is attenuated in mice lacking the serotonin reuptake transporter. Psychopharmacology (Berl) 180:12-20.

Quednow BB, Treyer V, Hasler F, Dörig N, Wyss MT, Burger C, Rentsch KM, Westera G, Schubiger PA, Buck A, and Vollenweider FX (2012) Assessment of serotonin release capacity in the human brain using dexfenfluramine challenge and $\left[{ }^{18} \mathrm{~F}\right]$ altanserin positron emission tomography. Neuroimage 59:3922-3932

Quesseveur G, David DJ, Gaillard MC, Pla P, Wu MV, Nguyen HT, Nicolas V, Auregan G, David I, Dranovsky A, et al. (2013) BDNF overexpression in mouse hippocampal astrocytes promotes local neurogenesis and elicits anxiolytic-like activities. Transl Psychiatry 3:e253.

Quick MW, Simon MI, Davidson N, Lester HA, and Aragay AM (1994) Differential coupling of $\mathrm{G}$ protein alpha subunits to seven-helix receptors expressed in Xenopus oocytes. J Biol Chem 269:30164-30172.

Quiedeville A, Boulouard M, Hamidouche K, Da Silva Costa-Aze V, Nee G, Rochais C Dallemagne P, Fabis F, Freret T, and Bouet V (2015) Chronic activation of 5-HT4 receptors or blockade of 5-HT6 receptors improve memory performances. Behav Brain Res 293:10-17.

Quinn JC, Johnson-Farley NN, Yoon J, and Cowen DS (2002) Activation of extracellular-regulated kinase by 5-hydroxytryptamine $(2 \mathrm{~A})$ receptors in PC12 cells is protein kinase $\mathrm{C}$-independent and requires calmodulin and tyrosine kinases. $J$ Pharmacol Exp Ther 303:746-752.

Quirk PL, Rao S, Roth BL, and Siegel RE (2004) Three putative N-glycosylation sites within the murine 5-HT3A receptor sequence affect plasma membrane targeting, ligand binding, and calcium influx in heterologous mammalian cells. $J$ Neurosci Res 77:498-506.

Qvigstad E, Brattelid T, Sjaastad I, Andressen KW, Krobert KA, Birkeland JA Sejersted OM, Kaumann AJ, Skomedal T, Osnes JB, et al. (2005a) Appearance of a ventricular $5-\mathrm{HT}_{4}$ receptor-mediated inotropic response to serotonin in heart failure. Cardiovasc Res 65:869-878.

Qvigstad E, Brattelid T, Sjaastad I, Molenaar P, Birkeland JA, Andressen KW, Krobert KA, Sejersted OM, Skomedal T, Osnes J-B, et al. (2005b) Rationale for treatment of heart failure by blockade of ventricular serotonin receptors appearing in heart failure, in Proceedings of the 25th European Section Meeting, International Society for Heart Research; June 21-25; Tromso, Norway. pp 7-12, Medimond International Proceedings, Bologna, Italy.

Qvigstad E, Sjaastad I, Brattelid T, Nunn C, Swift F, Birkeland JA, Krobert KA, Andersen GØ, Sejersted OM, Osnes JB, et al. (2005c) Dual serotonergic regulation 
of ventricular contractile force through $5-\mathrm{HT}_{2 \mathrm{~A}}$ and $5-\mathrm{HT}_{4}$ receptors induced in the acute failing heart. Circ Res 97:268-276.

Radja F, Laporte AM, Daval G, Vergé D, Gozlan H, and Hamon M (1991) Autoradiography of serotonin receptor subtypes in the central nervous system. Neurochem Int 18:1-15.

Rahme MM, Cotter B, Leistad E, Wadhwa MK, Mohabir R, Ford AP, Eglen RM, and Feld GK (1999) Electrophysiological and antiarrhythmic effects of the atrial selective 5-HT(4) receptor antagonist RS-100302 in experimental atrial flutter and fibrillation. Circulation 100:2010-2017.

Rajagopal L, Massey BW, Michael E, and Meltzer HY (2016) Serotonin (5-HT)1A receptor agonism and 5-HT7 receptor antagonism ameliorate the subchronic phencyclidine-induced deficit in executive functioning in mice. Psychopharmacology (Berl) 233:649-660.

Ramadan NM and Buchanan TM (2006) New and future migraine therapy. Pharmacol Ther 112:199-212.

Ramadan NM, Skljarevski V, Phebus LA, and Johnson KW (2003) 5-HT 1 F receptor agonists in acute migraine treatment: a hypothesis. Cephalalgia 23 776-785.

Ramage AG (1990) Influence of 5-HT1A receptor agonists on sympathetic and parasympathetic nerve activity. J Cardiovasc Pharmcol 15 (Suppl 7):S75-S85.

Ramage AG, Clement ME, and McCall RB (1992) 8-OH-DPAT-induced inhibition of renal sympathetic nerve activity and serotonin neuronal firing. Eur $J$ Pharmaco 219:165-167.

Ramage AG and Villalón CM (2008) 5-hydroxytryptamine and cardiovascular regulation. Trends Pharmacol Sci 29:472-481.

Rammes G, Rupprecht R, Ferrari U, Zieglgänsberger W, and Parsons CG (2001) The N-methyl-D-aspartate receptor channel blockers memantine, MRZ 2/579 and other amino-alkyl-cyclohexanes antagonise 5-HT(3) receptor currents in cultured HEK 293 and N1E-115 cell systems in a non-competitive manner. Neurosci Lett 306 $81-84$

Ramos AJ, Rubio MD, Defagot C, Hischberg L, Villar MJ, and Brusco A (2004) The $5 \mathrm{HT} 1 \mathrm{~A}$ receptor agonist, 8-OH-DPAT, protects neurons and reduces astroglial reaction after ischemic damage caused by cortical devascularization. Brain Res 1030 201-220.

Rapport MM, Green AA, and Page IH (1947) Purification of the substance which is responsible for the vasoconstrictor activity of serum. Fed Proc 6:184

Rauser L, Savage JE, Meltzer HY, and Roth BL (2001) Inverse agonist actions of typical and atypical antipsychotic drugs at the human 5-hydroxytryptamine $(2 \mathrm{C})$ receptor. J Pharmacol Exp Ther 299:83-89.

Raybould HE, Glatzle J, Robin C, Meyer JH, Phan T, Wong H, and Sternini C (2003) Expression of 5- $\mathrm{HT}_{3}$ receptors by extrinsic duodenal afferents contribute to intestinal inhibition of gastric emptying. Am J Physiol Gastrointest Liver Physiol 284:G367-G372.

Raymond JR, Kim J, Beach RE, and Tisher CC (1993) Immunohistochemical mapping of cellular and subcellular distribution of 5-HT1A receptors in rat and human kidneys. Am J Physiol 264:F9-F19.

Raymond JR, Mukhin YV, Gelasco A, Turner J, Collinsworth G, Gettys TW, Grewal JS, and Garnovskaya MN (2001) Multiplicity of mechanisms of serotonin receptor signal transduction. Pharmacol Ther 92:179-212.

Raymond JR, Mukhin YV, Gettys TW, and Garnovskaya MN (1999) The recombinant 5-HT1A receptor: G protein coupling and signalling pathways. $\mathrm{Br} J$ Pharmacol 127:1751-1764.

Raymond JR, Turner JH, Gelasco AK, Ayiku HB, Coaxum SD, Arthur JM, and Garnovskaya MN (2006) 5-HT receptor signal transduction pathways, in The Serotonin Receptors ( Roth B ed) Humana Press, Toyota, NJ.

Razzaque Z, Heald MA, Pickard JD, Maskell L, Beer MS, Hill RG, and Longmore J (1999) Vasoconstriction in human isolated middle meningeal arteries: determining the contribution of 5- $\mathrm{HT}_{1 \mathrm{~B}^{-}}$and $5-\mathrm{HT}_{1 \mathrm{~F}}$-receptor activation. $\mathrm{Br} \mathrm{J}$ Clin Pharmacol 47:75-82.

Rees S, den Daas I, Foord S, Goodson S, Bull D, Kilpatrick G, and Lee M (1994) Cloning and characterisation of the human 5-HT5A serotonin receptor. FEBS Lett 355:242-246.

Reeves DC, Goren EN, Akabas MH, and Lummis SC (2001) Structural and electrostatic properties of the 5-HT3 receptor pore revealed by substituted cysteine accessibility mutagenesis. J Biol Chem 276:42035-42042.

Reid TE, Kumar K, and Wang XS (2013) Predictive in silico studies of human 5 -hydroxytryptamine receptor subtype $2 \mathrm{~B}\left(5-\mathrm{HT}_{2 \mathrm{~B}}\right)$ and valvular heart disease. Curr Top Med Chem 13:1353-1362.

Reigstad CS, Salmonson CE, Rainey JF III, Szurszewski JH, Linden DR, Sonnenburg JL, Farrugia G, and Kashyap PC (2015) Gut microbes promote colonic serotonin production through an effect of short-chain fatty acids on enterochromaffin cells. FASEB J 29:1395-1403.

Reisoli E, De Lucchini S, Nardi I, and Ori M (2010) Serotonin ${ }_{2 B}$ receptor signaling is required for craniofacial morphogenesis and jaw joint formation in Xenopus. Development 137:2927-2937.

Ren J, Zhou X, and Galligan JJ (2008) 5-HT4 receptor activation facilitates recovery from synaptic rundown and increases transmitter release from single varicosities of myenteric neurons. Am J Physiol Gastrointest Liver Physiol 294: G1376-G1383.

Renner U, Zeug A, Woehler A, Niebert M, Dityatev A, Dityateva G, Gorinski N, Guseva D, Abdel-Galil D, Fröhlich M, et al. (2012) Heterodimerization of serotonin receptors 5-HT1A and 5-HT7 differentially regulates receptor signalling and trafficking. $J$ Cell Sci 125:2486-2499.

Repapi E, Sayers I, Wain LV, Burton PR, Johnson T, Obeidat M, Zhao JH, Ramasamy A, Zhai G, Vitart V, et al.; Wellcome Trust Case Control Consortium; NSHD Respiratory Study Team (2010) Genome-wide association study identifies five loci associated with lung function. Nat Genet 42:36-44.

Restivo L, Roman F, Dumuis A, Bockaert J, Marchetti E, and Ammassari-Teule M (2008) The promnesic effect of G-protein-coupled 5-HT4 receptors activation is mediated by a potentiation of learning-induced spine growth in the mouse hippocampus. Neuropsychopharmacology 33:2427-2434.

Reuveny E, Slesinger PA, Inglese J, Morales JM, Iñiguez-Lluhi JA, Lefkowitz RJ, Bourne HR, Jan YN, and Jan LY (1994) Activation of the cloned muscarinic potassium channel by G protein beta gamma subunits. Nature 370:143-146.

Reynolds GP, Arranz B, Templeman LA, Fertuzinhos S, and San L (2006) Effect of 5 -HT1A receptor gene polymorphism on negative and depressive symptom response to antipsychotic treatment of drug-naive psychotic patients. Am J Psychiatry 163:1826-1829.

Reynolds GP, Templeman LA, and Zhang ZJ (2005) The role of 5-HT2C receptor polymorphisms in the pharmacogenetics of antipsychotic drug treatment. Prog Neuropsychopharmacol Biol Psychiatry 29:1021-1028.

Reynolds GP, Zhang Z, and Zhang X (2003) Polymorphism of the promoter region of the serotonin 5-HT(2C) receptor gene and clozapine-induced weight gain. Am $J$ Psychiatry 160:677-679.

Rezvani AH, Cauley MC, and Levin ED (2014) Lorcaserin, a selective 5-HT(2C) receptor agonist, decreases alcohol intake in female alcohol preferring rats. Phar macol Biochem Behav 125:8-14.

Riad M, Garcia S, Watkins KC, Jodoin N, Doucet E, Langlois X, el Mestikawy S, Hamon M, and Descarries L (2000) Somatodendritic localization of 5-HT1A and preterminal axonal localization of 5-HT1B serotonin receptors in adult rat brain. $J$ Comp Neurol 417:181-194.

Riad M, Tong XK, el Mestikawy S, Hamon M, Hamel E, and Descarries L (1998) Endothelial expression of the 5-hydroxytryptamine1B antimigraine drug receptor in rat and human brain microvessels. Neuroscience 86:1031-1035.

Ricceri L, De Filippis B, and Laviola G (2013) Rett syndrome treatment in mouse models: searching for effective targets and strategies. Neuropharmacology 68 $106-115$

Riccio O, Jacobshagen M, Golding B, Vutskits L, Jabaudon D, Hornung JP, and Dayer AG (2011) Excess of serotonin affects neocortical pyramidal neuron migration. Transl Psychiatry 1:e47.

Riccio O, Potter G, Walzer C, Vallet P, Szabó G, Vutskits L, Kiss JZ, and Dayer AG (2009) Excess of serotonin affects embryonic interneuron migration through activation of the serotonin receptor 6. Mol Psychiatry 14:280-290.

Riccioni T, Bordi F, Minetti P, Spadoni G, Yun HM, Im BH, Tarzia G, Rhim H, and Borsini F (2011) ST1936 stimulates cAMP, Ca2+, ERK1/2 and Fyn kinase through a full activation of cloned human 5-HT6 receptors. Eur J Pharmacol 661: 8-14.

Richardson-Jones JW, Craige CP, Guiard BP, Stephen A, Metzger KL, Kung HF Gardier AM, Dranovsky A, David DJ, Beck SG, et al. (2010) 5-HT1A autoreceptor levels determine vulnerability to stress and response to antidepressants. Neuron 65:40-52.

Richardson-Jones JW, Craige CP, Nguyen TH, Kung HF, Gardier AM, Dranovsky A, David DJ, Guiard BP, Beck SG, Hen R, et al. (2011) Serotonin-1A autoreceptors are necessary and sufficient for the normal formation of circuits underlying innate anxiety. J Neurosci 31:6008-6018.

Richtand NM, Welge JA, Logue AD, Keck PE Jr, Strakowski SM, and McNamara RK (2007) Dopamine and serotonin receptor binding and antipsychotic efficacy. Neuropsychopharmacology 32:1715-1726.

Richtand NM, Welge JA, Logue AD, Keck PE Jr, Strakowski SM, and McNamara RK (2008) Role of serotonin and dopamine receptor binding in antipsychotic efficacy. Prog Brain Res 172:155-175.

Richter DW, Manzke T, Wilken B, and Ponimaskin E (2003) Serotonin receptors: guardians of stable breathing. Trends $\mathrm{Mol}$ Med 9:542-548.

Rickli A, Kopf S, Hoener MC, and Liechti ME (2015) Pharmacological profile of novel psychoactive benzofurans. Br J Pharmacol 172:3412-3425.

Riga MS, Sánchez C, Celada P, and Artigas F (2016) Involvement of 5-HT3 receptors in the action of vortioxetine in rat brain: focus on glutamatergic and GABAergic neurotransmission. Neuropharmacology 108:73-81.

Rippberger H, van Gaalen MM, Schwarting RK, and Wohr M (2015) Environmental and pharmacological modulation of amphetamine- induced $50-\mathrm{kHz}$ ultrasonic vocalizations in rats. Curr Neuropharmacol 13:220-232.

Rizzi CA, Coccini T, Onori L, Manzo L, and Tonini M (1992) Benzimidazolone derivatives: a new class of 5-hydroxytryptamine4 receptor agonists with prokinetic and acetylcholine releasing properties in the guinea pig ileum. J Pharmacol Exp Ther 261:412-419.

Rizzoli PB (2014) Emerging therapeutic options for acute migraine: focus on the potential of lasmiditan. Neuropsychiatr Dis Treat 10:547-552.

Roberts A, Grafton G, Powell AD, Brock K, Chen C, Xie D, Huang J, Liu S, Cooper AJ, Brady CA, et al. (2020) CSTI-300 (SMP-100); a novel 5-HT H $_{3}$ receptor partial agonist with potential to treat patients with irritable bowel syndrome or carcinoid syndrome. J Pharmacol Exp Ther 373:122-134.

Roberts AJ, Krucker T, Levy CL, Slanina KA, Sutcliffe JG, and Hedlund PB (2004a) Mice lacking 5-HT receptors show specific impairments in contextual learning. Eur $J$ Neurosci 19:1913-1922.

Roberts C, Thomas DR, Bate ST, and Kew JN (2004b) GABAergic modulation of 5 -HT7 receptor-mediated effects on 5-HT efflux in the guinea-pig dorsal raphe nucleus. Neuropharmacology 46:935-941.

Robertson DN, Johnson MS, Moggach LO, Holland PJ, Lutz EM, and Mitchell R (2003) Selective interaction of ARF1 with the carboxy-terminal tail domain of the 5-HT2A receptor. Mol Pharmacol 64:1239-1250.

Robiolio PA, Rigolin VH, Wilson JS, Harrison JK, Sanders LL, Bashore TM, and Feldman JM (1995) Carcinoid heart disease. Correlation of high serotonin levels with valvular abnormalities detected by cardiac catheterization and echocardiography. Circulation 92:790-795.

Rocha BA, Goulding EH, O'Dell LE, Mead AN, Coufal NG, Parsons LH, and Tecott LH (2002) Enhanced locomotor, reinforcing, and neurochemical effects of cocaine in serotonin 5-hydroxytryptamine $2 \mathrm{C}$ receptor mutant mice. J Neurosci 22: 10039-10045. 
Rocha-González HI, Meneses A, Carlton SM, and Granados-Soto V (2005) Pronociceptive role of peripheral and spinal 5-HT7 receptors in the formalin test. Pain 117: 182-192.

Rochais C, Lecoutey C, Gaven F, Giannoni P, Hamidouche K, Hedou D, Dubost E, Genest D, Yahiaoui S, Freret T, et al. (2015) Novel multitarget-directed ligands (MTDLs) with acetylcholinesterase (AChE) inhibitory and serotonergic subtype 4 receptor (5-HT4R) agonist activities as potential agents against Alzheimer's disease: the design of donecopride. J Med Chem 58:3172-3187.

Rock PL, Harmer CJ, McTavish SF, Goodwin GM, and Rogers RD (2013) Short-term quetiapine treatment alters the use of reinforcement signals during risky decisionmaking and promotes the choice of negative expected values in healthy adult males. J Neurosci 33:15588-15595.

Rodgers RJ, Holch P, and Tallett AJ (2010) Behavioural satiety sequence (BSS): separating wheat from chaff in the behavioural pharmacology of appetite. Pharmacol Biochem Behav 97:3-14.

Rojas C, Raje M, Tsukamoto T, and Slusher BS (2014) Molecular mechanisms of $\left.5-\mathrm{HT}_{3}\right)$ and $\mathrm{NK}\left({ }_{1}\right)$ receptor antagonists in prevention of emesis. Eur J Pharmacol 722:26-37.

Romero L, Celada P, Martín-Ruiz R, Díaz-Mataix L, Mourelle M, Delgadillo J, Hervás $\mathrm{I}$, and Artigas F (2003) Modulation of serotonergic function in rat brain by VN2222, a serotonin reuptake inhibitor and 5-HT1A receptor agonist. Neuropsychopharmacology 28:445-456.

Romero G, Sánchez E, Pujol M, Pérez P, Codony X, Holenz J, Buschmann H, and Pauwels PJ (2006) Efficacy of selective 5-HT6 receptor ligands determined by monitoring 5-HT6 receptor-mediated cAMP signaling pathways. $\mathrm{Br} J$ Pharmacol 148:1133-1143.

Rondé P, Ansanay H, Dumuis A, Miller R, and Bockaert J (1995) Homologous desensitization of 5-hydroxytryptamine4 receptors in rat esophagus: functional and second messenger studies. J Pharmacol Exp Ther 272:977-983.

Rose D, Khater-Boidin J, Toussaint P, and Duron B (1995) Central effects of 5-HT on respiratory and hypoglossal activities in the adult cat. Respir Physiol 101:59-69.

Rosendorff A, Ebersole BJ, and Sealfon SC (2000) Conserved helix 7 tyrosine functions as an activation relay in the serotonin $5 \mathrm{HT}(2 \mathrm{C})$ receptor. Brain Res Mol Brain Res 84:90-96.

Rosenzweig-Lipson S, Dunlop J, and Marquis KL (2007a) 5-HT2C receptor agonists as an innovative approach for psychiatric disorders. Drug News Perspect 20:565-571.

Rosenzweig-Lipson S, Sabb A, Stack G, Mitchell P, Lucki I, Malberg JE, Grauer S, Brennan J, Cryan JF, Sukoff Rizzo SJ, et al. (2007b) Antidepressant-like effects of the novel, selective, 5-HT2C receptor agonist WAY-163909 in rodents. Psychopharmacology (Berl) 192:159-170.

Ross S, Bossis A, Guss J, et al. (2016) Rapid and sustained symptom reduction following psilocybin treatment for anxiety and depression in patients with lifethreatening cancer: a randomized controlled trial. $J$ Psychopharmacol 30 $1165-1180$

Roth BL (2007) Drugs and valvular heart disease. N Engl J Med 356:6-9.

Roth BL and Ciaranello RD (1991) Chronic mianserin treatment decreases 5-HT2 receptor binding without altering 5-HT2 receptor mRNA levels. Eur J Pharmacol 207:169-172.

Roth BL, Ciaranello RD, and Meltzer HY (1992) Binding of typical and atypical antipsychotic agents with transiently expressed 5-HT1C receptors. J Pharmacol Exp Ther 260:1361-1365.

Rothman RB, Baumann MH, Savage JE, Rauser L, McBride A, Hufeisen SJ, and Roth BL (2000) Evidence for possible involvement of 5-HT(2B) receptors in the cardiac valvulopathy associated with fenfluramine and other serotonergic medications. Circulation 102:2836-2841.

Rouquet G, Moore DE, Spain M, Allwood DM, Battilocchio C, Blakemore DC, Fish PV, Jenkinson S, Jessiman AS, Ley SV, et al. (2015) Design, synthesis, and evaluation of tetrasubstituted pyridines as potent $5-\mathrm{HT} 2 \mathrm{C}$ receptor agonists. ACS Med Chem Lett 6:329-333.

Rousselle JC, Plantefol M, Fillion MP, Massot O, Pauwels PJ, and Fillion G (1998) Specific interaction of 5-HT-moduline with human 5-HT1b as well as 5-HT1d receptors expressed in transfected cultured cells. Naunyn Schmiedebergs Arch Pharmacol 358:279-286.

Routledge C (1996) Development of 5-HT1A receptor antagonists. Behav Brain Res 73:153-156.

Ruat M, Traiffort E, Arrang JM, Tardivel-Lacombe J, Diaz J, Leurs R, and Schwartz JC (1993a) A novel rat serotonin (5-HT6) receptor: molecular cloning, localization and stimulation of cAMP accumulation. Biochem Biophys Res Commun 193: 268-276.

Ruat M, Traiffort E, Leurs R, Tardivel-Lacombe J, Diaz J, Arrang JM, and Schwartz JC (1993b) Molecular cloning, characterization, and localization of a high-affinity serotonin receptor (5-HT7) activating cAMP formation. Proc Natl Acad Sci USA 90: $8547-8551$.

Ruddell RG, Oakley F, Hussain Z, Yeung I, Bryan-Lluka LJ, Ramm GA, and Mann DA (2006) A role for serotonin (5-HT) in hepatic stellate cell function and liver fibrosis. Am J Pathol 169:861-876.

Rüedi-Bettschen D, Spealman RD, and Platt DM (2015) Attenuation of cocaine-in duced reinstatement of drug seeking in squirrel monkeys by direct and indirect activation of 5-HT2C receptors. Psychopharmacology (Berl) 232:2959-2968.

Rueffert H, Thieme V, Wallenborn J, Lemnitz N, Bergmann A, Rudlof K, Wehner M, Olthoff D, and Kaisers UX (2009) Do variations in the 5- $\mathrm{HT}_{3} \mathrm{~A}$ and $5-\mathrm{HT}_{3} \mathrm{~B}$ serotonin receptor genes (HTR3A and HTR3B) influence the occurrence of postoperative vomiting? Anesth Analg 109:1442-1447.

Rueter SM, Dawson TR, and Emeson RB (1999) Regulation of alternative splicing by RNA editing. Nature 399:75-80.

Ruf BM and Bhagwagar Z (2009) The 5-HT1B receptor: a novel target for the pathophysiology of depression. Curr Drug Targets 10:1118-1138.

Rüsch D, Braun HA, Wulf H, Schuster A, and Raines DE (2007) Inhibition of human 5 -HT(3A) and 5-HT(3AB) receptors by etomidate, propofol and pentobarbital. Eur J Pharmacol 573:60-64.
Russell A, Banes A, Berlin H, Fink GD, and Watts SW (2002) 5-Hydroxytryptamine( ${ }_{2 \mathrm{~B}}$ ) receptor function is enhanced in the N(omega)-nitro-L-arginine hypertensive rat. $J$ Pharmacol Exp Ther 303:179-187.

Sagalajev B, Bourbia N, Beloushko E, Wei H, and Pertovaara A (2015) Bidirectional amygdaloid control of neuropathic hypersensitivity mediated by descending serotonergic pathways acting on spinal 5-HT3 and 5-HT1A receptors. Behav Brain Res 282:14-24.

Sahibzada N, Ferreira M, Wasserman AM, Taveira-DaSilva AM, and Gillis RA (2000) Reversal of morphine-induced apnea in the anesthetized rat by drugs that activate 5-hydroxytryptamine(1A) receptors. J Pharmacol Exp Ther 292: $704-713$

Sahin-Erdemli I, Hoyer D, Stoll A, Seiler MP, and Schoeffter P (1991) 5-HT1-like receptors mediate 5-hydroxytryptamine-induced contraction of guinea-pig isolated iliac artery. $\mathrm{Br} J$ Pharmacol 102:386-390.

Salom D, Wang B, Dong Z, Sun W, Padayatti P, Jordan S, Salon JA, and Palczewski K (2012) Post-translational modifications of the serotonin type 4 receptor heterologously expressed in mouse rod cells. Biochemistry 51:214-224.

Saltzman AG, Morse B, Whitman MM, Ivanshchenko Y, Jaye M, and Felder S (1991) Cloning of the human serotonin 5-HT2 and 5-HT1C receptor subtypes. Biochem Biophys Res Commun 181:1469-1478.

SAMHSA (2015) Behavioral health trends in the United States: results from the 2014 National Survey on Drug Use and Health. Substance Abuse and Mental Health Services Administration. Center for Behavioral Health Statistics and Quality. Rockville, MD. September 8, 2016

Samuels BA, Mendez-David I, Faye C, David SA, Pierz KA, Gardier AM, Hen R, and David DJ (2016) Serotonin 1A and serotonin 4 receptors: essential mediators of the neurogenic and behavioral actions of antidepressants. Neuroscientist 22:26-45

Sanchez C, Asin KE, and Artigas F (2015) Vortioxetine, a novel antidepressant with multimodal activity: review of preclinical and clinical data. Pharmacol Ther $\mathbf{1 4 5}$ $43-57$.

Sánchez-Lopez A, Centurión D, Vázquez E, Arulmani U, Saxena PR, and Villalón CM (2003) Pharmacological profile of the 5-HT-induced inhibition of cardioaccelerator sympathetic outflow in pithed rats: correlation with 5 -HT1 and putative 5 -ht5A/5B receptors. $B r J$ Pharmacol 140:725-735.

Sánchez-López A, Centurión D, Vázquez E, Arulmani U, Saxena PR, and Villalón CM (2004) Further characterization of the 5-HT1 receptors mediating cardiac sympatho-inhibition in pithed rats: pharmacological correlation with the 5-HT1B and 5-HT1D subtypes. Naunyn Schmiedebergs Arch Pharmacol 369:220-227.

Sánchez-Maldonado C, López-Sánchez P, Anguiano-Robledo L, Leopoldo M, Lacivita E, and Terrón JA (2015) GR-127935-sensitive mechanism mediating hypotension in anesthetized rats: are 5-HT5B receptors involved? J Cardiovasc Pharmacol 65 $335-341$.

Sandén N, Thorlin T, Blomstrand F, Persson PA, and Hansson E (2000) 5-Hydroxytryptamine $_{2 \mathrm{~B}}$ receptors stimulate $\mathrm{Ca} 2+$ increases in cultured astrocytes from three different brain regions. Neurochem Int 36:427-434.

Sanders L and Kaumann AJ (1992) A 5-HT4-like receptor in human left atrium. Naunyn Schmiedebergs Arch Pharmacol 345:382-386.

Sanders-Bush E and Conn PJ (1986) Effector systems coupled to serotonin receptors in brain: serotonin stimulated phosphoinositide hydrolysis. Psychopharmacol Bull 22:829-836.

Sangare A, Dubourget R, Geoffroy H, Gallopin T, and Rancillac A (2016) Serotonin differentially modulates excitatory and inhibitory synaptic inputs to putative sleep-promoting neurons of the ventrolateral preoptic nucleus. Neuropharmacology 109:29-40.

Sanger GJ (1987a) Increased gut cholinergic activity and antagonism of 5-hydroxytryptamine M-receptors by BRL 24924: potential clinical importance of BRL 24924. $\mathrm{Br} J$ Pharmacol 91:77-87.

Sanger GJ (1987b) Activation of a myenteric 5-hydroxytryptamine-like receptor by metoclopramide. J Pharm Pharmacol 39:449-453.

Sanger GJ (2008) 5-hydroxytryptamine and the gastrointestinal tract: where next? Trends Pharmacol Sci 29:465-471.

Sanger GJ (2009) Translating 5-HT receptor pharmacology. Neurogastroenterol Motil 21:1235-1238.

Sanger GJ and Andrews PLR (2006) Treatment of nausea and vomiting: gaps in our knowledge. Auton Neurosci 129:3-16.

Sanger GJ, Banner SE, Smith MI, and Wardle KA (1998) SB-207266: 5-HT4 receptor antagonism in human isolated gut and prevention of 5-HT-evoked sensitization of peristalsis and increased defaecation in animal models. Neurogastroenterol Motil 10:271-279.

Sanger GJ, Broad J, and Andrews PLR (2013a) The relationship between gastric motility and nausea: gastric prokinetic agents as treatments. Eur J Pharmacol 715:10-14

Sanger GJ, Broad J, Kung V, and Knowles CH (2013b) Translational neuropharmacology: the use of human isolated gastrointestinal tissues. $\mathrm{Br}$ J Pharmacol 168:28-43.

Sanger GJ, Hellström PM, and Näslund E (2011a) The hungry stomach: physiology, disease, and drug development opportunities. Front Pharmacol 1:145.

Sanger GJ, Holbrook JD, and Andrews PLR (2011b) The translational value of rodent gastrointestinal functions: a cautionary tale. Trends Pharmacol Sci 32:402-409.

Sanger GJ and Lee K (2008) Hormones of the gut-brain axis as targets for the treatment of upper gastrointestinal disorders. Nat Rev Drug Discov 7:241-254.

Sanger GJ and Wardle KA (1994) Constipation evoked by $5-\mathrm{HT}_{3}$-receptor antagonism: evidence for heterogeneous efficacy among different antagonists in guineapigs. $J$ Pharm Pharmacol 46:666-670.

Sanger GJ, Yoshida M, Yahyah M, and Kitazumi K (2000) Increased defecation during stress or after 5-hydroxytryptophan: selective inhibition by the 5-HT(4) receptor antagonist, SB-207266. $\mathrm{Br}$ J Pharmacol 130:706-712.

Santana N, Bortolozzi A, Serrats J, Mengod G, and Artigas F (2004) Expression of serotonin1A and serotonin2A receptors in pyramidal and GABAergic neurons of the rat prefrontal cortex. Cereb Cortex 14:1100-1109. 
Santana N, Mengod G, and Artigas F (2013) Expression of $\alpha$ (1)-adrenergic receptors in rat prefrontal cortex: cellular co-localization with 5-HT(2A) receptors. Int $J$ Neuropsychopharmacol 16:1139-1151.

Saper CB, Chou TC, and Elmquist JK (2002) The need to feed: homeostatic and hedonic control of eating. Neuron 36:199-211.

Sari Y, Miquel MC, Brisorgueil MJ, Ruiz G, Doucet E, Hamon M, and Vergé D (1999) Cellular and subcellular localization of 5-hydroxytryptamine1B receptors in the rat central nervous system: immunocytochemical, autoradiographic and lesion studies. Neuroscience 88:899-915.

Sarkisyan G and Hedlund PB (2009) The 5-HT7 receptor is involved in allocentric spatial memory information processing. Behav Brain Res 202:26-31.

Sarkisyan G, Roberts AJ, and Hedlund PB (2010) The 5-HT(7) receptor as a mediator and modulator of antidepressant-like behavior. Behav Brain Res 209:99-108.

Satała G, Duszyńska B, Lenda T, Nowak G, and Bojarski AJ (2018) Allosteric inhibition of serotonin 5-HT7 receptors by zinc ions. Mol Neurobiol 55:2897-2910.

Sauguet L, Howard RJ, Malherbe L, Lee US, Corringer P-J, Harris RA, and Delarue $M$ (2013) Structural basis for potentiation by alcohols and anaesthetics in a ligandgated ion channel. Nat Commun 4:1697.

Sauguet L, Shahsavar A, and Delarue M (2015) Crystallographic studies of pharmacological sites in pentameric ligand-gated ion channels. Biochim Biophys Acta 1850:511-523.

Savastano DM and Covasa M (2007) Intestinal nutrients elicit satiation through concomitant activation of CCK(1) and 5-HT(3) receptors. Physiol Behav 92:434-442.

Savoye G, Brung-Lefebvre M, Bouin M, Maillot C, Denis P, and Ducrotté P (2007) Effects of ondansetron on gastric tone and motility changes induced by a prolonged intraduodenal infusion of nutrients. Results of a placebo-controlled study. Dig Dis Sci 52:2676-2683.

Sawant-Basak A, Coffman KJ, Walker GS, Ryder TF, Tseng E, Miller E, Lee C, Vanase-Frawley MA, Wong JW, Brodney MA, et al. (2013) Metabolism of a serotonin-4 receptor partial agonist 4-\{4-[4-tetrahydrofuran-3-yloxy)-benzo[d]isoxazol3-yloxymethyl]-piperidin-1-ylmethyl\}-tetrahydropyran-4-ol (TBPT): identification of an unusual pharmacologically active cyclized oxazolidine metabolite in human. $J$ Pharm Sci 102:3277-3293.

Saxena PR (1974) Selective vasoconstriction in carotid vascular bed by methysergide: possible relevance to its antimigraine effect. Eur $J$ Pharmacol 27:99-105.

Saxena PR, De Vries P, Heiligers JP, Bax WA, Maassen VanDenBrink A, and Yocca FD (1998) BMS-181885, a 5-HT1B/1D receptor ligand, in experimental models predictive of antimigraine activity and coronary side-effect potential. Eur $J$ Pharmacol 351:329-339.

Saxena PR and Villalón CM (1990) Cardiovascular effects of serotonin agonists and antagonists. J Cardiovasc Pharmacol 15 (Suppl 7):S17-S34.

Saxena PR and Villalón CM (1991) 5-Hydroxytryptamine: a chameleon in the heart. Trends Pharmacol Sci 12:223-227.

Scarr E, Pavey G, Copolov D, and Dean B (2004) Hippocampal 5-hydroxytryptamine receptors: abnormalities in postmortem brain from schizophrenic subjects. Schizophr Res 71:383-392.

Schaerlinger B, Hickel P, Etienne N, Guesnier L, and Maroteaux L (2003) Agonist actions of dihydroergotamine at 5-HT2B and 5-HT2C receptors and their possible relevance to antimigraine efficacy. $\mathrm{Br} J$ Pharmacol 140:277-284.

Schapira AH, Bezard E, Brotchie J, Calon F, Collingridge GL, Ferger B, Hengerer B, Hirsch E, Jenner P, Le Novère N, et al. (2006) Novel pharmacological targets for the treatment of Parkinson's disease. Nat Rev Drug Discov 5:845-854

Schechter LE, Lin Q, Smith DL, Zhang G, Shan Q, Platt B, Brandt MR, Dawson LA, Cole D, Bernotas R, et al. (2008) Neuropharmacological profile of novel and selective 5-HT6 receptor agonists: WAY-181187 and WAY-208466. Neuropsychopharmacology 33:1323-1335.

Schellekens H, De Francesco PN, Kandil D, Theeuwes WF, McCarthy T, van Oeffelen WE, Perelló M, Giblin L, Dinan TG, and Cryan JF (2015) Ghrelin's orexigenic effect is modulated via a serotonin $2 \mathrm{C}$ receptor interaction. ACS Chem Neurosci 6 1186-1197.

Schiller LR and Johnson DA (2008) Balancing drug risk and benefit: toward refining the process of FDA decisions affecting patient care. Am J Gastroenterol 103:815-819.

Schlag BD, Lou Z, Fennell M, and Dunlop J (2004) Ligand dependency of 5-hydroxytryptamine 2C receptor internalization. J Pharmacol Exp Ther 310:865-870.

Schlenstedt J, Balfanz S, Baumann A, and Blenau W (2006) Am5-HT7: molecular and pharmacological characterization of the first serotonin receptor of the honeybee (Apis mellifera). J Neurochem 98:1985-1998.

Schlicker E, Fink K, Göthert M, Hoyer D, Molderings G, Roschke I, and Schoeffter P (1989) The pharmacological properties of the presynaptic serotonin autoreceptor in the pig brain cortex conform to the 5-HT1D receptor subtype. Naunyn Schmiedebergs Arch Pharmacol 340:45-51.

Schmauss C, Zimnisky R, Mehta M, and Shapiro LP (2010) The roles of phospholipase $\mathrm{C}$ activation and alternative ADAR1 and ADAR2 pre-mRNA splicing in modulating serotonin 2C-receptor editing in vivo. RNA 16:1779-1785.

Schmid CL and Bohn LM (2010) Serotonin, but not N-methyltryptamines, activates the serotonin $2 \mathrm{~A}$ receptor via a $B$-arrestin2/Src/Akt signaling complex in vivo. $J$ Neurosci 30:13513-13524.

Schmid CL, Raehal KM, and Bohn LM (2008) Agonist-directed signaling of the serotonin 2A receptor depends on beta-arrestin-2 interactions in vivo. Proc Natl Acad Sci USA 105:1079-1084

Schmid CL, Streicher JM, Meltzer HY, and Bohn LM (2014) Clozapine acts as an agonist at serotonin 2A receptors to counter MK-801-induced behaviors through a Barrestin2-independent activation of Akt. Neuropsychopharmacology $\mathbf{3 9}$ $1902-1913$

Schmidt AW and Peroutka SJ (1989) Three-dimensional steric molecular modeling of the 5-hydroxytryptamine3 receptor pharmacophore. Mol Pharmacol 36:505-511.

Schmitz B, Ullmer C, Segelcke D, Gwarek M, Zhu X-R, and Lübbert H (2015) BF-1-a novel selective $5-\mathrm{HT}_{2 \mathrm{~B}}$ receptor antagonist blocking neurogenic dural plasma protein extravasation in guinea pigs. Eur J Pharmacol 751:73-80.
Schmuck K, Ullmer C, Engels P, and Lübbert H (1994) Cloning and functional characterization of the human 5-HT2B serotonin receptor. FEBS Lett 342-85-90. Schmuck K, Ullmer C, Kalkman HO, Probst A, and Lübbert H (1996) Activation of meningeal $5-\mathrm{HT}_{2 \mathrm{~B}}$ receptors: an early step in the generation of migraine headache? Eur J Neurosci 8:959-967.

Schneider B, Pietri M, Mouillet-Richard S, Ermonval M, Mutel V, Launay JM, and Kellermann $\mathrm{O}$ (2006) Control of bioamine metabolism by $5-\mathrm{HT}_{2 \mathrm{~B}}$ and alpha $1 \mathrm{D}$ autoreceptors through reactive oxygen species and tumor necrosis factor-alpha signaling in neuronal cells. Ann N Y Acad Sci 1091:123-141.

Schoeffter P and Hoyer D (1989a) 5-Hydroxytryptamine 5-HT1B and 5-HT1D receptors mediating inhibition of adenylate cyclase activity. Pharmacological comparison with special reference to the effects of yohimbine, rauwolscine and some betaadrenoceptor antagonists. Naunyn Schmiedebergs Arch Pharmacol 340:285-292.

Schoeffter P and Hoyer D (1989b) How selective is GR 43175? interactions with functional 5-HT1A, 5-HT1B, 5-HT1C and 5-HT1D receptors. Naunyn Schmiedebergs Arch Pharmacol 340:135-138.

Schoeffter P and Hoyer D (1989c) Is the sumatriptan (GR 43175)-induced endothelium-dependent relaxation of pig coronary arteries mediated by $5-\mathrm{HT}_{1 \mathrm{D}}$ receptors? Eur J Pharmacol 166:117-119.

Schoeffter P and Hoyer D (1990) 5-Hydroxytryptamine (5-HT)-induced endotheliumdependent relaxation of pig coronary arteries is mediated by 5 -HT receptors similar to the 5-HT $1 \mathrm{D}$ receptor subtype. $J$ Pharmacol Exp Ther 252:387-395.

Schoeffter P, Waeber C, Palacios JM, and Hoyer D (1988) The serotonin 5-HT1D receptor subtype is negatively coupled to adenylate cyclase in calf substantia nigra. Naunyn Schmiedeberg's Arch Pharmacol 337:602-608.

Schotte A, Janssen PFM, Gommeren W, Luyten WHML, Van Gompel P, Lesage AS, De Loore K, and Leysen JE (1996) Risperidone compared with new and reference antipsychotic drugs: in vitro and in vivo receptor binding. Psychopharmacology 124:57-73.

Schraenen A, Lemaire K, de Faudeur G, Hendrickx N, Granvik M, Van Lommel L, Mallet J, Vodjdani G, Gilon P, Binart N, et al. (2010) Placental lactogens induce erotonin biosynthesis in a subset of mouse beta cells during pregnancy. Diabetologia 53:2589-2599.

Schreiber R and Newman-Tancredi A (2014) Improving cognition in schizophrenia with antipsychotics that elicit neurogenesis through 5-HT(1A) receptor activation. Neurobiol Learn Mem 110:72-80.

Schwörer H, Münke H, Stöckmann F, and Ramadori G (1995) Treatment of diarrhea in carcinoid syndrome with ondansetron, tropisetron, and clonidine. Am J Gas troenterol 90:645-648.

Scorza MC, Lladó-Pelfort L, Oller S, Cortés R, Puigdemont D, Portella MJ, PérezEgea R, Alvarez E, Celada P, Pérez V, et al. (2012) Preclinical and clinical characterization of the selective 5-HT(1A) receptor antagonist DU-125530 for antidepressant treatment. Br J Pharmacol 167:1021-1034.

Scotton WJ, Hill LJ, Williams AC, and Barnes NM (2019) Serotonin syndrome: pathophysiology, clinical features, management, and potential future directions. Int J Tryptophan Res 12:1178646919873925.

Sealfon SC, Chi L, Ebersole BJ, Rodic V, Zhang D, Ballesteros JA, and Weinstein H (1995) Related contribution of specific helix 2 and 7 residues to conformational activation of the serotonin 5-HT2A receptor. J Biol Chem 270:16683-16688.

Sebben M, Ansanay H, Bockaert J, and Dumuis A (1994) 5-HT6 receptors positively coupled to adenylyl cyclase in striatal neurones in culture. Neuroreport 5 2553-2557.

Seeman P and Tallerico T (1998) Antipsychotic drugs which elicit little or no parkinsonism bind more loosely than dopamine to brain D2 receptors, yet occupy high levels of these receptors. Mol Psychiatry 3:123-134.

Seggel MR, Qureshi GD, and Glennon RA (1987) Effect of 5-HT2-selective agonists on cat platelet aggregation. Life Sci 41:1077-1081.

Selvaraj S, Arnone D, Cappai A, and Howes O (2014) Alterations in the serotonin system in schizophrenia: a systematic review and meta-analysis of postmortem and molecular imaging studies. Neurosci Biobehav Rev 45:233-245.

Semenova S, Geyer MA, Sutcliffe JG, Markou A, and Hedlund PB (2008) Inactivation of the 5-HT(7) receptor partially blocks phencyclidine-induced disruption of prepulse inhibition. Biol Psychiatry 63:98-105.

Sengupta A, Bocchio M, Bannerman DM, Sharp T, and Capogna M (2017) Control of amygdala circuits by 5 -HT neurons via 5 -HT and glutamate cotransmission. $J$ Neurosci 37:1785-1796.

Seo J and Tsai LH (2014) Neuronal differentiation: 5-HT6R can do it alone. Nat Chem Biol 10:488-489.

Serafeim A, Grafton G, Chamba A, Gregory CD, Blakely RD, Bowery NG, Barnes NM, and Gordon J (2002) 5-Hydroxytryptamine drives apoptosis in biopsylike Burkitt lymphoma cells: reversal by selective serotonin reuptake inhibitors. Blood 99:2545-2553.

Serafeim A, Holder MJ, Grafton G, Chamba A, Drayson MT, Luong QT, Bunce CM, Gregory CD, Barnes NM, and Gordon J (2003) Selective serotonin reuptake inhibitors directly signal for apoptosis in biopsy-like Burkitt lymphoma cells. Blood 101:3212-3219.

Serrats J, Mengod G, and Cortés R (2005) Expression of serotonin 5-HT2C receptors in GABAergic cells of the anterior raphe nuclei. J Chem Neuroanat 29:83-91.

Serrats J, Raurich A, Vilaró MT, Mengod G, and Cortés R (2004) 5-ht5B receptor mRNA in the raphe nuclei: coexpression with serotonin transporter. Synapse $\mathbf{5 1}$ $102-111$

Sessa B and Nutt D (2015) Making a medicine out of MDMA. Br J Psychiatry 206:4-6 Seto SW, Lam HY, Lau WS, Au AL, Lam TY, Chim SS, Ngai SM, Chan SW, Leung TY, Yeung JH, et al. (2009) Role of monoamine oxidases in the exaggerated 5 -hydroxytryptamine-induced tension development of human isolated preeclamptic umbilical artery. Eur J Pharmacol 605:129-137

Setola V, Hufeisen S.J, Grande-Allen KJ, Vesely I, Glennon RA, Blough B, Rothman RB, and Roth BL (2003) 3,4-methylenedioxymethamphetamine (MDMA "Ecstasy") induces fenfluramine-like proliferative actions on human cardiac valvular interstitial cells in vitro. Mol Pharmacol 63:1223-1229. 
Setola V and Roth BL (2003) Why mice are neither miniature humans nor small rats: a cautionary tale involving 5-hydroxytryptamine-6 serotonin receptor species variants. Mol Pharmacol 64:1277-1278.

Sévoz-Couche C, Spyer KM, and Jordan D (2000) In vivo modulation of vagal-identified dorsal medullary neurones by activation of different 5 -Hydroxytryptamine(2) receptors in rats. $\mathrm{Br} J$ Pharmacol 131:1445-1453.

Sevy S, Brown S-L, Wetzler S, Kotler M, Molcho A, Plutchik R, and van Praag HM (1994) Effects of alprazolam on increases in hormonal and anxiety levels induced by meta-chlorophenylpiperazine. Psychiatry Res 53:219-229.

Sgard F, Faure C, and Graham D (1996) Evidence for 5-HT1D beta but not 5-HT1D alpha receptor subtype expression in canine large coronary arteries and saphenous vein. Cardiovasc Res 31:793-799.

Shahid M, Walker GB, Zorn SH, and Wong EHF (2009) Asenapine: a novel psychopharmacologic agent with a unique human receptor signature. J Psychopharmacol 23:65-73.

Shajib MS and Khan WI (2015) The role of serotonin and its receptors in activation of immune responses and inflammation. Acta Physiol (Oxf) 213:561-574.

Shams TA and Müller DJ (2014) Antipsychotic induced weight gain: genetics, epigenetics, and biomarkers reviewed. Curr Psychiatry Rep 16:473.

Shapiro DA, Renock S, Arrington E, Chiodo LA, Liu LX, Sibley DR, Roth BL, and Mailman R (2003) Aripiprazole, a novel atypical antipsychotic drug with a unique and robust pharmacology. Neuropsychopharmacology 28:1400-1411.

Sharif NA, Kelly CR, Crider JR, and Davis TL (2006a) Serotonin-2 (5-HT2) receptormediated signal transduction in human ciliary muscle cells: role in ocular hypotension. J Ocul Pharmacol Ther 22:389-401.

Sharif NA, Kelly CR, and McLaughlin M (2006b) Human trabecular meshwork cells express functional serotonin-2A (5HT2A) receptors: role in IOP reduction. In vestigative Ophthalmology \& Visual Science 47:4001-4010.

Sharif NA, McLaughlin MA, and Kelly CR (2007) AL-34662: a potent, selective, and efficacious ocular hypotensive serotonin-2 receptor agonist. J Ocul Pharmacol Ther 23:1-13.

Sharif NA and Senchyna M (2006) Serotonin receptor subtype mRNA expression in human ocular tissues, determined by RT-PCR. Mol Vis 12:1040-1047.

Sharp T (2010) Serotonergic feedback control, in Handbook of the Behavioural Neurobiology of Serotonin (Muller CP and Jacobs B eds) pp 233-248, Elesevier, London.

Sharp T, Boothman L, Raley J, and Quérée P (2007) Important messages in the 'post': recent discoveries in 5-HT neurone feedback control. Trends Pharmacol Sci 28 $629-636$

Sharp T, Bramwell SR, and Grahame-Smith DG (1989) 5-HT1 agonists reduce 5 -hydroxytryptamine release in rat hippocampus in vivo as determined by brain microdialysis. $\mathrm{Br} J$ Pharmacol 96:283-290.

Sharpley AL, Solomon RA, Fernando AI, da Roza Davis JM, and Cowen PJ (1990) Dose-related effects of selective 5-HT2 receptor antagonists on slow wave sleep in humans. Psychopharmacology (Berl) 101:568-569

Sharpley AL, Vassallo CM, and Cowen PJ (2000) Olanzapine increases slow-wave sleep: evidence for blockade of central 5-HT(2C) receptors in vivo. Biol Psychiatry 47:468-470.

Sheffler DJ, Kroeze WK, Garcia BG, Deutch AY, Hufeisen SJ, Leahy P, Brüning JC, and Roth BL (2006) p90 ribosomal S6 kinase 2 exerts a tonic brake on G proteincoupled receptor signaling. Proc Natl Acad Sci USA 103:4717-4722.

Sheldon PW and Aghajanian GK (1991) Excitatory responses to serotonin (5-HT) in neurons of the rat piriform cortex: evidence for mediation by 5 -HT1C receptors in pyramidal cells and 5-HT2 receptors in interneurons. Synapse 9:208-218.

Shelton J, Bonaventure P, Li X, Yun S, Lovenberg T, and Dugovic C (2009) 5-HT7 receptor deletion enhances REM sleep suppression induced by selective serotonin reuptake inhibitors, but not by direct stimulation of 5-HT1A receptor. Neuropharmacology 56:448-454.

Shelton J, Yun S, Losee Olson S, Turek F, Bonaventure P, Dvorak C, Lovenberg T, and Dugovic C (2015) Selective pharmacological blockade of the 5-HT7 receptor attenuates light and 8-OH-DPAT induced phase shifts of mouse circadian wheel running activity. Front Behav Neurosci 8:453.

Shen C, Li H, and Meller E (2002) Repeated treatment with antidepressants differentially alters 5-HT1A agonist-stimulated [35S]GTP gamma S binding in rat brain regions. Neuropharmacology 42:1031-1038.

Shen JH, Zhao Y, Rosenzweig-Lipson S, Popp D, Williams JB, Giller E, Detke MJ, and Kane JM (2014) A 6-week randomized, double-blind, placebo-controlled, comparator referenced trial of vabicaserin in acute schizophrenia. J Psychiatr Res 53:14-22.

Shen M, Bellaousov S, Hiller M, de La Grange P, Creamer TP, Malina O, Sperling R, Mathews DH, Stoilov P, and Stamm S (2013) Pyrvinium pamoate changes alternative splicing of the serotonin receptor $2 \mathrm{C}$ by influencing its RNA structure. Nucleic Acids Res 41:3819-3832.

Shen RY and Andrade R (1998) 5-Hydroxytryptamine ${ }_{2}$ receptor facilitates GABAergic neurotransmission in rat hippocampus. J Pharmacol Exp Ther 285:805-812.

Shen Y, Monsma FJ Jr, Metcalf MA, Jose PA, Hamblin MW, and Sibley DR (1993) Molecular cloning and expression of a 5 -hydroxytryptamine serotonin receptor subtype. J Biol Chem 268:18200-18204

Shenker A, Maayani S, Weinstein H, and Green JP (1987) Pharmacological characterization of two 5-hydroxytryptamine receptors coupled to adenylate cyclase in guinea pig hippocampal membranes. Mol Pharmacol 31:357-367.

Shepherd JK, Grewal SS, Fletcher A, Bill DJ, and Dourish CT (1994) Behavioural and pharmacological characterisation of the elevated "zero-maze" as an animal model of anxiety. Psychopharmacology (Berl) 116:56-64

Shepherd SL, Williamson DJ, Beer MS, Hill RG, and Hargreaves RJ (1997) Differential effects of 5-HT1B/1D receptor agonists on neurogenic dural plasma extravasation and vasodilation in anaesthetized rats. Neuropharmacol 36:525-533.

Shepheard S, Edvinsson L, Cumberbatch M, Williamson D, Mason G, Webb J, Boyce S, Hill R, and Hargreaves R (1999) Possible antimigraine mechanisms of action of the $5 \mathrm{HT}_{1 \mathrm{~F}}$ receptor agonist LY334370. Cephalalgia 19:851-858.
Shimizu M, Nishida A, Zensho H, and Yamawaki S (1996) Chronic antidepressant exposure enhances 5-hydroxytryptamine7 receptor-mediated cyclic adenosine monophosphate accumulation in rat frontocortical astrocytes. J Pharmacol Exp Ther 279:1551-1558.

Shimron-Abarbanell D, Erdmann J, Vogt IR, Bryant SP, Spurr NK, Knapp M, Propping P, and Nöthen MM (1997) Human 5-HT5A receptor gene: systematic screening for DNA sequence variation and linkage mapping on chromosome 7q34q36 using a polymorphism in the $5^{\prime}$ untranslated region. Biochem Biophys Res Commun 233:6-9.

Shin A, Camilleri M, Kolar G, Erwin P, West CP, and Murad MH (2014) Systematic review with meta-analysis: highly selective 5 -HT4 agonists (prucalopride, velusetrag or naronapride) in chronic constipation. Aliment Pharmacol Ther 39:239-253. Shioda K, Nisijima K, Yamauchi Y, Ohtuka K, and Kato S (2006) Use of a serotonin $1 \mathrm{~A}$ receptor agonist to treat restless legs syndrome. J Clin Psychopharmacol 26: 673-675.

Shiotani A, Kusunoki H, Ishii M, Imamura H, Manabe N, Kamada T, Hata J, Merchant JL, and Haruma K (2015) Pilot study of Biomarkers for predicting effectiveness of ramosetron in diarrhea-predominant irritable bowel syndrome: expression of S100A10 and polymorphisms of TPH1. Neurogastroenterol Motil 27: $82-91$.

Shirley RL, Walter NA, Reilly MT, Fehr C, and Buck KJ (2004) Mpdz is a quantitative trait gene for drug withdrawal seizures. Nat Neurosci 7:699-700

Shum JK, Melendez JA, and Jeffrey JJ (2002) Serotonin-induced MMP-13 production is mediated via phospholipase C, protein kinase C, and ERK1/2 in rat uterine smooth muscle cells. J Biol Chem 277:42830-42840.

Sia TC, Whiting M, Kyloh M, Nicholas SJ, Oliver J, Brookes SJ, Dinning PG, Wattchow DA, and Spencer NJ (2013) 5-HT3 and 5-HT4 antagonists inhibit peristaltic contractions in guinea-pig distal colon by mechanisms independent of endogenous 5-HT. Front Neurosci 7:136

Sim LJ, Xiao R, and Childers SR (1997) In vitro autoradiographic localization of 5-HT1A receptor-activated G-proteins in the rat brain. Brain Res Bull 44:39-45.

Simmons M, Meador-Woodruff JH, and Sodhi MS (2010) Increased cortical expression of an RNA editing enzyme occurs in major depressive suicide victims. $\mathrm{Neu}$ roreport 21:993-997.

Simonin F, Karcher P, Boeuf JJ, Matifas A, and Kieffer BL (2004) Identification of a novel family of $\mathrm{G}$ protein-coupled receptor associated sorting proteins. J Neurochem 89:766-775.

Singer JH, Bellingham MC, and Berger AJ (1996) Presynaptic inhibition of glutamatergic synaptic transmission to rat motoneurons by serotonin. J Neurophysiol 76:799-807.

Singh M, Singh MM, Na E, Agassandian K, Zimmerman MB, and Johnson AK (2011) Altered ADAR 2 equilibrium and $5 \mathrm{HT}(2 \mathrm{C}) \mathrm{R}$ editing in the prefrontal cortex of ADAR 2 transgenic mice. Genes Brain Behav 10:637-647.

Singh N, Halliday AC, Thomas JM, Kuznetsova OV, Baldwin R, Woon EC, Aley PK, Antoniadou I, Sharp T, Vasudevan SR, et al. (2013) A safe lithium mimetic for bipolar disorder. Nat Commun 4:1332.

Singh VP, Jain NK, and Kulkarni SK (2003) Fluoxetine suppresses morphine tolerance and dependence: modulation of NO-cGMP/DA/serotoninergic pathways. Methods Find Exp Clin Pharmacol 25:273-280.

Siuciak JA, Chapin DS, McCarthy SA, Guanowsky V, Brown J, Chiang P, Marala R, Patterson T, Seymour PA, Swick A, et al. (2007) CP-809,101, a selective 5-HT2C agonist, shows activity in animal models of antipsychotic activity. Neuropharmacology 52:279-290.

Skingle M, Beattie DT, Scopes DI, Starkey SJ, Connor HE, Feniuk W, and Tyers MB (1996) GR127935: a potent and selective 5-HT1D receptor antagonist. Behav Brain Res 73:157-161.

Sleight AJ, Boess FG, Bös M, Levet-Trafit B, Riemer C, and Bourson A (1998) Characterization of $\mathrm{R}_{0}$ 04-6790 and $\mathrm{R}_{0}$ 63-0563: potent and selective antagonists at human and rat 5-HT6 receptors. Br J Pharmacol 124:556-562.

Sleight AJ, Carolo C, Petit N, Zwingelstein C, and Bourson A (1995) Identification of 5-hydroxytryptamine7 receptor binding sites in rat hypothalamus: sensitivity to chronic antidepressant treatment. Mol Pharmacol 47:99-103.

Sleight AJ, Stam NJ, Mutel V, and Vanderheyden PM (1996) Radiolabelling of the human 5-HT2A receptor with an agonist, a partial agonist and an antagonist: effects on apparent agonist affinities. Biochem Pharmacol 51:71-76.

Slominski A, Pisarchik A, and Wortsman J (2004) Expression of genes coding melatonin and serotonin receptors in rodent skin. Biochim Biophys Acta 1680: $67-70$

Slominski A, Pisarchik A, Zbytek B, Tobin DJ, Kauser S, and Wortsman J (2003) Functional activity of serotoninergic and melatoninergic systems expressed in the skin. J Cell Physiol 196:144-153.

Smeraldi E (1998) Amisulpride versus fluoxetine in patients with dysthymia or major depression in partial remission: a double-blind, comparative study. J Affect Disord 48:47-56.

Smith AK, Dimulescu I, Falkenberg VR, Narasimhan S, Heim C, Vernon SD, and Rajeevan MS (2008) Genetic evaluation of the serotonergic system in chronic fatigue syndrome. Psychoneuroendocrinology 33:188-197.

Smith C, Toohey N, Knight JA, Klein MT, and Teitler M (2011) Risperidone-induced inactivation and clozapine-induced reactivation of rat cortical astrocyte 5-hydroxytryptamine ${ }_{7}$ receptors: evidence for in situ G protein-coupled receptor homodimer protomer cross-talk. Mol Pharmacol 79:318-325.

Smith DE, Raswyck GE, and Davidson LD (2014a) From Hofmann to the Haight Ashbury, and into the future: the past and potential of lysergic acid diethlyamide. $J$ Psychoactive Drugs 46:3-10.

Smith MI, Banner SE, and Sanger GJ (1999) 5- $\mathrm{HT}_{4}$ receptor antagonism potentiates inhibition of intestinal allodynia by $5-\mathrm{HT}_{3}$ receptor antagonism in conscious rats. Neurosci Lett 271:61-64.

Smith RM, Papp AC, Webb A, Ruble CL, Munsie LM, Nisenbaum LK, Kleinman JE Lipska BK, and Sadee W (2013) Multiple regulatory variants modulate expression of 5-hydroxytryptamine 2A receptors in human cortex. Biol Psychiatry 73:546-554. 
Smith SR, Prosser WA, Donahue DJ, Morgan Me, Anderson CM, Shanahan WR, and Group S (2009) Lorcaserin (APD356), a selective 5-HT(2C) agonist, reduce body weight in obese men and women. Obesity(SilverSpring) 17:494-503.

Smith TK, Dickson EJ, Heredia DJ, Hennig GW, and Bayguinov PO (2010) Controversies involving the role of 5-hydroxytryptamine in generating colonic migrating motor complexes: what is spontaneous? Gastroenterology 138:1213-1214, author reply $1214-1215$.

Smith TK and Gershon MD (2015a) CrossTalk proposal: 5-HT is necessary for peristalsis. J Physiol 593:3225-3227.

Smith TK and Gershon MD (2015b) Rebuttal from Terence K. Smith and Michael D. Gershon. J Physiol 593:3233.

Smith TK, Park KJ, and Hennig GW (2014b) Colonic migrating motor complexes, high amplitude propagating contractions, neural reflexes and the importance of neuronal and mucosal serotonin. J Neurogastroenterol Motil 20:423-446.

Snigdha S and Neill JC (2008) Improvement of phencyclidine-induced social behaviour deficits in rats: involvement of 5-HT1A receptors. Behav Brain Res 191:26-31.

Snoeren EM, Veening JG, Olivier B, and Oosting RS (2014a) Serotonin 1A receptors and sexual behavior in male rats: a review. Pharmacol Biochem Behav 121: $102-114$

Snoeren EM, Veening JG, Olivier B, and Oosting RS (2014b) Serotonin 1A receptors and sexual behavior in female rats: a review. Pharmacol Biochem Behav 121: $43-52$

Sodhi MSK, Airey DC, Lambert W, Burnet PWJ, Harrison PJ, and Sanders-Bush E (2005) A rapid new assay to detect RNA editing reveals antipsychotic-induced changes in serotonin-2C transcripts. Mol Pharmacol 68:711-719.

Söhle J, Machuy N, Smailbegovic E, Holtzmann U, Grönniger E, Wenck H, Stäb F, and Winnefeld M (2012) Identification of new genes involved in human adipogenesis and fat storage. PLoS One 7:e31193.

Sohn JW, Xu Y, Jones JE, Wickman K, Williams KW, and Elmquist JK (2011) Serotonin $2 \mathrm{C}$ receptor activates a distinct population of arcuate pro-opiomelanocortin neurons via TRPC channels. Neuron 71:488-497.

Sole MJ, Madapallimattam A, Baines, and AD (1986) An active pathway for serotonin synthesis by renal proximal tubules. Kidney Int 29:689-694.

Soler Artigas, M, Loth, DW, Wain, LV, Gharib, SA, Obeidat, M, Tang, W, Zhai, G, Zhao, JH, Smith, AV, Huffman, JE, et al.; International Lung Cancer Consortium, GIANT consortium (2011) Genome-wide association and large-scale follow up identifies 16 new loci influencing lung function. Nat Genet 43:1082-1090.

Soll C, Jang JH, Riener M-O, Moritz W, Wild PJ, Graf R, and Clavien P-A (2010) Serotonin promotes tumor growth in human hepatocellular cancer. Hepatology $\mathbf{5 1}$ $1244-1254$

Soll C, Riener M-O, Oberkofler CE, Hellerbrand C, Wild PJ, DeOliveira ML, and Clavien P-A (2012) Expression of serotonin receptors in human hepatocellular cancer. Clin Cancer Res 18:5902-5910.

Solt K, Stevens RJ, Davies PA, and Raines DE (2005) General anesthetic-induced channel gating enhancement of 5-hydroxytryptamine type 3 receptors depends on receptor subunit composition. J Pharmacol Exp Ther 315:771-776.

Somerville EM, Horwood JM, Lee MD, Kennett GA, and Clifton PG (2007) 5-HT(2C) receptor activation inhibits appetitive and consummatory components of feeding and increases brain c-fos immunoreactivity in mice. Eur $J$ Neurosci 25:3115-3124.

Song C and Leonard BE (2005) The olfactory bulbectomised rat as a model of depression. Neurosci Biobehav Rev 29:627-647.

Song HR, Gu A, and Schanen NC (1999) Identification of a new polymorphism in the 3 -untranslated region of the human serotonin receptor $2 \mathrm{C}$ (5-HT2C) gene. $\mathrm{Mol}$ Genet Metab 66:224-227.

Southwick SM, Krystal JH, Bremner JD, Morgan CA III, Nicolaou AL, Nagy LM, Johnson DR, Heninger GR, and Charney DS (1997) Noradrenergic and serotonergic function in posttraumatic stress disorder. Arch Gen Psychiatry 54:749-758.

Sparkes RS, Lan N, Klisak I, Mohandas T, Diep A, Kojis T, Heinzmann C, and Shih JC (1991) Assignment of a serotonin 5HT-2 receptor gene (HTR2) to human chromosome 13q14-q21 and mouse chromosome 14. Genomics 9:461-465.

Speake T, Kibble JD, and Brown PD (2004) Kv1.1 and Kv1.3 channels contribute to the delayed-rectifying $\mathrm{K}+$ conductance in rat choroid plexus epithelial cells. Am J Physiol Cell Physiol 286:C611-C620.

Spedding M, Newman-Tancredi A, Millan MJ, Dacquet C, Michel AN, Jacoby E, Vickery B, and Tallentire D (1998) Interaction of the anxiogenic agent, RS-30199, with 5-HT1A receptors: modulation of sexual activity in the male rat. Neuropharmacology 37:769-780.

Spencer NJ, Sia TC, Brookes SJ, Costa M, and Keating DJ (2015a) CrossTalk opposing view: 5-HT is not necessary for peristalsis. $J$ Physiol 593:3229-3231.

Spencer NJ, Sia TC, Brookes SJ, Costa M, and Keating DJ (2015b) Rebuttal from Nick J. Spencer, Tiong Cheng Sia, Simon J Brookes, Marcello Costa and Damien J. Keating. J Physiol 593:3235.

Speranza L, Chambery A, Di Domenico M, Crispino M, Severino V, Volpicelli F, Leopoldo M, Bellenchi GC, di Porzio U, and Perrone-Capano C (2013) The serotonin receptor 7 promotes neurite outgrowth via ERK and Cdk5 signaling pathways. Neuropharmacology 67:155-167.

Speranza L, Giuliano T, Volpicelli F, De Stefano ME, Lombardi L, Chambery A Lacivita E, Leopoldo M, Bellenchi GC, di Porzio U, et al. (2015) Activation of 5-HT7 receptor stimulates neurite elongation through mTOR, Cdc42 and actin filaments dynamics. Front Behav Neurosci 9:62.

Speranza L, Labus J, Volpicelli F, Guseva D, Lacivita E, Leopoldo M, Bellenchi GC, di Porzio U, Bijata M, Perrone-Capano C, et al. (2017) Serotonin 5-HT7 receptor increases the density of dendritic spines and facilitates synaptogenesis in forebrain neurons. J Neurochem 141:647-661.

Spiller R (2008a) Serotonin and GI clinical disorders. Neuropharmacology 55 $1072-1080$

Spiller R (2008b) Serotonergic agents and the irritable bowel syndrome: what goes wrong? Curr Opin Pharmacol 8:709-714.

Spiller RC (2011) Targeting the 5-HT(3) receptor in the treatment of irritable bowel syndrome. Curr Opin Pharmacol 11:68-74.
Sprouse JS, Reynolds LS, Braselton JP, Rollema H, and Zorn SH (1999) Comparison of the novel antipsychotic ziprasidone with clozapine and olanzapine: inhibition of dorsal raphe cell firing and the role of 5-HT1A receptor activation. Neuropsychopharmacology 21:622-631.

Sprouse J, Reynolds L, Li X, Braselton J, and Schmidt A (2004) 8-OH-DPAT as a 5-HT7 agonist: phase shifts of the circadian biological clock through increases in cAMP production. Neuropharmacology 46:52-62.

Stacher G, Bergmann H, Schneider C, Steiner-Mittelbach G, Gaupmann G, Stein ringer H, Abatzi TA, and Stacher-Janotta G (1990) Effects of the 5-HT ${ }_{3}$ receptor antagonist ICS 205-930 on fat-delayed gastric emptying and antral motor activity. Br J Clin Pharmacol 30:41-48.

Stahl SM (2015) Mechanism of action of flibanserin, a multifunctional serotonin agonist and antagonist (MSAA), in hypoactive sexual desire disorder. CNS Spectr 20:1-6

Stahl SM, Sommer B, and Allers KA (2011) Multifunctional pharmacology of flibanserin: possible mechanism of therapeutic action in hypoactive sexual desire disorder. J Sex Med 8:15-27.

Stam NJ, Vanderheyden P, van Alebeek C, Klomp J, de Boer T, van Delft AML, and Olijve W (1994) Genomic organisation and functional expression of the gene encoding the human serotonin 5- $\mathrm{HT}_{2 \mathrm{C}}$ receptor. Eur $J$ Pharmacol 269:339-348.

Stam NJ, Van Huizen F, Van Alebeek C, Brands J, Dijkema R, Tonnaer JA and Olijve W (1992) Genomic organization, coding sequence and functional expression of human 5-HT2 and 5-HT1A receptor genes. Eur $J$ Pharmacol 227: 153-162.

Staner L, Kempenaers C, Simonnet MP, Fransolet L, and Mendlewicz J (1992) 5-HT2 receptor antagonism and slow-wave sleep in major depression. Acta Psychiatr Scand 86:133-137.

Stanford IM, Kantaria MA, Chahal HS, Loucif KC, and Wilson CL (2005) 5-Hydroxytryptamine induced excitation and inhibition in the subthalamic nucleus: action at 5-HT(2C), 5-HT(4) and 5-HT(1A) receptors. Neuropharmacology 49: $1228-1234$

Stanton JA and Beer MS (1997) Characterisation of a cloned human 5-HT1A receptor cell line using [35S]GTP gamma S binding. Eur J Pharmacol 320:267-275.

Stanton JA, Middlemiss DN, and Beer MS (1996) Autoradiographic localization of 5-CT-insensitive 5-HT1-like recognition sites in guinea pig and rat brain. Neuropharmacology 35:223-229.

Starr KR, Price GW, Watson JM, Atkinson PJ, Arban R, Melotto S, Dawson LA Hagan JJ, Upton N, and Duxon MS (2007) SB-649915-B, a novel 5-HT1A/B autoreceptor antagonist and serotonin reuptake inhibitor, is anxiolytic and displays fast onset activity in the rat high light social interaction test. Neuropsychopharmacology 32:2163-2172.

Steed E, Jones CA, and McCreary AC (2011) Serotonergic involvement in methamphetamine-induced locomotor activity: a detailed pharmacological study. Behav Brain Res 220:9-19.

Stefulj J, Jernej B, Cicin-Sain L, Rinner I, and Schauenstein K (2000) mRNA expression of serotonin receptors in cells of the immune tissues of the rat. Brain Behav Immun 14:219-224.

Stein C, Davidowa H, and Albrecht D (2000) 5- $\mathrm{HT}_{1 \mathrm{~A}}$ receptor-mediated inhibition and $5-\mathrm{HT}_{2}$ as well as $5-\mathrm{HT}_{3}$ receptor-mediated excitation in different subdivisions of the rat amygdala. Synapse 38:328-337.

Stein DJ, Miczek KA, Lucion AB, and de Almeida RM (2013) Aggression-reducing effects of F15599, a novel selective 5-HT1A receptor agonist, after microinjection into the ventral orbital prefrontal cortex, but not in infralimbic cortex in male mice. Psychopharmacology (Berl) 230:375-387.

Stephens EK, Avesar D, and Gulledge AT (2014) Activity-dependent serotonergic excitation of callosal projection neurons in the mouse prefrontal cortex. Front Neural Circuits 8:97.

Stevens R, Rüsch D, Solt K, Raines DE, and Davies PA (2005) Modulation of human 5 -hydroxytryptamine type $3 \mathrm{AB}$ receptors by volatile anesthetics and n-alcohols. $J$ Pharmacol Exp Ther 314:338-345.

Stier CT Jr and Itskovitz HD (1985) Formation of serotonin by rat kidneys in vivo. Proc Soc Exp Biol Med 180:550-557.

Stone TW and Darlington LG (2002) Endogenous kynurenines as targets for drug discovery and development. Nat Rev Drug Discov 1:609-620.

Storer RI, Brennan PE, Brown AD, Bungay PJ, Conlon KM, Corbett MS, DePianta RP, Fish PV, Heifetz A, Ho DK, et al. (2014) Multiparameter optimization in CNS drug discovery: design of pyrimido[4,5-d]azepines as potent 5-hydroxytryptamine $2 \mathrm{C}\left(5-\mathrm{HT}_{2} \mathrm{C}\right)$ receptor agonists with exquisite functional selectivity over $5-\mathrm{HT}_{2} \mathrm{~A}$ and 5- $\mathrm{HT}_{2} \mathrm{~B}$ receptors. J Med Chem 57:5258-5269.

Stowe RL and Barnes NM (1998) Selective labelling of 5-HT7 receptor recognition sites in rat brain using $[3 \mathrm{H}] 5$-carboxamidotryptamine. Neuropharmacology $\mathbf{3 7}$ $1611-1619$

Stoyanova II and Gulubova MV (2002) Mast cells and inflammatory mediators in chronic ulcerative colitis. Acta Histochem 104:185-192.

Strachan RT, Sheffler DJ, Willard B, Kinter M, Kiselar JG, and Roth BL (2009) Ribosomal S6 kinase 2 directly phosphorylates the 5-hydroxytryptamine 2A (5HT2A) serotonin receptor, thereby modulating 5-HT2A signaling. J Biol Chem 284 $5557-5573$

Stratz C, Trenk D, Bhatia HS, Valina C, Neumann FJ, and Fiebich BL (2008) Identification of 5-HT3 receptors on human platelets: increased surface immunoreactivity after activation with adenosine diphosphate (ADP) and thrombin receptor-activating peptide (TRAP). Thromb Haemost 99:784-786.

Strong PV, Christianson JP, Loughridge AB, Amat J, Maier SF, Fleshner M, and Greenwood $\mathrm{BN}$ (2011) 5-hydroxytryptamine $2 \mathrm{C}$ receptors in the dorsal striatum mediate stress-induced interference with negatively reinforced instrumenta escape behavior. Neuroscience 197:132-144.

Strong PV, Greenwood BN, and Fleshner M (2009) The effects of the selective 5 -HT(2C) receptor antagonist SB 242084 on learned helplessness in male Fischer 344 rats. Psychopharmacology (Berl) 203:665-675. 
Stroth N and Svenningsson P (2015) S100B interacts with the serotonin 5-HT7 receptor to regulate a depressive-like behavior. Eur Neuropsychopharmacol 25: $2372-2380$.

Stunes AK, Reseland JE, Hauso O, Kidd M, Tømmerås K, Waldum HL, Syversen U, and Gustafsson BI (2011) Adipocytes express a functional system for serotonin synthesis, reuptake and receptor activation. Diabetes Obes Metab 13:551-558.

Suchanek B, Struppeck H, and Fahrig T (1998) The 5-HT1A receptor agonist BAY x 3702 prevents staurosporine-induced apoptosis. Eur J Pharmacol 355:95-101.

Sugai T, Suzuki Y, Sawamura K, Fukui N, Inoue Y, and Someya T (2006) The effect of 5 -hydroxytryptamine $3 \mathrm{~A}$ and $3 \mathrm{~B}$ receptor genes on nausea induced by paroxetine. Pharmacogenomics $J$ 6:351-356.

Sugimoto Y, Takashima N, Noma T, and Yamada J (2005) Inhibitory effects of the 5 -HT(1A) receptor agonist buspirone on stress-induced hyperglycemia in mice: involvement of insulin and a buspirone metabolite, 1-(2-pyrimidinyl)piperazine (1PP). Biol Pharm Bull 28:733-735.

Sugimoto Y, Yamada J, and Horisaka K (1991) Activation of peripheral serotonin2 receptors induces hypothermia in mice. Life Sci 48:419-423.

Sugiuar T, Bielefeldt K, and Gebhart GF (2004) TRPV1 function in mouse colon sensory neurons is enhanced by metabotropic 5-hydroxytryptamine receptor activation. $J$ Neurosci 24:9521-9530.

Sukma M, Tohda M, Watanabe H, and Matsumoto K (2005) The mRNA expression differences of RNA editing enzymes in differentiated and undifferentiated NG10815 cells. J Pharmacol Sci 98:467-470.

Sullivan LC, Clarke WP, and Berg KA (2015) Atypical antipsychotics and inverse agonism at 5-HT2 receptors. Curr Pharm Des 21:3732-3738.

Sumara G, Sumara O, Kim JK, and Karsenty G (2012) Gut-derived serotonin is a multifunctional determinant to fasting adaptation. Cell Metab 16:588-600.

Sumiyoshi T, Higuchi Y, Matsui M, Arai H, Takamiya C, Meltzer HY, and Kurachi M (2007) Effective adjunctive use of tandospirone with perospirone for enhancing verbal memory and quality of life in schizophrenia. Prog Neuropsychopharmacol Biol Psychiatry 31:965-967.

Sumiyoshi T, Matsui M, Nohara S, Yamashita I, Kurachi M, Sumiyoshi C, Jayathilake K, and Meltzer HY (2001a) Enhancement of cognitive performance in schizophrenia by addition of tandospirone to neuroleptic treatment. Am J Psychiatry 158:1722-1725

Sumiyoshi T, Matsui M, Yamashita I, Nohara S, Kurachi M, Uehara T, Sumiyoshi S, Sumiyoshi C, and Meltzer HY (2001b) The effect of tandospirone, a serotonin(1A) agonist, on memory function in schizophrenia. Biol Psychiatry 49:861-868.

Sung DJ, Noh HJ, Kim JG, Park SW, Kim B, Cho H, and Bae YM (2013) Serotonin contracts the rat mesenteric artery by inhibiting 4-aminopyridine-sensitive $\mathrm{Kv}$ channels via the 5-HT2A receptor and Src tyrosine kinase. Exp Mol Med 45:e67.

Suwa B, Bock N, Preusse S, Rothenberger A, and Manzke T (2014) Distribution of serotonin 4(a) receptors in the juvenile rat brain and spinal cord. J Chem Neuroanat 55:67-77.

Svejda B, Kidd M, Giovinazzo F, Eltawil K, Gustafsson BI, Pfragner R, and Modlin IM (2010) The 5-HT( $\left.{ }_{2 \mathrm{~B}}\right)$ receptor plays a key regulatory role in both neuroendocrine tumor cell proliferation and the modulation of the fibroblast component of the neoplastic microenvironment. Cancer 116:2902-2912.

Svenningsson P (2014) Reductions of p11 and 5-HT1B receptor availability in limbic brain regions in cocaine dependence. Biol Psychiatry 76:763-764.

Svenningsson P, Chergui K, Rachleff I, Flajolet M, Zhang X, El Yacoubi M, Vaugeois JM, Nomikos GG, and Greengard P (2006) Alterations in 5-HT1B receptor function by 11 in depression-like states. Science 311:77-80.

Svenningsson P and Greengard P (2007) p11 (S100A10)-an inducible adaptor protein that modulates neuronal functions. Curr Opin Pharmacol 7:27-32.

Svenningsson P, Kim Y, Warner-Schmidt J, Oh YS, and Greengard P (2013) p11 and its role in depression and therapeutic responses to antidepressants. Nat Rev Neurosci 14:673-680

Svenningsson P, Rosenblad C, Af Edholm Arvidsson K, Wictorin K, Keywood C, Shankar B, Lowe DA, Björklund A, and Widner H (2015) Eltoprazine counteracts l-DOPA-induced dyskinesias in Parkinson's disease: a dose-finding study. Brain 138:963-973.

Svenningsson P, Tzavara ET, Liu F, Fienberg AA, Nomikos GG, and Greengard P (2002) DARPP-32 mediates serotonergic neurotransmission in the forebrain. Proc Natl Acad Sci USA 99:3188-3193.

Svenningsson P, Tzavara ET, Qi H, Carruthers R, Witkin JM, Nomikos GG, and Greengard P (2007) Biochemical and behavioral evidence for antidepressantlike effects of 5-HT6 receptor stimulation. J Neurosci 27:4201-4209.

Swinford-Jackson SE, Anastasio NC, Fox RG, Stutz SJ, and Cunningham KA (2016) Incubation of cocaine cue reactivity associates with neuroadaptations in the cortical serotonin (5-HT) 5-HT2C receptor (5-HT2CR) system. Neuroscience 324:50-61.

Tack J, Caenepeel P, Corsetti M, and Janssens J (2004) Role of tension receptors in dyspeptic patients with hypersensitivity to gastric distention. Gastroenterology 127:1058-1066.

Tack J, Camilleri M, Chang L, Chey WD, Galligan JJ, Lacy BE, Müller-Lissner S, Quigley EM, Schuurkes J, De Maeyer JH, et al. (2012) Systematic review: cardiovascular safety profile of 5-HT(4) agonists developed for gastrointestinal disorders. Aliment Pharmacol Ther 35:745-767.

Tack J, Quigley E, Camilleri M, Vandeplassche L, and Kerstens R (2013) Efficacy and safety of oral prucalopride in women with chronic constipation in whom laxatives have failed: an integrated analysis. United European Gastroenterol J 1:48-59.

Tack J, Stanghellini V, Dubois D, Joseph A, Vandeplassche L, and Kerstens R (2014) Effect of prucalopride on symptoms of chronic constipation. Neurogastroenterol Motil 26:21-27.

Tack J, Van Den Elzen B, Tytgat G, Wajs E, Van Nueten L, De Ridder F, and Boeckxstaens G (2009) A placebo-controlled trial of the 5-HT $1 \mathrm{~A}$ agonist R-137696 on symptoms, visceral hypersensitivity and on impaired accommodation in functional dyspepsia. Neurogastroenterol Motil 21:619-626, e23-e24.
Tadros SF, D’Souza M, Zettel ML, Zhu X, Lynch-Erhardt M, and Frisina RD (2007) Serotonin $2 \mathrm{~B}$ receptor: upregulated with age and hearing loss in mouse auditory system. Neurobiol Aging 28:1112-1123.

Takahashi A, Quadros IM, de Almeida RM, and Miczek KA (2012) Behavioral and pharmacogenetics of aggressive behavior. Curr Top Behav Neurosci 12:73-138.

Takaki M, Goto K, and Kawahara I (2014) The 5-hydroxytryptamine 4 receptor agonist-induced actions and enteric neurogenesis in the gut. $J$ Neurogastroenterol Motil 20:17-30.

Talbot JN, Jutkiewicz EM, Graves SM, Clemans CF, Nicol MR, Mortensen RM, Huang X, Neubig RR, and Traynor JR (2010) RGS inhibition at G(alpha)i2 selectively potentiates 5-HT1A-mediated antidepressant effects. Proc Natl Acad Sci USA 107:11086-11091.

Talley EM, Lei Q, Sirois JE, and Bayliss DA (2000) TASK-1, a two-pore domain K+ channel, is modulated by multiple neurotransmitters in motoneurons. Neuron 25: 399-410.

Talley NJ (2015) Functional dyspepsia and the Rome criteria: a success story. Neurogastroenterol Motil 27:1052-1056.

Talley NJ, Phillips SF, Haddad A, Miller LJ, Twomey C, Zinsmeister AR, MacCarty $\mathrm{RL}$, and Ciociola A (1990) GR $38032 \mathrm{~F}$ (ondansetron), a selective $5 \mathrm{HT}_{3}$ receptor antagonist, slows colonic transit in healthy man. Dig Dis Sci 35:477-480.

Talley NJ, Van Zanten SV, Saez LR, Dukes G, Perschy T, Heath M, Kleoudis C, and Mangel AW (2001) A dose-ranging, placebo-controlled, randomized trial of alosetron in patients with functional dyspepsia. Aliment Pharmacol Ther 15: 525-537.

Tan PZ, Baldwin RM, van Dyck CH, Al Tikriti M, Roth B, Khan N, Charney DS, and Innis RB (1999) Characterization of radioactive metabolites of 5-HT2A receptor PET ligand $\left[{ }^{18} \mathrm{~F}\right]$ altanserin in human and rodent. Nucl Med Biol 26: $601-608$

Tanaka E and North RA (1993) Actions of 5-hydroxytryptamine on neurons of the rat cingulate cortex. $J$ Neurophysiol 69:1749-1757.

Tanaka KF, Samuels BA, and Hen R (2012) Serotonin receptor expression along the dorsal-ventral axis of mouse hippocampus. Philos Trans $R$ Soc Lond B Biol Sci $\mathbf{3 6 7}$. $2395-2401$

Tanaka M, Kobayashi D, Murakami Y, Ozaki N, Suzuki T, Iwata N, Haraguchi K, Ieiri I, Kinukawa N, Hosoi M, et al. (2008a) Genetic polymorphisms in the 5 -hydroxytryptamine type $3 \mathrm{~B}$ receptor gene and paroxetine-induced nausea. Int $J$ Neuropsychopharmacol 11:261-267.

Tanaka N, Nakamura E, Ohkura M, Kuwabara M, Yamashita A, Onitsuka T, Asada Y, Hisa H, and Yamamoto R (2008b) Both 5-hydroxytryptamine 5-HT2A and 5 -HT1B receptors are involved in the vasoconstrictor response to 5-HT in the human isolated internal thoracic artery. Clin Exp Pharmacol Physiol 35:836-840.

Tanaka T, Serneo FF, Tseng HC, Kulkarni AB, Tsai LH, and Gleeson JG (2004) Cdk5 phosphorylation of doublecortin ser297 regulates its effect on neuronal migration. Neuron 41:215-227.

Tang G, Gudsnuk K, Kuo SH, Cotrina ML, Rosoklija G, Sosunov A, Sonders MS, Kanter E, Castagna C, Yamamoto A, et al. (2014a) Loss of mTOR-dependent macroautophagy causes autistic-like synaptic pruning deficits. Neuron $\mathbf{8 3}$ 1131-1143.

Tang H, Dalton CF, Srisawat U, Zhang ZJ, and Reynolds GP (2014b) Methylation at a transcription factor-binding site on the 5-HT1A receptor gene correlates with negative symptom treatment response in first episode schizophrenia. Int $\mathrm{J} \mathrm{Neu}$ ropsychopharmacol 17:645-649.

Tang L, Todd RD, Heller A, and O'Malley KL (1994) Pharmacological and functional characterization of D2, D3 and D4 dopamine receptors in fibroblast and dopaminergic cell lines. J Pharmacol Exp Ther 268:495-502.

Tao R and Auerbach SB (1994) Increased extracellular serotonin in rat brain after systemic or intraraphe administration of morphine. J Neurochem 63:517-524.

Tao R, Ma Z, and Auerbach SB (1998) Alteration in regulation of serotonin release in rat dorsal raphe nucleus after prolonged exposure to morphine. J Pharmacol Exp Ther 286:481-488.

Tarsy D and Baldessarini RJ (1984) Tardive dyskinesia. Annu Rev Med 35:605-623. Tarsy D, Baldessarini RJ, and Tarazi FI (2002) Effects of newer antipsychotics on extrapyramidal function. CNS Drugs 16:23-45.

Tartaglia LA, Dembski M, Weng X, Deng N, Culpepper J, Devos R, Richards GJ, Campfield LA, Clark FT, Deeds J, et al. (1995) Identification and expression cloning of a leptin receptor, OB-R. Cell 83:1263-1271.

Tassone A, Madeo G, Schirinzi T, Vita D, Puglisi F, Ponterio G, Borsini F, Pisani A, and Bonsi P (2011) Activation of 5-HT6 receptors inhibits corticostriatal glutamatergic transmission. Neuropharmacology 61:632-637.

Tavares AA, Caillé F, Barret O, Papin C, Lee H, Morley TJ, Fowles K, Holden D, Seibyl JP, Alagille D, et al. (2014) In vivo evaluation of 18F-MNI698: an 18Flabeled radiotracer for imaging of serotonin 4 receptors in brain. J Nucl Med $\mathbf{5 5}$ : 858-864.

Taylor DP, Eison MS, Riblet LA, and Vandermaelen CP (1985) Pharmacological and clinical effects of buspirone. Pharmacol Biochem Behav 23:687-694.

Taylor SF, Tandon R, Shipley JE, and Eiser AS (1991) Effect of neuroleptic treatment on polysomnographic measures in schizophrenia. Biol Psychiatry 30:904-912.

Teal P, Davis S, Hacke W, Kaste M, Lyden PD, and Fierus M; Modified Randomized Exposure Controlled Trial Study Investigators; Bayer HealthCare AG (2009) A randomized, double-blind, placebo-controlled trial to evaluate the efficacy, safety, tolerability, and pharmacokinetic/pharmacodynamic effects of a targeted exposure of intravenous repinotan in patients with acute ischemic stroke: modified Randomized Exposure Controlled Trial (mRECT). Stroke 40:3518-3525.

Tecott L and Brennan TJ (2000) Serotonin 5-HT6 receptor knockout mouse. The Regents of the University of California (Oakland, CA), United States, 6060642.

Tecott LH, Sun LM, Akana SF, Strack AM, Lowenstein DH, Dallman MF, and Julius D (1995) Eating disorder and epilepsy in mice lacking 5-HT2c serotonin receptors. Nature 374:542-546. 
Teitler M and Klein MT (2012) A new approach for studying GPCR dimers: druginduced inactivation and reactivation to reveal GPCR dimer function in vitro, in primary culture, and in vivo. Pharmacol Ther 133:205-217.

Teitler M, Toohey N, Knight JA, Klein MT, and Smith C (2010) Clozapine and other competitive antagonists reactivate risperidone-inactivated h5-HT7 receptors: radioligand binding and functional evidence for GPCR homodimer protomer interactions. Psychopharmacology (Berl) 212:687-697.

Temkin P, Lauffer B, Jäger S, Cimermancic P, Krogan NJ, and von Zastrow M (2011) SNX27 mediates retromer tubule entry and endosome-to-plasma membrane trafficking of signalling receptors. Nat Cell Biol 13:715-721.

Templeman LA, Reynolds GP, Arranz B, and San L (2005) Polymorphisms of the 5-HT2C receptor and leptin genes are associated with antipsychotic drug-induced weight gain in Caucasian subjects with a first-episode psychosis. Pharmacogenet Genomics 15:195-200.

Terranova JP, Chabot C, Barnouin MC, Perrault G, Depoortere R, Griebel G, and Scatton B (2005) SSR181507, a dopamine $\mathrm{D}(2)$ receptor antagonist and 5 -HT(1A) receptor agonist, alleviates disturbances of novelty discrimination in a social context in rats, a putative model of selective attention deficit. Psychopharmacology (Berl) 181:134-144.

Terrón JA (1996) The relaxant 5-HT receptor in the dog coronary artery smooth muscle: pharmacological resemblance to the cloned 5-ht7 receptor subtype. $\mathrm{Br} J$ Pharmacol 118:1421-1428.

Terrón JA, Bouchelet I, and Hamel E (2001) 5-HT7 receptor mRNA expression in human trigeminal ganglia. Neurosci Lett 302:9-12.

Terry AV Jr, Buccafusco JJ, Jackson WJ, Prendergast MA, Fontana DJ, Wong EH, Bonhaus DW, Weller P, and Eglen RM (1998) Enhanced delayed matching performance in younger and older macaques administered the 5-HT4 receptor agonist, RS 17017. Psychopharmacology (Berl) 135:407-415.

Tesseur I, Pimenova AA, Lo AC, Ciesielska M, Lichtenthaler SF, De Maeyer JH, Schuurkes JA, D'Hooge R, and De Strooper B (2013) Chronic 5-HT4 receptor activation decreases $\mathrm{A} \beta$ production and deposition in hAPP/PS1 mice. Neurobiol Aging 34:1779-1789.

Tian MK, Schmidt EF, and Lambe EK (2016) Serotonergic suppression of mouse prefrontal circuits implicated in task attention. eNeuro 3:ENEURO.0269-16.2016.

Tharayil VS, Wouters MM, Stanich JE, Roeder JL, Lei S, Beyder A, Gomez-Pinilla PJ, Gershon MD, Maroteaux L, Gibbons SJ, et al. (2010) Lack of serotonin 5-HT $\mathrm{H}_{2 \mathrm{~B}}$ receptor alters proliferation and network volume of interstitial cells of Cajal in vivo. Neurogastroenterol Motil 22:462-469, e109-e110.

Theisen FM, Hinney A, Brömel T, Heinzel-Gutenbrunner M, Martin M, Krieg JC, Remschmidt H, and Hebebrand $\mathrm{J}$ (2004) Lack of association between the -759C/T polymorphism of the 5-HT2C receptor gene and clozapine-induced weight gain among German schizophrenic individuals. Psychiatr Genet 14:139-142.

Thomas DR (2006) 5-ht5A receptors as a therapeutic target. Pharmacol Ther 111: 707-714.

Thomas DR, Atkinson PJ, Hastie PG, Roberts JC, Middlemiss DN, and Price GW (2002) $[3 \mathrm{H}]-\mathrm{SB}-269970$ radiolabels 5 -HT7 receptors in rodent, pig and primate brain tissues. Neuropharmacology 42:74-81.

Thomas DR and Hagan JJ (2004) 5-HT7 receptors. Curr Drug Targets CNS Neurol Disord 3:81-90.

Thomas DR, Larminie CG, Lyons HR, Fosberry A, Hill MJ, and Hayes PD (2004) Cloning and pharmacological characterisation of the guinea pig 5-ht5A receptor. Eur $J$ Pharmacol 494:91-99.

Thomas DR, Melotto S, Massagrande M, Gribble AD, Jeffrey P, Stevens AJ, Deeks NJ, Eddershaw PJ, Fenwick SH, Riley G, et al. (2003) SB-656104-A, a novel selective 5-HT7 receptor antagonist, modulates REM sleep in rats. $\mathrm{Br} J$ Pharmacol 139:705-714

Thomas DR, Soffin EM, Roberts C, Kew JNC, de la Flor RM, Dawson LA, Fry VA, Coggon SA, Faedo S, Hayes PD, et al. (2006) SB-699551-A (3-cyclopentyl-N-[2 (dimethylamino)ethyl]-N-[(4'-[(2-phenylethyl)amino]methyl-4-biphenylyl)methyl]propanamide dihydrochloride), a novel 5-ht5A receptor-selective antagonist, enhances 5-HT neuronal function: evidence for an autoreceptor role for the 5-ht5A receptor in guinea pig brain. Neuropharmacology 51:566-577.

Thomas EA, Carson MJ, Neal MJ, and Sutcliffe JG (1997a) Unique allosteric regulation of 5-hydroxytryptamine receptor-mediated signal transduction by oleamide. Proc Natl Acad Sci USA 94:14115-14119.

Thomas EA, Carson MJ, and Sutcliffe JG (1998) Oleamide-induced modulation of 5-hydroxytryptamine receptor-mediated signaling. Ann N Y Acad Sci 861:183-189.

Thomas EA, Cravatt BF, Danielson PE, Gilula NB, and Sutcliffe JG (1997b) Fatty acid amide hydrolase, the degradative enzyme for anandamide and oleamide, has selective distribution in neurons within the rat central nervous system. $J$ Neurosci Res 50:1047-1052.

Thomas EA, Cravatt BF, and Sutcliffe JG (1999) The endogenous lipid oleamide activates serotonin 5 -HT7 neurons in mouse thalamus and hypothalamus. $J$ Neurochem 72:2370-2378.

Thomas EA, Matli JR, Hu JL, Carson MJ, and Sutcliffe JG (2000) Pertussis toxin treatment prevents 5-HT(5a) receptor-mediated inhibition of cyclic AMP accumulation in rat C6 glioma cells. J Neurosci Res 61:75-81.

Thomas JM, Dourish CT, Tomlinson JW, Hassan-Smith Z, and Higgs S (2014) Effects of the 5-HT2C receptor agonist meta-chlorophenylpiperazine on appetite, food intake and emotional processing in healthy volunteers. Psychopharmacology (Berl) 231:2449-2459.

Thompson AJ, Duke RK, and Lummis SC (2011a) Binding sites for bilobalide, diltiazem, ginkgolide, and picrotoxinin at the 5-HT3 receptor. Mol Pharmacol 80 : 183-190.

Thompson AJ, Lester HA, and Lummis SC (2010) The structural basis of function in Cys-loop receptors. Q Rev Biophys 43:449-499.

Thompson AJ and Lummis SC (2003) A single ring of charged amino acids at one end of the pore can control ion selectivity in the 5-HT3 receptor. $\mathrm{Br} J$ Pharmacol 140: $359-365$
Thompson AJ and Lummis SC (2007) The 5-HT3 receptor as a therapeutic target. Expert Opin Ther Targets 11:527-540.

Thompson AJ and Lummis SCR (2013) Discriminating between 5- $\mathrm{HT}_{3} \mathrm{~A}$ and 5- $\mathrm{HT}_{3} \mathrm{AB}$ receptors. $\mathrm{Br} J$ Pharmacol 169:736-747.

Thompson AJ, Price KL, and Lummis SC (2011b) Cysteine modification reveals which subunits form the ligand binding site in human heteromeric 5-HT3AB receptors. J Physiol 589:4243-4257.

Thompson AJ, Sullivan NL, and Lummis SC (2006) Characterization of 5-HT3 receptor mutations identified in schizophrenic patients. J Mol Neurosci 30:273-281.

Thomsen WJ, Grottick AJ, Menzaghi F, Reyes-Saldana H, Espitia S, Yuskin D, Whelan K, Martin M, Morgan M, Chen W, et al. (2008) Lorcaserin, a novel selective human 5-hydroxytryptamine2C agonist: in vitro and in vivo pharmacological characterization. J Pharmacol Exp Ther 325:577-587.

Thorp J, Simon J, Dattani D, Taylor L, Kimura T, Garcia M Jr, Lesko L, and Pyke R DAISY trial investigators (2012) Treatment of hypoactive sexual desire disorder in premenopausal women: efficacy of flibanserin in the DAISY study. J Sex Med $\mathbf{9}$ : 793-804.

Tian Y, Graf R, El-Badry AM, Lesurtel M, Furrer K, Moritz W, and Clavien P-A (2011) Activation of serotonin receptor- ${ }_{2 \mathrm{~B}}$ rescues small-for-size liver graft failure in mice. Hepatology 53:253-262.

Tiniakov R and Scrogin KE (2009) The spleen is required for $5-\mathrm{HT}_{1 \mathrm{~A}}$ receptor agonistmediated increases in mean circulatory filling pressure during hemorrhagic shock in the rat. Am J Physiol Regul Integr Comp Physiol 296:R1392-R1401.

Titeler M, Herrick K, Lyon RA, McKenney JD, and Glennon RA (1985) [ $\left.{ }^{3} \mathrm{H}\right] \mathrm{DOB}$ a specific agonist radioligand for $5-\mathrm{HT}_{2}$ serotonin receptors. Eur J Pharmacol 117: 145-146.

Titeler M, Lyon RA, Davis KH, and Glennon RA (1987) Selectivity of serotonergic drugs for multiple brain serotonin receptors. Role of [3H]-4-bromo-2,5-dimethoxyphenylisopropylamine ([3H]DOB), a 5-HT2 agonist radioligand. Biochem Pharmacol 36:3265-3271.

To ZP, Bonhaus DW, Eglen RM, and Jakeman LB (1995) Characterization and distribution of putative 5-ht7 receptors in guinea-pig brain. $\mathrm{Br} J$ Pharmacol 115: 107-116.

Todd RD and Ciaranello RD (1985) Demonstration of inter- and intraspecies differences in serotonin binding sites by antibodies from an autistic child. Proc Natl Acad Sci USA 82:612-616.

Tohda M, Sukma M, and Watanabe H (2004) RNA editing and short variant of serotonin 2C receptor mRNA in neuronally differentiated NG108-15 cells. $J$ Pharmacol Sci 96:164-169.

Tomkins DM, Joharchi N, Tampakeras M, Martin JR, Wichmann J, and Higgins GA (2002) An investigation of the role of 5-HT(2C) receptors in modifying ethanol selfadministration behaviour. Pharmacol Biochem Behav 71:735-744.

Tong Z, Chandrasekaran A, DeMaio W, Jordan R, Li H, Moore R, Poola N, Burghart P, Hultin T, and Scatina J (2010) Species differences in the formation of vabicaserin carbamoyl glucuronide. Drug Metab Dispos 38:581-590.

Tonini M, Galligan JJ, and North RA (1989) Effects of cisapride on cholinergic neurotransmission and propulsive motility in the guinea pig ileum. Gastroenterology 96:1257-1264.

Tonini M, Messori E, Franceschetti GP, Rizzi CA, Castoldi AF, Coccini T, and Candura SM (1994) Characterization of the 5-HT receptor potentiating neuromuscular cholinergic transmission in strips of human isolated detrusor muscle. Br J Pharmacol 113:1-2.

Tonini M, Vicini R, Cervio E, De Ponti F, De Giorgio R, Barbara G, Stanghellini V, Dellabianca A, and Sternini C (2005) 5-HT7 receptors modulate peristalsis and accommodation in the guinea pig ileum. Gastroenterology 129:1557-1566.

Torrecilla I and Tobin AB (2006) Co-ordinated covalent modification of G-protein coupled receptors. Curr Pharm Des 12:1797-1808.

Toth M, Ding D, and Shenk T (1994) The 5' flanking region of the serotonin 2 receptor gene directs brain specific expression in transgenic animals. Brain Res Mol Brain Res 27:315-319.

Tournois C, Mutel V, Manivet P, Launay JM, and Kellermann O (1998) Cross-talk between 5-hydroxytryptamine receptors in a serotonergic cell line. Involvement of arachidonic acid metabolism. $J$ Biol Chem 273:17498-17503.

Traber J and Glaser T (1987) 5-HT1A receptor-related anxiolytics. Trends Pharmacol Sci 8:432-437.

Trattnig SM, Harpsøe K, Thygesen SB, Rahr LM, Ahring PK, Balle T, and Jensen AA (2012) Discovery of a novel allosteric modulator of 5-HT3 receptors: inhibition and potentiation of Cys-loop receptor signaling through a conserved transmembrane intersubunit site. J Biol Chem 287:25241-25254.

Tremblay PB, Kaiser R, Sezer O, Rosler N, Schelenz C, Possinger K, Roots I, and Brockmoller J (2003) Variations in the 5-hydroxytryptamine type 3B receptor gene as predictors of the efficacy of antiemetic treatment in cancer patients. J Clin Oncol 21:2147-2155.

Tsai SJ, Hong CJ, Yu YW, and Lin CH (2002) -759C/T genetic variation of 5HT(2C) receptor and clozapine-induced weight gain. Lancet 360:1790.

Tschentscher F, Hüsing J, Hölter T, Kruse E, Dresen IG, Jöckel KH, Anastassiou G, Schilling H, Bornfeld N, Horsthemke B, et al. (2003) Tumor classification based on gene expression profiling shows that uveal melanomas with and without monosomy 3 represent two distinct entities. Cancer Res 63:2578-2584.

Tsetlin V and Hucho F (2009) Nicotinic acetylcholine receptors at atomic resolution. Curr Opin Pharmacol 9:306-310.

Tsou AP, Kosaka A, Bach C, Zuppan P, Yee C, Tom L, Alvarez R, Ramsey S, Bonhaus DW, Stefanich E, et al. (1994) Cloning and expression of a 5-hydroxytryptamine7 receptor positively coupled to adenylyl cyclase. J Neurochem 63:456-464.

Tsuji D, Kim YI, Nakamichi H, Daimon T, Suwa K, Iwabe Y, Hayashi H, Inoue K Yoshida M, and Itoh K (2013) Association of ABCB1 polymorphisms with the antiemetic efficacy of granisetron plus dexamethasone in breast cancer patients. Drug Metab Pharmacokinet 28:299-304. 
Tuladhar BR, Ge L, and Naylor RJ (2003) 5-HT 7 receptors mediate the inhibitory effect of 5-HT on peristalsis in the isolated guinea-pig ileum. $\mathrm{Br} J$ Pharmacol 138 : $1210-1214$

Turner JH, Garnovskaya MN, Coaxum SD, Vlasova TM, Yakutovich M, Lefler DM, and Raymond JR (2007) Ca2+-calmodulin and janus kinase 2 are required for activation of sodium-proton exchange by the Gi-coupled 5-hydroxytryptamine $1 \mathrm{a}$ receptor. J Pharmacol Exp Ther 320:314-322.

Turner JH, Gelasco AK, and Raymond JR (2004) Calmodulin interacts with the third intracellular loop of the serotonin 5-hydroxytryptamine1A receptor at two distinct sites: putative role in receptor phosphorylation by protein kinase C. J Biol Chem 279:17027-17037.

Turner JH and Raymond JR (2005) Interaction of calmodulin with the serotonin 5 -hydroxytryptamine $2 \mathrm{~A}$ receptor. A putative regulator of $\mathrm{G}$ protein coupling and receptor phosphorylation by protein kinase C. J Biol Chem 280:30741-30750.

Turner JT, Sullivan DM, Rovira I, and Camden JM (1996) A regulatory role in mammalian salivary glands for 5-hydroxytryptamine receptors coupled to increased cyclic AMP production. J Dent Res 75:935-941.

Twarog BM and Page IH (1953) Serotonin content of some mammalian tissues and urine and a method for its determination. Am J Physiol 175:157-161.

Tzingounis AV, von Zastrow M, and Yudowski GA (2010) Beta-blocker drugs mediate calcium signaling in native central nervous system neurons by beta-arrestin-biased agonism. Proc Natl Acad Sci USA 107:21028-21033.

Tzvetkov MV, Meineke C, Oetjen E, Hirsch-Ernst K, and Brockmöller J (2007) Tissue-specific alternative promoters of the serotonin receptor gene HTR3B in human brain and intestine. Gene 386:52-62.

Uhlhaas PJ and Singer W (2010) Abnormal neural oscillations and synchrony in schizophrenia. Nat Rev Neurosci 11:100-113.

Ulens C, Spurny R, Thompson AJ, Alqazzaz M, Debaveye S, Han L, Price K, Villalgordo JM, Tresadern G, Lynch JW, et al. (2014) The prokaryote ligand-gated ion channel ELIC captured in a pore blocker-bound conformation by the Alzheimer's disease drug memantine. Structure 22:1399-1407.

Ullmer C, Boddeke HG, Schmuck K, and Lübbert H (1996a) $5-\mathrm{HT}_{2 \mathrm{~B}}$ receptor-mediated calcium release from ryanodine-sensitive intracellular stores in human pulmonary artery endothelial cells. Br J Pharmacol 117:1081-1088.

Ullmer C, Engels P, Abdel'Al S, and Lübbert H (1996b) Distribution of 5-HT4 receptor mRNA in the rat brain. Naunyn Schmiedebergs Arch Pharmacol 354: $210-212$

Ullmer C, Schmuck K, Figge A, and Lübbert H (1998) Cloning and characterization of MUPP1, a novel PDZ domain protein. FEBS Lett 424:63-68.

Ullmer C, Schmuck K, Kalkman HO, and Lübbert H (1995) Expression of serotonin receptor mRNAs in blood vessels. FEBS Lett 370:215-221.

Ulugol A, Oltulu C, Gunduz O, Citak C, Carrara R, Shaqaqi MR, Sanchez AM, and Dogrul A (2012) 5-HT7 receptor activation attenuates thermal hyperalgesia in streptozocin-induced diabetic mice. Pharmacol Biochem Behav 102:344-348.

Unett DJ, Gatlin J, Anthony TL, Buzard DJ, Chang S, Chen C, Chen X, Dang HT-M Frazer J, Le MK, et al. (2013) Kinetics of 5- $\mathrm{HT}_{2 \mathrm{~B}}$ receptor signaling: profound agonist-dependent effects on signaling onset and duration. J Pharmacol Exp Ther 347:645-659

Unsworth CD and Molinoff PB (1994) Characterization of a 5-hydroxytryptamine receptor in mouse neuroblastoma N18TG2 cells. J Pharmacol Exp Ther 269:246-255.

Upton N, Chuang TT, Hunter AJ, and Virley DJ (2008) 5-HT6 receptor antagonists as novel cognitive enhancing agents for Alzheimer's disease. Neurotherapeutics 5 458-469

Upton N, Stean T, Middlemiss D, Blackburn T, and Kennett G (1998) Studies on the role of 5-HT2C and 5-HT2B receptors in regulating generalised seizure threshold in rodents. Eur $J$ Pharmacol 359:33-40.

Urbina M, Arroyo R, and Lima L (2014) 5-HT7 receptors and tryptophan hydroxylase in lymphocytes of rats: mitogen activation, physical restraint or treatment with reserpine Neuroimmunomodulation 21:240-249.

Urtikova N, Berson N, Van Steenwinckel J, Doly S, Truchetto J, Maroteaux L, Pohl M, and Conrath M (2012) Antinociceptive effect of peripheral serotonin 5-HT2B receptor activation on neuropathic pain. Pain 153:1320-1331.

Valdivia LF, Centurión D, Arulmani U, Saxena PR, and Villalón CM (2004) 5-HT1B receptors, alpha2A/2C- and, to a lesser extent, alpha1-adrenoceptors mediate the external carotid vasoconstriction to ergotamine in vagosympathectomised dogs. Naunyn Schmiedebergs Arch Pharmacol 370:46-53.

Valdizán EM, Castro E, and Pazos A (2010) Agonist-dependent modulation of G-protein coupling and transduction of 5-HT1A receptors in rat dorsal raphe nucleus. Int $J$ Neuropsychopharmacol 13:835-843.

Valenti D, de Bari L, Vigli D, Lacivita E, Leopoldo M, Laviola G, Vacca RA, and De Filippis B (2017) Stimulation of the brain serotonin receptor 7 rescues mitochondrial dysfunction in female mice from two models of Rett syndrome. Neuropharmacology 121:79-88.

Valentin N, Acosta A, and Camilleri M (2015) Early investigational therapeutics for gastrointestinal motility disorders: from animal studies to Phase II trials. Expert Opin Investig Drugs 24:769-779.

Valentini V, Piras G, De Luca MA, Perra V, Bordi F, Borsini F, Frau R, and Di Chiara G (2013) Evidence for a role of a dopamine/5-HT6 receptor interaction in cocaine reinforcement. Neuropharmacology 65:58-64.

Valic M, Pecotic R, and Dogas Z (2008) Phrenic nerve activity is enhanced by 5-HT1A receptor agonist 8-OH-DPAT in spontaneously breathing anesthetized rats. $J$ Physiol Pharmacol 59:17-25.

van de Kar LD and Lorens SA (1979) Differential serotonergic innervation of individual hypothalamic nuclei and other forebrain regions by the dorsal and median midbrain raphe nuclei. Brain Res 162:45-54

van den Broek RW, Bhalla P, VanDenBrink AM, de Vries R, Sharma HS, and Saxena PR (2002) Characterization of sumatriptan-induced contractions in human isolated blood vessels using selective $5-\mathrm{HT}_{(1 \mathrm{~B})}$ and $5-\mathrm{HT}_{(1 \mathrm{D})}$ receptor antagonists and in situ hybridization. Cephalalgia 22:83-93.
Vandermaelen CP and Aghajanian GK (1983) Electrophysiological and pharmacological characterization of serotonergic dorsal raphe neurons recorded extracellularly and intracellularly in rat brain slices. Brain Res 289:109-119.

Vane JR (1957) A sensitive method for the assay of 5-hydroxytryptamine. $\mathrm{Br} J$ Pharmacol Chemother 12:344-349.

van Gaalen MM, Schetters D, Schoffelmeer AN, and De Vries TJ (2010) 5-HT6 antagonism attenuates cue-induced relapse to cocaine seeking without affecting cocaine reinforcement. Int $J$ Neuropsychopharmacol 13:961-965.

van Gils W, Lodder EM, Mensink HW, Kiliç E, Naus NC, Brüggenwirth HT, van Ijcken W, Paridaens D, Luyten GP, and de Klein A (2008) Gene expression profiling in uveal melanoma: two regions on $3 p$ related to prognosis. Invest Ophthalmol Vis Sci 49:4254-4262.

van Goethem NP, Schreiber R, Newman-Tancredi A, Varney M, and Prickaerts J (2015) Divergent effects of the 'biased' 5-HT1 A receptor agonists F15599 and F13714 in a novel object pattern separation task. Br J Pharmacol 172.2532-2543.

Vanheel H, Vanuytsel T, Van Oudenhove L, Farré R, Verbeke K, and Tack J (2013) Postprandial symptoms originating from the stomach in functional dyspepsia. Neurogastroenterol Motil 25:911-e703.

Van Lelyveld N, Ter Linde J, Baron A, Mundt M, Wajs E, and Samsom M (2006) The 5-HT $\mathrm{H}_{4}$ antagonist R216073 does not affect gastric motor and sensory function in patients with functional dyspepsia. Aliment Pharmacol Ther 24:669-677.

van Lelyveld N, Ter Linde J, Schipper M, and Samsom M (2008) Serotonergic signalling in the stomach and duodenum of patients with gastroparesis. Neurogastroenterol Motil 20:448-455.

Van Obberghen-Schilling E, Vouret-Craviari V, Haslam RJ, Chambard JC, and Pouysségur J (1991) Cloning, functional expression and role in cell growth regulation of a hamster 5-HT2 receptor subtype. Mol Endocrinol 5:881-889.

Vanover KE, Weiner DM, Makhay M, Veinbergs I, Gardell LR, Lameh J, Del Tredici AL, Piu F, Schiffer HH, Ott TR, et al. (2006) Pharmacological and behavioral profile of N-(4-fluorophenylmethyl)-N-(1-methylpiperidin-4-yl)-N'-(4-(2-methylpropyloxy)phenylmethyl) carbamide (2R,3R)-dihydroxybutanedioate (2:1) (ACP-103), a novel 5-hydroxytryptamine(2A) receptor inverse agonist. J Pharmacol Exp Ther 317:910-918.

Varnäs K, Hall H, Bonaventure P, and Sedvall G (2001) Autoradiographic mapping of $5-\mathrm{HT}(1 \mathrm{~B})$ and 5-HT(1D) receptors in the post mortem human brain using [(3)H]GR 125743. Brain Res 915:47-57.

Varnäs K, Thomas DR, Tupala E, Tiihonen J, and Hall H (2004) Distribution of 5-HT7 receptors in the human brain: a preliminary autoradiographic study using [3H]SB-269970. Neurosci Lett 367:313-316.

Varrault A and Bockaert J (1992) Differential coupling of 5-HT1A receptors occupied by 5-HT or 8-OH-DPAT to adenylyl cyclase. Naunyn Schmiedebergs Arch Pharmacol 346:367-374.

Vázquez-Borsetti P, Cortés R, and Artigas F (2009) Pyramidal neurons in rat prefrontal cortex projecting to ventral tegmental area and dorsal raphe nucleus express 5-HT2A receptors. Cereb Cortex 19:1678-1686.

Venero JL, Vizuete ML, Machado A, and Cano J (1997) Developmental expression of 5 -HT7 receptor mRNA in rat brain visual structures after neonatal enucleation. Neuroreport 8:1531-1535.

Venzi M, David F, Bellet J, Cavaccini A, Bombardi C, Crunelli V, and Di Giovanni G (2016) Role for serotonin2A (5-HT2A) and 2C (5-HT2C) receptors in experimental absence seizures. Neuropharmacology 108:292-304.

Vergé D, Daval G, Marcinkiewicz M, Patey A, el Mestikawy S, Gozlan H, and Hamon M (1986) Quantitative autoradiography of multiple 5-HT1 receptor subtypes in the brain of control or 5,7-dihydroxytryptamine-treated rats. J Neurosci 6:3474-3482.

Verheggen R, Hundeshagen AG, Brown AM, Schindler M, and Kaumann AJ (1998) 5 $\mathrm{HT}_{1 \mathrm{~B}}$ receptor-mediated contractions in human temporal artery: evidence from selective antagonists and 5-HT receptor mRNA expression. $\mathrm{Br} J$ Pharmacol 124: 1345-1354

Verheggen R, Meier A, Werner I, Wienekamp A, Kruschat T, Brattelid T, Levy FO, and Kaumann A (2004) Functional 5-HT receptors in human occipital artery. Naunyn Schmiedebergs Arch Pharmacol 369:391-401.

Verheij MH, Thompson AJ, van Muijlwijk-Koezen JE, Lummis SC, Leurs R, and de Esch IJ (2012) Design, synthesis, and structure-activity relationships of highly potent $5-\mathrm{HT}_{3}$ receptor ligands. J Med Chem 55:8603-8614.

Verhofstad AA and Jonsson G (1983) Immunohistochemical and neurochemical evidence for the presence of serotonin in the adrenal medulla of the rat. Neuroscience 10:1443-1453.

Verma S, Cikurel K, Koralnik IJ, Morgello S, Cunningham-Rundles C, Weinstein ZR Bergmann C, and Simpson DM (2007) Mirtazapine in progressive multifocal leukoencephalopathy associated with polycythemia vera. J Infect Dis 196:709-711.

Veselinović T, Paulzen M, and Gründer G (2013) Cariprazine, a new, orally active dopamine D2/3 receptor partial agonist for the treatment of schizophrenia, bipolar mania and depression. Expert Rev Neurother 13:1141-1159.

Vialli M and Erspamer V (1933) Cellule enterocromaffine e cellule basigranulose acidofile nei vertebrati. $Z$ Zellforsch Mikroskop Anat 19:743-749.

Vianna DM and Carrive P (2009) Inhibition of the cardiovascular response to stress by systemic $5-\mathrm{HT}_{1 \mathrm{~A}}$ activation: sympathoinhibition or anxiolysis? Am J Physiol Regul Integr Comp Physiol 297:R495-R501.

Vickers SP, Clifton PG, Dourish CT, and Tecott LH (1999) Reduced satiating effect of $d$-fenfluramine in serotonin $5-\mathrm{HT}\left({ }_{2 \mathrm{C}}\right)$ receptor mutant mice. Psychopharmacology (Berl) 143:309-314.

Vidal BFS, Billard T, Newman-Tancredi A, and Zimmer L (2014a) Radiopharmacological evaluation of $[18 \mathrm{~F}] \mathrm{F} 13640$, a novel 5-HT1A receptor agonist. $J$ Nucl Med 55:1100.

Vidal R, Castro E, Pilar-Cuéllar F, Pascual-Brazo J, Díaz A, Rojo ML, Linge R, Martín A, Valdizán EM, and Pazos A (2014b) Serotonin 5-HT4 receptors: a new strategy for developing fast acting antidepressants? Curr Pharm Des 20 3751-3762.

Viguier F, Michot B, Hamon M, and Bourgoin S (2013) Multiple roles of serotonin in pain control mechanisms-implications of $5-\mathrm{HT}_{7}$ and other 5 -HT receptor types. Eur J Pharmacol 716:8-16. 
Viguier F, Michot B, Kayser V, Bernard JF, Vela JM, Hamon M, and Bourgoin S (2012) GABA, but not opioids, mediates the anti-hyperalgesic effects of 5-HT7 receptor activation in rats suffering from neuropathic pain. Neuropharmacology 63 : 1093-1106.

Vilaró MT, Cortés R, Gerald C, Branchek TA, Palacios JM, and Mengod G (1996) Localization of 5-HT4 receptor mRNA in rat brain by in situ hybridization histochemistry. Brain Res Mol Brain Res 43:356-360.

Vilaró MT, Doménech T, Palacios JM, and Mengod G (2002) Cloning and characterization of a novel human $5-\mathrm{HT}_{4}$ receptor variant that lacks the alternatively spliced carboxy terminal exon. RT-PCR distribution in human brain and periphery of multiple 5- $\mathrm{HT}_{4}$ receptor variants. Neuropharmacology 42:60-73.

Villalobos C, Beique JC, Gingrich JA, and Andrade R (2005) Serotonergic regulation of calcium-activated potassium currents in rodent prefrontal cortex. Eur J Neurosci 22:1120-1126.

Villalobos C, Foehring RC, Lee JC, and Andrade R (2011) Essential role for phosphatidylinositol 4,5-bisphosphate in the expression, regulation, and gating of the slow afterhyperpolarization current in the cerebral cortex. $J$ Neurosci $\mathbf{3 1}$ 18303-18312.

Villalón CM and Centurión D (2007) Cardiovascular responses produced by 5-hydroxytryptamine: a pharmacological update on the receptors/mechanisms involved and therapeutic implications. Naunyn-Schmiedeberg's Arch Pharmacol $\mathbf{3 7 6}$ 45-63.

Villalón CM, Centurión D, Luján-Estrada M, Terrón JA, and Sánchez-López A (1997a) Mediation of 5-HT-induced external carotid vasodilatation in GR 127935pretreated vagosympathectomized dogs by the putative 5-HT7 receptor. $\mathrm{Br} J$ Pharmacol 120:1319-1327.

Villalón CM, Centurión D, Sánchez-López A, De Vries P, and Saxena PR (1999) 5HT receptors mediating external carotid vasoconstriction in vagosympathectomized dogs. Acta Pharmacol. Sin 20:1057-1067.

Villalón CM, Centurión D, Rabelo G, De Vries P, Saxena PR, and Sánchez-López A (1998) The 5- $\mathrm{HT}_{1}$-like receptors mediating inhibition of sympathetic vasopressor outflow in the pithed rat: operational correlation with the $5-\mathrm{HT}_{1 \mathrm{~A}}, 5-\mathrm{HT}_{1 \mathrm{~B}}$ and 5- $\mathrm{HT}_{1 \mathrm{D}}$ subtypes. Brit J Pharmacol 124:1001-1011.

Villalón CM, Centurión D, Valdivia LF, de Vries P, and Saxena PR (2003) Migraine: an updated review on pathophysiology, pharmacology, therapy and future trends. Curr Vasc Pharmacol 1:71-84.

Villalón CM, den Boer MO, Heiligers JP, and Saxena PR (1990) Mediation of 5 -hydroxytryptamine-induced tachycardia in the pig by the putative $5-\mathrm{HT}_{4}$ receptor. Br J Pharmacol 100:665-667.

Villalón CM, den Boer MO, Heiligers JP, and Saxena PR (1991) Further characterization, by use of tryptamine and benzamide derivatives, of the putative $5-\mathrm{HT}_{4}$ receptor mediating tachycardia in the pig. $\mathrm{Br} J$ Pharmacol 102:107-112.

Villalón CM, Heiligers JP, Centurión D, De Vries P, and Saxena PR (1997b) Characterization of putative $5-\mathrm{HT}_{7}$ receptors mediating tachycardia in the cat. $\mathrm{Br} J$ Pharmacol 121:1187-1195.

Villalón CM and Olesen J (2009) The role of CGRP in the pathophysiology of migraine and efficacy of CGRP receptor antagonists as acute antimigraine drugs. Pharmacol Ther 124:309-323.

Villalón CM, Ramírez-San Juan E, Castillo C, López-Muñoz FJ, and Terrón JA (1995) Pharmacological profile of the receptors that mediate external carotid vasoconstriction by $5-\mathrm{HT}$ in vagosympathectomized dogs. $\mathrm{Br} J$ Pharmacol 116 $2778-2784$.

Villalón CM, Sánchez-López A, Centurión D, and Saxena PR (2001) Unravelling the pharmacological profile of the canine external carotid vasodilator '5-HT1-like' receptors: coexistence of sympatho-inhibitory $5-\mathrm{HT}_{1 \mathrm{~B}}$ and postjunctional $5-\mathrm{HT}_{7}$ receptors. Naunyn Schmiedebergs Arch Pharmacol 363:73-80.

Viñals X, Moreno E, Lanfumey L, Cordomí A, Pastor A, de La Torre R, Gasperini P, Navarro G, Howell LA, Pardo L, et al. (2015) Cognitive impairment induced by delta9-tetrahydrocannabinol occurs through heteromers between cannabinoid $\mathrm{CB}_{1}$ and serotonin 5- $\mathrm{HT}_{2 \mathrm{~A}}$ receptors. PLoS Biol 13:e1002194.

Vines A, Delattre AM, Lima MM, Rodrigues LS, Suchecki D, Machado RB, Tufik S, Pereira SI, Zanata SM, and Ferraz AC (2012) The role of $5-\mathrm{HT}_{1} \mathrm{~A}$ receptors in fish oil-mediated increased BDNF expression in the rat hippocampus and cortex: a possible antidepressant mechanism. Neuropharmacology 62:184-191.

Vogelgesang S, Niebert M, Bischoff AM, Hülsmann S, and Manzke T (2018) Persistent expression of serotonin receptor $5 \mathrm{~b}$ alters breathing behavior in male MeCP2 knockout mice. Front Mol Neurosci 11:28.

Vogelgesang S, Niebert S, Renner U, Möbius W, Hülsmann S, Manzke T, and Niebert M (2017) Analysis of the serotonergic system in a mouse model of Rett syndrome reveals unusual upregulation of serotonin receptor 5b. Front Mol Neurosci 10:61.

Vogrig A, Dorr L, Bouzidi N, Boucherle B, Wattiez AS, Cassier E, Vallon G, Ripoche I, Abrunhosa-Thomas I, Marin P, et al. (2013) Structure-based design of PDZ ligands as inhibitors of 5-HT(2A) receptor/PSD-95 PDZ1 domain interaction possessing anti-hyperalgesic activity. ACS Chem Biol 8:2209-2216.

Voigt JP and Fink H (2015) Serotonin controlling feeding and satiety. Behav Brain Res 277:14-31.

Voigt MM, Laurie DJ, Seeburg PH, and Bach A (1991) Molecular cloning and characterization of a rat brain cDNA encoding a 5-hydroxytryptamine1B receptor. EMBO J 10:4017-4023.

Volkow ND, Wang GJ, Fowler JS, Tomasi D, and Baler R (2012) Food and drug reward: overlapping circuits in human obesity and addiction. Curr Top Behav Neurosci 11:1-24.

Volkow ND, Wang GJ, Fowler JS, Tomasi D, Telang F, and Baler R (2010) Addiction: decreased reward sensitivity and increased expectation sensitivity conspire to overwhelm the brain's control circuit. BioEssays 32:748-755.

von der Ohe MR, Camilleri M, Kvols LK, and Thomforde GM (1993) Motor dysfunction of the small bowel and colon in patients with the carcinoid syndrome and diarrhea. N Engl J Med 329:1073-1078. von der Ohe MR, Hanson RB, and Camilleri M (1994) Serotonergic mediation of postprandial colonic tonic and phasic responses in humans. Gut 35:536-541.

von Mentzer B, Murata Y, Ahlstedt I, Lindström E, and Martínez V (2007) Functional CRF receptors in BON cells stimulate serotonin release. Biochem Pharmacol 73:805-813.

Vysokanov A, Flores-Hernandez J, and Surmeier DJ (1998) mRNAs for clozapinesensitive receptors co-localize in rat prefrontal cortex neurons. Neurosci Lett 258: 179-182.

Wacker D, Stevens RC, and Roth BL (2017a) How ligands illuminate GPCR molecular pharmacology. Cell 170:414-427.

Wacker D, Wang C, Katritch V, Han GW, Huang XP, Vardy E, McCorvy JD, Jiang Y, Chu M, Siu FY, et al. (2013) Structural features for functional selectivity at serotonin receptors. Science 340:615-619.

Wacker D, Wang S, McCorvy JD, Betz RM, Venkatakrishnan AJ, Levit A, Lansu K, Schools ZL, Che T, Nichols DE, et al. (2017b) Crystal structure of an LSD-bound human serotonin receptor. Cell 168:377-389.e12.

Wade JM, Juneja P, MacKay AW, Graham J, Havel PJ, Tecott LH, and Goulding EH (2008) Synergistic impairment of glucose homeostasis in ob/ob mice lacking functional serotonin 2C receptors. Endocrinology 149:955-961.

Wade PR, Chen J, Jaffe B, Kassem IS, Blakely RD, and Gershon MD (1996) Localization and function of a 5-HT transporter in crypt epithelia of the gastrointestinal tract. J Neurosci 16:2352-2364.

Wade PR and Westfall JA (1985) Ultrastructure of enterochromaffin cells and associated neural and vascular elements in the mouse duodenum. Cell Tissue Res 241:557-563.

Waeber C, Dietl MM, Hoyer D, Probst A, and Palacios JM (1988a) Visualization of a novel serotonin recognition site (5-HT1D) in the human brain by autoradiography. Neurosci Lett 88:11-16.

Waeber C, Grailhe R, Yu XJ, Hen R, and Moskowitz MA (1998) Putative 5-ht5 receptors: localization in the mouse CNS and lack of effect in the inhibition of dural protein extravasation. Ann N Y Acad Sci 861:85-90.

Waeber C, Hoyer D, and Palacios JM (1989a) GR 43175: a preferential 5-HT1D agent in monkey and human 1rains as shown by autoradiography. Synapse 4:168-170.

Waeber C and Moskowitz MA (1995a) Autoradiographic visualisation of [3H]5-carboxamidotryptamine binding sites in the guinea pig and rat brain. Eur J Pharmacol 283:31-46.

Waeber C and Moskowitz MA (1995b) [3H] sumatriptan labels both 5-HT1D and 5 -HT1F receptor binding sites in the guinea pig brain: an autoradiographic study. Naunyn Schmiedebergs Arch Pharmacol 352:263-275.

Waeber C, Schoeffter P, Hoyer D, and Palacios JM (1990a) The serotonin 5-HT1D receptor: a progress review. Neurochem Res 15:567-582.

Waeber C, Schoeffter P, Palacios JM, and Hoyer D (1988b) Molecular pharmacology of 5-HT1D recognition sites: radioligand binding studies in human, pig and calf brain membranes. Naunyn Schmiedebergs Arch Pharmacol 337:595-601.

Waeber C, Schoeffter P, Palacios JM and Hoyer D (1989b) 5-HT1D receptors in guinea-pig and pigeon brain. Radioligand binding and biochemical studies. Naunyn Schmiedebergs Arch Pharmacol 340:479-485.

Waeber C, Sebben M, Bockaert J, and Dumuis A (1996) Regional distribution and ontogeny of 5-HT4 binding sites in rat brain. Behav Brain Res 73:259-262.

Waeber C, Sebben M, Grossman C, Javoy-Agid F, Bockaert J, and Dumuis A (1993) [3H]-GR113808 labels 5-HT4 receptors in the human and guinea-pig brain. Neuroreport 4:1239-1242.

Waeber C, Sebben M, Nieoullon A, Bockaert J, and Dumuis A (1994) Regional distribution and ontogeny of 5-HT4 binding sites in rodent brain. Neuropharmacology 33:527-541.

Waeber C, Zhang LA, and Palacios JM (1990b) 5-HT1D receptors in the guinea pig brain: pre- and postsynaptic localizations in the striatonigral pathway. Brain Res 528:197-206.

Waikar MV, Ford AP, and Clarke DE (1994) Evidence for an inhibitory 5-HT4 receptor in urinary bladder of rhesus and Cynomolgus monkeys. $\mathrm{Br} J$ Pharmacol 111:213-218.

Wainscott DB, Cohen ML, Schenck KW, Audia JE, Nissen JS, Baez M, Kursar JD, Lucaites VL, and Nelson DL (1993) Pharmacological characteristics of the newly cloned rat 5-hydroxytryptamine2F receptor. Mol Pharmacol 43:419-426.

Wainscott DB, Johnson KW, Phebus LA, Schaus JM, and Nelson DL (1998) Human 5-HT1F receptor-stimulated [35S]GTPgammaS binding: correlation with inhibition of guinea pig dural plasma protein extravasation. Eur J Pharmacol $\mathbf{3 5 2}$ 117-124.

Wainscott DB, Krushinski JH Jr, Audia JE, Schaus JM, Zgombick JM, Lucaites VL, and Nelson DL (2005) $\left[{ }^{3} \mathrm{H}\right] \mathrm{LY} 334370$, a novel radioligand for the $5-\mathrm{HT}_{1 \mathrm{~F}}$ receptor. I. In vitro characterization of binding properties. Naunyn Schmiedebergs Arch Pharmacol 371:169-177.

Wainscott DB, Lucaites VL, Kursar JD, Baez M, and Nelson DL (1996) Pharmacologic characterization of the human 5-hydroxytryptamine2B receptor: evidence for species differences. $J$ Pharmacol Exp Ther 276:720-727.

Wallace TJ, Zai CC, Brandl EJ, and Müller DJ (2011) Role of 5-HT(2C) receptor gene variants in antipsychotic-induced weight gain. Pharm Genomics Pers Med 4:83-93.

Walstab J, Rappold G, and Niesler B (2010) 5-HT(3) receptors: role in disease and target of drugs. Pharmacol Ther 128:146-169.

Walstab J, Steinhagen F, Brüss M, Göthert M, and Bönisch H (2011) Differences between human wild-type and C23S variant 5-HT2C receptors in inverse agonistinduced resensitization. Pharmacol Rep 63:45-53.

Walther C, Caetano FA, Dunn HA, and Ferguson SS (2015) PDZK1/NHERF3 differentially regulates corticotropin-releasing factor receptor 1 and serotonin $2 \mathrm{~A}$ receptor signaling and endocytosis. Cell Signal 27:519-531.

Walther DJ, Peter J-U, Bashammakh S, Hörtnagl H, Voits M, Fink H, and Bader M (2003a) Synthesis of serotonin by a second tryptophan hydroxylase isoform. Science 299:76.

Walther DJ, Peter J-U, Winter S, Höltje M, Paulmann N, Grohmann M, Vowinckel J, Alamo-Bethencourt V, Wilhelm CS, Ahnert-Hilger G, et al. (2003b) Serotonylation 
of small GTPases is a signal transduction pathway that triggers platelet alphagranule release. Cell 115:851-862.

Walther DJ, Stahlberg S, and Vowinckel J (2011) Novel roles for biogenic monoamines: from monoamines in transglutaminase-mediated post-translational protein modification to monoaminylation deregulation diseases. FEBS $J$ 278: 4740-4755.

Wang B and Chehab FF (2006) Deletion of the serotonin 2c receptor from transgenic mice overexpressing leptin does not affect their lipodystrophy but exacerbates their diet-induced obesity. Biochem Biophys Res Commun 351:418-423.

Wang C, Jiang Y, Ma J, Wu H, Wacker D, Katritch V, Han GW, Liu W, Huang XP, Vardy E, et al. (2013a) Structural basis for molecular recognition at serotonin receptors. Science 340:610-614.

Wang CC, Lin HC, Chan YH, Gean PW, Yang YK, and Chen PS (2013b) 5-HT1Areceptor agonist modified amygdala activity and amygdala-associated social behavior in a valproate-induced rat autism model. Int $J$ Neuropsychopharmacol 16 2027-2039.

Wang CD, Gallaher TK, and Shih JC (1993) Site-directed mutagenesis of the serotonin 5-hydroxytrypamine2 receptor: identification of amino acids necessary for ligand binding and receptor activation. Mol Pharmacol 43:931-940.

Wang DG, Fan JB, Siao CJ, Berno A, Young P, Sapolsky R, Ghandour G, Perkins N, Winchester E, Spencer J, et al. (1998) Large-scale identification, mapping, and genotyping of single-nucleotide polymorphisms in the human genome. Science $\mathbf{2 8 0}$ : 1077-1082.

Wang HM, Wang Y, Liu M, Bai Y, Zhang XH, Sun YX, and Wang HL (2012) Fluoxetine inhibits monocrotaline-induced pulmonary arterial remodeling involved in inhibition of RhoA-Rho kinase and Akt signalling pathways in rats. Can J Physiol Pharmacol 90:1506-1515.

Wang L, Lv Y, Deng W, Peng X, Xiao Z, Xi Z, Chen G, and Wang X (2015) 5-HT6 receptor recruitment of mTOR modulates seizure activity in epilepsy. Mol Neurobiol 51:1292-1299.

Wang Q, Miyakoda M, Yang W, Khillan J, Stachura DL, Weiss MJ, and Nishikura K (2004) Stress-induced apoptosis associated with null mutation of ADAR1 RNA editing deaminase gene. J Biol Chem 279:4952-4961.

Wang Q, O'Brien PJ, Chen CX, Cho DS, Murray JM, and Nishikura K (2000a) Altered $\mathrm{G}$ protein-coupling functions of RNA editing isoform and splicing variant serotonin2C receptors. J Neurochem 74:1290-1300.

Wang X, Fang Y, Liang J, Yan M, Hu R, and Pan X (2014) 5-HT7 receptors are involved in neurogenic dural vasodilatation in an experimental model of migraine. J Mol Neurosci 54:164-170.

Wang Y, Joharchi N, Fletcher PJ, Sellers EM, and Higgins GA (1995) Further studies to examine the nature of dexfenfluramine-induced suppression of heroin self-administration. Psychopharmacology (Berl) 120:134-141.

Wang ZY, Keith IM, Beckman MJ, Brownfield MS, Vidruk EH, and Bisgard GE (2000b) 5-HT5a receptors in the carotid body chemoreception pathway of rat. Neurosci Lett 278:9-12

Ward RJ, Jenkins L, and Milligan G (2009) Selectivity and functional consequences of interactions of family A G protein-coupled receptors with neurochondrin and periplakin. J Neurochem 109:182-192.

Ward RJ, Pediani JD, Godin AG, and Milligan G (2015) Regulation of oligomeric organization of the serotonin 5-hydroxytryptamine 2C (5-HT2C) receptor observed by spatial intensity distribution analysis. J Biol Chem 290:12844-12857.

Ward RP and Dorsa DM (1996) Colocalization of serotonin receptor subtypes 5-HT2A, 5-HT2C, and 5-HT6 with neuropeptides in rat striatum. J Comp Neurol 370:405-414.

Ward RP, Hamblin MW, Lachowicz JE, Hoffman BJ, Sibley DR, and Dorsa DM (1995) Localization of serotonin subtype 6 receptor messenger RNA in the rat brain by in situ hybridization histochemistry. Neuroscience 64:1105-1111.

Ward SJ, Lefever TW, Jackson C, Tallarida RJ, and Walker EA (2008) Effects of a Cannabinoid1 receptor antagonist and Serotonin2C receptor agonist alone and in combination on motivation for palatable food: a dose-addition analysis study in mice. J Pharmacol Exp Ther 325:567-576.

Warner-Schmidt JL, Flajolet M, Maller A, Chen EY, Qi H, Svenningsson P, and Greengard P (2009) Role of p11 in cellular and behavioral effects of 5-HT4 receptor stimulation. $J$ Neurosci 29:1937-1946.

Warr D (2012) Management of highly emetogenic chemotherapy. Curr Opin Oncol 24: 371-375.

Warr D and DeAngelis C (2009) Controlling nausea and vomiting in patients undergoing Chemotherapy. Toward more effective clinical practice. Oncology Exchange 8:23-27.

Watanabe Y, Yoshimoto K, Tatebe H, Kita M, Nishikura K, Kimura M, and Tanaka M (2014) Enhancement of alcohol drinking in mice depends on alterations in RNA editing of serotonin 2C receptors. Int $J$ Neuropsychopharmacol 17:739-751.

Wattiez AS, Pichon X, Dupuis A, Hernández A, Privat AM, Aissouni Y, Chalus M, Pelissier T, Eschalier A, Marin P, et al. (2013) Disruption of 5-HT2A receptor-PDZ protein interactions alleviates mechanical hypersensitivity in carrageenan-induced inflammation in rats. PLoS One 8:e74661.

Watts SW (1996) Serotonin activates the mitogen-activated protein kinase pathway in vascular smooth muscle: use of the mitogen-activated protein kinase kinase inhibitor PD098059. J Pharmacol Exp Ther 279:1541-1550.

Watts SW, Baez M, and Webb RC (1996) The 5-hydroxytryptamine ${ }_{2 B}$ receptor and 5 -HT receptor signal transduction in mesenteric arteries from deoxycorticosterone acetate-salt hypertensive rats. J Pharmacol Exp Ther 277:1103-1113.

Watts SW and Cohen ML (1992) Characterization of the contractile serotonergic receptor in guinea pig trachea with agonists and antagonists. J Pharmacol Exp Ther 260:1101-1106.

Watts SW, Darios ES, Seitz BM, and Thompson JM (2015) 5-HT is a potent relaxant in rat superior mesenteric veins. Pharmacol Res Perspect 3:e00103.

Watts SW and Fink GD (1999) 5-HT ${ }_{2 B}$-receptor antagonist LY-272015 is antihypertensive in DOCA-salt-hypertensive rats. Am J Physiol 276:H944-H952.
Watts SW, Gilbert L, and Webb RC (1995) 5-Hydroxytryptamine ${ }_{2 \mathrm{~B}}$ receptor mediates contraction in the mesenteric artery of mineralocorticoid hypertensive rats. $\mathrm{Hy}$ pertension 26:1056-1059.

Watts SW, Morrison SF, Davis RP, and Barman SM (2012) Serotonin and blood pressure regulation. Pharmacol Rev 64:359-388.

Watts SW, Priestley JR, and Thompson JM (2009) Serotonylation of vascular proteins important to contraction. PLoS One 4:e5682.

Watts SW, Yang P, Banes AK, and Baez M (2001) Activation of Erk mitogen-activated protein kinase proteins by vascular serotonin receptors. J Cardiovasc Pharmacol 38:539-551.

Weber ET and Andrade R (2010) Htr2a gene and 5-HT(2A) receptor expression in the cerebral cortex studied using genetically modified mice. Front Neurosci 4:36

Wei L, Warburton RR, Preston IR, Roberts KE, Comhair SA, Erzurum SC, Hill NS, and Fanburg BL (2012) Serotonylated fibronectin is elevated in pulmonary hypertension. Am J Physiol Lung Cell Mol Physiol 302:L1273-L1279.

Weinberger DR and Lipska BK (1995) Cortical maldevelopment, anti-psychotic drugs, and schizophrenia: a search for common ground. Schizophr Res 16:87-110. Weiner DM, Burstein ES, Nash N, Croston GE, Currier EA, Vanover KE, Harvey SC, Donohue E, Hansen HC, Andersson CM, et al. (2001) 5-hydroxytryptamine 2 receptor inverse agonists as antipsychotics. J Pharmacol Exp Ther 299:268-276.

Weinshank RL, Branchek T, and Hartig PR (1994) inventors. DNA encoding a human $5-\mathrm{HT}_{1 \mathrm{~F}}$ receptor, vectors, and host cells. U.S. patent 5,360,735.

Weinshank RL, Zgombick JM, Macchi MJ, Branchek TA, and Hartig PR (1992) Human serotonin $1 \mathrm{D}$ receptor is encoded by a subfamily of two distinct genes: 5-HT ${ }_{1 \mathrm{D} \alpha}$ and 5-HT ${ }_{1 \mathrm{D} \beta}$. Proc Natl Acad Sci USA 89:3630-3634.

Weir EK, Obreztchikova M, and Hong Z (2008) Fenfluramine: riddle or Rosetta stone? Eur Respir $J$ 31:232-235.

Weiss B, Mertz A, Schröck E, Koenen M, and Rappold G (1995) Assignment of a human homolog of the mouse Htr3 receptor gene to chromosome 11q23.1-q23.2 Genomics 29:304-305.

Weissmann-Nanopoulos D, Mach E, Magre J, Demassey Y, and Pujol JF (1985) Evidence for the localization of 5HT1A binding sites on serotonin containing neurons in the raphe dorsalis and raphe centralis nuclei of the rat brain. Neurochem Int 7: 1061-1072.

Weisstaub NV, Zhou M, Lira A, Lambe E, González-Maeso J, Hornung JP, Sibille E Underwood M, Itohara S, Dauer WT, et al. (2006) Cortical 5-HT2A receptor signaling modulates anxiety-like behaviors in mice. Science 313:536-540.

Weninger S, De Maeyer JH, and Lefebvre RA (2012) Study of the regulation of the inotropic response to $5-\mathrm{HT}_{4}$ receptor activation via phosphodiesterases and its cross-talk with C-type natriuretic peptide in porcine left atrium. Naunyn Schmiedebergs Arch Pharmacol 385:565-577.

Weninger S, Van Craenenbroeck K, Cameron RT, Vandeput F, Movsesian MA, Baillie GS, and Lefebvre RA (2014) Phosphodiesterase 4 interacts with the 5-HT4(b) receptor to regulate cAMP signaling. Cell Signal 26:2573-2582.

Wenkert D, Schoneberg T, Merendino JJ Jr, Rodriguez Pena MS, Vinitsky R, Goldsmith PK, Wess J, and Spiegel AM (1996) Functional characterization of five V2 vasopressin receptor gene mutations. Mol Cell Endocrinol 124:43-50.

Werry TD, Gregory KJ, Sexton PM, and Christopoulos A (2005) Characterization of serotonin 5-HT2C receptor signaling to extracellular signal-regulated kinases 1 and 2. $J$ Neurochem 93:1603-1615.

Werry TD, Stewart GD, Crouch MF, Watts A, Sexton PM, and Christopoulos A (2008) Pharmacology of $5 \mathrm{HT}(2 \mathrm{C})$ receptor-mediated ERK1/2 phosphorylation: agonistspecific activation pathways and the impact of RNA editing. Biochem Pharmacol 76:1276-1287.

Wesołowska A and Kowalska M (2008) Influence of serotonin 5-HT(7) receptor blockade on the behavioral and neurochemical effects of imipramine in rats. Pharmacol Rep 60:464-474.

Wesołowska A, Nikiforuk A, and Stachowicz K (2006a) Potential anxiolytic and antidepressant effects of the selective 5-HT7 receptor antagonist SB 269970 after intrahippocampal administration to rats. Eur J Pharmacol 553:185-190.

Wesołowska A, Nikiforuk A, Stachowicz K, and Tatarczyńska E (2006b) Effect of the selective 5-HT7 receptor antagonist SB 269970 in animal models of anxiety and depression. Neuropharmacology 51:578-586.

Westbroek I, van der Plas A, de Rooij KE, Klein-Nulend J, and Nijweide PJ (2001) Expression of serotonin receptors in bone. J Biol Chem 276:28961-28968.

Westphal RS, Backstrom JR, and Sanders-Bush E (1995) Increased basal phosphorylation of the constitutively active serotonin $2 \mathrm{C}$ receptor accompanies agonistmediated desensitization. Mol Pharmacol 48:200-205.

Westphal RS and Sanders-Bush E (1996) Differences in agonist-independent and -dependent 5-hydroxytryptamine2C receptor-mediated cell division. Mol Pharmacol 49:474-480.

Westrich L, Sprouse J, and Sánchez C (2013) The effects of combining serotonin reuptake inhibition and 5-HT7 receptor blockade on circadian rhythm regulation in rodents. Physiol Behav 110-111:42-50.

Wetter TC, Lauer CJ, Gillich G, and Pollmächer T (1996) The electroencephalographic sleep pattern in schizophrenic patients treated with clozapine or classical antipsychotic drugs. J Psychiatr Res 30:411-419.

Weydert A, Cloez-Tayarani I, Fillion MP, Simon-Chazottes D, Guenet JL, and Fillion $\mathrm{G}$ (1992) Molecular cloning of two partial serotonin 5-HT1D receptor sequences in mouse and one in guinea pig. C R Acad Sci III 314:429-435.

Whale R, Bhagwagar Z, and Cowen PJ (1999) Zolmitriptan-induced growth hormone release in humans: mediation by 5-HT1D receptors? Psychopharmacology (Berl) 145:223-226.

Whalen EJ, Rajagopal S, and Lefkowitz RJ (2011) Therapeutic potential of $\beta$-arrestin- and G protein-biased agonists. Trends Mol Med 17:126-139.

Whitfield TW Jr, Shi X, Sun WL, and McGinty JF (2011) The suppressive effect of an intra-prefrontal cortical infusion of BDNF on cocaine-seeking is Trk receptor and extracellular signal-regulated protein kinase mitogen-activated protein kinase dependent. J Neurosci 31:834-842. 
Wienecke J, Westerdahl A-C, Hultborn H, Kiehn O, and Ryge J (2010) Global gene expression analysis of rodent motor neurons following spinal cord injury associates molecular mechanisms with development of postinjury spasticity. $J$ Neurophysiol 103:761-778

Wild C, Cunningham KA, and Zhou J (2014) Allosteric modulation of G proteincoupled receptors: an emerging approach of drug discovery. Austin J Pharmacol Ther 2:1101.

Wild CT, Miszkiel JM, Wold EA, Soto CA, Ding C, Hartley RM, White MA, Anastasio NC, Cunningham KA, and Zhou J (2019) Design, synthesis, and characterization of 4-undecylpiperidine-2-carboxamides as positive allosteric modulators of the serotonin (5-HT) 5-HT2C receptor. J Med Chem 62:288-305.

Wilken B, Lalley P, Bischoff AM, Christen HJ, Behnke J, Hanefeld F, and Richter DW (1997) Treatment of apneustic respiratory disturbance with a serotonin-receptor agonist. $J$ Pediatr 130:89-94.

Wilkinson D, Windfeld K, and Colding-Jørgensen E (2014) Safety and efficacy of idalopirdine, a 5-HT6 receptor antagonist, in patients with moderate Alzheimer's disease (LADDER): a randomised, double-blind, placebo-controlled phase 2 trial. Lancet Neurol 13:1092-1099.

Willins DL, Alsayegh L, Berry SA, Backstrom JR, Sanders-Bush E, Friedman L, Khan N, and Roth BL (1998) Serotonergic antagonist effects on trafficking of serotonin 5-HT2A receptors in vitro and in vivo. Ann N Y Acad Sci 861: $121-127$

Willins DL, Berry SA, Alsayegh L, Backstrom JR, Sanders-Bush E, Friedman L, and Roth BL (1999) Clozapine and other 5-hydroxytryptamine-2A receptor antagonists alter the subcellular distribution of 5-hydroxytryptamine-2A receptors in vitro and in vivo. Neuroscience 91:599-606.

Wilmer A, Tack J, Coremans G, Janssens J, Peeters T, and Vantrappen G (1993) 5 hydroxytryptamine- 3 receptors are involved in the initiation of gastric phase-3 motor activity in humans. Gastroenterology 105:773-780.

Wilson H, Coffman WJ, and Cohen ML (1990) 5-hydroxytryptamine3 receptors mediate tachycardia in conscious instrumented dogs. J Pharmacol Exp Ther $\mathbf{2 5 2}$ $683-688$

Winstanley CA (2011) The utility of rat models of impulsivity in developing pharmacotherapies for impulse control disorders. Br J Pharmacol 164:1301-1321.

Winstanley CA, Chudasama Y, Dalley JW, Theobald DE, Glennon JC, and Robbins TW (2003) Intra-prefrontal 8-OH-DPAT and M100907 improve visuospatial attention and decrease impulsivity on the five-choice serial reaction time task in rats. Psychopharmacology (Berl) 167:304-314.

Winstanley CA, Theobald DE, Dalley JW, Glennon JC, and Robbins TW (2004) 5HT2A and 5-HT2C receptor antagonists have opposing effects on a measure of impulsivity: interactions with global 5-HT depletion. Psychopharmacology (Berl) 176:376-385

Wirshing DA, Wirshing WC, Kysar L, Berisford MA, Goldstein D, Pashdag J, Mintz J, and Marder SR (1999) Novel antipsychotics: comparison of weight gain liabilities. $J$ Clin Psychiatry 60:358-363.

Wischhof L, Hollensteiner KJ, and Koch M (2011) Impulsive behaviour in rats induced by intracortical DOI infusions is antagonized by co-administration of an mGlu2/3 receptor agonist. Behav Pharmacol 22:805-813.

Wisden W, Parker EM, Mahle CD, Grisel DA, Nowak HP, Yocca FD, Felder CC, Seeburg PH, and Voigt MM (1993) Cloning and characterization of the rat 5-HT5B receptor. Evidence that the 5 -HT5B receptor couples to a G protein in mammalian cell membranes. FEBS Lett 333:25-31.

Witkin JM, Baez M, Yu J, Barton ME, and Shannon HE (2007) Constitutive deletion of the serotonin-7 (5-HT(7)) receptor decreases electrical and chemical seizure thresholds. Epilepsy Res 75:39-45.

Woehler A and Ponimaskin EG (2009) G protein-mediated signaling: same receptor, multiple effectors. Curr Mol Pharmacol 2:237-248.

Wöhr M, Rippberger H, Schwarting RK, and van Gaalen MM (2015) Critical involvement of 5-HT2C receptor function in amphetamine-induced $50-\mathrm{kHz}$ ultrasonic vocalizations in rats. Psychopharmacology (Berl) 232:1817-1829.

Wolf ME (2016) Synaptic mechanisms underlying persistent cocaine craving. Nat Rev Neurosci 17:351-365.

Wolf WA and Schutz LJ (1997) The serotonin 5-HT2C receptor is a prominent serotonin receptor in basal ganglia: evidence from functional studies on serotoninmediated phosphoinositide hydrolysis. J Neurochem 69:1449-1458.

Wolff MC and Leander JD (2000) A comparison of the behavioural effects of 5-HT2A and 5-HT2C receptor agonists in the pigeon. Behav Pharmacol 11:355-364.

Wood MD, Reavill C, Trail B, Wilson A, Stean T, Kennett GA, Lightowler S, Blackburn TP, Thomas D, Gager TL, et al. (2001) SB-243213; a selective 5-HT2C receptor inverse agonist with improved anxiolytic profile: lack of tolerance and withdrawal anxiety. Neuropharmacology 41:186-199.

Woods S, Clarke NN, Layfield R, and Fone KC (2012) 5-HT(6) receptor agonists and antagonists enhance learning and memory in a conditioned emotion response paradigm by modulation of cholinergic and glutamatergic mechanisms. $\mathrm{Br} J$ Pharmacol 167:436-449.

Woodward RM, Panicker MM, and Miledi R (1992) Actions of dopamine and dopaminergic drugs on cloned serotonin receptors expressed in Xenopus oocytes. Proc Natl Acad Sci USA 89:4708-4712.

Woolley ML, Bentley JC, Sleight AJ, Marsden CA, and Fone KC (2001) A role for 5 -ht6 receptors in retention of spatial learning in the Morris water maze. Neuropharmacology 41:210-219.

Woolley ML, Marsden CA, and Fone KC (2004) 5-ht6 receptors. Curr Drug Targets CNS Neurol Disord 3:59-79.

Won SJ and Lin MT (1988) 5-Hydroxytryptamine receptors in the hypothalamus mediate thermoregulatory responses in rabbits. Naunyn Schmiedebergs Arch Pharmacol 338:256-261.

Wong H, Dockens RC, Pajor L, Yeola S, Grace JE Jr, Stark AD, Taub RA, Yocca FD, Zaczek RC, and Li YW (2007) 6-Hydroxybuspirone is a major active metabolite of buspirone: assessment of pharmacokinetics and 5-hydroxytryptamine1A receptor occupancy in rats. Drug Metab Dispos 35:1387-1392.
Wouters W, Tulp MT, and Bevan P (1988) Flesinoxan lowers blood pressure and heart rate in cats via 5-HT 1 receptors. Eur $J$ Pharmacol 149:213-223.

Wright DE, Seroogy KB, Lundgren KH, Davis BM, and Jennes L (1995) Comparative localization of serotonin ${ }_{1 \mathrm{~A}},{ }_{1 \mathrm{C}}$, and ${ }_{2}$ receptor subtype mRNAs in rat brain. J Comp Neurol 351:357-373.

Wu S, Zhu M, Wang W, Wang Y, Li Y, and Yew DT (2001) Changes of the expression of 5-HT receptor subtype mRNAs in rat dorsal root ganglion by complete Freund's adjuvant-induced inflammation. Neurosci Lett 307:183-186.

Wu X, Pang G, Zhang YM, Li G, Xu S, Dong L, Stackman RW Jr, and Zhang G (2015a) Activation of serotonin 5-HT(2C) receptor suppresses behavioral sensitization and naloxone-precipitated withdrawal symptoms in heroin-treated mice. Neurosci Lett 607:23-28

Wu ZS, Cheng H, Jiang Y, Melcher K, and Xu HE (2015b) Ion channels gated by acetylcholine and serotonin: structures, biology, and drug discovery. Acta Pharmacol Sin 36:895-907.

Wurch T, Palmier C, Colpaert FC, and Pauwels PJ (1997) Sequence and functional analysis of cloned guinea-pig and rat $5-\mathrm{HT}_{1 \mathrm{D}}$ receptors: common pharmacological features within the 5-HT 1 receptor family. J. Neurochem. 68:410-418.

Wynants M, Vengethasamy L, Ronisz A, Meyns B, Delcroix M, and Quarck R (2013) NF- $\mathrm{kB}$ pathway is involved in CRP-induced effects on pulmonary arterial endothelial cells in chronic thromboembolic pulmonary hypertension. Am J Physiol Lung Cell Mol Physiol 305:L934-L942.

Xia Z, Hufeisen SJ, Gray JA, and Roth BL (2003) The PDZ-binding domain is essential for the dendritic targeting of 5-HT2A serotonin receptors in cortical pyramidal neurons in vitro. Neuroscience 122:907-920.

Xia Z and Storm DR (1997) Calmodulin-regulated adenylyl cyclases and neuromodulation. Curr Opin Neurobiol 7:391-396.

Xie E, Zhu L, Zhao L, and Chang LS (1996) The human serotonin 5-HT ${ }_{2 \mathrm{C}}$ receptor: complete cDNA, genomic structure, and alternatively spliced variant. Genomics $\mathbf{3 5}$ : 551-561.

Xie Z, Lee SP, O'Dowd BF, and George SR (1999) Serotonin 5-HT1B and 5-HT1D receptors form homodimers when expressed alone and heterodimers when co-expressed. FEBS Lett 456:63-67.

Xie Z, Sanada K, Samuels BA, Shih H, and Tsai LH (2003) Serine 732 phosphorylation of FAK by Cdk5 is important for microtubule organization, nuclear movement and neuronal migration. Cell 114:469-482.

$\mathrm{Xu} \mathrm{P}, \mathrm{He} \mathrm{Y}$, Cao X, et al. (2017) Activation of serotonin 2C receptors in dopamine neurons inhibits binge-like eating in mice. Biol Psychiatry 81:737-747.

Xu R, Hong J, Morse CL, and Pike VW (2010) Synthesis, structure-affinity relationships, and radiolabeling of selective high-affinity 5-HT4 receptor ligands as prospective imaging probes for positron emission tomography. J Med Chem $\mathbf{5 3}$ 7035-7047

$\mathrm{Xu}$ T and Pandey SC (2000) Cellular localization of serotonin(2A) (5HT(2A)) receptors in the rat brain. Brain Res Bull 51:499-505.

Xu XF, Tsai HJ, Li L, Chen YF, Zhang C, and Wang GF (2009) Modulation of leak $\mathrm{K}(+)$ channel in hypoglossal motoneurons of rats by serotonin and/or variation of $\mathrm{pH}$ value. Sheng Li Xue Bao 61:305-316.

Xu Y, Jones JE, Kohno D, Williams KW, Lee CE, Choi MJ, Anderson JG, Heisler LK, Zigman JM, Lowell BB, et al. (2008) 5-HT2CRs expressed by pro-opiomelanocortin neurons regulate energy homeostasis. Neuron 60:582-589.

Xu YC, Johnson KW, Phebus LA, Cohen M, Nelson DL, Schenck K, Walker CD, Fritz JE, Kaldor SW, LeTourneau ME, et al. (2001) N-[3-(2-Dimethylaminoethyl)-2-methyl$1 \mathrm{H}$ - indol-5-yl]-4-fluorobenzamide: a potent, selective, and orally active 5 - $\mathrm{HT}\left({ }_{1 \mathrm{~F}}\right)$ receptor agonist potentially useful for migraine therapy. J Med Chem 44:4031-4034.

Yaakob NS, Chinkwo KA, Chetty N, Coupar IM, and Irving HR (2015) Distribution of 5-HT3, 5-HT4, and 5-HT7 receptors along the human colon. J Neurogastroenterol Motil 21:361-369.

Yabanoglu S, Akkiki M, Seguelas MH, Mialet-Perez J, Parini A, and Pizzinat N (2009) Platelet derived serotonin drives the activation of rat cardiac fibroblasts by 5-HT2A receptors. J Mol Cell Cardiol 46:518-525.

Yadav PN, Kroeze WK, Farrell MS, and Roth BL (2011) Antagonist functional selectivity: 5-HT2A serotonin receptor antagonists differentially regulate 5-HT2A receptor protein level in vivo. J Pharmacol Exp Ther 339:99-105.

Yadav VK, Oury F, Suda N, Liu Z-W, Gao X-B, Confavreux C, Klemenhagen KC, Tanaka KF, Gingrich JA, Guo XE, et al. (2009) A serotonin-dependent mechanism explains the leptin regulation of bone mass, appetite, and energy expenditure. Cell 138:976-989.

Yagaloff KA and Hartig PR (1985) 125I-lysergic acid diethylamide binds to a nove serotonergic site on rat choroid plexus epithelial cells. J Neurosci 5:3178-3183.

Yager LM, Garcia AF, Wunsch AM, and Ferguson SM (2015) The ins and outs of the striatum: role in drug addiction. Neuroscience 301:529-541.

Yakel JL, Lagrutta A, Adelman JP, and North RA (1993) Single amino acid substitution affects desensitization of the 5-hydroxytryptamine type 3 receptor expressed in Xenopus oocytes. Proc Natl Acad Sci USA 90:5030-5033.

Yamada J, Sugimoto Y, Wakita H, and Horisaka K (1988) The involvement of serotonergic and dopaminergic systems in hypothermia induced in mice by intracerebroventricular injection of serotonin. Jpn J Pharmacol 48:145-148.

Yamamoto R, Hatano N, Sugai T, and Kato N (2014) Serotonin induces depolarization in lateral amygdala neurons by activation of TRPC-like current and inhibition of GIRK current depending on 5-HT(2C) receptor. Neuropharmacology 82:49-58

Yamashita PS, de Bortoli VC, and Zangrossi H Jr (2011) 5-HT2C receptor regulation of defensive responses in the rat dorsal periaqueductal gray. Neuropharmacology 60:216-222.

Yamazaki M, Harada K, Yamamoto N, Yarimizu J, Okabe M, Shimada T, Ni K, and Matsuoka N (2014) ASP5736, a novel 5-HT5A receptor antagonist, ameliorates positive symptoms and cognitive impairment in animal models of schizophrenia. Eur Neuropsychopharmacol 24:1698-1708.

Yamazaki M, Okabe M, Yamamoto N, Yarimizu J, and Harada K (2015) Novel 5-HT5A receptor antagonists ameliorate scopolamine-induced working memory 
deficit in mice and reference memory impairment in aged rats. $J$ Pharmacol $S c i$ 127:362-369.

Yanarates O, Dogrul A, Yildirim V, Sahin A, Sizlan A, Seyrek M, Akgül O, Kozak O, Kurt E, and Aypar U (2010) Spinal 5-HT7 receptors play an important role in the antinociceptive and antihyperalgesic effects of tramadol and its metabolite, O-desmethyltramadol, via activation of descending serotonergic pathways. Anesthesiology 112:696-710.

Yan C, Yang Y, Saito K, Xu P, Wang C, Hinton AO Jr, Yan X, Wu Q, Tong Q, Elmquist JK, et al. (2015) Meta-chlorophenylpiperazine enhances leptin sensitivity in diet-induced obese mice. Br J Pharmacol 172:3510-3521.

Yang D, Soulier JL, Sicsic S, Mathé-Allainmat M, Brémont B, Croci T, Cardamone R, Aureggi G, and Langlois M (1997) New esters of 4-amino-5-chloro-2-methoxybenzoic acid as potent agonists and antagonists for 5-HT4 receptors. J Med Chem 40:608-621.

Yang EJ, Han SK, and Park SJ (2014) Functional expression of 5-HT ${ }^{7}$ receptor on the substantia gelatinosa neurons of the trigeminal subnucleus caudalis in mice. Brain Res 1543:73-82

Yang G-B and Lackner AA (2004) Proximity between 5-HT secreting enteroendocrine cells and lymphocytes in the gut mucosa of rhesus macaques (Macaca mulatta) is suggestive of a role for enterochromaffin cell 5 -HT in mucosal immunity. $J \mathrm{Neu}$ roimmunol 146:46-49.

Yang J (1990) Ion permeation through 5-hydroxytryptamine-gated channels in neuroblastoma N18 cells. J Gen Physiol 96:1177-1198.

Yang K, Belrose J, Trepanier CH, Lei G, Jackson MF, and MacDonald JF (2011) Fyn, a potential target for Alzheimer's disease. J Alzheimers Dis 27:243-252.

Yang M, Li K, Ng PC, Chuen CK, Lau TK, Cheng YS, Liu YS, Li CK, Yuen PM, James $\mathrm{AE}$, et al. (2007) Promoting effects of serotonin on hematopoiesis: ex vivo expansion of cord blood CD34+ stem/progenitor cells, proliferation of bone marrow stromal cells, and antiapoptosis. Stem Cells 25:1800-1806.

Yang W, Chen K, Lan NC, Gallaher TK, and Shih JC (1992) Gene structure and expression of the mouse 5-HT2 receptor. J Neurosci Res 33:196-204.

Yang W, Wang Q, Kanes SJ, Murray JM, and Nishikura K (2004) Altered RNA editing of serotonin 5-HT2C receptor induced by interferon: implications for depression associated with cytokine therapy. Brain Res Mol Brain Res 124:70-78.

Yang Z, Liu X, Yin Y, Sun S, and Deng X (2012) Involvement of 5- $\mathrm{HT}_{7}$ receptors in the pathogenesis of temporal lobe epilepsy. Eur J Pharmacol 685:52-58.

Yano JM, Yu K, Donaldson GP, Shastri GG, Ann P, Ma L, Nagler CR, Ismagilov RF, Mazmanian SK, and Hsiao EY (2015) Indigenous bacteria from the gut microbiota regulate host serotonin biosynthesis. Cell 161:264-276.

Yasuno F, Suhara T, Nakayama T, Ichimiya T, Okubo Y, Takano A, Ando T, Inoue M, Maeda J, and Suzuki K (2003) Inhibitory effect of hippocampal 5-HT1A receptors on human explicit memory. Am J Psychiatry 160:334-340.

Ye JY, Liang EY, Cheng YS, Chan GCF, Ding Y, Meng F, Ng MHL, Chong BH, Lian Q, and Yang M (2014) Serotonin enhances megakaryopoiesis and proplatelet formation via p-Erk1/2 and F-actin reorganization. Stem Cells 32:2973-2982.

Yildiz O, Smith JR, and Purdy RE (1998) Serotonin and vasoconstrictor synergism. Life Sci 62:1723-1732.

Yin J, Albert RH, Tretiakova AP, and Jameson BA (2006) 5-HT(1B) receptors play a prominent role in the proliferation of T-lymphocytes. $J$ Neuroimmunol 181:68-81.

Yocca FD, Iben L, and Meller E (1992) Lack of apparent receptor reserve at postsynaptic 5-hydroxytryptamine1A receptors negatively coupled to adenylyl cyclase activity in rat hippocampal membranes. Mol Pharmacol 41:1066-1072.

Yoshimoto K, Watanabe Y, Tanaka M, and Kimura M (2012) Serotonin2C receptors in the nucleus accumbens are involved in enhanced alcohol-drinking behavior. Eur $J$ Neurosci 35:1368-1380.

Yoshio R, Taniguchi T, Itoh H, and Muramatsu I (2001) Affinity of serotonin receptor antagonists and agonists to recombinant and native $\alpha_{1}$-adrenoceptor subtypes. Jpn $J$ Pharmacol 86:189-195.

You HJ, Colpaert FC, and Arendt-Nielsen L (2005) The novel analgesic and high-efficacy 5-HT1A receptor agonist F 13640 inhibits nociceptive responses, wind-up, and afterdischarges in spinal neurons and withdrawal reflexes. Exp Neurol 191:174-183.

Young MR, Kut JL, Coogan MP, Wright MA, Young ME, and Matthews J (1993) Stimulation of splenic T-lymphocyte function by endogenous serotonin and by lowdose exogenous serotonin. Immunology 80:395-400.

Yu L, Nguyen H, Le H, Bloem LJ, Kozak CA, Hoffman BJ, Snutch TP, Lester HA Davidson N, and Lübbert $\mathrm{H}$ (1991) The mouse $5-\mathrm{HT}_{1 \mathrm{C}}$ receptor contains eight hydrophobic domains and is X-linked. Brain Res Mol Brain Res 11:143-149.

Yu Y, Chen J-H, Li H, Yang Z, Du X, Hong L, Liao H, Jiang L, Shi J, Zhao L, et al. (2015) Involvement of 5- $\mathrm{HT}_{3}$ and $5-\mathrm{HT}_{4}$ receptors in colonic motor patterns in rats Neurogastroenterol Motil 27:914-928.

Yuan S, Filipek S, and Vogel H (2016) A gating mechanism of the serotonin 5-HT receptor. Structure 24:816-825.

Yuan X, Yamada K, Ishiyama-Shigemoto S, Koyama W, and Nonaka K (2000) Identification of polymorphic loci in the promoter region of the serotonin 5-HT2C receptor gene and their association with obesity and type II diabetes. Diabetologia 43:373-376.

Yun HM, Baik JH, Kang I, Jin C, and Rhim H (2010) Physical interaction of Jab1 with human serotonin 6 G-protein-coupled receptor and their possible roles in cell survival. J Biol Chem 285:10016-10029.

Yun HM, Kim S, Kim HJ, Kostenis E, Kim JI, Seong JY, Baik JH, and Rhim H (2007) The novel cellular mechanism of human 5-HT6 receptor through an interaction with Fyn. $J$ Biol Chem 282:5496-5505.

Zayara AE, McIver G, Valdivia PN, Lominac KD, McCreary AC, and Szumlinski KK (2011) Blockade of nucleus accumbens 5-HT2A and 5-HT2C receptors prevents the expression of cocaine-induced behavioral and neurochemical sensitization in rats. Psychopharmacology (Berl) 213:321-335.

Zgombick JM, Bard JA, Kucharewicz SA, Urquhart DA, Weinshank RL, and Branchek TA (1997) Molecular cloning and pharmacological characterization of guinea pig 5-HT1B and 5-HT1D receptors. Neuropharmacology 36:513-524.

Zgombick JM and Branchek TA (1998) Native 5-HT1B receptors expressed in OK cells display dual coupling to elevation of intracellular calcium concentrations and inhibition of adenylate cyclase. Naunyn Schmiedebergs Arch Pharmacol 358:503-508.
Zgombick JM, Schechter LE, Kucharewicz SA, Weinshank RL, and Branchek TA (1995) Ketanserin and ritanserin discriminate between recombinant human 5-HT1D alpha and 5-HT1D beta receptor subtypes. Eur J Pharmacol 291:9-15.

Zgombick JM, Schechter LE, Macchi M, Hartig PR, Branchek TA, and Weinshank RL (1992) Human gene S31 encodes the pharmacologically defined serotonin 5-hydroxytryptamine1E receptor. Mol Pharmacol 42:180-185.

Zgombick JM, Weinshank RL, Macchi M, Schechter LE, Branchek TA, and Hartig PR (1991) Expression and pharmacological characterization of a canine 5-hydroxytryptamine1D receptor subtype. Mol Pharmacol 40:1036-1042.

Zhang D, Blanco MJ, Ying BP, Kohlman D, Liang SX, Victor F, Chen Q, Krushinski J, Filla SA, Hudziak KJ, et al. (2015) Discovery of selective N-[3-(1-methyl-piperidine4-carbonyl)-phenyl]-benzamide-based 5-HT1F receptor agonists: evolution from bicyclic to monocyclic cores. Bioorg Med Chem Lett 25:4337-4341.

Zhang D, Kohlman D, Krushinski J, Liang S, Ying BP, Reilly JE, Dinn SR, Wainscott DB, Nutter S, Gough W, et al. (2004) Design, synthesis and evaluation of bicyclic benzamides as novel $5-\mathrm{HT}_{1 \mathrm{~F}}$ receptor agonists. Bioorg Med Chem Lett 14 $6011-6016$

Zhang G and Stackman RW Jr (2015) The role of serotonin 5-HT2A receptors in memory and cognition. Front Pharmacol 6:225

Zhang G, Wu X, Zhang YM, Liu H, Jiang Q, Pang G, Tao X, Dong L, and Stackman RW Jr (2016) Activation of serotonin 5-HT(2C) receptor suppresses behavioral sensitization and naloxone-precipitated withdrawal symptoms in morphine-dependent mice. Neuropharmacology 101:246-254.

Zhang H, Herman AI, Kranzler HR, Anton RF, Zhao H, Zheng W, and Gelernter J (2013a) Array-based profiling of DNA methylation changes associated with alcohol dependence. Alcohol Clin Exp Res 37 (Suppl 1):E108-E115.

Zhang Q, Zhu Y, Zhou W, Gao L, Yuan L, and Han X (2013b) Serotonin receptor 2C and insulin secretion. PLoS One 8:e54250.

Zhang Y, Damjanoska KJ, Carrasco GA, Dudas B, D'Souza DN, Tetzlaff J, Garcia F, Hanley NR, Scripathirathan K, Petersen BR, et al. (2002) Evidence that 5-HT2A receptors in the hypothalamic paraventricular nucleus mediate neuroendocrine responses to (-)DOI. J Neurosci 22:9635-9642.

Zhang Y, Smith EM, Baye TM, Eckert JV, Abraham LJ, Moses EK, Kissebah AH, Martin LJ, and Olivier M (2010) Serotonin (5-HT) receptor 5A sequence variants affect human plasma triglyceride levels. Physiol Genomics 42:168-176.

Zhang Y, Yang Y, Chen L, and Zhang J (2014a) Expression analysis of genes and pathways associated with liver metastases of the uveal melanoma. BMC Med Genet 15.29.

Zhang Z, Falaleeva M, Agranat-Tamir L, Pages A, Eyras E, Sperling J, Sperling R, and Stamm S (2013c) The 5' untranslated region of the serotonin receptor $2 \mathrm{C}$ premRNA generates miRNAs and is expressed in non-neuronal cells. Exp Brain Res 230:387-394.

Zhang ZF, Duan ZJ, Wang LX, Yang D, Zhao G, and Zhang L (2014b) The serotonin transporter gene polymorphism (5-HTTLPR) and irritable bowel syndrome: a meta-analysis of 25 studies. BMC Gastroenterol 14:23.

Zhang ZJ, Wang D, Man SC, Ng R, McAlonan GM, Wong HK, Wong W, Lee J, and Tan QR (2014c) Platelet 5-HT( $\left.{ }_{1 \mathrm{~A}}\right)$ receptor correlates with major depressive disorder in drug-free patients. Prog Neuropsychopharmacol Biol Psychiatry 53:74-79.

Zhang ZW and Arsenault D (2005) Gain modulation by serotonin in pyramidal neurones of the rat prefrontal cortex. $J$ Physiol 566:379-394.

Zhou FM and Hablitz JJ (1999) Activation of serotonin receptors modulates synaptic transmission in rat cerebral cortex. J Neurophysiol 82:2989-2999.

Zhou L, Sutton GM, Rochford JJ, Semple RK, Lam DD, Oksanen LJ, Thornton-Jones ZD, Clifton PG, Yueh CY, Evans ML, et al. (2007) Serotonin 2C receptor agonists improve type 2 diabetes via melanocortin-4 receptor signaling pathways. Cell Metab 6:398-405.

Zhou X, Ding M, Ding C, Yao J, Pang H, Xing J, Xuan J, and Wang B (2013) Relationship between genetic polymorphisms in the HTR1A gene and paranoid schizophrenia in a Northern Han Chinese population. J Mol Neurosci 49:625-631.

Zhu B, Chen C, Moyzis RK, Dong Q, Chen C, He Q, Li J, Lei X, and Lin C (2012a) Association between the $\mathrm{HTR}_{2 \mathrm{~B}}$ gene and the personality trait of fun seeking. Pers Individ Dif 53:1029-1033.

Zhu H, Urban DJ, Blashka J, McPheeters MT, Kroeze WK, Mieczkowski P, Overholser JC, Jurjus GJ, Dieter L, Mahajan GJ, et al. (2012b) Quantitative analysis of focused a-to-I RNA editing sites by ultra-high-throughput sequencing in psychiatric disorders. PLoS One 7:e43227.

Zhu QS, Chen K, and Shih JC (1995) Characterization of the human 5-HT2A receptor gene promoter. J Neurosci 15:4885-4895.

Zighelboim J, Talley NJ, Phillips SF, Harmsen WS, and Zinsmeister AR (1995) Visceral perception in irritable bowel syndrome. Rectal and gastric responses to distension and serotonin type 3 antagonism. Dig Dis Sci 40:819-827.

Zlojutro M, Manz N, Rangaswamy M, Xuei X, Flury-Wetherill L, Koller D, Bierut LJ, Goate A, Hesselbrock V, Kuperman S, et al. (2011) Genome-wide association study of theta band event-related oscillations identifies serotonin receptor gene HTR7 influencing risk of alcohol dependence. Am J Med Genet B Neuropsychiatr Genet 156B: $44-58$

Zopf DA, das Neves LA, Nikula KJ, Huang J, Senese PB, and Gralinski MR (2011) C122 , a novel antagonist of serotonin receptor 5 -HT2B, prevents monocrotalineinduced pulmonary arterial hypertension in rats. Eur J Pharmacol 670:195-203.

Zoto T, Kilickap S, Yasar U, Celik I, Bozkurt A, and Babaoglu MO (2015) Improved anti-emetic efficacy of $5-\mathrm{HT}_{3}$ receptor antagonists in cancer patients with genetic polymorphisms of ABCB1 (MDR1) drug transporter. Basic Clin Pharmacol Toxicol 116:354-360.

Zsippai A, Szabó DR, Szabó PM, Tömböl Z, Bendes MR, Nagy Z, Rácz K, and Igaz P (2011) mRNA and microRNA expression patterns in adrenocortical cancer. Am $J$ Cancer Res 1:618-628.

Zuideveld KP, Rusiç-Pavletic J, Maas HJ, Peletier LA, Van der Graaf PH, and Danhof M (2002) Pharmacokinetic-pharmacodynamic modeling of buspirone and its metabolite 1-(2-pyrimidinyl)-piperazine in rats. J Pharmacol Exp Ther 303: 1130-1137. 